Available on the World Wide Web at:

http://www.eia.doe.gov/oil_gas/natgas/nga4v2.html

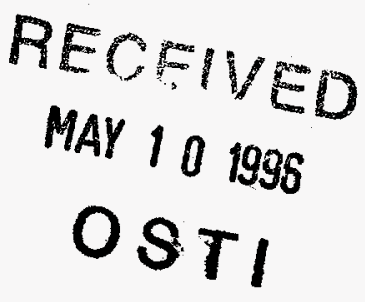

\title{
Natural Gas Annual 1994 Volume 2
}

\section{November 1995}

Energy Information Administration

Office of Oil and Gas

U.S. Department of Energy

Washington, DC 20585 


\section{Contacts}

The Natural Gas Annual is prepared by the Energy Information Administration, Office of Oil and Gas, Reserves and Natural Gas Division, under the direction of Joan E. Heinkel.

General information for this document may be obtained from Kendrick E. Brown, Jr. (202/586-6077), Chief of the Data Operations Branch. Questions and comments con- cerning the contents of the Natural Gas Annual may be directed to Ann M. Ducca (202/586-6137) and Margo Natof (202/586-6303). Specific inquiries should be referred to the following subject specialists: Supply Donna Guerrina (202/586-6135), Transmission - Dolly Tolson (202/586-6664), Demand - Sylvia Norris (202/586-6106), and Electronic versions -- Sheila Darnell (202/586-6165). 


\section{DISCLAMMER}

Portions of this document may be illegible in electronic image products. Images are produced from the best available original document. 


\section{Preface}

The Natural Gas Annual provides information on the supply and disposition of natural gas to a wide audience including industry, consumers, Federal and State agencies, and educational institutions. This report, Volume 2, presents historical data for the Nation from 1930 to 1994, and by State from 1967 to 1994.

The data in the Natural Gas Annual 1994 are taken from surveys conducted by the Energy Information Administration (EIA), U.S. Department of Energy (DOE), to fulfill its responsibilities for gathering and reporting energy data. Two EIA surveys provide most of the information presented in this report-the mandatory Form EIA-176, "Annual Report of Natural and Supplemental Gas Supply and Disposition," and the voluntary Form EIA-627, "Annual Quantity and Value of Natural Gas Report." Form EIA-176 was submitted by respondents out of an identified universe of operators of fields, wells, or natural gas processing plants who distribute gas to end users or transport gas to or across a State border; operators of synthetic natural gas plants; natural gas distributors; natural gas pipeline companies; and companies that operate underground natural gas storage facilities. Data collected on Form EIA-176 are not proprietary. Form EIA-627 was submitted by the appropriate agencies of the 33 natural gas producing States.

Other EIA surveys that provided information for this report are Forms EIA-816, "Monthly Natural Gas Liquids Report," and ELA-64A, "Annual Report of the Origin of Natural Gas Liquids Production," for gas processed, plant fuel, and extraction loss data; Form EIA-857, "Monthly Report of Natural Gas Purchases and Deliveries to Consumers," for data on the city gate prices; Forms EIA-759, "Monthly Power Plant Report," and FERC-423, "Monthly Report of Cost and Quality of Fuels for Electric Plants," for data on the quantity and price of natural gas consumed by electric utilities; and Form

FPC-14, "Annual Report for Importers and Exporters of Natural Gas," for data on the quantity and price of natural gas imports and exports. The EIA report, U.S. Crude Oil, Natural Gas, and Natural Gas Liquids Reserves, 1994 Annual Report, was the source of the reserves data.
Some of the data are collected under the authority of the Federal Energy Regulatory Commission (FERC), an independent commission within the DOE that has jurisdiction primarily in the regulation of electric utilities and the interstate natural gas industry. The United States Geological Survey (USGS) and the United States Minerals Management Service (MMS) of the Department of the Interior, and the Interstate Oil and Gas Compact Commission (IOGCC) were sources of supplemental information on production, the number of producing gas and gas-condensate wells, and wellhead values. The geographic coverage is the 50 States and the District of Columbia.

See Appeneix A of Volume 1 of this report for a description of the data collection surveys, the report methodology, and survey response rates.

All volumes of natural gas in this publication are reported at 14.73 pounds per square inch absolute and 60 degrees Fahrenheit, except where noted. A glossary of terms is provided to assist users in understanding the data presented. A description of the data collection surveys appears in Appendix A. Appendix $B$ describes metric and thermal conversion factors, and Appendix $C$ lists additional natural gas information sources.

The tables of data that appear in this report are available on personal computer diskettes and the Internet. See the inside cover for further details. 


\section{Contents}

Page

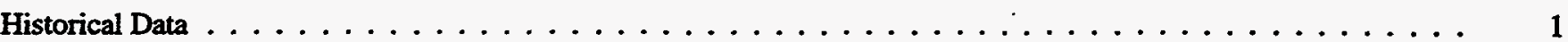

Appendix

A. Selected Recurring Natural Gas and Related Reports . . . . . . . . . . . . . . . . . . . . .

Glossary

307

\section{Tables}

1. Quantity and Average Price of Natural Gas Production in the United States, 1930-1994 . . . . . . . . . . . . . . 3

2. Supply and Disposition of Natural Gas in the United States, 1930-1994 . . . . . . . . . . . . . . . . . . . . . 6

3. Natural Gas Consumption in the United States, 1930-1994 ... . . . . . . . . . . . . . . . . . . . 9

4. Average Price of Natural Gas Delivered to U. S. Consumers, 1967-1994 . . . . . . . . . . . . . . . . . . . . . 12

5. Gross Withdrawals and Marketed Production of Natural Gas by State, 1967-1994 . . . . . . . . . . . . . . . . . 13

6. Number of Producing Gas and Gas Condensate Wells by State as of December 31, 1967-1994 . . . . . . . . . . . . . 31

7. Wellhead Value and Marketed Production of Natural Gas by State, 1967-1994 . . . . . . . . . . . . . . . . . 35

8. Movements of Natural Gas by State, 1967-1994 . . . . . . . . . . . . . . . . . . . . . . . . . 52

9. Changes in Natural Gas Underground Storage by State, 1967-1975 . . . . . . . . . . . . . . . . . . . . . . 80

10. Changes in Natural Gas Underground Storage by State, 1976-1979 . . . . . . . . . . . . . . . . . . . . . . 86

11. Changes in Natural Gas Storage by State, 1980-1994 . . . . . . . . . . . . . . . . . . . . . . 88

12. Supplemental Gas Supplies by State, 1980-1994 . . . . . . . . . . . . . . . . . . . . . . . . . . . . . . 100

13. Natural Gas Production, Transmission, and Consumption by State, 1967-1994 . . . . . . . . . . . . . . . . 110

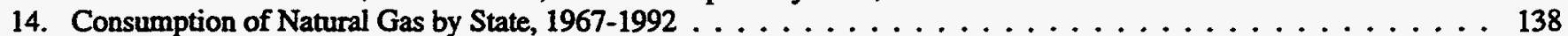

15. Consumption of Natural Gas by State, 1993-1994 . . . . . . . . . . . . . . . . . . . . . . . . . . 164

16. Natural Gas Delivered to Consumers by State, 1967-1994 . . . . . . . . . . . . . . . . . . . . . . . . . . 166

17. Firm Natural Gas Deliveries to Consumers by State, 1993-1994 . . . . . . . . . . . . . . . . . . . . . 222

18. Interruptible Natural Gas Deliveries to Consumers by State, 1993-1994 . . . . . . . . . . . . . . . . . . . . 224

19. Natural Gas Deliveries to Commercial Consumers by State, 1993-1994 . . . . . . . . . . . . . . . . . . 226

20. Natural Gas Deliveries to Industrial Consumers by State, 1993-1994 . . . . . . . . . . . . . . . . . . . . . . . 228

21. Natural Gas Deliveries to Electric Utilities by State, 1993-1994 . . . . . . . . . . . . . . . . . . . . . . . . . . 230

22. Natural Gas Delivered to Consumers by Census Division, 1967-1994 . . . . . . . . . . . . . . . . . 232

23. Average Price of Natural Gas Delivered to U.S. Residential Consumers by State, 1967-1994 . . . . . . . . . . . 246

24. Average Price of Natural Gas Delivered to U.S. Commercial Consumers by State, 1967-1992 . . . . . . . . . . 250

25. Average Price of Natural Gas Delivered to U.S. Commercial Consumers by State, 1993-1994 . . . . . . . . . . 254

26. Prices of Natural Gas Deliveries to Commercial Consumers by State, 1993-1994 . . . . . . . . . . . . . . . . . 255

27. Average Price of Natural Gas Delivered to U.S. Industrial Consumers by State, 1967-1992 . . . . . . . . . . 257

28. Average Price of Natural Gas Delivered to U.S. Industrial Consumers by State, 1993-1994 . . . . . . . . . . . . . 261

29. Prices of Natural Gas Deliveries to Industrial Consumers by State, 1993-1994 . . . . . . . . . . . . . . . . . . . . 262

30. Average Price of Natural Gas Delivered to U.S. Vehicle Fuel Consumers by State, 1990-1994 . . . . . . . . 264

31. Average Price of Natural Gas Delivered to U.S. Electric Utilities by State, 1967-1994 . . . . . . . . . . . . . . . 265

32. Prices of Natural Gas Deliveries to Electric Utilities by State, 1993-1994 . . . . . . . . . . . . . . . . . . . 269

33. Average Price of Natural Gas Delivered to All Consumers by State, 1967-1986 . . . . . . . . . . . . . . . 271

34. Average Consumption and Annual Cost of Natural Gas per Consumer by State, 1967-1989 . . . . . . . . . . . . 275

35. Average Consumption and Annual Cost of Natural Gas per Consumer by State, 1990-1994 . . . . . . . . . . . 298 


\section{Illustrations}

1. Natural Gas Supply and Disposition in the United States, $1965-1994 \ldots \ldots \ldots$. . . . . . . . . . . . . . . . . . 5

2. Natural Gas Delivered to Consumers in the United States, 1930-1994 . . . . . . . . . . . . . . . . . . . . 8

3. Average Price of Natural Gas Delivered to U.S. Consumers, $1967-1994 \ldots \ldots \ldots \ldots$. . . . . . . . . . . . 11 


\section{Historical Data}

Dry production of natural gas continues to be a large contributor to the Nation's domestic energy supply. In 1973, the drop in oil imports due to the oil embargo by OPEC nations resulted in natural gas production reaching an alltime high of 21.7 trillion cubic feet. During 1994, dry production was 18.7 trillion cubic feet, 4 percent above the 1993 level (Table 1).

The early 1970's brought record levels in the total U.S. consumption of natural gas with a peak level of 22.1 trillion cubic feet in 1972. Deliveries of natural gas to the residential and electric utility sectors set record levels that same year, and deliveries to industrials peaked in 1973. Between 1982 and 1991 total U.S. consumption of natural gas remained in the range of 16 to 19 trillion cubic feet (Table 3). It rose to 20.3 trillion cubic feet in 1993 and increased slightly in 1994 (20.8 trillion cubic feet).
Industrial users are the leading consumers of natural gas. Industrial consumption reached 8.2 trillion cubic feet in 1994, up 2 percent from the 1993 level and the highest level since 1974. Much of the increase can be attributed to natural gas consumption by nonutility generators (NUG's). NUG's generate electricity for their own use and for sale to electric utilities, which in turn distribute it to consumers.

Natural gas consumption in the residential sector, the second leading consuming sector, responds largely to weather-related home-heating requirements. The winter of 1993-94 was warmer than normal. Residential consumption in 1994 was slightly lower than in 1993 and 3 percent higher than in 1992. During 1994, residential consumption was 4.8 trillion cubic feet. 
Commercial consumption, which also responds to variations in the weather, was at almost the same record-setting level of 2.9 trillion cubic feet set in 1993. Historically, the electric utility sector has had the third largest amount of consumption. In 1992 and 1993, it was surpassed by commercial; however in 1994 electric utility consumption was almost at 3 trillion cubic feet. Consumption increased 10 percent in the electric utility sector from 1993 to 1994.

\section{Changes to Data Collection Programs}

The Bureau of Mines, U.S. Department of the Interior, conducted surveys of the natural gas industry until 1977, when this function was transferred to the newly formed U.S. Department of Energy (DOE). Since that time the Energy Information Administration (EIA) within the DOE has collected information on natural gas production, transmission, consumption, and prices. Some of the data are collected on behalf of the Federal Energy Regulatory Commission (FERC), an independent commission within the DOE, which has jurisdiction primarily in the regulation of electric utilities and the interstate natural gas industry.

The EIA made many changes to data collection forms and procedures that became effective for the collection of 1980 data. These changes provided more complete natural gas information with minimal changes in respondent burden. In some instances voluntary data collection efforts were changed to mandatory surveys. The Form EIA-176 combined and expanded two voluntary predecessor forms from the Bureau of Mines (BOM-1340-A and BOM-1341-A) into a new mandatory form.

In 1980, the Form EIA-627, "Annual Quantity and Value of Natural Gas Report," was introduced to collect data, previously collected on an informal basis, from the appropriate agencies of the producing States. In addition to volumes of gas produced from gas and oil wells, the form requested data on the quantities of nonhydrocarbon gases removed in treating or processing operations, quantities of gas used for repressuring as well as gas vented and flared, and marketed production. In 1991, the Form ElA-627 was revised to also collect quantities of fuel used on the lease.

The United States Geological Survey provided supplemental production data, including production data for the Outer Continental Shelf, until 1982, when this function was transferred to the United States Minerals Management Service.

In 1982, the Form EIA-176 was revised and expanded into the version that was used for data collection through 1986. The Form EIA-176 was reapproved in 1988 for the collection of 1987 through 1989 data. The form was changed to include collection of data on the transportation of gas to. commercial consumers for the account of others and to add a short form of the EIA-176 to be filed by small companies with limited activities. In 1991, the Form EIA-176 was reapproved for the collection of 1990 through 1992 data. The major changes to the form were: deliveries of gas to be used as vehicle fuel are reported and the data reported on the form are no longer considered confidential.

In 1993, the Office of Management and Budget approved the revised Form EIA-176. All deliveries to consumers are now categorized as firm or interruptible. Commercial and industrial consumers are further categorized as nonutility power producers or as those excluding nonutility power producers. See Appendix A of Volume I for further information about the history of data collection. 
Table 1. Quantity and Average Price of Natural Gas Production in the United States, 1930-1994 (Volumes in Million Cubic Feet, Prices in Dollars per Thousand Cubic Feet)

\begin{tabular}{|c|c|c|c|c|c|c|c|c|}
\hline Yar & $\begin{array}{c}\text { Gross } \\
\text { Writhdrencals }\end{array}$ & $\begin{array}{l}\text { Used for } \\
\text { Represenuring }\end{array}$ & $\begin{array}{l}\text { Nonhydro- } \\
\text { carbon } \\
\text { Geaces } \\
\text { Remowed }\end{array}$ & $\begin{array}{l}\text { Vented and } \\
\text { Flared }\end{array}$ & $\begin{array}{l}\text { Marketud } \\
\text { Production }\end{array}$ & $\begin{array}{l}\text { Extraction } \\
\text { Loss }\end{array}$ & $\begin{array}{c}\text { Dry } \\
\text { Production }\end{array}$ & $\begin{array}{l}\text { Averege } \\
\text { Wollhoud } \\
\text { Pries of } \\
\text { Marketed } \\
\text { Production }\end{array}$ \\
\hline $\begin{array}{l}1930 \ldots \ldots \\
1931 \ldots \ldots \\
1933 \ldots \ldots \\
1934 \ldots \ldots \ldots\end{array}$ & $\begin{array}{l}\text { NA } \\
\text { NA } \\
\text { NA } \\
\text { NA }\end{array}$ & $\begin{array}{l}\text { NA } \\
\text { NA } \\
\text { NA } \\
\text { NA } \\
\text { NA }\end{array}$ & $\begin{array}{l}\text { NA } \\
\text { NA } \\
\text { NA } \\
\text { NA }\end{array}$ & $\begin{array}{l}\text { NA } \\
\text { NA } \\
\text { NA } \\
\text { NA. }\end{array}$ & $\begin{array}{l}1,978,911 \\
1,721,902 \\
1,593,798 \\
1,596,673 \\
1,815,796\end{array}$ & $\begin{array}{l}75,140 \\
62,288 \\
51,816 \\
48,280 \\
52,190\end{array}$ & $\begin{array}{l}1,903,771 \\
1,659,614 \\
1,541,982 \\
1,548,393 \\
1,763,606\end{array}$ & $\begin{array}{l}0.08 \\
0.07 \\
0.06 \\
0.06 \\
0.06\end{array}$ \\
\hline 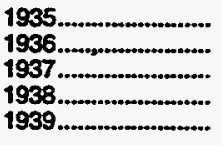 & $\begin{array}{r}\text { NA } \\
2,691,512 \\
3,084,567 \\
3,108,858 \\
3,387,095\end{array}$ & $\begin{array}{r}N A \\
73,507 \\
84,925 \\
101,551 \\
171,401\end{array}$ & $\begin{array}{l}\text { NA } \\
\text { NA } \\
\text { NA } \\
\text { NA }\end{array}$ & $\begin{array}{r}N A \\
392,528 \\
526,159 \\
649,106 \\
677,311\end{array}$ & $\begin{array}{l}1,968,963 \\
2,225,477 \\
2,473,483 \\
2,358,201 \\
2,538,383\end{array}$ & $\begin{array}{l}55,488 \\
61,064 \\
70,210 \\
73,338 \\
73,746\end{array}$ & $\begin{array}{l}1,913,475 \\
2,164,413 \\
2,403,273 \\
2,284,863 \\
2,464,637\end{array}$ & $\begin{array}{l}0.06 \\
0.06 \\
0.05 \\
0.05 \\
0.05\end{array}$ \\
\hline $\begin{array}{l}1940 \\
1941 \\
1942 \ldots \ldots \ldots \ldots \\
1943 \ldots \ldots \ldots \ldots\end{array}$ & $\begin{array}{l}3,752,702 \\
4,168,116 \\
4,525,095 \\
5,024,449 \\
5,708,288\end{array}$ & $\begin{array}{l}362,916 \\
644,379 \\
752,619 \\
824,803 \\
882,979\end{array}$ & $\begin{array}{l}\text { NA } \\
\text { NA } \\
\text { NA } \\
\text { NA } \\
\text { NA }\end{array}$ & $\begin{array}{r}655,967 \\
630,212 \\
626,782 \\
684,115 \\
1,010,285\end{array}$ & $\begin{array}{l}2,733,819 \\
2,893,525 \\
3,145,694 \\
3,515,531 \\
3,815,024\end{array}$ & $\begin{array}{r}79,526 \\
115,464 \\
119,000 \\
121,788 \\
142,868\end{array}$ & $\begin{array}{l}2,654,293 \\
2,778,061 \\
3,026,694 \\
3,393,743 \\
3,672,156\end{array}$ & $\begin{array}{l}0.05 \\
0.05 \\
0.05 \\
0.05 \\
0.05\end{array}$ \\
\hline 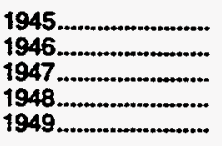 & $\begin{array}{l}6,000,161 \\
6,293,037 \\
6,733,230 \\
7,178,777 \\
7,546,825\end{array}$ & $\begin{array}{l}1,061,951 \\
1,038,242 \\
1,083,119 \\
1,220,579 \\
1,273,205\end{array}$ & $\begin{array}{l}\text { NA } \\
\text { NA } \\
\text { NA } \\
\text { NA }\end{array}$ & $\begin{array}{r}896,208 \\
1,102,033 \\
1,067,938 \\
810,178 \\
853,884\end{array}$ & $\begin{array}{l}4,042,002 \\
4,152,762 \\
4,582,173 \\
5,148,020 \\
5,419,736\end{array}$ & $\begin{array}{l}159,936 \\
165,274 \\
188,734 \\
209,508 \\
224,332\end{array}$ & $\begin{array}{l}3,882,066 \\
3,987,488 \\
4,393,439 \\
4,938,512 \\
5,195,404\end{array}$ & $\begin{array}{l}0.05 \\
0.05 \\
0.06 \\
0.06 \\
0.06\end{array}$ \\
\hline $\begin{array}{l}1950 \ldots \ldots \\
1951 \ldots \ldots \ldots \\
1952 \ldots \ldots \ldots \\
1953 \ldots \ldots \ldots \\
1954 \ldots \ldots \ldots \ldots\end{array}$ & $\begin{array}{r}8,479,650 \\
9,689,372 \\
10,272,566 \\
10,645,798 \\
10,984,850\end{array}$ & $\begin{array}{l}1,396,546 \\
1,438,827 \\
1,410,501 \\
1,438,606 \\
1,518,737\end{array}$ & $\begin{array}{l}\text { NA } \\
\text { NA } \\
\text { NA } \\
\text { NA }\end{array}$ & $\begin{array}{l}801,044 \\
793,186 \\
848,608 \\
810,276 \\
723,567\end{array}$ & $\begin{array}{l}6,282,060 \\
7,457,359 \\
8,013,457 \\
8,396,916 \\
8,742,546\end{array}$ & $\begin{array}{l}259,862 \\
292,400 \\
319,158 \\
340,068 \\
354,348\end{array}$ & $\begin{array}{l}6,022,198 \\
7,164,959 \\
7,694,299 \\
8,056,848 \\
8,388,198\end{array}$ & $\begin{array}{l}0.07 \\
0.07 \\
0.08 \\
0.09 \\
0.10\end{array}$ \\
\hline 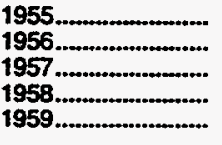 & $\begin{array}{l}11,719,794 \\
12,372,905 \\
12,906,669 \\
13,146,635 \\
14,229,272\end{array}$ & $\begin{array}{l}1,540,804 \\
1,426,648 \\
1,417,263 \\
1,482,975 \\
1,612,109\end{array}$ & $\begin{array}{l}\text { NA } \\
\text { NA } \\
\text { NA } \\
\text { NA } \\
\text { NA }\end{array}$ & $\begin{array}{l}773,639 \\
864,334 \\
809,148 \\
633,412 \\
571,048\end{array}$ & $\begin{array}{r}9,405,351 \\
10,081,923 \\
10,680,258 \\
11,030,248 \\
12,046,115\end{array}$ & $\begin{array}{l}376,686 \\
418,013 \\
433,636 \\
458,040 \\
498,457\end{array}$ & $\begin{array}{r}9,028,665 \\
9,653,910 \\
10,246,622 \\
10,572,208 \\
11,547,658\end{array}$ & $\begin{array}{l}0.10 \\
0.11 \\
0.11 \\
0.12 \\
0.13\end{array}$ \\
\hline 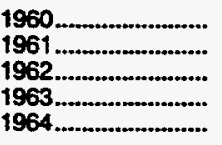 & $\begin{array}{l}15,087,911 \\
15,460,312 \\
16,038,973 \\
16,973,368 \\
17,535,553\end{array}$ & $\begin{array}{l}1,753,996 \\
1,682,754 \\
1,736,722 \\
1,843,297 \\
1,647,108\end{array}$ & $\begin{array}{l}\text { NA } \\
\text { NA } \\
\text { NA } \\
\text { NA } \\
\text { NA }\end{array}$ & $\begin{array}{l}562,877 \\
523,533 \\
425,629 \\
383,408 \\
341,853\end{array}$ & $\begin{array}{l}12,771,038 \\
13,254,025 \\
13,876,622 \\
14,746,663 \\
15,546,592\end{array}$ & $\begin{array}{l}542,890 \\
592,446 \\
623,616 \\
670,251 \\
722,565\end{array}$ & $\begin{array}{l}12,228,148 \\
12,661,579 \\
13,253,006 \\
14,076,412 \\
14,824,027\end{array}$ & $\begin{array}{l}0.14 \\
0.15 \\
0.16 \\
0.16 \\
0.15\end{array}$ \\
\hline 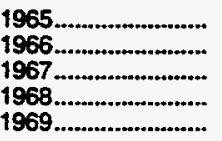 & $\begin{array}{l}17,963,100 \\
19,033,839 \\
20,251,776 \\
21,325,000 \\
22,679,195\end{array}$ & $\begin{array}{l}1,604,204 \\
1,451,516 \\
1,590,574 \\
1,486,092 \\
1,455,205\end{array}$ & $\begin{array}{l}\text { NA } \\
\text { NA } \\
\text { NA } \\
\text { NA } \\
\text { NA }\end{array}$ & $\begin{array}{l}319,143 \\
375,695 \\
489,877 \\
516,508 \\
525,750\end{array}$ & $\begin{array}{l}16,039,753 \\
17,206,628 \\
18,171,325 \\
19,322,400 \\
20,698,240\end{array}$ & $\begin{array}{l}753,473 \\
739,308 \\
784,534 \\
827,877 \\
866,560\end{array}$ & $\begin{array}{l}15,286,280 \\
16,467,320 \\
17,386,791 \\
18,494,523 \\
19,831,680\end{array}$ & $\begin{array}{l}0.16 \\
0.16 \\
0.16 \\
0.16 \\
0.17\end{array}$ \\
\hline
\end{tabular}

See footnotes at end of table. 
Table 1. Quantity and Average Price of Natural Gas Production in the United States, 1930-1994 (Continued) (Volumes in Million Cubic Feet, Prices in Dollars per Thousand Cubic Feet)

\begin{tabular}{|c|c|c|c|c|c|c|c|c|}
\hline Year & $\begin{array}{l}\text { Gross } \\
\text { Wthdrumel }\end{array}$ & $\begin{array}{l}\text { Uned for } \\
\text { Repreastring }\end{array}$ & $\begin{array}{l}\text { Monhydino } \\
\text { Carben } \\
\text { Gases } \\
\text { Remowed }\end{array}$ & $\begin{array}{l}\text { Vented and } \\
\text { Franed }\end{array}$ & $\begin{array}{l}\text { Mertatud } \\
\text { Production }\end{array}$ & $\begin{array}{l}\text { Extraction } \\
\text { Loss }\end{array}$ & $\begin{array}{l}\text { Dry } \\
\text { Production }\end{array}$ & $\begin{array}{l}\text { Avorage } \\
\text { Wellined } \\
\text { Price of } \\
\text { Marketied } \\
\text { Production }\end{array}$ \\
\hline 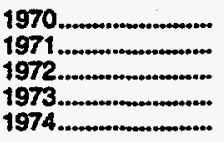 & $\begin{array}{l}23,786,453 \\
24,099,031 \\
24,016,109 \\
24,057,202 \\
22,849,793\end{array}$ & $\begin{array}{l}1,376,351 \\
1,310,458 \\
1,236,292 \\
1,171,361 \\
1,079,890\end{array}$ & $\begin{array}{l}\text { NA } \\
\text { NA } \\
\text { NA } \\
\text { NA }\end{array}$ & $\begin{array}{l}489,460 \\
284,561 \\
248,119 \\
248,292 \\
169,381 .\end{array}$ & $\begin{array}{l}21,920,642 \\
22,493,012 \\
22,531,698 \\
22,647,549 \\
21,600,522\end{array}$ & $\begin{array}{l}906,413 \\
883,127 \\
907,993 \\
916,551 \\
887,490\end{array}$ & $\begin{array}{l}21,014,229 \\
21,609,885 \\
21,623,705 \\
21,730,998 \\
20,713,032\end{array}$ & $\begin{array}{l}0.17 \\
0.18 \\
0.19 \\
0.22 \\
0.30\end{array}$ \\
\hline 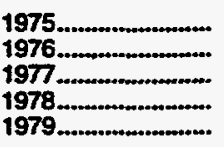 & $\begin{array}{l}21,103,530 \\
20,943,778 \\
21,097,071 \\
21,309,815 \\
21,883,353\end{array}$ & $\begin{array}{r}860,956 \\
859,410 \\
934,801 \\
1,181,432 \\
1,245,074\end{array}$ & $\begin{array}{l}\text { NA } \\
\text { NA } \\
\text { NA } \\
\text { NA }\end{array}$ & $\begin{array}{l}133,913 \\
131,930 \\
136,807 \\
153,350 \\
167,019\end{array}$ & $\begin{array}{l}20,108,661 \\
19,952,438 \\
20,025,463 \\
19,974,033 \\
20,471,260\end{array}$ & $\begin{array}{l}872,282 \\
854,086 \\
862,563 \\
852,130 \\
807,845\end{array}$ & $\begin{array}{l}19,236,379 \\
19,098,352 \\
19,162,900 \\
19,121,903 \\
19,663,415\end{array}$ & $\begin{array}{l}0.44 \\
0.58 \\
0.79 \\
0.91 \\
1.18\end{array}$ \\
\hline $\begin{array}{l}1980 \\
1981 \ldots \\
1982 \ldots \\
1984 \ldots \ldots\end{array}$ & $\begin{array}{l}21,869,692 \\
21,587,453 \\
20,272,254 \\
18,659,046 \\
20,266,522\end{array}$ & $\begin{array}{l}1,365,454 \\
1,311,735 \\
1,388,392 \\
1,458,054 \\
1,630,152\end{array}$ & $\begin{array}{l}199,063 \\
221,878 \\
208,492 \\
221,937 \\
224,118\end{array}$ & $\begin{array}{r}125,451 \\
98,017 \\
93,355 \\
94,962 \\
107,913\end{array}$ & $\begin{array}{l}20,179,724 \\
19,955,823 \\
18,582,005 \\
16,884,093 \\
18,304,339\end{array}$ & $\begin{array}{l}776,605 \\
774,562 \\
761,942 \\
789,632 \\
837,867\end{array}$ & $\begin{array}{l}19,403,119 \\
19,181,261 \\
17,820,063 \\
16,094,461 \\
17,466,472\end{array}$ & $\begin{array}{l}1.59 \\
1.98 \\
2.46 \\
2.59 \\
2.66\end{array}$ \\
\hline 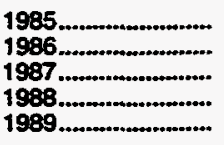 & $\begin{array}{l}19,605,699 \\
19,130,711 \\
20,140,200 \\
20,999,255 \\
21,074,425\end{array}$ & $\begin{array}{l}1,915,197 \\
1,837,552 \\
2,207,559 \\
2,478,382 \\
2,475,179\end{array}$ & $\begin{array}{l}326,497 \\
336,851 \\
376,033 \\
459,883 \\
362,457\end{array}$ & $\begin{array}{r}94,778 \\
97,633 \\
123,707 \\
142,525 \\
141,642\end{array}$ & $\begin{array}{l}17,270,227 \\
16,858,675 \\
17,432,901 \\
17,918,465 \\
18,095,147\end{array}$ & $\begin{array}{l}816,370 \\
799,645 \\
812,320 \\
815,844 \\
784,502\end{array}$ & $\begin{array}{l}16,453,857 \\
16,059,030 \\
16,620,581 \\
17,102,621 \\
17,310,645\end{array}$ & $\begin{array}{l}2.51 \\
1.94 \\
1.67 \\
1.69 \\
1.69\end{array}$ \\
\hline 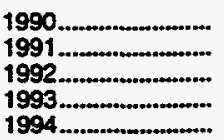 & $\begin{array}{r}21,522,622 \\
21,750,108 \\
22,132,249 \\
R_{22,725,642} \\
23,608,654\end{array}$ & $\begin{array}{r}2,489,040 \\
2,771,928 \\
2,972,552 \\
R_{3,103,014} \\
3,332,644\end{array}$ & $\begin{array}{l}289,374 \\
275,831 \\
280,370 \\
413,971 \\
412,178\end{array}$ & $\begin{array}{r}150,415 \\
169,909 \\
167,519 \\
n_{226,743} \\
228,336\end{array}$ & $\begin{array}{r}18,593,792 \\
18,532,439 \\
18,711,808 \\
R_{18,981,915} \\
19,635,495\end{array}$ & $\begin{array}{l}784,118 \\
834,637 \\
871,905 \\
886,455 \\
888,500\end{array}$ & $\begin{array}{r}17,809,674 \\
17,697,802 \\
17,839,903 \\
R_{18,095,460} \\
18,746,995\end{array}$ & $\begin{array}{r}1.71 \\
1.64 \\
1.74 \\
P_{2.04} \\
1.88\end{array}$ \\
\hline
\end{tabular}

A = Revised data. NA = Not Avallable.
Notes: Beginning with 1965 data, all volumes are shown on a pressure base of 14.73 psia at 60 degrees fahrenheit. For prior years, the pressure base is 14.65 psia at 60

degrees Fahrenheit

Sources: 1930-1975: Bureau of Mines, Minerals Yearbook, "Natural Gas" chapter. 1976-1978: Energy information Administration (ElA). Energy Data Reports, Natural Gas Annual, 1979: ElA, Natural Gas Proctuetion and Consumption, 1979. 1980-1994: ElA, Form EIA-627, 'Asnual Ouantity and Vahue of Natural Gas Aeport"; Form ElA-176, -Annual Repont of Natural and Supplemental Gas Supply end Disposition"; Fom EIA-64A, "Annual Report of the Origin of Natural Gas Liquids Production"; and Fom ElA-816. "Monthly Natural Gas Liquids Report." 
Figure 1. Natural Gas Supply and Disposition in the United States, 1965-1994

Dry Production

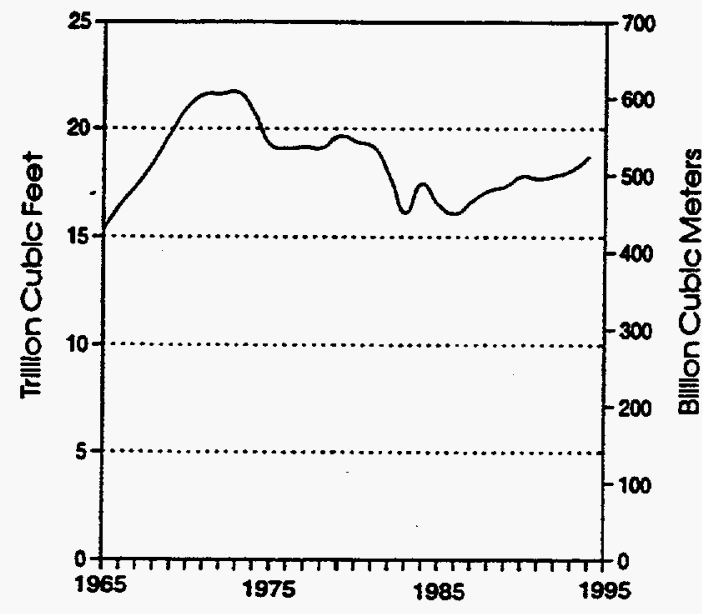

Net Additions to Storage

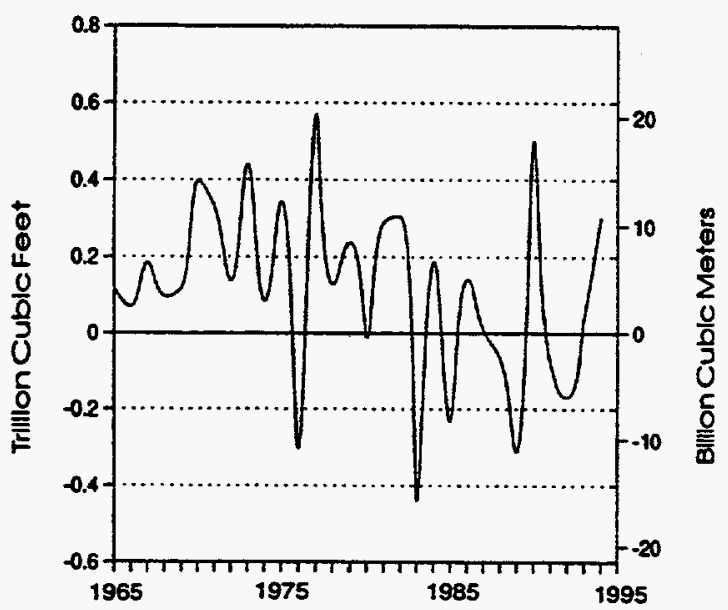

Wellhead Price

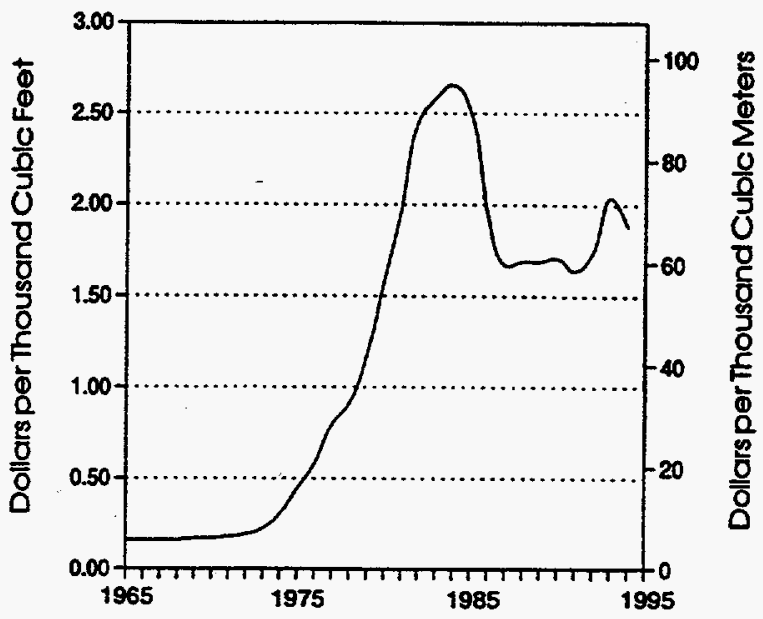

Net Imports

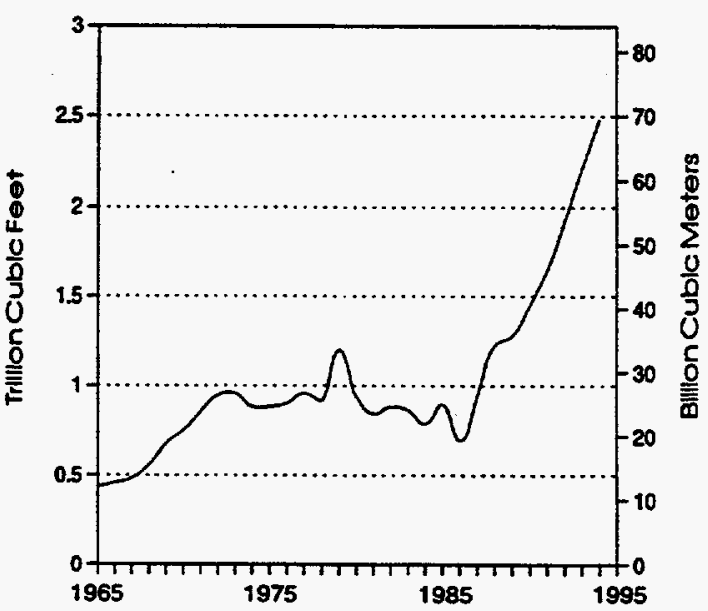

Sources: 1960-1975: Bureau of Mines, Minerals Yearbook, Natural Gas" chapter. 1976-1978: Energy Intormation Administration (ElA), Energy Data Reports, Natural Gas Annual. 1979: ElA, Natural Gas Production and Consumption, 1979. 1980-1994: ElA, Form ElA-176, "Annual Pleport of Natural and Supplemental Gas Supply and Disposition"; Forms EIA-191/FERC-B, Underground Gas Storage Report"; Form-64A, "Anmual Report of the Origin of Natural Gas Liquids Proctuction"; Form ElA-627, "Annual Quantity and Value of Natural Gas Report"; and Form FPC-14. "Annual Report for Importers and Exporters of Natural Gas." 
Table 2. Supply and Disposition of Natural Gas in the United States, 1930-1994 (Million Cubic Feet)

\begin{tabular}{|c|c|c|c|c|c|c|c|c|c|}
\hline \multirow[b]{2}{*}{ Year } & \multicolumn{5}{|c|}{ Supply } & \multicolumn{4}{|c|}{ Disposition } \\
\hline & $\begin{array}{l}\text { Dry } \\
\text { Production }\end{array}$ & $\begin{array}{l}\text { Writhdrumals } \\
\text { from } \\
\text { storege }\end{array}$ & Inperts & $\begin{array}{c}\text { Balaneing } \\
\text { them }\end{array}$ & Toral & $\begin{array}{l}\text { Additions } \\
\text { to } \\
\text { Storige }\end{array}$ & Exports & Consumption & Total \\
\hline 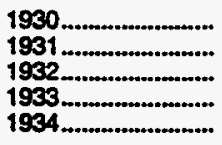 & $\begin{array}{l}1,903,771 \\
1,659,614 \\
1,541,992 \\
1,548,393 \\
1,763,606\end{array}$ & $\begin{array}{l}\text { NA } \\
\text { NA } \\
\text { NA } \\
\text { NA }\end{array}$ & $\begin{array}{l}21 \\
44 \\
38 \\
83 \\
68\end{array}$ & $\begin{array}{l}-35,490 \\
-35,465 \\
-37,808 \\
-41,199 \\
-45,075\end{array}$ & $\begin{array}{l}1,868,302 \\
1,624,192 \\
1,504,212 \\
1,507,277 \\
1,718,599\end{array}$ & $\begin{array}{l}\text { NA } \\
\text { NA } \\
\text { NA } \\
\text { NA } \\
\text { NA }\end{array}$ & $\begin{array}{l}1,798 \\
2,231 \\
1,693 \\
2,158 \\
5,801\end{array}$ & $\begin{array}{l}1,866,504 \\
1,621,961 \\
1,502,519 \\
1,505,119 \\
1,712,798\end{array}$ & $\begin{array}{l}1,868,302 \\
1,624,192 \\
1,504,212 \\
1,507,277 \\
1,718,599\end{array}$ \\
\hline 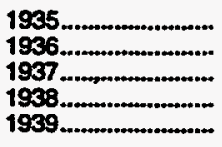 & $\begin{array}{l}1,913,475 \\
2,164,413 \\
2,403,273 \\
2,284,863 \\
2,464,637\end{array}$ & $\begin{array}{l}\text { NA } \\
\text { NA } \\
\text { NA } \\
\text { NA }\end{array}$ & $\begin{array}{l}106 \\
152 \\
289 \\
372 \\
131\end{array}$ & $\begin{array}{l}-41,074 \\
-46,677 \\
-52,157 \\
-47,658 \\
-53,595\end{array}$ & $\begin{array}{l}1,872,507 \\
2,117,888 \\
2,351,405 \\
2,237,577 \\
2,411,173\end{array}$ & $\begin{array}{r}11,294 \\
10,998 \\
13,706 \\
14,981 \\
8,032\end{array}$ & $\begin{array}{l}6,800 \\
7,436 \\
4,868 \\
1,837 \\
3,122\end{array}$ & $\begin{array}{l}1,854,413 \\
2,099,454 \\
2,332,831 \\
2,220,759 \\
2,400,019\end{array}$ & $\begin{array}{l}1,872,507 \\
2,117,888 \\
2,351,405 \\
2,237,577 \\
2,411,173\end{array}$ \\
\hline 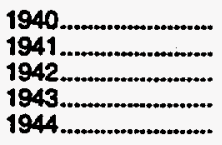 & $\begin{array}{l}2,654,293 \\
2,778,061 \\
3,026,694 \\
3,393,743 \\
3,672,156\end{array}$ & $\begin{array}{r}\text { NA } \\
\text { NA } \\
\text { NA } \\
\text { NA } \\
33,585\end{array}$ & $\begin{array}{l}0 \\
0 \\
0 \\
0 \\
0\end{array}$ & $\begin{array}{l}-58,602 \\
-64,616 \\
-71,195 \\
-81,889 \\
-94,068\end{array}$ & $\begin{array}{l}2,595,691 \\
2,713,445 \\
2,955,499 \\
3,311,854 \\
3,611,673\end{array}$ & $\begin{array}{l}14,995 \\
16,251 \\
21,024 \\
18,953 \\
43,502\end{array}$ & $\begin{array}{r}5,563 \\
7,466 \\
8,702 \\
11,210 \\
14,576\end{array}$ & $\begin{array}{l}2.575,133 \\
2,689,728 \\
2,925,773 \\
3,281,691 \\
3,553,595\end{array}$ & $\begin{array}{l}2,595,691 \\
2,713,445 \\
2,955,499 \\
3,311,854 \\
3,611,673\end{array}$ \\
\hline 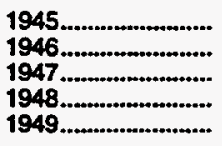 & $\begin{array}{l}3,882,066 \\
3,987,488 \\
4,393,439 \\
4,939,512 \\
5,195,404\end{array}$ & $\begin{array}{r}36,167 \\
56,138 \\
86,643 \\
79,035 \\
106,368\end{array}$ & $\begin{array}{l}0 \\
0 \\
0 \\
0 \\
0\end{array}$ & $\begin{array}{r}-97,981 \\
-102,837 \\
-127,807 \\
-126,796 \\
-138,515\end{array}$ & $\begin{array}{l}3,820,252 \\
3,940,789 \\
4,352,275 \\
4,890,751 \\
5,163,257\end{array}$ & $\begin{array}{r}61,502 \\
75,458 \\
96,316 \\
136,406 \\
172,051\end{array}$ & $\begin{array}{l}18,207 \\
17,675 \\
18,149 \\
18,704 \\
20,054\end{array}$ & $\begin{array}{l}3,740,543 \\
3,847,656 \\
4,237,810 \\
4,735,641 \\
4,971,152\end{array}$ & $\begin{array}{l}3,820,252 \\
3,940,789 \\
4,352,275 \\
4,890,751 \\
5,163,257\end{array}$ \\
\hline 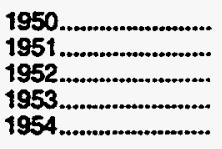 & $\begin{array}{l}6,022,198 \\
7,164,959 \\
7,694,299 \\
8,056,848 \\
8,388,198\end{array}$ & $\begin{array}{l}175,260 \\
209,428 \\
221,909 \\
246,802 \\
330,177\end{array}$ & $\begin{array}{r}0 \\
0 \\
7,807 \\
9,225 \\
6,847\end{array}$ & $\begin{array}{l}-175,437 \\
-192,372 \\
-203,646 \\
-240,445 \\
-215,709\end{array}$ & $\begin{array}{l}6,022,021 \\
7,182,015 \\
7,720,369 \\
8,072,430 \\
\mathbf{8}, 509,513\end{array}$ & $\begin{array}{l}229,752 \\
347,690 \\
398,593 \\
404,838 \\
432,283\end{array}$ & $\begin{array}{l}25,727 \\
24,163 \\
27,456 \\
28,322 \\
28,726\end{array}$ & $\begin{array}{l}5,766,542 \\
6,810,162 \\
7,294,320 \\
7,639,270 \\
8,048,504\end{array}$ & $\begin{array}{l}6,022,021 \\
7,182,015 \\
7,720,369 \\
8,072,430 \\
8,509,513\end{array}$ \\
\hline $\begin{array}{l}1955 \ldots \ldots \\
1956 \ldots \\
1958 \ldots \ldots \\
1959 \ldots \ldots \ldots\end{array}$ & $\begin{array}{r}9,028,665 \\
9,653,910 \\
10,246,622 \\
10,572,208 \\
11,547,658\end{array}$ & $\begin{array}{l}437,251 \\
452,762 \\
480,981 \\
621,091 \\
668,743\end{array}$ & $\begin{array}{r}10,888 \\
10,380 \\
37,941 \\
135,797 \\
133,990\end{array}$ & $\begin{array}{l}-246,933 \\
-212,992 \\
-205,373 \\
-283,597 \\
-223,312\end{array}$ & $\begin{array}{r}9,229,871 \\
9,914,060 \\
10,560,171 \\
11,045,499 \\
12,127,079\end{array}$ & $\begin{array}{l}505,185 \\
589,232 \\
672,377 \\
704,172 \\
787,485\end{array}$ & $\begin{array}{l}31,029 \\
35,963 \\
41,655 \\
38,719 \\
18,413\end{array}$ & $\begin{array}{r}8,693,657 \\
9,288,865 \\
9,846,139 \\
10,302,608 \\
11,321,181\end{array}$ & $\begin{array}{r}9,229,871 \\
9,914,060 \\
10,560,171 \\
11,045,499 \\
12,127,079\end{array}$ \\
\hline $\begin{array}{l}1960 \ldots \ldots \\
1961 \ldots \ldots \\
1962 \ldots \ldots \ldots \\
1963 \ldots \ldots \ldots \\
1964 \ldots \ldots \ldots \ldots\end{array}$ & $\begin{array}{l}12,228,148 \\
12,661,579 \\
13,253,006 \\
14,076,412 \\
14,824,027\end{array}$ & $\begin{array}{l}712,658 \\
698,050 \\
854,356 \\
916,720 \\
885,307\end{array}$ & $\begin{array}{l}155,646 \\
218,860 \\
401,534 \\
406,204 \\
443,326\end{array}$ & $\begin{array}{l}-274,231 \\
-234,808 \\
-285,726 \\
-364,658 \\
-304,435\end{array}$ & $\begin{array}{l}12,822,221 \\
13,343,681 \\
14,223,150 \\
15,034,678 \\
15,848,225\end{array}$ & $\begin{array}{r}844,352 \\
843,666 \\
940,823 \\
1,047,492 \\
1,014,814\end{array}$ & $\begin{array}{l}11,332 \\
10,747 \\
15,814 \\
16,957 \\
19,603\end{array}$ & $\begin{array}{l}11,966,537 \\
12,489,268 \\
13,266,513 \\
13,970,229 \\
14,813,808\end{array}$ & $\begin{array}{l}12,822,221 \\
13,343,681 \\
14,223,150 \\
15,034,678 \\
15,848,225\end{array}$ \\
\hline 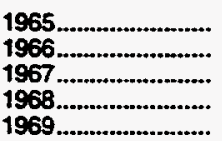 & $\begin{array}{l}15,286,280 \\
16,467,320 \\
17,386,791 \\
18,494,523 \\
19,831,680\end{array}$ & $\begin{array}{r}959,865 \\
1,141,614 \\
1,132,534 \\
1,329,536 \\
1,379,488\end{array}$ & $\begin{array}{l}456,394 \\
479,780 \\
564,226 \\
651,885 \\
726,951\end{array}$ & $\begin{array}{l}-318,711 \\
-401,203 \\
-296,214 \\
-325,062 \\
-334,168\end{array}$ & $\begin{array}{l}16,383,828 \\
17,687,511 \\
18,787,337 \\
20,150,882 \\
21,603,951\end{array}$ & $\begin{array}{l}1.077,980 \\
1.210,469 \\
1,317,363 \\
1,425,075 \\
1,498,988\end{array}$ & $\begin{array}{l}26,132 \\
24,639 \\
81,614 \\
93,745 \\
51,304\end{array}$ & $\begin{array}{l}15,279,716 \\
16,452,403 \\
17,388,360 \\
18,632,062 \\
20,056,240\end{array}$ & $\begin{array}{l}16,383,828 \\
17,687,511 \\
18,787,337 \\
20,150,882 \\
21,606,532\end{array}$ \\
\hline
\end{tabular}

See footnotes at end of table. 
Table 2. Supply and Disposition of Natural Gas in the United States, 1930-1994 (Continued) (Milion Cubic Feet)

\begin{tabular}{|c|c|c|c|c|c|c|c|c|c|}
\hline \multirow[b]{2}{*}{ Year } & \multicolumn{5}{|c|}{ Supply } & \multicolumn{4}{|c|}{ Disposition } \\
\hline & $\begin{array}{l}\text { Dry } \\
\text { Production }\end{array}$ & $\begin{array}{l}\text { Withdrewrals } \\
\text { trom } \\
\text { storage }\end{array}$ & Imperts & $\begin{array}{l}\text { Balancing } \\
\text { nom }\end{array}$ & Total & $\begin{array}{l}\text { Additions } \\
\text { to } \\
\text { Storegh }\end{array}$ & Exports & Consumption & Total \\
\hline 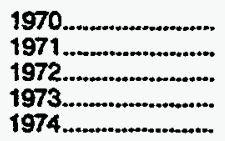 & $\begin{array}{l}21,014,229 \\
21,609,885 \\
21,623,705 \\
21,730,998 \\
20,713,032\end{array}$ & $\begin{array}{l}1,458,607 \\
1,507,630 \\
1,757,218 \\
1,532,820 \\
1,700,546\end{array}$ & $\begin{array}{r}820,780 \\
934,548 \\
1,019,496 \\
1,032,901 \\
959,284\end{array}$ & $\begin{array}{l}-227,650 \\
-338,999 \\
-328,002 \\
-195,863 \\
-288,731\end{array}$ & $\begin{array}{l}23,065,966 \\
23,713,064 \\
24,072,417 \\
24,100,856 \\
23,084,131\end{array}$ & $\begin{array}{l}1,856,767 \\
1,839,398 \\
1,892,952 \\
1,974,324 \\
1,784,209\end{array}$ & $\begin{array}{l}69,813 \\
80,212 \\
78,013 \\
77,169 \\
76,789\end{array}$ & $\begin{array}{l}21,139,386 \\
21,793,454 \\
22,101,452 \\
22,049,363 \\
21,223,133\end{array}$ & $\begin{array}{l}23,065,966 \\
23,713,064 \\
24,072,417 \\
24,100,856 \\
23,084,131\end{array}$ \\
\hline 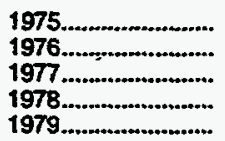 & $\begin{array}{l}19,236,379 \\
19,098,352 \\
19,162,900 \\
19,121,903 \\
19,663,415\end{array}$ & $\begin{array}{l}1,759,565 \\
2,059,898 \\
1,735,868 \\
2,150,928 \\
2,057,020\end{array}$ & $\begin{array}{r}953,008 \\
963,766 \\
1,011,002 \\
965,545 \\
1,253,383\end{array}$ & $\begin{array}{r}-235,065 \\
-216,240 \\
-41,063 \\
-287,201 \\
-372,330\end{array}$ & $\begin{array}{l}21,713,887 \\
21,905,778 \\
21,868,707 \\
21,951,175 \\
22,601,488\end{array}$ & $\begin{array}{l}2,103,619 \\
1,755,690 \\
2,306,515 \\
2,278,002 \\
2,295,034\end{array}$ & $\begin{array}{l}72,675 \\
64,711 \\
55,626 \\
52,532 \\
55,673\end{array}$ & $\begin{array}{l}19,537,593 \\
19,946,496 \\
19,520,581 \\
19,627,478 \\
20,240,761\end{array}$ & $\begin{array}{l}21,713,887 \\
21,766,897 \\
21,882,722 \\
21,958,012 \\
22,591,468\end{array}$ \\
\hline 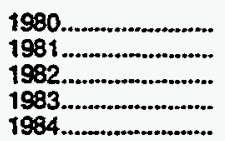 & $\begin{array}{l}19,557,709 \\
19,356,963 \\
17,964,874 \\
16,226,355 \\
17,576,449\end{array}$ & $\begin{array}{l}1,972,333 \\
1,930,092 \\
2,164,184 \\
2,269,654 \\
2,098,303\end{array}$ & $\begin{array}{l}984,767 \\
903,949 \\
933,336 \\
918,407 \\
843,060\end{array}$ & $\begin{array}{l}-639,721 \\
-500,444 \\
-537,061 \\
-703,342 \\
-217,308\end{array}$ & $\begin{array}{l}21,875,088 \\
21,690,560 \\
20,525,333 \\
18,711,074 \\
20,300,504\end{array}$ & $\begin{array}{l}1,949,064 \\
2,227,522 \\
2,472,383 \\
1,822,354 \\
2,295,138\end{array}$ & $\begin{array}{l}48,731 \\
59,372 \\
51,728 \\
54,639 \\
54,753\end{array}$ & $\begin{array}{l}19,877,293 \\
19,403,858 \\
18,001,055 \\
16,834,914 \\
17,950,524\end{array}$ & $\begin{array}{l}21,875,088 \\
21,690,752 \\
20,525,166 \\
18,711,907 \\
20,300,415\end{array}$ \\
\hline 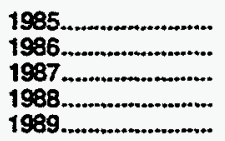 & $\begin{array}{l}16,580,220 \\
16,172,219 \\
16,721,963 \\
17,203,755 \\
17,417,390\end{array}$ & $\begin{array}{l}2,397,359 \\
1,836,693 \\
1,905,419 \\
2,270,011 \\
2,854,061\end{array}$ & $\begin{array}{r}949,715 \\
750,449 \\
992,532 \\
1,293,812 \\
1,381,520\end{array}$ & $\begin{array}{l}-428,120 \\
-494,491 \\
-443,231 \\
-452,492 \\
-217,526\end{array}$ & $\begin{array}{l}19,499,174 \\
18,264,870 \\
19,176,683 \\
20,315,086 \\
21,435,445\end{array}$ & $\begin{array}{l}2,162,603 \\
1,983,603 \\
1,911,489 \\
2,211,277 \\
2,527,750\end{array}$ & $\begin{array}{r}55,268 \\
61,271 \\
54,020 \\
73,638 \\
106,871\end{array}$ & $\begin{array}{l}17,280,943 \\
16,221,296 \\
17,210,809 \\
18,029,588 \\
18,800,826\end{array}$ & $\begin{array}{l}19,498,814 \\
18,266,170 \\
19,176,318 \\
20,314,503 \\
21,435,447\end{array}$ \\
\hline 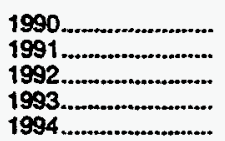 & $\begin{array}{r}17,932,480 \\
17,810,408 \\
17,957,822 \\
A_{18,214,459} \\
18,857,821\end{array}$ & $\begin{array}{l}1,986,330 \\
2,751,818 \\
2,772,308 \\
2,799,253 \\
2,562,116\end{array}$ & $\begin{array}{l}1,532,259 \\
1,773,313 \\
2,137,504 \\
2,350,115 \\
2,659,673\end{array}$ & $\begin{array}{r}-151,863 \\
-499,779 \\
-507,565 \\
R_{-109,593} \\
-296,577\end{array}$ & $\begin{array}{r}21,299,206 \\
21,835,760 \\
22,360,069 \\
A_{23,254,234} \\
23,783,033\end{array}$ & $\begin{array}{l}2,499,264 \\
2,671,632 \\
2,599,426 \\
2,834,955 \\
2,864,757\end{array}$ & $\begin{array}{r}85,565 \\
129,244 \\
216,282 \\
140,183 \\
178,066\end{array}$ & $\begin{array}{r}18,715,090 \\
19,035,156 \\
19,544,364 \\
A_{20,279,095} \\
20,755,471\end{array}$ & $\begin{array}{r}21,299,919 \\
21,836,032 \\
22,360,072 \\
R_{23,254,233} \\
23,798,294\end{array}$ \\
\hline
\end{tabular}

R = Revised data.

NA = Not Available. (LNG). Beginning with 1976 data, total supply and disposition do not balance on equivalent data in Table 1 due to the exciusion of intransit receipts and deliveries. Beginning with 1965 data, all volumes are shown on a pressure base of 14.73 psia at degrees Fahrentert. For prior years, the pressure base is 14.65 psia at 60 degrees Fahrenheit.

Sources: 1930-1975: Bureau of Mines, Minerals Yearbook. "Natural Gas" chapter. 1976-1978: Energy Iniormation Administration (ElA), Energy Data Report, Natural Gas Annual. 1979: ElA, Natural Gas Froduction and Consumption, 1979. 1980-1994: EIA, Form EIA-176, "Annual Report of Natural and Supplemental Gas Supply and

Disposition": Form ElA-191. "Underground Gas Storage Roport"; Form ElA-64A, "Annual Report of the Origin of Natural Gas Liquids Production"; Form E1A-627, "Annual 
Figure 2. Natural Gas Delivered to Consumers in the United States, 1930 - 1994

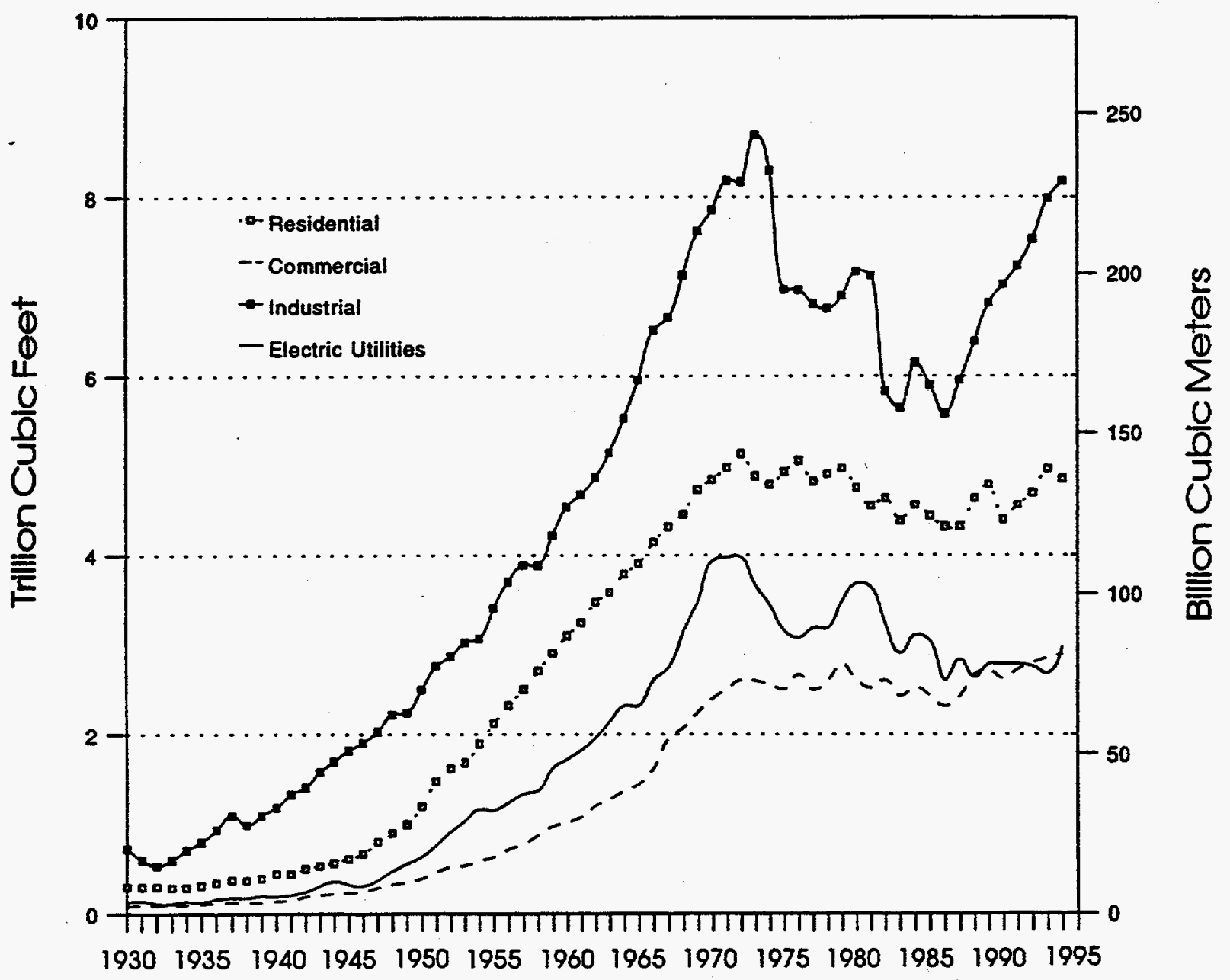

Sources: 1930-1975: Bureau of Mines, Minerals Yeabook, Natural Gas' chapter. 1976-1978: Energy tntomation Adminietration (ElA), Energy Data Reports, Natural Gas Annual. 1979: EIA, Natural Gas Production and Consumption, 1979. 1980-1994: Form ElA-176, Anmual Report of Natural and Supplemental Gas Supply and Dispostion" and Form ElA-759 "Monthly Power Plant Roport" 
Table 3. Natural Gas Consumption in the United States, 1930-1994 (Million Cubic Feet)

\begin{tabular}{|c|c|c|c|c|c|c|c|c|c|}
\hline \multirow{2}{*}{ Year } & \multirow{2}{*}{$\begin{array}{l}\text { Leane } \\
\text { and } \\
\text { Plant Fuel }\end{array}$} & \multirow{2}{*}{$\begin{array}{l}\text { Pipeline } \\
\text { Fenf }\end{array}$} & \multicolumn{6}{|c|}{ Delivered to Consumers } & \multirow{2}{*}{$\begin{array}{l}\text { Total } \\
\text { Consumption }\end{array}$} \\
\hline & & & Residential & Comnercial & Induetrial & Vohiels Funl & $\begin{array}{l}\text { Electiric } \\
\text { Utilities }\end{array}$ & Total & \\
\hline 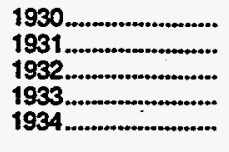 & $\begin{array}{l}648,025 \\
509,077 \\
477,562 \\
442,879 \\
502,352\end{array}$ & $\begin{array}{l}\text { NA } \\
\text { NA } \\
\text { NA } \\
\text { NA }\end{array}$ & $\begin{array}{l}295,700 \\
294,406 \\
298,520 \\
283,197 \\
288,236\end{array}$ & $\begin{array}{l}80,707 \\
86,491 \\
87,367 \\
85,577 \\
91,261\end{array}$ & $\begin{array}{l}721,782 \\
593,644 \\
531,831 \\
590,865 \\
703,053\end{array}$ & $\begin{array}{l}\text { NA } \\
\text { NA } \\
\text { NA } \\
\text { NA } \\
\text { NA }\end{array}$ & $\begin{array}{l}120,290 \\
138,343 \\
107,239 \\
102,601 \\
127,896\end{array}$ & $\begin{array}{l}1,218,479 \\
1,112,884 \\
1,024,957 \\
1,062,240 \\
1,210,446\end{array}$ & $\begin{array}{l}1,866,504 \\
1,621,961 \\
1,502,519 \\
1,505,119 \\
1,712,798\end{array}$ \\
\hline 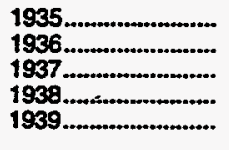 & $\begin{array}{l}\mathbf{5 2 4 , 9 2 6} \\
\mathbf{5 5 7 , 4 0 4} \\
\mathbf{5 8 1 , 1 1 0} \\
\mathbf{5 8 5 , 8 6 5} \\
\mathbf{6 0 7 , 1 3 8}\end{array}$ & $\begin{array}{l}\text { NA } \\
\text { NA } \\
\text { NA } \\
\text { NA }\end{array}$ & $\begin{array}{l}313,498 \\
343,346 \\
371,844 \\
367,772 \\
391,153\end{array}$ & $\begin{array}{l}100,187 \\
111,623 \\
117,390 \\
114,296 \\
118,334\end{array}$ & $\begin{array}{r}790,563 \\
931,001 \\
1,091,920 \\
982,838 \\
1,092,263\end{array}$ & $\begin{array}{l}\text { NA } \\
\text { NA } \\
\text { NA } \\
\text { NA }\end{array}$ & $\begin{array}{l}125,239 \\
156,080 \\
170,567 \\
169,988 \\
191,131\end{array}$ & $\begin{array}{l}1,329,487 \\
1,542,050 \\
1,751,721 \\
1,634,894 \\
1,792,881\end{array}$ & $\begin{array}{l}1,854,413 \\
2,099,454 \\
2,332,831 \\
2,220,759 \\
2,400,019\end{array}$ \\
\hline 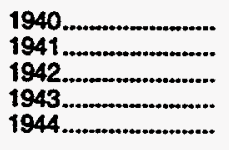 & $\begin{array}{l}632,335 \\
570,694 \\
602,063 \\
659,198 \\
712,312\end{array}$ & $\begin{array}{l}\text { NA } \\
\text { NA } \\
\text { NA } \\
\text { NA } \\
\text { NA }\end{array}$ & $\begin{array}{l}443,646 \\
442,057 \\
498,557 \\
529,444 \\
562,183\end{array}$ & $\begin{array}{l}134,644 \\
144,844 \\
183,603 \\
204,793 \\
220,747\end{array}$ & $\begin{array}{l}1,181,352 \\
1,326,967 \\
1,402,834 \\
1,582,680 \\
1,698,608\end{array}$ & $\begin{array}{l}\text { NA } \\
\text { NA } \\
\text { NA } \\
\text { NA } \\
\text { NA }\end{array}$ & $\begin{array}{l}183,156 \\
205,156 \\
238,736 \\
305,576 \\
359,745\end{array}$ & $\begin{array}{l}1,942,798 \\
2,119,034 \\
2,323,710 \\
2,622,493 \\
2,841,283\end{array}$ & $\begin{array}{l}2,575,133 \\
2,689,728 \\
2,925,773 \\
3,281,691 \\
3,553,595\end{array}$ \\
\hline 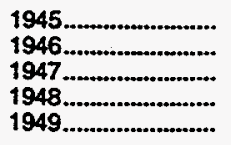 & $\begin{array}{l}757,016 \\
732,535 \\
745,027 \\
812,005 \\
835,297\end{array}$ & $\begin{array}{l}\text { NA } \\
\text { NA } \\
\text { NA } \\
\text { NA } \\
\text { NA }\end{array}$ & $\begin{array}{l}607,400 \\
660,820 \\
802,150 \\
896,348 \\
992,544\end{array}$ & $\begin{array}{l}230,099 \\
241,802 \\
285,213 \\
323,054 \\
347,818\end{array}$ & $\begin{array}{l}1,819,838 \\
i, 905,575 \\
2,032,383 \\
2,226,137 \\
2,245,372\end{array}$ & $\begin{array}{l}\text { NA } \\
\text { NA } \\
\text { NA } \\
\text { NA } \\
\text { NA }\end{array}$ & $\begin{array}{l}326,190 \\
306,924 \\
373,037 \\
478,097 \\
550,121\end{array}$ & $\begin{array}{l}2,983,527 \\
3,115,121 \\
3,492,783 \\
3,923,636 \\
4,135,855\end{array}$ & $\begin{array}{l}3,740,543 \\
3,847,656 \\
4,237,810 \\
4,735,641 \\
4,971,152\end{array}$ \\
\hline 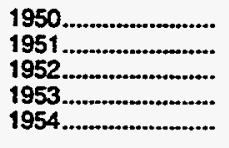 & $\begin{array}{r}927,611 \\
1,149,470 \\
1,164,596 \\
1,131,017 \\
1,102,535\end{array}$ & $\begin{array}{l}125,546 \\
192,496 \\
207,207 \\
230,314 \\
230,615\end{array}$ & $\begin{array}{l}1,198,369 \\
1,474,725 \\
1,621,966 \\
1,685,503 \\
1,894,248\end{array}$ & $\begin{array}{l}387,838 \\
464,309 \\
515,669 \\
530,650 \\
584,957\end{array}$ & $\begin{array}{l}2,498,259 \\
2,765,264 \\
2,874,765 \\
3,027,514 \\
3,070,651\end{array}$ & $\begin{array}{l}\text { NA } \\
\text { NA } \\
\text { NA } \\
\text { NA } \\
\text { NA }\end{array}$ & $\begin{array}{r}628,919 \\
763,898 \\
910,117 \\
1,034,272 \\
1,165,498\end{array}$ & $\begin{array}{l}4,713,385 \\
5,468,196 \\
5,922,517 \\
6,277.939 \\
6,715,354\end{array}$ & $\begin{array}{l}5,766,542 \\
6,810,162 \\
7,294,320 \\
7,639,270 \\
8,048,504\end{array}$ \\
\hline 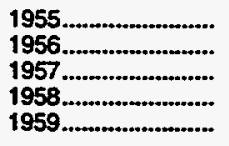 & $\begin{array}{l}1,130,985 \\
1,002,537 \\
1,046,084 \\
1,146,064 \\
1,238,945\end{array}$ & $\begin{array}{l}245,246 \\
295,972 \\
299,235 \\
312,221 \\
349,348\end{array}$ & $\begin{array}{l}2,123,952 \\
2,327,564 \\
2,500,269 \\
2,714,251 \\
2,912,601\end{array}$ & $\begin{array}{l}629.219 \\
716,871 \\
775,916 \\
871,774 \\
975,107\end{array}$ & $\begin{array}{l}3,410,975 \\
3,706,610 \\
3,888,494 \\
3,885,445 \\
4,216,671\end{array}$ & $\begin{array}{l}\text { NA } \\
\text { NA } \\
\text { NA } \\
\text { NA } \\
\text { NA }\end{array}$ & $\begin{array}{l}1,153,280 \\
1,239,311 \\
1,336,141 \\
1,372,853 \\
1,628,509\end{array}$ & $\begin{array}{l}7,317,426 \\
7,990,356 \\
8,500,820 \\
8,844,323 \\
9,732,888\end{array}$ & $\begin{array}{r}8,693,657 \\
9,288,865 \\
9,846,139 \\
10,302,608 \\
11,321,181\end{array}$ \\
\hline 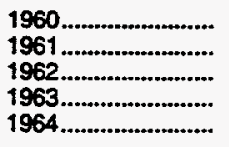 & $\begin{array}{l}1,236,781 \\
1,288,762 \\
1,369,512 \\
1,411,088 \\
1,370,835\end{array}$ & $\begin{array}{l}347,075 \\
377,607 \\
382,496 \\
423,783 \\
435,570\end{array}$ & $\begin{array}{l}3,103,167 \\
3,248,578 \\
3,478,563 \\
3,589,021 \\
3,787,292\end{array}$ & $\begin{array}{l}1,020,222 \\
1,076,849 \\
1,206,668 \\
1,267,783 \\
1,374,717\end{array}$ & $\begin{array}{l}4,534,530 \\
4,672,355 \\
4,863,300 \\
5,134,081 \\
5,522,498\end{array}$ & $\begin{array}{l}\text { NA } \\
\text { NA } \\
\text { NA } \\
\text { NA } \\
\text { NA }\end{array}$ & $\begin{array}{l}1,724,762 \\
1,825,117 \\
1,965,974 \\
2,144,473 \\
2,322,896\end{array}$ & $\begin{array}{l}10,382,681 \\
10,822,899 \\
11,514,505 \\
12,135,358 \\
13,007,403\end{array}$ & $\begin{array}{l}11,966,537 \\
12,489,268 \\
13,266,513 \\
13,970,229 \\
14,813,808\end{array}$ \\
\hline 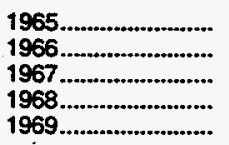 & $\begin{array}{l}1,156,224 \\
1,033,400 \\
1,140,966 \\
1,237,131 \\
1,345,648\end{array}$ & $\begin{array}{l}500,524 \\
535,353 \\
575,752 \\
590,965 \\
630,962\end{array}$ & $\begin{array}{l}3,902,802 \\
4,138,259 \\
4,313,304 \\
4,450,354 \\
4,728,281\end{array}$ & $\begin{array}{l}1,443,648 \\
1,622,740 \\
1,958,970 \\
2,075,736 \\
2,253,206\end{array}$ & $\begin{array}{l}5,955,417 \\
6,512,702 \\
6,653,016 \\
7,129,967 \\
7,610,501\end{array}$ & $\begin{array}{l}\text { NA } \\
\text { NA } \\
\text { NA } \\
\text { NA } \\
\text { NA }\end{array}$ & $\begin{array}{l}2,321,101 \\
2,609,949 \\
2,746,352 \\
3,147,909 \\
3,487,642\end{array}$ & $\begin{array}{l}13,622,968 \\
14,883,650 \\
15,671,642 \\
16,803,966 \\
18,079,630\end{array}$ & $\begin{array}{l}15,279,716 \\
16,452,403 \\
17,388,360 \\
18,632,062 \\
20,056,240\end{array}$ \\
\hline
\end{tabular}

See footnotes al end of table. 
Table 3. Natural Gas Consumption in the United States, 1930-1994 (Continued) (Million Cubic Feet)

\begin{tabular}{|c|c|c|c|c|c|c|c|c|c|}
\hline \multirow{2}{*}{ Year } & \multirow{2}{*}{$\begin{array}{l}\text { Leand } \\
\text { and } \\
\text { Plent Fud }\end{array}$} & \multirow{2}{*}{ Pipeline } & \multicolumn{6}{|c|}{ Detivered to Convumere } & \multirow{2}{*}{$\begin{array}{c}\text { Total } \\
\text { Consumption }\end{array}$} \\
\hline & & & Rosidential & Commerciel & Induretrial & Venich Fus & $\begin{array}{l}\text { Electric } \\
\text { Untitios }\end{array}$ & Total & \\
\hline 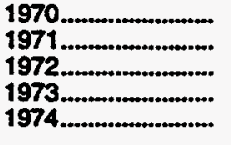 & $\begin{array}{l}1,398,758 \\
1,413,650 \\
1,455,563 \\
1,495,915 \\
1,477,386\end{array}$ & $\begin{array}{l}722,166 \\
742,592 \\
766,156 \\
728,177 \\
668,792\end{array}$ & $\begin{array}{l}4,837,432 \\
4,971,690 \\
5,125,982 \\
4,879,387 \\
4,786,128\end{array}$ & $\begin{array}{l}2,398,510 \\
2,508,977 \\
2,607,982 \\
2,597,037 \\
2,555,617\end{array}$ & $\begin{array}{l}7,850,660 \\
8,180,527 \\
8,168,855 \\
8,688,675 \\
8,291,782\end{array}$ & $\begin{array}{l}\mathbf{N A} \\
\mathbf{N A} \\
\mathbf{N A} \\
\mathbf{N A} \\
\mathbf{N A}\end{array}$ & $\begin{array}{l}3,931,860 \\
3,976,018 \\
3,976,914 \\
3,660,172 \\
3,443,428\end{array}$ & $\begin{array}{l}19,018,462 \\
19,637,212 \\
19,879,733 \\
19,825,271 \\
19,076,955\end{array}$ & $\begin{array}{l}21,139,386 \\
21,793,454 \\
22,101,452 \\
22,049,363 \\
21,223,133\end{array}$ \\
\hline $1975 \ldots$ & $\begin{array}{l}1,396,277 \\
1,634,355 \\
1,659,145 \\
1,647,911 \\
1,498,530\end{array}$ & $\begin{array}{l}582,963 \\
548,323 \\
532,669 \\
580,451 \\
600,964\end{array}$ & $\begin{array}{l}4,924,124 \\
5,051,360 \\
4,821,485 \\
4,903,006 \\
4,965,365\end{array}$ & $\begin{array}{l}2,508,293 \\
2,667,740 \\
2,500,793 \\
2,601.106 \\
2,785,961\end{array}$ & $\begin{array}{l}6,958,267 \\
6,953,850 \\
6,815,289 \\
6,756,641 \\
6,899,418\end{array}$ & $\begin{array}{l}\text { NA } \\
\text { NA } \\
\text { NA } \\
\text { NA } \\
\text { NA }\end{array}$ & $\begin{array}{l}3,157,659 \\
3,080,868 \\
3,191,200 \\
3,188,363 \\
3,490,523\end{array}$ & $\begin{array}{l}17,558,353 \\
17,763,818 \\
17,328,767 \\
17,449,116 \\
18,141,267\end{array}$ & $\begin{array}{l}19,537,593 \\
19,946,496 \\
19,520,581 \\
19,627,478 \\
20,240,761\end{array}$ \\
\hline 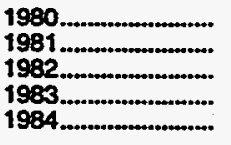 & $\begin{array}{r}1,026,438 \\
927,591 \\
1,109,398 \\
978,249 \\
1,076,881\end{array}$ & $\begin{array}{l}634,622 \\
642,325 \\
595,411 \\
490,042 \\
528,754\end{array}$ & $\begin{array}{l}4,752,082 \\
4,546,450 \\
4,633,035 \\
4,390,599 \\
4,555,465\end{array}$ & $\begin{array}{l}2,610,895 \\
2,519,791 \\
2,605,523 \\
2,432,547 \\
2,524,244\end{array}$ & $\begin{array}{l}7,171,661 \\
7,127,547 \\
5,831,170 \\
5,642,708 \\
6,153,841\end{array}$ & $\begin{array}{l}\text { NA }: " \\
\text { NA } \\
\text { NA } \\
\text { NA }\end{array}$ & $\begin{array}{l}3,681,595 \\
3,640,154 \\
3,225,518 \\
2,910,767 \\
3,111,342\end{array}$ & $\begin{array}{l}18,216,233 \\
17,833,942 \\
16,295,245 \\
15,366,621 \\
16,344,893\end{array}$ & $\begin{array}{l}19,877,293 \\
19,403,858 \\
18,001,055 \\
16,834,914 \\
17,950,524\end{array}$ \\
\hline 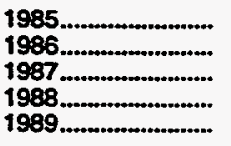 & $\begin{array}{r}966,047 \\
922,524 \\
1,149,383 \\
1,095,883 \\
1,069,902\end{array}$ & $\begin{array}{l}503,766 \\
485,041 \\
519,170 \\
613,912 \\
629,308\end{array}$ & $\begin{array}{l}4,433,377 \\
4,313,969 \\
4,314,833 \\
4,630,330 \\
4,780,638\end{array}$ & $\begin{array}{l}2,432,382 \\
2,318,335 \\
2,430,064 \\
2,670,465 \\
2,717,722\end{array}$ & $\begin{array}{l}\mathbf{5 , 9 0 1 , 2 8 8} \\
\mathbf{5 , 5 7 9 , 0 5 7} \\
\mathbf{5 , 9 5 3 , 3 0 8} \\
\mathbf{6 , 3 8 3 , 3 8 2} \\
\mathbf{6 , 8 1 6 , 2 4 4}\end{array}$ & $\begin{array}{l}\mathbf{N A} \\
\mathbf{N A} \\
\mathbf{N A} \\
\mathbf{N A} \\
\mathbf{N A}\end{array}$ & $\begin{array}{l}3,044,083 \\
2,602,370 \\
2,844,051 \\
2,635,616 \\
2,787,012\end{array}$ & $\begin{array}{l}15,811,130 \\
14,813,731 \\
15,542,256 \\
16,319,793 \\
17,101,615\end{array}$ & $\begin{array}{l}17,280,943 \\
16,221,296 \\
17,210,809 \\
18,029,588 \\
18,800,826\end{array}$ \\
\hline 1990 & $\begin{array}{r}1,236,392 \\
1,129,268 \\
1,170,821 \\
1,171,940 \\
1,160,556\end{array}$ & $\begin{array}{l}659,816 \\
601,305 \\
587,710 \\
624,308 \\
685,327\end{array}$ & $\begin{array}{r}4,391,324 \\
4,555,659 \\
4,690,065 \\
4,956,445 \\
4,847,702\end{array}$ & $\begin{array}{r}2,622,721 \\
2,728,581 \\
2,802,751 \\
R_{2,861,569} \\
2,895,034\end{array}$ & $\begin{array}{r}7,018,414 \\
7,230,962 \\
7,526,898 \\
97,981,433 \\
8,177,975\end{array}$ & $\begin{array}{r}270 \\
367 \\
511 \\
960 \\
1,730\end{array}$ & $\begin{array}{l}2,786,153 \\
2,789,014 \\
2,765,608 \\
2,682,440 \\
2,987,146\end{array}$ & $\begin{array}{r}16,818,882 \\
17,304,582 \\
17,785,833 \\
R_{18,482,847} \\
18,909,587\end{array}$ & $\begin{array}{r}18,715,090 \\
19,035,156 \\
19,544,364 \\
R_{20,279,095} \\
20,755,471\end{array}$ \\
\hline
\end{tabular}

R = Revised data

NA $=$ Not Availabie

Notes: Beginning with 1965 data, all volumes are shown on a pressure base of 14.73 psia at 60 degrees Fahrenheit. For prior years, the pressure base is 14.65 psia at 60 degrees Fahrenhein. Number of vehicle fuel consumers generalfy relers to the number of fueling stations.

Sources: 1930-1975: Bureau of Mines, Minerals Yearbook, Natural Gas" chapter. 1976-1978: Energy Information Administration (ElA), Energy Data Reports, Natural Cas Annual. 1979: EIA, Natural Gas Production and Consumption, 1979. 1980-1989: ElA, Fom EIA-176, Annutal Report of Naturai and Supplemental Gas Supply and Disposition" and Form ElA-759, "Monthly Power Plant Report, 1990: ElA, Form EIA-176, Form EIA-759, and Form ElA-64A, "Annual Report of the Origin of Natural Gas Liquids Production"; 1991-1994: EIA. Form EIA-176, Form ElA-759, Form EIA-64A, end Fom EIA-627, "Annual Quantity and Value of Natural Gas Report" 
Figure 3. Average Price of Natural Gas Delivered to U.S. Consumers, 1967-1994

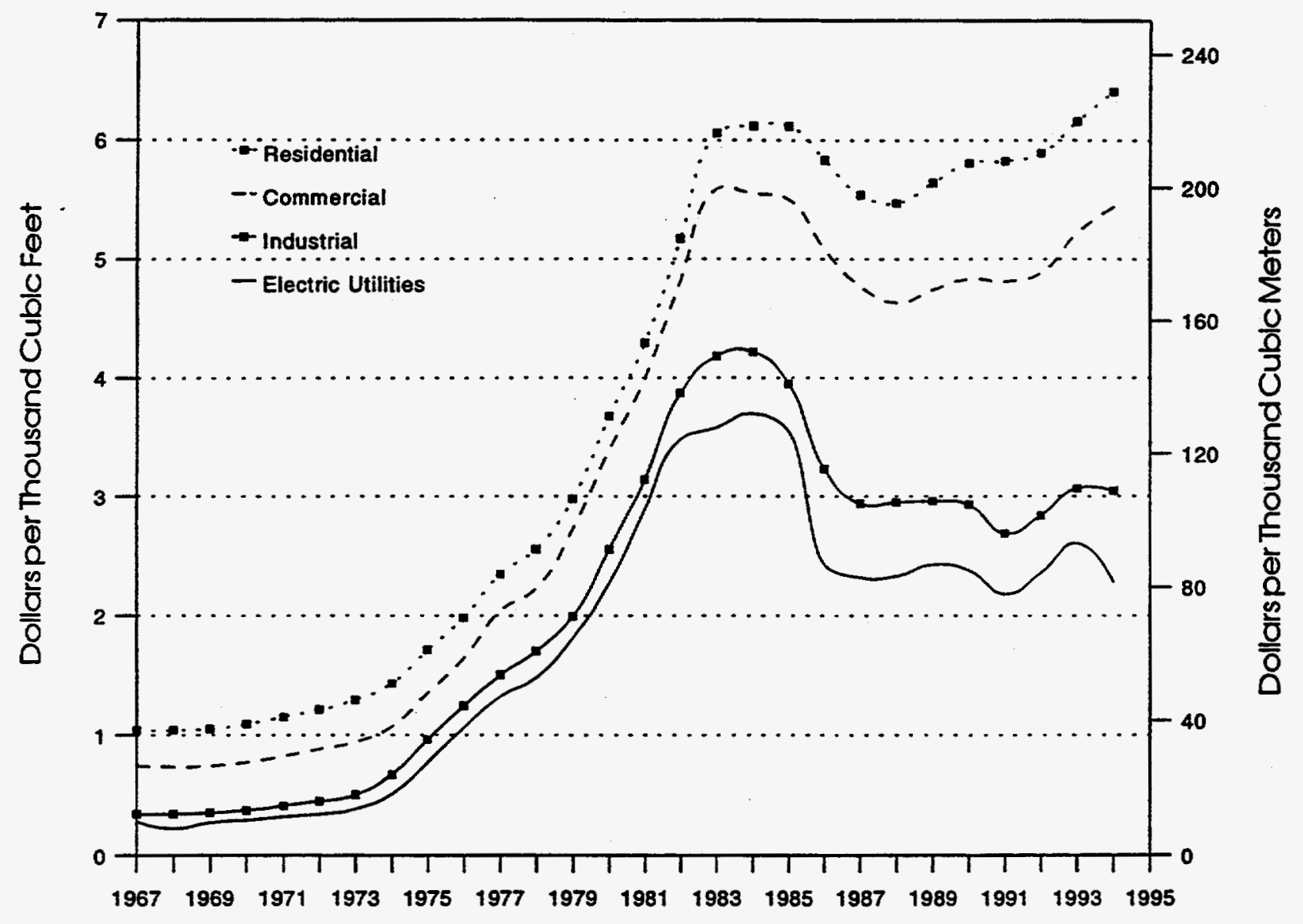

Sources: Eectric Utitities: 1967-1977: Federal Power Commission (FPC). 1978-1993: Energy Information Administration (ElA). Form ElA-759, Monthly Power Plant Report" Federal Energy Regulatory Commission (FERC). Form FERC-423, "Cost and Quality of Fuels for Electric Utitity Plants" and Form ElA-176. "Annual Report of Natural and Supplemental Gas Supply and Disposition." All other data: 1967-1975: Bureau of Mines, Minerals Yearbook, Natural Gas" chapter. 1976-1978: Energy Information Administration, Energy Data Report, Natural Gas Annual. 1979: Energy Information Administration, Natural Gas Production and Consumption 1979. 1980-1994: Energy Information Administration (EIA), Form EIA-176, "Annual Report of Natural and Supplemental Gas Supply and Disposition" and Federal Energy Regulatory Commission (FERC), Form FERC-423, Monthly Report of Cost and Quality of Fuels for Electric Piants." 
Table 4. Average Price of Natural Gas Delivered to U. S. Consumers, 1967-1994 (Dollars per Thousand Cubic Feet)

\begin{tabular}{|c|c|c|c|c|c|}
\hline \multirow{2}{*}{ Year } & \multicolumn{5}{|c|}{ Belivered to Coneumers } \\
\hline & Aeatidontial & Commercial & Industrial & Vehicle & $\begin{array}{l}\text { Electric } \\
\text { Utiluties }\end{array}$ \\
\hline 1967 & $\begin{array}{l}1.04 \\
1.04 \\
1.05 \\
1.09 \\
1.15\end{array}$ & $\begin{array}{l}0.74 \\
0.73 \\
0.74 \\
0.77 \\
0.82\end{array}$ & $\begin{array}{l}0.34 \\
0.34 \\
0.35 \\
0.37 \\
0.41\end{array}$ & $\begin{array}{l}\mathbf{N A} \\
\mathbf{N A} \\
\mathbf{N A} \\
\mathbf{N A}\end{array}$ & $\begin{array}{l}0.28 \\
0.22 \\
0.27 \\
0.29 \\
0.32\end{array}$ \\
\hline 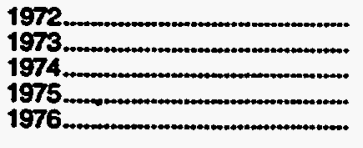 & $\begin{array}{l}1.21 \\
1.29 \\
1.43 \\
1.71 \\
1.98\end{array}$ & $\begin{array}{l}0.88 \\
0.94 \\
1.07 \\
1.35 \\
1.64\end{array}$ & $\begin{array}{l}0.45 \\
0.50 \\
0.67 \\
0.96 \\
1.24\end{array}$ & $\begin{array}{l}\text { NA } \\
\text { NA } \\
\text { NA } \\
\text { NA } \\
\text { NA }\end{array}$ & $\begin{array}{l}0.34 \\
0.38 \\
0.51 \\
0.77 \\
1.06\end{array}$ \\
\hline 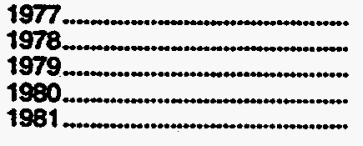 & $\begin{array}{l}2.35 \\
2.56 \\
2.98 \\
3.68 \\
4.29\end{array}$ & $\begin{array}{l}2.04 \\
2.23 \\
2.73 \\
3.39 \\
4.00\end{array}$ & $\begin{array}{l}1.50 \\
1.70 \\
1.99 \\
2.56 \\
3.14\end{array}$ & $\begin{array}{l}\text { NA } \\
\text { NA } \\
\text { NA } \\
\text { NA }\end{array}$ & $\begin{array}{l}1.32 \\
1.48 \\
1.81 \\
2.27 \\
2.89\end{array}$ \\
\hline 1982 $1983 . \ldots$ & $\begin{array}{l}5.17 \\
6.06 \\
6.12 \\
6.12 \\
5.83\end{array}$ & $\begin{array}{l}\mathbf{4 . 8 2} \\
\mathbf{5 . 5 9} \\
\mathbf{5 . 5 5} \\
\mathbf{5 . 5 0} \\
\mathbf{5 . 0 8}\end{array}$ & $\begin{array}{l}3.87 \\
4.18 \\
4.22 \\
3.95 \\
3.23\end{array}$ & $\begin{array}{l}\text { NA } \\
\text { NA } \\
\text { NA } \\
\text { NA } \\
\text { NA }\end{array}$ & $\begin{array}{l}3.48 \\
3.58 \\
3.70 \\
3.55 \\
2.43\end{array}$ \\
\hline 1987 & $\begin{array}{l}\mathbf{5 . 5 4} \\
\mathbf{5 . 4 7} \\
\mathbf{5 . 6 4} \\
\mathbf{5 . 8 0} \\
\mathbf{5 . 8 2}\end{array}$ & $\begin{array}{l}4.77 \\
4.63 \\
4.74 \\
4.83 \\
4.81\end{array}$ & $\begin{array}{l}2.94 \\
2.95 \\
2.96 \\
2.93 \\
2.69\end{array}$ & $\begin{array}{r}\text { NA } \\
\text { NA } \\
\text { NA } \\
3.39 \\
3.96\end{array}$ & $\begin{array}{l}2.32 \\
2.33 \\
2.43 \\
2.38 \\
2.18\end{array}$ \\
\hline 1992 & $\begin{array}{l}5.89 \\
6.16 \\
6.41\end{array}$ & $\begin{array}{r}4.88 \\
\begin{array}{r}5.22 \\
5.44\end{array}\end{array}$ & $\begin{array}{r}2.84 \\
R_{3.07} \\
3.05\end{array}$ & $\begin{array}{l}4.05 \\
4.27 \\
4.13\end{array}$ & $\begin{array}{l}2.36 \\
2.61 \\
2.28\end{array}$ \\
\hline
\end{tabular}

$A=$ Revised data.

NA = Not Available

Notes: Beginning in 1987, prices for deliveries to consumers are calculated using oniy on-system sales data. Due to large amounts of missing data for values of lease and plant fuel since 1987, prices are not estimated. In previous years, imputations were made for missing data and a price was calculated using reported and inputed data to

derive a total value for gas consumed. Since total consumption value estimates were not made since 1987, no lease and plant fuel value estimate was made.

Sounces: Eectric Utifities: 1967-1977: Federal Power Commission (FPC). 1978-1994: Energy Information Administration (ElA), Form ElA-759, Monthly Power Plant Report; Federal Energy Regulatory Commission (FERC). Form FERC-423, 'Cost and Quality of Fuels for Eectric Utimy Plants"; and Form ElA-176. "Annulal Report of Nahural and Supplemental Gas Supply and Disposition." All Cther data: 1967-1975: Bureau of Mines, Minerals Yearboak "Natumal Gas" chapter, 1976-1978. Energy Intormation

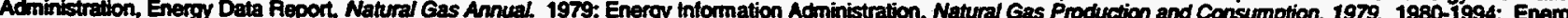
Information Administration (EIA). Form EIA-176, Annusal Roport of Natural and Supolemental Gas Supphy and Disposition." 
Table 5. Gross Withdrawals and Marketed Production of Natural Gas by State, 1967-1994 (Million Cubic Feet)

\begin{tabular}{|c|c|c|c|c|c|c|c|}
\hline \multirow{2}{*}{ Stato } & \multicolumn{3}{|c|}{$\begin{array}{c}\text { Croses } \\
\text { Whthdremels }\end{array}$} & \multirow{2}{*}{ Represeuring } & \multirow{2}{*}{$\begin{array}{c}\text { Non- } \\
\text { hydrocarbon } \\
\text { Geses Removed }\end{array}$} & \multirow{2}{*}{$\begin{array}{l}\text { Vented } \\
\text { and } \\
\text { Flaned }\end{array}$} & \multirow{2}{*}{$\begin{array}{l}\text { Martceted } \\
\text { Production }\end{array}$} \\
\hline & $\begin{array}{l}\text { From } \\
\text { Gas Wells }\end{array}$ & $\begin{array}{l}\text { From } \\
\text { Oil Wolls }\end{array}$ & Total & & & & \\
\hline & \multicolumn{7}{|c|}{1967} \\
\hline 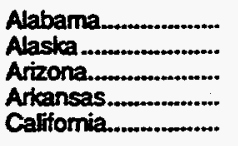 & $\begin{array}{r}1,298 \\
42,688 \\
b \\
81,491 \\
287,681\end{array}$ & $\begin{array}{r}902 \\
23,129 \\
b \\
46,038 \\
573,639\end{array}$ & $\begin{array}{r}2,200 \\
65,817 \\
b \\
127,529 \\
861,320\end{array}$ & $\begin{array}{r}35 \\
39,989 \\
b \\
10,010 \\
176,675\end{array}$ & $\begin{array}{l}\text { NA } \\
\text { NA } \\
\text { NA } \\
\text { NA } \\
\text { NA }\end{array}$ & $\begin{array}{r}360 \\
11,390 \\
b \\
997 \\
3,565\end{array}$ & $\begin{array}{r}248 \\
14,438 \\
1,255 \\
116,522 \\
681,080\end{array}$ \\
\hline 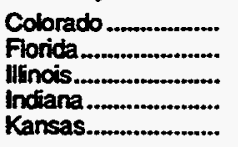 & $\begin{array}{r}89,866 \\
b \\
199 \\
106 \\
730,762\end{array}$ & $\begin{array}{r}38,148 \\
b \\
5,071 \\
92 \\
145,591\end{array}$ & $\begin{array}{r}128,014 \\
b \\
5,270 \\
198 \\
876,353\end{array}$ & $\begin{array}{r}8,501 \\
b \\
0 \\
0 \\
1,752\end{array}$ & $\begin{array}{l}\text { NA } \\
\text { NA } \\
\text { NA } \\
\text { NA } \\
\text { NA }\end{array}$ & $\begin{array}{r}2,656 \\
b \\
126 \\
0 \\
2,630\end{array}$ & $\begin{array}{r}116,857 \\
123 \\
5,144 \\
198 \\
871,971\end{array}$ \\
\hline 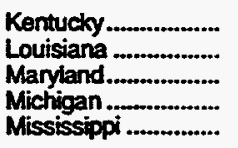 & $\begin{array}{r}88,817 \\
5,070,825 \\
621 \\
22,709 \\
139,608\end{array}$ & $\begin{array}{r}357 \\
1,016,600 \\
0 \\
20,383 \\
41,701\end{array}$ & $\begin{array}{r}89,174 \\
6,087,425 \\
621 \\
43,092 \\
181,309\end{array}$ & $\begin{array}{r}0 \\
208,719 \\
0 \\
7,642 \\
34,714\end{array}$ & $\begin{array}{l}\text { NA } \\
\text { NA } \\
\text { NA } \\
\text { NA } \\
\text { NA }\end{array}$ & $\begin{array}{r}6 \\
161,849 \\
0 \\
1,861 \\
7,098\end{array}$ & $\begin{array}{r}89,168 \\
5.716,857 \\
621 \\
33,589 \\
139,497\end{array}$ \\
\hline $\begin{array}{l}\text { Missouri .................... } \\
\text { Montana................... } \\
\text { Nebrasia ............... } \\
\text { New Mexico .............. } \\
\text { New York............... }\end{array}$ & $\begin{array}{r}b \\
10,308 \\
6,180 \\
774,007 \\
3,740\end{array}$ & $\begin{array}{r}b \\
21,302 \\
3,902 \\
301,003 \\
97\end{array}$ & $\begin{array}{r}b \\
31,610 \\
10,082 \\
1,075,010 \\
3,837\end{array}$ & $\begin{array}{r}b \\
722 \\
1.629 \\
1.508 \\
0\end{array}$ & $\begin{array}{l}\text { NA } \\
\text { NA } \\
\text { NA } \\
\text { NA } \\
\text { NA }\end{array}$ & $\begin{array}{r}b \\
5,022 \\
0 \\
5,992 \\
0\end{array}$ & $\begin{array}{r}121 \\
25,866 \\
8,453 \\
1,067,510 \\
3,837\end{array}$ \\
\hline $\begin{array}{l}\text { North Dakota............. } \\
\text { Ohio ...................... } \\
\text { Oktahoma ................ } \\
\text { Pennsytvania ........... } \\
\text { Tennessee............... }\end{array}$ & $\begin{array}{r}265 \\
34,291 \\
1,133,163 \\
89,751 \\
b\end{array}$ & $\begin{array}{r}65,992 \\
7,024 \\
488,173 \\
590 \\
b\end{array}$ & $\begin{array}{r}66,257 \\
41,315 \\
1,621,336 \\
90,341 \\
b\end{array}$ & $\begin{array}{r}0 \\
0 \\
81,755 \\
375 \\
b\end{array}$ & $\begin{array}{l}\text { NA } \\
\text { NA } \\
\text { NA } \\
\text { NA } \\
\text { NA }\end{array}$ & $\begin{array}{r}25,795 \\
0 \\
126,629 \\
0 \\
b\end{array}$ & $\begin{array}{r}40,462 \\
41,315 \\
1,412,952 \\
89,966 \\
58\end{array}$ \\
\hline 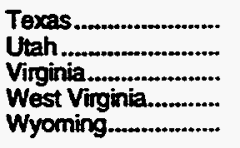 & $\begin{array}{r}6,280,148 \\
21,685 \\
3,818 \\
209,545 \\
221,850\end{array}$ & $\begin{array}{r}2,011,361 \\
56,599 \\
0 \\
2,545 \\
36,115\end{array}$ & $\begin{array}{r}8,291,509 \\
78,284 \\
3,818 \\
212,090 \\
257,965\end{array}$ & $\begin{array}{r}973,206 \\
26,319 \\
0 \\
630 \\
16,393\end{array}$ & $\begin{array}{l}\text { NA } \\
\text { NA } \\
\text { NA } \\
\text { NA }\end{array}$ & $\begin{array}{r}129,403 \\
3,000 \\
0 \\
0 \\
1,498\end{array}$ & $\begin{array}{r}7,188,900 \\
48,965 \\
3,818 \\
211,460 \\
240,074\end{array}$ \\
\hline 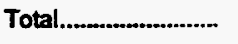 & $15,345,422$ & $4,906,354$ & $20,251,776$ & $1,590,574$ & NA & 489,877 & $18,171,325$ \\
\hline$\therefore$ & \multicolumn{7}{|c|}{1968} \\
\hline $\begin{array}{l}\text { Alabama.................... } \\
\text { Alaska ..................... } \\
\text { Arizona................... } \\
\text { Arkansas.................. } \\
\text { Califomia.................. }\end{array}$ & $\begin{array}{r}907 \\
48,933 \\
b \\
110,898 \\
505,605\end{array}$ & $\begin{array}{r}8895 \\
50,370 \\
b \\
51,257 \\
311,320\end{array}$ & $\begin{array}{r}1,802 \\
99,303 \\
b \\
162,155 \\
816,925\end{array}$ & $\begin{array}{r}999 \\
57,702 \\
b \\
4,633 \\
99,252\end{array}$ & $\begin{array}{l}\text { NA } \\
\text { NA } \\
\text { NA } \\
\text { NA } \\
\text { NA }\end{array}$ & $\begin{array}{r}8422 \\
24,258 \\
b \\
895 \\
2,780\end{array}$ & $\begin{array}{r}230 \\
17,343 \\
881 \\
156,627 \\
714,893\end{array}$ \\
\hline 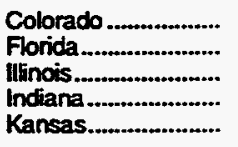 & $\begin{array}{r}93,556 \\
b \\
183 \\
234 \\
690,216\end{array}$ & $\begin{array}{r}36,027 \\
b \\
4,299 \\
0 \\
149,557\end{array}$ & $\begin{array}{r}129,583 \\
b \\
4,482 \\
234 \\
839,773\end{array}$ & $\begin{array}{r}6,645 \\
b \\
0 \\
0 \\
1,689\end{array}$ & $\begin{array}{l}\text { NA } \\
\text { NA } \\
\text { NA } \\
\text { NA } \\
\text { NA }\end{array}$ & $\begin{array}{r}1,514 \\
b \\
102 \\
0 \\
2,529\end{array}$ & $\begin{array}{r}121,424 \\
108 \\
4,380 \\
234 \\
835,555\end{array}$ \\
\hline $\begin{array}{l}\text { Kentucisy................... } \\
\text { Louisiana ................. } \\
\text { Maryland .................. } \\
\text { Michigan .................. } \\
\text { Mississippi ................ }\end{array}$ & $\begin{array}{r}88,709 \\
5,623,961 \\
864 \\
24,151 \\
136,972\end{array}$ & $\begin{array}{r}330 \\
1,153,555 \\
0 \\
19,779 \\
34,645\end{array}$ & $\begin{array}{r}89,039 \\
6,77,516 \\
864 \\
43,930 \\
171,617\end{array}$ & $\begin{array}{r}0 \\
195,062 \\
0 \\
2,330 \\
30,656\end{array}$ & $\begin{array}{l}\text { NA } \\
\text { NA } \\
\text { NA } \\
\text { NA } \\
\text { NA }\end{array}$ & $\begin{array}{r}15 \\
166,439 \\
0 \\
1,120 \\
5,910\end{array}$ & $\begin{array}{r}89,024 \\
6,416,015 \\
864 \\
40,480 \\
135,051\end{array}$ \\
\hline $\begin{array}{l}\text { Missouri ..................... } \\
\text { Montana................. } \\
\text { Nebraska ................ } \\
\text { New Mexico ............ } \\
\text { New York................. }\end{array}$ & $\begin{array}{r}b \\
11,208 \\
5,681 \\
873,211 \\
4,632\end{array}$ & $\begin{array}{r}b \\
21.021 \\
3,648 \\
297,313 \\
0\end{array}$ & $\begin{array}{r}b \\
32,229 \\
9,329 \\
1,170,524 \\
4,632\end{array}$ & $\begin{array}{r}b \\
365 \\
1,200 \\
355 \\
0\end{array}$ & $\begin{array}{l}\text { NA } \\
\text { NA } \\
\text { NA } \\
\text { NA }\end{array}$ & $\begin{array}{r}b \\
12,551 \\
0 \\
5,987 \\
0\end{array}$ & $\begin{array}{r}14 \\
19,313 \\
8,129 \\
1,164,182 \\
4,632\end{array}$ \\
\hline $\begin{array}{l}\text { North Dakota............ } \\
\text { Ohio ....................... } \\
\text { Okdahoma ............... } \\
\text { Pennsytrania ............ } \\
\text { Tennessee ............... }\end{array}$ & $\begin{array}{r}225 \\
33,742 \\
1,225,620 \\
87,627 \\
b\end{array}$ & $\begin{array}{r}62,848 \\
8,931 \\
380,957 \\
680 \\
b\end{array}$ & $\begin{array}{r}63,073 \\
42,673 \\
1,606,577 \\
88,307 \\
b\end{array}$ & $\begin{array}{r}0 \\
0 \\
86,285 \\
320 \\
b\end{array}$ & $\begin{array}{l}\text { NA } \\
\text { NA } \\
\text { NA } \\
\text { NA } \\
\text { NA }\end{array}$ & $\begin{array}{r}22,050 \\
0 \\
129,408 \\
0 \\
b\end{array}$ & $\begin{array}{r}41,023 \\
42,673 \\
1,390,884 \\
87,987 \\
48\end{array}$ \\
\hline
\end{tabular}

See footnotes at end of table. 
Table 5. Gross Withdrawals and Marketed Production of Natural Gas by State, 1967-1994 (Continued) (Milion Cubic Feet)

\begin{tabular}{|c|c|c|c|c|c|c|c|}
\hline \multirow{2}{*}{ Strito } & \multicolumn{3}{|c|}{$\begin{array}{l}\text { Groes: } \\
\text { Writhdrowals }\end{array}$} & \multirow{2}{*}{ Represustring } & \multirow{2}{*}{$\begin{array}{c}\text { Mont } \\
\text { hydroceston } \\
\text { caseses Removind }\end{array}$} & \multirow{2}{*}{$\begin{array}{l}\text { Vonted } \\
\text { end } \\
\text { Flaned }\end{array}$} & \multirow{2}{*}{$\begin{array}{l}\text { Marketted } \\
\text { Production }\end{array}$} \\
\hline & $\begin{array}{l}\text { From } \\
\text { Cats Wolls }\end{array}$ & $\begin{array}{l}\text { From } \\
\text { Oif Wolls }\end{array}$ & Total & & & & \\
\hline & \multicolumn{7}{|c|}{1958} \\
\hline 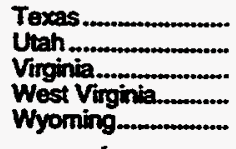 & $\begin{array}{r}6,477,441 \\
20,443 \\
3,389 \\
234,361 \\
237,156\end{array}$ & $\begin{array}{r}2,088,647 \\
58,856 \\
0 \\
3,380 \\
46,760\end{array}$ & $\begin{array}{r}8,566,088 \\
79,299 \\
3,389 \\
237,741 \\
288,916\end{array}$ & $\begin{array}{r}946,090 \\
30,242 \\
0 \\
770 \\
22,397\end{array}$ & $\begin{array}{l}\text { NA } \\
\text { NA } \\
\text { NA } \\
\text { NA }\end{array}$ & $\begin{array}{r}124,584 \\
2,906 \\
0 \\
0 \\
13,088\end{array}$ & $\begin{array}{r}7,495,414 \\
46,151 \\
3,389 \\
236,971 \\
248,481\end{array}$ \\
\hline \multirow[t]{2}{*}{ Total. } & $16,539,925$ & $4,785,075$ & $21,325,000$ & $1,486,092$ & NA & 516,508 & $19,322,400$ \\
\hline & \multicolumn{7}{|c|}{1969} \\
\hline 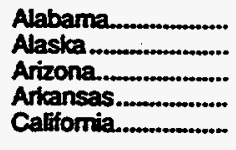 & $\begin{array}{r}1,794 \\
77,816 \\
b \\
119,230 \\
294,026\end{array}$ & $\begin{array}{r}791 \\
71,831 \\
b \\
56,105 \\
473,316\end{array}$ & $\begin{array}{r}2,585 \\
149,647 \\
b \\
175,335 \\
767,342\end{array}$ & $\begin{array}{r}241 \\
66,240 \\
b \\
4,752 \\
86,579\end{array}$ & $\begin{array}{l}\text { NA } \\
\text { NA } \\
\text { NA } \\
\text { NA } \\
\text { NA }\end{array}$ & $\begin{array}{r}795 \\
32,543 \\
b \\
1,326 \\
3,074\end{array}$ & $\begin{array}{r}180 \\
50,864 \\
1,136 \\
169,257 \\
677,689\end{array}$ \\
\hline 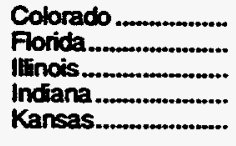 & $\begin{array}{r}92,133 \\
\mathrm{~b} \\
158 \\
171 \\
744,631\end{array}$ & $\begin{array}{r}31,204 \\
b \\
3,735 \\
0 \\
142,972\end{array}$ & $\begin{array}{r}123,337 \\
b \\
3,893 \\
171 \\
887,603\end{array}$ & $\begin{array}{r}3,257 \\
b \\
0 \\
0 \\
1,781\end{array}$ & $\begin{array}{l}\text { NA } \\
\text { NA } \\
\text { NA } \\
\text { NA } \\
\text { NA }\end{array}$ & $\begin{array}{r}1,326 \\
b \\
93 \\
0 \\
2,666\end{array}$ & $\begin{array}{r}118,754 \\
50 \\
3,800 \\
171 \\
883,156\end{array}$ \\
\hline 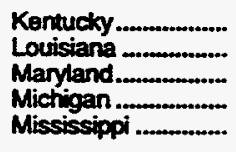 & $\begin{array}{r}81,086 \\
6,305,897 \\
978 \\
22,285 \\
133,105\end{array}$ & $\begin{array}{r}218 \\
1,255,130 \\
0 \\
16,405 \\
35,609\end{array}$ & $\begin{array}{r}81,304 \\
7,561,027 \\
978 \\
38,690 \\
168,714\end{array}$ & $\begin{array}{r}0 \\
174,349 \\
0 \\
1,719 \\
29,383\end{array}$ & $\begin{array}{l}\text { NA } \\
\text { NA } \\
\text { NA } \\
\text { NA } \\
\text { NA }\end{array}$ & $\begin{array}{r}0 \\
158,852 \\
0 \\
808 \\
8,097\end{array}$ & $\begin{array}{r}81,304 \\
7,227,826 \\
978 \\
36,163 \\
131,234\end{array}$ \\
\hline 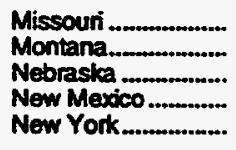 & $\begin{array}{r}b \\
37,163 \\
4,739 \\
837,521 \\
4,861\end{array}$ & $\begin{array}{r}\text { b } \\
30,501 \\
2,677 \\
305,073 \\
0\end{array}$ & $\begin{array}{r}b \\
68,064 \\
7,416 \\
1,142,594 \\
4,861\end{array}$ & $\begin{array}{r}377 \\
427 \\
403 \\
0\end{array}$ & $\begin{array}{l}\text { NA } \\
\text { NA } \\
\text { NA } \\
\text { NA } \\
\text { NA }\end{array}$ & $\begin{array}{r}b \\
26,458 \\
0 \\
4,058 \\
0\end{array}$ & $\begin{array}{r}126 \\
41,229 \\
6,989 \\
1,138,133 \\
4,861\end{array}$ \\
\hline $\begin{array}{l}\text { North Dakota............ } \\
\text { Ohio ....................... } \\
\text { Okdahoma .............. } \\
\text { Pennsylvania .......... } \\
\text { Tennessee ............... }\end{array}$ & $\begin{array}{r}127 \\
38,540 \\
1,356,766 \\
763 \\
b\end{array}$ & $\begin{array}{r}56,415 \\
11,253 \\
384,911 \\
78,693 \\
b\end{array}$ & $\begin{array}{r}56,542 \\
49,793 \\
1,741,677 \\
79,446 \\
b\end{array}$ & $\begin{array}{r}0 \\
0 \\
87,196 \\
312 \\
6\end{array}$ & $\begin{array}{l}\text { NA } \\
\text { NA } \\
\text { NA } \\
\text { NA } \\
\text { NA }\end{array}$ & $\begin{array}{r}22,955 \\
0 \\
130,766 \\
0 \\
b\end{array}$ & $\begin{array}{r}33,587 \\
49,793 \\
1,523,715 \\
79,134 \\
57\end{array}$ \\
\hline 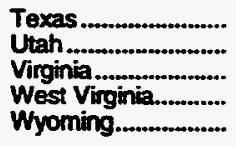 & $\begin{array}{r}6,800,882 \\
21,510 \\
2,846 \\
229,815 \\
280,572\end{array}$ & $\begin{array}{r}2,113,912 \\
53,657 \\
0 \\
2,556 \\
62,426\end{array}$ & $\begin{array}{r}8,914,794 \\
75,167 \\
2,846 \\
232,371 \\
342,998\end{array}$ & $\begin{array}{r}950,096 \\
25,632 \\
0 \\
612 \\
21,849\end{array}$ & $\begin{array}{l}\mathbf{N A} \\
\mathbf{N A} \\
\mathbf{N A} \\
\mathbf{N A} \\
\mathbf{N A}\end{array}$ & $\begin{array}{r}111,499 \\
2,802 \\
0 \\
0 \\
17.632\end{array}$ & $\begin{array}{r}7,853,199 \\
46,733 \\
2,846 \\
231,759 \\
303,517\end{array}$ \\
\hline \multirow[t]{2}{*}{ Total................................. } & $17,489,415$ & $5,189,780$ & $22,679,195$ & $1,455,205$ & NA & 525,750 & $20,698,240$ \\
\hline & \multicolumn{7}{|c|}{1970} \\
\hline 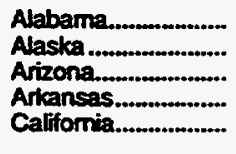 & $\begin{array}{r}1,406 \\
130,491 \\
b \\
128,241 \\
296,001\end{array}$ & $\begin{array}{r}1,581 \\
87,363 \\
b \\
55,409 \\
431,244\end{array}$ & $\begin{array}{r}2,987 \\
217,854 \\
b \\
183,650 \\
727,245\end{array}$ & $\begin{array}{r}452 \\
71,470 \\
b \\
2,073 \\
75,629\end{array}$ & $\begin{array}{l}\text { NA } \\
\text { NA } \\
\text { NA } \\
\text { NA }\end{array}$ & $\begin{array}{r}656 \\
34,808 \\
b \\
226 \\
2,499\end{array}$ & $\begin{array}{r}627 \\
111,576 \\
1,101 \\
181,351 \\
649,117\end{array}$ \\
\hline 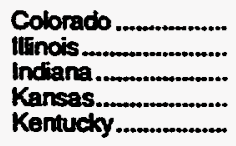 & $\begin{array}{r}93,221 \\
198 \\
153 \\
752,934 \\
77,695\end{array}$ & $\begin{array}{r}21,936 \\
4,774 \\
0 \\
151,541 \\
197\end{array}$ & $\begin{array}{r}115,157 \\
4,972 \\
153 \\
904,475 \\
77,892\end{array}$ & $\begin{array}{r}2.227 \\
0 \\
0 \\
1.807 \\
0\end{array}$ & $\begin{array}{l}\text { NA } \\
\text { NA } \\
\text { NA } \\
\text { NA }\end{array}$ & $\begin{array}{r}7.126 \\
122 \\
0 \\
2,713 \\
0\end{array}$ & $\begin{array}{r}105,804 \\
4,850 \\
153 \\
899,955 \\
77,892\end{array}$ \\
\hline 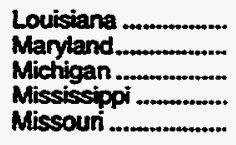 & $\begin{array}{r}6,811,334 \\
813 \\
23,774 \\
123,737 \\
b\end{array}$ & $\begin{array}{r}1,264,823 \\
0 \\
16,264 \\
33,283 \\
b\end{array}$ & $\begin{array}{r}8,076,157 \\
813 \\
40,038 \\
157,020 \\
b\end{array}$ & $\begin{array}{r}133,792 \\
0 \\
378 \\
23,756 \\
b\end{array}$ & $\begin{array}{l}\mathbf{N A} \\
\mathbf{N A} \\
\mathbf{N A} \\
\mathbf{N A} \\
\mathbf{N A}\end{array}$ & $\begin{array}{r}154,089 \\
0 \\
809 \\
7,233 \\
b\end{array}$ & $\begin{array}{r}7,788,276 \\
813 \\
38,851 \\
126,081 \\
87\end{array}$ \\
\hline Montana.................... & 37,684 & 10.618 & 48,302 & 394 & NA & 5,203 & 42,705 \\
\hline
\end{tabular}

See tootnotes at end of table. 
Table 5. Gross Withdrawals and Marketed Production of Natural Gas by State, 1967-1994 (Continued) (Million Cubic Feet)

\begin{tabular}{|c|c|c|c|c|c|c|c|}
\hline \multirow{2}{*}{ Suto } & \multicolumn{3}{|c|}{$\begin{array}{c}\text { Growe } \\
\text { Withdramels }\end{array}$} & \multirow{2}{*}{ Ropreaturing } & \multirow{2}{*}{$\begin{array}{c}\text { Non- } \\
\text { mydrocarbon } \\
\text { Canes Removed }\end{array}$} & \multirow{2}{*}{$\begin{array}{l}\text { Vented } \\
\text { and } \\
\text { Fined }\end{array}$} & \multirow{2}{*}{$\begin{array}{l}\text { Warketed } \\
\text { Production }\end{array}$} \\
\hline & $\begin{array}{c}\text { From } \\
\text { cos Woils }\end{array}$ & $\begin{array}{l}\text { From } \\
\text { Oit Wels: }\end{array}$ & Total & & & & \\
\hline
\end{tabular}

1970

\begin{tabular}{|c|c|c|c|c|c|c|c|}
\hline 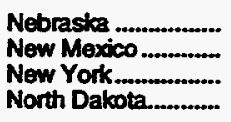 & $\begin{array}{r}3,990 \\
832,771 \\
3,358 \\
140\end{array}$ & $\begin{array}{r}2,319 \\
309,118 \\
0 \\
54,611\end{array}$ & $\begin{array}{r}6,309 \\
1,141,889 \\
3,358 \\
54,751\end{array}$ & $\begin{array}{r}318 \\
0 \\
0 \\
0\end{array}$ & $\begin{array}{l}\text { NA } \\
\text { NA } \\
\text { NA } \\
\text { NA }\end{array}$ & $\begin{array}{r}0 \\
2,909 \\
0 \\
19,862\end{array}$ & $\begin{array}{r}5,991 \\
1,138,980 \\
3,358 \\
34,889\end{array}$ \\
\hline 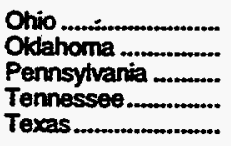 & $\begin{array}{r}39,694 \\
1,429,408 \\
76,716 \\
b \\
7,165,388\end{array}$ & $\begin{array}{r}12,419 \\
381,596 \\
398 \\
b \\
2,233,138\end{array}$ & $\begin{array}{r}52,113 \\
1,811,004 \\
77,114 \\
6 \\
9,398,526\end{array}$ & $\begin{array}{r}0 \\
86,432 \\
273 \\
b \\
940,505\end{array}$ & $\begin{array}{l}\text { NA } \\
\text { NA } \\
\text { NA } \\
\text { NA }\end{array}$ & $\begin{array}{r}0 \\
129,629 \\
0 \\
b \\
100,305\end{array}$ & $\begin{array}{r}52,113 \\
1,594,943 \\
76,841 \\
64 \\
8,357,716\end{array}$ \\
\hline 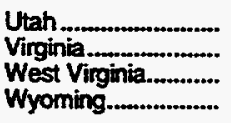 & $\begin{array}{r}21,609 \\
2,805 \\
239,787 \\
301,310\end{array}$ & $\begin{array}{r}51,777 \\
0 \\
3,194 \\
64,192\end{array}$ & $\begin{array}{r}73,386 \\
2,805 \\
242,981 \\
365,502\end{array}$ & $\begin{array}{r}27,753 \\
0 \\
529 \\
8,563\end{array}$ & $\begin{array}{l}\text { NA } \\
\text { NA } \\
\text { NA }\end{array}$ & $\begin{array}{r}2,852 \\
0 \\
0 \\
18,419\end{array}$ & $\begin{array}{r}42,781 \\
2,805 \\
242,452 \\
338,520\end{array}$ \\
\hline Total............................ & $18,594,658$ & $5,191,795$ & $23,786,453$ & $1,376,351$ & $N A$ & 489,460 & $21,920,642$ \\
\hline
\end{tabular}

1971

\begin{tabular}{|c|c|c|c|c|c|c|c|}
\hline 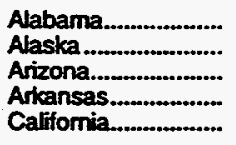 & $\begin{array}{r}2 \\
125,169 \\
873 \\
120,454 \\
293,254\end{array}$ & $\begin{array}{r}661 \\
103,003 \\
342 \\
54,429 \\
385,990\end{array}$ & $\begin{array}{r}663 \\
228,172 \\
1,215 \\
174,883 \\
679,244\end{array}$ & $\begin{array}{r}0 \\
72,674 \\
0 \\
995 \\
66,040\end{array}$ & $\begin{array}{l}\text { NA } \\
\text { NA } \\
\text { NA } \\
\text { NA } \\
\text { NA }\end{array}$ & $\begin{array}{r}308 \\
33,880 \\
347 \\
1,734 \\
575\end{array}$ & $\begin{array}{r}355 \\
121.618 \\
868 \\
172,154 \\
612,629\end{array}$ \\
\hline 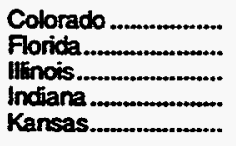 & $\begin{array}{r}84,303 \\
0 \\
498 \\
537 \\
729,262\end{array}$ & $\begin{array}{r}29,037 \\
1,258 \\
3,997 \\
0 \\
160,330\end{array}$ & $\begin{array}{r}113,340 \\
1,258 \\
4,495 \\
537 \\
889,592\end{array}$ & $\begin{array}{r}1,960 \\
0 \\
0 \\
0 \\
1,779\end{array}$ & $\begin{array}{l}\text { NA } \\
\text { NA } \\
\text { NA } \\
\text { NA } \\
\text { NA }\end{array}$ & $\begin{array}{r}2,843 \\
355 \\
3,997 \\
0 \\
2,669\end{array}$ & $\begin{array}{r}108,537 \\
903 \\
498 \\
537 \\
885,144\end{array}$ \\
\hline $\begin{array}{l}\text { Kentucky................... } \\
\text { Louisiana ................ } \\
\text { Maryland.................. } \\
\text { Michigan ................. } \\
\text { Mississippi ............... }\end{array}$ & $\begin{array}{r}72,546 \\
7,011,666 \\
214 \\
10,968 \\
107,727\end{array}$ & $\begin{array}{r}177 \\
1,306,885 \\
0 \\
15,482 \\
28,809\end{array}$ & $\begin{array}{r}72,723 \\
8,318,551 \\
214 \\
26,450 \\
136,536\end{array}$ & $\begin{array}{r}0 \\
133,080 \\
0 \\
788 \\
12,641\end{array}$ & $\begin{array}{l}\text { NA } \\
\text { NA } \\
\text { NA } \\
\text { NA } \\
\text { NA }\end{array}$ & $\begin{array}{r}0 \\
103,554 \\
0 \\
0 \\
5,090\end{array}$ & $\begin{array}{r}72,723 \\
8,081,907 \\
214 \\
25,662 \\
118,805\end{array}$ \\
\hline 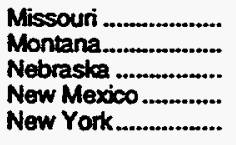 & $\begin{array}{r}22 \\
31,195 \\
3,028 \\
861,520 \\
2,202\end{array}$ & $\begin{array}{r}0 \\
6,941 \\
2,026 \\
308,880 \\
0\end{array}$ & $\begin{array}{r}22 \\
38,136 \\
5,054 \\
1,170,400 \\
2,202\end{array}$ & $\begin{array}{r}0 \\
499 \\
0 \\
0 \\
0\end{array}$ & $\begin{array}{l}\text { NA } \\
\text { NA } \\
\text { NA } \\
\text { NA }\end{array}$ & $\begin{array}{r}0 \\
4,917 \\
1,558 \\
2,823 \\
0\end{array}$ & $\begin{array}{r}22 \\
32,720 \\
3,496 \\
1,167,577 \\
2,202\end{array}$ \\
\hline $\begin{array}{l}\text { North Dakota............ } \\
\text { Ohio ....................... } \\
\text { Okdahoma ............ } \\
\text { Pernsylvania ........... } \\
\text { South Dakota........... }\end{array}$ & $\begin{array}{r}146 \\
61,845 \\
1,425,847 \\
74,081 \\
0\end{array}$ & $\begin{array}{r}36,404 \\
18,058 \\
383,239 \\
2,370 \\
9\end{array}$ & $\begin{array}{r}36,550 \\
79,903 \\
1,809,086 \\
76,451 \\
9\end{array}$ & $\begin{array}{r}0 \\
0 \\
85,027 \\
0 \\
9\end{array}$ & $\begin{array}{l}\text { NA } \\
\text { NA } \\
\text { NA } \\
\text { NA } \\
\text { NA }\end{array}$ & $\begin{array}{r}2,686 \\
0 \\
39,799 \\
0 \\
0\end{array}$ & $\begin{array}{r}33,864 \\
79,903 \\
1,684,260 \\
76,451 \\
0\end{array}$ \\
\hline 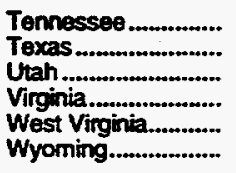 & $\begin{array}{r}99 \\
7,327,186 \\
26,571 \\
2,619 \\
232,205 \\
319,097\end{array}$ & $\begin{array}{r}398 \\
2,191,458 \\
47,689 \\
0 \\
2,109 \\
72,914\end{array}$ & $\begin{array}{r}497 \\
9,518,644 \\
74,260 \\
2,619 \\
234,314 \\
392,011\end{array}$ & $\begin{array}{r}0 \\
897,717 \\
28,916 \\
0 \\
287 \\
8,046\end{array}$ & $\begin{array}{l}\text { NA } \\
\text { NA } \\
\text { NA } \\
\text { NA } \\
\text { NA } \\
\text { NA }\end{array}$ & $\begin{array}{r}408 \\
70,222 \\
2,926 \\
0 \\
0 \\
3,660\end{array}$ & $\begin{array}{r}89 \\
8,550,705 \\
42,418 \\
2,619 \\
234,027 \\
380,105\end{array}$ \\
\hline \multirow[t]{2}{*}{ 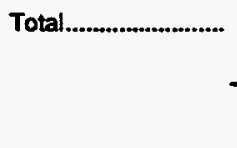 } & $18,925,136$ & $5,162,895$ & $24,088,031$ & $1,310,458$ & NA & 284,561 & $22,493,012$ \\
\hline & \multicolumn{7}{|c|}{1972} \\
\hline 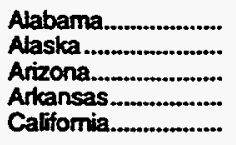 & $\begin{array}{r}2,601 \\
126,198 \\
431 \\
125,319 \\
304,049\end{array}$ & $\begin{array}{r}2,009 \\
96,707 \\
378 \\
43,852 \\
251,343\end{array}$ & $\begin{array}{r}4,610 \\
222,905 \\
809 \\
169,171 \\
555,392\end{array}$ & $\begin{array}{r}0 \\
75,719 \\
0 \\
0 \\
68,114\end{array}$ & $\begin{array}{l}\text { NA } \\
\text { NA } \\
\text { NA } \\
\text { NA } \\
\text { NA }\end{array}$ & $\begin{array}{r}956 \\
21,590 \\
367 \\
2,649 \\
0\end{array}$ & $\begin{array}{r}3,644 \\
125,596 \\
442 \\
166,522 \\
487,278\end{array}$ \\
\hline 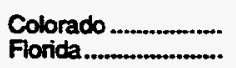 & $\begin{array}{r}94,401 \\
0\end{array}$ & $\begin{array}{l}27.721 \\
15,805\end{array}$ & $\begin{array}{r}122,122 \\
15,805\end{array}$ & $\begin{array}{r}415 \\
0\end{array}$ & $\begin{array}{l}\text { NA } \\
\text { NA }\end{array}$ & $\begin{array}{r}4,758 \\
284\end{array}$ & $\begin{array}{r}116,949 \\
15,521\end{array}$ \\
\hline
\end{tabular}

See footnotes at end of table. 
Table 5. Gross Withdrawals and Marketed Production of Natural Gas by State, 1967-1994 (Continued) (Million Cubic Feet)

\begin{tabular}{|c|c|c|c|c|c|c|c|}
\hline \multirow{2}{*}{ Sute } & \multicolumn{3}{|c|}{ Croses } & \multirow{2}{*}{ Repnowing } & \multirow{2}{*}{$\begin{array}{c}\text { Non- } \\
\text { hydrocarbon } \\
\text { Cesses Removed }\end{array}$} & \multirow{2}{*}{$\begin{array}{l}\text { Ventad } \\
\text { and } \\
\text { Fuared }\end{array}$} & \multirow{2}{*}{ Production } \\
\hline & $\begin{array}{l}\text { From } \\
\text { cens Wells }\end{array}$ & $\begin{array}{l}\text { From } \\
\text { Oil Welts }\end{array}$ & Total & & & & \\
\hline
\end{tabular}

1972

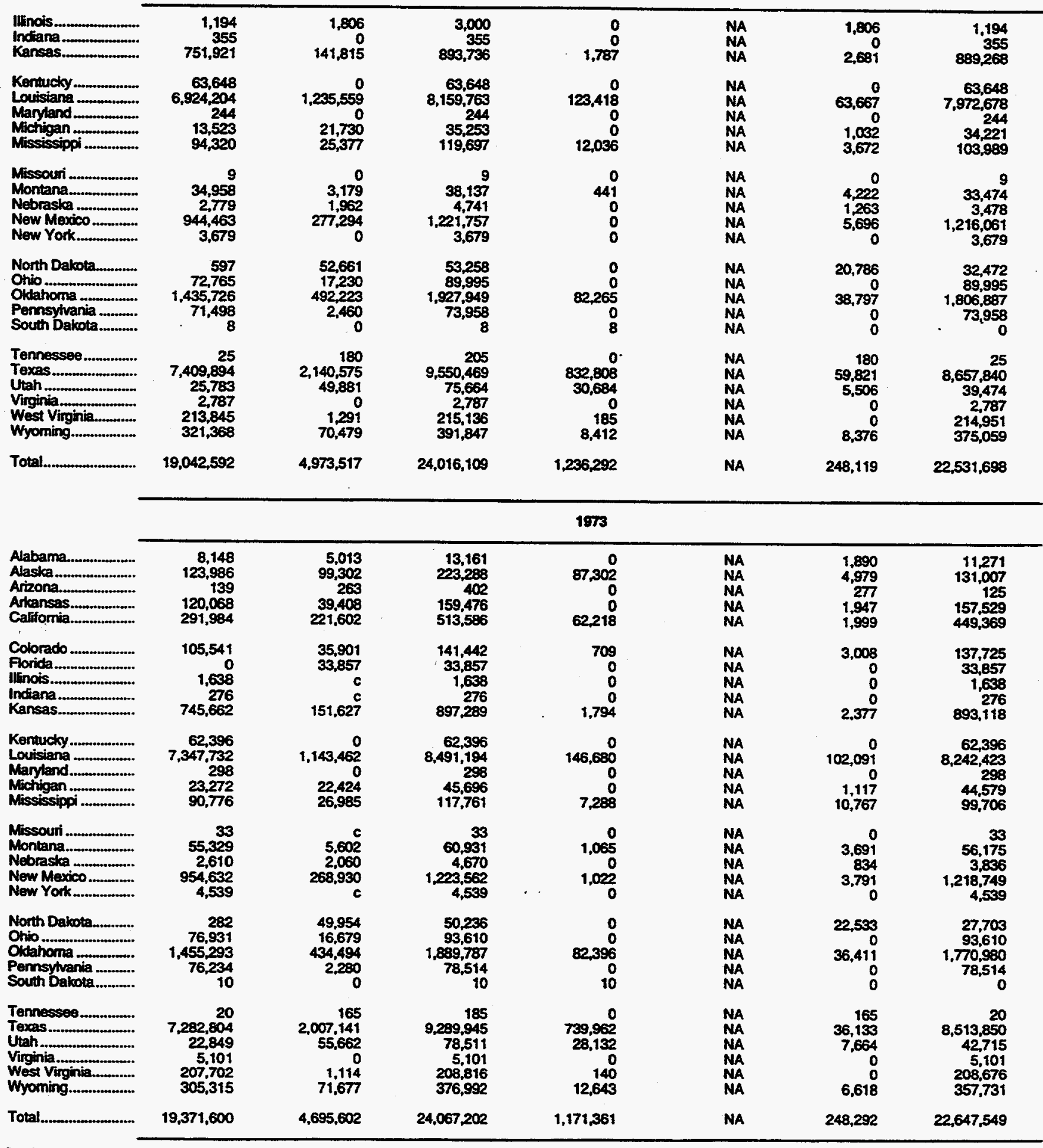

See foomotes at end of table. 
Table 5. Gross Withdrawals and Marketed Production of Natural Gas by State, 1967-1994 (Continued) (Million Cubic Feet)

\begin{tabular}{|c|c|c|c|c|c|c|c|}
\hline \multirow{2}{*}{ Sente } & \multicolumn{3}{|c|}{$\begin{array}{l}\text { Groses } \\
\text { Withdremals }\end{array}$} & \multirow{2}{*}{ Represouring } & \multirow{2}{*}{$\begin{array}{c}\text { Non- } \\
\text { mydrocarbon } \\
\text { Caeses Removed }\end{array}$} & \multirow{2}{*}{$\begin{array}{l}\text { Vented } \\
\text { and } \\
\text { Fined }\end{array}$} & \multirow{2}{*}{$\begin{array}{l}\text { Marketed } \\
\text { Production }\end{array}$} \\
\hline & $\begin{array}{l}\text { From } \\
\text { Cas Welles }\end{array}$ & $\begin{array}{l}\text { From } \\
\text { oil welle }\end{array}$ & Total & & & & \\
\hline
\end{tabular}

1974

\begin{tabular}{|c|c|c|c|c|c|c|c|}
\hline 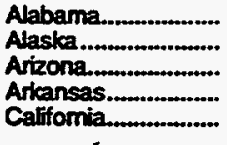 & $\begin{array}{r}23,970 \\
125,349 \\
27 \\
92,265 \\
222,673\end{array}$ & $\begin{array}{r}5,387 \\
104,614 \\
223 \\
33,426 \\
204,301\end{array}$ & $\begin{array}{r}29,357 \\
229,963 \\
250 \\
125,691 \\
426,974\end{array}$ & $\begin{array}{r}0 \\
89,504 \\
0 \\
0 \\
60,060\end{array}$ & $\begin{array}{l}\text { NA } \\
\text { NA } \\
\text { NA } \\
\text { NA }\end{array}$ & $\begin{array}{r}1,492 \\
11,524 \\
26 \\
1,716 \\
1,550\end{array}$ & $\begin{array}{r}27,865 \\
128,935 \\
224 \\
123,975 \\
365,354\end{array}$ \\
\hline 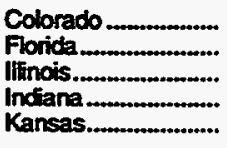 & $\begin{array}{r}108,962 \\
0 \\
1,436 \\
176 \\
747,580\end{array}$ & $\begin{array}{r}38,890 \\
38,137 \\
c \\
c \\
141,870\end{array}$ & $\begin{array}{r}147,852 \\
38,137 \\
1,436 \\
176 \\
889,450\end{array}$ & $\begin{array}{r}266 \\
0 \\
0 \\
0 \\
1,779\end{array}$ & $\begin{array}{l}\text { NA } \\
\text { NA } \\
\text { NA } \\
\text { NA }\end{array}$ & $\begin{array}{r}2,957 \\
0 \\
0 \\
0 \\
889\end{array}$ & $\begin{array}{r}144,629 \\
38,137 \\
1,436 \\
176 \\
886,782\end{array}$ \\
\hline 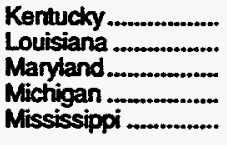 & $\begin{array}{r}71,876 \\
7,037,239 \\
133 \\
45,745 \\
76,295\end{array}$ & $\begin{array}{r}0 \\
882,571 \\
0 \\
24,719 \\
22,700\end{array}$ & $\begin{array}{r}71,876 \\
7,919,810 \\
133 \\
70,464 \\
98,995\end{array}$ & $\begin{array}{r}0 \\
134,607 \\
0 \\
63 \\
9,421\end{array}$ & $\begin{array}{l}\text { NA } \\
\text { NA } \\
\text { NA } \\
\text { NA }\end{array}$ & $\begin{array}{r}0 \\
31,572 \\
0 \\
1,268 \\
10,787\end{array}$ & $\begin{array}{r}71,876 \\
7,753,631 \\
133 \\
69,133 \\
78,787\end{array}$ \\
\hline $\begin{array}{l}\text { Missouri } \\
\text { Montana........................ } \\
\text { Nebraska .................... } \\
\text { New Mexico } \\
\text { New York.................... }\end{array}$ & $\begin{array}{r}33 \\
51,644 \\
2,194 \\
944,515 \\
4,990\end{array}$ & $\begin{array}{r}c \\
7,880 \\
2,481 \\
309,784 \\
c\end{array}$ & $\begin{array}{r}33 \\
59,524 \\
4,675 \\
1,254,299 \\
4,990\end{array}$ & $\begin{array}{r}0 \\
750 \\
0 \\
8,293 \\
0\end{array}$ & $\begin{array}{l}\text { NA } \\
\text { NA } \\
\text { NA } \\
\text { NA } \\
\text { NA }\end{array}$ & $\begin{array}{r}0 \\
3,901 \\
2,137 \\
1,227 \\
0\end{array}$ & $\begin{array}{r}33 \\
54,873 \\
2,538 \\
1,244,779 \\
4,990\end{array}$ \\
\hline 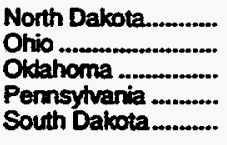 & $\begin{array}{r}287 \\
77,114 \\
1,425,283 \\
82,735 \\
48\end{array}$ & $\begin{array}{r}48,779 \\
16,749 \\
331,346 \\
c \\
0\end{array}$ & $\begin{array}{r}49,066 \\
93,863 \\
1,756,629 \\
82,735 \\
48\end{array}$ & $\begin{array}{r}0 \\
1,808 \\
83,488 \\
0 \\
48\end{array}$ & $\begin{array}{l}\text { NA } \\
\text { NA } \\
\text { NA } \\
\text { NA } \\
\text { NA }\end{array}$ & $\begin{array}{r}17.860 \\
0 \\
34,199 \\
98 \\
0\end{array}$ & $\begin{array}{r}31,206 \\
92,055 \\
1,638,942 \\
82,637 \\
0\end{array}$ \\
\hline 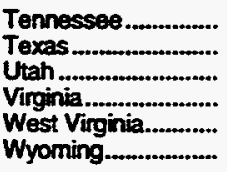 & $\begin{array}{r}17 \\
7,029,873 \\
21,433 \\
7,096 \\
202,306 \\
265,918\end{array}$ & $\begin{array}{r}376 \\
1,829,171 \\
58,540 \\
0 \\
c \\
78,637\end{array}$ & $\begin{array}{r}393 \\
8,859,044 \\
79,973 \\
7,096 \\
202,306 \\
344,555\end{array}$ & $\begin{array}{r}0 \\
653,815 \\
24,192 \\
0 \\
0 \\
11,796\end{array}$ & $\begin{array}{l}\text { NA } \\
\text { NA } \\
\text { NA } \\
\text { NA } \\
\text { NA } \\
\text { NA }\end{array}$ & $\begin{array}{r}376 \\
34,431 \\
5,259 \\
0 \\
0 \\
6,102\end{array}$ & $\begin{array}{r}17 \\
8,170,798 \\
50,522 \\
7,096 \\
202,306 \\
326,657\end{array}$ \\
\hline Total............................ & $18,669,212$ & $4,180,581$ & $22,849,793$ & $1,079,890$ & NA & 169,381 & $21,600,522$ \\
\hline
\end{tabular}

1975

\begin{tabular}{|c|c|c|c|c|c|c|c|}
\hline 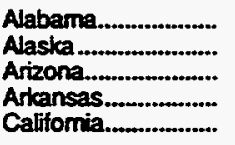 & $\begin{array}{r}33,660 \\
138,153 \\
4 \\
91,270 \\
173,499\end{array}$ & $\begin{array}{r}5,261 \\
115,074 \\
251 \\
30,248 \\
194,154\end{array}$ & $\begin{array}{r}38,921 \\
253,227 \\
255 \\
121,518 \\
367,653\end{array}$ & $\begin{array}{r}0 \\
82,556 \\
0 \\
3,953 \\
47,808\end{array}$ & $\begin{array}{l}\text { NA } \\
\text { NA } \\
\text { NA } \\
\text { NA } \\
\text { NA }\end{array}$ & $\begin{array}{r}1,107 \\
10.401 \\
47 \\
1.318 \\
1.537\end{array}$ & $\begin{array}{r}37,814 \\
160,270 \\
208 \\
116,237 \\
318,308\end{array}$ \\
\hline 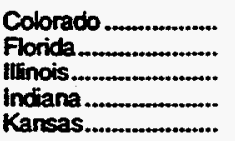 & $\begin{array}{r}130,743 \\
0 \\
1,440 \\
346 \\
705,746\end{array}$ & $\begin{array}{r}43,402 \\
44,383 \\
c \\
c \\
140,418\end{array}$ & $\begin{array}{r}174,145 \\
44,383 \\
1,440 \\
346 \\
846,164\end{array}$ & $\begin{array}{r}0 \\
0 \\
0 \\
0 \\
1.693\end{array}$ & $\begin{array}{l}\text { NA } \\
\text { NA } \\
\text { NA } \\
\text { NA }\end{array}$ & $\begin{array}{r}2,516 \\
0 \\
0 \\
0 \\
846\end{array}$ & $\begin{array}{r}171,629 \\
44,383 \\
1,440 \\
346 \\
843,625\end{array}$ \\
\hline 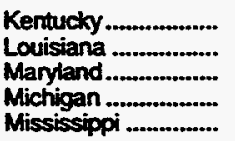 & $\begin{array}{r}60,511 \\
6,455,690 \\
93 \\
71,907 \\
74,367\end{array}$ & $\begin{array}{r}c \\
786,718 \\
0 \\
31,994 \\
18,133\end{array}$ & $\begin{array}{r}60,511 \\
7,242,408 \\
93 \\
103,901 \\
92,500\end{array}$ & $\begin{array}{r}0 \\
126,304 \\
0 \\
176 \\
6,293\end{array}$ & $\begin{array}{l}\text { NA } \\
\mathbf{N A} \\
\mathbf{N A} \\
\mathbf{N A} \\
\mathbf{N A}\end{array}$ & $\begin{array}{r}0 \\
25,459 \\
0 \\
1,612 \\
11,862\end{array}$ & $\begin{array}{r}60,511 \\
7,090,645 \\
93 \\
102,113 \\
74,345\end{array}$ \\
\hline $\begin{array}{l}\text { Missouri .................... } \\
\text { Montana................... } \\
\text { Nebraska ................. } \\
\text { New Mexico ............... } \\
\text { New York................. }\end{array}$ & $\begin{array}{r}30 \\
41,474 \\
1,605 \\
915,370 \\
7,628\end{array}$ & $\begin{array}{r}c \\
3,073 \\
2,358 \\
311,830 \\
c\end{array}$ & $\begin{array}{r}30 \\
44,547 \\
3,963 \\
1,227,200 \\
7,628\end{array}$ & $\begin{array}{r}0 \\
611 \\
0 \\
8,128 \\
0\end{array}$ & $\begin{array}{l}\mathbf{N A} \\
\mathbf{N A} \\
\mathbf{N A} \\
\mathbf{N A} \\
\mathbf{N A}\end{array}$ & $\begin{array}{r}0 \\
3,202 \\
1,398 \\
1,642 \\
0\end{array}$ & $\begin{array}{r}30 \\
40,734 \\
2,565 \\
1,217,430 \\
7,028\end{array}$ \\
\hline 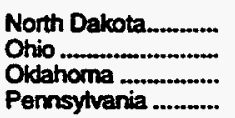 & $\begin{array}{r}287 \\
85,810 \\
1,412,637 \\
84,772\end{array}$ & $\begin{array}{r}26,654 \\
c \\
308,061 \\
c\end{array}$ & $\begin{array}{r}26,941 \\
85,810 \\
1,720,698 \\
84,772\end{array}$ & $\begin{array}{r}0 \\
850 \\
83,486 \\
0\end{array}$ & $\begin{array}{l}\text { NA } \\
\text { NA } \\
\text { NA } \\
\text { NA }\end{array}$ & $\begin{array}{r}2,155 \\
0 \\
31,802 \\
96\end{array}$ & $\begin{array}{r}24,786 \\
84,960 \\
1,605,410 \\
84,676\end{array}$ \\
\hline
\end{tabular}

See footnotes at end of table. 
Table 5. Gross Withdrawals and Marketed Production of Natural Gas by State, 1967-1994 (Continued) (Million Cubic Feet)

\begin{tabular}{|c|c|c|c|c|c|c|c|}
\hline \multirow{2}{*}{ Sinte } & \multicolumn{3}{|c|}{$\begin{array}{c}\text { Croses } \\
\text { wandrewals }\end{array}$} & \multirow{2}{*}{ Repreasuring } & \multirow{2}{*}{$\begin{array}{c}\text { Non- } \\
\text { hydrocarbon } \\
\text { Geses Remourd }\end{array}$} & \multirow{2}{*}{$\begin{array}{l}\text { Veriod } \\
\text { and } \\
\text { Fored }\end{array}$} & \multirow{2}{*}{ Production } \\
\hline & $\begin{array}{l}\text { From } \\
\text { Ges Wells }\end{array}$ & $\begin{array}{l}\text { From } \\
\text { otivells }\end{array}$ & Total & & & & \\
\hline
\end{tabular}

1975

\begin{tabular}{|c|c|c|c|c|c|c|c|}
\hline South Dalrota............ & 39 & $\mathbf{c}$ & 39 & 35 & NA & 4 & 0 \\
\hline 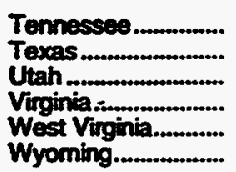 & $\begin{array}{r}27 \\
6,463,095 \\
19,001 \\
6,723 \\
154,484 \\
249,882\end{array}$ & $\begin{array}{r}585 \\
1,525,678 \\
58,606 \\
0 \\
c \\
76,356\end{array}$ & $\begin{array}{r}612 \\
7,988,773 \\
77,607 \\
6,723 \\
154,484 \\
326,238\end{array}$ & $\begin{array}{r}0 \\
471,714 \\
20,447 \\
0 \\
0 \\
6,892\end{array}$ & $\begin{array}{l}\text { NA } \\
\text { NA } \\
\text { NA } \\
\text { NA } \\
\text { NA }\end{array}$ & $\begin{array}{r}595 \\
31,295 \\
1,806 \\
0 \\
0 \\
3,223\end{array}$ & $\begin{array}{r}27 \\
7,485,764 \\
55,354 \\
6,723 \\
154,484 \\
316,123\end{array}$ \\
\hline Total............................ & $17,380,293$ & $3,723,237$ & $21,108,530$ & 860,956 & NA & 133,913 & $20,108,661$ \\
\hline
\end{tabular}

\begin{tabular}{|c|c|c|c|c|c|c|c|}
\hline \multirow[b]{2}{*}{ 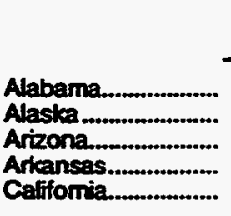 } & \multicolumn{7}{|c|}{1976} \\
\hline & $\begin{array}{r}37,832 \\
142,944 \\
3 \\
91,166 \\
174,477\end{array}$ & $\begin{array}{r}5,768 \\
126,167 \\
291 \\
29,981 \\
253,163\end{array}$ & $\begin{array}{r}43,600 \\
269,111 \\
294 \\
121,147 \\
427,640\end{array}$ & $\begin{array}{r}1,085 \\
96,485 \\
0 \\
10,387 \\
72,018\end{array}$ & $\begin{array}{l}\text { NA } \\
\text { NA } \\
\text { NA } \\
\text { NA } \\
\text { NA }\end{array}$ & $\begin{array}{r}1,088 \\
6,554 \\
32 \\
1,227 \\
1,288\end{array}$ & $\begin{array}{r}41,427 \\
166,072 \\
262 \\
109,533 \\
354,334\end{array}$ \\
\hline 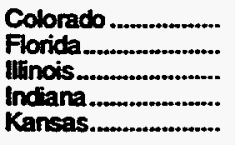 & $\begin{array}{r}134,110 \\
0 \\
1,556 \\
192 \\
704,197\end{array}$ & $\begin{array}{r}51,918 \\
46,513 \\
c \\
c \\
127,467\end{array}$ & $\begin{array}{r}186,028 \\
46,513 \\
1,556 \\
192 \\
831,664\end{array}$ & $\begin{array}{r}220 \\
2,511 \\
0 \\
0 \\
1,663\end{array}$ & $\begin{array}{l}\text { NA } \\
\text { NA } \\
\text { NA } \\
\text { NA } \\
\text { NA }\end{array}$ & $\begin{array}{r}1,836 \\
837 \\
0 \\
0 \\
831\end{array}$ & $\begin{array}{r}183,972 \\
43,165 \\
1,556 \\
192 \\
829,170\end{array}$ \\
\hline 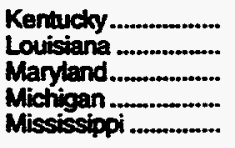 & $\begin{array}{r}65,137 \\
6,365,774 \\
75 \\
81,628 \\
73,138\end{array}$ & $\begin{array}{r}c \\
777,266 \\
0 \\
40,005 \\
16,776\end{array}$ & $\begin{array}{r}66,137 \\
7,143,040 \\
75 \\
121,631 \\
89,914\end{array}$ & $\begin{array}{r}0 \\
104,977 \\
0 \\
327 \\
5,553\end{array}$ & $\begin{array}{l}\text { NA } \\
\text { NA } \\
\text { NA } \\
\text { NA }\end{array}$ & $\begin{array}{r}0 \\
31,467 \\
0 \\
2,042 \\
13,599\end{array}$ & $\begin{array}{r}66,137 \\
7,006,596 \\
75 \\
119,262 \\
70,762\end{array}$ \\
\hline 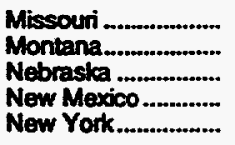 & $\begin{array}{r}29 \\
41,685 \\
899 \\
939,491 \\
9,235\end{array}$ & $\begin{array}{r}c \\
3,412 \\
2,409 \\
300,161 \\
C\end{array}$ & $\begin{array}{r}29 \\
45,097 \\
3,308 \\
1,239,652 \\
9,235\end{array}$ & $\begin{array}{r}0 \\
464 \\
0 \\
7,157 \\
0\end{array}$ & $\begin{array}{l}\text { NA } \\
\text { NA } \\
\text { NA } \\
\text { NA }\end{array}$ & $\begin{array}{r}0 \\
2,070 \\
797 \\
1,519 \\
0\end{array}$ & $\begin{array}{r}29 \\
42,563 \\
2,511 \\
1,230,976 \\
9,205\end{array}$ \\
\hline $\begin{array}{l}\text { North Dakola............ } \\
\text { Ohio } \\
\text { Oldahoma ................... } \\
\text { Pernsytvania ........... } \\
\text { South Dakota.......... }\end{array}$ & $\begin{array}{r}285 \\
89,780 \\
1,491,165 \\
89,485 \\
52\end{array}$ & $\begin{array}{r}33,922 \\
\mathrm{c} \\
351,024 \\
\mathrm{c} \\
\mathrm{C}\end{array}$ & $\begin{array}{r}34,207 \\
89,780 \\
1,842,189 \\
\mathbf{8 9 , 4 8 5} \\
\mathbf{5 2}\end{array}$ & $\begin{array}{r}0 \\
889 \\
85,479 \\
0 \\
47\end{array}$ & $\begin{array}{l}\text { NA } \\
\text { NA } \\
\text { NA } \\
\text { NA }\end{array}$ & $\begin{array}{r}2,737 \\
0 \\
30,197 \\
99 \\
5\end{array}$ & $\begin{array}{r}31,470 \\
88,891 \\
1,726,513 \\
89,386 \\
0\end{array}$ \\
\hline 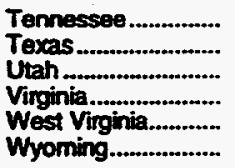 & $\begin{array}{r}47 \\
6.213,395 \\
18,927 \\
6,937 \\
153,322 \\
262,692\end{array}$ & $\begin{array}{r}485 \\
1,452,537 \\
59,719 \\
0 \\
C \\
74,141\end{array}$ & $\begin{array}{r}532 \\
7,665,932 \\
78,646 \\
6,937 \\
153,322 \\
336,833\end{array}$ & $\begin{array}{r}146 \\
443,671 \\
20,182 \\
0 \\
0 \\
6,149\end{array}$ & $\begin{array}{l}\text { NA } \\
\text { NA } \\
\text { NA } \\
\text { NA } \\
\text { NA }\end{array}$ & $\begin{array}{r}339 \\
30,402 \\
1,048 \\
0 \\
0 \\
1,916\end{array}$ & $\begin{array}{r}47 \\
7,191,859 \\
57,416 \\
6,937 \\
153,322 \\
328,768\end{array}$ \\
\hline \multirow[t]{2}{*}{ Total.............................. } & $17,190,655$ & $3,753,123$ & $20,843,778$ & 859,410 & NA & 131,930 & $19,952,438$ \\
\hline & \multicolumn{7}{|c|}{1977} \\
\hline 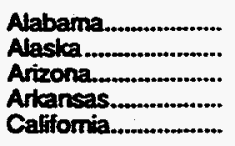 & $\begin{array}{r}54,844 \\
150,409 \\
3 \\
86,175 \\
171,600\end{array}$ & $\begin{array}{r}6,423 \\
223,382 \\
340 \\
36,581 \\
215,897\end{array}$ & $\begin{array}{r}61,267 \\
373,791 \\
343 \\
122,756 \\
387,497\end{array}$ & $\begin{array}{r}2,860 \\
170,258 \\
103 \\
17,507 \\
74,997\end{array}$ & $\begin{array}{l}\text { NA } \\
\text { NA } \\
\text { NA } \\
\text { NA }\end{array}$ & $\begin{array}{r}1,180 \\
15,644 \\
0 \\
1,153 \\
1,038\end{array}$ & $\begin{array}{r}57,227 \\
187,889 \\
240 \\
104,096 \\
311,462\end{array}$ \\
\hline 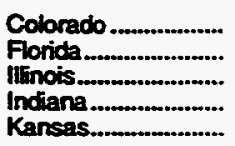 & $\begin{array}{r}138,306 \\
0 \\
1,003 \\
183 \\
678,286\end{array}$ & $\begin{array}{r}52,341 \\
48,778 \\
c \\
c \\
105,351\end{array}$ & $\begin{array}{r}190,647 \\
48,778 \\
1,003 \\
183 \\
783,637\end{array}$ & $\begin{array}{r}327 \\
0 \\
0 \\
0 \\
1,565\end{array}$ & $\begin{array}{l}\text { NA } \\
\text { NA } \\
\text { NA } \\
\text { NA } \\
\text { NA }\end{array}$ & $\begin{array}{r}1,528 \\
607 \\
0 \\
0 \\
783\end{array}$ & $\begin{array}{r}188,792 \\
48,171 \\
1,003 \\
183 \\
781,289\end{array}$ \\
\hline $\begin{array}{l}\text { Kentucky ................... } \\
\text { Louisiana ................ } \\
\text { Maryland................... }\end{array}$ & $\begin{array}{r}60,902 \\
6,612,018 \\
82\end{array}$ & $\begin{array}{r}0 \\
738,911 \\
0\end{array}$ & $\begin{array}{r}60,902 \\
7,350,929 \\
82\end{array}$ & $\begin{array}{r}0 \\
102,672 \\
0\end{array}$ & $\begin{array}{l}\text { NA } \\
\text { NA }\end{array}$ & $\begin{array}{r}0 \\
33,251 \\
0\end{array}$ & $\begin{array}{r}60,902 \\
7,215,006 \\
82\end{array}$ \\
\hline
\end{tabular}

See tootnotes at end of table. 
Table 5. Gross Withdrawals and Marketed Production of Natural Gas by State, 1967-1994 (Continued) (Million Cubic Feet)

\begin{tabular}{|c|c|c|c|c|c|c|c|}
\hline \multirow{2}{*}{ Stut } & \multicolumn{3}{|c|}{$\begin{array}{l}\text { Cross } \\
\text { Withdrewels }\end{array}$} & \multirow{2}{*}{ Represesuring } & \multirow{2}{*}{$\begin{array}{c}\text { Non- } \\
\text { mydrocarben } \\
\text { Geses Ramoved }\end{array}$} & \multirow{2}{*}{$\begin{array}{l}\text { Vonted } \\
\text { and } \\
\text { Fiared }\end{array}$} & \multirow{2}{*}{$\begin{array}{l}\text { Marketed } \\
\text { Production }\end{array}$} \\
\hline & $\begin{array}{c}\text { From } \\
\text { Ces Wolle }\end{array}$ & $\begin{array}{l}\text { From } \\
\text { oil Wolls }\end{array}$ & Total & & & & \\
\hline
\end{tabular}

1977

\begin{tabular}{|c|c|c|c|c|c|c|c|}
\hline $\begin{array}{l}\text { Michigan ................ } \\
\text { Mississippi ............. }\end{array}$ & $\begin{array}{l}86,037 \\
84,993\end{array}$ & $\begin{array}{l}47,189 \\
17,162\end{array}$ & $\begin{array}{l}133,226 \\
102,155\end{array}$ & $\begin{array}{r}981 \\
5,646\end{array}$ & $\begin{array}{l}\text { NA } \\
\text { NA }\end{array}$ & $\begin{array}{r}2,291 \\
13,514\end{array}$ & $\begin{array}{r}129,954 \\
82,995\end{array}$ \\
\hline $\begin{array}{l}\text { Missouri .................... } \\
\text { Montana .................. } \\
\text { Nebraska ................. } \\
\text { New Mexico .............. } \\
\text { New York................ }\end{array}$ & $\begin{array}{r}20 \\
44,502 \\
627 \\
935,731 \\
10,682\end{array}$ & $\begin{array}{r}c \\
3,679 \\
2,222 \\
287,139 \\
0\end{array}$ & $\begin{array}{r}20 \\
48,181 \\
2,849 \\
1,222,870 \\
10,682\end{array}$ & $\begin{array}{r}0 \\
267 \\
0 \\
14,832 \\
0\end{array}$ & $\begin{array}{l}\text { NA } \\
\text { NA } \\
\text { NA } \\
\text { NA } \\
\text { NA }\end{array}$ & $\begin{array}{r}0 \\
1,095 \\
60 \\
5,065 \\
0\end{array}$ & $\begin{array}{r}20 \\
46,819 \\
2,789 \\
1,202,975 \\
10,682\end{array}$ \\
\hline $\begin{array}{l}\text { North Dakota............ } \\
\text { Ohio ........................ } \\
\text { Okdahoma .............. } \\
\text { Pemsytrania ........... } \\
\text { South Dakota.......... }\end{array}$ & $\begin{array}{r}311 \\
99,657 \\
1,554,799 \\
91,792 \\
69\end{array}$ & $\begin{array}{r}29,978 \\
c \\
333,271 \\
c \\
c\end{array}$ & $\begin{array}{r}30,289 \\
99,657 \\
1,888,070 \\
91,792 \\
69\end{array}$ & $\begin{array}{r}0 \\
0 \\
89,365 \\
0 \\
64\end{array}$ & $\begin{array}{l}\text { NA } \\
\text { NA } \\
\text { NA } \\
\text { NA } \\
\text { NA }\end{array}$ & $\begin{array}{r}1.116 \\
330 \\
29,186 \\
75 \\
5\end{array}$ & $\begin{array}{r}29,173 \\
99,327 \\
1,769,519 \\
91,717 \\
0\end{array}$ \\
\hline 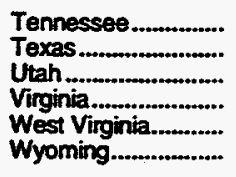 & $\begin{array}{r}263 \\
6,090,074 \\
21,040 \\
8,220 \\
152,767 \\
280,588\end{array}$ & $\begin{array}{r}592 \\
1,405,839 \\
61,559 \\
0 \\
c \\
64,454\end{array}$ & $\begin{array}{r}855 \\
7,495,913 \\
82,599 \\
8,220 \\
152,767 \\
345,042\end{array}$ & $\begin{array}{r}436 \\
417,546 \\
21,212 \\
0 \\
0 \\
14,163\end{array}$ & $\begin{array}{l}\text { NA } \\
\text { NA } \\
\text { NA } \\
\text { NA } \\
\text { NA } \\
\text { NA }\end{array}$ & $\begin{array}{r}156 \\
27,340 \\
691 \\
0 \\
0 \\
699\end{array}$ & $\begin{array}{r}260 \\
7,051,027 \\
60,696 \\
8,220 \\
152,767 \\
330,180\end{array}$ \\
\hline Total.......................... & $17,415,983$ & $3,681,088$ & $21,097,071$ & 934,801 & NA & 136,807 & $20,025,463$ \\
\hline
\end{tabular}

\begin{tabular}{|c|c|c|c|c|c|c|c|}
\hline \multirow[b]{2}{*}{ 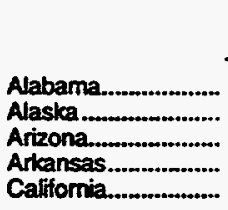 } & \multicolumn{7}{|c|}{1978} \\
\hline & $\begin{array}{r}83,025 \\
165,943 \\
0 \\
88,872 \\
220,373\end{array}$ & $\begin{array}{r}6,987 \\
430,891 \\
286 \\
39,082 \\
163,128\end{array}$ & $\begin{array}{r}90,012 \\
596,834 \\
286 \\
127,954 \\
383,501\end{array}$ & $\begin{array}{r}2,718 \\
385,254 \\
0 \\
20,293 \\
71,457\end{array}$ & $\begin{array}{l}\text { NA } \\
\text { NA } \\
\text { NA } \\
\text { NA } \\
\text { NA }\end{array}$ & $\begin{array}{r}1,695 \\
8,492 \\
0 \\
869 \\
960\end{array}$ & $\begin{array}{r}85,599 \\
203,088 \\
286 \\
106,792 \\
311,084\end{array}$ \\
\hline 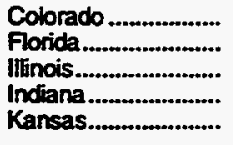 & $\begin{array}{r}129,412 \\
0 \\
1,159 \\
163 \\
737,575\end{array}$ & $\begin{array}{r}55,607 \\
51,595 \\
c \\
c \\
119,496\end{array}$ & $\begin{array}{r}185,019 \\
51,595 \\
1,159 \\
163 \\
857,071\end{array}$ & $\begin{array}{r}218 \\
0 \\
0 \\
0 \\
1,726\end{array}$ & $\begin{array}{l}\text { NA } \\
\text { NA } \\
\text { NA } \\
\text { NA } \\
\text { NA }\end{array}$ & $\begin{array}{r}1,108 \\
0 \\
0 \\
0 \\
861\end{array}$ & $\begin{array}{r}183,693 \\
51,595 \\
1,159 \\
163 \\
854,484\end{array}$ \\
\hline $\begin{array}{l}\text { Kentucky.................... } \\
\text { Louisiana ................. } \\
\text { Maryland................. } \\
\text { Michigan .................. } \\
\text { Mississippi ............... }\end{array}$ & $\begin{array}{r}70,044 \\
6,860,529 \\
88 \\
97,866 \\
135,283\end{array}$ & $\begin{array}{r}c \\
778,402 \\
0 \\
54,318 \\
13,199\end{array}$ & $\begin{array}{r}70,044 \\
7,638,931 \\
88 \\
152,184 \\
148,482\end{array}$ & $\begin{array}{r}0 \\
132,627 \\
0 \\
1,401 \\
5,630\end{array}$ & $\begin{array}{l}\text { NA } \\
\text { NA } \\
\text { NA } \\
\text { NA } \\
\text { NA }\end{array}$ & $\begin{array}{r}0 \\
29,807 \\
0 \\
2,736 \\
36,273\end{array}$ & $\begin{array}{r}70,044 \\
7,476,497 \\
88 \\
148,047 \\
106,579\end{array}$ \\
\hline $\begin{array}{l}\text { Montana................... } \\
\text { Nebraska ................ } \\
\text { New Mexico ............. } \\
\text { New York................... } \\
\text { North Dakota........... }\end{array}$ & $\begin{array}{r}44,656 \\
766 \\
924,495 \\
13,900 \\
274\end{array}$ & $\begin{array}{r}3,841 \\
2,116 \\
274,098 \\
0 \\
37,013\end{array}$ & $\begin{array}{r}48,497 \\
2,882 \\
1,198,593 \\
13,900 \\
37,287\end{array}$ & $\begin{array}{r}567 \\
0 \\
16,232 \\
0 \\
0\end{array}$ & $\begin{array}{l}\text { NA } \\
\text { NA } \\
\text { NA } \\
\text { NA } \\
\text { NA }\end{array}$ & $\begin{array}{r}1,408 \\
0 \\
8,163 \\
0 \\
6,788\end{array}$ & $\begin{array}{r}46,522 \\
2,882 \\
1,174,198 \\
13,900 \\
30,499\end{array}$ \\
\hline $\begin{array}{l}\text { Ohio ........................ } \\
\text { Oktahoma .............. } \\
\text { Pennsytvania ........... } \\
\text { Tennessee ................ } \\
\text { Texas....................... }\end{array}$ & $\begin{array}{r}115,239 \\
1,5 \times 9,176 \\
97,763 \\
468 \\
5,612,336\end{array}$ & $\begin{array}{r}0 \\
353,237 \\
c \\
1,014 \\
1,375,507\end{array}$ & $\begin{array}{r}115,239 \\
1,892,413 \\
97,763 \\
1,482 \\
6,987,843\end{array}$ & $\begin{array}{r}1,141 \\
91,342 \\
0 \\
897 \\
414,103\end{array}$ & $\begin{array}{l}\text { NA } \\
\text { NA } \\
\text { NA } \\
\text { NA } \\
\text { NA }\end{array}$ & $\begin{array}{r}0 \\
27,489 \\
0 \\
117 \\
25,556\end{array}$ & $\begin{array}{r}114,098 \\
1,773,582 \\
97,763 \\
468 \\
6,548,184\end{array}$ \\
\hline 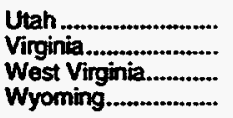 & $\begin{array}{r}21,325 \\
8,492 \\
148.564 \\
276.427\end{array}$ & $\begin{array}{r}58,902 \\
0 \\
\mathbf{C} \\
95,883\end{array}$ & $\begin{array}{r}80,227 \\
8,492 \\
148,564 \\
372,310\end{array}$ & $\begin{array}{r}21,342 \\
0 \\
0 \\
14,484\end{array}$ & $\begin{array}{l}\text { NA } \\
\text { NA } \\
\text { NA } \\
\text { NA }\end{array}$ & $\begin{array}{r}469 \\
0 \\
0 \\
559\end{array}$ & $\begin{array}{r}58,416 \\
8,492 \\
148,564 \\
357,267\end{array}$ \\
\hline \multirow[t]{2}{*}{ Total............................. } & $17,394,213$ & $3,914,602$ & $21,308,815$ & $1.181,432$ & NA & 153,350 & $19,974,033$ \\
\hline & \multicolumn{7}{|c|}{1979} \\
\hline 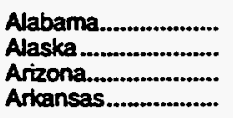 & $\begin{array}{r}83,902 \\
172,281 \\
3 \\
86,869\end{array}$ & $\begin{array}{r}6.793 \\
560.709 \\
345 \\
40.600\end{array}$ & $\begin{array}{r}90,695 \\
732,990 \\
348 \\
127,469\end{array}$ & $\begin{array}{r}3,383 \\
507,710 \\
0 \\
17,546\end{array}$ & $\begin{array}{l}\text { NA } \\
\text { NA } \\
\text { NA }\end{array}$ & $\begin{array}{r}1,497 \\
4,526 \\
101 \\
471\end{array}$ & $\begin{array}{r}85,815 \\
220,754 \\
247 \\
109,452\end{array}$ \\
\hline
\end{tabular}

See tootnotes at end of table. 
Table 5. Gross Withdrawals and Marketed Production of Natural Gas by State, 1967-1994 (Continued) (Million Cubic Feet)

\begin{tabular}{|c|c|c|c|c|c|c|c|}
\hline \multirow{2}{*}{ Stus } & \multicolumn{3}{|c|}{$\begin{array}{l}\text { Gross } \\
\text { Whatrewals }\end{array}$} & \multirow{2}{*}{ Peprosenting } & \multirow{2}{*}{$\begin{array}{c}\text { Non- } \\
\text { Iydrocembon } \\
\text { Geses Romoned }\end{array}$} & \multirow{2}{*}{$\begin{array}{l}\text { Vented } \\
\text { Find } \\
\text { Flered }\end{array}$} & \multirow{2}{*}{$\begin{array}{l}\text { Marketed } \\
\text { Production }\end{array}$} \\
\hline & $\begin{array}{l}\text { From } \\
\text { Cas Whets }\end{array}$ & $\begin{array}{l}\text { From } \\
\text { Oil Wells }\end{array}$ & Total & & & & \\
\hline & \multicolumn{7}{|c|}{1979} \\
\hline Cafifomia. & 172,776 & 164,721 & 337,497 & 88,058 & NA & 1,253 & 248,206 \\
\hline 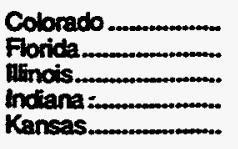 & $\begin{array}{r}138,155 \\
0 \\
1,585 \\
350 \\
677,727\end{array}$ & $\begin{array}{r}54,589 \\
50,180 \\
c \\
c \\
122,486\end{array}$ & $\begin{array}{r}192,694 \\
50,190 \\
1,585 \\
350 \\
800,163\end{array}$ & $\begin{array}{r}256 \\
0 \\
0 \\
0 \\
1,600\end{array}$ & $\begin{array}{l}\text { NA } \\
\text { NA } \\
\text { NA } \\
\text { NA }\end{array}$ & $\begin{array}{r}1,199 \\
0 \\
0 \\
0 \\
801\end{array}$ & $\begin{array}{r}191,239 \\
50,190 \\
1,525 \\
350 \\
797,762\end{array}$ \\
\hline 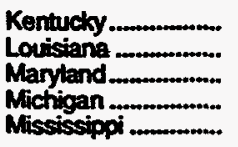 & $\begin{array}{r}59,520 \\
6,743,420 \\
28 \\
102,048 \\
180,353\end{array}$ & $\begin{array}{r}c \\
615,375 \\
0 \\
62,812 \\
12,023\end{array}$ & $\begin{array}{r}59,520 \\
7,358,795 \\
28 \\
164,860 \\
192,376\end{array}$ & $\begin{array}{r}0 \\
66,517 \\
0 \\
2,169 \\
9,882\end{array}$ & $\begin{array}{l}\text { NA } \\
\text { NA } \\
\text { NA } \\
\text { NA }\end{array}$ & $\begin{array}{r}0 \\
26,051 \\
0 \\
2,950 \\
38,417\end{array}$ & $\begin{array}{r}59,520 \\
7,266,217 \\
28 \\
159,731 \\
144,077\end{array}$ \\
\hline 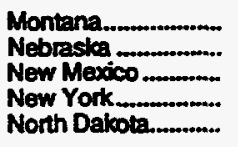 & $\begin{array}{r}51,528 \\
578 \\
935,523 \\
15,500 \\
249\end{array}$ & $\begin{array}{r}4,566 \\
2,650 \\
264,946 \\
0 \\
45,151\end{array}$ & $\begin{array}{r}56,094 \\
3,208 \\
1,200,469 \\
15,500 \\
45,400\end{array}$ & $\begin{array}{r}517 \\
0 \\
14,470 \\
0 \\
0\end{array}$ & $\begin{array}{l}\text { NA } \\
\text { NA } \\
\text { NA } \\
\text { NA } \\
\text { NA }\end{array}$ & $\begin{array}{r}1,689 \\
0 \\
4,636 \\
0 \\
26,932\end{array}$ & $\begin{array}{r}53,888 \\
3,208 \\
1,181,363 \\
15,500 \\
18,468\end{array}$ \\
\hline 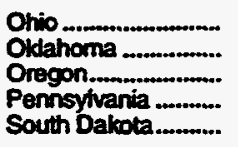 & $\begin{array}{r}124,665 \\
1,587,935 \\
2 \\
96,313 \\
861\end{array}$ & $\begin{array}{r}c \\
370,402 \\
0 \\
c \\
58\end{array}$ & $\begin{array}{r}124,665 \\
1,958,337 \\
2 \\
96,313 \\
919\end{array}$ & $\begin{array}{r}1,204 \\
95,366 \\
0 \\
0 \\
0\end{array}$ & $\begin{array}{l}\text { NA } \\
\text { NA } \\
\text { NA } \\
\text { NA }\end{array}$ & $\begin{array}{r}0 \\
26,605 \\
0 \\
0 \\
5\end{array}$ & $\begin{array}{r}123,431 \\
1,835,366 \\
2 \\
96,313 \\
914\end{array}$ \\
\hline 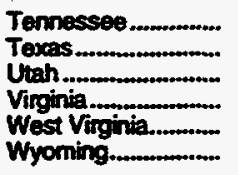 & $\begin{array}{r}941 \\
6,262,643 \\
27,064 \\
8,544 \\
150,505 \\
352,011\end{array}$ & $\begin{array}{r}664 \\
1,350,901 \\
51,610 \\
0 \\
c \\
88,003\end{array}$ & $\begin{array}{r}1,605 \\
7,593,544 \\
78,674 \\
8,544 \\
150,505 \\
440,014\end{array}$ & $\begin{array}{r}538 \\
391,571 \\
19,509 \\
0 \\
0 \\
23,768\end{array}$ & $\begin{array}{l}\text { NA } \\
\text { NA } \\
\text { NA } \\
\text { NA } \\
\text { NA }\end{array}$ & $\begin{array}{r}126 \\
27,350 \\
550 \\
0 \\
0 \\
1,830\end{array}$ & $\begin{array}{r}941 \\
7,174,623 \\
58,605 \\
8,544 \\
150,505 \\
414,416\end{array}$ \\
\hline \multirow[t]{2}{*}{ Total } & $18,033,879$ & $3,849,474$ & $21,883,353$ & $1,245,074$ & NA & 167.019 & $20,471,260$ \\
\hline & \multicolumn{7}{|c|}{1980} \\
\hline 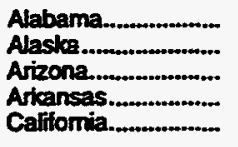 & $\begin{array}{r}105,447 \\
167,607 \\
2 \\
87,994 \\
152,441\end{array}$ & $\begin{array}{r}6,389 \\
726,152 \\
355 \\
39,702 \\
254,710\end{array}$ & $\begin{array}{r}111,836 \\
893,759 \\
357 \\
127,696 \\
407,151\end{array}$ & $\begin{array}{r}3,134 \\
658,351 \\
0 \\
15,494 \\
95,992\end{array}$ & $\begin{array}{r}40,233 \\
0 \\
0 \\
0 \\
349\end{array}$ & $\begin{array}{r}3,175 \\
4,820 \\
143 \\
394 \\
1,386\end{array}$ & $\begin{array}{r}65,294 \\
230,588 \\
214 \\
111,808 \\
309,434\end{array}$ \\
\hline 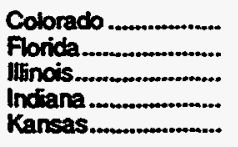 & $\begin{array}{r}147.273 \\
0 \\
1,334 \\
463 \\
604,778\end{array}$ & $\begin{array}{r}44,533 \\
46,421 \\
240 \\
C \\
132,468\end{array}$ & $\begin{array}{r}191,806 \\
46,421 \\
1,574 \\
463 \\
737,246\end{array}$ & $\begin{array}{r}196 \\
0 \\
N A \\
N A \\
1,474\end{array}$ & $\begin{array}{r}2.813 \\
5,106 \\
N A \\
N A \\
N A\end{array}$ & $\begin{array}{l}796 \\
677 \\
N A \\
N A \\
737\end{array}$ & $\begin{array}{r}188,001 \\
40,638 \\
1,574 \\
463 \\
735,035\end{array}$ \\
\hline 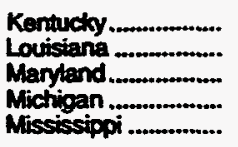 & $\begin{array}{r}57,180 \\
6,417,127 \\
68 \\
89,651 \\
202,711\end{array}$ & $\begin{array}{r}c \\
591,362 \\
0 \\
74,459 \\
12,394\end{array}$ & $\begin{array}{r}57,180 \\
7,008,489 \\
68 \\
164,110 \\
215,105\end{array}$ & $\begin{array}{r}N A \\
45,714 \\
0 \\
2,375 \\
13,009\end{array}$ & $\begin{array}{r}\text { NA } \\
\text { NA } \\
0 \\
N A \\
10.408\end{array}$ & $\begin{array}{r}N A \\
22,851 \\
0 \\
3,433 \\
16,627\end{array}$ & $\begin{array}{r}57,180 \\
6,939,924 \\
68 \\
158,302 \\
175,061\end{array}$ \\
\hline $\begin{array}{l}\text { Montana................... } \\
\text { Nebraska .................. } \\
\text { New Mexico ............ } \\
\text { New York................ } \\
\text { North Dalrota.......... }\end{array}$ & $\begin{array}{r}48,929 \\
566 \\
920,168 \\
15,650 \\
480\end{array}$ & $\begin{array}{r}4,873 \\
1,084 \\
247,881 \\
0 \\
49,841\end{array}$ & $\begin{array}{r}53,802 \\
2,550 \\
1,168,049 \\
15,650 \\
50,321\end{array}$ & $\begin{array}{r}230 \\
13,057 \\
0 \\
\mathrm{NA}\end{array}$ & $\begin{array}{r}\text { NA } \\
1,695 \\
0 \\
N A\end{array}$ & $\begin{array}{r}1,705 \\
5,211 \\
7 \\
7,975\end{array}$ & $\begin{array}{r}51,867 \\
2,550 \\
1,148,086 \\
15,643 \\
42,346\end{array}$ \\
\hline 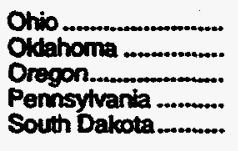 & $\begin{array}{r}138,856 \\
1,613,584 \\
5 \\
97,439 \\
1,143\end{array}$ & $\begin{array}{r}c \\
404,993 \\
0 \\
c \\
55\end{array}$ & $\begin{array}{r}138,856 \\
2,018,577 \\
5 \\
97,439 \\
1,198\end{array}$ & $\begin{array}{r}\text { NA } \\
101.198 \\
0 \\
\text { NA } \\
0\end{array}$ & $\begin{array}{r}\text { NA } \\
\text { NA } \\
\text { NA } \\
0\end{array}$ & $\begin{array}{r}N A \\
25,555 \\
0 \\
N A \\
5\end{array}$ & $\begin{array}{r}138,856 \\
1,891,824 \\
5 \\
97,439 \\
1,193\end{array}$ \\
\hline 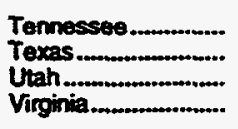 & $\begin{array}{r}478 \\
6,322,180 \\
d \\
7,812\end{array}$ & $\begin{array}{r}763 \\
1,333,881 \\
87,766 \\
0\end{array}$ & $\begin{array}{r}1,241 \\
7,656,061 \\
87,766 \\
7,812\end{array}$ & $\begin{array}{r}\text { NA } \\
375,345 \\
N A \\
0\end{array}$ & $\begin{array}{r}\text { NA } \\
135,990 \\
\text { NA } \\
0\end{array}$ & $\begin{array}{r}\text { NA } \\
28,837 \\
N A \\
0\end{array}$ & $\begin{array}{r}1,241 \\
7,115,889 \\
87,766 \\
7,812\end{array}$ \\
\hline
\end{tabular}

See tootnotes at end of table. 
Table 5. Gross Withdrawals and Marketed Production of Natural Gas by State, 1967-1994 (Continued) (Million Cubic Feet)

\begin{tabular}{|c|c|c|c|c|c|c|c|}
\hline \multirow{2}{*}{ Sten } & \multicolumn{3}{|c|}{$\begin{array}{c}\text { Groess } \\
\text { Whitrewals }\end{array}$} & \multirow{2}{*}{ Repressuring } & \multirow{2}{*}{$\begin{array}{c}\text { Mon- } \\
\text { hydrocerbon } \\
\text { ceses Removed }\end{array}$} & \multirow{2}{*}{$\begin{array}{l}\text { Vented } \\
\text { and } \\
\text { Flared }\end{array}$} & \multirow{2}{*}{$\begin{array}{l}\text { Marketed } \\
\text { Production }\end{array}$} \\
\hline & $\begin{array}{c}\text { From } \\
\text { Cas Wells }\end{array}$ & $\begin{array}{c}\text { From } \\
\text { Oit Wells }\end{array}$ & Total & & & & \\
\hline
\end{tabular}

\begin{tabular}{|c|c|c|c|c|c|c|c|}
\hline \multirow[b]{2}{*}{$\begin{array}{l}\text { West Virginia........... } \\
\text { Wyoming...................... }\end{array}$} & \multicolumn{7}{|c|}{1880} \\
\hline & $\begin{array}{l}156,551 \\
214,609\end{array}$ & 235,944 & $\begin{array}{l}156,551 \\
450,553\end{array}$ & $\begin{array}{r}\text { NA } \\
39,895\end{array}$ & $\begin{array}{r}N A \\
2,469\end{array}$ & $\begin{array}{r}\text { NA } \\
1.117\end{array}$ & $\begin{array}{l}156,551 \\
407,072\end{array}$ \\
\hline Total.................................... & $17,572,526$ & $4,297,166$ & $21,869,692$ & $1,365,454$ & 199,063 & 125,451 & $20,179,724$ \\
\hline
\end{tabular}

\begin{tabular}{|c|c|c|c|c|c|c|c|}
\hline \multirow[b]{2}{*}{$\begin{array}{l}\text { Alabama.................. } \\
\text { Alaska..................... } \\
\text { Arizona..................... } \\
\text { Arkansas................ } \\
\text { Calitornia................. }\end{array}$} & \multicolumn{7}{|c|}{1981} \\
\hline & $\begin{array}{r}119,662 \\
181,560 \\
3 \\
91,032 \\
207,476\end{array}$ & $\begin{array}{r}5,962 \\
761,499 \\
290 \\
41,497 \\
274,357\end{array}$ & $\begin{array}{r}125,624 \\
943,059 \\
293 \\
132,529 \\
481,833\end{array}$ & $\begin{array}{r}3,805 \\
694,865 \\
0 \\
38,991 \\
99,196\end{array}$ & $\begin{array}{r}40,090 \\
0 \\
0 \\
0 \\
371\end{array}$ & $\begin{array}{r}2,485 \\
5,630 \\
106 \\
552 \\
1,907\end{array}$ & $\begin{array}{r}79,244 \\
242,564 \\
187 \\
92,986 \\
380,359\end{array}$ \\
\hline 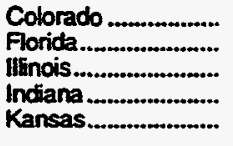 & $\begin{array}{r}153,161 \\
0 \\
1,282 \\
330 \\
532,385\end{array}$ & $\begin{array}{r}47,578 \\
38,539 \\
13 \\
c \\
109,448\end{array}$ & $\begin{array}{r}200,739 \\
38,539 \\
1,295 \\
330 \\
641,833\end{array}$ & $\begin{array}{r}398 \\
2,173 \\
0 \\
N A \\
1,078\end{array}$ & $\begin{array}{r}3,440 \\
3,468 \\
N A \\
0 \\
N A\end{array}$ & $\begin{array}{r}1,195 \\
428 \\
N A \\
N A \\
641\end{array}$ & $\begin{array}{r}195,706 \\
32,470 \\
1,295 \\
330 \\
640,114\end{array}$ \\
\hline $\begin{array}{l}\text { Kentucky.................... } \\
\text { Louisiana ................. } \\
\text { Maryland ................. } \\
\text { Michigan .................. } \\
\text { Mississippi ............... }\end{array}$ & $\begin{array}{r}61,312 \\
6,229,907 \\
56 \\
93,198 \\
220,273\end{array}$ & $\begin{array}{r}c \\
599,600 \\
0 \\
65,095 \\
12,597\end{array}$ & $\begin{array}{r}61,312 \\
6,829,507 \\
56 \\
158,293 \\
232,870\end{array}$ & $\begin{array}{r}\mathrm{NA} \\
26,281 \\
0 \\
2,390 \\
9,311\end{array}$ & $\begin{array}{r}N A \\
N A \\
0 \\
N A \\
30,133\end{array}$ & $\begin{array}{r}\mathrm{NA} \\
23,042 \\
0 \\
3,310 \\
12,188\end{array}$ & $\begin{array}{r}61,312 \\
6,780,184 \\
56 \\
152,593 \\
181,238\end{array}$ \\
\hline $\begin{array}{l}\text { Montana.................... } \\
\text { Nebraska................. } \\
\text { New Mexico ............ } \\
\text { New York................. } \\
\text { North Dakota........... }\end{array}$ & $\begin{array}{r}44,837 \\
622 \\
917,987 \\
19,000 \\
335\end{array}$ & $\begin{array}{r}13,665 \\
2,091 \\
235,176 \\
0 \\
51,620\end{array}$ & $\begin{array}{r}58,502 \\
2,713 \\
1,153,163 \\
19,000 \\
51,955\end{array}$ & $\begin{array}{r}4 ! \\
12,173 \\
0 \\
8,694\end{array}$ & $\begin{array}{r}N A \\
2,047 \\
0 \\
N A\end{array}$ & $\begin{array}{r}1,896 \\
194 \\
6,877 \\
2,926 \\
698\end{array}$ & $\begin{array}{r}56,565 \\
2,519 \\
1,132,066 \\
16,074 \\
42,573\end{array}$ \\
\hline 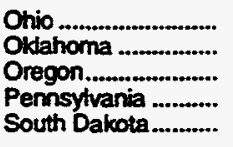 & $\begin{array}{r}141,134 \\
1,605,256 \\
5 \\
122,454 \\
1,155\end{array}$ & $\begin{array}{r}c \\
413,943 \\
0 \\
C \\
52\end{array}$ & $\begin{array}{r}141,134 \\
2,019,199 \\
5 \\
122,454 \\
1,207\end{array}$ & $\begin{array}{r}N A \\
N A \\
0 \\
N A \\
0\end{array}$ & $\begin{array}{r}\text { NA } \\
\text { NA } \\
0 \\
\text { NA } \\
0\end{array}$ & $\begin{array}{c}\mathbf{N A} \\
\mathbf{N A} \\
0 \\
\mathbf{N A} \\
\mathbf{5 2}\end{array}$ & $\begin{array}{r}141,134 \\
2,019,199 \\
5 \\
122,454 \\
1,155\end{array}$ \\
\hline 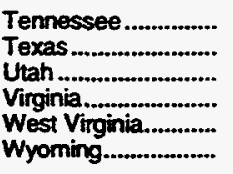 & $\begin{array}{r}521 \\
6,085,714 \\
d \\
8,903 \\
161,251 \\
336,051\end{array}$ & $\begin{array}{r}1,198 \\
1,365,878 \\
91,191 \\
0 \\
c \\
119,302\end{array}$ & $\begin{array}{r}1,719 \\
7,451,592 \\
91,191 \\
8,903 \\
161,251 \\
455,353\end{array}$ & $\begin{array}{r}\text { NA } \\
368,478 \\
N A \\
0 \\
N A \\
43,871\end{array}$ & $\begin{array}{r}\text { NA } \\
140,186 \\
N A \\
0 \\
N A \\
2,143\end{array}$ & $\begin{array}{r}\text { NA } \\
32,907 \\
N A \\
0 \\
N A \\
983\end{array}$ & $\begin{array}{r}1,719 \\
6,910,021 \\
91,191 \\
8,903 \\
161,251 \\
408,356\end{array}$ \\
\hline \multirow[t]{2}{*}{ Total ........................... } & $17,336,862$ & $4,250,591$ & $21,587,453$ & $1,311,735$ & 221,878 & 98,017 & $19,955,823$ \\
\hline & \multicolumn{7}{|c|}{1982} \\
\hline 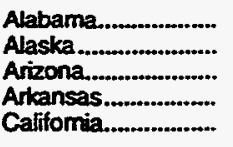 & $\begin{array}{r}128,209 \\
189,799 \\
9 \\
104,547 \\
162,550\end{array}$ & $\begin{array}{r}5,090 \\
894,933 \\
252 \\
45,315 \\
321,364\end{array}$ & $\begin{array}{r}133,298 \\
1,084,732 \\
261 \\
149,862 \\
483,914\end{array}$ & $\begin{array}{r}8,304 \\
813,421 \\
0 \\
24,278 \\
97,490\end{array}$ & $\begin{array}{r}47,185 \\
0 \\
0 \\
0 \\
540\end{array}$ & $\begin{array}{r}2,806 \\
6,946 \\
162 \\
973 \\
1,907\end{array}$ & $\begin{array}{r}75,003 \\
264,364 \\
99 \\
124,611 \\
383,977\end{array}$ \\
\hline 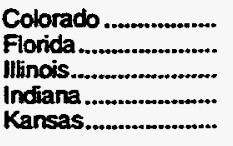 & $\begin{array}{r}165,962 \\
0 \\
993 \\
233 \\
354,602\end{array}$ & $\begin{array}{r}48,971 \\
26,397 \\
169 \\
c \\
87,641\end{array}$ & $\begin{array}{r}214,933 \\
26,397 \\
1,162 \\
233 \\
442,243\end{array}$ & $\begin{array}{r}227 \\
1.094 \\
N A \\
\text { NA } \\
861\end{array}$ & $\begin{array}{r}3,591 \\
2,353 \\
\text { NA } \\
0 \\
\text { e }\end{array}$ & $\begin{array}{r}1,223 \\
435 \\
N A \\
N A \\
431\end{array}$ & $\begin{array}{r}209,892 \\
22,515 \\
1.162 \\
233 \\
440,951\end{array}$ \\
\hline $\begin{array}{l}\text { Kentucky................... } \\
\text { Louisiana .................. } \\
\text { Maryland................ } \\
\text { Michigan ................... } \\
\text { Mississippi .............. }\end{array}$ & $\begin{array}{r}51,924 \\
5,616,590 \\
36 \\
95,461 \\
209,874\end{array}$ & $\begin{array}{r}c \\
600,278 \\
0 \\
63,310 \\
11,822\end{array}$ & $\begin{array}{r}51,924 \\
6,216,868 \\
36 \\
158,771 \\
221,696\end{array}$ & $\begin{array}{r}N A \\
25,459 \\
0 \\
2,400 \\
8,767\end{array}$ & $\begin{array}{r}\text { NA } \\
N A \\
0 \\
N A \\
34,898\end{array}$ & $\begin{array}{r}N A \\
19,781 \\
0 \\
3,320 \\
10,799\end{array}$ & $\begin{array}{r}51,924 \\
6,171,627 \\
36 \\
153,051 \\
167,231\end{array}$ \\
\hline $\begin{array}{l}\text { Montana.................. } \\
\text { Nebraska } \\
\text { New Mexico .................. }\end{array}$ & $\begin{array}{r}44,283 \\
477 \\
804,444\end{array}$ & $\begin{array}{r}13,901 \\
1,803 \\
205,439\end{array}$ & $\begin{array}{r}58,184 \\
2.280 \\
1,009,883\end{array}$ & $\begin{array}{r}0 \\
12,339\end{array}$ & $\begin{array}{r}\text { NA } \\
1,599\end{array}$ & $\begin{array}{l}1,667 \\
4,767\end{array}$ & $\begin{array}{r}56,517 \\
2,280 \\
991,178\end{array}$ \\
\hline
\end{tabular}

See tootnotes at end of table. 
Table 5. Gross Withdrawals and Marketed Production of Natural Gas by State, 1967-1994 (Continued) (Million Cubic Feet)

\begin{tabular}{|c|c|c|c|c|c|c|c|}
\hline \multirow{2}{*}{ stan } & \multicolumn{3}{|c|}{ Cross } & \multirow{2}{*}{ Reposenting } & \multirow{2}{*}{$\begin{array}{c}\text { Non- } \\
\text { mydrocearbon } \\
\text { Cades Ramovid }\end{array}$} & \multirow{2}{*}{$\begin{array}{l}\text { Yootud } \\
\text { and } \\
\text { Fined }\end{array}$} & \multirow{2}{*}{ Prodictiotion } \\
\hline & $\begin{array}{c}\text { From } \\
\text { cen Wolls }\end{array}$ & $\begin{array}{l}\text { From } \\
\text { OAf Wells }\end{array}$ & Total & & & & \\
\hline
\end{tabular}

1982

\begin{tabular}{|c|c|c|c|c|c|c|c|}
\hline 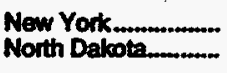 & $\begin{array}{r}18,481 \\
446\end{array}$ & $\begin{array}{r}279 \\
53,373\end{array}$ & $\begin{array}{l}18,760 \\
53,819\end{array}$ & $\begin{array}{l}0 \\
0\end{array}$ & $\begin{array}{r}0 \\
\text { NA }\end{array}$ & $\begin{array}{r}2,883 \\
1\end{array}$ & $\begin{array}{l}15,877 \\
53,818\end{array}$ \\
\hline 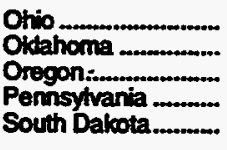 & $\begin{array}{r}138,391 \\
1,493,009 \\
3 \\
121,111 \\
1,846\end{array}$ & $\begin{array}{r}c \\
492,375 \\
0 \\
c \\
539\end{array}$ & $\begin{array}{r}138,391 \\
1,985,384 \\
3 \\
121,111 \\
2,385\end{array}$ & $\begin{array}{r}\text { NA } \\
\text { NA } \\
N A \\
0\end{array}$ & $\begin{array}{r}\mathbf{N A} \\
\mathbf{N A} \\
\mathbf{0} \\
\mathbf{N A} \\
\mathbf{0}\end{array}$ & $\begin{array}{r}\text { NA } \\
N A \\
0 \\
N A \\
54\end{array}$ & $\begin{array}{r}138,391 \\
1,985,384 \\
3 \\
121,111 \\
2,331\end{array}$ \\
\hline 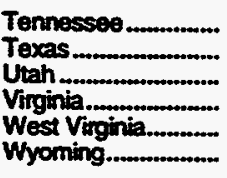 & $\begin{array}{r}d \\
5,566,472 \\
d \\
6,880 \\
150,850 \\
381,364\end{array}$ & $\begin{array}{r}2,976 \\
1,409,147 \\
94,255 \\
0 \\
c \\
83,779\end{array}$ & $\begin{array}{r}2,976 \\
6,975,620 \\
94,255 \\
6,880 \\
150,850 \\
465,143\end{array}$ & $\begin{array}{r}\text { NA } \\
358,584 \\
N A \\
0 \\
N A \\
35,168\end{array}$ & $\begin{array}{r}N A \\
115,157 \\
N A \\
0 \\
N A \\
3,169\end{array}$ & $\begin{array}{r}\text { NA } \\
33,061 \\
\text { NA } \\
0 \\
N A \\
2,149\end{array}$ & $\begin{array}{r}2,976 \\
6,468,817 \\
94,255 \\
6,880 \\
150,850 \\
424,657\end{array}$ \\
\hline Total & $15,808,845$ & $4,463,408$ & $20,272,254$ & $1,388,392$ & 208,492 & 93,365 & $18,582,005$ \\
\hline
\end{tabular}

\begin{tabular}{|c|c|c|c|c|c|c|c|}
\hline \multirow[b]{2}{*}{ 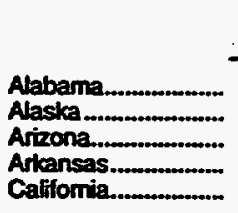 } & \multicolumn{5}{|c|}{1888} & \multicolumn{2}{|r|}{ - } \\
\hline & $\begin{array}{r}120,717 \\
196,587 \\
10 \\
104,686 \\
186,044\end{array}$ & $\begin{array}{r}5,172 \\
968,015 \\
230 \\
49,224 \\
323,370\end{array}$ & $\begin{array}{r}125,889 \\
1,164,602 \\
240 \\
153,911 \\
509,414\end{array}$ & $\begin{array}{r}11,042 \\
882,884 \\
0 \\
25,376 \\
92,518\end{array}$ & $\begin{array}{r}22,252 \\
0 \\
0 \\
0 \\
437\end{array}$ & $\begin{array}{r}1,793 \\
5,027 \\
108 \\
973 \\
1,135\end{array}$ & $\begin{array}{r}90,801 \\
276,691 \\
132 \\
127,561 \\
415,324\end{array}$ \\
\hline 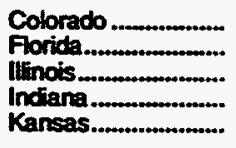 & $\begin{array}{r}131,270 \\
0 \\
858 \\
135 \\
358,943\end{array}$ & $\begin{array}{r}41,572 \\
23,356 \\
172 \\
C \\
89,572\end{array}$ & $\begin{array}{r}172,842 \\
23,356 \\
1,030 \\
135 \\
448,515\end{array}$ & $\begin{array}{r}388 \\
0 \\
N A \\
N A \\
872\end{array}$ & $\begin{array}{r}7,549 \\
2,103 \\
0 \\
0 \\
e\end{array}$ & $\begin{array}{r}1,360 \\
198 \\
N A \\
N A \\
436\end{array}$ & $\begin{array}{r}163,545 \\
21,056 \\
1,030 \\
135 \\
447,207\end{array}$ \\
\hline 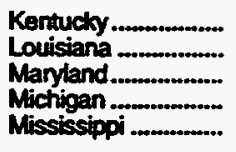 & $\begin{array}{r}46,720 \\
4,737,392 \\
31 \\
74,486 \\
188,767\end{array}$ & $\begin{array}{r}c \\
641,967 \\
0 \\
70,088 \\
13,216\end{array}$ & $\begin{array}{r}46,720 \\
5,379,359 \\
31 \\
144,574 \\
201,984\end{array}$ & $\begin{array}{r}N A \\
21,596 \\
0 \\
2,340 \\
7,048\end{array}$ & $\begin{array}{r}\mathrm{NA} \\
\mathrm{NA} \\
0 \\
\mathrm{NA} \\
35,038\end{array}$ & $\begin{array}{r}N A \\
25,651 \\
0 \\
3,324 \\
8,694\end{array}$ & $\begin{array}{r}46,720 \\
5,332,113 \\
31 \\
138,910 \\
151,204\end{array}$ \\
\hline 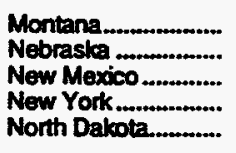 & $\begin{array}{r}41,456 \\
330 \\
714,572 \\
20,666 \\
160\end{array}$ & $\begin{array}{r}12,060 \\
1,761 \\
202,587 \\
914 \\
70,268\end{array}$ & $\begin{array}{r}53,516 \\
2,091 \\
917,158 \\
21.580 \\
70,428\end{array}$ & $\begin{array}{r}0 \\
13,759 \\
0 \\
113\end{array}$ & $\begin{array}{r}\text { NA } \\
1,884 \\
0 \\
N A\end{array}$ & $\begin{array}{r}1,549 \\
6,236 \\
3,744 \\
996\end{array}$ & $\begin{array}{r}51,967 \\
2,091 \\
895,279 \\
17,836 \\
69,319\end{array}$ \\
\hline 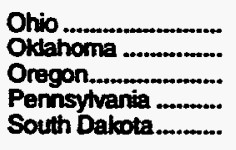 & $\begin{array}{r}151,300 \\
1,329,549 \\
3 \\
118,372 \\
1,286\end{array}$ & $\begin{array}{r}0 \\
449,992 \\
0 \\
C \\
844\end{array}$ & $\begin{array}{r}151,300 \\
1,779,541 \\
3 \\
118,372 \\
2,130\end{array}$ & $\begin{array}{r}\text { NA } \\
\text { NA } \\
0 \\
N A \\
200\end{array}$ & $\begin{array}{r}\text { NA } \\
\text { NA } \\
0 \\
N A \\
0\end{array}$ & $\begin{array}{r}N A \\
N A \\
0 \\
N A \\
85\end{array}$ & $\begin{array}{r}151,300 \\
1,779,541 \\
3 \\
118,372 \\
1,846\end{array}$ \\
\hline 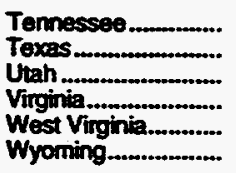 & $\begin{array}{r}d \\
4,988,179 \\
63,158 \\
4,346 \\
130,078 \\
442,762\end{array}$ & $\begin{array}{r}3,950 \\
1,440,840 \\
c \\
0 \\
c \\
97,012\end{array}$ & $\begin{array}{r}3,950 \\
6,429,019 \\
63,158 \\
4,346 \\
130,078 \\
539,774\end{array}$ & $\begin{array}{r}\text { NA } \\
354,048 \\
\text { NA } \\
0 \\
\text { NA } \\
45,870\end{array}$ & $\begin{array}{r}\text { NA } \\
107,991 \\
\text { NA } \\
0 \\
\text { NA } \\
44,683\end{array}$ & $\begin{array}{r}\mathrm{NA} \\
28,420 \\
\mathrm{NA} \\
0 \\
\mathrm{NA} \\
5,233\end{array}$ & $\begin{array}{r}3,950 \\
5,938,561 \\
63,158 \\
4,346 \\
130,078 \\
443,988\end{array}$ \\
\hline \multirow[t]{2}{*}{ Total........................... } & $14,152,863$ & $4,506,182$ & $18,659,046$ & $1,458,054$ & 221,937 & 94,962 & $16,884,093$ \\
\hline & \multicolumn{7}{|c|}{1984} \\
\hline 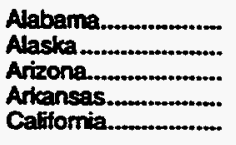 & $\begin{array}{r}130,872 \\
199,209 \\
10 \\
117,620 \\
235,002\end{array}$ & $\begin{array}{r}5,555 \\
1,007,161 \\
217 \\
45,125 \\
339,636\end{array}$ & $\begin{array}{r}136,427 \\
1,206,370 \\
227 \\
162,744 \\
574,638\end{array}$ & $\begin{array}{r}12,557 \\
905,571 \\
0 \\
25,359 \\
96,094\end{array}$ & $\begin{array}{r}20,220 \\
0 \\
0 \\
0 \\
95\end{array}$ & $\begin{array}{r}1,829 \\
11,670 \\
182 \\
2,225 \\
2,116\end{array}$ & $\begin{array}{r}101,821 \\
289,129 \\
45 \\
135,161 \\
476,333\end{array}$ \\
\hline 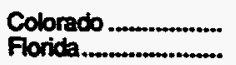 & $\begin{array}{r}140,608 \\
0\end{array}$ & $\begin{array}{l}40,009 \\
13,867\end{array}$ & $\begin{array}{r}180,616 \\
13,867\end{array}$ & $\begin{array}{r}94 \\
0\end{array}$ & $\begin{array}{l}6,265 \\
1,248\end{array}$ & $\begin{array}{r}1,000 \\
34\end{array}$ & $\begin{array}{r}173,257 \\
12,585\end{array}$ \\
\hline
\end{tabular}

See tootnotes at end of taible. 
Table 5. Gross Withdrawals and Marketed Production of Natural Gas by State, 1967-1994 (Continued) (Million Cubic Feet)

\begin{tabular}{|c|c|c|c|c|c|c|c|}
\hline \multirow{2}{*}{ State } & \multicolumn{3}{|c|}{$\begin{array}{l}\text { Groes } \\
\text { withdrumits }\end{array}$} & \multirow{2}{*}{ Represenring } & \multirow{2}{*}{$\begin{array}{c}\text { Non- } \\
\text { hydrecwron } \\
\text { Gases Removed }\end{array}$} & \multirow{2}{*}{$\begin{array}{l}\text { Vented } \\
\text { end } \\
\text { Fianed }\end{array}$} & \multirow{2}{*}{$\begin{array}{l}\text { Marketed } \\
\text { Production }\end{array}$} \\
\hline & $\begin{array}{c}\text { From } \\
\text { Gex Wolls }\end{array}$ & $\begin{array}{c}\text { From } \\
\text { oti Wells }\end{array}$ & Total & & & & \\
\hline
\end{tabular}

1984

\begin{tabular}{|c|c|c|c|c|c|c|c|}
\hline 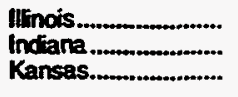 & $\begin{array}{r}1,400 \\
394 \\
384,825\end{array}$ & $\begin{array}{r}130 \\
c \\
96,788\end{array}$ & $\begin{array}{r}1,530 \\
394 \\
481,614\end{array}$ & $\begin{array}{l}\text { NA } \\
\text { Na } \\
935\end{array}$ & $\begin{array}{l}\mathbf{0} \\
\mathbf{0} \\
\theta\end{array}$ & $\begin{array}{l}\text { NA } \\
\text { NA } \\
467\end{array}$ & $\begin{array}{r}1,530 \\
394 \\
480,211\end{array}$ \\
\hline $\begin{array}{l}\text { Kentucky .................. } \\
\text { Louisiand ................. } \\
\text { Manyland ................. } \\
\text { Michigan ................. } \\
\text { Mississippi ................ }\end{array}$ & $\begin{array}{r}61,518 \\
5,189,943 \\
60 \\
82,098 \\
195,387\end{array}$ & $\begin{array}{r}c \\
698,099 \\
0 \\
68,103 \\
13,881\end{array}$ & $\begin{array}{r}61,518 \\
5,888,043 \\
60 \\
150,201 \\
209,268\end{array}$ & $\begin{array}{r}- \\
37,980 \\
0 \\
2,340 \\
7,788\end{array}$ & $\begin{array}{r}\text { NA } \\
0 \\
N A \\
33,707\end{array}$ & $\begin{array}{r} \\
25,008 \\
0 \\
3,324 \\
9,862\end{array}$ & $\begin{array}{r}61,518 \\
5,825,055 \\
60 \\
144,537 \\
157,911\end{array}$ \\
\hline $\begin{array}{l}\text { Missouri ................... } \\
\text { Montana................ } \\
\text { Nebraska ............... } \\
\text { New Mexico ............ } \\
\text { New York............... }\end{array}$ & $\begin{array}{r}4 \\
41.774 \\
354 \\
758,699 \\
26,300\end{array}$ & $\begin{array}{r}0 \\
11,156 \\
1,946 \\
219,537 \\
1,300\end{array}$ & $\begin{array}{r}4 \\
52,930 \\
2,300 \\
978,236 \\
27,600\end{array}$ & $\begin{array}{r}0 \\
171 \\
12,520 \\
0\end{array}$ & $\begin{array}{r}0 \\
N A \\
2,016 \\
0\end{array}$ & $\begin{array}{r}0 \\
1,285 \\
6,335 \\
2,400\end{array}$ & $\begin{array}{r}4 \\
51,474 \\
2,300 \\
957,366 \\
25,200\end{array}$ \\
\hline 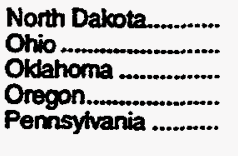 & $\begin{array}{r}154 \\
186,480 \\
1,557,729 \\
2,790 \\
166,342\end{array}$ & $\begin{array}{r}78,598 \\
c \\
488,610 \\
0 \\
C\end{array}$ & $\begin{array}{r}78,752 \\
186,480 \\
2,046,339 \\
2,790 \\
166,342\end{array}$ & $\begin{array}{r}0 \\
N A \\
N A \\
0 \\
N A\end{array}$ & $\begin{array}{r}6,238 \\
N A \\
N A \\
0 \\
N A\end{array}$ & $\begin{array}{r}2.018 \\
\text { NA } \\
\text { NA } \\
0 \\
\text { NA }\end{array}$ & $\begin{array}{r}70,496 \\
186,480 \\
2,046,339 \\
2,790 \\
166,342\end{array}$ \\
\hline 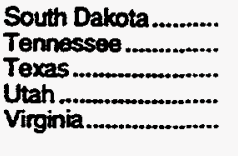 & $\begin{array}{r}834 \\
d \\
5,196,636 \\
184,606 \\
8,928\end{array}$ & $\begin{array}{r}1,649 \\
5,022 \\
1,515,689 \\
c \\
0\end{array}$ & $\begin{array}{r}2,483 \\
5,022 \\
6,712,325 \\
184,606 \\
8,928\end{array}$ & $\begin{array}{r}371 \\
N A \\
374,612 \\
107,469 \\
0\end{array}$ & $\begin{array}{r}0 \\
N A \\
120,435 \\
N A \\
0\end{array}$ & $\begin{array}{r}165 \\
N A \\
32,256 \\
2,439 \\
27\end{array}$ & $\begin{array}{r}1,947 \\
5,022 \\
6,185,021 \\
74,698 \\
8,901\end{array}$ \\
\hline $\begin{array}{l}\text { West Vinginia........... } \\
\text { Wyoming................. }\end{array}$ & $\begin{array}{l}143,730 \\
498,237\end{array}$ & 101,901 & $\begin{array}{l}143,730 \\
600,138\end{array}$ & $\begin{array}{r}\text { NA } \\
46,291\end{array}$ & $\begin{array}{r}\text { NA } \\
33,893\end{array}$ & $\begin{array}{r}\mathbf{N A} \\
3,271\end{array}$ & $\begin{array}{l}143,730 \\
516,683\end{array}$ \\
\hline \multirow[t]{2}{*}{ Total............................ } & $15,520,013$ & $4,753,978$ & $20,266,522$ & $1,630,152$ & 224,118 & 107,913 & $18,304,339$ \\
\hline & \multicolumn{7}{|c|}{1885} \\
\hline $\begin{array}{l}\text { Alabama.................. } \\
\text { Alasika...................... } \\
\text { Arizona.................. } \\
\text { Arlansas.................. } \\
\text { Calffornia................. }\end{array}$ & $\begin{array}{r}136,864 \\
205,249 \\
12 \\
131,406 \\
243,263\end{array}$ & $\begin{array}{r}6,556 \\
1,138,304 \\
197 \\
50,553 \\
353,105\end{array}$ & $\begin{array}{r}143,420 \\
1,343,553 \\
209 \\
181,959 \\
596,368\end{array}$ & $\begin{array}{r}14,769 \\
1,015,911 \\
0 \\
26,036 \\
102,758\end{array}$ & $\begin{array}{r}19,882 \\
0 \\
0 \\
0 \\
127\end{array}$ & $\begin{array}{r}1,426 \\
6,296 \\
124 \\
824 \\
2,200\end{array}$ & $\begin{array}{r}107,342 \\
321,346 \\
85 \\
155,099 \\
491,283\end{array}$ \\
\hline 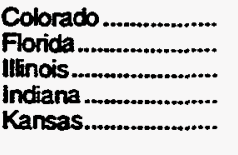 & $\begin{array}{r}132,073 \\
0 \\
1,228 \\
367 \\
423,502\end{array}$ & $\begin{array}{r}57,492 \\
11,604 \\
96 \\
c \\
106,073\end{array}$ & $\begin{array}{r}189,565 \\
11,604 \\
1,324 \\
367 \\
529,575\end{array}$ & $\begin{array}{r}748 \\
0 \\
N A \\
N A \\
1,028\end{array}$ & $\begin{array}{r}8.763 \\
1,045 \\
0 \\
0 \\
0\end{array}$ & $\begin{array}{r}1.821 \\
13 \\
N A \\
N A \\
514\end{array}$ & $\begin{array}{r}178,233 \\
10,545 \\
1,324 \\
367 \\
528,032\end{array}$ \\
\hline 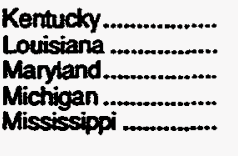 & $\begin{array}{r}73,126 \\
4,494,257 \\
39 \\
77,218 \\
180,212\end{array}$ & $\begin{array}{r}c \\
723,841 \\
0 \\
60,301 \\
11,685\end{array}$ & $\begin{array}{r}73,126 \\
5,218,098 \\
39 \\
137,519 \\
191,898\end{array}$ & $\begin{array}{r}179,383 \\
0 \\
2,340 \\
7,552\end{array}$ & $\begin{array}{r}\text { NA } \\
0 \\
N A \\
36,076\end{array}$ & $\begin{array}{r}25,013 \\
0 \\
3,324 \\
4,097\end{array}$ & $\begin{array}{r}73,126 \\
5,013,702 \\
39 \\
131,855 \\
144,172\end{array}$ \\
\hline $\begin{array}{l}\text { Missouri .................... } \\
\text { Montana................... } \\
\text { Nebraska ................. } \\
\text { New Mexico ............. } \\
\text { New York................ }\end{array}$ & $\begin{array}{r}4 \\
41,816 \\
270 \\
707,265 \\
32,601\end{array}$ & $\begin{array}{r}0 \\
12,335 \\
1,674 \\
218,909 \\
2,733\end{array}$ & $\begin{array}{r}4 \\
54,151 \\
1,944 \\
926,174 \\
35,334\end{array}$ & $\begin{array}{r}0 \\
197 \\
14,993 \\
0\end{array}$ & $\begin{array}{r}0 \\
\text { NA } \\
40 \\
0\end{array}$ & $\begin{array}{r}0 \\
1,460 \\
5,869 \\
3,773\end{array}$ & $\begin{array}{r}4 \\
52,494 \\
1,944 \\
905,272 \\
31,561\end{array}$ \\
\hline 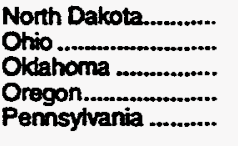 & $\begin{array}{r}193 \\
182,245 \\
1,486,126 \\
4,080 \\
150,234\end{array}$ & $\begin{array}{r}84,438 \\
c \\
507,279 \\
0 \\
c\end{array}$ & $\begin{array}{r}84,631 \\
182,245 \\
1,993,405 \\
4,080 \\
150,234\end{array}$ & $\begin{array}{r}2,358 \\
N A \\
N A \\
0 \\
N A\end{array}$ & $\begin{array}{r}6,656 \\
N A \\
N A \\
0 \\
N A\end{array}$ & $\begin{array}{r}2,984 \\
N A \\
N A \\
0 \\
N A\end{array}$ & $\begin{array}{r}72,633 \\
182,245 \\
1,993,405 \\
4,080 \\
150,234\end{array}$ \\
\hline 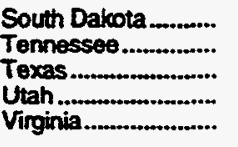 & $\begin{array}{r}1,211 \\
d \\
5,059,681 \\
213,302 \\
15,041\end{array}$ & $\begin{array}{r}1,934 \\
4,686 \\
1,517,238 \\
c \\
0\end{array}$ & $\begin{array}{r}3,146 \\
4,686 \\
6,576,919 \\
213,302 \\
15,041\end{array}$ & $\begin{array}{r}394 \\
N A \\
371,466 \\
127,157 \\
0\end{array}$ & $\begin{array}{r}0 \\
N A \\
122.014 \\
N A \\
0\end{array}$ & $\begin{array}{r}194 \\
N A \\
30,776 \\
2,740 \\
0\end{array}$ & $\begin{array}{r}2,558 \\
4,686 \\
6,052,663 \\
83,405 \\
15,041\end{array}$ \\
\hline
\end{tabular}

See footnotes at end of table. 
Table 5. Gross Withdrawals and Marketed Production of Natural Gas by State, 1967-1994 (Continued) (Million Cubic Feet)

\begin{tabular}{|c|c|c|c|c|c|c|c|}
\hline \multirow{2}{*}{ Sule } & \multicolumn{3}{|c|}{$\begin{array}{l}\text { Grose } \\
\text { Withdrenets }\end{array}$} & \multirow{2}{*}{ Pepucearing } & \multirow{2}{*}{$\begin{array}{c}\text { Non } \\
\text { mydrocerton } \\
\text { ersec Rowowed }\end{array}$} & \multirow{2}{*}{$\begin{array}{l}\text { Yented } \\
\text { and } \\
\text { Fianed }\end{array}$} & \multirow{2}{*}{$\begin{array}{l}\text { Marketed } \\
\text { Production }\end{array}$} \\
\hline & From & $\begin{array}{l}\text { From } \\
\text { oil Welle }\end{array}$ & Total & & & & \\
\hline & \multicolumn{7}{|c|}{1885} \\
\hline $\begin{array}{l}\text { West Vinginia. } \\
\text { Wyoming }\end{array}$ & $\begin{array}{l}144,883 \\
397,601\end{array}$ & 200,295 & $\begin{array}{l}144,883 \\
597,896\end{array}$ & $\begin{array}{r}N A \\
48,107\end{array}$ & $\begin{array}{r}\mathrm{NA} \\
131,894\end{array}$ & $\underset{1,330}{N A}$ & $\begin{array}{l}144,883 \\
416,565\end{array}$ \\
\hline \multirow[t]{3}{*}{ Totral.......................... } & $14,535,369$ & $5,071,328$ & $19,606,699$ & $1,915,197$ & 326,497 & 94,778 & $17,270,227$ \\
\hline & & & & $\dot{-}$ & & & \\
\hline & \multicolumn{7}{|c|}{1986} \\
\hline 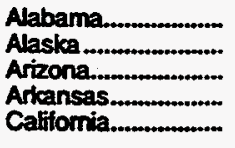 & $\begin{array}{r}137,202 \\
181,126 \\
2 \\
107,567 \\
225,007\end{array}$ & $\begin{array}{r}8,423 \\
1,193,928 \\
183 \\
45,598 \\
333,317\end{array}$ & $\begin{array}{r}145,625 \\
1,375,054 \\
185 \\
153,165 \\
558,324\end{array}$ & $\begin{array}{r}18,238 \\
1,061,351 \\
0 \\
20,329 \\
93,351\end{array}$ & $\begin{array}{r}18,893 \\
0 \\
0 \\
0 \\
5\end{array}$ & $\begin{array}{r}1,310 \\
8,862 \\
122 \\
1,760 \\
2,750\end{array}$ & $\begin{array}{r}107,184 \\
304,841 \\
63 \\
131,075 \\
462,218\end{array}$ \\
\hline 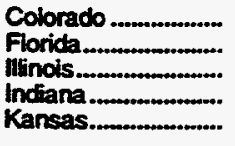 & $\begin{array}{r}111,164 \\
0 \\
1,446 \\
365 \\
468,220\end{array}$ & $\begin{array}{r}64,454 \\
9,766 \\
441 \\
c \\
c\end{array}$ & $\begin{array}{r}175,618 \\
9,766 \\
1,887 \\
365 \\
480,166\end{array}$ & $\begin{array}{r}485 \\
0 \\
N A \\
N A \\
753\end{array}$ & $\begin{array}{r}9,872 \\
879 \\
0 \\
0 \\
e\end{array}$ & $\begin{array}{r}1,57 \\
54 \\
\mathrm{NA} \\
\mathrm{NA} \\
450\end{array}$ & $\begin{array}{r}163,684 \\
8,833 \\
1,887 \\
365 \\
478,963\end{array}$ \\
\hline 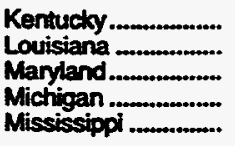 & $\begin{array}{r}80,195 \\
4,217,384 \\
20 \\
71,583 \\
194,954\end{array}$ & $\begin{array}{r}c \\
747,374 \\
0 \\
61,368 \\
15,132\end{array}$ & $\begin{array}{r}80,195 \\
4,964,758 \\
20 \\
132,951 \\
210,086\end{array}$ & $\begin{array}{r} \\
45,191 \\
0 \\
2,340 \\
18,913\end{array}$ & $\begin{array}{r}N A \\
0 \\
N A \\
45,494\end{array}$ & $\begin{array}{r}0 \\
24,173 \\
0 \\
3,324 \\
4,845\end{array}$ & $\begin{array}{r}80,195 \\
4,895,394 \\
20 \\
127,287 \\
140,833\end{array}$ \\
\hline 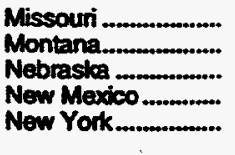 & $\begin{array}{r}4 \\
36,296 \\
278 \\
501,730 \\
32,050\end{array}$ & $\begin{array}{r}0 \\
11,950 \\
1,125 \\
219,487 \\
1,634\end{array}$ & $\begin{array}{r}4 \\
48,246 \\
1,403 \\
721,217 \\
33,684\end{array}$ & $\begin{array}{r}0 \\
186 \\
14,485 \\
0\end{array}$ & $\begin{array}{r}0 \\
\text { NA } \\
38 \\
0\end{array}$ & $\begin{array}{r}0 \\
1,468 \\
4,080 \\
3,720\end{array}$ & $\begin{array}{r}4 \\
46,592 \\
1,403 \\
702,614 \\
29,964\end{array}$ \\
\hline 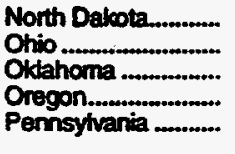 & $\begin{array}{r}252 \\
182,072 \\
1,471,153 \\
4,600 \\
159,889\end{array}$ & $\begin{array}{r}70,703 \\
c \\
500,835 \\
0 \\
C\end{array}$ & $\begin{array}{r}70,955 \\
182,072 \\
1,971,988 \\
4,600 \\
159,889\end{array}$ & $\begin{array}{r}0 \\
N A \\
N A \\
0 \\
N A\end{array}$ & $\begin{array}{r}9,004 \\
N A \\
N A \\
0 \\
N A\end{array}$ & $\begin{array}{r}6,853 \\
N A \\
N A \\
0 \\
N A\end{array}$ & $\begin{array}{r}55,098 \\
182,072 \\
1,971,988 \\
4,600 \\
159,889\end{array}$ \\
\hline 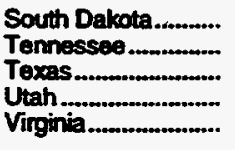 & $\begin{array}{r}1,064 \\
d \\
5,189,688 \\
238,388 \\
15,427\end{array}$ & $\begin{array}{r}1,398 \\
-3,464 \\
1,466,649 \\
c \\
0\end{array}$ & $\begin{array}{r}2,463 \\
3,464 \\
6,656,337 \\
238,388 \\
15,427\end{array}$ & $\begin{array}{r}92 \\
N A \\
364,168 \\
144,693 \\
0\end{array}$ & $\begin{array}{r}0 \\
N A \\
114,344 \\
N A \\
0\end{array}$ & $\begin{array}{r}140 \\
N A \\
26,050 \\
3,682 \\
0\end{array}$ & $\begin{array}{r}2,231 \\
3,464 \\
6,151,775 \\
90,013 \\
15,427\end{array}$ \\
\hline $\begin{array}{l}\text { West Virginia.............................. } \\
\text { Wyoming }\end{array}$ & $\begin{array}{l}135,431 \\
389,230\end{array}$ & $\begin{array}{r}c \\
207,748\end{array}$ & $\begin{array}{l}135,431 \\
596,978\end{array}$ & N2,977 & $\begin{array}{r}\text { NA } \\
138,322\end{array}$ & $\begin{array}{r}\text { NA } \\
2.413\end{array}$ & $\begin{array}{l}135,431 \\
403,266\end{array}$ \\
\hline \multirow{2}{*}{$\begin{array}{l}\text { Total.......................... } \\
-\end{array}$} & $14,153,787$ & $4,976,923$ & $19,130,711$ & $1,837,552$ & 336,851 & 97,633 & $16,858,675$ \\
\hline & \multicolumn{7}{|c|}{1987} \\
\hline 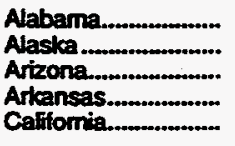 & $\begin{array}{r}148,238 \\
185,342 \\
0 \\
123,118 \\
193,394\end{array}$ & $\begin{array}{r}6,905 \\
1,509,528 \\
185 \\
43,880 \\
334,092\end{array}$ & $\begin{array}{r}155,143 \\
1,694,870 \\
185 \\
166,998 \\
527,486\end{array}$ & $\begin{array}{r}17,850 \\
1,319,430 \\
0 \\
24,779 \\
100,128\end{array}$ & $\begin{array}{r}18,697 \\
0 \\
0 \\
0 \\
3\end{array}$ & $\begin{array}{r}1,356 \\
15,603 \\
125 \\
1,068 \\
2,734\end{array}$ & $\begin{array}{r}117,241 \\
359,837 \\
60 \\
141,151 \\
424,621\end{array}$ \\
\hline 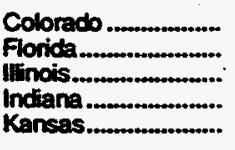 & $\begin{array}{r}118,517 \\
0 \\
1,156 \\
217 \\
377,625\end{array}$ & $\begin{array}{r}67,769 \\
9,132 \\
215 \\
c \\
96,501\end{array}$ & $\begin{array}{r}186,286 \\
9,132 \\
1,371 \\
217 \\
474,127\end{array}$ & $\begin{array}{r}598 \\
0 \\
0 \\
0 \\
917\end{array}$ & $\begin{array}{r}18,776 \\
822 \\
0 \\
0 \\
N A\end{array}$ & $\begin{array}{r}2,360 \\
30 \\
0 \\
N A \\
458\end{array}$ & $\begin{array}{r}164,557 \\
8,281 \\
1,371 \\
217 \\
472,752\end{array}$ \\
\hline 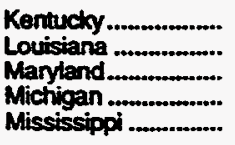 & $\begin{array}{r}70,125 \\
4,506,475 \\
44 \\
85,852 \\
210,520\end{array}$ & $\begin{array}{r}c \\
698,508 \\
0 \\
67,455 \\
14,463\end{array}$ & $\begin{array}{r}70,125 \\
5,204,984 \\
44 \\
153,307 \\
224,983\end{array}$ & $\begin{array}{r}5 \\
57,185 \\
0 \\
2,606 \\
22,091\end{array}$ & $\begin{array}{r}\text { NA } \\
0 \\
\mathrm{NA} \\
59,053\end{array}$ & $\begin{array}{r} \\
25,290 \\
0 \\
3,705 \\
4,112\end{array}$ & $\begin{array}{r}70,125 \\
5,122,509 \\
44 \\
146,996 \\
139,727\end{array}$ \\
\hline Missouri .................... & 4 & 0 & 4 & 0 & 0 & 0 & 4 \\
\hline
\end{tabular}

See tootnotes at end of table. 
Table 5. Gross Withdrawals and Marketed Production of Natural Gas by State, 1967-1994 (Continued) (Million Cubic Feet)

\begin{tabular}{|c|c|c|c|c|c|c|c|}
\hline \multirow{2}{*}{ Stats } & \multicolumn{3}{|c|}{$\begin{array}{c}\text { Crose } \\
\text { Withdrewnls }\end{array}$} & \multirow{2}{*}{ Represeuring } & \multirow{2}{*}{$\begin{array}{c}\text { Non } \\
\text { hydrocentoon } \\
\text { Geses Removed }\end{array}$} & \multirow{2}{*}{$\begin{array}{l}\text { Vented } \\
\text { and } \\
\text { Fined }\end{array}$} & \multirow{2}{*}{$\begin{array}{l}\text { Marketed } \\
\text { Production }\end{array}$} \\
\hline & $\begin{array}{l}\text { From } \\
\text { Ges Wells }\end{array}$ & $\begin{array}{c}\text { From } \\
\text { on Wolls }\end{array}$ & Total & & & & \\
\hline
\end{tabular}

\begin{tabular}{|c|c|c|c|c|c|c|c|}
\hline \multirow[b]{2}{*}{$\begin{array}{l}\text { Montana................. } \\
\text { Nebraska } \\
\text { New Mexico .................. } \\
\text { New York................ }\end{array}$} & \multicolumn{7}{|c|}{1987} \\
\hline & $\begin{array}{r}36,556 \\
583 \\
9626,848 \\
27,031\end{array}$ & $\begin{array}{r}11,289 \\
678 \\
218,630 \\
1,447\end{array}$ & $\begin{array}{r}47,845 \\
1,261 \\
845,478 \\
28,478\end{array}$ & $\begin{array}{r}208 \\
15,465 \\
0\end{array}$ & $\begin{array}{r}\text { NA } \\
2,430 \\
0\end{array}$ & $\begin{array}{l}1,181 \\
3,811 \\
2,802\end{array}$ & $\begin{array}{r}46,456 \\
1,261 \\
823,773 \\
25,676\end{array}$ \\
\hline 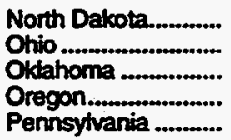 & $\begin{array}{r}125 \\
166,593 \\
1,582,709 \\
3,800 \\
163,318\end{array}$ & $\begin{array}{r}71,612 \\
c \\
490,753 \\
0 \\
c\end{array}$ & $\begin{array}{r}71,737 \\
166,593 \\
2,073,461 \\
3,800 \\
163,318\end{array}$ & $\begin{array}{r}0 \\
N A \\
N A \\
0 \\
N A\end{array}$ & $\begin{array}{r}6,708 \\
\text { NA } \\
\text { NA } \\
0 \\
\text { NA }\end{array}$ & $\begin{array}{r}2,771 \\
N A \\
N A \\
0 \\
N A\end{array}$ & $\begin{array}{r}62,258 \\
166,593 \\
2,073,461 \\
3,800 \\
163,318\end{array}$ \\
\hline 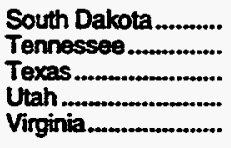 & $\begin{array}{r}1,425 \\
d \\
5,305,442 \\
188,486 \\
19,520\end{array}$ & $\begin{array}{r}2,237 \\
2,707 \\
1,382,247 \\
73,425 \\
0\end{array}$ & $\begin{array}{r}3,662 \\
2,707 \\
6,687,689 \\
261,911 \\
19,520\end{array}$ & $\begin{array}{r}231 \\
N A \\
406,291 \\
173,181 \\
0\end{array}$ & $\begin{array}{r}0 \\
N A \\
125,757 \\
N A \\
0\end{array}$ & $\begin{array}{r}0 \\
N A \\
29,325 \\
1,572 \\
297\end{array}$ & $\begin{array}{r}3,431 \\
2,707 \\
6,126,315 \\
87,158 \\
19,223\end{array}$ \\
\hline $\begin{array}{l}\text { West Virginia............ } \\
\text { Wyoming.............. }\end{array}$ & $\begin{array}{l}160,000 \\
503,899\end{array}$ & $\begin{array}{r}c \\
229,579\end{array}$ & $\begin{array}{l}160,000 \\
733,478\end{array}$ & $\begin{array}{r}\text { NA } \\
66,604\end{array}$ & $\begin{array}{r}N A \\
143,787\end{array}$ & $\begin{array}{r}N A \\
25,107\end{array}$ & $\begin{array}{l}160,000 \\
497,980\end{array}$ \\
\hline \multirow[t]{2}{*}{ Total............................... } & $14,806,962$ & $5,333,237$ & $20,140,200$ & $2,207,559$ & 376,033 & 123,707 & $17,432,901$ \\
\hline & \multicolumn{7}{|c|}{1988} \\
\hline 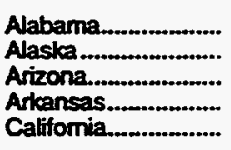 & $\begin{array}{r}168,484 \\
186,554 \\
0 \\
146,898 \\
174,698\end{array}$ & $\begin{array}{r}6,570 \\
1,746,493 \\
179 \\
43,780 \\
326,346\end{array}$ & $\begin{array}{r}175,054 \\
1,933,047 \\
179 \\
190,678 \\
501,044\end{array}$ & $\begin{array}{r}23,444 \\
1,545,391 \\
0 \\
22,994 \\
97,816\end{array}$ & $\begin{array}{r}20.262 \\
0 \\
0 \\
0 \\
832\end{array}$ & $\begin{array}{l}1,824 \\
9,018 \\
123 \\
1,110 \\
2,733\end{array}$ & $\begin{array}{r}129,524 \\
378,638 \\
56 \\
166,573 \\
399,663\end{array}$ \\
\hline 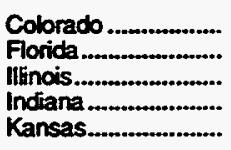 & $\begin{array}{r}142,215 \\
0 \\
1.157 \\
412 \\
483,257\end{array}$ & $\begin{array}{r}69,815 \\
8,407 \\
181 \\
\mathrm{c} \\
111,129\end{array}$ & $\begin{array}{r}212,030 \\
8,407 \\
1,338 \\
412 \\
594,386\end{array}$ & $\begin{array}{r}2,241 \\
0 \\
\text { NA } \\
\text { NA } \\
963\end{array}$ & $\begin{array}{r}13,652 \\
757 \\
0 \\
0 \\
N A\end{array}$ & $\begin{array}{r}4,593 \\
166 \\
0 \\
N A \\
578\end{array}$ & $\begin{array}{r}191,544 \\
7,484 \\
1,338 \\
412 \\
592,845\end{array}$ \\
\hline $\begin{array}{l}\text { Kentuclyy ................... } \\
\text { Louisiana ................. } \\
\text { Maryland ................. } \\
\text { Michigan ................ } \\
\text { Mississippi ................ }\end{array}$ & $\begin{array}{r}73,629 \\
4,607,205 \\
29 \\
85,013 \\
222,539\end{array}$ & $\begin{array}{r}c \\
641,000 \\
0 \\
66,796 \\
14,640\end{array}$ & $\begin{array}{r}73,629 \\
5,248,205 \\
29 \\
151,809 \\
237,180\end{array}$ & $\begin{array}{r}* \\
45,103 \\
0 \\
2,340 \\
38,948\end{array}$ & $\begin{array}{r}\text { NA } \\
0 \\
N A \\
68,667\end{array}$ & $\begin{array}{r}* \\
22,835 \\
0 \\
3,324 \\
5,512\end{array}$ & $\begin{array}{r}73,629 \\
5,180,267 \\
29 \\
146,145 \\
124,053\end{array}$ \\
\hline 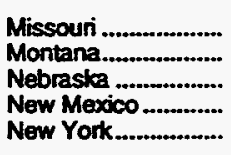 & $\begin{array}{r}4 \\
42,066 \\
322 \\
602,740 \\
26,423\end{array}$ & $\begin{array}{r}0 \\
10,948 \\
588 \\
209,253 \\
1,044\end{array}$ & $\begin{array}{r}4 \\
53,014 \\
910 \\
811,994 \\
27,467\end{array}$ & $\begin{array}{r}0 \\
214 \\
15,184 \\
0\end{array}$ & $\begin{array}{r}0 \\
N A \\
1,408 \\
0\end{array}$ & $\begin{array}{r}0 \\
1,146 \\
3,582 \\
4,012\end{array}$ & $\begin{array}{r}4 \\
51,654 \\
910 \\
791,819 \\
23,455\end{array}$ \\
\hline 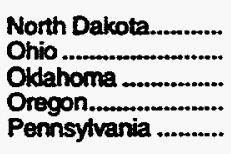 & $\begin{array}{r}225 \\
166,690 \\
1,705,643 \\
4,000 \\
167,089\end{array}$ & $\begin{array}{r}66,093 \\
c \\
461,407 \\
0 \\
c\end{array}$ & $\begin{array}{r}66,318 \\
166,690 \\
2,167,050 \\
4,000 \\
167,009\end{array}$ & $\begin{array}{r}0 \\
N A \\
N A \\
0 \\
N A\end{array}$ & $\begin{array}{r}5.800 \\
\text { NA } \\
\text { NA } \\
0 \\
\text { NA }\end{array}$ & $\begin{array}{r}2,771 \\
N A \\
N A \\
0 \\
N A\end{array}$ & $\begin{array}{r}57,747 \\
166,690 \\
2,167,050 \\
4,000 \\
167,089\end{array}$ \\
\hline 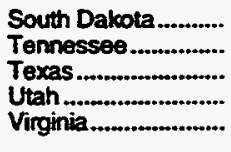 & $\begin{array}{r}1,034 \\
d \\
5,518,260 \\
174,421 \\
18,682\end{array}$ & $\begin{array}{r}3,248 \\
2,100 \\
1,400,362 \\
103,489 \\
0\end{array}$ & $\begin{array}{r}4,283 \\
2,100 \\
6,918,622 \\
277,910 \\
18,682\end{array}$ & $\begin{array}{r}363 \\
N A \\
456,627 \\
174,772 \\
0\end{array}$ & $\begin{array}{r}0 \\
N A \\
144,134 \\
N A \\
0\end{array}$ & $\begin{array}{r}0 \\
N A \\
31,832 \\
1,766 \\
258\end{array}$ & $\begin{array}{r}3,920 \\
2,100 \\
6,286,029 \\
101,372 \\
18,424\end{array}$ \\
\hline $\begin{array}{l}\text { West Vigginia............. } \\
\text { Wyoming................. }\end{array}$ & $\begin{array}{l}174,942 \\
572,392\end{array}$ & 238,361 & $\begin{array}{l}174,942 \\
810,753\end{array}$ & $\begin{array}{r}\text { NA } \\
51,982\end{array}$ & $\begin{array}{r}\text { NA } \\
204,371\end{array}$ & $\begin{array}{r}\mathrm{NA} \\
45,342\end{array}$ & $\begin{array}{l}174,942 \\
509,058\end{array}$ \\
\hline 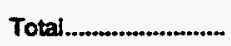 & $15,467,023$ & $5,532,229$ & $20,999,255$ & $2,478,382$ & 459,883 & 142,525 & $17,918,465$ \\
\hline
\end{tabular}

See footnotes at end of table. 
Table 5. Gross Withdrawals and Marketed Production of Natural Gas by State, 1967-1994 (Continued) (Million Cubic Feet)

\begin{tabular}{|c|c|c|c|c|c|c|c|}
\hline \multirow{2}{*}{ Stev } & \multicolumn{3}{|c|}{$\begin{array}{l}\text { Croses } \\
\text { Wrthdrewals }\end{array}$} & \multirow{2}{*}{ Represeuring } & \multirow{2}{*}{$\begin{array}{l}\text { Non- } \\
\text { mydrocatbon } \\
\text { Geases Pemoved }\end{array}$} & \multirow{2}{*}{$\begin{array}{l}\text { Vented } \\
\text { and } \\
\text { Finered }\end{array}$} & \multirow{2}{*}{$\begin{array}{l}\text { Marketud } \\
\text { Production }\end{array}$} \\
\hline & From & $\begin{array}{l}\text { From } \\
\text { of welts }\end{array}$ & Tot: & & & & \\
\hline & \multicolumn{7}{|c|}{1889} \\
\hline 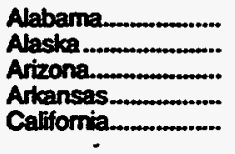 & $\begin{array}{r}174,345 \\
194,262 \\
1,306 \\
155,740 \\
146,771\end{array}$ & $\begin{array}{r}5,955 \\
1,770,751 \\
149 \\
43,365 \\
319,722\end{array}$ & $\begin{array}{r}180,300 \\
1,965,013 \\
1,455 \\
199,105 \\
466,493\end{array}$ & $\begin{array}{r}28,256 \\
1,561,498 \\
0 \\
23,937 \\
99,799\end{array}$ & $\begin{array}{r}22.131 \\
0 \\
0 \\
0 \\
1,103\end{array}$ & $\begin{array}{r}1,503 \\
9,786 \\
95 \\
1,110 \\
2,731\end{array}$ & $\begin{array}{r}128,411 \\
393,729 \\
1,360 \\
174,158 \\
362,860\end{array}$ \\
\hline 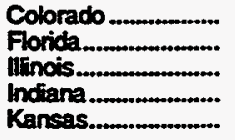 & $\begin{array}{r}172,658 \\
0 \\
1,268 \\
416 \\
510,391\end{array}$ & $\begin{array}{r}64,704 \\
8,773 \\
209 \\
6 \\
92,331\end{array}$ & $\begin{array}{r}237,372 \\
8,773 \\
1,477 \\
416 \\
602,722\end{array}$ & $\begin{array}{r}6,703 \\
0 \\
N A \\
N A \\
1,017\end{array}$ & $\begin{array}{r}9,971 \\
790 \\
0 \\
0 \\
N A\end{array}$ & $\begin{array}{r}3.961 \\
450 \\
0 \\
\mathrm{NA} \\
509\end{array}$ & $\begin{array}{r}216.737 \\
7.534 \\
1.477 \\
416 \\
601.196\end{array}$ \\
\hline 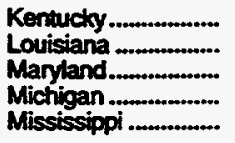 & $\begin{array}{r}72,417 \\
4,556,530 \\
34 \\
94,439 \\
184,000\end{array}$ & $\begin{array}{r}c \\
586,441 \\
0 \\
68,387 \\
15,856\end{array}$ & $\begin{array}{r}72,417 \\
15,142,971 \\
34 \\
162,826 \\
199,856\end{array}$ & $\begin{array}{r}\bullet \\
42,948 \\
0 \\
2,768 \\
30,390\end{array}$ & $\begin{array}{r}N A \\
0 \\
N A \\
62,619\end{array}$ & $\begin{array}{r}= \\
21,898 \\
0 \\
4,070 \\
4,201\end{array}$ & $\begin{array}{r}72,417 \\
5,078,125 \\
34 \\
155,988 \\
102,645\end{array}$ \\
\hline 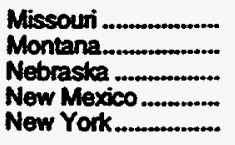 & $\begin{array}{r}4 \\
42,985 \\
285 \\
685,363 \\
24,343\end{array}$ & $\begin{array}{r}0 \\
9,598 \\
593 \\
192,717 \\
1.126\end{array}$ & $\begin{array}{r}4 \\
52,583 \\
878 \\
878,080 \\
25,469\end{array}$ & $\begin{array}{r}0 \\
177 \\
17.104 \\
0\end{array}$ & $\begin{array}{r}0 \\
\text { NA } \\
1.942 \\
0\end{array}$ & $\begin{array}{r}0 \\
1,099 \\
4,419 \\
5,036\end{array}$ & $\begin{array}{r}4 \\
51,307 \\
878 \\
854,615 \\
20,433\end{array}$ \\
\hline 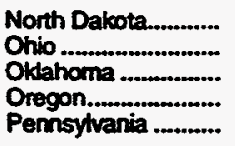 & $\begin{array}{r}256 \\
159,730 \\
1,801,763 \\
2,500 \\
191,774\end{array}$ & $\begin{array}{r}58,070 \\
C \\
435,274 \\
0 \\
C\end{array}$ & $\begin{array}{r}58,326 \\
159,730 \\
2,237,037 \\
2,500 \\
191,774\end{array}$ & $\begin{array}{r}0 \\
N A \\
N A \\
0 \\
N A\end{array}$ & $\begin{array}{r}5,102 \\
N A \\
N A \\
0 \\
N A\end{array}$ & $\begin{array}{r}2,050 \\
N A \\
N A \\
0 \\
N A\end{array}$ & $\begin{array}{r}51,174 \\
159,730 \\
2,237,037 \\
2,500 \\
191,774\end{array}$ \\
\hline 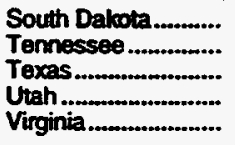 & $\begin{array}{r}757 \\
d \\
5,523,698 \\
201,723 \\
17,935\end{array}$ & $\begin{array}{r}3,947 \\
1,900 \\
1,357,343 \\
76,358 \\
0\end{array}$ & $\begin{array}{r}4,704 \\
1,900 \\
6,881,041 \\
278,081 \\
17,035\end{array}$ & $\begin{array}{r}335 \\
N A \\
450,733 \\
156,831 \\
0\end{array}$ & $\begin{array}{r}0 \\
N A \\
159,113 \\
N A \\
0\end{array}$ & $\begin{array}{r}0 \\
N A \\
29,770 \\
1,161 \\
0\end{array}$ & $\begin{array}{r}4,369 \\
1,900 \\
6,241,425 \\
120,089 \\
17,935\end{array}$ \\
\hline $\begin{array}{l}\text { West Virginia.......... } \\
\text { Wyoming................. }\end{array}$ & $\begin{array}{l}177,192 \\
613,966\end{array}$ & 251,995 & $\begin{array}{l}177,192 \\
865,961\end{array}$ & $\frac{N A}{52,783}$ & $\begin{array}{r}\mathrm{NA} \\
99,686\end{array}$ & $\frac{N A}{47,793}$ & $\begin{array}{l}177,192 \\
665,699\end{array}$ \\
\hline \multirow[t]{2}{*}{ Total.................................. } & $15,708,861$ & $5,365,564$ & $21,074,425$ & $2,475,179$ & 362,457 & 141,642 & $18,095,147$ \\
\hline & \multicolumn{7}{|c|}{1980} \\
\hline 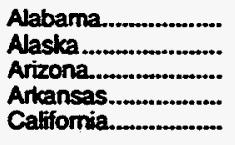 & $\begin{array}{r}181,324 \\
204,093 \\
2,080 \\
161,148 \\
146,252\end{array}$ & $\begin{array}{r}5,219 \\
1,849,231 \\
67 \\
34,256 \\
299,748\end{array}$ & $\begin{array}{r}186,542 \\
2,053,324 \\
2,147 \\
195,405 \\
446,000\end{array}$ & $\begin{array}{r}28,540 \\
1,639,689 \\
0 \\
20,165 \\
81,159\end{array}$ & $\begin{array}{r}20,792 \\
0 \\
0 \\
0 \\
849\end{array}$ & $\begin{array}{r}1,933 \\
10,727 \\
22 \\
284 \\
1,244\end{array}$ & $\begin{array}{r}135,276 \\
402,907 \\
2,125 \\
174,956 \\
362,748\end{array}$ \\
\hline 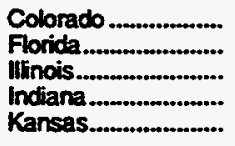 & $\begin{array}{r}199,805 \\
0 \\
653 \\
399 \\
467,467\end{array}$ & $\begin{array}{r}68,878 \\
7,566 \\
24 \\
c \\
107,622\end{array}$ & $\begin{array}{r}288,683 \\
7,566 \\
677 \\
399 \\
575,090\end{array}$ & $\begin{array}{r}10,986 \\
115 \\
N A \\
N A \\
930\end{array}$ & $\begin{array}{r}9,981 \\
681 \\
0 \\
0 \\
\text { NA }\end{array}$ & $\begin{array}{r}4,719 \\
286 \\
0 \\
N A \\
557\end{array}$ & $\begin{array}{r}242,997 \\
6,483 \\
677 \\
399 \\
573,603\end{array}$ \\
\hline 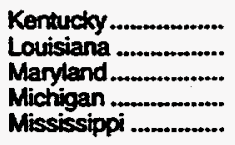 & $\begin{array}{r}75,333 \\
4,726,927 \\
22 \\
106,689 \\
180,609\end{array}$ & $\begin{array}{r}\mathrm{c} \\
576,558 \\
0 \\
71,126 \\
19,983\end{array}$ & $\begin{array}{r}75,333 \\
5,303,485 \\
22 \\
177,815 \\
200,592\end{array}$ & $\begin{array}{r} \\
40,836 \\
0 \\
2,340 \\
36,262\end{array}$ & $\begin{array}{r}N A \\
0 \\
N A \\
66,087\end{array}$ & $\begin{array}{r}20,660 \\
0 \\
3,324 \\
3,628\end{array}$ & $\begin{array}{r}75,333 \\
5,241,989 \\
22 \\
172,151 \\
94,616\end{array}$ \\
\hline 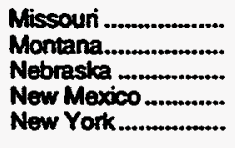 & $\begin{array}{r}7 \\
42,369 \\
114 \\
783,963 \\
24,010\end{array}$ & $\begin{array}{r}0 \\
9,168 \\
679 \\
200,716 \\
1,388\end{array}$ & $\begin{array}{r}7 \\
51,537 \\
793 \\
994,679 \\
25,398\end{array}$ & $\begin{array}{r}0 \\
222 \\
16,125 \\
0\end{array}$ & $\begin{array}{r}0 \\
\text { NA } \\
1,772 \\
0\end{array}$ & $\begin{array}{r}0 \\
886 \\
1,679 \\
375\end{array}$ & $\begin{array}{r}7 \\
50,429 \\
793 \\
955,104 \\
25,023\end{array}$ \\
\hline 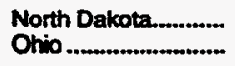 & $\begin{array}{r}13,736 \\
154,619\end{array}$ & $\begin{array}{r}49,854 \\
C\end{array}$ & $\begin{array}{r}63,590 \\
154,619\end{array}$ & $\begin{array}{r}2,386 \\
\text { NA }\end{array}$ & $\begin{array}{r}5.393 \\
N A\end{array}$ & $\begin{array}{r}3,642 \\
\mathrm{NA}\end{array}$ & $\begin{array}{r}52,169 \\
154,619\end{array}$ \\
\hline
\end{tabular}

See toomotes at end of table. 
Table 5. Gross Withdrawals and Marketed Production of Natural Gas by State, 1967-1994 (Continued) (Million Cubic Feet)

\begin{tabular}{|c|c|c|c|c|c|c|c|}
\hline \multirow{2}{*}{ Stato } & \multicolumn{3}{|c|}{$\begin{array}{c}\text { Gross } \\
\text { Withdrewels }\end{array}$} & \multirow{2}{*}{ Represeuring } & \multirow{2}{*}{$\begin{array}{c}\text { Mon- } \\
\text { Mrdrocarbon } \\
\text { Gaves Removed }\end{array}$} & \multirow{2}{*}{$\begin{array}{l}\text { Vented } \\
\text { and } \\
\text { Fiared }\end{array}$} & \multirow{2}{*}{$\begin{array}{l}\text { Markoted } \\
\text { Production }\end{array}$} \\
\hline & $\begin{array}{c}\text { From } \\
\text { Ges Wolls }\end{array}$ & $\begin{array}{l}\text { From } \\
\text { Oat weds }\end{array}$ & Total & & & & \\
\hline
\end{tabular}

\begin{tabular}{|c|c|c|c|c|c|c|c|}
\hline \multirow[b]{2}{*}{$\begin{array}{l}\text { Oldahoma } \\
\text { Oregon .............................. } \\
\text { Pennsybania ........... }\end{array}$} & \multicolumn{7}{|c|}{1990} \\
\hline & $\begin{array}{r}1,830,380 \\
2,815 \\
171,748\end{array}$ & $\begin{array}{r}428,091 \\
0 \\
5,861\end{array}$ & $\begin{array}{r}2,258,471 \\
2,815 \\
177,609\end{array}$ & $\begin{array}{r}\text { NA } \\
0 \\
\mathbf{N A}\end{array}$ & $\begin{array}{r}\text { NA } \\
0 \\
\text { NA }\end{array}$ & $\begin{array}{r}\text { NA } \\
\mathbf{0} \\
\mathbf{N A}\end{array}$ & $\begin{array}{r}2,258,471 \\
2,815 \\
177,609\end{array}$ \\
\hline 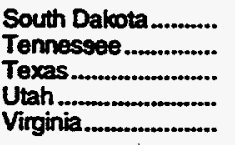 & $\begin{array}{r}549 \\
d \\
5,574,740 \\
238,062 \\
14,774\end{array}$ & $\begin{array}{r}4,233 \\
2,057 \\
1,332,316 \\
81,570 \\
0\end{array}$ & $\begin{array}{r}4,782 \\
2,067 \\
6,907,056 \\
319,632 \\
14,774\end{array}$ & $\begin{array}{r}253 \\
N A \\
380,032 \\
172,419 \\
0\end{array}$ & $\begin{array}{r}0 \\
N A \\
155,631 \\
N A \\
0\end{array}$ & $\begin{array}{r}3,648 \\
\mathrm{NA} \\
28,247 \\
1,338 \\
0\end{array}$ & $\begin{array}{r}881 \\
2,067 \\
6,343,146 \\
145,875 \\
14,774\end{array}$ \\
\hline $\begin{array}{l}\text { West Virginia............. } \\
\text { Wyoming................ }\end{array}$ & $\begin{array}{l}178,000 \\
570,879\end{array}$ & 312,834 & $\begin{array}{l}178,000 \\
883,713\end{array}$ & $\begin{array}{r}N A \\
56,581\end{array}$ & $\begin{array}{r}N A \\
28,188\end{array}$ & $\begin{array}{r}\mathbf{N A} \\
63,216\end{array}$ & $\begin{array}{l}178,000 \\
735,728\end{array}$ \\
\hline Total.......................... & $16,053,566$ & $5,469,055$ & $21,522,622$ & $2,489,040$ & 289,374 & 150,415 & $18,593,792$ \\
\hline
\end{tabular}

\begin{tabular}{|c|c|c|c|c|c|c|c|}
\hline \multirow[b]{2}{*}{$\begin{array}{l}\text { Alabama................... } \\
\text { Alaska..................... } \\
\text { Arizona.................... } \\
\text { Arkansas................. } \\
\text { Calfornia................ }\end{array}$} & \multicolumn{7}{|c|}{1991} \\
\hline & $\begin{array}{r}218,145 \\
197,502 \\
1,123 \\
153,583 \\
170,242\end{array}$ & $\begin{array}{r}5,731 \\
2,181,393 \\
158 \\
16,049 \\
289,594\end{array}$ & $\begin{array}{r}223,876 \\
2,378,896 \\
1,280 \\
169,632 \\
459,836\end{array}$ & $\begin{array}{r}30,689 \\
1,930,290 \\
0 \\
4,722 \\
79,235\end{array}$ & $\begin{array}{r}20,146 \\
0 \\
0 \\
0 \\
788\end{array}$ & $\begin{array}{r}2,193 \\
10,784 \\
56 \\
208 \\
1,429\end{array}$ & $\begin{array}{r}170,847 \\
437,822 \\
1,225 \\
164,702 \\
378,384\end{array}$ \\
\hline 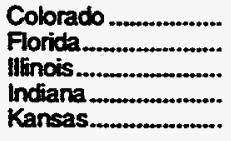 & $\begin{array}{r}222,909 \\
0 \\
453 \\
232 \\
550,241\end{array}$ & $\begin{array}{r}72,209 \\
5,898 \\
13 \\
c \\
79,943\end{array}$ & $\begin{array}{r}295,118 \\
5,898 \\
466 \\
232 \\
630,185\end{array}$ & $\begin{array}{r}6,267 \\
0 \\
0 \\
\mathrm{NA} \\
1,098\end{array}$ & $\begin{array}{r}0 \\
531 \\
0 \\
0 \\
N A\end{array}$ & $\begin{array}{r}2,890 \\
482 \\
0 \\
N A \\
628\end{array}$ & $\begin{array}{r}285,961 \\
4,884 \\
466 \\
232 \\
628,459\end{array}$ \\
\hline $\begin{array}{l}\text { Kentucky .................... } \\
\text { Louisiana ............... } \\
\text { Maryland................ } \\
\text { Michigan ................. } \\
\text { Mississippi ............... }\end{array}$ & $\begin{array}{r}78,904 \\
4,483,691 \\
29 \\
120,848 \\
158,617\end{array}$ & $\begin{array}{r}c \\
616,378 \\
0 \\
80,565 \\
22,155\end{array}$ & $\begin{array}{r}78,904 \\
5,100,068 \\
29 \\
201,413 \\
180,772\end{array}$ & $\begin{array}{r}45,292 \\
0 \\
2,340 \\
23,929\end{array}$ & $\begin{array}{r}N A \\
0 \\
N A \\
46,013\end{array}$ & $\begin{array}{r}20,415 \\
0 \\
3,324 \\
2,799\end{array}$ & $\begin{array}{r}78,904 \\
5,034,361 \\
29 \\
195,749 \\
108,031\end{array}$ \\
\hline 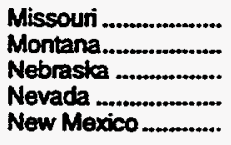 & $\begin{array}{r}15 \\
44,449 \\
126 \\
0 \\
840,767\end{array}$ & $\begin{array}{r}0 \\
8,553 \\
657 \\
53 \\
217,852\end{array}$ & $\begin{array}{r}15 \\
53,002 \\
784 \\
53 \\
1,058,619\end{array}$ & $\begin{array}{r}0 \\
231 \\
17,094\end{array}$ & $\begin{array}{r}0 \\
N A \\
\dot{0} \\
1,876\end{array}$ & $\begin{array}{r}0 \\
772 \\
0 \\
1,365\end{array}$ & $\begin{array}{r}15 \\
51,999 \\
784 \\
53 \\
1,038,284\end{array}$ \\
\hline 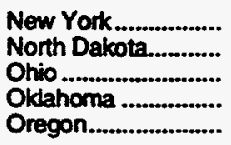 & $\begin{array}{r}21,877 \\
13,359 \\
147,651 \\
1,794,138 \\
2,741\end{array}$ & $\begin{array}{r}901 \\
49,298 \\
c \\
359,714 \\
0\end{array}$ & $\begin{array}{r}22,778 \\
62,657 \\
147,651 \\
2,153,852 \\
2,741\end{array}$ & $\begin{array}{r}0 \\
2.128 \\
N A \\
N A \\
0\end{array}$ & $\begin{array}{r}0 \\
4,447 \\
\text { NA } \\
\text { NA } \\
0\end{array}$ & $\begin{array}{r}1 \\
2,603 \\
\text { NA } \\
\text { NA } \\
0\end{array}$ & $\begin{array}{r}22,777 \\
53,479 \\
147,651 \\
2,153,852 \\
2,741\end{array}$ \\
\hline 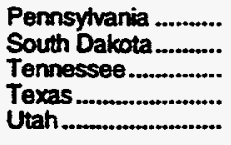 & $\begin{array}{r}152,500 \\
489 \\
d \\
5,538,692 \\
238,133\end{array}$ & $\begin{array}{r}c \\
5,315 \\
1,856 \\
1,306,851 \\
85,527\end{array}$ & $\begin{array}{r}152,500 \\
5,804 \\
1,856 \\
6,845,543 \\
323,660\end{array}$ & $\begin{array}{r}\text { NA } \\
77 \\
N A \\
360,852 \\
177,218\end{array}$ & $\begin{array}{r}\text { NA } \\
0 \\
N A \\
173,399 \\
N A\end{array}$ & $\begin{array}{r}\mathrm{NA} \\
4,844 \\
\mathrm{NA} \\
30,638 \\
1,625\end{array}$ & $\begin{array}{r}152,500 \\
882 \\
1,856 \\
6,280,654 \\
144,817\end{array}$ \\
\hline $\begin{array}{l}\text { Virginia.................... } \\
\text { West Virginia........... } \\
\text { Wyoming.................. }\end{array}$ & $\begin{array}{r}14,906 \\
198,605 \\
652,659\end{array}$ & $\begin{array}{r}0 \\
c \\
325,819\end{array}$ & $\begin{array}{r}14,906 \\
198,605 \\
978,478\end{array}$ & $\begin{array}{r}0 \\
N A \\
90,465\end{array}$ & $\begin{array}{r}0 \\
\mathrm{NA} \\
28,631\end{array}$ & $\begin{array}{r}0 \\
N A \\
82,854\end{array}$ & $\begin{array}{r}14,906 \\
198,605 \\
776,528\end{array}$ \\
\hline \multirow[t]{2}{*}{ Total } & $16,017,626$ & $5,732,482$ & $21,750,108$ & $2,771,928$ & 275.831 & 169,909 & $18,532,439$ \\
\hline & \multicolumn{7}{|c|}{1992} \\
\hline $\begin{array}{c}\text { Alabama Total.......... } \\
\text { Onshore.............. } \\
\text { State Offshore....... } \\
\text { Federal Oftshore... } \\
\text { Alaska Total............. } \\
\text { Onshore............... } \\
\text { State Offshore....... } \\
\text { Federal Offshore... }\end{array}$ & $\begin{array}{r}1403,848 \\
212,243 \\
112,311 \\
79,294 \\
198,603 \\
88,537 \\
110,067 \\
0\end{array}$ & $\begin{array}{r}9,766 \\
9,766 \\
0 \\
0 \\
2,427,110 \\
2,320,799 \\
106,311 \\
0\end{array}$ & $\begin{array}{r}413,614 \\
222,009 \\
112,311 \\
79,294 \\
2,625,713 \\
2,409,336 \\
216,377 \\
0\end{array}$ & $\begin{array}{r}29,996 \\
29,996 \\
0 \\
0 \\
2,168,019 \\
2,083,399 \\
84,620 \\
0\end{array}$ & $\begin{array}{r}26,719 \\
21,066 \\
5,653 \\
0 \\
0 \\
0 \\
0 \\
0\end{array}$ & $\begin{array}{r}1,799 \\
1,727 \\
72 \\
0 \\
14,097 \\
9,481 \\
4,616 \\
0\end{array}$ & $\begin{array}{r}355,099 \\
169,220 \\
106,586 \\
79,294 \\
443,597 \\
316,456 \\
127,142 \\
0\end{array}$ \\
\hline
\end{tabular}

See tootnotes at end of table. 
Table 5. Gross Withdrawals and Marketed Production of Natural Gas by State, 1967-1994 (Continued) (Million Cubic Feet)

\begin{tabular}{|c|c|c|c|c|c|c|c|}
\hline \multirow{2}{*}{ State } & \multicolumn{3}{|c|}{$\begin{array}{l}\text { Gross: } \\
\text { Withdrumels }\end{array}$} & \multirow{2}{*}{ Represeuring } & \multirow{2}{*}{$\begin{array}{c}\text { Non- } \\
\text { hydroeston } \\
\text { Ceaes Removed }\end{array}$} & \multirow{2}{*}{$\begin{array}{l}\text { Vomed } \\
\text { and } \\
\text { Fiared }\end{array}$} & \multirow{2}{*}{$\begin{array}{l}\text { Marketed } \\
\text { Production }\end{array}$} \\
\hline & $\begin{array}{l}\text { From } \\
\text { cess Welts }\end{array}$ & $\begin{array}{l}\text { From } \\
\text { Oil Wells }\end{array}$ & Total & & & & \\
\hline & \multicolumn{7}{|c|}{1992} \\
\hline $\begin{array}{l}\text { Arizona. } \\
\text { Arkansas.................. } \\
\text { Calfomia Total......... } \\
\text { Onshore................ } \\
\text { State Offshore....... } \\
\text { Federa Oftshore... }\end{array}$ & $\begin{array}{r}721 \\
171,543 \\
154,055 \\
140,108 \\
0 \\
13,947\end{array}$ & $\begin{array}{r}72 \\
39,364 \\
294,800 \\
246,274 \\
7,242 \\
41,284\end{array}$ & $\begin{array}{r}794 \\
210,906 \\
448,855 \\
386,382 \\
7,242 \\
55,231\end{array}$ & $\begin{array}{r}0 \\
8,056 \\
81,330 \\
77,660 \\
31 \\
3,639\end{array}$ & $\begin{array}{r}0 \\
0 \\
1,142 \\
1,142 \\
N A \\
N A\end{array}$ & $\begin{array}{l}23 \\
371 \\
751 \\
751 \\
\mathrm{NA} \\
\mathrm{NA}\end{array}$ & $\begin{array}{r}771 \\
202,479 \\
365,632 \\
306,829 \\
7,211 \\
51,592\end{array}$ \\
\hline 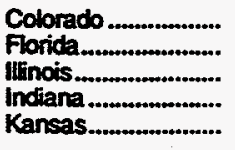 & 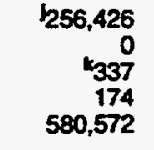 & $\begin{array}{r}77,568 \\
7,584 \\
10 \\
c \\
79,169\end{array}$ & $\begin{array}{r}333,994 \\
7,584 \\
347 \\
174 \\
659,741\end{array}$ & $\begin{array}{r}9,085 \\
0 \\
0 \\
N A \\
1,092\end{array}$ & $\begin{array}{r}0 \\
682 \\
0 \\
0 \\
N A\end{array}$ & $\begin{array}{r}1,868 \\
245 \\
0 \\
N A \\
642\end{array}$ & $\begin{array}{r}323,041 \\
6,657 \\
347 \\
174 \\
658,007\end{array}$ \\
\hline $\begin{array}{l}\text { Kentucky................ } \\
\text { Louisiana Total ....... } \\
\text { Onshore.............. } \\
\text { State Offshore...... } \\
\text { Federal Oftshore... }\end{array}$ & $\begin{array}{r}79,690 \\
4,347,709 \\
1,363,397 \\
116,470 \\
2,867,842\end{array}$ & $\begin{array}{r}c \\
629,760 \\
171,636 \\
21,631 \\
436,493\end{array}$ & $\begin{array}{r}79,690 \\
t_{4,977,470} \\
1,535,033 \\
138,101 \\
3,304,336\end{array}$ & $\begin{array}{r} \\
42,631 \\
3,223 \\
\mathrm{NA} \\
39,408\end{array}$ & $\begin{array}{l}\text { NA } \\
\text { NA } \\
\text { NA }\end{array}$ & $\begin{array}{r}20.538 \\
20,538 \\
\text { NA } \\
\text { NA }\end{array}$ & $\begin{array}{r}79,690 \\
4,914,300 \\
1,511,271 \\
138,101 \\
3,264,929\end{array}$ \\
\hline 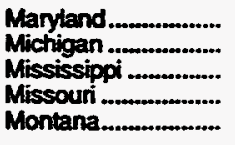 & $\begin{array}{r}33 \\
120,287 \\
145,153 \\
27 \\
46,918\end{array}$ & $\begin{array}{r}0 \\
80,192 \\
20,384 \\
0 \\
7,892\end{array}$ & $\begin{array}{r}33 \\
200,479 \\
165,538 \\
27 \\
54,810\end{array}$ & $\begin{array}{r}0 \\
2,340 \\
24,993 \\
0 \\
180\end{array}$ & $\begin{array}{r}0 \\
\mathrm{NA} \\
45,772 \\
\mathbf{0} \\
\mathrm{NA}\end{array}$ & $\begin{array}{r}0 \\
3,324 \\
3,076 \\
0 \\
763\end{array}$ & $\begin{array}{r}33 \\
194,815 \\
91,697 \\
27 \\
53,867\end{array}$ \\
\hline $\begin{array}{l}\text { Nebraska .................. } \\
\text { Nevada ................. } \\
\text { New Mexico ............ } \\
\text { New York................ } \\
\text { North Dakota.......... }\end{array}$ & $\begin{array}{r}486 \\
0 \\
m_{1,067,477} \\
22,697 \\
12,461\end{array}$ & $\begin{array}{r}691 \\
30 \\
222,303 \\
824 \\
47,518\end{array}$ & $\begin{array}{r}1,177 \\
30 \\
1,289,780 \\
23,521 \\
59,979\end{array}$ & $\begin{array}{r}0 \\
0 \\
16,540 \\
0 \\
2,391\end{array}$ & $\begin{array}{r}0 \\
0 \\
2,751 \\
0 \\
508\end{array}$ & $\begin{array}{r}0 \\
0 \\
1,626 \\
13 \\
2,197\end{array}$ & $\begin{array}{r}1,177 \\
30 \\
1,268,863 \\
23,508 \\
54,883\end{array}$ \\
\hline 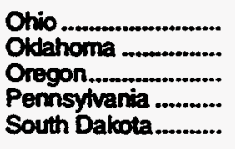 & $\begin{array}{r}144,815 \\
1,674,405 \\
2,580 \\
138,675 \\
1,006\end{array}$ & $\begin{array}{r}c \\
342,950 \\
0 \\
c \\
5,957\end{array}$ & $\begin{array}{r}144,815 \\
2,017,356 \\
2,580 \\
138,675 \\
6,963\end{array}$ & $\begin{array}{r}\text { NA } \\
\text { NA } \\
0 \\
N A \\
\text { SO }\end{array}$ & $\begin{array}{r}\text { NA } \\
\text { NA } \\
0 \\
N A \\
0\end{array}$ & $\begin{array}{r}N A \\
N A \\
0 \\
N A \\
5,476\end{array}$ & $\begin{array}{r}144,815 \\
2,017,356 \\
2,580 \\
138,675 \\
1,456\end{array}$ \\
\hline $\begin{array}{l}\text { Tennessee................ } \\
\text { Texas Total ............. } \\
\text { Onshore............... } \\
\text { State Otishore....... } \\
\text { Federal Otfshore... }\end{array}$ & $\begin{array}{r}d \\
5,406,256 \\
4,032,016 \\
76,638 \\
1,297,602\end{array}$ & $\begin{array}{r}1,770 \\
1,301,756 \\
1,264,850 \\
1,625 \\
35,281\end{array}$ & $\begin{array}{r}1,770 \\
6,708,012 \\
5,296,865 \\
78,263 \\
1,332,883\end{array}$ & $\begin{array}{r}\text { NA } \\
362,458 \\
362,458 \\
\text { NA } \\
\text { NA }\end{array}$ & $\begin{array}{r}\text { NA } \\
180,003 \\
180,003 \\
\text { NA } \\
\text { NA }\end{array}$ & $\begin{array}{r}N A \\
19,689 \\
19.689 \\
N A \\
N A\end{array}$ & $\begin{array}{r}1,770 \\
6,145,862 \\
4,734,715 \\
78,263 \\
1,332,883\end{array}$ \\
\hline 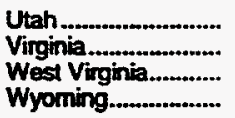 & $\begin{array}{r}229,494 \\
24,733 \\
E_{182,000} \\
751,693\end{array}$ & $\begin{array}{r}84,781 \\
0 \\
c \\
285,125\end{array}$ & $\begin{array}{r}314,275 \\
24,733 \\
\varepsilon_{182,000} \\
1,036,817\end{array}$ & $\begin{array}{r}141,698 \\
0 \\
\mathrm{NA} \\
81,712\end{array}$ & $\begin{array}{r}\text { NA } \\
0 \\
N A \\
22,793\end{array}$ & $\begin{array}{r}1,284 \\
0 \\
N A \\
89,736\end{array}$ & $\begin{array}{r}171,293 \\
24,733 \\
E_{182,000} \\
842,576\end{array}$ \\
\hline \multirow[t]{2}{*}{ 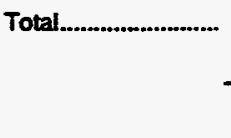 } & $16,164,874$ & $5,967,376$ & $22,132,249$ & $2,972,552$ & 280,370 & 167,519 & $18,711,808$ \\
\hline & \multicolumn{7}{|c|}{1993} \\
\hline $\begin{array}{c}\text { Alabama Total.......... } \\
\text { Onshore............... } \\
\text { State Offshore....... } \\
\text { Federal Ofishore... } \\
\text { Alaska Total............ } \\
\text { Onshore................ } \\
\text { State Oftshore....... } \\
\text { Federal Offshore.... }\end{array}$ & $\begin{array}{r}435,066 \\
217,043 \\
131,508 \\
86,515 \\
190,139 \\
62,305 \\
127,834 \\
0\end{array}$ & $\begin{array}{r}11,255 \\
11,255 \\
0 \\
0 \\
0 \\
2,588,202 \\
2,482,839 \\
105,363 \\
0\end{array}$ & $\begin{array}{r}446,321 \\
228,298 \\
131,508 \\
86,515 \\
2,778,341 \\
2,545,144 \\
233,198 \\
0\end{array}$ & $\begin{array}{r}31,179 \\
31,179 \\
0 \\
0 \\
2,325,506 \\
2,225,370 \\
100,136 \\
0\end{array}$ & $\begin{array}{r}25,320 \\
19,398 \\
5,922 \\
0 \\
0 \\
0 \\
0 \\
0\end{array}$ & $\begin{array}{r}1,798 \\
1,513 \\
284 \\
0 \\
22,485 \\
11,262 \\
11,224 \\
0\end{array}$ & $\begin{array}{r}388,024 \\
176,208 \\
125,302 \\
86,515 \\
430,350 \\
308,512 \\
121,838 \\
0\end{array}$ \\
\hline 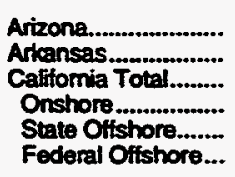 & $\begin{array}{r}508 \\
166,273 \\
120,205 \\
109,587 \\
0 \\
10,618\end{array}$ & $\begin{array}{r}110 \\
38,279 \\
285,162 \\
237,146 \\
6,484 \\
41,532\end{array}$ & $\begin{array}{r}618 \\
204,552 \\
405,367 \\
346,733 \\
6,484 \\
52,150\end{array}$ & $\begin{array}{r}0 \\
7,773 \\
87,806 \\
84,463 \\
17 \\
3,326\end{array}$ & $\begin{array}{r}0 \\
0 \\
1,130 \\
1,130 \\
\text { NA } \\
\text { NA }\end{array}$ & $\begin{array}{l}21 \\
409 \\
580 \\
580 \\
\text { NA } \\
\text { NA }\end{array}$ & $\begin{array}{r}597 \\
196,370 \\
315,851 \\
260,560 \\
6,467 \\
48,825\end{array}$ \\
\hline $\begin{array}{l}\text { Colorado ................... } \\
\text { Florida ........................ } \\
\text { lilinois.................... }\end{array}$ & $\begin{array}{r}320,849 \\
0 \\
330\end{array}$ & $\begin{array}{r}93,155 \\
8,011 \\
10\end{array}$ & $\begin{array}{r}414,004 \\
8,011 \\
340\end{array}$ & $\begin{array}{r}10,995 \\
0 \\
0\end{array}$ & $\begin{array}{r}0 \\
721 \\
0\end{array}$ & $\begin{array}{r}2,024 \\
205 \\
0\end{array}$ & $\begin{array}{r}400,985 \\
7.085 \\
340\end{array}$ \\
\hline
\end{tabular}

Sea footnotes at end of table. 
Table 5. Gross Withdrawals and Marketed Production of Natural Gas by State, 1967-1994 (Continued) (Million Cubic Feet)

\begin{tabular}{|c|c|c|c|c|c|c|c|}
\hline \multirow{2}{*}{ Stute } & \multicolumn{3}{|c|}{$\begin{array}{l}\text { Gross } \\
\text { Withdrownels }\end{array}$} & \multirow{2}{*}{ Reproverring } & \multirow{2}{*}{$\begin{array}{l}\text { Non- } \\
\text { mydrocearbon } \\
\text { Gases Remowed }\end{array}$} & \multirow{2}{*}{$\begin{array}{l}\text { Vonted } \\
\text { and } \\
\text { Fared }\end{array}$} & \multirow{2}{*}{$\begin{array}{l}\text { Marketed } \\
\text { Production }\end{array}$} \\
\hline & $\begin{array}{l}\text { From } \\
\text { ces Wells }\end{array}$ & $\begin{array}{l}\text { From } \\
\text { Oit Wells }\end{array}$ & Tolal & & & & \\
\hline & \multicolumn{7}{|c|}{1993} \\
\hline Indiana & $\begin{array}{r}192 \\
605,578\end{array}$ & $\begin{array}{r}0 \\
82,579\end{array}$ & $\begin{array}{r}192 \\
688,157\end{array}$ & $\begin{array}{r}\mathrm{NA} \\
1,140\end{array}$ & $\begin{array}{l}\text { NA } \\
\text { NA }\end{array}$ & $\begin{array}{r}\text { NA } \\
670\end{array}$ & $\begin{array}{r}192 \\
686,347\end{array}$ \\
\hline $\begin{array}{l}\text { Kentucky } \\
\text { Louisiana Total ..................... } \\
\text { Onshore............... } \\
\text { State Offshore..... } \\
\text { Federal Offshore... }\end{array}$ & $\begin{array}{r}86,966 \\
R_{4,375,820} \\
R_{1,358,799} \\
A_{133,261} \\
2,883,761\end{array}$ & $\begin{array}{r}0 \\
R_{670,803} \\
R_{179,712} \\
R_{23,750} \\
467,340\end{array}$ & $\begin{array}{r}86,956 \\
R_{5,046,623} \\
R_{1,538,511} \\
R_{157,011} \\
3,351,101\end{array}$ & $\begin{array}{r} \\
R_{35,504} \\
R_{1,516} \\
0 \\
34,388\end{array}$ & $\begin{array}{l}\text { NA } \\
\text { NA } \\
\text { NA } \\
\text { NA }\end{array}$ & $\begin{array}{r}R_{19,580} \\
R_{19,580} \\
N A \\
N A\end{array}$ & $\begin{array}{r}86,956 \\
R_{4,991,138} \\
R_{1,517,415} \\
R_{157,011} \\
3,316,713\end{array}$ \\
\hline 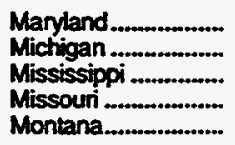 & $\begin{array}{r}28 \\
126,179 \\
129,395 \\
14 \\
48,187\end{array}$ & $\begin{array}{r}0 \\
84,119 \\
15,631 \\
0 \\
7,330\end{array}$ & $\begin{array}{r}28 \\
210,299 \\
145,026 \\
14 \\
55,517\end{array}$ & $\begin{array}{r}0 \\
2,340 \\
14,092 \\
0 \\
231\end{array}$ & $\begin{array}{r}0 \\
\text { NA } \\
48,017 \\
0 \\
N A\end{array}$ & $\begin{array}{r}0 \\
3,324 \\
2,222 \\
0 \\
758\end{array}$ & $\begin{array}{r}28 \\
204,635 \\
80,695 \\
14 \\
54,528\end{array}$ \\
\hline $\begin{array}{l}\text { Nebraska .................. } \\
\text { Nevada ................. } \\
\text { New Mexico ............ } \\
\text { New York................ } \\
\text { North Dakta.......... }\end{array}$ & $\begin{array}{r}1,391 \\
0 \\
1,208,771 \\
20,587 \\
18,892\end{array}$ & $\begin{array}{r}723 \\
21 \\
221,560 \\
610 \\
46,059\end{array}$ & $\begin{array}{r}2,114 \\
21 \\
1,430,331 \\
21,197 \\
64,951\end{array}$ & $\begin{array}{r}\dot{0} \\
0 \\
16,568 \\
0 \\
2,231\end{array}$ & $\begin{array}{r}0 \\
0 \\
2,753 \\
0 \\
532\end{array}$ & $\begin{array}{r}0 \\
1,581 \\
14 \\
2,337\end{array}$ & $\begin{array}{r}2,114 \\
21 \\
1,409,429 \\
21,183 \\
59,851\end{array}$ \\
\hline 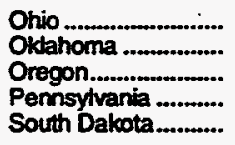 & $\begin{array}{r}137,285 \\
1,732,997 \\
4,003 \\
132,130 \\
R_{254}\end{array}$ & $\begin{array}{r}0 \\
316,945 \\
0 \\
0 \\
R_{6,204}\end{array}$ & $\begin{array}{r}137,285 \\
2,049,942 \\
4,003 \\
132,130 \\
87,057\end{array}$ & $\begin{array}{r}\text { NA } \\
\text { NA } \\
0 \\
\mathbf{N A}_{19}\end{array}$ & $\begin{array}{r}\text { NA } \\
\text { NA } \\
0 \\
\text { NA } \\
0\end{array}$ & $\begin{array}{r}\text { NA } \\
\text { NA } \\
\mathbf{0} \\
\text { NA } \\
R_{5,732}\end{array}$ & $\begin{array}{r}137,285 \\
2,049,942 \\
4,003 \\
132,130 \\
R_{1}, 306\end{array}$ \\
\hline $\begin{array}{c}\text { Tennessee.............. } \\
\text { Texas Total .............. } \\
\text { Onshore............... } \\
\text { State Offshore...... } \\
\text { Federal Offshore... }\end{array}$ & $\begin{array}{r}0 \\
5,474,559 \\
4,162,554 \\
77,883 \\
1,234,121\end{array}$ & $\begin{array}{r}1,660 \\
1,342,368 \\
1,299,039 \\
1,350 \\
41,978\end{array}$ & $\begin{array}{r}1,660 \\
6,816,927 \\
5,461,594 \\
79,234 \\
1,276,099\end{array}$ & $\begin{array}{r}N A \\
348,558 \\
348,558 \\
N A \\
N A\end{array}$ & $\begin{array}{r}\text { NA } \\
184,258 \\
184,258 \\
\text { NA } \\
\text { NA }\end{array}$ & $\begin{array}{r}\text { NA } \\
34,486 \\
34,486 \\
\text { NA } \\
\text { NA }\end{array}$ & $\begin{array}{r}1,660 \\
6,249,624 \\
4,894,291 \\
79,234 \\
1,276,099\end{array}$ \\
\hline 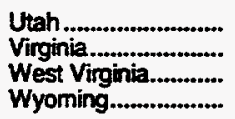 & $\begin{array}{r}264,481 \\
37,840 \\
R_{171,024} \\
880,596\end{array}$ & $\begin{array}{r}71,702 \\
0 \\
c \\
142,006\end{array}$ & $\begin{array}{r}336,183 \\
37,840 \\
R_{171,024} \\
1,022,602\end{array}$ & $\begin{array}{r}108,629 \\
0 \\
N A \\
R_{110,044}\end{array}$ & $\begin{array}{r}\text { NA } \\
0 \\
\text { NA } \\
151.239\end{array}$ & $\begin{array}{r}2,153 \\
0 \\
N A \\
R_{126,362}\end{array}$ & $\begin{array}{r}225,401 \\
37,840 \\
R_{171,024} \\
R_{634,957}\end{array}$ \\
\hline \multirow[t]{2}{*}{ Total........................ } & $\mathbf{R}_{16,691,139}$ & $R_{6,034,504}$ & $n_{22,725,642}$ & $A_{3,103,014}$ & 413,971 & $A_{226,743}$ & $R_{18,981,915}$ \\
\hline & \multicolumn{7}{|c|}{1994} \\
\hline $\begin{array}{c}\text { Alabama Total.......... } \\
\text { Onshore................ } \\
\text { State Offshore....... } \\
\text { Federal Oftshore.... } \\
\text { Alaska Total............. } \\
\text { Onshore................ } \\
\text { State Otfshore....... } \\
\text { Federal Oftshore.... }\end{array}$ & $\begin{array}{r}566,140 \\
219,955 \\
228,878 \\
117,308 \\
180,639 \\
80,839 \\
99,801 \\
0\end{array}$ & $\begin{array}{r}12,722 \\
9,528 \\
0 \\
3,194 \\
2,905,261 \\
2,780,760 \\
124,501 \\
0\end{array}$ & $\begin{array}{r}578,862 \\
229,483 \\
228,878 \\
120,502 \\
3,085,900 \\
2,861,599 \\
224,301 \\
0\end{array}$ & $\begin{array}{r}33,961 \\
33,961 \\
0 \\
0 \\
2,619,236 \\
2,517,259 \\
101,977 \\
0\end{array}$ & $\begin{array}{r}26,980 \\
18,912 \\
8,068 \\
0 \\
0 \\
0 \\
0 \\
0\end{array}$ & $\begin{array}{r}2,650 \\
2,072 \\
577 \\
0 \\
13,240 \\
8.733 \\
4,507 \\
0\end{array}$ & $\begin{array}{r}515,271 \\
174,537 \\
220,233 \\
120,502 \\
453,425 \\
335,608 \\
117,817 \\
0\end{array}$ \\
\hline 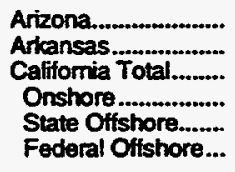 & $\begin{array}{r}711 \\
161,967 \\
113,525 \\
102,461 \\
0 \\
11,064\end{array}$ & $\begin{array}{r}48 \\
33,446 \\
282,227 \\
232,526 \\
7,204 \\
42,497\end{array}$ & $\begin{array}{r}759 \\
195,413 \\
395,752 \\
334,987 \\
7,204 \\
53,561\end{array}$ & $\begin{array}{r}0 \\
7,426 \\
84,369 \\
81,641 \\
0 \\
2,728\end{array}$ & $\begin{array}{r}0 \\
0 \\
1,126 \\
1,126 \\
\text { NA } \\
\text { NA }\end{array}$ & $\begin{array}{r}8 \\
313 \\
830 \\
830 \\
\text { NA } \\
\text { NA }\end{array}$ & $\begin{array}{r}752 \\
187,673 \\
309,427 \\
251,390 \\
7,204 \\
50,833\end{array}$ \\
\hline 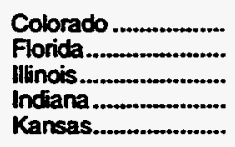 & $\begin{array}{r}365,651 \\
0 \\
323 \\
107 \\
628,900\end{array}$ & $\begin{array}{r}101,379 \\
8,468 \\
10 \\
0 \\
85,759\end{array}$ & $\begin{array}{r}467,031 \\
8,468 \\
333 \\
107 \\
714,659\end{array}$ & $\begin{array}{r}11,347 \\
0 \\
0 \\
\mathrm{NA} \\
1,215\end{array}$ & $\begin{array}{r}0 \\
762 \\
0 \\
\text { NA } \\
\text { NA }\end{array}$ & $\begin{array}{r}2.476 \\
220 \\
0 \\
N A \\
715\end{array}$ & $\begin{array}{r}453,207 \\
7,466 \\
333 \\
107 \\
712,730\end{array}$ \\
\hline $\begin{array}{l}\text { Kentucky................ } \\
\text { Lotusiana Total ....... } \\
\text { Onshore.............. } \\
\text { State Otfshore....... } \\
\text { Federal Ottshore... }\end{array}$ & $\begin{array}{r}73,081 \\
4,527,042 \\
1,393,543 \\
137,823 \\
2,995,676\end{array}$ & $\begin{array}{r}0 \\
699,055 \\
159,060 \\
21,690 \\
518,305\end{array}$ & $\begin{array}{r}73,081 \\
5,226,097 \\
1,552,603 \\
159,513 \\
3,513,981\end{array}$ & $\begin{array}{r} \\
36,703 \\
1,421 \\
0 \\
35,282\end{array}$ & $\begin{array}{l}\text { NA } \\
\text { NA } \\
\text { NA } \\
\text { NA }\end{array}$ & $\begin{array}{r}19,689 \\
19,689 \\
\text { NA } \\
\text { NA }\end{array}$ & $\begin{array}{r}73,081 \\
5,169,705 \\
1,531,493 \\
159,513 \\
3,478,699\end{array}$ \\
\hline Maryland................... & 26 & 0 & 26 & 0 & 0 & 0 & 26 \\
\hline
\end{tabular}

See tootnotes al end of table. 
Table 5. Gross Withdrawals and Marketed Production of Natural Gas by State, 1967-1994 (Continued) : (Million Cubic Feet)

\begin{tabular}{|c|c|c|c|c|c|c|c|}
\hline \multirow{2}{*}{ Stab } & \multicolumn{3}{|c|}{$\begin{array}{c}\text { Crotes } \\
\text { Withdremals }\end{array}$} & \multirow{2}{*}{ Represeuring } & \multirow{2}{*}{$\begin{array}{c}\text { Non- } \\
\text { hydrocarbon } \\
\text { exses Riemowed }\end{array}$} & \multirow{2}{*}{$\begin{array}{l}\text { Vemed } \\
\text { and } \\
\text { Flaned }\end{array}$} & \multirow{2}{*}{ Production } \\
\hline & $\begin{array}{l}\text { From } \\
\text { ces Wills }\end{array}$ & $\begin{array}{l}\text { From } \\
\text { Oil Wolts }\end{array}$ & Total & & & & \\
\hline & \multicolumn{7}{|c|}{1994} \\
\hline 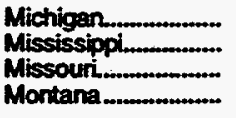 & $\begin{array}{r}136,989 \\
112,205 \\
8 \\
44,350\end{array}$ & $\begin{array}{r}91,302 \\
9,597 \\
0 \\
6,722\end{array}$ & $\begin{array}{r}228,321 \\
121,802 \\
8 \\
51,072\end{array}$ & $\begin{array}{r}2,340 \\
12,083 \\
0 \\
105\end{array}$ & $\begin{array}{r}N A \\
44,344 \\
0 \\
N A\end{array}$ & $\begin{array}{r}3,324 \\
1,928 \\
0 \\
551\end{array}$ & $\begin{array}{r}222,657 \\
63,448 \\
8 \\
50,416\end{array}$ \\
\hline 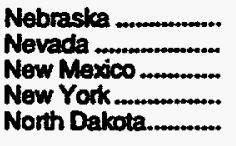 & $\begin{array}{r}2,093 \\
0 \\
1,381,756 \\
19,937 \\
19,592\end{array}$ & $\begin{array}{r}805 \\
16 \\
200,041 \\
589 \\
43,640\end{array}$ & $\begin{array}{r}2,898 \\
16 \\
1,581,797 \\
20,476 \\
63,232\end{array}$ & $\begin{array}{r}0 \\
0 \\
18,982 \\
0 \\
2,577\end{array}$ & $\begin{array}{r}0 \\
0 \\
3,164 \\
0 \\
358\end{array}$ & $\begin{array}{r}\dot{0} \\
1,963 \\
11 \\
2,492\end{array}$ & $\begin{array}{r}2,898 \\
16 \\
1,557,689 \\
20,465 \\
57,805\end{array}$ \\
\hline 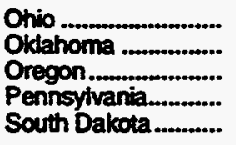 & $\begin{array}{r}132,151 \\
1,626,858 \\
4,200 \\
E_{148,763} \\
1,000\end{array}$ & $\begin{array}{r}0 \\
308,006 \\
0 \\
1,465 \\
6,264\end{array}$ & $\begin{array}{r}132,151 \\
1,934,864 \\
4,200 \\
E_{150,228} \\
7,264\end{array}$ & $\begin{array}{r}\mathbf{N A} \\
\mathbf{N A} \\
\mathbf{N A} \\
\mathbf{2 2}\end{array}$ & $\begin{array}{c}\text { NA } \\
\text { NA } \\
924 \\
\text { NA } \\
0\end{array}$ & $\begin{array}{r}\text { NA } \\
\text { NA } \\
0 \\
N A \\
5,805\end{array}$ & $\begin{array}{r}132,151 \\
1,934,864 \\
3,221 \\
150,228 \\
1,437\end{array}$ \\
\hline 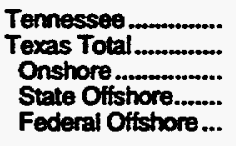 & $\begin{array}{r}0 \\
5,643,577 \\
4,310,086 \\
83,577 \\
1,249,914\end{array}$ & $\begin{array}{r}1,990 \\
1,268,127 \\
1,208,892 \\
996 \\
58,240\end{array}$ & $\begin{array}{r}1,990 \\
6,911,705 \\
5,518,978 \\
84,573 \\
1,308,154\end{array}$ & $\begin{array}{r}\text { NA } \\
319,360 \\
319,360 \\
N A \\
N A\end{array}$ & $\begin{array}{r}\text { NA } \\
196,463 \\
196,463 \\
N A \\
N A\end{array}$ & $\begin{array}{r}N A \\
42,037 \\
42,037 \\
N A \\
N A\end{array}$ & $\begin{array}{r}1,990 \\
6,353,844 \\
4,961,1117 \\
84,573 \\
1,308,154\end{array}$ \\
\hline 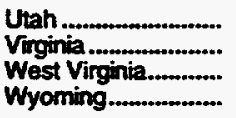 & $\begin{array}{r}304,347 \\
50,259 \\
E_{182,000} \\
949,343\end{array}$ & $\begin{array}{r}42,672 \\
0 \\
c \\
121,519\end{array}$ & $\begin{array}{r}347,019 \\
50,259 \\
E_{182,000} \\
1,070,862\end{array}$ & $\begin{array}{r}72,798 \\
0 \\
N A \\
110,064\end{array}$ & $\begin{array}{r}\text { NA } \\
0 \\
\text { NA } \\
138,056\end{array}$ & $\begin{array}{r}3,363 \\
0 \\
\mathrm{NA} \\
126,722\end{array}$ & $\begin{array}{r}270,858 \\
50,259 \\
182,000 \\
696,018\end{array}$ \\
\hline 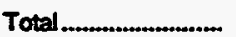 & $17,377,544$ & $6,231,110$ & $23,608,654$ & $3,302,644$ & 412,178 & 228,336 & $19,635,495$ \\
\hline
\end{tabular}

- Includes Arizona, Forida, Missouri, and Tennessee.

- Included with Alabama.

C Inctuded in gross withdrawals from gas wells. Breakdown not provided by State agency.

Included in gross withdrawals from oil wells. Breakdown not provided by State agency.

- Ouanthy of nonhydrocarbon gases removed at processing plants was estimated by the Kansas Corporation Commission to be less than 0.5 percent of total gross withdrawats.

t Exchudes most quantities of nonhydrocarbon gases removed on leases.

- Nonhydrocarbon gases removed have been excluded from repotted gross withdrawats.

in Excludes gas used for tuel on leases, and nonhydrocarbon gases removed on leases.

i includes 36,282 milion cubic feet produced from coal seam methane drainage projects.

I inctudes 25,427 million cubic teet produced from coal bed methane seams.

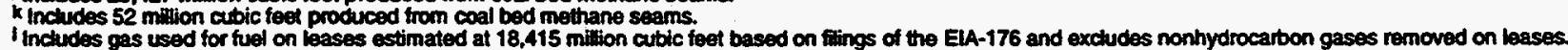

incudes gas used for fuel on leases estimated at 18,415 milion cubic teet based

n includes gas used for fuel on leases estimated at 72,318 milion cubic feet based on filings of the ElA-176 and excludes nontrydrocarbon gases removed on leases, gas used for repressuing, and quantities vented or flared.

$E=$ Estimated data.

NA $=$ Not Avallable.
$=$ Vohme is less than 500,000 cubic feet.

$=$ Vohme is less

$A=$ Revised data.

Note: Totals may not equal sum of components due to independent rounding.

Soutces: 1967-1975: Figures based on reports received trom State agencies and Bureau of Mines estimates. 1976-1979: Appropriate State agencies' responses to intomal data requests and the United States Geological Survey (USGS). 1980-1981: Energy Information Administration (EIA), Form ELA-@27, Annual Quantity and Vatue of Natural Gas Report, and the USGS. 1982-1994: Form EIA-627 and the United States Minerals Management Service; West Virginia, 1994: EIA, U.S. Crude Oi, Natural Gas, and Natural Cas Liquids Reserves, 1994 Annual Report, DOERELA-0216(94); and EU Computations. 
Table 6. Number of Producing Gas and Gas Condensate Wells by State as of December 31, 1967-1994

\begin{tabular}{|c|c|c|c|c|c|c|c|}
\hline Statos & 1967 & 1968 & 1969 & 1970 & 1971 & 1972 & 1973 \\
\hline 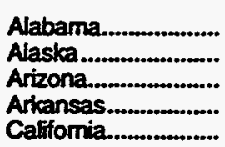 & $\begin{array}{r}0 \\
21 \\
7 \\
909 \\
1,059\end{array}$ & $\begin{array}{r}1 \\
18 \\
4 \\
947 \\
994\end{array}$ & $\begin{array}{r}1 \\
44 \\
4 \\
998 \\
897\end{array}$ & $\begin{array}{r}2 \\
51 \\
17 \\
1,008 \\
980\end{array}$ & $\begin{array}{r}0 \\
40 \\
5 \\
1,013 \\
962\end{array}$ & $\begin{array}{r}15 \\
50 \\
4 \\
1,041 \\
1,086\end{array}$ & $\begin{array}{r}15 \\
52 \\
4 \\
876 \\
1,095\end{array}$ \\
\hline 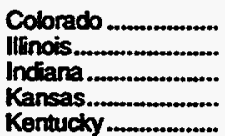 & $\begin{array}{r}827 \\
3 \\
271 \\
8,603 \\
6,215\end{array}$ & $\begin{array}{r}810 \\
5 \\
265 \\
8,509 \\
6,290\end{array}$ & $\begin{array}{r}805 \\
5 \\
263 \\
8,567 \\
6,413\end{array}$ & $\begin{array}{r}861 \\
8 \\
50 \\
8,660 \\
6,913\end{array}$ & $\begin{array}{r}928 \\
14 \\
50 \\
8,585 \\
7,413\end{array}$ & $\begin{array}{r}934 \\
31 \\
87 \\
8,621 \\
7,099\end{array}$ & $\begin{array}{r}1,050 \\
36 \\
106 \\
8,785 \\
7,224\end{array}$ \\
\hline 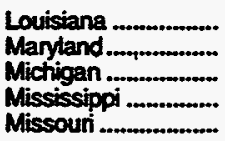 & $\begin{array}{r}9,036 \\
13 \\
244 \\
360 \\
11\end{array}$ & $\begin{array}{r}9,163 \\
15 \\
199 \\
347 \\
11\end{array}$ & $\begin{array}{r}9,354 \\
13 \\
211 \\
322 \\
11\end{array}$ & $\begin{array}{r}9,690 \\
16 \\
1.235 \\
3225 \\
11\end{array}$ & $\begin{array}{r}8,822 \\
14 \\
1.171 \\
400 \\
2\end{array}$ & $\begin{array}{r}9.456 \\
16 \\
1.317 \\
252 \\
3\end{array}$ & $\begin{array}{r}10,551 \\
15 \\
1.145 \\
250 \\
2\end{array}$ \\
\hline 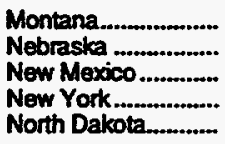 & $\begin{array}{r}648 \\
37 \\
8,274 \\
1,159 \\
31\end{array}$ & $\begin{array}{r}1,196 \\
36 \\
8,754 \\
1,155 \\
19\end{array}$ & $\begin{array}{r}1,098 \\
35 \\
9,100 \\
818 \\
33\end{array}$ & $\begin{array}{r}739 \\
35 \\
8.848 \\
600 \\
29\end{array}$ & $\begin{array}{r}1,056 \\
29 \\
9.388 \\
600 \\
29\end{array}$ & $\begin{array}{r}1,116 \\
29 \\
9,679 \\
650 \\
21\end{array}$ & $\begin{array}{r}1,118 \\
29 \\
9,711 \\
789 \\
44\end{array}$ \\
\hline 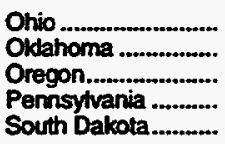 & $\begin{array}{r}3,865 \\
7,726 \\
0 \\
17,700 \\
0\end{array}$ & $\begin{array}{r}7,211 \\
8,337 \\
0 \\
17,000 \\
0\end{array}$ & $\begin{array}{r}7,334 \\
8,432 \\
0 \\
16,600 \\
0\end{array}$ & $\begin{array}{r}7,789 \\
8,168 \\
0 \\
16,239 \\
0\end{array}$ & $\begin{array}{r}8,179 \\
8,507 \\
0 \\
16,586 \\
0\end{array}$ & $\begin{array}{r}8,630 \\
8,457 \\
0 \\
16,600 \\
0\end{array}$ & $\begin{array}{r}9,406 \\
8,868 \\
0 \\
16,600 \\
0\end{array}$ \\
\hline 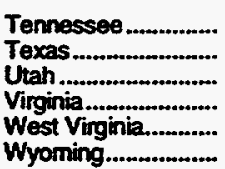 & $\begin{array}{r}21 \\
23,760 \\
168 \\
104 \\
20,500 \\
749\end{array}$ & $\begin{array}{r}23 \\
23,805 \\
165 \\
111 \\
18,214 \\
787\end{array}$ & $\begin{array}{r}26 \\
23,689 \\
171 \\
111 \\
18,600 \\
521\end{array}$ & $\begin{array}{r}15 \\
23,417 \\
173 \\
115 \\
20,702 \\
800\end{array}$ & $\begin{array}{r}20 \\
23,280 \\
178 \\
115 \\
21,025 \\
840\end{array}$ & $\begin{array}{r}45 \\
23,373 \\
200 \\
130 \\
21,324 \\
887\end{array}$ & $\begin{array}{r}6 \\
23,805 \\
158 \\
178 \\
21,400 \\
850\end{array}$ \\
\hline Total............................. & 112,321 & 114,391 & 114,476 & 117,496 & 119,251 & 121,153 & 124,168 \\
\hline
\end{tabular}

See footnotos at ond of table. 
Table 6. Number of Producing Gas and Gas Condensate Wells by State as of December 31, 1967-1994 (Continued)

\begin{tabular}{|c|c|c|c|c|c|c|c|}
\hline State & 1974 & 1975 & 1976 & 1977 & 1978 & 1979 & 8980 \\
\hline 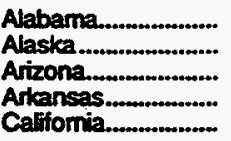 & $\begin{array}{r}6 \\
52 \\
1 \\
1,172 \\
1,142\end{array}$ & $\begin{array}{r}9 \\
61 \\
1 \\
1,128 \\
1,585\end{array}$ & $\begin{array}{r}66 \\
50 \\
1 \\
1,223 \\
1,123\end{array}$ & $\begin{array}{r}69 \\
50 \\
1 \\
1,253 \\
1,050\end{array}$ & $\begin{array}{r}189 \\
52 \\
1 \\
1,335 \\
1,131\end{array}$ & $\begin{array}{r}250 \\
58 \\
1 \\
1.402 \\
1,117\end{array}$ & $\begin{array}{r}-314 \\
71 \\
1 \\
1,114 \\
1,125\end{array}$ \\
\hline 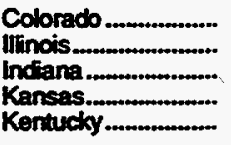 & $\begin{array}{r}1,347 \\
37 \\
474 \\
8,800 \\
7,307\end{array}$ & $\begin{array}{r}1,662 \\
41 \\
478 \\
8,865 \\
7,386\end{array}$ & $\begin{array}{r}1,500 \\
34 \\
563 \\
9,330 \\
7,505\end{array}$ & $\begin{array}{r}2,053 \\
34 \\
596 \\
9,375 \\
7,649\end{array}$ & $\begin{array}{r}2,318 \\
51 \\
641 \\
9,450 \\
7,776\end{array}$ & $\begin{array}{r}2,574 \\
51 \\
655 \\
10,544 \\
7,883\end{array}$ & $\begin{array}{r}2,997 \\
70 \\
698 \\
12,890 \\
7,984\end{array}$ \\
\hline 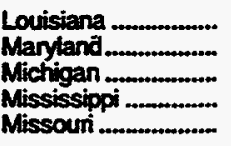 & $\begin{array}{r}9,248 \\
15 \\
503 \\
239 \\
3\end{array}$ & $\begin{array}{r}9,182 \\
15 \\
209 \\
248 \\
3\end{array}$ & $\begin{array}{r}11,370 \\
14 \\
214 \\
257 \\
3\end{array}$ & $\begin{array}{r}12,484 \\
12 \\
212 \\
365 \\
7\end{array}$ & $\begin{array}{r}13,333 \\
12 \\
376 \\
402 \\
7\end{array}$ & $\begin{array}{r}14,464 \\
12 \\
376 \\
433 \\
0\end{array}$ & $\begin{array}{r}16,190 \\
9 \\
423 \\
447 \\
0\end{array}$ \\
\hline 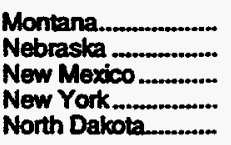 & $\begin{array}{r}1,450 \\
25 \\
9,915 \\
700 \\
34\end{array}$ & $\begin{array}{r}1,235 \\
19 \\
10,352 \\
900 \\
18\end{array}$ & $\begin{array}{r}1,490 \\
17 \\
10,674 \\
1,400 \\
34\end{array}$ & $\begin{array}{r}1,438 \\
18 \\
11,812 \\
1,600 \\
34\end{array}$ & $\begin{array}{r}1,755 \\
22 \\
12,609 \\
1,900 \\
23\end{array}$ & $\begin{array}{r}1,881 \\
20 \\
13,598 \\
2,200 \\
78\end{array}$ & $\begin{array}{r}1,881 \\
22 \\
14,571 \\
2,076 \\
80\end{array}$ \\
\hline 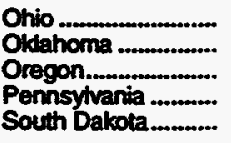 & $\begin{array}{r}10,038 \\
9,401 \\
0 \\
17,123 \\
0\end{array}$ & $\begin{array}{r}10,382 \\
9,769 \\
0 \\
17,500 \\
20\end{array}$ & $\begin{array}{r}11,509 \\
10,436 \\
0 \\
17,500 \\
20\end{array}$ & $\begin{array}{r}13,032 \\
11,570 \\
0 \\
17,396 \\
20\end{array}$ & $\begin{array}{r}14,197 \\
12,861 \\
0 \\
18,900 \\
20\end{array}$ & $\begin{array}{r}15,827 \\
14,417 \\
5 \\
19,800 \\
10\end{array}$ & $\begin{array}{r}17,251 \\
16,419 \\
5 \\
19,900 \\
13\end{array}$ \\
\hline 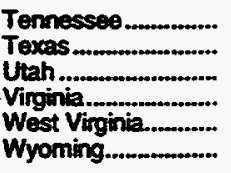 & $\begin{array}{r}13 \\
24,646 \\
114 \\
174 \\
21.450 \\
900\end{array}$ & $\begin{array}{r}5 \\
26,184 \\
271 \\
186 \\
21,700 \\
950\end{array}$ & $\begin{array}{r}7 \\
27.762 \\
170 \\
180 \\
22.100 \\
990\end{array}$ & $\begin{array}{r}49 \\
31,512 \\
170 \\
202 \\
22,600 \\
995\end{array}$ & $\begin{array}{r}75 \\
33,157 \\
171 \\
227 \\
23,575 \\
688\end{array}$ & $\begin{array}{r}184 \\
35,650 \\
182 \\
258 \\
24,725 \\
1,236\end{array}$ & $\begin{array}{r}177 \\
37,724 \\
200 \\
258 \\
25,900 \\
1,264\end{array}$ \\
\hline Total................................. & 126,329 & 130,364 & 137,542 & 147,658 & 157,454 & 169,891 & 182,004 \\
\hline
\end{tabular}

See tootnotes at end of table. 
Table 6. Number of Producing Gas and Gas Condensate Wells by State as of December 31, 1967-1994 (Continued) -

\begin{tabular}{|c|c|c|c|c|c|c|c|}
\hline Sens & 1981 & 1982 & 1983 & 1984 & 2985 & 1986 & 1987 \\
\hline 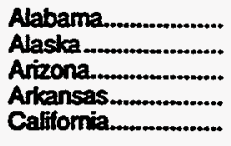 & $\begin{array}{r}385 \\
79 \\
1 \\
1,600 \\
1,110\end{array}$ & $\begin{array}{r}489 \\
97 \\
1 \\
1,959 \\
1,352\end{array}$ & $\begin{array}{r}461 \\
78 \\
1 \\
1,763 \\
1,413\end{array}$ & $\begin{array}{r}690 \\
81 \\
1 \\
2,371 \\
1,469\end{array}$ & $\begin{array}{r}863 \\
84 \\
1 \\
2,623 \\
1,566\end{array}$ & $\begin{array}{r}1,029 \\
85 \\
1 \\
2,719 \\
1,316\end{array}$ & $\begin{array}{r}1,135 \\
85 \\
0 \\
2,847 \\
1,294\end{array}$ \\
\hline 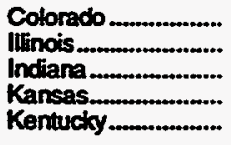 & $\begin{array}{r}3,543 \\
70 \\
720 \\
15,550 \\
8,151\end{array}$ & $\begin{array}{r}4,008 \\
57 \\
735 \\
13,800 \\
8,219\end{array}$ & $\begin{array}{r}4,391 \\
64 \\
737 \\
14,100 \\
8,532\end{array}$ & $\begin{array}{r}4,549 \\
81 \\
758 \\
14,925 \\
8,798\end{array}$ & $\begin{array}{r}4,401 \\
123 \\
1,272 \\
15,980 \\
9,285\end{array}$ & $\begin{array}{r}4,398 \\
152 \\
1,289 \\
11,485 \\
9,747\end{array}$ & $\begin{array}{r}4,530 \\
169 \\
1,298 \\
13,631 \\
10,366\end{array}$ \\
\hline 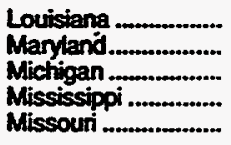 & $\begin{array}{r}17,048 \\
10 \\
448 \\
470 \\
0\end{array}$ & $\begin{array}{r}16,586 \\
8 \\
484 \\
596 \\
0\end{array}$ & $\begin{array}{r}16,700 \\
8 \\
414 \\
552 \\
0\end{array}$ & $\begin{array}{r}17,124 \\
9 \\
535 \\
683 \\
4\end{array}$ & $\begin{array}{r}16,716 \\
7 \\
655 \\
710 \\
4\end{array}$ & $\begin{array}{r}15,313 \\
6 \\
651 \\
414 \\
9\end{array}$ & $\begin{array}{r}15,890 \\
8 \\
722 \\
775 \\
3\end{array}$ \\
\hline $\begin{array}{l}\text { Montana.................... } \\
\text { Nebrasica .................. } \\
\text { New Mexico ............. } \\
\text { New York } \\
\text { North Dakota............... }\end{array}$ & $\begin{array}{r}2,140 \\
25 \\
15,560 \\
2,636 \\
65\end{array}$ & $\begin{array}{r}2,111 \\
23 \\
16,967 \\
2,969 \\
66\end{array}$ & $\begin{array}{r}2,133 \\
23 \\
17,547 \\
3,423 \\
51\end{array}$ & $\begin{array}{r}2,153 \\
23 \\
17,806 \\
3,500 \\
55\end{array}$ & $\begin{array}{r}2,260 \\
19 \\
18,308 \\
4,500 \\
62\end{array}$ & $\begin{array}{r}2,799 \\
16 \\
18,647 \\
4,947 \\
61\end{array}$ & $\begin{array}{r}2,349 \\
20 \\
18,806 \\
5,167 \\
61\end{array}$ \\
\hline 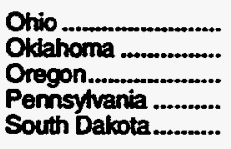 & $\begin{array}{r}19,405 \\
18,451 \\
9 \\
21,500 \\
39\end{array}$ & $\begin{array}{r}22,112 \\
20,742 \\
6 \\
23,000 \\
38\end{array}$ & $\begin{array}{r}25,762 \\
22,230 \\
8 \\
24,000 \\
40\end{array}$ & $\begin{array}{r}28,657 \\
23,691 \\
6 \\
25,500 \\
42\end{array}$ & $\begin{array}{r}31,343 \\
24,756 \\
9 \\
26,500 \\
44\end{array}$ & $\begin{array}{r}32,721 \\
25,762 \\
14 \\
27,600 \\
44\end{array}$ & $\begin{array}{r}33,616 \\
26,595 \\
10 \\
27,800 \\
52\end{array}$ \\
\hline 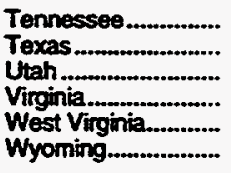 & $\begin{array}{r}255 \\
40,612 \\
226 \\
288 \\
27,200 \\
1,243\end{array}$ & $\begin{array}{r}340 \\
44,130 \\
282 \\
298 \\
27,450 \\
1,827\end{array}$ & $\begin{array}{r}540 \\
44,699 \\
322 \\
299 \\
29,675 \\
1,986\end{array}$ & $\begin{array}{r}780 \\
45.139 \\
700 \\
425 \\
31.150 \\
2.148\end{array}$ & $\begin{array}{r}988 \\
44,320 \\
755 \\
495 \\
32,475 \\
2,220\end{array}$ & $\begin{array}{r}921 \\
42,713 \\
594 \\
573 \\
33,400 \\
2,101\end{array}$ & $\begin{array}{r}840 \\
43,375 \\
645 \\
689 \\
34,300 \\
2,147\end{array}$ \\
\hline 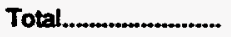 & 198,839 & 210,753 & 221,952 & 233,853 & 243,344 & 241,527 & 249,225 \\
\hline
\end{tabular}

See footnotes at end of table. 
Table 6. Number of Producing Gas and Gas Condensate Wells by State as of December 31, 1967-1994 (Continued)

\begin{tabular}{|c|c|c|c|c|c|c|c|}
\hline Stus & 1906 & 1909 & 1900 & 1991 & 1992 & 1993 & 1924 \\
\hline 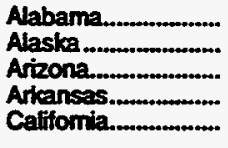 & $\begin{array}{r}1,264 \\
91 \\
0 \\
2,996 \\
1,469\end{array}$ & $\begin{array}{r}1,701 \\
108 \\
3 \\
2,830 \\
1,214\end{array}$ & $\begin{array}{r}2,362 \\
111 \\
5 \\
2,952 \\
1,162\end{array}$ & $\begin{array}{r}3,392 \\
110 \\
6 \\
2,780 \\
1,377\end{array}$ & $\begin{array}{r}3,350 \\
112 \\
6 \\
3,500 \\
1,126\end{array}$ & $\begin{array}{r}3,514 \\
113 \\
6 \\
3,500 \\
R_{1,092}\end{array}$ & $\begin{array}{r}3,565 \\
104 \\
19 \\
3,500 \\
1,261\end{array}$ \\
\hline 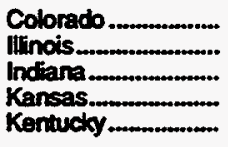 & $\begin{array}{r}4,426 \\
293 \\
1,295 \\
15,300 \\
10,777\end{array}$ & $\begin{array}{r}5,125 \\
241 \\
1,310 \\
13,935 \\
11,248\end{array}$ & $\begin{array}{r}5,741 \\
356 \\
1,307 \\
16,080 \\
11,713\end{array}$ & $\begin{array}{r}5,562 \\
373 \\
1,334 \\
17,948 \\
12,169\end{array}$ & $\begin{array}{r}5,912 \\
382 \\
1,333 \\
18,400 \\
12,483\end{array}$ & $\begin{array}{r}6,372 \\
385 \\
1,356 \\
19,472 \\
12,836\end{array}$ & $\begin{array}{r}7,056 \\
390 \\
1,348 \\
19,365 \\
13,036\end{array}$ \\
\hline 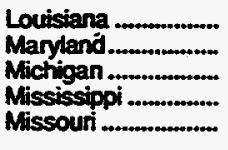 & $\begin{array}{r}14,071 \\
8 \\
988 \\
634 \\
4\end{array}$ & $\begin{array}{r}16,309 \\
8 \\
1,207 \\
543 \\
4\end{array}$ & $\begin{array}{r}16,889 \\
7 \\
1,438 \\
585 \\
8\end{array}$ & $\begin{array}{r}15,271 \\
7 \\
2,620 \\
629 \\
6\end{array}$ & $\begin{array}{r}13,512 \\
9 \\
3,257 \\
507 \\
5\end{array}$ & $\begin{array}{r}R_{15,569} \\
7 \\
5,500 \\
620 \\
8\end{array}$ & $\begin{array}{r}12,958 \\
7 \\
6,000 \\
583 \\
12\end{array}$ \\
\hline 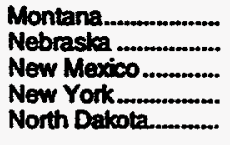 & $\begin{array}{r}2,553 \\
18 \\
15,909 \\
5,090 \\
61\end{array}$ & $\begin{array}{r}2,700 \\
15 \\
17,087 \\
5,304 \\
61\end{array}$ & $\begin{array}{r}2,607 \\
11 \\
17,124 \\
5,525 \\
103\end{array}$ & $\begin{array}{r}2,802 \\
12 \\
20,021 \\
5,737 \\
100\end{array}$ & $\begin{array}{r}2,890 \\
22 \\
18,040 \\
5,906 \\
104\end{array}$ & $\begin{array}{r}3,075 \\
59 \\
20,846 \\
5,757 \\
101\end{array}$ & $\begin{array}{r}2,940 \\
87 \\
23,292 \\
5,884 \\
104\end{array}$ \\
\hline 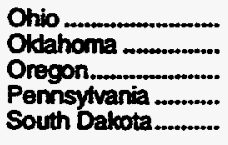 & $\begin{array}{r}33,793 \\
27,307 \\
14 \\
28,000 \\
51\end{array}$ & $\begin{array}{r}34,450 \\
27,443 \\
18 \\
30,000 \\
53\end{array}$ & $\begin{array}{r}34,586 \\
24,547 \\
19 \\
30,300 \\
54\end{array}$ & $\begin{array}{r}34,760 \\
28,216 \\
16 \\
31,000 \\
54\end{array}$ & $\begin{array}{r}34,784 \\
28,902 \\
16 \\
31,000 \\
38\end{array}$ & $\begin{array}{r}34,782 \\
29,118 \\
18 \\
31,100 \\
447\end{array}$ & $\begin{array}{r}34,731 \\
29,121 \\
19 \\
31,150 \\
55\end{array}$ \\
\hline 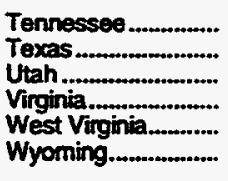 & $\begin{array}{r}802 \\
50,588 \\
655 \\
728 \\
35,800 \\
2,284\end{array}$ & $\begin{array}{r}700 \\
48,609 \\
834 \\
752 \\
36,240 \\
2,431\end{array}$ & $\begin{array}{r}P_{0} \\
50,867 \\
822 \\
819 \\
37,500 \\
2,600\end{array}$ & $\begin{array}{r}P_{0} \\
47,615 \\
913 \\
886 \\
37,800 \\
2,821\end{array}$ & $\begin{array}{r}R_{0} \\
46,298 \\
1,006 \\
1,153 \\
38,250 \\
3,111\end{array}$ & $\begin{array}{r}R_{0} \\
47,101 \\
1,061 \\
1,426 \\
R_{33,716} \\
3,615\end{array}$ & $\begin{array}{r}0 \\
48,654 \\
1,303 \\
1,470 \\
35,250 \\
3,942\end{array}$ \\
\hline Total. & 257,279 & 262,483 & $R_{269,100}$ & $R_{276,337}$ & $R_{275,414}$ & $P_{282,152}$ & 287,206 \\
\hline
\end{tabular}

$\mathbf{R}=$ Revised data.

Note: Totats may not equal sum of components due to independent rounding.

Sources: 1967-1975: Bureau of Mines, U.S. Department of interior, Natural Gas Production and Consumption. 1976-1978: Appropriate State agencies' responses to infomal data requests, the United States Geological Survey (USGS), and Woild Oil magazine. 1980-1981: U.S. Department of Energy, Energy Information Administration (EIA), Form EIA-627. Annued Quantity and Vahe of Natural Gas Report" the USGS, and Workd Orl magazine. 1982-1994: Form EIA-6e7, the United States Minerals Managenent Senvice, and Word Oil magazine. 
Table 7. Wellhead Value and Marketed Production of Natural Gas by State, 1967-1994

\begin{tabular}{|c|c|c|c|}
\hline Sun & $\begin{array}{l}\text { Averege Welthead } \\
\text { Price } \\
\text { (doling per } \\
\text { thouand cubic feot) }\end{array}$ & $\begin{array}{l}\text { Markotad } \\
\text { Production } \\
\text { (mition } \\
\text { cubie feet) }\end{array}$ & $\begin{array}{l}\text { Imputed Wollined } \\
\text { Value of } \\
\text { Mrrtroted Production } \\
\text { (thousend dollese) }\end{array}$ \\
\hline & \multicolumn{3}{|c|}{1967} \\
\hline 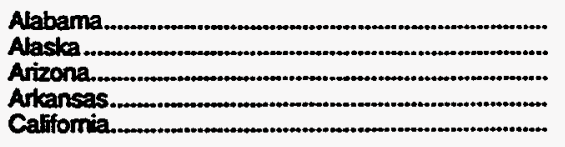 & $\begin{array}{l}0.13 \\
0.25 \\
0.15 \\
0.15 \\
0.30\end{array}$ & $\begin{array}{r}248 \\
14,438 \\
1,255 \\
116,522 \\
681,080\end{array}$ & $\begin{array}{r}31 \\
3,610 \\
193 \\
17,828 \\
202,090\end{array}$ \\
\hline 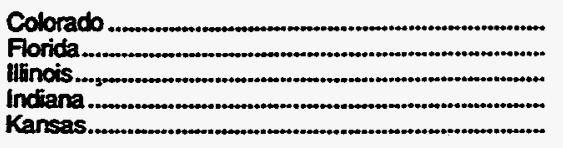 & $\begin{array}{l}0.13 \\
0.15 \\
0.12 \\
0.23 \\
0.13\end{array}$ & $\begin{array}{r}116,857 \\
123 \\
5,144 \\
198 \\
871.971\end{array}$ & $\begin{array}{r}15,542 \\
18 \\
602 \\
46 \\
116,844\end{array}$ \\
\hline 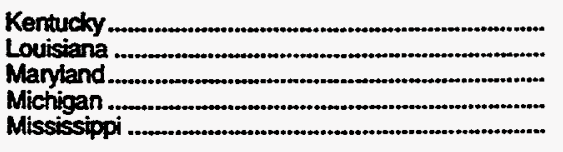 & $\begin{array}{l}0.24 \\
0.19 \\
0.26 \\
0.25 \\
0.17\end{array}$ & $\begin{array}{r}89,168 \\
5,716,857 \\
621 \\
33,589 \\
139,497\end{array}$ & $\begin{array}{r}21,400 \\
1,057,619 \\
159 \\
8,296 \\
24,133\end{array}$ \\
\hline 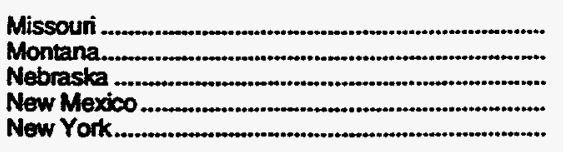 & $\begin{array}{l}0.25 \\
0.08 \\
0.17 \\
0.13 \\
0.31\end{array}$ & $\begin{array}{r}121 \\
25,866 \\
8,453 \\
1,057,510 \\
3,837\end{array}$ & $\begin{array}{r}30 \\
2,173 \\
1,454 \\
138,776 \\
1,201\end{array}$ \\
\hline $\begin{array}{l}\text { North Dakota. } \\
\text { Ohio } \\
\text { Oktahoma } \\
\text { Pennsytrania } \\
\text { Tennessed }\end{array}$ & $\begin{array}{l}0.16 \\
0.24 \\
0.14 \\
0.28 \\
0.19\end{array}$ & $\begin{array}{r}40,462 \\
41,315 \\
1,412,952 \\
89,966 \\
58\end{array}$ & $\begin{array}{r}6,636 \\
9,957 \\
202,052 \\
25,280 \\
11\end{array}$ \\
\hline 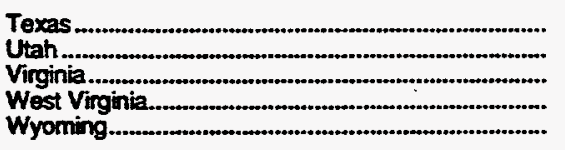 & $\begin{array}{l}0.13 \\
0.13 \\
0.30 \\
0.24 \\
0.15\end{array}$ & $\begin{array}{r}7,188,900 \\
48,965 \\
3,818 \\
211,460 \\
240,074\end{array}$ & $\begin{array}{r}948,935 \\
6,463 \\
1,149 \\
50,962 \\
35,051\end{array}$ \\
\hline \multirow[t]{2}{*}{ Total } & 0.16 & $18,171,325$ & $2,898,741$ \\
\hline & \multicolumn{3}{|c|}{1968} \\
\hline 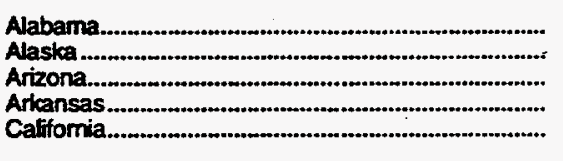 & $\begin{array}{r}0.13 \\
0.25 \\
0.16 \\
0.16 \\
0.31\end{array}$ & $\begin{array}{r}230 \\
17,343 \\
881 \\
156,627 \\
714,893\end{array}$ & $\begin{array}{r}30 \\
4,388 \\
142 \\
24,456 \\
221,077\end{array}$ \\
\hline 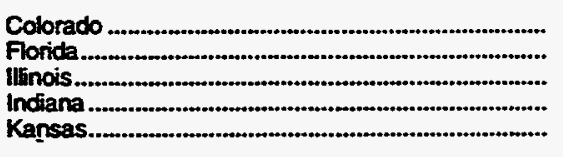 & $\begin{array}{l}0.13 \\
0.15 \\
0.13 \\
0.24 \\
0.14\end{array}$ & $\begin{array}{r}121,424 \\
108 \\
4,380 \\
234 \\
835,555\end{array}$ & $\begin{array}{r}16,392 \\
16 \\
552 \\
55 \\
115,307\end{array}$ \\
\hline 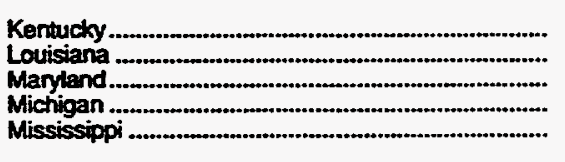 & $\begin{array}{l}0.25 \\
0.19 \\
0.26 \\
0.25 \\
0.17\end{array}$ & $\begin{array}{r}89,024 \\
6,416,015 \\
864 \\
40,480 \\
135,051\end{array}$ & $\begin{array}{r}22,256 \\
1,212,627 \\
221 \\
10,160 \\
22,601\end{array}$ \\
\hline 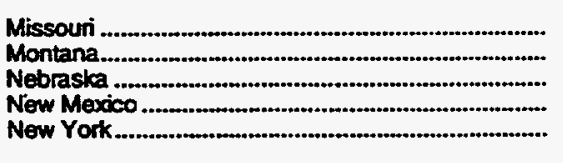 & $\begin{array}{l}0.29 \\
0.09 \\
0.18 \\
0.13 \\
0.30\end{array}$ & $\begin{array}{r}14 \\
19,313 \\
8,129 \\
1,164,182 \\
4,632\end{array}$ & $\begin{array}{r}4 \\
1,757 \\
1,423 \\
156,000 \\
1,390\end{array}$ \\
\hline $\begin{array}{l}\text { North Dakota } \\
\text { Ohio } \\
\text { Oktahoma } \\
\text { Pennsytrania } \\
\text { Tennessee }\end{array}$ & $\begin{array}{l}0.17 \\
0.25 \\
0.14 \\
0.28 \\
0.19\end{array}$ & $\begin{array}{r}41,023 \\
42,673 \\
1,390,884 \\
87,987 \\
48\end{array}$ & $\begin{array}{r}6,769 \\
10,540 \\
197,506 \\
24,460 \\
9\end{array}$ \\
\hline
\end{tabular}

See footnotes at end of table. 
Table 7. Wellhead Value and Marketed Production of Natural Gas by State, 1967-1994 (Continued)

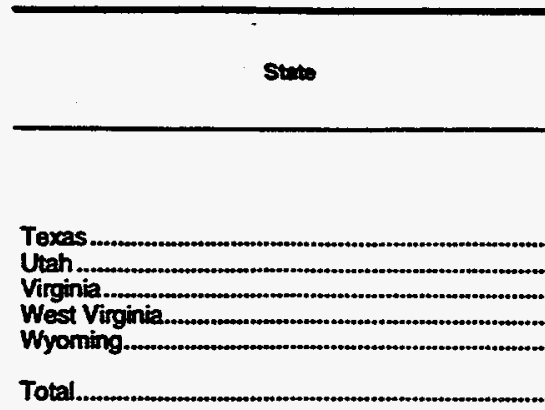

Average Wothad
Price
(dotlers por
thouband eubic ient)

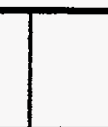

Marketed
Production
(million
cubic feet)

Impurad Welthead Vatue of Markewd Production

1968

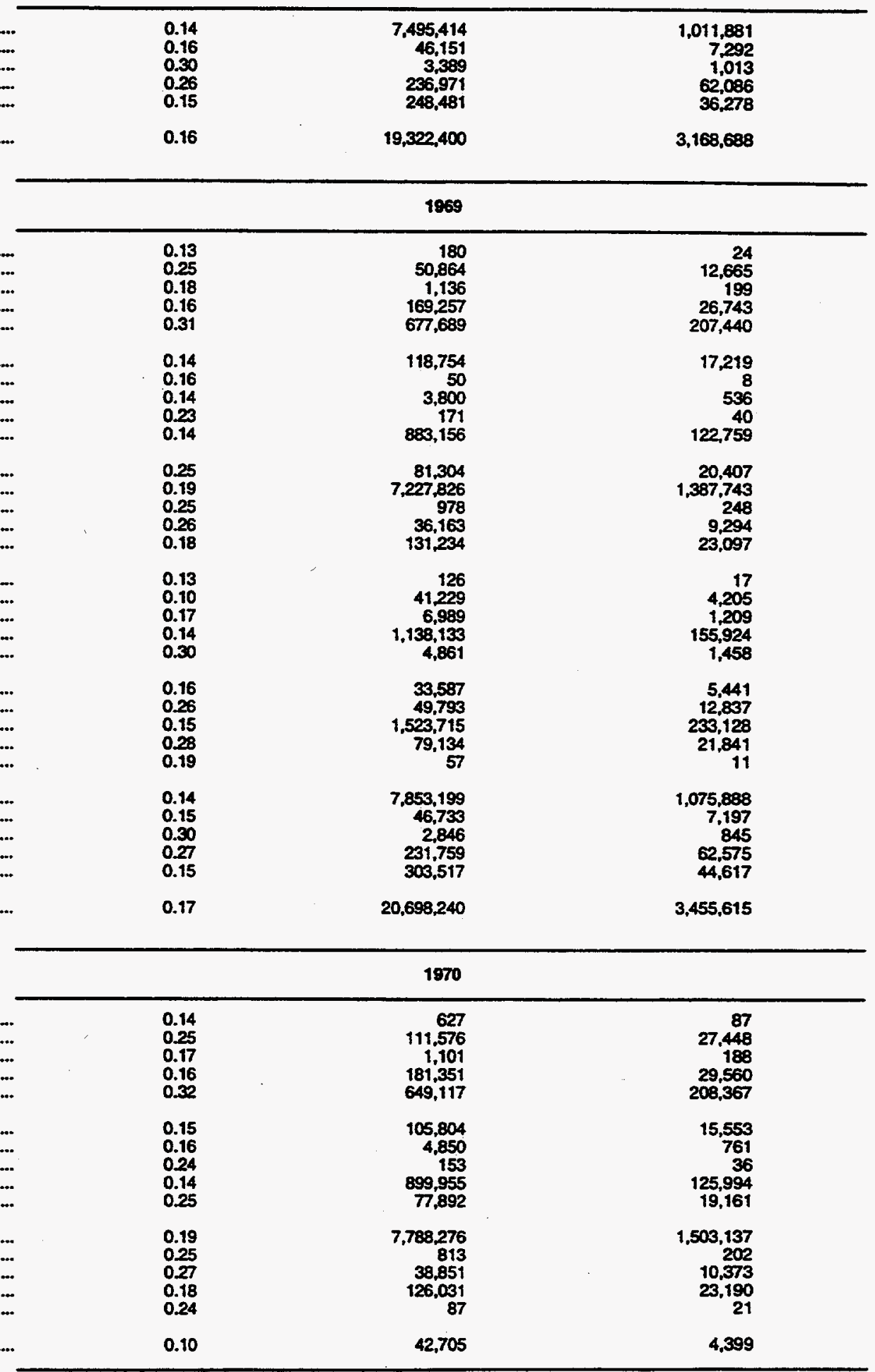

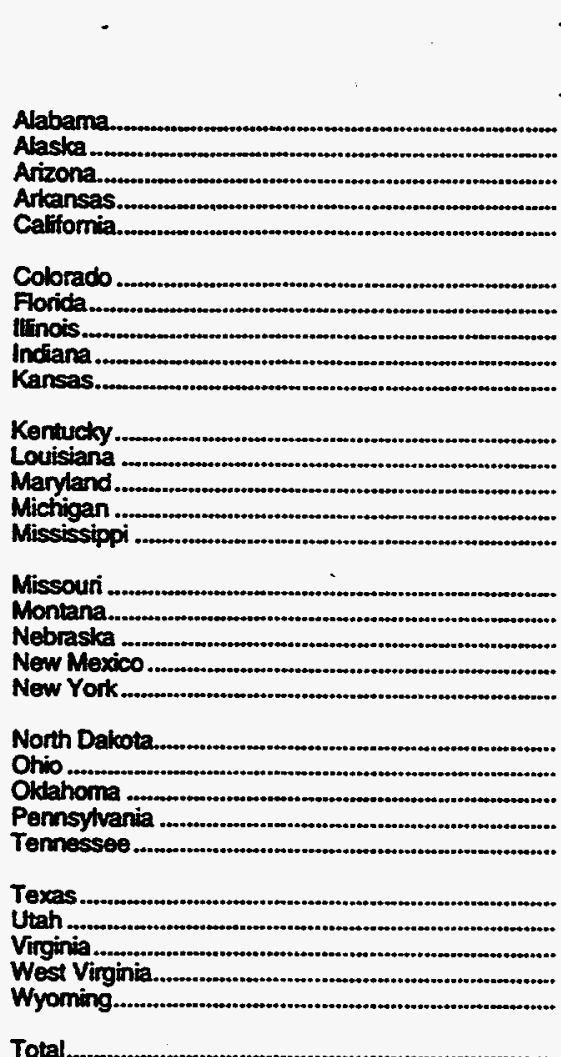

Total.

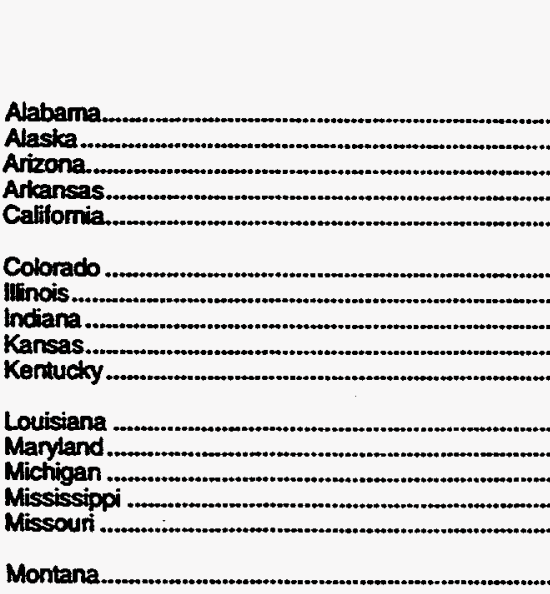

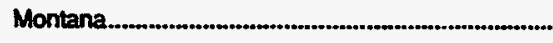

See footnotes at end of table. 
Table 7. Wellhead Value and Marketed Production of Natural Gas by State, 1967-1994 (Continued)

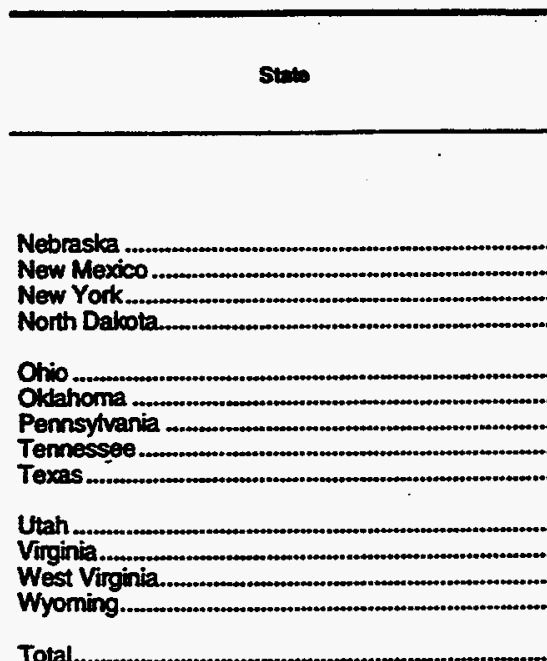

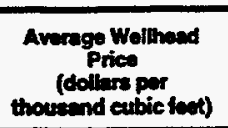

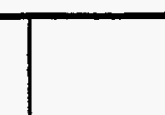

Martioted
Production
(miltion
cubie feet)

inpurtad Wellhead Velue of (thousend dollers)

1970

\begin{tabular}{rrrr}
\hline .17 & 5,991 & 1,024 \\
$\ldots$. & 0.14 & $1,138,980$ & 162,874 \\
$\ldots$. & 0.30 & 3,358 & 1,017 \\
$\ldots .16$ & 34,889 & 5,722 \\
$\ldots$. & 0.27 & 52,113 & 14,123 \\
$\ldots$. & 0.16 & $1,594,943$ & 248,811 \\
$\ldots .28$ & 76,841 & 21,439 \\
$\ldots$. & 0.20 & 64 & 13 \\
$\ldots .14$ & 0.14 & $8,357,716$ & $1,208,511$ \\
& 0.15 & 42,781 & 6,460 \\
& 0.31 & 2,805 & 864 \\
& 0.25 & 242,452 & 61,583 \\
& 0.15 & 388,520 & 49,762 \\
& 0.17 & $21,920,642$ & $3,745,680$
\end{tabular}

\begin{tabular}{|c|c|c|}
\hline & 1971 & \\
\hline $\begin{array}{l}0.15 \\
0.24 \\
0.18 \\
0.17 \\
0.33\end{array}$ & $\begin{array}{r}355 \\
121,618 \\
868 \\
172,154 \\
612,629\end{array}$ & $\begin{array}{r}54 \\
28,945 \\
153 \\
29,426 \\
199,717\end{array}$ \\
\hline $\begin{array}{l}0.16 \\
0.30 \\
0.18 \\
0.25 \\
0.14\end{array}$ & $\begin{array}{r}108,537 \\
903 \\
498 \\
537 \\
885,144\end{array}$ & $\begin{array}{r}16,932 \\
270 \\
88 \\
132 \\
127,267\end{array}$ \\
\hline $\begin{array}{l}0.25 \\
0.20 \\
0.24 \\
0.26 \\
0.21\end{array}$ & $\begin{array}{r}72,723 \\
8,081,907 \\
214 \\
25,662 \\
118,805\end{array}$ & $\begin{array}{r}18,253 \\
1,632,545 \\
52 \\
6,776 \\
24,830\end{array}$ \\
\hline $\begin{array}{l}0.23 \\
0.12 \\
0.18 \\
0.15 \\
0.30\end{array}$ & $\begin{array}{r}22 \\
32,720 \\
3,496 \\
1,167,577 \\
2,202\end{array}$ & $\begin{array}{r}5 \\
3,959 \\
612 \\
175,137 \\
661\end{array}$ \\
\hline $\begin{array}{l}0.17 \\
0.34 \\
0.16 \\
0.27 \\
0.22\end{array}$ & $\begin{array}{r}33,864 \\
79,903 \\
1,684,260 \\
76,451 \\
89\end{array}$ & $\begin{array}{r}5,655 \\
27,007 \\
273,945 \\
20,770 \\
20\end{array}$ \\
\hline $\begin{array}{l}0.16 \\
0.17 \\
0.31 \\
0.26 \\
0.15\end{array}$ & $\begin{array}{r}8,550,705 \\
42,418 \\
2,619 \\
234,027 \\
380,105\end{array}$ & $\begin{array}{r}1,376,664 \\
7,084 \\
822 \\
60,613 \\
58,156\end{array}$ \\
\hline 0.18 & $22,493,012$ & $4,096,550$ \\
\hline \multicolumn{3}{|c|}{1972} \\
\hline $\begin{array}{l}0.35 \\
0.15 \\
0.18 \\
0.17 \\
0.37\end{array}$ & $\begin{array}{r}3,644 \\
125,596 \\
442 \\
166,522 \\
487,278\end{array}$ & $\begin{array}{r}1,282 \\
18,463 \\
80 \\
28,808 \\
179,318\end{array}$ \\
\hline $\begin{array}{l}0.16 \\
0.32 \\
0.28\end{array}$ & $\begin{array}{r}116,949 \\
15,521 \\
1,194\end{array}$ & $\begin{array}{r}19,296 \\
4,967 \\
334\end{array}$ \\
\hline
\end{tabular}

See tootnotes at end of table. 
Table 7. Wellhead Value and Marketed Production of Natural Gas by State, 1967-1994 (Continued)

\begin{tabular}{|c|c|c|c|}
\hline State & $\begin{array}{l}\text { Average Wellhand } \\
\text { Price } \\
\text { (dollars per } \\
\text { thousend cubic tad) }\end{array}$ & $\begin{array}{l}\text { Marketed } \\
\text { Production } \\
\text { (million } \\
\text { cubic foet) }\end{array}$ & $\begin{array}{l}\text { inputed Wellowed } \\
\text { Velies of } \\
\text { Merketid Production } \\
\text { (thousend dellers) }\end{array}$ \\
\hline & \multicolumn{3}{|c|}{1972} \\
\hline Indiana & $\begin{array}{l}0.15 \\
0.14\end{array}$ & $\begin{array}{r}355 \\
889,268\end{array}$ & 127,859 \\
\hline 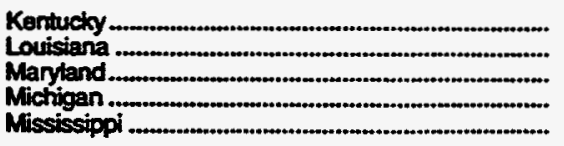 & $\begin{array}{l}0.25 \\
0.20 \\
0.21 \\
0.31 \\
0.27\end{array}$ & $\begin{array}{r}63,648 \\
7,972,678 \\
244 \\
34,221 \\
103,989\end{array}$ & $\begin{array}{r}15,976 \\
1,626,426 \\
51 \\
10,506 \\
28,077\end{array}$ \\
\hline 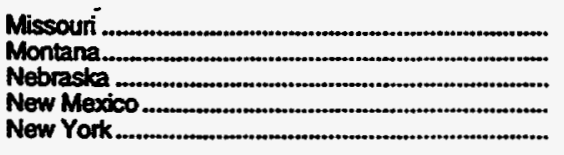 & $\begin{array}{l}0.22 \\
0.12 \\
0.18 \\
0.19 \\
0.33\end{array}$ & $\begin{array}{r}9 \\
33,474 \\
3,478 \\
1,216,061 \\
3,679\end{array}$ & $\begin{array}{r}2 \\
4,117 \\
619 \\
225,420 \\
1,199\end{array}$ \\
\hline $\begin{array}{l}\text { North Dakota. } \\
\text { Ohio } \\
\text { Okdahoma } \\
\text { Pennsylvania } \\
\text { Tennessee }\end{array}$ & $\begin{array}{l}0.17 \\
0.39 \\
0.16 \\
0.30 \\
0.32\end{array}$ & $\begin{array}{r}32,472 \\
89,995 \\
1,806,887 \\
73,958 \\
25\end{array}$ & $\begin{array}{r}5,455 \\
35,271 \\
294,523 \\
22,389 \\
8\end{array}$ \\
\hline 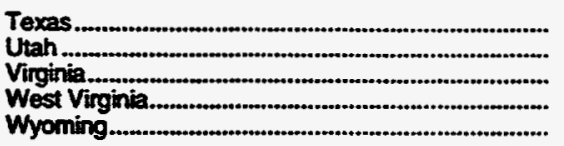 & $\begin{array}{l}0.16 \\
0.17 \\
0.32 \\
0.30 \\
0.16\end{array}$ & $\begin{array}{r}8,657,840 \\
\mathbf{3 9 , 4 7 4} \\
2,787 \\
214,951 \\
375,059\end{array}$ & $\begin{array}{r}1,419,886 \\
6,711 \\
892 \\
64,485 \\
60,760\end{array}$ \\
\hline \multirow[t]{2}{*}{ Total } & 0.19 & $22,531,698$ & $4,203,235$ \\
\hline & \multicolumn{3}{|c|}{1973} \\
\hline 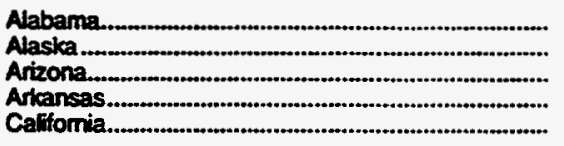 & $\begin{array}{l}0.38 \\
0.15 \\
0.18 \\
0.18 \\
0.37\end{array}$ & $\begin{array}{r}11,271 \\
131,007 \\
125 \\
157,529 \\
449,369\end{array}$ & $\begin{array}{r}4,307 \\
19,483 \\
23 \\
28,985 \\
167,615\end{array}$ \\
\hline 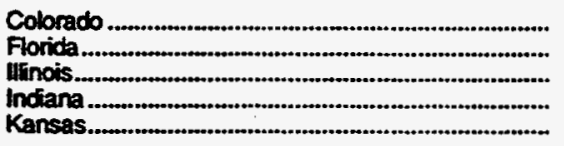 & $\begin{array}{l}0.18 \\
0.34 \\
0.35 \\
0.14 \\
0.16\end{array}$ & $\begin{array}{r}137.725 \\
33,857 \\
1,638 \\
276 \\
893,118\end{array}$ & $\begin{array}{r}24,304 \\
11,613 \\
573 \\
38 \\
138,521\end{array}$ \\
\hline 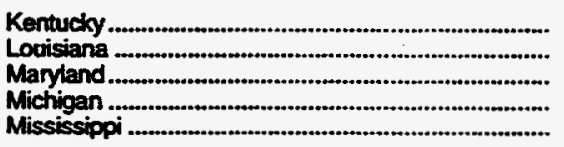 & $\begin{array}{l}0.35 \\
0.22 \\
0.23 \\
0.39 \\
0.23\end{array}$ & $\begin{array}{r}62,396 \\
8,242,423 \\
298 \\
44,579 \\
99,706\end{array}$ & $\begin{array}{r}21,839 \\
1,846,303 \\
69 \\
17,495 \\
22,846\end{array}$ \\
\hline 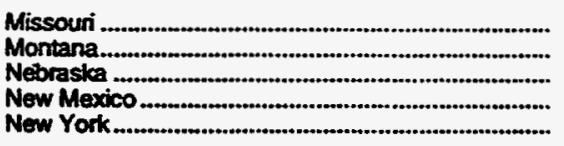 & $\begin{array}{l}0.24 \\
0.24 \\
0.18 \\
0.24 \\
0.35\end{array}$ & $\begin{array}{r}33 \\
56,175 \\
3,836 \\
1,218,749 \\
4,539\end{array}$ & $\begin{array}{r}8 \\
13,240 \\
698 \\
287,889 \\
1,590\end{array}$ \\
\hline 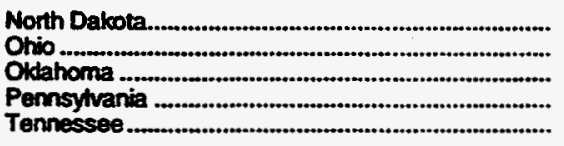 & $\begin{array}{l}0.20 \\
0.43 \\
0.19 \\
0.42 \\
0.30\end{array}$ & $\begin{array}{r}27,703 \\
93,610 \\
1,770,980 \\
78,514 \\
20\end{array}$ & $\begin{array}{r}5,457 \\
39,786 \\
334,110 \\
32,976 \\
6\end{array}$ \\
\hline 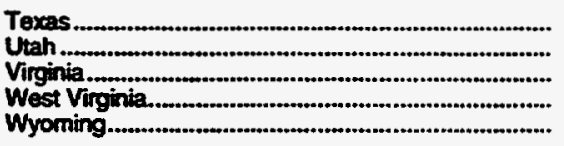 & $\begin{array}{l}0.20 \\
0.19 \\
0.33 \\
0.31 \\
0.18\end{array}$ & $\begin{array}{r}8,513,850 \\
42,715 \\
5,101 \\
208,676 \\
357,731\end{array}$ & $\begin{array}{r}1,735,221 \\
8,159 \\
1,688 \\
64,481 \\
64,749\end{array}$ \\
\hline Total & 0.22 & $22,647,549$ & $4,894,072$ \\
\hline
\end{tabular}

See toctnotes at end of table. 
Table 7. Wellhead Value and Marketed Production of Natural Gas by State, 1967-1994 (Continued)

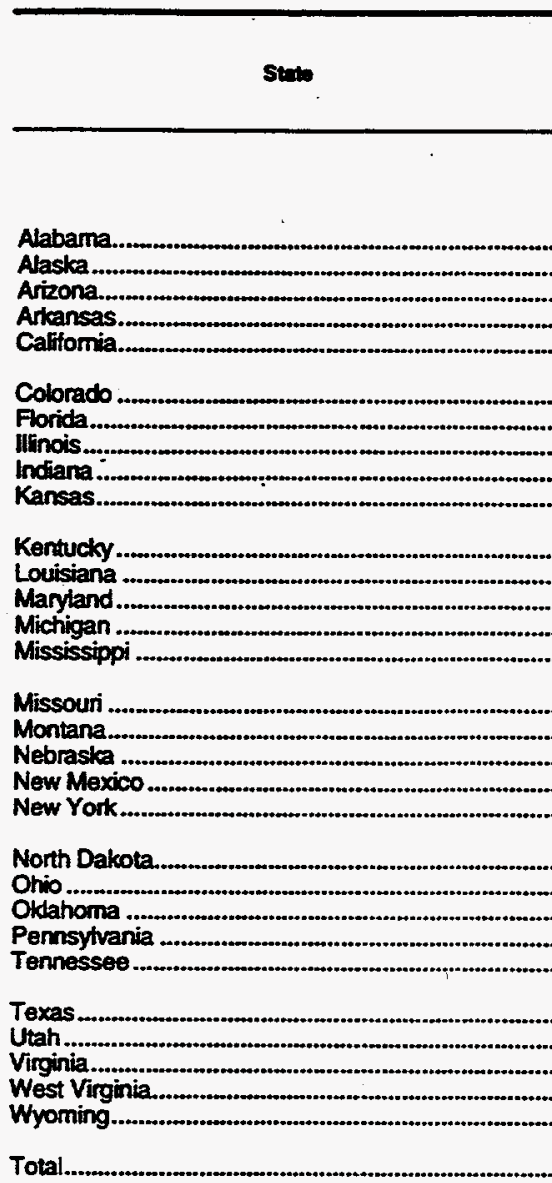

Awrege Woltheot
Price
(doliars per
thouasend eubic fect)

Murketad
Production
(milition
cubicted)

Inputed Wolthead

Value of

Marketed Production

1974

\begin{tabular}{|c|c|c|}
\hline $\begin{array}{l}0.74 \\
0.17 \\
0.20 \\
0.26 \\
0.44\end{array}$ & $\begin{array}{r}27,865 \\
128,935 \\
224 \\
123,975 \\
365,354\end{array}$ & $\begin{array}{r}20,704 \\
21,919 \\
45 \\
32,234 \\
160,756\end{array}$ \\
\hline $\begin{array}{l}0.20 \\
0.54 \\
0.40 \\
0.14 \\
0.17\end{array}$ & $\begin{array}{r}144,629 \\
38,137 \\
1,436 \\
176 \\
885,782\end{array}$ & $\begin{array}{r}28,926 \\
20,441 \\
574 \\
25 \\
147,206\end{array}$ \\
\hline $\begin{array}{l}0.50 \\
0.31 \\
0.24 \\
0.50 \\
0.29\end{array}$ & $\begin{array}{r}71,876 \\
7,753,631 \\
133 \\
69,133 \\
78,787\end{array}$ & $\begin{array}{r}35,938 \\
2,380,365 \\
32 \\
34,843 \\
23,242\end{array}$ \\
\hline $\begin{array}{l}0.30 \\
0.25 \\
0.34 \\
0.31 \\
0.55\end{array}$ & $\begin{array}{r}33 \\
54,873 \\
2,538 \\
1,244,779 \\
4,990\end{array}$ & $\begin{array}{r}10 \\
13,883 \\
863 \\
390,861 \\
2,745\end{array}$ \\
\hline $\begin{array}{l}0.20 \\
0.48 \\
0.28 \\
0.44 \\
0.35\end{array}$ & $\begin{array}{r}31,206 \\
92,055 \\
1,638,942 \\
82,637 \\
17\end{array}$ & $\begin{array}{r}6,210 \\
44,371 \\
458,904 \\
36,360 \\
6\end{array}$ \\
\hline $\begin{array}{l}0.31 \\
0.41 \\
0.51 \\
0.33 \\
0.25\end{array}$ & $\begin{array}{r}8,170,798 \\
50,522 \\
7,096 \\
202,306 \\
326,657\end{array}$ & $\begin{array}{r}2,541,118 \\
20,815 \\
3,619 \\
66,356 \\
80,031\end{array}$ \\
\hline 0.30 & $21,600,522$ & $6,573,402$ \\
\hline
\end{tabular}

\begin{tabular}{|c|c|c|c|}
\hline \multirow{3}{*}{$\begin{array}{l} \\
\text { Alabama.... }\end{array}$} & & & \\
\hline & \multicolumn{3}{|c|}{1975} \\
\hline & $\begin{array}{r}0.87 \\
0.30 \\
.0 .28 \\
0.35 \\
0.70\end{array}$ & $\begin{array}{r}37.814 \\
160.270 \\
208 \\
116,237 \\
318,308\end{array}$ & $\begin{array}{r}32,898 \\
48,402 \\
58 \\
40,334 \\
222,816\end{array}$ \\
\hline 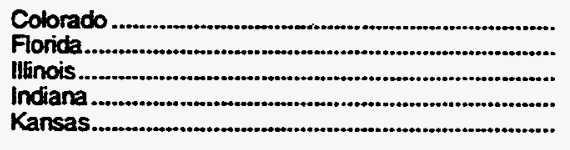 & $\begin{array}{l}0.26 \\
0.97 \\
0.70 \\
0.39 \\
0.17\end{array}$ & $\begin{array}{r}171,629 \\
44,383 \\
1,440 \\
346 \\
843,625\end{array}$ & $\begin{array}{r}44,624 \\
43,185 \\
1,008 \\
135 \\
145,103\end{array}$ \\
\hline $\begin{array}{l}\text { Kentucky } \\
\text { Louisiana } \\
\text { Maryland } \\
\text { Michigan } \\
\text { Mississippi }\end{array}$ & $\begin{array}{l}0.54 \\
0.42 \\
0.27 \\
0.63 \\
0.50\end{array}$ & $\begin{array}{r}60,511 \\
7,090,645 \\
93 \\
102,113 \\
74,345\end{array}$ & $\begin{array}{r}32,676 \\
2,999,179 \\
25 \\
64,740 \\
36,875\end{array}$ \\
\hline 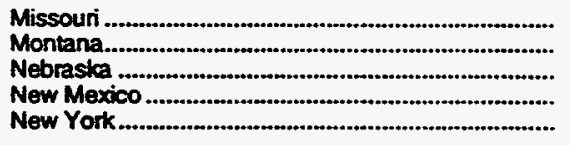 & $\begin{array}{l}0.33 \\
0.43 \\
0.54 \\
0.40 \\
0.74\end{array}$ & $\begin{array}{r}30 \\
40,734 \\
2,565 \\
1,217,430 \\
7,628\end{array}$ & $\begin{array}{r}10 \\
17,638 \\
1,388 \\
493,059 \\
5,645\end{array}$ \\
\hline $\begin{array}{l}\text { North Dakota } \\
\text { Ohio } \\
\text { Oktahoma } \\
\text { Pennsytvania } \\
\text { Tennessee }\end{array}$ & $\begin{array}{l}0.23 \\
0.71 \\
0.32 \\
0.67 \\
0.44\end{array}$ & $\begin{array}{r}24,786 \\
84,960 \\
1,605,410 \\
84,676 \\
27\end{array}$ & $\begin{array}{r}5,701 \\
59,982 \\
513,731 \\
57,156 \\
12\end{array}$ \\
\hline
\end{tabular}

See tootnotes at end of table. 
Table 7. Wellhead Value and Marketed Production of Natural Gas by State, 1967-1994 (Continued)

\begin{tabular}{|c|c|c|c|}
\hline Ston & $\begin{array}{c}\text { Avmrage Welthed } \\
\text { Price } \\
\text { (dollars por } \\
\text { thousend cubic feet) }\end{array}$ & $\begin{array}{l}\text { Marketid } \\
\text { Production } \\
\text { (milion } \\
\text { cubic feet) }\end{array}$ & $\begin{array}{l}\text { Imputed Wellihead } \\
\text { Velue of } \\
\text { Wurketed Production } \\
\text { (thousand doftars) }\end{array}$ \\
\hline & \multicolumn{3}{|c|}{1975} \\
\hline $\begin{array}{l}\text { Texas } \\
\text { Utah } \\
\text { Virginia, } \\
\text { West Viginia..... } \\
\text { Wyoming. }\end{array}$ & $\begin{array}{l}0.52 \\
0.48 \\
0.51 \\
0.37 \\
0.34\end{array}$ & $\begin{array}{r}7,485,764 \\
55,354 \\
6,723 \\
154,484 \\
316,123\end{array}$ & $\begin{array}{r}3,885,112 \\
26,570 \\
3,462 \\
57,005 \\
106,533\end{array}$ \\
\hline (n) & 0.44 & $20,108,661$ & $8,945,062$ \\
\hline & \multicolumn{3}{|c|}{1976} \\
\hline 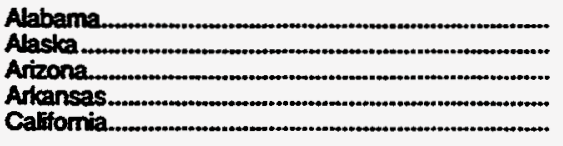 & $\begin{array}{l}0.99 \\
0.39 \\
0.28 \\
0.53 \\
0.94\end{array}$ & $\begin{array}{r}41,427 \\
166,072 \\
262 \\
109,533 \\
354,334\end{array}$ & $\begin{array}{r}40,806 \\
64,602 \\
74 \\
58,052 \\
333,074\end{array}$ \\
\hline 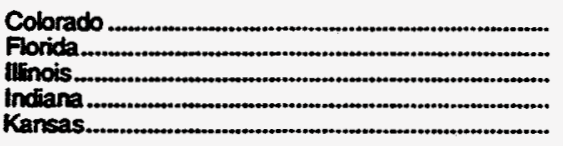 & $\begin{array}{l}0.48 \\
0.98 \\
0.99 \\
0.52 \\
0.42\end{array}$ & $\begin{array}{r}183,972 \\
43,165 \\
1,556 \\
192 \\
829,170\end{array}$ & $\begin{array}{r}88,307 \\
42,388 \\
1,533 \\
100 \\
348,251\end{array}$ \\
\hline 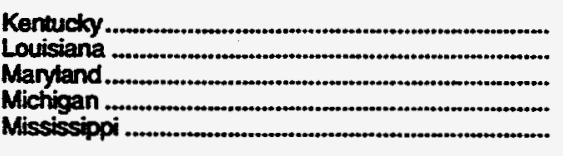 & $\begin{array}{l}0.55 \\
0.46 \\
0.32 \\
0.89 \\
0.71\end{array}$ & $\begin{array}{r}66,137 \\
7,006,596 \\
75 \\
119,262 \\
70,762\end{array}$ & $\begin{array}{r}36,375 \\
3,223,034 \\
24 \\
106,739 \\
50,241\end{array}$ \\
\hline 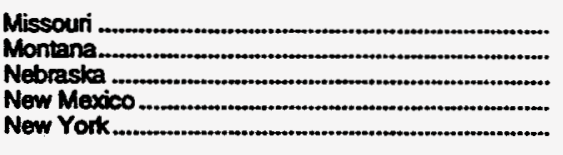 & $\begin{array}{l}0.34 \\
0.45 \\
0.51 \\
0.56 \\
1.13\end{array}$ & $\begin{array}{r}29 \\
42,563 \\
2,511 \\
1,230,976 \\
9,235\end{array}$ & $\begin{array}{r}10 \\
18,941 \\
1,288 \\
695,501 \\
10,436\end{array}$ \\
\hline 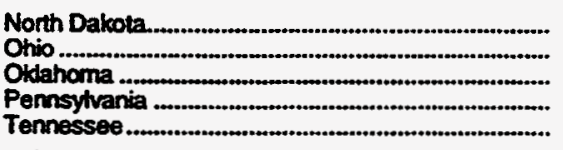 & $\begin{array}{l}0.34 \\
1.02 \\
0.50 \\
0.68 \\
0.51\end{array}$ & $\begin{array}{r}31,470 \\
88,891 \\
1,726,513 \\
89,386 \\
47\end{array}$ & $\begin{array}{r}10,699 \\
90,491 \\
866,710 \\
61.229 \\
24\end{array}$ \\
\hline 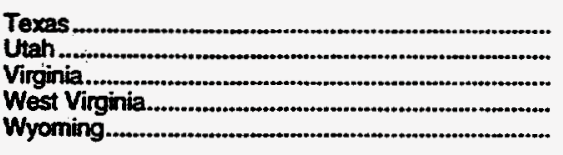 & $\begin{array}{l}0.72 \\
0.50 \\
1.14 \\
0.57 \\
0.41\end{array}$ & $\begin{array}{r}7,191,859 \\
57,416 \\
6,937 \\
153,322 \\
328,768\end{array}$ & $\begin{array}{r}5,163,755 \\
28,995 \\
7,908 \\
87,394 \\
134,795\end{array}$ \\
\hline \multirow[t]{2}{*}{ 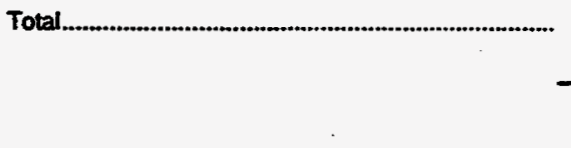 } & 0.58 & $19,952,438$ & $11,571,776$ \\
\hline & \multicolumn{3}{|c|}{1977} \\
\hline 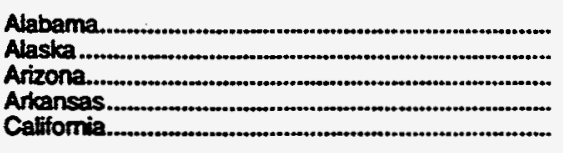 & $\begin{array}{l}1.47 \\
0.40 \\
0.33 \\
0.58 \\
1.17\end{array}$ & $\begin{array}{r}57,227 \\
187,889 \\
240 \\
104,096 \\
311,462\end{array}$ & $\begin{array}{r}84,124 \\
75,531 \\
80 \\
60,896 \\
364,099\end{array}$ \\
\hline 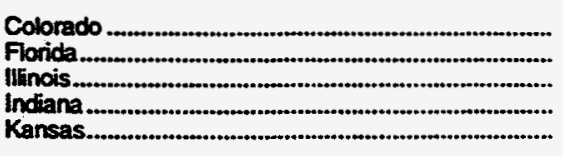 & $\begin{array}{l}0.81 \\
1.09 \\
1.20 \\
0.69 \\
0.48\end{array}$ & $\begin{array}{r}188,792 \\
48,171 \\
1,003 \\
183 \\
781,289\end{array}$ & $\begin{array}{r}152,922 \\
52,458 \\
1,204 \\
126 \\
378,925\end{array}$ \\
\hline $\begin{array}{l}\text { Kentucky. } \\
\text { Louisiana } \\
\text { Manyland } \\
\text { Michigan } \\
\text { Mississippi }\end{array}$ & $\begin{array}{l}0.55 \\
0.70 \\
0.39 \\
1.01 \\
0.73\end{array}$ & $\begin{array}{r}60,902 \\
7,215,006 \\
82 \\
129,954 \\
82,995\end{array}$ & $\begin{array}{r}33,496 \\
5,068,295 \\
32 \\
131,254 \\
60,589\end{array}$ \\
\hline 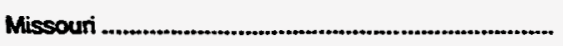 & 0.40 & 20 & 8 \\
\hline
\end{tabular}

See footnotes at end of table. 
Table 7. Wellhead Value and Marketed Production of Natural Gas by State, 1967-1994 (Continued)

\begin{tabular}{|c|c|c|c|}
\hline Stum & 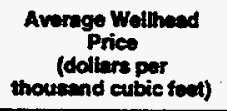 & $\begin{array}{l}\text { Markotied } \\
\text { Production } \\
\text { (million } \\
\text { cubie teot) }\end{array}$ & $\begin{array}{l}\text { Imputed Wollhead } \\
\text { Velue of } \\
\text { Marketed Production } \\
\text { (thousend dollars) }\end{array}$ \\
\hline & \multicolumn{3}{|c|}{1977} \\
\hline 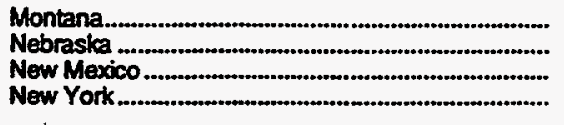 & $\begin{array}{l}0.72 \\
0.65 \\
0.81 \\
1.16\end{array}$ & $\begin{array}{r}46,819 \\
2,789 \\
1,202,973 \\
10,682\end{array}$ & $\begin{array}{r}33,663 \\
1,818 \\
974,408 \\
12,391\end{array}$ \\
\hline 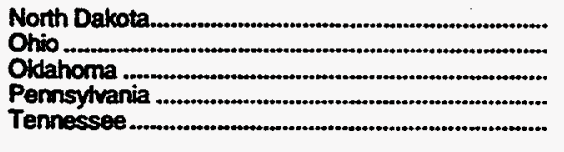 & $\begin{array}{l}0.35 \\
1.40 \\
0.79 \\
0.80 \\
0.74\end{array}$ & $\begin{array}{r}29,173 \\
99,327 \\
1,769,519 \\
91,717 \\
263\end{array}$ & $\begin{array}{r}10,303 \\
138,760 \\
1,397,920 \\
73,374 \\
195\end{array}$ \\
\hline 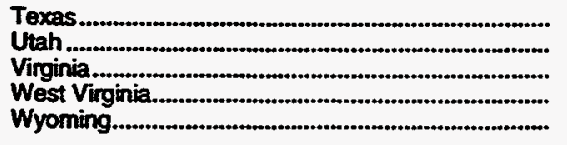 & $\begin{array}{l}0.90 \\
0.61 \\
1.26 \\
0.61 \\
0.64\end{array}$ & $\begin{array}{r}7,051,027 \\
60,696 \\
8,220 \\
152,767 \\
330,180\end{array}$ & $\begin{array}{r}6,367,077 \\
37,146 \\
10,357 \\
93,188 \\
211,315\end{array}$ \\
\hline \multirow[t]{2}{*}{ 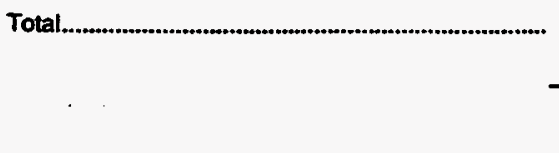 } & 0.79 & $20,025,463$ & $15,825,954$ \\
\hline & \multicolumn{3}{|c|}{1978} \\
\hline 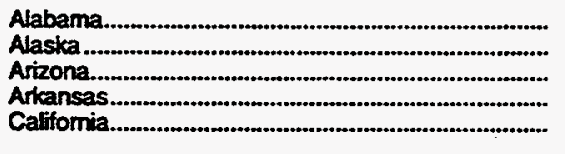 & $\begin{array}{l}1.50 \\
0.52 \\
0.37 \\
0.75 \\
1.36\end{array}$ & $\begin{array}{r}85,599 \\
203,088 \\
286 \\
106,792 \\
311,084\end{array}$ & $\begin{array}{r}128,399 \\
105,809 \\
106 \\
80,094 \\
422,141\end{array}$ \\
\hline 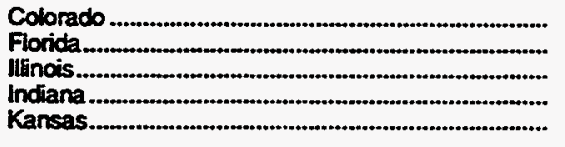 & $\begin{array}{l}0.84 \\
1.39 \\
1.29 \\
0.71 \\
0.57\end{array}$ & $\begin{array}{r}183,693 \\
51,595 \\
1,159 \\
163 \\
854,484\end{array}$ & $\begin{array}{r}154,302 \\
71,717 \\
1,495 \\
116 \\
487,056\end{array}$ \\
\hline 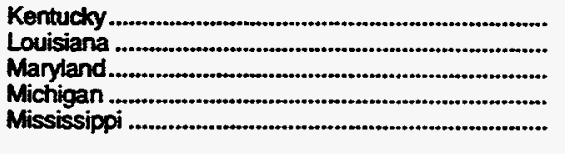 & $\begin{array}{l}0.58 \\
0.84 \\
0.61 \\
1.20 \\
1.15\end{array}$ & $\begin{array}{r}70,044 \\
7,476,497 \\
88 \\
148,047 \\
106,579\end{array}$ & $\begin{array}{r}40,626 \\
6,252,572 \\
54 \\
177,212 \\
122,140\end{array}$ \\
\hline 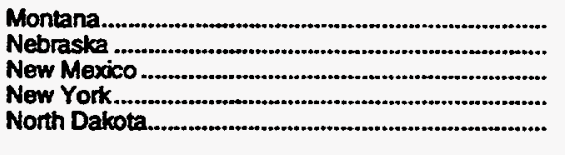 & $\begin{array}{l}0.85 \\
0.68 \\
0.99 \\
1.19 \\
0.46\end{array}$ & $\begin{array}{r}46,522 \\
2,882 \\
1,174,198 \\
13,900 \\
30,499\end{array}$ & $\begin{array}{r}39,404 \\
1,960 \\
1,160,108 \\
16,541 \\
14,091\end{array}$ \\
\hline 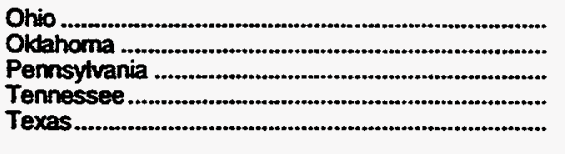 & $\begin{array}{l}1.57 \\
0.90 \\
0.86 \\
1.64 \\
0.99\end{array}$ & $\begin{array}{r}114,098 \\
1,773,582 \\
97,763 \\
468 \\
6,548,184\end{array}$ & $\begin{array}{r}179,134 \\
1,599,771 \\
84,076 \\
768 \\
6,515,443\end{array}$ \\
\hline 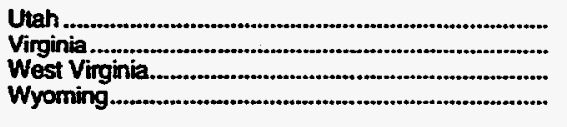 & $\begin{array}{l}0.64 \\
1.31 \\
0.66 \\
0.79\end{array}$ & $\begin{array}{r}\mathbf{5 8 , 4 1 6} \\
\mathbf{8 , 4 9 2} \\
148,564 \\
\mathbf{3 5 7}, 267\end{array}$ & $\begin{array}{r}37,561 \\
11,150 \\
97,755 \\
283,313\end{array}$ \\
\hline \multirow[t]{2}{*}{ Total } & 0.91 & $19,974,033$ & $18,084,914$ \\
\hline & \multicolumn{3}{|c|}{1979} \\
\hline 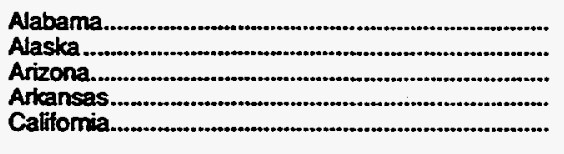 & $\begin{array}{l}2.04 \\
0.52 \\
0.41 \\
0.96 \\
1.70\end{array}$ & $\begin{array}{r}85,815 \\
220,754 \\
247 \\
109,452 \\
248,206\end{array}$ & $\begin{array}{r}174,977 \\
114,351 \\
102 \\
104,964 \\
423,191\end{array}$ \\
\hline 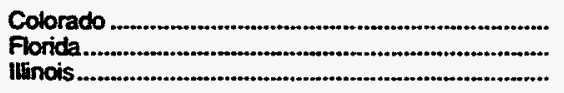 & $\begin{array}{l}1.41 \\
1.57 \\
1.86\end{array}$ & $\begin{array}{r}191,239 \\
50,190 \\
1,585\end{array}$ & $\begin{array}{r}269,647 \\
78,899 \\
2,949\end{array}$ \\
\hline
\end{tabular}

See foctnotes at end of table. 
Table 7. Wellhead Value and Marketed Production of Natural Gas by State, 1967-1994 (Continued)

\begin{tabular}{|c|c|c|c|}
\hline State & $\begin{array}{l}\text { Awerege Wellinad } \\
\text { Price } \\
\text { (dollare par } \\
\text { thousend eubic feot) }\end{array}$ & $\begin{array}{l}\text { Marketed } \\
\text { Production } \\
\text { (miltion } \\
\text { cubic feot) }\end{array}$ & $\begin{array}{l}\text { Impurted Wolthoed } \\
\text { Value of } \\
\text { Marketed Production } \\
\text { (thousand dotlars) }\end{array}$ \\
\hline & \multicolumn{3}{|c|}{1979} \\
\hline Indiana & $\begin{array}{l}1.05 \\
0.76\end{array}$ & 797,762 & $\begin{array}{r}369 \\
603,108\end{array}$ \\
\hline 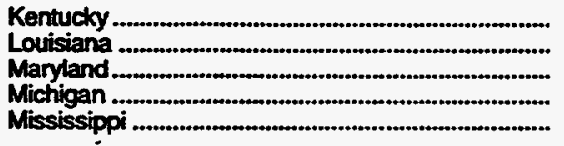 & $\begin{array}{l}0.95 \\
1.11 \\
1.04 \\
1.74 \\
1.60\end{array}$ & $\begin{array}{r}59,520 \\
7,266,217 \\
28 \\
159,731 \\
144,077\end{array}$ & $\begin{array}{r}56,365 \\
8,100,795 \\
29 \\
277,932 \\
230,523\end{array}$ \\
\hline 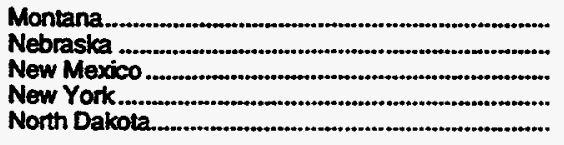 & $\begin{array}{l}1.21 \\
0.85 \\
1.37 \\
1.27 \\
1.28\end{array}$ & $\begin{array}{r}53,888 \\
3,208 \\
1,181,363 \\
15,500 \\
18,468\end{array}$ & $\begin{array}{r}65,258 \\
2,727 \\
1,613,742 \\
19,623 \\
23,639\end{array}$ \\
\hline 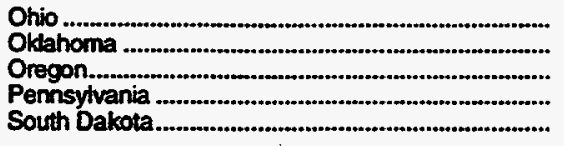 & $\begin{array}{l}1.81 \\
1.12 \\
2.00 \\
1.33 \\
2.11\end{array}$ & $\begin{array}{r}123,431 \\
1,835,366 \\
2 \\
96,313 \\
914\end{array}$ & $\begin{array}{r}222,824 \\
2,062,951 \\
4 \\
127,711 \\
1,926\end{array}$ \\
\hline 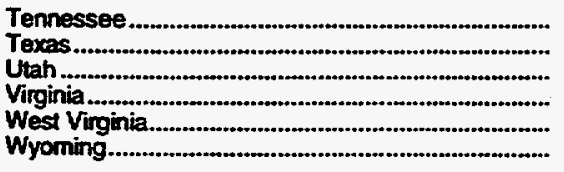 & $\begin{array}{l}1.70 \\
1.23 \\
0.72 \\
1.08 \\
1.05 \\
1.13\end{array}$ & $\begin{array}{r}941 \\
7,174,623 \\
58,605 \\
8,544 \\
150,505 \\
414,416\end{array}$ & $\begin{array}{r}1,600 \\
8,850,782 \\
41,961 \\
14,365 \\
158,030 \\
468,290\end{array}$ \\
\hline \multirow[t]{2}{*}{ 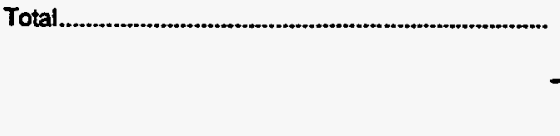 } & 1.18 & $20,471.260$ & $24,113,634$ \\
\hline & \multicolumn{3}{|c|}{1980} \\
\hline 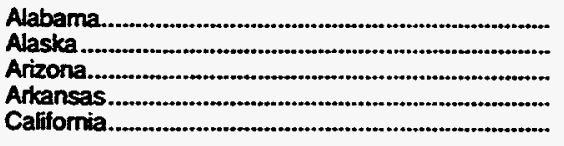 & $\begin{array}{r}3.19 \\
0.73 \\
N A \\
0.70 \\
2.17\end{array}$ & $\begin{array}{r}65,294 \\
230.588 \\
214 \\
111,808 \\
309,434\end{array}$ & $\begin{array}{r}208,000 \\
168,790 \\
N A \\
77,818 \\
671,472\end{array}$ \\
\hline 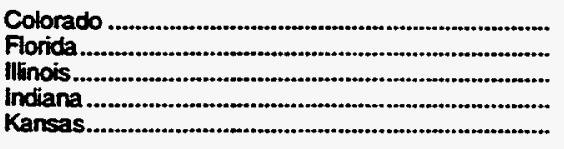 & $\begin{array}{l}1.47 \\
1.73 \\
1.90 \\
1.35 \\
0.77\end{array}$ & $\begin{array}{r}188,001 \\
40,638 \\
1,574 \\
463 \\
735,035\end{array}$ & $\begin{array}{r}276,361 \\
70,304 \\
2,991 \\
625 \\
567,447\end{array}$ \\
\hline 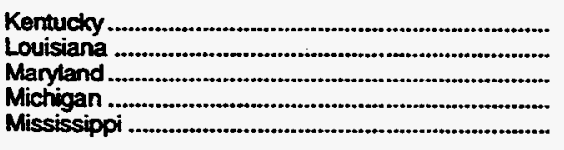 & $\begin{array}{r}0.89 \\
-1.61 \\
0.46 \\
2.35 \\
2.32\end{array}$ & $\begin{array}{r}57,180 \\
6,939,924 \\
68 \\
158,302 \\
175,061\end{array}$ & $\begin{array}{r}51,062 \\
11,149,233 \\
31 \\
372,801 \\
405,616\end{array}$ \\
\hline 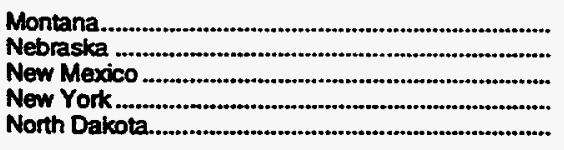 & $\begin{array}{l}1.45 \\
0.83 \\
1.76 \\
1.95 \\
1.19\end{array}$ & $\begin{array}{r}51,867 \\
2,550 \\
1,148,086 \\
15,643 \\
42,346\end{array}$ & $\begin{array}{r}75,415 \\
2,114 \\
2,020,631 \\
30,488 \\
50,307\end{array}$ \\
\hline 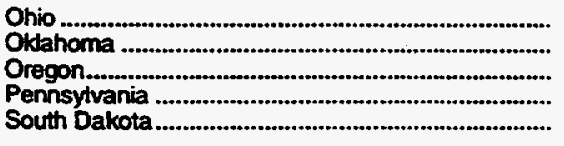 & $\begin{array}{l}1.98 \\
1.51 \\
2.40 \\
2.13 \\
\text { NA }\end{array}$ & $\begin{array}{r}138,856 \\
1,891,824 \\
5 \\
97,439 \\
1,193\end{array}$ & $\begin{array}{r}274,518 \\
2,851,667 \\
12 \\
207,253 \\
\mathrm{NA}\end{array}$ \\
\hline 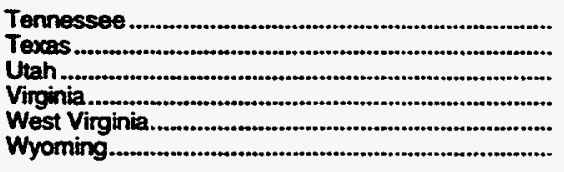 & $\begin{array}{l}1.76 \\
1.56 \\
1.12 \\
2.85 \\
3.00 \\
1.92\end{array}$ & $\begin{array}{r}1,241 \\
7,115,889 \\
87,766 \\
7,812 \\
156,551 \\
407,072\end{array}$ & $\begin{array}{r}2,184 \\
11,135,034 \\
98,035 \\
22,264 \\
469,653 \\
781,578\end{array}$ \\
\hline 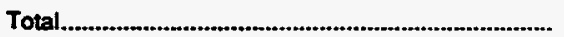 & 1.59 & $20,179,724$ & $32,043,704$ \\
\hline
\end{tabular}

See footnoles at end of table. 
Table 7. Wellhead Value and Marketed Production of Natural Gas by State, 1967-1994 (Continued)

\begin{tabular}{|c|c|c|c|c|}
\hline Stute & $\begin{array}{l}\text { Average Wollmead } \\
\text { Pries } \\
\text { (doltars por } \\
\text { thousend etbic fect) }\end{array}$ & $\begin{array}{l}\text { Marketed } \\
\text { Production } \\
\text { (million } \\
\text { cubic fient) }\end{array}$ & $\begin{array}{l}\text { Imputted Wollhead } \\
\text { Value of } \\
\text { Marketad Production } \\
\text { (thousand dollers) }\end{array}$ & \\
\hline & & 1981 & & \\
\hline 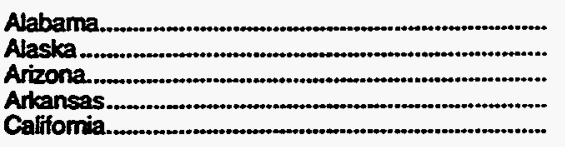 & $\begin{array}{r}4.77 \\
0.62 \\
N A \\
b_{1} .81 \\
2.57\end{array}$ & $\begin{array}{r}79,244 \\
242,564 \\
187 \\
92,986 \\
380,359\end{array}$ & $\begin{array}{r}378,000 \\
150,390 \\
\text { NA } \\
168,305 \\
977,523\end{array}$ & \\
\hline 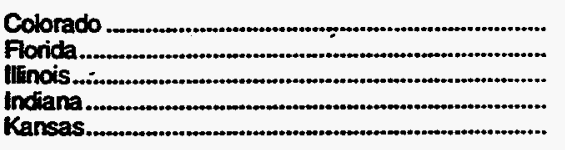 & $\begin{array}{r}1.97 \\
2.71 \\
2.47 \\
2.08 \\
0.92\end{array}$ & $\begin{array}{r}195,706 \\
32,470 \\
1,295 \\
330 \\
640,114\end{array}$ & $\begin{array}{r}385,541 \\
87,994 \\
3,200 \\
688 \\
588,905\end{array}$ & \\
\hline 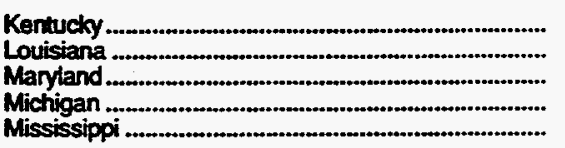 & $\begin{array}{l}1.01 \\
2.07 \\
0.48 \\
2.86 \\
3.21\end{array}$ & $\begin{array}{r}61,312 \\
6,780,184 \\
56 \\
152,593 \\
181,238\end{array}$ & $\begin{array}{r}61,837 \\
14,034,981 \\
27 \\
436,937 \\
581,774\end{array}$ & . \\
\hline 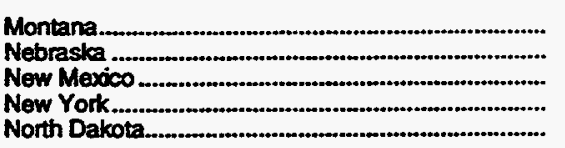 & $\begin{array}{l}1.91 \\
1.45 \\
2.13 \\
2.67 \\
1.94\end{array}$ & $\begin{array}{r}56,565 \\
2,519 \\
1,132,066 \\
16,074 \\
42,573\end{array}$ & $\begin{array}{r}108,039 \\
3,654 \\
2,411,301 \\
42,869 \\
82,677\end{array}$ & \\
\hline 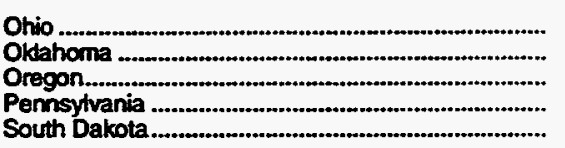 & $\begin{array}{r}2.17 \\
1.88 \\
2.60 \\
62.33 \\
2.75\end{array}$ & $\begin{array}{r}141,134 \\
2,019,199 \\
5 \\
122,454 \\
1,155\end{array}$ & $\begin{array}{r}306,261 \\
3,805,410 \\
13 \\
285,318 \\
3,182\end{array}$ & \\
\hline 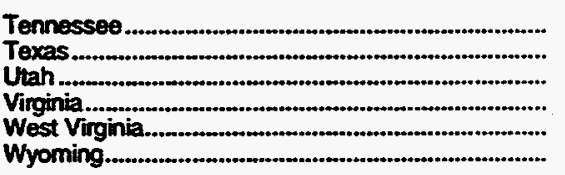 & $\begin{array}{r}2.55 \\
1.87 \\
1.10 \\
2.15 \\
3.00 \\
2.77\end{array}$ & $\begin{array}{r}1,719 \\
6,910,021 \\
91,191 \\
8,903 \\
161,251 \\
408,356\end{array}$ & $\begin{array}{r}4,383 \\
12,907,735 \\
100,310 \\
19,100 \\
483,753 \\
1,131,146\end{array}$ & \\
\hline \multirow[t]{2}{*}{ Total. } & 1.98 & $19,955,823$ & $39,551,253$ & \\
\hline & \multicolumn{4}{|c|}{1982} \\
\hline 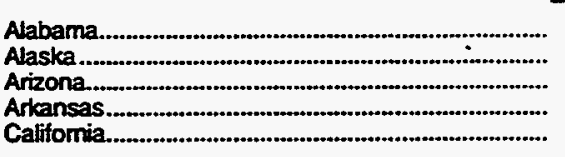 & $\begin{array}{r}3.44 \\
0.63 \\
2.59 \\
b 2.13 \\
3.09\end{array}$ & $\begin{array}{r}75,003 \\
264,364 \\
99 \\
124,611 \\
383,977\end{array}$ & $\begin{array}{r}258,298 \\
166,549 \\
256 \\
265,030 \\
1,184,904\end{array}$ & \\
\hline 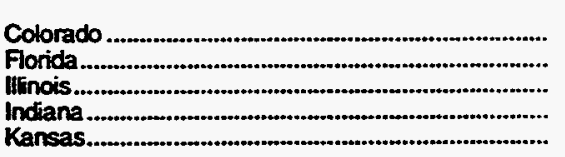 & $\begin{array}{r}3.17 \\
2.46 \\
2.62 \\
1.55 \\
-1.51\end{array}$ & $\begin{array}{r}209,892 \\
22,515 \\
1,162 \\
233 \\
440,951\end{array}$ & $\begin{array}{r}664,323 \\
55,420 \\
3,043 \\
360 \\
664,282\end{array}$ & \\
\hline 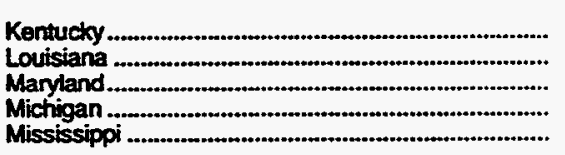 & $\begin{array}{l}1.52 \\
2.60 \\
0.78 \\
3.19 \\
3.91\end{array}$ & $\begin{array}{r}51,924 \\
6.171,627 \\
36 \\
153,051 \\
167,231\end{array}$ & $\begin{array}{r}78,830 \\
16,033,702 \\
28 \\
488,233 \\
653,873\end{array}$ & \\
\hline 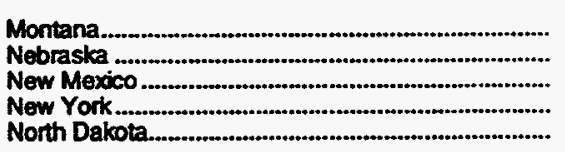 & $\begin{array}{l}2.15 \\
1.99 \\
2.47 \\
3.75 \\
2.30\end{array}$ & $\begin{array}{r}56,517 \\
2,280 \\
991,178 \\
15,877 \\
53,818\end{array}$ & $\begin{array}{r}121,251 \\
4.536 \\
2,443,891 \\
59,500 \\
123,781\end{array}$ & \\
\hline 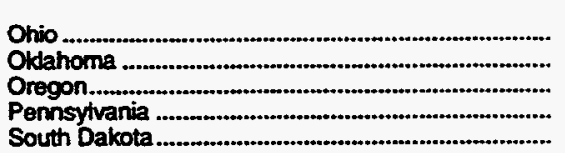 & $\begin{array}{l}2.71 \\
2.74 \\
3.33 \\
2.80 \\
3.08\end{array}$ & $\begin{array}{r}138,391 \\
1,985,384 \\
3 \\
121,111 \\
2,331\end{array}$ & $\begin{array}{r}375,588 \\
5,439,751 \\
10 \\
339,110 \\
7.181\end{array}$ & \\
\hline
\end{tabular}

See tootnotes at end of table. 
Table 7. Wellhead Value and Marketed Production of Natural Gas by State, 1967-1994 (Continued)

\begin{tabular}{|c|c|c|c|}
\hline Stane & $\begin{array}{l}\text { Awernge Wethed } \\
\text { Price } \\
\text { (dollars par } \\
\text { thousend cubie feed) }\end{array}$ & $\begin{array}{l}\text { Nartrotad } \\
\text { Production } \\
\text { (million } \\
\text { cubic finet) }\end{array}$ & $\begin{array}{l}\text { Imputed Wollhead } \\
\text { Velue of } \\
\text { Mierkind Production } \\
\text { (thousend dollers) }\end{array}$ \\
\hline & \multicolumn{3}{|c|}{1982} \\
\hline 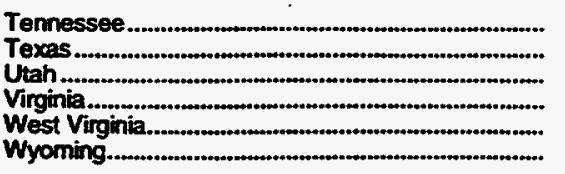 & $\begin{array}{r}3.00 \\
2.17 \\
3.06 \\
3.69 \\
3.20 \\
3.22\end{array}$ & $\begin{array}{r}2,976 \\
6,468,817 \\
94,255 \\
6,880 \\
150,850 \\
424,657\end{array}$ & $\begin{array}{r}8,928 \\
14,047,213 \\
288,761 \\
25,363 \\
482,720 \\
1,368,858\end{array}$ \\
\hline \multirow[t]{2}{*}{ 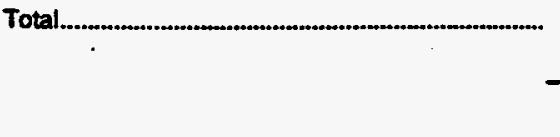 } & 2.46 & $18,582,005$ & $45,653,572$ \\
\hline & \multicolumn{3}{|c|}{1883} \\
\hline 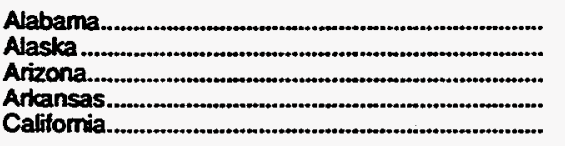 & $\begin{array}{r}b_{4.28} \\
0.73 \\
3.08 \\
6.29 \\
3.57\end{array}$ & $\begin{array}{r}90,801 \\
276,691 \\
132 \\
127,561 \\
415,324\end{array}$ & $\begin{array}{r}388,938 \\
202,057 \\
406 \\
292,482 \\
1,481,615\end{array}$ \\
\hline 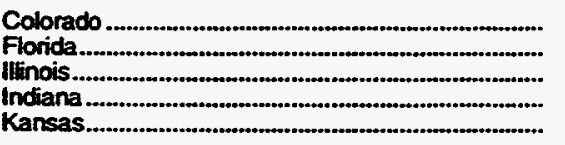 & $\begin{array}{r}3.38 \\
2.33 \\
2.84 \\
2.09 \\
1.57\end{array}$ & $\begin{array}{r}163,545 \\
21,056 \\
1,030 \\
135 \\
447,207\end{array}$ & $\begin{array}{r}552,174 \\
49,104 \\
2,926 \\
282 \\
701,444\end{array}$ \\
\hline 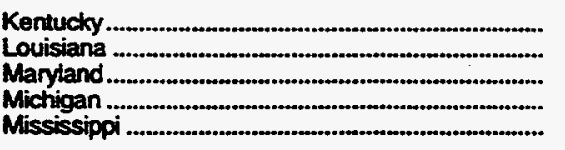 & $\begin{array}{l}1.51 \\
2.67 \\
0.55 \\
3.58 \\
3.78\end{array}$ & $\begin{array}{r}46,720 \\
5,332,113 \\
31 \\
138,910 \\
151,204\end{array}$ & $\begin{array}{r}70,548 \\
14,218,602 \\
17 \\
497,298 \\
571,564\end{array}$ \\
\hline 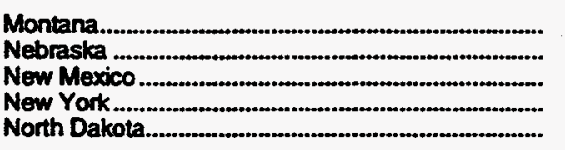 & $\begin{array}{l}2.41 \\
2.93 \\
2.68 \\
3.85 \\
2.27\end{array}$ & $\begin{array}{r}51,967 \\
2,091 \\
895,279 \\
17,836 \\
69,319\end{array}$ & $\begin{array}{r}125,241 \\
6,128 \\
2,402,769 \\
68,678 \\
157,355\end{array}$ \\
\hline 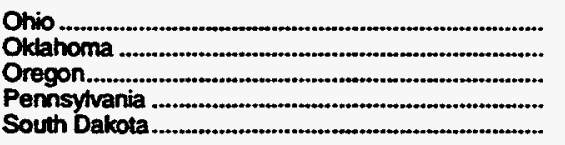 & $\begin{array}{l}3.24 \\
2.83 \\
3.33 \\
3.00 \\
\mathbf{3 . 3 7}\end{array}$ & $\begin{array}{r}151,300 \\
1,779,541 \\
3 \\
118,372 \\
1,846\end{array}$ & $\begin{array}{r}489,908 \\
5,035,281 \\
10 \\
355,116 \\
6,218\end{array}$ \\
\hline 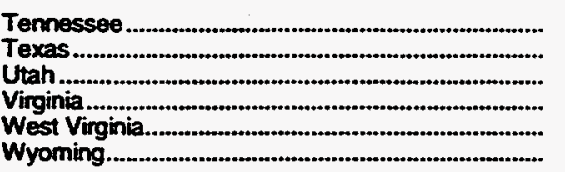 & $\begin{array}{r}2.50 \\
2.36 \\
3.40 \\
3.30 \\
3.10 \\
3.18\end{array}$ & $\begin{array}{r}3,950 \\
5,938,561 \\
63,158 \\
4,346 \\
130,078 \\
443,988\end{array}$ & $\begin{array}{r}9,875 \\
14,043,367 \\
215,010 \\
14,343 \\
403,242 \\
1,411,978\end{array}$ \\
\hline \multirow[t]{2}{*}{ Total } & 2.59 & $16,884,093$ & $43,773,976$ \\
\hline & \multicolumn{3}{|c|}{1984} \\
\hline 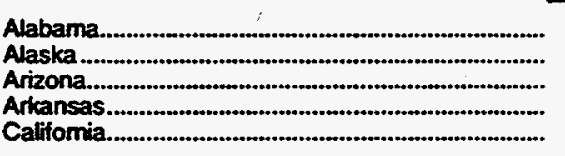 & $\begin{array}{l}3.73 \\
0.73 \\
2.90 \\
2.54 \\
3.80\end{array}$ & $\begin{array}{r}101,821 \\
289.129 \\
45 \\
135,161 \\
476,333\end{array}$ & $\begin{array}{r}380,281 \\
210,734 \\
131 \\
343,823 \\
1,809,501\end{array}$ \\
\hline 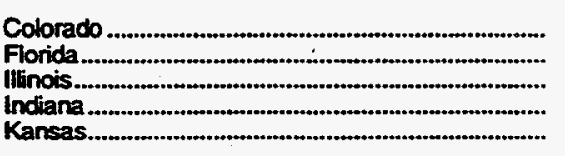 & $\begin{array}{l}3.43 \\
2.57 \\
2.78 \\
3.38 \\
1.49\end{array}$ & $\begin{array}{r}173,257 \\
12,585 \\
1,530 \\
394 \\
480,211\end{array}$ & $\begin{array}{r}595,006 \\
32,373 \\
4,254 \\
1,332 \\
714,607\end{array}$ \\
\hline 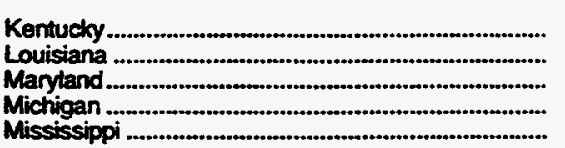 & $\begin{array}{l}1.70 \\
2.73 \\
0.55 \\
3.76 \\
3.47\end{array}$ & $\begin{array}{r}61,518 \\
5,825,055 \\
60 \\
144,537 \\
157,911\end{array}$ & $\begin{array}{r}104,570 \\
15,915,681 \\
35 \\
543,316 \\
547,582\end{array}$ \\
\hline
\end{tabular}

See footnoles at end of table. 
Table 7. Wellhead Value and Marketed Production of Natural Gas by State, 1967-1994 (Continued)

\begin{tabular}{|c|c|c|c|}
\hline State & $\begin{array}{l}\text { Averege Wolthead } \\
\text { Price } \\
\text { (dollars per } \\
\text { thousend aubic foot) }\end{array}$ & $\begin{array}{l}\text { Marketed } \\
\text { Production } \\
\text { (milion } \\
\text { cesbic feot) }\end{array}$ & $\begin{array}{l}\text { Imputud Wolthoad } \\
\text { Velue of } \\
\text { Marketed Production } \\
\text { (thousend dollers) }\end{array}$ \\
\hline & \multicolumn{3}{|c|}{1984} \\
\hline 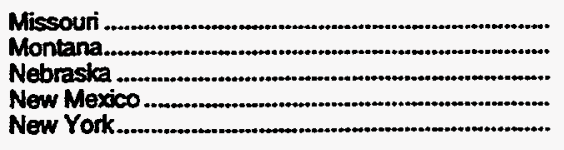 & $\begin{array}{l}3.75 \\
2.46 \\
2.24 \\
2.71 \\
4.00\end{array}$ & $\begin{array}{r}51,474 \\
2,300 \\
957,366 \\
25,200\end{array}$ & $\begin{array}{r}15 \\
126,626 \\
5,153 \\
2,599,121 \\
100,800\end{array}$ \\
\hline $\begin{array}{l}\text { North Dakota. } \\
\text { Ohio } \\
\text { Oklahoraa } \\
\text { Oregon } \\
\text { Pemsylvania }\end{array}$ & $\begin{array}{l}2.26 \\
3.19 \\
2.72 \\
2.78 \\
3.25\end{array}$ & $\begin{array}{r}70,496 \\
186,480 \\
2,046,339 \\
2,790 \\
166,342\end{array}$ & $\begin{array}{r}159,607 \\
594,183 \\
5,561,828 \\
7,760 \\
540,612\end{array}$ \\
\hline 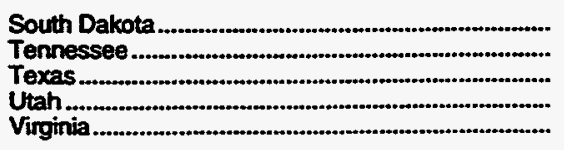 & $\begin{array}{r}3.67 \\
3.50 \\
2.45 \\
4.08 \\
3.00\end{array}$ & $\begin{array}{r}1,947 \\
5,022 \\
6,185,021 \\
74,698 \\
8,901\end{array}$ & $\begin{array}{r}7,146 \\
17,577 \\
15,125,333 \\
304,907 \\
26,704\end{array}$ \\
\hline 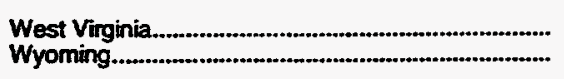 & $\begin{array}{l}3.45 \\
3.32\end{array}$ & $\begin{array}{r}143,730 \\
516,683\end{array}$ & $\begin{array}{r}495,869 \\
1,713,828\end{array}$ \\
\hline 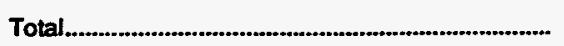 & 2.66 & $18,304,339$ & $48,590,295$ \\
\hline
\end{tabular}

\begin{tabular}{|c|c|c|c|}
\hline & & & \\
\hline & & 1985 & \\
\hline 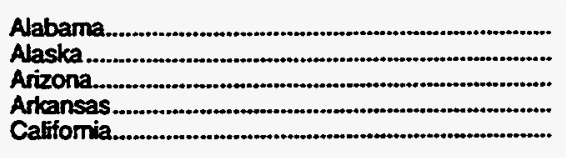 & $\begin{array}{r}3.71 \\
0.74 \\
\text { NA } \\
2.55 \\
3.36\end{array}$ & $\begin{array}{r}107,342 \\
321,346 \\
85 \\
155,099 \\
491,283\end{array}$ & $\begin{array}{r}398,307 \\
236,355 \\
\mathrm{NA} \\
393,321 \\
1,653,019\end{array}$ \\
\hline $\begin{array}{l}\text { Colorado } \\
\text { Florida } \\
\text { Illinois. } \\
\text { Indiana } \\
\text { Kansas }\end{array}$ & $\begin{array}{l}2.90 \\
2.43 \\
2.77 \\
2.51 \\
1.27\end{array}$ & $\begin{array}{r}178,233 \\
10,545 \\
1,324 \\
367 \\
528,032\end{array}$ & $\begin{array}{r}516.672 \\
25.658 \\
3.657 \\
920 \\
670.803\end{array}$ \\
\hline $\begin{array}{l}\text { Kentucky } \\
\text { Louisiana } \\
\text { Maryland } \\
\text { Michigan } \\
\text { Mississippi }\end{array}$ & $\begin{array}{l}2.39 \\
2.66 \\
0.59 \\
3.60 \\
3.17\end{array}$ & $\begin{array}{r}73,126 \\
5,013,702 \\
39 \\
131,855 \\
144,172\end{array}$ & $\begin{array}{r}174,448 \\
13,355,289 \\
23 \\
474,678 \\
456,333\end{array}$ \\
\hline 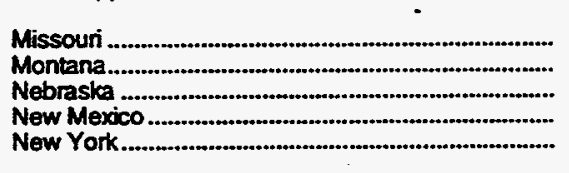 & $\begin{array}{l}3.50 \\
2.39 \\
3.01 \\
2.62 \\
3.37\end{array}$ & $\begin{array}{r}4 \\
52,494 \\
1,944 \\
905,272 \\
31,561\end{array}$ & $\begin{array}{r}14 \\
125,461 \\
5,853 \\
2,369,980 \\
106,361\end{array}$ \\
\hline $\begin{array}{l}\text { North Dakota } \\
\text { Ohio } \\
\text { Oklahoma } \\
\text { Oregon } \\
\text { Pennsyivania }\end{array}$ & $\begin{array}{l}1.90 \\
3.08 \\
2.47 \\
2.40 \\
3.16\end{array}$ & $\begin{array}{r}72,633 \\
182,245 \\
1,993,405 \\
4,080 \\
150,234\end{array}$ & $\begin{array}{r}137,697 \\
560,442 \\
4,929,990 \\
9,800 \\
474,204\end{array}$ \\
\hline $\begin{array}{l}\text { South Dakota. } \\
\text { Tennessee } \\
\text { Texas } \\
\text { Utah } \\
\text { Virginia }\end{array}$ & $\begin{array}{r}2.51 \\
2.48 \\
2.33 \\
3.52 \\
3.02\end{array}$ & $\begin{array}{r}2,558 \\
4,686 \\
6,052,663 \\
83,405 \\
15,041\end{array}$ & $\begin{array}{r}6.430 \\
11,621 \\
14.096,949 \\
293.185 \\
45,423\end{array}$ \\
\hline 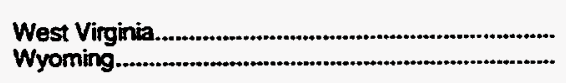 & $\begin{array}{l}3.85 \\
3.01\end{array}$ & $\begin{array}{l}144,883 \\
416,565\end{array}$ & $\begin{array}{r}557,800 \\
1,252,096\end{array}$ \\
\hline Total & 2.51 & $17,270,227$ & $43,342,799$ \\
\hline
\end{tabular}

See tootnoles at end of table. 
Table 7. Wellhead Value and Marketed Production of Natural Gas by State, 1967-1994 (Continued)

\begin{tabular}{|c|c|c|c|c|}
\hline Stato & $\begin{array}{l}\text { Averege Wellhed } \\
\text { Price } \\
\text { (dollars per } \\
\text { thouend eubic teet) }\end{array}$ & $\begin{array}{l}\text { Marketed } \\
\text { Prodiction } \\
\text { (milion } \\
\text { cubic foen) }\end{array}$ & $\begin{array}{l}\text { Imputed Wellinead } \\
\text { Value of } \\
\text { Marketed Production } \\
\text { (thousend dollars) }\end{array}$ & \\
\hline & \multicolumn{4}{|c|}{1986} \\
\hline 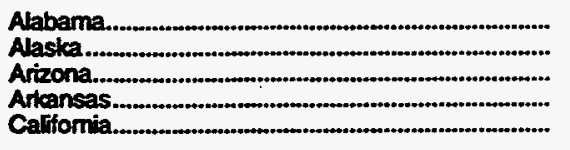 & $\begin{array}{r}2.89 \\
0.50 \\
N A \\
b_{2.51} \\
b_{2.89}\end{array}$ & $\begin{array}{r}107,184 \\
304,841 \\
63 \\
131,075 \\
462,218\end{array}$ & $\begin{array}{r}309,981 \\
152,735 \\
\mathrm{NA} \\
329,540 \\
1,337,887\end{array}$ & \\
\hline 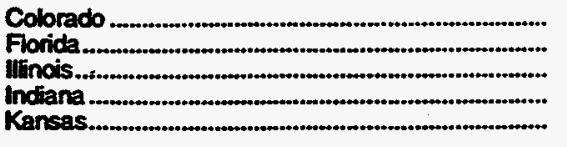 & $\begin{array}{r}2.05 \\
1.20 \\
2.57 \\
1.23 \\
1.21\end{array}$ & $\begin{array}{r}163,684 \\
8,853 \\
1,887 \\
365 \\
478,963\end{array}$ & $\begin{array}{r}335,551 \\
10,621 \\
4,851 \\
450 \\
581,417\end{array}$ & \\
\hline 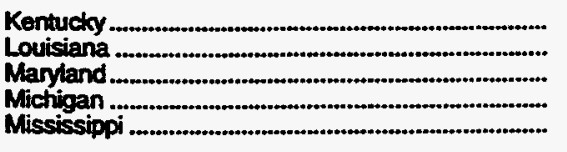 & $\begin{array}{l}1.88 \\
2.21 \\
0.65 \\
3.60 \\
2.13\end{array}$ & $\begin{array}{r}80,195 \\
4,895,394 \\
20 \\
127,287 \\
140,833\end{array}$ & $\begin{array}{r}151,041 \\
10,827,045 \\
13 \\
458,233 \\
300,182\end{array}$ & $-a$ \\
\hline 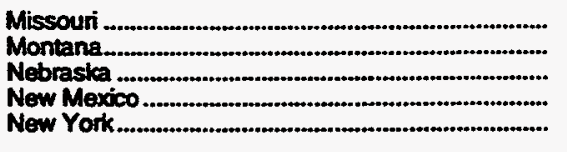 & $\begin{array}{l}3.75 \\
2.05 \\
2.82 \\
1.87 \\
3.39\end{array}$ & $\begin{array}{r}4 \\
46,592 \\
1,403 \\
702,614 \\
29,964\end{array}$ & $\begin{array}{r}15 \\
95,513 \\
3,958 \\
1,314,084 \\
101,654\end{array}$ & \\
\hline 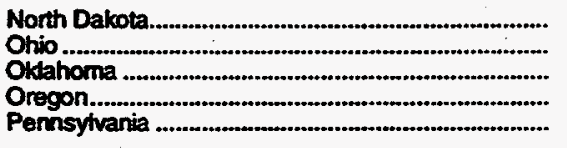 & $\begin{array}{l}1.35 \\
2.84 \\
1.71 \\
2.00 \\
2.50\end{array}$ & $\begin{array}{r}55,098 \\
182,072 \\
1,971,988 \\
4,600 \\
159,889\end{array}$ & $\begin{array}{r}74,473 \\
517,178 \\
3,367,458 \\
9,200 \\
399,723\end{array}$ & \\
\hline 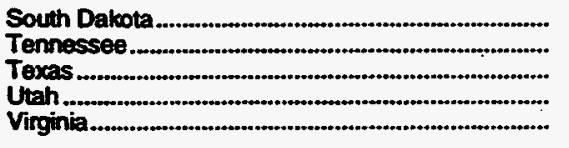 & $\begin{array}{r}2.46 \\
1.78 \\
1.65 \\
2.90 \\
2.45\end{array}$ & $\begin{array}{r}2,231 \\
3,464 \\
6,151,775 \\
90,013 \\
15,427\end{array}$ & $\begin{array}{r}5,495 \\
6.166 \\
10,179,705 \\
260,691 \\
37,797\end{array}$ & \\
\hline 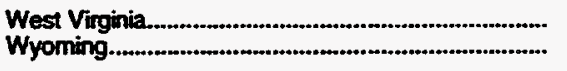 & $\begin{array}{l}3.90 \\
2.52\end{array}$ & $\begin{array}{l}135,431 \\
403,266\end{array}$ & $\begin{array}{r}528,181 \\
1,016,229\end{array}$ & \\
\hline \multirow[t]{2}{*}{ 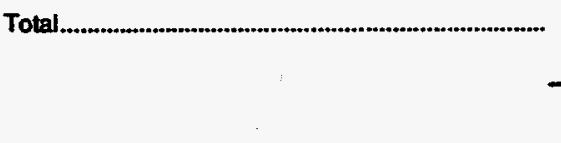 } & 1.94 & $16,858,675$ & $32,717,067$ & \\
\hline & \multicolumn{4}{|c|}{1987} \\
\hline 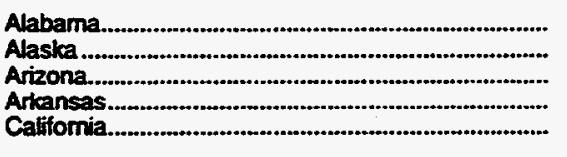 & $\begin{array}{r}2.97 \\
0.94 \\
1.4 A \\
b_{2} .29 \\
2.37\end{array}$ & $\begin{array}{r}117,241 \\
359,837 \\
60 \\
141,151 \\
424,621\end{array}$ & $\begin{array}{r}347,974 \\
339,999 \\
\mathrm{NA} \\
323,383 \\
1,005,600\end{array}$ & \\
\hline 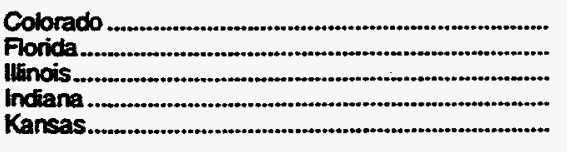 & $\begin{array}{r}1.76 \\
1.68 \\
2.24 \\
1.71 \\
1.15\end{array}$ & $\begin{array}{r}164,557 \\
8,281 \\
1,371 \\
217 \\
472,752\end{array}$ & $\begin{array}{r}289,620 \\
13,920 \\
3,07 t \\
37 t \\
543,965\end{array}$ & \\
\hline 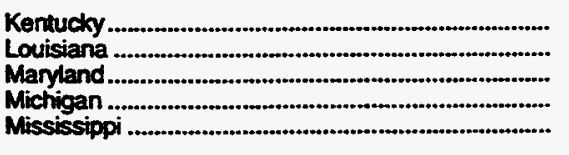 & $\begin{array}{l}1.82 \\
1.78 \\
0.55 \\
3.24 \\
1.94\end{array}$ & $\begin{array}{r}70,125 \\
5,122,509 \\
44 \\
146,996 \\
139,727\end{array}$ & $\begin{array}{r}127,928 \\
9,120,013 \\
24 \\
476,267 \\
270,945\end{array}$ & \\
\hline 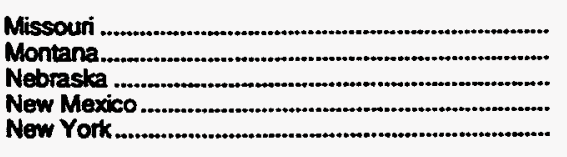 & $\begin{array}{l}3.75 \\
1.80 \\
2.42 \\
1.66 \\
2.00\end{array}$ & $\begin{array}{r}4 \\
46,456 \\
1,261 \\
823,773 \\
25,676\end{array}$ & $\begin{array}{r}15 \\
83,621 \\
3,052 \\
1,367,620 \\
51,352\end{array}$ & \\
\hline 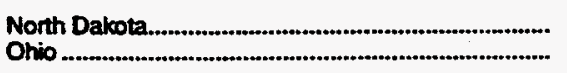 & $\begin{array}{l}1.30 \\
2.58\end{array}$ & $\begin{array}{r}62,258 \\
166,593\end{array}$ & $\begin{array}{r}80,915 \\
429,917\end{array}$ & \\
\hline
\end{tabular}

See footnotes at end of table. 
Table 7. Wellhead Value and Marketed Production of Natural Gas by State, 1967-1994 (Continued)

\begin{tabular}{|c|c|c|c|}
\hline$\therefore \quad$ Stito & $\begin{array}{l}\text { Average Wolthoed } \\
\text { Price } \\
\text { (dollars por } \\
\text { thousend cubic faet) }\end{array}$ & $\begin{array}{l}\text { Marketed } \\
\text { Production } \\
\text { (mullion } \\
\text { cubic feot) }\end{array}$ & $\begin{array}{l}\text { Imputiod Wellhoud } \\
\text { Value of } \\
\text { Warketod Production } \\
\text { (thousand dollars) }\end{array}$ \\
\hline & \multicolumn{3}{|c|}{1987} \\
\hline 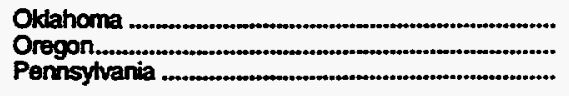 & $\begin{array}{l}1.47 \\
1.45 \\
2.25\end{array}$ & $\begin{array}{r}2,073,461 \\
3,800 \\
163,318\end{array}$ & $\begin{array}{r}3,039,247 \\
5,500 \\
367,466\end{array}$ \\
\hline $\begin{array}{l}\text { South Dakota } \\
\text { Tennessee. } \\
\text { Texas } \\
\text { Utah } \\
\text { Virginia }\end{array}$ & $\begin{array}{l}2.71 \\
1.31 \\
1.47 \\
1.88 \\
2.08\end{array}$ & $\begin{array}{r}3,431 \\
2,707 \\
6,126,315 \\
87,158 \\
19,223\end{array}$ & $\begin{array}{r}9,281 \\
3,546 \\
9,006,908 \\
163,872 \\
39,982\end{array}$ \\
\hline 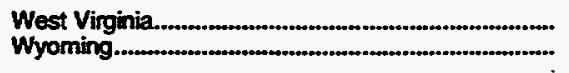 & $\begin{array}{l}3.85 \\
1.76\end{array}$ & $\begin{array}{l}160,000 \\
497,980\end{array}$ & $\begin{array}{l}616,000 \\
876,246\end{array}$ \\
\hline \multirow[t]{2}{*}{ Total } & 1.67 & $17,432,901$ & $29,007,622$ \\
\hline & \multicolumn{3}{|c|}{1988} \\
\hline 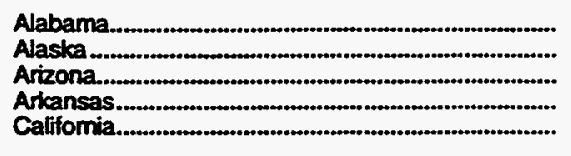 & $\begin{array}{r}2.65 \\
1.27 \\
N A \\
1.94 \\
2.39\end{array}$ & $\begin{array}{r}129,524 \\
378,638 \\
56 \\
166,573 \\
399,663\end{array}$ & $\begin{array}{r}343,583 \\
479,689 \\
\text { NA } \\
323,297 \\
957,121\end{array}$ \\
\hline 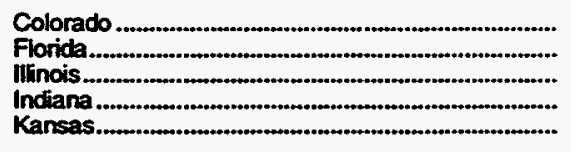 & $\begin{array}{r}1.59 \\
01.53 \\
2.19 \\
1.57 \\
1.36\end{array}$ & $\begin{array}{r}191,544 \\
7,484 \\
1,338 \\
412 \\
592,845\end{array}$ & $\begin{array}{r}304,555 \\
11,439 \\
2,927 \\
647 \\
587,899\end{array}$ \\
\hline 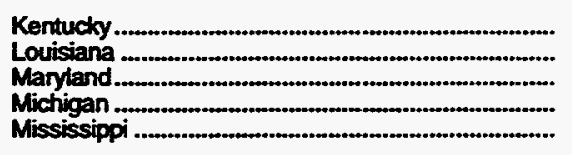 & $\begin{array}{l}2.56 \\
1.81 \\
0.93 \\
3.18 \\
1.86\end{array}$ & $\begin{array}{r}73,629 \\
5,180,267 \\
29 \\
146,145 \\
124,053\end{array}$ & $\begin{array}{r}188,798 \\
9,356,391 \\
27 \\
464,535 \\
230,817\end{array}$ \\
\hline 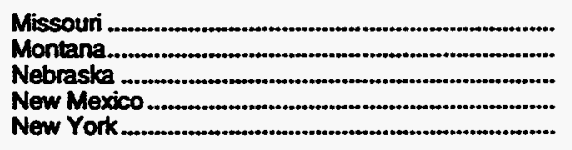 & $\begin{array}{l}3.75 \\
1.70 \\
2.66 \\
1.70 \\
2.30\end{array}$ & $\begin{array}{r}4 \\
51,654 \\
910 \\
791,819 \\
23,455\end{array}$ & $\begin{array}{r}15 \\
87,812 \\
2,422 \\
1,346,924 \\
53,945\end{array}$ \\
\hline $\begin{array}{l}\text { North Dakota. } \\
\text { Ohio } \\
\text { Okdahoma } \\
\text { Oregon } \\
\text { Pennsytrania }\end{array}$ & $\begin{array}{l}1.00 \\
2.55 \\
1.55 \\
1.60 \\
2.15\end{array}$ & $\begin{array}{r}57,747 \\
166,690 \\
2,167,050 \\
4,000 \\
167,089\end{array}$ & $\begin{array}{r}115,328 \\
425,201 \\
3,348,616 \\
6,400 \\
359,241\end{array}$ \\
\hline $\begin{array}{l}\text { South Dakota } \\
\text { Tennessee } \\
\text { Texas } \\
\text { Utah }\end{array}$ & $\begin{array}{l}1.95 \\
1.50 \\
1.51 \\
2.39 \\
2.08\end{array}$ & $\begin{array}{r}3,920 \\
2,100 \\
6,286,029 \\
101,372 \\
18,424\end{array}$ & $\begin{array}{r}7,646 \\
3,150 \\
9,471,034 \\
242,278 \\
38,323\end{array}$ \\
\hline 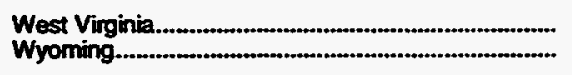 & $\begin{array}{l}3.05 \\
1.53\end{array}$ & $\begin{array}{l}174,942 \\
509,058\end{array}$ & $\frac{533,573}{777,576}$ \\
\hline \multirow[t]{2}{*}{ 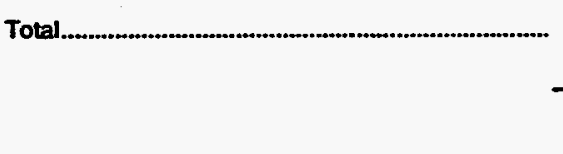 } & 1.69 & $17,918,465$ & $30,286,936$ \\
\hline & \multicolumn{3}{|c|}{1989} \\
\hline 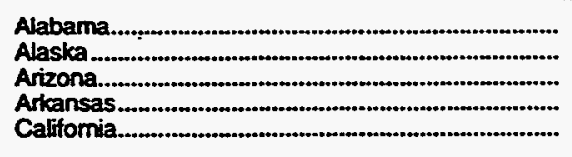 & $\begin{array}{r}2.72 \\
1.36 \\
1.80 \\
2.41 \\
6.32\end{array}$ & $\begin{array}{r}128,411 \\
393,729 \\
1,360 \\
174,158 \\
362,860\end{array}$ & $\begin{array}{r}349,478 \\
536,342 \\
2,448 \\
419,594 \\
841,414\end{array}$ \\
\hline 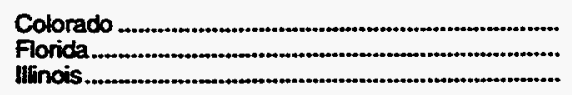 & $\begin{array}{r}1.52 \\
2.05 \\
2.15\end{array}$ & $\begin{array}{r}216.737 \\
7.534 \\
1,477\end{array}$ & $\begin{array}{r}329,440 \\
15,445 \\
3,175\end{array}$ \\
\hline
\end{tabular}

See tootnotes at end of table. 
Table 7. Wellhead Value and Marketed Production of Natural Gas by State, 1967-1994 (Continued)

\begin{tabular}{|c|c|c|c|}
\hline Strit & $\begin{array}{l}\text { Average Wollhead } \\
\text { Price } \\
\text { (doilars por } \\
\text { thousand eubic teet) }\end{array}$ & $\begin{array}{l}\text { Marketed } \\
\text { Production } \\
\text { (million } \\
\text { cubic ficot) }\end{array}$ & $\begin{array}{l}\text { Impritad Wollhead } \\
\text { Velue of } \\
\text { marteted Production } \\
\text { (thoteand dolles) }\end{array}$ \\
\hline & \multicolumn{3}{|c|}{1889} \\
\hline 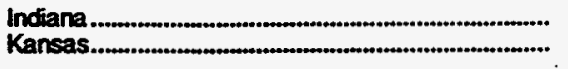 & $\begin{array}{l}1.71 \\
1.44\end{array}$ & $\begin{array}{r}416 \\
601,196\end{array}$ & 867,436 \\
\hline 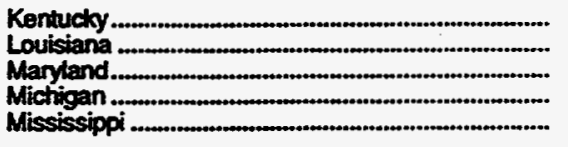 & $\begin{array}{l}2.13 \\
1.82 \\
0.85 \\
3.16 \\
1.97\end{array}$ & $\begin{array}{r}72,417 \\
5,078,125 \\
34 \\
155,988 \\
102,645\end{array}$ & $\begin{array}{r}154,224 \\
9,256,203 \\
29 \\
492,261 \\
201,834\end{array}$ \\
\hline 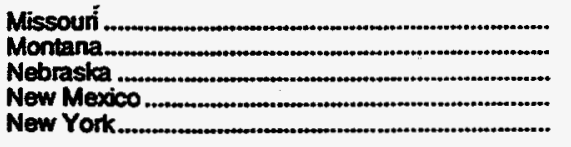 & $\begin{array}{l}3.50 \\
1.55 \\
2.23 \\
1.56 \\
2.20\end{array}$ & $\begin{array}{r}4 \\
51,307 \\
878 \\
854,615 \\
20,433\end{array}$ & $\begin{array}{r}14 \\
79,310 \\
1,958 \\
1,337,002 \\
44,953\end{array}$ \\
\hline $\begin{array}{l}\text { North Dakota. } \\
\text { Ohio } \\
\text { Oktahoma } \\
\text { Oregon } \\
\text { Pennsytvania }\end{array}$ & $\begin{array}{r}1.78 \\
2.55 \\
1.59 \\
1.40 \\
2.40\end{array}$ & $\begin{array}{r}51,174 \\
159,730 \\
2,237,037 \\
2,500 \\
191,774\end{array}$ & $\begin{array}{r}91,222 \\
407,840 \\
3,549,808 \\
3,500 \\
460,258\end{array}$ \\
\hline 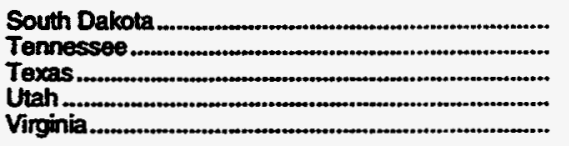 & $\begin{array}{l}1.11 \\
1.65 \\
1.53 \\
1.58 \\
2.19\end{array}$ & $\begin{array}{r}4,369 \\
1,900 \\
6,241,425 \\
120,089 \\
17,935\end{array}$ & $\begin{array}{r}4,832 \\
3,135 \\
9,570,664 \\
189,742 \\
39,278\end{array}$ \\
\hline 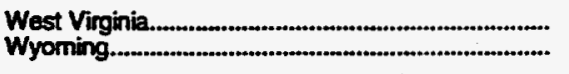 & $\begin{array}{l}3.11 \\
1.24\end{array}$ & $\begin{array}{l}177,192 \\
665,699\end{array}$ & $\begin{array}{l}551,067 \\
822,598\end{array}$ \\
\hline \multirow[t]{2}{*}{ 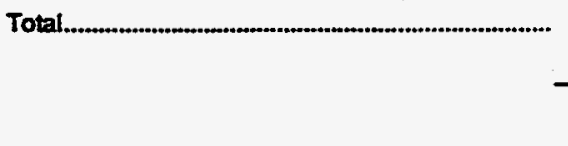 } & 1.69 & $18,095,147$ & $30,627,215$ \\
\hline & \multicolumn{3}{|c|}{1990} \\
\hline 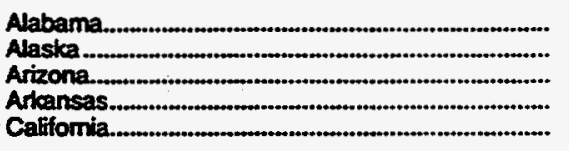 & $\begin{array}{l}2.75 \\
1.38 \\
1.20 \\
2.06 \\
2.36\end{array}$ & $\begin{array}{r}135,276 \\
402,907 \\
2,125 \\
174,956 \\
362,748\end{array}$ & $\begin{array}{r}372,522 \\
554,376 \\
2,550 \\
360,348 \\
\mathbf{8 5 7 , 4 0 6}\end{array}$ \\
\hline 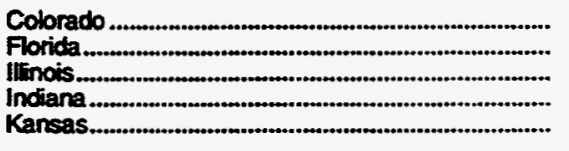 & $\begin{array}{l}1.55 \\
2.25 \\
2.11 \\
2.01 \\
1.56\end{array}$ & $\begin{array}{r}242,997 \\
6,483 \\
677 \\
399 \\
573,600\end{array}$ & $\begin{array}{r}376,645 \\
14,570 \\
1,428 \\
802 \\
893,473\end{array}$ \\
\hline 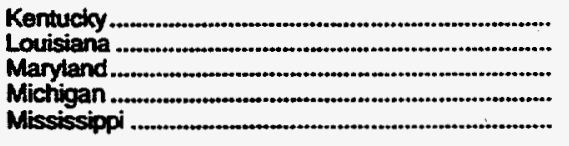 & $\begin{array}{l}2.24 \\
1.83 \\
1.14 \\
3.00 \\
1.76\end{array}$ & $\begin{array}{r}75,333 \\
5,241,989 \\
22 \\
172,151 \\
94,616\end{array}$ & $\begin{array}{r}168,880 \\
9,587,021 \\
25 \\
516,661 \\
166,915\end{array}$ \\
\hline 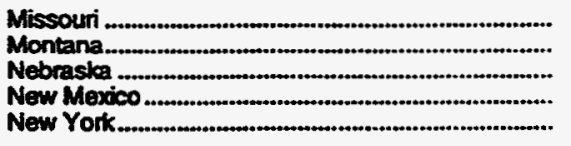 & $\begin{array}{l}1.57 \\
1.79 \\
2.26 \\
1.69 \\
2.20\end{array}$ & $\begin{array}{r}7 \\
50,429 \\
793 \\
965,104 \\
25,023\end{array}$ & $\begin{array}{r}11 \\
90,113 \\
1.793 \\
1,629,289 \\
55,050\end{array}$ \\
\hline 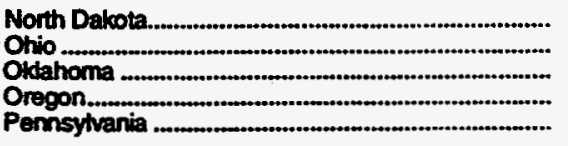 & $\begin{array}{l}1.79 \\
2.54 \\
1.57 \\
1.39 \\
2.35\end{array}$ & $\begin{array}{r}52,169 \\
154,619 \\
2,258,471 \\
2,815 \\
177,609\end{array}$ & $\begin{array}{r}93,183 \\
393,045 \\
3,547,990 \\
3,900 \\
417,381\end{array}$ \\
\hline $\begin{array}{l}\text { South Dakota. } \\
\text { Tennessee } \\
\text { Texas } \ldots \ldots \\
\text { Utah } \\
\text { Virginia }\end{array}$ & $\begin{array}{r}1.56 \\
1.65 \\
1.57 \\
1.70 \\
2.30\end{array}$ & $\begin{array}{r}881 \\
2,067 \\
6,343,146 \\
145,875 \\
14,774\end{array}$ & $\begin{array}{r}1,373 \\
3,410 \\
9,939,202 \\
248,330 \\
33,925\end{array}$ \\
\hline 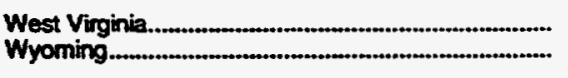 & $\begin{array}{r}3.19 \\
1.16\end{array}$ & $\begin{array}{l}178,000 \\
735,728\end{array}$ & $\begin{array}{l}567,681 \\
855,505\end{array}$ \\
\hline Total & 1.71 & $18,593,792$ & $31,754,803$ \\
\hline
\end{tabular}

See foctnotes at end of table. 
Table 7. Wellhead Value and Marketed Production of Natural Gas by State, 1967-1994 (Continued)

\begin{tabular}{|c|c|c|c|}
\hline Stot & $\begin{array}{l}\text { Avernge Wolthend } \\
\text { Price } \\
\text { (dollare por } \\
\text { thousend cubic foet) }\end{array}$ & $\begin{array}{l}\text { Marketed } \\
\text { Production } \\
\text { (million } \\
\text { cubic feet) }\end{array}$ & $\begin{array}{l}\text { Imputed Welliviad } \\
\text { Value of } \\
\text { Marketad Production } \\
\text { (thouseand dollers) }\end{array}$ \\
\hline & \multicolumn{3}{|c|}{1991} \\
\hline 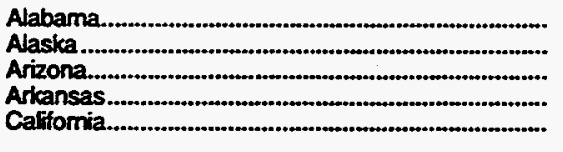 & $\begin{array}{r}2.33 \\
1.48 \\
1.50 \\
1.92 \\
2.46\end{array}$ & $\begin{array}{r}170,847 \\
437,822 \\
1,225 \\
164,702 \\
378,384\end{array}$ & $\begin{array}{r}398,074 \\
647,976 \\
1,837 \\
316,227 \\
930,825\end{array}$ \\
\hline 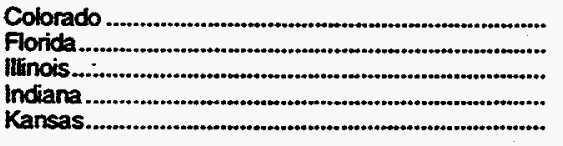 & $\begin{array}{l}1.41 \\
2.46 \\
2.17 \\
1.72 \\
1.37\end{array}$ & $\begin{array}{r}285,961 \\
4,884 \\
466 \\
232 \\
628,459\end{array}$ & $\begin{array}{r}403,205 \\
12,015 \\
1,011 \\
399 \\
860,989\end{array}$ \\
\hline $\begin{array}{l}\text { Kentucky } \\
\text { Louisiana } \\
\text { Maryland } \\
\text { Mictigan } \\
\text { Mississippi }\end{array}$ & $\begin{array}{r}2.03 \\
1.73 \\
1.55 \\
2.79 \\
1.66\end{array}$ & $\begin{array}{r}78,904 \\
5,034,361 \\
29 \\
195,749 \\
108,031\end{array}$ & $\begin{array}{r}160,175 \\
8,709,445 \\
46 \\
546,140 \\
179,332\end{array}$ \\
\hline 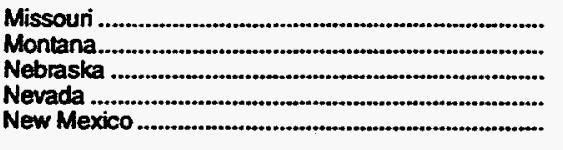 & $\begin{array}{r}1.32 \\
1.66 \\
2.06 \\
1.37\end{array}$ & $\begin{array}{r}15 \\
51,999 \\
784 \\
553 \\
1,038,284\end{array}$ & $\begin{array}{r}20 \\
85,318 \\
1,614 \\
0 \\
1,422,450\end{array}$ \\
\hline 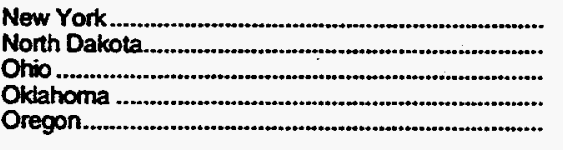 & $\begin{array}{l}2.15 \\
1.67 \\
2.38 \\
1.47 \\
1.42\end{array}$ & $\begin{array}{r}22,777 \\
53,479 \\
147,651 \\
2,153,852 \\
2,741\end{array}$ & $\begin{array}{r}48,971 \\
89,310 \\
351,409 \\
3,166,162 \\
3,892\end{array}$ \\
\hline 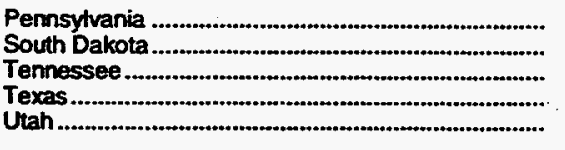 & $\begin{array}{l}2.20 \\
1.12 \\
1.72 \\
1.59 \\
1.54\end{array}$ & $\begin{array}{r}152,500 \\
882 \\
1,856 \\
6,280,654 \\
144,817\end{array}$ & $\begin{array}{r}335,500 \\
988 \\
3,192 \\
9,986,239 \\
223,018\end{array}$ \\
\hline 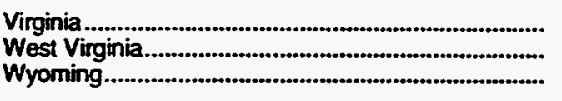 & $\begin{array}{l}1.88 \\
2.97 \\
1.06\end{array}$ & $\begin{array}{r}14,906 \\
198,605 \\
776,528\end{array}$ & $\begin{array}{r}28,023 \\
589,857 \\
823,120\end{array}$ \\
\hline \multirow[t]{2}{*}{ Total } & 1.64 & $18,532,439$ & $30,327,779$ \\
\hline & \multicolumn{3}{|c|}{1992} \\
\hline 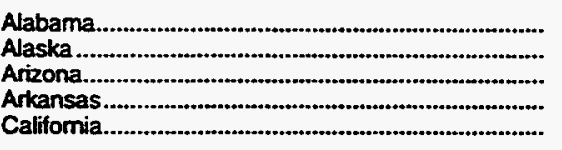 & $\begin{array}{l}2.29 \\
1.41 \\
1.85 \\
2.15 \\
b 2.34\end{array}$ & $\begin{array}{r}355,099 \\
443,597 \\
771 \\
202,479 \\
365,632\end{array}$ & $\begin{array}{r}813,178 \\
625,471 \\
1,426 \\
435,330 \\
855,579\end{array}$ \\
\hline 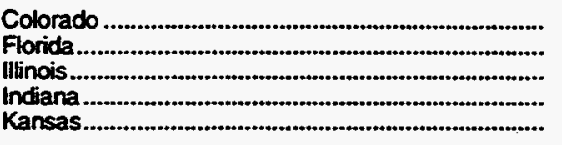 & $\begin{array}{l}1.37 \\
2.51 \\
2.15 \\
2.01 \\
1.54\end{array}$ & $\begin{array}{r}323,041 \\
6,657 \\
347 \\
174 \\
658,007\end{array}$ & $\begin{array}{r}442,566 \\
16,708 \\
746 \\
350 \\
1,013,330\end{array}$ \\
\hline 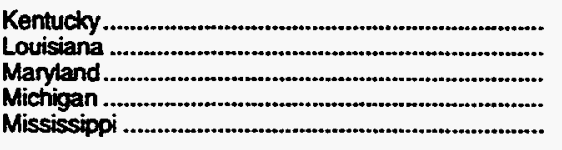 & $\begin{array}{l}1.92 \\
1.73 \\
1.91 \\
2.71 \\
1.64\end{array}$ & $\begin{array}{r}79,690 \\
4,914,300 \\
33 \\
194,815 \\
91,697\end{array}$ & $\begin{array}{r}153,005 \\
8,501,739 \\
63 \\
527,949 \\
150,382\end{array}$ \\
\hline $\begin{array}{l}\text { Missouri } \\
\text { Montana } \\
\text { Nebraska } \\
\text { Nevada } \\
\text { New Mexico }\end{array}$ & $\begin{array}{r}1.56 \\
1.62 \\
1.78 \\
1.60\end{array}$ & $\begin{array}{r}27 \\
53,867 \\
1,177 \\
30 \\
1,268,863\end{array}$ & $\begin{array}{r}87,265 \\
2,094 \\
0 \\
2,000,181\end{array}$ \\
\hline 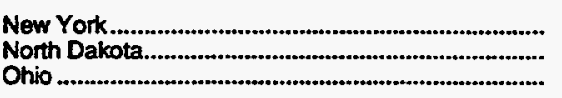 & $\begin{array}{l}2.25 \\
1.97 \\
2.35\end{array}$ & $\begin{array}{r}23,508 \\
54,883 \\
144,815\end{array}$ & $\begin{array}{r}52,893 \\
108,120 \\
340,315\end{array}$ \\
\hline
\end{tabular}

See footnotes at end of table. 
Table 7. Wellhead Value and Marketed Production of Natural Gas by State, 1967-1994 (Continued)

\begin{tabular}{|c|c|c|c|}
\hline State & $\begin{array}{l}\text { Average Wellhead } \\
\text { Price } \\
\text { (dollare per } \\
\text { thousand cubic teot) }\end{array}$ & $\begin{array}{l}\text { Marketad } \\
\text { Production } \\
\text { (million } \\
\text { cubic iset) }\end{array}$ & $\begin{array}{l}\text { Impunted Welthead } \\
\text { Volue of } \\
\text { Markind Production } \\
\text { (thousand dollers) }\end{array}$ \\
\hline & \multicolumn{3}{|c|}{1992} \\
\hline $\begin{array}{l}\text { Oldahoma } \\
\text { Oregon }\end{array}$ & $\begin{array}{l}1.70 \\
1.29\end{array}$ & $\begin{array}{r}2,017,356 \\
2,580\end{array}$ & $\begin{array}{r}3,429,505 \\
3,328\end{array}$ \\
\hline 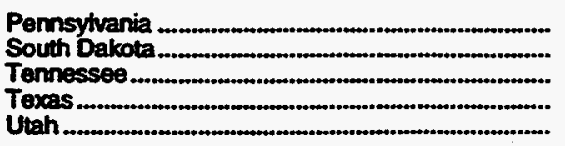 & $\begin{array}{r}1.95 \\
1.79 \\
1.79 \\
1.77 \\
1.63\end{array}$ & $\begin{array}{r}138,675 \\
1,456 \\
1,770 \\
6,145,862 \\
171,293\end{array}$ & $\begin{array}{r}270,416 \\
2,607 \\
3,168 \\
10,878,176 \\
279,208\end{array}$ \\
\hline 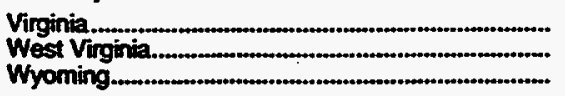 & $\begin{array}{r}1.85 \\
3.01 \\
1.13\end{array}$ & $\begin{array}{r}24,733 \\
E_{182,000} \\
842,576\end{array}$ & $\begin{array}{r}45,756 \\
E_{547,820} \\
952,111\end{array}$ \\
\hline \multirow[t]{2}{*}{ TOtal } & 1.74 & $18,711,808$ & $32,570,827$ \\
\hline & \multicolumn{3}{|c|}{1998} \\
\hline 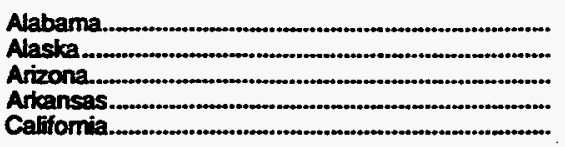 & $\begin{array}{l}2.46 \\
1.42 \\
1.30 \\
2.81 \\
2.38\end{array}$ & $\begin{array}{r}388,024 \\
430,350 \\
597 \\
196,370 \\
315,851\end{array}$ & $\begin{array}{r}956,293 \\
611,260 \\
777 \\
551,042 \\
752,605\end{array}$ \\
\hline 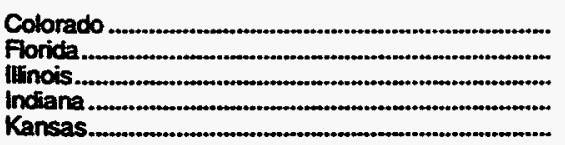 & $\begin{array}{r}1.61 \\
2.17 \\
2.30 \\
2.09 \\
1.80\end{array}$ & $\begin{array}{r}400,985 \\
7.085 \\
340 \\
192 \\
686,347\end{array}$ & $\begin{array}{r}645,590 \\
15,358 \\
782 \\
401 \\
1,238,396\end{array}$ \\
\hline 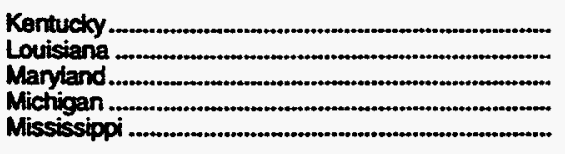 & $\begin{array}{l}2.28 \\
2.14 \\
2.44 \\
2.38 \\
1.73\end{array}$ & $\begin{array}{r}86,966 \\
R_{4,991,138} \\
288 \\
204,635 \\
80,695\end{array}$ & $\begin{array}{r}198,368 \\
A_{10,678,391} \\
68 \\
486,934 \\
139,361\end{array}$ \\
\hline 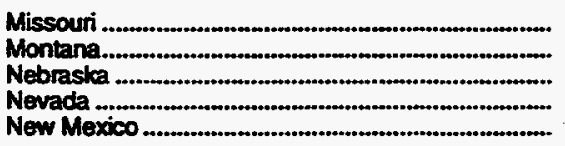 & $\begin{array}{r}1.57 \\
1.55 \\
1.81 \\
R_{1.79}\end{array}$ & $\begin{array}{r}14 \\
54,528 \\
2,114 \\
21 \\
1,409,429\end{array}$ & $\begin{array}{r}21 \\
84,370 \\
3,627 \\
0 \\
R_{2,525,499}\end{array}$ \\
\hline 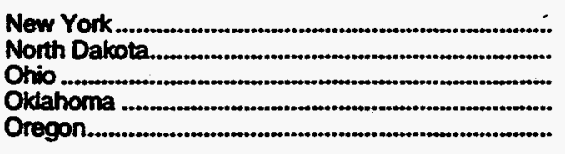 & $\begin{array}{r}2.40 \\
E_{1.84} \\
2.46 \\
1.88 \\
1.70\end{array}$ & $\begin{array}{r}21,183 \\
59,851 \\
137,285 \\
2,049,942 \\
4,003\end{array}$ & $\begin{array}{r}50,839 \\
110,129 \\
337,074 \\
3,858,893 \\
6,790\end{array}$ \\
\hline 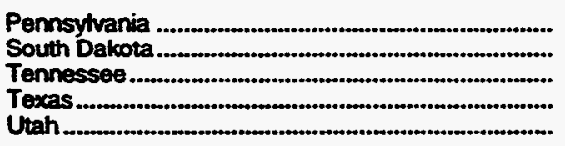 & $\begin{array}{r}2.71 \\
R_{2.13} \\
2.65 \\
2.09 \\
1.77\end{array}$ & $\begin{array}{r}132,130 \\
r_{1}, 306 \\
1,660 \\
6,249,624 \\
225,401\end{array}$ & $\begin{array}{r}358,659 \\
R_{2,781} \\
4,400 \\
13,058,965 \\
398,202\end{array}$ \\
\hline 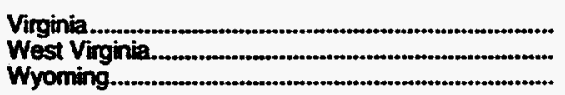 & $\begin{array}{r}2.29 \\
1.50 \\
1.99\end{array}$ & $\begin{array}{r}37,840 \\
A_{171,024} \\
f_{634,957}\end{array}$ & $\begin{array}{r}86,654 \\
R_{598,413} \\
R_{1,262,675}\end{array}$ \\
\hline \multirow[t]{2}{*}{ Total } & $R_{2.04}$ & $R_{18,981,915}$ & $\mathrm{~A}_{38,810,612}$ \\
\hline & \multicolumn{3}{|c|}{1994} \\
\hline 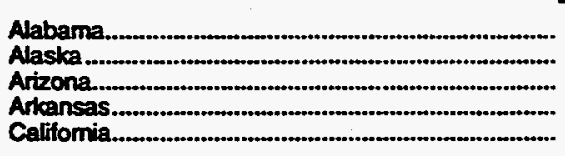 & $\begin{array}{l}2.17 \\
1.27 \\
1.40 \\
2.65 \\
3.04\end{array}$ & $\begin{array}{r}515,271 \\
453,425 \\
752 \\
187,673 \\
309,427\end{array}$ & $\begin{array}{r}1,118,726 \\
577,858 \\
1,052 \\
496,986 \\
940,092\end{array}$ \\
\hline $\begin{array}{l}\text { Colorado } \\
\text { Florida }\end{array}$ & $\begin{array}{l}1.39 \\
1.28\end{array}$ & $\begin{array}{r}453,207 \\
7,486\end{array}$ & $\begin{array}{r}628,653 \\
9,583\end{array}$ \\
\hline
\end{tabular}

See focthotes at end of table. 
Table 7. Wellhead Value and Marketed Production of Natural Gas by State, 1967-1994 (Continued)

\begin{tabular}{|c|c|c|c|}
\hline State & $\begin{array}{l}\text { Averege Welthead } \\
\text { Price } \\
\text { (dollars por } \\
\text { thousand cubic teet) }\end{array}$ & $\begin{array}{l}\text { Marketud } \\
\text { Production } \\
\text { (million } \\
\text { cubic teat) }\end{array}$ & $\begin{array}{l}\text { Imputad Wellhead } \\
\text { Value of } \\
\text { Merketed Production } \\
\text { (thousind dollers) }\end{array}$ \\
\hline & \multicolumn{3}{|c|}{1994} \\
\hline 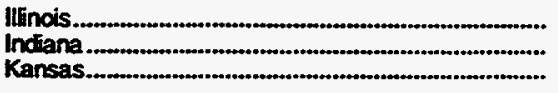 & $\begin{array}{l}2.40 \\
1.97 \\
1.60\end{array}$ & $\begin{array}{r}333 \\
107 \\
712,730\end{array}$ & $\begin{array}{r}799 \\
211 \\
1,138,785\end{array}$ \\
\hline $\begin{array}{l}\text { Kentucky } \\
\text { Louisiana } \\
\text { Maryland } \\
\text { Michigan } \\
\text { Mississippi }\end{array}$ & $\begin{array}{l}2.24 \\
2.08 \\
1.37 \\
1.96 \\
1.49\end{array}$ & $\begin{array}{r}73,081 \\
5,169,705 \\
26 \\
222,657 \\
63,448\end{array}$ & $\begin{array}{r}163,938 \\
10,728,016 \\
35 \\
435,984 \\
94,834\end{array}$ \\
\hline 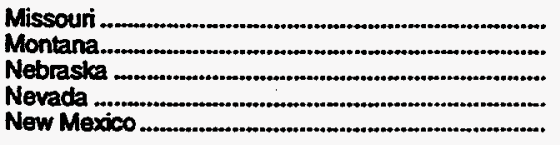 & $\begin{array}{r}1.49 \\
1.46 \\
1.60 \\
1.58\end{array}$ & $\begin{array}{r}8 \\
50,416 \\
2,898 \\
\bullet 16 \\
1,557,689\end{array}$ & $\begin{array}{r}12 \\
73,360 \\
4,649 \\
0 \\
2,463,313\end{array}$ \\
\hline $\begin{array}{l}\text { New York } \\
\text { North Dakota. } \\
\text { Ohio } \\
\text { Okdahoma } \\
\text { Oregon }\end{array}$ & $\begin{array}{r}2.35 \\
\text { NA } \\
2.43 \\
1.70 \\
2.06\end{array}$ & $\begin{array}{r}20,465 \\
57,805 \\
132,151 \\
1,934,864 \\
3,221\end{array}$ & $\begin{array}{r}48,093 \\
N A \\
320,875 \\
3,289,965 \\
6,640\end{array}$ \\
\hline 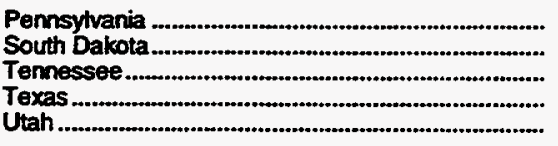 & $\begin{array}{l}2.76 \\
1.73 \\
2.16 \\
1.89 \\
1.54\end{array}$ & $\begin{array}{r}150,228 \\
1,437 \\
1,990 \\
6,353,844 \\
270,858\end{array}$ & $\begin{array}{r}414,242 \\
2,492 \\
4,300 \\
11,985,129 \\
417,034\end{array}$ \\
\hline 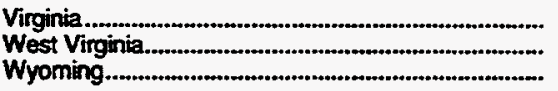 & $\begin{array}{l}2.15 \\
2.64 \\
2.05\end{array}$ & $\begin{array}{r}50,259 \\
182,000 \\
696,018\end{array}$ & $\begin{array}{r}108,058 \\
480,071 \\
1,429,163\end{array}$ \\
\hline Total & 1.88 & $19,635,495$ & $36,849,541$ \\
\hline
\end{tabular}

- Cuantity and value data are for the period beginning June 1, 1980, and ending May 31, 1981.

buantity and value data obtained from Energy Information Administration (ElA), U.S. Department of Energy. Form ElA-176, Annual Report of Natural and Supplemental Gas Supply and Disposition.

c Quantity and value data obtained from published annual reports from Pacific Gas and Electric Company and Pacific Lighting Corporation.

d Weighted average price oblained from seperate State and Outer Continental Shelf average price calculations.

- Most of Nevada's marketed production was consumed as lease fuel.

F = Revised data.

= Estimated data.

NA = Not Avaitable.

Note: Totals may nol equal sum of components due to independent rounding.

Sources: 1967-1975: Figures based on reports received from State agencies and Buraau of Mines estimates. 1976-1979: State Conservation agencies. 1979: State Conservation agencies and the United States Geological Survey (USGS). 1980-1981: Energy Information Administration (EIA), Form ELA-627, Annual Quantity and Value of Natural Gas Report," and the USGS. 1982-1994: EIA, Form EIA-627, "Annual Quantity and Value of Natural Gas Report"; Form ElA-176, "Annual Report of Natural and Supplemental Gas Supply and Disposition": and the Uniled States Minerals Maragement Service. 
Table 8. Movements of Natural Gas by State, 1967-1994. (Million Cubic Feet)

\begin{tabular}{|c|c|c|c|c|c|c|}
\hline \multirow[t]{2}{*}{ stane } & \multicolumn{3}{|c|}{ Intorntates } & \multicolumn{3}{|c|}{$\begin{array}{l}\text { Movementes Acroes } \\
\text { U.S. Borders }\end{array}$} \\
\hline & Roceips & Deliverios: & inet & Alocelipts & Defiveries & Net \\
\hline & \multicolumn{6}{|c|}{1967} \\
\hline 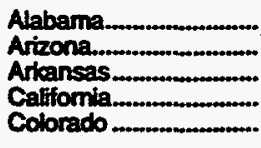 & $\begin{array}{r}2,509,299 \\
1,316,669 \\
2,457,182 \\
1,329,287 \\
218,751\end{array}$ & $\begin{array}{r}2,254,258 \\
1,154,223 \\
2,259,392 \\
0 \\
93,325\end{array}$ & $\begin{array}{r}255,041 \\
162,446 \\
197,790 \\
1,329,287 \\
125,426\end{array}$ & $\begin{array}{l}0 \\
0 \\
0 \\
0 \\
0\end{array}$ & $\begin{array}{r}0 \\
3,716 \\
0 \\
0 \\
0\end{array}$ & $\begin{array}{r}0 \\
-3,716 \\
0 \\
0 \\
0\end{array}$ \\
\hline $\begin{array}{l}\text { Connecticut. } \\
\text { D.C. } \\
\text { Delaware. } \\
\text { Forida } \\
\text { Georgia.......... }\end{array}$ & $\begin{array}{r}135,569 \\
a \\
23,389 \\
227,439 \\
1,055,687\end{array}$ & $\begin{array}{r}83,826 \\
a \\
1,518 \\
0 \\
797,663\end{array}$ & $\begin{array}{r}51,743 \\
21,87 \\
21,871 \\
227,439 \\
258,024\end{array}$ & $\begin{array}{l}0 \\
\mathbf{a} \\
0 \\
0 \\
0\end{array}$ & $\begin{array}{l}0 \\
a \\
0 \\
0 \\
0\end{array}$ & $\begin{array}{l}0 \\
a \\
0 \\
0 \\
0\end{array}$ \\
\hline 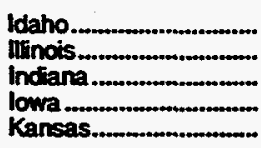 & $\begin{array}{r}69,417 \\
2,163,355 \\
1,813,968 \\
1,173,314 \\
1,693,221\end{array}$ & $\begin{array}{r}288,469 \\
1,152,186 \\
1,371,265 \\
882,504 \\
2,083,980\end{array}$ & $\begin{array}{r}-219,052 \\
1,011,169 \\
442,703 \\
290,810 \\
-390,759\end{array}$ & $\begin{array}{r}253,707 \\
0 \\
0 \\
0 \\
0\end{array}$ & $\begin{array}{l}0 \\
0 \\
0 \\
0 \\
0\end{array}$ & $\begin{array}{r}253,707 \\
0 \\
0 \\
0 \\
0\end{array}$ \\
\hline $\begin{array}{l}\text { Kentucky. } \\
\text { Louisiana } \\
\text { Maine } \\
\text { Marytand } \\
\text { Massachusetts..................... }\end{array}$ & $\begin{array}{r}3,083,696 \\
1,237,137 \\
6,391 \\
693,372 \\
143,318\end{array}$ & $\begin{array}{r}2,962,722 \\
5,383,284 \\
0 \\
543,626 \\
12,682\end{array}$ & $\begin{array}{r}120,974 \\
-4,146,147 \\
6,391 \\
149,746 \\
130,636\end{array}$ & $\begin{array}{r}0 \\
0 \\
613 \\
0 \\
0\end{array}$ & $\begin{array}{l}0 \\
0 \\
0 \\
0 \\
0\end{array}$ & $\begin{array}{r}0 \\
0 \\
613 \\
0 \\
0\end{array}$ \\
\hline 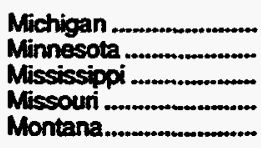 & $\begin{array}{r}698,475 \\
304,672 \\
4,980,531 \\
1,661,867 \\
35,750\end{array}$ & $\begin{array}{r}0 \\
105,102 \\
4,833,931 \\
1,291,995 \\
11,389\end{array}$ & $\begin{array}{r}698,475 \\
199,570 \\
146,600 \\
369,872 \\
24,361\end{array}$ & $\begin{array}{r}0 \\
83,718 \\
0 \\
0 \\
30,769\end{array}$ & $\begin{array}{r}40,418 \\
0 \\
0 \\
0 \\
106\end{array}$ & $\begin{array}{r}-40,418 \\
83,718 \\
0 \\
0 \\
30,663\end{array}$ \\
\hline $\begin{array}{l}\text { Nebraska } \\
\text { Nevada } \\
\text { New Hampshire.............. } \\
\text { New Jersey................. } \\
\text { New Mexico ................. }\end{array}$ & $\begin{array}{r}1,156,110 \\
35,627 \\
b \\
673,228 \\
623,090\end{array}$ & $\begin{array}{r}973,066 \\
0 \\
b \\
420,719 \\
1,376,027\end{array}$ & $\begin{array}{r}183,044 \\
35,627 \\
b \\
252,509 \\
-752,937\end{array}$ & $\begin{array}{l}0 \\
0 \\
b \\
0 \\
0\end{array}$ & $\begin{array}{l}0 \\
0 \\
b \\
0 \\
0\end{array}$ & $\begin{array}{l}0 \\
0 \\
b \\
0 \\
0\end{array}$ \\
\hline $\begin{array}{l}\text { New York } \\
\text { North Carolina. } \\
\text { North Dakota............ } \\
\text { Ohio } \\
\text { Oldahoma }\end{array}$ & $\begin{array}{r}840,028 \\
673,861 \\
6,374 \\
2,553,517 \\
1,054,717\end{array}$ & $\begin{array}{r}222,877 \\
\mathbf{5 7 4 , 6 7 6} \\
9,512 \\
1,628,374 \\
1,936,297\end{array}$ & $\begin{array}{r}617,151 \\
99,185 \\
-3,138 \\
925,143 \\
-881,580\end{array}$ & $\begin{array}{r}4,020 \\
0 \\
0 \\
0 \\
0\end{array}$ & $\begin{array}{r}29,932 \\
0 \\
0 \\
0 \\
0\end{array}$ & $\begin{array}{r}-25,912 \\
0 \\
0 \\
0 \\
0\end{array}$ \\
\hline 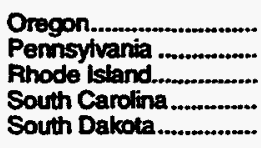 & $\begin{array}{r}276,786 \\
1,826,672 \\
88,523 \\
778,373 \\
28,868\end{array}$ & $\begin{array}{r}205,166 \\
1,209,168 \\
69,418 \\
673,861 \\
1,004\end{array}$ & $\begin{array}{r}71,620 \\
617,504 \\
19,105 \\
104,512 \\
27,864\end{array}$ & $\begin{array}{l}0 \\
0 \\
0 \\
0 \\
0\end{array}$ & $\begin{array}{l}0 \\
0 \\
0 \\
0 \\
0\end{array}$ & $\begin{array}{l}0 \\
0 \\
0 \\
0 \\
0\end{array}$ \\
\hline $\begin{array}{l}\text { Tennessee } \\
\text { Texas } \\
\text { Utah } \\
\text { Vemont } \\
\text { Virginia }\end{array}$ & $\begin{array}{r}3,312,635 \\
272,830 \\
199,031 \\
b \\
795,107\end{array}$ & $\begin{array}{r}3.074,312 \\
3,520,811 \\
138,978 \\
b \\
680,254\end{array}$ & $\begin{array}{r}238,323 \\
-3,247,981 \\
60,053 \\
b \\
114,853\end{array}$ & $\begin{array}{r}0 \\
50,971 \\
0 \\
b \\
0\end{array}$ & $\begin{array}{r}0 \\
7.442 \\
0 \\
b \\
0\end{array}$ & $\begin{array}{r}0 \\
43,529 \\
0 \\
b \\
0\end{array}$ \\
\hline 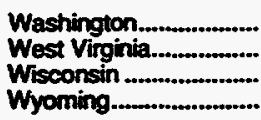 & $\begin{array}{r}254,223 \\
1,090,403 \\
267,045 \\
77,441\end{array}$ & $\begin{array}{r}264,821 \\
1,124,633 \\
14,142 \\
230,789\end{array}$ & $\begin{array}{r}-10,598 \\
-34,230 \\
252,903 \\
-153,348\end{array}$ & $\begin{array}{r}140,428 \\
0 \\
0 \\
0\end{array}$ & $\begin{array}{l}0 \\
0 \\
0 \\
0\end{array}$ & $\begin{array}{r}140,428 \\
0 \\
0 \\
0\end{array}$ \\
\hline Total & $45,916,245$ & $45,916,245$ & 0 & 564,226 & 81,614 & 482,612 \\
\hline
\end{tabular}

See footnotes at end of table. 
Table 8. Movements of Natural Gas by State, 1967-1994 (Continued) (Million Cubic Feet)

\begin{tabular}{|c|c|c|c|c|c|c|c|}
\hline \multirow[t]{2}{*}{ Sinde } & \multicolumn{3}{|c|}{$\begin{array}{l}\text { Intoratute } \\
\text { Movements }\end{array}$} & \multicolumn{4}{|c|}{$\begin{array}{l}\text { Mowements Acrois: } \\
\text { U.S. Bordurs }\end{array}$} \\
\hline & Preceipts & Deliveries & Not & Recolpts & Deliveries & Net & \\
\hline & \multicolumn{7}{|c|}{1968} \\
\hline 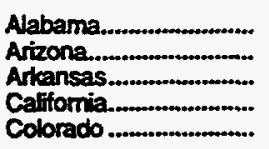 & $\begin{array}{r}2,929,775 \\
1,377,431 \\
2,505,614 \\
1,416,580 \\
250,125\end{array}$ & $\begin{array}{r}2,641,104 \\
1,197,090 \\
2,329,995 \\
0 \\
105,486\end{array}$ & $\begin{array}{r}288,671 \\
180,341 \\
175,619 \\
1,416,580 \\
144,639\end{array}$ & $\begin{array}{l}0 \\
0 \\
0 \\
0 \\
0\end{array}$ & $\begin{array}{r}0 \\
3,891 \\
0 \\
0 \\
0\end{array}$ & $\begin{array}{r}0 \\
-3,891 \\
0 \\
0 \\
0\end{array}$ & \\
\hline 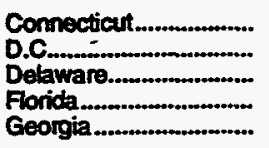 & $\begin{array}{r}142,353 \\
a \\
26,095 \\
277,626 \\
1,208,829\end{array}$ & $\begin{array}{r}87,094 \\
8 \\
1,750 \\
0 \\
917,165\end{array}$ & $\begin{array}{r}55,259 \\
\mathrm{a} \\
24,345 \\
277,626 \\
291,664\end{array}$ & $\begin{array}{l}0 \\
a \\
0 \\
0 \\
0\end{array}$ & $\begin{array}{l}0 \\
a \\
0 \\
0 \\
0\end{array}$ & $\begin{array}{l}0 \\
a \\
0 \\
0 \\
0\end{array}$ & \\
\hline 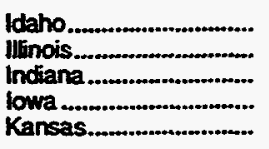 & $\begin{array}{r}85,879 \\
2,144,948 \\
1,754,225 \\
1,240,460 \\
1,841,240\end{array}$ & $\begin{array}{r}337,505 \\
1,066,373 \\
1,288,462 \\
935,395 \\
2,129,987\end{array}$ & $\begin{array}{r}-251,626 \\
1,078,575 \\
465,763 \\
305,065 \\
-288,747\end{array}$ & $\begin{array}{r}291,801 \\
0 \\
0 \\
0 \\
0\end{array}$ & $\begin{array}{l}0 \\
0 \\
0 \\
0 \\
0\end{array}$ & $\begin{array}{r}291,801 \\
0 \\
0 \\
0 \\
0\end{array}$ & . \\
\hline 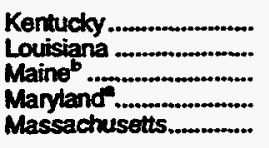 & $\begin{array}{r}3,340,555 \\
1,219,066 \\
7,091 \\
766,725 \\
150,594\end{array}$ & $\begin{array}{r}3,215,291 \\
5,941,616 \\
1,403 \\
610,974 \\
13,703\end{array}$ & $\begin{array}{r}125,264 \\
-4,722,550 \\
5,688 \\
155,751 \\
136,891\end{array}$ & $\begin{array}{r}0 \\
0 \\
1,452 \\
0 \\
0\end{array}$ & $\begin{array}{l}0 \\
0 \\
0 \\
0 \\
0\end{array}$ & $\begin{array}{r}0 \\
0 \\
1,452 \\
0 \\
0\end{array}$ & \\
\hline 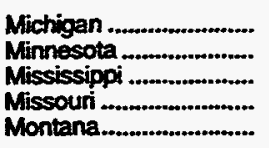 & $\begin{array}{r}742,934 \\
332,984 \\
5,515,327 \\
1,611,649 \\
30,124\end{array}$ & $\begin{array}{r}1 \\
142,839 \\
5,338,335 \\
1,246,146 \\
12,281\end{array}$ & $\begin{array}{r}742,933 \\
190,145 \\
176,992 \\
365,503 \\
17,843\end{array}$ & $\begin{array}{r}0 \\
120,862 \\
0 \\
0 \\
36,635\end{array}$ & $\begin{array}{r}68,044 \\
0 \\
0 \\
0 \\
104\end{array}$ & $\begin{array}{r}-68,044 \\
120,862 \\
0 \\
0 \\
36,531\end{array}$ & \\
\hline $\begin{array}{l}\text { Nebraska ..................... } \\
\text { Nevada ................... } \\
\text { New Hampshire .......... } \\
\text { New Jersey ................. } \\
\text { New Mexico .................. }\end{array}$ & $\begin{array}{r}1,229,265 \\
37,376 \\
b \\
741,435 \\
689,089\end{array}$ & $\begin{array}{r}1,031,229 \\
0 \\
b \\
460,243 \\
1,537,473\end{array}$ & $\begin{array}{r}198,036 \\
37,376 \\
b \\
281,192 \\
+848,384\end{array}$ & $\begin{array}{l}0 \\
0 \\
b \\
0 \\
0\end{array}$ & $\begin{array}{l}0 \\
0 \\
b \\
0 \\
0\end{array}$ & $\begin{array}{l}0 \\
0 \\
b \\
0 \\
0\end{array}$ & \\
\hline 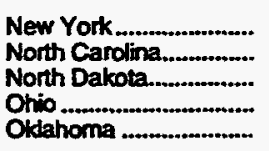 & $\begin{array}{r}885,390 \\
763,794 \\
7,191 \\
2,672,596 \\
1,293,066\end{array}$ & $\begin{array}{r}228,565 \\
648,101 \\
9,350 \\
1,712,919 \\
2,119,168\end{array}$ & $\begin{array}{r}656,825 \\
115,693 \\
-2,159 \\
959,677 \\
-826,102\end{array}$ & $\begin{array}{r}4,869 \\
0 \\
0 \\
0 \\
0\end{array}$ & $\begin{array}{r}13,499 \\
0 \\
0 \\
0 \\
0\end{array}$ & $\begin{array}{r}-8,630 \\
0 \\
0 \\
0 \\
0\end{array}$ & \\
\hline 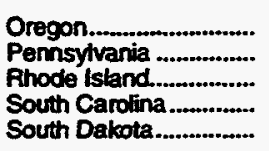 & $\begin{array}{r}320,466 \\
1,891,020 \\
92,031 \\
895,084 \\
30,409\end{array}$ & $\begin{array}{r}240,631 \\
1,222,364 \\
70,649 \\
763,794 \\
1,149\end{array}$ & $\begin{array}{r}79,835 \\
668,656 \\
21,382 \\
131,290 \\
29,260\end{array}$ & $\begin{array}{l}0 \\
0 \\
0 \\
0 \\
0\end{array}$ & $\begin{array}{l}0 \\
0 \\
0 \\
0 \\
0\end{array}$ & $\begin{array}{l}0 \\
0 \\
0 \\
0 \\
0\end{array}$ & \\
\hline 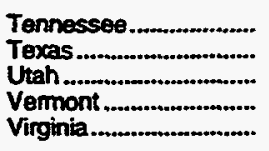 & $\begin{array}{r}3,574,364 \\
388,348 \\
229,148 \\
b \\
869,322\end{array}$ & $\begin{array}{r}3,332,244 \\
3,750,818 \\
161,188 \\
b \\
745,344\end{array}$ & $\begin{array}{r}242,120 \\
-3,362,470 \\
67,960 \\
b \\
122,978\end{array}$ & $\begin{array}{r}0 \\
47,423 \\
0 \\
b \\
0\end{array}$ & $\begin{array}{r}0 \\
8,206 \\
0 \\
b \\
0\end{array}$ & $\begin{array}{r}0 \\
39,217 \\
0 \\
b \\
0\end{array}$ & \\
\hline 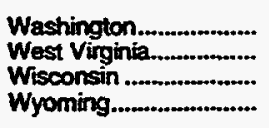 & $\begin{array}{r}290,442 \\
1,299,699 \\
292,179 \\
93,424\end{array}$ & $\begin{array}{r}298,511 \\
1,345,085 \\
15,733 \\
247,815\end{array}$ & $\begin{array}{r}-8,069 \\
-45,386 \\
276,446 \\
-154,391\end{array}$ & $\begin{array}{r}148,843 \\
0 \\
0 \\
0\end{array}$ & $\begin{array}{l}0 \\
0 \\
0 \\
0\end{array}$ & $\begin{array}{r}148,843 \\
0 \\
0 \\
0\end{array}$ & \\
\hline Total................................... & $49,502,357$ & $49,502,367$ & 0 & 651,885 & 93,745 & 558,140 & \\
\hline
\end{tabular}

See foctnotes at end of table. 
Table 8. Movements of Natural Gas by State, 1967-1994 (Continued) (Million Cubic Feet)

\begin{tabular}{|c|c|c|c|c|c|c|}
\hline \multirow{2}{*}{ State } & \multicolumn{3}{|c|}{ Monemente } & \multicolumn{3}{|c|}{$\begin{array}{l}\text { Wovements Acroess } \\
\text { US. Borders: }\end{array}$} \\
\hline & Receipts & Deriveries: & Net & Rocaipts & Deliveries & Net \\
\hline & \multicolumn{6}{|c|}{1959} \\
\hline 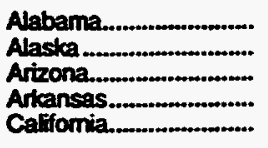 & $\begin{array}{r}3,162,432 \\
0 \\
1,421,296 \\
2,711,753 \\
1,452,623\end{array}$ & $\begin{array}{r}2,863,081 \\
0 \\
1,222,800 \\
2,519,758 \\
0\end{array}$ & $\begin{array}{r}299,351 \\
0 \\
198,495 \\
191,995 \\
1,452,623\end{array}$ & $\begin{array}{l}0 \\
0 \\
0 \\
0 \\
0\end{array}$ & $\begin{array}{r}0 \\
2,982 \\
3,880 \\
0 \\
0\end{array}$ & $\begin{array}{r}0 \\
-2,982 \\
-3,880 \\
0 \\
0\end{array}$ \\
\hline 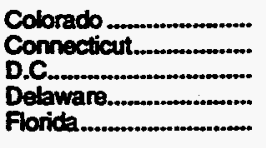 & $\begin{array}{r}253,398 \\
148,570 \\
a \\
27,559 \\
314,216\end{array}$ & $\begin{array}{r}89,723 \\
89,137 \\
a \\
1,922 \\
0\end{array}$ & $\begin{array}{r}163,675 \\
59,433 \\
a \\
25,637 \\
314,216\end{array}$ & $\begin{array}{l}0 \\
0 \\
a \\
0 \\
0\end{array}$ & $\begin{array}{l}0 \\
0 \\
a \\
0 \\
0\end{array}$ & $\begin{array}{l}0 \\
0 \\
2 \\
0 \\
0\end{array}$ \\
\hline 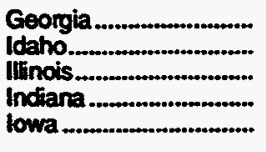 & $\begin{array}{r}1,353,701 \\
90,641 \\
2,230,926 \\
1,802,014 \\
1,296,021\end{array}$ & $\begin{array}{r}1,016,515 \\
360,618 \\
1,073,480 \\
1,254,114 \\
973,565\end{array}$ & $\begin{array}{r}317,186 \\
-269,977 \\
1,157,446 \\
547,900 \\
322,456\end{array}$ & $\begin{array}{r}0 \\
312,096 \\
0 \\
0 \\
0\end{array}$ & $\begin{array}{l}0 \\
0 \\
0 \\
0 \\
0\end{array}$ & $\begin{array}{r}0 \\
312,096 \\
0 \\
0 \\
0\end{array}$ \\
\hline 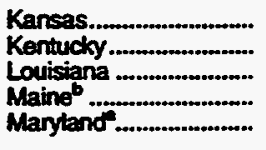 & $\begin{array}{r}1,956,738 \\
3,658,171 \\
1,278,995 \\
9,482 \\
830,054\end{array}$ & $\begin{array}{r}2,251,021 \\
3,480,571 \\
6,522,705 \\
1,887 \\
661,936\end{array}$ & $\begin{array}{r}-294,283 \\
177,600 \\
-5,243,710 \\
7,595 \\
168,118\end{array}$ & $\begin{array}{r}0 \\
0 \\
0 \\
2,095 \\
0\end{array}$ & $\begin{array}{l}0 \\
0 \\
0 \\
0 \\
0\end{array}$ & $\begin{array}{r}0 \\
0 \\
0 \\
2,095 \\
0\end{array}$ \\
\hline 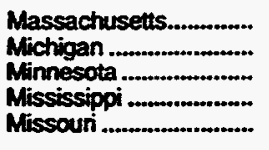 & $\begin{array}{r}159,908 \\
776,010 \\
345,279 \\
6,062,845 \\
1,706,524\end{array}$ & $\begin{array}{r}21,537 \\
5 \\
156,936 \\
5,860,437 \\
1,308,335\end{array}$ & $\begin{array}{l}138,371 \\
776,005 \\
188,343 \\
202,408 \\
398,189\end{array}$ & $\begin{array}{r}0 \\
0 \\
137,687 \\
0 \\
0\end{array}$ & $\begin{array}{r}0 \\
29.765 \\
0 \\
0 \\
0\end{array}$ & $\begin{array}{r}0 \\
-29,765 \\
137,687 \\
0 \\
0\end{array}$ \\
\hline $\begin{array}{l}\text { Montana......................... } \\
\text { Nebraske ....................... } \\
\text { Nevada Hampshire ............. } \\
\text { New Jersey................. }\end{array}$ & $\begin{array}{r}31,347 \\
1,276,858 \\
44,899 \\
b \\
801,428\end{array}$ & $\begin{array}{r}20,677 \\
1,073,502 \\
0 \\
b \\
484,644\end{array}$ & $\begin{array}{r}10,670 \\
203,385 \\
44,899 \\
b \\
316,784\end{array}$ & $\begin{array}{r}39,830 \\
0 \\
0 \\
b \\
0\end{array}$ & $\begin{array}{r}112 \\
0 \\
0 \\
b \\
0\end{array}$ & $\begin{array}{r}39,718 \\
0 \\
0 \\
b \\
0\end{array}$ \\
\hline 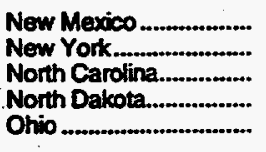 & $\begin{array}{r}745,257 \\
920,580 \\
848,423 \\
12,823 \\
2,830,201\end{array}$ & $\begin{array}{r}1,564,480 \\
229,149 \\
710,066 \\
8,383 \\
1,846,031\end{array}$ & $\begin{array}{r}-819,223 \\
691,431 \\
138,357 \\
4,440 \\
984,170\end{array}$ & $\begin{array}{r}0 \\
16,460 \\
0 \\
0 \\
0\end{array}$ & $\begin{array}{r}0 \\
5,054 \\
0 \\
0 \\
0\end{array}$ & $\begin{array}{r}0 \\
11,406 \\
0 \\
0 \\
0\end{array}$ \\
\hline 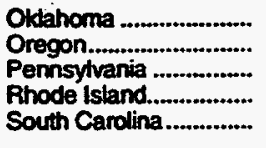 & $\begin{array}{r}1,376,159 \\
350,678 \\
2,022,425 \\
94,348 \\
994,488\end{array}$ & $\begin{array}{r}2,253,047 \\
260,308 \\
1,291,854 \\
71,218 \\
848,423\end{array}$ & $\begin{array}{r}-886,888 \\
90,370 \\
730,571 \\
23,130 \\
146,065\end{array}$ & $\begin{array}{l}0 \\
0 \\
0 \\
0 \\
0\end{array}$ & $\begin{array}{l}0 \\
0 \\
0 \\
0 \\
0\end{array}$ & $\begin{array}{l}0 \\
0 \\
0 \\
0 \\
0\end{array}$ \\
\hline 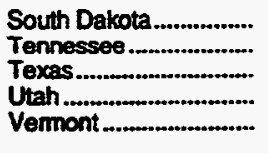 & $\begin{array}{r}36,258 \\
3,921,292 \\
438,448 \\
220,174 \\
b\end{array}$ & $\begin{array}{r}1,286 \\
3,657,812 \\
3,983,752 \\
141,310 \\
b\end{array}$ & $\begin{array}{r}34,972 \\
263,480 \\
-3,545,304 \\
78,854 \\
b\end{array}$ & $\begin{array}{r}0 \\
0 \\
46,845 \\
0 \\
b\end{array}$ & $\begin{array}{r}0 \\
0 \\
9.511 \\
0 \\
b\end{array}$ & $\begin{array}{r}0 \\
0 \\
37,334 \\
0 \\
b\end{array}$ \\
\hline 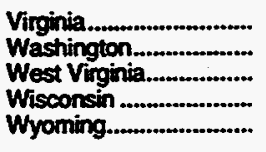 & $\begin{array}{r}957,370 \\
315,872 \\
1,356,800 \\
336,019 \\
74,071\end{array}$ & $\begin{array}{r}823,196 \\
341,012 \\
1,408,566 \\
17,888 \\
258,667\end{array}$ & $\begin{array}{r}134,174 \\
-25,140 \\
-51,766 \\
318,131 \\
-184,596\end{array}$ & $\begin{array}{r}0 \\
171,938 \\
0 \\
0 \\
0\end{array}$ & $\begin{array}{l}0 \\
0 \\
0 \\
0 \\
0\end{array}$ & $\begin{array}{r}0 \\
171,938 \\
0 \\
0 \\
0\end{array}$ \\
\hline Total & $53,035,354$ & $53,035,354$ & 0 & 726,951 & 51,304 & 675,647 \\
\hline
\end{tabular}

See foothotes at end of table. 
Table 8. Movements of Natural Gas by State, 1967-1994 (Continued) (Million Cubic Feet)

\begin{tabular}{|c|c|c|c|c|c|c|c|}
\hline \multirow[t]{2}{*}{ sumes } & \multicolumn{3}{|c|}{$\begin{array}{l}\text { Interetsto } \\
\text { Morrenents }\end{array}$} & \multicolumn{4}{|c|}{$\begin{array}{l}\text { Monenenta Acroess } \\
\text { U.S. Borders }\end{array}$} \\
\hline & Receipts & Detiveries & Not & Receipts & Deliveries & Not & \\
\hline & \multicolumn{7}{|c|}{1970} \\
\hline 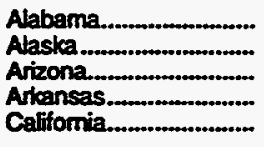 & $\begin{array}{r}3,331,382 \\
0 \\
1,501,765 \\
2,875,836 \\
1,566,146\end{array}$ & $\begin{array}{r}3,036,629 \\
0 \\
1,303,743 \\
2,658,022 \\
0\end{array}$ & $\begin{array}{r}294,753 \\
0 \\
198,022 \\
217,814 \\
1,566,146\end{array}$ & $\begin{array}{l}0 \\
0 \\
0 \\
0 \\
0\end{array}$ & $\begin{array}{r}0 \\
44,257 \\
4,044 \\
0 \\
0\end{array}$ & $\begin{array}{r}0 \\
44,257 \\
4,044 \\
0 \\
0\end{array}$ & \\
\hline $\begin{array}{l}\text { Colorado. } \\
\text { Connecticut.... } \\
\text { D.C. } \\
\text { Delawrare. } \\
\text { Florida }\end{array}$ & $\begin{array}{r}300,071 \\
159,916 \\
a \\
28,913 \\
335,829\end{array}$ & $\begin{array}{r}120,686 \\
97,541 \\
a \\
2,014 \\
0\end{array}$ & $\begin{array}{r}179,385 \\
62,375 \\
\text { a } \\
26,899 \\
335,829\end{array}$ & $\begin{array}{l}0 \\
0 \\
a \\
0 \\
0\end{array}$ & $\begin{array}{l}0 \\
0 \\
a \\
0 \\
0\end{array}$ & $\begin{array}{l}0 \\
0 \\
a \\
0 \\
0\end{array}$ & \\
\hline $\begin{array}{l}\text { Georgia } \\
\text { ldaho. } \\
\text { Ilinois... } \\
\text { Indiana. } \\
\text { lowa }\end{array}$ & $\begin{array}{r}1,451,528 \\
108,518 \\
2,368,114 \\
1,905,929 \\
1,385,306\end{array}$ & $\begin{array}{r}1,114,192 \\
414,340 \\
1,099,907 \\
1,344,232 \\
1,023,394\end{array}$ & $\begin{array}{r}337,336 \\
-305,822 \\
1,268,207 \\
561,697 \\
361,912\end{array}$ & $\begin{array}{r}0 \\
353,640 \\
0 \\
0 \\
0\end{array}$ & $\begin{array}{l}0 \\
0 \\
0 \\
0 \\
0\end{array}$ & $\begin{array}{r}0 \\
353,640 \\
0 \\
0 \\
0\end{array}$ & 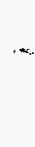 \\
\hline 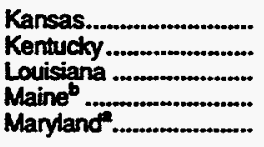 & $\begin{array}{r}2,106,380 \\
3,841,778 \\
1,242,036 \\
10,269 \\
893,459\end{array}$ & $\begin{array}{r}2,375,467 \\
3,653,585 \\
6,911,945 \\
1,916 \\
705,782\end{array}$ & $\begin{array}{r}-269,087 \\
188,193 \\
-5,669,909 \\
8,353 \\
187,677\end{array}$ & $\begin{array}{r}0 \\
0 \\
0 \\
2,532 \\
0\end{array}$ & $\begin{array}{l}0 \\
0 \\
0 \\
0 \\
0\end{array}$ & $\begin{array}{r}0 \\
0 \\
0 \\
2,532 \\
0\end{array}$ & \\
\hline $\begin{array}{l}\text { Massactusetts.. } \\
\text { Michigan } \\
\text { Minnesota } \\
\text { Mississippi } \\
\text { Missouti }\end{array}$ & $\begin{array}{r}183,981 \\
791,773 \\
354,694 \\
6,427,316 \\
1,729,750\end{array}$ & $\begin{array}{r}36,489 \\
0 \\
181,757 \\
6,179,522 \\
1,292,000\end{array}$ & $\begin{array}{l}147,492 \\
791,773 \\
172,937 \\
247,794 \\
437,750\end{array}$ & $\begin{array}{r}757 \\
0 \\
172,219 \\
0 \\
0\end{array}$ & $\begin{array}{r}0 \\
10,643 \\
0 \\
0 \\
0\end{array}$ & $\begin{array}{r}757 \\
-10,643 \\
172,219 \\
0 \\
0\end{array}$ & \\
\hline 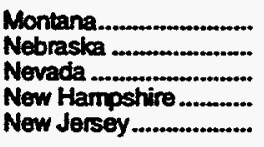 & $\begin{array}{r}47,619 \\
1,401,041 \\
53,293 \\
b \\
850,669\end{array}$ & $\begin{array}{r}27,303 \\
1,197,396 \\
0 \\
b \\
516,649\end{array}$ & $\begin{array}{r}20,316 \\
203,645 \\
53,293 \\
b \\
334,020\end{array}$ & $\begin{array}{r}42.560 \\
0 \\
0 \\
b \\
0\end{array}$ & $\begin{array}{r}109 \\
0 \\
0 \\
b \\
0\end{array}$ & $\begin{array}{r}42,451 \\
0 \\
0 \\
b \\
0\end{array}$ & \\
\hline 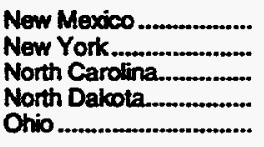 & $\begin{array}{r}897,381 \\
946,097 \\
928,285 \\
8,899 \\
2,922,669\end{array}$ & $\begin{array}{r}1,707,781 \\
244,902 \\
773,117 \\
7,264 \\
1,927,523\end{array}$ & $\begin{array}{r}-810,400 \\
701,195 \\
155,168 \\
1,635 \\
995,146\end{array}$ & $\begin{array}{r}0 \\
33,638 \\
0 \\
0 \\
0\end{array}$ & $\begin{array}{r}0 \\
126 \\
0 \\
0 \\
0\end{array}$ & $\begin{array}{r}0 \\
33,512 \\
0 \\
0 \\
0\end{array}$ & \\
\hline 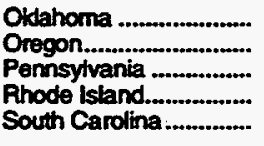 & $\begin{array}{r}1,544,187 \\
395,557 \\
2,107,804 \\
102,880 \\
1,092,190\end{array}$ & $\begin{array}{r}2,454,115 \\
296,839 \\
1,344,650 \\
76,820 \\
928,285\end{array}$ & $\begin{array}{r}-909,928 \\
98,718 \\
763,154 \\
26,060 \\
163,905\end{array}$ & $\begin{array}{l}0 \\
0 \\
0 \\
0 \\
0\end{array}$ & $\begin{array}{l}0 \\
0 \\
0 \\
0 \\
0\end{array}$ & $\begin{array}{l}0 \\
0 \\
0 \\
0 \\
0\end{array}$ & \\
\hline 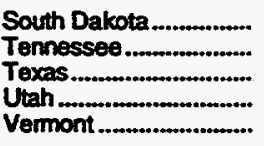 & $\begin{array}{r}46,551 \\
4,104,085 \\
513,070 \\
261,741 \\
b\end{array}$ & $\begin{array}{r}9,392 \\
3,840,823 \\
4,288,792 \\
179,333 \\
\text { b }\end{array}$ & $\begin{array}{r}37,159 \\
263,262 \\
-3.775 .722 \\
82,408 \\
b\end{array}$ & $\begin{array}{r}0 \\
0 \\
41,336 \\
0 \\
b\end{array}$ & $\begin{array}{r}0 \\
0 \\
10,634 \\
0 \\
b\end{array}$ & $\begin{array}{r}0 \\
0 \\
30,702 \\
0 \\
b\end{array}$ & \\
\hline $\begin{array}{l}\text { Virginia } \\
\text { Washington } \\
\text { West Virginia.................. } \\
\text { Wisconsin } \\
\text { Wyoming }\end{array}$ & $\begin{array}{r}1,022,945 \\
359,646 \\
1,374,977 \\
369,637 \\
87,625\end{array}$ & $\begin{array}{r}893,702 \\
376,204 \\
1,391,586 \\
20,620 \\
293,278\end{array}$ & $\begin{array}{r}139,243 \\
-16,558 \\
-16,609 \\
349,017 \\
-205,653\end{array}$ & $\begin{array}{r}0 \\
174,098 \\
0 \\
0 \\
0\end{array}$ & $\begin{array}{l}0 \\
0 \\
0 \\
0 \\
0\end{array}$ & $\begin{array}{r}0 \\
174,098 \\
0 \\
0 \\
0\end{array}$ & \\
\hline Total & $56,339,537$ & $56,339,537$ & 0 & 820,780 & 69,813 & 750,967 & \\
\hline
\end{tabular}

See footnotes at end of table. 
Table 8. Movements of Natural Gas by State, 1967-1994 (Continued)

(Milion Cubic Feet)

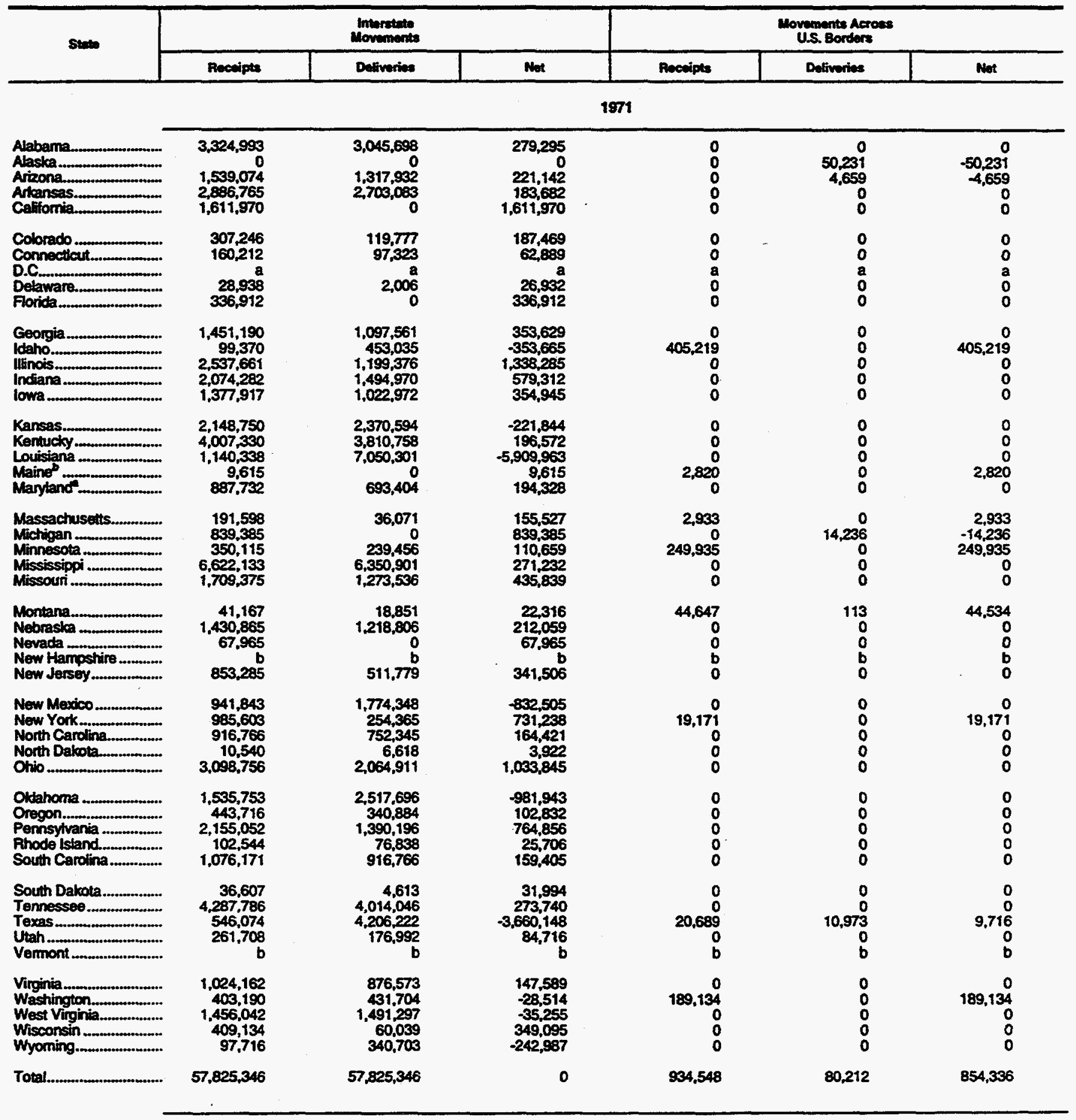

See footnotes at end of table. 
Table 8. Movements of Natural Gas by State, 1967-1994. (Continued)

(Million Cubic Feet)

\begin{tabular}{|c|c|c|c|c|c|c|}
\hline \multirow[t]{2}{*}{ Stato } & \multicolumn{3}{|c|}{ Intorstate } & \multicolumn{3}{|c|}{$\begin{array}{l}\text { Movements Aerces: } \\
\text { US. Borders }\end{array}$} \\
\hline & Recoipts & Detrueries & Net & Roceipts & Dolimeries & Not \\
\hline & \multicolumn{6}{|c|}{1972} \\
\hline 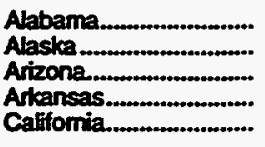 & $\begin{array}{r}3,280,337 \\
0 \\
1,697,235 \\
2,862,507 \\
1,778,649\end{array}$ & $\begin{array}{r}2,999,002 \\
0 \\
1,460,502 \\
2,687,122 \\
0\end{array}$ & $\begin{array}{r}281,335 \\
0 \\
236,733 \\
175,385 \\
1,778,649\end{array}$ & $\begin{array}{l}0 \\
0 \\
0 \\
0 \\
0\end{array}$ & $\begin{array}{r}0 \\
47,882 \\
4,521 \\
0 \\
0\end{array}$ & $\begin{array}{r}0 \\
-47,882 \\
4,521 \\
0 \\
0\end{array}$ \\
\hline $\begin{array}{l}\text { Colorado } \\
\text { Connecticut.... } \\
\text { D.C. } \\
\text { Delaware } \\
\text { Florida }\end{array}$ & $\begin{array}{r}330,661 \\
162,824 \\
a \\
25,962 \\
287,250\end{array}$ & $\begin{array}{r}126,293 \\
95,939 \\
a \\
1,966 \\
0\end{array}$ & $\begin{array}{r}204,368 \\
66,885 \\
a \\
23,996 \\
287,250\end{array}$ & $\begin{array}{l}0 \\
0 \\
a \\
0 \\
0\end{array}$ & $\begin{array}{l}0 \\
0 \\
a \\
0 \\
0\end{array}$ & $\begin{array}{l}0 \\
0 \\
a \\
0 \\
0\end{array}$ \\
\hline 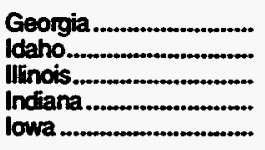 & $\begin{array}{r}1,400,727 \\
81,015 \\
2,470,725 \\
2,106,027 \\
1,402,943\end{array}$ & $\begin{array}{r}1,064,294 \\
455,378 \\
1,201,533 \\
1,517,039 \\
1,052,903\end{array}$ & $\begin{array}{r}336,433 \\
-374,363 \\
1,269,192 \\
588,988 \\
350,040\end{array}$ & $\begin{array}{r}0 \\
434,836 \\
0 \\
0 \\
0\end{array}$ & $\begin{array}{l}0 \\
0 \\
0 \\
0 \\
0\end{array}$ & $\begin{array}{r}0 \\
434,836 \\
0 \\
0 \\
0\end{array}$ \\
\hline $\begin{array}{l}\text { Kansas... } \\
\text { Kentucky. } \\
\text { Kouisiana } \\
\text { Maineb } \\
\text { Marylana }\end{array}$ & $\begin{array}{r}2,194,730 \\
3,957,250 \\
1,247,034 \\
10,282 \\
882,661\end{array}$ & $\begin{array}{r}2,411,550 \\
3,750,891 \\
7,069,882 \\
0 \\
670,572\end{array}$ & $\begin{array}{r}-216,820 \\
216,359 \\
-5,822,848 \\
10,282 \\
212,089\end{array}$ & $\begin{array}{r}0 \\
0 \\
0 \\
3,745 \\
0\end{array}$ & $\begin{array}{l}0 \\
0 \\
0 \\
0 \\
0\end{array}$ & $\begin{array}{r}0 \\
0 \\
0 \\
3,745 \\
0\end{array}$ \\
\hline $\begin{array}{l}\text { Massachusetts... } \\
\text { Michigan } \\
\text { Minnesota } \\
\text { Mississippi } \\
\text { Missoun }\end{array}$ & $\begin{array}{r}189,487 \\
823,515 \\
334,609 \\
6,582,428 \\
1,717,673\end{array}$ & $\begin{array}{r}25,033 \\
0 \\
235,116 \\
6,222.130 \\
1,282,951\end{array}$ & $\begin{array}{r}164,454 \\
823,515 \\
99,493 \\
360,298 \\
434,722\end{array}$ & $\begin{array}{r}2,262 \\
0 \\
256,856 \\
0 \\
0\end{array}$ & $\begin{array}{r}0 \\
15.426 \\
0 \\
0 \\
0\end{array}$ & $\begin{array}{r}2,262 \\
-15,426 \\
256,856 \\
0 \\
0\end{array}$ \\
\hline 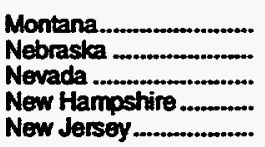 & $\begin{array}{r}18,112 \\
1,458,769 \\
71,214 \\
b \\
828,129\end{array}$ & $\begin{array}{r}12,363 \\
1,220,005 \\
0 \\
b \\
495,237\end{array}$ & $\begin{array}{r}5,749 \\
238,764 \\
71,214 \\
6 \\
332,892\end{array}$ & $\begin{array}{r}48,589 \\
0 \\
0 \\
b \\
0\end{array}$ & $\begin{array}{r}127 \\
0 \\
0 \\
b \\
0\end{array}$ & $\begin{array}{r}48,462 \\
0 \\
0 \\
b \\
0\end{array}$ \\
\hline 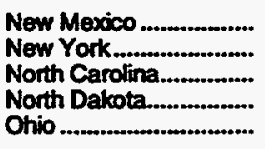 & $\begin{array}{r}1,036,716 \\
940,149 \\
893,642 \\
17,739 \\
2,995,531\end{array}$ & $\begin{array}{r}1,902,655 \\
265,808 \\
725,356 \\
9,401 \\
1,947,957\end{array}$ & $\begin{array}{r}-865,939 \\
674,341 \\
168,286 \\
8,338 \\
1,047,574\end{array}$ & $\begin{array}{r}0 \\
9,571 \\
0 \\
0 \\
0\end{array}$ & $\begin{array}{l}0 \\
0 \\
0 \\
0 \\
0\end{array}$ & $\begin{array}{r}0 \\
9,571 \\
0 \\
0 \\
0\end{array}$ \\
\hline 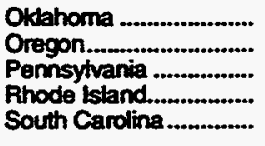 & $\begin{array}{r}1,422,394 \\
487,064 \\
2,074,454 \\
101,359 \\
1,044,679\end{array}$ & $\begin{array}{r}2,531,603 \\
371,989 \\
1,307,827 \\
77,868 \\
893,642\end{array}$ & $\begin{array}{r}-1,109,209 \\
115,075 \\
766,627 \\
23,491 \\
151,037\end{array}$ & $\begin{array}{l}0 \\
0 \\
0 \\
0 \\
0\end{array}$ & $\begin{array}{l}0 \\
0 \\
0 \\
0 \\
0\end{array}$ & $\begin{array}{l}0 \\
0 \\
0 \\
0 \\
0\end{array}$ \\
\hline $\begin{array}{l}\text { South Dakota } \\
\text { Tennessee } \\
\text { Texas } \\
\text { Texa } \\
\text { Utah } \\
\text { Vermont }\end{array}$ & $\begin{array}{r}36,164 \\
4,259,140 \\
550,684 \\
236,460 \\
b\end{array}$ & $\begin{array}{r}1,351 \\
3,975,797 \\
4,290,834 \\
135,143 \\
\text { b }\end{array}$ & $\begin{array}{r}34,813 \\
283,343 \\
-3,740,150 \\
101,317 \\
b\end{array}$ & $\begin{array}{r}0 \\
0 \\
8,141 \\
0 \\
b\end{array}$ & $\begin{array}{r}0 \\
0 \\
10,057 \\
0 \\
b\end{array}$ & $\begin{array}{r}0 \\
0 \\
-1,916 \\
0 \\
b\end{array}$ \\
\hline 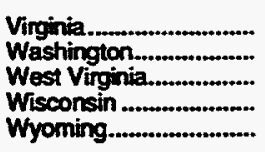 & $\begin{array}{r}1,028,270 \\
426,649 \\
1,430,913 \\
436,534 \\
83,781\end{array}$ & $\begin{array}{r}870,773 \\
499,728 \\
1,429,773 \\
105,675 \\
314,196\end{array}$ & $\begin{array}{r}157,497 \\
-73,079 \\
1,140 \\
330,859 \\
-230,415\end{array}$ & $\begin{array}{r}0 \\
255,496 \\
0 \\
0 \\
0\end{array}$ & $\begin{array}{l}0 \\
0 \\
0 \\
0 \\
0\end{array}$ & $\begin{array}{r}0 \\
255,496 \\
. \quad 0 \\
0 \\
0\end{array}$ \\
\hline Total................................ & $57,715,077$ & $57.715,077$ & 0 & $1,019,496$ & 78,013 & 941,483 \\
\hline
\end{tabular}

See footnotes at end of table. 
Table 8. Movements of Natural Gas by State, 1967-1994 (Continued) (Million Cubic Feet)

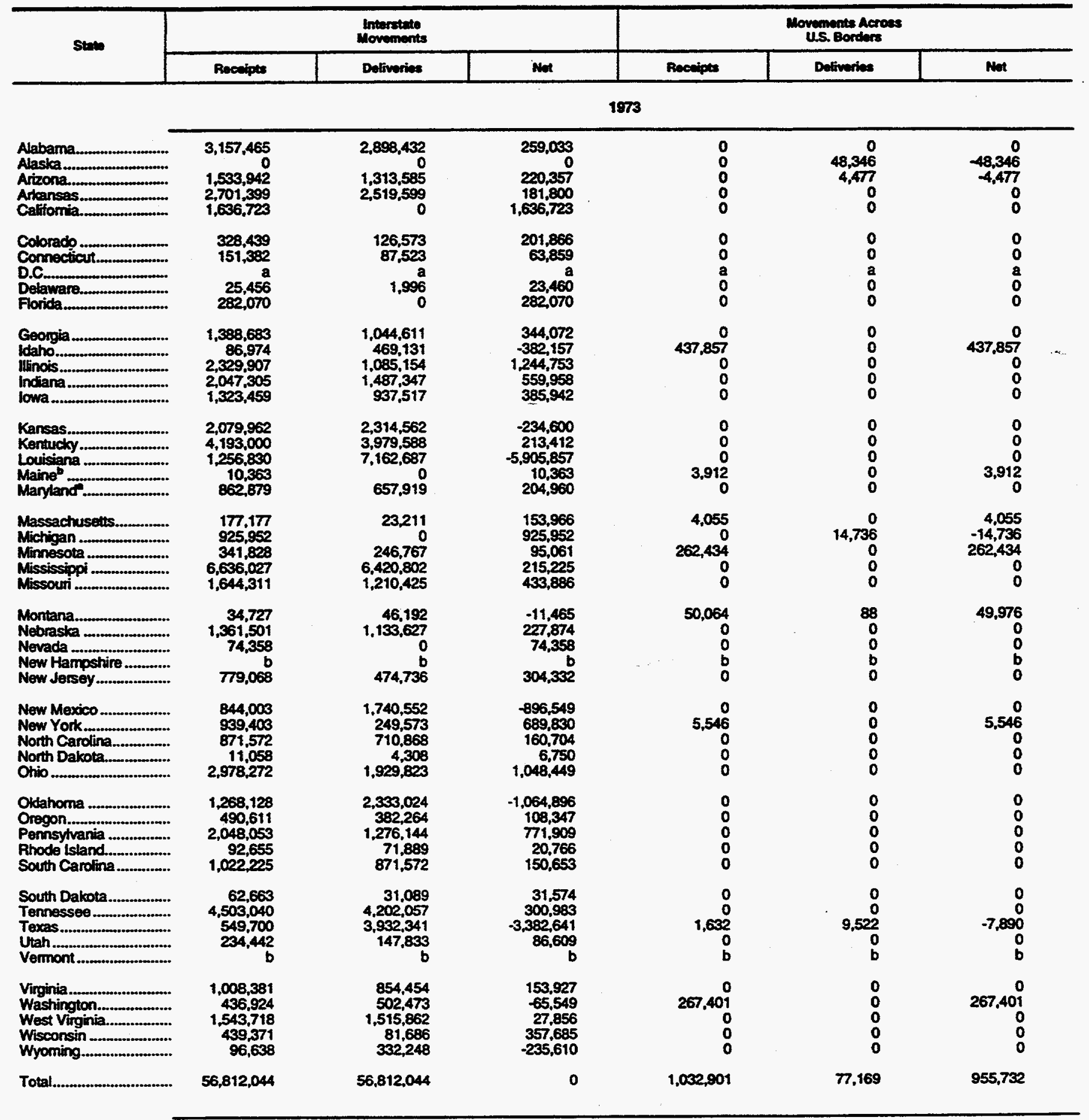


Table 8. Movements of Natural Gas by State, 1967-1994 (Continued) (Million Cubic Feet)

\begin{tabular}{|c|c|c|c|c|c|c|}
\hline \multirow[t]{2}{*}{ stam } & \multicolumn{3}{|c|}{$\begin{array}{l}\text { Intorstate } \\
\text { iloverentes }\end{array}$} & \multicolumn{3}{|c|}{$\begin{array}{l}\text { Mowwnents Across } \\
\text { U.S. Bordors }\end{array}$} \\
\hline & Rocsipts & Deliveries & Net & Recoupese & Deliverios & Not \\
\hline & \multicolumn{6}{|c|}{1974} \\
\hline 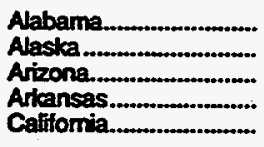 & $\begin{array}{r}2,927,510 \\
0 \\
1,491,149 \\
2,421,412 \\
1,598,378\end{array}$ & $\begin{array}{r}2,673,216 \\
0 \\
1,291,148 \\
2,249,394 \\
0\end{array}$ & $\begin{array}{r}254,294 \\
0 \\
200,001 \\
172,018 \\
1,598,378\end{array}$ & $\begin{array}{l}0 \\
0 \\
0 \\
0 \\
0\end{array}$ & $\begin{array}{r}0 \\
50,258 \\
4,217 \\
0 \\
0\end{array}$ & $\begin{array}{r}0 \\
-50,258 \\
-4,217 \\
0 \\
0\end{array}$ \\
\hline $\begin{array}{l}\text { Colorado } \\
\text { Connecticutt... } \\
\text { D.C. } \\
\text { Delaware. } \\
\text { Forida. }\end{array}$ & $\begin{array}{r}295,181 \\
160,854 \\
a \\
22,193 \\
255,493\end{array}$ & $\begin{array}{r}118,486 \\
94,299 \\
a \\
1,457 \\
0\end{array}$ & $\begin{array}{r}176,695 \\
66,555 \\
a \\
20,736 \\
255,493\end{array}$ & $\begin{array}{l}0 \\
0 \\
a \\
0 \\
0\end{array}$ & $\begin{array}{l}0 \\
0 \\
8 \\
0 \\
0\end{array}$ & $\begin{array}{l}0 \\
0 \\
a \\
0 \\
0\end{array}$ \\
\hline 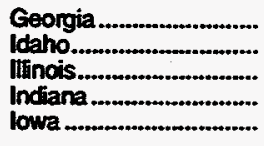 & $\begin{array}{r}1,227,583 \\
101,380 \\
2,213,790 \\
1,967,486 \\
1,379,323\end{array}$ & $\begin{array}{r}892,111 \\
453,673 \\
991,334 \\
1,435,665 \\
995,699\end{array}$ & $\begin{array}{r}335,472 \\
-352,293 \\
1,222,456 \\
531,821 \\
383,624\end{array}$ & $\begin{array}{r}0 \\
405,499 \\
0 \\
0 \\
0\end{array}$ & $\begin{array}{l}0 \\
0 \\
0 \\
0 \\
0\end{array}$ & $\begin{array}{r}0 \\
405,499 \\
0 \\
0 \\
0\end{array}$ \\
\hline 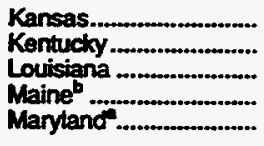 & $\begin{array}{r}2,100,454 \\
3,854,479 \\
972,873 \\
12,369 \\
752,816\end{array}$ & $\begin{array}{r}2,345,003 \\
3,684,235 \\
6,499,158 \\
1,934 \\
548,930\end{array}$ & $\begin{array}{r}-244,549 \\
170,244 \\
-5,526,285 \\
10,435 \\
203,886\end{array}$ & $\begin{array}{r}0 \\
0 \\
0 \\
4,891 \\
0\end{array}$ & $\begin{array}{l}0 \\
0 \\
0 \\
0 \\
0\end{array}$ & $\begin{array}{r}0 \\
0 \\
0 \\
4,891 \\
0\end{array}$ \\
\hline $\begin{array}{l}\text { Massachusetts. } \\
\text { Michigan } \\
\text { Minnesota } \\
\text { Mississippi } \\
\text { Missoun } \\
\end{array}$ & $\begin{array}{r}182,472 \\
869,059 \\
321,258 \\
6,064,296 \\
1,603,047\end{array}$ & $\begin{array}{r}26,779 \\
0 \\
223,040 \\
5,858,875 \\
1,184,299\end{array}$ & $\begin{array}{r}155,693 \\
869,059 \\
98,218 \\
205,421 \\
418,748\end{array}$ & $\begin{array}{r}0 \\
0 \\
256,100 \\
0 \\
0\end{array}$ & $\begin{array}{r}0 \\
13,232 \\
0 \\
0 \\
0\end{array}$ & $\begin{array}{r}0 \\
-13,232 \\
256,100 \\
0 \\
0\end{array}$ \\
\hline 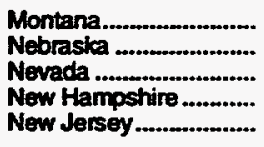 & $\begin{array}{r}22,934 \\
1,373,156 \\
64,593 \\
b \\
700,511\end{array}$ & $\begin{array}{r}25,183 \\
1,149,267 \\
0 \\
b \\
426,406\end{array}$ & $\begin{array}{r}-2,249 \\
223,889 \\
64,593 \\
b \\
274,105\end{array}$ & $\begin{array}{r}48,111 \\
0 \\
0 \\
b \\
0\end{array}$ & $\begin{array}{l}31 \\
0 \\
0 \\
b \\
0\end{array}$ & $\begin{array}{r}48,080 \\
0 \\
0 \\
b \\
0\end{array}$ \\
\hline 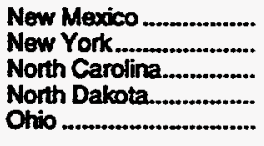 & $\begin{array}{r}784,918 \\
883,182 \\
732,669 \\
16,053 \\
2,778,124\end{array}$ & $\begin{array}{r}1,700,380 \\
256,725 \\
589,735 \\
6,301 \\
1,794,255\end{array}$ & $\begin{array}{r}-915,462 \\
626,457 \\
142,934 \\
9,752 \\
983,869\end{array}$ & $\begin{array}{r}0 \\
5,556 \\
0 \\
0 \\
0\end{array}$ & $\begin{array}{l}0 \\
0 \\
0 \\
0 \\
0\end{array}$ & $\begin{array}{r}0 \\
5,556 \\
0 \\
0 \\
0\end{array}$ \\
\hline 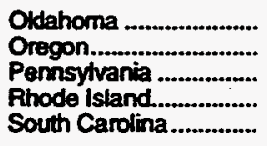 & $\begin{array}{r}1,451,639 \\
464,072 \\
1,776,519 \\
99,154 \\
869,771\end{array}$ & $\begin{array}{r}2,367,371 \\
359,991 \\
1,181,508 \\
75,696 \\
732,669\end{array}$ & $\begin{array}{r}-915,732 \\
104,081 \\
595,011 \\
23,458 \\
137,102\end{array}$ & $\begin{array}{l}0 \\
0 \\
0 \\
0 \\
0\end{array}$ & $\begin{array}{l}0 \\
0 \\
0 \\
0 \\
0\end{array}$ & $\begin{array}{l}0 \\
0 \\
0 \\
0 \\
0\end{array}$ \\
\hline $\begin{array}{l}\text { South Dakota.......... } \\
\text { Tennessee } \\
\text { Texas } \\
\text { Utah } \\
\text { Vermont }\end{array}$ & $\begin{array}{r}34,107 \\
4,127,109 \\
536,392 \\
238,164 \\
b\end{array}$ & $\begin{array}{r}1,901 \\
3,863,265 \\
3,757,200 \\
161,740 \\
\text { b }\end{array}$ & $\begin{array}{r}32,206 \\
263,844 \\
-3,220,808 \\
76,424 \\
b\end{array}$ & $\begin{array}{r}0 \\
0 \\
222 \\
0 \\
b\end{array}$ & $\begin{array}{r}0 \\
0 \\
9,051 \\
0 \\
0\end{array}$ & $\begin{array}{r}0 \\
0 \\
-8,829 \\
0 \\
b\end{array}$ \\
\hline 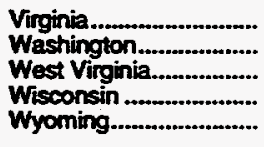 & $\begin{array}{r}889,360 \\
425,795 \\
1,295,565 \\
465,509 \\
97,006\end{array}$ & $\begin{array}{r}747,850 \\
477,866 \\
1,300,577 \\
79,739 \\
296,797\end{array}$ & $\begin{array}{r}141,510 \\
-52,071 \\
-5,012 \\
385,770 \\
-199,791\end{array}$ & $\begin{array}{r}0 \\
238,905 \\
0 \\
0 \\
0\end{array}$ & $\begin{array}{l}0 \\
0 \\
0 \\
0 \\
0\end{array}$ & $\begin{array}{r}0 \\
238,905 \\
0 \\
0 \\
0\end{array}$ \\
\hline 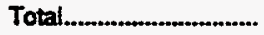 & $52,921,157$ & $52,921,157$ & 0 & 959.284 & 76,789 & 882,495 \\
\hline
\end{tabular}

See footnotes at end of table. 
Table 8. Movements of Natural Gas by State, 1967-1994. (Continued) (Million Cubic Feet)

\begin{tabular}{|c|c|c|c|c|c|c|}
\hline \multirow{2}{*}{ State } & \multicolumn{3}{|c|}{$\begin{array}{l}\text { Inswreteste } \\
\text { Mownents }\end{array}$} & \multicolumn{3}{|c|}{$\begin{array}{l}\text { Movements Across } \\
\text { U.S. Bordins }\end{array}$} \\
\hline & Recolpte & Dellueries & Nint & Recelpos & Dofivmeries & Net \\
\hline & \multicolumn{6}{|c|}{1975} \\
\hline 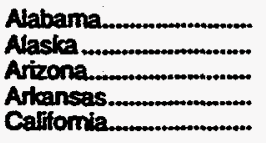 & $\begin{array}{r}2,716,837 \\
0 \\
1,388,649 \\
2,365,936 \\
1,569,946\end{array}$ & $\begin{array}{r}2,476,511 \\
0 \\
1,231,323 \\
2,218,627 \\
0\end{array}$ & $\begin{array}{r}240,326 \\
0 \\
157,326 \\
147,309 \\
1,569,946\end{array}$ & $\begin{array}{l}0 \\
0 \\
0 \\
0 \\
0\end{array}$ & $\begin{array}{r}0 \\
53,002 \\
3,203 \\
0 \\
0\end{array}$ & $\begin{array}{r}0 \\
-58,002 \\
-3,223 \\
0 \\
0\end{array}$ \\
\hline 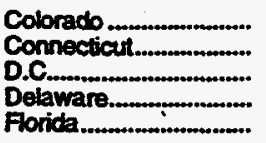 & $\begin{array}{r}279,070 \\
155,741 \\
a \\
20,894 \\
246,566\end{array}$ & $\begin{array}{r}134,124 \\
91,871 \\
a \\
1,221 \\
0\end{array}$ & $\begin{array}{r}144,946 \\
63,870 \\
a \\
19,673 \\
246,566\end{array}$ & $\begin{array}{l}0 \\
0 \\
a \\
0 \\
0\end{array}$ & $\begin{array}{l}0 \\
0 \\
\mathbf{a} \\
\mathbf{0} \\
\mathbf{0}\end{array}$ & $\begin{array}{l}0 \\
0 \\
\mathbf{2} \\
0 \\
0\end{array}$ \\
\hline $\begin{array}{l}\text { Georgia } \\
\text { Idaho } \\
\text { Illinois } \\
\text { Inctiana } \\
\text { lowa }\end{array}$ & $\begin{array}{r}1,137,354 \\
100,600 \\
2,112,982 \\
1,838,901 \\
1,309,669\end{array}$ & $\begin{array}{r}809,093 \\
421,876 \\
933,892 \\
1,353,199 \\
952,599\end{array}$ & $\begin{array}{r}328,261 \\
-321,276 \\
1,179,090 \\
485,702 \\
357,070\end{array}$ & $\begin{array}{r}0 \\
380,232 \\
0 \\
0 \\
0\end{array}$ & $\begin{array}{l}0 \\
0 \\
0 \\
0 \\
0\end{array}$ & $\begin{array}{r}0 \\
380,232 \\
0 \\
0 \\
0\end{array}$ \\
\hline 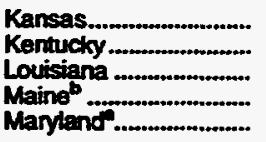 & $\begin{array}{r}1,852,575 \\
3,684,713 \\
1,181,696 \\
9,799 \\
676,710\end{array}$ & $\begin{array}{r}2,137,528 \\
3,513,056 \\
6,218,499 \\
0 \\
508,502\end{array}$ & $\begin{array}{r}-284,953 \\
171,657 \\
-5,036,803 \\
9,799 \\
168,208\end{array}$ & $\begin{array}{r}0 \\
0 \\
0 \\
4,124 \\
0\end{array}$ & $\begin{array}{l}0 \\
0 \\
0 \\
0 \\
0\end{array}$ & $\begin{array}{r}0 \\
0 \\
0 \\
4,124 \\
0\end{array}$ \\
\hline 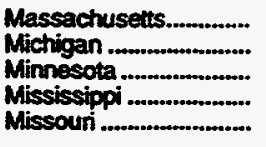 & $\begin{array}{r}178,298 \\
826,505 \\
308,975 \\
5,683,382 \\
1,535,678\end{array}$ & $\begin{array}{r}23,271 \\
0 \\
224,678 \\
5,521,131 \\
1,158,783\end{array}$ & $\begin{array}{r}155,027 \\
826,505 \\
84,297 \\
162,251 \\
376,895\end{array}$ & $\begin{array}{r}4,893 \\
0 \\
253,638 \\
0 \\
0\end{array}$ & $\begin{array}{r}0 \\
10,153 \\
0 \\
0 \\
0\end{array}$ & $\begin{array}{r}4,893 \\
-10,153 \\
253,638 \\
0 \\
0\end{array}$ \\
\hline 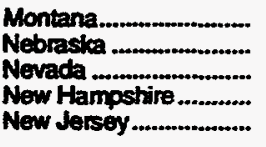 & $\begin{array}{r}14,061 \\
1,305,434 \\
61,463 \\
b \\
633,893\end{array}$ & $\begin{array}{r}23,587 \\
1,081,139 \\
0 \\
b \\
384,050\end{array}$ & $\begin{array}{r}-9,526 \\
224,296 \\
61,463 \\
b \\
249,843\end{array}$ & $\begin{array}{r}42,180 \\
0 \\
0 \\
b \\
0\end{array}$ & $\begin{array}{r}66 \\
0 \\
0 \\
b \\
0\end{array}$ & $\begin{array}{r}42,114 \\
0 \\
0 \\
b \\
0\end{array}$ \\
\hline 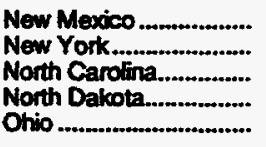 & $\begin{array}{r}717,762 \\
821,004 \\
659,826 \\
18,655 \\
2,641,647\end{array}$ & $\begin{array}{r}1,629,530 \\
250,455 \\
541,983 \\
3,490 \\
1,723,553\end{array}$ & $\begin{array}{r}-911,768 \\
570,549 \\
117,893 \\
15,165 \\
918,094\end{array}$ & $\begin{array}{r}0 \\
5,497 \\
0 \\
0 \\
0\end{array}$ & $\begin{array}{l}0 \\
0 \\
0 \\
0 \\
0\end{array}$ & $\begin{array}{r}0 \\
5,497 \\
0 \\
0 \\
0\end{array}$ \\
\hline 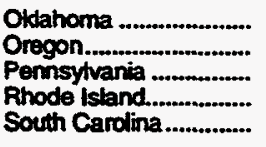 & $\begin{array}{r}1,220,782 \\
517,337 \\
1,721,102 \\
97,119 \\
786,871\end{array}$ & $\begin{array}{r}2,090,214 \\
403,477 \\
1,097,990 \\
75,886 \\
659,826\end{array}$ & $\begin{array}{r}-869,432 \\
113,850 \\
623,112 \\
21,233 \\
127,045\end{array}$ & $\begin{array}{l}0 \\
0 \\
0 \\
0 \\
0\end{array}$ & $\begin{array}{l}0 \\
0 \\
0 \\
0 \\
0\end{array}$ & $\begin{array}{l}0 \\
0 \\
0 \\
0 \\
0\end{array}$ \\
\hline 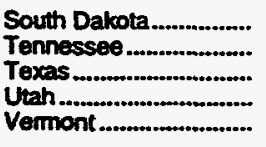 & $\begin{array}{r}34,677 \\
3,912,003 \\
544,730 \\
206,470 \\
b\end{array}$ & $\begin{array}{r}1,428 \\
3,690,655 \\
3,616,338 \\
131,094 \\
b\end{array}$ & $\begin{array}{r}33,249 \\
221,348 \\
-3,071,609 \\
75,376 \\
b\end{array}$ & $\begin{array}{l}0 \\
0 \\
0 \\
0 \\
b\end{array}$ & $\begin{array}{r}0 \\
0 \\
6,230 \\
0 \\
b\end{array}$ & $\begin{array}{r}0 \\
0 \\
-6,230 \\
0 \\
b\end{array}$ \\
\hline 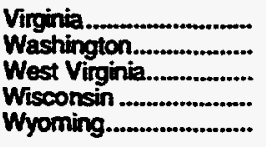 & $\begin{array}{r}791,615 \\
389,810 \\
1,241,589 \\
464,271 \\
104,385\end{array}$ & $\begin{array}{r}672,911 \\
485,271 \\
1,194,850 \\
93,154 \\
307,368\end{array}$ & $\begin{array}{r}118,704 \\
-95,461 \\
46,739 \\
371,117 \\
-202,983\end{array}$ & $\begin{array}{r}0 \\
262.443 \\
0 \\
0 \\
0\end{array}$ & $\begin{array}{l}0 \\
0 \\
0 \\
0 \\
0\end{array}$ & $\begin{array}{r}0 \\
262,443 \\
0 \\
0 \\
0\end{array}$ \\
\hline Total & $50,087,982$ & $50,087,982$ & 0 & 953,008 & 72,675 & 880,333 \\
\hline
\end{tabular}

See footnotes at end of table. 
Table 8. Movements of Natural Gas by State, 1967-1994 (Continued) (Million Cubic Feet)

\begin{tabular}{|c|c|c|c|c|c|c|}
\hline \multirow[t]{2}{*}{ stato } & \multicolumn{3}{|c|}{$\begin{array}{l}\text { Imierstate } \\
\text { Movements }\end{array}$} & \multicolumn{3}{|c|}{$\begin{array}{l}\text { Movenemes Acroes } \\
\text { U.S. Bordiors }\end{array}$} \\
\hline & Rocelpts & Detiveriese & Not & Rocsipts & Deliverios: & Net \\
\hline & \multicolumn{6}{|c|}{1976} \\
\hline 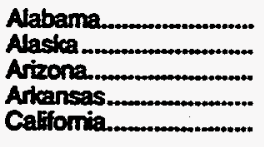 & $\begin{array}{r}2,686,071 \\
0 \\
1,265,930 \\
2,349,241 \\
1,474,658\end{array}$ & $\begin{array}{r}2,496,561 \\
0 \\
1,093,797 \\
2,192,542 \\
0\end{array}$ & $\begin{array}{r}189,510 \\
0 \\
172,133 \\
156,699 \\
1,474,658\end{array}$ & $\begin{array}{l}0 \\
0 \\
0 \\
0 \\
0\end{array}$ & $\begin{array}{r}0 \\
49,780 \\
1,665 \\
0 \\
0\end{array}$ & $\begin{array}{r}0 \\
-49,780 \\
-1,665 \\
0 \\
0\end{array}$ \\
\hline 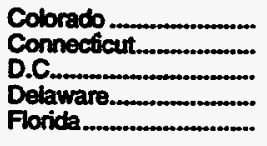 & $\begin{array}{r}269,218 \\
144,040 \\
a \\
20,179 \\
259,717\end{array}$ & $\begin{array}{r}137.180 \\
78,530 \\
a \\
1,178 \\
0\end{array}$ & $\begin{array}{r}132,038 \\
65,510 \\
a \\
19,001 \\
259,717\end{array}$ & $\begin{array}{l}0 \\
0 \\
a \\
0 \\
0\end{array}$ & $\begin{array}{l}0 \\
0 \\
\mathbf{a} \\
0 \\
0\end{array}$ & $\begin{array}{l}0 \\
0 \\
a \\
0 \\
0\end{array}$ \\
\hline 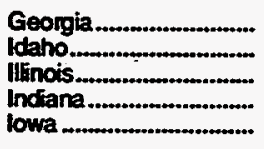 & $\begin{array}{r}1,047,507 \\
94,110 \\
2,140,583 \\
1,663,876 \\
1,325,699\end{array}$ & $\begin{array}{r}786,275 \\
487,023 \\
896,971 \\
1,239,222 \\
991,843\end{array}$ & $\begin{array}{r}261,232 \\
-392,913 \\
1,243,612 \\
424,654 \\
333,856\end{array}$ & $\begin{array}{r}0 \\
440,276 \\
0 \\
0 \\
0\end{array}$ & $\begin{array}{l}0 \\
0 \\
0 \\
0 \\
0\end{array}$ & $\begin{array}{r}0 \\
440,276 \\
0 \\
0 \\
0\end{array}$ \\
\hline $\begin{array}{l}\text { Kansas... } \\
\text { Kentucky } \\
\text { Louisiana } \\
\text { Maine } \\
\text { Marylanct. }\end{array}$ & $\begin{array}{r}1,877,945 \\
3,407,936 \\
985,150 \\
9,823 \\
634,812\end{array}$ & $\begin{array}{r}2,151,678 \\
3,219,540 \\
5,770,752 \\
0 \\
457,011\end{array}$ & $\begin{array}{r}-273,733 \\
188,396 \\
-4,785,602 \\
9,823 \\
177,801\end{array}$ & $\begin{array}{r}0 \\
0 \\
0 \\
4,066 \\
0\end{array}$ & $\begin{array}{l}0 \\
0 \\
0 \\
0 \\
0\end{array}$ & $\begin{array}{r}0 \\
0 \\
0 \\
4,066 \\
0\end{array}$ \\
\hline 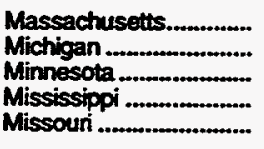 & $\begin{array}{r}175,739 \\
742,482 \\
308,975 \\
5,233,400 \\
1,517,775\end{array}$ & $\begin{array}{r}28,932 \\
0 \\
238,474 \\
5,112,309 \\
1,139,598\end{array}$ & $\begin{array}{r}146,807 \\
742,482 \\
70,501 \\
121,091 \\
378,177\end{array}$ & $\begin{array}{r}10,155 \\
0 \\
254,858 \\
0 \\
0\end{array}$ & $\begin{array}{r}0 \\
7,461 \\
0 \\
0 \\
0\end{array}$ & $\begin{array}{r}10,155 \\
-7,461 \\
254,858 \\
0 \\
0\end{array}$ \\
\hline 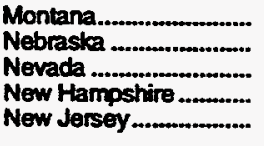 & $\begin{array}{r}8.189 \\
1,341,096 \\
67,300 \\
b \\
705,488\end{array}$ & $\begin{array}{r}22,447 \\
1,138,711 \\
0 \\
b \\
375,966\end{array}$ & $\begin{array}{r}-14,258 \\
202,385 \\
67,300 \\
b \\
329,516\end{array}$ & $\begin{array}{r}35,633 \\
0 \\
0 \\
b \\
0\end{array}$ & $\begin{array}{r}45 \\
0 \\
0 \\
b \\
0\end{array}$ & $\begin{array}{r}35,588 \\
0 \\
0 \\
b \\
0\end{array}$ \\
\hline 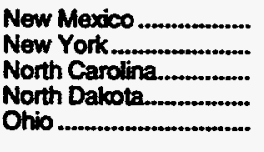 & $\begin{array}{r}630,215 \\
819,575 \\
600,683 \\
15,530 \\
2,512,997\end{array}$ & $\begin{array}{r}1,512,447 \\
242,378 \\
495,998 \\
1,403 \\
1,634,534\end{array}$ & $\begin{array}{l}-882,232 \\
577,197 \\
104,685 \\
14,127 \\
878,463\end{array}$ & $\begin{array}{r}0 \\
5,537 \\
0 \\
0 \\
0\end{array}$ & $\begin{array}{l}0 \\
0 \\
0 \\
0 \\
0\end{array}$ & $\begin{array}{r}0 \\
5.537 \\
0 \\
0 \\
0\end{array}$ \\
\hline 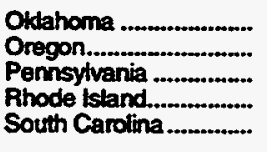 & $\begin{array}{r}1,245,596 \\
546,601 \\
1,728,941 \\
83,390 \\
768,722\end{array}$ & $\begin{array}{r}2,161,079 \\
451,649 \\
1,178,012 \\
63,648 \\
600,683\end{array}$ & $\begin{array}{r}-915,483 \\
94,952 \\
550,929 \\
19,742 \\
163,039\end{array}$ & $\begin{array}{l}0 \\
0 \\
0 \\
0 \\
0\end{array}$ & $\begin{array}{l}0 \\
0 \\
0 \\
0 \\
0\end{array}$ & $\begin{array}{l}0 \\
0 \\
0 \\
0 \\
0\end{array}$ \\
\hline $\begin{array}{l}\text { South Dakola } \\
\text { Tennessee } \\
\text { Texas } \\
\text { Textah } \\
\text { Vermont } \\
\text { Ver..... }\end{array}$ & $\begin{array}{r}41,498 \\
3,631,175 \\
634,907 \\
220,219 \\
\text { b }\end{array}$ & $\begin{array}{r}1,385 \\
3,415,042 \\
3,391,257 \\
122,503 \\
b\end{array}$ & $\begin{array}{r}40,113 \\
216,133 \\
-2,756,350 \\
97,716 \\
b\end{array}$ & $\begin{array}{l}0 \\
0 \\
0 \\
0 \\
b\end{array}$ & $\begin{array}{r}0 \\
0 \\
5,760 \\
0 \\
b\end{array}$ & $\begin{array}{r}0 \\
0 \\
-5.760 \\
0 \\
b\end{array}$ \\
\hline 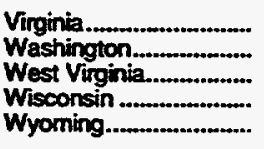 & $\begin{array}{r}755.515 \\
436.144 \\
1.195 .503 \\
473.612 \\
104.394\end{array}$ & $\begin{array}{r}633,272 \\
495,722 \\
1,259,379 \\
157,996 \\
322,223\end{array}$ & $\begin{array}{r}122,243 \\
-59,578 \\
-63,876 \\
315,616 \\
-217,829\end{array}$ & $\begin{array}{r}0 \\
213,243 \\
0 \\
0 \\
0\end{array}$ & $\begin{array}{l}0 \\
0 \\
0 \\
0 \\
0\end{array}$ & $\begin{array}{r}0 \\
213,243 \\
0 \\
0 \\
0\end{array}$ \\
\hline Total..................... & $48,197,150$ & $48,197,150$ & 0 & 963,768 & 64,711 & 899.057 \\
\hline
\end{tabular}

See foomoles at end of table. 
Table 8. Movements of Natural Gas by State, 1967-1994. (Continued) (Million Cubic Feet)

\begin{tabular}{|c|c|c|c|c|c|c|}
\hline \multirow[t]{2}{*}{ Stute } & \multicolumn{3}{|c|}{$\begin{array}{c}\text { Intorstate } \\
\text { Mowernents }\end{array}$} & \multicolumn{3}{|c|}{$\begin{array}{c}\text { Movements Acroas } \\
\text { U.S. Borders }\end{array}$} \\
\hline & Aocoipts & Detiveries & Not & Roceipts & Defiveries & Not \\
\hline & \multicolumn{6}{|c|}{1977} \\
\hline 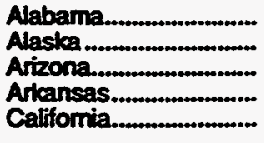 & $\begin{array}{r}2,582,686 \\
0 \\
1,273,610 \\
2,224,850 \\
1,484,303\end{array}$ & $\begin{array}{r}2,398,807 \\
0 \\
1,106,086 \\
2,101,603 \\
0\end{array}$ & $\begin{array}{r}183,879 \\
0 \\
167,524 \\
123,247 \\
1,484,303\end{array}$ & $\begin{array}{l}0 \\
0 \\
0 \\
0 \\
0\end{array}$ & $\begin{array}{r}0 \\
51,655 \\
672 \\
0 \\
0\end{array}$ & $\begin{array}{r}0 \\
-51,655 \\
-672 \\
0 \\
0\end{array}$ \\
\hline 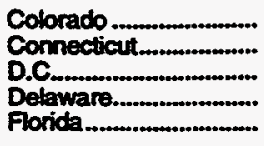 & $\begin{array}{r}252,362 \\
155,096 \\
17,094 \\
257,996\end{array}$ & $\begin{array}{r}155,732 \\
89,668 \\
a \\
0 \\
0\end{array}$ & $\begin{array}{r}96,680 \\
65,428 \\
a \\
17,084 \\
257,996\end{array}$ & $\begin{array}{r}0 \\
0 \\
a \\
224 \\
0\end{array}$ & $\begin{array}{l}0 \\
0 \\
a \\
0 \\
0\end{array}$ & $\begin{array}{r}0 \\
0 \\
a \\
224 \\
0\end{array}$ \\
\hline 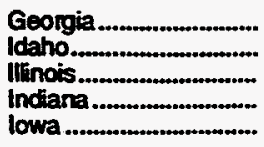 & $\begin{array}{r}951,567 \\
99,573 \\
2,134,641 \\
1,566,492 \\
1,260,124\end{array}$ & $\begin{array}{r}679,433 \\
443,519 \\
884,741 \\
1,165,698 \\
950,776\end{array}$ & $\begin{array}{r}272,134 \\
-343,946 \\
1,249,900 \\
400,794 \\
309,348\end{array}$ & $\begin{array}{r}0 \\
390,095 \\
0 \\
0 \\
0\end{array}$ & $\begin{array}{l}0 \\
0 \\
0 \\
0 \\
0\end{array}$ & $\begin{array}{r}0 \\
390,095 \\
0 \\
0 \\
0\end{array}$ \\
\hline 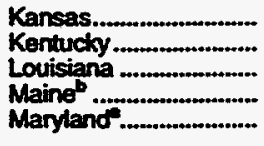 & $\begin{array}{r}1,807,647 \\
3,386,909 \\
1,026,909 \\
21,992 \\
589,471\end{array}$ & $\begin{array}{r}2,029,120 \\
3,207,686 \\
5,815,429 \\
2,115 \\
424,605\end{array}$ & $\begin{array}{r}-221,473 \\
179,223 \\
-4,788,520 \\
19,867 \\
164,866\end{array}$ & $\begin{array}{r}0 \\
0 \\
0 \\
4,263 \\
0\end{array}$ & $\begin{array}{l}0 \\
0 \\
0 \\
0 \\
0\end{array}$ & $\begin{array}{r}0 \\
0 \\
0 \\
4,263 \\
0\end{array}$ \\
\hline 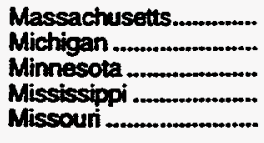 & $\begin{array}{r}220,596 \\
664,617 \\
331,219 \\
5.087,125 \\
1,520,721\end{array}$ & $\begin{array}{r}60,655 \\
0 \\
306,038 \\
4,960,512 \\
1,153,708\end{array}$ & $\begin{array}{r}159,941 \\
664,617 \\
25,181 \\
126,613 \\
367,013\end{array}$ & $\begin{array}{r}11,522 \\
0 \\
276,453 \\
0 \\
0\end{array}$ & $\begin{array}{l}0 \\
0 \\
0 \\
0 \\
0\end{array}$ & $\begin{array}{r}11,522 \\
0 \\
276,453 \\
0 \\
0\end{array}$ \\
\hline 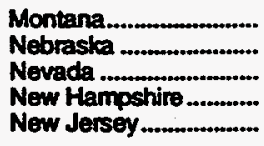 & $\begin{array}{r}15,919 \\
1,248,780 \\
71,052 \\
b \\
597,845\end{array}$ & $\begin{array}{r}17,587 \\
1,087,828 \\
0 \\
b \\
362,275\end{array}$ & $\begin{array}{r}-1,668 \\
160,952 \\
71,052 \\
b \\
235,570\end{array}$ & $\begin{array}{r}31.619 \\
0 \\
0 \\
b \\
150\end{array}$ & $\begin{array}{r}31 \\
0 \\
0 \\
b \\
0\end{array}$ & $\begin{array}{r}31,588 \\
0 \\
0 \\
b \\
150\end{array}$ \\
\hline 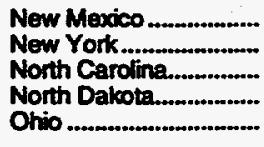 & $\begin{array}{r}598,738 \\
741,393 \\
517,264 \\
11,388 \\
2,461,503\end{array}$ & $\begin{array}{r}1,518,098 \\
277,228 \\
450,232 \\
0 \\
1,671,667\end{array}$ & $\begin{array}{r}-919,360 \\
464,105 \\
67,032 \\
11,388 \\
789,836\end{array}$ & $\begin{array}{r}0 \\
7,854 \\
0 \\
0 \\
0\end{array}$ & $\begin{array}{l}0 \\
0 \\
0 \\
0 \\
0\end{array}$ & $\begin{array}{r}0 \\
7.854 \\
0 \\
0 \\
0\end{array}$ \\
\hline 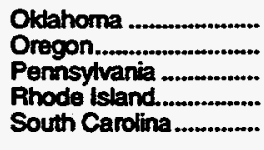 & $\begin{array}{r}1,181,518 \\
581,615 \\
1,665,935 \\
95,018 \\
659,591\end{array}$ & $\begin{array}{r}2,045,675 \\
514,363 \\
1,014,084 \\
63,648 \\
517,264\end{array}$ & $\begin{array}{r}-864,157 \\
67,252 \\
651,851 \\
31,370 \\
142,327\end{array}$ & $\begin{array}{l}0 \\
0 \\
0 \\
0 \\
0\end{array}$ & $\begin{array}{l}0 \\
0 \\
0 \\
0 \\
0\end{array}$ & $\begin{array}{l}0 \\
0 \\
0 \\
0 \\
0\end{array}$ \\
\hline $\begin{array}{l}\text { South Dakota } \\
\text { Tennessee } \\
\text { Texas } \\
\text { Utah } \\
\text { Vermont }\end{array}$ & $\begin{array}{r}40,216 \\
3,583,552 \\
812,304 \\
166,523 \\
\mathrm{~b}\end{array}$ & $\begin{array}{r}3,507 \\
3,394,257 \\
3,246,816 \\
120,468 \\
\text { b }\end{array}$ & $\begin{array}{r}36,709 \\
189,295 \\
-2,434,512 \\
46,055 \\
b\end{array}$ & $\begin{array}{r}0 \\
0 \\
2,384 \\
0 \\
b\end{array}$ & $\begin{array}{r}0 \\
0 \\
3,268 \\
0 \\
b\end{array}$ & $\begin{array}{r}0 \\
0 \\
-884 \\
0 \\
b\end{array}$ \\
\hline 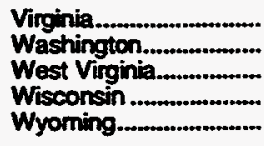 & $\begin{array}{r}686,485 \\
434,241 \\
1,274,217 \\
510,029 \\
78,096\end{array}$ & $\begin{array}{r}574,675 \\
572,337 \\
1,182,381 \\
124,835 \\
255,586\end{array}$ & $\begin{array}{r}111,810 \\
-138,096 \\
91,836 \\
385,194 \\
-177,490\end{array}$ & $\begin{array}{r}0 \\
286,437 \\
0 \\
0 \\
0\end{array}$ & $\begin{array}{l}0 \\
0 \\
0 \\
0 \\
0\end{array}$ & $\begin{array}{r}0 \\
286,437 \\
0 \\
0 \\
0\end{array}$ \\
\hline Total & $46,950,742$ & $46,950,742$ & 0 & $1,011,002$ & 55,626 & $\mathbf{9 5 5 , 3 7 6}$ \\
\hline
\end{tabular}

See fooinotes at end of tabie. 
Table 8. Movements of Natural Gas by State, 1967-1994 (Continued) (Million Cubic Feet)

\begin{tabular}{|c|c|c|c|c|c|c|}
\hline \multirow{2}{*}{ state } & \multicolumn{3}{|c|}{$\begin{array}{l}\text { Interztete } \\
\text { Movoments: }\end{array}$} & \multicolumn{3}{|c|}{$\begin{array}{c}\text { Movements Acros: } \\
\text { U.S. Borders }\end{array}$} \\
\hline & Recolptis & Defiveries & Net & Rocaipts & Deflivarios & Net \\
\hline & \multicolumn{6}{|c|}{1978} \\
\hline 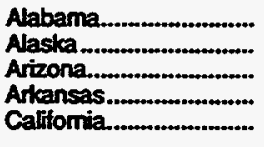 & $\begin{array}{r}2,566,115 \\
0 \\
1,106,300 \\
2,346,437 \\
1,252,011\end{array}$ & $\begin{array}{r}2,406,395 \\
0 \\
933,769 \\
2,224,216 \\
0\end{array}$ & $\begin{array}{r}159,720 \\
0 \\
172,531 \\
122,221 \\
1,252,011\end{array}$ & $\begin{array}{l}0 \\
0 \\
0 \\
0 \\
0\end{array}$ & $\begin{array}{r}0 \\
48,434 \\
0 \\
0 \\
0\end{array}$ & $\begin{array}{r}0 \\
-48,434 \\
0 \\
0 \\
0\end{array}$ \\
\hline $\begin{array}{l}\text { Colorado } \\
\text { Connecticut..... } \\
\text { D.C.C. } \\
\text { Delaware } \\
\text { Florida }\end{array}$ & $\begin{array}{r}267,866 \\
146,892 \\
a \\
20,920 \\
281,170\end{array}$ & $\begin{array}{r}165,043 \\
85,378 \\
a \\
0 \\
0\end{array}$ & $\begin{array}{r}102,823 \\
61,514 \\
a \\
20,920 \\
281,170\end{array}$ & $\begin{array}{l}0 \\
0 \\
a \\
0 \\
0\end{array}$ & $\begin{array}{l}0 \\
0 \\
a \\
0 \\
0\end{array}$ & $\begin{array}{l}0 \\
0 \\
a \\
0 \\
0\end{array}$ \\
\hline 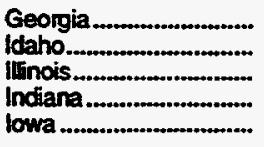 & $\begin{array}{r}943,636 \\
59,758 \\
2,245,661 \\
1,640,895 \\
1,220,827\end{array}$ & $\begin{array}{r}684,739 \\
399,341 \\
1,037,504 \\
1,189,675 \\
970,927\end{array}$ & $\begin{array}{r}258,897 \\
-339,583 \\
1,208,157 \\
451,220 \\
249,900\end{array}$ & $\begin{array}{r}22,358 \\
384,536 \\
0 \\
0 \\
0\end{array}$ & $\begin{array}{l}0 \\
0 \\
0 \\
0 \\
0\end{array}$ & $\begin{array}{r}22,358 \\
384,536 \\
0 \\
0 \\
0\end{array}$ \\
\hline 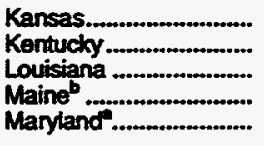 & $\begin{array}{r}1,662,386 \\
3,437,020 \\
677,122 \\
10,570 \\
543,974\end{array}$ & $\begin{array}{r}1,951,995 \\
3,276,196 \\
5,716,788 \\
0 \\
015,482\end{array}$ & $\begin{array}{r}-289,609 \\
160,824 \\
-5,039,666 \\
10,570 \\
128,492\end{array}$ & $\begin{array}{r}0 \\
0 \\
0 \\
4,224 \\
47,496\end{array}$ & $\begin{array}{l}0 \\
0 \\
0 \\
0 \\
0\end{array}$ & $\begin{array}{r}0 \\
0 \\
0 \\
4,224 \\
47,496\end{array}$ \\
\hline $\begin{array}{l}\text { Massachusetts... } \\
\text { Michigan } \\
\text { Minnesota } \\
\text { Mississippi } \\
\text { Missoun }\end{array}$ & $\begin{array}{r}169,023 \\
664,144 \\
308,975 \\
5,102,266 \\
1,537,431\end{array}$ & $\begin{array}{r}22,185 \\
0 \\
235,732 \\
4,994,098 \\
1,168,810\end{array}$ & $\begin{array}{r}146,838 \\
664,144 \\
73,243 \\
108,168 \\
368,621\end{array}$ & $\begin{array}{r}14,568 \\
0 \\
248,453 \\
0 \\
0\end{array}$ & $\begin{array}{l}0 \\
0 \\
0 \\
0 \\
0\end{array}$ & $\begin{array}{r}14,568 \\
0 \\
248,453 \\
0 \\
0\end{array}$ \\
\hline 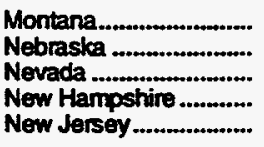 & $\begin{array}{r}17,424 \\
1,201,335 \\
65,507 \\
\mathbf{b} \\
601,305\end{array}$ & $\begin{array}{r}18,325 \\
1,041,156 \\
0 \\
b \\
371,219\end{array}$ & $\begin{array}{r}-901 \\
160,179 \\
65,507 \\
b \\
230,086\end{array}$ & $\begin{array}{r}28,102 \\
0 \\
0 \\
b \\
0\end{array}$ & $\begin{array}{r}66 \\
0 \\
0 \\
b \\
0\end{array}$ & $\begin{array}{r}28,036 \\
0 \\
0 \\
b \\
0\end{array}$ \\
\hline 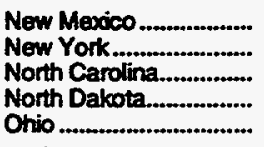 & $\begin{array}{r}413,935 \\
793,109 \\
539,601 \\
13,155 \\
2,469,659\end{array}$ & $\begin{array}{r}1,309,836 \\
241,313 \\
454,777 \\
500 \\
1,625,596\end{array}$ & $\begin{array}{r}-895,901 \\
551,796 \\
84,824 \\
12,655 \\
844,003\end{array}$ & $\begin{array}{r}0 \\
6,231 \\
0 \\
0 \\
0\end{array}$ & $\begin{array}{l}0 \\
0 \\
0 \\
0 \\
0\end{array}$ & $\begin{array}{r}0 \\
6,231 \\
0 \\
0 \\
0\end{array}$ \\
\hline 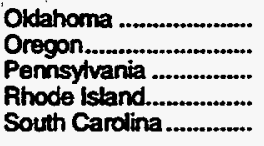 & $\begin{array}{r}902,256 \\
475,712 \\
1,667,275 \\
90,876 \\
660,057\end{array}$ & $\begin{array}{r}1,817,265 \\
387,285 \\
1,065,881 \\
69,080 \\
539,601\end{array}$ & $\begin{array}{r}-915,009 \\
88,427 \\
601,394 \\
21,796 \\
120,456\end{array}$ & $\begin{array}{l}0 \\
0 \\
0 \\
0 \\
0\end{array}$ & $\begin{array}{l}0 \\
0 \\
0 \\
0 \\
0\end{array}$ & $\begin{array}{l}0 \\
0 \\
0 \\
0 \\
0\end{array}$ \\
\hline $\begin{array}{l}\text { South Dakota } \\
\text { Tennessee } \\
\text { Texas } \\
\text { Utah } \\
\text { Vermont }\end{array}$ & $\begin{array}{r}39,252 \\
3,630,187 \\
673,642 \\
168,495 \\
\text { b }\end{array}$ & $\begin{array}{r}1,423 \\
3,443,194 \\
2,523,974 \\
101,036 \\
b\end{array}$ & $\begin{array}{r}37,829 \\
186,993 \\
-1,850,332 \\
67,459 \\
b\end{array}$ & $\begin{array}{l}0 \\
0 \\
0 \\
0 \\
b\end{array}$ & $\begin{array}{r}0 \\
0 \\
4,032 \\
0 \\
b\end{array}$ & $\begin{array}{r}0 \\
0 \\
-4,032 \\
0 \\
b\end{array}$ \\
\hline 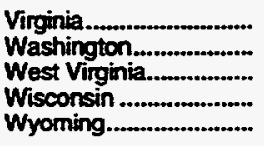 & $\begin{array}{r}689,776 \\
399,341 \\
1,250,535 \\
512,647 \\
77,861\end{array}$ & $\begin{array}{r}540,278 \\
475,712 \\
1,216,200 \\
132,490 \\
289,927\end{array}$ & $\begin{array}{r}129,498 \\
-76,371 \\
34,335 \\
380,157 \\
-212,066\end{array}$ & $\begin{array}{r}0 \\
209,577 \\
0 \\
0 \\
0\end{array}$ & $\begin{array}{l}0 \\
0 \\
0 \\
0 \\
0\end{array}$ & $\begin{array}{r}0 \\
209,577 \\
0 \\
0 \\
0\end{array}$ \\
\hline Total ........................... & $45,544,341$ & $45,544,341$ & 0 & $\mathbf{9 6 5 . 5 4 5}$ & $\mathbf{5 2 , 5 3 2}$ & 913,013 \\
\hline
\end{tabular}

See footnotes at end of table. 
Table 8. Movements of Natural Gas by State, 1967-1994 (Continued) (Million Cubic Feet)

\begin{tabular}{|c|c|c|c|c|c|c|}
\hline \multirow{2}{*}{ Stuto } & \multicolumn{3}{|c|}{$\begin{array}{l}\text { Interstate } \\
\text { Movements }\end{array}$} & \multicolumn{3}{|c|}{$\begin{array}{l}\text { Mowments Acroess } \\
\text { US. Borders }\end{array}$} \\
\hline & Peceipts & Defiveries & $\mathrm{Nom}$ & Alocesipts & Defiveries & Not \\
\hline & \multicolumn{6}{|c|}{1878} \\
\hline $\begin{array}{l}\text { Alabama. } \\
\text { Alaska } \\
\text { Arizona. } \\
\text { Avkansas..... } \\
\text { California }\end{array}$ & $\begin{array}{r}2,720,629 \\
0 \\
1,328,521 \\
2,610,559 \\
1,626,812\end{array}$ & $\begin{array}{r}2,517,934 \\
0 \\
1,154,774 \\
2,454,689 \\
0\end{array}$ & $\begin{array}{r}202,695 \\
0 \\
173,747 \\
155,870 \\
1,626,812\end{array}$ & $\begin{array}{l}0 \\
0 \\
0 \\
0 \\
0\end{array}$ & $\begin{array}{r}0 \\
51,289 \\
706 \\
0 \\
0\end{array}$ & $\begin{array}{r}0 \\
-51,289 \\
-706 \\
0 \\
0\end{array}$ \\
\hline $\begin{array}{l}\text { Colorado } \\
\text { Connecticut... } \\
\text { D.C. } \\
\text { Delaware. } \\
\text { Florida. }\end{array}$ & $\begin{array}{r}274,941 \\
152,009 \\
\text { a } \\
26,992 \\
307,587\end{array}$ & $\begin{array}{r}149,485 \\
82,026 \\
8 \\
1,684 \\
0\end{array}$ & $\begin{array}{r}125,456 \\
69,983 \\
\text { a } \\
25,308 \\
307,587\end{array}$ & $\begin{array}{l}0 \\
0 \\
\mathrm{a} \\
0 \\
0\end{array}$ & $\begin{array}{l}0 \\
0 \\
a \\
0 \\
0\end{array}$ & $\begin{array}{l}0 \\
0 \\
8 \\
0 \\
0\end{array}$ \\
\hline 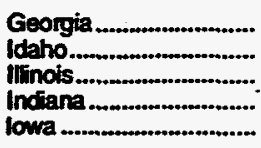 & $\begin{array}{r}1,041,167 \\
93,426 \\
2,239,878 \\
1,776,965 \\
1,182,263\end{array}$ & $\begin{array}{r}810,314 \\
470,848 \\
1,031,254 \\
1,259,512 \\
874,890\end{array}$ & $\begin{array}{r}230,853 \\
-377,422 \\
1,208,624 \\
517,453 \\
307,373\end{array}$ & $\begin{array}{r}87,729 \\
431,334 \\
0 \\
0 \\
0\end{array}$ & $\begin{array}{l}0 \\
0 \\
0 \\
0 \\
0\end{array}$ & $\begin{array}{r}87,729 \\
431,334 \\
0 \\
0 \\
0\end{array}$ \\
\hline 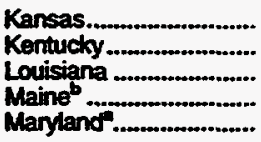 & $\begin{array}{r}1,753,120 \\
3,590,045 \\
1,290,824 \\
12,899 \\
776,495\end{array}$ & $\begin{array}{r}1,899,244 \\
3,414,944 \\
6,397,908 \\
1,855 \\
707,568\end{array}$ & $\begin{array}{r}-146,124 \\
175,101 \\
-5,107,084 \\
11,044 \\
68,927\end{array}$ & $\begin{array}{r}0 \\
0 \\
0 \\
4,545 \\
136,313\end{array}$ & $\begin{array}{l}0 \\
0 \\
0 \\
0 \\
0\end{array}$ & $\begin{array}{r}0 \\
0 \\
0 \\
4,545 \\
136,313\end{array}$ \\
\hline $\begin{array}{l}\text { Massachusetts........... } \\
\text { Michigan } \\
\text { Mimesota } \\
\text { Mississippi } \\
\text { Missoun }\end{array}$ & $\begin{array}{r}191,662 \\
806,346 \\
337,592 \\
5,459,097 \\
1,657,515\end{array}$ & $\begin{array}{r}60,060 \\
393 \\
283,878 \\
5,355,528 \\
1,303,530\end{array}$ & $\begin{array}{r}131,602 \\
805,953 \\
53,714 \\
103,569 \\
353,985\end{array}$ & $\begin{array}{r}28,566 \\
0 \\
286,290 \\
0 \\
0\end{array}$ & $\begin{array}{l}0 \\
0 \\
0 \\
0 \\
0\end{array}$ & $\begin{array}{r}28,566 \\
0 \\
286,290 \\
0 \\
0\end{array}$ \\
\hline 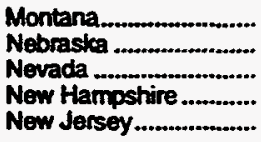 & $\begin{array}{r}30,321 \\
1,129,595 \\
85,313 \\
b \\
664,027\end{array}$ & $\begin{array}{r}34,992 \\
954,368 \\
0 \\
b \\
390,995\end{array}$ & $\begin{array}{r}-4,671 \\
175,227 \\
85,313 \\
b \\
273,032\end{array}$ & $\begin{array}{r}30,081 \\
0 \\
0 \\
b \\
0\end{array}$ & $\begin{array}{r}76 \\
0 \\
0 \\
b \\
0\end{array}$ & $\begin{array}{r}30,005 \\
0 \\
0 \\
b \\
0\end{array}$ \\
\hline $\begin{array}{l}\text { Now Mexico } \\
\text { New York } \\
\text { North Carolina................ } \\
\text { North Dakota.... } \\
\text { Ohio }\end{array}$ & $\begin{array}{r}632,203 \\
938,935 \\
661,536 \\
13,548 \\
2,694,620\end{array}$ & $\begin{array}{r}1,544,893 \\
302,390 \\
528,650 \\
720 \\
1,889,780\end{array}$ & $\begin{array}{r}-912,690 \\
636,545 \\
132,886 \\
12,828 \\
804,840\end{array}$ & $\begin{array}{r}0 \\
9,157 \\
0 \\
0 \\
0\end{array}$ & $\begin{array}{l}0 \\
0 \\
0 \\
0 \\
0\end{array}$ & $\begin{array}{r}0 \\
9.157 \\
0 \\
0 \\
0\end{array}$ \\
\hline 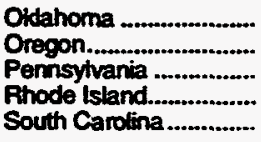 & $\begin{array}{r}1,073,641 \\
513,926 \\
1,986,465 \\
92,800 \\
783,573\end{array}$ & $\begin{array}{r}1,988,047 \\
420,930 \\
1,279,419 \\
64,734 \\
661,536\end{array}$ & $\begin{array}{r}-914,406 \\
92,996 \\
707,046 \\
28,066 \\
122,037\end{array}$ & $\begin{array}{l}0 \\
0 \\
0 \\
0 \\
0\end{array}$ & $\begin{array}{l}0 \\
0 \\
0 \\
0 \\
0\end{array}$ & $\begin{array}{l}0 \\
0 \\
0 \\
0 \\
0\end{array}$ \\
\hline $\begin{array}{l}\text { South Dakota } \\
\text { Tennessee } \\
\text { Texas } \\
\text { Utah } \\
\text { Vermont }\end{array}$ & $\begin{array}{r}25,609 \\
3,828,223 \\
815,548 \\
144,159 \\
\mathrm{~b}\end{array}$ & $\begin{array}{r}398 \\
3,597,245 \\
3,584,006 \\
70,397 \\
b\end{array}$ & $\begin{array}{r}25,211 \\
230,978 \\
-2,768,458 \\
73,762 \\
b\end{array}$ & $\begin{array}{l}0 \\
0 \\
0 \\
0 \\
b\end{array}$ & $\begin{array}{r}0 \\
0 \\
3.602 \\
0 \\
b\end{array}$ & $\begin{array}{r}0 \\
0 \\
-3,602 \\
0 \\
b\end{array}$ \\
\hline 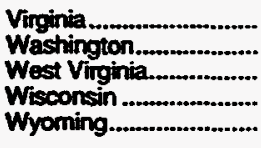 & $\begin{array}{r}880,271 \\
427,938 \\
1,277,700 \\
480,579 \\
80,589\end{array}$ & $\begin{array}{r}750,366 \\
505,004 \\
1,236,170 \\
112,729 \\
368,376\end{array}$ & $\begin{array}{r}129,905 \\
-77,066 \\
41,530 \\
367,850 \\
-287,787\end{array}$ & $\begin{array}{r}0 \\
239,368 \\
0 \\
0 \\
0\end{array}$ & $\begin{array}{l}0 \\
0 \\
0 \\
0 \\
0\end{array}$ & $\begin{array}{r}0 \\
239,368 \\
0 \\
0 \\
0\end{array}$ \\
\hline 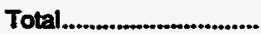 & $50,518,463$ & $50,518,463$ & 0 & $1,253,383$ & 55,673 & $1,197,710$ \\
\hline
\end{tabular}

See tootnotes at end of table. 
Table 8. Movements of Natural Gas by State, 1967-1994 (Continued) (Million Cubic Feet)

\begin{tabular}{|c|c|c|c|c|c|c|}
\hline \multirow{2}{*}{ Stato } & \multicolumn{3}{|c|}{$\begin{array}{l}\text { Intercetetes } \\
\text { Movements }\end{array}$} & \multicolumn{3}{|c|}{$\begin{array}{l}\text { Movements Across } \\
\text { U.S. Borders }\end{array}$} \\
\hline & Receipts & Delivaries: & Net & Rocoipts. & Deliveries & Net \\
\hline & \multicolumn{6}{|c|}{1980} \\
\hline 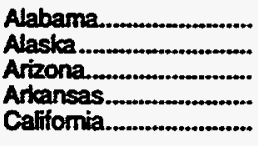 & $\begin{array}{r}2,901,573 \\
0 \\
1,398,841 \\
2,855,625 \\
1,481,832\end{array}$ & $\begin{array}{r}2,703,544 \\
0 \\
1,215,974 \\
2,687,070 \\
0\end{array}$ & $\begin{array}{r}198,029 \\
0 \\
182,857 \\
168,555 \\
1,481,832\end{array}$ & $\begin{array}{l}0 \\
0 \\
0 \\
0 \\
0\end{array}$ & $\begin{array}{r}0 \\
44,732 \\
686 \\
0 \\
0\end{array}$ & $\begin{array}{r}0 \\
-44,732 \\
-686 \\
0 \\
0\end{array}$ \\
\hline $\begin{array}{l}\text { Colorade } \\
\text { Connecticut } \\
\text { D.C. } \\
\text { Delaware.... } \\
\text { Florida. }\end{array}$ & $\begin{array}{r}207,996 \\
166,127 \\
28,096 \\
4,268 \\
276,295\end{array}$ & $\begin{array}{r}174,197 \\
90,101 \\
0 \\
1,452 \\
0\end{array}$ & $\begin{array}{r}33,799 \\
76,026 \\
28,096 \\
2,816 \\
276,295\end{array}$ & $\begin{array}{l}0 \\
0 \\
0 \\
0 \\
0\end{array}$ & $\begin{array}{l}0 \\
0 \\
0 \\
0 \\
0\end{array}$ & $\begin{array}{l}0 \\
0 \\
0 \\
0 \\
0\end{array}$ \\
\hline 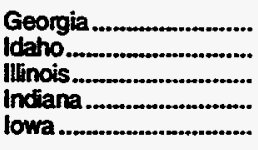 & $\begin{array}{r}1,321,780 \\
75,680 \\
2,312,585 \\
1,687,205 \\
1,160,209\end{array}$ & $\begin{array}{r}1,013,310 \\
417,488 \\
1,031,428 \\
1,227,308 \\
908,461\end{array}$ & $\begin{array}{r}308,470 \\
-341,808 \\
1,281,157 \\
459,897 \\
251,748\end{array}$ & $\begin{array}{r}24,603 \\
352,015 \\
0 \\
0 \\
0\end{array}$ & $\begin{array}{l}0 \\
0 \\
0 \\
0 \\
0\end{array}$ & $\begin{array}{r}24,603 \\
352,015 \\
0 \\
0 \\
0\end{array}$ \\
\hline 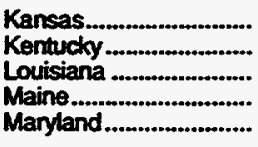 & $\begin{array}{r}1,430,150 \\
3,377,276 \\
1,246,163 \\
2,207 \\
910,356\end{array}$ & $\begin{array}{r}1,856,216 \\
3,214,552 \\
6,181,011 \\
0 \\
787,956\end{array}$ & $\begin{array}{r}426,066 \\
162,724 \\
-4,934,848 \\
2,207 \\
122,400\end{array}$ & $\begin{array}{r}0 \\
0 \\
0 \\
0 \\
36,973\end{array}$ & $\begin{array}{l}0 \\
0 \\
0 \\
0 \\
0\end{array}$ & $\begin{array}{r}0 \\
0 \\
0 \\
0 \\
36,973\end{array}$ \\
\hline $\begin{array}{l}\text { Massachusetts. } \\
\text { Michigan } \\
\text { Mississippi } \\
\text { Missouri }\end{array}$ & $\begin{array}{r}208,470 \\
862,303 \\
282,412 \\
5,512,802 \\
1,563,023\end{array}$ & $\begin{array}{r}45,703 \\
0 \\
488,173 \\
5,420,674 \\
1,237,618\end{array}$ & $\begin{array}{r}162,767 \\
862,303 \\
-205,761 \\
92,128 \\
325,405\end{array}$ & $\begin{array}{r}24,274 \\
236 \\
529,676 \\
0 \\
0\end{array}$ & $\begin{array}{r}0 \\
256,152 \\
9,819 \\
0 \\
0\end{array}$ & $\begin{array}{r}24,274 \\
-255,916 \\
519,857 \\
0 \\
0\end{array}$ \\
\hline 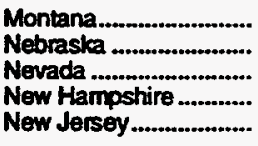 & $\begin{array}{r}22,777 \\
1,336,951 \\
59,932 \\
6,807 \\
859,553\end{array}$ & $\begin{array}{r}5,691 \\
1,175,024 \\
0 \\
2,207 \\
384,175\end{array}$ & $\begin{array}{r}17,086 \\
161,927 \\
59,932 \\
4,600 \\
475,378\end{array}$ & $\begin{array}{r}22,350 \\
0 \\
0 \\
0 \\
0\end{array}$ & $\begin{array}{r}15,196 \\
0 \\
0 \\
0 \\
0\end{array}$ & $\begin{array}{r}7.154 \\
0 \\
0 \\
0 \\
0\end{array}$ \\
\hline 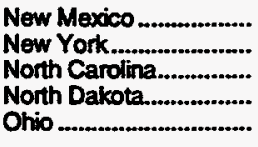 & $\begin{array}{r}816,621 \\
918,815 \\
868,660 \\
5,218 \\
2,388,034\end{array}$ & $\begin{array}{r}1,583,501 \\
328,201 \\
725,642 \\
6,349 \\
1,680,895\end{array}$ & $\begin{array}{r}-766,880 \\
590,614 \\
143,018 \\
-1,131 \\
707,139\end{array}$ & $\begin{array}{r}0 \\
14,867 \\
0 \\
0 \\
0\end{array}$ & $\begin{array}{r}0 \\
295 \\
0 \\
0 \\
0\end{array}$ & $\begin{array}{r}0 \\
14,572 \\
0 \\
0 \\
0\end{array}$ \\
\hline 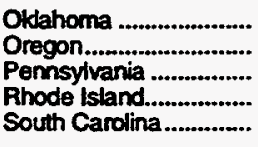 & $\begin{array}{r}1,009,941 \\
387,393 \\
2,112,132 \\
96,336 \\
987,633\end{array}$ & $\begin{array}{r}1,713,727 \\
308,551 \\
1,429,770 \\
69,928 \\
868,660\end{array}$ & $\begin{array}{r}-703,786 \\
78,842 \\
682,362 \\
26,408 \\
118,973\end{array}$ & $\begin{array}{l}0 \\
0 \\
0 \\
0 \\
0\end{array}$ & $\begin{array}{l}0 \\
0 \\
0 \\
0 \\
0\end{array}$ & $\begin{array}{l}0 \\
0 \\
0 \\
0 \\
0\end{array}$ \\
\hline $\begin{array}{l}\text { South Dakota } \\
\text { Tennessee } \\
\text { Texas } \\
\text { Utah } \\
\text { Vermont }\end{array}$ & $\begin{array}{r}23,990 \\
3,638,105 \\
880,500 \\
160,420 \\
0\end{array}$ & $\begin{array}{r}906 \\
3,385,302 \\
3,658,707 \\
80,264 \\
0\end{array}$ & $\begin{array}{r}23,084 \\
252,803 \\
-2,778,207 \\
80,156 \\
0\end{array}$ & $\begin{array}{r}0 \\
0 \\
102,410 \\
0 \\
4,221\end{array}$ & $\begin{array}{r}0 \\
0 \\
3.200 \\
0 \\
0\end{array}$ & $\begin{array}{r}0 \\
0 \\
99,210 \\
0 \\
4,221\end{array}$ \\
\hline 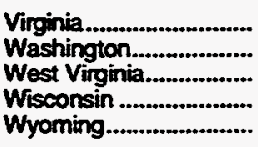 & $\begin{array}{r}1,045,465 \\
349,580 \\
1,261,669 \\
725,678 \\
90,465\end{array}$ & $\begin{array}{r}908,811 \\
340.115 \\
1.229 .175 \\
364,181 \\
373,927\end{array}$ & $\begin{array}{r}136,654 \\
9,465 \\
32,494 \\
361,497 \\
-283,462\end{array}$ & $\begin{array}{r}0 \\
154,488 \\
0 \\
0 \\
0\end{array}$ & $\begin{array}{l}0 \\
0 \\
0 \\
0 \\
0\end{array}$ & $\begin{array}{r}0 \\
154,488 \\
0 \\
0 \\
0\end{array}$ \\
\hline Total & $51,325,948$ & $51,325,948$ & 0 & $1,266.116$ & 330,080 & 936,036 \\
\hline
\end{tabular}

See footnotes at end of table. 
Table 8. Movements of Natural Gas by State, 1967-1994. (Continued) (Million Cubic Feet)

\begin{tabular}{|c|c|c|c|c|c|c|}
\hline \multirow{2}{*}{ Sinte } & \multicolumn{3}{|c|}{$\begin{array}{l}\text { interetate } \\
\text { Movernems }\end{array}$} & \multicolumn{3}{|c|}{$\begin{array}{l}\text { Wownents deross } \\
\text { U.S. Borders }\end{array}$} \\
\hline & Recoipts & Delineries & $N$ Not & Receipts & Detriveries & Nat \\
\hline & \multicolumn{6}{|c|}{1981} \\
\hline 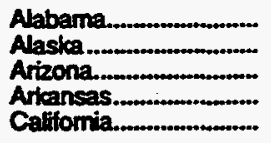 & $\begin{array}{r}2,904,870 \\
0 \\
1,497,434 \\
2,852,414 \\
1,512,595\end{array}$ & $\begin{array}{r}2,726,721 \\
0 \\
1,300,640 \\
2,679,369 \\
0\end{array}$ & $\begin{array}{r}178,149 \\
0 \\
196,794 \\
173,075 \\
1,512,595\end{array}$ & $\begin{array}{l}0 \\
0 \\
0 \\
0 \\
0\end{array}$ & $\begin{array}{r}0 \\
55,929 \\
904 \\
0 \\
0\end{array}$ & $\begin{array}{r}0 \\
-55.929 \\
-904 \\
0 \\
0\end{array}$ \\
\hline 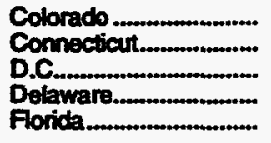 & $\begin{array}{r}281,075 \\
161,068 \\
29,299 \\
32,310 \\
291,318\end{array}$ & $\begin{array}{r}241,968 \\
82,021 \\
0 \\
1,769 \\
0\end{array}$ & $\begin{array}{r}39,107 \\
79,047 \\
29,299 \\
30,541 \\
291,318\end{array}$ & $\begin{array}{l}0 \\
0 \\
0 \\
0 \\
0\end{array}$ & $\begin{array}{l}0 \\
0 \\
0 \\
0 \\
0\end{array}$ & $\begin{array}{l}0 \\
0 \\
0 \\
0 \\
0\end{array}$ \\
\hline 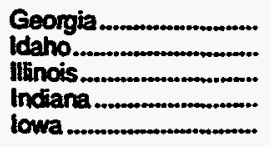 & $\begin{array}{r}1,387,833 \\
92,572 \\
2,264,715 \\
1,743,506 \\
1,082,708\end{array}$ & $\begin{array}{r}1,043,121 \\
386,605 \\
1,138,477 \\
1,089,140 \\
865,684\end{array}$ & $\begin{array}{r}344,712 \\
-294,033 \\
1,126,238 \\
654,366 \\
217,024\end{array}$ & $\begin{array}{r}0 \\
303,936 \\
0 \\
0 \\
0\end{array}$ & $\begin{array}{l}0 \\
0 \\
0 \\
0 \\
0\end{array}$ & $\begin{array}{r}0 \\
303,936 \\
0 \\
0 \\
0\end{array}$ \\
\hline 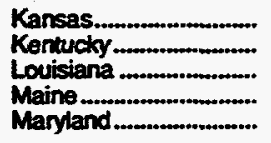 & $\begin{array}{r}1,617,860 \\
3,391,713 \\
1,465,289 \\
2,267 \\
905,278\end{array}$ & $\begin{array}{r}1,792,482 \\
3,243,894 \\
6,188,796 \\
0 \\
731,363\end{array}$ & $\begin{array}{r}-174,622 \\
147,819 \\
-4,723,507 \\
2,257 \\
173,915\end{array}$ & $\begin{array}{l}0 \\
0 \\
0 \\
0 \\
0\end{array}$ & $\begin{array}{l}0 \\
0 \\
0 \\
0 \\
0\end{array}$ & $\begin{array}{l}0 \\
0 \\
0 \\
0 \\
0\end{array}$ \\
\hline 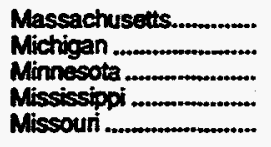 & $\begin{array}{r}170,128 \\
728,736 \\
266,470 \\
5,566,506 \\
1,421,730\end{array}$ & $\begin{array}{r}28,301 \\
27,046 \\
504,359 \\
5,480,593 \\
1,130,012\end{array}$ & $\begin{array}{r}141,827 \\
701,680 \\
-237,889 \\
85,913 \\
291,718\end{array}$ & $\begin{array}{r}36,824 \\
10,440 \\
555,516 \\
0 \\
0\end{array}$ & $\begin{array}{r}32 \\
283,347 \\
8,904 \\
0 \\
0\end{array}$ & $\begin{array}{r}36,792 \\
-272,907 \\
557,612 \\
0 \\
0\end{array}$ \\
\hline 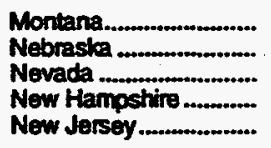 & $\begin{array}{r}16,924 \\
1,238,716 \\
75,667 \\
6,859 \\
891,285\end{array}$ & $\begin{array}{r}7,523 \\
1,095,943 \\
0 \\
2,133 \\
408,951\end{array}$ & $\begin{array}{r}9,401 \\
142,773 \\
75,657 \\
4,726 \\
482,384\end{array}$ & $\begin{array}{r}20,865 \\
0 \\
0 \\
6 \\
0\end{array}$ & $\begin{array}{r}13,175 \\
0 \\
0 \\
0 \\
0\end{array}$ & $\begin{array}{r}7,690 \\
0 \\
0 \\
6 \\
0\end{array}$ \\
\hline 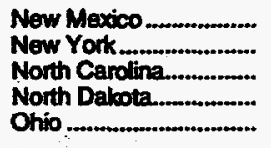 & $\begin{array}{r}849,033 \\
891,449 \\
901,437 \\
4,701 \\
2,318,930\end{array}$ & $\begin{array}{r}1,680,770 \\
260,901 \\
755,544 \\
6,630 \\
1,637,760\end{array}$ & $\begin{array}{r}-831,737 \\
630,548 \\
145,893 \\
-1,929 \\
681,170\end{array}$ & $\begin{array}{r}0 \\
26,983 \\
0 \\
0 \\
0\end{array}$ & $\begin{array}{l}0 \\
0 \\
0 \\
0 \\
0\end{array}$ & $\begin{array}{r}0 \\
26,993 \\
0 \\
0 \\
0\end{array}$ \\
\hline 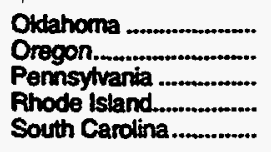 & $\begin{array}{r}801,924 \\
332,716 \\
2,176,824 \\
90,272 \\
1,019,156\end{array}$ & $\begin{array}{r}1,882,457 \\
258,831 \\
1,441,152 \\
61,253 \\
901,437\end{array}$ & $\begin{array}{r}-1,080,533 \\
73,885 \\
735,672 \\
29,019 \\
117,719\end{array}$ & $\begin{array}{l}0 \\
0 \\
0 \\
0 \\
0\end{array}$ & $\begin{array}{l}0 \\
0 \\
0 \\
0 \\
0\end{array}$ & $\begin{array}{l}0 \\
0 \\
0 \\
0 \\
0\end{array}$ \\
\hline 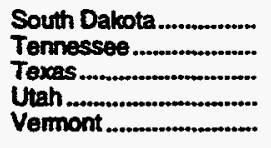 & $\begin{array}{r}21,723 \\
3,634,770 \\
819,919 \\
140,716 \\
0\end{array}$ & $\begin{array}{r}858 \\
3,399,600 \\
3,565,013 \\
74,701 \\
0\end{array}$ & $\begin{array}{r}20,865 \\
235,170 \\
-2,745,094 \\
66,015 \\
0\end{array}$ & $\begin{array}{r}0 \\
0 \\
105,013 \\
0 \\
4,589\end{array}$ & $\begin{array}{r}0 \\
0 \\
2,433 \\
0 \\
0\end{array}$ & $\begin{array}{r}0 \\
0 \\
102,580 \\
0 \\
4,589\end{array}$ \\
\hline 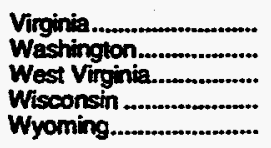 & $\begin{array}{r}1,053,672 \\
302,502 \\
1,396,558 \\
723,161 \\
86,025\end{array}$ & $\begin{array}{r}902,638 \\
281,646 \\
1,364,807 \\
391,211 \\
400,543\end{array}$ & $\begin{array}{r}151,034 \\
20,856 \\
31,751 \\
331,950 \\
-314,518\end{array}$ & $\begin{array}{r}0 \\
134,322 \\
0 \\
0 \\
0\end{array}$ & $\begin{array}{l}0 \\
0 \\
0 \\
0 \\
0\end{array}$ & $\begin{array}{r}0 \\
134,322 \\
0 \\
0 \\
0\end{array}$ \\
\hline 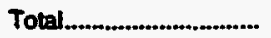 & $51,464,633$ & $51,464,633$ & 0 & $1,209,493$ & 364,724 & 844,769 \\
\hline
\end{tabular}

See footnotes at end of table. 
Table 8. Movements of Natural Gas by State, 1967-1994 (Continued) (Million Cubic Feet)

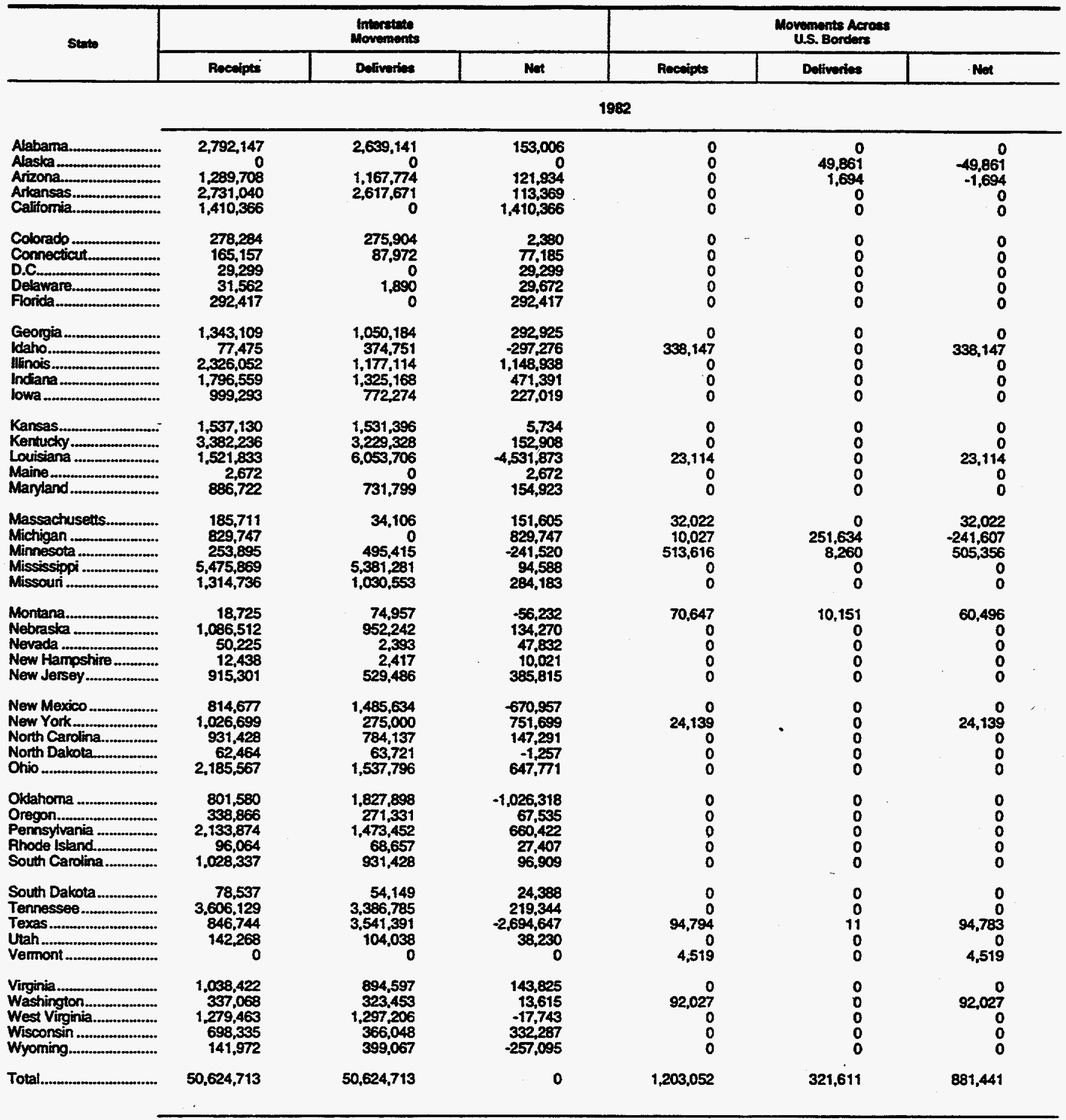

See footnotes at end of table. 
Table 8. Movements of Natural Gas by State, 1967-1994 (Continued)

(Million Cubic Feet)

\begin{tabular}{|c|c|c|c|c|c|c|}
\hline \multirow[t]{2}{*}{ Sunto } & \multicolumn{3}{|c|}{$\begin{array}{l}\text { Inevertede } \\
\text { Movements }\end{array}$} & \multicolumn{3}{|c|}{$\begin{array}{l}\text { Movements Acroess } \\
\text { U.S. Borderes }\end{array}$} \\
\hline & Recaipta & Dofiverias & Not & Rocsipts & Dativeries & Neat \\
\hline & \multicolumn{6}{|c|}{1983} \\
\hline 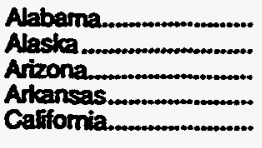 & $\begin{array}{r}2,730,841 \\
0 \\
1,130,306 \\
2,221,118 \\
1,238,601\end{array}$ & $\begin{array}{r}2,579,069 \\
0 \\
1,011,375 \\
2,115,459 \\
0\end{array}$ & $\begin{array}{r}151,772 \\
0 \\
118,931 \\
105,659 \\
1,238,601\end{array}$ & $\begin{array}{l}0 \\
0 \\
0 \\
0 \\
0\end{array}$ & $\begin{array}{r}52,07 \\
1,646 \\
0 \\
0\end{array}$ & $\begin{array}{r}0 \\
-52,857 \\
-1,646 \\
0 \\
0\end{array}$ \\
\hline 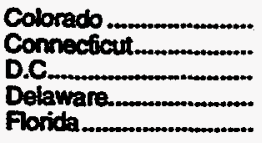 & $\begin{array}{r}378,709 \\
181,304 \\
29,566 \\
38,782 \\
293,075\end{array}$ & $\begin{array}{r}320,3399 \\
104,468 \\
0 \\
2,003 \\
977\end{array}$ & $\begin{array}{r}58,370 \\
76,836 \\
29,566 \\
36,719 \\
292,098\end{array}$ & $\begin{array}{l}0 \\
0 \\
0 \\
0 \\
0\end{array}$ & $\begin{array}{l}0 \\
0 \\
0 \\
0 \\
0\end{array}$ & $\begin{array}{l}0 \\
0 \\
0 \\
0 \\
0\end{array}$ \\
\hline $\begin{array}{l}\text { Georgia } \\
\text { ldaho. } \\
\text { Ilinois... } \\
\text { Inctiana } \\
\text { lowa }\end{array}$ & $\begin{array}{r}1,269,604 \\
77,305 \\
1,854,416 \\
1,464,094 \\
1,001,729\end{array}$ & $\begin{array}{r}965,347 \\
353,270 \\
920,448 \\
1,056,485 \\
804,228\end{array}$ & $\begin{array}{r}304,257 \\
-275,965 \\
938,968 \\
407,609 \\
197,501\end{array}$ & $\begin{array}{r}0 \\
310,811 \\
0 \\
0 \\
0\end{array}$ & $\begin{array}{l}0 \\
0 \\
0 \\
0 \\
0\end{array}$ & $\begin{array}{r}0 \\
310,811 \\
0 \\
0 \\
0\end{array}$ \\
\hline 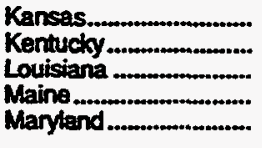 & $\begin{array}{r}1,249,165 \\
2,763,767 \\
1,430,057 \\
2,397 \\
783,232\end{array}$ & $\begin{array}{r}1,336,973 \\
2,626,651 \\
5,247,893 \\
0 \\
628,291\end{array}$ & $\begin{array}{r}-87,808 \\
137,116 \\
-3,817,836 \\
2,397 \\
154,941\end{array}$ & $\begin{array}{r}0 \\
0 \\
96,945 \\
0 \\
0\end{array}$ & $\begin{array}{l}0 \\
0 \\
0 \\
0 \\
0\end{array}$ & $\begin{array}{r}0 \\
0 \\
96,945 \\
0 \\
0\end{array}$ \\
\hline 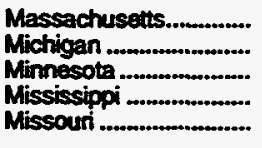 & $\begin{array}{r}191,701 \\
625,986 \\
383,185 \\
4,775,876 \\
1,183,703\end{array}$ & $\begin{array}{r}29,533 \\
0 \\
510,430 \\
4,712,056 \\
920,322\end{array}$ & $\begin{array}{r}162,168 \\
625,986 \\
-127,246 \\
63,820 \\
263,381\end{array}$ & $\begin{array}{r}34.178 \\
6,951 \\
381,039 \\
0 \\
0\end{array}$ & $\begin{array}{r}0 \\
218,264 \\
8,705 \\
0 \\
0\end{array}$ & $\begin{array}{r}34,178 \\
-211,313 \\
372,335 \\
0 \\
0\end{array}$ \\
\hline 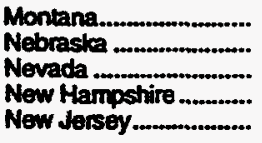 & $\begin{array}{r}41,239 \\
1,068,515 \\
41,093 \\
11,978 \\
924,060\end{array}$ & $\begin{array}{r}145,266 \\
945,695 \\
2,327 \\
2,287 \\
514,435\end{array}$ & $\begin{array}{r}-104,027 \\
122,820 \\
38,766 \\
9,691 \\
409,625\end{array}$ & $\begin{array}{r}136.508 \\
0 \\
0 \\
0 \\
0\end{array}$ & $\begin{array}{r}9,255 \\
0 \\
0 \\
0 \\
0\end{array}$ & $\begin{array}{r}127,253 \\
0 \\
0 \\
0 \\
0\end{array}$ \\
\hline 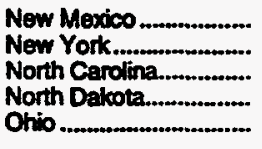 & $\begin{array}{r}592,185 \\
998,082 \\
857,732 \\
138,101 \\
1,974,508\end{array}$ & $\begin{array}{r}1,284,703 \\
295,242 \\
717,080 \\
162,743 \\
1,390,020\end{array}$ & $\begin{array}{l}-692,518 \\
702,840 \\
140,652 \\
-24,642 \\
584,488\end{array}$ & $\begin{array}{r}0 \\
22,348 \\
0 \\
0 \\
0\end{array}$ & $\begin{array}{l}0 \\
0 \\
0 \\
0 \\
0\end{array}$ & $\begin{array}{r}0 \\
22,348 \\
0 \\
0 \\
0\end{array}$ \\
\hline 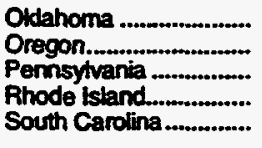 & $\begin{array}{r}641,333 \\
315,215 \\
1,957,169 \\
111,470 \\
960,964\end{array}$ & $\begin{array}{r}1,601,634 \\
268,603 \\
1,472,641 \\
81,855 \\
857,732\end{array}$ & $\begin{array}{r}-960,301 \\
46,612 \\
484,528 \\
29,615 \\
103,232\end{array}$ & $\begin{array}{l}0 \\
0 \\
0 \\
0 \\
0\end{array}$ & $\begin{array}{l}0 \\
0 \\
0 \\
0 \\
0\end{array}$ & $\begin{array}{l}0 \\
0 \\
0 \\
0 \\
0\end{array}$ \\
\hline $\begin{array}{l}\text { South Dakota............ } \\
\text { Tennessee } \\
\text { Texas } \\
\text { Utah } \\
\text { Vermont }\end{array}$ & $\begin{array}{r}154,136 \\
2,996,742 \\
737,616 \\
104,760 \\
0\end{array}$ & $\begin{array}{r}132,093 \\
2,770,062 \\
3,057,348 \\
59,568 \\
0\end{array}$ & $\begin{array}{r}22,043 \\
226,680 \\
-2,319,732 \\
45,192 \\
0\end{array}$ & $\begin{array}{r}0 \\
0 \\
75,361 \\
0 \\
4,610\end{array}$ & $\begin{array}{l}0 \\
0 \\
0 \\
0 \\
0\end{array}$ & $\begin{array}{r}0 \\
0 \\
75,361 \\
0 \\
4,610\end{array}$ \\
\hline 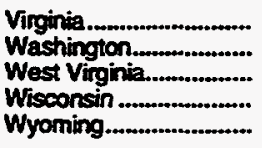 & $\begin{array}{r}944,050 \\
329,645 \\
1.173,584 \\
605,634 \\
167,530\end{array}$ & $\begin{array}{r}798.296 \\
291,317 \\
1,278,569 \\
286,829 \\
483,838\end{array}$ & $\begin{array}{r}145,754 \\
38,328 \\
-104,985 \\
318,805 \\
-316,308\end{array}$ & $\begin{array}{r}0 \\
87,242 \\
0 \\
0 \\
0\end{array}$ & $\begin{array}{r}0 \\
666 \\
0 \\
0 \\
0\end{array}$ & $\begin{array}{r}0 \\
86,576 \\
0 \\
0 \\
0\end{array}$ \\
\hline Total................................. & $45,145,860$ & $45,145,860$ & 0 & $1,155,993$ & 291,393 & 864,600 \\
\hline
\end{tabular}

See foctnotes at end of table. 
Table 8. Movements of Natural Gas by State, 1967-1994 (Continued) (Million Cubic Feet)

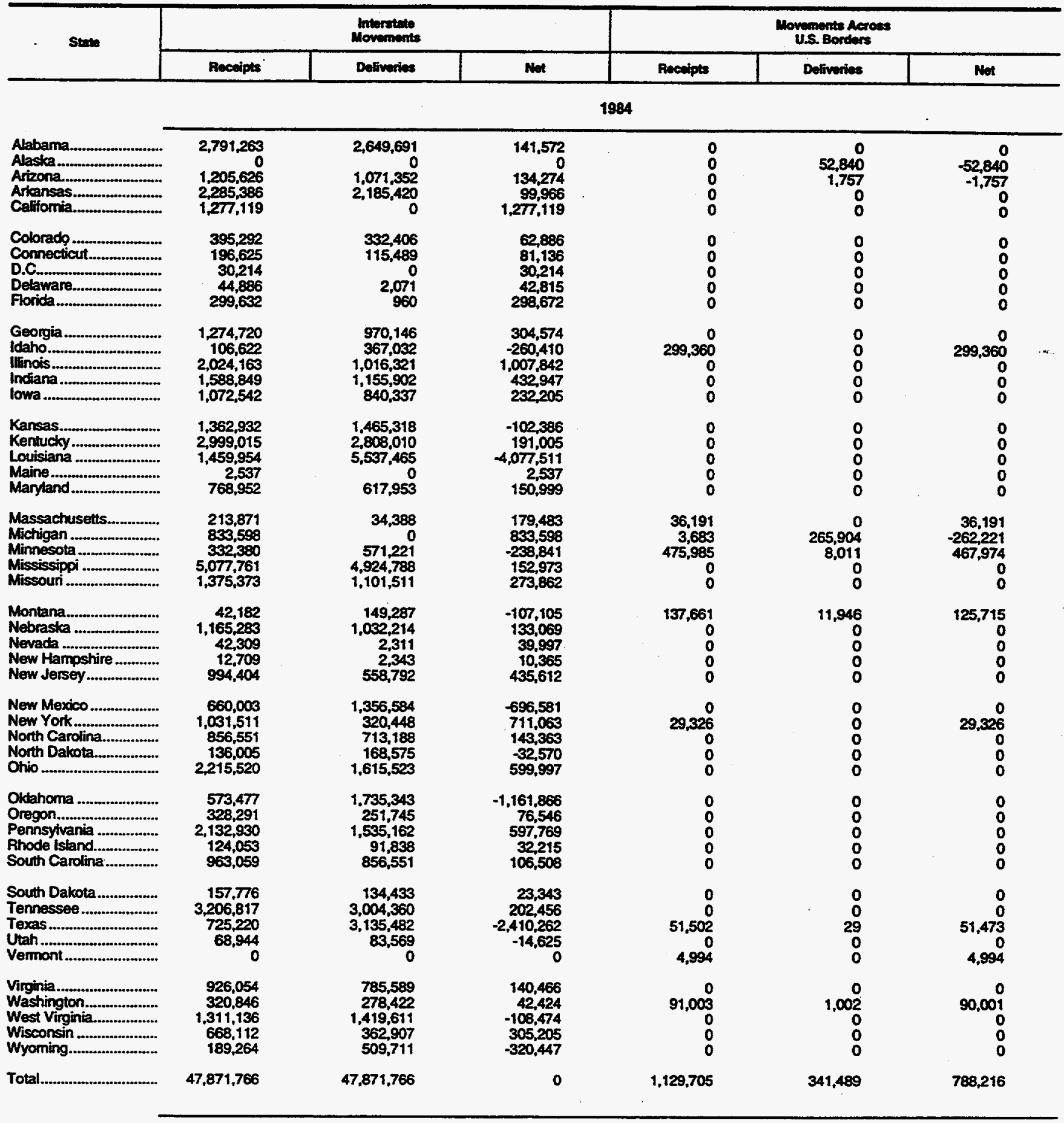

See footnoles at end of table. 
Table 8. Movements of Natural Gas by State, 1967-1994 (Continued) (Million Cubic Feet)

\begin{tabular}{|c|c|c|c|c|c|c|}
\hline \multirow{2}{*}{ State } & \multicolumn{3}{|c|}{$\begin{array}{l}\text { intorstete } \\
\text { Movements }\end{array}$} & \multicolumn{3}{|c|}{$\begin{array}{l}\text { Movements Across } \\
\text { U.S. Borders }\end{array}$} \\
\hline & Receipts & Deliveries & Siet & Peccipts & Dellweries & Not \\
\hline & \multicolumn{6}{|c|}{1985} \\
\hline 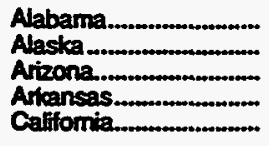 & $\begin{array}{r}2,476,383 \\
0 \\
1,249,968 \\
2,099,656 \\
1,340,239\end{array}$ & $\begin{array}{r}2,336,142 \\
0 \\
1,066,147 \\
2,041,747 \\
0\end{array}$ & $\begin{array}{r}140,241 \\
0 \\
183,821 \\
57,909 \\
1,340,239\end{array}$ & $\begin{array}{l}0 \\
0 \\
0 \\
0 \\
0\end{array}$ & $\begin{array}{r}0 \\
52,883 \\
1,813 \\
0 \\
0\end{array}$ & $\begin{array}{r}0 \\
-52,883 \\
-1,813 \\
0 \\
0\end{array}$ \\
\hline 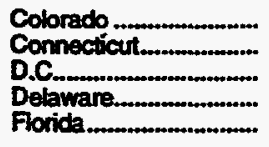 & $\begin{array}{r}427,666 \\
208,446 \\
29,344 \\
40,802 \\
273,348\end{array}$ & $\begin{array}{r}387,305 \\
131,499 \\
0 \\
2,085 \\
297\end{array}$ & $\begin{array}{r}40,361 \\
71,947 \\
29,344 \\
39,767 \\
273,051\end{array}$ & $\begin{array}{l}0 \\
0 \\
0 \\
0 \\
0\end{array}$ & $\begin{array}{l}0 \\
0 \\
0 \\
0 \\
0\end{array}$ & $\begin{array}{l}0 \\
0 \\
0 \\
0 \\
0\end{array}$ \\
\hline 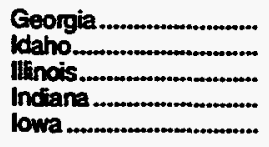 & $\begin{array}{r}1,222,557 \\
68,640 \\
1,959,775 \\
1,437,123 \\
1,143,876\end{array}$ & $\begin{array}{l}926,049 \\
440,434 \\
970,738 \\
989,109 \\
897,378\end{array}$ & $\begin{array}{r}296,508 \\
-371,794 \\
989,037 \\
448,014 \\
246,498\end{array}$ & $\begin{array}{r}0 \\
411,380 \\
0 \\
0 \\
0\end{array}$ & $\begin{array}{l}0 \\
0 \\
0 \\
0 \\
0\end{array}$ & $\begin{array}{r}0 \\
411,380 \\
0 \\
0 \\
0\end{array}$ \\
\hline 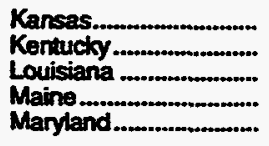 & $\begin{array}{r}1,384,222 \\
2,670,242 \\
1,297,299 \\
2,664 \\
810,397\end{array}$ & $\begin{array}{r}1,498,697 \\
2,531,793 \\
4,836,028 \\
0 \\
664,606\end{array}$ & $\begin{array}{r}-164,475 \\
138,449 \\
-3,538,729 \\
2,664 \\
145,791\end{array}$ & $\begin{array}{l}0 \\
0 \\
0 \\
0 \\
0\end{array}$ & $\begin{array}{l}0 \\
0 \\
0 \\
0 \\
0\end{array}$ & $\begin{array}{l}0 \\
0 \\
0 \\
0 \\
0\end{array}$ \\
\hline 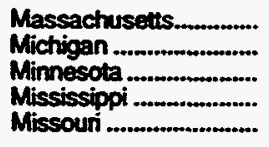 & $\begin{array}{r}243,676 \\
764,145 \\
394,368 \\
4,542,097 \\
1,297,658\end{array}$ & $\begin{array}{r}47,050 \\
0 \\
613,634 \\
4,488,750 \\
1,023,757\end{array}$ & $\begin{array}{r}196,626 \\
764,145 \\
-219,266 \\
53,347 \\
273,901\end{array}$ & $\begin{array}{r}23,659 \\
467 \\
474,353 \\
0 \\
0\end{array}$ & $\begin{array}{r}0 \\
249,918 \\
6,063 \\
0 \\
0\end{array}$ & $\begin{array}{r}23,659 \\
-249,451 \\
468,290 \\
0 \\
0\end{array}$ \\
\hline 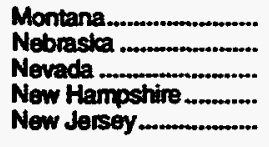 & $\begin{array}{r}38,734 \\
1,208,753 \\
42,181 \\
12,589 \\
953,145\end{array}$ & $\begin{array}{r}172,755 \\
1,077,085 \\
2,334 \\
2,354 \\
590,915\end{array}$ & $\begin{array}{r}-134,021 \\
131,668 \\
39,847 \\
10,235 \\
362,230\end{array}$ & $\begin{array}{r}155,377 \\
0 \\
0 \\
0 \\
0\end{array}$ & $\begin{array}{r}12,148 \\
0 \\
0 \\
0 \\
0\end{array}$ & $\begin{array}{r}143,229 \\
0 \\
0 \\
0 \\
0\end{array}$ \\
\hline 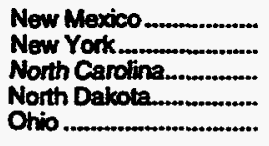 & $\begin{array}{r}697,489 \\
1,087,340 \\
819,112 \\
157,948 \\
1,948,185\end{array}$ & $\begin{array}{r}1,392,041 \\
324,177 \\
681,309 \\
224,131 \\
1,384,582\end{array}$ & $\begin{array}{r}-694,554 \\
763,163 \\
137,803 \\
-66,183 \\
563,603\end{array}$ & $\begin{array}{r}0 \\
47,677 \\
0 \\
0 \\
0\end{array}$ & $\begin{array}{l}0 \\
0 \\
0 \\
0 \\
0\end{array}$ & $\begin{array}{r}0 \\
47,677 \\
0 \\
0 \\
0\end{array}$ \\
\hline 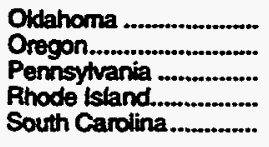 & $\begin{array}{r}596,415 \\
402,173 \\
1,950,891 \\
139,610 \\
920,594\end{array}$ & $\begin{array}{r}1,778,481 \\
321,928 \\
1,525,409 \\
108,552 \\
819,112\end{array}$ & $\begin{array}{r}-1,182,066 \\
80,245 \\
425,482 \\
31,058 \\
101,482\end{array}$ & $\begin{array}{l}0 \\
0 \\
0 \\
0 \\
0\end{array}$ & $\begin{array}{l}0 \\
0 \\
0 \\
0 \\
0\end{array}$ & $\begin{array}{l}0 \\
0 \\
0 \\
0 \\
0\end{array}$ \\
\hline 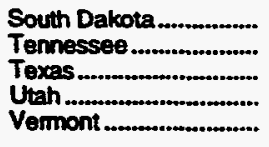 & $\begin{array}{r}214,468 \\
2,859,222 \\
667,141 \\
56,766 \\
0\end{array}$ & $\begin{array}{r}190,758 \\
2,672,435 \\
2,920,140 \\
43,794 \\
0\end{array}$ & $\begin{array}{r}23,710 \\
186,797 \\
-2,252,999 \\
12,972 \\
0\end{array}$ & $\begin{array}{r}0 \\
0 \\
0 \\
0 \\
5,213\end{array}$ & $\begin{array}{r}0 \\
0 \\
394 \\
0 \\
0\end{array}$ & $\begin{array}{r}0 \\
0 \\
-394 \\
0 \\
5,213\end{array}$ \\
\hline 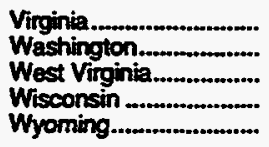 & $\begin{array}{r}927,392 \\
433,168 \\
1,212,710 \\
652,627 \\
170,208\end{array}$ & $\begin{array}{r}803,990 \\
390,991 \\
1,326,139 \\
335,237 \\
516,606\end{array}$ & $\begin{array}{r}123,402 \\
42,177 \\
-113,429 \\
317,390 \\
-346,398\end{array}$ & $\begin{array}{r}0 \\
101,357 \\
0 \\
0 \\
0\end{array}$ & $\begin{array}{r}0 \\
2,157 \\
0 \\
0 \\
0\end{array}$ & $\begin{array}{r}0 \\
99.180 \\
0 \\
0 \\
0\end{array}$ \\
\hline Total.............................. & $45,498,452$ & $45,498,452$ & 0 & $1,219,463$ & 325,376 & 894,087 \\
\hline
\end{tabular}

See focthotes at end of table. 
Table 8. Movements of Natural Gas by State, 1967-1994 (Continued) (Million Cubic Feet)

\begin{tabular}{|c|c|c|c|c|c|c|}
\hline \multirow[t]{2}{*}{ State } & \multicolumn{3}{|c|}{ Intoretate } & \multicolumn{3}{|c|}{$\begin{array}{c}\text { Mowments Acroess } \\
\text { U.S. Borders }\end{array}$} \\
\hline & Recelipts & Detheriot: & Not & Receipts & Defirveries & Net \\
\hline & \multicolumn{6}{|c|}{1986} \\
\hline 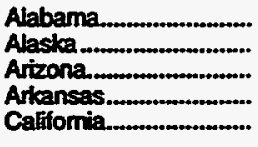 & $\begin{array}{r}2,446,444 \\
0 \\
1,043,759 \\
2,107,365 \\
1,170,859\end{array}$ & $\begin{array}{r}2,328,949 \\
0 \\
943,306 \\
2,058,532 \\
0\end{array}$ & $\begin{array}{r}117,495 \\
0 \\
100,453 \\
48,835 \\
1,170,859\end{array}$ & $\begin{array}{l}0 \\
0 \\
0 \\
0 \\
0\end{array}$ & $\begin{array}{r}0 \\
50,172 \\
1,525 \\
0 \\
0\end{array}$ & $\begin{array}{r}0 \\
-50,172 \\
-1,525 \\
0 \\
0\end{array}$ \\
\hline 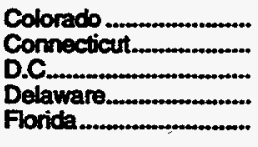 & $\begin{array}{r}414,997 \\
189,519 \\
29,956 \\
34,394 \\
275,182\end{array}$ & $\begin{array}{r}319,531 \\
110,207 \\
0 \\
1,926 \\
287\end{array}$ & $\begin{array}{r}95,466 \\
79,312 \\
29,956 \\
32,468 \\
274,895\end{array}$ & $\begin{array}{l}0 \\
0 \\
0 \\
0 \\
0\end{array}$ & $\begin{array}{l}0 \\
0 \\
0 \\
0 \\
0\end{array}$ & $\begin{array}{l}0 \\
0 \\
0 \\
0 \\
0\end{array}$ \\
\hline 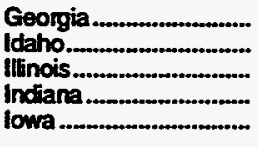 & $\begin{array}{r}1,217,373 \\
49,531 \\
1,935,509 \\
1,626,913 \\
957,733\end{array}$ & $\begin{array}{r}942,159 \\
362,124 \\
1,047,869 \\
1,222,332 \\
745,415\end{array}$ & $\begin{array}{r}275,214 \\
-312,593 \\
887,640 \\
404,582 \\
212,318\end{array}$ & $\begin{array}{r}0 \\
348,307 \\
0 \\
0 \\
0\end{array}$ & $\begin{array}{l}0 \\
0 \\
0 \\
0 \\
0\end{array}$ & $\begin{array}{r}0 \\
348,307 \\
0 \\
0 \\
0\end{array}$ \\
\hline 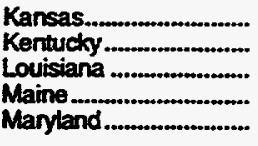 & $\begin{array}{r}1,232,696 \\
2,865,860 \\
1,498,208 \\
2,562 \\
829,464\end{array}$ & $\begin{array}{r}1,380,015 \\
2,762,789 \\
4,850,695 \\
0 \\
669,729\end{array}$ & $\begin{array}{r}-147,319 \\
103,071 \\
-3,352,487 \\
2,562 \\
159,735\end{array}$ & $\begin{array}{l}0 \\
0 \\
0 \\
0 \\
0\end{array}$ & $\begin{array}{l}0 \\
0 \\
0 \\
0 \\
0\end{array}$ & $\begin{array}{l}0 \\
0 \\
0 \\
0 \\
0\end{array}$ \\
\hline $\begin{array}{l}\text { Massachusetts.......... } \\
\text { Michigan } \\
\text { Minnesota } \\
\text { Mississippi } \\
\text { Missouni }\end{array}$ & $\begin{array}{r}211,244 \\
907,933 \\
336,917 \\
4,689,745 \\
1,171,668\end{array}$ & $\begin{array}{r}22,430 \\
0 \\
571,718 \\
4,668,235 \\
925,412\end{array}$ & $\begin{array}{r}188,814 \\
907,933 \\
-234,801 \\
21,510 \\
246,256\end{array}$ & $\begin{array}{r}1,669 \\
0 \\
485,505 \\
0 \\
0\end{array}$ & $\begin{array}{r}0 \\
321,194 \\
6,183 \\
0 \\
0\end{array}$ & $\begin{array}{r}1,669 \\
-321,194 \\
479,322 \\
0 \\
0\end{array}$ \\
\hline 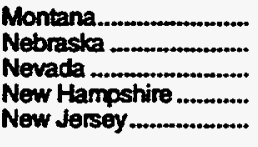 & $\begin{array}{r}39,479 \\
1,022,406 \\
32,709 \\
12,584 \\
940,391\end{array}$ & $\begin{array}{r}114,214 \\
911,908 \\
2,203 \\
2,435 \\
570,213\end{array}$ & $\begin{array}{r}-74,735 \\
110,498 \\
30,506 \\
10,149 \\
370,178\end{array}$ & $\begin{array}{r}95,958 \\
0 \\
0 \\
0 \\
0\end{array}$ & $\begin{array}{r}9,524 \\
0 \\
0 \\
0 \\
0\end{array}$ & $\begin{array}{r}86.434 \\
0 \\
0 \\
0 \\
0\end{array}$ \\
\hline 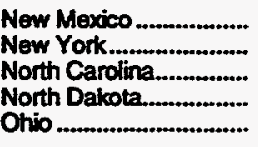 & $\begin{array}{r}781,653 \\
1,003,593 \\
844,801 \\
97,599 \\
1,963,447\end{array}$ & $\begin{array}{r}1,157,115 \\
316,105 \\
708,279 \\
172,405 \\
1,375,756\end{array}$ & $\begin{array}{l}-375,462 \\
687,488 \\
136,522 \\
-74,806 \\
587,691\end{array}$ & $\begin{array}{r}0 \\
35,720 \\
0 \\
0 \\
0\end{array}$ & $\begin{array}{l}0 \\
0 \\
0 \\
0 \\
0\end{array}$ & $\begin{array}{r}0 \\
35,720 \\
0 \\
0 \\
0\end{array}$ \\
\hline 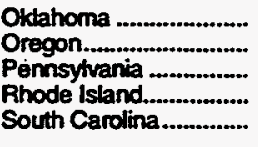 & $\begin{array}{r}542,020 \\
344,001 \\
1,966,448 \\
116,107 \\
943,995\end{array}$ & $\begin{array}{r}1,724,092 \\
278,055 \\
1,440,738 \\
89,471 \\
844,801\end{array}$ & $\begin{array}{r}-1,182,072 \\
65,946 \\
525,710 \\
26,636 \\
99,194\end{array}$ & $\begin{array}{l}0 \\
0 \\
0 \\
0 \\
0\end{array}$ & $\begin{array}{l}0 \\
0 \\
0 \\
0 \\
0\end{array}$ & $\begin{array}{l}0 \\
0 \\
0 \\
0 \\
0\end{array}$ \\
\hline 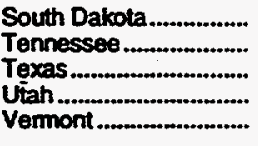 & $\begin{array}{r}159,809 \\
3,058,204 \\
615,297 \\
119,557 \\
0\end{array}$ & $\begin{array}{r}137,631 \\
2,868,649 \\
3,093,141 \\
80,968 \\
0\end{array}$ & $\begin{array}{r}22,178 \\
189,555 \\
-2,477,844 \\
38,589 \\
0\end{array}$ & $\begin{array}{r}0 \\
0 \\
0 \\
0 \\
5,137\end{array}$ & $\begin{array}{r}0 \\
0 \\
372 \\
0 \\
0\end{array}$ & $\begin{array}{r}0 \\
0 \\
-372 \\
0 \\
5,137\end{array}$ \\
\hline 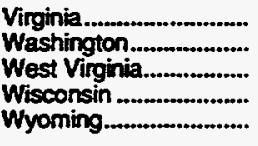 & $\begin{array}{r}945,391 \\
346,128 \\
1,292,550 \\
698,900 \\
115,297\end{array}$ & $\begin{array}{r}830,616 \\
344,001 \\
1,389,831 \\
397,527 \\
464,379\end{array}$ & $\begin{array}{r}114,775 \\
2,127 \\
-97,281 \\
301,373 \\
-349,082\end{array}$ & $\begin{array}{r}0 \\
107,212 \\
0 \\
0 \\
0\end{array}$ & $\begin{array}{r}0 \\
61 \\
0 \\
0 \\
0\end{array}$ & $\begin{array}{r}0 \\
107,151 \\
0 \\
0 \\
0\end{array}$ \\
\hline Total............................. & $45,248,194$ & $45,248,194$ & 0 & $1,079,508$ & 389,030 & 690,478 \\
\hline
\end{tabular}

See footnotes at end of table. 
Table 8. Movements of Natural Gas by State, 1967-1994 (Continued) (Million Cubic Feet)

\begin{tabular}{|c|c|c|c|c|c|c|}
\hline \multirow[t]{2}{*}{ state } & \multicolumn{3}{|c|}{$\begin{array}{l}\text { Imborstate } \\
\text { Movernents }\end{array}$} & \multicolumn{3}{|c|}{$\begin{array}{l}\text { Movements Aeroses } \\
\text { U.S. Borders }\end{array}$} \\
\hline & Roceipts & Deliverios & Net & Roceipts & Dotiverios & Not \\
\hline & \multicolumn{6}{|c|}{1987} \\
\hline 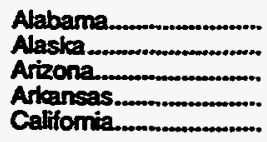 & $\begin{array}{r}2,537,793 \\
0 \\
1,320,262 \\
2,060,704 \\
1,553,144\end{array}$ & $\begin{array}{r}2,423,579 \\
0 \\
1,204,302 \\
2,007,028 \\
0\end{array}$ & $\begin{array}{r}114,214 \\
0 \\
115,960 \\
53,676 \\
1,553,144\end{array}$ & $\begin{array}{l}0 \\
0 \\
0 \\
0 \\
0\end{array}$ & $\begin{array}{r}0 \\
48,599 \\
1.757 \\
0 \\
0\end{array}$ & $\begin{array}{r}0 \\
-48,599 \\
-1,757 \\
0 \\
0\end{array}$ \\
\hline $\begin{array}{l}\text { Colorado } \\
\text { Connecticut. } \\
\text { D.C. } \\
\text { Dolaware. } \\
\text { Forich }\end{array}$ & $\begin{array}{r}437,073 \\
234,298 \\
31,907 \\
38,426 \\
308,955\end{array}$ & $\begin{array}{r}381,721 \\
140,079 \\
0 \\
2,531 \\
1,165\end{array}$ & $\begin{array}{r}\mathbf{5 5 , 3 5 3} \\
94,219 \\
31,907 \\
35,895 \\
307,790\end{array}$ & $\begin{array}{l}0 \\
0 \\
0 \\
0 \\
0\end{array}$ & $\begin{array}{l}0 \\
0 \\
0 \\
0 \\
0\end{array}$ & $\begin{array}{l}0 \\
0 \\
0 \\
0 \\
0\end{array}$ \\
\hline 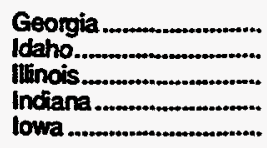 & $\begin{array}{r}1,280,796 \\
52,138 \\
1,829,079 \\
1,587,276 \\
1,079,859\end{array}$ & $\begin{array}{r}957,516 \\
499,704 \\
952,376 \\
1,204,207 \\
871,808\end{array}$ & $\begin{array}{r}323,279 \\
-447,566 \\
876,703 \\
383,069 \\
208,051\end{array}$ & $\begin{array}{r}0 \\
483,547 \\
0 \\
0 \\
0\end{array}$ & $\begin{array}{l}0 \\
0 \\
0 \\
0 \\
0\end{array}$ & $\begin{array}{r}0 \\
483,547 \\
0 \\
0 \\
0\end{array}$ \\
\hline 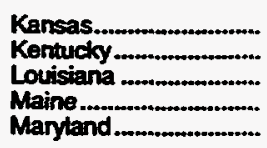 & $\begin{array}{r}1,348,168 \\
3,014,749 \\
1,502,000 \\
2,758 \\
840,250\end{array}$ & $\begin{array}{r}1,463,576 \\
2,822,857 \\
5,036,474 \\
0 \\
648,022\end{array}$ & $\begin{array}{r}-115,409 \\
191,792 \\
-3,534,474 \\
2,758 \\
192,228\end{array}$ & $\begin{array}{l}0 \\
0 \\
0 \\
0 \\
0\end{array}$ & $\begin{array}{l}0 \\
0 \\
0 \\
0 \\
0\end{array}$ & $\begin{array}{l}0 \\
0 \\
0 \\
0 \\
0\end{array}$ \\
\hline 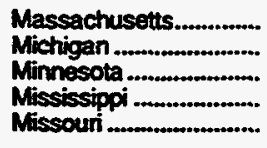 & $\begin{array}{r}265,324 \\
941,957 \\
413,730 \\
4,907,867 \\
1,121,724\end{array}$ & $\begin{array}{r}27,826 \\
374 \\
630,410 \\
4,891,035 \\
884,569\end{array}$ & $\begin{array}{r}237,497 \\
941,583 \\
-216,679 \\
16,832 \\
237,155\end{array}$ & $\begin{array}{r}0 \\
136 \\
454,180 \\
0 \\
0\end{array}$ & $\begin{array}{r}0 \\
306,724 \\
6,079 \\
0 \\
0\end{array}$ & $\begin{array}{r}0 \\
-306,588 \\
448,101 \\
0 \\
0\end{array}$ \\
\hline 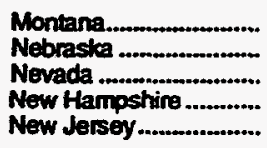 & $\begin{array}{r}42,435 \\
1,048,843 \\
43,709 \\
15,440 \\
1,028,386\end{array}$ & $\begin{array}{r}196,665 \\
931,739 \\
2,350 \\
2,495 \\
635,106\end{array}$ & $\begin{array}{r}-154,230 \\
117,104 \\
41,359 \\
12,945 \\
393,279\end{array}$ & $\begin{array}{r}178,262 \\
0 \\
0 \\
0 \\
0\end{array}$ & $\begin{array}{r}10,938 \\
0 \\
0 \\
0 \\
0\end{array}$ & $\begin{array}{r}167,324 \\
0 \\
0 \\
0 \\
0\end{array}$ \\
\hline 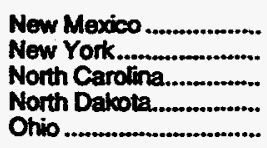 & $\begin{array}{r}850,344 \\
1,126,174 \\
839,769 \\
177,986 \\
2,143,475\end{array}$ & $\begin{array}{r}1,407,542 \\
390,995 \\
689,638 \\
258,647 \\
1,590,135\end{array}$ & $\begin{array}{r}-557,197 \\
735,178 \\
150,131 \\
80,661 \\
553,339\end{array}$ & $\begin{array}{r}0 \\
52,013 \\
0 \\
0 \\
0\end{array}$ & $\begin{array}{l}0 \\
0 \\
0 \\
0 \\
0\end{array}$ & $\begin{array}{r}0 \\
52,013 \\
0 \\
0 \\
0\end{array}$ \\
\hline 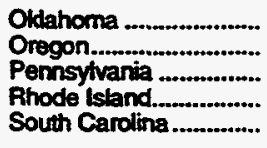 & $\begin{array}{r}477,426 \\
485,741 \\
2,104,595 \\
149,839 \\
952,856\end{array}$ & $\begin{array}{r}1,853,323 \\
403,639 \\
1,592,245 \\
114,336 \\
839,769\end{array}$ & $\begin{array}{r}-1,375,897 \\
82,102 \\
512,349 \\
35,503 \\
113,087\end{array}$ & $\begin{array}{l}0 \\
0 \\
0 \\
0 \\
0\end{array}$ & $\begin{array}{l}0 \\
0 \\
0 \\
0 \\
0\end{array}$ & $\begin{array}{l}0 \\
0 \\
0 \\
0 \\
0\end{array}$ \\
\hline $\begin{array}{l}\text { South Dakota. } \\
\text { Tennessee } \\
\text { Texas } \\
\text { Utah } \\
\text { Vermont }\end{array}$ & $\begin{array}{r}241,032 \\
3,197,553 \\
570,819 \\
131,513 \\
0\end{array}$ & $\begin{array}{r}221,432 \\
3,019,976 \\
2,929,521 \\
76,388 \\
233\end{array}$ & $\begin{array}{r}19,600 \\
177,577 \\
-2,358,702 \\
55,125 \\
-233\end{array}$ & $\begin{array}{r}0 \\
0 \\
0 \\
0 \\
5,453\end{array}$ & $\begin{array}{r}0 \\
0 \\
368 \\
0 \\
0\end{array}$ & $\begin{array}{r}0 \\
0 \\
-368 \\
0 \\
5,453\end{array}$ \\
\hline $\begin{array}{l}\text { Virginia } \\
\text { Washington. } \\
\text { West Virginia. } \\
\text { Wisconsin } \\
\text { Wyoming }\end{array}$ & $\begin{array}{r}963,316 \\
480,668 \\
1,347,578 \\
666,957 \\
102,011\end{array}$ & $\begin{array}{r}846,246 \\
485,741 \\
1,469,624 \\
396,280 \\
493,375\end{array}$ & $\begin{array}{r}117,070 \\
-5,073 \\
-122,045 \\
270,677 \\
-391,364\end{array}$ & $\begin{array}{r}0 \\
139.021 \\
0 \\
0 \\
0\end{array}$ & $\begin{array}{l}0 \\
0 \\
0 \\
0 \\
0\end{array}$ & $\begin{array}{r}0 \\
139,021 \\
0 \\
0 \\
0\end{array}$ \\
\hline 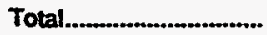 & $47,898,699$ & $47,898,699$ & $\mathbf{0}$ & $1,312,612$ & 374,464 & 938.148 \\
\hline
\end{tabular}

See footnotes at end of table. 
Table 8. Movements of Natural Gas by State, 1967-1994 (Continued) (Million Cubic Feet)

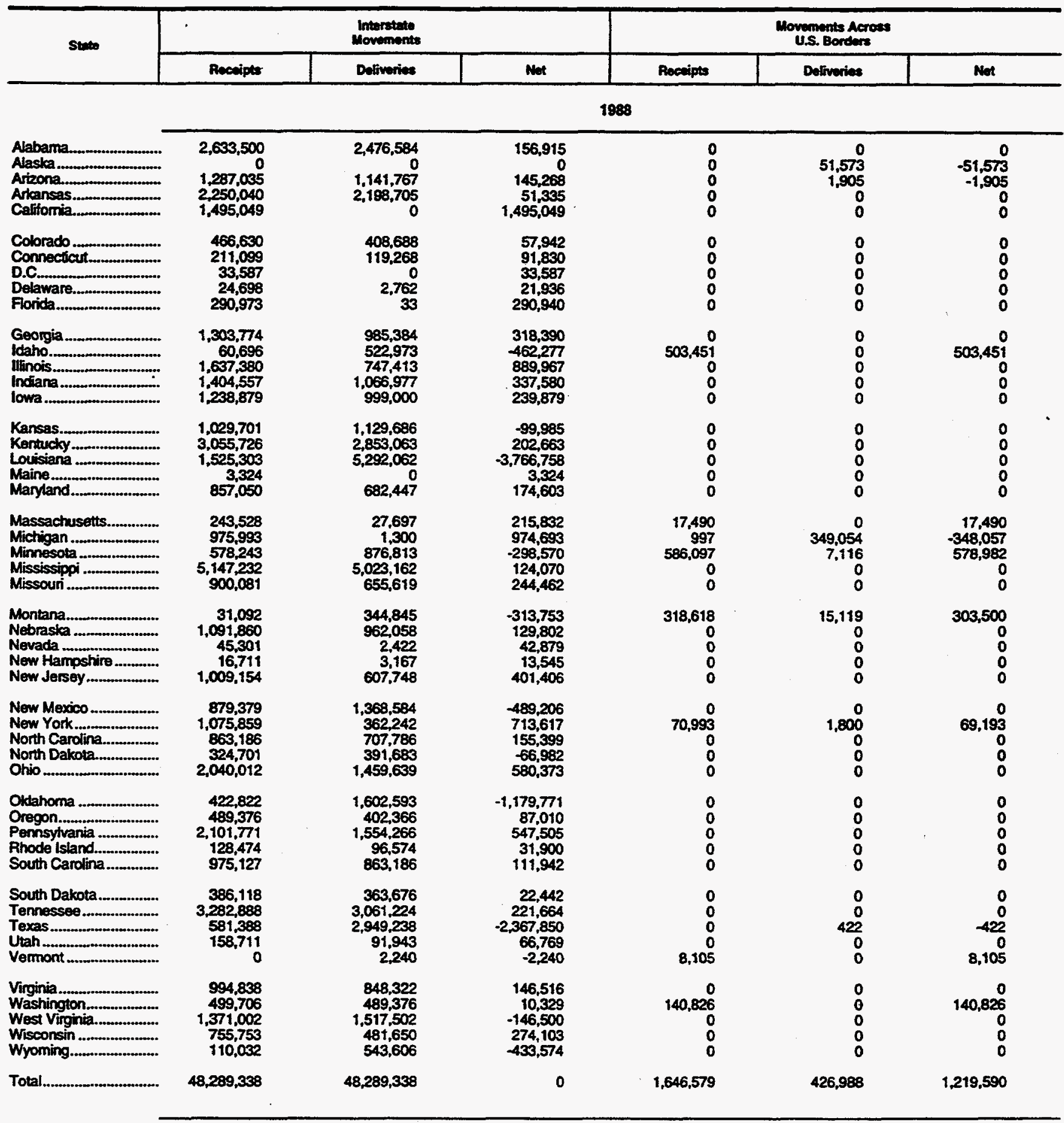

See footnotes at end of table. 
Table 8. Movements of Natural Gas by State, 1967-1994 (Continued) (Million Cubic Feet)

\begin{tabular}{|c|c|c|c|c|c|c|}
\hline \multirow[t]{2}{*}{ state } & \multicolumn{3}{|c|}{ Interstete } & \multicolumn{3}{|c|}{$\begin{array}{l}\text { Wovwments Across } \\
\text { U.S. Borders }\end{array}$} \\
\hline & Pecoipts & Dotiveries & Not & Recoipts & Deliverios & Net \\
\hline & \multicolumn{6}{|c|}{1989} \\
\hline $\begin{array}{l}\text { Alabarna. } \\
\text { Alaska } \\
\text { Arizona } \\
\text { Arkanses.... } \\
\text { Calformia. }\end{array}$ & $\begin{array}{r}2,682,687 \\
0 \\
1,443,075 \\
2,393,404 \\
1,627,420\end{array}$ & $\begin{array}{r}2,538,496 \\
0 \\
1,275,692 \\
2,334,761 \\
0\end{array}$ & $\begin{array}{r}144,191 \\
0 \\
167,384 \\
58,643 \\
1,627,420\end{array}$ & $\begin{array}{l}0 \\
0 \\
0 \\
0 \\
0\end{array}$ & $\begin{array}{r}0 \\
51,424 \\
1,469 \\
0 \\
0\end{array}$ & $\begin{array}{r}0 \\
-51,424 \\
-1,469 \\
0 \\
0\end{array}$ \\
\hline $\begin{array}{l}\text { Colorado } \\
\text { Cormecticut. } \\
\text { D.C. } \\
\text { Detaware..... } \\
\text { Florida }\end{array}$ & $\begin{array}{r}473,834 \\
234,593 \\
34,598 \\
39,248 \\
322,798\end{array}$ & $\begin{array}{r}433,066 \\
137,224 \\
0 \\
3,005 \\
32\end{array}$ & $\begin{array}{r}\mathbf{4 0 , 7 6 8} \\
\mathbf{9 7 , 3 6 9} \\
34,598 \\
36,242 \\
322,766\end{array}$ & $\begin{array}{l}0 \\
0 \\
0 \\
0 \\
0\end{array}$ & $\begin{array}{l}0 \\
0 \\
0 \\
0 \\
0\end{array}$ & $\begin{array}{l}0 \\
0 \\
0 \\
0 \\
0\end{array}$ \\
\hline 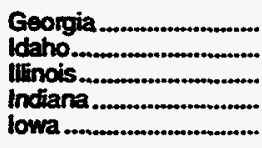 & $\begin{array}{r}1,320,609 \\
78,911 \\
2,071,383 \\
1,607,719 \\
1,168,434\end{array}$ & $\begin{array}{r}1,007,074 \\
534,497 \\
1,048,895 \\
1,182,560 \\
946,728\end{array}$ & $\begin{array}{r}313,535 \\
455,586 \\
1,022,488 \\
425,159 \\
221,706\end{array}$ & $\begin{array}{r}0 \\
501,477 \\
0 \\
0 \\
0\end{array}$ & $\begin{array}{l}0 \\
0 \\
0 \\
0 \\
0\end{array}$ & $\begin{array}{r}0 \\
501,477 \\
0 \\
0 \\
0\end{array}$ \\
\hline 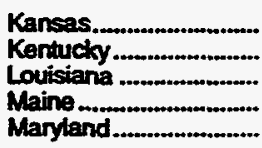 & $\begin{array}{r}1,136,401 \\
3,208,031 \\
1,632,234 \\
3,686 \\
893,124\end{array}$ & $\begin{array}{r}1,426,927 \\
2,948,517 \\
5,482,027 \\
0 \\
681,700\end{array}$ & $\begin{array}{r}-290,526 \\
259,514 \\
-3,849,793 \\
3,686 \\
211,424\end{array}$ & $\begin{array}{r}0 \\
0 \\
3,934 \\
0 \\
0\end{array}$ & $\begin{array}{l}0 \\
0 \\
0 \\
0 \\
0\end{array}$ & $\begin{array}{r}0 \\
0 \\
3,934 \\
0 \\
0\end{array}$ \\
\hline $\begin{array}{l}\text { Massachusetts............. } \\
\text { Michigan } \\
\text { Mirnessissippi } \\
\text { Missouri }\end{array}$ & $\begin{array}{r}248,715 \\
972,991 \\
581,545 \\
5,299,819 \\
1,333,176\end{array}$ & $\begin{array}{r}23,294 \\
1,495 \\
895,058 \\
5,172,100 \\
1,009,819\end{array}$ & $\begin{array}{r}225,422 \\
971,496 \\
-313,513 \\
127,719 \\
263,357\end{array}$ & $\begin{array}{r}38,229 \\
0 \\
609,215 \\
0 \\
0\end{array}$ & $\begin{array}{r}0 \\
363,680 \\
7,119 \\
0 \\
0\end{array}$ & $\begin{array}{r}38,229 \\
-363,680 \\
602,096 \\
0 \\
0\end{array}$ \\
\hline 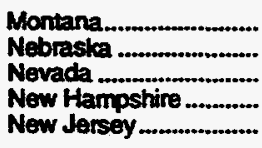 & $\begin{array}{r}22,259 \\
1,011,038 \\
65,715 \\
17,736 \\
1,039,568\end{array}$ & $\begin{array}{r}358,128 \\
888,303 \\
2,556 \\
3,657 \\
615,094\end{array}$ & $\begin{array}{r}-335,869 \\
122,736 \\
63,158 \\
14,079 \\
424,475\end{array}$ & $\begin{array}{r}323,538 \\
0 \\
0 \\
0 \\
0\end{array}$ & $\begin{array}{r}14,454 \\
0 \\
0 \\
0 \\
0\end{array}$ & $\begin{array}{r}309,084 \\
0 \\
0 \\
0 \\
0\end{array}$ \\
\hline 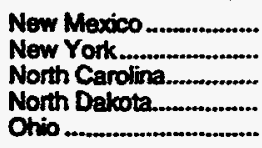 & $\begin{array}{r}846,451 \\
1,066,665 \\
878,416 \\
338,072 \\
2,198,268\end{array}$ & $\begin{array}{r}1,523,896 \\
375,695 \\
711,800 \\
402,546 \\
1,550,668\end{array}$ & $\begin{array}{l}-677,445 \\
690,969 \\
166,617 \\
-64,474 \\
647,600\end{array}$ & $\begin{array}{r}0 \\
67,956 \\
0 \\
0 \\
0\end{array}$ & $\begin{array}{l}0 \\
0 \\
0 \\
0 \\
0\end{array}$ & $\begin{array}{r}0 \\
67,956 \\
0 \\
0 \\
0\end{array}$ \\
\hline 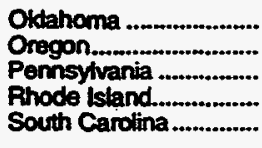 & $\begin{array}{r}320,324 \\
510,333 \\
2,141,761 \\
146,218 \\
993,292\end{array}$ & $\begin{array}{r}1,655,455 \\
390,029 \\
1,586,513 \\
111,986 \\
876,596\end{array}$ & $\begin{array}{r}-1,335,130 \\
120,304 \\
555,248 \\
34,232 \\
116,696\end{array}$ & $\begin{array}{l}0 \\
0 \\
0 \\
0 \\
0\end{array}$ & $\begin{array}{l}0 \\
0 \\
0 \\
0 \\
0\end{array}$ & $\begin{array}{l}0 \\
0 \\
0 \\
0 \\
0\end{array}$ \\
\hline $\begin{array}{l}\text { South Dakota } \\
\text { Tennessee................... } \\
\text { Texas } \\
\text { Utah } \\
\text { Vermont }\end{array}$ & $\begin{array}{r}408,928 \\
3,399,413 \\
531,621 \\
126,786 \\
0\end{array}$ & $\begin{array}{r}384,461 \\
3,212,302 \\
2,922,632 \\
84,990 \\
6,872\end{array}$ & $\begin{array}{r}24,467 \\
187.111 \\
-2,391,011 \\
41,796 \\
6,872\end{array}$ & $\begin{array}{r}0 \\
0 \\
0 \\
0 \\
13,152\end{array}$ & $\begin{array}{r}0 \\
0 \\
15,535 \\
0 \\
0\end{array}$ & $\begin{array}{r}0 \\
0 \\
-15,535 \\
0 \\
13,152\end{array}$ \\
\hline $\begin{array}{l}\text { Virginia } \\
\text { Washington. } \\
\text { West Virginia. } \\
\text { Wisconsin } \\
\text { Wyoming }\end{array}$ & $\begin{array}{r}1,029,161 \\
497,794 \\
1,411,412 \\
775,925 \\
111,823\end{array}$ & $\begin{array}{r}880,831 \\
510,333 \\
1,470,635 \\
465,397 \\
563,073\end{array}$ & $\begin{array}{r}148,330 \\
-12,539 \\
-59,220 \\
310,528 \\
-451,250\end{array}$ & $\begin{array}{r}0 \\
170,832 \\
0 \\
0 \\
0\end{array}$ & $\begin{array}{l}0 \\
0 \\
0 \\
0 \\
0\end{array}$ & $\begin{array}{r}0 \\
170,832 \\
0 \\
0 \\
0\end{array}$ \\
\hline Total.................................. & $50,697,415$ & $50,697,415$ & 0 & $1,728,333$ & 453,682 & $1,274,651$ \\
\hline
\end{tabular}


Table 8. Movements of Natural Gas by State, 1967-1994 (Continued) (Million Cubic Feet)

\begin{tabular}{|c|c|c|c|c|c|c|}
\hline \multirow{2}{*}{ suts } & \multicolumn{3}{|c|}{$\begin{array}{l}\text { Interstate } \\
\text { Moverents }\end{array}$} & \multicolumn{3}{|c|}{$\begin{array}{l}\text { Movoments Aeross } \\
\text { U.S. Bordere }\end{array}$} \\
\hline & Receipts & Dativeries & Net & Rocesipts & Delimeria: & Net \\
\hline & \multicolumn{6}{|c|}{1990} \\
\hline $\begin{array}{l}\text { Alabama } \\
\text { Alaska } \\
\text { Avizona } \\
\text { Avkansas... } \\
\text { Caltomia.... }\end{array}$ & $\begin{array}{r}2,818,949 \\
0 \\
1,428,400 \\
2,223,388 \\
1,620,132\end{array}$ & $\begin{array}{r}2,688,474 \\
0 \\
1,270,461 \\
2,179,835 \\
0\end{array}$ & $\begin{array}{r}130,475 \\
0 \\
157,939 \\
43,553 \\
1,020,132\end{array}$ & $\begin{array}{l}0 \\
0 \\
0 \\
0 \\
0\end{array}$ & $\begin{array}{r}0 \\
52,546 \\
1,676 \\
0 \\
0\end{array}$ & $\begin{array}{r}0 \\
-52.546 \\
-1.676 \\
0 \\
0\end{array}$ \\
\hline $\begin{array}{l}\text { Colorado } \\
\text { Connecticut. } \\
\text { D.C. } \\
\text { Delawrare } \\
\text { Forida }\end{array}$ & $\begin{array}{r}497,558 \\
227,723 \\
29,321 \\
37,742 \\
325,897\end{array}$ & $\begin{array}{r}490,561 \\
131,255 \\
0 \\
2,730 \\
34\end{array}$ & $\begin{array}{r}6,997 \\
96,469 \\
29,321 \\
35,012 \\
325,863\end{array}$ & $\begin{array}{l}0 \\
0 \\
0 \\
0 \\
0\end{array}$ & $\begin{array}{l}0 \\
0 \\
0 \\
0 \\
0\end{array}$ & $\begin{array}{l}0 \\
0 \\
0 \\
0 \\
0\end{array}$ \\
\hline 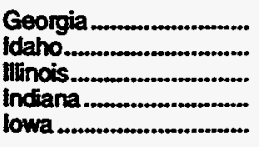 & $\begin{array}{r}1,361,415 \\
80,926 \\
2,051,448 \\
1,596,047 \\
1,135,682\end{array}$ & $\begin{array}{r}1,057,288 \\
546,339 \\
1,023,874 \\
1,159,628 \\
895,053\end{array}$ & $\begin{array}{r}304,127 \\
465,413 \\
1,027,573 \\
436,420 \\
240,629\end{array}$ & $\begin{array}{r}0 \\
514,597 \\
0 \\
0 \\
0\end{array}$ & $\begin{array}{l}0 \\
0 \\
0 \\
0 \\
0\end{array}$ & $\begin{array}{r}0 \\
514,597 \\
0 \\
0 \\
0\end{array}$ \\
\hline $\begin{array}{l}\text { Kansas. } \\
\text { Kentucky } \\
\text { Kaisiana } \\
\text { Maryland }\end{array}$ & $\begin{array}{r}1,036,161 \\
3,303,547 \\
1,718,218 \\
4,471 \\
931,632\end{array}$ & $\begin{array}{r}1,330,368 \\
2,963,545 \\
5,388,681 \\
0 \\
749,836\end{array}$ & $\begin{array}{r}-294,207 \\
340,002 \\
-3,670,463 \\
4,471 \\
181,796\end{array}$ & $\begin{array}{r}0 \\
0 \\
30,750 \\
0 \\
0\end{array}$ & $\begin{array}{l}0 \\
0 \\
0 \\
0 \\
0\end{array}$ & $\begin{array}{r}0 \\
0 \\
30,750 \\
0 \\
0\end{array}$ \\
\hline 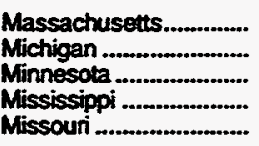 & $\begin{array}{r}232,459 \\
\mathbf{9 9 3 , 2 6 4} \\
\mathbf{5 8 4 , 8 1 5} \\
\mathbf{5 , 3 4 9 , 2 2 8} \\
1,236,536\end{array}$ & $\begin{array}{r}22,950 \\
3,088 \\
958,389 \\
5,204,455 \\
996,135\end{array}$ & $\begin{array}{r}209,509 \\
990,176 \\
-373,575 \\
144,773 \\
240,401\end{array}$ & $\begin{array}{r}53,443 \\
0 \\
664,982 \\
0 \\
0\end{array}$ & $\begin{array}{r}0 \\
349,146 \\
7,813 \\
0 \\
0\end{array}$ & $\begin{array}{r}53,443 \\
-349,146 \\
657,169 \\
0 \\
0\end{array}$ \\
\hline $\begin{array}{l}\text { Montana..................... } \\
\text { Nebrasta } \\
\text { Nevada } \\
\text { New Hampshire } \\
\text { New Jersey }\end{array}$ & $\begin{array}{r}28,628 \\
970,896 \\
68,994 \\
18,090 \\
1,036,853\end{array}$ & $\begin{array}{r}368,321 \\
845,834 \\
2,548 \\
4,457 \\
631,471\end{array}$ & $\begin{array}{r}-339,694 \\
125,062 \\
66,446 \\
13,634 \\
405,382\end{array}$ & $\begin{array}{r}343,716 \\
0 \\
0 \\
0 \\
0\end{array}$ & $\begin{array}{r}16,088 \\
0 \\
0 \\
0 \\
0\end{array}$ & $\begin{array}{r}327.628 \\
0 \\
0 \\
0 \\
0\end{array}$ \\
\hline 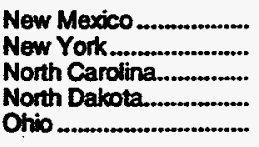 & $\begin{array}{r}780,741 \\
1,039,598 \\
\mathbf{9 3 1 , 4 8 5} \\
351,741 \\
2,154,654\end{array}$ & $\begin{array}{r}1,519,563 \\
360,693 \\
765,691 \\
416,428 \\
1,622,075\end{array}$ & $\begin{array}{l}-738,821 \\
678,905 \\
165,794 \\
-64,687 \\
532,579\end{array}$ & $\begin{array}{r}0 \\
98,217 \\
0 \\
0 \\
0\end{array}$ & $\begin{array}{l}0 \\
0 \\
0 \\
0 \\
0\end{array}$ & $\begin{array}{r}0 \\
98,217 \\
0 \\
0 \\
0\end{array}$ \\
\hline 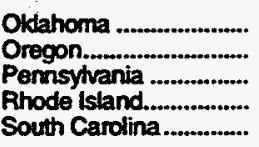 & $\begin{array}{r}313,884 \\
500,269 \\
2,245,534 \\
140,431 \\
1,042,099\end{array}$ & $\begin{array}{r}1,758,270 \\
387,778 \\
1,538,925 \\
103,518 \\
926,742\end{array}$ & $\begin{array}{r}-1,444,386 \\
112,491 \\
706,609 \\
36,912 \\
115,357\end{array}$ & $\begin{array}{l}0 \\
0 \\
0 \\
0 \\
0\end{array}$ & $\begin{array}{l}0 \\
0 \\
0 \\
0 \\
0\end{array}$ & $\begin{array}{l}0 \\
0 \\
0 \\
0 \\
0\end{array}$ \\
\hline $\begin{array}{l}\text { South Dakota } \\
\text { Tennessee } \\
\text { Texas } \\
\text { Utah } \\
\text { Vemont }\end{array}$ & $\begin{array}{r}417.567 \\
3,403,840 \\
653,332 \\
156,942 \\
0\end{array}$ & $\begin{array}{r}393,476 \\
3,299,107 \\
2,883,075 \\
72,020 \\
7,887\end{array}$ & $\begin{array}{r}24,092 \\
104,733 \\
-2,229,743 \\
84,922 \\
-7,887\end{array}$ & $\begin{array}{r}0 \\
0 \\
0 \\
0 \\
14,512\end{array}$ & $\begin{array}{r}0 \\
0 \\
13,983 \\
0 \\
0\end{array}$ & $\begin{array}{r}0 \\
0 \\
-13,983 \\
0 \\
14,512\end{array}$ \\
\hline 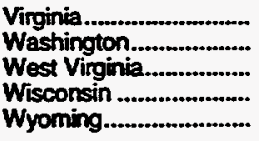 & $\begin{array}{r}1,059,259 \\
508,705 \\
1,463,155 \\
788,801 \\
122,436\end{array}$ & $\begin{array}{r}914,223 \\
500,269 \\
1,513,864 \\
489,196 \\
634,485\end{array}$ & $\begin{array}{r}145,036 \\
8,436 \\
50,709 \\
299,606 \\
-512,049\end{array}$ & $\begin{array}{r}0 \\
168,441 \\
0 \\
0 \\
0\end{array}$ & $\begin{array}{l}0 \\
0 \\
0 \\
0 \\
0\end{array}$ & $\begin{array}{r}0 \\
168,441 \\
0 . \\
0 \\
0\end{array}$ \\
\hline 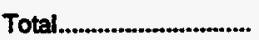 & $51,022,894$ & $51,022,894$ & 0 & $1,888,660$ & 441,253 & $1,447,407$ \\
\hline
\end{tabular}

See foctnotes at end of table. 
Table 8. Movements of Natural Gas by State, 1967-1994 (Continued) (Million Cubic Feet)

\begin{tabular}{|c|c|c|c|c|c|c|}
\hline \multirow{2}{*}{ State } & \multicolumn{3}{|c|}{$\begin{array}{l}\text { Interstate } \\
\text { Mownements }\end{array}$} & \multicolumn{3}{|c|}{$\begin{array}{l}\text { Movoments Acros:s: } \\
\text { U.S. Bordere }\end{array}$} \\
\hline & Recaipse & Dotiverios: & Net & Receipts & Detiveries & Not \\
\hline & \multicolumn{6}{|c|}{1991} \\
\hline 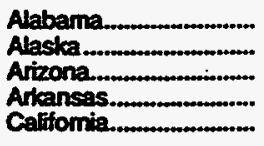 & $\begin{array}{r}2,782,487 \\
0 \\
1,430,709 \\
2,263,622 \\
1,623,693\end{array}$ & $\begin{array}{r}2,674,828 \\
0 \\
1,279,952 \\
2,199,198 \\
0\end{array}$ & $\begin{array}{r}107,659 \\
0 \\
150,756 \\
64,424 \\
1,623,693\end{array}$ & $\begin{array}{l}0 \\
0 \\
0 \\
0 \\
0\end{array}$ & $\begin{array}{r}0 \\
54,005 \\
1,597 \\
0 \\
0\end{array}$ & $\begin{array}{r}0 \\
-54,005 \\
-1,597 \\
0 \\
0\end{array}$ \\
\hline 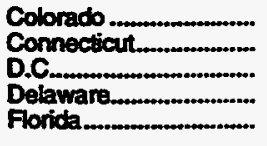 & $\begin{array}{r}576,054 \\
239,690 \\
31,872 \\
41,760 \\
335,763\end{array}$ & $\begin{array}{r}580,145 \\
138,751 \\
0 \\
2,894 \\
29\end{array}$ & $\begin{array}{r}-4,091 \\
100,939 \\
31,872 \\
38,866 \\
335,734\end{array}$ & $\begin{array}{l}0 \\
0 \\
0 \\
0 \\
0\end{array}$ & $\begin{array}{l}0 \\
0 \\
0 \\
0 \\
0\end{array}$ & $\begin{array}{l}0 \\
0 \\
0 \\
0 \\
0\end{array}$ \\
\hline $\begin{array}{l}\text { Georgia } \\
\text { ldaho } \\
\text { llinois. } \\
\text { Indiana } \\
\text { lowa }\end{array}$ & $\begin{array}{r}1,397,050 \\
87,575 \\
1,991,216 \\
1,467,559 \\
1,075,376\end{array}$ & $\begin{array}{r}1,070,813 \\
532,277 \\
981,904 \\
1,018,361 \\
867,098\end{array}$ & $\begin{array}{r}326,237 \\
-444,702 \\
1,009,311 \\
449,198 \\
208,278\end{array}$ & $\begin{array}{r}0 \\
496,967 \\
0 \\
0 \\
0\end{array}$ & $\begin{array}{l}0 \\
0 \\
0 \\
0 \\
0\end{array}$ & $\begin{array}{r}0 \\
496,967 \\
0 \\
0 \\
0\end{array}$ \\
\hline 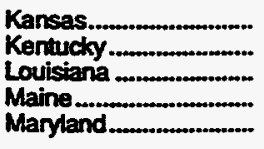 & $\begin{array}{r}906,394 \\
3,030,350 \\
1,654,594 \\
4,839 \\
931,110\end{array}$ & $\begin{array}{r}1,182,773 \\
2,826,802 \\
5,181,474 \\
0 \\
738,910\end{array}$ & $\begin{array}{r}-276,379 \\
203,548 \\
-3,526,880 \\
4,839 \\
192,200\end{array}$ & $\begin{array}{r}0 \\
0 \\
33,284 \\
0 \\
0\end{array}$ & $\begin{array}{l}0 \\
0 \\
0 \\
0 \\
0\end{array}$ & $\begin{array}{r}0 \\
0 \\
33,284 \\
0 \\
0\end{array}$ \\
\hline 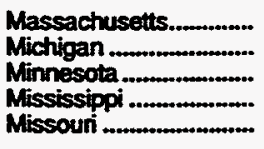 & $\begin{array}{r}272,029 \\
942,159 \\
638,534 \\
5,193,842 \\
1,221,675\end{array}$ & $\begin{array}{r}41,353 \\
2,506 \\
1,065,366 \\
5,069,990 \\
965,344\end{array}$ & $\begin{array}{r}230,676 \\
939,653 \\
-426,832 \\
123,852 \\
256,332\end{array}$ & $\begin{array}{r}30,312 \\
1,151 \\
741,353 \\
0 \\
0\end{array}$ & $\begin{array}{r}0 \\
361,041 \\
0 \\
0 \\
0\end{array}$ & $\begin{array}{r}30,312 \\
-359,890 \\
741,353 \\
0 \\
0\end{array}$ \\
\hline 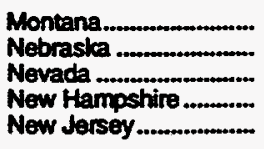 & $\begin{array}{r}22,128 \\
924,993 \\
69,164 \\
19,494 \\
1,049,018\end{array}$ & $\begin{array}{r}408,507 \\
786,554 \\
2,230 \\
4,815 \\
662,376\end{array}$ & $\begin{array}{r}-386,379 \\
138,439 \\
66,934 \\
14,680 \\
386,642\end{array}$ & $\begin{array}{r}393,463 \\
0 \\
0 \\
0 \\
0\end{array}$ & $\begin{array}{r}16,338 \\
0 \\
0 \\
0 \\
0\end{array}$ & $\begin{array}{r}377,125 \\
0 \\
0 \\
0 \\
0\end{array}$ \\
\hline 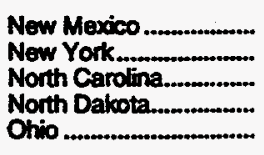 & $\begin{array}{r}707,737 \\
1,105,278 \\
928,505 \\
394,319 \\
1,889,579\end{array}$ & $\begin{array}{r}1,517,997 \\
414,155 \\
751,862 \\
454,014 \\
1,295,980\end{array}$ & $\begin{array}{l}-810,260 \\
691,123 \\
176,643 \\
-59,695 \\
593,599\end{array}$ & $\begin{array}{r}0 \\
188,233 \\
0 \\
0 \\
0\end{array}$ & $\begin{array}{l}0 \\
0 \\
0 \\
0 \\
0\end{array}$ & $\begin{array}{r}0 \\
188,233 \\
0 \\
0 \\
0\end{array}$ \\
\hline 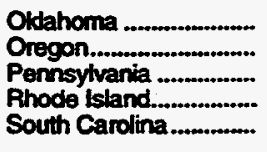 & $\begin{array}{r}330,531 \\
488,666 \\
2,032,791 \\
166,305 \\
1,050,481\end{array}$ & $\begin{array}{r}1,756,711 \\
405,163 \\
1,591,144 \\
110,202 \\
923,920\end{array}$ & $\begin{array}{r}-1,426,181 \\
83,503 \\
441,647 \\
56,103 \\
126,562\end{array}$ & $\begin{array}{l}0 \\
0 \\
0 \\
0 \\
0\end{array}$ & $\begin{array}{l}0 \\
0 \\
0 \\
0 \\
0\end{array}$ & $\begin{array}{l}0 \\
0 \\
0 \\
0 \\
0\end{array}$ \\
\hline $\begin{array}{l}\text { South Dakota } \\
\text { Tennessee } \\
\text { Texas } \\
\text { Utah } \\
\text { Vemont }\end{array}$ & $\begin{array}{r}459,068 \\
3,210,927 \\
709,907 \\
85,735 \\
0\end{array}$ & $\begin{array}{r}434,073 \\
3,025,125 \\
2,742,234 \\
48,664 \\
8,651\end{array}$ & $\begin{array}{r}24,995 \\
185,802 \\
-2,032,327 \\
37,071 \\
-8,651\end{array}$ & $\begin{array}{r}0 \\
0 \\
0 \\
0 \\
15,796\end{array}$ & $\begin{array}{r}0 \\
0 \\
58,851 \\
0 \\
0\end{array}$ & $\begin{array}{r}0 \\
0 \\
-58,851 \\
0 \\
15,796\end{array}$ \\
\hline 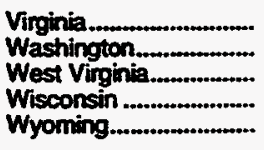 & $\begin{array}{r}1,077,858 \\
493,474 \\
1,322,383 \\
872,520 \\
157,598\end{array}$ & $\begin{array}{r}916,463 \\
488,666 \\
1,354,722 \\
549,079 \\
634,337\end{array}$ & $\begin{array}{r}161,395 \\
4,807 \\
-32,339 \\
323,441 \\
-476,738\end{array}$ & $\begin{array}{r}0 \\
235,614 \\
0 \\
0 \\
0\end{array}$ & $\begin{array}{l}0 \\
0 \\
0 \\
0 \\
0\end{array}$ & $\begin{array}{r}0 \\
235,614 \\
0 \\
0 \\
0\end{array}$ \\
\hline Total.............................. & $49,708,414$ & $49,708,414$ & 0 & $2,136,174$ & 491,832 & $1.644,341$ \\
\hline
\end{tabular}


Table 8. Movements of Natural Gas by State, 1967-1994 (Continued) (Million Cubic Feet)

\begin{tabular}{|c|c|c|c|c|c|c|}
\hline \multirow[t]{2}{*}{ State } & \multicolumn{3}{|c|}{$\begin{array}{l}\text { Imberstute } \\
\text { Movements }\end{array}$} & \multicolumn{3}{|c|}{$\begin{array}{c}\text { Movements Acrous } \\
\text { U.S. Bonders }\end{array}$} \\
\hline & Bocoipt: & Deliverios: & Not & Receipts. & Defiveries & Not \\
\hline & \multicolumn{6}{|c|}{1992} \\
\hline 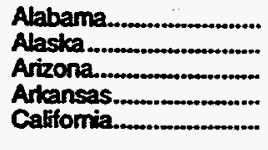 & $\begin{array}{r}2,792,910 \\
0 \\
1,244,223 \\
2,235,546 \\
1,610,708\end{array}$ & $\begin{array}{r}2,833,444 \\
0 \\
1,117,497 \\
2,193,258 \\
0\end{array}$ & $\begin{array}{r}-40,535 \\
0 \\
126,726 \\
42,289 \\
1,610,708\end{array}$ & $\begin{array}{l}0 \\
0 \\
0 \\
0 \\
0\end{array}$ & $\begin{array}{r}0 \\
52,532 \\
2,565 \\
0 \\
0\end{array}$ & $\begin{array}{r}0 \\
-52,532 \\
-2,565 \\
0 \\
0\end{array}$ \\
\hline 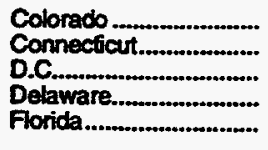 & $\begin{array}{r}\mathbf{5 2 3 , 1 2 4} \\
\mathbf{3 3 6 , 9 7 2} \\
33,422 \\
40,864 \\
341,354\end{array}$ & $\begin{array}{r}573,771 \\
218,371 \\
0 \\
3,230 \\
29\end{array}$ & $\begin{array}{r}-50,647 \\
118,601 \\
33,422 \\
37,634 \\
341,325\end{array}$ & $\begin{array}{l}0 \\
0 \\
0 \\
0 \\
0\end{array}$ & $\begin{array}{l}0 \\
0 \\
0 \\
0 \\
0\end{array}$ & $\begin{array}{l}0 \\
0 \\
0 \\
0 \\
0\end{array}$ \\
\hline 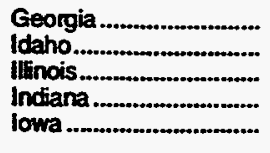 & $\begin{array}{r}1,418,312 \\
103,589 \\
2,134,256 \\
1,563,152 \\
1,270,083\end{array}$ & $\begin{array}{r}1,085,345 \\
543,842 \\
1,112,815 \\
1,082,783 \\
1,027,408\end{array}$ & $\begin{array}{r}332,967 \\
440,253 \\
1,021,441 \\
480,369 \\
242,675\end{array}$ & $\begin{array}{r}0 \\
496.451 \\
0 \\
0 \\
0\end{array}$ & $\begin{array}{l}0 \\
0 \\
0 \\
0 \\
0\end{array}$ & $\begin{array}{r}0 \\
496,451 \\
0 \\
0 \\
0\end{array}$ \\
\hline 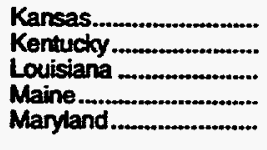 & $\begin{array}{r}1,047,474 \\
3,197,882 \\
1,870,183 \\
5,161 \\
959,084\end{array}$ & $\begin{array}{r}1,305,142 \\
3,023,149 \\
5,165,877 \\
0 \\
766,661\end{array}$ & $\begin{array}{r}-257,668 \\
174,733 \\
-3,295,694 \\
5,161 \\
192,423\end{array}$ & $\begin{array}{r}0 \\
0 \\
12,637 \\
0 \\
0\end{array}$ & $\begin{array}{l}0 \\
0 \\
0 \\
0 \\
0\end{array}$ & $\begin{array}{r}0 \\
0 \\
12,637 \\
0 \\
0\end{array}$ \\
\hline 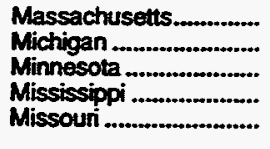 & $\begin{array}{r}334,816 \\
1,135,780 \\
706,629 \\
5,198,262 \\
1,219,024\end{array}$ & $\begin{array}{r}\mathbf{6 2 , 1 9 4} \\
\mathbf{6 , 2 6 8} \\
1,288,392 \\
\mathbf{5 . 1 0 3 , 1 5 6} \\
\mathbf{9 7 4 , 3 9 4}\end{array}$ & $\begin{array}{r}272,622 \\
1,129,512 \\
-581,763 \\
95,107 \\
244,630\end{array}$ & $\begin{array}{r}30,479 \\
38,568 \\
855,300 \\
0 \\
0\end{array}$ & $\begin{array}{r}0 \\
539,369 \\
0 \\
0 \\
0\end{array}$ & $\begin{array}{r}30,479 \\
-500,801 \\
855,300 \\
0 \\
0\end{array}$ \\
\hline 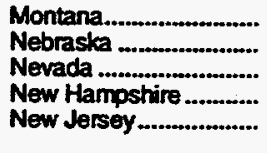 & $\begin{array}{r}21,791 \\
1,021,817 \\
259,899 \\
24,110 \\
1,108,758\end{array}$ & $\begin{array}{r}478,815 \\
898,635 \\
180,832 \\
5,135 \\
628,131\end{array}$ & $\begin{array}{r}-457,024 \\
123,182 \\
79,067 \\
18,975 \\
480,627\end{array}$ & $\begin{array}{r}467,036 \\
0 \\
0 \\
0 \\
0\end{array}$ & $\begin{array}{r}14,569 \\
0 \\
0 \\
0 \\
0\end{array}$ & $\begin{array}{r}452,467 \\
0 \\
0 \\
0 \\
0\end{array}$ \\
\hline 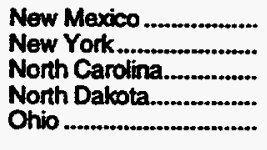 & $\begin{array}{r}436,787 \\
1,121,178 \\
943,723 \\
465,592 \\
2,125,670\end{array}$ & $\begin{array}{r}1,348,520 \\
559,844 \\
752,237 \\
528,330 \\
1,481,800\end{array}$ & $\begin{array}{r}-911,733 \\
561,333 \\
191,486 \\
-62,738 \\
643,869\end{array}$ & $\begin{array}{r}0 \\
435,470 \\
0 \\
0 \\
0\end{array}$ & $\begin{array}{l}0 \\
0 \\
0 \\
0 \\
0\end{array}$ & $\begin{array}{r}0 \\
435,470 \\
0 \\
0 \\
0\end{array}$ \\
\hline 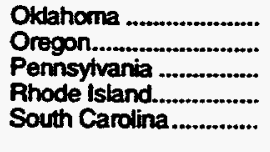 & $\begin{array}{r}545,863 \\
541,201 \\
2,240,904 \\
205,808 \\
1,065,954\end{array}$ & $\begin{array}{r}1,812,379 \\
450,261 \\
1,661,664 \\
132,486 \\
937,086\end{array}$ & $\begin{array}{r}-1,266,516 \\
90,940 \\
579,240 \\
73,322 \\
128,868\end{array}$ & $\begin{array}{l}0 \\
0 \\
0 \\
0 \\
0\end{array}$ & $\begin{array}{l}0 \\
0 \\
0 \\
0 \\
0\end{array}$ & $\begin{array}{l}0 \\
0 \\
0 \\
0 \\
0\end{array}$ \\
\hline 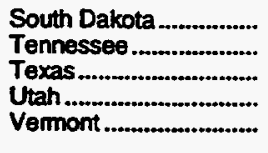 & $\begin{array}{r}532,549 \\
3,361,934 \\
566,789 \\
333,653 \\
0\end{array}$ & $\begin{array}{r}506,324 \\
3,193,074 \\
2,748,086 \\
273,310 \\
9,653\end{array}$ & $\begin{array}{r}26,225 \\
168,860 \\
-2,181,297 \\
60,343 \\
-9,653\end{array}$ & $\begin{array}{r}0 \\
0 \\
0 \\
0 \\
17,248\end{array}$ & $\begin{array}{r}0 \\
0 \\
93,408 \\
0 \\
0\end{array}$ & $\begin{array}{r}0 \\
0 \\
-93,408 \\
0 \\
17,248\end{array}$ \\
\hline 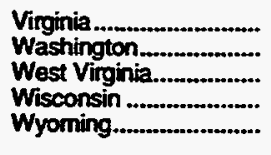 & $\begin{array}{r}1.119,418 \\
491,200 \\
1,466,319 \\
1,057,942 \\
193,125\end{array}$ & $\begin{array}{r}930,018 \\
542,972 \\
1,543,220 \\
706,270 \\
778,686\end{array}$ & $\begin{array}{r}189,401 \\
-51,722 \\
-76,901 \\
351,672 \\
-585,561\end{array}$ & $\begin{array}{r}270,47 \\
0 \\
0 \\
0\end{array}$ & $\begin{array}{l}0 \\
0 \\
0 \\
0 \\
0\end{array}$ & $\begin{array}{r}0 \\
270,477 \\
0 \\
0 \\
0\end{array}$ \\
\hline Total.......... & $52,574,795$ & $52,574,795$ & 0 & $2,623,667$ & 702,442 & $1,921,225$ \\
\hline
\end{tabular}

See footnotes at end of table. 
Table 8. Movements of Natural Gas by State, 1967-1994 (Continued) (Million Cubic Feet)

\begin{tabular}{|c|c|c|c|c|c|c|}
\hline \multirow{2}{*}{ Stute } & \multicolumn{3}{|c|}{ Moventinents } & \multicolumn{3}{|c|}{$\begin{array}{l}\text { Movements Acroes: } \\
\text { U.S. Borders }\end{array}$} \\
\hline & Rocoipts & Deliveries & Net & Racelipts & Delivedie: & Nent \\
\hline & \multicolumn{6}{|c|}{1993} \\
\hline 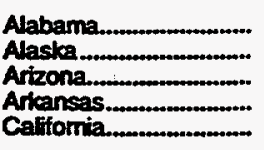 & $\begin{array}{r}2,849,645 \\
0 \\
1,270,649 \\
2,384,562 \\
1,654,143\end{array}$ & $\begin{array}{r}2,904,162 \\
0 \\
1,069,293 \\
2,353,378 \\
0\end{array}$ & $\begin{array}{r}-54,517 \\
0 \\
201,356 \\
31,184 \\
1,654,143\end{array}$ & $\begin{array}{l}0 \\
0 \\
0 \\
0 \\
0\end{array}$ & $\begin{array}{r}0 \\
55,989 \\
3,253 \\
0 \\
0\end{array}$ & $\begin{array}{r}0 \\
-55,989 \\
-3,253 \\
0 \\
0\end{array}$ \\
\hline 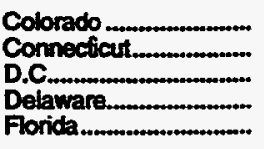 & $\begin{array}{r}503,217 \\
302,126 \\
33,373 \\
43,788 \\
336,185\end{array}$ & $\begin{array}{r}636,724 \\
188,443 \\
0 \\
2,963 \\
30\end{array}$ & $\begin{array}{r}-133,507 \\
113,682 \\
33,373 \\
40,826 \\
336,155\end{array}$ & $\begin{array}{l}0 \\
0 \\
0 \\
0 \\
0\end{array}$ & $\begin{array}{l}0 \\
0 \\
0 \\
0 \\
0\end{array}$ & $\begin{array}{l}0 \\
0 \\
0 \\
0 \\
0\end{array}$ \\
\hline $\begin{array}{l}\text { Georgia } \\
\text { Idaho } \\
\text { llinois } \\
\text { Indiana } \\
\text { lowa }\end{array}$ & $\begin{array}{r}1,371,442 \\
91,967 \\
2,269,660 \\
1,751,885 \\
1,232,578\end{array}$ & $\begin{array}{r}1,041,851 \\
554,834 \\
1,234,731 \\
1,239,776 \\
935,411\end{array}$ & $\begin{array}{r}329,591 \\
-462,867 \\
1,034,929 \\
512,110 \\
297,167\end{array}$ & $\begin{array}{r}0 \\
511,727 \\
0 \\
0 \\
0\end{array}$ & $\begin{array}{l}0 \\
0 \\
0 \\
0 \\
0\end{array}$ & $\begin{array}{r}0 \\
511,727 \\
0 \\
0 \\
0\end{array}$ \\
\hline 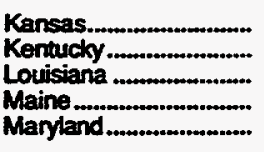 & $\begin{array}{r}974,939 \\
3,314,559 \\
1,831,797 \\
4,989 \\
855,001\end{array}$ & $\begin{array}{r}1,246,045 \\
3,143,992 \\
5,336,593 \\
0 \\
697,939\end{array}$ & $\begin{array}{r}-271,105 \\
170,567 \\
-3,504,796 \\
4,989 \\
157,062\end{array}$ & $\begin{array}{r}0 \\
0 \\
30,790 \\
0 \\
0\end{array}$ & $\begin{array}{l}0 \\
0 \\
0 \\
0 \\
0\end{array}$ & $\begin{array}{r}0 \\
0 \\
30,790 \\
0 \\
0\end{array}$ \\
\hline 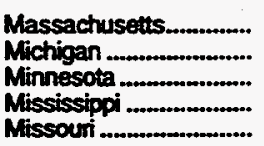 & $\begin{array}{r}278,925 \\
1,042,778 \\
756,282 \\
5,279,804 \\
1,306,977\end{array}$ & $\begin{array}{r}60,665 \\
431 \\
1,335,315 \\
5,157,115 \\
1,086,225\end{array}$ & $\begin{array}{r}218,261 \\
1,042,347 \\
-579,033 \\
122,689 \\
270,752\end{array}$ & $\begin{array}{r}50,895 \\
34,874 \\
707,795 \\
0 \\
0\end{array}$ & $\begin{array}{r}0 \\
368,505 \\
0 \\
0 \\
0\end{array}$ & $\begin{array}{r}50,695 \\
-333,631 \\
707,795 \\
0 \\
0\end{array}$ \\
\hline 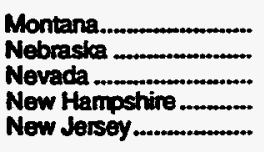 & $\begin{array}{r}19,293 \\
933,217 \\
329,846 \\
24,232 \\
1,018,950\end{array}$ & $\begin{array}{r}530,201 \\
809,216 \\
241,471 \\
4,962 \\
552,903\end{array}$ & $\begin{array}{r}-510,908 \\
124,001 \\
88,376 \\
19,270 \\
466,047\end{array}$ & $\begin{array}{r}511,294 \\
0 \\
0 \\
0 \\
0\end{array}$ & $\begin{array}{r}106 \\
0 \\
0 \\
0 \\
0\end{array}$ & $\begin{array}{r}511,188 \\
0 \\
0 \\
0 \\
0\end{array}$ \\
\hline 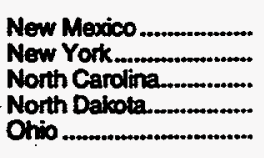 & $\begin{array}{r}289,001 \\
881,247 \\
902,203 \\
517,897 \\
2,226,113\end{array}$ & $\begin{array}{r}1,362,958 \\
495,010 \\
700,015 \\
581,442 \\
1,369,698\end{array}$ & $\begin{array}{r}-1,073,957 \\
386,236 \\
202,188 \\
-63,545 \\
856,415\end{array}$ & $\begin{array}{r}0 \\
502,701 \\
0 \\
0 \\
0\end{array}$ & $\begin{array}{l}0 \\
0 \\
0 \\
0 \\
0\end{array}$ & $\begin{array}{r}0 \\
502,701 \\
0 \\
0 \\
0\end{array}$ \\
\hline 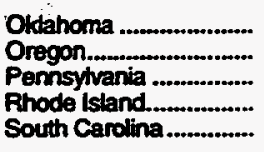 & $\begin{array}{r}511,429 \\
540,702 \\
2,167,583 \\
159,848 \\
1,024,140\end{array}$ & $\begin{array}{r}1,670,651 \\
435,002 \\
1,370,888 \\
96,034 \\
893,469\end{array}$ & $\begin{array}{r}-1,159,222 \\
105,699 \\
796,695 \\
63,814 \\
130,670\end{array}$ & $\begin{array}{l}0 \\
0 \\
0 \\
0 \\
0\end{array}$ & $\begin{array}{l}0 \\
0 \\
0 \\
0 \\
0\end{array}$ & $\begin{array}{l}0 \\
0 \\
0 \\
0 \\
0\end{array}$ \\
\hline $\begin{array}{l}\text { South Dakota } \\
\text { Tennessee } \\
\text { Texas } \\
\text { Utah } \\
\text { Vermont }\end{array}$ & $\begin{array}{r}592,248 \\
3,510,786 \\
538,183 \\
398,269 \\
0\end{array}$ & $\begin{array}{r}561,602 \\
3,310,172 \\
2,571,929 \\
361,042 \\
9,097\end{array}$ & $\begin{array}{r}30,646 \\
200,614 \\
-2,033,746 \\
32,227 \\
-9,097\end{array}$ & $\begin{array}{r}0 \\
0 \\
1,678 \\
0 \\
16,424\end{array}$ & $\begin{array}{r}0 \\
0 \\
36,423 \\
0 \\
0\end{array}$ & $\begin{array}{r}0 \\
0 \\
-34,745 \\
0 \\
16,424\end{array}$ \\
\hline 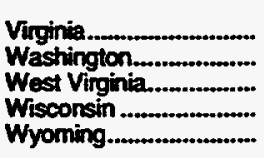 & $\begin{array}{r}1,035,590 \\
515,637 \\
1,517,304 \\
1,101,129 \\
182,933\end{array}$ & $\begin{array}{r}851,890 \\
540,711 \\
1,656,271 \\
688,237 \\
833,269\end{array}$ & $\begin{array}{r}183,700 \\
-25,073 \\
-138,967 \\
412,892 \\
-650,336\end{array}$ & $\begin{array}{r}0 \\
306,030 \\
0 \\
0 \\
0\end{array}$ & $\begin{array}{l}0 \\
0 \\
0 \\
0 \\
0\end{array}$ & $\begin{array}{r}0 \\
306,030 \\
0 \\
0 \\
0\end{array}$ \\
\hline 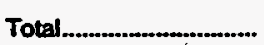 & $52,674,053$ & $52,674,053$ & 0 & $2,674,207$ & 464,276 & $2,209,931$ \\
\hline
\end{tabular}

See foctnotes at end of table. 
Table 8. Movements of Natural Gas by State, 1967-1994 (Continued) (Million Cubic Feet)

\begin{tabular}{|c|c|c|c|c|c|c|}
\hline \multirow[t]{2}{*}{ Stante } & \multicolumn{3}{|c|}{$\begin{array}{l}\text { Intertetis } \\
\text { Mowements }\end{array}$} & \multicolumn{3}{|c|}{$\begin{array}{l}\text { Movements Across } \\
\text { U.S. Bordars }\end{array}$} \\
\hline & Receipts & Detiverios & Net & Rocelpts & Defiverie: & Net \\
\hline & \multicolumn{6}{|c|}{1994} \\
\hline 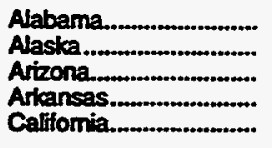 & $\begin{array}{r}2,715,849 \\
0 \\
1,234,695 \\
2,865,799 \\
1,887,149\end{array}$ & $\begin{array}{r}2,888,962 \\
0 \\
1,119,548 \\
2,801,918 \\
0\end{array}$ & $\begin{array}{r}-173,112 \\
0 \\
115,147 \\
63,880 \\
1,887,149\end{array}$ & $\begin{array}{l}0 \\
0 \\
0 \\
0 \\
0\end{array}$ & $\begin{array}{r}0 \\
62,682 \\
2,459 \\
0 \\
0\end{array}$ & $\begin{array}{r}0 \\
-62,682 \\
-2,459 \\
0 \\
0\end{array}$ \\
\hline 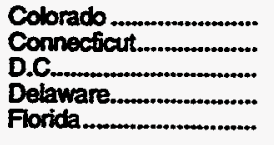 & $\begin{array}{r}585,207 \\
324,576 \\
29,806 \\
52,304 \\
359,172\end{array}$ & $\begin{array}{r}798,437 \\
214,098 \\
0 \\
2,896 \\
30\end{array}$ & $\begin{array}{r}-213,230 \\
110,478 \\
29,806 \\
49,408 \\
359,143\end{array}$ & $\begin{array}{l}0 \\
0 \\
0 \\
0 \\
0\end{array}$ & $\begin{array}{l}0 \\
0 \\
0 \\
0 \\
0\end{array}$ & $\begin{array}{l}\mathbf{0} \\
0 \\
0 \\
0 \\
0\end{array}$ \\
\hline 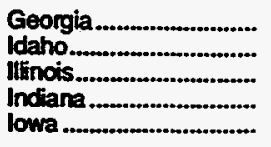 & $\begin{array}{r}1,371,651 \\
98,230 \\
2,489,443 \\
2,233,089 \\
1,443,469\end{array}$ & $\begin{array}{r}1,039,839 \\
759,717 \\
1,328,116 \\
1,632,229 \\
1,156,188\end{array}$ & $\begin{array}{r}331,812 \\
-661,486 \\
1,161,327 \\
600,860 \\
287,281\end{array}$ & $\begin{array}{r}0 \\
723,071 \\
0 \\
0 \\
0\end{array}$ & $\begin{array}{l}0 \\
0 \\
0 \\
0 \\
0\end{array}$ & $\begin{array}{r}0 \\
723,071 \\
0 \\
0 \\
0\end{array}$ \\
\hline 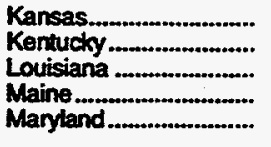 & $\begin{array}{r}1,127,799 \\
3,653,838 \\
1,844,714 \\
4,928 \\
883,179\end{array}$ & $\begin{array}{r}1,390,051 \\
3,577,873 \\
5,649,614 \\
0 \\
656,585\end{array}$ & $\begin{array}{r}-262,252 \\
85,965 \\
-3,804,900 \\
4,928 \\
226,594\end{array}$ & $\begin{array}{r}0 \\
0 \\
17,887 \\
0 \\
0\end{array}$ & $\begin{array}{l}0 \\
0 \\
0 \\
0 \\
0\end{array}$ & $\begin{array}{r}0 \\
0 \\
17,887 \\
0 \\
0\end{array}$ \\
\hline 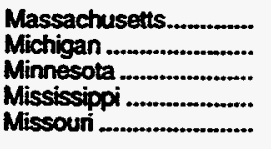 & $\begin{array}{r}292,161 \\
1,495,917 \\
814,096 \\
5,660,877 \\
1,442,661\end{array}$ & $\begin{array}{r}48,281 \\
0 \\
1,377,432 \\
5,493,256 \\
1,196,675\end{array}$ & $\begin{array}{r}243,880 \\
1,495,917 \\
-563,335 \\
167,621 \\
245,985\end{array}$ & $\begin{array}{r}32,891 \\
17,320 \\
881,692 \\
0 \\
0\end{array}$ & $\begin{array}{r}0 \\
538,297 \\
0 \\
0 \\
0\end{array}$ & $\begin{array}{r}32,891 \\
-520,977 \\
881,692 \\
0 \\
0\end{array}$ \\
\hline 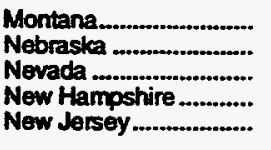 & $\begin{array}{r}20,408 \\
1,170,211 \\
348,147 \\
20,249 \\
1,119,949\end{array}$ & $\begin{array}{r}551,660 \\
1,019,871 \\
245,519 \\
4,884 \\
589,632\end{array}$ & $\begin{array}{r}-531,252 \\
150,340 \\
102,628 \\
15,365 \\
530,317\end{array}$ & $\begin{array}{r}525,855 \\
0 \\
0 \\
0 \\
0\end{array}$ & $\begin{array}{r}3,087 \\
0 \\
0 \\
0 \\
0\end{array}$ & $\begin{array}{r}532,768 \\
0 \\
0 \\
0 \\
0\end{array}$ \\
\hline 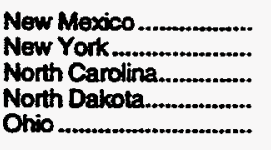 & $\begin{array}{r}334,650 \\
926,727 \\
901,123 \\
543,543 \\
2,617,648\end{array}$ & $\begin{array}{r}1,417,608 \\
549,862 \\
702,517 \\
607,129 \\
1,838,402\end{array}$ & $\begin{array}{r}-1,082,958 \\
376,865 \\
198,606 \\
-63,586 \\
779,245\end{array}$ & $\begin{array}{r}0 \\
588,983 \\
0 \\
1,617 \\
0\end{array}$ & $\begin{array}{l}0 \\
0 \\
0 \\
0 \\
0\end{array}$ & $\begin{array}{r}0 \\
588,983 \\
0 \\
1,617 \\
0\end{array}$ \\
\hline $\begin{array}{l}\text { Oldahoma ..................... } \\
\text { Oregon........................ } \\
\text { Penisylvania ................. } \\
\text { Phode lsiand................ } \\
\text { South Caralina.............. }\end{array}$ & $\begin{array}{r}543,679 \\
765,764 \\
2,165,861 \\
184,516 \\
1,025,779\end{array}$ & $\begin{array}{r}1,785,764 \\
628,931 \\
1,476,943 \\
125,766 \\
896,007\end{array}$ & $\begin{array}{r}-1,242,085 \\
136,833 \\
688,918 \\
58,749 \\
129,772\end{array}$ & $\begin{array}{l}0 \\
0 \\
0 \\
0 \\
0\end{array}$ & $\begin{array}{l}0 \\
0 \\
0 \\
0 \\
0\end{array}$ & $\begin{array}{l}0 \\
0 \\
0 \\
0 \\
0\end{array}$ \\
\hline 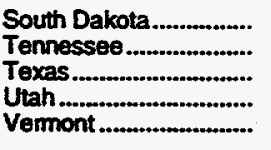 & $\begin{array}{r}613,908 \\
3,878,897 \\
603,826 \\
444,646 \\
0\end{array}$ & $\begin{array}{r}583,653 \\
3,658,815 \\
2,672,096 \\
440,415 \\
10,789\end{array}$ & $\begin{array}{r}30,255 \\
220,081 \\
-2,068,270 \\
4,231 \\
-10,789\end{array}$ & $\begin{array}{r}0 \\
0 \\
7,013 \\
0 \\
18,091\end{array}$ & $\begin{array}{r}0 \\
0 \\
44,041 \\
0 \\
0\end{array}$ & $\begin{array}{r}0 \\
0 \\
-37,029 \\
0 \\
18,091\end{array}$ \\
\hline 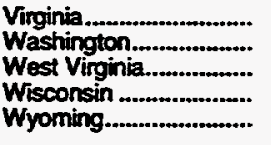 & $\begin{array}{r}1,025,827 \\
713,101 \\
1,620,921 \\
1.179,011 \\
280,941\end{array}$ & $\begin{array}{r}885,104 \\
765,840 \\
1,725,985 \\
698,586 \\
956,416\end{array}$ & $\begin{array}{r}140,723 \\
-52,739 \\
-105,063 \\
480,425 \\
-675,475\end{array}$ & $\begin{array}{r}0 \\
323,013 \\
0 \\
0 \\
0\end{array}$ & $\begin{array}{l}0 \\
0 \\
0 \\
0 \\
0\end{array}$ & $\begin{array}{r}0 \\
323,013 \\
0 \\
0 \\
0\end{array}$ \\
\hline Total_.......................................... & $57,969,941$ & $57,969,941$ & 0 & $3,147,433$ & 650,565 & $2,496,868$ \\
\hline
\end{tabular}

- Data for the District of Columbia are included with data for Maryland.

- Data for Now Hampshire and Vermont are included with data for Maine.

Note: Totals may not equal sim of components due to independent rounding.

Source: Energy Information Administration (EIA), Form ElA-176 "Anmual Feport of Natural and Supplemental Gas Supply and Disposition." 
Table 9. Changes in Natural Gas Underground Storage by State, 1967-1975 (Million Cubic Feet)

\begin{tabular}{|c|c|c|c|c|}
\hline \multirow{2}{*}{ Sute } & \multicolumn{4}{|c|}{ Underground Storago } \\
\hline & Injections & Wrthdrumels & Not & \\
\hline \multicolumn{5}{|c|}{1957} \\
\hline 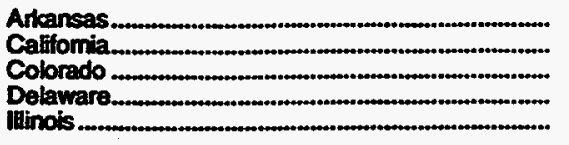 & $\begin{array}{r}1,317 \\
71,148 \\
6,391 \\
1,274 \\
119,125\end{array}$ & $\begin{array}{r}891 \\
67,944 \\
5,257 \\
880 \\
87,680\end{array}$ & $\begin{array}{r}426 \\
3,204 \\
1,134 \\
294 \\
31,495\end{array}$ & \\
\hline 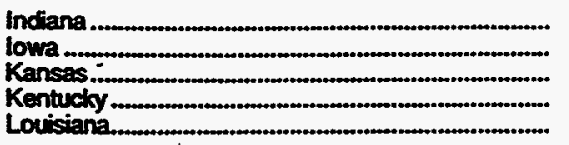 & $\begin{array}{l}25,027 \\
49,603 \\
41,661 \\
26,084 \\
47,474\end{array}$ & $\begin{array}{l}20,236 \\
36,481 \\
44,172 \\
23,848 \\
2,745\end{array}$ & $\begin{array}{r}4,791 \\
13,122 \\
-2,511 \\
2,236 \\
44,729\end{array}$ & \\
\hline 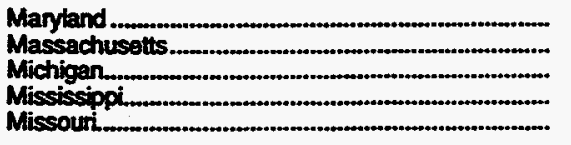 & $\begin{array}{r}12,465 \\
293 \\
222,800 \\
4,701 \\
10,206\end{array}$ & $\begin{array}{r}3,677 \\
119 \\
229,952 \\
5,177 \\
10,137\end{array}$ & $\begin{array}{r}8,788 \\
174 \\
-7,152 \\
-476 \\
69\end{array}$ & . \\
\hline $\begin{array}{l}\text { Montana. } \\
\text { Nebraska } \\
\text { New Jersey } \\
\text { New Mexico }\end{array}$ & $\begin{array}{r}19,919 \\
5,012 \\
805 \\
383 \\
42,344\end{array}$ & $\begin{array}{r}6,100 \\
4,366 \\
811 \\
165 \\
39,616\end{array}$ & $\begin{array}{r}13,819 \\
646 \\
-6 \\
218 \\
2,728\end{array}$ & \\
\hline 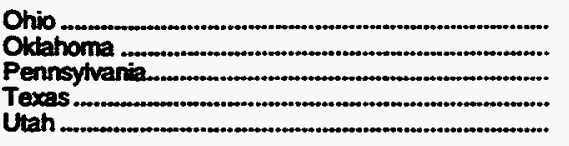 & $\begin{array}{r}142,717 \\
47,438 \\
219,010 \\
34,836 \\
609\end{array}$ & $\begin{array}{r}141,418 \\
20,933 \\
201,444 \\
23,767 \\
389\end{array}$ & $\begin{array}{r}1,299 \\
26,505 \\
17,566 \\
11,069 \\
220\end{array}$ & \\
\hline $\begin{array}{l}\text { Virginia } \\
\text { Washington } \\
\text { West Virginia } \\
\text { Wyoming }\end{array}$ & $\begin{array}{r}158 \\
1,270 \\
159,545 \\
3,748\end{array}$ & $\begin{array}{r}86 \\
206 \\
149,030 \\
4,957\end{array}$ & $\begin{array}{r}72 \\
1,064 \\
10,515 \\
-1,209\end{array}$ & \\
\hline \multirow[t]{2}{*}{ Total } & $1,317,363$ & $1,132,534$ & 184,829 & \\
\hline & \multicolumn{3}{|c|}{1968} & \\
\hline 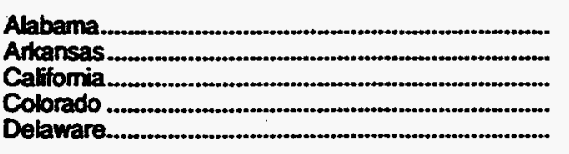 & $\begin{array}{r}536 \\
1,210 \\
58,085 \\
6,849 \\
1,500\end{array}$ & $\begin{array}{r}509 \\
854 \\
62,631 \\
6,850 \\
1,255\end{array}$ & $\begin{array}{r}27 \\
356 \\
-4,546 \\
-1 \\
245\end{array}$ & \\
\hline 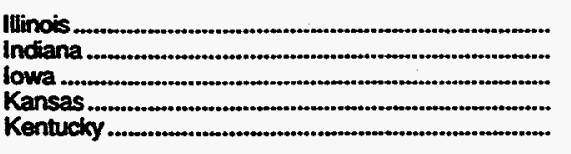 & $\begin{array}{r}143,180 \\
26,679 \\
57,082 \\
44,524 \\
28,993\end{array}$ & $\begin{array}{l}97,146 \\
24,906 \\
54,574 \\
41,190 \\
28,049\end{array}$ & $\begin{array}{r}46,034 \\
1,773 \\
2,508 \\
3,334 \\
944\end{array}$ & \\
\hline 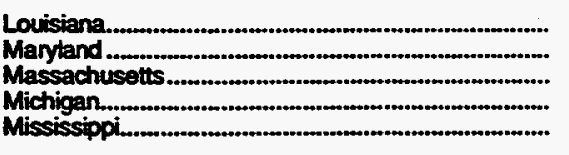 & $\begin{array}{r}33,037 \\
10,520 \\
769 \\
255,365 \\
6,904\end{array}$ & $\begin{array}{r}22,799 \\
6,235 \\
657 \\
250,874 \\
6,710\end{array}$ & $\begin{array}{r}10,238 \\
4,285 \\
102 \\
4,491 \\
194\end{array}$ & \\
\hline $\begin{array}{l}\text { Missouri. } \\
\text { Montana } \\
\text { Nebraska } \\
\text { New Jersey } \\
\text { New Mexico }\end{array}$ & $\begin{array}{r}8,919 \\
17,398 \\
2,959 \\
975 \\
74\end{array}$ & $\begin{array}{r}10,167 \\
8,009 \\
3,764 \\
968 \\
60\end{array}$ & $\begin{array}{r}-1,248 \\
9,389 \\
805 \\
7 \\
14\end{array}$ & \\
\hline $\begin{array}{l}\text { Now York } \\
\text { Ohio } \\
\text { Okdahoma } \\
\text { Pennsylvania. } \\
\text { Tennessee }\end{array}$ & $\begin{array}{r}44,978 \\
169,955 \\
46,871 \\
235,415 \\
2,140\end{array}$ & $\begin{array}{r}45,482 \\
158,914 \\
36,464 \\
235,570 \\
1,906\end{array}$ & $\begin{array}{r}504 \\
11.041 \\
10.407 \\
-155 \\
234\end{array}$ & \\
\hline
\end{tabular}

See footnotes at end of table. 
Table 9. Changes in Natural Gas Underground Storage by State, 1967-1975 (Continued) (Million Cubic Feet)

\begin{tabular}{|c|c|c|c|c|}
\hline \multirow{2}{*}{ State } & \multicolumn{4}{|c|}{ Underground Storegre } \\
\hline & Injection & Withdramels & $\mathrm{Net}$ & \\
\hline & \multicolumn{4}{|c|}{1968} \\
\hline 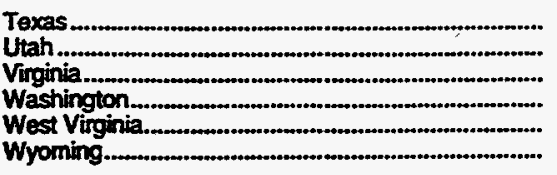 & $\begin{array}{r}31,597 \\
640 \\
272 \\
974 \\
181,338 \\
5,337\end{array}$ & $\begin{array}{r}34,242 \\
611 \\
104 \\
974 \\
182,982 \\
4,070\end{array}$ & $\begin{array}{r}-2,645 \\
29 \\
168 \\
0 \\
-1,644 \\
1,267\end{array}$ & \\
\hline \multirow{2}{*}{ Total } & $1,425,075$ & $1,329,536$ & 95,539 & \\
\hline & \multicolumn{4}{|c|}{1969} \\
\hline 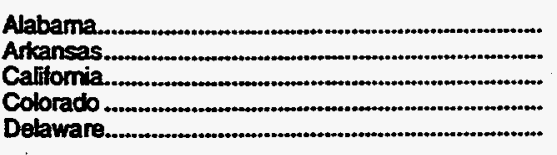 & $\begin{array}{r}577 \\
1,168 \\
77,617 \\
8,653 \\
179\end{array}$ & $\begin{array}{r}435 \\
507 \\
64,590 \\
8,128 \\
878\end{array}$ & $\begin{array}{r}142 \\
661 \\
13,027 \\
535 \\
-699\end{array}$ & 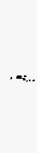 \\
\hline 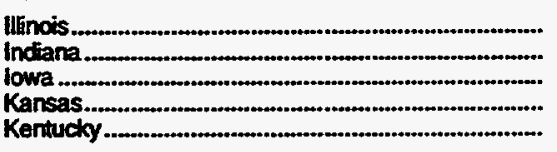 & $\begin{array}{r}153,497 \\
26,483 \\
43,037 \\
50,772 \\
31,726\end{array}$ & $\begin{array}{r}105,337 \\
22,385 \\
45,343 \\
50,140 \\
27,966\end{array}$ & $\begin{array}{r}48,160 \\
4,098 \\
-2,306 \\
632 \\
3,760\end{array}$ & \\
\hline 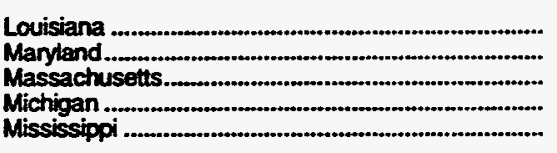 & $\begin{array}{r}58,753 \\
5,281 \\
314 \\
257,737 \\
7,493\end{array}$ & $\begin{array}{r}43,521 \\
9,417 \\
567 \\
260,981 \\
8,398\end{array}$ & $\begin{array}{r}15,232 \\
-4,136 \\
-253 \\
-3,244 \\
-905\end{array}$ & \\
\hline $\begin{array}{l}\text { Missouri } \\
\text { Montana. } \\
\text { Nebrasta } \\
\text { New Jersey } \\
\text { New Mexico }\end{array}$ & $\begin{array}{r}9,044 \\
20,409 \\
4,808 \\
1,281 \\
383\end{array}$ & $\begin{array}{r}9,909 \\
10,854 \\
3,526 \\
1,075 \\
165\end{array}$ & $\begin{array}{r}-865 \\
9.555 \\
1,312 \\
206 \\
218\end{array}$ & \\
\hline $\begin{array}{l}\text { New York } \\
\text { Ohio } \\
\text { Ohdahoma } \\
\text { Penmsytvania } \\
\text { Texas }\end{array}$ & $\begin{array}{r}41,874 \\
168,142 \\
53,945 \\
244,892 \\
33,943\end{array}$ & $\begin{array}{r}39,148 \\
172,078 \\
37,786 \\
240,373 \\
30,582\end{array}$ & $\begin{array}{r}2,726 \\
-3,936 \\
16,159 \\
4,519 \\
3,361\end{array}$ & \\
\hline 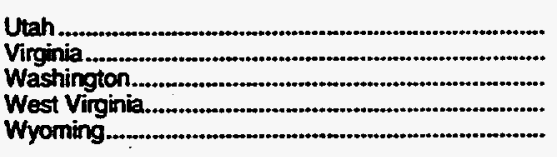 & $\begin{array}{r}580 \\
2,143 \\
1,827 \\
183,114 \\
6,695\end{array}$ & $\begin{array}{r}367 \\
134 \\
735 \\
181,142 \\
3,021\end{array}$ & $\begin{array}{r}213 \\
2,009 \\
1,092 \\
1,972 \\
3,674\end{array}$ & \\
\hline \multirow[t]{2}{*}{ 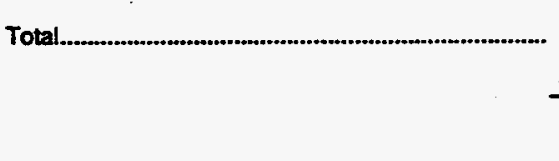 } & $1,496,407$ & $1,379,488$ & 116,919 & \\
\hline & \multicolumn{4}{|c|}{1970} \\
\hline 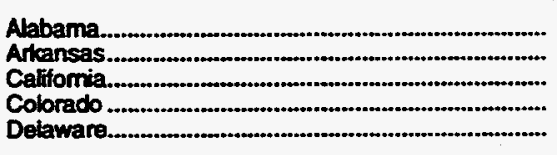 & $\begin{array}{r}1,153 \\
1,467 \\
80,260 \\
8,757 \\
391\end{array}$ & $\begin{array}{r}587 \\
1,261 \\
52,235 \\
5,650 \\
602\end{array}$ & $\begin{array}{r}566 \\
206 \\
28,025 \\
3,127 \\
-211\end{array}$ & \\
\hline 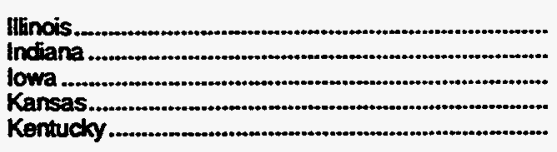 & $\begin{array}{r}190,661 \\
35,065 \\
46,301 \\
52,966 \\
38,968\end{array}$ & $\begin{array}{r}112,468 \\
25,040 \\
42,068 \\
47,068 \\
28,592\end{array}$ & $\begin{array}{r}78,193 \\
10,025 \\
4,233 \\
5,898 \\
10,376\end{array}$ & \\
\hline 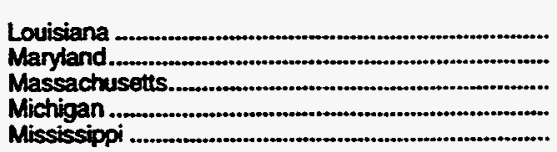 & $\begin{array}{r}110,680 \\
10,421 \\
770 \\
344,524 \\
12,489\end{array}$ & $\begin{array}{r}48,170 \\
8,069 \\
570 \\
317,397 \\
8,579\end{array}$ & $\begin{array}{r}62,510 \\
2,352 \\
200 \\
27,127 \\
3,910\end{array}$ & \\
\hline
\end{tabular}

See foctnotes at end of table. 
Table 9. Changes in Natural Gas Underground Storage by State, 1967-1975 (Continued) (Million Cubic Feet)

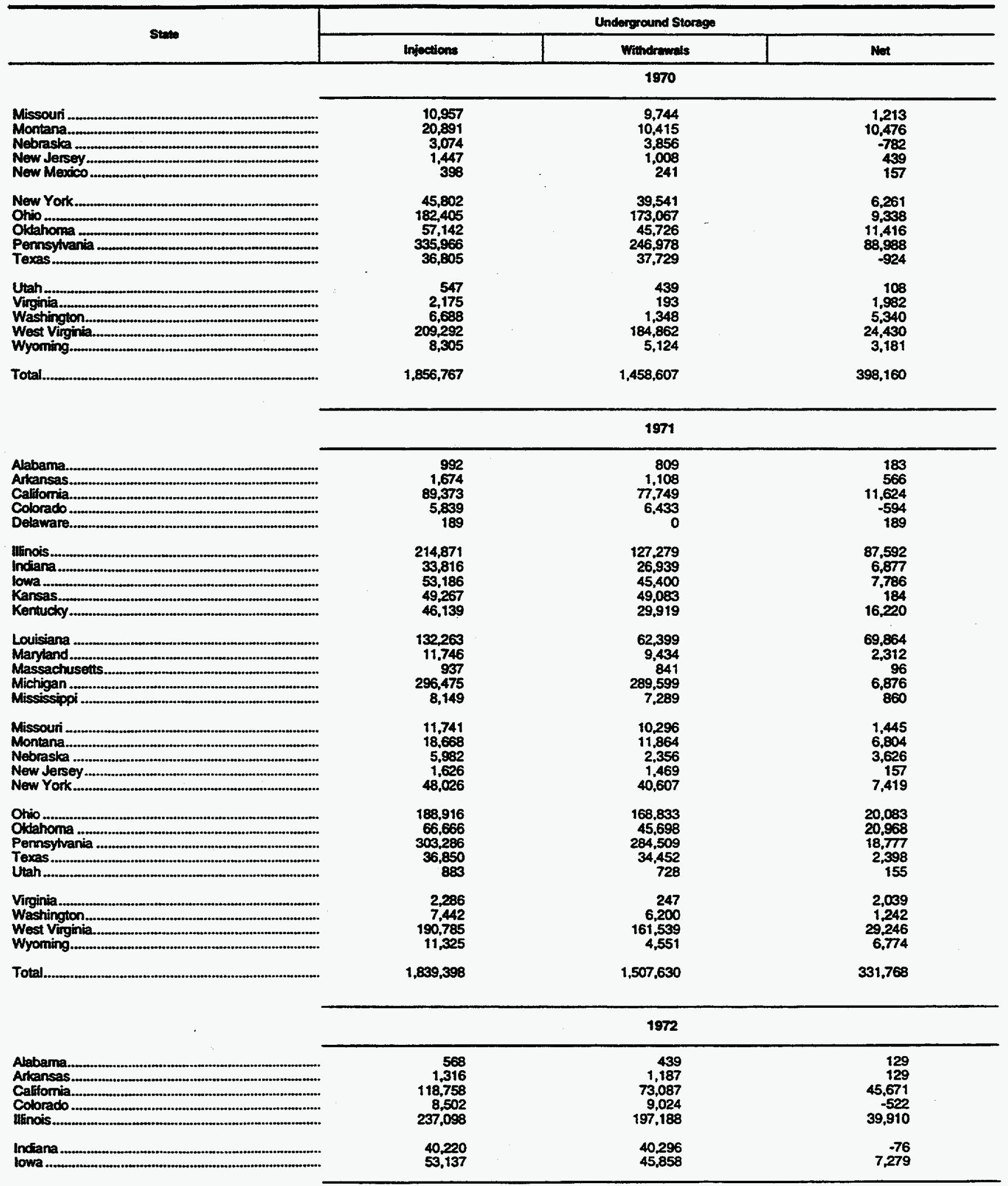

See foothotes at end of table. 
Table 9. Changes in Natural Gas Underground Storage by State, 1967-1975 (Continued) (Million Cubic Feet)

\begin{tabular}{|c|c|c|c|}
\hline \multirow{2}{*}{ Stente } & \multicolumn{3}{|c|}{ Undarground Storngo } \\
\hline & Injections & Whithotremels & Not \\
\hline \multicolumn{4}{|c|}{1972} \\
\hline 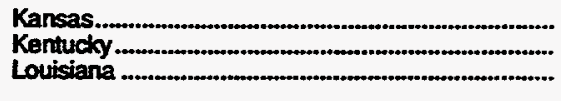 & $\begin{array}{l}46,810 \\
51,437 \\
84,201\end{array}$ & $\begin{array}{l}48,391 \\
43,138 \\
\mathbf{8 4 , 7 3 4}\end{array}$ & $\begin{array}{r}-1,581 \\
8,299 \\
-533\end{array}$ \\
\hline 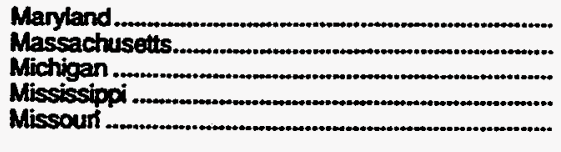 & $\begin{array}{r}7,920 \\
1,496 \\
275,460 \\
83,548 \\
10,188\end{array}$ & $\begin{array}{r}8,192 \\
422 \\
306,491 \\
7,944 \\
8,692\end{array}$ & $\begin{array}{r}-272 \\
1,074 \\
-31,031 \\
75,604 \\
1,496\end{array}$ \\
\hline $\begin{array}{l}\text { Montana } \\
\text { Nebraska } \\
\text { New Jersey } \\
\text { New York } \\
\text { Ohio }\end{array}$ & $\begin{array}{r}8,801 \\
8,837 \\
1,765 \\
32,777 \\
163,884\end{array}$ & $\begin{array}{r}7,281 \\
2,282 \\
1,785 \\
42,894 \\
185,454\end{array}$ & $\begin{array}{r}1,520 \\
6,555 \\
-20 \\
-10,117 \\
-21,570\end{array}$ \\
\hline 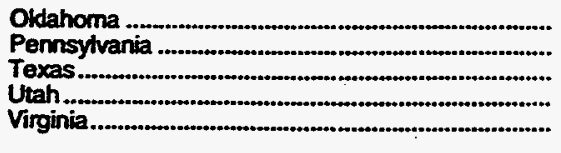 & $\begin{array}{r}59,061 \\
315,183 \\
87,251 \\
906 \\
278\end{array}$ & $\begin{array}{r}66,852 \\
322,254 \\
47,269 \\
691 \\
93\end{array}$ & $\begin{array}{r}-7,791 \\
-7,071 \\
39,982 \\
215 \\
185\end{array}$ \\
\hline 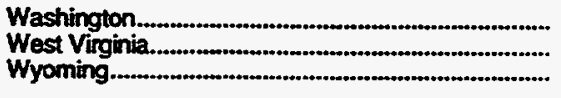 & $\begin{array}{r}9,608 \\
171,946 \\
11,996\end{array}$ & $\begin{array}{r}6,365 \\
194,109 \\
4,806\end{array}$ & $\begin{array}{r}3,243 \\
-22,163 \\
7,190\end{array}$ \\
\hline \multirow[t]{2}{*}{ Total } & $1,892,952$ & $1,757,218$ & 135,734 \\
\hline & \multicolumn{3}{|c|}{1973} \\
\hline 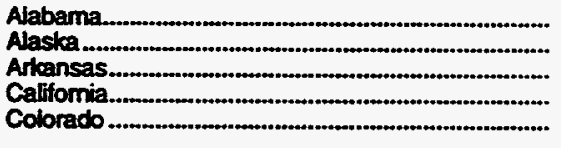 & $\begin{array}{r}1,070 \\
16,327 \\
2,218 \\
92,331 \\
10,673\end{array}$ & $\begin{array}{r}516 \\
0 \\
1,632 \\
65,516 \\
5,383\end{array}$ & $\begin{array}{r}554 \\
16,327 \\
586 \\
26,815 \\
5,290\end{array}$ \\
\hline 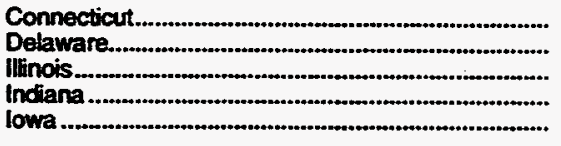 & $\begin{array}{r}683 \\
255 \\
233,112 \\
46,617 \\
57,011\end{array}$ & $\begin{array}{r}441 \\
0 \\
158,590 \\
32,466 \\
40,352\end{array}$ & $\begin{array}{r}242 \\
255 \\
74,522 \\
14,151 \\
16,659\end{array}$ \\
\hline 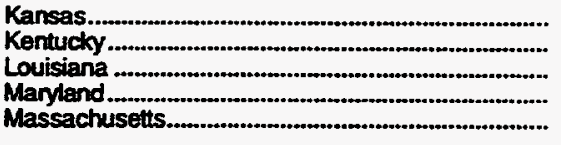 & $\begin{array}{r}42,910 \\
54,392 \\
151,287 \\
11,328 \\
413\end{array}$ & $\begin{array}{r}33,258 \\
38,147 \\
66,376 \\
12,229 \\
2,891\end{array}$ & $\begin{array}{r}9,652 \\
16,245 \\
84,911 \\
-901 \\
-2,468\end{array}$ \\
\hline 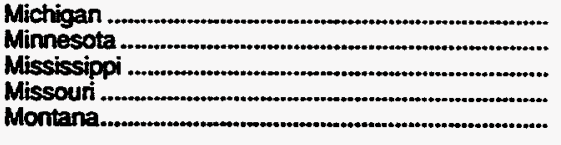 & $\begin{array}{r}299,766 \\
829 \\
29,089 \\
10,847 \\
16,969\end{array}$ & $\begin{array}{r}268,071 \\
298 \\
22,601 \\
9,730 \\
12,404\end{array}$ & $\begin{array}{r}31,695 \\
531 \\
6,488 \\
1,117 \\
4,565\end{array}$ \\
\hline 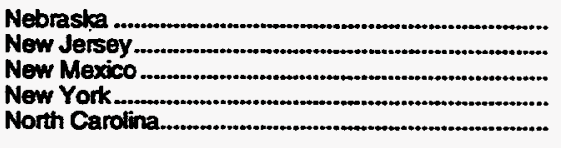 & $\begin{array}{r}5,280 \\
1,867 \\
5,067 \\
40,277 \\
97\end{array}$ & $\begin{array}{r}2,128 \\
1,463 \\
2,024 \\
39,117 \\
0\end{array}$ & $\begin{array}{r}3,152 \\
404 \\
3,043 \\
1,160 \\
97\end{array}$ \\
\hline 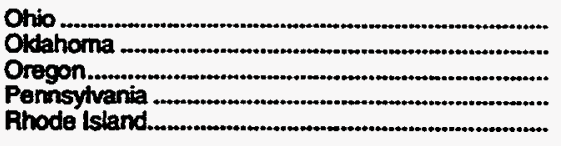 & $\begin{array}{r}179,078 \\
88,000 \\
189 \\
321,757 \\
97\end{array}$ & $\begin{array}{r}153,667 \\
65,798 \\
0 \\
277,187 \\
91\end{array}$ & $\begin{array}{r}25,411 \\
22,202 \\
189 \\
44,570 \\
6\end{array}$ \\
\hline 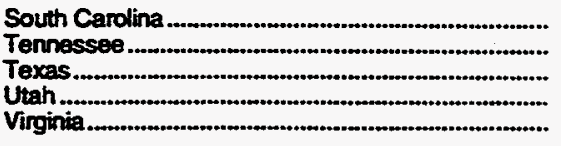 & $\begin{array}{r}48 \\
1,606 \\
46,592 \\
2,320 \\
320\end{array}$ & $\begin{array}{r}42 \\
26 \\
45,188 \\
693 \\
137\end{array}$ & $\begin{array}{r}6 \\
1,580 \\
1,404 \\
1,627 \\
183\end{array}$ \\
\hline
\end{tabular}

See footnotes at end of table. 
Table 9. Changes in Natural Gas Underground Storage by State, 1967-1975 (Continued) (Million Cubic Feet)

\begin{tabular}{|c|c|c|c|c|}
\hline \multirow{2}{*}{ Stute } & \multicolumn{4}{|c|}{ Underground Storage } \\
\hline & Injections & Wundrowils & Net & \\
\hline & \multicolumn{3}{|c|}{1973} & \\
\hline 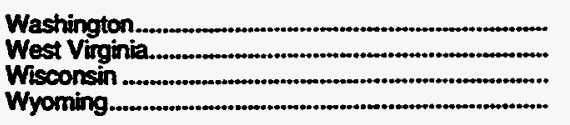 & $\begin{array}{r}8,598 \\
184,984 \\
166 \\
9,854\end{array}$ & $\begin{array}{r}5,680 \\
161,474 \\
0 \\
7,214\end{array}$ & $\begin{array}{r}2,918 \\
23,510 \\
166 \\
2,640\end{array}$ & \\
\hline \multirow[t]{2}{*}{ 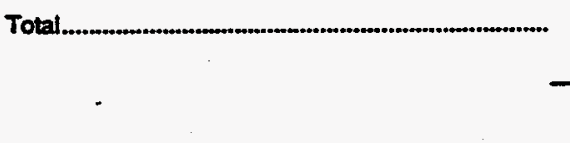 } & $1,974,324$ & $1,532,820$ & 441,504 & \\
\hline & \multicolumn{3}{|c|}{1974} & \\
\hline 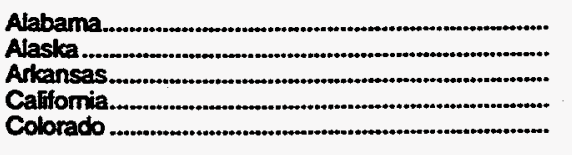 & $\begin{array}{r}410 \\
13,253 \\
1,783 \\
129,945 \\
11,444\end{array}$ & $\begin{array}{r}621 \\
0 \\
1,448 \\
50,411 \\
12,354\end{array}$ & $\begin{array}{r}-211 \\
13,253 \\
335 \\
79,534 \\
-910\end{array}$ & $\approx$ \\
\hline 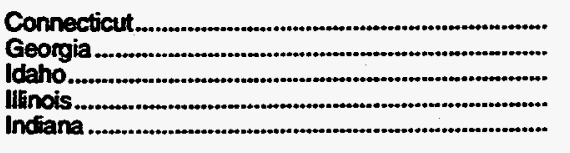 & $\begin{array}{r}740 \\
123 \\
112 \\
232,284 \\
36,070\end{array}$ & $\begin{array}{r}1,241 \\
33 \\
0 \\
184,540 \\
37,288\end{array}$ & $\begin{array}{r}-501 \\
90 \\
112 \\
47,744 \\
-1,218\end{array}$ & \\
\hline 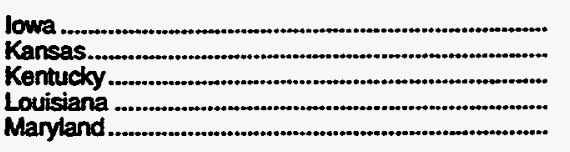 & $\begin{array}{l}56,505 \\
45,642 \\
50,903 \\
81,960 \\
11,016\end{array}$ & $\begin{array}{r}44,114 \\
37,155 \\
49,047 \\
79,140 \\
9,724\end{array}$ & $\begin{array}{r}12,391 \\
8,487 \\
1,856 \\
2,820 \\
1,292\end{array}$ & \\
\hline 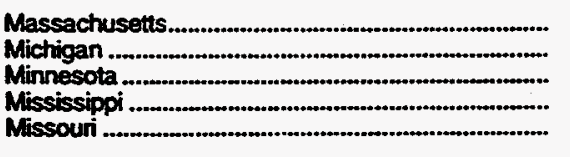 & $\begin{array}{r}408 \\
287,776 \\
1,502 \\
25,439 \\
9,413\end{array}$ & $\begin{array}{r}2,110 \\
305,092 \\
979 \\
25,409 \\
8,225\end{array}$ & $\begin{array}{r}-1,707 \\
-17,316 \\
523 \\
30 \\
1,188\end{array}$ & \\
\hline 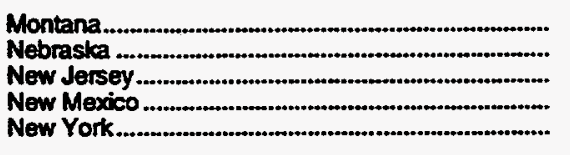 & $\begin{array}{r}19,791 \\
5,667 \\
3,953 \\
12,589 \\
56,403\end{array}$ & $\begin{array}{r}14,347 \\
363 \\
3,329 \\
58 \\
58,712\end{array}$ & $\begin{array}{r}5,444 \\
5,304 \\
624 \\
12,531 \\
2,691\end{array}$ & \\
\hline $\begin{array}{l}\text { North Carolina. } \\
\text { Ohio } \\
\text { Oldahoma } \\
\text { Oregon } \\
\text { Pernsylvania }\end{array}$ & $\begin{array}{r}2,626 \\
152,580 \\
70,076 \\
5 \\
265,901\end{array}$ & $\begin{array}{r}2,483 \\
178,990 \\
78,355 \\
0 \\
306,548\end{array}$ & $\begin{array}{r}143 \\
-26,410 \\
-8,279 \\
5 \\
-40,647\end{array}$ & \\
\hline 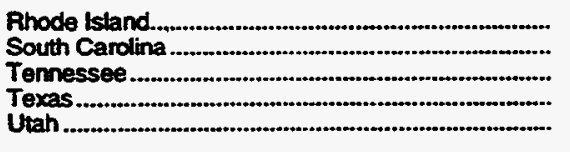 & $\begin{array}{r}243 \\
80 \\
1,750 \\
54.705 \\
999\end{array}$ & $\begin{array}{r}654 \\
53 \\
804 \\
55,309 \\
317\end{array}$ & $\begin{array}{r}-411 \\
27 \\
946 \\
-604 \\
682\end{array}$ & \\
\hline 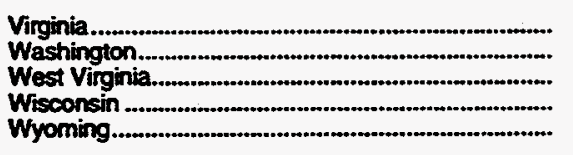 & $\begin{array}{r}112 \\
7,993 \\
124,988 \\
0 \\
7,025\end{array}$ & $\begin{array}{r}258 \\
5,510 \\
141,995 \\
331 \\
8,199\end{array}$ & $\begin{array}{r}-146 \\
2,483 \\
-17,007 \\
-331 \\
-1,174\end{array}$ & \\
\hline \multirow[t]{2}{*}{ 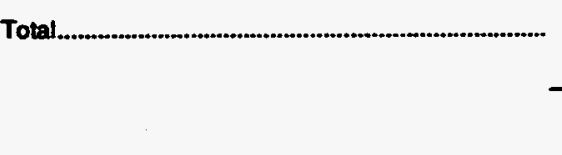 } & $1,784,209$ & $1,700,546$ & 83,663 & \\
\hline & \multicolumn{3}{|c|}{1975} & \\
\hline 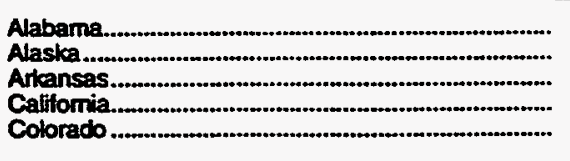 & $\begin{array}{r}434 \\
15,555 \\
1,555 \\
105,167 \\
13,420\end{array}$ & $\begin{array}{r}532 \\
0 \\
1,225 \\
101,101 \\
15,885\end{array}$ & $\begin{array}{r}-98 \\
15,555 \\
330 \\
4,066 \\
-2,465\end{array}$ & \\
\hline 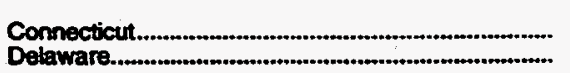 & $\begin{array}{r}746 \\
2,012\end{array}$ & $\begin{array}{l}2,017 \\
1,463\end{array}$ & $\begin{array}{r}-1,271 \\
549\end{array}$ & \\
\hline
\end{tabular}

See footnotes at end of table. 
Table 9. Changes in Natural Gas Underground Storage by State, 1967-1975 (Continued) (Million Cubic Feet)

\begin{tabular}{|c|c|c|c|}
\hline \multirow{2}{*}{ Stat } & \multicolumn{3}{|c|}{ Underground Storage } \\
\hline & Injection: & Writhdrumals & Net \\
\hline & \multicolumn{3}{|c|}{1975} \\
\hline 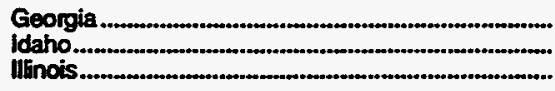 & $\begin{array}{r}366 \\
395 \\
294,689\end{array}$ & $\begin{array}{r}27 \\
0 \\
225,383\end{array}$ & $\begin{array}{r}339 \\
395 \\
69,305\end{array}$ \\
\hline 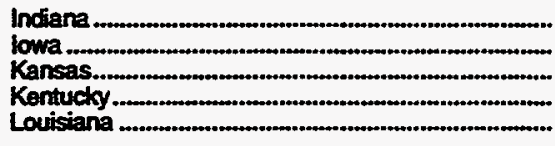 & $\begin{array}{r}43,845 \\
59,065 \\
52,045 \\
70,609 \\
149,966\end{array}$ & $\begin{array}{l}39,626 \\
53,404 \\
38,077 \\
58,571 \\
91,281\end{array}$ & $\begin{array}{r}4,219 \\
5,661 \\
13,968 \\
12,038 \\
58,685\end{array}$ \\
\hline 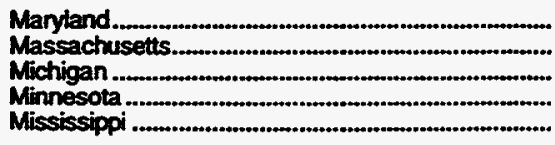 & $\begin{array}{r}6,830 \\
3,912 \\
322,950 \\
839 \\
27,345\end{array}$ & $\begin{array}{r}8,267 \\
1,727 \\
294,867 \\
843 \\
27,398\end{array}$ & $\begin{array}{r}-1,437 \\
2.185 \\
28,093 \\
-4 \\
-53\end{array}$ \\
\hline $\begin{array}{l}\text { Missouri } \\
\text { Montana } \\
\text { Nebraska } \\
\text { New Jersey } \\
\text { New Mexico }\end{array}$ & $\begin{array}{r}8,658 \\
13,090 \\
5,459 \\
6,378 \\
4,160\end{array}$ & $\begin{array}{r}8,690 \\
21,725 \\
778 \\
2,509 \\
850\end{array}$ & $\begin{array}{r}-32 \\
-8,635 \\
4,681 \\
3,869 \\
3,310\end{array}$ \\
\hline $\begin{array}{l}\text { New York } \\
\text { North Carolina. } \\
\text { Ohio } \\
\text { Okdahoma } \\
\text { Oregon }\end{array}$ & $\begin{array}{r}43,207 \\
2,019 \\
183,032 \\
87,459 \\
46\end{array}$ & $\begin{array}{r}45,498 \\
1,910 \\
145,224 \\
84,476 \\
0\end{array}$ & $\begin{array}{r}-2,291 \\
509 \\
37,808 \\
2,983 \\
46\end{array}$ \\
\hline 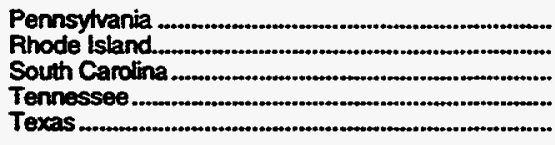 & $\begin{array}{r}332,183 \\
137 \\
70 \\
2,325 \\
54,333\end{array}$ & $\begin{array}{r}280,307 \\
678 \\
116 \\
1.797 \\
50,801\end{array}$ & $\begin{array}{r}51,876 \\
-541 \\
-46 \\
528 \\
3,532\end{array}$ \\
\hline 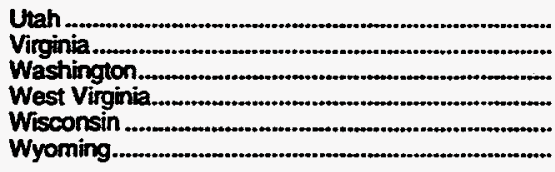 & $\begin{array}{r}1,340 \\
1,079 \\
12,009 \\
161,604 \\
0 \\
13,276\end{array}$ & $\begin{array}{r}602 \\
2,472 \\
12,108 \\
126,860 \\
428 \\
10,042\end{array}$ & $\begin{array}{r}738 \\
-1,393 \\
-99 \\
34,744 \\
-428 \\
3,234\end{array}$ \\
\hline Total & $2,103,619$ & $1,759,565$ & 344,054 \\
\hline
\end{tabular}

Note: Totais may not equal sum of components due to independent rounding.

Source: American Gas Association, Committee on Underground Storage, The Storage of Gas in the United States and Canada. 
Table 10. Changes in Natural Gas Underground Storage by State, 1976-1979 (Million Cubic Feet)

\begin{tabular}{|c|c|c|c|c|}
\hline \multirow{2}{*}{ Stus } & \multicolumn{4}{|c|}{ Undergeound Stornge } \\
\hline & Injection & Withdrumals & Adjustments & Not \\
\hline & \multicolumn{4}{|c|}{1976} \\
\hline 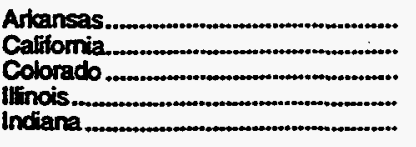 & $\begin{array}{r}1,033 \\
107,749 \\
16,987 \\
235,310 \\
18,252\end{array}$ & $\begin{array}{r}561 \\
62,484 \\
13,855 \\
207,921 \\
23,319\end{array}$ & $\begin{array}{r}0 \\
-1 \\
399 \\
-1,545 \\
-109\end{array}$ & $\begin{array}{r}472 \\
45,264 \\
3,531 \\
25,844 \\
-5,176\end{array}$ \\
\hline 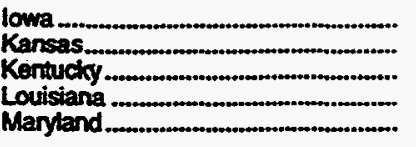 & $\begin{array}{r}55,005 \\
48,582 \\
69,954 \\
132,724 \\
19,012\end{array}$ & $\begin{array}{l}49,749 \\
46,390 \\
75,397 \\
95,866 \\
21,304\end{array}$ & $\begin{array}{r}0 \\
-2,927 \\
-77 \\
-1 \\
0\end{array}$ & $\begin{array}{r}5,256 \\
-735 \\
-5,520 \\
36,857 \\
-2,292\end{array}$ \\
\hline 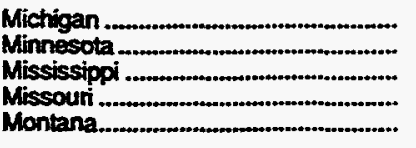 & $\begin{array}{r}342,010 \\
551 \\
50,545 \\
6,634 \\
12,507\end{array}$ & $\begin{array}{r}380,555 \\
1,111 \\
61,563 \\
9,118 \\
19,848\end{array}$ & $\begin{array}{r}-3,978 \\
0 \\
0 \\
0 \\
0\end{array}$ & $\begin{array}{r}-42,463 \\
-560 \\
-11,018 \\
-2,484 \\
-7,341\end{array}$ \\
\hline $\begin{array}{l}\text { Nebraska } \\
\text { New Mexico } \\
\text { New York } \\
\text { Ohio } \\
\text { Okdahoma }\end{array}$ & $\begin{array}{r}4,508 \\
1,005 \\
42,565 \\
146,228 \\
88,577\end{array}$ & $\begin{array}{r}742 \\
1,270 \\
52,049 \\
206,536 \\
90,173\end{array}$ & $\begin{array}{r}-35 \\
-6 \\
-1,106 \\
0 \\
-2,162\end{array}$ & $\begin{array}{r}3,731 \\
-271 \\
-10,590 \\
-60,308 \\
-3,758\end{array}$ \\
\hline 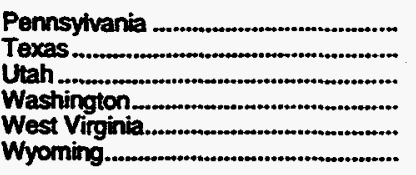 & $\begin{array}{r}293,596 \\
61,110 \\
1,069 \\
13,858 \\
138,767 \\
10,404\end{array}$ & $\begin{array}{r}373,431 \\
49,479 \\
1,370 \\
10,685 \\
194,046 \\
11,076\end{array}$ & $\begin{array}{r}-8,313 \\
-71 \\
529 \\
0 \\
-4,627 \\
-1\end{array}$ & $\begin{array}{r}-88,148 \\
11,560 \\
228 \\
3.173 \\
-59,906 \\
-673\end{array}$ \\
\hline \multirow[t]{2}{*}{ TOtal } & $1,918,541$ & $2,059,898$ & $-23,970$ & $-165,327$ \\
\hline & \multicolumn{4}{|c|}{1977} \\
\hline 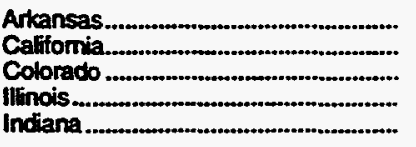 & $\begin{array}{r}1,462 \\
109,760 \\
21,717 \\
293,311 \\
32,090\end{array}$ & $\begin{array}{r}763 \\
84,859 \\
13,820 \\
213,842 \\
20,003\end{array}$ & $\begin{array}{r}0 \\
11 \\
-870 \\
-565 \\
-1,373\end{array}$ & $\begin{array}{r}699 \\
24,912 \\
7,027 \\
78,904 \\
10,709\end{array}$ \\
\hline 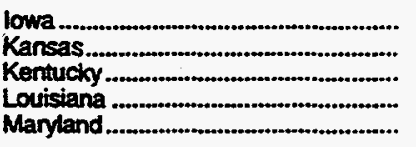 & $\begin{array}{r}71,002 \\
51,344 \\
69,097 \\
144,053 \\
16,820\end{array}$ & $\begin{array}{l}44,965 \\
40,409 \\
55,497 \\
84,166 \\
17,061\end{array}$ & $\begin{array}{r}0 \\
-1,834 \\
2,240 \\
-170 \\
0\end{array}$ & $\begin{array}{r}26,037 \\
9,101 \\
15,840 \\
59,717 \\
-241\end{array}$ \\
\hline 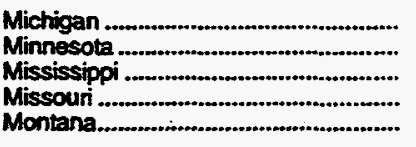 & $\begin{array}{r}372,262 \\
1,326 \\
65,693 \\
8,074 \\
15,908\end{array}$ & $\begin{array}{r}327,422 \\
1,003 \\
49,388 \\
6,764 \\
17,598\end{array}$ & $\begin{array}{r}-58 \\
0 \\
69 \\
-1 \\
0\end{array}$ & $\begin{array}{r}44.782 \\
323 \\
16,374 \\
1,310 \\
-1,690\end{array}$ \\
\hline 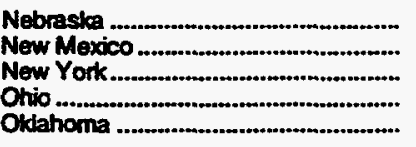 & $\begin{array}{r}7,053 \\
2,378 \\
53,768 \\
188,721 \\
104,347\end{array}$ & $\begin{array}{r}1,110 \\
2,452 \\
46,398 \\
143,567 \\
75,145\end{array}$ & $\begin{array}{r}-40 \\
0 \\
926 \\
-3,488 \\
-1,783\end{array}$ & $\begin{array}{r}5,903 \\
-74 \\
8,296 \\
41,666 \\
27,419\end{array}$ \\
\hline 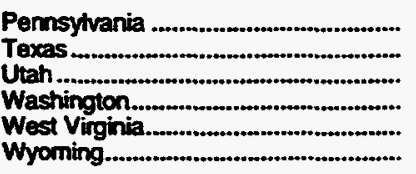 & $\begin{array}{r}364,262 \\
85,913 \\
1,446 \\
15,540 \\
195,861 \\
10,061\end{array}$ & $\begin{array}{r}292,908 \\
36,983 \\
1,116 \\
12,838 \\
135,134 \\
10,653\end{array}$ & $\begin{array}{r}-3,790 \\
45 \\
0 \\
0 \\
0 \\
0\end{array}$ & $\begin{array}{r}67.564 \\
48,885 \\
330 \\
2,702 \\
60,727 \\
-592\end{array}$ \\
\hline 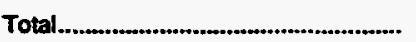 & $2,303,268$ & $1,735,868$ & $-10,769$ & 556,631 \\
\hline
\end{tabular}

See footnotes at end of table. 
Table 10. Changes in Natural Gas Underground Storage by State, 1976-1979 (Continued) (Million Cubic Feet)

\begin{tabular}{|c|c|c|c|c|}
\hline \multirow{2}{*}{ Stato } & \multicolumn{4}{|c|}{ Underground Storage } \\
\hline & Injections & Writhdrements & Adjustments & Not \\
\hline & \multicolumn{4}{|c|}{1978} \\
\hline $\begin{array}{l}\text { Arlicansas. } \\
\text { Calforria. } \\
\text { Colorado } \\
\text { Il } \\
\text { Incinois }\end{array}$ & $\begin{array}{r}1,572 \\
108,432 \\
20,630 \\
236,669 \\
25,903\end{array}$ & $\begin{array}{r}1,398 \\
130,075 \\
21,925 \\
230,526 \\
22,392\end{array}$ & $\begin{array}{r}0 \\
-1,376 \\
-368 \\
336 \\
1,914\end{array}$ & $\begin{array}{r}174 \\
-23,019 \\
-1,663 \\
6,479 \\
5,425\end{array}$ \\
\hline $\begin{array}{l}\text { lowa } \\
\text { Kansas. } \\
\text { Kentucky } \\
\text { Louisiana } \\
\text { Maryland }\end{array}$ & $\begin{array}{r}68,772 \\
52,242 \\
72,674 \\
155,450 \\
19,121\end{array}$ & $\begin{array}{r}61,256 \\
51,282 \\
72,960 \\
142,178 \\
15,188\end{array}$ & $\begin{array}{r}0 \\
-1,888 \\
-251 \\
0 \\
0\end{array}$ & $\begin{array}{r}7,516 \\
-928 \\
-537 \\
13,272 \\
3,933\end{array}$ \\
\hline 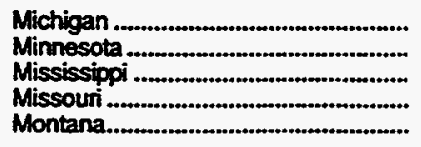 & $\begin{array}{r}390,610 \\
1,267 \\
63,032 \\
8,836 \\
16,351\end{array}$ & $\begin{array}{r}386,571 \\
1,286 \\
55,071 \\
7,583 \\
19,937\end{array}$ & $\begin{array}{r}0 \\
0 \\
-1,238 \\
-3 \\
0\end{array}$ & $\begin{array}{r}4,039 \\
-19 \\
6,723 \\
1,250 \\
-3,586\end{array}$ \\
\hline $\begin{array}{l}\text { Nebraska } \\
\text { New Mexico } \\
\text { New York } \\
\text { Ohio } \\
\text { Oldahoma }\end{array}$ & $\begin{array}{r}9,995 \\
472 \\
51,620 \\
199,851 \\
109,076\end{array}$ & $\begin{array}{r}2,873 \\
2,045 \\
51,242 \\
182,593 \\
101,468\end{array}$ & $\begin{array}{r}-43 \\
0 \\
76 \\
-336 \\
613\end{array}$ & $\begin{array}{r}7,079 \\
-1,573 \\
454 \\
16,922 \\
8,221\end{array}$ \\
\hline 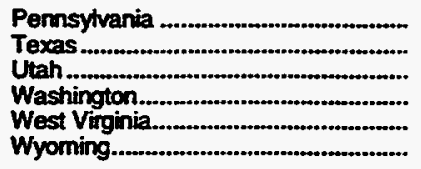 & $\begin{array}{r}372,402 \\
91,373 \\
1,180 \\
7,358 \\
177,263 \\
8,812\end{array}$ & $\begin{array}{r}350,408 \\
53,950 \\
1,446 \\
7,056 \\
168,337 \\
9,882\end{array}$ & $\begin{array}{r}4,100 \\
-42 \\
0 \\
0 \\
-1,294 \\
0\end{array}$ & $\begin{array}{r}26,094 \\
37,381 \\
-266 \\
302 \\
7,632 \\
-1,070\end{array}$ \\
\hline Total. & $2,270,961$ & $2,150,928$ & 204 & 120,237 \\
\hline
\end{tabular}

1979

\begin{tabular}{|c|c|c|c|c|}
\hline 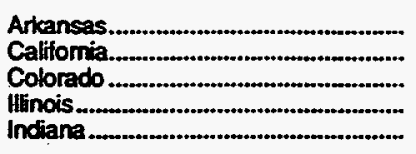 & $\begin{array}{r}2,081 \\
100,522 \\
25,334 \\
253,320 \\
27,177\end{array}$ & $\begin{array}{r}2,693 \\
88,924 \\
21,193 \\
209,924 \\
23,709\end{array}$ & $\begin{array}{r}1 \\
15,777 \\
-1,135 \\
612 \\
3,514\end{array}$ & $\begin{array}{r}-611 \\
27,375 \\
3,006 \\
44,008 \\
6,982\end{array}$ \\
\hline 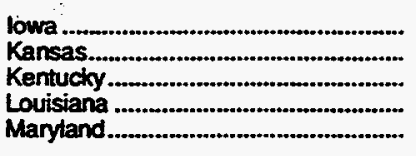 & $\begin{array}{r}70,967 \\
59,148 \\
68,961 \\
140,433 \\
19,715\end{array}$ & $\begin{array}{r}61,018 \\
52,028 \\
63,328 \\
141,487 \\
19,448\end{array}$ & $\begin{array}{r}-233 \\
-2,296 \\
201 \\
-2,120 \\
0\end{array}$ & $\begin{array}{r}9,716 \\
4,824 \\
5,834 \\
-3,174 \\
267\end{array}$ \\
\hline 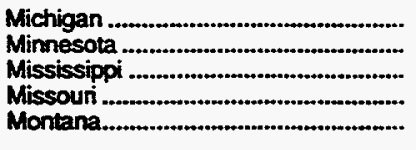 & $\begin{array}{r}424,176 \\
987 \\
60,597 \\
8,836 \\
23,254\end{array}$ & $\begin{array}{r}364,649 \\
668 \\
67,100 \\
7,583 \\
15,497\end{array}$ & $\begin{array}{r}2,009 \\
-388 \\
-500 \\
-1,253 \\
0\end{array}$ & $\begin{array}{r}61,536 \\
-69 \\
-7,003 \\
0 \\
7,757\end{array}$ \\
\hline 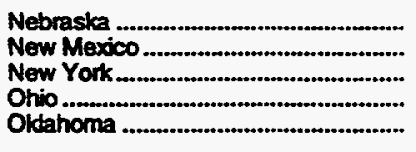 & $\begin{array}{r}10,087 \\
39 \\
46,439 \\
193,251 \\
110,354\end{array}$ & $\begin{array}{r}3,051 \\
7,687 \\
40,110 \\
179,685 \\
103,983\end{array}$ & $\begin{array}{r}42 \\
0 \\
1,089 \\
0 \\
-3,078\end{array}$ & $\begin{array}{r}6,994 \\
-7,648 \\
7,418 \\
13,566 \\
3,293\end{array}$ \\
\hline 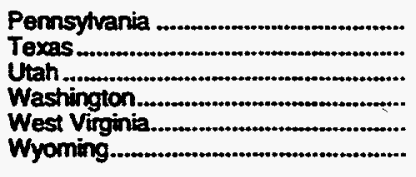 & $\begin{array}{r}357,234 \\
82,325 \\
1,193 \\
14,332 \\
173,060 \\
11,193\end{array}$ & $\begin{array}{r}333,184 \\
68,918 \\
966 \\
12,405 \\
159,319 \\
8,465\end{array}$ & $\begin{array}{r}3,416 \\
-2,088 \\
0 \\
0 \\
6,563 \\
-6\end{array}$ & $\begin{array}{r}27,466 \\
11,319 \\
2227 \\
1,927 \\
20,304 \\
2,722\end{array}$ \\
\hline 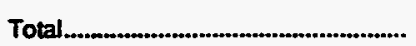 & $2,285,016$ & $2,057,020$ & 20,037 & 248,034 \\
\hline
\end{tabular}

Note: Totals may not equal sum of components due to independent rounding.

Source: American Gas Association, Committee on Underground Storage, The Storage of Gas in the United States and Canada. 
Table 11. Changes in Natural Gas Storage by State, 1980-1994 (Million Cubic Feet)

\begin{tabular}{|c|c|c|c|c|c|c|c|}
\hline \multirow{2}{*}{ Seate } & \multicolumn{3}{|c|}{$\begin{array}{l}\text { Underground } \\
\text { Storege }\end{array}$} & \multicolumn{3}{|c|}{ LWG Storage" } & \multirow{2}{*}{$\begin{array}{l}\text { Net Chengs in } \\
\text { Sternge }\end{array}$} \\
\hline & Injections & Withedrewals & Not & Additions & Whadrumels & 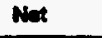 & \\
\hline & \multicolumn{7}{|c|}{1980} \\
\hline 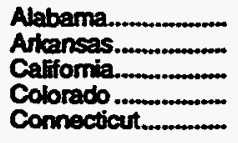 & $\begin{array}{r}0 \\
1,107 \\
93,556 \\
32,974 \\
0\end{array}$ & $\begin{array}{r}0 \\
1,853 \\
90,870 \\
18,155 \\
0\end{array}$ & $\begin{array}{r}0 \\
-746 \\
2,686 \\
14,819 \\
0\end{array}$ & $\begin{array}{r}655 \\
14 \\
0 \\
0 \\
1,306\end{array}$ & $\begin{array}{r}470 \\
0 \\
916 \\
3 \\
2,156\end{array}$ & $\begin{array}{r}185 \\
14 \\
-916 \\
-3 \\
-820\end{array}$ & $\begin{array}{r}185 \\
-732 \\
1,770 \\
14,816 \\
820\end{array}$ \\
\hline 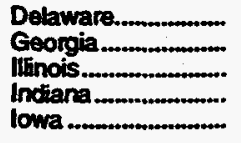 & $\begin{array}{r}0 \\
0 \\
197,385 \\
24,509 \\
61,413\end{array}$ & $\begin{array}{r}0 \\
0 \\
180,764 \\
25,773 \\
57,949\end{array}$ & $\begin{array}{r}0 \\
0 \\
16,621 \\
-1,264 \\
3,464\end{array}$ & $\begin{array}{r}113 \\
20,484 \\
277 \\
1,107 \\
3,053\end{array}$ & $\begin{array}{r}0 \\
19,950 \\
318 \\
1,236 \\
3,672\end{array}$ & $\begin{array}{r}113 \\
534 \\
-41 \\
-129 \\
-609\end{array}$ & $\begin{array}{r}113 \\
534 \\
16,580 \\
-1,393 \\
2,855\end{array}$ \\
\hline 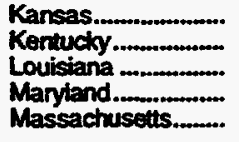 & $\begin{array}{r}87,788 \\
49,142 \\
134,386 \\
16,907 \\
0\end{array}$ & $\begin{array}{r}78,485 \\
65,689 \\
144,014 \\
20,919 \\
0\end{array}$ & $\begin{array}{r}9,303 \\
-16,547 \\
-9,628 \\
-4,012 \\
0\end{array}$ & $\begin{array}{r}0 \\
0 \\
0 \\
\mathbf{4 4 3} \\
7,885\end{array}$ & $\begin{array}{r}0 \\
0 \\
0 \\
2,851 \\
11,268\end{array}$ & $\begin{array}{r}0 \\
0 \\
0 \\
-2,408 \\
-3,383\end{array}$ & $\begin{array}{r}9,303 \\
-16,547 \\
-9,628 \\
-6,420 \\
-3,383\end{array}$ \\
\hline 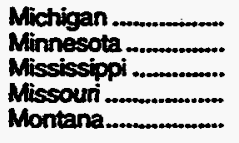 & $\begin{array}{r}290,497 \\
1,217 \\
59,653 \\
5,305 \\
29,751\end{array}$ & $\begin{array}{r}317,830 \\
626 \\
57,898 \\
6,409 \\
15,635\end{array}$ & $\begin{array}{r}-27,333 \\
591 \\
1,755 \\
-1,104 \\
14,116\end{array}$ & $\begin{array}{r}0 \\
4,838 \\
0 \\
0 \\
0\end{array}$ & $\begin{array}{r}0 \\
5,427 \\
0 \\
0 \\
0\end{array}$ & $\begin{array}{r}0 \\
-589 \\
0 \\
0 \\
0\end{array}$ & $\begin{array}{r}-27,333 \\
2 \\
1,755 \\
-1,104 \\
14,116\end{array}$ \\
\hline $\begin{array}{l}\text { Nebraska ............... } \\
\text { New Hampshire...... } \\
\text { New Jersey .............. } \\
\text { New Mexico............ } \\
\text { New York.................. }\end{array}$ & $\begin{array}{r}6,557 \\
0 \\
0 \\
2,871 \\
41,857\end{array}$ & $\begin{array}{r}803 \\
0 \\
0 \\
3,989 \\
45,520\end{array}$ & $\begin{array}{r}5,754 \\
0 \\
0 \\
-1,118 \\
-3,663\end{array}$ & $\begin{array}{r}225 \\
5 \\
3,617 \\
0 \\
432\end{array}$ & $\begin{array}{r}130 \\
27 \\
3,300 \\
8 \\
150\end{array}$ & $\begin{array}{r}95 \\
-22 \\
317 \\
-8 \\
282\end{array}$ & $\begin{array}{r}5,849 \\
-22 \\
317 \\
-1,126 \\
-3,381\end{array}$ \\
\hline 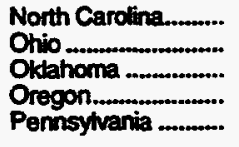 & $\begin{array}{r}0 \\
169,268 \\
112,403 \\
0 \\
212,048\end{array}$ & $\begin{array}{r}0 \\
166,361 \\
101,688 \\
0 \\
250,087\end{array}$ & $\begin{array}{r}0 \\
2,907 \\
10,715 \\
0 \\
48,039\end{array}$ & $\begin{array}{r}597 \\
0 \\
0 \\
251 \\
4,046\end{array}$ & $\begin{array}{r}0 \\
0 \\
0 \\
264 \\
4,915\end{array}$ & $\begin{array}{r}597 \\
0 \\
0 \\
-13 \\
-869\end{array}$ & $\begin{array}{r}597 \\
2,907 \\
10,715 \\
-13 \\
-48,908\end{array}$ \\
\hline 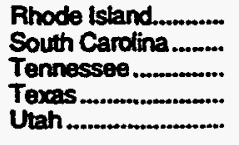 & $\begin{array}{r}0 \\
0 \\
0 \\
109,242 \\
2,381\end{array}$ & $\begin{array}{r}0 \\
0 \\
0 \\
92,184 \\
1,190\end{array}$ & $\begin{array}{r}0 \\
0 \\
0 \\
17,058 \\
1.191\end{array}$ & $\begin{array}{r}61 \\
345 \\
1,222 \\
0 \\
0\end{array}$ & $\begin{array}{r}316 \\
342 \\
2,865 \\
0 \\
0\end{array}$ & $\begin{array}{r}-255 \\
3 \\
-1,643 \\
0 \\
0\end{array}$ & $\begin{array}{r}255 \\
3 \\
-1,643 \\
17,058 \\
1,191\end{array}$ \\
\hline $\begin{array}{l}\text { Virginia................... } \\
\text { Washington............. } \\
\text { West Virginia............ } \\
\text { Wisconsin ................ } \\
\text { Wyoming.................. }\end{array}$ & $\begin{array}{r}22 \\
14,408 \\
128,443 \\
0 \\
11,194\end{array}$ & $\begin{array}{r}0 \\
11,573 \\
137,474 \\
0 \\
6,163\end{array}$ & $\begin{array}{r}22 \\
2,835 \\
-9,031 \\
0 \\
5,031\end{array}$ & $\begin{array}{r}1,626 \\
0 \\
0 \\
136 \\
0\end{array}$ & $\begin{array}{r}1,633 \\
0 \\
0 \\
212 \\
0\end{array}$ & $\begin{array}{r}-7 \\
0 \\
0 \\
-76 \\
0\end{array}$ & $\begin{array}{r}15 \\
2,835 \\
-9,031 \\
-76 \\
5,031\end{array}$ \\
\hline \multirow[t]{2}{*}{ Total } & $1,896,284$ & $1,909,902$ & $-13,618$ & 52,780 & 62,431 & $-9,651$ & $-23,269$ \\
\hline & \multicolumn{7}{|c|}{1981} \\
\hline 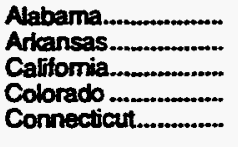 & $\begin{array}{r}0 \\
1,690 \\
99,397 \\
25,291 \\
0\end{array}$ & $\begin{array}{r}0 \\
1,171 \\
92,214 \\
25,932 \\
0\end{array}$ & $\begin{array}{r}0 \\
519 \\
7.183 \\
-641 \\
0\end{array}$ & $\begin{array}{r}908 \\
5 \\
371 \\
0 \\
2,160\end{array}$ & $\begin{array}{r}878 \\
24 \\
476 \\
0 \\
1,459\end{array}$ & $\begin{array}{r}30 \\
-19 \\
-105 \\
0 \\
701\end{array}$ & $\begin{array}{r}30 \\
500 \\
7.078 \\
641 \\
701\end{array}$ \\
\hline 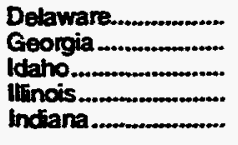 & $\begin{array}{r}0 \\
0 \\
0 \\
141,824 \\
24,301\end{array}$ & $\begin{array}{r}0 \\
0 \\
0 \\
169,502 \\
22,949\end{array}$ & $\begin{array}{r}0 \\
0 \\
0 \\
-27,678 \\
1,352\end{array}$ & $\begin{array}{r}99 \\
1,508 \\
110 \\
327 \\
1,966\end{array}$ & $\begin{array}{r}102 \\
3,106 \\
91 \\
305 \\
1,762\end{array}$ & $\begin{array}{r}-3 \\
-1,598 \\
19 \\
22 \\
204\end{array}$ & $\begin{array}{r}-3 \\
-1,598 \\
19 \\
-27,656 \\
1,556\end{array}$ \\
\hline 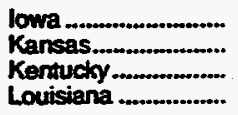 & $\begin{array}{r}48,918 \\
101,892 \\
67,518 \\
212,267\end{array}$ & $\begin{array}{r}48,971 \\
87,629 \\
57,603 \\
110,544\end{array}$ & $\begin{array}{r}-53 \\
14,263 \\
9,915 \\
101,723\end{array}$ & $\begin{array}{r}2,576 \\
0 \\
0 \\
0\end{array}$ & $\begin{array}{r}2,835 \\
0 \\
0 \\
0\end{array}$ & $\begin{array}{r}-259 \\
0 \\
0 \\
0\end{array}$ & $\begin{array}{r}\mathbf{3 1 2} \\
14,263 \\
9,915 \\
101,723\end{array}$ \\
\hline
\end{tabular}

See tootnotes at end of table. 
Table 11. Changes in Natural Gas Storage by State, 1980-1994 (Continued) (Million Cubic Feet)

\begin{tabular}{|c|c|c|c|c|c|c|c|}
\hline \multirow{2}{*}{ State } & \multicolumn{3}{|c|}{$\begin{array}{l}\text { Underground } \\
\text { Storege }\end{array}$} & \multicolumn{3}{|c|}{ LWe Storage" } & \multirow{2}{*}{$\begin{array}{l}\text { Not Change in } \\
\text { Storge }\end{array}$} \\
\hline & Injection: & Wratrawels & int & Addition: & Wethdirumeis & Not & \\
\hline
\end{tabular}

\begin{tabular}{|c|c|c|c|c|c|c|c|}
\hline 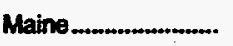 & 0 & $\mathbf{0}$ & 0 & $\mathbf{0}$ & 86 & 86 & -86 \\
\hline 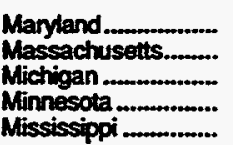 & $\begin{array}{r}18,753 \\
0 \\
354,911 \\
1,125 \\
42,916\end{array}$ & $\begin{array}{r}14,673 \\
0 \\
347,592 \\
477 \\
40,688\end{array}$ & $\begin{array}{r}4,080 \\
0 \\
7,319 \\
648 \\
2,228\end{array}$ & $\begin{array}{r}714 \\
15,234 \\
0 \\
4,402 \\
0\end{array}$ & $\begin{array}{r}623 \\
12,649 \\
0 \\
3,663 \\
0\end{array}$ & $\begin{array}{r}91 \\
2,585 \\
0 \\
739 \\
0\end{array}$ & $\begin{array}{l}4,171 \\
2,585 \\
7,319 \\
1,387 \\
2,228\end{array}$ \\
\hline 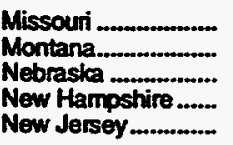 & $\begin{array}{r}4,727 \\
30,147 \\
7,198 \\
0 \\
0\end{array}$ & $\begin{array}{r}5,004 \\
13,008 \\
809 \\
0 \\
0\end{array}$ & $\begin{array}{r}-277 \\
17,139 \\
6,389 \\
0 \\
0\end{array}$ & $\begin{array}{r}7 \\
0 \\
119 \\
0 \\
4,658\end{array}$ & $\begin{array}{r}33 \\
0 \\
173 \\
11 \\
3,541\end{array}$ & $\begin{array}{r}-26 \\
0 \\
-54 \\
-11 \\
1,117\end{array}$ & $\begin{array}{r}303 \\
17,139 \\
6,335 \\
-11 \\
1.117\end{array}$ \\
\hline $\begin{array}{l}\text { New Mexico .............. } \\
\text { New York............... } \\
\text { North Carolina........ } \\
\text { Ohio .......................... } \\
\text { Oidahoma ................. }\end{array}$ & $\begin{array}{r}2,801 \\
57,610 \\
0 \\
177,387 \\
111,148\end{array}$ & $\begin{array}{r}1,980 \\
40,250 \\
0 \\
162,268 \\
83,696\end{array}$ & $\begin{array}{r}821 \\
17,360 \\
0 \\
15,119 \\
27,452\end{array}$ & $\begin{array}{r}0 \\
1,240 \\
1,497 \\
0 \\
0\end{array}$ & $\begin{array}{r}0 \\
878 \\
1,591 \\
0 \\
0\end{array}$ & $\begin{array}{r}0 \\
362 \\
-94 \\
0 \\
0\end{array}$ & $\begin{array}{r}821 \\
17,722 \\
-94 \\
15,119 \\
27,452\end{array}$ \\
\hline $\begin{array}{l}\text { Oregon................. } \\
\text { Pernsylvania .......... } \\
\text { Rhode Island.......... } \\
\text { South Carotina......... } \\
\text { Tennessee ............. }\end{array}$ & $\begin{array}{r}0 \\
360,752 \\
0 \\
0 \\
0\end{array}$ & $\begin{array}{r}0 \\
311,051 \\
0 \\
0 \\
0\end{array}$ & $\begin{array}{r}0 \\
49,701 \\
0 \\
0 \\
0\end{array}$ & $\begin{array}{r}265 \\
4,051 \\
265 \\
736 \\
2,508\end{array}$ & $\begin{array}{r}268 \\
3,084 \\
192 \\
546 \\
2,742\end{array}$ & $\begin{array}{r}-3 \\
957 \\
73 \\
190 \\
-234\end{array}$ & $\begin{array}{r}50.668 \\
73 \\
190 \\
-234\end{array}$ \\
\hline 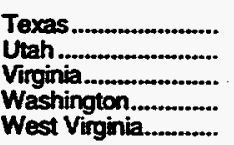 & $\begin{array}{r}124,439 \\
11,107 \\
0 \\
11,083 \\
127,788\end{array}$ & $\begin{array}{r}96,961 \\
10,910 \\
0 \\
11,243 \\
125,753\end{array}$ & $\begin{array}{r}27,478 \\
197 \\
0 \\
-160 \\
2,035\end{array}$ & $\begin{array}{r}0 \\
0 \\
1,876 \\
0 \\
0\end{array}$ & $\begin{array}{r}0 \\
0 \\
1,881 \\
0 \\
0\end{array}$ & $\begin{array}{r}0 \\
0 \\
-5 \\
0 \\
0\end{array}$ & $\begin{array}{r}27.478 \\
197 \\
-5 \\
-160 \\
2,035\end{array}$ \\
\hline $\begin{array}{l}\text { Wisconsin .................. } \\
\text { Wyoming..................... }\end{array}$ & $\begin{array}{r}0 \\
12,695\end{array}$ & $\begin{array}{r}0 \\
4,060\end{array}$ & $\begin{array}{r}.0 \\
8,635\end{array}$ & $\begin{array}{r}238 \\
0\end{array}$ & $\begin{array}{r}151 \\
0\end{array}$ & $\begin{array}{r}87 \\
0\end{array}$ & $\begin{array}{r}87 \\
8,635\end{array}$ \\
\hline Total........................... & $2,179,683$ & $1,886,940$ & 292,743 & 47,839 & 43,152 & 4,687 & 297,430 \\
\hline
\end{tabular}

\begin{tabular}{|c|c|c|c|c|c|c|c|}
\hline $\begin{array}{l}\text { Alabama.................... } \\
\text { Aukansas.................. } \\
\text { Calffornia.................. } \\
\text { Colorado.................... } \\
\text { Connecticut............... }\end{array}$ & $\begin{array}{r}0 \\
1,854 \\
112,916 \\
32,861 \\
0\end{array}$ & $\begin{array}{r}0 \\
1,440 \\
145,654 \\
25,198 \\
0\end{array}$ & $\begin{array}{r}0 \\
414 \\
-32,738 \\
7,663 \\
0\end{array}$ & $\begin{array}{r}754 \\
21 \\
514 \\
0 \\
1.766\end{array}$ & $\begin{array}{r}688 \\
32 \\
495 \\
0 \\
3,122\end{array}$ & $\begin{array}{r}66 \\
-11 \\
19 \\
0 \\
-1.356\end{array}$ & $\begin{array}{r}66 \\
403 \\
-32,719 \\
7,663 \\
-1,356\end{array}$ \\
\hline 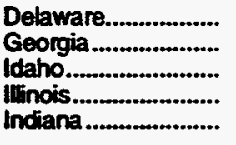 & $\begin{array}{r}0 \\
0 \\
0 \\
217,536 \\
25,489\end{array}$ & $\begin{array}{r}0 \\
0 \\
0 \\
193,480 \\
23,284\end{array}$ & $\begin{array}{r}0 \\
0 \\
0 \\
24,056 \\
2,205\end{array}$ & $\begin{array}{r}118 \\
1,555 \\
361 \\
524 \\
4,352\end{array}$ & $\begin{array}{r}121 \\
2,914 \\
229 \\
477 \\
2,361\end{array}$ & $\begin{array}{r}-3 \\
-1,359 \\
132 \\
47 \\
1.991\end{array}$ & $\begin{array}{r}-3 \\
-1,359 \\
132 \\
24,103 \\
4,196\end{array}$ \\
\hline 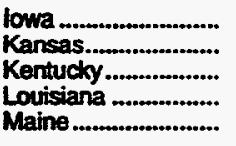 & $\begin{array}{r}61,121 \\
128,737 \\
64,789 \\
177,194 \\
0\end{array}$ & $\begin{array}{r}49,187 \\
84,877 \\
56,611 \\
149,813 \\
0\end{array}$ & $\begin{array}{r}11,934 \\
43,860 \\
8,178 \\
27,381 \\
0\end{array}$ & $\begin{array}{r}5,243 \\
0 \\
0 \\
22,711 \\
364\end{array}$ & $\begin{array}{r}4,517 \\
0 \\
0 \\
18,720 \\
349\end{array}$ & $\begin{array}{r}726 \\
0 \\
0 \\
3,991 \\
15\end{array}$ & $\begin{array}{r}12,660 \\
43,860 \\
8,178 \\
31,372 \\
15\end{array}$ \\
\hline $\begin{array}{l}\text { Maryland.................... } \\
\text { Massachusetts......... } \\
\text { Michigan .................. } \\
\text { Minnesota .............. } \\
\text { Mississippi ............... }\end{array}$ & $\begin{array}{r}19,476 \\
0 \\
371,216 \\
1,601 \\
43,834\end{array}$ & $\begin{array}{r}19,096 \\
0 \\
342,046 \\
1,232 \\
47,306\end{array}$ & $\begin{array}{r}380 \\
0 \\
29.170 \\
369 \\
-3.472\end{array}$ & $\begin{array}{r}676 \\
14,021 \\
0 \\
4,505 \\
0\end{array}$ & $\begin{array}{r}581 \\
15,609 \\
0 \\
4,800 \\
0\end{array}$ & $\begin{array}{r}95 \\
-1,618 \\
0 \\
-295 \\
0\end{array}$ & $\begin{array}{r}475 \\
-1,618 \\
29,170 \\
74 \\
-3,472\end{array}$ \\
\hline $\begin{array}{l}\text { Missouri .................... } \\
\text { Montana } \\
\text { Nebraska ..................... } \\
\text { Nevada ................... } \\
\text { New Hlampshire ....... }\end{array}$ & $\begin{array}{r}4,407 \\
25,180 \\
7,455 \\
0 \\
0\end{array}$ & $\begin{array}{r}4,251 \\
18,721 \\
3,693 \\
0 \\
0\end{array}$ & $\begin{array}{r}156 \\
6,459 \\
3,762 \\
0 \\
0\end{array}$ & $\begin{array}{r}26 \\
0 \\
7 \\
294 \\
21\end{array}$ & $\begin{array}{r}39 \\
0 \\
293 \\
5 \\
21\end{array}$ & $\begin{array}{r}-13 \\
0 \\
-286 \\
289 \\
0\end{array}$ & $\begin{array}{r}143 \\
6,459 \\
3,476 \\
289 \\
0\end{array}$ \\
\hline New Jersey............... & 0 & 0 & 0 & 4,518 & 4,329 & 189 & 189 \\
\hline
\end{tabular}

See footnotes at end of table. 
Table 11. Changes in Natural Gas Storage by State, 1980-1994 (Continued) (Million Cubic Feet)

\begin{tabular}{|c|c|c|c|c|c|c|c|}
\hline \multirow[t]{2}{*}{ Stro } & \multicolumn{3}{|c|}{$\begin{array}{l}\text { Underground } \\
\text { Stornge }\end{array}$} & \multicolumn{3}{|c|}{ WNG Stornge" } & \multirow{2}{*}{$\begin{array}{l}\text { Not Change in } \\
\text { Storngs }\end{array}$} \\
\hline & Injections & Withdrewe's & Net & Additions & Whotrawels & Net & \\
\hline & \multicolumn{7}{|c|}{1982} \\
\hline 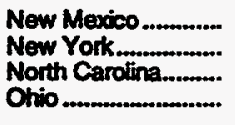 & $\begin{array}{r}19,894 \\
55,213 \\
0 \\
193,275\end{array}$ & $\begin{array}{r}2,483 \\
42,991 \\
0 \\
150,195\end{array}$ & $\begin{array}{r}17,411 \\
12,222 \\
0 \\
43,080\end{array}$ & $\begin{array}{r}0 \\
1,124 \\
1,372 \\
0\end{array}$ & $\begin{array}{r}0 \\
1,170 \\
1,483 \\
0\end{array}$ & $\begin{array}{r}0 \\
-46 \\
-111 \\
0\end{array}$ & $\begin{array}{r}17,411 \\
12,176 \\
-111 \\
43,080\end{array}$ \\
\hline 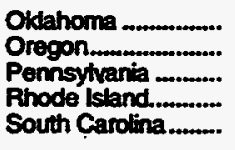 & $\begin{array}{r}104,572 \\
0 \\
405,477 \\
0 \\
0\end{array}$ & $\begin{array}{r}87,048 \\
0 \\
370,581 \\
0 \\
0\end{array}$ & $\begin{array}{r}17,524 \\
0 \\
34,896 \\
0 \\
0\end{array}$ & $\begin{array}{r}0 \\
28 \\
3,234 \\
243 \\
35\end{array}$ & $\begin{array}{r}0 \\
29 \\
3,526 \\
260 \\
401\end{array}$ & $\begin{array}{r}0 \\
-1 \\
-292 \\
-17 \\
-366\end{array}$ & $\begin{array}{r}17,524 \\
-1 \\
34,604 \\
-17 \\
-366\end{array}$ \\
\hline 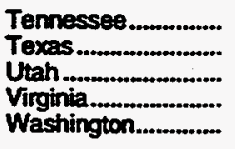 & $\begin{array}{r}0 \\
141,811 \\
12,089 \\
0 \\
5,344\end{array}$ & $\begin{array}{r}0 \\
120,665 \\
24,369 \\
0 \\
6,433\end{array}$ & $\begin{array}{r}0 \\
21,146 \\
-12,280 \\
0 \\
-1,089\end{array}$ & $\begin{array}{r}2,491 \\
0 \\
0 \\
1,865 \\
0\end{array}$ & $\begin{array}{r}1,850 \\
0 \\
0 \\
1,879 \\
0\end{array}$ & $\begin{array}{r}641 \\
0 \\
0 \\
-14 \\
0\end{array}$ & $\begin{array}{r}641 \\
21,146 \\
-12,280 \\
-14 \\
-1,089\end{array}$ \\
\hline 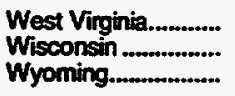 & $\begin{array}{r}144,153 \\
0 \\
21,860\end{array}$ & $\begin{array}{r}119,103 \\
0 \\
3,887\end{array}$ & $\begin{array}{r}25,050 \\
0 \\
17,973\end{array}$ & $\begin{array}{r}0 \\
283 \\
0\end{array}$ & $\begin{array}{r}0 \\
207 \\
0\end{array}$ & $\begin{array}{r}0 \\
76 \\
0\end{array}$ & $\begin{array}{r}25,050 \\
76 \\
17,973\end{array}$ \\
\hline \multirow[t]{2}{*}{ Total } & $2,399,355$ & $2,093,644$ & 305,711 & 73,028 & 70,540 & 2,488 & 308,199 \\
\hline & \multicolumn{7}{|c|}{1983} \\
\hline 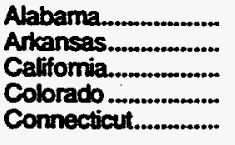 & $\begin{array}{r}0 \\
241 \\
97,424 \\
26,361 \\
0\end{array}$ & $\begin{array}{r}0 \\
997 \\
86,157 \\
30,288 \\
0\end{array}$ & $\begin{array}{r}0 \\
-756 \\
11,267 \\
-3,927 \\
0\end{array}$ & $\begin{array}{r}353 \\
0 \\
66 \\
0 \\
980\end{array}$ & $\begin{array}{r}933 \\
34 \\
496 \\
0 \\
1,365\end{array}$ & $\begin{array}{r}-580 \\
-34 \\
-430 \\
0 \\
-385\end{array}$ & $\begin{array}{r}-580 \\
-790 \\
10,837 \\
-3,927 \\
-385\end{array}$ \\
\hline 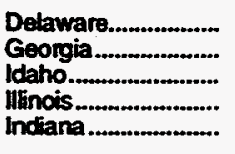 & $\begin{array}{r}0 \\
0 \\
0 \\
122,620 \\
20,160\end{array}$ & $\begin{array}{r}0 \\
0 \\
0 \\
165,746 \\
25,165\end{array}$ & $\begin{array}{r}0 \\
0 \\
0 \\
-43,126 \\
-5,005\end{array}$ & $\begin{array}{r}94 \\
1.024 \\
110 \\
338 \\
785\end{array}$ & $\begin{array}{r}123 \\
1,193 \\
126 \\
868 \\
1,283\end{array}$ & $\begin{array}{r}-29 \\
-169 \\
-16 \\
-530 \\
-498\end{array}$ & $\begin{array}{r}-29 \\
-169 \\
-16 \\
-43,656 \\
-5,503\end{array}$ \\
\hline 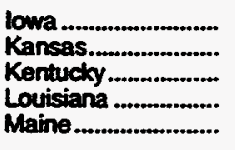 & $\begin{array}{r}49,523 \\
70,412 \\
42,090 \\
148,679 \\
0\end{array}$ & $\begin{array}{r}74,291 \\
95,404 \\
59,633 \\
192,973 \\
0\end{array}$ & $\begin{array}{r}-24,768 \\
-24,992 \\
-17,543 \\
-44,294 \\
0\end{array}$ & $\begin{array}{r}256 \\
0 \\
0 \\
96,945 \\
166\end{array}$ & $\begin{array}{r}1,476 \\
0 \\
0 \\
94,323 \\
251\end{array}$ & $\begin{array}{r}-1,220 \\
0 \\
0 \\
2,622 \\
-85\end{array}$ & $\begin{array}{r}-25,988 \\
-24,992 \\
-17,543 \\
-41,672 \\
-85\end{array}$ \\
\hline $\begin{array}{l}\text { Maryland................... } \\
\text { Massachusetts........ } \\
\text { Michigan ................... } \\
\text { Minnesota ............... } \\
\text { Mississippi ............. }\end{array}$ & $\begin{array}{r}16,298 \\
0 \\
227,107 \\
646 \\
44,467\end{array}$ & $\begin{array}{r}16,871 \\
0 \\
327,954 \\
559 \\
51,910\end{array}$ & $\begin{array}{r}-573 \\
0 \\
-100,847 \\
87 \\
-7,443\end{array}$ & $\begin{array}{r}235 \\
6,599 \\
0 \\
1,277 \\
0\end{array}$ & $\begin{array}{r}394 \\
7,299 \\
0 \\
1,770 \\
0\end{array}$ & $\begin{array}{r}-159 \\
-700 \\
0 \\
-493 \\
0\end{array}$ & $\begin{array}{r}-732 \\
-700 \\
-100,847 \\
-406 \\
-7,443\end{array}$ \\
\hline $\begin{array}{l}\text { Missouti ................. } \\
\text { Montana....e.............. } \\
\text { Nebraska ................. } \\
\text { Nevada ................... } \\
\text { New Hiampshire....... }\end{array}$ & $\begin{array}{r}924 \\
33,262 \\
3,869 \\
0 \\
0\end{array}$ & $\begin{array}{r}3,537 \\
13,221 \\
4,949 \\
0 \\
0\end{array}$ & $\begin{array}{r}-2,613 \\
20,041 \\
-1,080 \\
0 \\
0\end{array}$ & $\begin{array}{r}29 \\
0 \\
283 \\
241 \\
0\end{array}$ & $\begin{array}{r}43 \\
0 \\
121 \\
92 \\
84\end{array}$ & $\begin{array}{r}-14 \\
0 \\
162 \\
149 \\
-84\end{array}$ & $\begin{array}{r}-2,627 \\
20,041 \\
-918 \\
149 \\
-84\end{array}$ \\
\hline $\begin{array}{l}\text { New Jersey .............. } \\
\text { New Mexico .............. } \\
\text { New York................ } \\
\text { North Carolina.......... } \\
\text { Ohio ......................... }\end{array}$ & $\begin{array}{r}0 \\
2,500 \\
43,106 \\
0 \\
129,541\end{array}$ & $\begin{array}{r}0 \\
4,887 \\
53,205 \\
0 \\
156,531\end{array}$ & $\begin{array}{r}0 \\
-2,387 \\
-10,099 \\
0 \\
-26,990\end{array}$ & $\begin{array}{r}4,770 \\
0 \\
1,174 \\
1.145 \\
0\end{array}$ & $\begin{array}{r}4,979 \\
0 \\
1,050 \\
1,427 \\
0\end{array}$ & $\begin{array}{r}-209 \\
0 \\
124 \\
-282 \\
0\end{array}$ & $\begin{array}{r}-209 \\
-2,387 \\
-9,975 \\
-282 \\
-26,990\end{array}$ \\
\hline 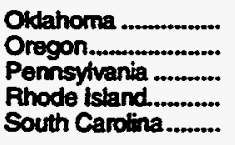 & $\begin{array}{r}75,872 \\
0 \\
284,948 \\
0 \\
0\end{array}$ & $\begin{array}{r}111,292 \\
0 \\
342,623 \\
0 \\
0\end{array}$ & $\begin{array}{r}-35,420 \\
0 \\
-57,675 \\
0 \\
0\end{array}$ & $\begin{array}{r}0 \\
649 \\
1.970 \\
47 \\
132\end{array}$ & $\begin{array}{r}0 \\
773 \\
3,090 \\
55 \\
292\end{array}$ & $\begin{array}{r}0 \\
-124 \\
-1,120 \\
-8 \\
-160\end{array}$ & $\begin{array}{r}-35,420 \\
-124 \\
-58,795 \\
-8 \\
-160\end{array}$ \\
\hline $\begin{array}{l}\text { Ternessee....e.......... } \\
\text { Texas ........................ } \\
\text { Utah .......................... }\end{array}$ & $\begin{array}{r}0 \\
135,309 \\
19,948\end{array}$ & $\begin{array}{r}0 \\
181,770 \\
17,824\end{array}$ & $\begin{array}{r}0 \\
-46,461 \\
2,124\end{array}$ & $\begin{array}{r}977 \\
0 \\
0\end{array}$ & $\begin{array}{r}2,222 \\
0 \\
0\end{array}$ & $\begin{array}{r}-1,245 \\
0 \\
0\end{array}$ & $\begin{array}{r}-1,245 \\
-46,461 \\
2,124\end{array}$ \\
\hline
\end{tabular}


Table 11. Changes in Natural Gas Storage by State, 1980-1994 (Continued) (Million Cubic Feet)

\begin{tabular}{|c|c|c|c|c|c|c|c|}
\hline \multirow[t]{2}{*}{ State } & \multicolumn{3}{|c|}{$\begin{array}{l}\text { Underground } \\
\text { Storage }\end{array}$} & \multicolumn{3}{|c|}{ LNG Storage" } & \multirow{2}{*}{$\begin{array}{l}\text { Not Change in } \\
\text { Storage }\end{array}$} \\
\hline & Injections & Writhdrawels & Not & Additions & Withdrawals & Net & \\
\hline & \multicolumn{7}{|c|}{1983} \\
\hline 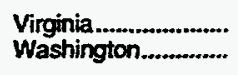 & $\begin{array}{r}0 \\
6,218\end{array}$ & 8.481 & $\begin{array}{r}0 \\
-2,263\end{array}$ & $\begin{array}{r}1,223 \\
0\end{array}$ & $\begin{array}{r}1,310 \\
0\end{array}$ & $\begin{array}{r}-87 \\
0\end{array}$ & $-2,263$ \\
\hline 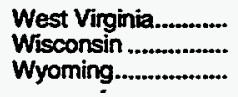 & $\begin{array}{r}87,355 \\
0 \\
11,546\end{array}$ & $\begin{array}{r}106,200 \\
0 \\
9,560\end{array}$ & $\begin{array}{r}-18,845 \\
0 \\
1,986\end{array}$ & $\begin{array}{r}0 \\
60 \\
0\end{array}$ & $\begin{array}{r}0 \\
153 \\
0\end{array}$ & $\begin{array}{r}0 \\
-93 \\
0\end{array}$ & $\begin{array}{r}-18,845 \\
-93 \\
1,986\end{array}$ \\
\hline \multirow[t]{2}{*}{ Total..................................... } & $1,700,426$ & $2,142,027$ & $-441,602$ & 121,928 & 127,627 & $-5,699$ & $-447,301$ \\
\hline & \multicolumn{7}{|c|}{1984} \\
\hline 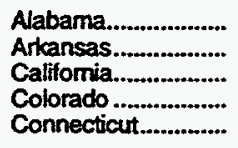 & $\begin{array}{r}0 \\
1,817 \\
103,983 \\
26,228 \\
0\end{array}$ & $\begin{array}{r}0 \\
1,817 \\
112,525 \\
21,531 \\
0\end{array}$ & $\begin{array}{r}0 \\
0 \\
-8,542 \\
4,697 \\
0\end{array}$ & $\begin{array}{r}838 \\
44 \\
191 \\
0 \\
1,673\end{array}$ & $\begin{array}{r}379 \\
8 \\
526 \\
0 \\
1,129\end{array}$ & $\begin{array}{r}459 \\
36 \\
-335 \\
0 \\
544\end{array}$ & $\begin{array}{r}459 \\
36 \\
-8,877 \\
4,697 \\
544\end{array}$ \\
\hline 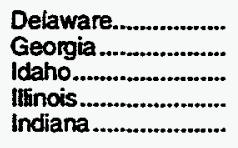 & $\begin{array}{r}0 \\
0 \\
0 \\
194,327 \\
22,069\end{array}$ & $\begin{array}{r}0 \\
0 \\
0 \\
173,305 \\
17,597\end{array}$ & $\begin{array}{r}0 \\
0 \\
0 \\
21,022 \\
4,472\end{array}$ & $\begin{array}{r}149 \\
678 \\
230 \\
1,034 \\
2,714\end{array}$ & $\begin{array}{l}110 \\
881 \\
282 \\
381 \\
836\end{array}$ & $\begin{array}{r}39 \\
-203 \\
-52 \\
653 \\
1,878\end{array}$ & $\begin{array}{r}40 \\
-203 \\
-52 \\
21,675 \\
6,350\end{array}$ \\
\hline 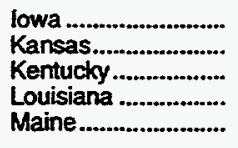 & $\begin{array}{r}44,355 \\
104,782 \\
63,617 \\
193,096 \\
0\end{array}$ & $\begin{array}{r}56,503 \\
81,635 \\
50,776 \\
174,405 \\
0\end{array}$ & $\begin{array}{r}-12,148 \\
23,147 \\
12,841 \\
18,691 \\
0\end{array}$ & $\begin{array}{r}3,089 \\
0 \\
0 \\
0 \\
203\end{array}$ & $\begin{array}{r}2,074 \\
0 \\
0 \\
3,556 \\
198\end{array}$ & $\begin{array}{r}1,015 \\
0 \\
0 \\
-3,556 \\
5\end{array}$ & $\begin{array}{r}-11,133 \\
23,147 \\
12,841 \\
15,134 \\
5\end{array}$ \\
\hline 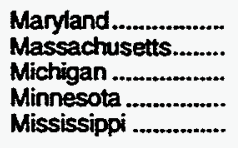 & $\begin{array}{r}16,154 \\
0 \\
379,036 \\
1,113 \\
54,186\end{array}$ & $\begin{array}{r}16,886 \\
0 \\
357,896 \\
416 \\
36,551\end{array}$ & $\begin{array}{r}-732 \\
0 \\
21,140 \\
696 \\
17,635\end{array}$ & $\begin{array}{r}650 \\
9,844 \\
0 \\
4,954 \\
0\end{array}$ & $\begin{array}{r}500 \\
7,110 \\
0 \\
4,523 \\
0\end{array}$ & $\begin{array}{r}150 \\
2,734 \\
0 \\
431 \\
0\end{array}$ & $\begin{array}{r}.582 \\
2,733 \\
21,140 \\
1,127 \\
17,635\end{array}$ \\
\hline 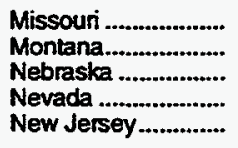 & $\begin{array}{r}4,431 \\
39,814 \\
5,628 \\
0 \\
0\end{array}$ & $\begin{array}{r}1,992 \\
23,577 \\
5,453 \\
0 \\
0\end{array}$ & $\begin{array}{r}2,438 \\
16,237 \\
175 \\
0 \\
0\end{array}$ & $\begin{array}{r}57 \\
0 \\
65 \\
133 \\
4.781\end{array}$ & $\begin{array}{r}10 \\
0 \\
135 \\
65 \\
3,313\end{array}$ & $\begin{array}{r}47 \\
0 \\
-70 \\
68 \\
1,468\end{array}$ & $\begin{array}{r}2,485 \\
16,237 \\
106 \\
68 \\
1,469\end{array}$ \\
\hline $\begin{array}{l}\text { New Mexico ............ } \\
\text { New York............. } \\
\text { North Carolina......... } \\
\text { Ohio ......................... } \\
\text { Okdahoma ................ }\end{array}$ & $\begin{array}{r}4,033 \\
59,702 \\
0 \\
156,006 \\
105,055\end{array}$ & $\begin{array}{r}9,102 \\
47,907 \\
0 \\
177,388 \\
78,919\end{array}$ & $\begin{array}{r}-5,069 \\
11,795 \\
0 \\
-21,382 \\
26,137\end{array}$ & $\begin{array}{r}0 \\
1,017 \\
1,511 \\
0 \\
0\end{array}$ & $\begin{array}{r}0 \\
836 \\
1,063 \\
0 \\
0\end{array}$ & $\begin{array}{r}0 \\
181 \\
448 \\
0 \\
0\end{array}$ & $\begin{array}{r}-5,069 \\
11,977 \\
448 \\
-21,382 \\
26,137\end{array}$ \\
\hline $\begin{array}{l}\text { Oregon.............. } \\
\text { Pennsylvania ......... } \\
\text { Rhode Istand......... } \\
\text { South Carolina ........ } \\
\text { Tennessee .............. }\end{array}$ & $\begin{array}{r}0 \\
362,878 \\
0 \\
0 \\
0\end{array}$ & $\begin{array}{r}0 \\
323,951 \\
0 \\
0 \\
0\end{array}$ & $\begin{array}{r}0 \\
38,927 \\
0 \\
0 \\
0\end{array}$ & $\begin{array}{r}304 \\
3,714 \\
97 \\
362 \\
2,376\end{array}$ & $\begin{array}{r}272 \\
2,266 \\
66 \\
258 \\
1,303\end{array}$ & $\begin{array}{r}32 \\
1,448 \\
31 \\
104 \\
1,073\end{array}$ & $\begin{array}{r}32 \\
40,376 \\
31 \\
104 \\
1,073\end{array}$ \\
\hline 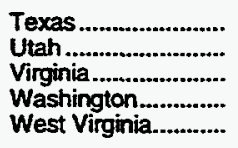 & $\begin{array}{r}145,916 \\
17,291 \\
0 \\
12,002 \\
128,717\end{array}$ & $\begin{array}{r}149,642 \\
20,988 \\
0 \\
10,747 \\
106,758\end{array}$ & $\begin{array}{r}-3,726 \\
-3,697 \\
0 \\
1,255 \\
21,959\end{array}$ & $\begin{array}{r}0 \\
0 \\
1,812 \\
0 \\
0\end{array}$ & $\begin{array}{r}0 \\
0 \\
1.771 \\
0 \\
0\end{array}$ & $\begin{array}{r}0 \\
0 \\
41 \\
0 \\
0\end{array}$ & $\begin{array}{r}-3,726 \\
-3,697 \\
41 \\
1,255 \\
21,959\end{array}$ \\
\hline 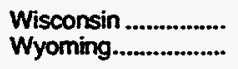 & $\begin{array}{r}0 \\
6,110\end{array}$ & $\begin{array}{r}0 \\
6,024\end{array}$ & $\begin{array}{r}0 \\
86\end{array}$ & $\begin{array}{r}272 \\
0\end{array}$ & $\begin{array}{r}162 \\
0\end{array}$ & $\begin{array}{r}110 \\
0\end{array}$ & $\begin{array}{r}110 \\
86\end{array}$ \\
\hline 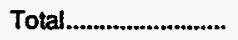 & $2,252,347$ & $2,064,292$ & 188,055 & 42,791 & 34,011 & 8,780 & 196,835 \\
\hline
\end{tabular}

See footnotes at end of table. 
Table 11. Changes in Natural Gas Storage by State, 1980-1994 (Continued) (Million Cubic Feet)

\begin{tabular}{|c|c|c|c|c|c|c|c|}
\hline \multirow{2}{*}{ State } & \multicolumn{3}{|c|}{$\begin{array}{l}\text { Underground } \\
\text { Storege }\end{array}$} & \multicolumn{3}{|c|}{ LNG Storage } & \multirow{2}{*}{$\begin{array}{l}\text { Not Change in } \\
\text { Storage }\end{array}$} \\
\hline & Injections & Withdrawals & Not & Additions & Withdrawnals & Net & \\
\hline & \multicolumn{7}{|c|}{1985} \\
\hline 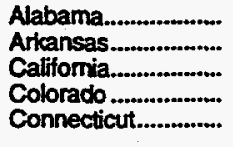 & $\begin{array}{r}0 \\
4,359 \\
124,099 \\
26,722 \\
0\end{array}$ & $\begin{array}{r}0 \\
1,427 \\
145,492 \\
28,711 \\
0\end{array}$ & $\begin{array}{r}0 \\
2,932 \\
-21,393 \\
-1,989 \\
0\end{array}$ & $\begin{array}{r}512 \\
18 \\
20 \\
0 \\
1,466\end{array}$ & $\begin{array}{r}971 \\
26 \\
227 \\
0 \\
1,653\end{array}$ & $\begin{array}{r}-459 \\
-8 \\
-207 \\
0 \\
-187\end{array}$ & $\begin{array}{r}-459 \\
2,924 \\
-21,600 \\
-1,989 \\
-187\end{array}$ \\
\hline 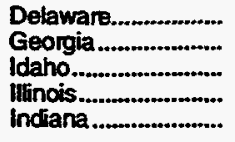 & $\begin{array}{r}0 \\
0 \\
0 \\
165,688 \\
21,885\end{array}$ & $\begin{array}{r}0 \\
0 \\
0 \\
183,650 \\
23,537\end{array}$ & $\begin{array}{r}0 \\
0 \\
0 \\
-17,962 \\
-1,652\end{array}$ & $\begin{array}{r}133 \\
1.834 \\
287 \\
653 \\
923\end{array}$ & $\begin{array}{r}126 \\
2,359 \\
921 \\
858 \\
494\end{array}$ & $\begin{array}{r}7 \\
-525 \\
-634 \\
-205 \\
429\end{array}$ & $\begin{array}{r}7 \\
-525 \\
-634 \\
-18,167 \\
-1,223\end{array}$ \\
\hline $\begin{array}{l}\text { lowa ......................... } \\
\text { Kansas................... } \\
\text { Kentucky.................. } \\
\text { Louisiana .................. } \\
\text { Maine ........................ }\end{array}$ & $\begin{array}{r}64,993 \\
96,153 \\
62,202 \\
184,351 \\
0\end{array}$ & $\begin{array}{r}63,117 \\
114,502 \\
57,307 \\
212,372 \\
0\end{array}$ & $\begin{array}{r}1,876 \\
-18,349 \\
4,895 \\
-28,021 \\
0\end{array}$ & $\begin{array}{r}289 \\
0 \\
0 \\
0 \\
308\end{array}$ & $\begin{array}{r}1,102 \\
0 \\
0 \\
0 \\
296\end{array}$ & $\begin{array}{r}-813 \\
0 \\
0 \\
0 \\
12\end{array}$ & $\begin{array}{r}1,063 \\
-18,349 \\
4,895 \\
-28,021 \\
12\end{array}$ \\
\hline $\begin{array}{l}\text { Maryland ................. } \\
\text { Massachusetts........ } \\
\text { Michigan ................... } \\
\text { Minnesota ............... } \\
\text { Mississippi .............. }\end{array}$ & $\begin{array}{r}17,362 \\
0 \\
325,729 \\
1,640 \\
54,105\end{array}$ & $\begin{array}{r}18,551 \\
0 \\
338,737 \\
2,050 \\
42,682\end{array}$ & $\begin{array}{r}-1,189 \\
0 \\
-13,008 \\
-410 \\
11,423\end{array}$ & $\begin{array}{r}786 \\
9,261 \\
0 \\
3,190 \\
0\end{array}$ & $\begin{array}{r}867 \\
9,216 \\
0 \\
3,424 \\
0\end{array}$ & $\begin{array}{r}-81 \\
45 \\
0 \\
-234 \\
0\end{array}$ & $\begin{array}{r}-1,270 \\
45 \\
-13,008 \\
-644 \\
11,423\end{array}$ \\
\hline $\begin{array}{l}\text { Missouri ...................... } \\
\text { Montana................... } \\
\text { Nebraska ................. } \\
\text { Nevada ..................... } \\
\text { New Jersey .............. }\end{array}$ & $\begin{array}{r}4,537 \\
36,786 \\
6,848 \\
0 \\
0\end{array}$ & $\begin{array}{r}5,018 \\
27,361 \\
5,920 \\
0 \\
0\end{array}$ & $\begin{array}{r}-481 \\
9,425 \\
928 \\
0 \\
0\end{array}$ & $\begin{array}{r}21 \\
0 \\
4 \\
419 \\
4,317\end{array}$ & $\begin{array}{r}31 \\
0 \\
140 \\
330 \\
4,064\end{array}$ & $\begin{array}{r}-10 \\
0 \\
-136 \\
89 \\
253\end{array}$ & $\begin{array}{r}-491 \\
9,425 \\
792 \\
89 \\
253\end{array}$ \\
\hline $\begin{array}{l}\text { New Mexico .............. } \\
\text { New York................. } \\
\text { North Carolina.......... } \\
\text { Ohio......................... } \\
\text { Okdahoma ................ }\end{array}$ & $\begin{array}{r}14,552 \\
48,748 \\
0 \\
138,801 \\
87,860\end{array}$ & $\begin{array}{r}13,872 \\
53,515 \\
0 \\
169,453 \\
106,914\end{array}$ & $\begin{array}{r}680 \\
-4,767 \\
0 \\
-30,652 \\
-19,054\end{array}$ & $\begin{array}{r}0 \\
1,312 \\
1,164 \\
0 \\
0\end{array}$ & $\begin{array}{r}0 \\
1,073 \\
1,397 \\
0 \\
0\end{array}$ & $\begin{array}{r}0 \\
239 \\
-233 \\
0 \\
0\end{array}$ & $\begin{array}{r}680 \\
-4,528 \\
-233 \\
-30,652 \\
-19,054\end{array}$ \\
\hline $\begin{array}{l}\text { Oregon..................... } \\
\text { Pennsyivania ........... } \\
\text { Rhode Island............ } \\
\text { South Carolina ......... } \\
\text { Tennessee............... }\end{array}$ & $\begin{array}{r}0 \\
350,022 \\
0 \\
0 \\
0\end{array}$ & $\begin{array}{r}0 \\
400,420 \\
0 \\
0 \\
0\end{array}$ & $\begin{array}{r}0 \\
-50,398 \\
0 \\
0 \\
0\end{array}$ & $\begin{array}{r}461 \\
2,309 \\
147 \\
484 \\
2,105\end{array}$ & $\begin{array}{r}283 \\
2,936 \\
120 \\
293 \\
2,477\end{array}$ & $\begin{array}{r}178 \\
-627 \\
27 \\
191 \\
-372\end{array}$ & $\begin{array}{r}178 \\
-51,025 \\
27 \\
191 \\
-372\end{array}$ \\
\hline $\begin{array}{l}\text { Texas ....................... } \\
\text { Utah ...................... } \\
\text { Virginia................... } \\
\text { Washington.............. } \\
\text { West Virginia........... }\end{array}$ & $\begin{array}{r}125,560 \\
20,386 \\
0 \\
7,847 \\
129,134\end{array}$ & $\begin{array}{r}154,554 \\
22,453 \\
0 \\
7,162 \\
149,952\end{array}$ & $\begin{array}{r}-28,994 \\
-2,067 \\
0 \\
685 \\
-20,818\end{array}$ & $\begin{array}{r}0 \\
0 \\
2.117 \\
0 \\
0\end{array}$ & $\begin{array}{r}0 \\
0 \\
2,120 \\
0 \\
0\end{array}$ & $\begin{array}{r}0 \\
0 \\
-3 \\
0 \\
0\end{array}$ & $\begin{array}{r}-28,994 \\
-2,067 \\
-3 \\
685 \\
-20,818\end{array}$ \\
\hline $\begin{array}{l}\text { Wisconsin ................. } \\
\text { Wyoming................. }\end{array}$ & $\begin{array}{r}0 \\
7,565\end{array}$ & $\begin{array}{r}0 \\
10,676\end{array}$ & $\begin{array}{r}0 \\
-3,1+1\end{array}$ & $\begin{array}{r}131 \\
0\end{array}$ & $\begin{array}{r}151 \\
0\end{array}$ & $\begin{array}{r}-20 \\
0\end{array}$ & $\begin{array}{r}-20 \\
-3,111\end{array}$ \\
\hline \multirow[t]{2}{*}{ Total.............................. } & $2,127,932$ & $2,359,405$ & $-231,473$ & 34,671 & 37,954 & $-3,283$ & $-234,756$ \\
\hline & \multicolumn{7}{|c|}{1986} \\
\hline 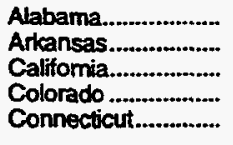 & $\begin{array}{r}0 \\
1,871 \\
89,891 \\
24,313 \\
0\end{array}$ & $\begin{array}{r}0 \\
789 \\
89,527 \\
21,743 \\
0\end{array}$ & $\begin{array}{r}0 \\
1,082 \\
364 \\
2,570 \\
0\end{array}$ & $\begin{array}{r}581 \\
22 \\
18 \\
0 \\
1,035\end{array}$ & $\begin{array}{r}449 \\
18 \\
23 \\
0 \\
837\end{array}$ & $\begin{array}{r}132 \\
4 \\
-5 \\
0 \\
198\end{array}$ & $\begin{array}{r}132 \\
1,086 \\
359 \\
2,570 \\
198\end{array}$ \\
\hline 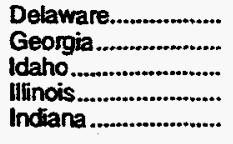 & $\begin{array}{r}0 \\
0 \\
0 \\
156,754 \\
22,118\end{array}$ & $\begin{array}{r}0 \\
0 \\
0 \\
140,510 \\
18,981\end{array}$ & $\begin{array}{r}0 \\
0 \\
0 \\
16,244 \\
3,137\end{array}$ & $\begin{array}{r}0 \\
1,942 \\
93 \\
199 \\
777\end{array}$ & $\begin{array}{r}71 \\
1,346 \\
1,025 \\
469 \\
162\end{array}$ & $\begin{array}{r}-71 \\
596 \\
-932 \\
-270 \\
615\end{array}$ & $\begin{array}{r}-71 \\
596 \\
-932 \\
15,974 \\
3,752\end{array}$ \\
\hline lowa & 52,084 & 49,133 & 2,951 & 154 & 650 & -496 & 2,455 \\
\hline
\end{tabular}

See lootnotes at end of table. 
Table 11. Changes in Natural Gas Storage by State, 1980-1994 (Continued) (Million Cubic Feet)

\begin{tabular}{|c|c|c|c|c|c|c|c|}
\hline \multirow{2}{*}{ State } & \multicolumn{3}{|c|}{$\begin{array}{l}\text { Underground } \\
\text { Storage }\end{array}$} & \multicolumn{3}{|c|}{ LNG Storege" } & \multirow{2}{*}{$\begin{array}{l}\text { Net Change in } \\
\text { Storage }\end{array}$} \\
\hline & Injections & Withdrawals & Not & Addritions & Withdrawals & Net & \\
\hline & \multicolumn{3}{|c|}{ - } & 1986 & & & \\
\hline 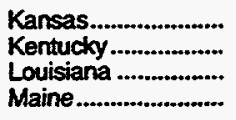 & $\begin{array}{r}97,214 \\
43,698 \\
174,222 \\
0\end{array}$ & $\begin{array}{r}85,306 \\
41,420 \\
192,473 \\
0\end{array}$ & $\begin{array}{r}11,908 \\
2,278 \\
-18,251 \\
0\end{array}$ & $\begin{array}{r}0 \\
0 \\
0 \\
127\end{array}$ & $\begin{array}{r}0 \\
0 \\
0 \\
121\end{array}$ & $\begin{array}{l}0 \\
0 \\
0 \\
6\end{array}$ & $\begin{array}{r}11,908 \\
2,278 \\
-18,251 \\
6\end{array}$ \\
\hline $\begin{array}{l}\text { Manyland .................. } \\
\text { Massachusetts........ } \\
\text { Michigan ................... } \\
\text { Minnesota ............... } \\
\text { Mississippi ............... }\end{array}$ & $\begin{array}{r}16,330 \\
0 \\
366,672 \\
1,146 \\
38,678\end{array}$ & $\begin{array}{r}17,080 \\
0 \\
317,743 \\
646 \\
41,779\end{array}$ & $\begin{array}{r}-750 \\
0 \\
48,929 \\
500 \\
-3,101\end{array}$ & $\begin{array}{r}769 \\
6,184 \\
0 \\
4,679 \\
0\end{array}$ & $\begin{array}{r}616 \\
5,591 \\
0 \\
1,043 \\
0\end{array}$ & $\begin{array}{r}153 \\
593 \\
0 \\
3,636 \\
0\end{array}$ & $\begin{array}{r}-597 \\
593 \\
48,929 \\
4,136 \\
-3,101\end{array}$ \\
\hline $\begin{array}{l}\text { Missouri ..................... } \\
\text { Montana.................. } \\
\text { Nebraska ................. } \\
\text { Nevada .................. } \\
\text { New Hampshire ....... }\end{array}$ & $\begin{array}{r}2,835 \\
22,084 \\
5,748 \\
0 \\
0\end{array}$ & $\begin{array}{r}2,084 \\
11,220 \\
3,468 \\
0 \\
0\end{array}$ & $\begin{array}{r}751 \\
10,864 \\
2,280 \\
0 \\
0\end{array}$ & $\begin{array}{r}28 \\
0 \\
81 \\
217 \\
0\end{array}$ & $\begin{array}{r}23 \\
0 \\
129 \\
107 \\
100\end{array}$ & $\begin{array}{r}5 \\
0 \\
-48 \\
110 \\
-100\end{array}$ & $\begin{array}{r}756 \\
10,864 \\
2,232 \\
110 \\
-100\end{array}$ \\
\hline $\begin{array}{l}\text { New Jersey............... } \\
\text { New Mexico ............. } \\
\text { New York................. } \\
\text { North Carolina......... } \\
\text { Ohio .......................... }\end{array}$ & $\begin{array}{r}0 \\
11,531 \\
49,185 \\
0 \\
163,093\end{array}$ & $\begin{array}{r}0 \\
15,729 \\
44,696 \\
0 \\
142,235\end{array}$ & $\begin{array}{r}0 \\
-4,198 \\
4,489 \\
0 \\
20,858\end{array}$ & $\begin{array}{r}5,384 \\
0 \\
647 \\
1,663 \\
0\end{array}$ & $\begin{array}{r}3,468 \\
0 \\
777 \\
977 \\
0\end{array}$ & $\begin{array}{r}1,916 \\
0 \\
-130 \\
686 \\
0\end{array}$ & $\begin{array}{r}1,916 \\
-4,198 \\
4,359 \\
686 \\
20,858\end{array}$ \\
\hline $\begin{array}{l}\text { Oklahoma ................ } \\
\text { Oregon.................. } \\
\text { Pennsyivania .......... } \\
\text { Rhode Island........... } \\
\text { South Carolina ......... }\end{array}$ & $\begin{array}{r}84,072 \\
0 \\
249,028 \\
0 \\
0\end{array}$ & $\begin{array}{r}84,943 \\
0 \\
239,233 \\
0 \\
0\end{array}$ & $\begin{array}{r}-871 \\
0 \\
9,795 \\
0 \\
0\end{array}$ & $\begin{array}{r}0 \\
0 \\
2,657 \\
20 \\
403\end{array}$ & $\begin{array}{r}0 \\
346 \\
2,398 \\
36 \\
342\end{array}$ & $\begin{array}{r}0 \\
-346 \\
259 \\
-16 \\
61\end{array}$ & $\begin{array}{r}-871 \\
-346 \\
10,054 \\
-16 \\
61\end{array}$ \\
\hline $\begin{array}{l}\text { Tennessee ................ } \\
\text { Texas ..................... } \\
\text { Utah ....................... } \\
\text { Virginia.................. } \\
\text { Washington........... }\end{array}$ & $\begin{array}{r}0 \\
121,631 \\
9,542 \\
0 \\
6,269\end{array}$ & $\begin{array}{r}0 \\
113,331 \\
7,688 \\
0 \\
3,217\end{array}$ & $\begin{array}{r}0 \\
8,300 \\
1,854 \\
0 \\
3,052\end{array}$ & $\begin{array}{r}1,766 \\
0 \\
0 \\
1,989 \\
0\end{array}$ & $\begin{array}{r}1,695 \\
0 \\
0 \\
2,038 \\
0\end{array}$ & $\begin{array}{r}71 \\
0 \\
0 \\
-49 \\
0\end{array}$ & $\begin{array}{r}71 \\
8,300 \\
1,854 \\
-49 \\
3,052\end{array}$ \\
\hline $\begin{array}{l}\text { West Virginia............ } \\
\text { Wisconsin .................. } \\
\text { Wyoming.................. }\end{array}$ & $\begin{array}{r}134,394 \\
0 \\
7,701\end{array}$ & $\begin{array}{r}114,872 \\
0 \\
11,849\end{array}$ & $\begin{array}{r}19,522 \\
0 \\
-4,148\end{array}$ & $\begin{array}{r}0 \\
64 \\
0\end{array}$ & $\begin{array}{r}0 \\
138 \\
0\end{array}$ & $\begin{array}{r}0 \\
-74 \\
0\end{array}$ & $\begin{array}{r}19,522 \\
-74 \\
-4,148\end{array}$ \\
\hline \multirow[t]{2}{*}{ 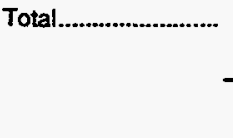 } & $1,952,103$ & $1,811,697$ & 140,406 & 31,500 & 24,996 & 6,504 & 146,910 \\
\hline & & 1987 & & & \\
\hline $\begin{array}{l}\text { Alabama.................... } \\
\text { Arkansas................. } \\
\text { Califomia.................. } \\
\text { Colorado ................... } \\
\text { Connecticut............... }\end{array}$ & $\begin{array}{r}0 \\
398 \\
130,990 \\
24,083 \\
0\end{array}$ & $\begin{array}{r}0 \\
332 \\
159,681 \\
25,601 \\
0\end{array}$ & $\begin{array}{r}0 \\
67 \\
-28,692 \\
-1,518 \\
0\end{array}$ & $\begin{array}{r}465 \\
52 \\
18 \\
0 \\
1,281\end{array}$ & $\begin{array}{r}511 \\
43 \\
19 \\
0 \\
1,160\end{array}$ & $\begin{array}{r}-46 \\
9 \\
0 \\
0 \\
121\end{array}$ & $\begin{array}{r}-46 \\
76 \\
-28,692 \\
-1,518 \\
121\end{array}$ \\
\hline $\begin{array}{l}\text { Delaware................... } \\
\text { Georgia ..................... } \\
\text { Idaho......................... } \\
\text { Ilinois........................... } \\
\text { Indiana ...................... }\end{array}$ & $\begin{array}{r}0 \\
0 \\
0 \\
125,066 \\
15,844\end{array}$ & $\begin{array}{r}0 \\
0 \\
0 \\
124,889 \\
16,317\end{array}$ & $\begin{array}{r}0 \\
0 \\
0 \\
177 \\
-473\end{array}$ & $\begin{array}{r}6 \\
1,150 \\
0 \\
223 \\
806\end{array}$ & $\begin{array}{r}66 \\
1,001 \\
86 \\
320 \\
265\end{array}$ & $\begin{array}{r}-60 \\
149 \\
-86 \\
-96 \\
541\end{array}$ & $\begin{array}{r}-60 \\
149 \\
-86 \\
81 \\
68\end{array}$ \\
\hline 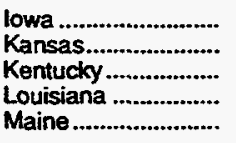 & $\begin{array}{r}45,128 \\
87,570 \\
42,388 \\
188,110 \\
0\end{array}$ & $\begin{array}{r}41,856 \\
92,360 \\
38,780 \\
175,623 \\
0\end{array}$ & $\begin{array}{r}3,272 \\
-4,790 \\
3,608 \\
12,486 \\
0\end{array}$ & $\begin{array}{r}670 \\
0 \\
0 \\
0 \\
226\end{array}$ & $\begin{array}{r}878 \\
0 \\
0 \\
0 \\
227\end{array}$ & $\begin{array}{r}-208 \\
0 \\
0 \\
0 \\
0\end{array}$ & $\begin{array}{r}3,064 \\
-4,790 \\
3,608 \\
12,486 \\
0\end{array}$ \\
\hline $\begin{array}{l}\text { Manyland ................. } \\
\text { Massachusetts........ } \\
\text { Michigan .................. } \\
\text { Minnesota ............... } \\
\text { Mississippi ............... }\end{array}$ & $\begin{array}{r}16,539 \\
0 \\
268,325 \\
476 \\
43,550\end{array}$ & $\begin{array}{r}17,081 \\
0 \\
268,785 \\
369 \\
35,520\end{array}$ & $\begin{array}{r}-543 \\
0 \\
-461 \\
107 \\
8,029\end{array}$ & $\begin{array}{r}482 \\
5,732 \\
0 \\
3,109 \\
0\end{array}$ & $\begin{array}{r}480 \\
7,775 \\
0 \\
2,488 \\
0\end{array}$ & $\begin{array}{r}2 \\
-2,043 \\
0 \\
621 \\
0\end{array}$ & $\begin{array}{r}-541 \\
-2,043 \\
-461 \\
728 \\
8,029\end{array}$ \\
\hline $\begin{array}{l}\text { Missouri ................... } \\
\text { Montana.................. } \\
\text { Nebraska ............... }\end{array}$ & $\begin{array}{r}1,337 \\
22,894 \\
6,241\end{array}$ & $\begin{array}{l}1,019 \\
8,596 \\
4,575\end{array}$ & $\begin{array}{r}318 \\
14,297 \\
1,666\end{array}$ & $\begin{array}{r}58 \\
0 \\
130\end{array}$ & $\begin{array}{r}48 \\
0 \\
115\end{array}$ & $\begin{array}{r}10 \\
0 \\
14\end{array}$ & $\begin{array}{r}328 \\
14,297 \\
1,681\end{array}$ \\
\hline
\end{tabular}

See footnotes at end of table. 
Fable 11. Changes in Natural Gas Storage by State, 1980-1994 (Continued) (Million Cubic Feet)

\begin{tabular}{|c|c|c|c|c|c|c|c|}
\hline \multirow{2}{*}{ State } & \multicolumn{3}{|c|}{$\begin{array}{l}\text { Underground } \\
\text { Storage }\end{array}$} & \multicolumn{3}{|c|}{ LNG Storage } & \multirow{2}{*}{$\begin{array}{l}\text { Net Change in } \\
\text { Storage }\end{array}$} \\
\hline & Injoctions & Withdirowals & Not & Additions & Whithenals & Net & \\
\hline & & & . & 1987 & & & \\
\hline $\begin{array}{l}\text { Nevada .................... } \\
\text { New Hampshire ...... }\end{array}$ & $\begin{array}{l}\mathbf{0} \\
\mathbf{0}\end{array}$ & $\begin{array}{l}0 \\
0\end{array}$ & $\begin{array}{l}0 \\
0\end{array}$ & $\begin{array}{r}441 \\
0\end{array}$ & $\begin{array}{r}185 \\
91\end{array}$ & $\begin{array}{l}256 \\
-91\end{array}$ & $\begin{array}{l}256 \\
-91\end{array}$ \\
\hline $\begin{array}{l}\text { New Jersey............... } \\
\text { New Mexico............ } \\
\text { New York................ } \\
\text { North Carolina......... } \\
\text { Ohio .......................... }\end{array}$ & $\begin{array}{r}0 \\
14,892 \\
42,616 \\
0 \\
143,588\end{array}$ & $\begin{array}{r}0 \\
15,769 \\
43,252 \\
0 \\
143,827\end{array}$ & $\begin{array}{r}0 \\
-877 \\
-636 \\
0 \\
-239\end{array}$ & $\begin{array}{r}3,236 \\
0 \\
1,188 \\
1,609 \\
0\end{array}$ & $\begin{array}{r}3,422 \\
0 \\
892 \\
1,571 \\
0\end{array}$ & $\begin{array}{r}-185 \\
0 \\
296 \\
39 \\
0\end{array}$ & $\begin{array}{r}-185 \\
-877 \\
-341 \\
39 \\
-239\end{array}$ \\
\hline $\begin{array}{l}\text { Okdahoma ................. } \\
\text { Oregon................. } \\
\text { Pennsyivania ........... } \\
\text { Phode Island........... } \\
\text { South Carolina......... }\end{array}$ & $\begin{array}{r}84,031 \\
4,148 \\
335,166 \\
0 \\
0\end{array}$ & $\begin{array}{r}75,151 \\
0 \\
335,670 \\
0 \\
0\end{array}$ & $\begin{array}{r}8,880 \\
4,148 \\
-504 \\
0 \\
0\end{array}$ & $\begin{array}{r}0 \\
183 \\
1,381 \\
65 \\
545\end{array}$ & $\begin{array}{r}0 \\
305 \\
247 \\
295 \\
481\end{array}$ & $\begin{array}{r}0 \\
-122 \\
1,135 \\
-230 \\
64\end{array}$ & $\begin{array}{r}8,880 \\
4,026 \\
631 \\
-230 \\
64\end{array}$ \\
\hline 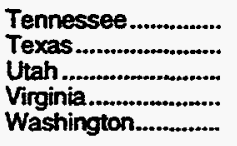 & $\begin{array}{r}0 \\
121,245 \\
14,359 \\
0 \\
6,884\end{array}$ & $\begin{array}{r}0 \\
114,434 \\
14,905 \\
0 \\
7,787\end{array}$ & $\begin{array}{r}0 \\
6,811 \\
-547 \\
0 \\
-903\end{array}$ & $\begin{array}{r}1,135 \\
0 \\
0 \\
112 \\
0\end{array}$ & $\begin{array}{r}1,228 \\
0 \\
0 \\
108 \\
0\end{array}$ & $\begin{array}{r}-93 \\
0 \\
0 \\
4 \\
0\end{array}$ & $\begin{array}{r}-93 \\
6,811 \\
-547 \\
4 \\
-903\end{array}$ \\
\hline $\begin{array}{l}\text { West Virginia........... } \\
\text { Wisconsin .................. } \\
\text { Wyoming............... }\end{array}$ & $\begin{array}{r}98,311 \\
0 \\
2,932\end{array}$ & $\begin{array}{r}104,225 \\
0 \\
14,545\end{array}$ & $\begin{array}{r}-5,914 \\
0 \\
-11,613\end{array}$ & $\begin{array}{r}0 \\
74 \\
0\end{array}$ & $\begin{array}{r}0 \\
164 \\
0\end{array}$ & $\begin{array}{r}0 \\
-90 \\
0\end{array}$ & $\begin{array}{r}-5,914 \\
-90 \\
-11,613\end{array}$ \\
\hline \multirow[t]{2}{*}{ 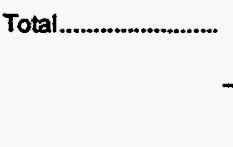 } & $1,887,110$ & $1,880,951$ & 6,159 & 24,379 & 24,468 & -89 & 6,070 \\
\hline & \multicolumn{7}{|c|}{1988} \\
\hline $\begin{array}{l}\text { Alabama................... } \\
\text { Aktansas.................. } \\
\text { Califomia................... } \\
\text { Colorado .................. } \\
\text { Connecticut............. }\end{array}$ & $\begin{array}{r}0 \\
1,522 \\
120,167 \\
25,898 \\
0\end{array}$ & $\begin{array}{r}0 \\
974 \\
104,375 \\
26,380 \\
0\end{array}$ & $\begin{array}{r}0 \\
548 \\
15,792 \\
-481 \\
0\end{array}$ & $\begin{array}{r}607 \\
42 \\
9 \\
0 \\
1,229\end{array}$ & $\begin{array}{r}444 \\
54 \\
20 \\
0 \\
1,154\end{array}$ & $\begin{array}{r}164 \\
-12 \\
-11 \\
0 \\
75\end{array}$ & $\begin{array}{r}164 \\
536 \\
15,781 \\
-481 \\
75\end{array}$ \\
\hline $\begin{array}{l}\text { Delaware.................. } \\
\text { Georgia ...................... } \\
\text { Idaho........................ } \\
\text { Illinois....................... } \\
\text { Indiana ..................... }\end{array}$ & $\begin{array}{r}0 \\
0 \\
0 \\
166,713 \\
24,423\end{array}$ & $\begin{array}{r}0 \\
0 \\
0 \\
157,954 \\
23,199\end{array}$ & $\begin{array}{r}0 \\
0 \\
0 \\
8,759 \\
1,224\end{array}$ & $\begin{array}{r}93 \\
1,702 \\
528 \\
393 \\
6,321\end{array}$ & $\begin{array}{r}89 \\
1,157 \\
194 \\
325 \\
244\end{array}$ & $\begin{array}{r}4 \\
545 \\
334 \\
69 \\
6,077\end{array}$ & $\begin{array}{r}4 \\
545 \\
334 \\
8,827 \\
7,301\end{array}$ \\
\hline 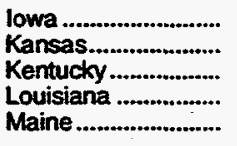 & $\begin{array}{r}55,076 \\
107,182 \\
55,774 \\
194,251 \\
0\end{array}$ & $\begin{array}{r}54,659 \\
90,238 \\
68,676 \\
156,364 \\
0\end{array}$ & $\begin{array}{r}417 \\
16,944 \\
-12,902 \\
37,886 \\
0\end{array}$ & $\begin{array}{r}477 \\
0 \\
0 \\
0 \\
157\end{array}$ & $\begin{array}{r}648 \\
0 \\
0 \\
0 \\
157\end{array}$ & $\begin{array}{r}-171 \\
0 \\
0 \\
0 \\
0\end{array}$ & $\begin{array}{r}246 \\
16,944 \\
-12,902 \\
37,886 \\
-\quad 0\end{array}$ \\
\hline $\begin{array}{l}\text { Maryland.................. } \\
\text { Massachusetts....... } \\
\text { Michigan ................... } \\
\text { Minnesota ............... } \\
\text { Mississippi ............... }\end{array}$ & $\begin{array}{r}14,653 \\
0 \\
341,649 \\
1,142 \\
41,780\end{array}$ & $\begin{array}{r}19,397 \\
0 \\
342,472 \\
5,210 \\
42,348\end{array}$ & $\begin{array}{r}-4,744 \\
0 \\
-823 \\
-4.068 \\
-567\end{array}$ & $\begin{array}{r}764 \\
5,782 \\
0 \\
5,391 \\
0\end{array}$ & $\begin{array}{r}771 \\
7,427 \\
0 \\
949 \\
0\end{array}$ & $\begin{array}{r}-7 \\
-1,644 \\
0 \\
4,442 \\
0\end{array}$ & $\begin{array}{r}-4,751 \\
-1,644 \\
-823 \\
374 \\
-567\end{array}$ \\
\hline $\begin{array}{l}\text { Missouri ...................... } \\
\text { Montana................. } \\
\text { Nebraska ................ } \\
\text { Nevada ................. } \\
\text { New Hampshire ....... }\end{array}$ & $\begin{array}{r}4,240 \\
13,782 \\
7,615 \\
0 \\
0\end{array}$ & $\begin{array}{r}4,054 \\
20,351 \\
7,567 \\
0 \\
0\end{array}$ & $\begin{array}{r}186 \\
-6,570 \\
48 \\
0 \\
0\end{array}$ & $\begin{array}{r}0 \\
0 \\
299 \\
213 \\
0\end{array}$ & $\begin{array}{r}0 \\
0 \\
167 \\
383 \\
142\end{array}$ & $\begin{array}{r}0 \\
0 \\
132 \\
-170 \\
-142\end{array}$ & $\begin{array}{r}186 \\
6,570 \\
180 \\
-170 \\
-142\end{array}$ \\
\hline $\begin{array}{l}\text { New Jersey.............. } \\
\text { New Mexico .............. } \\
\text { New York................ } \\
\text { North Carolina.......... } \\
\text { Ohio ............................ }\end{array}$ & $\begin{array}{r}0 \\
19,407 \\
56,332 \\
0 \\
162,801\end{array}$ & $\begin{array}{r}0 \\
14,411 \\
52,735 \\
0 \\
336,351\end{array}$ & $\begin{array}{r}0 \\
4,996 \\
3,598 \\
0 \\
-173,550\end{array}$ & $\begin{array}{r}3,243 \\
0 \\
449 \\
2,151 \\
0\end{array}$ & $\begin{array}{r}3.202 \\
0 \\
370 \\
1,890 \\
0\end{array}$ & $\begin{array}{r}40 \\
0 \\
80 \\
261 \\
0\end{array}$ & $\begin{array}{r}40 \\
4,996 \\
3,677 \\
261 \\
-173,550\end{array}$ \\
\hline $\begin{array}{l}\text { Okdahoma ................. } \\
\text { Oregon.................... } \\
\text { Pennsytvania .......... } \\
\text { Rhode istand.......... } \\
\text { South Carolina........ }\end{array}$ & $\begin{array}{r}95,241 \\
0 \\
377,046 \\
0 \\
0\end{array}$ & $\begin{array}{r}81,021 \\
0 \\
368,481 \\
0 \\
0\end{array}$ & $\begin{array}{r}14,220 \\
0 \\
8,565 \\
0 \\
0\end{array}$ & $\begin{array}{r}0 \\
803 \\
3,023 \\
174 \\
503\end{array}$ & $\begin{array}{r}0 \\
243 \\
3,186 \\
143 \\
547\end{array}$ & $\begin{array}{r}0 \\
560 \\
-163 \\
31 \\
-44\end{array}$ & $\begin{array}{r}14,220 \\
560 \\
8,402 \\
31 \\
-44\end{array}$ \\
\hline
\end{tabular}

See footnotes at end of table. 
Table 11. Changes in Natural Gas Storage by State, 1980-1994 (Continued) (Million Cubic Feet)

\begin{tabular}{|c|c|c|c|c|c|c|c|}
\hline \multirow{2}{*}{ State } & \multicolumn{3}{|c|}{$\begin{array}{l}\text { Underground } \\
\text { Storage }\end{array}$} & \multicolumn{3}{|c|}{ ENG Storage" } & \multirow{2}{*}{$\begin{array}{l}\text { Net Change is } \\
\text { Storage }\end{array}$} \\
\hline & Injections & Withdrawals & Net & Additions & Withdravels & Net & \\
\hline & \multicolumn{7}{|c|}{1988} \\
\hline 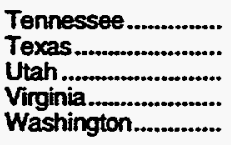 & $\begin{array}{r}0 \\
146,758 \\
19,426 \\
0 \\
5,415\end{array}$ & $\begin{array}{r}0 \\
107,769 \\
19,959 \\
0 \\
6,014\end{array}$ & $\begin{array}{r}0 \\
38,989 \\
-533 \\
0 \\
-600\end{array}$ & $\begin{array}{r}2,109 \\
0 \\
0 \\
231 \\
0\end{array}$ & $\begin{array}{r}2,053 \\
0 \\
0 \\
260 \\
0\end{array}$ & $\begin{array}{r}56 \\
0 \\
0 \\
-29 \\
0\end{array}$ & $\begin{array}{r}56 \\
38,989 \\
-533 \\
-29 \\
-600\end{array}$ \\
\hline $\begin{array}{l}\text { West Virginia........... } \\
\text { Wisconsin ................ } \\
\text { Wyoming................. }\end{array}$ & $\begin{array}{r}106,318 \\
0 \\
9,719\end{array}$ & $\begin{array}{r}127,909 \\
0 \\
4,753\end{array}$ & $\begin{array}{r}-21,591 \\
0 \\
4,965\end{array}$ & $\begin{array}{r}0 \\
253 \\
0\end{array}$ & $\begin{array}{r}0 \\
172 \\
0\end{array}$ & $\begin{array}{r}0 \\
81 \\
0\end{array}$ & $\begin{array}{r}-21,591 \\
81 \\
4,965\end{array}$ \\
\hline \multirow[t]{2}{*}{ 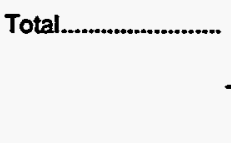 } & $2,174,328$ & $2,243,621$ & $-69,293$ & 36,949 & 26,390 & 10,559 & $-58,734$ \\
\hline & \multicolumn{7}{|c|}{1989} \\
\hline $\begin{array}{l}\text { Alabama................... } \\
\text { Artcansas.................. } \\
\text { California.................. } \\
\text { Colorado ................... } \\
\text { Connecticutt.............. }\end{array}$ & $\begin{array}{r}0 \\
1,299 \\
140,933 \\
28,165 \\
0\end{array}$ & $\begin{array}{r}0 \\
1,252 \\
151,488 \\
26,942 \\
0\end{array}$ & $\begin{array}{r}0 \\
47 \\
-10,554 \\
1,223 \\
0\end{array}$ & $\begin{array}{r}512 \\
30 \\
19 \\
0 \\
1,115\end{array}$ & $\begin{array}{r}934 \\
62 \\
18 \\
0 \\
1,720\end{array}$ & $\begin{array}{r}-422 \\
-32 \\
0 \\
0 \\
-604\end{array}$ & $\begin{array}{r}-422 \\
15 \\
-10,554 \\
1,223 \\
-604\end{array}$ \\
\hline 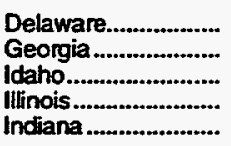 & $\begin{array}{r}0 \\
0 \\
0 \\
199,165 \\
24,816\end{array}$ & $\begin{array}{r}0 \\
0 \\
0 \\
216,543 \\
26,700\end{array}$ & $\begin{array}{r}0 \\
0 \\
0 \\
-17,378 \\
-1,884\end{array}$ & $\begin{array}{r}39 \\
2,930 \\
258 \\
0 \\
737\end{array}$ & $\begin{array}{r}76 \\
2,586 \\
93 \\
579 \\
393\end{array}$ & $\begin{array}{r}-38 \\
343 \\
165 \\
-579 \\
344\end{array}$ & $\begin{array}{r}-38 \\
343 \\
165 \\
-17,957 \\
-1,540\end{array}$ \\
\hline $\begin{array}{l}\text { lowa ........................ } \\
\text { Kansas..................... } \\
\text { Kentucky................... } \\
\text { Louisiana .................. } \\
\text { Maine....................... }\end{array}$ & $\begin{array}{r}58,386 \\
104,735 \\
55,277 \\
178,222 \\
0\end{array}$ & $\begin{array}{r}67,421 \\
121,895 \\
69,423 \\
242,403 \\
0\end{array}$ & $\begin{array}{r}-9,035 \\
-17,160 \\
-14,147 \\
-64,181 \\
0\end{array}$ & $\begin{array}{r}1,008 \\
0 \\
0 \\
0 \\
29\end{array}$ & $\begin{array}{r}715 \\
0 \\
0 \\
0 \\
25\end{array}$ & $\begin{array}{r}292 \\
0 \\
0 \\
0 \\
4\end{array}$ & $\begin{array}{r}-8,743 \\
-17,160 \\
-14,147 \\
-64,181 \\
4\end{array}$ \\
\hline $\begin{array}{l}\text { Maryland .................. } \\
\text { Massachusetts......... } \\
\text { Michigan .................. } \\
\text { Minnesota ............... } \\
\text { Mississippi ............... }\end{array}$ & $\begin{array}{r}18,548 \\
0 \\
414,819 \\
1,226 \\
50,478\end{array}$ & $\begin{array}{r}19,166 \\
0 \\
436,508 \\
1,555 \\
63,872\end{array}$ & $\begin{array}{r}-619 \\
0 \\
-21,688 \\
-330 \\
-13,394\end{array}$ & $\begin{array}{r}697 \\
10,004 \\
0 \\
6,453 \\
0\end{array}$ & $\begin{array}{r}760 \\
16,450 \\
0 \\
6,916 \\
0\end{array}$ & $\begin{array}{r}-62 \\
-6.447 \\
0 \\
-462 \\
0\end{array}$ & $\begin{array}{r}681 \\
6,447 \\
-21,688 \\
-792 \\
-13,394\end{array}$ \\
\hline $\begin{array}{l}\text { Missouri ..................... } \\
\text { Montana................... } \\
\text { Nebraska ................. } \\
\text { Nevada ................. } \\
\text { New Hampshire ....... }\end{array}$ & $\begin{array}{r}2,911 \\
10,479 \\
6,952 \\
0 \\
0\end{array}$ & $\begin{array}{r}4,557 \\
32,537 \\
8,309 \\
0 \\
0\end{array}$ & $\begin{array}{r}-1,647 \\
-22,058 \\
-1,357 \\
0 \\
0\end{array}$ & $\begin{array}{r}0 \\
0 \\
210 \\
690 \\
0\end{array}$ & $\begin{array}{r}0 \\
0 \\
414 \\
491 \\
213\end{array}$ & $\begin{array}{r}0 \\
0 \\
-204 \\
205 \\
-213\end{array}$ & $\begin{array}{r}-1,647 \\
-22,058 \\
-1,561 \\
205 \\
-213\end{array}$ \\
\hline $\begin{array}{l}\text { New Jersey............... } \\
\text { New Mexico ............. } \\
\text { New York................ } \\
\text { North Carolina.......... } \\
\text { Ohio .......................... }\end{array}$ & $\begin{array}{r}0 \\
14,036 \\
53,490 \\
0 \\
132,898\end{array}$ & $\begin{array}{r}0 \\
17,774 \\
64,708 \\
0 \\
144,607\end{array}$ & $\begin{array}{r}0 \\
-3,739 \\
-11,218 \\
0 \\
-11,709\end{array}$ & $\begin{array}{r}1,433 \\
0 \\
564 \\
1,597 \\
0\end{array}$ & $\begin{array}{r}2,444 \\
0 \\
595 \\
2,803 \\
0\end{array}$ & $\begin{array}{r}-1,011 \\
0 \\
-31 \\
-1,205 \\
0\end{array}$ & $\begin{array}{r}-1,011 \\
-3,739 \\
-11,249 \\
-1,205 \\
-11,709\end{array}$ \\
\hline $\begin{array}{l}\text { Okdahoma ................. } \\
\text { Oregon.................... } \\
\text { Pennsylvania .......... } \\
\text { Rhode Island........... } \\
\text { South Carolina........ }\end{array}$ & $\begin{array}{r}98,370 \\
4,944 \\
572,180 \\
0 \\
0\end{array}$ & $\begin{array}{r}112,700 \\
2,223 \\
631,258 \\
0 \\
0\end{array}$ & $\begin{array}{r}-14,331 \\
2,721 \\
-59,078 \\
0 \\
0\end{array}$ & $\begin{array}{r}0 \\
940 \\
2,268 \\
164 \\
490\end{array}$ & $\begin{array}{r}0 \\
890 \\
4,242 \\
202 \\
547\end{array}$ & $\begin{array}{r}0 \\
49 \\
-1,974 \\
-38 \\
-57\end{array}$ & $\begin{array}{r}-14,331 \\
2,770 \\
-61,052 \\
-38 \\
-57\end{array}$ \\
\hline $\begin{array}{l}\text { Ternessee ................ } \\
\text { Texas ......................... } \\
\text { Utah ........................ } \\
\text { Virginia.................... } \\
\text { Washington.............. }\end{array}$ & $\begin{array}{r}0 \\
161,181 \\
16,885 \\
0 \\
12,921\end{array}$ & $\begin{array}{r}0 \\
177,116 \\
18,869 \\
0 \\
12,081\end{array}$ & $\begin{array}{r}0 \\
-15,935 \\
-1,984 \\
0 \\
840\end{array}$ & $\begin{array}{r}1,879 \\
0 \\
0 \\
2,167 \\
0\end{array}$ & $\begin{array}{r}3,757 \\
0 \\
0 \\
2,173 \\
0\end{array}$ & $\begin{array}{r}-1,879 \\
0 \\
0 \\
-6 \\
0\end{array}$ & $\begin{array}{r}-1,879 \\
-15,935 \\
-1,984 \\
-6 \\
840\end{array}$ \\
\hline 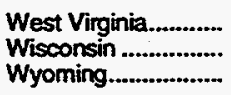 & $\begin{array}{r}115,421 \\
0 \\
12,546\end{array}$ & $\begin{array}{r}125,796 \\
0 \\
6,081\end{array}$ & $\begin{array}{r}-10,375 \\
0 \\
6,465\end{array}$ & $\begin{array}{r}0 \\
228 \\
0\end{array}$ & $\begin{array}{r}0 \\
174 \\
0\end{array}$ & $\begin{array}{r}0 \\
54 \\
0\end{array}$ & $\begin{array}{r}-10,375 \\
54 \\
6,465\end{array}$ \\
\hline 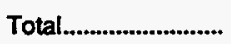 & $2,491,283$ & $2,803,787$ & $-312,505$ & 36,467 & 50,274 & $-13,807$ & $-326,312$ \\
\hline
\end{tabular}

See footnotes at end of table. 
Table 11. Changes in Natural Gas Storage by State, 1980-1994 (Continued) (Million Cubic Feet)

\begin{tabular}{|c|c|c|c|c|c|c|c|}
\hline \multirow{2}{*}{ State } & \multicolumn{3}{|c|}{$\begin{array}{l}\text { Underground } \\
\text { Storage }\end{array}$} & \multicolumn{3}{|c|}{ UNG Storege } & \multirow{2}{*}{$\begin{array}{l}\text { Net Change in } \\
\text { Storage }\end{array}$} \\
\hline & Injections & Writhdrewrals & Net & Additions & Withdramais & Not & \\
\hline \multicolumn{4}{|c|}{1990} & & & & \\
\hline 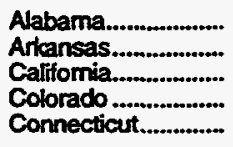 & $\begin{array}{r}0 \\
1,938 \\
147,074 \\
27,674 \\
0\end{array}$ & $\begin{array}{r}0 \\
472 \\
137,752 \\
31,174 \\
0\end{array}$ & $\begin{array}{r}0 \\
1,466 \\
9,322 \\
-3,500 \\
0\end{array}$ & $\begin{array}{r}893 \\
128 \\
14 \\
0 \\
1,696\end{array}$ & $\begin{array}{r}437 \\
23 \\
15 \\
0 \\
874\end{array}$ & $\begin{array}{r}456 \\
105 \\
0 \\
0 \\
822\end{array}$ & $\begin{array}{r}456 \\
1,572 \\
9,322 \\
3,500 \\
822\end{array}$ \\
\hline 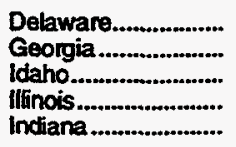 & $\begin{array}{r}0 \\
0 \\
0 \\
213,076 \\
23,054\end{array}$ & $\begin{array}{r}0 \\
0 \\
0 \\
197,150 \\
19,644\end{array}$ & $\begin{array}{r}0 \\
0 \\
0 \\
15,926 \\
3,410\end{array}$ & $\begin{array}{r}88 \\
2,779 \\
291 \\
883 \\
1,027\end{array}$ & $\begin{array}{r}81 \\
1.435 \\
268 \\
302 \\
796\end{array}$ & $\begin{array}{r}6 \\
1,345 \\
23 \\
580 \\
230\end{array}$ & $\begin{array}{r}6 \\
1,345 \\
23 \\
16,506 \\
3,641\end{array}$ \\
\hline $\begin{array}{l}\text { lowa .......................... } \\
\text { Kansas...................... } \\
\text { Kentucky .................. } \\
\text { Loutisiana ................. } \\
\text { Maine....................... }\end{array}$ & $\begin{array}{r}44,471 \\
108,143 \\
66,195 \\
200,183 \\
0\end{array}$ & $\begin{array}{r}47,770 \\
95,377 \\
45,078 \\
127,294 \\
0\end{array}$ & $\begin{array}{r}-3,299 \\
12,766 \\
21,117 \\
72,890 \\
0\end{array}$ & $\begin{array}{r}1,196 \\
0 \\
0 \\
27,903 \\
18\end{array}$ & $\begin{array}{r}655 \\
0 \\
0 \\
26,206 \\
22\end{array}$ & $\begin{array}{r}541 \\
0 \\
0 \\
1,697 \\
-4\end{array}$ & $\begin{array}{r}-2,758 \\
12,766 \\
21,117 \\
74,587 \\
-4\end{array}$ \\
\hline $\begin{array}{l}\text { Maryland.................. } \\
\text { Massachusetts........ } \\
\text { Michigan ................... } \\
\text { Minnesota .................. } \\
\text { Mississippi ................ }\end{array}$ & $\begin{array}{r}19,431 \\
0 \\
415,309 \\
1,256 \\
53,161\end{array}$ & $\begin{array}{r}14,074 \\
0 \\
314,461 \\
1,077 \\
33,655\end{array}$ & $\begin{array}{r}5,357 \\
0 \\
100,848 \\
179 \\
19,505\end{array}$ & $\begin{array}{r}769 \\
6,586 \\
0 \\
4,714 \\
0\end{array}$ & $\begin{array}{r}377 \\
6,279 \\
0 \\
4,670 \\
0\end{array}$ & $\begin{array}{r}392 \\
308 \\
0 \\
44 \\
0\end{array}$ & $\begin{array}{r}5,748 \\
308 \\
100,848 \\
223 \\
19,505\end{array}$ \\
\hline $\begin{array}{l}\text { Missouri .................... } \\
\text { Montana................... } \\
\text { Nebraska ................. } \\
\text { Nevada ..................... } \\
\text { New Jersey ............... }\end{array}$ & $\begin{array}{r}5,316 \\
14,648 \\
7,395 \\
0 \\
0\end{array}$ & $\begin{array}{r}3,992 \\
21,786 \\
9,772 \\
0 \\
0\end{array}$ & $\begin{array}{r}1,324 \\
-7,138 \\
-2,376 \\
0 \\
0\end{array}$ & $\begin{array}{r}0 \\
0 \\
493 \\
356 \\
3,740\end{array}$ & $\begin{array}{r}0 \\
0 \\
155 \\
904 \\
2,298\end{array}$ & $\begin{array}{r}0 \\
0 \\
339 \\
-548 \\
1,442\end{array}$ & $\begin{array}{r}1,324 \\
-7,138 \\
-2,038 \\
-548 \\
1,442\end{array}$ \\
\hline $\begin{array}{l}\text { New Mexico .............. } \\
\text { New York................. } \\
\text { Noth Carolina......... } \\
\text { Ohio ......................... } \\
\text { Oktahoma ................. }\end{array}$ & $\begin{array}{r}22,352 \\
63,690 \\
0 \\
154,452 \\
95,274\end{array}$ & $\begin{array}{r}13,126 \\
49,842 \\
0 \\
119,117 \\
80,976\end{array}$ & $\begin{array}{r}9,226 \\
13,848 \\
0 \\
35,334 \\
14,298\end{array}$ & $\begin{array}{r}0 \\
1,205 \\
2,023 \\
0 \\
0\end{array}$ & $\begin{array}{r}0 \\
303 \\
578 \\
0 \\
0\end{array}$ & $\begin{array}{r}0 \\
902 \\
1,445 \\
0 \\
0\end{array}$ & $\begin{array}{r}9,226 \\
14,749 \\
1,445 \\
35,334 \\
14,298\end{array}$ \\
\hline $\begin{array}{l}\text { Oregon..................... } \\
\text { Pennsylvania ........... } \\
\text { Rhode Island.......... } \\
\text { South Carolina ......... } \\
\text { Tennessee. ............... }\end{array}$ & $\begin{array}{r}5,894 \\
388,569 \\
0 \\
0 \\
0\end{array}$ & $\begin{array}{r}4,531 \\
287,053 \\
0 \\
0 \\
0\end{array}$ & $\begin{array}{r}1,363 \\
101,516 \\
0 \\
0 \\
0\end{array}$ & $\begin{array}{r}754 \\
4,311 \\
142 \\
394 \\
3,008\end{array}$ & $\begin{array}{r}1,003 \\
1,679 \\
188 \\
247 \\
2,377\end{array}$ & $\begin{array}{r}-249 \\
2,632 \\
-46 \\
147 \\
631\end{array}$ & $\begin{array}{r}1,114 \\
104,147 \\
-46 \\
147 \\
631\end{array}$ \\
\hline $\begin{array}{l}\text { Texas ...................... } \\
\text { Uhah ......................... } \\
\text { Virginia................. } \\
\text { Washington............. } \\
\text { West Virginia............ }\end{array}$ & $\begin{array}{r}175,039 \\
27,196 \\
0 \\
14,296 \\
126,217\end{array}$ & $\begin{array}{r}150,250 \\
22,000 \\
0 \\
15,622 \\
82,558\end{array}$ & $\begin{array}{r}24,789 \\
5,196 \\
0 \\
-1,325 \\
43,659\end{array}$ & $\begin{array}{r}0 \\
0 \\
190 \\
96 \\
0\end{array}$ & $\begin{array}{r}0 \\
0 \\
142 \\
104 \\
0\end{array}$ & $\begin{array}{r}0 \\
0 \\
48 \\
-8 \\
0\end{array}$ & $\begin{array}{r}24,789 \\
5,196 \\
48 \\
-1,334 \\
43,659\end{array}$ \\
\hline $\begin{array}{l}\text { Wiscorsin ................. } \\
\text { Wyoming............... }\end{array}$ & $\begin{array}{r}0 \\
12,146\end{array}$ & $\begin{array}{r}0 \\
8,183\end{array}$ & $\begin{array}{r}0 \\
3,962\end{array}$ & $\begin{array}{r}116 \\
0\end{array}$ & $\begin{array}{r}126 \\
0\end{array}$ & $\begin{array}{r}-10 \\
0\end{array}$ & $\begin{array}{r}-10 \\
3,962\end{array}$ \\
\hline \multirow[t]{2}{*}{ Total............................... } & $2,433,450$ & $1,933,786$ & 499,663 & 65,814 & 52,544 & 13,271 & 512,934 \\
\hline & \multicolumn{7}{|c|}{1991} \\
\hline $\begin{array}{l}\text { Alabama................... } \\
\text { Arkansas.................. } \\
\text { Califormia................. } \\
\text { Cobrado................... } \\
\text { Connecticut.............. }\end{array}$ & $\begin{array}{r}0 \\
1,044 \\
136,433 \\
30,584 \\
0\end{array}$ & $\begin{array}{r}0 \\
3,010 \\
124,156 \\
23,214 \\
0\end{array}$ & $\begin{array}{r}0 \\
-1,966 \\
12,276 \\
7,370 \\
0\end{array}$ & $\begin{array}{r}511 \\
38 \\
50 \\
0 \\
1,010\end{array}$ & $\begin{array}{r}530 \\
49 \\
19 \\
0 \\
1,112\end{array}$ & $\begin{array}{r}-19 \\
-11 \\
32 \\
0 \\
-103\end{array}$ & $\begin{array}{r}-19 \\
-1,976 \\
12,308 \\
7,370 \\
-103\end{array}$ \\
\hline 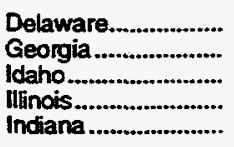 & $\begin{array}{r}0 \\
0 \\
0 \\
212,232 \\
23,654\end{array}$ & $\begin{array}{r}0 \\
0 \\
0 \\
213,210 \\
24,580\end{array}$ & $\begin{array}{r}0 \\
0 \\
0 \\
-978 \\
-926\end{array}$ & $\begin{array}{r}79 \\
1,969 \\
340 \\
115 \\
1,517\end{array}$ & $\begin{array}{r}72 \\
1.579 \\
227 \\
344 \\
922\end{array}$ & $\begin{array}{r}7 \\
390 \\
113 \\
-229 \\
595\end{array}$ & $\begin{array}{r}7 \\
390 \\
113 \\
-1,207 \\
-331\end{array}$ \\
\hline lowa & 57,278 & 62,486 & $-5,207$ & 2,012 & 669 & 1,343 & $-3,864$ \\
\hline
\end{tabular}

See footnotes at end of table. 
Table 11. Changes in Natural Gas Storage by State,-1980-1994 (Continued) (Million Cubic Feet)

\begin{tabular}{|c|c|c|c|c|c|c|c|}
\hline \multirow{2}{*}{ State } & \multicolumn{3}{|c|}{$\begin{array}{l}\text { Underground } \\
\text { Storege }\end{array}$} & \multicolumn{3}{|c|}{ LNG Storage" } & \multirow{2}{*}{$\begin{array}{l}\text { Net Change in } \\
\text { Storage }\end{array}$} \\
\hline & Injections & Writhdramels & Not & Additions & Withdrewais & Net & \\
\hline & \multicolumn{7}{|c|}{1991} \\
\hline 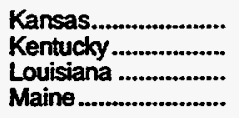 & $\begin{array}{r}109,627 \\
47,425 \\
178,002 \\
0\end{array}$ & $\begin{array}{r}98,805 \\
48,822 \\
202,991 \\
0\end{array}$ & $\begin{array}{r}10,822 \\
-1,397 \\
-24,989 \\
0\end{array}$ & $\begin{array}{r}0 \\
0 \\
33,284 \\
25\end{array}$ & $\begin{array}{r}0 \\
0 \\
32,726 \\
23\end{array}$ & $\begin{array}{r}0 \\
0 \\
558 \\
1\end{array}$ & $\begin{array}{r}10,822 \\
-1,397 \\
-24,432 \\
1\end{array}$ \\
\hline $\begin{array}{l}\text { Maryland .................. } \\
\text { Massachusetts....... } \\
\text { Michigan ................... } \\
\text { Minnesota .............. } \\
\text { Mississippi .............. }\end{array}$ & $\begin{array}{r}22,508 \\
0 \\
354,996 \\
1,285 \\
48,054\end{array}$ & $\begin{array}{r}20,656 \\
0 \\
394,196 \\
1,018 \\
53,938\end{array}$ & $\begin{array}{r}1,852 \\
0 \\
-39,200 \\
257 \\
-5,884\end{array}$ & $\begin{array}{r}657 \\
4,399 \\
0 \\
5,974 \\
0\end{array}$ & $\begin{array}{r}531 \\
8,366 \\
0 \\
6,044 \\
0\end{array}$ & $\begin{array}{r}126 \\
-3,967 \\
0 \\
-70 \\
0\end{array}$ & $\begin{array}{r}1,978 \\
-3,967 \\
-39,200 \\
197 \\
-5,884\end{array}$ \\
\hline $\begin{array}{l}\text { Missouri ..................... } \\
\text { Montana................. } \\
\text { Nebraska ................. } \\
\text { Nevada ................... } \\
\text { New Jersey.............. }\end{array}$ & $\begin{array}{r}4,972 \\
12,392 \\
8,916 \\
0 \\
0\end{array}$ & $\begin{array}{r}3,855 \\
22,129 \\
8,687 \\
0 \\
0\end{array}$ & $\begin{array}{r}1,117 \\
-9,737 \\
229 \\
0 \\
0\end{array}$ & $\begin{array}{r}0 \\
0 \\
92 \\
767 \\
2,683\end{array}$ & $\begin{array}{r}0 \\
0 \\
211 \\
39 \\
2,221\end{array}$ & $\begin{array}{r}0 \\
0 \\
-119 \\
728 \\
461\end{array}$ & $\begin{array}{r}1,117 \\
-9,737 \\
110 \\
728 \\
461\end{array}$ \\
\hline $\begin{array}{l}\text { New Mexico .............. } \\
\text { New York ................... } \\
\text { North Carolina........ } \\
\text { Ohio........................... } \\
\text { Oklahoma ............... }\end{array}$ & $\begin{array}{r}21,563 \\
63,411 \\
0 \\
134,060 \\
94,221\end{array}$ & $\begin{array}{r}17,868 \\
51,792 \\
0 \\
133,629 \\
106,360\end{array}$ & $\begin{array}{r}3,694 \\
11,619 \\
0 \\
431 \\
-12,139\end{array}$ & $\begin{array}{r}0 \\
559 \\
1,219 \\
0 \\
0\end{array}$ & $\begin{array}{r}0 \\
309 \\
1,232 \\
0 \\
0\end{array}$ & $\begin{array}{r}0 \\
250 \\
-13 \\
0 \\
0\end{array}$ & $\begin{array}{r}3,694 \\
11,869 \\
-13 \\
431 \\
-12,139\end{array}$ \\
\hline $\begin{array}{l}\text { Oregon } \\
\text { Pennsylvania ............... } \\
\text { Rhode Island............ } \\
\text { South Carolina......... } \\
\text { South Dakota........... }\end{array}$ & $\begin{array}{r}5,853 \\
707,371 \\
0 \\
0 \\
0\end{array}$ & $\begin{array}{r}5,288 \\
718,706 \\
0 \\
0 \\
0\end{array}$ & $\begin{array}{r}566 \\
-11,335 \\
0 \\
0 \\
0\end{array}$ & $\begin{array}{r}609 \\
2,390 \\
749 \\
346 \\
0\end{array}$ & $\begin{array}{r}389 \\
2,412 \\
355 \\
396 \\
15\end{array}$ & $\begin{array}{l}220 \\
-22 \\
393 \\
-50 \\
-15\end{array}$ & $\begin{array}{r}786 \\
-11,357 \\
393 \\
-50 \\
-15\end{array}$ \\
\hline $\begin{array}{l}\text { Tennessee ................. } \\
\text { Texas ........................ } \\
\text { Utah....................... } \\
\text { Virginia...................... } \\
\text { Washington.............. }\end{array}$ & $\begin{array}{r}0 \\
170,908 \\
32,248 \\
0 \\
14,214\end{array}$ & $\begin{array}{r}0 \\
164,510 \\
42,224 \\
0 \\
11,013\end{array}$ & $\begin{array}{r}0 \\
6,398 \\
-9,976 \\
0 \\
3,200\end{array}$ & $\begin{array}{r}1,522 \\
0 \\
0 \\
173 \\
2\end{array}$ & $\begin{array}{r}1,923 \\
0 \\
0 \\
243 \\
0\end{array}$ & $\begin{array}{r}-401 \\
0 \\
0 \\
-71 \\
2\end{array}$ & $\begin{array}{r}-401 \\
6,398 \\
-9,976 \\
-71 \\
3,203\end{array}$ \\
\hline $\begin{array}{l}\text { West Virginia............ } \\
\text { Wisconsin ................ } \\
\text { Wyoming.................. }\end{array}$ & $\begin{array}{r}104,251 \\
0 \\
10,872\end{array}$ & $\begin{array}{r}121,139 \\
0 \\
10,446\end{array}$ & $\begin{array}{r}-16,888 \\
0 \\
426\end{array}$ & $\begin{array}{r}0 \\
167 \\
0\end{array}$ & $\begin{array}{r}0 \\
131 \\
0\end{array}$ & $\begin{array}{r}0 \\
35 \\
0\end{array}$ & $\begin{array}{r}-16,888 \\
35 \\
426\end{array}$ \\
\hline \multirow[t]{2}{*}{ 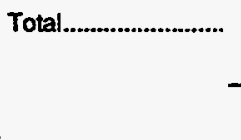 } & $2,608,373$ & $2,688,728$ & $-80,355$ & 63,259 & 63,090 & 169 & $-80,186$ \\
\hline & \multicolumn{7}{|c|}{1992} \\
\hline $\begin{array}{l}\text { Alabama................... } \\
\text { Arkansas.................... } \\
\text { California................. } \\
\text { Colorado .................. } \\
\text { Connecticut.............. }\end{array}$ & $\begin{array}{r}0 \\
2,461 \\
148,039 \\
23,061 \\
0\end{array}$ & $\begin{array}{r}0 \\
2,975 \\
176,158 \\
27,921 \\
0\end{array}$ & $\begin{array}{r}0 \\
-514 \\
-28,120 \\
-4,860 \\
0\end{array}$ & $\begin{array}{r}501 \\
50 \\
13 \\
0 \\
359\end{array}$ & $\begin{array}{r}262 \\
51 \\
51 \\
0 \\
714\end{array}$ & $\begin{array}{r}239 \\
-1 \\
-38 \\
0 \\
-355\end{array}$ & $\begin{array}{r}239 \\
-515 \\
-28,158 \\
-4,860 \\
-355\end{array}$ \\
\hline 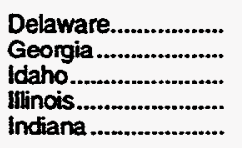 & $\begin{array}{r}0 \\
0 \\
0 \\
214,404 \\
25,770\end{array}$ & $\begin{array}{r}0 \\
0 \\
0 \\
223,012 \\
26,611\end{array}$ & $\begin{array}{r}0 \\
0 \\
0 \\
-8,608 \\
-840\end{array}$ & $\begin{array}{r}61 \\
1,573 \\
1,338 \\
570 \\
849\end{array}$ & $\begin{array}{r}66 \\
1,557 \\
1,385 \\
348 \\
1,188\end{array}$ & $\begin{array}{r}-5 \\
16 \\
-47 \\
222 \\
-339\end{array}$ & $\begin{array}{r}-5 \\
16 \\
-47 \\
-8,387 \\
-1,179\end{array}$ \\
\hline $\begin{array}{l}\text { lowa ........................ } \\
\text { Kansas....................... } \\
\text { Kentucky................. } \\
\text { Louisiana .................. } \\
\text { Maine........................ }\end{array}$ & $\begin{array}{r}65,818 \\
84,249 \\
49,367 \\
193,051 \\
0\end{array}$ & $\begin{array}{r}70,077 \\
102,735 \\
42,795 \\
207,010 \\
0\end{array}$ & $\begin{array}{r}-4,259 \\
-18,486 \\
6,573 \\
-13,958 \\
0\end{array}$ & $\begin{array}{r}4,659 \\
0 \\
0 \\
12,545 \\
26\end{array}$ & $\begin{array}{r}4,247 \\
0 \\
0 \\
12,097 \\
22\end{array}$ & $\begin{array}{r}412 \\
0 \\
0 \\
448 \\
4\end{array}$ & $\begin{array}{r}-3,846 \\
-18,486 \\
6,573 \\
-13,511 \\
4\end{array}$ \\
\hline $\begin{array}{l}\text { Maryland ................... } \\
\text { Massachusetts......... } \\
\text { Michigan ................... } \\
\text { Minnesota ............... } \\
\text { Mississippi ............... }\end{array}$ & $\begin{array}{r}19,502 \\
0 \\
390,465 \\
1,372 \\
55,105\end{array}$ & $\begin{array}{r}19,169 \\
0 \\
392,716 \\
1,329 \\
53,373\end{array}$ & $\begin{array}{r}333 \\
0 \\
-2,251 \\
43 \\
1,732\end{array}$ & $\begin{array}{r}804 \\
5,147 \\
0 \\
3,594 \\
0\end{array}$ & $\begin{array}{r}715 \\
6,990 \\
0 \\
3,380 \\
0\end{array}$ & $\begin{array}{r}89 \\
-1,844 \\
0 \\
213 \\
0\end{array}$ & $\begin{array}{r}422 \\
-1,844 \\
-2,251 \\
256 \\
1,732\end{array}$ \\
\hline $\begin{array}{l}\text { Missouri ................... } \\
\text { Montana ................... } \\
\text { Nebraska ................ }\end{array}$ & $\begin{array}{r}3,080 \\
11,708 \\
10,254\end{array}$ & $\begin{array}{r}3,094 \\
24,310 \\
9,848\end{array}$ & $\begin{array}{r}-15 \\
-12,602 \\
407\end{array}$ & $\begin{array}{r}0 \\
0 \\
283\end{array}$ & $\begin{array}{r}0 \\
0 \\
173\end{array}$ & $\begin{array}{r}0 \\
0 \\
111\end{array}$ & $\begin{array}{r}-15 \\
-12,602 \\
517\end{array}$ \\
\hline
\end{tabular}

See footnotes at end of table. 
Table 11. Changes in Natural Gas Storage by State, 1980-1994 (Continued) (Million Cubic Feet)

\begin{tabular}{|c|c|c|c|c|c|c|c|}
\hline \multirow{2}{*}{ State } & \multicolumn{3}{|c|}{$\begin{array}{l}\text { Underground } \\
\text { Storege }\end{array}$} & \multicolumn{3}{|c|}{ UNG Storage } & \multirow{2}{*}{$\begin{array}{l}\text { Net Changs in } \\
\text { Storage }\end{array}$} \\
\hline & Injections & Withdramals & Net & Addritions & Withdrwwals & Not & \\
\hline & \multicolumn{7}{|c|}{1992} \\
\hline $\begin{array}{l}\text { Nevada ...................... } \\
\text { New Jersey.............. }\end{array}$ & $\begin{array}{l}0 \\
0\end{array}$ & $\begin{array}{l}0 \\
0\end{array}$ & $\begin{array}{l}0 \\
0\end{array}$ & $\begin{array}{r}83 \\
2,422\end{array}$ & $\begin{array}{r}155 \\
2,471\end{array}$ & $\begin{array}{l}-71 \\
-49\end{array}$ & $\begin{array}{l}-71 \\
-49\end{array}$ \\
\hline $\begin{array}{l}\text { New Mexico .............. } \\
\text { New York............... } \\
\text { North Carolina.......... } \\
\text { Ohio ......................... } \\
\text { Oktahoma ................ }\end{array}$ & $\begin{array}{r}18,963 \\
62,265 \\
0 \\
160,009 \\
97,468\end{array}$ & $\begin{array}{r}21,421 \\
60,693 \\
0 \\
175,682 \\
107,526\end{array}$ & $\begin{array}{r}-2,458 \\
1,572 \\
0 \\
-15,672 \\
-10,058\end{array}$ & $\begin{array}{r}0 \\
732 \\
1,030 \\
0 \\
0\end{array}$ & $\begin{array}{r}2,599 \\
363 \\
1,122 \\
0 \\
0\end{array}$ & $\begin{array}{r}-2,599 \\
370 \\
-92 \\
0 \\
0\end{array}$ & $\begin{array}{r}-5,057 \\
1,942 \\
-92 \\
-15,672 \\
-10,058\end{array}$ \\
\hline $\begin{array}{l}\text { Oregon..................... } \\
\text { Pennsyivania .......... } \\
\text { Rhode Island........... } \\
\text { South Carolina........ } \\
\text { South Dakota........... }\end{array}$ & $\begin{array}{r}6,114 \\
383,762 \\
0 \\
0 \\
0\end{array}$ & $\begin{array}{r}6,985 \\
377,889 \\
0 \\
0 \\
0\end{array}$ & $\begin{array}{r}-872 \\
5,873 \\
0 \\
0 \\
0\end{array}$ & $\begin{array}{r}376 \\
2,869 \\
796 \\
339 \\
24\end{array}$ & $\begin{array}{r}409 \\
2,797 \\
1,216 \\
323 \\
13\end{array}$ & $\begin{array}{r}-33 \\
72 \\
-420 \\
16 \\
11\end{array}$ & $\begin{array}{r}-904 \\
5,945 \\
-420 \\
16 \\
11\end{array}$ \\
\hline 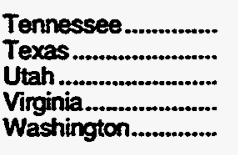 & $\begin{array}{r}0 \\
340,602 \\
31,222 \\
0 \\
13,294\end{array}$ & $\begin{array}{r}0 \\
384,042 \\
26,740 \\
0 \\
18,960\end{array}$ & $\begin{array}{r}0 \\
-43,441 \\
4,482 \\
0 \\
-5,667\end{array}$ & $\begin{array}{r}2,759 \\
0 \\
0 \\
173 \\
0\end{array}$ & $\begin{array}{r}3,065 \\
0 \\
0 \\
168 \\
471\end{array}$ & $\begin{array}{r}-306 \\
0 \\
0 \\
6 \\
-471\end{array}$ & $\begin{array}{r}-306 \\
-43,441 \\
4,482 \\
6 \\
-6,137\end{array}$ \\
\hline $\begin{array}{l}\text { West Virginia............. } \\
\text { Wisconsin .................. } \\
\text { Wyoming................. }\end{array}$ & $\begin{array}{r}138,647 \\
0 \\
5,340\end{array}$ & $\begin{array}{r}146,827 \\
0 \\
13,876\end{array}$ & $\begin{array}{r}-8,180 \\
0 \\
-8,536\end{array}$ & $\begin{array}{r}0 \\
57 \\
0\end{array}$ & $\begin{array}{r}0 \\
117 \\
0\end{array}$ & $\begin{array}{r}0 \\
-59 \\
0\end{array}$ & $\begin{array}{r}-8,180 \\
-59 \\
-8,536\end{array}$ \\
\hline \multirow[t]{2}{*}{ Total.......................... } & $2,555,393$ & $2,723,774$ & $-168,381$ & 44,033 & 48,534 & $-4,501$ & $-172,882$ \\
\hline & \multicolumn{7}{|c|}{1993} \\
\hline 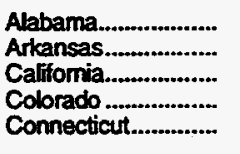 & $\begin{array}{r}0 \\
272 \\
155,135 \\
51,132 \\
0\end{array}$ & $\begin{array}{r}0 \\
8,481 \\
135,442 \\
54,294 \\
0\end{array}$ & $\begin{array}{r}0 \\
-8,208 \\
19,693 \\
-3,162 \\
0\end{array}$ & $\begin{array}{r}612 \\
53 \\
13 \\
0 \\
610\end{array}$ & $\begin{array}{r}396 \\
44 \\
37 \\
0 \\
640\end{array}$ & $\begin{array}{r}215 \\
9 \\
-24 \\
0 \\
-29\end{array}$ & $\begin{array}{r}215 \\
-8,199 \\
19,668 \\
-3,162 \\
-29\end{array}$ \\
\hline 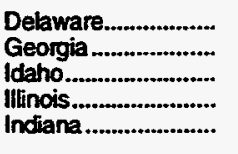 & $\begin{array}{r}0 \\
0 \\
0 \\
240,515 \\
25,928\end{array}$ & $\begin{array}{r}0 \\
0 \\
0 \\
228,319 \\
25,332\end{array}$ & $\begin{array}{r}0 \\
0 \\
0 \\
12,196 \\
596\end{array}$ & $\begin{array}{r}99 \\
1,855 \\
1,389 \\
417 \\
2,320\end{array}$ & $\begin{array}{r}95 \\
1,896 \\
1,339 \\
448 \\
1,582\end{array}$ & $\begin{array}{r}3 \\
-42 \\
51 \\
-31 \\
738\end{array}$ & $\begin{array}{r}3 \\
-42 \\
51 \\
12,165 \\
1,334\end{array}$ \\
\hline 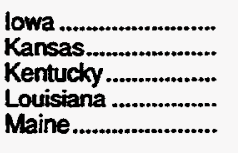 & $\begin{array}{r}64,184 \\
116,284 \\
48,117 \\
229,568 \\
0\end{array}$ & $\begin{array}{r}61,007 \\
109,475 \\
59,742 \\
221,931 \\
0\end{array}$ & $\begin{array}{r}3,176 \\
6,809 \\
-11,625 \\
7,638 \\
0\end{array}$ & $\begin{array}{r}5,671 \\
0 \\
0 \\
30,677 \\
16\end{array}$ & $\begin{array}{r}5,597 \\
0 \\
0 \\
32,033 \\
19\end{array}$ & $\begin{array}{r}75 \\
0 \\
0 \\
-1,356 \\
-2\end{array}$ & $\begin{array}{r}3,251 \\
6,809 \\
-11,625 \\
6,282 \\
-2\end{array}$ \\
\hline $\begin{array}{l}\text { Maryland................... } \\
\text { Massachusetts........ } \\
\text { Michigan ................... } \\
\text { Minnesota ................. } \\
\text { Mississippi ................ }\end{array}$ & $\begin{array}{r}15,314 \\
0 \\
476,312 \\
1,762 \\
55,903\end{array}$ & $\begin{array}{r}20,420 \\
0 \\
437,280 \\
1,834 \\
55,786\end{array}$ & $\begin{array}{r}-5,106 \\
0 \\
39,033 \\
-72 \\
117\end{array}$ & $\begin{array}{r}696 \\
5,531 \\
0 \\
6,330 \\
0\end{array}$ & $\begin{array}{r}610 \\
7,900 \\
0 \\
5,864 \\
0\end{array}$ & $\begin{array}{r}85 \\
-2,368 \\
0 \\
466 \\
0\end{array}$ & $\begin{array}{r}-5,021 \\
-2,368 \\
39,033 \\
394 \\
117\end{array}$ \\
\hline $\begin{array}{l}\text { Missouri ...................... } \\
\text { Montana.................. } \\
\text { Nebraska .................. } \\
\text { Nevada ................... } \\
\text { New Jersey ............... }\end{array}$ & $\begin{array}{r}4,711 \\
10,894 \\
14,485 \\
0 \\
0\end{array}$ & $\begin{array}{r}4,779 \\
32,202 \\
11,718 \\
0 \\
0\end{array}$ & $\begin{array}{r}-68 \\
-21,308 \\
2,767 \\
0 \\
0\end{array}$ & $\begin{array}{r}0 \\
0 \\
287 \\
253 \\
2,620\end{array}$ & $\begin{array}{r}0 \\
0 \\
222 \\
244 \\
2,313\end{array}$ & $\begin{array}{r}0 \\
0 \\
65 \\
9 \\
307\end{array}$ & $\begin{array}{r}-68 \\
-21,308 \\
2,832 \\
9 \\
307\end{array}$ \\
\hline $\begin{array}{l}\text { New Mexico .............. } \\
\text { New York.............. } \\
\text { North Carolina......... } \\
\text { Ohio ......................... } \\
\text { Oktahoma ............... }\end{array}$ & $\begin{array}{r}16,369 \\
68,532 \\
0 \\
175,630 \\
151,249\end{array}$ & $\begin{array}{r}24,794 \\
67,643 \\
0 \\
188,899 \\
136,715\end{array}$ & $\begin{array}{r}-8,426 \\
889 \\
0 \\
-13,269 \\
14,535\end{array}$ & $\begin{array}{r}0 \\
810 \\
1,681 \\
0 \\
0\end{array}$ & $\begin{array}{r}0 \\
440 \\
1,823 \\
0 \\
0\end{array}$ & $\begin{array}{r}0 \\
371 \\
-142 \\
0 \\
0\end{array}$ & $\begin{array}{r}-8,426 \\
1,259 \\
-142 \\
-13,269 \\
14,535\end{array}$ \\
\hline $\begin{array}{l}\text { Oregon..................... } \\
\text { Pennsylvania ........... } \\
\text { Rhode Island........... } \\
\text { South Carolina ......... } \\
\text { Tennessee................ }\end{array}$ & $\begin{array}{r}6,202 \\
381,711 \\
0 \\
0 \\
0\end{array}$ & $\begin{array}{r}6,302 \\
381,060 \\
0 \\
0 \\
0\end{array}$ & $\begin{array}{r}-100 \\
650 \\
0 \\
0 \\
0\end{array}$ & $\begin{array}{r}1,137 \\
4,329 \\
462 \\
1,231 \\
2,663\end{array}$ & $\begin{array}{r}1,360 \\
4,534 \\
800 \\
752 \\
2,931\end{array}$ & $\begin{array}{l}-222 \\
-204 \\
-337 \\
478 \\
-268\end{array}$ & $\begin{array}{r}-323 \\
446 \\
-337 \\
478 \\
-268\end{array}$ \\
\hline
\end{tabular}

See footnotes at end of table. 
Table 11. Changes in Natural Gas Storage by State, 1980-1994 (Continued) (Million Cubic Feet)

\begin{tabular}{|c|c|c|c|c|c|c|c|}
\hline \multirow{2}{*}{ State } & \multicolumn{3}{|c|}{$\begin{array}{l}\text { Undarground } \\
\text { Storage }\end{array}$} & \multicolumn{3}{|c|}{ LNG Storage } & \multirow{2}{*}{$\begin{array}{l}\text { Net Change in } \\
\text { Storage }\end{array}$} \\
\hline & Injections & Whindrewals & Net & Additions & Withdrawals & Net & \\
\hline & \multicolumn{7}{|c|}{1993} \\
\hline 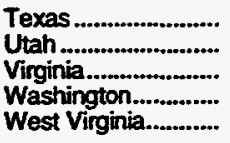 & $\begin{array}{r}221,412 \\
34,488 \\
0 \\
19,575 \\
160,450\end{array}$ & $\begin{array}{r}232,070 \\
27,216 \\
0 \\
17,661 \\
151,836\end{array}$ & $\begin{array}{r}-10,658 \\
7,271 \\
0 \\
1,915 \\
8,614\end{array}$ & $\begin{array}{r}0 \\
0 \\
173 \\
3,167 \\
0\end{array}$ & $\begin{array}{r}0 \\
0 \\
274 \\
7,886 \\
0\end{array}$ & $\begin{array}{r}0 \\
0 \\
-102 \\
-4,718 \\
0\end{array}$ & $\begin{array}{r}-10,658 \\
7,271 \\
-102 \\
-2,804 \\
8,614\end{array}$ \\
\hline 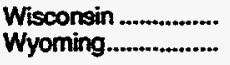 & 13,605 & $\begin{array}{r}0 \\
14,826\end{array}$ & $\begin{array}{r}0 \\
-1,221\end{array}$ & $\begin{array}{r}112 \\
0\end{array}$ & $\begin{array}{r}110 \\
0\end{array}$ & $\begin{array}{l}2 \\
0\end{array}$ & $-1,221$ \\
\hline \multirow[t]{2}{*}{ Total............................ } & $2,759,738$ & $2,717,064$ & 42,674 & 75,217 & 82,189 & $-6,972$ & 35,701 \\
\hline & \multicolumn{7}{|c|}{1994} \\
\hline $\begin{array}{l}\text { Alabama................... } \\
\text { Arkansas.................... } \\
\text { Califomia.................. } \\
\text { Colorado ................... } \\
\text { Connecticut.............. }\end{array}$ & $\begin{array}{r}694 \\
3,249 \\
155,910 \\
31,185 \\
0\end{array}$ & $\begin{array}{r}55 \\
5,731 \\
150,844 \\
30,085 \\
0\end{array}$ & $\begin{array}{r}639 \\
-2,482 \\
5,066 \\
1,100 \\
0\end{array}$ & $\begin{array}{r}944 \\
73 \\
13 \\
0 \\
1,435\end{array}$ & $\begin{array}{r}497 \\
68 \\
94 \\
0 \\
1,497\end{array}$ & $\begin{array}{r}448 \\
5 \\
-80 \\
0 \\
-61\end{array}$ & $\begin{array}{r}1,087 \\
-2,478 \\
4,985 \\
1,100 \\
-61\end{array}$ \\
\hline 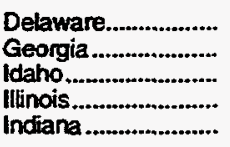 & $\begin{array}{r}0 \\
0 \\
0 \\
235,778 \\
24,656\end{array}$ & $\begin{array}{r}0 \\
0 \\
0 \\
222,871 \\
21,081\end{array}$ & $\begin{array}{r}0 \\
0 \\
0 \\
12,907 \\
3,576\end{array}$ & $\begin{array}{r}225 \\
3,788 \\
554 \\
1,326 \\
2,638\end{array}$ & $\begin{array}{r}202 \\
3,881 \\
373 \\
1,317 \\
2,733\end{array}$ & $\begin{array}{r}23 \\
-94 \\
182 \\
9 \\
-95\end{array}$ & $\begin{array}{r}23 \\
-94 \\
182 \\
12,916 \\
3,481\end{array}$ \\
\hline 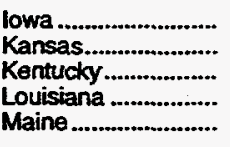 & $\begin{array}{r}70,926 \\
106,069 \\
59,831 \\
224,525 \\
0\end{array}$ & $\begin{array}{r}68,162 \\
99,854 \\
54,986 \\
184,731 \\
0\end{array}$ & $\begin{array}{r}2,764 \\
6,215 \\
4,845 \\
39,794 \\
0\end{array}$ & $\begin{array}{r}3,867 \\
0 \\
0 \\
17,823 \\
27\end{array}$ & $\begin{array}{r}3,521 \\
0 \\
0 \\
18,252 \\
22\end{array}$ & $\begin{array}{r}346 \\
0 \\
0 \\
-429 \\
5\end{array}$ & $\begin{array}{r}3,109 \\
6,215 \\
4,845 \\
39,364 \\
5\end{array}$ \\
\hline $\begin{array}{l}\text { Maryland.................. } \\
\text { Massachusetts........ } \\
\text { Michigan .................. } \\
\text { Minnesota ................. } \\
\text { Mississippi .............. }\end{array}$ & $\begin{array}{r}15,316 \\
0 \\
470,220 \\
1,556 \\
64,972\end{array}$ & $\begin{array}{r}17,406 \\
0 \\
389,224 \\
1,192 \\
50,526\end{array}$ & $\begin{array}{r}-2,090 \\
0 \\
80,996 \\
365 \\
14,446\end{array}$ & $\begin{array}{r}939 \\
5,550 \\
0 \\
6,167 \\
0\end{array}$ & $\begin{array}{r}529 \\
12,369 \\
0 \\
5,537 \\
0\end{array}$ & $\begin{array}{r}410 \\
-6,820 \\
0 \\
630 \\
0\end{array}$ & $\begin{array}{r}-1,680 \\
-6,820 \\
80,996 \\
994 \\
14,446\end{array}$ \\
\hline $\begin{array}{l}\text { Missouri .................... } \\
\text { Montana.................. } \\
\text { Nebraska .................. } \\
\text { Nevada ...................... } \\
\text { New Jersey .............. }\end{array}$ & $\begin{array}{r}4,997 \\
14,690 \\
12,524 \\
0 \\
0\end{array}$ & $\begin{array}{r}5,082 \\
22,509 \\
10,052 \\
0 \\
0\end{array}$ & $\begin{array}{r}-85 \\
-7,819 \\
2,471 \\
0 \\
0\end{array}$ & $\begin{array}{r}0 \\
0 \\
393 \\
241 \\
4,835\end{array}$ & $\begin{array}{r}0 \\
0 \\
367 \\
271 \\
3,565\end{array}$ & $\begin{array}{r}0 \\
0 \\
26 \\
-30 \\
1,270\end{array}$ & $\begin{array}{r}-85 \\
-7,819 \\
2,497 \\
-30 \\
1,270\end{array}$ \\
\hline $\begin{array}{l}\text { New Mexico .............. } \\
\text { New York............... } \\
\text { North Carolina......... } \\
\text { Ohio ............................ } \\
\text { Okdahoma ................ }\end{array}$ & $\begin{array}{r}18,551 \\
66,627 \\
0 \\
191,660 \\
123,576\end{array}$ & $\begin{array}{r}17,172 \\
64,803 \\
0 \\
163,084 \\
104,738\end{array}$ & $\begin{array}{r}1,379 \\
1,824 \\
0 \\
28,576 \\
18,838\end{array}$ & $\begin{array}{r}0 \\
1,125 \\
2,118 \\
0 \\
0\end{array}$ & $\begin{array}{r}0 \\
835 \\
1.802 \\
0 \\
0\end{array}$ & $\begin{array}{r}0 \\
290 \\
316 \\
0 \\
0\end{array}$ & $\begin{array}{r}1,379 \\
2,115 \\
316 \\
28,576 \\
18,838\end{array}$ \\
\hline $\begin{array}{l}\text { Oregon ................... } \\
\text { Pennsylvania .......... } \\
\text { Rhode Island............ } \\
\text { South Carotina......... } \\
\text { Tennessee................ }\end{array}$ & $\begin{array}{r}5,956 \\
339,512 \\
0 \\
0 \\
0\end{array}$ & $\begin{array}{r}5,237 \\
340,334 \\
0 \\
0 \\
0\end{array}$ & $\begin{array}{r}720 \\
-823 \\
0 \\
0 \\
0\end{array}$ & $\begin{array}{r}860 \\
5,826 \\
1,156 \\
847 \\
2,985\end{array}$ & $\begin{array}{r}1,117 \\
5,030 \\
996 \\
682 \\
2,879\end{array}$ & $\begin{array}{r}-257 \\
797 \\
160 \\
165 \\
106\end{array}$ & $\begin{array}{l}463 \\
-26 \\
160 \\
165 \\
106\end{array}$ \\
\hline $\begin{array}{l}\text { Texas ....................... } \\
\text { Utah ...................... } \\
\text { Virginia................... } \\
\text { Washington.............. } \\
\text { West Virginia........... }\end{array}$ & $\begin{array}{r}310,273 \\
42,508 \\
0 \\
18,705 \\
171,216\end{array}$ & $\begin{array}{r}257,318 \\
22,921 \\
0 \\
17,133 \\
156,284\end{array}$ & $\begin{array}{r}52,956 \\
19,587 \\
0 \\
1,572 \\
14,932\end{array}$ & $\begin{array}{r}0 \\
0 \\
116 \\
2,340 \\
0\end{array}$ & $\begin{array}{r}0 \\
0 \\
236 \\
1,701 \\
0\end{array}$ & $\begin{array}{r}0 \\
0 \\
-121 \\
640 \\
0\end{array}$ & $\begin{array}{r}52,956 \\
19,587 \\
-121 \\
2,212 \\
14,932\end{array}$ \\
\hline $\begin{array}{l}\text { Wisconsin ................. } \\
\text { Wyoming............... }\end{array}$ & $\begin{array}{r}0 \\
10,596\end{array}$ & $\begin{array}{r}0 \\
8,012\end{array}$ & $\begin{array}{r}0 \\
2,584\end{array}$ & $\begin{array}{r}266 \\
0\end{array}$ & $\begin{array}{r}316 \\
0\end{array}$ & $\begin{array}{r}-50 \\
0\end{array}$ & $\begin{array}{r}-50 \\
2,584\end{array}$ \\
\hline 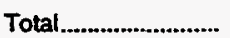 & $2,796,279$ & $2,491,427$ & 304,852 & 68,478 & 70,689 & $-2,211$ & 302,641 \\
\hline
\end{tabular}

Data on liquefied natural gas (LNG) was not collected prior to 1980.

Note: Totals may not equal sum of components due to independent rounding.

Source: Energy lnformation Administration (EIA), Form EIA-176 "Annual Feport of Natural and Supplemental Gas Supply and Disposition." 
Table 12. Supplemental Gas Supplies by State, 1980-1994 (Million Cubic Feet)

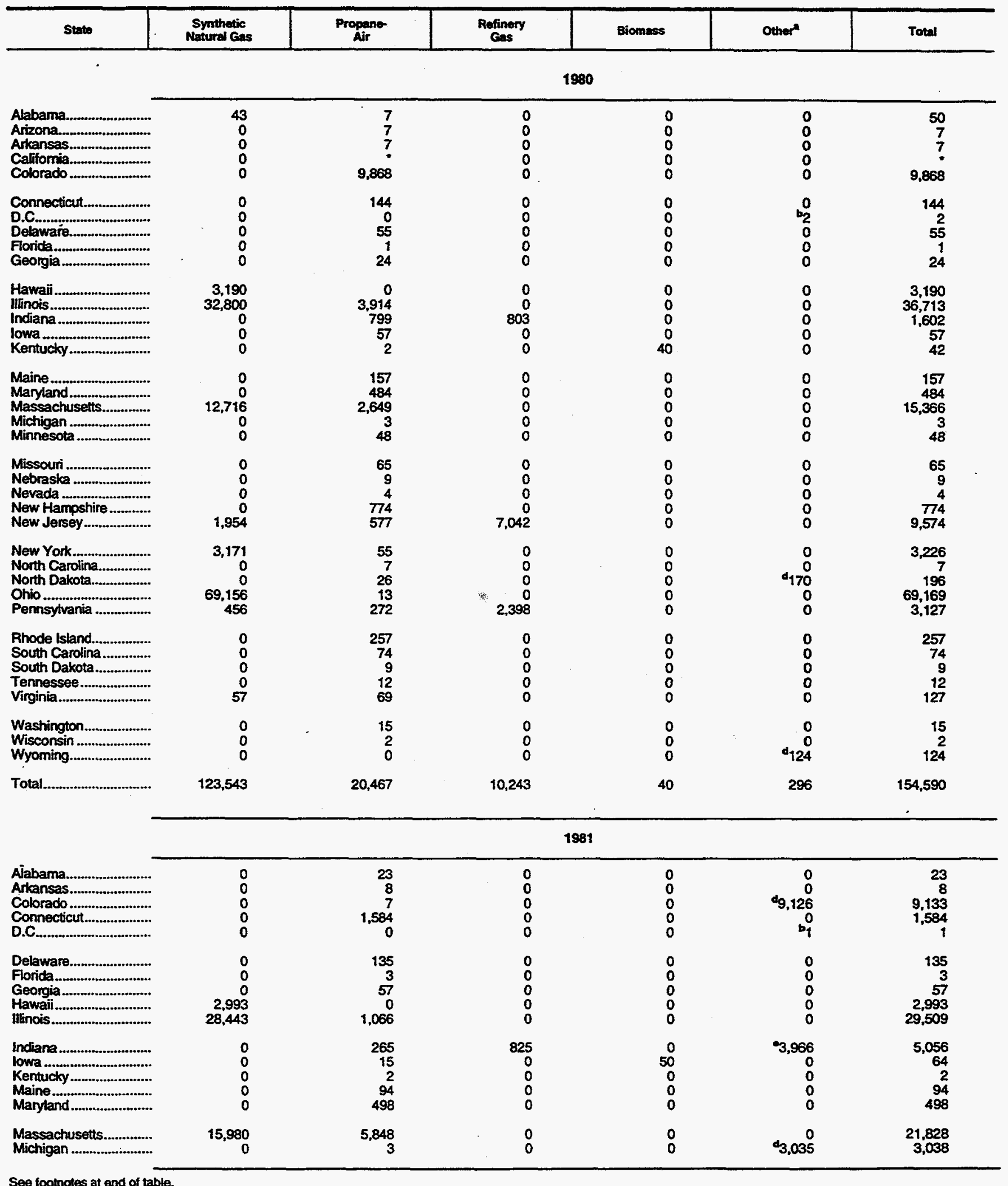

See footnotes at end of table. 
Table 12. Supplemental Gas Supplies by State, 1980-1994 (Continued) (Million Cubic Feet)

\begin{tabular}{|c|c|c|c|c|c|c|}
\hline State & $\begin{array}{l}\text { Symthetic } \\
\text { Natural Gas }\end{array}$ & $\begin{array}{l}\text { Propane- } \\
\text { Air }\end{array}$ & $\begin{array}{l}\text { Rofinery } \\
\text { Cas }\end{array}$ & Biomess & Other & Total \\
\hline & \multicolumn{6}{|c|}{1981} \\
\hline 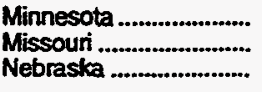 & $\begin{array}{l}0 \\
0 \\
0\end{array}$ & $\begin{array}{r}106 \\
60 \\
35\end{array}$ & $\begin{array}{l}0 \\
0 \\
0\end{array}$ & $\begin{array}{l}0 \\
0 \\
0\end{array}$ & $\begin{array}{r}0 \\
0 \\
1,804\end{array}$ & $\begin{array}{r}106 \\
60 \\
1,838\end{array}$ \\
\hline $\begin{array}{l}\text { Nevada ........................ } \\
\text { New Hampshire ............ } \\
\text { New Jersey..................... } \\
\text { New Mexico................. } \\
\text { New York..................... }\end{array}$ & $\begin{array}{r}0 \\
0 \\
1,452 \\
0 \\
2,528\end{array}$ & $\begin{array}{r}720 \\
1,308 \\
1 \\
32\end{array}$ & $\begin{array}{r}0 \\
0 \\
7,816 \\
0 \\
0\end{array}$ & $\begin{array}{l}0 \\
0 \\
0 \\
0 \\
0\end{array}$ & $\begin{array}{r}0 \\
0 \\
6927 \\
0 \\
2,163\end{array}$ & $\begin{array}{r}720 \\
11,504 \\
1 \\
4,722\end{array}$ \\
\hline $\begin{array}{l}\text { North Carolina................ } \\
\text { North Dakota................ } \\
\text { Ohio ............................ } \\
\text { Pennsylvania ............... } \\
\text { Rhode Island............... }\end{array}$ & $\begin{array}{r}0 \\
0 \\
69,756 \\
6,742 \\
0\end{array}$ & $\begin{array}{r}42 \\
29 \\
94 \\
1,200 \\
951\end{array}$ & $\begin{array}{r}0 \\
0 \\
0 \\
2,590 \\
0\end{array}$ & $\begin{array}{l}0 \\
0 \\
0 \\
0 \\
0\end{array}$ & $\begin{array}{r}0 \\
\$ 388 \\
0 \\
0 \\
0\end{array}$ & $\begin{array}{r}42 \\
417 \\
69,850 \\
10,532 \\
951\end{array}$ \\
\hline 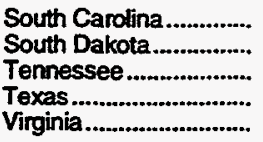 & $\begin{array}{r}0 \\
0 \\
0 \\
0 \\
109\end{array}$ & $\begin{array}{r}184 \\
24 \\
42 \\
334\end{array}$ & $\begin{array}{l}0 \\
0 \\
0 \\
0 \\
0\end{array}$ & $\begin{array}{l}0 \\
0 \\
0 \\
0 \\
0\end{array}$ & $\begin{array}{l}0 \\
0 \\
0 \\
0 \\
0\end{array}$ & $\begin{array}{r}184 \\
24 \\
42 \\
\\
443\end{array}$ \\
\hline 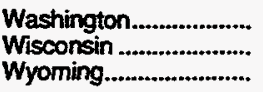 & $\begin{array}{l}0 \\
0 \\
0\end{array}$ & $\begin{array}{r}13 \\
4 \\
0\end{array}$ & $\begin{array}{l}0 \\
0 \\
0\end{array}$ & $\begin{array}{l}0 \\
0 \\
0\end{array}$ & $\begin{array}{r}0 \\
0 \\
422\end{array}$ & $\begin{array}{r}13 \\
4 \\
222\end{array}$ \\
\hline 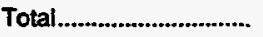 & 128,003 & 14,785 & 11,231 & 50 & 21,632 & 175,702 \\
\hline
\end{tabular}

1982

\begin{tabular}{|c|c|c|c|c|c|c|}
\hline 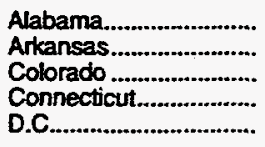 & $\begin{array}{l}0 \\
0 \\
0 \\
0 \\
0\end{array}$ & $\begin{array}{r}91 \\
6 \\
4 \\
1,077 \\
0\end{array}$ & $\begin{array}{l}0 \\
0 \\
0 \\
0 \\
0\end{array}$ & $\begin{array}{l}0 \\
0 \\
0 \\
0 \\
0\end{array}$ & $\begin{array}{r}0 \\
0 \\
8,873 \\
0 \\
b 46\end{array}$ & $\begin{array}{r}91 \\
6 \\
8,877 \\
1,077 \\
46\end{array}$ \\
\hline 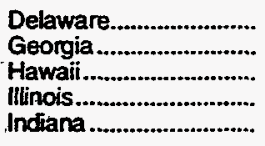 & $\begin{array}{r}0 \\
0 \\
2,899 \\
18,761 \\
0\end{array}$ & $\begin{array}{r}56 \\
151 \\
0 \\
244 \\
406\end{array}$ & $\begin{array}{r}0 \\
0 \\
0 \\
0 \\
1,038\end{array}$ & $\begin{array}{l}0 \\
0 \\
0 \\
0 \\
0\end{array}$ & $\begin{array}{r}0 \\
0 \\
0 \\
0 \\
2,052\end{array}$ & $\begin{array}{r}56 \\
151 \\
2,899 \\
19,005 \\
3,496\end{array}$ \\
\hline 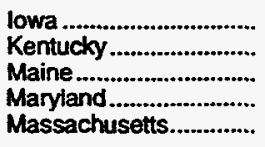 & $\begin{array}{r}0 \\
0 \\
0 \\
436 \\
13,739\end{array}$ & $\begin{array}{r}46 \\
30 \\
71 \\
548 \\
3,847\end{array}$ & $\begin{array}{l}0 \\
0 \\
0 \\
0 \\
0\end{array}$ & $\begin{array}{r}22 \\
0 \\
0 \\
0 \\
0\end{array}$ & $\begin{array}{r}0 \\
d_{101} \\
0 \\
0 \\
0\end{array}$ & $\begin{array}{r}68 \\
131 \\
71 \\
984 \\
17,586\end{array}$ \\
\hline 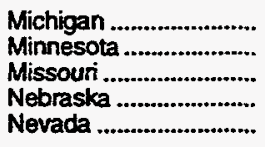 & $\begin{array}{l}0 \\
0 \\
0 \\
0 \\
0\end{array}$ & $\begin{array}{r}3 \\
337 \\
2,129 \\
63 \\
2\end{array}$ & $\begin{array}{l}0 \\
0 \\
0 \\
0 \\
0\end{array}$ & $\begin{array}{l}0 \\
0 \\
0 \\
0 \\
0\end{array}$ & $\begin{array}{r}d_{2,470} \\
0 \\
0 \\
0 \\
0\end{array}$ & $\begin{array}{r}2,473 \\
337 \\
2,129 \\
63 \\
2\end{array}$ \\
\hline $\begin{array}{l}\text { New Hampshire ............ } \\
\text { New Jersey.................. } \\
\text { New Mexico .................. } \\
\text { New York................ } \\
\text { North Carolina............... }\end{array}$ & $\begin{array}{r}0 \\
392 \\
0 \\
606 \\
0\end{array}$ & $\begin{array}{r}582 \\
786 \\
3 \\
248 \\
58\end{array}$ & $\begin{array}{r}0 \\
7,957 \\
0 \\
0 \\
0\end{array}$ & $\begin{array}{r}0 \\
0 \\
0 \\
1,496 \\
0\end{array}$ & $\begin{array}{r}0 \\
b_{651} \\
0 \\
0 \\
0\end{array}$ & $\begin{array}{r}582 \\
9,786 \\
3 \\
2,350 \\
58\end{array}$ \\
\hline 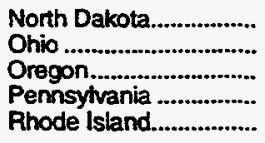 & $\begin{array}{r}0 \\
64,430 \\
0 \\
1,743 \\
0\end{array}$ & $\begin{array}{r}102 \\
382 \\
24 \\
873 \\
718\end{array}$ & $\begin{array}{r}0 \\
0 \\
0 \\
3,005 \\
0\end{array}$ & $\begin{array}{l}0 \\
0 \\
0 \\
0 \\
0\end{array}$ & $\begin{array}{l}0 \\
0 \\
0 \\
0 \\
0\end{array}$ & $\begin{array}{r}102 \\
64,812 \\
24 \\
5,621 \\
718\end{array}$ \\
\hline 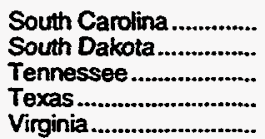 & $\begin{array}{r}0 \\
0 \\
0 \\
0 \\
18\end{array}$ & $\begin{array}{r}63 \\
50 \\
90 \\
1 \\
436\end{array}$ & $\begin{array}{l}0 \\
0 \\
0 \\
0 \\
0\end{array}$ & $\begin{array}{l}0 \\
0 \\
0 \\
0 \\
0\end{array}$ & $\begin{array}{l}0 \\
0 \\
0 \\
0 \\
0\end{array}$ & $\begin{array}{r}63 \\
50 \\
90 \\
1 \\
454\end{array}$ \\
\hline
\end{tabular}

See footnotes at end of table. 
Table 12. Supplemental Gas Supplies by State, 1980-1994 (Continued) (Million Cubic Feet)

\begin{tabular}{|c|c|c|c|c|c|c|}
\hline State & $\begin{array}{l}\text { Synthetic } \\
\text { Naturd Gess }\end{array}$ & $\begin{array}{l}\text { Propane- } \\
\text { Air }\end{array}$ & $\begin{array}{l}\text { Refinery } \\
\text { Cass }\end{array}$ & Biomess & Other" & Total \\
\hline & \multicolumn{6}{|c|}{1982} \\
\hline $\begin{array}{l}\text { Washington................... } \\
\text { Wisconsin ....................... } \\
\text { Wyoming.................. }\end{array}$ & $\begin{array}{l}0 \\
0 \\
0\end{array}$ & $\begin{array}{r}15 \\
13 \\
0\end{array}$ & $\begin{array}{l}0 \\
0 \\
0\end{array}$ & $\begin{array}{l}0 \\
0 \\
0\end{array}$ & $\begin{array}{r}0 \\
0 \\
518\end{array}$ & $\begin{array}{r}15 \\
13 \\
518\end{array}$ \\
\hline Total................................. & 103,025 & 13,555 & 12,001 & 1,518 & $14,71 t$ & 144,811 \\
\hline$\cdot$ & \multicolumn{6}{|c|}{1983} \\
\hline 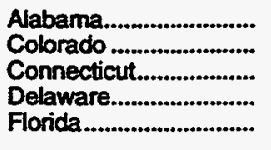 & $\begin{array}{l}0 \\
0 \\
0 \\
0 \\
0\end{array}$ & $\begin{array}{r}9 \\
5 \\
291 \\
20 \\
1\end{array}$ & $\begin{array}{l}0 \\
0 \\
0 \\
0 \\
0\end{array}$ & $\begin{array}{l}0 \\
0 \\
0 \\
0 \\
0\end{array}$ & $\begin{array}{r}0 \\
7,922 \\
0 \\
0 \\
0\end{array}$ & $\begin{array}{r}9 \\
7.927 \\
291 \\
20 \\
1\end{array}$ \\
\hline 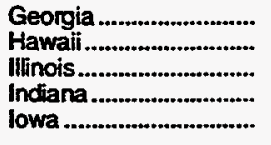 & $\begin{array}{r}0 \\
2,775 \\
19,409 \\
0 \\
0\end{array}$ & $\begin{array}{r}84 \\
0 \\
325 \\
575 \\
1\end{array}$ & $\begin{array}{r}0 \\
0 \\
0 \\
972 \\
0\end{array}$ & $\begin{array}{r}0 \\
0 \\
0 \\
0 \\
22\end{array}$ & $\begin{array}{r}0 \\
0 \\
0 \\
2,595 \\
0\end{array}$ & $\begin{array}{r}84 \\
2,775 \\
19,734 \\
4,142 \\
23\end{array}$ \\
\hline 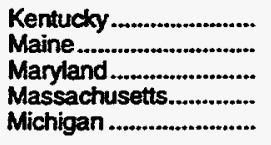 & $\begin{array}{r}0 \\
0 \\
166 \\
9,412 \\
0\end{array}$ & $\begin{array}{r}259 \\
12 \\
186 \\
1,311\end{array}$ & $\begin{array}{l}0 \\
0 \\
0 \\
9 \\
0\end{array}$ & $\begin{array}{l}0 \\
0 \\
0 \\
0 \\
0\end{array}$ & $\begin{array}{r}0 \\
0 \\
0 \\
0 \\
2,956\end{array}$ & $\begin{array}{r}259 \\
12 \\
352 \\
10,732 \\
2,956\end{array}$ \\
\hline $\begin{array}{l}\text { Minnesota ....................... } \\
\text { Missouri ......................... } \\
\text { Nebraska ....................... } \\
\text { Nevada ......................... } \\
\text { New Hampshire ............. }\end{array}$ & $\begin{array}{l}0 \\
0 \\
0 \\
0 \\
0\end{array}$ & $\begin{array}{r}1 \\
1,278 \\
17 \\
2 \\
328\end{array}$ & $\begin{array}{l}0 \\
0 \\
0 \\
0 \\
0\end{array}$ & $\begin{array}{l}0 \\
0 \\
0 \\
0 \\
0\end{array}$ & $\begin{array}{r}0 \\
0 \\
\alpha_{1,989} \\
0 \\
0\end{array}$ & $\begin{array}{r}1 \\
1,278 \\
2,006 \\
2 \\
328\end{array}$ \\
\hline $\begin{array}{l}\text { New Jersey..................... } \\
\text { New Mexico ..................... } \\
\text { New York....................... } \\
\text { North Carolina............... } \\
\text { Ohio ................................ }\end{array}$ & $\begin{array}{r}507 \\
0 \\
894 \\
0 \\
60,785\end{array}$ & $\begin{array}{r}536 \\
31 \\
59 \\
1,248\end{array}$ & $\begin{array}{r}8,853 \\
0 \\
0 \\
0 \\
0\end{array}$ & $\begin{array}{r}0 \\
0 \\
721 \\
0 \\
0\end{array}$ & $\begin{array}{l}0 \\
0 \\
0 \\
0 \\
0\end{array}$ & $\begin{array}{r}9,896 \\
1,646 \\
59 \\
62,032\end{array}$ \\
\hline $\begin{array}{l}\text { Oregon......................... } \\
\text { Pennsylvania ................ } \\
\text { Rhode Island................. } \\
\text { South Carolina ............... } \\
\text { South Dakota................. }\end{array}$ & $\begin{array}{r}0 \\
1,615 \\
0 \\
0 \\
0\end{array}$ & $\begin{array}{r}3 \\
41 \\
595 \\
73 \\
1\end{array}$ & $\begin{array}{r}0 \\
2,188 \\
0 \\
0 \\
0\end{array}$ & $\begin{array}{l}0 \\
0 \\
0 \\
0 \\
0\end{array}$ & $\begin{array}{l}0 \\
0 \\
0 \\
0 \\
0\end{array}$ & $\begin{array}{r}3 \\
3,844 \\
594 \\
73 \\
1\end{array}$ \\
\hline 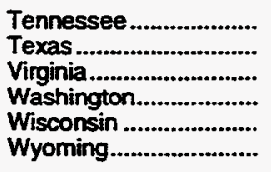 & $\begin{array}{r}0 \\
0 \\
71 \\
0 \\
0 \\
0\end{array}$ & $\begin{array}{r}39 \\
14 \\
304 \\
11 \\
2 \\
373\end{array}$ & $\begin{array}{l}0 \\
0 \\
0 \\
0 \\
0 \\
0\end{array}$ & $\begin{array}{l}0 \\
0 \\
0 \\
0 \\
0 \\
0\end{array}$ & $\begin{array}{l}0 \\
0 \\
0 \\
0 \\
0 \\
0\end{array}$ & $\begin{array}{r}39 \\
14 \\
375 \\
11 \\
2 \\
373\end{array}$ \\
\hline \multirow[t]{2}{*}{ Total } & 95.634 & 8,034 & 12,021 & 743 & 15,462 & 131,894 \\
\hline & \multicolumn{6}{|c|}{1984} \\
\hline $\begin{array}{l}\text { Alabama.......................... } \\
\text { Colorado ........................ } \\
\text { Connecticut.................. } \\
\text { Delaware......................... } \\
\text { Georgia ............................. }\end{array}$ & $\begin{array}{l}0 \\
0 \\
0 \\
0 \\
0\end{array}$ & $\begin{array}{r}54 \\
4 \\
239 \\
13 \\
28\end{array}$ & $\begin{array}{l}0 \\
0 \\
0 \\
0 \\
0\end{array}$ & $\begin{array}{l}0 \\
0 \\
0 \\
0 \\
0\end{array}$ & $\begin{array}{r}0 \\
9.133 \\
0 \\
0 \\
0\end{array}$ & $\begin{array}{r}54 \\
9.137 \\
239 \\
13 \\
28\end{array}$ \\
\hline 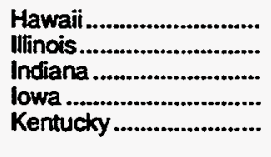 & $\begin{array}{r}2,449 \\
17,165 \\
0 \\
0 \\
0\end{array}$ & $\begin{array}{r}0 \\
129 \\
479 \\
0 \\
94\end{array}$ & $\begin{array}{r}0 \\
14 \\
972 \\
0 \\
0\end{array}$ & $\begin{array}{r}0 \\
0 \\
0 \\
53 \\
0\end{array}$ & $\begin{array}{r}0 \\
0 \\
2,575 \\
0 \\
0\end{array}$ & $\begin{array}{r}2,449 \\
17,308 \\
4,027 \\
53 \\
94\end{array}$ \\
\hline $\begin{array}{l}\text { Maryland....................... } \\
\text { Massachusetts............. } \\
\text { Michigan ......................... }\end{array}$ & $\begin{array}{r}92 \\
5,843 \\
0\end{array}$ & $\begin{array}{r}91 \\
686\end{array}$ & $\begin{array}{r}0 \\
15 \\
0\end{array}$ & $\begin{array}{r}148 \\
0 \\
0\end{array}$ & $\begin{array}{r}0 \\
0 \\
4,773\end{array}$ & $\begin{array}{r}332 \\
6,545 \\
2,773\end{array}$ \\
\hline
\end{tabular}

See footnotes at end of table. 
Table 12. Supplemental Gas Supplies by State, 1980-1994 (Continued) (Million Cubic Feet)

\begin{tabular}{|c|c|c|c|c|c|c|}
\hline State & $\begin{array}{l}\text { Symthetic } \\
\text { Natural Gas }\end{array}$ & $\begin{array}{l}\text { Propane- } \\
\text { Air }\end{array}$ & $\begin{array}{l}\text { Refinery } \\
\text { Ces }\end{array}$ & Biomess & Other & Total \\
\hline & \multicolumn{6}{|c|}{1984} \\
\hline 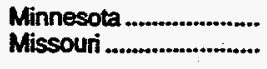 & $\begin{array}{l}0 \\
0\end{array}$ & $\begin{array}{r}3 \\
326\end{array}$ & $\begin{array}{l}0 \\
0\end{array}$ & $\begin{array}{l}0 \\
0\end{array}$ & $\begin{array}{l}0 \\
0\end{array}$ & 326 \\
\hline 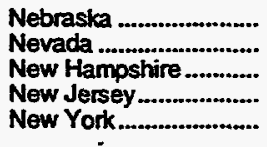 & $\begin{array}{r}0 \\
0 \\
0 \\
273 \\
578\end{array}$ & $\begin{array}{r}1 \\
2 \\
681 \\
465 \\
33\end{array}$ & $\begin{array}{r}0 \\
0 \\
0 \\
7,778 \\
0\end{array}$ & $\begin{array}{r}0 \\
0 \\
0 \\
0 \\
1,181\end{array}$ & $\begin{array}{r}2,469 \\
0 \\
0 \\
r_{100} \\
0\end{array}$ & $\begin{array}{r}2,470 \\
2 \\
681 \\
8,616 \\
1,792\end{array}$ \\
\hline 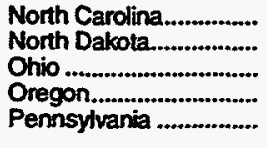 & $\begin{array}{r}0 \\
8,335 \\
43,847 \\
0 \\
1\end{array}$ & $\begin{array}{r}60 \\
19 \\
6 \\
78\end{array}$ & $\begin{array}{l}0 \\
0 \\
0 \\
0 \\
2\end{array}$ & $\begin{array}{l}0 \\
0 \\
0 \\
0 \\
0\end{array}$ & $\begin{array}{l}0 \\
0 \\
0 \\
0 \\
0\end{array}$ & $\begin{array}{r}60 \\
8,335 \\
43,866 \\
6 \\
82\end{array}$ \\
\hline 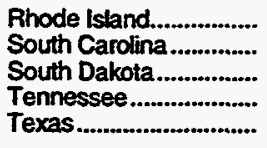 & $\begin{array}{l}0 \\
0 \\
0 \\
0 \\
0\end{array}$ & $\begin{array}{r}102 \\
62 \\
: \\
25 \\
2\end{array}$ & $\begin{array}{l}0 \\
0 \\
0 \\
0 \\
0\end{array}$ & $\begin{array}{l}0 \\
0 \\
0 \\
0 \\
0\end{array}$ & $\begin{array}{l}0 \\
0 \\
0 \\
0 \\
0\end{array}$ & $\begin{array}{r}102 \\
62 \\
25 \\
2\end{array}$ \\
\hline 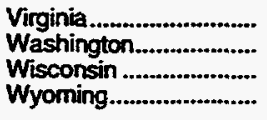 & $\begin{array}{r}49 \\
0 \\
0 \\
0\end{array}$ & $\begin{array}{r}160 \\
11 \\
6 \\
258\end{array}$ & $\begin{array}{l}0 \\
0 \\
0 \\
0\end{array}$ & $\begin{array}{l}0 \\
0 \\
0 \\
0\end{array}$ & $\begin{array}{r}0 \\
0 \\
0 \\
\alpha_{13}\end{array}$ & $\begin{array}{r}209 \\
11 \\
6 \\
271\end{array}$ \\
\hline Total...................................... & 78,632 & 4,118 & 8,782 & 1,382 & 17,063 & 109,977 \\
\hline
\end{tabular}

1985

Alabama.

Colorado .........................

Connecticut.................

Florida.

Georgia ...................

Hawail.

Indiana

Kentuck

Marylano

(n)

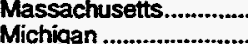

Minnesota

Missouri

Nebraska

Nevada

New Jersey

New York.

North Carolin

na.

North Dakota..................

Ohio...

Oregon.

Pennsytvania

Rhode Istand.

South Carolina ...............

South Dakota

Texas

Viminia

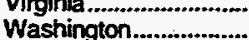

Wisconsin .

Wyoming.

Total.

$\begin{array}{rrr}0 & 14 & 0 \\ 0 & 17 & 0 \\ 0 & 343 & 0 \\ 0 & 12 & 0 \\ 0 & 3 & 0 \\ 0 & 121 & 0 \\ 2,655 & 0 & 0 \\ 19,668 & 137 & 0 \\ 0 & 159 & 893 \\ 0 & 0 & 0 \\ 0 & & 0 \\ 130 & 4 & 121 \\ 2,766 & 122 & 19 \\ 0 & 883 & 0 \\ 0 & 8 & 0 \\ 0 & 11 & 0 \\ 0 & & 0 \\ 0 & 351 & 0 \\ 0 & 1 & 0 \\ 391 & 4 & 12,371\end{array}$

$\begin{array}{rrr}0 & 0 & 14 \\ 0 & 8,917 & 8,934 \\ 0 & 0 & 343 \\ 0 & 0 & 12 \\ 0 & 0 & 3\end{array}$

$\begin{array}{llll}687 & 92 & 0 & 1,018\end{array}$

, 018
0

40,370

24,334

92
43
0
110

0
0
0
0
0

0
0
0
0
45

$0 \quad 121$

2,655

0
1,659
0

2,711

0

$\begin{array}{rr}0 & 4 \\ 0 & 373 \\ 0 & 3,668\end{array}$

$\begin{array}{rr}0 & 3,668 \\ 2,781 & 2,789\end{array}$

11

$0 \quad 351$

$\begin{array}{rr}0 & 351 \\ 2,688 & 2,689\end{array}$

$\begin{array}{rr}0 & 2,689 \\ 0 & 509\end{array}$

b582 13,421

$0 \quad 1,797$

1,797

40,370

24,444

221

221
130

87

32

9

345
9
14

14
249

4,127

91,074

3

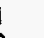

4

See foothotes at end of table. 
-Table 12. Supplemental Gas Supplies by State, 1980-1994 (Continued) (Million Cubic Feet)

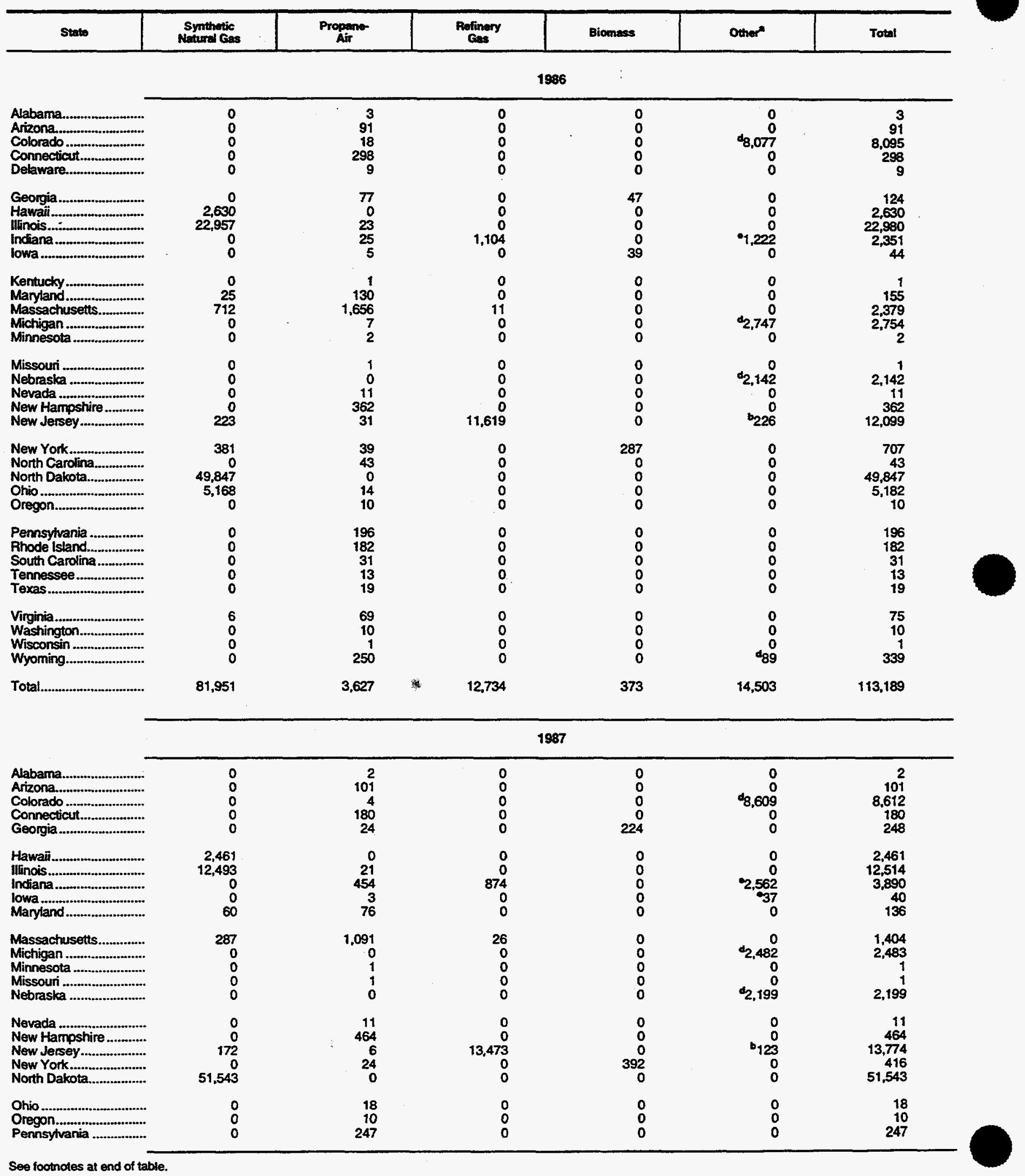


Table 12. Supplemental Gas Supplies by State, 1980-1.994 (Continued)

(Million Cubic Feet)

\begin{tabular}{|c|c|c|c|c|c|c|}
\hline State & $\begin{array}{l}\text { Synthetic } \\
\text { Naturad Gas }\end{array}$ & $\begin{array}{l}\text { Propano- } \\
\text { Air }\end{array}$ & $\begin{array}{c}\text { Refinery } \\
\text { Gass }\end{array}$ & Biomass & Other" & Total \\
\hline & \multicolumn{6}{|c|}{1987} \\
\hline $\begin{array}{l}\text { Rhode Istand........................................ } \\
\text { South Carolina }\end{array}$ & $\begin{array}{l}0 \\
0\end{array}$ & $\begin{array}{r}109 \\
22\end{array}$ & $\begin{array}{l}0 \\
0\end{array}$ & $\begin{array}{l}0 \\
0\end{array}$ & $\begin{array}{l}0 \\
0\end{array}$ & $\begin{array}{r}109 \\
22\end{array}$ \\
\hline 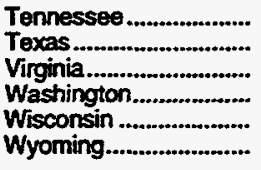 & $\begin{array}{l}0 \\
0 \\
0 \\
0 \\
0 \\
0\end{array}$ & $\begin{array}{r}26 \\
4 \\
141 \\
21 \\
1 \\
0\end{array}$ & $\begin{array}{l}0 \\
0 \\
0 \\
0 \\
0 \\
0\end{array}$ & $\begin{array}{l}0 \\
0 \\
0 \\
0 \\
0 \\
0\end{array}$ & $\begin{array}{r}0 \\
0 \\
0 \\
0 \\
0 \\
303\end{array}$ & $\begin{array}{r}26 \\
4 \\
141 \\
21 \\
1 \\
303\end{array}$ \\
\hline 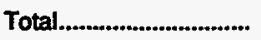 & 67,017 & 3.061 & $.14,373$ & 616 & 16,315 & 101,382 \\
\hline
\end{tabular}

\begin{tabular}{|c|c|c|c|c|c|c|}
\hline \multirow[b]{2}{*}{ 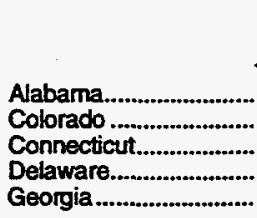 } & \multicolumn{6}{|c|}{1988} \\
\hline & $\begin{array}{l}0 \\
0 \\
0 \\
0 \\
0\end{array}$ & $\begin{array}{r}17 \\
270 \\
245 \\
2 \\
41\end{array}$ & $\begin{array}{l}0 \\
0 \\
0 \\
0 \\
0\end{array}$ & $\begin{array}{r}0 \\
0 \\
0 \\
0 \\
200\end{array}$ & $\begin{array}{r}0 \\
b_{10,052} \\
0 \\
0 \\
0\end{array}$ & $\begin{array}{r}17 \\
10,322 \\
245 \\
2 \\
241\end{array}$ \\
\hline 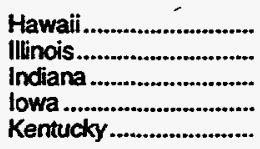 & $\begin{array}{r}2,801 \\
9,733 \\
0 \\
0 \\
0\end{array}$ & $\begin{array}{r}0 \\
70 \\
384 \\
5 \\
6\end{array}$ & $\begin{array}{r}0 \\
0 \\
782 \\
0 \\
0\end{array}$ & $\begin{array}{r}0 \\
0 \\
0 \\
29 \\
0\end{array}$ & $\begin{array}{r}0 \\
0 \\
3,078 \\
0 \\
0\end{array}$ & $\begin{array}{r}2,801 \\
9,803 \\
4,243 \\
34 \\
6\end{array}$ \\
\hline 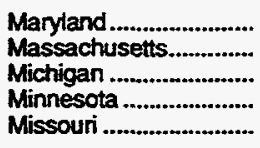 & $\begin{array}{r}68 \\
0 \\
0 \\
0 \\
0\end{array}$ & $\begin{array}{r}675 \\
876 \\
0 \\
385 \\
2\end{array}$ & $\begin{array}{l}0 \\
0 \\
0 \\
0 \\
0\end{array}$ & $\begin{array}{l}0 \\
0 \\
0 \\
0 \\
0\end{array}$ & $\begin{array}{r}0 \\
0 \\
2,402 \\
0 \\
0\end{array}$ & $\begin{array}{r}743 \\
876 \\
2,402 \\
385 \\
2\end{array}$ \\
\hline 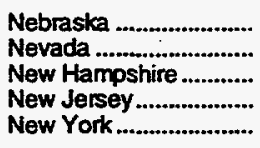 & $\begin{array}{r}0 \\
0 \\
0 \\
417 \\
0\end{array}$ & $\begin{array}{r}25 \\
32 \\
492 \\
8 \\
98\end{array}$ & $\begin{array}{r}0 \\
0 \\
0 \\
14,217 \\
0\end{array}$ & $\begin{array}{r}0 \\
0 \\
0 \\
0 \\
630\end{array}$ & $\begin{array}{r}b_{1,922} \\
0 \\
0 \\
204 \\
0\end{array}$ & $\begin{array}{r}1,948 \\
32 \\
492 \\
14,846 \\
728\end{array}$ \\
\hline 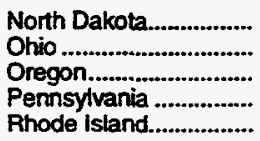 & $\begin{array}{r}49,002 \\
0 \\
0 \\
0 \\
0\end{array}$ & $\begin{array}{r}12 \\
44 \\
6 \\
254 \\
391\end{array}$ & $\begin{array}{l}0 \\
0 \\
0 \\
0 \\
0\end{array}$ & $\begin{array}{l}0 \\
0 \\
0 \\
0 \\
0\end{array}$ & $\begin{array}{l}0 \\
0 \\
0 \\
0 \\
0\end{array}$ & $\begin{array}{r}49,014 \\
44 \\
6 \\
254 \\
391\end{array}$ \\
\hline 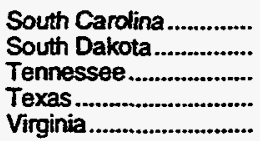 & $\begin{array}{l}0 \\
0 \\
0 \\
0 \\
0\end{array}$ & $\begin{array}{r}191 \\
10 \\
36 \\
4 \\
643\end{array}$ & $\begin{array}{l}0 \\
0 \\
0 \\
0 \\
0\end{array}$ & $\begin{array}{l}0 \\
0 \\
0 \\
0 \\
0\end{array}$ & $\begin{array}{l}0 \\
0 \\
0 \\
0 \\
0\end{array}$ & $\begin{array}{r}191 \\
10 \\
36 \\
4 \\
643\end{array}$ \\
\hline 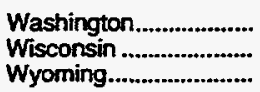 & $\begin{array}{l}0 \\
0 \\
0\end{array}$ & $\begin{array}{r}13 \\
2 \\
0\end{array}$ & $\begin{array}{l}0 \\
\vdots \\
0\end{array}$ & $\begin{array}{r}66 \\
0 \\
0\end{array}$ & $\begin{array}{r}0 \\
0 \\
2291\end{array}$ & $\begin{array}{r}79 \\
2 \\
291\end{array}$ \\
\hline \multirow[t]{2}{*}{ Total................................... } & 62,021 & 5,241 & 14,999 & 925 & 17,949 & 101,134 \\
\hline & \multicolumn{6}{|c|}{1989} \\
\hline 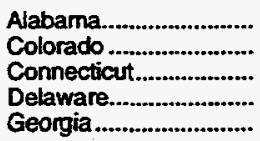 & $\begin{array}{l}0 \\
0 \\
0 \\
0 \\
0\end{array}$ & $\begin{array}{r}16 \\
34 \\
251 \\
18 \\
89\end{array}$ & $\begin{array}{l}0 \\
0 \\
0 \\
0 \\
0\end{array}$ & $\begin{array}{r}0 \\
0 \\
0 \\
0 \\
203\end{array}$ & $\begin{array}{r}0 \\
9,156 \\
0 \\
0 \\
0\end{array}$ & $\begin{array}{r}16 \\
9.190 \\
251 \\
18 \\
292\end{array}$ \\
\hline 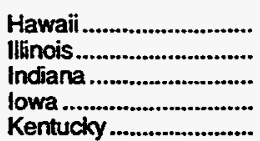 & $\begin{array}{r}2,844 \\
9.407 \\
0 \\
0 \\
0\end{array}$ & $\begin{array}{r}0 \\
70 \\
229 \\
28 \\
44\end{array}$ & $\begin{array}{r}0 \\
0 \\
651 \\
0 \\
0\end{array}$ & $\begin{array}{c}0 \\
0 \\
0 \\
54 \\
0\end{array}$ & $\begin{array}{r}0 \\
0 \\
d 2,632 \\
0 \\
0\end{array}$ & $\begin{array}{r}2,844 \\
9,477 \\
3,512 \\
82 \\
44\end{array}$ \\
\hline
\end{tabular}

See footnotes at end of table. 
Table 12. Supplemental Gas Supplies by State, 1980-1994 (Continued) (Million Cubic Feet)

\begin{tabular}{|c|c|c|c|c|c|c|}
\hline State & $\begin{array}{l}\text { Synthetic } \\
\text { Naturd Gas }\end{array}$ & $\begin{array}{l}\text { Propane- } \\
\text { Air }\end{array}$ & $\begin{array}{c}\text { Refinery } \\
\text { Cas }\end{array}$ & Biomass & Other" & Total \\
\hline & \multicolumn{6}{|c|}{1989} \\
\hline 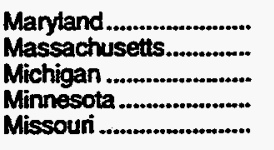 & $\begin{array}{r}34 \\
139 \\
0 \\
0 \\
0\end{array}$ & $\begin{array}{r}865 \\
553 \\
3 \\
315 \\
1,875\end{array}$ & $\begin{array}{l}0 \\
0 \\
0 \\
0 \\
0\end{array}$ & $\begin{array}{l}0 \\
0 \\
0 \\
0 \\
0\end{array}$ & $\begin{array}{r}0 \\
0 \\
b_{2,399} \\
0 \\
0\end{array}$ & $\begin{array}{r}899 \\
692 \\
2,402 \\
315 \\
1.875\end{array}$ \\
\hline $\begin{array}{l}\text { Nebraska ........................ } \\
\text { Nevada .......................... } \\
\text { New Haimpshire ............ } \\
\text { New Jersey ..................... } \\
\text { New York....................... }\end{array}$ & $\begin{array}{r}0 \\
0 \\
0 \\
363 \\
0\end{array}$ & $\begin{array}{r}84 \\
37 \\
592 \\
10 \\
149\end{array}$ & $\begin{array}{r}0 \\
0 \\
0 \\
14,010 \\
0\end{array}$ & $\begin{array}{r}0 \\
0 \\
0 \\
0 \\
1,090\end{array}$ & $\begin{array}{r}b_{2,005} \\
0 \\
0 \\
155 \\
0\end{array}$ & $\begin{array}{r}2,088 \\
37 \\
592 \\
14,539 \\
1,239\end{array}$ \\
\hline 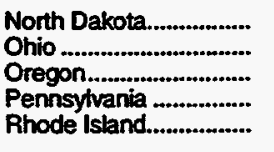 & $\begin{array}{r}54,403 \\
0 \\
0 \\
0 \\
0\end{array}$ & $\begin{array}{r}4 \\
348 \\
3 \\
305 \\
219\end{array}$ & $\begin{array}{l}0 \\
0 \\
0 \\
0 \\
0\end{array}$ & $\begin{array}{l}0 \\
0 \\
0 \\
0 \\
0\end{array}$ & $\begin{array}{l}0 \\
0 \\
0 \\
0 \\
0\end{array}$ & $\begin{array}{r}54,408 \\
348 \\
3 \\
305 \\
219\end{array}$ \\
\hline 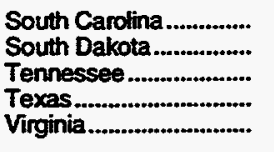 & $\begin{array}{l}0 \\
0 \\
0 \\
0 \\
0\end{array}$ & $\begin{array}{r}201 \\
16 \\
78 \\
9 \\
428\end{array}$ & $\begin{array}{l}0 \\
0 \\
0 \\
0 \\
0\end{array}$ & $\begin{array}{l}0 \\
0 \\
0 \\
0 \\
0\end{array}$ & $\begin{array}{l}0 \\
0 \\
0 \\
0 \\
0\end{array}$ & $\begin{array}{r}201 \\
16 \\
78 \\
9 \\
428\end{array}$ \\
\hline $\begin{array}{l}\text { Washington.................... } \\
\text { Wisconsin ..................... } \\
\text { Wyoming }\end{array}$ & $\begin{array}{l}0 \\
0 \\
0\end{array}$ & $\begin{array}{r}11 \\
5 \\
0\end{array}$ & $\begin{array}{l}0 \\
0 \\
0\end{array}$ & $\begin{array}{r}143 \\
0 \\
0\end{array}$ & $\begin{array}{r}0 \\
0 \\
b_{167}\end{array}$ & $\begin{array}{r}154 \\
5 \\
167\end{array}$ \\
\hline \multirow[t]{2}{*}{ 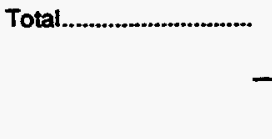 } & 67,190 & 6,890 & 14,661 & 1,490 & 16,514 & 106,745 \\
\hline & \multicolumn{6}{|c|}{1990} \\
\hline 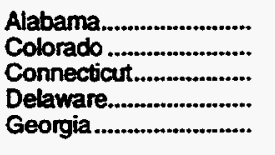 & $\begin{array}{l}0 \\
0 \\
0 \\
0 \\
0\end{array}$ & $\begin{array}{r}14 \\
21 \\
111 \\
0 \\
4\end{array}$ & $\begin{array}{r}0 \\
0 \\
0 \\
4,410 \\
0\end{array}$ & $\begin{array}{r}306 \\
0 \\
0 \\
0 \\
205\end{array}$ & $\begin{array}{r}0 \\
b_{15,358} \\
0 \\
0 \\
0\end{array}$ & $\begin{array}{r}320 \\
15,379 \\
111 \\
4,410 \\
209\end{array}$ \\
\hline 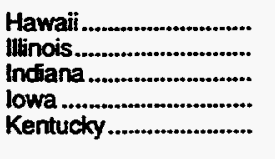 & $\begin{array}{r}2,817 \\
8,115 \\
0 \\
0 \\
0\end{array}$ & $\begin{array}{r}0 \\
25 \\
130 \\
24 \\
2\end{array}$ & $\begin{array}{r}0 \\
0 \\
633 \\
0 \\
0\end{array}$ & $\begin{array}{r}0 \\
0 \\
0 \\
58 \\
0\end{array}$ & $\begin{array}{r}0 \\
0 \\
2,252 \\
0 \\
0\end{array}$ & $\begin{array}{r}2,817 \\
8,140 \\
3,015 \\
81 \\
2\end{array}$ \\
\hline $\begin{array}{l}\text { Maryland....................... } \\
\text { Massachusetts.............. } \\
\text { Michigan .......................... } \\
\text { Minnesota .................... } \\
\text { Nebraska ....................... }\end{array}$ & $\begin{array}{l}0 \\
0 \\
0 \\
0 \\
0\end{array}$ & $\begin{array}{r}24 \\
317 \\
3 \\
56 \\
4\end{array}$ & $\begin{array}{l}0 \\
0 \\
0 \\
0 \\
0\end{array}$ & $\begin{array}{l}0 \\
0 \\
0 \\
0 \\
0\end{array}$ & $\begin{array}{r}0 \\
0 \\
b_{19,103} \\
0 \\
b_{2,356}\end{array}$ & $\begin{array}{r}24 \\
317 \\
19,106 \\
56 \\
2,361\end{array}$ \\
\hline $\begin{array}{l}\text { Nevada ........................ } \\
\text { New Harmpshire ........... } \\
\text { New Jersey ...................... } \\
\text { New York..................... } \\
\text { North Dakota................. }\end{array}$ & $\begin{array}{r}0 \\
0 \\
0 \\
0 \\
53,141\end{array}$ & $\begin{array}{r}125 \\
205 \\
25 \\
30 \\
4\end{array}$ & $\begin{array}{r}0 \\
0 \\
9,930 \\
0 \\
0\end{array}$ & $\begin{array}{r}0 \\
0 \\
0 \\
355 \\
0\end{array}$ & $\begin{array}{l}0 \\
0 \\
7 \\
0 \\
0\end{array}$ & $\begin{array}{r}125 \\
205 \\
9,962 \\
385 \\
53,144\end{array}$ \\
\hline 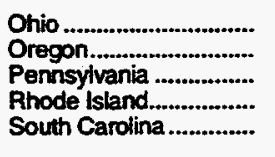 & $\begin{array}{l}0 \\
0 \\
0 \\
0 \\
0\end{array}$ & $\begin{array}{r}12 \\
3 \\
220 \\
51 \\
17\end{array}$ & $\begin{array}{l}0 \\
0 \\
0 \\
0 \\
0\end{array}$ & $\begin{array}{r}837 \\
0 \\
0 \\
0 \\
0\end{array}$ & $\begin{array}{l}0 \\
0 \\
0 \\
0 \\
0\end{array}$ & $\begin{array}{r}849 \\
3 \\
220 \\
51 \\
17\end{array}$ \\
\hline 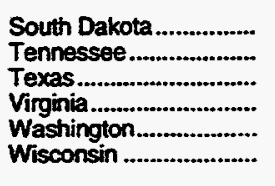 & $\begin{array}{l}0 \\
0 \\
0 \\
0 \\
0 \\
0\end{array}$ & $\begin{array}{r}7 \\
3 \\
8 \\
14 \\
16 \\
1\end{array}$ & $\begin{array}{l}0 \\
0 \\
0 \\
0 \\
0 \\
0\end{array}$ & $\begin{array}{r}3 \\
0 \\
1,233 \\
45 \\
166 \\
0\end{array}$ & $\begin{array}{l}0 \\
0 \\
0 \\
0 \\
0 \\
0\end{array}$ & $\begin{array}{r}10 \\
3 \\
1,240 \\
59 \\
181 \\
1\end{array}$ \\
\hline 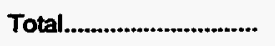 & 64,073 & 1,476 & 14,973 & 3,208 & 39,076 & 122,806 \\
\hline
\end{tabular}

See tootnotes at end of table. 
Table 12. Supplemental Gas Supplies by State, 1980-1994 (Continued) (Million Cubic Feet)

\begin{tabular}{|c|c|c|c|c|c|c|}
\hline State & $\begin{array}{l}\text { Synthetic } \\
\text { Naturat Gas }\end{array}$ & Propano- & $\begin{array}{l}\text { Refinery } \\
\text { Gas }\end{array}$ & Biomess & Othere & Total \\
\hline & \multicolumn{5}{|c|}{1991} & . \\
\hline 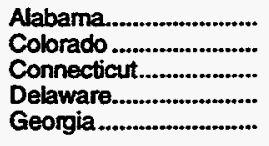 & $\begin{array}{l}0 \\
0 \\
0 \\
0 \\
0\end{array}$ & $\begin{array}{r}28 \\
21 \\
146 \\
47 \\
11\end{array}$ & $\begin{array}{r}0 \\
0 \\
0 \\
4,215 \\
0\end{array}$ & $\begin{array}{r}303 \\
0 \\
0 \\
0 \\
174\end{array}$ & $\begin{array}{r}0 \\
6,757 \\
0 \\
0 \\
0\end{array}$ & $\begin{array}{r}332 \\
6,778 \\
146 \\
4,262 \\
185\end{array}$ \\
\hline 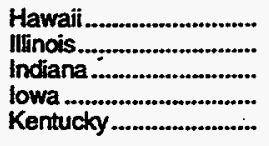 & $\begin{array}{r}2,725 \\
6,849 \\
0 \\
0 \\
0\end{array}$ & $\begin{array}{r}0 \\
21 \\
232 \\
3 \\
2\end{array}$ & $\begin{array}{r}0 \\
0 \\
604 \\
0 \\
0\end{array}$ & $\begin{array}{r}0 \\
0 \\
0 \\
43 \\
0\end{array}$ & $\begin{array}{r}0 \\
0 \\
2,241 \\
0 \\
0\end{array}$ & $\begin{array}{r}2,725 \\
6,869 \\
3,077 \\
46 \\
2\end{array}$ \\
\hline 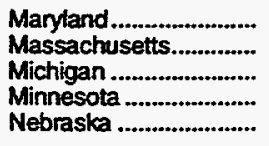 & $\begin{array}{l}0 \\
0 \\
0 \\
0 \\
0\end{array}$ & $\begin{array}{r}72 \\
120 \\
3 \\
49 \\
3\end{array}$ & $\begin{array}{l}0 \\
0 \\
0 \\
0 \\
0\end{array}$ & $\begin{array}{l}0 \\
0 \\
0 \\
0 \\
0\end{array}$ & $\begin{array}{r}0 \\
0 \\
\cdot 15,012 \\
0 \\
b_{2,029}\end{array}$ & $\begin{array}{r}72 \\
120 \\
15,016 \\
49 \\
2,032\end{array}$ \\
\hline 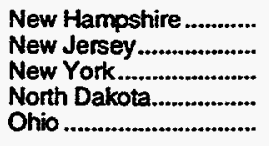 & $\begin{array}{r}0 \\
0 \\
0 \\
52,557 \\
0\end{array}$ & $\begin{array}{r}128 \\
0 \\
35 \\
0 \\
18\end{array}$ & $\begin{array}{r}0 \\
13,237 \\
0 \\
0 \\
0\end{array}$ & $\begin{array}{r}0 \\
0 \\
643 \\
0 \\
873\end{array}$ & $\begin{array}{r}0 \\
b, d 1,552 \\
0 \\
0 \\
0\end{array}$ & $\begin{array}{r}128 \\
14,789 \\
678 \\
52,557 \\
891\end{array}$ \\
\hline 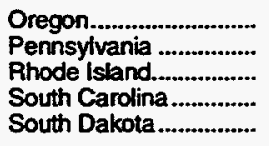 & $\begin{array}{l}0 \\
0 \\
0 \\
0 \\
0\end{array}$ & $\begin{array}{r}4 \\
222 \\
92 \\
47 \\
1\end{array}$ & $\begin{array}{l}0 \\
0 \\
0 \\
0 \\
0\end{array}$ & $\begin{array}{l}0 \\
0 \\
0 \\
0 \\
2\end{array}$ & $\begin{array}{l}0 \\
0 \\
0 \\
0 \\
0\end{array}$ & $\begin{array}{r}4 \\
222 \\
92 \\
47 \\
3\end{array}$ \\
\hline 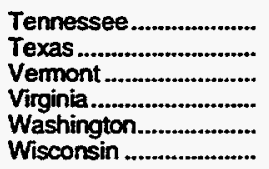 & $\begin{array}{l}0 \\
0 \\
0 \\
0 \\
0 \\
0\end{array}$ & $\begin{array}{r}8 \\
1 \\
6 \\
240 \\
13 \\
1\end{array}$ & $\begin{array}{l}0 \\
0 \\
0 \\
0 \\
0 \\
0\end{array}$ & $\begin{array}{r}0 \\
1,075 \\
0 \\
0 \\
140 \\
0\end{array}$ & $\begin{array}{l}0 \\
0 \\
0 \\
0 \\
0 \\
0\end{array}$ & $\begin{array}{r}8 \\
1,076 \\
6 \\
240 \\
154 \\
1\end{array}$ \\
\hline \multirow[t]{2}{*}{ 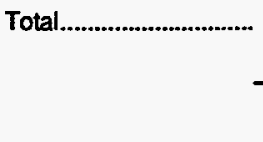 } & 62,131 & 1,575 & 18,055 & 3,253 & 27,591 & 112,606 \\
\hline & \multicolumn{6}{|c|}{1992} \\
\hline 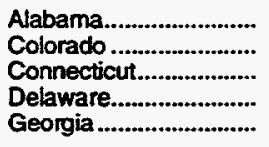 & $\begin{array}{l}0 \\
0 \\
0 \\
0 \\
0\end{array}$ & $\begin{array}{r}25 \\
5 \\
40 \\
0 \\
12\end{array}$ & $\begin{array}{r}0 \\
0 \\
0 \\
3,665 \\
0\end{array}$ & $\begin{array}{r}146 \\
0 \\
0 \\
0 \\
154\end{array}$ & $\begin{array}{r}0 \\
7,153 \\
0 \\
0 \\
0\end{array}$ & $\begin{array}{r}171 \\
7,158 \\
40 \\
3,665 \\
166\end{array}$ \\
\hline 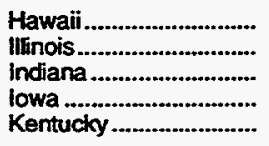 & $\begin{array}{r}2,711 \\
8,021 \\
0 \\
0 \\
0\end{array}$ & $\begin{array}{r}0 \\
21 \\
380 \\
2 \\
5\end{array}$ & $\begin{array}{r}0 \\
0 \\
457 \\
0 \\
0\end{array}$ & $\begin{array}{r}0 \\
0 \\
0 \\
43 \\
0\end{array}$ & $\begin{array}{r}0 \\
0 \\
d_{2,670} \\
0 \\
0\end{array}$ & $\begin{array}{r}2,711 \\
8,042 \\
3,507 \\
45 \\
5\end{array}$ \\
\hline 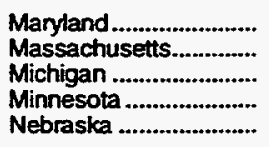 & $\begin{array}{l}0 \\
0 \\
0 \\
0 \\
0\end{array}$ & $\begin{array}{r}126 \\
105 \\
2 \\
52 \\
14\end{array}$ & $\begin{array}{l}0 \\
0 \\
0 \\
0 \\
0\end{array}$ & $\begin{array}{l}0 \\
0 \\
0 \\
0 \\
0\end{array}$ & $\begin{array}{r}0 \\
0 \\
\cdot 14,692 \\
0 \\
b 1,422\end{array}$ & $\begin{array}{r}126 \\
105 \\
14,694 \\
52 \\
1,437\end{array}$ \\
\hline $\begin{array}{l}\text { Nevada } \\
\text { New Hampshire ........... } \\
\text { New Jersey ................ } \\
\text { New York................ } \\
\text { North Carolina............... }\end{array}$ & $\begin{array}{l}0 \\
0 \\
0 \\
0 \\
0\end{array}$ & $\begin{array}{r}30 \\
96 \\
0 \\
67 \\
2\end{array}$ & $\begin{array}{r}0 \\
0 \\
12,610 \\
0 \\
0\end{array}$ & $\begin{array}{r}0 \\
0 \\
0 \\
1,123 \\
0\end{array}$ & $\begin{array}{r}0 \\
0 \\
b, d_{1,751} \\
0 \\
0\end{array}$ & $\begin{array}{r}30 \\
96 \\
14,362 \\
1,190 \\
2\end{array}$ \\
\hline 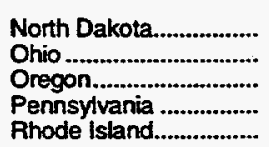 & $\begin{array}{r}58,496 \\
0 \\
0 \\
0 \\
0\end{array}$ & $\begin{array}{r}0 \\
20 \\
2 \\
132 \\
155\end{array}$ & $\begin{array}{l}0 \\
0 \\
0 \\
0 \\
0\end{array}$ & $\begin{array}{r}0 \\
1,030 \\
0 \\
0 \\
0\end{array}$ & $\begin{array}{l}0 \\
0 \\
0 \\
0 \\
0\end{array}$ & $\begin{array}{r}58,496 \\
1,051 \\
2 \\
132 \\
155\end{array}$ \\
\hline
\end{tabular}

See foomotes at end of table. 
Table 12. Supplemental Gas Supplies by State, 1980-1994 (Continued) (Million Cubic Feet)

\begin{tabular}{|c|c|c|c|c|c|c|}
\hline State & $\begin{array}{l}\text { Symthetic } \\
\text { Natural Gas }\end{array}$ & $\begin{array}{l}\text { Propano- } \\
\text { Air }\end{array}$ & $\begin{array}{l}\text { Refinery } \\
\text { Cens }\end{array}$ & Biomase & Other" & Total \\
\hline & \multicolumn{6}{|c|}{1992} \\
\hline 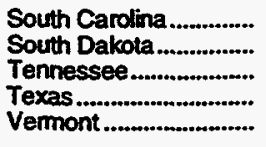 & $\begin{array}{l}0 \\
0 \\
0 \\
0 \\
0\end{array}$ & $\begin{array}{r}26 \\
8 \\
12 \\
1 \\
3\end{array}$ & $\begin{array}{l}0 \\
0 \\
0 \\
0 \\
0\end{array}$ & $\begin{array}{l}0 \\
3 \\
0 \\
0 \\
0\end{array}$ & $\begin{array}{l}0 \\
0 \\
0 \\
0 \\
0\end{array}$ & $\begin{array}{r}26 \\
10 \\
12 \\
1 \\
3\end{array}$ \\
\hline $\begin{array}{l}\text { Virginia...................... } \\
\text { Washington.................. } \\
\text { Wisconsin .................. }\end{array}$ & $\begin{array}{l}0 \\
0 \\
0\end{array}$ & $\begin{array}{r}245 \\
24 \\
1\end{array}$ & $\begin{array}{l}0 \\
0 \\
0\end{array}$ & $\begin{array}{r}0 \\
157 \\
0\end{array}$ & $\begin{array}{l}\mathbf{0} \\
\mathbf{0} \\
\mathbf{0}\end{array}$ & $\begin{array}{r}245 \\
180 \\
1\end{array}$ \\
\hline \multirow[t]{2}{*}{ 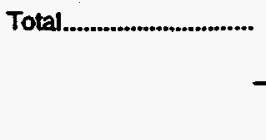 } & 69,229 & 1,613 & 16.732 & 2,656 & 27,688 & 117,919 \\
\hline & \multicolumn{6}{|c|}{1993} \\
\hline 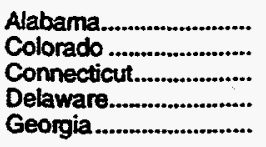 & $\begin{array}{l}0 \\
0 \\
0 \\
0 \\
0\end{array}$ & $\begin{array}{r}44 \\
20 \\
94 \\
4 \\
31\end{array}$ & $\begin{array}{r}0 \\
0 \\
0 \\
3,594 \\
0\end{array}$ & $\begin{array}{r}366 \\
0 \\
0 \\
0 \\
169\end{array}$ & $\begin{array}{r}0 \\
8,436 \\
0 \\
0 \\
0\end{array}$ & $\begin{array}{r}410 \\
8,456 \\
94 \\
3,597 \\
199\end{array}$ \\
\hline 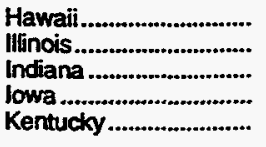 & $\begin{array}{r}2,705 \\
9,665 \\
0 \\
0 \\
0\end{array}$ & $\begin{array}{r}0 \\
95 \\
560 \\
84 \\
16\end{array}$ & $\begin{array}{l}0 \\
0 \\
0 \\
0 \\
0\end{array}$ & $\begin{array}{l}0 \\
0 \\
0 \\
0 \\
0\end{array}$ & $\begin{array}{r}0 \\
0 \\
2,671 \\
0 \\
0\end{array}$ & $\begin{array}{r}2,705 \\
9,760 \\
3,232 \\
84 \\
16\end{array}$ \\
\hline 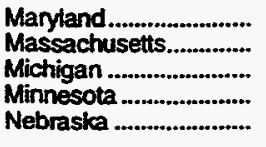 & $\begin{array}{l}0 \\
0 \\
0 \\
0 \\
0\end{array}$ & $\begin{array}{r}418 \\
61 \\
1 \\
78 \\
9\end{array}$ & $\begin{array}{l}0 \\
0 \\
0 \\
0 \\
0\end{array}$ & $\begin{array}{l}0 \\
0 \\
0 \\
0 \\
0\end{array}$ & $\begin{array}{r}0 \\
0 \\
-12,794 \\
0 \\
6781\end{array}$ & $\begin{array}{r}418 \\
61 \\
12,795 \\
78 \\
791\end{array}$ \\
\hline $\begin{array}{l}\text { Nevada ..................... } \\
\text { New Hampshire........... } \\
\text { New Jersey.................. } \\
\text { New York................... } \\
\text { North Carolina............... }\end{array}$ & $\begin{array}{l}0 \\
0 \\
0 \\
0 \\
0\end{array}$ & $\begin{array}{r}38 \\
154 \\
0 \\
372 \\
4\end{array}$ & $\begin{array}{r}0 \\
0 \\
13,130 \\
0 \\
0\end{array}$ & $\begin{array}{r}0 \\
0 \\
1,765 \\
1,266 \\
0\end{array}$ & $\begin{array}{r}0 \\
0 \\
{ }^{5} 5 \\
0 \\
0\end{array}$ & $\begin{array}{r}38 \\
154 \\
14,950 \\
1,638 \\
4\end{array}$ \\
\hline $\begin{array}{l}\text { North Dakota................. } \\
\text { Ohio ............................. } \\
\text { Oregon................... } \\
\text { Pennsytvania ............... } \\
\text { Rhode Istand............... }\end{array}$ & $\begin{array}{r}57,680 \\
0 \\
0 \\
0 \\
0\end{array}$ & $\begin{array}{r}0 \\
74 \\
3 \\
110 \\
126\end{array}$ & $\begin{array}{l}0 \\
0 \\
0 \\
0 \\
0\end{array}$ & $\begin{array}{r}0 \\
918 \\
0 \\
0 \\
0\end{array}$ & $\begin{array}{l}0 \\
0 \\
0 \\
0 \\
0\end{array}$ & $\begin{array}{r}57.680 \\
992 \\
3 \\
110 \\
126\end{array}$ \\
\hline 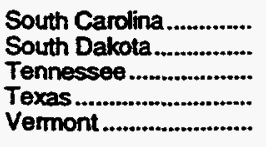 & $\begin{array}{l}0 \\
0 \\
0 \\
0 \\
0\end{array}$ & $\begin{array}{r}34 \\
9 \\
13 \\
3 \\
4\end{array}$ & $\begin{array}{l}0 \\
0 \\
0 \\
0 \\
0\end{array}$ & $\begin{array}{l}0 \\
0 \\
0 \\
0 \\
0\end{array}$ & $\begin{array}{l}0 \\
0 \\
0 \\
0 \\
0\end{array}$ & $\begin{array}{r}34 \\
9 \\
13 \\
3 \\
4\end{array}$ \\
\hline 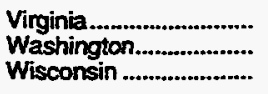 & $\begin{array}{l}0 \\
0 \\
0\end{array}$ & $\begin{array}{r}538 \\
4 \\
3\end{array}$ & $\begin{array}{l}0 \\
0 \\
0\end{array}$ & $\begin{array}{l}0 \\
0 \\
0\end{array}$ & $\begin{array}{l}0 \\
0 \\
0\end{array}$ & $\begin{array}{r}538 \\
4 \\
3\end{array}$ \\
\hline \multirow[t]{2}{*}{ 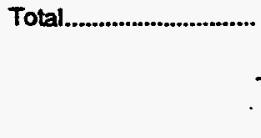 } & 70,051 & 3,002 & 16,724 & 0 & 0 & 118,999 \\
\hline & \multicolumn{6}{|c|}{1994} \\
\hline 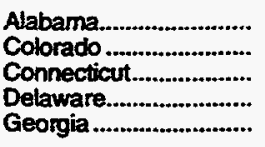 & $\begin{array}{l}0 \\
0 \\
0 \\
0 \\
0\end{array}$ & $\begin{array}{r}5 \\
19 \\
29 \\
2 \\
60\end{array}$ & $\begin{array}{r}0 \\
0 \\
0 \\
3,030 \\
0\end{array}$ & $\begin{array}{r}65 \\
0 \\
0 \\
0 \\
63\end{array}$ & $\begin{array}{r}0 \\
8,149 \\
0 \\
0 \\
0\end{array}$ & $\begin{array}{r}69 \\
8,168 \\
29 \\
3,032 \\
123\end{array}$ \\
\hline 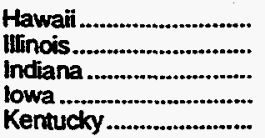 & $\begin{array}{r}2,831 \\
7,734 \\
0 \\
0 \\
0\end{array}$ & $\begin{array}{r}0 \\
137 \\
308 \\
30 \\
50\end{array}$ & $\begin{array}{l}0 \\
0 \\
0 \\
0 \\
0\end{array}$ & $\begin{array}{r}0 \\
0 \\
0 \\
93 \\
0\end{array}$ & $\begin{array}{r}0 \\
0 \\
\alpha_{2,148} \\
0 \\
0\end{array}$ & $\begin{array}{r}2,831 \\
7,871 \\
2,457 \\
123 \\
50\end{array}$ \\
\hline
\end{tabular}

See footnotes at end of table. 
Table 12. Supplemental Gas Supplies by State, 1980-1994 (Continued).

(Million Cubic Feet)

\begin{tabular}{|c|c|c|c|c|c|c|}
\hline State & $\begin{array}{l}\text { Synthetic } \\
\text { Natural Gas }\end{array}$ & $\begin{array}{l}\text { Propano- } \\
\text { Air }\end{array}$ & $\underset{\text { Reifinery }}{\text { Res }}$ & Biomass & Other & Total \\
\hline & \multicolumn{6}{|c|}{1994} \\
\hline 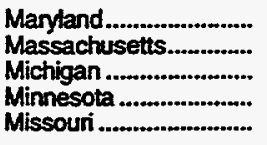 & $\begin{array}{l}0 \\
0 \\
0 \\
0 \\
0\end{array}$ & $\begin{array}{r}987 \\
154 \\
1 \\
289 \\
371\end{array}$ & $\begin{array}{l}0 \\
0 \\
0 \\
0 \\
0\end{array}$ & $\begin{array}{l}0 \\
0 \\
0 \\
0 \\
0\end{array}$ & $\begin{array}{r}0 \\
0 \\
-13,687 \\
0 \\
0\end{array}$ & $\begin{array}{r}987 \\
154 \\
13,688 \\
289 \\
371\end{array}$ \\
\hline $\begin{array}{l}\text { Nebraska ........................ } \\
\text { Nevada ...................... } \\
\text { New Hampshire ............. } \\
\text { New Jersey.................... } \\
\text { New York..................... }\end{array}$ & $\begin{array}{l}0 \\
0 \\
0 \\
0 \\
0\end{array}$ & $\begin{array}{r}18 \\
9 \\
160 \\
44 \\
142\end{array}$ & $\begin{array}{r}0 \\
0 \\
0 \\
5,905 \\
0\end{array}$ & $\begin{array}{r}0 \\
0 \\
0 \\
1,675 \\
1,318\end{array}$ & $\begin{array}{r}872 \\
0 \\
0 \\
6114 \\
0\end{array}$ & $\begin{array}{r}890 \\
9 \\
160 \\
7,737 \\
1,460\end{array}$ \\
\hline $\begin{array}{l}\text { North Carolina.............. } \\
\text { North Dakota.............. } \\
\text { Ohio .......................... } \\
\text { Oregon.................... } \\
\text { Pennsytuania ............... }\end{array}$ & $\begin{array}{r}0 \\
57,127 \\
0 \\
0 \\
0\end{array}$ & $\begin{array}{r}3 \\
0 \\
491 \\
2 \\
252\end{array}$ & $\begin{array}{l}0 \\
0 \\
0 \\
0 \\
0\end{array}$ & $\begin{array}{r}0 \\
0 \\
941 \\
0 \\
0\end{array}$ & $\begin{array}{l}0 \\
0 \\
0 \\
0 \\
0\end{array}$ & $\begin{array}{r}3 \\
57,127 \\
1,432 \\
2 \\
252\end{array}$ \\
\hline $\begin{array}{l}\text { South Carolina ................ } \\
\text { South Dakota............... } \\
\text { Tennessee..................... } \\
\text { Texas......................... } \\
\text { Vermont ........................ }\end{array}$ & $\begin{array}{l}0 \\
0 \\
0 \\
0 \\
0\end{array}$ & $\begin{array}{r}154 \\
61 \\
84 \\
1 \\
9\end{array}$ & $\begin{array}{l}0 \\
0 \\
0 \\
0 \\
0\end{array}$ & $\begin{array}{l}0 \\
0 \\
0 \\
0 \\
0\end{array}$ & $\begin{array}{l}0 \\
0 \\
0 \\
0 \\
0\end{array}$ & $\begin{array}{r}154 \\
61 \\
84 \\
1 \\
9\end{array}$ \\
\hline 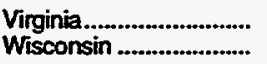 & $\begin{array}{l}0 \\
0\end{array}$ & $\begin{array}{r}1,195 \\
5\end{array}$ & $\begin{array}{l}0 \\
0\end{array}$ & $\begin{array}{l}0 \\
0\end{array}$ & $\begin{array}{l}0 \\
0\end{array}$ & $\begin{array}{r}1,195 \\
5\end{array}$ \\
\hline 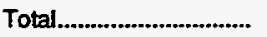 & 67,693 & 5,073 & 8,935 & 4,155 & 24,970 & 110,826 \\
\hline
\end{tabular}

a Includes coke oven gas, blast fumace gas, manufactured gas, and air injection for Btu stabilization.

b Manufactured gas.

c Blast fumace gas.

Air injection for Btu stabilization.

- Coke oven gas.

- Volume is less than 500,000 cubic feet.

Note: Tolals may not equal sum of components due to independent rounding.

Source: Energy Information Administration (EIA), Form EIA-176 *Annual Report of Natural and Supplemental Gas Supply and Disposition." 
Table 13. Natural Gas Production, Transmission, and Consumption by State, 1967-1994 (Million Cubic Feet)

\begin{tabular}{|c|c|c|c|c|c|c|c|c|}
\hline State & $\begin{array}{l}\text { Marketed } \\
\text { Production }\end{array}$ & $\begin{array}{l}\text { Extraction } \\
\text { Loss }\end{array}$ & $\begin{array}{l}\text { Balancing } \\
\text { thom }\end{array}$ & $\begin{array}{c}\text { Net } \\
\text { Imterstate } \\
\text { Movements }\end{array}$ & $\begin{array}{l}\text { Nat Move } \\
\text { ments Across } \\
\text { U.S. Borders }\end{array}$ & $\begin{array}{c}\text { Net } \\
\text { Storage } \\
\text { Changes }\end{array}$ & $\begin{array}{c}\text { Supplemental } \\
\text { Gas } \\
\text { Supplies }\end{array}$ & Consumption \\
\hline & \multicolumn{8}{|c|}{1967} \\
\hline $\begin{array}{l}\text { Alabama................. } \\
\text { Alaska ...................... } \\
\text { Arizona.................. } \\
\text { Arkansas................. } \\
\text { Califomia................. }\end{array}$ & $\begin{array}{r}248 \\
14,438 \\
1,255 \\
116,522 \\
681,080\end{array}$ & $\begin{array}{r}0 \\
0 \\
0 \\
3,499 \\
34,803\end{array}$ & $\begin{array}{r}-1,113 \\
-2,549 \\
-1,219 \\
-14,927 \\
-61,228\end{array}$ & $\begin{array}{r}255,041 \\
0 \\
162,446 \\
197,790 \\
1,329,287\end{array}$ & $\begin{array}{r}0 \\
0 \\
-3,716 \\
0 \\
0\end{array}$ & $\begin{array}{r}0 \\
0 \\
0 \\
426 \\
3,204\end{array}$ & $\begin{array}{l}\text { NA } \\
\text { NA } \\
\text { NA } \\
\text { NA }\end{array}$ & $\begin{array}{r}254,176 \\
11,889 \\
158,766 \\
295,460 \\
1,911,132\end{array}$ \\
\hline 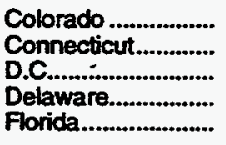 & $\begin{array}{r}116,857 \\
0 \\
a \\
0 \\
123\end{array}$ & $\begin{array}{r}4,126 \\
0 \\
a \\
0 \\
0\end{array}$ & $\begin{array}{r}-5,515 \\
-1,963 \\
a \\
-514 \\
-2,031\end{array}$ & $\begin{array}{r}125,426 \\
51,743 \\
a \\
21,871 \\
227,439\end{array}$ & $\begin{array}{l}0 \\
0 \\
a \\
0 \\
0\end{array}$ & $\begin{array}{r}1,134 \\
0 \\
2 \\
294 \\
0\end{array}$ & $\begin{array}{l}\text { NA } \\
\text { NA } \\
\text { NA } \\
\text { NA }\end{array}$ & $\begin{array}{r}231,508 \\
49,780 \\
2 \\
21,063 \\
225,531\end{array}$ \\
\hline 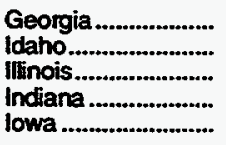 & $\begin{array}{r}0 \\
0 \\
5,144 \\
198 \\
0\end{array}$ & $\begin{array}{r}0 \\
0 \\
13,725 \\
0 \\
0\end{array}$ & $\begin{array}{r}-3,690 \\
-372 \\
-22,740 \\
-3,478 \\
-4,838\end{array}$ & $\begin{array}{r}258,024 \\
-219,052 \\
1,011,169 \\
442,703 \\
290,810\end{array}$ & $\begin{array}{r}0 \\
253,707 \\
0 \\
0 \\
0\end{array}$ & $\begin{array}{r}0 \\
0 \\
31,495 \\
4,791 \\
13,122\end{array}$ & $\begin{array}{l}\text { NA } \\
\text { NA } \\
\text { NA } \\
\text { NA }\end{array}$ & $\begin{array}{r}254,334 \\
34,283 \\
948,353 \\
434,632 \\
272,850\end{array}$ \\
\hline $\begin{array}{l}\text { Kansas..................... } \\
\text { Kentucky ................ } \\
\text { Louisiana ................ } \\
\text { Maine }{ }^{b} \text {...................... } \\
\text { Marytand'................ }\end{array}$ & $\begin{array}{r}871,971 \\
89,168 \\
5,716,857 \\
0 \\
621\end{array}$ & $\begin{array}{r}30,480 \\
11,500 \\
115,177 \\
0 \\
0\end{array}$ & $\begin{array}{r}-2,280 \\
-3,942 \\
-16,428 \\
-426 \\
-1,726\end{array}$ & $\begin{array}{r}-390,759 \\
120,974 \\
-4,146,147 \\
6,391 \\
149,746\end{array}$ & $\begin{array}{r}0 \\
0 \\
0 \\
613 \\
0\end{array}$ & $\begin{array}{r}-2,511 \\
2,236 \\
44,729 \\
0 \\
8,788\end{array}$ & $\begin{array}{l}\text { NA } \\
\text { NA } \\
\text { NA } \\
\text { NA }\end{array}$ & $\begin{array}{r}450,963 \\
192,464 \\
1,394,376 \\
6,578 \\
139,853\end{array}$ \\
\hline $\begin{array}{l}\text { Massachusetts........ } \\
\text { Michigan ................. } \\
\text { Minnesota .............. } \\
\text { Mississippi ............... } \\
\text { Missour ................. }\end{array}$ & $\begin{array}{r}0 \\
33,589 \\
0 \\
139,497 \\
121\end{array}$ & $\begin{array}{r}0 \\
3,351 \\
0 \\
1,127 \\
0\end{array}$ & $\begin{array}{r}-2,245 \\
-9,352 \\
-202 \\
-3,286 \\
-9,221\end{array}$ & $\begin{array}{l}130,636 \\
698,475 \\
199,570 \\
146,600 \\
369,872\end{array}$ & $\begin{array}{r}0 \\
-40,418 \\
83,718 \\
0 \\
0\end{array}$ & $\begin{array}{r}174 \\
-7.152 \\
0 \\
-476 \\
69\end{array}$ & $\begin{array}{l}\text { NA } \\
\text { NA } \\
\text { NA } \\
\text { NA }\end{array}$ & $\begin{array}{l}128,217 \\
686,095 \\
283,086 \\
282,160 \\
360,703\end{array}$ \\
\hline $\begin{array}{l}\text { Montana................... } \\
\text { Nebraska ................ } \\
\text { Nevada .................. } \\
\text { New Hampshire ...... } \\
\text { New Jersey............ }\end{array}$ & $\begin{array}{r}25,866 \\
8,453 \\
0 \\
b \\
0\end{array}$ & $\begin{array}{r}744 \\
1,170 \\
0 \\
b \\
0\end{array}$ & $\begin{array}{r}-1,289 \\
-1,020 \\
-592 \\
b \\
-1,033\end{array}$ & $\begin{array}{r}24,361 \\
183,044 \\
35,627 \\
b \\
252,509\end{array}$ & $\begin{array}{r}30,663 \\
0 \\
0 \\
b \\
0\end{array}$ & $\begin{array}{r}13,819 \\
646 \\
0 \\
b \\
-6\end{array}$ & $\begin{array}{l}\text { NA } \\
\text { NA } \\
\text { NA } \\
\text { NA }\end{array}$ & $\begin{array}{r}65,038 \\
188,661 \\
35,035 \\
b \\
251,482\end{array}$ \\
\hline $\begin{array}{l}\text { New Mexico ............. } \\
\text { New York.............. } \\
\text { North Carolina......... } \\
\text { North Dakota............ } \\
\text { Ohio ......................... }\end{array}$ & $\begin{array}{r}1,067,510 \\
3,837 \\
0 \\
40,462 \\
41,315\end{array}$ & $\begin{array}{r}46,149 \\
0 \\
0 \\
5,150 \\
0\end{array}$ & $\begin{array}{r}-12,616 \\
-3,228 \\
-1,204 \\
-316 \\
-2,338\end{array}$ & $\begin{array}{r}-752,937 \\
617,151 \\
99,185 \\
-3,138 \\
925,143\end{array}$ & $\begin{array}{r}0 \\
-25,912 \\
0 \\
0 \\
0\end{array}$ & $\begin{array}{r}218 \\
2,728 \\
0 \\
0 \\
1,299\end{array}$ & $\begin{array}{l}\text { NA } \\
\text { NA } \\
\text { NA } \\
\text { NA } \\
\text { NA }\end{array}$ & $\begin{array}{r}255,590 \\
589,120 \\
97,981 \\
31,858 \\
962,821\end{array}$ \\
\hline $\begin{array}{l}\text { Oklahoma ................ } \\
\text { Oregon.................... } \\
\text { Pennsytvania .......... } \\
\text { Rhode Island.......... } \\
\text { South Carolina........ }\end{array}$ & $\begin{array}{r}1,412,952 \\
0 \\
89,966 \\
0 \\
0\end{array}$ & $\begin{array}{r}50,952 \\
0 \\
121 \\
0 \\
0\end{array}$ & $\begin{array}{r}-4,537 \\
-1,743 \\
-11,305 \\
-612 \\
-3,973\end{array}$ & $\begin{array}{r}-881,580 \\
71,620 \\
617,504 \\
19,105 \\
104,512\end{array}$ & $\begin{array}{l}0 \\
0 \\
0 \\
0 \\
0\end{array}$ & $\begin{array}{r}26,505 \\
0 \\
17,566 \\
0 \\
0\end{array}$ & $\begin{array}{l}\text { NA } \\
\text { NA } \\
\text { NA } \\
\text { NA } \\
\text { NA }\end{array}$ & $\begin{array}{r}449,378 \\
69,877 \\
678,478 \\
18,493 \\
100,539\end{array}$ \\
\hline $\begin{array}{l}\text { South Dakota.......... } \\
\text { Tennessee............... } \\
\text { Texas..................... } \\
\text { Utah .......................... } \\
\text { Vermont ................. }\end{array}$ & $\begin{array}{r}0 \\
58 \\
7,188,900 \\
48,965 \\
b\end{array}$ & $\begin{array}{r}0 \\
0 \\
433,684 \\
2,633 \\
b\end{array}$ & $\begin{array}{r}-129 \\
-6,169 \\
-54,449 \\
-1,113 \\
b\end{array}$ & $\begin{array}{r}27,864 \\
238,323 \\
-3,247,981 \\
60,053 \\
b\end{array}$ & $\begin{array}{r}0 \\
0 \\
43,529 \\
0 \\
b\end{array}$ & $\begin{array}{r}0 \\
0 \\
11,069 \\
220 \\
b\end{array}$ & $\begin{array}{l}\text { NA } \\
\text { NA } \\
\text { NA } \\
\text { NA }\end{array}$ & $\begin{array}{r}27,735 \\
232,212 \\
3,485,246 \\
105,052 \\
b\end{array}$ \\
\hline $\begin{array}{l}\text { Virginia } \\
\text { Washington................. } \\
\text { West Virginia........... } \\
\text { Wisconsin ................. } \\
\text { Wyoming................ }\end{array}$ & $\begin{array}{r}3,818 \\
0 \\
211,460 \\
0 \\
240,074\end{array}$ & $\begin{array}{r}0 \\
0 \\
14,150 \\
0 \\
11,993\end{array}$ & $\begin{array}{l}-2,712 \\
-1,536 \\
-1,487 \\
-4,870 \\
-2,658\end{array}$ & $\begin{array}{r}114,853 \\
-10,598 \\
-34,230 \\
252,903 \\
-153,348\end{array}$ & $\begin{array}{r}0 \\
140,428 \\
0 \\
0 \\
0\end{array}$ & $\begin{array}{r}72 \\
1,064 \\
10,515 \\
0 \\
-1,209\end{array}$ & $\begin{array}{l}\text { NA } \\
\text { NA } \\
\text { NA } \\
\text { NA } \\
\text { NA }\end{array}$ & $\begin{array}{r}115,887 \\
127,230 \\
151,078 \\
248,033 \\
73,284\end{array}$ \\
\hline Total........................... & $18,171,325$ & 784,534 & $-296,214$ & 0 & 482,612 & 184,829 & NA & $17,388,360$ \\
\hline
\end{tabular}


Table 13. Natural Gas Production, Transmission, and Consumption by State, 1967-1994 (Continued) (Million Cubic Feet)

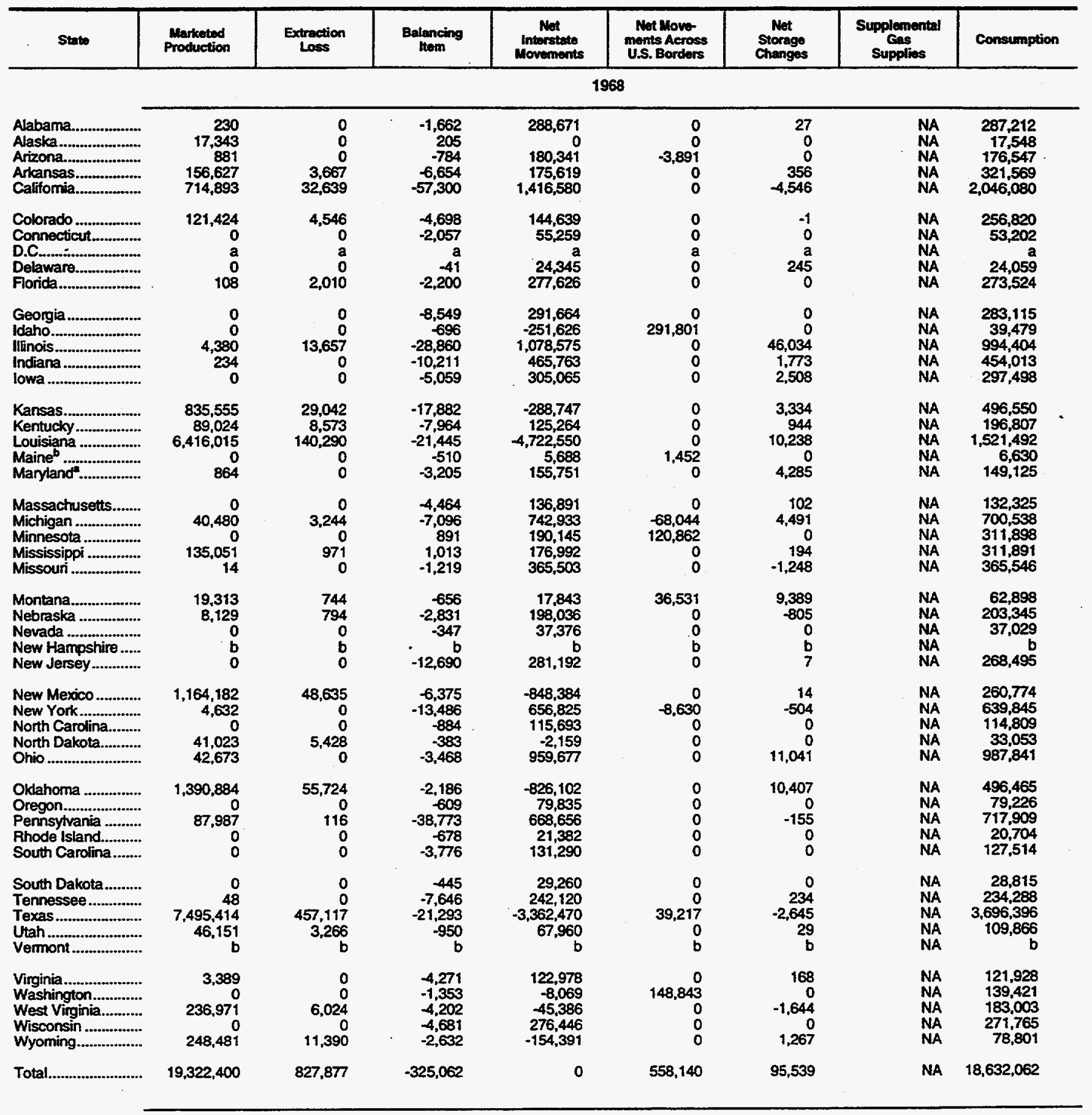

See footnotes at end of table. 
Table 13. Natural Gas Production, Jransmission, and Consumption by State, 1967-1994 (Continued) (Million Cubic Feet)

\begin{tabular}{|c|c|c|c|c|c|c|c|c|}
\hline State & $\begin{array}{l}\text { Marketed } \\
\text { Production }\end{array}$ & $\begin{array}{l}\text { Extraction } \\
\text { Loss }\end{array}$ & $\begin{array}{l}\text { Balancing } \\
\text { Hem }\end{array}$ & $\begin{array}{c}\text { Net } \\
\text { Interstate } \\
\text { Movements }\end{array}$ & $\begin{array}{l}\text { Net Mowo- } \\
\text { ments Across } \\
\text { U.S. Bonders }\end{array}$ & $\begin{array}{c}\text { Net } \\
\text { Storage } \\
\text { Changes }\end{array}$ & $\begin{array}{c}\text { Supplemental } \\
\text { Gas } \\
\text { Supplies }\end{array}$ & Consumption \\
\hline & \multicolumn{8}{|c|}{1969} \\
\hline $\begin{array}{l}\text { Alabama.................. } \\
\text { Alaska..................... } \\
\text { Arizona................... } \\
\text { Avkantsas................. } \\
\text { California................ }\end{array}$ & $\begin{array}{r}180 \\
50,864 \\
1,136 \\
169,257 \\
677,689\end{array}$ & $\begin{array}{r}236 \\
188 \\
0 \\
3,475 \\
30,334\end{array}$ & $\begin{array}{r}1,739 \\
-4,968 \\
-276 \\
-7,126 \\
-38,417\end{array}$ & $\begin{array}{r}299,351 \\
0 \\
198,496 \\
191,995 \\
1,452,623\end{array}$ & $\begin{array}{r}0 \\
-2,982 \\
-3,880 \\
0 \\
0\end{array}$ & $\begin{array}{r}142 \\
0 \\
0 \\
661 \\
13,027\end{array}$ & $\begin{array}{l}\text { NA } \\
\text { NA } \\
\text { NA } \\
\text { NA } \\
\text { NA }\end{array}$ & $\begin{array}{r}300,892 \\
42,726 \\
195,476 \\
349,990 \\
2,048,534\end{array}$ \\
\hline 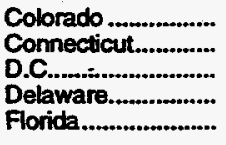 & $\begin{array}{r}118,754 \\
0 \\
2 \\
0 \\
50\end{array}$ & $\begin{array}{r}4,058 \\
0 \\
a \\
0 \\
1,723\end{array}$ & $\begin{array}{r}-5,399 \\
-1,948 \\
a \\
-473 \\
-658\end{array}$ & $\begin{array}{r}163,675 \\
59,433 \\
a \\
25,637 \\
314,216\end{array}$ & $\begin{array}{l}0 \\
0 \\
a \\
0 \\
0\end{array}$ & $\begin{array}{r}535 \\
0 \\
a \\
-699 \\
0\end{array}$ & $\begin{array}{l}\text { NA } \\
\text { NA } \\
\text { NA } \\
\text { NA } \\
\text { NA }\end{array}$ & $\begin{array}{r}272,437 \\
57,485 \\
a \\
25,863 \\
311,885\end{array}$ \\
\hline 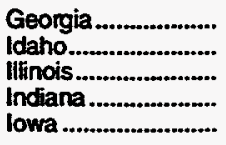 & $\begin{array}{r}0 \\
0 \\
3,800 \\
171 \\
0\end{array}$ & $\begin{array}{r}0 \\
0 \\
13,425 \\
0 \\
0\end{array}$ & $\begin{array}{r}-5,643 \\
-683 \\
-14,269 \\
-12,992 \\
-6,421\end{array}$ & $\begin{array}{r}317,186 \\
-269,977 \\
1,157,446 \\
547,900 \\
322,456\end{array}$ & $\begin{array}{r}0 \\
312,096 \\
0 \\
0 \\
0\end{array}$ & $\begin{array}{r}0 \\
0 \\
48,160 \\
4,098 \\
-2,306\end{array}$ & $\begin{array}{l}\text { NA } \\
\text { NA } \\
\text { NA } \\
\text { NA }\end{array}$ & $\begin{array}{r}311,543 \\
41,436 \\
1,085,392 \\
530,981 \\
318,341\end{array}$ \\
\hline $\begin{array}{l}\text { Kansas...................... } \\
\text { Kentucky ................ } \\
\text { Louisiana ................. } \\
\text { Maine }{ }^{b} \text {...................... } \\
\text { Mantand ................. }\end{array}$ & $\begin{array}{r}883,156 \\
81,304 \\
7,227,826 \\
0 \\
978\end{array}$ & $\begin{array}{r}35,813 \\
8,579 \\
179,117 \\
0 \\
0\end{array}$ & $\begin{array}{r}-5,201 \\
-11,683 \\
-26,812 \\
-494 \\
-4,288\end{array}$ & $\begin{array}{r}-294,283 \\
177,600 \\
-5,243,710 \\
7,595 \\
168,118\end{array}$ & $\begin{array}{r}0 \\
0 \\
0 \\
2,095 \\
0\end{array}$ & $\begin{array}{r}632 \\
3,760 \\
15,232 \\
0 \\
-4,136\end{array}$ & $\begin{array}{l}\text { NA } \\
\text { NA } \\
\text { NA } \\
\text { NA }\end{array}$ & $\begin{array}{r}547,227 \\
234,882 \\
1,762,955 \\
9,196 \\
168,944\end{array}$ \\
\hline $\begin{array}{l}\text { Massachusetts........ } \\
\text { Michigan ................ } \\
\text { Minnesota ............... } \\
\text { Mississippi ............... } \\
\text { Missouri .................. }\end{array}$ & $\begin{array}{r}0 \\
36,163 \\
0 \\
131,234 \\
126\end{array}$ & $\begin{array}{r}0 \\
2,705 \\
0 \\
1,334 \\
0\end{array}$ & $\begin{array}{r}-1,636 \\
-6,369 \\
-343 \\
-7,048 \\
-483\end{array}$ & $\begin{array}{l}138,371 \\
776,005 \\
188,343 \\
202,408 \\
398,189\end{array}$ & $\begin{array}{r}0 \\
-29,765 \\
137,687 \\
0 \\
0\end{array}$ & $\begin{array}{r}-253 \\
-3,244 \\
0 \\
-905 \\
-865\end{array}$ & $\begin{array}{l}\text { NA } \\
\text { NA } \\
\text { NA } \\
\text { NA } \\
\text { NA }\end{array}$ & $\begin{array}{l}136,988 \\
776,573 \\
325,687 \\
326,165 \\
398,697\end{array}$ \\
\hline $\begin{array}{l}\text { Montana ................... } \\
\text { Nebraska ............... } \\
\text { Nevada ................... } \\
\text { New Hampshire..... } \\
\text { New Jersey............. }\end{array}$ & $\begin{array}{r}41,229 \\
6,989 \\
0 \\
b \\
0\end{array}$ & $\begin{array}{r}705 \\
598 \\
0 \\
b \\
0\end{array}$ & $\begin{array}{r}-3,074 \\
1,618 \\
-759 \\
b \\
-11,743\end{array}$ & $\begin{array}{r}10,670 \\
203,336 \\
44,899 \\
b \\
316,784\end{array}$ & $\begin{array}{r}39,718 \\
0 \\
0 \\
b \\
0\end{array}$ & $\begin{array}{r}9,555 \\
1,312 \\
0 \\
b \\
206\end{array}$ & $\begin{array}{l}\text { NA } \\
\text { NA } \\
\text { NA } \\
\text { NA }\end{array}$ & $\begin{array}{r}78,283 \\
210,033 \\
44,140 \\
b \\
304,835\end{array}$ \\
\hline $\begin{array}{l}\text { New Mexico............. } \\
\text { New York............... } \\
\text { North Carolina........ } \\
\text { North Dakota........... } \\
\text { Ohio ........................ }\end{array}$ & $\begin{array}{r}1,138,133 \\
4,861 \\
0 \\
33,587 \\
49,793\end{array}$ & $\begin{array}{r}50,484 \\
0 \\
0 \\
4,707 \\
0\end{array}$ & $\begin{array}{r}-16,303 \\
-21,284 \\
-1,706 \\
-638 \\
-5,936\end{array}$ & $\begin{array}{r}-819,223 \\
691,431 \\
138,357 \\
4,440 \\
984,170\end{array}$ & $\begin{array}{r}0 \\
11,406 \\
0 \\
0 \\
0\end{array}$ & $\begin{array}{r}218 \\
2,726 \\
0 \\
0 \\
-3,936\end{array}$ & $\begin{array}{l}\text { NA } \\
\text { NA } \\
\text { NA } \\
\text { NA } \\
\text { NA }\end{array}$ & $\begin{array}{r}251,905 \\
683,688 \\
136,651 \\
32,682 \\
1,031,963\end{array}$ \\
\hline $\begin{array}{l}\text { Okdahoma ............... } \\
\text { Oregon.................. } \\
\text { Pernsylvania .......... } \\
\text { Rhode lsland.......... } \\
\text { South Carolina ........ }\end{array}$ & $\begin{array}{r}1,523,715 \\
0 \\
79,134 \\
0 \\
0\end{array}$ & $\begin{array}{r}57.270 \\
0 \\
93 \\
0 \\
0\end{array}$ & $\begin{array}{r}-17,207 \\
-2,516 \\
-39,152 \\
-575 \\
-5,239\end{array}$ & $\begin{array}{r}-886,888 \\
90,370 \\
730,571 \\
23,130 \\
146,065\end{array}$ & $\begin{array}{l}0 \\
0 \\
0 \\
0 \\
0\end{array}$ & $\begin{array}{r}16,159 \\
0 \\
4,519 \\
0 \\
0\end{array}$ & $\begin{array}{l}\text { NA } \\
\text { NA } \\
\text { NA } \\
\text { NA } \\
\text { NA }\end{array}$ & $\begin{array}{r}546,191 \\
87,854 \\
765,941 \\
22,555 \\
140,826\end{array}$ \\
\hline 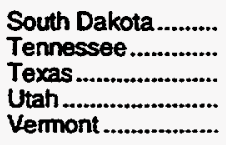 & $\begin{array}{r}0 \\
57 \\
7,853,199 \\
46,733 \\
b\end{array}$ & $\begin{array}{r}0 \\
0 \\
447,325 \\
3,412 \\
b\end{array}$ & $\begin{array}{r}-1,146 \\
-15,680 \\
-17,167 \\
-2,093 \\
b\end{array}$ & $\begin{array}{r}34,972 \\
263,480 \\
-3,545,304 \\
78,864 \\
b\end{array}$ & $\begin{array}{r}0 \\
0 \\
37,334 \\
0 \\
b\end{array}$ & $\begin{array}{r}0 \\
0 \\
3.361 \\
213 \\
b\end{array}$ & $\begin{array}{l}\text { NA } \\
\text { NA } \\
\text { NA } \\
\text { NA } \\
\text { NA }\end{array}$ & $\begin{array}{r}33,826 \\
247,857 \\
3,877,376 \\
119,879 \\
\cdot \quad b\end{array}$ \\
\hline $\begin{array}{l}\text { Virginia..................... } \\
\text { Washington............ } \\
\text { West Virginia........... } \\
\text { Wisconsin ................ } \\
\text { Wyoming............... }\end{array}$ & $\begin{array}{r}2,846 \\
0 \\
231,759 \\
0 \\
303,517\end{array}$ & $\begin{array}{r}0 \\
0 \\
8,439 \\
0 \\
12,540\end{array}$ & $\begin{array}{r}-6,263 \\
-1,185 \\
259 \\
-1,852 \\
-2,636\end{array}$ & $\begin{array}{r}134,174 \\
-25,140 \\
-51,766 \\
318,131 \\
-184,596\end{array}$ & $\begin{array}{r}0 \\
171,938 \\
0 \\
0 \\
0\end{array}$ & $\begin{array}{r}2,009 \\
1,092 \\
1,972 \\
0 \\
3,674\end{array}$ & $\begin{array}{l}\text { NA } \\
\text { NA } \\
\text { NA } \\
\text { NA } \\
\text { NA }\end{array}$ & $\begin{array}{l}128,748 \\
144,521 \\
169,841 \\
316,279 \\
100,071\end{array}$ \\
\hline 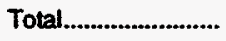 & $20,698,240$ & 866,560 & $-334,168$ & 0 & 675,647 & 116,919 & NA & $20,056,240$ \\
\hline
\end{tabular}

See footholes at end of table. 
Table 13. Natural Gas Production, Transmission, and Consumption by State, 1967-1994 (Continued) (Million Cubic Feet)

\begin{tabular}{|c|c|c|c|c|c|c|c|c|}
\hline State & $\begin{array}{l}\text { Marketod } \\
\text { Production }\end{array}$ & $\begin{array}{c}\text { Extraction } \\
\text { Loss }\end{array}$ & $\begin{array}{l}\text { Balencing } \\
\text { nem }\end{array}$ & $\begin{array}{c}\text { Net } \\
\text { Interstate } \\
\text { Movements }\end{array}$ & $\begin{array}{l}\text { Not Howo- } \\
\text { ments Across } \\
\text { U.S. Borders }\end{array}$ & $\begin{array}{l}\text { Net } \\
\text { Storage } \\
\text { Changes }\end{array}$ & $\begin{array}{c}\text { Supplemental } \\
\text { Gas } \\
\text { Supplies }\end{array}$ & Consumption \\
\hline & \multicolumn{8}{|c|}{1970} \\
\hline $\begin{array}{l}\text { Alabama.................... } \\
\text { Alaska ...................... } \\
\text { Arizona................... } \\
\text { Arkansas................. } \\
\text { California................ }\end{array}$ & $\begin{array}{r}627 \\
111,576 \\
1,101 \\
181,351 \\
649,117\end{array}$ & $\begin{array}{r}225 \\
264 \\
0 \\
3,235 \\
29,901\end{array}$ & $\begin{array}{r}3,908 \\
-3,329 \\
-2,083 \\
-13,773 \\
-30,871\end{array}$ & $\begin{array}{r}294,753 \\
0 \\
198,022 \\
217,814 \\
1,566,146\end{array}$ & $\begin{array}{r}0 \\
-44,257 \\
-4,044 \\
0 \\
0\end{array}$ & $\begin{array}{r}566 \\
0 \\
0 \\
206 \\
28,025\end{array}$ & $\begin{array}{l}\text { NA } \\
\text { NA } \\
\text { NA } \\
\text { NA }\end{array}$ & $\begin{array}{r}298,497 \\
63,726 \\
192,996 \\
381,951 \\
2,126,466\end{array}$ \\
\hline 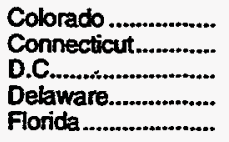 & $\begin{array}{r}105,804 \\
0 \\
a \\
0 \\
0\end{array}$ & $\begin{array}{r}3,405 \\
0 \\
a \\
0 \\
1,829\end{array}$ & $\begin{array}{r}3,671 \\
-1,801 \\
a \\
-689 \\
2,816\end{array}$ & $\begin{array}{r}179,385 \\
62,375 \\
a \\
26,899 \\
335,829\end{array}$ & $\begin{array}{l}0 \\
0 \\
a \\
0 \\
0\end{array}$ & $\begin{array}{r}3,127 \\
0 \\
2 \\
-211 \\
0\end{array}$ & $\begin{array}{l}\text { NA } \\
\text { NA } \\
\text { NA } \\
\text { NA }\end{array}$ & $\begin{array}{r}282,328 \\
60,574 \\
a \\
26,421 \\
336,816\end{array}$ \\
\hline 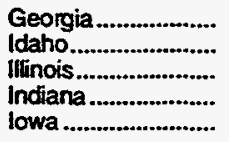 & $\begin{array}{r}0 \\
0 \\
4,850 \\
153 \\
0\end{array}$ & $\begin{array}{r}0 \\
0 \\
14,165 \\
0 \\
0\end{array}$ & $\begin{array}{l}-4,810 \\
-1,248 \\
-6,821 \\
-6,457 \\
-9,017\end{array}$ & $\begin{array}{r}337,336 \\
-305,822 \\
1,268,207 \\
561,697 \\
361,912\end{array}$ & $\begin{array}{r}0 \\
353,640 \\
0 \\
0 \\
0\end{array}$ & $\begin{array}{r}0 \\
0 \\
78,193 \\
10,025 \\
4,233\end{array}$ & $\begin{array}{l}\text { NA } \\
\text { NA } \\
\text { NA } \\
\text { NA } \\
\text { NA }\end{array}$ & $\begin{array}{r}332,526 \\
46,570 \\
1,173,878 \\
545,368 \\
348,652\end{array}$ \\
\hline $\begin{array}{l}\text { Kansas.................... } \\
\text { Kentucky................ } \\
\text { Louisiana ................ } \\
\text { Maineb ...................... } \\
\text { Maryiand ................ }\end{array}$ & $\begin{array}{r}899,955 \\
77,892 \\
7,788,276 \\
0 \\
813\end{array}$ & $\begin{array}{r}38,843 \\
6,574 \\
193,209 \\
0 \\
0\end{array}$ & $\begin{array}{r}-10,433 \\
-1,087 \\
-21,808 \\
-194 \\
-4,003\end{array}$ & $\begin{array}{r}-269,087 \\
188,193 \\
-5,669,909 \\
8,353 \\
187,677\end{array}$ & $\begin{array}{r}0 \\
0 \\
0 \\
2,532 \\
0\end{array}$ & $\begin{array}{r}5,898 \\
10,376 \\
62,510 \\
0 \\
2,352\end{array}$ & $\begin{array}{l}\text { NA } \\
\text { NA } \\
\text { NA } \\
\text { NA } \\
\text { NA }\end{array}$ & $\begin{array}{r}575,694 \\
248,048 \\
1,840,840 \\
10,691 \\
182,135\end{array}$ \\
\hline $\begin{array}{l}\text { Massachusetts........ } \\
\text { Michigan ................ } \\
\text { Minnesota .............. } \\
\text { Mississippi ............... } \\
\text { Missouri .................. }\end{array}$ & $\begin{array}{r}0 \\
38,851 \\
0 \\
126,031 \\
87\end{array}$ & $\begin{array}{r}0 \\
2,330 \\
0 \\
1,270 \\
0\end{array}$ & $\begin{array}{r}-742 \\
18,600 \\
-2,834 \\
-8,263 \\
-7,098\end{array}$ & $\begin{array}{l}147,492 \\
791,773 \\
172,937 \\
247,794 \\
437,750\end{array}$ & $\begin{array}{r}757 \\
-10,643 \\
172,219 \\
0 \\
0\end{array}$ & $\begin{array}{r}200 \\
27,127 \\
0 \\
3,910 \\
1,213\end{array}$ & $\begin{array}{l}\text { NA } \\
\text { NA } \\
\text { NA } \\
\text { NA } \\
\text { NA }\end{array}$ & $\begin{array}{l}147,307 \\
809,124 \\
342,322 \\
360,382 \\
429,526\end{array}$ \\
\hline $\begin{array}{l}\text { Montana.................... } \\
\text { Nebraska ............... } \\
\text { Nevada ................. } \\
\text { New Hampshire ...... } \\
\text { New Jersey............. }\end{array}$ & $\begin{array}{r}42,705 \\
5,991 \\
0 \\
b \\
0\end{array}$ & $\begin{array}{r}3,032 \\
555 \\
0 \\
b \\
0\end{array}$ & $\begin{array}{r}-4,173 \\
12,472 \\
-735 \\
0 \\
-10,728\end{array}$ & $\begin{array}{r}20,316 \\
203,645 \\
53,293 \\
b \\
334,020\end{array}$ & $\begin{array}{r}42,451 \\
0 \\
0 \\
b \\
0\end{array}$ & $\begin{array}{r}10,476 \\
-782 \\
0 \\
b \\
439\end{array}$ & $\begin{array}{l}\text { NA } \\
\text { NA } \\
\text { NA } \\
\text { NA } \\
\text { NA }\end{array}$ & $\begin{array}{r}87,791 \\
222,335 \\
52,558 \\
b \\
322,853\end{array}$ \\
\hline $\begin{array}{l}\text { New Mexico ............. } \\
\text { New Yokk............... } \\
\text { North Carolina........ } \\
\text { North Dakota........... } \\
\text { Ohio ......................... }\end{array}$ & $\begin{array}{r}1,138,980 \\
3,358 \\
0 \\
34,889 \\
52,113\end{array}$ & $\begin{array}{r}52,647 \\
0 \\
0 \\
4,490 \\
0\end{array}$ & $\begin{array}{r}-5,673 \\
-20,919 \\
-3,941 \\
683 \\
15,012\end{array}$ & $\begin{array}{r}-810,400 \\
701,195 \\
155,168 \\
1,635 \\
995,146\end{array}$ & $\begin{array}{r}0 \\
33,512 \\
0 \\
0 \\
0\end{array}$ & $\begin{array}{r}157 \\
6,261 \\
0 \\
0 \\
9,338\end{array}$ & $\begin{array}{l}\text { NA } \\
\text { NA } \\
\text { NA } \\
\text { NA } \\
\text { NA }\end{array}$ & $\begin{array}{r}270,103 \\
710,885 \\
151,227 \\
32,717 \\
1,052,933\end{array}$ \\
\hline $\begin{array}{l}\text { Okjahoma ................ } \\
\text { Oregon................. } \\
\text { Pennsylvania .......... } \\
\text { Rhode Island........... } \\
\text { South Carolina ........ }\end{array}$ & $\begin{array}{r}1,594,943 \\
0 \\
76,841 \\
0 \\
0\end{array}$ & $\begin{array}{r}58,926 \\
0 \\
79 \\
0 \\
0\end{array}$ & $\begin{array}{r}-17,504 \\
-3,434 \\
21,460 \\
-967 \\
-4,075\end{array}$ & $\begin{array}{r}-909,928 \\
98,718 \\
763,154 \\
26,060 \\
163,905\end{array}$ & $\begin{array}{l}0 \\
0 \\
0 \\
0 \\
0\end{array}$ & $\begin{array}{r}11,416 \\
0 \\
88,988 \\
0 \\
0\end{array}$ & $\begin{array}{l}\text { NA } \\
\text { NA } \\
\text { NA } \\
\text { NA }\end{array}$ & $\begin{array}{r}597,169 \\
95,284 \\
772,388 \\
25,093 \\
159,830\end{array}$ \\
\hline $\begin{array}{l}\text { South Dakota.......... } \\
\text { Tennessee.............. } \\
\text { Texas...................... } \\
\text { Utah ......................... } \\
\text { Vemont .................. }\end{array}$ & $\begin{array}{r}0 \\
64 \\
8,357,716 \\
42,781 \\
b\end{array}$ & $\begin{array}{r}0 \\
0 \\
466,016 \\
1,493 \\
b\end{array}$ & $\begin{array}{r}-840 \\
-7,178 \\
-54,247 \\
-1,651 \\
b\end{array}$ & $\begin{array}{r}37,159 \\
263,262 \\
-3,775,722 \\
82,408 \\
\text { b }\end{array}$ & $\begin{array}{r}0 \\
0 \\
30,702 \\
0 \\
b\end{array}$ & $\begin{array}{r}0 \\
0 \\
-924 \\
108 \\
b\end{array}$ & $\begin{array}{l}\text { NA } \\
\text { NA } \\
\text { NA } \\
\text { NA } \\
\text { NA }\end{array}$ & $\begin{array}{r}36,319 \\
256,148 \\
4,093,357 \\
121,937 \\
b\end{array}$ \\
\hline $\begin{array}{l}\text { Virginia................... } \\
\text { Washington............ } \\
\text { West Virginia.......... } \\
\text { Wisconsin ............... } \\
\text { Wyoming................. }\end{array}$ & $\begin{array}{r}2,805 \\
0 \\
242,452 \\
0 \\
338,520\end{array}$ & $\begin{array}{r}0 \\
0 \\
11,062 \\
0 \\
12,863\end{array}$ & $\begin{array}{r}-3,543 \\
-2,208 \\
-9,073 \\
-11,195 \\
-6,827\end{array}$ & $\begin{array}{r}139,243 \\
-16,558 \\
-16,609 \\
349,017 \\
-205,653\end{array}$ & $\begin{array}{r}0 \\
174,098 \\
0 \\
0 \\
0\end{array}$ & $\begin{array}{r}1,982 \\
5,340 \\
24,430 \\
0 \\
3,181\end{array}$ & $\begin{array}{l}\text { NA } \\
\text { NA } \\
\text { NA } \\
\text { NA } \\
\text { NA }\end{array}$ & $\begin{array}{l}136,523 \\
149,992 \\
181,278 \\
337,822 \\
109,996\end{array}$ \\
\hline Total........................... & $21,920,642$ & 906,413 & $-227,650$ & $\therefore 0$ & 750,967 & 398,160 & NA & $21,139,386$ \\
\hline
\end{tabular}

See footnotes at end of table. 
Table 13. Naturat Gas Production, Transmission, and Consumption by State, 1967-1994 (Continued) (Million Cubic Feet)

\begin{tabular}{|c|c|c|c|c|c|c|c|c|}
\hline State & $\begin{array}{l}\text { Marketed } \\
\text { Production }\end{array}$ & $\begin{array}{c}\text { Extraction } \\
\text { Loss }\end{array}$ & $\begin{array}{l}\text { Balancing } \\
\text { Hem }\end{array}$ & $\begin{array}{c}\text { Net } \\
\text { Interstate } \\
\text { Movements }\end{array}$ & $\begin{array}{l}\text { Net Movo- } \\
\text { ments Across } \\
\text { U.S. Borders }\end{array}$ & $\begin{array}{l}\text { Net } \\
\text { Storage } \\
\text { Changes }\end{array}$ & $\begin{array}{c}\text { Supplemental } \\
\text { Gas } \\
\text { Supplies }\end{array}$ & Consumption \\
\hline & \multicolumn{8}{|c|}{1971} \\
\hline 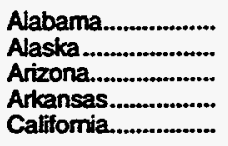 & $\begin{array}{r}355 \\
121,618 \\
868 \\
172,154 \\
612,629\end{array}$ & $\begin{array}{r}281 \\
99 \\
0 \\
2,563 \\
27,585\end{array}$ & $\begin{array}{r}6,787 \\
-3,582 \\
-4,038 \\
-19,063 \\
-36,126\end{array}$ & $\begin{array}{r}279,295 \\
0 \\
221,142 \\
183,682 \\
1,611,970\end{array}$ & $\begin{array}{r}0 \\
-50,231 \\
-4,659 \\
0 \\
0\end{array}$ & $\begin{array}{r}183 \\
0 \\
0 \\
566 \\
11,624\end{array}$ & $\begin{array}{l}\text { NA } \\
\text { NA } \\
\text { NA } \\
\text { NA }\end{array}$ & $\begin{array}{r}285,973 \\
67,706 \\
213,313 \\
333,644 \\
2,149,264\end{array}$ \\
\hline 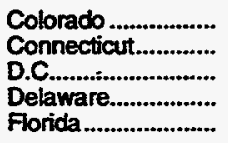 & $\begin{array}{r}108,537 \\
0 \\
a \\
0 \\
903\end{array}$ & $\begin{array}{r}4,152 \\
0 \\
a \\
0 \\
180\end{array}$ & $\begin{array}{r}-3,079 \\
-1,455 \\
a \\
-291 \\
-914\end{array}$ & $\begin{array}{r}187,469 \\
62,889 \\
a \\
26,932 \\
336,912\end{array}$ & $\begin{array}{l}0 \\
0 \\
a \\
0 \\
0\end{array}$ & $\begin{array}{r}-594 \\
0 \\
a \\
189 \\
0\end{array}$ & $\begin{array}{l}\text { NA } \\
\text { NA } \\
\text { NA } \\
\text { NA } \\
\text { NA }\end{array}$ & $\begin{array}{r}289,369 \\
61,434 \\
a \\
26,452 \\
336,721\end{array}$ \\
\hline 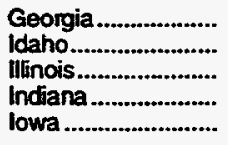 & $\begin{array}{r}0 \\
0 \\
498 \\
537 \\
0\end{array}$ & $\begin{array}{r}0 \\
0 \\
13,520 \\
0 \\
0\end{array}$ & $\begin{array}{r}-11,050 \\
-1,458 \\
-8,394 \\
-5,976 \\
-2,520\end{array}$ & $\begin{array}{r}353,629 \\
-353,665 \\
1,338,285 \\
579,312 \\
354,945\end{array}$ & $\begin{array}{r}0 \\
405,219 \\
0 \\
0 \\
0\end{array}$ & $\begin{array}{r}0 \\
0 \\
87,592 \\
6,877 \\
7,786\end{array}$ & $\begin{array}{l}\text { NA } \\
\text { NA } \\
\text { NA } \\
\text { NA } \\
\text { NA }\end{array}$ & $\begin{array}{r}342,579 \\
50,096 \\
1,229,277 \\
566,996 \\
344,639\end{array}$ \\
\hline 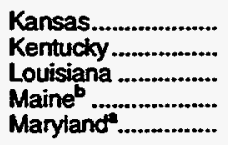 & $\begin{array}{r}885,144 \\
72,723 \\
8,081,907 \\
0 \\
214\end{array}$ & $\begin{array}{r}39,741 \\
6,133 \\
195,072 \\
0 \\
0\end{array}$ & $\begin{array}{r}-16,386 \\
-2,582 \\
-23,084 \\
-347 \\
-3,859\end{array}$ & $\begin{array}{r}-221,844 \\
196,572 \\
-5,909,963 \\
9,615 \\
194,328\end{array}$ & $\begin{array}{r}0 \\
0 \\
0 \\
2,820 \\
0\end{array}$ & $\begin{array}{r}184 \\
16,220 \\
69,864 \\
0 \\
2,312\end{array}$ & $\begin{array}{l}\text { NA } \\
\text { NA } \\
\text { NA } \\
\text { NA } \\
\text { NA }\end{array}$ & $\begin{array}{r}606,989 \\
244,360 \\
1,883,924 \\
12,088 \\
188,371\end{array}$ \\
\hline $\begin{array}{l}\text { Massachusetts........ } \\
\text { Michigan ................. } \\
\text { Minnesota ................ } \\
\text { Mississippi .............. } \\
\text { Missouri .................. }\end{array}$ & $\begin{array}{r}0 \\
25,662 \\
0 \\
118,805 \\
22\end{array}$ & $\begin{array}{r}0 \\
2,013 \\
0 \\
1,217 \\
0\end{array}$ & $\begin{array}{r}-1,913 \\
8,640 \\
-9,152 \\
-9,639 \\
-5,311\end{array}$ & $\begin{array}{l}155,527 \\
839,385 \\
110,659 \\
271,232 \\
435,839\end{array}$ & $\begin{array}{r}2,933 \\
-14,236 \\
249,935 \\
0 \\
0\end{array}$ & $\begin{array}{r}96 \\
6,876 \\
0 \\
860 \\
1,445\end{array}$ & $\begin{array}{l}\text { NA } \\
\text { NA } \\
\text { NA } \\
\text { NA }\end{array}$ & $\begin{array}{l}156,451 \\
850,562 \\
351,442 \\
378,321 \\
429,105\end{array}$ \\
\hline $\begin{array}{l}\text { Montana .................. } \\
\text { Nebraska ............... } \\
\text { Nevada ................. } \\
\text { New Hampshire...... } \\
\text { New Jersey............. }\end{array}$ & $\begin{array}{r}32,720 \\
3,496 \\
0 \\
b \\
0\end{array}$ & $\begin{array}{r}750 \\
599 \\
0 \\
b \\
0\end{array}$ & $\begin{array}{r}-3,745 \\
12,344 \\
-1,454 \\
b \\
-14,581\end{array}$ & $\begin{array}{r}22,316 \\
212,059 \\
67,965 \\
b \\
341,506\end{array}$ & $\begin{array}{r}44,534 \\
0 \\
0 \\
b \\
0\end{array}$ & $\begin{array}{r}6,804 \\
3,626 \\
0 \\
b \\
157\end{array}$ & $\begin{array}{l}\text { NA } \\
\text { NA } \\
\text { NA } \\
\text { NA } \\
\text { NA }\end{array}$ & $\begin{array}{r}88,271 \\
223,674 \\
66,511 \\
b \\
326,768\end{array}$ \\
\hline $\begin{array}{l}\text { New Mexico ............ } \\
\text { New York.............. } \\
\text { North Carolina........ } \\
\text { North Dakota........... } \\
\text { Ohio ........................ }\end{array}$ & $\begin{array}{r}1,167,577 \\
2,202 \\
0 \\
33,864 \\
79,903\end{array}$ & $\begin{array}{r}53,810 \\
0 \\
0 \\
3,592 \\
0\end{array}$ & $\begin{array}{r}-11,894 \\
-28,642 \\
-3,854 \\
-617 \\
-6,539\end{array}$ & $\begin{array}{r}-832,505 \\
731,238 \\
164,421 \\
3,922 \\
1,033,845\end{array}$ & $\begin{array}{r}0 \\
19,171 \\
0 \\
0 \\
0\end{array}$ & $\begin{array}{r}0 \\
7,419 \\
0 \\
0 \\
20,083\end{array}$ & $\begin{array}{l}\text { NA } \\
\text { NA } \\
\text { NA } \\
\text { NA } \\
\text { NA }\end{array}$ & $\begin{array}{r}269,368 \\
716,550 \\
160,567 \\
33,577 \\
1,087,126\end{array}$ \\
\hline $\begin{array}{l}\text { Oklahoma ................. } \\
\text { Oregon.................. } \\
\text { Pennsylvania .......... } \\
\text { Phode Island.......... } \\
\text { South Carolina ........ }\end{array}$ & $\begin{array}{r}1,684,260 \\
0 \\
76,451 \\
0 \\
0\end{array}$ & $\begin{array}{r}55,914 \\
0 \\
55 \\
0 \\
0\end{array}$ & $\begin{array}{r}-13,853 \\
-1,935 \\
-20,362 \\
-44 \\
-3,142\end{array}$ & $\begin{array}{r}-981,943 \\
102,832 \\
764,856 \\
25,706 \\
159,405\end{array}$ & $\begin{array}{l}0 \\
0 \\
0 \\
0 \\
0\end{array}$ & $\begin{array}{r}20,968 \\
0 \\
18,777 \\
0 \\
0\end{array}$ & $\begin{array}{l}\text { NA } \\
\text { NA } \\
\text { NA } \\
\text { NA }\end{array}$ & $\begin{array}{r}611,582 \\
100,897 \\
802,113 \\
25,662 \\
156,263\end{array}$ \\
\hline $\begin{array}{l}\text { South Dakota ........... } \\
\text { Tennessee.............. } \\
\text { Texas ..................... } \\
\text { Utah .......................... } \\
\text { Vemont .................. }\end{array}$ & $\begin{array}{r}0 \\
89 \\
8,550,705 \\
42,418 \\
b\end{array}$ & $\begin{array}{r}0 \\
0 \\
448,288 \\
3,822 \\
b\end{array}$ & $\begin{array}{r}-162 \\
-8,818 \\
-84,859 \\
-1,754 \\
b\end{array}$ & $\begin{array}{r}31,994 \\
273,740 \\
-3,660,148 \\
84,716 \\
b\end{array}$ & $\begin{array}{r}0 \\
0 \\
9,716 \\
0 \\
\text { b }\end{array}$ & $\begin{array}{r}0 \\
0 \\
2,398 \\
155 \\
b\end{array}$ & $\begin{array}{l}\text { NA } \\
\text { NA } \\
\text { NA } \\
\text { NA } \\
\text { NA }\end{array}$ & $\begin{array}{r}31,832 \\
265,011 \\
4,364,728 \\
121,403 \\
b\end{array}$ \\
\hline $\begin{array}{l}\text { Virginia................... } \\
\text { Washington............ } \\
\text { West Virginia.......... } \\
\text { Wisconsin ................ } \\
\text { Wyoming................. }\end{array}$ & $\begin{array}{r}2,619 \\
0 \\
234,027 \\
0 \\
380,105\end{array}$ & $\begin{array}{r}0 \\
0 \\
10,939 \\
0 \\
12,802\end{array}$ & $\begin{array}{r}-4,155 \\
-2,715 \\
19,793 \\
-963 \\
-2,256\end{array}$ & $\begin{array}{r}147,589 \\
-28,514 \\
-35,255 \\
349,095 \\
-242,987\end{array}$ & $\begin{array}{r}0 \\
189.134 \\
0 \\
0 \\
0\end{array}$ & $\begin{array}{r}2,039 \\
1,242 \\
29,246 \\
0 \\
6,774\end{array}$ & $\begin{array}{l}\text { NA } \\
\text { NA } \\
\text { NA } \\
\text { NA } \\
\text { NA }\end{array}$ & $\begin{array}{l}144,014 \\
156,663 \\
178,380 \\
348,132 \\
115,286\end{array}$ \\
\hline 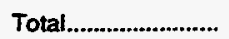 & $22,493,012$ & 883,127 & $-338,999$ & 0 & 854,336 & 331,768 & NA & $21,793,454$ \\
\hline
\end{tabular}

See footnotes at end of table. 
Table 13. Natural Gas Production, Transmission, and Consumption by State, 1967-1994 (Continued) (Million Cubic Feet)

\begin{tabular}{|c|c|c|c|c|c|c|c|c|}
\hline State & $\begin{array}{l}\text { Marketed } \\
\text { Production }\end{array}$ & $\begin{array}{l}\text { Extraction } \\
\text { Loss }\end{array}$ & $\begin{array}{l}\text { Balancing } \\
\text { ftom }\end{array}$ & $\begin{array}{c}\text { Net } \\
\text { Interstate } \\
\text { Movements }\end{array}$ & $\begin{array}{l}\text { Not Move- } \\
\text { ments Across } \\
\text { U.S. Borders }\end{array}$ & $\begin{array}{c}\text { Not } \\
\text { Storage } \\
\text { Changes }\end{array}$ & $\begin{array}{l}\text { Suppiemental } \\
\text { Cas } \\
\text { Supplies }\end{array}$ & Consumption \\
\hline & \multicolumn{8}{|c|}{1972} \\
\hline $\begin{array}{l}\text { Alabama.................. } \\
\text { Alaska.................... } \\
\text { Arizona................... } \\
\text { Arkansas............... } \\
\text { Calffomia................. }\end{array}$ & $\begin{array}{r}3,644 \\
125,596 \\
442 \\
166,522 \\
487,278\end{array}$ & $\begin{array}{r}243 \\
749 \\
0 \\
1,197 \\
24,156\end{array}$ & $\begin{array}{r}-6,140 \\
-2,307 \\
-4,745 \\
-24,206 \\
-10,557\end{array}$ & $\begin{array}{r}281,335 \\
0 \\
236,733 \\
175,385 \\
1,778,649\end{array}$ & $\begin{array}{r}0 \\
-47,882 \\
-4,521 \\
0 \\
0\end{array}$ & $\begin{array}{r}129 \\
0 \\
0 \\
129 \\
45,671\end{array}$ & $\begin{array}{l}\text { NA } \\
\text { NA } \\
\text { NA } \\
\text { NA }\end{array}$ & $\begin{array}{r}278,467 \\
74,658 \\
227,909 \\
316,375 \\
2,185,543\end{array}$ \\
\hline 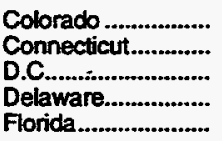 & $\begin{array}{r}116,949 \\
0 \\
a \\
0 \\
15,521\end{array}$ & $\begin{array}{r}4,114 \\
0 \\
a \\
0 \\
2,144\end{array}$ & $\begin{array}{r}-8,022 \\
-2,877 \\
a \\
92 \\
-1,650\end{array}$ & $\begin{array}{r}204,368 \\
66,885 \\
a \\
23,996 \\
287,250\end{array}$ & $\begin{array}{l}0 \\
0 \\
a \\
0 \\
0\end{array}$ & $\begin{array}{r}-522 \\
0 \\
a \\
0 \\
0\end{array}$ & $\begin{array}{l}\text { NA } \\
\text { NA } \\
\text { NA } \\
\text { NA }\end{array}$ & $\begin{array}{r}309,703 \\
64,008 \\
a \\
24,088 \\
298,977\end{array}$ \\
\hline 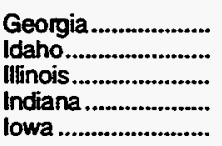 & $\begin{array}{r}0 \\
0 \\
1,194 \\
355 \\
0\end{array}$ & $\begin{array}{r}0 \\
0 \\
13,346 \\
0 \\
0\end{array}$ & $\begin{array}{r}-5,290 \\
-3,843 \\
-9,841 \\
-12,471 \\
1,755\end{array}$ & $\begin{array}{r}336,433 \\
-374,363 \\
1,269,192 \\
588,988 \\
350,040\end{array}$ & $\begin{array}{r}0 \\
434,836 \\
0 \\
0 \\
0\end{array}$ & $\begin{array}{r}0 \\
0 \\
39,910 \\
-76 \\
7,279\end{array}$ & $\begin{array}{l}\text { NA } \\
\text { NA } \\
\text { NA } \\
\text { NA }\end{array}$ & $\begin{array}{r}331,143 \\
56,630 \\
1,207,289 \\
576,948 \\
344,516\end{array}$ \\
\hline 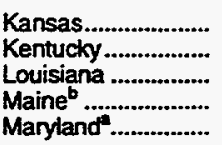 & $\begin{array}{r}889,268 \\
63,648 \\
7,972,678 \\
0 \\
244\end{array}$ & $\begin{array}{r}40,738 \\
6,063 \\
197,967 \\
0 \\
0\end{array}$ & $\begin{array}{r}-5,182 \\
-10,437 \\
-12,634 \\
-760 \\
-7,683\end{array}$ & $\begin{array}{r}-216,820 \\
216,359 \\
-5,822,848 \\
10,282 \\
212,089\end{array}$ & $\begin{array}{r}0 \\
0 \\
0 \\
3,745 \\
0\end{array}$ & $\begin{array}{r}-1,581 \\
8,299 \\
-533 \\
0 \\
-272\end{array}$ & $\begin{array}{l}\text { NA } \\
\text { NA } \\
\text { NA } \\
\text { NA }\end{array}$ & $\begin{array}{r}628,109 \\
255,208 \\
1,939,762 \\
13,267 \\
204,922\end{array}$ \\
\hline $\begin{array}{l}\text { Massachusetts........ } \\
\text { Michigan ................. } \\
\text { Minnesota ............. } \\
\text { Mississippi .............. } \\
\text { Missouri ................... }\end{array}$ & $\begin{array}{r}0 \\
34,221 \\
0 \\
103,989 \\
9\end{array}$ & $\begin{array}{r}0 \\
1,912 \\
0 \\
1,058 \\
0\end{array}$ & $\begin{array}{l}-5,362 \\
-6,659 \\
-4,941 \\
-9,639 \\
-6,020\end{array}$ & $\begin{array}{r}164,454 \\
823,515 \\
99,493 \\
360,298 \\
434,722\end{array}$ & $\begin{array}{r}2,262 \\
-15,426 \\
256,856 \\
0 \\
0\end{array}$ & $\begin{array}{r}1,074 \\
-31,031 \\
0 \\
75,604 \\
1,496\end{array}$ & $\begin{array}{l}\text { NA } \\
\text { NA } \\
\text { NA } \\
\text { NA }\end{array}$ & $\begin{array}{l}160,280 \\
864,770 \\
351,408 \\
377,986 \\
425,215\end{array}$ \\
\hline $\begin{array}{l}\text { Montana.................. } \\
\text { Nebraska .............. } \\
\text { Nevada .............. } \\
\text { New Hampshire ...... } \\
\text { New Jersey............ }\end{array}$ & $\begin{array}{r}33,474 \\
3,478 \\
0 \\
b \\
0\end{array}$ & $\begin{array}{r}839 \\
539 \\
0 \\
b \\
0\end{array}$ & $\begin{array}{r}-1,004 \\
-10,586 \\
-1,692 \\
b \\
-11,624\end{array}$ & $\begin{array}{r}5,749 \\
238,764 \\
71,214 \\
b \\
332,892\end{array}$ & $\begin{array}{r}48,462 \\
0 \\
0 \\
b \\
0\end{array}$ & $\begin{array}{r}1,520 \\
6,555 \\
0 \\
b \\
-20\end{array}$ & $\begin{array}{l}\text { NA } \\
\text { NA } \\
\text { NA } \\
\text { NA } \\
\text { NA }\end{array}$ & $\begin{array}{r}84,322 \\
224,562 \\
69,522 \\
b \\
321,288\end{array}$ \\
\hline $\begin{array}{l}\text { New Mexico ............. } \\
\text { New York............... } \\
\text { North Carolina........ } \\
\text { North Dakota.......... } \\
\text { Ohio .......................... }\end{array}$ & $\begin{array}{r}1,216,061 \\
3,679 \\
0 \\
32,472 \\
89,995\end{array}$ & $\begin{array}{r}54,157 \\
0 \\
0 \\
3,199 \\
0\end{array}$ & $\begin{array}{r}-7,972 \\
-4,978 \\
-4,389 \\
-1,138 \\
-11,335\end{array}$ & $\begin{array}{r}-865,939 \\
674,341 \\
168,286 \\
8,338 \\
1,047,574\end{array}$ & $\begin{array}{r}0 \\
9,571 \\
0 \\
0 \\
0\end{array}$ & $\begin{array}{r}0 \\
-10,117 \\
0 \\
0 \\
-21,570\end{array}$ & $\begin{array}{l}\text { NA } \\
\text { NA } \\
\text { NA } \\
\text { NA } \\
\text { NA }\end{array}$ & $\begin{array}{r}287,993 \\
692,730 \\
163,897 \\
36,473 \\
1,147,804\end{array}$ \\
\hline $\begin{array}{l}\text { Oklahoma ............... } \\
\text { Oregon................ } \\
\text { Pennsytvania ......... } \\
\text { Rhode Island......... } \\
\text { South Carolina ........ }\end{array}$ & $\begin{array}{r}1,806,887 \\
0 \\
73,958 \\
0 \\
0\end{array}$ & $\begin{array}{r}56,376 \\
0 \\
70 \\
0 \\
0\end{array}$ & $\begin{array}{r}-19,336 \\
-4,715 \\
-18,625 \\
-997 \\
-6,917\end{array}$ & $\begin{array}{r}-1,109,209 \\
115,075 \\
766,627 \\
23,491 \\
151,037\end{array}$ & $\begin{array}{l}0 \\
0 \\
0 \\
0 \\
0\end{array}$ & $\begin{array}{r}-7,791 \\
0 \\
-7,071 \\
0 \\
0\end{array}$ & $\begin{array}{l}\text { NA } \\
\text { NA } \\
\text { NA } \\
\text { NA } \\
\text { NA }\end{array}$ & $\begin{array}{r}629,757 \\
110,360 \\
828,961 \\
22,494 \\
144,120\end{array}$ \\
\hline 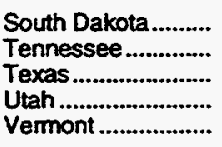 & $\begin{array}{r}0 \\
25 \\
8,657,840 \\
39,474 \\
b\end{array}$ & $\begin{array}{r}0 \\
0 \\
470,105 \\
3,382 \\
b\end{array}$ & $\begin{array}{r}-736 \\
-6,093 \\
6,949 \\
-13,101 \\
b\end{array}$ & $\begin{array}{r}34,813 \\
283,343 \\
-3,740,150 \\
101,317 \\
b\end{array}$ & $\begin{array}{r}0 \\
0 \\
-1,916 \\
0 \\
b\end{array}$ & $\begin{array}{r}0 \\
0 \\
39,982 \\
215 \\
b\end{array}$ & $\begin{array}{l}\text { NA } \\
\text { NA } \\
\text { NA } \\
\text { NA } \\
\text { NA }\end{array}$ & $\begin{array}{r}34,077 \\
277,275 \\
4,412,636 \\
124,093 \\
b\end{array}$ \\
\hline $\begin{array}{l}\text { Virginia ................ } \\
\text { Washington........... } \\
\text { West Virginia.......... } \\
\text { Wisconsin ............... } \\
\text { Wyoming................ }\end{array}$ & $\begin{array}{r}2,787 \\
0 \\
214,951 \\
0 \\
375,059\end{array}$ & $\begin{array}{r}0 \\
0 \\
9,411 \\
0 \\
16,228\end{array}$ & $\begin{array}{r}-4,441 \\
-8,726 \\
-29,702 \\
-10,033 \\
4,608\end{array}$ & $\begin{array}{r}157,497 \\
-73,079 \\
1,140 \\
330,859 \\
-230,415\end{array}$ & $\begin{array}{r}0 \\
255,496 \\
0 \\
0 \\
0\end{array}$ & $\begin{array}{r}185 \\
3,243 \\
-22,163 \\
0 \\
7,190\end{array}$ & $\begin{array}{l}\text { NA } \\
\text { NA } \\
\text { NA } \\
\text { NA }\end{array}$ & $\begin{array}{l}155,658 \\
170,448 \\
199,141 \\
320,826 \\
125,834\end{array}$ \\
\hline 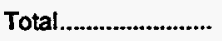 & $22,531,698$ & 907,993 & $-328,002$ & 0 & 941.483 & 135,734 & NA & $22,101,452$ \\
\hline
\end{tabular}

See footnotes at end of table. 
Table 13. Natural Gas Production, Transmission, and Consumption by State, 1967-1994 (Continued) (Million Cubic Feet)

\begin{tabular}{|c|c|c|c|c|c|c|c|c|}
\hline State & $\begin{array}{l}\text { Marketed } \\
\text { Production }\end{array}$ & $\begin{array}{c}\text { Extraction } \\
\text { Loss }\end{array}$ & $\begin{array}{l}\text { Balancing } \\
\text { Hem }\end{array}$ & $\begin{array}{c}\text { Net } \\
\text { Interstate } \\
\text { Movements }\end{array}$ & $\begin{array}{l}\text { Net Move } \\
\text { ments Across } \\
\text { U.S. Borders }\end{array}$ & $\begin{array}{c}\text { Net } \\
\text { Storage } \\
\text { Changes }\end{array}$ & $\begin{array}{c}\text { Supplemental } \\
\text { Cas } \\
\text { Supplies }\end{array}$ & Consumption \\
\hline & \multicolumn{8}{|c|}{1973} \\
\hline 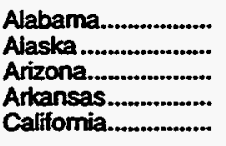 & $\begin{array}{r}11,271 \\
131,007 \\
125 \\
157,529 \\
449,369\end{array}$ & $\begin{array}{r}199 \\
986 \\
0 \\
1,118 \\
17,498\end{array}$ & $\begin{array}{r}2,517 \\
-2,275 \\
-1,682 \\
-9,822 \\
3,848\end{array}$ & $\begin{array}{r}259,033 \\
0 \\
220,357 \\
181,800 \\
1,636,723\end{array}$ & $\begin{array}{r}0 \\
-48,346 \\
-4,477 \\
0 \\
0\end{array}$ & $\begin{array}{r}554 \\
16,327 \\
0 \\
586 \\
26,815\end{array}$ & $\begin{array}{l}\text { NA } \\
\text { NA } \\
\text { NA } \\
\text { NA }\end{array}$ & $\begin{array}{r}272,068 \\
63,073 \\
214,323 \\
327,803 \\
2,045,627\end{array}$ \\
\hline $\begin{array}{l}\text { Colorado .................. } \\
\text { Connecticut.............. } \\
\text { D.C.......................... } \\
\text { Delaware................... } \\
\text { Florida...................... }\end{array}$ & $\begin{array}{r}137,725 \\
0 \\
a \\
0 \\
33,857\end{array}$ & $\begin{array}{r}4,674 \\
0 \\
a \\
0 \\
2,886\end{array}$ & $\begin{array}{r}-5,620 \\
-1,008 \\
a \\
-256 \\
-1,543\end{array}$ & $\begin{array}{r}201,866 \\
63,859 \\
a \\
23,460 \\
282,070\end{array}$ & $\begin{array}{l}0 \\
0 \\
a \\
0 \\
0\end{array}$ & $\begin{array}{r}5,290 \\
242 \\
a \\
255 \\
0\end{array}$ & $\begin{array}{l}\text { NA } \\
\text { NA } \\
\text { NA } \\
\text { NA }\end{array}$ & $\begin{array}{r}324,007 \\
62,609 \\
a \\
22,949 \\
311,498\end{array}$ \\
\hline $\begin{array}{l}\text { Georgia .................... } \\
\text { Idaho....................... } \\
\text { Illinois..................... } \\
\text { Indiana ...................... } \\
\text { lowa ......................... }\end{array}$ & $\begin{array}{r}0 \\
0 \\
1,638 \\
276 \\
0\end{array}$ & $\begin{array}{r}0 \\
0 \\
13,534 \\
0 \\
0\end{array}$ & $\begin{array}{r}4,017 \\
345 \\
-8,069 \\
-3,783 \\
-4,643\end{array}$ & $\begin{array}{r}344,072 \\
-382,157 \\
1,244,753 \\
559,958 \\
385,942\end{array}$ & $\begin{array}{r}0 \\
437,857 \\
0 \\
0 \\
0\end{array}$ & $\begin{array}{r}0 \\
0 \\
74,522 \\
14,151 \\
16,659\end{array}$ & $\begin{array}{l}\text { NA } \\
\text { NA } \\
\text { NA } \\
\text { NA }\end{array}$ & $\begin{array}{r}348,089 \\
56,045 \\
1,150,266 \\
542,300 \\
364,640\end{array}$ \\
\hline $\begin{array}{l}\text { Kansas.................... } \\
\text { Kentucky................ } \\
\text { Louisiana ................ } \\
\text { Maineb ................... } \\
\text { Maryland ................. }\end{array}$ & $\begin{array}{r}893,118 \\
62,396 \\
8,242,423 \\
0 \\
298\end{array}$ & $\begin{array}{r}43,909 \\
5,441 \\
206,833 \\
0 \\
0\end{array}$ & $\begin{array}{r}-497 \\
-8,650 \\
-34,963 \\
-394 \\
-4,198\end{array}$ & $\begin{array}{r}-234,600 \\
213,412 \\
-5,905,857 \\
10,363 \\
204,960\end{array}$ & $\begin{array}{r}0 \\
0 \\
0 \\
3,912 \\
0\end{array}$ & $\begin{array}{r}9,652 \\
16,245 \\
84,911 \\
0 \\
-901\end{array}$ & $\begin{array}{l}\text { NA } \\
\text { NA } \\
\text { NA } \\
\text { NA } \\
\text { NA }\end{array}$ & $\begin{array}{r}604,460 \\
245,472 \\
2,009,859 \\
13,881 \\
201,961\end{array}$ \\
\hline $\begin{array}{l}\text { Massachusetts........ } \\
\text { Michigan .................. } \\
\text { Minnesota .............. } \\
\text { Mississippi ............... } \\
\text { Missouni ................. }\end{array}$ & $\begin{array}{r}0 \\
44,579 \\
0 \\
99,706 \\
33\end{array}$ & $\begin{array}{r}0 \\
1,581 \\
0 \\
878 \\
0\end{array}$ & $\begin{array}{r}-4,942 \\
-2,168 \\
3,847 \\
6,427 \\
-5,995\end{array}$ & $\begin{array}{r}153,966 \\
925,952 \\
95,061 \\
215,225 \\
433,886\end{array}$ & $\begin{array}{r}4,055 \\
-14,736 \\
262,434 \\
0 \\
0\end{array}$ & $\begin{array}{r}-2,468 \\
31,695 \\
531 \\
6,488 \\
1,117\end{array}$ & $\begin{array}{l}\text { NA } \\
\text { NA } \\
\text { NA } \\
\text { NA } \\
\text { NA }\end{array}$ & $\begin{array}{l}155,547 \\
920,351 \\
360,811 \\
313,992 \\
426,807\end{array}$ \\
\hline $\begin{array}{l}\text { Montana................... } \\
\text { Nebraska ............... } \\
\text { Nevada .................. } \\
\text { New Hampshire ...... } \\
\text { New Jersey............. }\end{array}$ & $\begin{array}{r}56,175 \\
3,836 \\
0 \\
b \\
0\end{array}$ & $\begin{array}{r}918 \\
474 \\
0 \\
\mathrm{~b} \\
0\end{array}$ & $\begin{array}{r}1,027 \\
1,548 \\
-1,286 \\
b \\
-2,362\end{array}$ & $\begin{array}{r}-11,465 \\
227,874 \\
74,358 \\
b \\
304,332\end{array}$ & $\begin{array}{r}49,976 \\
0 \\
0 \\
b \\
0\end{array}$ & $\begin{array}{r}4,565 \\
3,152 \\
0 \\
b \\
404\end{array}$ & $\begin{array}{l}\text { NA } \\
\text { NA } \\
\text { NA } \\
\text { NA } \\
\text { NA }\end{array}$ & $\begin{array}{r}90,230 \\
229,632 \\
73,072 \\
\text { b } \\
301,566\end{array}$ \\
\hline $\begin{array}{l}\text { New Mexico ............. } \\
\text { New York.............. } \\
\text { North Carolina......... } \\
\text { North Dakota.......... } \\
\text { Ohio .......................... }\end{array}$ & $\begin{array}{r}1,218,749 \\
4,539 \\
0 \\
27,703 \\
93,610\end{array}$ & $\begin{array}{r}55,782 \\
0 \\
0 \\
2,969 \\
0\end{array}$ & $\begin{array}{r}-6,564 \\
-16,208 \\
264 \\
944 \\
-12,492\end{array}$ & $\begin{array}{r}-896,549 \\
689,830 \\
160,704 \\
6,750 \\
1,048,449\end{array}$ & $\begin{array}{r}0 \\
5,546 \\
0 \\
0 \\
0\end{array}$ & $\begin{array}{r}3,043 \\
1,160 \\
97 \\
0 \\
25,411\end{array}$ & $\begin{array}{l}\text { NA } \\
\text { NA } \\
\text { NA } \\
\text { NA } \\
\text { NA }\end{array}$ & $\begin{array}{r}256,811 \\
682,547 \\
160,871 \\
32,428 \\
1,104,156\end{array}$ \\
\hline $\begin{array}{l}\text { Oklahoma ............... } \\
\text { Oregon.................. } \\
\text { Pennsyivania .......... } \\
\text { Rhode Island.......... } \\
\text { South Carolina ........ }\end{array}$ & $\begin{array}{r}1,770,980 \\
0 \\
78,514 \\
0 \\
0\end{array}$ & $\begin{array}{r}61,647 \\
0 \\
71 \\
0 \\
0\end{array}$ & $\begin{array}{r}-10,497 \\
-197 \\
-22,485 \\
-201 \\
2,500\end{array}$ & $\begin{array}{r}-1,064,896 \\
108,347 \\
771,909 \\
20,766 \\
150,653\end{array}$ & $\begin{array}{l}0 \\
0 \\
0 \\
0 \\
0\end{array}$ & $\begin{array}{r}22,202 \\
189 \\
44,570 \\
6 \\
6\end{array}$ & $\begin{array}{l}\text { NA } \\
\text { NA } \\
\text { NA } \\
\text { NA } \\
\text { NA }\end{array}$ & $\begin{array}{r}611,738 \\
107,961 \\
783,297 \\
20,559 \\
153,147\end{array}$ \\
\hline $\begin{array}{l}\text { South Dakota .......... } \\
\text { Tennessee.............. } \\
\text { Texas ......................... } \\
\text { Utah ........................ } \\
\text { Vermont ................... }\end{array}$ & $\begin{array}{r}0 \\
20 \\
8,513,850 \\
42,715 \\
b\end{array}$ & $\begin{array}{r}0 \\
0 \\
466,143 \\
3,489 \\
b\end{array}$ & $\begin{array}{r}-353 \\
-5,803 \\
-34,394 \\
-1,102 \\
b\end{array}$ & $\begin{array}{r}31,574 \\
300,983 \\
-3,382,641 \\
86,609 \\
b\end{array}$ & $\begin{array}{r}0 \\
0 \\
-7,890 \\
0 \\
b\end{array}$ & $\begin{array}{r}0 \\
1,580 \\
1,404 \\
1,627 \\
b\end{array}$ & $\begin{array}{l}\text { NA } \\
\text { NA } \\
\text { NA } \\
\text { NA } \\
\text { NA }\end{array}$ & $\begin{array}{r}31,221 \\
293,620 \\
4,621,378 \\
123,106 \\
b\end{array}$ \\
\hline $\begin{array}{l}\text { Virginia.................... } \\
\text { Washington............ } \\
\text { West Virginia........... } \\
\text { Wisconsin ................ } \\
\text { Wyoming................ }\end{array}$ & $\begin{array}{r}5,101 \\
0 \\
208,676 \\
0 \\
357,731\end{array}$ & $\begin{array}{r}0 \\
0 \\
9,428 \\
0 \\
16.093\end{array}$ & $\begin{array}{r}-5,997 \\
-1,073 \\
-17,278 \\
10,442 \\
5,211\end{array}$ & $\begin{array}{r}153,927 \\
-65,549 \\
27,856 \\
357,685 \\
-235,610\end{array}$ & $\begin{array}{r}0 \\
267,401 \\
0 \\
0 \\
0\end{array}$ & $\begin{array}{r}183 \\
2,918 \\
23,510 \\
166 \\
2,640\end{array}$ & $\begin{array}{l}\text { NA } \\
\text { NA } \\
\text { NA } \\
\text { NA } \\
\text { NA }\end{array}$ & $\begin{array}{l}152,848 \\
197,861 \\
186,316 \\
367,961 \\
108,599\end{array}$ \\
\hline Total & $22,647,549$ & 916,551 & $-195,863$ & 0 & 955,732 & 441,504 & NA & $22,049,363$ \\
\hline
\end{tabular}

See footnotes at end of table. 
Table 13. Natural Gas Production, Transmission, and Consumption by State, 1967-1994 (Continued) (Million Cubic Feet)

\begin{tabular}{|c|c|c|c|c|c|c|c|c|}
\hline State & $\begin{array}{l}\text { Marketed } \\
\text { Production }\end{array}$ & $\begin{array}{c}\text { Extraction } \\
\text { Loss }\end{array}$ & $\begin{array}{l}\text { Balaneing } \\
\text { Itom }\end{array}$ & $\begin{array}{c}\text { Not } \\
\text { Interstate } \\
\text { Mowements }\end{array}$ & $\begin{array}{l}\text { Net Wovo } \\
\text { ments Across } \\
\text { U.S. Borders }\end{array}$ & $\begin{array}{c}\text { Net } \\
\text { Storage } \\
\text { Changes }\end{array}$ & $\begin{array}{l}\text { Supplemental } \\
\text { Gas } \\
\text { Supplies }\end{array}$ & Consumption \\
\hline & \multicolumn{8}{|c|}{1974} \\
\hline 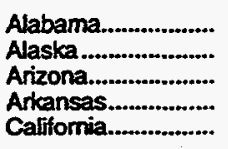 & $\begin{array}{r}27,865 \\
128,935 \\
224 \\
123,975 \\
365,354\end{array}$ & $\begin{array}{r}501 \\
1,097 \\
0 \\
952 \\
17,201\end{array}$ & $\begin{array}{r}-7,108 \\
-1,453 \\
-3,562 \\
-4,313 \\
-32,584\end{array}$ & $\begin{array}{r}254,294 \\
0 \\
200,001 \\
172,018 \\
1,598,378\end{array}$ & $\begin{array}{r}0 \\
-50,258 \\
4,217 \\
0 \\
0\end{array}$ & $\begin{array}{r}-211 \\
13,253 \\
0 \\
335 \\
79,534\end{array}$ & $\begin{array}{l}\text { NA } \\
\text { NA } \\
\text { NA } \\
\text { NA } \\
\text { NA }\end{array}$ & $\begin{array}{r}274,761 \\
62,874 \\
192,446 \\
290,393 \\
1,834,413\end{array}$ \\
\hline $\begin{array}{l}\text { Colorado ................ } \\
\text { Connecticut............. } \\
\text { D.C........................ } \\
\text { Delaware................ } \\
\text { Florida.................... }\end{array}$ & $\begin{array}{r}144,629 \\
0 \\
2 \\
0 \\
38,137\end{array}$ & $\begin{array}{r}6,210 \\
0 \\
a \\
0 \\
3,369\end{array}$ & $\begin{array}{r}-2,968 \\
-713 \\
a \\
-371 \\
-710\end{array}$ & $\begin{array}{r}176,695 \\
66,555 \\
a \\
a \\
20,736 \\
255,493\end{array}$ & $\begin{array}{l}0 \\
0 \\
\mathbf{a} \\
0 \\
0\end{array}$ & $\begin{array}{r}-910 \\
-501 \\
-\quad a \\
0 \\
0\end{array}$ & $\begin{array}{l}\text { NA } \\
\text { NA } \\
\text { NA } \\
\text { NA } \\
\text { NA }\end{array}$ & $\begin{array}{r}313,056 \\
66,343 \\
a \\
20,365 \\
289,551\end{array}$ \\
\hline 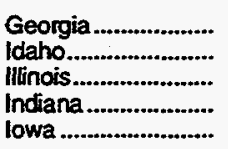 & $\begin{array}{r}0 \\
0 \\
1,436 \\
176 \\
0\end{array}$ & $\begin{array}{r}0 \\
0 \\
13,821 \\
0 \\
0\end{array}$ & $\begin{array}{r}-5,043 \\
-37 \\
-12,933 \\
-1,343 \\
-3,638\end{array}$ & $\begin{array}{r}335,472 \\
-352,293 \\
1,222,456 \\
531,821 \\
383,624\end{array}$ & $\begin{array}{r}0 \\
405,499 \\
0 \\
0 \\
0\end{array}$ & $\begin{array}{r}90 \\
112 \\
47,744 \\
-1,218 \\
12,391\end{array}$ & $\begin{array}{l}\text { NA } \\
\text { NA } \\
\text { NA } \\
\text { NA } \\
\text { NA }\end{array}$ & $\begin{array}{r}330,339 \\
53,057 \\
1,149,394 \\
531,872 \\
367,595\end{array}$ \\
\hline 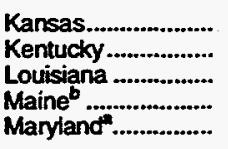 & $\begin{array}{r}886,782 \\
71,876 \\
7,753,631 \\
0 \\
133\end{array}$ & $\begin{array}{r}43,416 \\
5,557 \\
194,329 \\
0 \\
0\end{array}$ & $\begin{array}{r}-3,317 \\
-6,704 \\
-21,833 \\
-629 \\
-3,396\end{array}$ & $\begin{array}{r}-244,549 \\
170,244 \\
-5,526,285 \\
10,435 \\
203,886\end{array}$ & $\begin{array}{r}0 \\
0 \\
0 \\
4,891 \\
0\end{array}$ & $\begin{array}{r}8,487 \\
1,856 \\
2,820 \\
0 \\
1,292\end{array}$ & $\begin{array}{l}\text { NA } \\
\text { NA } \\
\text { NA } \\
\text { NA } \\
\text { NA }\end{array}$ & $\begin{array}{r}587,013 \\
228,003 \\
2,008,364 \\
14,697 \\
199,331\end{array}$ \\
\hline $\begin{array}{l}\text { Massachusetts........ } \\
\text { Michigan ............... } \\
\text { Minnesota .............. } \\
\text { Mississippi ............. } \\
\text { Missouri .................. }\end{array}$ & $\begin{array}{r}0 \\
69,133 \\
0 \\
78,787 \\
33\end{array}$ & $\begin{array}{r}0 \\
1,921 \\
0 \\
679 \\
0\end{array}$ & $\begin{array}{l}-2,132 \\
-4,312 \\
-2,151 \\
-7,300 \\
-7,709\end{array}$ & $\begin{array}{r}155,693 \\
869,059 \\
98,218 \\
205,421 \\
418,748\end{array}$ & $\begin{array}{r}0 \\
-13.232 \\
256,100 \\
0 \\
0\end{array}$ & $\begin{array}{r}-1,707 \\
-17,316 \\
523 \\
30 \\
1,188\end{array}$ & $\begin{array}{l}\text { NA } \\
\text { NA } \\
\text { NA } \\
\text { NA } \\
\text { NA }\end{array}$ & $\begin{array}{l}155,268 \\
936,043 \\
351,644 \\
276,199 \\
409,884\end{array}$ \\
\hline $\begin{array}{l}\text { Montana................ } \\
\text { Nebraska ................ } \\
\text { Nevada .............................. } \\
\text { New Hampshire..... } \\
\text { New Jersey............ }\end{array}$ & $\begin{array}{r}54,873 \\
2,538 \\
0 \\
b \\
0\end{array}$ & $\begin{array}{r}857 \\
460 \\
0 \\
b \\
0\end{array}$ & $\begin{array}{r}-14,494 \\
2,144 \\
-1,155 \\
b \\
1,569\end{array}$ & $\begin{array}{r}-2,249 \\
223,889 \\
64,593 \\
b \\
274,105\end{array}$ & $\begin{array}{r}48,080 \\
0 \\
0 \\
b \\
0\end{array}$ & $\begin{array}{r}5,444 \\
5,304 \\
0 \\
6 \\
624\end{array}$ & $\begin{array}{l}\text { NA } \\
\text { NA } \\
\text { NA } \\
\text { NA } \\
\text { NA }\end{array}$ & $\begin{array}{r}79,909 \\
222,807 \\
63,438 \\
b \\
275,050\end{array}$ \\
\hline 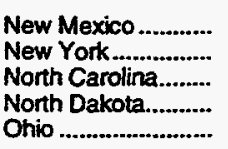 & $\begin{array}{r}1,244,779 \\
4,990 \\
0 \\
31,206 \\
92,055\end{array}$ & $\begin{array}{r}54,986 \\
0 \\
0 \\
2,571 \\
0\end{array}$ & $\begin{array}{r}-4,364 \\
-6,819 \\
-2,574 \\
-2,928 \\
-15,683\end{array}$ & $\begin{array}{r}-915,462 \\
626,457 \\
142,934 \\
9,752 \\
983,869\end{array}$ & $\begin{array}{r}0 \\
5,556 \\
0 \\
0 \\
0\end{array}$ & $\begin{array}{r}12,531 \\
2,691 \\
143 \\
0 \\
-26,410\end{array}$ & $\begin{array}{l}\text { NA } \\
\text { NA } \\
\text { NA } \\
\text { NA } \\
\text { NA }\end{array}$ & $\begin{array}{r}257,436 \\
627,493 \\
140,217 \\
35,459 \\
1,086,651\end{array}$ \\
\hline $\begin{array}{l}\text { Oklahoma ............... } \\
\text { Oregon.............................. } \\
\text { Pennsytvania ........ } \\
\text { Rhode Istand........ } \\
\text { South Carolina....... }\end{array}$ & $\begin{array}{r}1,638,942 \\
0 \\
82,637 \\
0 \\
0\end{array}$ & $\begin{array}{r}62,860 \\
0 \\
75 \\
0 \\
0\end{array}$ & $\begin{array}{r}-8,619 \\
-6,025 \\
-2,672 \\
-88 \\
-5,084\end{array}$ & $\begin{array}{r}-915,732 \\
104,081 \\
595,011 \\
23,458 \\
137,102\end{array}$ & $\begin{array}{l}0 \\
0 \\
0 \\
0 \\
0\end{array}$ & $\begin{array}{r}-8,279 \\
5 \\
-40,647 \\
-411 \\
27\end{array}$ & $\begin{array}{l}\text { NA } \\
\text { NA } \\
\text { NA } \\
\text { NA } \\
\text { NA }\end{array}$ & $\begin{array}{r}660,010 \\
98,051 \\
715,548 \\
23,781 \\
131,991\end{array}$ \\
\hline 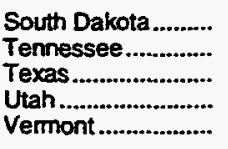 & $\begin{array}{r}0 \\
17 \\
8,170,798 \\
50,522 \\
b\end{array}$ & $\begin{array}{r}0 \\
0 \\
448,993 \\
3,958 \\
b\end{array}$ & $\begin{array}{r}-130 \\
-2,744 \\
-29,284 \\
-1,291 \\
b\end{array}$ & $\begin{array}{r}32,206 \\
263,844 \\
-3,220,808 \\
76,424 \\
b\end{array}$ & $\begin{array}{r}0 \\
0 \\
-8,829 \\
0 \\
b\end{array}$ & $\begin{array}{r}0 \\
946 \\
604 \\
682 \\
b\end{array}$ & $\begin{array}{l}\text { NA } \\
\text { NA } \\
\text { NA } \\
\text { NA } \\
\text { NA }\end{array}$ & $\begin{array}{r}32,076 \\
260,171 \\
4,463,488 \\
121,015 \\
b\end{array}$ \\
\hline 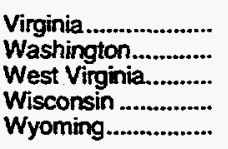 & $\begin{array}{r}7.096 \\
0 \\
202,306 \\
0 \\
326,657\end{array}$ & $\begin{array}{r}0 \\
0 \\
9,605 \\
0 \\
14,072\end{array}$ & $\begin{array}{r}-5,102 \\
-1,628 \\
-22,326 \\
-4,953 \\
-18,222\end{array}$ & $\begin{array}{r}141,510 \\
-52,071 \\
-5,012 \\
385,770 \\
-199,791\end{array}$ & $\begin{array}{r}0 \\
238,905 \\
0 \\
0 \\
0\end{array}$ & $\begin{array}{r}-146 \\
2,483 \\
-17,007 \\
-331 \\
-1,174\end{array}$ & $\begin{array}{l}\text { NA } \\
\text { NA } \\
\text { NA } \\
\text { NA } \\
\text { NA }\end{array}$ & $\begin{array}{r}143,650 \\
182,723 \\
182,370 \\
381,148 \\
95,746\end{array}$ \\
\hline 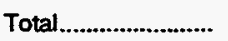 & $21,600,522$ & 887,490 & $-288,731$ & 0 & 882,495 & 83,663 & NA & $21,223,133$ \\
\hline
\end{tabular}

See footnotes at end of table. 
Table 13. Natural Gas Production, Transmission, and Consumption by State, 1967-1994 (Continued) (Million Cubic Feet)

\begin{tabular}{|c|c|c|c|c|c|c|c|c|}
\hline State & $\begin{array}{l}\text { Marketed } \\
\text { Production }\end{array}$ & $\begin{array}{l}\text { Extraction } \\
\text { Loss }\end{array}$ & $\begin{array}{l}\text { Balancing } \\
\text { trem }\end{array}$ & $\begin{array}{c}\text { Net } \\
\text { Imberstate } \\
\text { Movements }\end{array}$ & $\begin{array}{l}\text { Net Movo- } \\
\text { memts Across } \\
\text { U.S. Borders }\end{array}$ & $\begin{array}{c}\text { Net } \\
\text { Storege } \\
\text { Changes }\end{array}$ & $\begin{array}{c}\text { Supplemental } \\
\text { Cas } \\
\text { Supplies }\end{array}$ & Consumption \\
\hline & \multicolumn{8}{|c|}{1975} \\
\hline $\begin{array}{l}\text { Alabama.................. } \\
\text { Alaska..................... } \\
\text { Arizona................... } \\
\text { Arkansas.................. } \\
\text { Calfornia................ }\end{array}$ & $\begin{array}{r}37,814 \\
160,270 \\
208 \\
116,237 \\
318,308\end{array}$ & $\begin{array}{r}694 \\
1,244 \\
0 \\
899 \\
15,221\end{array}$ & $\begin{array}{r}-13,456 \\
-5,718 \\
1,911 \\
-4,097 \\
-36,118\end{array}$ & $\begin{array}{r}240,326 \\
0 \\
157,326 \\
147,309 \\
1,569,946\end{array}$ & $\begin{array}{r}0 \\
-53,002 \\
-3,223 \\
0 \\
0\end{array}$ & $\begin{array}{r}-98 \\
15,555 \\
0 \\
330 \\
4,066\end{array}$ & $\begin{array}{l}\text { NA } \\
\text { NA } \\
\text { NA } \\
\text { NA } \\
\text { NA }\end{array}$ & $\begin{array}{r}264,088 \\
84,751 \\
156,222 \\
258,220 \\
1,832,849\end{array}$ \\
\hline 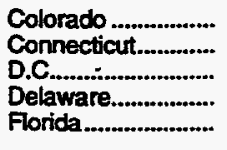 & $\begin{array}{r}171,629 \\
0 \\
a \\
0 \\
44,383\end{array}$ & $\begin{array}{r}9,620 \\
0 \\
a \\
0 \\
9,170\end{array}$ & $\begin{array}{r}-1,648 \\
-1,130 \\
a \\
-521 \\
-1,684\end{array}$ & $\begin{array}{r}144,946 \\
63,870 \\
a \\
19,673 \\
246,566\end{array}$ & $\begin{array}{l}0 \\
0 \\
a \\
0 \\
0\end{array}$ & $\begin{array}{r}-2,465 \\
-1,271 \\
2 \\
549 \\
0\end{array}$ & $\begin{array}{l}\text { NA } \\
\text { NA } \\
\text { NA } \\
\text { NA } \\
\text { NA }\end{array}$ & $\begin{array}{r}307,772 \\
64,011 \\
a \\
18,603 \\
280,095\end{array}$ \\
\hline $\begin{array}{l}\text { Georgia ................... } \\
\text { Idaho........................ } \\
\text { Illinois..................... } \\
\text { Indiana..................... } \\
\text { lowa ........................ }\end{array}$ & $\begin{array}{r}0 \\
0 \\
1,440 \\
346 \\
0\end{array}$ & $\begin{array}{r}0 \\
0 \\
12,785 \\
0 \\
0\end{array}$ & $\begin{array}{r}-1,363 \\
1,890 \\
-3,324 \\
-4,488 \\
-5,611\end{array}$ & $\begin{array}{r}328,261 \\
-321,276 \\
1,179,090 \\
485,702 \\
357,070\end{array}$ & $\begin{array}{r}0 \\
380,232 \\
0 \\
0 \\
0\end{array}$ & $\begin{array}{r}339 \\
395 \\
69,306 \\
4,219 \\
5,661\end{array}$ & $\begin{array}{l}\text { NA } \\
\text { NA } \\
\text { NA } \\
\text { NA }\end{array}$ & $\begin{array}{r}326,559 \\
60,451 \\
1,095,115 \\
477,341 \\
345,798\end{array}$ \\
\hline 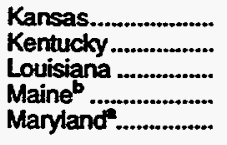 & $\begin{array}{r}843,625 \\
60,511 \\
7,090,645 \\
0 \\
93\end{array}$ & $\begin{array}{r}42,763 \\
5,454 \\
189,541 \\
0 \\
0\end{array}$ & $\begin{array}{r}-3,214 \\
-7,137 \\
-17,028 \\
-389 \\
-3,806\end{array}$ & $\begin{array}{r}-284,953 \\
171,657 \\
-5,036,803 \\
9,799 \\
168,208\end{array}$ & $\begin{array}{r}0 \\
0 \\
0 \\
4,124 \\
0\end{array}$ & $\begin{array}{r}13,968 \\
12,038 \\
58,685 \\
0 \\
-1,437\end{array}$ & $\begin{array}{l}\text { NA } \\
\text { NA } \\
\text { NA } \\
\text { NA }\end{array}$ & $\begin{array}{r}498,727 \\
207,539 \\
1,788,588 \\
13,534 \\
165,932\end{array}$ \\
\hline $\begin{array}{l}\text { Massachusetts........ } \\
\text { Michigan ................. } \\
\text { Minnesota .............. } \\
\text { Mississippi .............. } \\
\text { Missouri ................. }\end{array}$ & $\begin{array}{r}0 \\
102,113 \\
0 \\
74,345 \\
30\end{array}$ & $\begin{array}{r}0 \\
2,879 \\
0 \\
567 \\
0\end{array}$ & $\begin{array}{l}-3,768 \\
-3,309 \\
-6,753 \\
-6,029 \\
-7,337\end{array}$ & $\begin{array}{r}155,027 \\
826,505 \\
84,297 \\
162,251 \\
376,895\end{array}$ & $\begin{array}{r}4,893 \\
-10,153 \\
253,638 \\
0 \\
0\end{array}$ & $\begin{array}{r}2,185 \\
28,093 \\
-4 \\
-53 \\
-32\end{array}$ & $\begin{array}{l}\text { NA } \\
\text { NA } \\
\text { NA } \\
\text { NA }\end{array}$ & $\begin{array}{l}153,967 \\
884,184 \\
331,186 \\
230,053 \\
369,620\end{array}$ \\
\hline $\begin{array}{l}\text { Montana................... } \\
\text { Nebraska ................ } \\
\text { Nevada ................. } \\
\text { New Hampshire ...... } \\
\text { New Jersey............ }\end{array}$ & $\begin{array}{r}40,734 \\
2,565 \\
0 \\
b \\
0\end{array}$ & $\begin{array}{r}831 \\
313 \\
0 \\
b \\
0\end{array}$ & $\begin{array}{r}-1,606 \\
-3,033 \\
-212 \\
b \\
-1,872\end{array}$ & $\begin{array}{r}-9,526 \\
224,296 \\
61,463 \\
b \\
249,843\end{array}$ & $\begin{array}{r}42,114 \\
0 \\
0 \\
b \\
0\end{array}$ & $\begin{array}{r}8,635 \\
4,681 \\
0 \\
b \\
3,869\end{array}$ & $\begin{array}{l}\text { NA } \\
\text { NA } \\
\text { NA } \\
\text { NA }\end{array}$ & $\begin{array}{r}79,520 \\
218,834 \\
61,251 \\
b \\
244,102\end{array}$ \\
\hline $\begin{array}{l}\text { New Mexico ............. } \\
\text { New York.............. } \\
\text { Noth Carolina........ } \\
\text { North Dakota........... } \\
\text { Ohio ...................... }\end{array}$ & $\begin{array}{r}1,217,430 \\
7,628 \\
0 \\
24,786 \\
84,960\end{array}$ & $\begin{array}{r}56,109 \\
0 \\
0 \\
2,404 \\
0\end{array}$ & $\begin{array}{r}-5,983 \\
-9,082 \\
-2,962 \\
-721 \\
-8,370\end{array}$ & $\begin{array}{r}-911,768 \\
570,549 \\
117,893 \\
15,165 \\
918,094\end{array}$ & $\begin{array}{r}0 \\
5,497 \\
0 \\
0 \\
0\end{array}$ & $\begin{array}{r}3,310 \\
-2,291 \\
109 \\
0 \\
37,808\end{array}$ & $\begin{array}{l}\text { NA } \\
\text { NA } \\
\text { NA } \\
\text { NA }\end{array}$ & $\begin{array}{r}240,260 \\
576,883 \\
114,822 \\
36,826 \\
956,876\end{array}$ \\
\hline $\begin{array}{l}\text { Oklahoma ................ } \\
\text { Oregon................. } \\
\text { Pennsylvania .......... } \\
\text { Rhode Island.......... } \\
\text { South Carolina....... }\end{array}$ & $\begin{array}{r}1,605,410 \\
0 \\
84,676 \\
0 \\
0\end{array}$ & $\begin{array}{r}60,008 \\
0 \\
68 \\
0 \\
0\end{array}$ & $\begin{array}{r}-4,168 \\
-3,916 \\
-2,102 \\
1,355 \\
-4,142\end{array}$ & $\begin{array}{r}-869,432 \\
113,860 \\
623,112 \\
21,233 \\
127,045\end{array}$ & $\begin{array}{l}0 \\
0 \\
0 \\
0 \\
0\end{array}$ & $\begin{array}{r}2,983 \\
46 \\
51,876 \\
-541 \\
-46\end{array}$ & $\begin{array}{l}\text { NA } \\
\text { NA } \\
\text { NA } \\
\text { NA }\end{array}$ & $\begin{array}{r}668,819 \\
109,898 \\
653,742 \\
23,129 \\
122,949\end{array}$ \\
\hline $\begin{array}{l}\text { South Dakota.......... } \\
\text { Tennessee............... } \\
\text { Texas ........................ } \\
\text { Utah ........................ } \\
\text { Vermont ................... }\end{array}$ & $\begin{array}{r}0 \\
27 \\
7,485,764 \\
55,354 \\
b\end{array}$ & $\begin{array}{r}0 \\
0 \\
435,571 \\
3,659 \\
b\end{array}$ & $\begin{array}{r}-715 \\
-3,519 \\
-24,446 \\
-2,173 \\
b\end{array}$ & $\begin{array}{r}33,249 \\
221,348 \\
-3,071,608 \\
75,376 \\
b\end{array}$ & $\begin{array}{r}0 \\
0 \\
-6,230 \\
0 \\
b\end{array}$ & $\begin{array}{r}0 \\
528 \\
3,532 \\
738 \\
\mathrm{~b}\end{array}$ & $\begin{array}{l}\text { NA } \\
\text { NA } \\
\text { NA } \\
\text { NA } \\
\text { NA }\end{array}$ & $\begin{array}{r}32,534 \\
217,328 \\
3,944,377 \\
124,160 \\
b\end{array}$ \\
\hline $\begin{array}{l}\text { Virginia.................... } \\
\text { Washington........... } \\
\text { West Virginia............ } \\
\text { Wisconsin ............... } \\
\text { Wyoming................ }\end{array}$ & $\begin{array}{r}6,723 \\
0 \\
154,484 \\
0 \\
316,123\end{array}$ & $\begin{array}{r}0 \\
0 \\
9,258 \\
0 \\
13,224\end{array}$ & $\begin{array}{r}-5,500 \\
-2,747 \\
1,214 \\
-6,744 \\
-9,494\end{array}$ & $\begin{array}{r}118,704 \\
-95,461 \\
46,739 \\
371,117 \\
-202,983\end{array}$ & $\begin{array}{r}0 \\
262,443 \\
0 \\
0 \\
0\end{array}$ & $\begin{array}{r}-1,393 \\
-99 \\
34,744 \\
-428 \\
3,234\end{array}$ & $\begin{array}{l}\text { NA } \\
\text { NA } \\
\text { NA } \\
\text { NA }\end{array}$ & $\begin{array}{r}121,320 \\
164,334 \\
158,435 \\
364,801 \\
87,188\end{array}$ \\
\hline 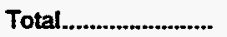 & $20,108,661$ & 872,282 & $-235,065$ & 0 & 880,333 & 344,054 & NA & $19,537,593$ \\
\hline
\end{tabular}

See footnotes at end of table. 
Table 13. Natural Gas Production, Transmission, and Consumption by State, 1967-1994 (Continued) (Million Cubic Feet)

\begin{tabular}{|c|c|c|c|c|c|c|c|c|}
\hline State & $\begin{array}{l}\text { Marketed } \\
\text { Production }\end{array}$ & $\begin{array}{l}\text { Extraction } \\
\text { Loss }\end{array}$ & $\begin{array}{l}\text { Balancing } \\
\text { nem }\end{array}$ & $\begin{array}{c}\text { Net } \\
\text { Intorstate } \\
\text { Movements }\end{array}$ & $\begin{array}{c}\text { Net Move- } \\
\text { ments Across } \\
\text { U.S. Borders }\end{array}$ & $\begin{array}{c}\text { Not } \\
\text { Storage } \\
\text { Changes }\end{array}$ & $\begin{array}{l}\text { Supplomental } \\
\text { Gas } \\
\text { Supplios }\end{array}$ & Consumption \\
\hline & \multicolumn{8}{|c|}{1976} \\
\hline 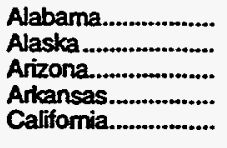 & $\begin{array}{r}41,427 \\
166,072 \\
262 \\
109,533 \\
354,334\end{array}$ & $\begin{array}{r}661 \\
1,229 \\
0 \\
823 \\
14,125\end{array}$ & $\begin{array}{r}-4,297 \\
-24,942 \\
545 \\
-15,996 \\
-12,992\end{array}$ & $\begin{array}{r}189,510 \\
0 \\
172,133 \\
156,699 \\
1,474,658\end{array}$ & $\begin{array}{r}0 \\
-49,780 \\
-1,665 \\
0 \\
0\end{array}$ & $\begin{array}{r}0 \\
0 \\
0 \\
472 \\
45,264\end{array}$ & $\begin{array}{l}\text { NA } \\
\text { NA } \\
\text { NA } \\
\text { NA } \\
\text { NA }\end{array}$ & $\begin{array}{r}225,979 \\
90,121 \\
171,275 \\
248,941 \\
1,756,611\end{array}$ \\
\hline 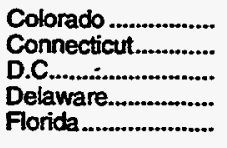 & $\begin{array}{r}183,972 \\
0 \\
a \\
0 \\
43,165\end{array}$ & $\begin{array}{r}11,944 \\
0 \\
a \\
0 \\
13,865\end{array}$ & $\begin{array}{r}1,749 \\
345 \\
a \\
181 \\
0\end{array}$ & $\begin{array}{r}132,038 \\
65,510 \\
a \\
19,001 \\
259,717\end{array}$ & $\begin{array}{l}0 \\
0 \\
a \\
0 \\
0\end{array}$ & $\begin{array}{r}3,531 \\
0 \\
\mathrm{a} \\
0 \\
0\end{array}$ & $\begin{array}{l}\text { NA } \\
\text { NA } \\
\text { NA } \\
\text { NA } \\
\text { NA }\end{array}$ & $\begin{array}{r}302,284 \\
65,855 \\
a \\
19,182 \\
289,017\end{array}$ \\
\hline 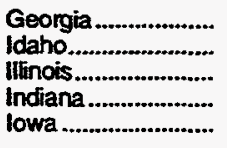 & $\begin{array}{r}0 \\
0 \\
1,556 \\
192 \\
0\end{array}$ & $\begin{array}{r}0 \\
0 \\
12,477 \\
0 \\
0\end{array}$ & $\begin{array}{r}88 \\
-207 \\
-31,612 \\
-4,801 \\
-17,175\end{array}$ & $\begin{array}{r}261,232 \\
-392,913 \\
1,243,612 \\
424,654 \\
333,856\end{array}$ & $\begin{array}{r}0 \\
440,276 \\
0 \\
0 \\
0\end{array}$ & $\begin{array}{r}0 \\
0 \\
25,844 \\
-5,176 \\
5,256\end{array}$ & $\begin{array}{l}\text { NA } \\
\text { NA } \\
\text { NA } \\
\text { NA } \\
\text { NA }\end{array}$ & $\begin{array}{r}261,320 \\
47,156 \\
1,175,235 \\
425,221 \\
311,425\end{array}$ \\
\hline 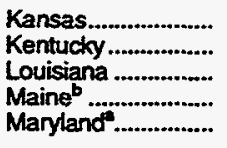 & $\begin{array}{r}829,170 \\
66,137 \\
7,006,596 \\
0 \\
75\end{array}$ & $\begin{array}{r}40,975 \\
5,231 \\
172,584 \\
0 \\
0\end{array}$ & $\begin{array}{r}0 \\
-8,855 \\
32,152 \\
-344 \\
-3,890\end{array}$ & $\begin{array}{r}-273,733 \\
188,396 \\
-4,785,602 \\
9,823 \\
177,801\end{array}$ & $\begin{array}{r}0 \\
0 \\
0 \\
4,066 \\
0\end{array}$ & $\begin{array}{r}-735 \\
-5,520 \\
36,857 \\
0 \\
-2,292\end{array}$ & $\begin{array}{l}\text { NA } \\
\text { NA } \\
\text { NA } \\
\text { NA } \\
\text { NA }\end{array}$ & $\begin{array}{r}515,197 \\
245,967 \\
2,043,705 \\
13,545 \\
176,272\end{array}$ \\
\hline 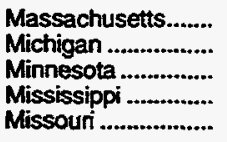 & $\begin{array}{r}0 \\
119,262 \\
0 \\
70,762 \\
29\end{array}$ & $\begin{array}{r}0 \\
6,665 \\
0 \\
520 \\
0\end{array}$ & $\begin{array}{r}-715 \\
-2,046 \\
-5,763 \\
-3,229 \\
-432\end{array}$ & $\begin{array}{r}146,807 \\
742,482 \\
70,501 \\
121,091 \\
378,177\end{array}$ & $\begin{array}{r}10,155 \\
-7,461 \\
254,858 \\
0 \\
0\end{array}$ & $\begin{array}{r}0 \\
-42,463 \\
-560 \\
-11,018 \\
-2,494\end{array}$ & $\begin{array}{l}\text { NA } \\
\text { NA } \\
\text { NA } \\
\text { NA } \\
\text { NA }\end{array}$ & $\begin{array}{l}156,247 \\
888,035 \\
320,156 \\
199,122 \\
380,258\end{array}$ \\
\hline 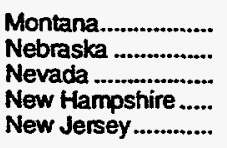 & $\begin{array}{r}42,563 \\
2,511 \\
0 \\
b \\
0\end{array}$ & $\begin{array}{r}761 \\
259 \\
0 \\
b \\
0\end{array}$ & $\begin{array}{r}3,898 \\
-2,272 \\
-503 \\
b \\
-7,981\end{array}$ & $\begin{array}{r}-14,258 \\
202,385 \\
67,300 \\
b \\
329,516\end{array}$ & $\begin{array}{r}35,588 \\
0 \\
0 \\
b \\
0\end{array}$ & $\begin{array}{r}-7,341 \\
3,731 \\
0 \\
b \\
0\end{array}$ & $\begin{array}{l}\text { NA } \\
\text { NA } \\
\text { NA } \\
\text { NA } \\
\text { NA }\end{array}$ & $\begin{array}{r}74,371 \\
198,634 \\
66,797 \\
b \\
321,535\end{array}$ \\
\hline $\begin{array}{l}\text { New Mexico ............. } \\
\text { New York.......... } \\
\text { North Carolina......... } \\
\text { North Dakota.......... } \\
\text { Ohio }\end{array}$ & $\begin{array}{r}1,230,976 \\
9,235 \\
0 \\
31,470 \\
88,891\end{array}$ & $\begin{array}{r}61,778 \\
0 \\
0 \\
2,421 \\
0\end{array}$ & $\begin{array}{r}-8,260 \\
-6,626 \\
-3,510 \\
-1,999 \\
-21,735\end{array}$ & $\begin{array}{r}-882,232 \\
577.197 \\
104,685 \\
14,127 \\
878,463\end{array}$ & $\begin{array}{r}0 \\
5,537 \\
0 \\
0 \\
0\end{array}$ & $\begin{array}{r}-271 \\
-10,590 \\
0 \\
0 \\
-60,308\end{array}$ & $\begin{array}{l}\text { NA } \\
\text { NA } \\
\text { NA } \\
\text { NA } \\
\text { NA }\end{array}$ & $\begin{array}{r}278,976 \\
595,933 \\
101,175 \\
41,177 \\
1,005,927\end{array}$ \\
\hline $\begin{array}{l}\text { Okfahoma ............... } \\
\text { Oregon................ } \\
\text { Pennsylvania ......... } \\
\text { Rhode istand......... } \\
\text { South Carolina ........ }\end{array}$ & $\begin{array}{r}1,726,513 \\
0 \\
89,386 \\
0 \\
0\end{array}$ & $\begin{array}{r}52,087 \\
0 \\
61 \\
0 \\
0\end{array}$ & $\begin{array}{r}-2.591 \\
-2,452 \\
-14,885 \\
955 \\
-14,050\end{array}$ & $\begin{array}{r}-915,483 \\
94,952 \\
550,929 \\
19,742 \\
163,039\end{array}$ & $\begin{array}{l}0 \\
0 \\
0 \\
0 \\
0\end{array}$ & $\begin{array}{r}-3,758 \\
0 \\
-88,148 \\
0 \\
0\end{array}$ & $\begin{array}{l}\text { NA } \\
\text { NA } \\
\text { NA } \\
\text { NA } \\
\text { NA }\end{array}$ & $\begin{array}{r}760,110 \\
92,500 \\
713,518 \\
20,697 \\
148,989\end{array}$ \\
\hline 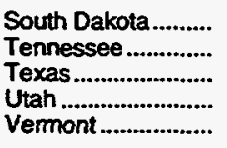 & $\begin{array}{r}0 \\
47 \\
7,191,859 \\
57,416 \\
\mathrm{~b}\end{array}$ & $\begin{array}{r}0 \\
0 \\
428,635 \\
4,032 \\
b\end{array}$ & $\begin{array}{r}-906 \\
-3,854 \\
-14,247 \\
-4,667 \\
b\end{array}$ & $\begin{array}{r}40,113 \\
216,133 \\
-2,756,350 \\
97,716 \\
b\end{array}$ & $\begin{array}{r}0 \\
0 \\
-5,760 \\
0 \\
b\end{array}$ & $\begin{array}{r}0 \\
0 \\
11,560 \\
228 \\
b\end{array}$ & $\begin{array}{l}\text { NA } \\
\text { NA } \\
\text { NA } \\
\text { NA } \\
\text { NA }\end{array}$ & $\begin{array}{r}39,207 \\
212,326 \\
3,975,307 \\
146,205 \\
b\end{array}$ \\
\hline 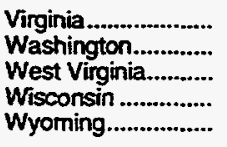 & $\begin{array}{r}6,937 \\
0 \\
153,322 \\
0 \\
328,768\end{array}$ & $\begin{array}{r}0 \\
0 \\
8,284 \\
0 \\
14,669\end{array}$ & $\begin{array}{r}-5,671 \\
-1,711 \\
9,655 \\
-462 \\
-10,124\end{array}$ & $\begin{array}{r}122,243 \\
-59,578 \\
-63,876 \\
315,616 \\
-217,829\end{array}$ & $\begin{array}{r}0 \\
213,243 \\
0 \\
0 \\
0\end{array}$ & $\begin{array}{r}0 \\
3,173 \\
-59,906 \\
0 \\
-673\end{array}$ & $\begin{array}{l}\text { NA } \\
\text { NA } \\
\text { NA } \\
\text { NA } \\
\text { NA }\end{array}$ & $\begin{array}{r}123,509 \\
148,781 \\
150,723 \\
315,154 \\
86,819\end{array}$ \\
\hline 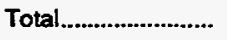 & $19,952,438$ & 854,086 & $-216,240$ & 0 & 899,057 & $-165,327$ & NA & $19,946,496$ \\
\hline
\end{tabular}

See footnotes at end of table. 
Table 13. Natural Gas Production, Transmission, and Consumption by State, 1967-1994 (Continued) (Million Cubic Feet)

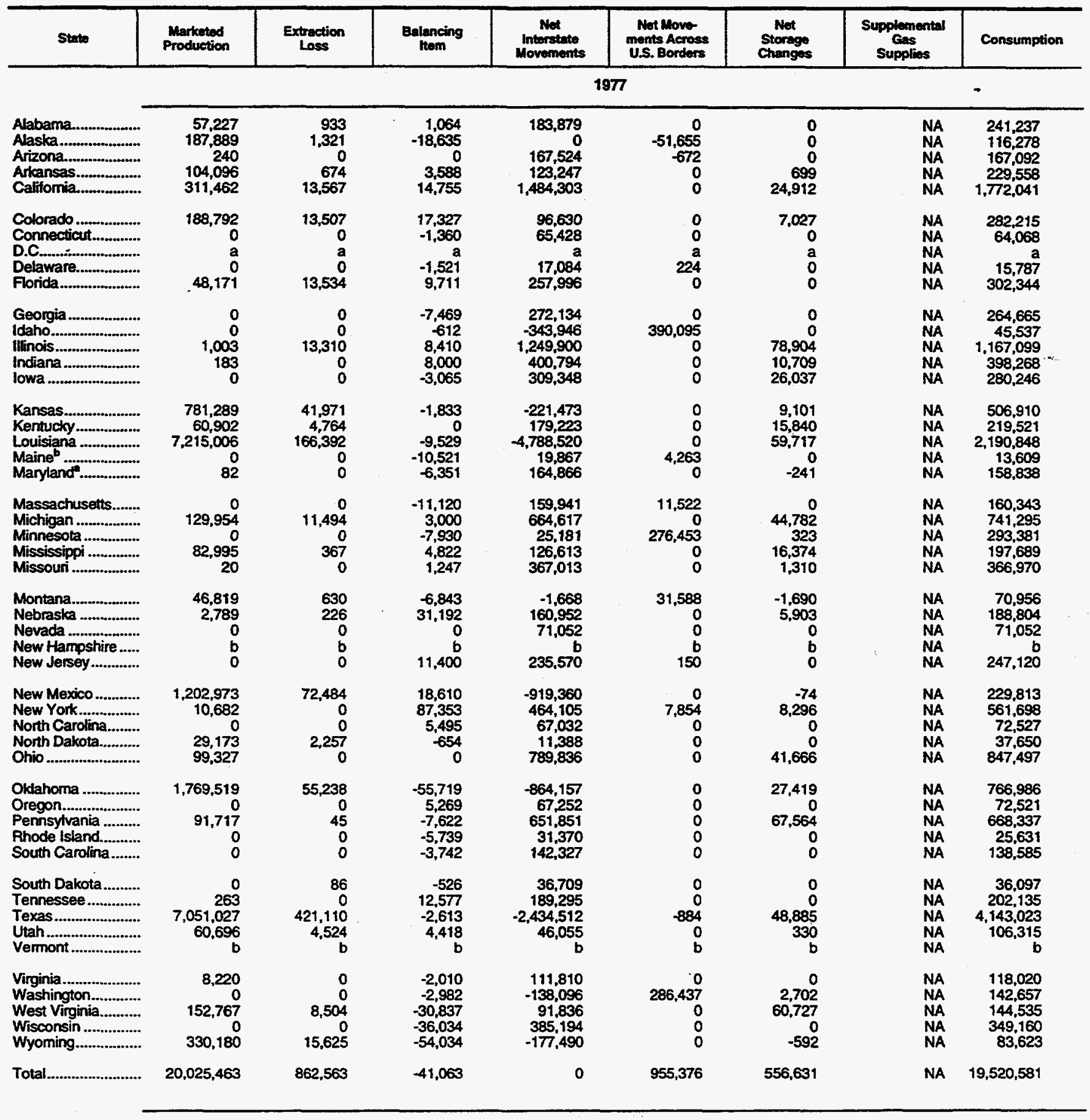

See footnotes at end of table. 
Table 13...Natural Gas Production, Transmission, and Consumption by State, 1967-1994 (Continued) (Million Cubic Feet)

\begin{tabular}{|c|c|c|c|c|c|c|c|c|}
\hline State & $\begin{array}{l}\text { Marketed } \\
\text { Production }\end{array}$ & $\begin{array}{l}\text { Extraction } \\
\text { Loss }\end{array}$ & $\begin{array}{l}\text { Balancing } \\
\text { Hem }\end{array}$ & $\begin{array}{l}\text { Net } \\
\text { interstate } \\
\text { Movements }\end{array}$ & $\begin{array}{l}\text { Net Move } \\
\text { ments Across } \\
\text { U.S. Borders }\end{array}$ & $\begin{array}{c}\text { Not } \\
\text { Storage } \\
\text { Changes }\end{array}$ & $\begin{array}{c}\text { Supplemental } \\
\text { Gas } \\
\text { Supplies }\end{array}$ & Consumption \\
\hline & \multicolumn{8}{|c|}{1978} \\
\hline $\begin{array}{l}\text { Alabama................. } \\
\text { Alaska .................... } \\
\text { Arizona................... } \\
\text { Aricansas................. } \\
\text { Califomia................ }\end{array}$ & $\begin{array}{r}85,599 \\
203,088 \\
286 \\
106,792 \\
311,084\end{array}$ & $\begin{array}{r}1,967 \\
954 \\
0 \\
883 \\
13,288\end{array}$ & $\begin{array}{l}-6,094 \\
-8,675 \\
2,224 \\
-7,257 \\
-9,654\end{array}$ & $\begin{array}{r}159,720 \\
0 \\
172,531 \\
122,221 \\
1,252,011\end{array}$ & $\begin{array}{r}0 \\
-48,434 \\
0 \\
0 \\
0\end{array}$ & $\begin{array}{r}0 \\
0 \\
0 \\
174 \\
-23,019\end{array}$ & $\begin{array}{l}\text { NA } \\
\text { NA } \\
\text { NA } \\
\text { NA }\end{array}$ & $\begin{array}{r}237,258 \\
145,025 \\
175,041 \\
220,699 \\
1,563,172\end{array}$ \\
\hline $\begin{array}{l}\text { Colorado .................. } \\
\text { Connecticut............ } \\
\text { D.C........................... } \\
\text { Delaware................. } \\
\text { Florida...................... }\end{array}$ & $\begin{array}{r}183,693 \\
0 \\
a \\
0 \\
51,595\end{array}$ & $\begin{array}{r}13,094 \\
0 \\
a \\
0 \\
17,436\end{array}$ & $\begin{array}{r}-7,247 \\
3,677 \\
2 \\
-294 \\
3,015\end{array}$ & $\begin{array}{r}102,823 \\
61,514 \\
a \\
20,920 \\
281,170\end{array}$ & $\begin{array}{l}0 \\
0 \\
a \\
0 \\
0\end{array}$ & $\begin{array}{r}-1,663 \\
0 \\
a \\
0 \\
0\end{array}$ & $\begin{array}{l}\text { NA } \\
\text { NA } \\
\text { NA } \\
\text { NA }\end{array}$ & $\begin{array}{r}267,838 \\
65,191 \\
a \\
20,626 \\
318,344\end{array}$ \\
\hline $\begin{array}{l}\text { Georgia ...................... } \\
\text { Idaho......................... } \\
\text { lllinois..................... } \\
\text { Indiana .................... } \\
\text { lowa ........................ }\end{array}$ & $\begin{array}{r}0 \\
0 \\
1,159 \\
163 \\
0\end{array}$ & $\begin{array}{r}0 \\
0 \\
13,173 \\
0 \\
0\end{array}$ & $\begin{array}{r}-2,983 \\
-743 \\
-14,730 \\
-5,004 \\
-4,155\end{array}$ & $\begin{array}{r}258,897 \\
-339,583 \\
1,208,157 \\
451,220 \\
249,900\end{array}$ & $\begin{array}{r}22,358 \\
384,536 \\
0 \\
0 \\
0\end{array}$ & $\begin{array}{r}0 \\
0 \\
6,479 \\
5,425 \\
7,516\end{array}$ & $\begin{array}{l}\text { NA } \\
\text { NA } \\
\text { NA } \\
\text { NA } \\
\text { NA }\end{array}$ & $\begin{array}{r}278,272 \\
44,210 \\
1,174,934 \\
440,955 \\
238,229\end{array}$ \\
\hline $\begin{array}{l}\text { Kansas.................. } \\
\text { Kentucky............... } \\
\text { Louisiana ............... } \\
\text { Maineb .................... } \\
\text { Marylandf................ }\end{array}$ & $\begin{array}{r}854,484 \\
70,044 \\
7,476,497 \\
0 \\
88\end{array}$ & $\begin{array}{r}45,582 \\
6,192 \\
161,511 \\
0 \\
0\end{array}$ & $\begin{array}{r}-875 \\
-12,300 \\
-12,876 \\
-755 \\
-10,448\end{array}$ & $\begin{array}{r}-289,609 \\
160,824 \\
-5,039,666 \\
10,570 \\
128,492\end{array}$ & $\begin{array}{r}0 \\
0 \\
0 \\
4,224 \\
47,496\end{array}$ & $\begin{array}{r}-928 \\
-537 \\
13,272 \\
0 \\
3,933\end{array}$ & $\begin{array}{l}\text { NA } \\
\text { NA } \\
\text { NA } \\
\text { NA } \\
\text { NA }\end{array}$ & $\begin{array}{r}519,346 \\
212,913 \\
2,249,172 \\
14,039 \\
161,695\end{array}$ \\
\hline $\begin{array}{l}\text { Massachusetts........ } \\
\text { Michigan ................. } \\
\text { Minnesota ............... } \\
\text { Mississippi ............... } \\
\text { Missoun ................. }\end{array}$ & $\begin{array}{r}0 \\
148,047 \\
0 \\
106,579 \\
0\end{array}$ & $\begin{array}{r}0 \\
14,641 \\
0 \\
485 \\
0\end{array}$ & $\begin{array}{r}-903 \\
-3,917 \\
-8,486 \\
-3,820 \\
-8,466\end{array}$ & $\begin{array}{r}146,838 \\
664,144 \\
73,243 \\
108,168 \\
368,621\end{array}$ & $\begin{array}{r}14,568 \\
0 \\
248,453 \\
0 \\
0\end{array}$ & $\begin{array}{r}0 \\
4,039 \\
-19 \\
6,723 \\
1,250\end{array}$ & $\begin{array}{l}\text { NA } \\
\text { NA } \\
\text { NA } \\
\text { NA }\end{array}$ & $\begin{array}{l}160,503 \\
789,594 \\
313,229 \\
203,719 \\
358,905\end{array}$ \\
\hline $\begin{array}{l}\text { Montana.................. } \\
\text { Nebraska ................ } \\
\text { Nevada ................. } \\
\text { New Hampshire ...... } \\
\text { New Jersey............. }\end{array}$ & $\begin{array}{r}46,522 \\
2,882 \\
0 \\
b \\
0\end{array}$ & $\begin{array}{r}503 \\
168 \\
0 \\
b \\
0\end{array}$ & $\begin{array}{r}-4,091 \\
7,237 \\
-1,001 \\
b \\
-1,243\end{array}$ & $\begin{array}{r}-901 \\
160,179 \\
65,507 \\
b \\
230,086\end{array}$ & $\begin{array}{r}28,036 \\
0 \\
0 \\
b \\
0\end{array}$ & $\begin{array}{r}-3,586 \\
7,079 \\
0 \\
b \\
0\end{array}$ & $\begin{array}{l}\text { NA } \\
\text { NA } \\
\text { NA } \\
\text { NA } \\
\text { NA }\end{array}$ & $\begin{array}{r}72,649 \\
163,051 \\
64,506 \\
b \\
228,843\end{array}$ \\
\hline $\begin{array}{l}\text { New Mexico ............ } \\
\text { New York............... } \\
\text { North Carolina........ } \\
\text { North Dakota.......... } \\
\text { Ohio......................... }\end{array}$ & $\begin{array}{r}1,174,198 \\
13,900 \\
0 \\
30,499 \\
114,098\end{array}$ & $\begin{array}{r}77,653 \\
0 \\
0 \\
2,394 \\
0\end{array}$ & $\begin{array}{r}11,481 \\
-1,771 \\
-2,835 \\
-1,693 \\
-11,645\end{array}$ & $\begin{array}{r}-895,901 \\
551,796 \\
84,824 \\
12,655 \\
844,063\end{array}$ & $\begin{array}{r}0 \\
6,231 \\
0 \\
0 \\
0\end{array}$ & $\begin{array}{r}-1,573 \\
454 \\
0 \\
0 \\
16,922\end{array}$ & $\begin{array}{l}\text { NA } \\
\text { NA } \\
\text { NA } \\
\text { NA }\end{array}$ & $\begin{array}{r}213,698 \\
569,702 \\
81,989 \\
39,067 \\
929,593\end{array}$ \\
\hline $\begin{array}{l}\text { Okdahoma ................ } \\
\text { Oregon................... } \\
\text { Pennsylvania ......... } \\
\text { Rhode Island........... } \\
\text { South Carolina....... }\end{array}$ & $\begin{array}{r}1,773,582 \\
0 \\
97,763 \\
0 \\
0\end{array}$ & $\begin{array}{r}61,868 \\
0 \\
64 \\
0 \\
0\end{array}$ & $\begin{array}{r}-18,235 \\
-2,287 \\
772 \\
1,246 \\
-2,883\end{array}$ & $\begin{array}{r}-915,009 \\
88,427 \\
601,394 \\
21,796 \\
120,456\end{array}$ & $\begin{array}{l}0 \\
0 \\
0 \\
0 \\
0\end{array}$ & $\begin{array}{r}8,221 \\
0 \\
26,094 \\
0 \\
0\end{array}$ & $\begin{array}{l}\text { NA } \\
\text { NA } \\
\text { NA } \\
\text { NA } \\
\text { NA }\end{array}$ & $\begin{array}{r}770,249 \\
86,140 \\
673,770 \\
23,042 \\
117,573\end{array}$ \\
\hline $\begin{array}{l}\text { South Dakota........... } \\
\text { Tennessee.............. } \\
\text { Texas ...................... } \\
\text { Utah .......................... } \\
\text { Vermont ................. }\end{array}$ & $\begin{array}{r}0 \\
468 \\
6,548,184 \\
58,416 \\
b\end{array}$ & $\begin{array}{r}4 \\
0 \\
393,819 \\
3,570 \\
b\end{array}$ & $\begin{array}{r}-2,402 \\
-3,413 \\
-51,188 \\
-4,058 \\
b\end{array}$ & $\begin{array}{r}37,829 \\
186,993 \\
-1,850,332 \\
67,459 \\
b\end{array}$ & $\begin{array}{r}0 \\
0 \\
-4,032 \\
0 \\
b\end{array}$ & $\begin{array}{r}0 \\
0 \\
37,381 \\
-266 \\
b\end{array}$ & $\begin{array}{l}\text { NA } \\
\text { NA } \\
\text { NA } \\
\text { NA } \\
\text { NA }\end{array}$ & $\begin{array}{r}35,423 \\
184,048 \\
4,211,432 \\
118,513 \\
b\end{array}$ \\
\hline $\begin{array}{l}\text { Virginia ..................... } \\
\text { Washington............ } \\
\text { West Virginia.......... } \\
\text { Wisconsin ................ } \\
\text { Wyoming................ }\end{array}$ & $\begin{array}{r}8,492 \\
0 \\
148,564 \\
0 \\
357,267\end{array}$ & $\begin{array}{r}0 \\
0 \\
8,518 \\
0 \\
14,363\end{array}$ & $\begin{array}{r}-3,846 \\
-5,624 \\
-14,909 \\
-9,431 \\
-44,616\end{array}$ & $\begin{array}{r}129,498 \\
-76,371 \\
34,335 \\
380,157 \\
-212,066\end{array}$ & $\begin{array}{r}0 \\
209,577 \\
0 \\
0 \\
0\end{array}$ & $\begin{array}{r}0 \\
302 \\
7,632 \\
0 \\
-1,070\end{array}$ & $\begin{array}{l}\text { NA } \\
\text { NA } \\
\text { NA } \\
\text { NA } \\
\text { NA }\end{array}$ & $\begin{array}{r}134,144 \\
127,280 \\
151,839 \\
370,726 \\
87,292\end{array}$ \\
\hline 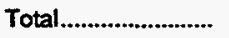 & $19,974,033$ & 852,130 & $-287,201$ & 0 & 913,013 & 120,237 & NA & $19,627,478$ \\
\hline
\end{tabular}

See footnotes at end of table. 
Table 13. Natural Gas Production, Transmission, and Consumption by State, 1967-1994 (Continued) (Million Cubic Feet)

\begin{tabular}{|c|c|c|c|c|c|c|c|c|}
\hline State & $\begin{array}{l}\text { Marketed } \\
\text { Production }\end{array}$ & $\begin{array}{l}\text { Extraction } \\
\text { Loss }\end{array}$ & $\begin{array}{l}\text { Balancing } \\
\text { Htem }\end{array}$ & $\begin{array}{c}\text { Net } \\
\text { Intorstate } \\
\text { Movements }\end{array}$ & $\begin{array}{l}\text { Net Mowo- } \\
\text { monts Across } \\
\text { U.S. Borders }\end{array}$ & $\begin{array}{c}\text { Not } \\
\text { Storage } \\
\text { Changes }\end{array}$ & $\begin{array}{c}\text { Suppiemental } \\
\text { Gas } \\
\text { Supplies }\end{array}$ & Consumption \\
\hline & \multicolumn{8}{|c|}{1979} \\
\hline 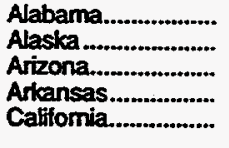 & $\begin{array}{r}85,815 \\
220,754 \\
247 \\
109,452 \\
248,206\end{array}$ & $\begin{array}{r}4,845 \\
701 \\
0 \\
1,308 \\
10,720\end{array}$ & $\begin{array}{r}-230 \\
-11,528 \\
-550 \\
-13,878 \\
-26,542\end{array}$ & $\begin{array}{r}202,695 \\
0 \\
173,747 \\
155,870 \\
1,626,812\end{array}$ & $\begin{array}{r}0 \\
-51,289 \\
-706 \\
0 \\
0\end{array}$ & $\begin{array}{r}0 \\
0 \\
0 \\
-611 \\
27,375\end{array}$ & $\begin{array}{l}\text { NA } \\
\text { NA } \\
\text { NA } \\
\text { NA } \\
\text { NA }\end{array}$ & $\begin{array}{r}283,435 \\
157,236 \\
172,738 \\
250,747 \\
1,810,381\end{array}$ \\
\hline 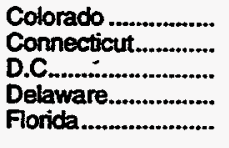 & $\begin{array}{r}191,239 \\
0 \\
2 \\
0 \\
50,190\end{array}$ & $\begin{array}{r}12,606 \\
0 \\
a \\
0 \\
15,954\end{array}$ & $\begin{array}{r}-8,811 \\
-2,026 \\
a \\
-327 \\
2,354\end{array}$ & $\begin{array}{r}125,456 \\
69,983 \\
a \\
25,308 \\
307,587\end{array}$ & $\begin{array}{l}0 \\
0 \\
a \\
0 \\
0\end{array}$ & $\begin{array}{r}3,006 \\
0 \\
a \\
0 \\
0\end{array}$ & $\begin{array}{l}\text { NA } \\
\text { NA } \\
\text { NA } \\
\text { NA }\end{array}$ & $\begin{array}{r}292,272 \\
67,957 \\
a \\
24,981 \\
344,177\end{array}$ \\
\hline $\begin{array}{l}\text { Georgia..................... } \\
\text { Idaho...................... } \\
\text { Itlinois...................... } \\
\text { Indiana .................... } \\
\text { lowa ........................ }\end{array}$ & $\begin{array}{r}0 \\
0 \\
1,585 \\
350 \\
0\end{array}$ & $\begin{array}{r}0 \\
0 \\
13,484 \\
72 \\
0\end{array}$ & $\begin{array}{r}-6,283 \\
325 \\
-9,985 \\
-6,564 \\
-6,136\end{array}$ & $\begin{array}{r}230,853 \\
-377,422 \\
1,208,624 \\
517,453 \\
307,373\end{array}$ & $\begin{array}{r}87,729 \\
431,334 \\
0 \\
0 \\
0\end{array}$ & $\begin{array}{r}0 \\
0 \\
44,008 \\
6,982 \\
9,716\end{array}$ & $\begin{array}{l}\text { NA } \\
\text { NA } \\
\text { NA } \\
\text { NA } \\
\text { NA }\end{array}$ & $\begin{array}{r}312,299 \\
54,237 \\
1,142,732 \\
504,185 \\
291,521\end{array}$ \\
\hline 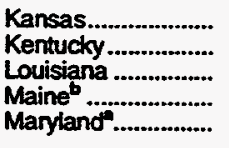 & $\begin{array}{r}797,762 \\
59,520 \\
7,266,217 \\
0 \\
28\end{array}$ & $\begin{array}{r}45,640 \\
3,923 \\
165,515 \\
0 \\
0\end{array}$ & $\begin{array}{r}-16,938 \\
-6,176 \\
-18,410 \\
-708 \\
-3,417\end{array}$ & $\begin{array}{r}-146,124 \\
175,101 \\
-5,107,084 \\
11,044 \\
68,927\end{array}$ & $\begin{array}{r}0 \\
0 \\
0 \\
4,545 \\
136,313\end{array}$ & $\begin{array}{r}4,824 \\
5,834 \\
-3,174 \\
0 \\
267\end{array}$ & $\begin{array}{l}\text { NA } \\
\text { NA } \\
\text { NA } \\
\text { NA } \\
\text { NA }\end{array}$ & $\begin{array}{r}584,236 \\
218,689 \\
1,978,382 \\
14,881 \\
201,584\end{array}$ \\
\hline $\begin{array}{l}\text { Massachusetts........ } \\
\text { Michigan ................ } \\
\text { Minnesota ............... } \\
\text { Mississippi ............... } \\
\text { Missouri .................. }\end{array}$ & $\begin{array}{r}0 \\
159,731 \\
0 \\
144,077 \\
0\end{array}$ & $\begin{array}{r}0 \\
15,686 \\
0 \\
1,146 \\
0\end{array}$ & $\begin{array}{r}-3,709 \\
-12,736 \\
-5,871 \\
863 \\
-6,728\end{array}$ & $\begin{array}{r}131,602 \\
805,953 \\
53,714 \\
103,569 \\
353,985\end{array}$ & $\begin{array}{r}28,566 \\
0 \\
286,290 \\
0 \\
0\end{array}$ & $\begin{array}{r}0 \\
61,536 \\
-69 \\
-7,003 \\
0\end{array}$ & $\begin{array}{l}\text { NA } \\
\text { NA } \\
\text { NA } \\
\text { NA } \\
\text { NA }\end{array}$ & $\begin{array}{l}156,459 \\
875,726 \\
334,202 \\
254,366 \\
347,257\end{array}$ \\
\hline $\begin{array}{l}\text { Montana................... } \\
\text { Nebraska ................ } \\
\text { Nevada ................... } \\
\text { New Hampshire ...... } \\
\text { New Jersey............ }\end{array}$ & $\begin{array}{r}53,888 \\
3,208 \\
0 \\
b \\
0\end{array}$ & $\begin{array}{r}776 \\
139 \\
0 \\
b \\
0\end{array}$ & $\begin{array}{r}-884 \\
-1,289 \\
-880 \\
b \\
-12,453\end{array}$ & $\begin{array}{r}-4,671 \\
175,227 \\
85,313 \\
b \\
273,032\end{array}$ & $\begin{array}{r}30,005 \\
0 \\
0 \\
b \\
0\end{array}$ & $\begin{array}{r}7,757 \\
6,994 \\
0 \\
b \\
0\end{array}$ & $\begin{array}{l}\text { NA } \\
\text { NA } \\
\text { NA } \\
\text { NA }\end{array}$ & $\begin{array}{r}69,805 \\
170,013 \\
84,433 \\
b \\
260,579\end{array}$ \\
\hline $\begin{array}{l}\text { New Mexico ............ } \\
\text { New York................. } \\
\text { North Carolina........ } \\
\text { North Dakota.......... } \\
\text { Ohio ......................... }\end{array}$ & $\begin{array}{r}1,181,363 \\
15,500 \\
0 \\
18,468 \\
123,431\end{array}$ & $\begin{array}{r}62,107 \\
0 \\
0 \\
2,986 \\
0\end{array}$ & $\begin{array}{r}-3,032 \\
-29,893 \\
-2,002 \\
926 \\
-16,676\end{array}$ & $\begin{array}{r}-912,690 \\
636,545 \\
132,886 \\
12,828 \\
804,840\end{array}$ & $\begin{array}{r}0 \\
9,157 \\
0 \\
0 \\
0\end{array}$ & $\begin{array}{r}-7,648 \\
7,418 \\
0 \\
0 \\
13,566\end{array}$ & $\begin{array}{l}\text { NA } \\
\text { NA } \\
\text { NA } \\
\text { NA } \\
\text { NA }\end{array}$ & $\begin{array}{r}211,182 \\
623,891 \\
130,884 \\
29,236 \\
898,029\end{array}$ \\
\hline $\begin{array}{l}\text { Okdahoma ................ } \\
\text { Oregon................... } \\
\text { Pennsylvania .......... } \\
\text { Rhode Island.......... } \\
\text { South Carolina ........ }\end{array}$ & $\begin{array}{r}1,835,366 \\
2 \\
96,313 \\
0 \\
0\end{array}$ & $\begin{array}{r}71,559 \\
0 \\
49 \\
0 \\
0\end{array}$ & $\begin{array}{r}-21,200 \\
709 \\
-35,027 \\
-847 \\
-2,718\end{array}$ & $\begin{array}{r}-914,406 \\
92,996 \\
707,046 \\
28,066 \\
122,037\end{array}$ & $\begin{array}{l}0 \\
0 \\
0 \\
0 \\
0\end{array}$ & $\begin{array}{r}3,293 \\
0 \\
27,466 \\
0 \\
0\end{array}$ & $\begin{array}{l}\text { NA } \\
\text { NA } \\
\text { NA } \\
\text { NA } \\
\text { NA }\end{array}$ & $\begin{array}{r}824,908 \\
93,707 \\
740,818 \\
27,219 \\
119,319\end{array}$ \\
\hline $\begin{array}{l}\text { South Dakota .......... } \\
\text { Tennessee .............. } \\
\text { Texas ....................... } \\
\text { Utah ........................ } \\
\text { Vemont ................... }\end{array}$ & $\begin{array}{r}914 \\
941 \\
7,174,623 \\
58,605 \\
b\end{array}$ & $\begin{array}{r}0 \\
0 \\
352,650 \\
3,950 \\
b\end{array}$ & $\begin{array}{r}-401 \\
-5,442 \\
-37,239 \\
-2,143 \\
b\end{array}$ & $\begin{array}{r}25,211 \\
230,978 \\
-2,768,458 \\
73,762 \\
b\end{array}$ & $\begin{array}{r}0 \\
0 \\
-3,602 \\
0 \\
b\end{array}$ & $\begin{array}{r}0 \\
0 \\
11,319 \\
227 \\
b\end{array}$ & $\begin{array}{l}\text { NA } \\
\text { NA } \\
\text { NA } \\
\text { NA } \\
\text { NA }\end{array}$ & $\begin{array}{r}25,724 \\
226,477 \\
4,001,355 \\
126,047 \\
b\end{array}$ \\
\hline $\begin{array}{l}\text { Virginia .................... } \\
\text { Washington............. } \\
\text { West Virginia.......... } \\
\text { Wisconsin ................ } \\
\text { Wyoming................. }\end{array}$ & $\begin{array}{r}8,544 \\
0 \\
150,505 \\
0 \\
414,416\end{array}$ & $\begin{array}{r}0 \\
0 \\
7,973 \\
0 \\
14,056\end{array}$ & $\begin{array}{r}-4,361 \\
-1,860 \\
-15,220 \\
-333 \\
-16,054\end{array}$ & $\begin{array}{r}129,905 \\
-77,066 \\
41,530 \\
367,850 \\
-287,787\end{array}$ & $\begin{array}{r}0 \\
239,358 \\
0 \\
0 \\
0\end{array}$ & $\begin{array}{r}0 \\
1,927 \\
20,304 \\
0 \\
2,722\end{array}$ & $\begin{array}{l}\text { NA } \\
\text { NA } \\
\text { NA } \\
\text { NA } \\
\text { NA }\end{array}$ & $\begin{array}{r}134,088 \\
158,515 \\
148,538 \\
367,517 \\
93,797\end{array}$ \\
\hline Total............................. & $20,471,260$ & 807,845 & $-372,330$ & 0 & $1,197.710$ & 248,034 & NA & $20,240,761$ \\
\hline
\end{tabular}

See footnotes at end of table. 
Table 13. Natural Gas Production, Transmission, and Consumption by State, 1967-1994 (Continued) (Million Cubic Feet)

\begin{tabular}{|c|c|c|c|c|c|c|c|c|}
\hline State & $\begin{array}{l}\text { Marketed } \\
\text { Production }\end{array}$ & $\begin{array}{l}\text { Extraction } \\
\text { Loss }\end{array}$ & $\begin{array}{l}\text { Balancing } \\
\text { Hem }\end{array}$ & $\begin{array}{c}\text { Net } \\
\text { Intarstate } \\
\text { Movements }\end{array}$ & $\begin{array}{l}\text { Net Move- } \\
\text { ments Across } \\
\text { U.S. Borders }\end{array}$ & $\begin{array}{c}\text { Not } \\
\text { Storage } \\
\text { Changes }\end{array}$ & $\begin{array}{c}\text { Supplemental } \\
\text { Gas } \\
\text { Supplies }\end{array}$ & Consumption \\
\hline & \multicolumn{8}{|c|}{1980} \\
\hline $\begin{array}{l}\text { Alabama.................. } \\
\text { Alaska ...................... } \\
\text { Arizona.................... } \\
\text { Arkansas................ } \\
\text { Califomia................. }\end{array}$ & $\begin{array}{r}65,294 \\
230,588 \\
214 \\
111,808 \\
309,434\end{array}$ & $\begin{array}{r}4,371 \\
483 \\
0 \\
1,351 \\
8,583\end{array}$ & $\begin{array}{r}10,423 \\
-32,028 \\
-16,552 \\
-6,031 \\
26,818\end{array}$ & $\begin{array}{r}198,029 \\
0 \\
182,867 \\
168,555 \\
1,481,832\end{array}$ & $\begin{array}{r}0 \\
-44,732 \\
-686 \\
0 \\
0\end{array}$ & $\begin{array}{r}185 \\
0 \\
0 \\
-732 \\
1,770\end{array}$ & $\begin{array}{r}50 \\
0 \\
7 \\
7 \\
?\end{array}$ & $\begin{array}{r}269,240 \\
153,345 \\
165,850 \\
273,720 \\
1,807,731\end{array}$ \\
\hline 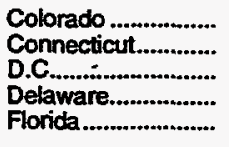 & $\begin{array}{r}188,001 \\
0 \\
0 \\
0 \\
40,638\end{array}$ & $\begin{array}{r}12,651 \\
0 \\
0 \\
0 \\
15,740\end{array}$ & $\begin{array}{r}52,162 \\
-4,407 \\
-230 \\
27,039 \\
15,394\end{array}$ & $\begin{array}{r}33,799 \\
76,026 \\
28,096 \\
2,816 \\
276,295\end{array}$ & $\begin{array}{l}0 \\
0 \\
0 \\
0 \\
0\end{array}$ & $\begin{array}{r}14,816 \\
-820 \\
0 \\
113 \\
0\end{array}$ & $\begin{array}{r}9,868 \\
144 \\
2 \\
55 \\
1\end{array}$ & $\begin{array}{r}256,363 \\
72,583 \\
27,868 \\
29,797 \\
316,588\end{array}$ \\
\hline 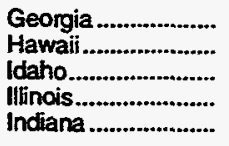 & $\begin{array}{r}0 \\
0 \\
0 \\
1,574 \\
463\end{array}$ & $\begin{array}{r}0 \\
0 \\
0 \\
13,340 \\
74\end{array}$ & $\begin{array}{r}-17,362 \\
-59 \\
38,840 \\
-199,804 \\
25,973\end{array}$ & $\begin{array}{r}308,470 \\
0 \\
-341,808 \\
1,281,157 \\
459,897\end{array}$ & $\begin{array}{r}24,603 \\
0 \\
352,015 \\
0 \\
0\end{array}$ & $\begin{array}{r}534 \\
0 \\
0 \\
16,580 \\
-1,393\end{array}$ & $\begin{array}{r}24 \\
3,190 \\
0 \\
36,713 \\
1,602\end{array}$ & $\begin{array}{r}315,201 \\
3,131 \\
49,047 \\
1,089,720 \\
489,254\end{array}$ \\
\hline $\begin{array}{l}\text { lowa ......................... } \\
\text { Kansas..................... } \\
\text { Kentucky.................. } \\
\text { Louisiana ................ } \\
\text { Maine....................... }\end{array}$ & $\begin{array}{r}0 \\
735,035 \\
57,180 \\
6,939,924 \\
0\end{array}$ & $\begin{array}{r}0 \\
39,130 \\
6,845 \\
142,171 \\
0\end{array}$ & $\begin{array}{r}20,631 \\
227,802 \\
-27,364 \\
-78,526 \\
-96\end{array}$ & $\begin{array}{r}251,748 \\
-426,066 \\
162,724 \\
-4,934,848 \\
2,207\end{array}$ & $\begin{array}{l}0 \\
0 \\
0 \\
0 \\
0\end{array}$ & $\begin{array}{r}2,855 \\
9,303 \\
-16,547 \\
-9,628 \\
0\end{array}$ & $\begin{array}{r}57 \\
0 \\
42 \\
0 \\
157\end{array}$ & $\begin{array}{r}269,581 \\
488,338 \\
202,284 \\
1,794,007 \\
2,268\end{array}$ \\
\hline $\begin{array}{l}\text { Maryland................. } \\
\text { Massachusetts........ } \\
\text { Michigan .................. } \\
\text { Minnesota .............. } \\
\text { Mississippi .............. }\end{array}$ & $\begin{array}{r}68 \\
0 \\
158,302 \\
0 \\
175,061\end{array}$ & $\begin{array}{r}0 \\
0 \\
15,933 \\
0 \\
553\end{array}$ & $\begin{array}{r}-6,101 \\
-23,203 \\
89,045 \\
-28,296 \\
-1,351\end{array}$ & $\begin{array}{r}122,400 \\
162,767 \\
862,303 \\
-205,761 \\
92,128\end{array}$ & $\begin{array}{r}36,973 \\
24,274 \\
-255,916 \\
519,857 \\
0\end{array}$ & $\begin{array}{r}-6,420 \\
-3,383 \\
-27,333 \\
2 \\
1,755\end{array}$ & $\begin{array}{r}484 \\
15,366 \\
3 \\
48 \\
0\end{array}$ & $\begin{array}{l}160,244 \\
182,587 \\
865,137 \\
285,846 \\
263,530\end{array}$ \\
\hline $\begin{array}{l}\text { Missouri ................... } \\
\text { Montana................. } \\
\text { Nebraska ................. } \\
\text { Nevada ................ } \\
\text { New Hampshire ...... }\end{array}$ & $\begin{array}{r}0 \\
51,867 \\
2,550 \\
0 \\
0\end{array}$ & $\begin{array}{r}0 \\
890 \\
126 \\
0 \\
0\end{array}$ & $\begin{array}{r}-8,124 \\
-377 \\
4,568 \\
-1,482 \\
4,078\end{array}$ & $\begin{array}{r}325,405 \\
17,086 \\
161,927 \\
59,932 \\
4,600\end{array}$ & $\begin{array}{r}0 \\
7,154 \\
0 \\
0 \\
0\end{array}$ & $\begin{array}{r}-1,104 \\
14,116 \\
5,849 \\
0 \\
-22\end{array}$ & $\begin{array}{r}65 \\
0 \\
9 \\
4 \\
774\end{array}$ & $\begin{array}{r}318,450 \\
60,724 \\
163,079 \\
58,454 \\
9,474\end{array}$ \\
\hline $\begin{array}{l}\text { New Jersey.............. } \\
\text { New Mexico ............ } \\
\text { New York................ } \\
\text { North Carolina......... } \\
\text { North Dakota.......... }\end{array}$ & $\begin{array}{r}0 \\
1,148,086 \\
15,643 \\
0 \\
42,346\end{array}$ & $\begin{array}{r}0 \\
59,457 \\
0 \\
0 \\
3,677\end{array}$ & $\begin{array}{r}-144,810 \\
-101,082 \\
110,007 \\
10,888 \\
-14,886\end{array}$ & $\begin{array}{r}475,378 \\
-766,880 \\
590,614 \\
143,018 \\
-1,131\end{array}$ & $\begin{array}{r}0 \\
0 \\
14,572 \\
0 \\
0\end{array}$ & $\begin{array}{r}317 \\
-1,126 \\
-3,381 \\
597 \\
0\end{array}$ & $\begin{array}{r}9,574 \\
0 \\
3,226 \\
7 \\
196\end{array}$ & $\begin{array}{r}339,825 \\
221,793 \\
737,443 \\
153,316 \\
22,848\end{array}$ \\
\hline $\begin{array}{l}\text { Ohio } \\
\text { Okdahoma .................. } \\
\text { Oregon................... } \\
\text { Pennsylvania ........... } \\
\text { Rhode Island........... }\end{array}$ & $\begin{array}{r}138,856 \\
1,891,824 \\
5 \\
97,439 \\
0\end{array}$ & $\begin{array}{r}0 \\
74,434 \\
0 \\
41 \\
0\end{array}$ & $\begin{array}{r}-15,274 \\
-380,571 \\
-157 \\
-56,080 \\
710\end{array}$ & $\begin{array}{r}707,139 \\
-703,786 \\
78,842 \\
682,362 \\
26,408\end{array}$ & $\begin{array}{l}0 \\
0 \\
0 \\
0 \\
0\end{array}$ & $\begin{array}{r}2,907 \\
10,715 \\
-13 \\
-48,908 \\
-255\end{array}$ & $\begin{array}{r}69,169 \\
0 \\
0 \\
3,127 \\
257\end{array}$ & $\begin{array}{r}896,983 \\
722,318 \\
78,703 \\
775,715 \\
27,630\end{array}$ \\
\hline $\begin{array}{l}\text { South Carolina ........ } \\
\text { South Dakota.......... } \\
\text { Tennessee ............... } \\
\text { Texas...................... } \\
\text { Utah........................ }\end{array}$ & $\begin{array}{r}0 \\
1,193 \\
1,241 \\
7,115,889 \\
87,766\end{array}$ & $\begin{array}{r}0 \\
0 \\
0 \\
350,312 \\
4,075\end{array}$ & $\begin{array}{r}23,184 \\
-208 \\
-26,038 \\
21,577 \\
-47,564\end{array}$ & $\begin{array}{r}118,973 \\
23,084 \\
252,803 \\
-2,778,207 \\
80,156\end{array}$ & $\begin{array}{r}0 \\
0 \\
0 \\
99,210 \\
0\end{array}$ & $\begin{array}{r}3 \\
0 \\
-1,643 \\
17,058 \\
1,191\end{array}$ & $\begin{array}{r}74 \\
9 \\
12 \\
0 \\
0\end{array}$ & $\begin{array}{r}142,228 \\
24,078 \\
229,661 \\
4,091,099 \\
115,092\end{array}$ \\
\hline $\begin{array}{l}\text { Vermont .................. } \\
\text { Virginia................. } \\
\text { Washington............ } \\
\text { West Virginia.......... } \\
\text { Wisconsin ................ } \\
\text { Wyoming................ }\end{array}$ & $\begin{array}{r}0 \\
7,812 \\
0 \\
156,551 \\
0 \\
407,072\end{array}$ & $\begin{array}{r}0 \\
0 \\
0 \\
8,786 \\
0 \\
13,582\end{array}$ & $\begin{array}{r}-230 \\
13,901 \\
-32,363 \\
-46,243 \\
-9,718 \\
-36,146\end{array}$ & $\begin{array}{r}0 \\
136,654 \\
9,465 \\
32,494 \\
361,497 \\
-283,462\end{array}$ & $\begin{array}{r}4,221 \\
0 \\
154,488 \\
0 \\
0 \\
0\end{array}$ & $\begin{array}{r}0 \\
15 \\
2,835 \\
-9,031 \\
-76 \\
5,031\end{array}$ & $\begin{array}{r}0 \\
127 \\
15 \\
0 \\
2 \\
124\end{array}$ & $\begin{array}{r}3,991 \\
158,479 \\
128,770 \\
143,047 \\
351,857 \\
68,975\end{array}$ \\
\hline Total ............................ & $20,179,724$ & 776,605 & $-639,721$ & 0 & 936,036 & $-23,269$ & 154,590 & $19,877,293$ \\
\hline
\end{tabular}

See footnotes at end of table. 
Table 13. Natural Gas Production, Transmission, and Consumption by State, 1967-1994 (Continued) (Million Cubic Feet)

\begin{tabular}{|c|c|c|c|c|c|c|c|c|}
\hline Stato & $\begin{array}{l}\text { Marketod } \\
\text { Production }\end{array}$ & $\begin{array}{l}\text { Extraction } \\
\text { Loss }\end{array}$ & $\begin{array}{l}\text { Balancing } \\
\text { trem }\end{array}$ & $\begin{array}{l}\text { Net } \\
\text { Intwrstate } \\
\text { Movements }\end{array}$ & $\begin{array}{l}\text { Net Move } \\
\text { ments Across } \\
\text { U.S. Borders }\end{array}$ & $\begin{array}{c}\text { Net } \\
\text { Storage } \\
\text { Chenges }\end{array}$ & $\begin{array}{c}\text { Supplemental } \\
\text { Ges } \\
\text { Supplios }\end{array}$ & Consumption \\
\hline & \multicolumn{8}{|c|}{1981} \\
\hline $\begin{array}{l}\text { Alabama................. } \\
\text { Alaska .................... } \\
\text { Arizona................... } \\
\text { Arkansas................. } \\
\text { Calfomia................ }\end{array}$ & $\begin{array}{r}79,244 \\
242,564 \\
187 \\
92,986 \\
380,359\end{array}$ & $\begin{array}{r}4,484 \\
529 \\
0 \\
1,327 \\
7,278\end{array}$ & $\begin{array}{r}18,378 \\
-64,379 \\
-13,544 \\
545 \\
-20,420\end{array}$ & $\begin{array}{r}178,149 \\
0 \\
196,794 \\
173,075 \\
1,512,595\end{array}$ & $\begin{array}{r}0 \\
-55,929 \\
-904 \\
0 \\
0\end{array}$ & $\begin{array}{r}30 \\
0 \\
0 \\
500 \\
7,078\end{array}$ & $\begin{array}{r}23 \\
0 \\
0 \\
8 \\
0\end{array}$ & $\begin{array}{r}271,280 \\
121,727 \\
182,533 \\
264,787 \\
1,858,178\end{array}$ \\
\hline 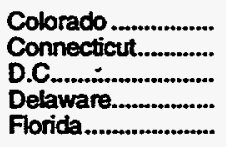 & $\begin{array}{r}195,706 \\
0 \\
0 \\
0 \\
32,470\end{array}$ & $\begin{array}{r}13,427 \\
0 \\
0 \\
0 \\
12,478\end{array}$ & $\begin{array}{r}-19,380 \\
-3,101 \\
-277 \\
-36 \\
26,244\end{array}$ & $\begin{array}{r}39,107 \\
79,047 \\
29,299 \\
30,541 \\
291,318\end{array}$ & $\begin{array}{l}0 \\
0 \\
0 \\
0 \\
0\end{array}$ & $\begin{array}{r}-641 \\
701 \\
0 \\
-3 \\
0\end{array}$ & $\begin{array}{r}9,133 \\
1,584 \\
1 \\
135 \\
3\end{array}$ & $\begin{array}{r}211,780 \\
76,829 \\
29,023 \\
30,643 \\
337,557\end{array}$ \\
\hline 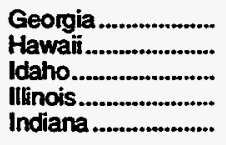 & $\begin{array}{r}0 \\
0 \\
0 \\
1,295 \\
330\end{array}$ & $\begin{array}{r}0 \\
0 \\
0 \\
13,264 \\
19\end{array}$ & $\begin{array}{r}-29,754 \\
-94 \\
35,076 \\
-109,477 \\
-161,828\end{array}$ & $\begin{array}{r}344,712 \\
0 \\
-294,033 \\
1,126,238 \\
654,366\end{array}$ & $\begin{array}{r}0 \\
0 \\
303,936 \\
0 \\
0\end{array}$ & $\begin{array}{r}-1,598 \\
0 \\
19 \\
-27,656 \\
1,556\end{array}$ & $\begin{array}{r}57 \\
2,993 \\
0 \\
29,509 \\
5,056\end{array}$ & $\begin{array}{r}316,613 \\
2,899 \\
44,960 \\
1,061,957 \\
496,349\end{array}$ \\
\hline 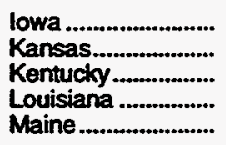 & $\begin{array}{r}0 \\
640,114 \\
61,312 \\
6,780,184 \\
0\end{array}$ & $\begin{array}{r}0 \\
36,653 \\
5,638 \\
142,423 \\
0\end{array}$ & $\begin{array}{r}35,831 \\
13,554 \\
5,865 \\
-30,815 \\
-121\end{array}$ & $\begin{array}{r}217,024 \\
-174,622 \\
147,819 \\
-4,723,507 \\
2,267\end{array}$ & $\begin{array}{l}0 \\
0 \\
0 \\
0 \\
0\end{array}$ & $\begin{array}{r}-312 \\
14,263 \\
9,915 \\
101,723 \\
-86\end{array}$ & $\begin{array}{r}64 \\
0 \\
2 \\
0 \\
94\end{array}$ & $\begin{array}{r}253,231 \\
428,130 \\
199,445 \\
1,781,716 \\
2,326\end{array}$ \\
\hline $\begin{array}{l}\text { Maryland............... } \\
\text { Massachusetts....... } \\
\text { Michigan ................. } \\
\text { Minnesota ............... } \\
\text { Mississippi ............... }\end{array}$ & $\begin{array}{r}56 \\
0 \\
152,593 \\
0 \\
181,238\end{array}$ & $\begin{array}{r}0 \\
0 \\
14,540 \\
0 \\
830\end{array}$ & $\begin{array}{r}4,991 \\
-13,287 \\
238,318 \\
-52,160 \\
-21,106\end{array}$ & $\begin{array}{r}173,915 \\
141,827 \\
701,690 \\
-237,889 \\
85,913\end{array}$ & $\begin{array}{r}0 \\
36,792 \\
-272,907 \\
557,612 \\
0\end{array}$ & $\begin{array}{l}4,171 \\
2,585 \\
7,319 \\
1,387 \\
2,228\end{array}$ & $\begin{array}{r}498 \\
21,828 \\
3,038 \\
106 \\
0\end{array}$ & $\begin{array}{l}175,289 \\
184,575 \\
800,873 \\
266,282 \\
242,987\end{array}$ \\
\hline $\begin{array}{l}\text { Missouri .................... } \\
\text { Montana................ } \\
\text { Nebraska ............... } \\
\text { Nevada .................. } \\
\text { New Hampshire..... }\end{array}$ & $\begin{array}{r}0 \\
56,565 \\
2,519 \\
0 \\
0\end{array}$ & $\begin{array}{r}0 \\
818 \\
153 \\
0 \\
0\end{array}$ & $\begin{array}{r}-8,567 \\
-3,247 \\
-2,320 \\
-2,485 \\
4,757\end{array}$ & $\begin{array}{r}291,718 \\
9,401 \\
142,773 \\
75,667 \\
4,726\end{array}$ & $\begin{array}{r}0 \\
7,690 \\
0 \\
0 \\
6\end{array}$ & $\begin{array}{r}-303 \\
17,139 \\
6,335 \\
0 \\
-11\end{array}$ & $\begin{array}{r}60 \\
0 \\
1,838 \\
720\end{array}$ & $\begin{array}{r}283,514 \\
52,452 \\
138,322 \\
73,182 \\
10,220\end{array}$ \\
\hline $\begin{array}{l}\text { New Jersey ............. } \\
\text { New Mexico ............ } \\
\text { New York................ } \\
\text { North Carolina........ } \\
\text { North Dakota.......... }\end{array}$ & $\begin{array}{r}0 \\
1,132,066 \\
16,074 \\
0 \\
42,573\end{array}$ & $\begin{array}{r}0 \\
60,544 \\
0 \\
0 \\
5,008\end{array}$ & $\begin{array}{r}-102,600 \\
-42,753 \\
99,858 \\
6,467 \\
-1,608\end{array}$ & $\begin{array}{r}482,334 \\
-831,737 \\
630,548 \\
145,893 \\
-1,929\end{array}$ & $\begin{array}{r}0 \\
0 \\
26,983 \\
0 \\
0\end{array}$ & $\begin{array}{r}1,117 \\
821 \\
17,722 \\
-94 \\
0\end{array}$ & $\begin{array}{r}11,504 \\
1 \\
4,722 \\
42 \\
417\end{array}$ & $\begin{array}{r}390,121 \\
196,212 \\
760,463 \\
152,496 \\
34,445\end{array}$ \\
\hline $\begin{array}{l}\text { Ohio ....................... } \\
\text { Okdahoma ............... } \\
\text { Oregon.................... } \\
\text { Pennsylvania .......... } \\
\text { Rhode Island.......... }\end{array}$ & $\begin{array}{r}141,134 \\
2,019,199 \\
5 \\
122,454 \\
0\end{array}$ & $\begin{array}{r}20 \\
80,401 \\
0 \\
29 \\
0\end{array}$ & $\begin{array}{r}-6,674 \\
-159,842 \\
1,669 \\
-33,270 \\
-695\end{array}$ & $\begin{array}{r}681,170 \\
-1,080,533 \\
73,885 \\
735,672 \\
29,019\end{array}$ & $\begin{array}{l}0 \\
0 \\
0 \\
0 \\
0\end{array}$ & $\begin{array}{r}15,119 \\
27,452 \\
-3 \\
50,668 \\
73\end{array}$ & $\begin{array}{r}69,850 \\
0 \\
0 \\
10,532 \\
951\end{array}$ & $\begin{array}{r}870,341 \\
670,971 \\
75,562 \\
784,691 \\
29,202\end{array}$ \\
\hline 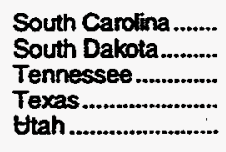 & $\begin{array}{r}0 \\
1,155 \\
1,719 \\
6,910,021 \\
91,191\end{array}$ & $\begin{array}{r}0 \\
0 \\
0 \\
345,262 \\
5,219\end{array}$ & $\begin{array}{r}24,211 \\
12 \\
-13,636 \\
31,920 \\
-49,551\end{array}$ & $\begin{array}{r}117,719 \\
20,865 \\
235,170 \\
-2,745,094 \\
66,015\end{array}$ & $\begin{array}{r}0 \\
0 \\
0 \\
102,580 \\
0\end{array}$ & $\begin{array}{r}190 \\
0 \\
-234 \\
27.478 \\
197\end{array}$ & $\begin{array}{r}184 \\
24 \\
42 \\
0\end{array}$ & $\begin{array}{r}141,924 \\
22,056 \\
223,529 \\
3,926,687 \\
102,239\end{array}$ \\
\hline $\begin{array}{l}\text { Vermont ................... } \\
\text { Virginia................. } \\
\text { Washington........... } \\
\text { West Virginia.......... } \\
\text { Wisconsin .............. } \\
\text { Wyoming............... }\end{array}$ & $\begin{array}{r}0 \\
8,903 \\
0 \\
161,251 \\
0 \\
408,356\end{array}$ & $\begin{array}{r}0 \\
0 \\
0 \\
9,060 \\
0 \\
15,160\end{array}$ & $\begin{array}{r}-206 \\
-8,648 \\
-30,409 \\
-33,380 \\
-7,256 \\
-1,209\end{array}$ & $\begin{array}{r}0 \\
151,034 \\
20,856 \\
31,751 \\
331,950 \\
-314,518\end{array}$ & $\begin{array}{r}4,589 \\
0 \\
134,322 \\
0 \\
0 \\
0\end{array}$ & $\begin{array}{r}0 \\
-5 \\
-160 \\
2.035 \\
87 \\
8.635\end{array}$ & $\begin{array}{r}0 \\
443 \\
13 \\
0 \\
4 \\
222\end{array}$ & $\begin{array}{r}4,383 \\
151,737 \\
124,942 \\
148,527 \\
324,611 \\
69,056\end{array}$ \\
\hline Total......................... & $19,955,823$ & 774,562 & $-500,444$ & 0 & 844,769 & 297,430 & 175,702 & $19,403,858$ \\
\hline
\end{tabular}

See footnotes at end of table. 
Table 13. Natural Gas Production, Transmission, and Consumption by State, 1967-1994 (Continued) (Million Cubic Feet)

\begin{tabular}{|c|c|c|c|c|c|c|c|c|}
\hline State & $\begin{array}{l}\text { Marketed } \\
\text { Production }\end{array}$ & $\begin{array}{l}\text { Extraction } \\
\text { Loss }\end{array}$ & $\begin{array}{l}\text { Baiancing } \\
\text { ttem }\end{array}$ & $\begin{array}{c}\text { Not } \\
\text { Intorstate } \\
\text { Movements }\end{array}$ & $\begin{array}{l}\text { Net How } \\
\text { ments Across } \\
\text { U.S. Borders }\end{array}$ & $\begin{array}{c}\text { Net } \\
\text { Storage } \\
\text { Changes }\end{array}$ & $\begin{array}{c}\text { Supplemental } \\
\text { Gas } \\
\text { Supplies }\end{array}$ & Consumption \\
\hline & \multicolumn{8}{|c|}{1982} \\
\hline $\begin{array}{l}\text { Alabama.................. } \\
\text { Alaska...................... } \\
\text { Arizona................... } \\
\text { Arkansas................. } \\
\text { Calfomia................. }\end{array}$ & $\begin{array}{r}75,003 \\
264,364 \\
99 \\
124,611 \\
383,977\end{array}$ & $\begin{array}{r}4,727 \\
468 \\
0 \\
1,287 \\
14,113\end{array}$ & $\begin{array}{r}17,650 \\
23,846 \\
14,692 \\
-9,355 \\
-130,231\end{array}$ & $\begin{array}{r}153,006 \\
0 \\
121,934 \\
113,369 \\
1,410,366\end{array}$ & $\begin{array}{r}0 \\
-49,861 \\
-1,694 \\
0 \\
0\end{array}$ & $\begin{array}{r}66 \\
0 \\
0 \\
403 \\
-32,719\end{array}$ & $\begin{array}{r}91 \\
0 \\
0 \\
6 \\
0\end{array}$ & $\begin{array}{r}240,957 \\
237,881 \\
135,031 \\
226,941 \\
1,682,718\end{array}$ \\
\hline 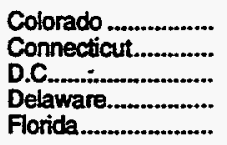 & $\begin{array}{r}209,892 \\
0 \\
0 \\
0 \\
22,515\end{array}$ & $\begin{array}{r}12,962 \\
0 \\
0 \\
0 \\
10,453\end{array}$ & $\begin{array}{r}24,467 \\
-1,372 \\
-65 \\
-1,898 \\
20,328\end{array}$ & $\begin{array}{r}2,380 \\
77,185 \\
29,299 \\
29,672 \\
292,417\end{array}$ & $\begin{array}{l}0 \\
0 \\
0 \\
0 \\
0\end{array}$ & $\begin{array}{r}7,663 \\
-1,356 \\
0 \\
-3 \\
0\end{array}$ & $\begin{array}{r}8,877 \\
1,077 \\
46 \\
56 \\
0\end{array}$ & $\begin{array}{r}224,991 \\
78,246 \\
29,280 \\
27,833 \\
324,807\end{array}$ \\
\hline $\begin{array}{l}\text { Georgia.................... } \\
\text { Hawaii ....................... } \\
\text { Idaho....................... } \\
\text { Hlinois....................... } \\
\text { Indiana....................... }\end{array}$ & $\begin{array}{r}0 \\
0 \\
0 \\
1,162 \\
233\end{array}$ & $\begin{array}{r}0 \\
0 \\
0 \\
11,741 \\
12\end{array}$ & $\begin{array}{r}216 \\
-95 \\
-768 \\
-139,082 \\
-3,070\end{array}$ & $\begin{array}{r}292,925 \\
0 \\
-297,276 \\
1,148,938 \\
471,391\end{array}$ & $\begin{array}{r}0 \\
0 \\
338,147 \\
0 \\
0\end{array}$ & $\begin{array}{r}-1,359 \\
0 \\
132 \\
24,103 \\
4,196\end{array}$ & $\begin{array}{r}151 \\
2,899 \\
0 \\
19,005 \\
3,496\end{array}$ & $\begin{array}{r}294,651 \\
2,804 \\
39,971 \\
994,179 \\
467,842\end{array}$ \\
\hline $\begin{array}{l}\text { lowa .......................... } \\
\text { Kansas.................... } \\
\text { Kentucky................. } \\
\text { Louisiana .................. } \\
\text { Maine....................... }\end{array}$ & $\begin{array}{r}0 \\
440,951 \\
51,924 \\
6,171,627 \\
0\end{array}$ & $\begin{array}{r}0 \\
23,023 \\
6,854 \\
128,858 \\
0\end{array}$ & $\begin{array}{r}22,662 \\
21,118 \\
-1,395 \\
53,414 \\
-37\end{array}$ & $\begin{array}{r}227,019 \\
5,734 \\
152,908 \\
-4,531,873 \\
2,672\end{array}$ & $\begin{array}{r}0 \\
0 \\
0 \\
23,114 \\
0\end{array}$ & $\begin{array}{r}12,660 \\
43,860 \\
8,178 \\
31,372 \\
15\end{array}$ & $\begin{array}{r}68 \\
0 \\
131 \\
0 \\
71\end{array}$ & $\begin{array}{r}237,089 \\
400,920 \\
188,536 \\
1,556,052 \\
2,691\end{array}$ \\
\hline $\begin{array}{l}\text { Maryland................. } \\
\text { Massachusetts....... } \\
\text { Michigan ................. } \\
\text { Minnesota ................ } \\
\text { Mississippi .............. }\end{array}$ & $\begin{array}{r}36 \\
0 \\
153,051 \\
0 \\
167,231\end{array}$ & $\begin{array}{r}0 \\
0 \\
14,182 \\
0 \\
831\end{array}$ & $\begin{array}{r}2,522 \\
-7,724 \\
47,829 \\
-2,060 \\
4,671\end{array}$ & $\begin{array}{r}154,923 \\
151,605 \\
829,747 \\
-241,520 \\
94,588\end{array}$ & $\begin{array}{r}0 \\
32,022 \\
-241,607 \\
505,356 \\
0\end{array}$ & $\begin{array}{r}475 \\
-1,618 \\
29,170 \\
74 \\
-3,472\end{array}$ & $\begin{array}{r}984 \\
17,586 \\
2,473 \\
337 \\
0\end{array}$ & $\begin{array}{l}157,990 \\
195,107 \\
748,141 \\
262,039 \\
269,131\end{array}$ \\
\hline $\begin{array}{l}\text { Missouri ................... } \\
\text { Montana ................... } \\
\text { Nebraska ................ } \\
\text { Nevada ................... } \\
\text { New Hampshire ...... }\end{array}$ & $\begin{array}{r}0 \\
56,517 \\
2,280 \\
0 \\
0\end{array}$ & $\begin{array}{r}0 \\
940 \\
133 \\
0 \\
0\end{array}$ & $\begin{array}{r}-6,720 \\
-1,174 \\
5,234 \\
-918 \\
-525\end{array}$ & $\begin{array}{r}284,183 \\
-56,232 \\
134,270 \\
47,832 \\
10,021\end{array}$ & $\begin{array}{r}0 \\
60,496 \\
0 \\
0 \\
0\end{array}$ & $\begin{array}{r}143 \\
6,459 \\
3,476 \\
289 \\
0\end{array}$ & $\begin{array}{r}2,129 \\
0 \\
63 \\
2 \\
582\end{array}$ & $\begin{array}{r}279,449 \\
52,208 \\
138,238 \\
46,627 \\
10,078\end{array}$ \\
\hline $\begin{array}{l}\text { New Jersey ............. } \\
\text { New Mexico ............. } \\
\text { New York............... } \\
\text { North Carolina......... } \\
\text { North Dakota........... }\end{array}$ & $\begin{array}{r}0 \\
991,178 \\
15,877 \\
0 \\
53,818\end{array}$ & $\begin{array}{r}0 \\
56,857 \\
0 \\
0 \\
5,602\end{array}$ & $\begin{array}{r}-19,752 \\
-41,793 \\
-6,621 \\
-5,331 \\
-18,691\end{array}$ & $\begin{array}{r}385,815 \\
-670,957 \\
751,699 \\
147,291 \\
-1,257\end{array}$ & $\begin{array}{r}0 \\
0 \\
24,139 \\
0 \\
0\end{array}$ & $\begin{array}{r}189 \\
17,411 \\
12,176 \\
-111 \\
0\end{array}$ & $\begin{array}{r}9,786 \\
3 \\
2,350 \\
58 \\
102\end{array}$ & $\begin{array}{r}375,660 \\
204,163 \\
775,268 \\
142,129 \\
28,370\end{array}$ \\
\hline $\begin{array}{l}\text { Ohio ......................... } \\
\text { Oldahoma ................. } \\
\text { Oregon................... } \\
\text { Pennsytvania .......... } \\
\text { Rhode Island........... }\end{array}$ & $\begin{array}{r}138,391 \\
1,985,384 \\
3 \\
121,111 \\
0\end{array}$ & $\begin{array}{r}23 \\
85,934 \\
0 \\
40 \\
0\end{array}$ & $\begin{array}{r}5,648 \\
-178,846 \\
3,261 \\
-57,871 \\
-268\end{array}$ & $\begin{array}{r}647,771 \\
-1,026,318 \\
67,535 \\
660,422 \\
27,407\end{array}$ & $\begin{array}{l}0 \\
0 \\
0 \\
0 \\
0\end{array}$ & $\begin{array}{r}43,080 \\
17,524 \\
-1 \\
34,604 \\
-17\end{array}$ & $\begin{array}{r}64,812 \\
0 \\
24 \\
5,621 \\
718\end{array}$ & $\begin{array}{r}813,519 \\
676,762 \\
70,824 \\
694,639 \\
27,874\end{array}$ \\
\hline $\begin{array}{l}\text { South Carolina ........ } \\
\text { South Dakota......... } \\
\text { Tennessee............ } \\
\text { Texas ....................... } \\
\text { Utah ........................ }\end{array}$ & $\begin{array}{r}0 \\
2,331 \\
2,976 \\
6,468,817 \\
94,255\end{array}$ & $\begin{array}{r}0 \\
0 \\
0 \\
356,406 \\
3,930\end{array}$ & $\begin{array}{r}762 \\
-1,680 \\
-14,608 \\
-96,998 \\
-23,129\end{array}$ & $\begin{array}{r}96,909 \\
24,388 \\
219,344 \\
-2,694,647 \\
38,230\end{array}$ & $\begin{array}{r}0 \\
0 \\
0 \\
94,783 \\
0\end{array}$ & $\begin{array}{r}-366 \\
0 \\
641 \\
21,146 \\
-12,280\end{array}$ & $\begin{array}{r}63 \\
50 \\
90 \\
1 \\
0\end{array}$ & $\begin{array}{r}98,100 \\
25,089 \\
207,161 \\
3.394,404 \\
117,706\end{array}$ \\
\hline $\begin{array}{l}\text { Vermont ................... } \\
\text { Virginia.................. } \\
\text { Washington............ } \\
\text { West Virginia.......... } \\
\text { Wisconsin ................ } \\
\text { Wyoming................ }\end{array}$ & $\begin{array}{r}0 \\
6,880 \\
0 \\
150,850 \\
0 \\
424,657\end{array}$ & $\begin{array}{r}0 \\
0 \\
0 \\
7,086 \\
0 \\
15,482\end{array}$ & $\begin{array}{r}-149 \\
-209 \\
1,907 \\
29,058 \\
-20,217 \\
-43,702\end{array}$ & $\begin{array}{r}0 \\
143,825 \\
13,615 \\
-17,743 \\
332,287 \\
-257,095\end{array}$ & $\begin{array}{r}4,519 \\
0 \\
92,027 \\
0 \\
0 \\
0\end{array}$ & $\begin{array}{r}0 \\
-14 \\
-1,089 \\
25,050 \\
76 \\
17,973\end{array}$ & $\begin{array}{r}0 \\
454 \\
15 \\
0 \\
13 \\
518\end{array}$ & $\begin{array}{r}4,370 \\
150,964 \\
108,653 \\
130,029 \\
312,007 \\
90,923\end{array}$ \\
\hline 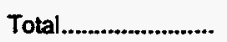 & $18,582,005$ & 761,942 & $-537,061$ & 0 & 881,441 & 308,199 & 144,811 & $18,001,055$ \\
\hline
\end{tabular}

See footnotes at end of table. 
Fable 13. Natural Gas Production, Transmission, and Consumption by State, 1967-1994 (Continued) (Million Cubic Feet)

\begin{tabular}{|c|c|c|c|c|c|c|c|c|}
\hline State & $\begin{array}{l}\text { Marketed } \\
\text { Production }\end{array}$ & $\begin{array}{l}\text { Extraction } \\
\text { Loss }\end{array}$ & $\begin{array}{l}\text { Balancing } \\
\text { Rem }\end{array}$ & $\begin{array}{c}\text { Net } \\
\text { Interstate } \\
\text { Movements }\end{array}$ & $\begin{array}{l}\text { Net Move } \\
\text { ments Across } \\
\text { U.S. Borders }\end{array}$ & $\begin{array}{c}\text { Net } \\
\text { Storage } \\
\text { Changes }\end{array}$ & $\begin{array}{c}\text { Supplemental } \\
\text { Gas } \\
\text { Supplies }\end{array}$ & Consumption \\
\hline & \multicolumn{8}{|c|}{1983} \\
\hline $\begin{array}{l}\text { Alabama.................. } \\
\text { Alaska..................... } \\
\text { Arizona..................... } \\
\text { Arkansas................. } \\
\text { California................ }\end{array}$ & $\begin{array}{r}90,801 \\
276,691 \\
132 \\
127,561 \\
415,324\end{array}$ & $\begin{array}{r}4,709 \\
440 \\
0 \\
1,258 \\
14,943\end{array}$ & $\begin{array}{r}-16,870 \\
15,806 \\
-2,184 \\
-25,786 \\
-93,114\end{array}$ & $\begin{array}{r}151,772 \\
0 \\
118,931 \\
105,659 \\
1,238,601\end{array}$ & $\begin{array}{r}0 \\
-52,857 \\
-1,646 \\
0 \\
0\end{array}$ & $\begin{array}{r}-580 \\
0 \\
0 \\
-790 \\
10,837\end{array}$ & $\begin{array}{l}9 \\
0 \\
0 \\
0 \\
0\end{array}$ & $\begin{array}{r}221,583 \\
239,200 \\
115,233 \\
206,966 \\
1,535,031\end{array}$ \\
\hline 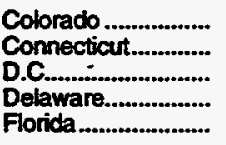 & $\begin{array}{r}163,545 \\
0 \\
0 \\
0 \\
21,056\end{array}$ & $\begin{array}{r}11,314 \\
0 \\
0 \\
0 \\
8,269\end{array}$ & $\begin{array}{r}-8,643 \\
-3,085 \\
-226 \\
-1,884 \\
1,421\end{array}$ & $\begin{array}{r}58,370 \\
76,836 \\
29,566 \\
36,719 \\
292,098\end{array}$ & $\begin{array}{l}0 \\
0 \\
0 \\
0 \\
0\end{array}$ & $\begin{array}{r}-3,927 \\
-385 \\
0 \\
-29 \\
0\end{array}$ & $\begin{array}{r}7,927 \\
291 \\
0 \\
20 \\
1\end{array}$ & $\begin{array}{r}213,812 \\
74,427 \\
29,340 \\
34,884 \\
306,307\end{array}$ \\
\hline 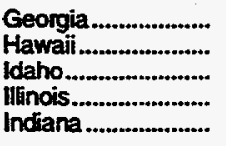 & $\begin{array}{r}0 \\
0 \\
0 \\
1,030 \\
135\end{array}$ & $\begin{array}{r}0 \\
0 \\
0 \\
12,843 \\
0\end{array}$ & $\begin{array}{r}-8,979 \\
-106 \\
317 \\
-47,205 \\
9,381\end{array}$ & $\begin{array}{r}304,257 \\
0 \\
-275,965 \\
933,968 \\
.407,609\end{array}$ & $\begin{array}{r}0 \\
0 \\
310,811 \\
0 \\
0\end{array}$ & $\begin{array}{r}-169 \\
0 \\
-16 \\
-43,656 \\
-5,503\end{array}$ & $\begin{array}{r}84 \\
2,775 \\
0 \\
19,734 \\
4,142\end{array}$ & $\begin{array}{r}295,531 \\
2,669 \\
35,179 \\
938,340 \\
426,770\end{array}$ \\
\hline 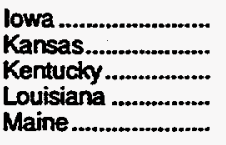 & $\begin{array}{r}0 \\
447,207 \\
46,720 \\
5,332,113 \\
0\end{array}$ & $\begin{array}{r}0 \\
28,561 \\
6,213 \\
124,193 \\
0\end{array}$ & $\begin{array}{r}-2,995 \\
-9,626 \\
-21,119 \\
-115,718 \\
-70\end{array}$ & $\begin{array}{r}197,501 \\
-87,808 \\
137,116 \\
-3,817,836 \\
2,397\end{array}$ & $\begin{array}{r}0 \\
0 \\
0 \\
96,945 \\
0\end{array}$ & $\begin{array}{r}-25,988 \\
-24,992 \\
-17,543 \\
-41,672 \\
-85\end{array}$ & $\begin{array}{r}23 \\
0 \\
259 \\
0 \\
12\end{array}$ & $\begin{array}{r}220,517 \\
346,204 \\
174,306 \\
1,412,983 \\
2,424\end{array}$ \\
\hline $\begin{array}{l}\text { Maryland .................. } \\
\text { Massachusetts....... } \\
\text { Michigan ................. } \\
\text { Minnesota ................ } \\
\text { Mississippi .............. }\end{array}$ & $\begin{array}{r}31 \\
0 \\
138,910 \\
0 \\
151,204\end{array}$ & $\begin{array}{r}0 \\
0 \\
13,537 \\
0 \\
633\end{array}$ & $\begin{array}{r}-10,428 \\
-15,963 \\
52,606 \\
-4,719 \\
16,025\end{array}$ & $\begin{array}{r}154,941 \\
162,168 \\
625,986 \\
-127,246 \\
63,820\end{array}$ & $\begin{array}{r}0 \\
34,178 \\
-211,313 \\
372,335 \\
0\end{array}$ & $\begin{array}{r}-732 \\
-700 \\
-100,847 \\
-406 \\
-7,443\end{array}$ & $\begin{array}{r}352 \\
10,732 \\
2,956 \\
1 \\
0\end{array}$ & $\begin{array}{l}145,628 \\
191,815 \\
696,455 \\
240,777 \\
237,859\end{array}$ \\
\hline $\begin{array}{l}\text { Missouri ................... } \\
\text { Montana................. } \\
\text { Nebraska ................. } \\
\text { Nevada ................... } \\
\text { New Hampshire ...... }\end{array}$ & $\begin{array}{r}0 \\
51,967 \\
2,091 \\
0 \\
0\end{array}$ & $\begin{array}{r}0 \\
1,049 \\
137 \\
0 \\
0\end{array}$ & $\begin{array}{r}-8,726 \\
-7,854 \\
1,592 \\
3,307 \\
-448\end{array}$ & $\begin{array}{r}263,381 \\
-104,027 \\
122,820 \\
38,766 \\
9,691\end{array}$ & $\begin{array}{r}0 \\
127,253 \\
0 \\
0 \\
0\end{array}$ & $\begin{array}{r}-2,627 \\
20,041 \\
-918 \\
149 \\
-84\end{array}$ & $\begin{array}{r}1,278 \\
0 \\
2,006 \\
2 \\
328\end{array}$ & $\begin{array}{r}258,560 \\
46,249 \\
129,290 \\
41,926 \\
9,655\end{array}$ \\
\hline $\begin{array}{l}\text { New Jersey.............. } \\
\text { New Mexico............ } \\
\text { New York................ } \\
\text { North Carolina........ } \\
\text { North Dakota.......... }\end{array}$ & $\begin{array}{r}0 \\
895,279 \\
17,836 \\
0 \\
69,319\end{array}$ & $\begin{array}{r}0 \\
56,304 \\
0 \\
0 \\
7,171\end{array}$ & $\begin{array}{r}-14,343 \\
29,854 \\
-34,247 \\
-4,414 \\
-11,380\end{array}$ & $\begin{array}{r}409,625 \\
-692,518 \\
702,840 \\
140,652 \\
-24,642\end{array}$ & $\begin{array}{r}0 \\
0 \\
22,348 \\
0 \\
0\end{array}$ & $\begin{array}{r}-209 \\
-2,387 \\
-9,975 \\
-282 \\
0\end{array}$ & $\begin{array}{r}9,896 \\
1,646 \\
59 \\
0\end{array}$ & $\begin{array}{r}405,387 \\
178,698 \\
720,398 \\
136,579 \\
26,126\end{array}$ \\
\hline $\begin{array}{l}\text { Ohio ...................... } \\
\text { Oklahoma .............. } \\
\text { Oregon.................. } \\
\text { Pennsyivania .......... } \\
\text { Ahode Island.......... }\end{array}$ & $\begin{array}{r}151,300 \\
1,779,541 \\
3 \\
118,372 \\
0\end{array}$ & $\begin{array}{r}29 \\
90,772 \\
0 \\
55 \\
0\end{array}$ & $\begin{array}{r}-77,513 \\
-134,938 \\
20,303 \\
-21,532 \\
-1,173\end{array}$ & $\begin{array}{r}584,488 \\
-960,301 \\
46,612 \\
484,528 \\
29,615\end{array}$ & $\begin{array}{l}0 \\
0 \\
0 \\
0 \\
0\end{array}$ & $\begin{array}{r}-26,990 \\
-35,420 \\
-124 \\
-58,795 \\
-8\end{array}$ & $\begin{array}{r}62,032 \\
0 \\
3 \\
3,844 \\
594\end{array}$ & $\begin{array}{r}747,268 \\
628,950 \\
67,045 \\
643,952 \\
29,044\end{array}$ \\
\hline $\begin{array}{l}\text { South Carolina ....... } \\
\text { South Dakota.......... } \\
\text { Tennessee.............. } \\
\text { Texas ....................... } \\
\text { Utah ........................ }\end{array}$ & $\begin{array}{r}0 \\
1,846 \\
3,950 \\
5,938,561 \\
63,158\end{array}$ & $\begin{array}{r}0 \\
0 \\
0 \\
375,849 \\
4,180\end{array}$ & $\begin{array}{r}-1,833 \\
-564 \\
-37,304 \\
-123,301 \\
8,139\end{array}$ & $\begin{array}{r}103,232 \\
22,043 \\
226,680 \\
-2,319,732 \\
45,192\end{array}$ & $\begin{array}{r}0 \\
0 \\
0 \\
75,361 \\
0\end{array}$ & $\begin{array}{r}-160 \\
0 \\
-1,245 \\
-46,461 \\
2,124\end{array}$ & $\begin{array}{r}73 \\
1 \\
39 \\
14 \\
0\end{array}$ & $\begin{array}{r}101,632 \\
23,326 \\
194,610 \\
3,241,515 \\
110,185\end{array}$ \\
\hline $\begin{array}{l}\text { Vermont ................... } \\
\text { Virginia.................... } \\
\text { Washington............ } \\
\text { West Virginia.......... } \\
\text { Wisconsin ................ } \\
\text { Wyoming................ }\end{array}$ & $\begin{array}{r}0 \\
4,346 \\
0 \\
130,078 \\
0 \\
443,988\end{array}$ & $\begin{array}{r}0 \\
0 \\
0 \\
7.505 \\
0 \\
19.668\end{array}$ & $\begin{array}{r}-251 \\
-7,618 \\
-19,985 \\
79,380 \\
-19,801 \\
-25,528\end{array}$ & $\begin{array}{r}0 \\
145,754 \\
38,328 \\
-104,985 \\
318,805 \\
-316,308\end{array}$ & $\begin{array}{r}4,610 \\
0 \\
86,576 \\
0 \\
0 \\
0\end{array}$ & $\begin{array}{r}0 \\
-87 \\
-2,263 \\
-18,845 \\
-93 \\
1,986\end{array}$ & $\begin{array}{r}0 \\
375 \\
11 \\
0 \\
2 \\
373\end{array}$ & $\begin{array}{r}4,359 \\
142,944 \\
107,193 \\
115,813 \\
299,099 \\
80,871\end{array}$ \\
\hline 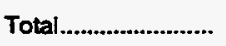 & $16,884,093$ & 789.632 & $-703,342$ & 0 & 864,600 & $-447,301$ & 131,894 & $16,834,914$ \\
\hline
\end{tabular}

See footnoles at end of tabie. 
Table 13. Natural Gas Production, Transmission, and Consumption by. State, 1967-1994 (Continued) (Million Cubic Feet)

\begin{tabular}{|c|c|c|c|c|c|c|c|c|}
\hline State & $\begin{array}{l}\text { Marketed } \\
\text { Production }\end{array}$ & $\begin{array}{l}\text { Extraction } \\
\text { Loss }\end{array}$ & $\begin{array}{l}\text { Balancing } \\
\text { hem }\end{array}$ & $\begin{array}{c}\text { Net } \\
\text { Interstate } \\
\text { Movements }\end{array}$ & $\begin{array}{l}\text { Net Move- } \\
\text { ments Across } \\
\text { U.S. Borders }\end{array}$ & $\begin{array}{c}\text { Not } \\
\text { Storage } \\
\text { Changes }\end{array}$ & $\begin{array}{c}\text { Supplemental } \\
\text { Gas } \\
\text { Supplies }\end{array}$ & Consumption \\
\hline & \multicolumn{8}{|c|}{1984} \\
\hline 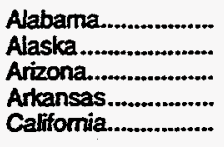 & $\begin{array}{r}101,821 \\
289,129 \\
45 \\
135,161 \\
476,333\end{array}$ & $\begin{array}{r}5,123 \\
2,849 \\
0 \\
1,200 \\
15,442\end{array}$ & $\begin{array}{r}-5,868 \\
24,085 \\
-11,413 \\
-23,870 \\
-77,181\end{array}$ & $\begin{array}{r}141,572 \\
0 \\
134,274 \\
99,966 \\
1,277,119\end{array}$ & $\begin{array}{r}0 \\
-52,840 \\
-1,757 \\
0 \\
0\end{array}$ & $\begin{array}{r}459 \\
0 \\
0 \\
36 \\
-8,877\end{array}$ & $\begin{array}{r}54 \\
0 \\
0 \\
0 \\
0\end{array}$ & $\begin{array}{r}231,997 \\
257,525 \\
121,149 \\
210,021 \\
1,669,705\end{array}$ \\
\hline 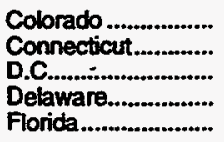 & $\begin{array}{r}173,257 \\
0 \\
0 \\
0 \\
12,585\end{array}$ & $\begin{array}{r}10,771 \\
0 \\
0 \\
0 \\
6,631\end{array}$ & $\begin{array}{r}-165 \\
308 \\
-765 \\
174 \\
-1,317\end{array}$ & $\begin{array}{r}62,886 \\
81,136 \\
30,214 \\
42,815 \\
298,672\end{array}$ & $\begin{array}{l}0 \\
0 \\
0 \\
0 \\
0\end{array}$ & $\begin{array}{r}4,697 \\
544 \\
0 \\
40 \\
0\end{array}$ & $\begin{array}{r}9.137 \\
239 \\
0 \\
13 \\
0\end{array}$ & $\begin{array}{r}229,647 \\
81,139 \\
29,449 \\
42,962 \\
303,309\end{array}$ \\
\hline 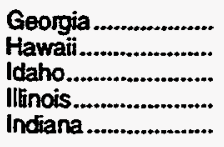 & $\begin{array}{r}0 \\
0 \\
0 \\
1,530 \\
394\end{array}$ & $\begin{array}{r}0 \\
0 \\
0 \\
11,687 \\
0\end{array}$ & $\begin{array}{r}2,518 \\
-74 \\
-398 \\
39,461 \\
21,266\end{array}$ & $\begin{array}{r}304,574 \\
0 \\
-260,410 \\
1,007,842 \\
432,947\end{array}$ & $\begin{array}{r}0 \\
0 \\
299,360 \\
0 \\
0\end{array}$ & $\begin{array}{r}-203 \\
0 \\
-52 \\
21,675 \\
6,350\end{array}$ & $\begin{array}{r}28 \\
2,449 \\
0 \\
17,308 \\
4,027\end{array}$ & $\begin{array}{r}307,323 \\
2,375 \\
38,604 \\
1,032,779 \\
452,284\end{array}$ \\
\hline 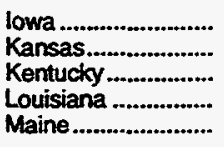 & $\begin{array}{r}0 \\
480,211 \\
61,518 \\
5,825,055 \\
0\end{array}$ & $\begin{array}{r}0 \\
29,707 \\
6,516 \\
132,501 \\
0\end{array}$ & $\begin{array}{r}-8,545 \\
38,700 \\
-44,005 \\
-5,562 \\
-83\end{array}$ & $\begin{array}{r}232,205 \\
-102,386 \\
191,005 \\
-4,077,511 \\
2,537\end{array}$ & $\begin{array}{l}0 \\
0 \\
0 \\
0 \\
0\end{array}$ & $\begin{array}{r}-11,133 \\
23,147 \\
12,841 \\
15,134 \\
5\end{array}$ & $\begin{array}{r}53 \\
0 \\
94 \\
0 \\
0\end{array}$ & $\begin{array}{r}234,846 \\
363,671 \\
189,255 \\
1,594,346 \\
2,449\end{array}$ \\
\hline $\begin{array}{l}\text { Maryland................ } \\
\text { Massachusetts....... } \\
\text { Michigan ................ } \\
\text { Minnesota ............... } \\
\text { Mississippi .............. }\end{array}$ & $\begin{array}{r}60 \\
0 \\
144,537 \\
0 \\
157,911\end{array}$ & $\begin{array}{r}0 \\
0 \\
12,829 \\
0 \\
618\end{array}$ & $\begin{array}{r}7,016 \\
-10,729 \\
33,385 \\
27,630 \\
-24,071\end{array}$ & $\begin{array}{r}150,999 \\
179,483 \\
833,598 \\
-238,841 \\
152,973\end{array}$ & $\begin{array}{r}0 \\
36,191 \\
-262,221 \\
467,974 \\
0\end{array}$ & $\begin{array}{r}-582 \\
2,733 \\
21,140 \\
1,127 \\
17,635\end{array}$ & $\begin{array}{r}332 \\
6,545 \\
2,773 \\
3 \\
0\end{array}$ & $\begin{array}{l}158,989 \\
208,758 \\
718,103 \\
255,638 \\
268,560\end{array}$ \\
\hline $\begin{array}{l}\text { Missouri .................. } \\
\text { Montana................ } \\
\text { Nebraska ................ } \\
\text { Nevada ............. } \\
\text { New Hampshire ..... }\end{array}$ & $\begin{array}{r}4 \\
51,474 \\
2,300 \\
0 \\
0\end{array}$ & $\begin{array}{r}0 \\
1,069 \\
132 \\
0 \\
0\end{array}$ & $\begin{array}{r}-6,753 \\
-5,914 \\
-3,136 \\
2,325 \\
-515\end{array}$ & $\begin{array}{r}273,862 \\
-107,105 \\
133,069 \\
39,997 \\
10,365\end{array}$ & $\begin{array}{r}0 \\
125,715 \\
0 \\
0 \\
0\end{array}$ & $\begin{array}{r}2,485 \\
16,237 \\
106 \\
68 \\
0\end{array}$ & $\begin{array}{r}326 \\
0 \\
2,470 \\
2 \\
681\end{array}$ & $\begin{array}{r}264,954 \\
46,864 \\
134,465 \\
42,256 \\
10,531\end{array}$ \\
\hline $\begin{array}{l}\text { New Jersey............ } \\
\text { New Mexico ........... } \\
\text { New York............. } \\
\text { North Carolina........ } \\
\text { North Dakota.......... }\end{array}$ & $\begin{array}{r}0 \\
957,366 \\
25,200 \\
0 \\
70,496\end{array}$ & $\begin{array}{r}0 \\
58,580 \\
0 \\
0 \\
7,860\end{array}$ & $\begin{array}{r}-24,539 \\
-45,424 \\
34,607 \\
879 \\
-8,249\end{array}$ & $\begin{array}{r}435,612 \\
-696,581 \\
711,063 \\
143,363 \\
-32,570\end{array}$ & $\begin{array}{r}0 \\
0 \\
29,326 \\
0 \\
0\end{array}$ & $\begin{array}{r}1,469 \\
-5,069 \\
11,977 \\
448 \\
0\end{array}$ & $\begin{array}{r}8,616 \\
0 \\
1,792 \\
60 \\
8,335\end{array}$ & $\begin{array}{r}418,220 \\
161,850 \\
790,011 \\
143,854 \\
30,153\end{array}$ \\
\hline $\begin{array}{l}\text { Ohio } \\
\text { Okdahoma ................... } \\
\text { Oregon................ } \\
\text { Pennsytrania .......... } \\
\text { Rhode Island.......... }\end{array}$ & $\begin{array}{r}186,480 \\
2,046,339 \\
2,790 \\
166,342 \\
0\end{array}$ & $\begin{array}{r}41 \\
98,307 \\
0 \\
61 \\
0\end{array}$ & $\begin{array}{r}-66,388 \\
-107,076 \\
-667 \\
-47,036 \\
-597\end{array}$ & $\begin{array}{r}599,997 \\
-1,161,866 \\
76,546 \\
597,769 \\
32,215\end{array}$ & $\begin{array}{l}0 \\
0 \\
0 \\
0 \\
0\end{array}$ & $\begin{array}{r}-21,382 \\
26,137 \\
32 \\
40,376 \\
31\end{array}$ & $\begin{array}{r}43,866 \\
0 \\
6 \\
82 \\
102\end{array}$ & $\begin{array}{r}785,297 \\
652,953 \\
78,643 \\
676,721 \\
31,689\end{array}$ \\
\hline 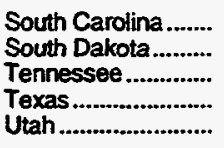 & $\begin{array}{r}0 \\
1,947 \\
5,022 \\
6,185,021 \\
74,698\end{array}$ & $\begin{array}{r}0 \\
0 \\
0 \\
393,873 \\
4,259\end{array}$ & $\begin{array}{r}1,963 \\
-698 \\
-77 \\
-3,464 \\
56,069\end{array}$ & $\begin{array}{r}106,508 \\
23,343 \\
202,456 \\
-2,410,262 \\
-14,625\end{array}$ & $\begin{array}{r}0 \\
0 \\
0 \\
51,473 \\
0\end{array}$ & $\begin{array}{r}104 \\
0 \\
1,073 \\
-3,726 \\
-3,697\end{array}$ & $\begin{array}{r}62 \\
25 \\
2 \\
0\end{array}$ & $\begin{array}{r}108,429 \\
24,592 \\
206,353 \\
3,432,624 \\
115,578\end{array}$ \\
\hline 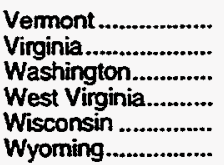 & $\begin{array}{r}0 \\
8,901 \\
0 \\
143,730 \\
0 \\
516,683\end{array}$ & $\begin{array}{r}0 \\
0 \\
0 \\
8,638 \\
0 \\
29,169\end{array}$ & $\begin{array}{r}-126 \\
-5,953 \\
-4,894 \\
119,708 \\
-25 \\
-81,828\end{array}$ & $\begin{array}{r}0 \\
140,466 \\
42,424 \\
-108,474 \\
305,205 \\
-320,447\end{array}$ & $\begin{array}{r}4,994 \\
0 \\
90,001 \\
0 \\
0 \\
0\end{array}$ & $\begin{array}{r}0 \\
41 \\
1,255 \\
21,959 \\
110 \\
86\end{array}$ & $\begin{array}{r}0 \\
209 \\
11 \\
0 \\
6 \\
271\end{array}$ & $\begin{array}{r}4,868 \\
143,582 \\
126,287 \\
124,368 \\
305,076 \\
85,423\end{array}$ \\
\hline 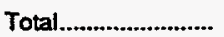 & $18,304,339$ & 837,867 & $-217,308$ & 0 & 788,216 & 196,835 & 109,977 & $17,950,524$ \\
\hline
\end{tabular}

See footnotes at end of table. 
Table 13. Natural Gas Production, Transmission, and Consumption by State, 1967-1994 (Continued) (Million Cubic Feet)

\begin{tabular}{|c|c|c|c|c|c|c|c|c|}
\hline State & $\begin{array}{l}\text { Markeled } \\
\text { Production }\end{array}$ & $\begin{array}{l}\text { Extraction } \\
\text { Loss }\end{array}$ & $\begin{array}{l}\text { Balancing } \\
\text { hem }\end{array}$ & $\begin{array}{c}\text { Net } \\
\text { Interatuto } \\
\text { Movements }\end{array}$ & $\begin{array}{l}\text { Net Mowe- } \\
\text { ments Aeross } \\
\text { U.S. Borders }\end{array}$ & $\begin{array}{c}\text { Net } \\
\text { Storage } \\
\text { Changes }\end{array}$ & $\begin{array}{l}\text { Supplemental } \\
\text { Gas } \\
\text { Supplies }\end{array}$ & Consumption \\
\hline & \multicolumn{8}{|c|}{1985} \\
\hline 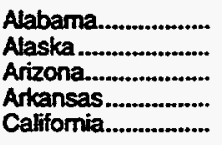 & $\begin{array}{r}107,342 \\
321,346 \\
85 \\
155,099 \\
491,283\end{array}$ & $\begin{array}{r}5,236 \\
6,703 \\
0 \\
1,141 \\
16,973\end{array}$ & $\begin{array}{r}-23,365 \\
-48,995 \\
-51,317 \\
-13,310 \\
9,929\end{array}$ & $\begin{array}{r}140,241 \\
0 \\
183,821 \\
57,909 \\
1,340,239\end{array}$ & $\begin{array}{r}0 \\
-52,883 \\
-1,813 \\
0 \\
0\end{array}$ & $\begin{array}{r}-459 \\
0 \\
0 \\
2,924 \\
-21,600\end{array}$ & $\begin{array}{r}14 \\
0 \\
0 \\
0 \\
0\end{array}$ & $\begin{array}{r}219,455 \\
212,765 \\
130,776 \\
195,633 \\
1,846,078\end{array}$ \\
\hline 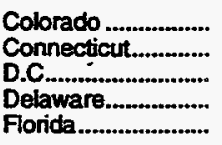 & $\begin{array}{r}178,233 \\
0 \\
0 \\
0 \\
10,545\end{array}$ & $\begin{array}{r}11,913 \\
0 \\
0 \\
0 \\
5,471\end{array}$ & $\begin{array}{r}1,338 \\
5,738 \\
-442 \\
-279 \\
11,578\end{array}$ & $\begin{array}{r}40,361 \\
71,947 \\
29,344 \\
38,767 \\
273,051\end{array}$ & $\begin{array}{l}0 \\
0 \\
0 \\
0 \\
0\end{array}$ & $\begin{array}{r}-1,989 \\
-187 \\
0 \\
7 \\
0\end{array}$ & $\begin{array}{r}8,934 \\
343 \\
0 \\
12 \\
3\end{array}$ & $\begin{array}{r}218,942 \\
78,215 \\
28,902 \\
38,493 \\
289,706\end{array}$ \\
\hline 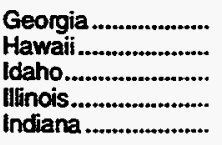 & $\begin{array}{r}0 \\
0 \\
0 \\
1,324 \\
367\end{array}$ & $\begin{array}{r}0 \\
0 \\
0 \\
11,436 \\
0\end{array}$ & $\begin{array}{r}-15,349 \\
-172 \\
-1,026 \\
-54,858 \\
-19,357\end{array}$ & $\begin{array}{r}296,508 \\
0 \\
-371,794 \\
989,037 \\
448,014\end{array}$ & $\begin{array}{r}0 \\
0 \\
411,380 \\
0 \\
0\end{array}$ & $\begin{array}{r}-525 \\
0 \\
-634 \\
-18,167 \\
-1,223\end{array}$ & $\begin{array}{r}121 \\
2,655 \\
0 \\
19,805 \\
2,711\end{array}$ & $\begin{array}{r}281,805 \\
2,483 \\
39,194 \\
962,039 \\
432,958\end{array}$ \\
\hline 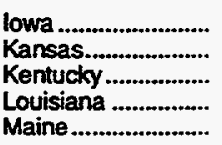 & $\begin{array}{r}0 \\
528,032 \\
73,126 \\
5,013,702 \\
0\end{array}$ & $\begin{array}{r}0 \\
28,964 \\
6,334 \\
117,736 \\
0\end{array}$ & $\begin{array}{r}-19,577 \\
2,525 \\
-27,840 \\
1,107 \\
-121\end{array}$ & $\begin{array}{r}246,498 \\
-164,475 \\
138,449 \\
-3,538,729 \\
2,664\end{array}$ & $\begin{array}{l}0 \\
0 \\
0 \\
0 \\
0\end{array}$ & $\begin{array}{r}1,063 \\
-18,349 \\
4,895 \\
-28,021 \\
12\end{array}$ & $\begin{array}{r}45 \\
0 \\
4 \\
0 \\
0\end{array}$ & $\begin{array}{r}225,903 \\
355,467 \\
172,510 \\
1,386,365 \\
2,531\end{array}$ \\
\hline $\begin{array}{l}\text { Maryland............... } \\
\text { Massachusetts....... } \\
\text { Michigan ................ } \\
\text { Minnesota .............. } \\
\text { Mississippi ............. }\end{array}$ & $\begin{array}{r}39 \\
0 \\
131,855 \\
0 \\
144,172\end{array}$ & $\begin{array}{r}0 \\
0 \\
11,129 \\
0 \\
458\end{array}$ & $\begin{array}{r}3,365 \\
-5,024 \\
58,015 \\
7,801 \\
41,025\end{array}$ & $\begin{array}{r}145,791 \\
196,626 \\
764,145 \\
-219,266 \\
53,347\end{array}$ & $\begin{array}{r}0 \\
23,659 \\
-249,451 \\
468,290 \\
0\end{array}$ & $\begin{array}{r}-1,270 \\
45 \\
-13,008 \\
-644 \\
11,423\end{array}$ & $\begin{array}{r}373 \\
3,668 \\
2,789 \\
11 \\
0\end{array}$ & $\begin{array}{l}150,838 \\
218,884 \\
709,232 \\
257,480 \\
226,663\end{array}$ \\
\hline $\begin{array}{l}\text { Missouri .................. } \\
\text { Montana................ } \\
\text { Nebraska ................ } \\
\text { Nevada ............... } \\
\text { New Hampshire ...... }\end{array}$ & $\begin{array}{r}4 \\
52,494 \\
1,944 \\
0 \\
0\end{array}$ & $\begin{array}{r}0 \\
1,189 \\
115 \\
0 \\
0\end{array}$ & $\begin{array}{r}-14,847 \\
-3,823 \\
-9,259 \\
-562 \\
-115\end{array}$ & $\begin{array}{r}273,901 \\
-134,021 \\
131,668 \\
39,847 \\
10,235\end{array}$ & $\begin{array}{r}0 \\
143,229 \\
0 \\
0 \\
0\end{array}$ & $\begin{array}{r}-491 \\
9.425 \\
792 \\
89 \\
0\end{array}$ & $\begin{array}{r}351 \\
0 \\
2,689 \\
4 \\
509\end{array}$ & $\begin{array}{r}259,900 \\
47,265 \\
126,135 \\
39,200 \\
10,629\end{array}$ \\
\hline $\begin{array}{l}\text { New Jersey............. } \\
\text { New Mexico........... } \\
\text { New York............. } \\
\text { North Carolina........ } \\
\text { North Dakota.......... }\end{array}$ & $\begin{array}{r}0 \\
905,272 \\
31,561 \\
0 \\
72,633\end{array}$ & $\begin{array}{r}0 \\
53,953 \\
0 \\
0 \\
8,420\end{array}$ & $\begin{array}{r}3,8832 \\
-4,957 \\
-86,105 \\
-4,254 \\
-10,304\end{array}$ & $\begin{array}{r}362,230 \\
-694,554 \\
763,163 \\
137,803 \\
-66,183\end{array}$ & $\begin{array}{r}0 \\
0 \\
47,677 \\
0 \\
0\end{array}$ & $\begin{array}{r}253 \\
680 \\
-4,528 \\
-233 \\
0\end{array}$ & $\begin{array}{r}13,421 \\
0 \\
1,797 \\
43 \\
40,370\end{array}$ & $\begin{array}{r}379,230 \\
151,128 \\
762,621 \\
133,825 \\
28,096\end{array}$ \\
\hline $\begin{array}{l}\text { Ohio .................... } \\
\text { Okdahoma ............. } \\
\text { Oregon................. } \\
\text { Pennsylvania .......... } \\
\text { Rhode Island.......... }\end{array}$ & $\begin{array}{r}182,245 \\
1,993,405 \\
4,080 \\
150,234 \\
0\end{array}$ & $\begin{array}{r}67 \\
99,933 \\
0 \\
145 \\
0\end{array}$ & $\begin{array}{r}-67,761 \\
-143,053 \\
-1,151 \\
-1,150 \\
-1,287\end{array}$ & $\begin{array}{r}563,603 \\
-1,182,066 \\
80,245 \\
425,482 \\
31,058\end{array}$ & $\begin{array}{l}0 \\
0 \\
0 \\
0 \\
0\end{array}$ & $\begin{array}{r}-30,652 \\
-19,054 \\
178 \\
-51,025 \\
27\end{array}$ & $\begin{array}{r}24,444 \\
0 \\
6 \\
221 \\
130\end{array}$ & $\begin{array}{r}733,116 \\
587,407 \\
83,002 \\
625,667 \\
29,874\end{array}$ \\
\hline 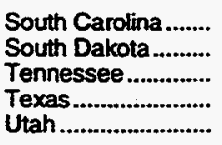 & $\begin{array}{r}0 \\
2,558 \\
4,686 \\
6,052,663 \\
83,405\end{array}$ & $\begin{array}{r}0 \\
0 \\
0 \\
383,719 \\
3,874\end{array}$ & $\begin{array}{r}-3,909 \\
-1,066 \\
-1,615 \\
-58,839 \\
20,547\end{array}$ & $\begin{array}{r}101,482 \\
23,710 \\
186,787 \\
-2,252,999 \\
12,972\end{array}$ & $\begin{array}{r}0 \\
0 \\
0 \\
-394 \\
0\end{array}$ & $\begin{array}{r}191 \\
0 \\
-372 \\
-28,994 \\
-2,067\end{array}$ & $\begin{array}{r}87 \\
36 \\
9 \\
0\end{array}$ & $\begin{array}{r}97,469 \\
25,202 \\
190,266 \\
3,385,715 \\
115,117\end{array}$ \\
\hline $\begin{array}{l}\text { Vermont .................... } \\
\text { Virginia ................... } \\
\text { Washington............ } \\
\text { West Virginia........... } \\
\text { Wisconsin ............... } \\
\text { Wyoming................ }\end{array}$ & $\begin{array}{r}0 \\
15,041 \\
0 \\
144,883 \\
0 \\
416,565\end{array}$ & $\begin{array}{r}0 \\
0 \\
0 \\
9,590 \\
0 \\
31,871\end{array}$ & $\begin{array}{r}-215 \\
598 \\
-6,082 \\
74,486 \\
-9,059 \\
40,449\end{array}$ & $\begin{array}{r}0 \\
123,402 \\
42,177 \\
-113,429 \\
317,390 \\
-346,398\end{array}$ & $\begin{array}{r}5,213 \\
0 \\
99,180 \\
0 \\
0 \\
0\end{array}$ & $\begin{array}{r}0 \\
-3 \\
685 \\
-20,818 \\
-20 \\
-3,111\end{array}$ & $\begin{array}{r}0 \\
414 \\
9 \\
0 \\
14 \\
316\end{array}$ & $\begin{array}{r}4,998 \\
139,458 \\
134,599 \\
117,168 \\
308,365 \\
82,172\end{array}$ \\
\hline 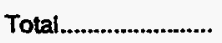 & $17,270,227$ & 816,370 & $-428,120$ & 0 & 894,087 & $-234,756$ & 126,363 & $17,280,943$ \\
\hline
\end{tabular}

See foomotes at end of table. 
Table 13.- Natural Gas Production, Transmission, and Consumption by State, 1967-1994 (Continued) (Million Cubic Feet)

\begin{tabular}{|c|c|c|c|c|c|c|c|c|}
\hline State & $\begin{array}{l}\text { Marketed } \\
\text { Production }\end{array}$ & $\begin{array}{l}\text { Extraction } \\
\text { Loss }\end{array}$ & $\begin{array}{l}\text { Balancing } \\
\text { Hem }\end{array}$ & $\begin{array}{c}\text { Not } \\
\text { Interstate } \\
\text { Movements }\end{array}$ & $\begin{array}{l}\text { Net Move } \\
\text { momts Across } \\
\text { U.S. Bordiers }\end{array}$ & $\begin{array}{c}\text { Mat } \\
\text { Storage } \\
\text { Changes }\end{array}$ & $\begin{array}{c}\text { Supplomental } \\
\text { Gas } \\
\text { Supplies }\end{array}$ & Consumption \\
\hline & \multicolumn{8}{|c|}{1986} \\
\hline 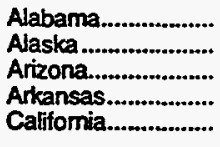 & $\begin{array}{r}107,184 \\
304,841 \\
63 \\
131,075 \\
462,218\end{array}$ & $\begin{array}{r}4,836 \\
4,206 \\
0 \\
1,318 \\
16,203\end{array}$ & $\begin{array}{r}-16,791 \\
-44,011 \\
2,167 \\
21,693 \\
-85,192\end{array}$ & $\begin{array}{r}117,495 \\
0 \\
100,453 \\
48,833 \\
1,170,859\end{array}$ & $\begin{array}{r}0 \\
-50,172 \\
-1,525 \\
0 \\
0\end{array}$ & $\begin{array}{r}132 \\
0 \\
0 \\
1,086 \\
359\end{array}$ & $\begin{array}{r}3 \\
0 \\
91 \\
0 \\
0\end{array}$ & $\begin{array}{r}202,923 \\
206,452 \\
101,249 \\
199,197 \\
1,531,323\end{array}$ \\
\hline 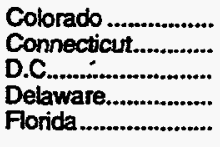 & $\begin{array}{r}163,684 \\
0 \\
0 \\
0 \\
8,833\end{array}$ & $\begin{array}{r}10,441 \\
0 \\
0 \\
0 \\
4,802\end{array}$ & $\begin{array}{r}-56,387 \\
-509 \\
-370 \\
461 \\
9,615\end{array}$ & $\begin{array}{r}95,466 \\
79,312 \\
29,956 \\
32,468 \\
274,895\end{array}$ & $\begin{array}{l}0 \\
0 \\
0 \\
0 \\
0\end{array}$ & $\begin{array}{r}2,570 \\
198 \\
0 \\
-71 \\
0\end{array}$ & $\begin{array}{r}8,095 \\
298 \\
0 \\
9 \\
0\end{array}$ & $\begin{array}{r}197,847 \\
78,903 \\
29,586 \\
33,009 \\
288,541\end{array}$ \\
\hline 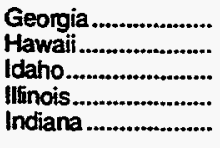 & $\begin{array}{r}0 \\
0 \\
0 \\
1,887 \\
365\end{array}$ & $\begin{array}{r}0 \\
0 \\
0 \\
9,259 \\
0\end{array}$ & $\begin{array}{r}4,340 \\
-167 \\
-1,925 \\
37,006 \\
-8,365\end{array}$ & $\begin{array}{r}275,214 \\
0 \\
-312,593 \\
887,640 \\
404,582\end{array}$ & $\begin{array}{r}0 \\
0 \\
348,307 \\
0 \\
0\end{array}$ & $\begin{array}{r}596 \\
0 \\
-932 \\
15,974 \\
3,752\end{array}$ & $\begin{array}{r}124 \\
2,630 \\
0 \\
22,980 \\
2,351\end{array}$ & $\begin{array}{r}279,082 \\
2,463 \\
34,721 \\
924,280 \\
395,181\end{array}$ \\
\hline $\begin{array}{l}\text { lowa ....................... } \\
\text { Kansas.................. } \\
\text { Kentucky................ } \\
\text { Louisiana ............... } \\
\text { Maine ...................... }\end{array}$ & $\begin{array}{r}0 \\
478,963 \\
80,195 \\
4,895,394 \\
0\end{array}$ & $\begin{array}{r}0 \\
27,050 \\
4,466 \\
115,604 \\
0\end{array}$ & $\begin{array}{r}-3,005 \\
19,994 \\
-9,350 \\
-6,991 \\
-83\end{array}$ & $\begin{array}{r}212,318 \\
-147,319 \\
103,071 \\
-3,352,487 \\
2,562\end{array}$ & $\begin{array}{l}0 \\
0 \\
0 \\
0 \\
0\end{array}$ & $\begin{array}{r}2,455 \\
11,908 \\
2,278 \\
-18,251 \\
6\end{array}$ & $\begin{array}{r}44 \\
0 \\
1 \\
0 \\
0\end{array}$ & $\begin{array}{r}206,902 \\
312,680 \\
167,173 \\
1,438,563 \\
2,473\end{array}$ \\
\hline $\begin{array}{l}\text { Maryland................ } \\
\text { Massachusetts....... } \\
\text { Michigan ............... } \\
\text { Minnesota .............. } \\
\text { Mississippi ............. }\end{array}$ & $\begin{array}{r}20 \\
0 \\
127,287 \\
0 \\
140,833\end{array}$ & $\begin{array}{r}0 \\
0 \\
11,644 \\
0 \\
463\end{array}$ & $\begin{array}{r}-7,965 \\
-5,920 \\
15,116 \\
4,385 \\
49,843\end{array}$ & $\begin{array}{r}159,735 \\
188,814 \\
907,933 \\
-234,801 \\
21,510\end{array}$ & $\begin{array}{r}0 \\
1,669 \\
-321,194 \\
479,322 \\
0\end{array}$ & $\begin{array}{r}-597 \\
593 \\
48,929 \\
4,136 \\
-3,101\end{array}$ & $\begin{array}{r}155 \\
2,379 \\
2,754 \\
2 \\
0\end{array}$ & $\begin{array}{l}152,542 \\
186,350 \\
671,323 \\
244,772 \\
214,824\end{array}$ \\
\hline $\begin{array}{l}\text { Missouri ................. } \\
\text { Montana................. } \\
\text { Nebraska ............... } \\
\text { Nevada ............... } \\
\text { New Hampshire ..... }\end{array}$ & $\begin{array}{r}4 \\
46,592 \\
1,403 \\
0 \\
0\end{array}$ & $\begin{array}{r}0 \\
1,086 \\
77 \\
0 \\
0\end{array}$ & $\begin{array}{r}-3,845 \\
-5,193 \\
-7,002 \\
3,383 \\
-320\end{array}$ & $\begin{array}{r}246,256 \\
-74,735 \\
110,498 \\
30,506 \\
10,149\end{array}$ & $\begin{array}{r}0 \\
86,434 \\
0 \\
0 \\
0\end{array}$ & $\begin{array}{r}756 \\
10,864 \\
2,232 \\
110 \\
-100\end{array}$ & $\begin{array}{r}1 \\
0 \\
2.142 \\
11 \\
362\end{array}$ & $\begin{array}{r}241,660 \\
41,148 \\
104,732 \\
33,790 \\
10,291\end{array}$ \\
\hline $\begin{array}{l}\text { New Jersey............ } \\
\text { New Mexico ........... } \\
\text { New York.............. } \\
\text { North Carolina........ } \\
\text { North Dakota......... }\end{array}$ & $\begin{array}{r}0 \\
702,614 \\
29,964 \\
0 \\
55,098\end{array}$ & $\begin{array}{r}0 \\
51,295 \\
0 \\
0 \\
6,956\end{array}$ & $\begin{array}{r}-26,896 \\
-145,857 \\
-20,718 \\
-60 \\
2,288\end{array}$ & $\begin{array}{r}370,178 \\
-375,462 \\
687,488 \\
136,522 \\
-74,806\end{array}$ & $\begin{array}{r}0 \\
0 \\
35,720 \\
0 \\
0\end{array}$ & $\begin{array}{r}1,916 \\
-4,198 \\
4,359 \\
686 \\
0\end{array}$ & $\begin{array}{r}12,099 \\
0 \\
707 \\
43 \\
49,847\end{array}$ & $\begin{array}{r}353,465 \\
134,198 \\
728,802 \\
135,819 \\
25,471\end{array}$ \\
\hline $\begin{array}{l}\text { Ohio ................... } \\
\text { Oktahoma ............ } \\
\text { Oregon................ } \\
\text { Pennsylvania ......... } \\
\text { Rhode Island......... }\end{array}$ & $\begin{array}{r}182,072 \\
1,971,988 \\
4,600 \\
159,889 \\
0\end{array}$ & $\begin{array}{r}68 \\
100,305 \\
0 \\
234 \\
0\end{array}$ & $\begin{array}{r}-37,241 \\
-136,357 \\
71 \\
-65,554 \\
-480\end{array}$ & $\begin{array}{r}587,691 \\
-1,182,072 \\
65,946 \\
525,710 \\
26,636\end{array}$ & $\begin{array}{l}0 \\
0 \\
0 \\
0 \\
0\end{array}$ & $\begin{array}{r}20,858 \\
-871 \\
-346 \\
10,054 \\
-16\end{array}$ & $\begin{array}{r}5,182 \\
0 \\
10 \\
196 \\
182\end{array}$ & $\begin{array}{r}716,778 \\
554,125 \\
70,973 \\
609,953 \\
26,354\end{array}$ \\
\hline 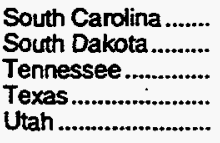 & $\begin{array}{r}0 \\
2,231 \\
3,464 \\
6,151,775 \\
90,013\end{array}$ & $\begin{array}{r}0 \\
0 \\
0 \\
384,693 \\
10,139\end{array}$ & $\begin{array}{r}-615 \\
-1,117 \\
-4,961 \\
-95,076 \\
-11,434\end{array}$ & $\begin{array}{r}99,194 \\
22,178 \\
189,555 \\
-2,477,844 \\
38,589\end{array}$ & $\begin{array}{r}0 \\
0 \\
0 \\
-372 \\
0\end{array}$ & $\begin{array}{r}61 \\
0 \\
71 \\
8,300 \\
1,854\end{array}$ & $\begin{array}{r}31 \\
0 \\
13 \\
19 \\
0\end{array}$ & $\begin{array}{r}98,549 \\
23,292 \\
188,000 \\
3,185,509 \\
105,175\end{array}$ \\
\hline $\begin{array}{l}\text { Vermont ................. } \\
\text { Vinginia................ } \\
\text { Washington.......... } \\
\text { West Virginia.......... } \\
\text { Wisconsin .............. } \\
\text { Wyoming............... }\end{array}$ & $\begin{array}{r}0 \\
15,427 \\
0 \\
0 \\
135,431 \\
0 \\
403,266\end{array}$ & $\begin{array}{r}0 \\
0 \\
0 \\
8,681 \\
0 \\
25,819\end{array}$ & $\begin{array}{r}-118 \\
10,698 \\
12,124 \\
102,626 \\
-22,600 \\
42,177\end{array}$ & $\begin{array}{r}0 \\
114,775 \\
2,127 \\
-97,281 \\
301,373 \\
-349,082\end{array}$ & $\begin{array}{r}5,137 \\
0 \\
107,151 \\
0 \\
0 \\
0\end{array}$ & $\begin{array}{r}0 \\
-49 \\
3,052 \\
19,522 \\
-74 \\
-4,148\end{array}$ & $\begin{array}{r}0 \\
75 \\
10 \\
0 \\
1 \\
339\end{array}$ & $\begin{array}{r}5,019 \\
141,024 \\
118,360 \\
112,573 \\
278,848 \\
75,029\end{array}$ \\
\hline 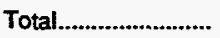 & $16,858,675$ & 799,645 & $-494,491$ & 0 & 690,478 & 146,910 & 113,189 & $16,221,296$ \\
\hline
\end{tabular}

See footnotes at end of table. 
-Table 13. Natural Gas Production,-Transmission, and Consumption by State, 1967-1994 (Continued) (Million Cubic Feet)

\begin{tabular}{|c|c|c|c|c|c|c|c|c|}
\hline State & $\begin{array}{l}\text { Marketed } \\
\text { Production }\end{array}$ & $\begin{array}{l}\text { Extraction } \\
\text { Loss }\end{array}$ & $\begin{array}{l}\text { Balancing } \\
\text { Hem }\end{array}$ & $\begin{array}{c}\text { Net } \\
\text { Interstaie } \\
\text { Movements }\end{array}$ & $\begin{array}{l}\text { Not Move- } \\
\text { ments Across } \\
\text { U.S. Bordors }\end{array}$ & $\begin{array}{l}\text { Net } \\
\text { Storege } \\
\text { Changes }\end{array}$ & $\begin{array}{c}\text { Supplemental } \\
\text { Gas } \\
\text { Supplies }\end{array}$ & Consumption \\
\hline & \multicolumn{8}{|c|}{1987} \\
\hline $\begin{array}{l}\text { Alabama................... } \\
\text { Alaska ...................... } \\
\text { Arizona................... } \\
\text { Arikansas................. } \\
\text { Califormia................ }\end{array}$ & $\begin{array}{r}117,241 \\
359,837 \\
60 \\
141,151 \\
424,621\end{array}$ & $\begin{array}{r}4,887 \\
19,590 \\
0 \\
1,275 \\
15,002\end{array}$ & $\begin{array}{r}-18,859 \\
-42,379 \\
2,824 \\
-23,851 \\
-56,545\end{array}$ & $\begin{array}{r}114,214 \\
0 \\
115,960 \\
53,676 \\
1,553,144\end{array}$ & $\begin{array}{r}0 \\
-48,599 \\
-1,757 \\
0 \\
0\end{array}$ & $\begin{array}{r}-46 \\
0 \\
0 \\
76 \\
-28,692\end{array}$ & $\begin{array}{r}2 \\
0 \\
101 \\
0 \\
0\end{array}$ & $\begin{array}{r}207,757 \\
249,269 \\
117,187 \\
169,626 \\
1,934,909\end{array}$ \\
\hline 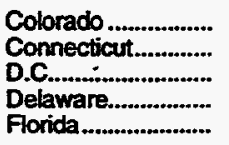 & $\begin{array}{r}164,557 \\
0 \\
0 \\
0 \\
8,281\end{array}$ & $\begin{array}{r}10,195 \\
0 \\
0 \\
0 \\
3,884\end{array}$ & $\begin{array}{r}-9,698 \\
-2,435 \\
-919 \\
749 \\
-11,848\end{array}$ & $\begin{array}{r}55,353 \\
94,219 \\
31,907 \\
35,895 \\
307,790\end{array}$ & $\begin{array}{l}0 \\
0 \\
0 \\
0 \\
0\end{array}$ & $\begin{array}{r}-1,518 \\
121 \\
0 \\
-60 \\
0\end{array}$ & $\begin{array}{r}8,612 \\
180 \\
0 \\
0 \\
0\end{array}$ & $\begin{array}{r}210,147 \\
91,842 \\
30,988 \\
36,703 \\
300,339\end{array}$ \\
\hline 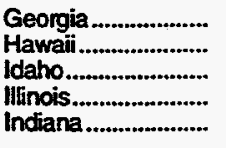 & $\begin{array}{r}0 \\
0 \\
0 \\
1,371 \\
217\end{array}$ & $\begin{array}{r}0 \\
0 \\
0 \\
6,662 \\
0\end{array}$ & $\begin{array}{r}-19,959 \\
149 \\
1,080 \\
-10,410 \\
25,480\end{array}$ & $\begin{array}{r}323,279 \\
0 \\
-447,566 \\
876,703 \\
383,069\end{array}$ & $\begin{array}{r}0 \\
0 \\
483,547 \\
0 \\
0\end{array}$ & $\begin{array}{r}149 \\
0 \\
-86 \\
81 \\
68\end{array}$ & $\begin{array}{r}248 \\
2,461 \\
0 \\
12,514 \\
3,890\end{array}$ & $\begin{array}{r}303,420 \\
2,610 \\
37,147 \\
873,436 \\
412,588\end{array}$ \\
\hline 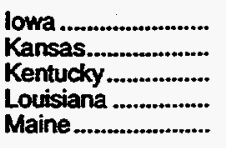 & $\begin{array}{r}0 \\
472,752 \\
70,125 \\
5,122,509 \\
0\end{array}$ & $\begin{array}{r}0 \\
28,397 \\
2,003 \\
124,890 \\
0\end{array}$ & $\begin{array}{r}-1,963 \\
-5,672 \\
-84,396 \\
50,020 \\
-117\end{array}$ & $\begin{array}{r}208,051 \\
-115,409 \\
191,792 \\
-3,534,474 \\
2,758\end{array}$ & $\begin{array}{l}0 \\
0 \\
0 \\
0 \\
0\end{array}$ & $\begin{array}{r}3,064 \\
-4,790 \\
3,608 \\
12,486 \\
0\end{array}$ & $\begin{array}{r}40 \\
0 \\
0 \\
0 \\
0\end{array}$ & $\begin{array}{r}203,064 \\
328,064 \\
171,910 \\
1,500,679 \\
2,641\end{array}$ \\
\hline $\begin{array}{l}\text { Maryland................. } \\
\text { Massachusetts....... } \\
\text { Michigan ................. } \\
\text { Minnesola ................ } \\
\text { Mississippi .............. }\end{array}$ & $\begin{array}{r}44 \\
0 \\
146,996 \\
0 \\
139,727\end{array}$ & $\begin{array}{r}0 \\
0 \\
10,876 \\
0 \\
437\end{array}$ & $\begin{array}{r}-24,396 \\
-14,124 \\
-116,663 \\
9,297 \\
60,490\end{array}$ & $\begin{array}{r}192,228 \\
237,497 \\
941,583 \\
-216,679 \\
16,832\end{array}$ & $\begin{array}{r}0 \\
0 \\
-306,588 \\
448,101 \\
0\end{array}$ & $\begin{array}{r}-541 \\
-2,043 \\
-461 \\
728 \\
8,029\end{array}$ & $\begin{array}{r}136 \\
1,404 \\
2,483 \\
1 \\
0\end{array}$ & $\begin{array}{l}168,553 \\
226,820 \\
657,396 \\
239,990 \\
208,582\end{array}$ \\
\hline $\begin{array}{l}\text { Missouri ................... } \\
\text { Montana.................. } \\
\text { Nebraska............. } \\
\text { Nevada ................... } \\
\text { New Hampshire ...... }\end{array}$ & $\begin{array}{r}4 \\
46,456 \\
1,261 \\
0 \\
0\end{array}$ & $\begin{array}{r}0 \\
1,058 \\
81 \\
0 \\
0\end{array}$ & $\begin{array}{r}-4,890 \\
-5,408 \\
-9,425 \\
219 \\
-1,531\end{array}$ & $\begin{array}{r}237,155 \\
-154,230 \\
117,104 \\
41,359 \\
12,945\end{array}$ & $\begin{array}{r}0 \\
167,324 \\
0 \\
0 \\
0\end{array}$ & $\begin{array}{r}328 \\
14,297 \\
1,681 \\
256 \\
-91\end{array}$ & $\begin{array}{r}1 \\
0 \\
2,199 \\
11 \\
464\end{array}$ & $\begin{array}{r}231,941 \\
38,786 \\
109,378 \\
41,333 \\
11,970\end{array}$ \\
\hline $\begin{array}{l}\text { New Jersey............. } \\
\text { New Mexico ............ } \\
\text { New York................ } \\
\text { North Carolina......... } \\
\text { North Dakota.......... }\end{array}$ & $\begin{array}{r}0 \\
823,773 \\
25,676 \\
0 \\
62,258\end{array}$ & $\begin{array}{r}0 \\
65,156 \\
0 \\
0 \\
7,859\end{array}$ & $\begin{array}{r}14,161 \\
-49,049 \\
-35,066 \\
-1,439 \\
-453\end{array}$ & $\begin{array}{r}393,279 \\
-557,197 \\
735,178 \\
150,131 \\
-80,661\end{array}$ & $\begin{array}{r}0 \\
0 \\
52,013 \\
0 \\
0\end{array}$ & $\begin{array}{r}-185 \\
-877 \\
-341 \\
39 \\
0\end{array}$ & $\begin{array}{r}13,774 \\
0 \\
416 \\
0 \\
51,543\end{array}$ & $\begin{array}{r}421,400 \\
153,247 \\
778,558 \\
148,653 \\
24,828\end{array}$ \\
\hline $\begin{array}{l}\text { Ohio ...................... } \\
\text { Oktahoma ............. } \\
\text { Oregon..................... } \\
\text { Pennsytvania .......... } \\
\text { Rhode Istand........... }\end{array}$ & $\begin{array}{r}166,593 \\
2,073,461 \\
3,800 \\
163,318 \\
0\end{array}$ & $\begin{array}{r}50 \\
99,170 \\
0 \\
318 \\
0\end{array}$ & $\begin{array}{r}-5,210 \\
6,578 \\
-1,636 \\
-38,809 \\
88\end{array}$ & $\begin{array}{r}\mathbf{5 5 3 , 3 3 9} \\
-1, \mathbf{3 7 5 , 8 9 7} \\
\mathbf{8 2 , 1 0 2} \\
\mathbf{5 1 2 , 3 4 9} \\
\mathbf{3 5 , 5 0 3}\end{array}$ & $\begin{array}{l}0 \\
0 \\
0 \\
0 \\
0\end{array}$ & $\begin{array}{r}-239 \\
8,880 \\
4,026 \\
631 \\
-230\end{array}$ & $\begin{array}{r}18 \\
0 \\
10 \\
247 \\
109\end{array}$ & $\begin{array}{r}714,929 \\
596,092 \\
80,249 \\
636,157 \\
35,930\end{array}$ \\
\hline $\begin{array}{l}\text { South Carolina ....... } \\
\text { South Dakota .......... } \\
\text { Tennessee.............. } \\
\text { Texas ....................... } \\
\text { Utah ....................... }\end{array}$ & $\begin{array}{r}0 \\
3,431 \\
2,707 \\
6,126,315 \\
87,158\end{array}$ & $\begin{array}{r}0 \\
0 \\
0 \\
364,477 \\
12,396\end{array}$ & $\begin{array}{l}-7,384 \\
-1,944 \\
20,168 \\
-92,680 \\
-31,447\end{array}$ & $\begin{array}{r}113,087 \\
19,600 \\
177,577 \\
-2,358,702 \\
55,125\end{array}$ & $\begin{array}{r}0 \\
0 \\
0 \\
-368 \\
0\end{array}$ & $\begin{array}{r}64 \\
0 \\
-93 \\
6,811 \\
-547\end{array}$ & $\begin{array}{r}22 \\
0 \\
26 \\
4 \\
0\end{array}$ & $\begin{array}{r}105,661 \\
21,087 \\
200,571 \\
3,303,281 \\
98,987\end{array}$ \\
\hline $\begin{array}{l}\text { Vermont .................. } \\
\text { Virginia.................. } \\
\text { Washington............ } \\
\text { West Virginia.......... } \\
\text { Wisconsin ............... } \\
\text { Wyoming................ }\end{array}$ & $\begin{array}{r}0 \\
19,223 \\
0 \\
160,000 \\
0 \\
497,980\end{array}$ & $\begin{array}{r}0 \\
0 \\
0 \\
8,830 \\
0 \\
24,827\end{array}$ & $\begin{array}{r}-39 \\
22,467 \\
-3,125 \\
80,169 \\
8,598 \\
-12,001\end{array}$ & $\begin{array}{r}-233 \\
117,070 \\
-5,073 \\
-122,045 \\
270,677 \\
-391,364\end{array}$ & $\begin{array}{r}5,453 \\
0 \\
139,021 \\
0 \\
0 \\
0\end{array}$ & $\begin{array}{r}0 \\
4 \\
-903 \\
-5,914 \\
-90 \\
-11,613\end{array}$ & $\begin{array}{r}0 \\
141 \\
21 \\
0 \\
1 \\
303\end{array}$ & $\begin{array}{r}5,181 \\
158,897 \\
131,746 \\
115,208 \\
279,366 \\
81,704\end{array}$ \\
\hline 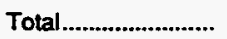 & $17,432,901$ & 812,320 & $-443,231$ & 0 & 938,148 & 6,070 & 101,382 & $17,210,809$ \\
\hline
\end{tabular}

See footnotes at end of table. 
Table 13. Natural Gas Production, Transmission, and Consumption by State, 1967-1994 (Continued) (Million Cubic Feet)

\begin{tabular}{|c|c|c|c|c|c|c|c|c|}
\hline State & $\begin{array}{l}\text { Mariketed } \\
\text { Production }\end{array}$ & $\begin{array}{l}\text { Extraction } \\
\text { Loss }\end{array}$ & $\begin{array}{l}\text { Baiancing } \\
\text { Item }\end{array}$ & $\begin{array}{c}\text { Met } \\
\text { Interstate } \\
\text { Movements }\end{array}$ & $\begin{array}{l}\text { Net Move- } \\
\text { ments Across } \\
\text { U.S. Bordiers }\end{array}$ & $\begin{array}{c}\text { Net } \\
\text { Storege } \\
\text { Changes }\end{array}$ & $\begin{array}{c}\text { Supplemental } \\
\text { Gas } \\
\text { Supplies }\end{array}$ & Consumption \\
\hline & \multicolumn{8}{|c|}{1988} \\
\hline $\begin{array}{l}\text { Alabama................... } \\
\text { Alaska...................... } \\
\text { Arizona.................... } \\
\text { Arkansas................. } \\
\text { Calfomia................. }\end{array}$ & $\begin{array}{r}129,524 \\
378,638 \\
56 \\
166,573 \\
399,663\end{array}$ & $\begin{array}{r}4,774 \\
23,240 \\
0 \\
1,061 \\
14,892\end{array}$ & $\begin{array}{r}-45,163 \\
-16,178 \\
-19,053 \\
525 \\
-59,587\end{array}$ & $\begin{array}{r}156,915 \\
0 \\
145,268 \\
51,335 \\
1,495,049\end{array}$ & $\begin{array}{r}0 \\
-51,573 \\
-1,905 \\
0 \\
0\end{array}$ & $\begin{array}{r}164 \\
0 \\
0 \\
536 \\
15,781\end{array}$ & $\begin{array}{r}17 \\
0 \\
0 \\
0 \\
0\end{array}$ & $\begin{array}{r}236,356 \\
287,648 \\
124,366 \\
216,836 \\
1,804,452\end{array}$ \\
\hline 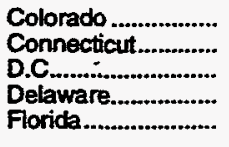 & $\begin{array}{r}191,544 \\
0 \\
0 \\
0 \\
7,484\end{array}$ & $\begin{array}{r}11,589 \\
0 \\
0 \\
0 \\
3,584\end{array}$ & $\begin{array}{r}-21,117 \\
-3,870 \\
-868 \\
7,324 \\
-1,407\end{array}$ & $\begin{array}{r}57,942 \\
91,830 \\
33,587 \\
21,936 \\
290,940\end{array}$ & $\begin{array}{l}0 \\
0 \\
0 \\
0 \\
0\end{array}$ & $\begin{array}{r}-481 \\
75 \\
0 \\
4 \\
0\end{array}$ & $\begin{array}{r}10,322 \\
245 \\
0 \\
2 \\
0\end{array}$ & $\begin{array}{r}227,584 \\
88,130 \\
32,719 \\
29,258 \\
293,433\end{array}$ \\
\hline 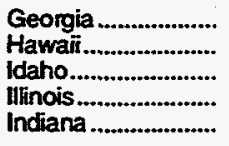 & $\begin{array}{r}0 \\
0 \\
0 \\
1,338 \\
412\end{array}$ & $\begin{array}{r}0 \\
0 \\
0 \\
61 \\
0\end{array}$ & $\begin{array}{r}4,944 \\
-187 \\
-104 \\
73,168 \\
121,879\end{array}$ & $\begin{array}{r}318,390 \\
0 \\
-462,277 \\
889,967 \\
337,580\end{array}$ & $\begin{array}{r}0 \\
0 \\
503,451 \\
0 \\
0\end{array}$ & $\begin{array}{r}545 \\
0 \\
334 \\
8,827 \\
7,301\end{array}$ & $\begin{array}{r}241 \\
2,801 \\
0 \\
9,803 \\
4,243\end{array}$ & $\begin{array}{r}323,030 \\
2,614 \\
40,736 \\
965,388 \\
456,812\end{array}$ \\
\hline 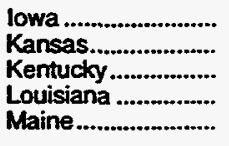 & $\begin{array}{r}0 \\
592,845 \\
73,629 \\
5,180,267 \\
0\end{array}$ & $\begin{array}{r}0 \\
29,800 \\
2,142 \\
120,092 \\
0\end{array}$ & $\begin{array}{r}-540 \\
-93,193 \\
-102,981 \\
190,173 \\
-127\end{array}$ & $\begin{array}{r}239,879 \\
-99,985 \\
202,663 \\
-3,766,758 \\
3,324\end{array}$ & $\begin{array}{l}0 \\
0 \\
0 \\
0 \\
0\end{array}$ & $\begin{array}{r}246 \\
16,944 \\
-12,902 \\
37,886 \\
0\end{array}$ & $\begin{array}{r}34 \\
0 \\
6 \\
0 \\
0\end{array}$ & $\begin{array}{r}239,127 \\
352,924 \\
184,078 \\
1,445,703 \\
3,197\end{array}$ \\
\hline $\begin{array}{l}\text { Maryland................. } \\
\text { Massachusetts....... } \\
\text { Michigan .................. } \\
\text { Minnesota .............. } \\
\text { Mississippi .............. }\end{array}$ & $\begin{array}{r}29 \\
0 \\
146,145 \\
0 \\
124,053\end{array}$ & $\begin{array}{r}0 \\
0 \\
10,483 \\
0 \\
811\end{array}$ & $\begin{array}{r}-7,224 \\
-24,866 \\
-16,298 \\
3,417 \\
-35,100\end{array}$ & $\begin{array}{r}174,603 \\
215,832 \\
974,693 \\
-298,570 \\
124,070\end{array}$ & $\begin{array}{r}0 \\
17,490 \\
-348,057 \\
578,982 \\
0\end{array}$ & $\begin{array}{r}-4,751 \\
-1,644 \\
-823 \\
374 \\
-567\end{array}$ & $\begin{array}{r}743 \\
876 \\
2,402 \\
385 \\
0\end{array}$ & $\begin{array}{l}172,901 \\
210,975 \\
749,225 \\
283,840 \\
212,779\end{array}$ \\
\hline $\begin{array}{l}\text { Missouri ................... } \\
\text { Montana.................. } \\
\text { Nebraska ................. } \\
\text { Nevada ................. } \\
\text { New Hampshire ...... }\end{array}$ & $\begin{array}{r}4 \\
51,654 \\
910 \\
0 \\
0\end{array}$ & $\begin{array}{r}0 \\
1,072 \\
59 \\
0 \\
0\end{array}$ & $\begin{array}{r}8,641 \\
-5,073 \\
-10,441 \\
5,145 \\
-1,170\end{array}$ & $\begin{array}{r}244,462 \\
-313,753 \\
129,802 \\
42,879 \\
13,545\end{array}$ & $\begin{array}{r}0 \\
303,500 \\
0 \\
0 \\
0\end{array}$ & $\begin{array}{r}186 \\
-6,570 \\
180 \\
-170 \\
-142\end{array}$ & $\begin{array}{r}2 \\
0 \\
1,948 \\
32 \\
492\end{array}$ & $\begin{array}{r}252,923 \\
41,825 \\
121,979 \\
48,226 \\
13,009\end{array}$ \\
\hline $\begin{array}{l}\text { New Jersey............. } \\
\text { New Mexico ............. } \\
\text { New York................ } \\
\text { North Carolina......... } \\
\text { North Dakota........... }\end{array}$ & $\begin{array}{r}0 \\
791,819 \\
23,455 \\
0 \\
57,747\end{array}$ & $\begin{array}{r}0 \\
63,355 \\
0 \\
0 \\
6,945\end{array}$ & $\begin{array}{r}-1,933 \\
-60,813 \\
-13,098 \\
-3,148 \\
-4,220\end{array}$ & $\begin{array}{r}401,406 \\
-489,206 \\
713,617 \\
155,399 \\
-66,982\end{array}$ & $\begin{array}{r}0 \\
0 \\
69,193 \\
0 \\
0\end{array}$ & $\begin{array}{r}40 \\
4,996 \\
3,677 \\
261 \\
0\end{array}$ & $\begin{array}{r}14,846 \\
0 \\
728 \\
0 \\
49,014\end{array}$ & $\begin{array}{r}414,279 \\
173,450 \\
790,218 \\
151,990 \\
28,614\end{array}$ \\
\hline $\begin{array}{l}\text { Ohio } \\
\text { Oklahoma ................. } \\
\text { Oregon.................. } \\
\text { Pennsylvania .......... } \\
\text { Rhode Island.......... }\end{array}$ & $\begin{array}{r}166,690 \\
2,167,050 \\
4,000 \\
167,089 \\
0\end{array}$ & $\begin{array}{r}44 \\
103,302 \\
0 \\
272 \\
0\end{array}$ & $\begin{array}{r}-115,304 \\
-280,961 \\
-3,293 \\
-37,513 \\
-1,473\end{array}$ & $\begin{array}{r}580,373 \\
-1,179,771 \\
87,010 \\
547,505 \\
31,900\end{array}$ & $\begin{array}{l}0 \\
0 \\
0 \\
0 \\
0\end{array}$ & $\begin{array}{r}-173,550 \\
14,220 \\
560 \\
8,402 \\
31\end{array}$ & $\begin{array}{r}44 \\
0 \\
6 \\
254 \\
391\end{array}$ & $\begin{array}{r}805,309 \\
588,796 \\
87,163 \\
668,661 \\
30,787\end{array}$ \\
\hline $\begin{array}{l}\text { South Carolina ........ } \\
\text { South Dakota.......... } \\
\text { Tennessee.............. } \\
\text { Texas....................... } \\
\text { Utah....................... }\end{array}$ & $\begin{array}{r}0 \\
3,920 \\
2,100 \\
6,286,029 \\
101,372\end{array}$ & $\begin{array}{r}0 \\
0 \\
0 \\
357,756 \\
21,237\end{array}$ & $\begin{array}{r}132 \\
-2,146 \\
-9,500 \\
9,993 \\
-38,483\end{array}$ & $\begin{array}{r}111,942 \\
22,442 \\
221,664 \\
-2,367,850 \\
66,769\end{array}$ & $\begin{array}{r}0 \\
0 \\
0 \\
-422 \\
0\end{array}$ & $\begin{array}{r}-44 \\
0 \\
56 \\
38,989 \\
-533\end{array}$ & $\begin{array}{r}191 \\
10 \\
36 \\
4 \\
0\end{array}$ & $\begin{array}{r}112,309 \\
24,227 \\
214,244 \\
3,531,008 \\
108,954\end{array}$ \\
\hline 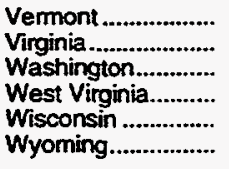 & $\begin{array}{r}0 \\
18,424 \\
0 \\
174,942 \\
0 \\
509,058\end{array}$ & $\begin{array}{r}0 \\
0 \\
0 \\
9,839 \\
0 \\
29,434\end{array}$ & $\begin{array}{r}-314 \\
-2,082 \\
-5,056 \\
81,946 \\
43,122 \\
40,987\end{array}$ & $\begin{array}{r}-2,240 \\
146,516 \\
10,329 \\
-146,500 \\
274,103 \\
-433,574\end{array}$ & $\begin{array}{r}8,105 \\
0 \\
140,826 \\
0 \\
0 \\
0\end{array}$ & $\begin{array}{r}0 \\
-29 \\
-600 \\
-21,591 \\
81 \\
4,965\end{array}$ & $\begin{array}{r}0 \\
643 \\
79 \\
0 \\
2 \\
291\end{array}$ & $\begin{array}{r}5,551 \\
163,529 \\
146,778 \\
122,140 \\
317,146 \\
82,363\end{array}$ \\
\hline 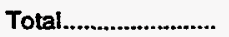 & $17,918,465$ & 815,844 & $-452,492$ & 0 & $1,219,590$ & $-58,734$ & 101,134 & $18,029,588$ \\
\hline
\end{tabular}

See footnotes at end of table. 
Table 13. Natural Gas Production, Transmission, and Consumption by State, 1967-1994 (Continued) (Million Cubic Feet)

\begin{tabular}{|c|c|c|c|c|c|c|c|c|}
\hline State & $\begin{array}{l}\text { Marketed } \\
\text { Production }\end{array}$ & $\begin{array}{l}\text { Extraction } \\
\text { Loss }\end{array}$ & $\begin{array}{c}\text { Balancing } \\
\text { them }\end{array}$ & $\begin{array}{c}\text { Net } \\
\text { Interstate } \\
\text { Movemonts }\end{array}$ & $\begin{array}{l}\text { Net Move- } \\
\text { memts Across } \\
\text { U.S. Bordors }\end{array}$ & $\begin{array}{l}\text { Net } \\
\text { Storage } \\
\text { Changes }\end{array}$ & $\begin{array}{c}\text { Supplemental } \\
\text { Gas } \\
\text { Supplies }\end{array}$ & Consumption \\
\hline & \multicolumn{8}{|c|}{1989} \\
\hline $\begin{array}{l}\text { Alabama.................. } \\
\text { Alaska................... } \\
\text { Arizona.................. } \\
\text { Arkansas................. } \\
\text { Calffomia............... }\end{array}$ & $\begin{array}{r}128,411 \\
393,729 \\
1,360 \\
174,158 \\
362,860\end{array}$ & $\begin{array}{r}5,022 \\
19,932 \\
0 \\
849 \\
13,376\end{array}$ & $\begin{array}{r}-22,937 \\
-844 \\
-21,633 \\
17,704 \\
-149,627\end{array}$ & $\begin{array}{r}144,191 \\
0 \\
167,384 \\
58,643 \\
1,627,420\end{array}$ & $\begin{array}{r}0 \\
-51,424 \\
-1,469 \\
0 \\
0\end{array}$ & $\begin{array}{r}-422 \\
0 \\
0 \\
15 \\
-10,554\end{array}$ & $\begin{array}{r}16 \\
0 \\
0 \\
0 \\
0\end{array}$ & $\begin{array}{r}245,081 \\
321,529 \\
145,642 \\
249,641 \\
1,837,831\end{array}$ \\
\hline 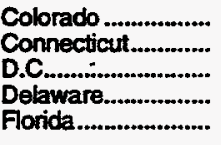 & $\begin{array}{r}216,737 \\
0 \\
0 \\
0 \\
7,534\end{array}$ & $\begin{array}{r}13,340 \\
0 \\
0 \\
0 \\
3,551\end{array}$ & $\begin{array}{l}-9,917 \\
-3,170 \\
-1,175 \\
-1,374 \\
-3,158\end{array}$ & $\begin{array}{r}40,768 \\
97,369 \\
34,598 \\
36,242 \\
322,766\end{array}$ & $\begin{array}{l}0 \\
0 \\
0 \\
0 \\
0\end{array}$ & $\begin{array}{r}1,223 \\
-604 \\
0 \\
-38 \\
0\end{array}$ & $\begin{array}{r}9,190 \\
251 \\
0 \\
18 \\
0\end{array}$ & $\begin{array}{r}242,215 \\
95,055 \\
33,422 \\
34,924 \\
323,591\end{array}$ \\
\hline 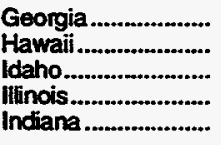 & $\begin{array}{r}0 \\
0 \\
0 \\
1,477 \\
416\end{array}$ & $\begin{array}{r}0 \\
0 \\
0 \\
81 \\
0\end{array}$ & $\begin{array}{r}4,119 \\
-150 \\
-55 \\
-55,786 \\
31,426\end{array}$ & $\begin{array}{r}313,535 \\
0 \\
-455,586 \\
1,022,488 \\
425,159\end{array}$ & $\begin{array}{r}0 \\
0 \\
501,477 \\
0 \\
0\end{array}$ & $\begin{array}{r}343 \\
0 \\
165 \\
-17,957 \\
-1,540\end{array}$ & $\begin{array}{r}292 \\
2,844 \\
0 \\
9,477 \\
3,512\end{array}$ & $\begin{array}{r}317,603 \\
2,694 \\
45,671 \\
995,532 \\
462,053\end{array}$ \\
\hline 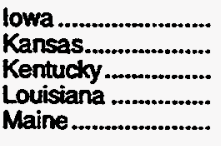 & $\begin{array}{r}0 \\
601,196 \\
72,417 \\
5,078,125 \\
0\end{array}$ & $\begin{array}{r}0 \\
30,273 \\
1,444 \\
121,425 \\
0\end{array}$ & $\begin{array}{r}-4,792 \\
43,732 \\
-156,157 \\
363,459 \\
-4\end{array}$ & $\begin{array}{r}221,706 \\
-290,526 \\
259,514 \\
-3,849,793 \\
3,686\end{array}$ & $\begin{array}{r}0 \\
0 \\
0 \\
3,934 \\
0\end{array}$ & $\begin{array}{r}-8,743 \\
-17,160 \\
-14,147 \\
-64,181 \\
4\end{array}$ & $\begin{array}{r}82 \\
0 \\
44 \\
0 \\
0\end{array}$ & $\begin{array}{r}225,739 \\
341,289 \\
188,520 \\
1,538,481 \\
3,678\end{array}$ \\
\hline $\begin{array}{l}\text { Maryland .............. } \\
\text { Massachusetts....... } \\
\text { Michigan ................. } \\
\text { Minnesota .............. } \\
\text { Mississippi .............. }\end{array}$ & $\begin{array}{r}34 \\
0 \\
155,988 \\
0 \\
102,645\end{array}$ & $\begin{array}{r}0 \\
0 \\
9,886 \\
0 \\
380\end{array}$ & $\begin{array}{r}-23,332 \\
-21,329 \\
-3,568 \\
10,195 \\
-17,753\end{array}$ & $\begin{array}{r}211,424 \\
225,422 \\
971,496 \\
-313,513 \\
127,719\end{array}$ & $\begin{array}{r}0 \\
38,229 \\
-363,680 \\
602,096 \\
0\end{array}$ & $\begin{array}{r}-681 \\
-6,447 \\
-21,688 \\
-792 \\
-13,394\end{array}$ & $\begin{array}{r}899 \\
692 \\
2,402 \\
315 \\
0\end{array}$ & $\begin{array}{l}189,706 \\
249,459 \\
774,439 \\
299,886 \\
225,625\end{array}$ \\
\hline $\begin{array}{l}\text { Missouri ................. } \\
\text { Montana ................ } \\
\text { Nebraska ................ } \\
\text { Nevada .............. } \\
\text { New Hampshire ..... }\end{array}$ & $\begin{array}{r}4 \\
51.307 \\
878 \\
0 \\
0\end{array}$ & $\begin{array}{r}0 \\
1,095 \\
29 \\
0 \\
0\end{array}$ & $\begin{array}{r}-14,356 \\
272 \\
-6,998 \\
676 \\
-939\end{array}$ & $\begin{array}{r}263,357 \\
-335,869 \\
122,736 \\
63,158 \\
14,079\end{array}$ & $\begin{array}{r}0 \\
309,084 \\
0 \\
0 \\
0\end{array}$ & $\begin{array}{r}-1,647 \\
-22,058 \\
-1,561 \\
205 \\
-213\end{array}$ & $\begin{array}{r}1,875 \\
0 \\
2,088 \\
37 \\
592\end{array}$ & $\begin{array}{r}252,527 \\
45,756 \\
120,235 \\
63,667 \\
13,945\end{array}$ \\
\hline $\begin{array}{l}\text { New Jersey.............. } \\
\text { New Mexico ............ } \\
\text { New York.............. } \\
\text { North Carolina........ } \\
\text { North Dakota.......... }\end{array}$ & $\begin{array}{r}0 \\
854,615 \\
20,433 \\
0 \\
51,174\end{array}$ & $\begin{array}{r}0 \\
61,594 \\
0 \\
0 \\
6,133\end{array}$ & $\begin{array}{l}17,084 \\
76,421 \\
54,006 \\
6,033 \\
-4,823\end{array}$ & $\begin{array}{r}424,475 \\
-677,445 \\
690,969 \\
166,617 \\
-64,474\end{array}$ & $\begin{array}{r}0 \\
0 \\
67,956 \\
0 \\
0\end{array}$ & $\begin{array}{r}-1,011 \\
-3,739 \\
-11,249 \\
-1,205 \\
0\end{array}$ & $\begin{array}{r}14,539 \\
0 \\
1,239 \\
0 \\
54,408\end{array}$ & $\begin{array}{r}457,108 \\
195,736 \\
845,853 \\
161,788 \\
30,152\end{array}$ \\
\hline $\begin{array}{l}\text { Ohio ........................ } \\
\text { Okdahoma .............. } \\
\text { Oregon................. } \\
\text { Pennsylvania .......... } \\
\text { Rhode Island.......... }\end{array}$ & $\begin{array}{r}159,730 \\
2,237,037 \\
2,500 \\
191,774 \\
0\end{array}$ & $\begin{array}{r}46 \\
94,889 \\
0 \\
254 \\
0\end{array}$ & $\begin{array}{r}-5,218 \\
-220,523 \\
-12,008 \\
-126,511 \\
-552\end{array}$ & $\begin{array}{r}647,600 \\
-1,335,130 \\
120,304 \\
555,248 \\
34,232\end{array}$ & $\begin{array}{l}0 \\
0 \\
0 \\
0 \\
0\end{array}$ & $\begin{array}{r}-11,709 \\
-14,331 \\
2,770 \\
-61,052 \\
-38\end{array}$ & $\begin{array}{r}348 \\
0 \\
3 \\
305 \\
219\end{array}$ & $\begin{array}{r}814,123 \\
600,824 \\
108,028 \\
681,614 \\
33,938\end{array}$ \\
\hline $\begin{array}{l}\text { South Carolina ........ } \\
\text { South Dakota......... } \\
\text { Tennessee............... } \\
\text { Texas...................... } \\
\text { Utah ....................... }\end{array}$ & $\begin{array}{r}0 \\
4,369 \\
1,900 \\
6,241,425 \\
120,089\end{array}$ & $\begin{array}{r}0 \\
0 \\
0 \\
343,233 \\
18,302\end{array}$ & $\begin{array}{r}-137 \\
-3,348 \\
30,514 \\
116,028 \\
-32,031\end{array}$ & $\begin{array}{r}116,696 \\
24,467 \\
187,111 \\
-2,391,011 \\
41,796\end{array}$ & $\begin{array}{r}0 \\
0 \\
0 \\
-15,535 \\
0\end{array}$ & $\begin{array}{r}-57 \\
0 \\
-1,879 \\
-15,935 \\
-1,984\end{array}$ & $\begin{array}{r}201 \\
16 \\
78 \\
9 \\
0\end{array}$ & $\begin{array}{r}116,818 \\
25,504 \\
221,482 \\
3,623,618 \\
113,536\end{array}$ \\
\hline 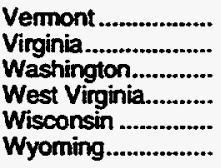 & $\begin{array}{r}0 \\
17,935 \\
0 \\
0 \\
177,192 \\
0 \\
065,699\end{array}$ & $\begin{array}{r}0 \\
0 \\
0 \\
10,121 \\
0 \\
29,247\end{array}$ & $\begin{array}{r}-129 \\
7,026 \\
5,171 \\
11,235 \\
20,314 \\
-96,541\end{array}$ & $\begin{array}{r}-6,872 \\
148,330 \\
-12,539 \\
-59,222 \\
310,528 \\
-451,250\end{array}$ & $\begin{array}{r}13,152 \\
0 \\
170,832 \\
0 \\
0 \\
0\end{array}$ & $\begin{array}{r}0 \\
-6 \\
840 \\
-10,375 \\
54 \\
6,465\end{array}$ & $\begin{array}{r}0 \\
428 \\
154 \\
0 \\
5 \\
167\end{array}$ & $\begin{array}{r}6,151 \\
173,725 \\
162,779 \\
129,460 \\
330,792 \\
82,362\end{array}$ \\
\hline 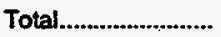 & $18,095,147$ & 784,502 & $-217,526$ & 0 & $1,274,651$ & $-326,312$ & 106,745 & $18,800,826$ \\
\hline
\end{tabular}

See footnotes at end of table. 
Table 13. Natural Gas Production, Transmission, and Consumption by State, 1967-1994 (Continued) (Million Cubic Feet)

\begin{tabular}{|c|c|c|c|c|c|c|c|c|}
\hline State & $\begin{array}{l}\text { Marketed } \\
\text { Production }\end{array}$ & $\begin{array}{l}\text { Extraction } \\
\text { Loss }\end{array}$ & $\begin{array}{l}\text { Balancing } \\
\text { Item }\end{array}$ & $\begin{array}{c}\text { Net } \\
\text { interstate } \\
\text { Movements }\end{array}$ & $\begin{array}{l}\text { Not Move } \\
\text { ments Across } \\
\text { U.S. Borders }\end{array}$ & $\begin{array}{c}\text { Net } \\
\text { Storage } \\
\text { Changes }\end{array}$ & $\begin{array}{c}\text { Supplemental } \\
\text { Gas } \\
\text { Supplies }\end{array}$ & Consumption \\
\hline & \multicolumn{8}{|c|}{1990} \\
\hline $\begin{array}{l}\text { Alabama................... } \\
\text { Alaska ..................... } \\
\text { Arizona................... } \\
\text { Arikansas................. } \\
\text { Califomia.................. }\end{array}$ & $\begin{array}{r}135,276 \\
402,907 \\
2,125 \\
174,956 \\
362,748\end{array}$ & $\begin{array}{r}4,939 \\
21,476 \\
0 \\
800 \\
12,424\end{array}$ & $\begin{array}{r}-16,872 \\
13,700 \\
-31,662 \\
16,237 \\
-97,077\end{array}$ & $\begin{array}{r}130,475 \\
0 \\
157,939 \\
43,553 \\
1,620,132\end{array}$ & $\begin{array}{r}0 \\
-52,546 \\
-1,676 \\
0 \\
0\end{array}$ & $\begin{array}{r}456 \\
0 \\
0 \\
1,572 \\
9,322\end{array}$ & $\begin{array}{r}320 \\
0 \\
0 \\
0 \\
0\end{array}$ & $\begin{array}{r}243,803 \\
342,585 \\
126,726 \\
232,374 \\
1,864,057\end{array}$ \\
\hline $\begin{array}{l}\text { Colorado ................... } \\
\text { Connecticut.............. } \\
\text { D.C...................... } \\
\text { Delaware................. } \\
\text { Florida ....................... }\end{array}$ & $\begin{array}{r}242,997 \\
0 \\
0 \\
0 \\
6,483\end{array}$ & $\begin{array}{r}13,178 \\
0 \\
0 \\
0 \\
2,831\end{array}$ & $\begin{array}{r}-16,583 \\
1,877 \\
-457 \\
-288 \\
-2,492\end{array}$ & $\begin{array}{r}6,997 \\
96,469 \\
29,321 \\
35,012 \\
325,863\end{array}$ & $\begin{array}{l}0 \\
0 \\
0 \\
0 \\
0\end{array}$ & $\begin{array}{r}-3,500 \\
822 \\
0 \\
6 \\
0\end{array}$ & $\begin{array}{r}15,379 \\
111 \\
0 \\
4,410 \\
0\end{array}$ & $\begin{array}{r}239,112 \\
97,634 \\
28,864 \\
39,127 \\
327,023\end{array}$ \\
\hline $\begin{array}{l}\text { Georgia.................... } \\
\text { Hawail ...................... } \\
\text { Idaho..................... } \\
\text { Illinois..................... } \\
\text { Indiana.................... }\end{array}$ & $\begin{array}{r}0 \\
0 \\
0 \\
677 \\
399\end{array}$ & $\begin{array}{r}0 \\
0 \\
0 \\
81 \\
0\end{array}$ & $\begin{array}{r}8,025 \\
-29 \\
-3,649 \\
-80,301 \\
14,761\end{array}$ & $\begin{array}{r}304,127 \\
0 \\
-465,413 \\
1,027,573 \\
436,420\end{array}$ & $\begin{array}{r}0 \\
0 \\
514,597 \\
0 \\
0\end{array}$ & $\begin{array}{r}1,345 \\
0 \\
23 \\
16,506 \\
3,641\end{array}$ & $\begin{array}{r}209 \\
2,817 \\
0 \\
8,140 \\
3,015\end{array}$ & $\begin{array}{r}311,015 \\
2,788 \\
45,512 \\
939,502 \\
450,954\end{array}$ \\
\hline $\begin{array}{l}\text { lowa .......................... } \\
\text { Kansas.................... } \\
\text { Kentucky................ } \\
\text { Louisiana ................ } \\
\text { Maine ....................... }\end{array}$ & $\begin{array}{r}0 \\
573,603 \\
75,333 \\
5,241,989 \\
0\end{array}$ & $\begin{array}{r}0 \\
29,642 \\
1,899 \\
119,405 \\
0\end{array}$ & $\begin{array}{r}-25,267 \\
115,792 \\
-207,989 \\
162,707 \\
-120\end{array}$ & $\begin{array}{r}240,629 \\
-294,207 \\
340,002 \\
-3,670,463 \\
4,471\end{array}$ & $\begin{array}{r}0 \\
0 \\
0 \\
30,750 \\
0\end{array}$ & $\begin{array}{r}-2,758 \\
12,766 \\
21,117 \\
74,587 \\
-4\end{array}$ & $\begin{array}{r}81 \\
0 \\
2 \\
0 \\
0\end{array}$ & $\begin{array}{r}218,201 \\
352,780 \\
184,333 \\
1,570,991 \\
4,354\end{array}$ \\
\hline $\begin{array}{l}\text { Maryland................. } \\
\text { Massachusetts........ } \\
\text { Michigan .................. } \\
\text { Minnesota ............... } \\
\text { Mississippi .............. }\end{array}$ & $\begin{array}{r}22 \\
0 \\
172,151 \\
0 \\
94,616\end{array}$ & $\begin{array}{r}0 \\
0 \\
8,317 \\
0 \\
445\end{array}$ & $\begin{array}{r}-3,827 \\
-4,748 \\
94,341 \\
7,160 \\
34,252\end{array}$ & $\begin{array}{r}181,796 \\
209,509 \\
990,176 \\
-373,575 \\
144,773\end{array}$ & $\begin{array}{r}0 \\
53,443 \\
-349,146 \\
657,169 \\
0\end{array}$ & $\begin{array}{r}5,748 \\
308 \\
100,848 \\
223 \\
19,505\end{array}$ & $\begin{array}{r}24 \\
317 \\
19,106 \\
56 \\
0\end{array}$ & $\begin{array}{l}172,267 \\
258,214 \\
817,463 \\
290,587 \\
253,690\end{array}$ \\
\hline $\begin{array}{l}\text { Missouri ................... } \\
\text { Montana.................. } \\
\text { Nebraska ................. } \\
\text { Nevada .................. } \\
\text { New Hampshire ...... }\end{array}$ & $\begin{array}{r}7 \\
50,429 \\
793 \\
0 \\
0\end{array}$ & $\begin{array}{r}0 \\
1,091 \\
0 \\
0 \\
0\end{array}$ & $\begin{array}{r}-375 \\
-1,241 \\
-19,191 \\
-2,243 \\
435\end{array}$ & $\begin{array}{r}240,401 \\
-339,694 \\
125,062 \\
66,446 \\
13,634\end{array}$ & $\begin{array}{r}0 \\
327,628 \\
0 \\
0 \\
0\end{array}$ & $\begin{array}{r}1,324 \\
-7,138 \\
-2,038 \\
-548 \\
0\end{array}$ & $\begin{array}{r}0 \\
0 \\
2,361 \\
125 \\
205\end{array}$ & $\begin{array}{r}238,709 \\
43,169 \\
111,063 \\
64,876 \\
14,274\end{array}$ \\
\hline $\begin{array}{l}\text { New Jersey............. } \\
\text { New Mexico............. } \\
\text { New York................ } \\
\text { North Carolina......... } \\
\text { North Dakota.......... }\end{array}$ & $\begin{array}{r}0 \\
965,104 \\
25,023 \\
0 \\
52,169\end{array}$ & $\begin{array}{r}0 \\
66,626 \\
0 \\
0 \\
6,444\end{array}$ & $\begin{array}{l}13,939 \\
88,100 \\
75,309 \\
-3,141 \\
-1,693\end{array}$ & $\begin{array}{r}405,382 \\
-738,821 \\
678,905 \\
165,794 \\
-64,687\end{array}$ & $\begin{array}{r}0 \\
0 \\
98,217 \\
0 \\
0\end{array}$ & $\begin{array}{r}1,442 \\
9,226 \\
14,749 \\
1,445 \\
0\end{array}$ & $\begin{array}{r}9,962 \\
0 \\
385 \\
0 \\
53,144\end{array}$ & $\begin{array}{r}427,842 \\
238,531 \\
863,090 \\
161,208 \\
32,490\end{array}$ \\
\hline $\begin{array}{l}\text { Ohio ........................ } \\
\text { Oklahoma .............. } \\
\text { Oregon.................. } \\
\text { Pennsylvania .......... } \\
\text { Rhode Island.......... }\end{array}$ & $\begin{array}{r}154,619 \\
2,258,471 \\
2,815 \\
177,609 \\
0\end{array}$ & $\begin{array}{r}58 \\
96,698 \\
0 \\
300 \\
0\end{array}$ & $\begin{array}{r}94,065 \\
-98,666 \\
-4,980 \\
-136,163 \\
-1,223\end{array}$ & $\begin{array}{r}532,579 \\
-1,444,386 \\
112,491 \\
706,609 \\
36,912\end{array}$ & $\begin{array}{l}0 \\
0 \\
0 \\
0 \\
0\end{array}$ & $\begin{array}{r}35,334 \\
14,298 \\
1,114 \\
104,147 \\
-46\end{array}$ & $\begin{array}{r}849 \\
0 \\
3 \\
220 \\
51\end{array}$ & $\begin{array}{r}746,719 \\
604,423 \\
109,215 \\
643,828 \\
35,787\end{array}$ \\
\hline $\begin{array}{l}\text { South Carolina ........ } \\
\text { South Dakota.......... } \\
\text { Tennessee.............. } \\
\text { Texas ...................... } \\
\text { Utah ........................ }\end{array}$ & $\begin{array}{r}0 \\
881 \\
2,067 \\
6,343,146 \\
145,875\end{array}$ & $\begin{array}{r}0 \\
0 \\
0 \\
342,186 \\
17,579\end{array}$ & $\begin{array}{r}15,226 \\
73 \\
113,660 \\
-131,857 \\
-91,373\end{array}$ & $\begin{array}{r}115,357 \\
24,092 \\
104,733 \\
-2,229,743 \\
84,922\end{array}$ & $\begin{array}{r}0 \\
0 \\
0 \\
-13,983 \\
0\end{array}$ & $\begin{array}{r}147 \\
0 \\
631 \\
24,789 \\
5,196\end{array}$ & $\begin{array}{r}17 \\
10 \\
3 \\
1,240 \\
0\end{array}$ & $\begin{array}{r}130,453 \\
25,056 \\
219,831 \\
3,601,828 \\
116,648\end{array}$ \\
\hline $\begin{array}{l}\text { Vermont ................ } \\
\text { Virginia ............... } \\
\text { Washington............ } \\
\text { West Virginia.......... } \\
\text { Wisconsin .............. } \\
\text { Wyoming................. }\end{array}$ & $\begin{array}{r}0 \\
14,774 \\
0 \\
178,000 \\
0 \\
735,728\end{array}$ & $\begin{array}{r}0 \\
0 \\
0 \\
9,108 \\
0 \\
28,591\end{array}$ & $\begin{array}{r}141 \\
21,047 \\
-15,658 \\
45,929 \\
9,464 \\
-98,936\end{array}$ & $\begin{array}{r}-7,887 \\
145,036 \\
8,436 \\
-50,709 \\
299,606 \\
-512,049\end{array}$ & $\begin{array}{r}14,512 \\
0 \\
168,441 \\
0 \\
0 \\
0\end{array}$ & $\begin{array}{r}0 \\
48 \\
-1,334 \\
43,659 \\
-10 \\
3,962\end{array}$ & $\begin{array}{r}0 \\
59 \\
181 \\
0 \\
1 \\
0\end{array}$ & $\begin{array}{r}6,766 \\
180,868 \\
162,735 \\
120,453 \\
309,080 \\
92,190\end{array}$ \\
\hline 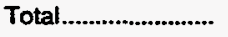 & $18,593,792$ & 784,118 & $-151,863$ & 0 & $1,447,407$ & 512,934 & 122,806 & $18,715,090$ \\
\hline
\end{tabular}

See footnotes at end of table. 
Table 13. Natural Gas Production, Transmission, and Consumption by State, 1967-1994 (Continued) (Million Cubic Feet)

\begin{tabular}{|c|c|c|c|c|c|c|c|c|}
\hline State & $\begin{array}{l}\text { Marketed } \\
\text { Production }\end{array}$ & $\begin{array}{c}\text { Extraction } \\
\text { Loss }\end{array}$ & $\begin{array}{l}\text { Baiancing } \\
\text { Htem }\end{array}$ & $\begin{array}{c}\text { Net } \\
\text { Interstate } \\
\text { Movements }\end{array}$ & $\begin{array}{l}\text { Net Movo } \\
\text { memts Across } \\
\text { U.S. Borders }\end{array}$ & $\begin{array}{c}\text { Not } \\
\text { Storage } \\
\text { Changes }\end{array}$ & $\begin{array}{c}\text { Supplemental } \\
\text { Gas } \\
\text { Supplies }\end{array}$ & Consumption \\
\hline & \multicolumn{8}{|c|}{1991} \\
\hline 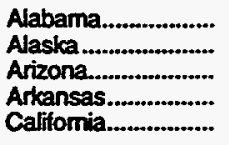 & $\begin{array}{r}170,847 \\
437,822 \\
1,225 \\
164,702 \\
378,384\end{array}$ & $\begin{array}{r}4,997 \\
28,440 \\
0 \\
290 \\
11,786\end{array}$ & $\begin{array}{r}-19,986 \\
11,841 \\
-25,332 \\
-21,688 \\
-7,275\end{array}$ & $\begin{array}{r}107,659 \\
0 \\
150,756 \\
64,424 \\
1,623,693\end{array}$ & $\begin{array}{r}0 \\
-54,005 \\
-1,597 \\
0 \\
0\end{array}$ & $\begin{array}{r}-19 \\
0 \\
0 \\
-1,976 \\
12,308\end{array}$ & $\begin{array}{r}332 \\
0 \\
0 \\
0 \\
0\end{array}$ & $\begin{array}{r}253,874 \\
367,218 \\
125,052 \\
209,124 \\
1,970,709\end{array}$ \\
\hline 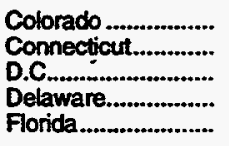 & $\begin{array}{r}285,961 \\
0 \\
0 \\
0 \\
4,884\end{array}$ & $\begin{array}{r}15,822 \\
0 \\
0 \\
0 \\
1,893\end{array}$ & $\begin{array}{r}-4,943 \\
715 \\
-771 \\
-1,172 \\
5,391\end{array}$ & $\begin{array}{r}-4,091 \\
100,939 \\
31,872 \\
38,866 \\
335,734\end{array}$ & $\begin{array}{l}0 \\
0 \\
0 \\
0 \\
0\end{array}$ & $\begin{array}{r}7,370 \\
-103 \\
0 \\
7 \\
0\end{array}$ & $\begin{array}{r}6,778 \\
146 \\
0 \\
4,262 \\
0\end{array}$ & $\begin{array}{r}260,513 \\
101,904 \\
31,101 \\
41,948 \\
344,116\end{array}$ \\
\hline 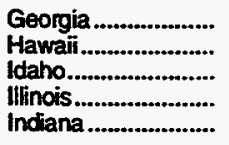 & $\begin{array}{r}0 \\
0 \\
0 \\
466 \\
232\end{array}$ & $\begin{array}{r}0 \\
0 \\
0 \\
100 \\
0\end{array}$ & $\begin{array}{r}-2,966 \\
-31 \\
-1,097 \\
-30,165 \\
4,474\end{array}$ & $\begin{array}{r}326,237 \\
0 \\
-444,702 \\
1,009,311 \\
449,198\end{array}$ & $\begin{array}{r}0 \\
0 \\
496,967 \\
0 \\
0\end{array}$ & $\begin{array}{r}390 \\
0 \\
113 \\
-1,207 \\
-331\end{array}$ & $\begin{array}{r}185 \\
2,725 \\
0 \\
6,869 \\
3,077\end{array}$ & $\begin{array}{r}323,066 \\
2,694 \\
51,055 \\
987,589 \\
457,311\end{array}$ \\
\hline 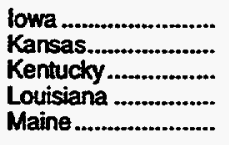 & $\begin{array}{r}0 \\
628,459 \\
78,904 \\
5,034,361 \\
0\end{array}$ & $\begin{array}{r}0 \\
41,848 \\
2,181 \\
129,154 \\
0\end{array}$ & $\begin{array}{r}20,993 \\
71,146 \\
-94,227 \\
72,065 \\
-45\end{array}$ & $\begin{array}{r}208,278 \\
-276,379 \\
203,548 \\
-3,526,880 \\
4,839\end{array}$ & $\begin{array}{r}0 \\
0 \\
0 \\
33,284 \\
0\end{array}$ & $\begin{array}{r}-3,864 \\
10,822 \\
-1,397 \\
-24,432 \\
1\end{array}$ & $\begin{array}{r}46 \\
0 \\
2 \\
0 \\
0\end{array}$ & $\begin{array}{r}233,182 \\
370,556 \\
187,443 \\
1,508,108 \\
4,792\end{array}$ \\
\hline $\begin{array}{l}\text { Maryland................. } \\
\text { Massachusetts....... } \\
\text { Michigan ................ } \\
\text { Minnesota ................ } \\
\text { Mississippi ............. }\end{array}$ & $\begin{array}{r}29 \\
0 \\
195,749 \\
0 \\
108,031\end{array}$ & $\begin{array}{r}0 \\
0 \\
8,103 \\
0 \\
511\end{array}$ & $\begin{array}{r}-17,242 \\
-13,536 \\
6,050 \\
102 \\
12,505\end{array}$ & $\begin{array}{r}192,200 \\
230,676 \\
939,653 \\
426,832 \\
123,852\end{array}$ & $\begin{array}{r}0 \\
30,312 \\
-359,890 \\
741,353 \\
0\end{array}$ & $\begin{array}{r}1,978 \\
-3,967 \\
-39,200 \\
197 \\
-5,884\end{array}$ & $\begin{array}{r}72 \\
120 \\
15,016 \\
49 \\
0\end{array}$ & $\begin{array}{l}173,081 \\
251,539 \\
827,674 \\
314,476 \\
249,761\end{array}$ \\
\hline $\begin{array}{l}\text { Missouri ................... } \\
\text { Montana................. } \\
\text { Nebraska ................ } \\
\text { Nevada .................... } \\
\text { New Hampshire ...... }\end{array}$ & $\begin{array}{r}15 \\
51,999 \\
784 \\
53 \\
0\end{array}$ & $\begin{array}{r}0 \\
1,055 \\
13 \\
0 \\
0\end{array}$ & $\begin{array}{r}1,099 \\
-6,025 \\
-25,323 \\
-1,400 \\
-681\end{array}$ & $\begin{array}{r}256,332 \\
-386,379 \\
138,439 \\
66,934 \\
14,680\end{array}$ & $\begin{array}{r}0 \\
377,125 \\
0 \\
0 \\
0\end{array}$ & $\begin{array}{r}1,117 \\
-9,737 \\
110 \\
728 \\
0\end{array}$ & $\begin{array}{r}0 \\
0 \\
2,032 \\
0 \\
128\end{array}$ & $\begin{array}{r}256,328 \\
45,402 \\
115,808 \\
64,859 \\
14,127\end{array}$ \\
\hline $\begin{array}{l}\text { New Jersey.............. } \\
\text { New Mexico ............ } \\
\text { New York............... } \\
\text { North Carolina......... } \\
\text { North Dakota........... }\end{array}$ & $\begin{array}{r}0 \\
1,038,284 \\
22,777 \\
0 \\
53,479\end{array}$ & $\begin{array}{r}0 \\
70,463 \\
0 \\
0 \\
6,342\end{array}$ & $\begin{array}{r}62,468 \\
64,893 \\
-15,759 \\
-10,276 \\
-211\end{array}$ & $\begin{array}{r}386,642 \\
-810,260 \\
691,123 \\
176,643 \\
-59,695\end{array}$ & $\begin{array}{r}0 \\
0 \\
188,233 \\
0 \\
0\end{array}$ & $\begin{array}{r}461 \\
3,694 \\
11,869 \\
-13 \\
0\end{array}$ & $\begin{array}{r}14,789 \\
0 \\
678 \\
0 \\
52,557\end{array}$ & $\begin{array}{r}463,437 \\
218,760 \\
875,184 \\
166,380 \\
39,789\end{array}$ \\
\hline $\begin{array}{l}\text { Ohio ..................... } \\
\text { Okdahoma ............. } \\
\text { Oregon.................. } \\
\text { Pennsydvania ........... } \\
\text { Rhode Island.......... }\end{array}$ & $\begin{array}{r}147,651 \\
2,153,852 \\
2,741 \\
152,500 \\
0\end{array}$ & $\begin{array}{r}49 \\
101,851 \\
0 \\
395 \\
0\end{array}$ & $\begin{array}{r}23,978 \\
-67,805 \\
37,975 \\
33,989 \\
-1,492\end{array}$ & $\begin{array}{r}593,599 \\
-1,426,181 \\
83,503 \\
441,647 \\
56,103\end{array}$ & $\begin{array}{l}0 \\
0 \\
0 \\
0 \\
0\end{array}$ & $\begin{array}{r}431 \\
-12,139 \\
786 \\
-11,357 \\
393\end{array}$ & $\begin{array}{r}891 \\
0 \\
4 \\
222 \\
92\end{array}$ & $\begin{array}{r}765,639 \\
570,154 \\
123,436 \\
639,319 \\
54,310\end{array}$ \\
\hline $\begin{array}{l}\text { South Carolina ........ } \\
\text { South Dakota .......... } \\
\text { Tennessee .............. } \\
\text { Texas....................... } \\
\text { Utah ......................... }\end{array}$ & $\begin{array}{r}0 \\
882 \\
1,856 \\
6,280,654 \\
144,817\end{array}$ & $\begin{array}{r}0 \\
0 \\
0 \\
353,737 \\
14,392\end{array}$ & $\begin{array}{r}7,170 \\
365 \\
39,041 \\
-270,304 \\
-44,706\end{array}$ & $\begin{array}{r}126,562 \\
24,995 \\
185,802 \\
-2,032,327 \\
37,071\end{array}$ & $\begin{array}{r}0 \\
0 \\
0 \\
-58,851 \\
0\end{array}$ & $\begin{array}{r}-50 \\
-15 \\
-401 \\
6,398 \\
-9,976\end{array}$ & $\begin{array}{r}47 \\
3 \\
8 \\
1,076 \\
0\end{array}$ & $\begin{array}{r}133,828 \\
26,260 \\
227,108 \\
3,560,113 \\
132,766\end{array}$ \\
\hline $\begin{array}{l}\text { Vermont .................. } \\
\text { Virginia.................. } \\
\text { Washington............ } \\
\text { West Virginia.......... } \\
\text { Wisconsin .............. } \\
\text { Wyoming................ }\end{array}$ & $\begin{array}{r}0 \\
14,906 \\
0 \\
198,605 \\
0 \\
776,528\end{array}$ & $\begin{array}{r}0 \\
0 \\
0 \\
0 \\
9,745 \\
0 \\
31,470\end{array}$ & $\begin{array}{r}-78 \\
-1,941 \\
-64,376 \\
-62,701 \\
8,118 \\
-170,602\end{array}$ & $\begin{array}{r}-8,651 \\
161,395 \\
4,807 \\
-32,339 \\
323,441 \\
-476,738\end{array}$ & $\begin{array}{r}15,796 \\
0 \\
235,614 \\
0 \\
0 \\
0\end{array}$ & $\begin{array}{r}0 \\
-71 \\
3,203 \\
-16,888 \\
35 \\
426\end{array}$ & $\begin{array}{r}6 \\
240 \\
154 \\
0 \\
1 \\
0\end{array}$ & $\begin{array}{r}7,073 \\
174,671 \\
172,996 \\
110,708 \\
331,524 \\
97,291\end{array}$ \\
\hline Total........................... & $18,532,439$ & 834,637 & -499.779 & 0 & $1,644,341$ & $-80,186$ & 112,606 & $19,035,156$ \\
\hline
\end{tabular}

See footnotes at end of table. 
Table 13. Natural Gas Production, Transmission, and Consumption by State, 1967-1994 (Continued) (Million Cubic Feet)

\begin{tabular}{|c|c|c|c|c|c|c|c|c|}
\hline State & $\begin{array}{l}\text { Marketed } \\
\text { Production }\end{array}$ & $\begin{array}{l}\text { Extraction } \\
\text { Loss }\end{array}$ & $\begin{array}{l}\text { Belaneing } \\
\text { Hem }\end{array}$ & $\begin{array}{c}\text { Nat } \\
\text { Interstate } \\
\text { Movements }\end{array}$ & $\begin{array}{l}\text { Net Move } \\
\text { ments Across } \\
\text { U.S. Borders }\end{array}$ & $\begin{array}{c}\text { Net } \\
\text { Storage } \\
\text { Changes }\end{array}$ & $\begin{array}{c}\text { Supplemental } \\
\text { Gas } \\
\text { Supplies }\end{array}$ & Consumption \\
\hline & \multicolumn{8}{|c|}{1992} \\
\hline $\begin{array}{l}\text { Alabama................... } \\
\text { Alaska ................... } \\
\text { Arizona................... } \\
\text { Arkansas............... } \\
\text { Calfitomia................. }\end{array}$ & $\begin{array}{r}355,099 \\
443,597 \\
771 \\
202,479 \\
365,632\end{array}$ & $\begin{array}{r}5,490 \\
32,004 \\
0 \\
413 \\
12,385\end{array}$ & $\begin{array}{r}-30,213 \\
24,060 \\
4,718 \\
-20,293 \\
38,452\end{array}$ & $\begin{array}{r}-40,535 \\
0 \\
126,726 \\
42,289 \\
1,610,708\end{array}$ & $\begin{array}{r}0 \\
-52,532 \\
-2,565 \\
0 \\
0\end{array}$ & $\begin{array}{r}239 \\
0 \\
0 \\
-515 \\
-28,158\end{array}$ & $\begin{array}{r}171 \\
0 \\
0 \\
0 \\
0\end{array}$ & $\begin{array}{r}278,794 \\
383,121 \\
129,650 \\
224,576 \\
2,030,564\end{array}$ \\
\hline 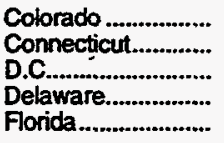 & $\begin{array}{r}323,041 \\
0 \\
0 \\
0 \\
6,657\end{array}$ & $\begin{array}{r}18,149 \\
0 \\
0 \\
0 \\
2,563\end{array}$ & $\begin{array}{r}-13,191 \\
-7,691 \\
-465 \\
-1,696 \\
7,573\end{array}$ & $\begin{array}{r}-50,647 \\
118,601 \\
33,422 \\
37,634 \\
341,325\end{array}$ & $\begin{array}{l}0 \\
0 \\
0 \\
0 \\
0\end{array}$ & $\begin{array}{r}-4,860 \\
-355 \\
0 \\
-5 \\
0\end{array}$ & $\begin{array}{r}7,158 \\
40 \\
0 \\
3,665 \\
0\end{array}$ & $\begin{array}{r}253,073 \\
111,305 \\
32,957 \\
39,608 \\
352,992\end{array}$ \\
\hline 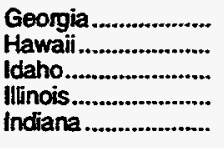 & $\begin{array}{r}0 \\
0 \\
0 \\
347 \\
174\end{array}$ & $\begin{array}{r}0 \\
0 \\
0 \\
100 \\
0\end{array}$ & $\begin{array}{r}9,847 \\
-16 \\
-7,330 \\
-44,689 \\
-1,733\end{array}$ & $\begin{array}{r}332,967 \\
0 \\
-440,253 \\
1,021,441 \\
480,369\end{array}$ & $\begin{array}{r}0 \\
0 \\
496,451 \\
0 \\
0\end{array}$ & $\begin{array}{r}16 \\
0 \\
-47 \\
-8,387 \\
-1,179\end{array}$ & $\begin{array}{r}166 \\
2,711 \\
0 \\
8.042 \\
3,507\end{array}$ & $\begin{array}{r}342,965 \\
2,695 \\
48,915 \\
993,428 \\
483,496\end{array}$ \\
\hline 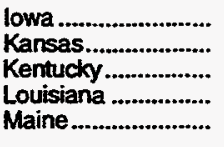 & $\begin{array}{r}0 \\
658,007 \\
79,690 \\
4,914,300 \\
0\end{array}$ & $\begin{array}{r}0 \\
42,733 \\
2,342 \\
132,656 \\
0\end{array}$ & $\begin{array}{r}-15,634 \\
-32,874 \\
-55,636 \\
33,706 \\
-26\end{array}$ & $\begin{array}{r}242,675 \\
-257,658 \\
174,733 \\
-3,295,694 \\
5,161\end{array}$ & $\begin{array}{r}0 \\
0 \\
0 \\
12,637 \\
0\end{array}$ & $\begin{array}{r}-3,846 \\
-18,486 \\
6,573 \\
-13,511 \\
4\end{array}$ & $\begin{array}{r}45 \\
0 \\
5 \\
0 \\
0\end{array}$ & $\begin{array}{r}230,932 \\
343,217 \\
189,877 \\
1,545,804 \\
5,131\end{array}$ \\
\hline 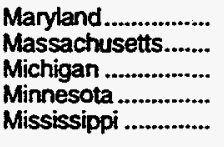 & $\begin{array}{r}33 \\
0 \\
194,815 \\
0 \\
91,697\end{array}$ & $\begin{array}{r}0 \\
0 \\
8,093 \\
0 \\
416\end{array}$ & $\begin{array}{r}-10,859 \\
-10,049 \\
58,803 \\
35,488 \\
54,787\end{array}$ & $\begin{array}{r}192,423 \\
272,622 \\
1,129,512 \\
-581,763 \\
95,107\end{array}$ & $\begin{array}{r}0 \\
30,479 \\
-500,801 \\
855,300 \\
0\end{array}$ & $\begin{array}{r}422 \\
-1,844 \\
-2,251 \\
256 \\
1,732\end{array}$ & $\begin{array}{r}126 \\
105 \\
14,694 \\
52 \\
0\end{array}$ & $\begin{array}{l}181,300 \\
295,001 \\
891,181 \\
308,821 \\
239,442\end{array}$ \\
\hline $\begin{array}{l}\text { Missouri .................. } \\
\text { Montana ................ } \\
\text { Nebraska ................ } \\
\text { Nevada ............. } \\
\text { New Hampshire ..... }\end{array}$ & $\begin{array}{r}27 \\
53,867 \\
1,177 \\
30 \\
0\end{array}$ & $\begin{array}{r}0 \\
907 \\
3 \\
0 \\
0\end{array}$ & $\begin{array}{r}-3,927 \\
-15,444 \\
-18,422 \\
-10,782 \\
-2,219\end{array}$ & $\begin{array}{r}244,630 \\
-457,024 \\
123,182 \\
79,067 \\
18,975\end{array}$ & $\begin{array}{r}0 \\
452,467 \\
0 \\
0 \\
0\end{array}$ & $\begin{array}{r}-15 \\
-12,602 \\
517 \\
-71 \\
0\end{array}$ & $\begin{array}{r}0 \\
0 \\
1.437 \\
30 \\
96\end{array}$ & $\begin{array}{r}240,745 \\
45,561 \\
106,853 \\
68,416 \\
16,852\end{array}$ \\
\hline $\begin{array}{l}\text { New Jersey............. } \\
\text { New Mexico ........... } \\
\text { New York.............. } \\
\text { North Carolina........ } \\
\text { North Dakota.......... }\end{array}$ & $\begin{array}{r}0 \\
1,268,863 \\
23,508 \\
0 \\
54,883\end{array}$ & $\begin{array}{r}0 \\
75,520 \\
0 \\
0 \\
6,055\end{array}$ & $\begin{array}{r}51,223 \\
-83,792 \\
-60,556 \\
-11,985 \\
-7,998\end{array}$ & $\begin{array}{r}480,627 \\
-911,733 \\
561,333 \\
191,486 \\
-62,738\end{array}$ & $\begin{array}{r}0 \\
0 \\
435,470 \\
0 \\
0\end{array}$ & $\begin{array}{r}-49 \\
-5,057 \\
1,942 \\
-92 \\
0\end{array}$ & $\begin{array}{r}14,362 \\
0 \\
1,190 \\
2 \\
58,496\end{array}$ & $\begin{array}{r}546,260 \\
202,875 \\
959,004 \\
179,595 \\
36,588\end{array}$ \\
\hline $\begin{array}{l}\text { Ohio ...................... } \\
\text { Oklahoma ............. } \\
\text { Oregon .................. } \\
\text { Permsylvania ......... } \\
\text { Rhode Island ........... }\end{array}$ & $\begin{array}{r}144,815 \\
2,017,356 \\
2,580 \\
138,675 \\
0\end{array}$ & $\begin{array}{r}72 \\
104,609 \\
0 \\
604 \\
0\end{array}$ & $\begin{array}{r}4,785 \\
-112,462 \\
27,923 \\
-28,977 \\
3,935\end{array}$ & $\begin{array}{r}643,869 \\
-1,266,516 \\
90,940 \\
579,240 \\
73,322\end{array}$ & $\begin{array}{l}0 \\
0 \\
0 \\
0 \\
0\end{array}$ & $\begin{array}{r}-15,672 \\
-10,058 \\
-904 \\
5,945 \\
-420\end{array}$ & $\begin{array}{r}1,051 \\
0 \\
2 \\
132 \\
155\end{array}$ & $\begin{array}{r}810,121 \\
543,827 \\
122,350 \\
682,521 \\
77,833\end{array}$ \\
\hline $\begin{array}{l}\text { South Carolina ........ } \\
\text { South Dakota ......... } \\
\text { Tennessee .............. } \\
\text { Texas....................... } \\
\text { Utah ........................ }\end{array}$ & $\begin{array}{r}0 \\
1,456 \\
1,770 \\
6,145,862 \\
171,293\end{array}$ & $\begin{array}{r}0 \\
0 \\
0 \\
374,126 \\
11,851\end{array}$ & $\begin{array}{r}9,179 \\
-1,036 \\
70,754 \\
-64,200 \\
-92,653\end{array}$ & $\begin{array}{r}128,868 \\
26,225 \\
168,860 \\
-2,181,297 \\
60,343\end{array}$ & $\begin{array}{r}0 \\
0 \\
0 \\
-93,408 \\
0\end{array}$ & $\begin{array}{r}16 \\
11 \\
-306 \\
-43,441 \\
4,482\end{array}$ & $\begin{array}{r}26 \\
10 \\
12 \\
1 \\
0\end{array}$ & $\begin{array}{r}138,057 \\
26,645 \\
241,702 \\
3,476,274 \\
122,649\end{array}$ \\
\hline $\begin{array}{l}\text { Vermont ............... } \\
\text { Virginia................. } \\
\text { Washington........... } \\
\text { West Virginia.......... } \\
\text { Wisconsin .............. } \\
\text { Wyoming............... }\end{array}$ & $\begin{array}{r}0 \\
24,733 \\
0 \\
E_{182,000} \\
0 \\
842,576\end{array}$ & $\begin{array}{r}0 \\
0 \\
0 \\
9,436 \\
0 \\
31,378\end{array}$ & $\begin{array}{r}3 \\
-14,334 \\
-55,862 \\
25,017 \\
-20,151 \\
-110,627\end{array}$ & $\begin{array}{r}-9,653 \\
189,401 \\
-51,772 \\
-76,901 \\
351,672 \\
-585,561\end{array}$ & $\begin{array}{r}17,248 \\
0 \\
270,477 \\
0 \\
0 \\
0\end{array}$ & $\begin{array}{r}0 \\
6 \\
-6,137 \\
-8,180 \\
-59 \\
-8,536\end{array}$ & $\begin{array}{r}3 \\
245 \\
180 \\
0 \\
1 \\
0\end{array}$ & $\begin{array}{r}7,601 \\
200,039 \\
169,161 \\
128,861 \\
331,581 \\
123,547\end{array}$ \\
\hline 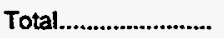 & $18,711,808$ & 871,905 & $-507,565$ & 0 & $1,921,225$ & $-172,882$ & 117,919 & $19,544,364$ \\
\hline
\end{tabular}

See footnoles at end of table. 
Table 13. Natural Gas Production, Transmission, and Consumption by State, 1967-1994 (Continued) (Million Cubic Feet)

\begin{tabular}{|c|c|c|c|c|c|c|c|c|}
\hline Stato & $\begin{array}{l}\text { Marketed } \\
\text { Production }\end{array}$ & $\begin{array}{l}\text { Extraction } \\
\text { Loss }\end{array}$ & $\begin{array}{l}\text { Balancing } \\
\text { Item }\end{array}$ & $\begin{array}{c}\text { Not } \\
\text { Interstate } \\
\text { Movements }\end{array}$ & $\begin{array}{l}\text { Net Move- } \\
\text { ments Across } \\
\text { U.S. Borders }\end{array}$ & $\begin{array}{c}\text { Net } \\
\text { Storage } \\
\text { Changes }\end{array}$ & $\begin{array}{c}\text { Supplemental } \\
\text { Cas } \\
\text { Supplies }\end{array}$ & Consumption \\
\hline & \multicolumn{8}{|c|}{1998} \\
\hline $\begin{array}{l}\text { Alabama................... } \\
\text { Alaska ...................... } \\
\text { Arizona.................... } \\
\text { Avkansas.................. } \\
\text { Califomia................ }\end{array}$ & $\begin{array}{r}388,024 \\
430,350 \\
597 \\
196,370 \\
315,851\end{array}$ & $\begin{array}{r}5,589 \\
32,257 \\
0 \\
507 \\
12,053\end{array}$ & $\begin{array}{r}-35,767 \\
36,136 \\
-83,894 \\
-4,044 \\
38,123\end{array}$ & $\begin{array}{r}-54,517 \\
0 \\
201,356 \\
31,184 \\
1,654,143\end{array}$ & $\begin{array}{r}0 \\
-55,989 \\
-3,253 \\
0 \\
0\end{array}$ & $\begin{array}{r}215 \\
0 \\
0 \\
-8,199 \\
19,668\end{array}$ & $\begin{array}{r}410 \\
0 \\
0 \\
0 \\
0\end{array}$ & $\begin{array}{r}292,346 \\
378,241 \\
114,806 \\
231,201 \\
1,976,397\end{array}$ \\
\hline 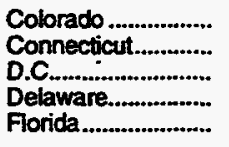 & $\begin{array}{r}400,985 \\
0 \\
0 \\
0 \\
7,085\end{array}$ & $\begin{array}{r}18,658 \\
0 \\
0 \\
0 \\
2,557\end{array}$ & $\begin{array}{r}23,747 \\
-2,305 \\
-279 \\
-2,807 \\
-4,795\end{array}$ & $\begin{array}{r}-133,507 \\
113,682 \\
33,373 \\
40,826 \\
336,155\end{array}$ & $\begin{array}{l}0 \\
0 \\
0 \\
0 \\
0\end{array}$ & $\begin{array}{r}-3,162 \\
-29 \\
0 \\
3 \\
0\end{array}$ & $\begin{array}{r}8,456 \\
94 \\
0 \\
3,597 \\
0\end{array}$ & $\begin{array}{r}284,185 \\
111,501 \\
33,093 \\
41,612 \\
R_{335,888}\end{array}$ \\
\hline $\begin{array}{l}\text { Georgia.................... } \\
\text { Hawaii...................... } \\
\text { Idaho....................... } \\
\text { Illinois......................... } \\
\text { Indiana................... }\end{array}$ & $\begin{array}{r}0 \\
0 \\
0 \\
340 \\
192\end{array}$ & $\begin{array}{r}0 \\
0 \\
0 \\
86 \\
0\end{array}$ & $\begin{array}{r}20,786 \\
-24 \\
7,351 \\
-1,526 \\
3,560\end{array}$ & $\begin{array}{r}329,591 \\
0 \\
-462,867 \\
1,034,929 \\
512,110\end{array}$ & $\begin{array}{r}0 \\
0 \\
511,727 \\
0 \\
0\end{array}$ & $\begin{array}{r}-42 \\
0 \\
51 \\
12,165 \\
1,334\end{array}$ & $\begin{array}{r}199 \\
2,705 \\
0 \\
9,760 \\
3,232\end{array}$ & $\begin{array}{r}\mathbf{3 5 0 , 6 1 8} \\
2,681 \\
56,160 \\
1,031,253 \\
517,760\end{array}$ \\
\hline $\begin{array}{l}\text { lowa ........................ } \\
\text { Kansas...................... } \\
\text { Kentucky................ } \\
\text { Louisiana ................ } \\
\text { Maine...................... }\end{array}$ & $\begin{array}{r}0 \\
686,347 \\
86,966 \\
R_{4,991,138} \\
0\end{array}$ & $\begin{array}{r}0 \\
44,014 \\
2,252 \\
130,336 \\
0\end{array}$ & $\begin{array}{r}R_{-45,975} \\
27,185 \\
-63,628 \\
A_{197,928} \\
-24\end{array}$ & $\begin{array}{r}297,167 \\
-271,105 \\
170,567 \\
-3,504,796 \\
4,989\end{array}$ & $\begin{array}{r}0 \\
0 \\
0 \\
30,790 \\
0\end{array}$ & $\begin{array}{r}3,251 \\
6,809 \\
-11,625 \\
6,282 \\
-2\end{array}$ & $\begin{array}{r}84 \\
0 \\
16 \\
0 \\
0\end{array}$ & $\begin{array}{r}R_{248,025} \\
391,604 \\
203,295 \\
R_{1,578,443} \\
4,968\end{array}$ \\
\hline $\begin{array}{l}\text { Maryland ................. } \\
\text { Massachusetts........ } \\
\text { Michigan ................. } \\
\text { Minnesota.............. } \\
\text { Mississippi .............. }\end{array}$ & $\begin{array}{r}28 \\
0 \\
204,635 \\
0 \\
80,695\end{array}$ & $\begin{array}{r}0 \\
0 \\
7,012 \\
0 \\
395\end{array}$ & $\begin{array}{r}18,085 \\
40,758 \\
32,932 \\
199,493 \\
27,069\end{array}$ & $\begin{array}{r}157,062 \\
218,261 \\
1,042,347 \\
-579,033 \\
122,689\end{array}$ & $\begin{array}{r}0 \\
50,895 \\
-333,631 \\
707,795 \\
0\end{array}$ & $\begin{array}{r}-5,021 \\
-2,368 \\
39,033 \\
394 \\
117\end{array}$ & $\begin{array}{r}418 \\
61 \\
12,795 \\
78 \\
0\end{array}$ & $\begin{array}{l}180,614 \\
312,343 \\
913,033 \\
327,939 \\
229,941\end{array}$ \\
\hline $\begin{array}{l}\text { Missouri .................... } \\
\text { Montana.................. } \\
\text { Nebraska ................. } \\
\text { Nevada ................... } \\
\text { New Hampshire...... }\end{array}$ & $\begin{array}{r}14 \\
54,528 \\
2,114 \\
21 \\
0\end{array}$ & $\begin{array}{r}0 \\
741 \\
0 \\
0 \\
0\end{array}$ & $\begin{array}{r}8,729 \\
-22,077 \\
2,039 \\
-3,470 \\
-2,506\end{array}$ & $\begin{array}{r}270,752 \\
-510,908 \\
124,001 \\
88,376 \\
19,270\end{array}$ & $\begin{array}{r}0 \\
511,188 \\
0 \\
0 \\
0\end{array}$ & $\begin{array}{r}-68 \\
-21,308 \\
2,832 \\
9 \\
0\end{array}$ & $\begin{array}{r}0 \\
0 \\
791 \\
38 \\
154\end{array}$ & $\begin{array}{r}279,562 \\
53,298 \\
126,112 \\
84,955 \\
16,918\end{array}$ \\
\hline $\begin{array}{l}\text { New Jersey ............. } \\
\text { New Mexico........... } \\
\text { New York............... } \\
\text { North Carolina......... } \\
\text { North Dakota.......... }\end{array}$ & $\begin{array}{r}0 \\
1,409,429 \\
21,183 \\
0 \\
59,851\end{array}$ & $\begin{array}{r}0 \\
83,193 \\
0 \\
0 \\
5,924\end{array}$ & $\begin{array}{r}71,249 \\
-44,265 \\
33,327 \\
-16,686 \\
-8,099\end{array}$ & $\begin{array}{r}466,047 \\
-1,073,957 \\
386,236 \\
202,188 \\
-63,545\end{array}$ & $\begin{array}{r}0 \\
0 \\
502,701 \\
0 \\
0\end{array}$ & $\begin{array}{r}307 \\
-8,426 \\
1,259 \\
-142 \\
0\end{array}$ & $\begin{array}{r}14,950 \\
0 \\
1,638 \\
4 \\
57,680\end{array}$ & $\begin{array}{r}551,939 \\
216,440 \\
943,826 \\
185,648 \\
39,962\end{array}$ \\
\hline $\begin{array}{l}\text { Ohio ......................... } \\
\text { Oklahoma ............... } \\
\text { Oregon................... } \\
\text { Pennsylvania .......... } \\
\text { Rhode Island........... }\end{array}$ & $\begin{array}{r}137,285 \\
2,049,942 \\
4,003 \\
132,130 \\
0\end{array}$ & $\begin{array}{r}.95 \\
101.962 \\
0 \\
513 \\
0\end{array}$ & $\begin{array}{r}-174,022 \\
-195,446 \\
25,583 \\
-236,955 \\
11,282\end{array}$ & $\begin{array}{r}856,415 \\
-1,159,222 \\
105,699 \\
796,695 \\
63,814\end{array}$ & $\begin{array}{l}0 \\
0 \\
0 \\
0 \\
0\end{array}$ & $\begin{array}{r}-13,269 \\
14,535 \\
-323 \\
446 \\
-337\end{array}$ & $\begin{array}{r}992 \\
0 \\
3 \\
110 \\
126\end{array}$ & $\begin{array}{r}833,845 \\
578,777 \\
135,611 \\
691,021 \\
75,559\end{array}$ \\
\hline $\begin{array}{l}\text { South Carolina ........ } \\
\text { South Dakota ........... } \\
\text { Tennessee .............. } \\
\text { Texas...................... } \\
\text { Utah ........................ }\end{array}$ & $\begin{array}{r}0 \\
R_{1}, 306 \\
1,660 \\
6,249,624 \\
225,401\end{array}$ & $\begin{array}{r}0 \\
0 \\
0 \\
385,063 \\
13,300\end{array}$ & $\begin{array}{r}R_{11,296} \\
R_{-650} \\
51,663 \\
R_{-65,481} \\
-99,012\end{array}$ & $\begin{array}{r}130,670 \\
30,646 \\
200,614 \\
-2,033,746 \\
32,227\end{array}$ & $\begin{array}{r}0 \\
0 \\
0 \\
-34,745 \\
0\end{array}$ & $\begin{array}{r}478 \\
0 \\
-268 \\
-10,658 \\
7,271\end{array}$ & $\begin{array}{r}34 \\
9 \\
13 \\
3 \\
0\end{array}$ & $\begin{array}{r}A_{141,522} \\
A_{31,311} \\
254,218 \\
R_{3,741,252} \\
138,044\end{array}$ \\
\hline $\begin{array}{l}\text { Vemont ................ } \\
\text { Virginia .................. } \\
\text { Washington............. } \\
\text { West Virginia.......... } \\
\text { Wisconsin ................ } \\
\text { Wyoming................ }\end{array}$ & $\begin{array}{r}0 \\
37,840 \\
0 \\
R_{171,024} \\
0 \\
A_{634,957}\end{array}$ & $\begin{array}{r}0 \\
0 \\
0 \\
10,830 \\
0 \\
29,118\end{array}$ & $\begin{array}{r}-103 \\
-4,287 \\
-85,384 \\
R_{122,550} \\
-64,879 \\
R_{147,925}\end{array}$ & $\begin{array}{r}-9,097 \\
183,700 \\
-25,073 \\
-138,967 \\
412,892 \\
-650,336\end{array}$ & $\begin{array}{r}16,424 \\
0 \\
306,030 \\
0 \\
0 \\
0\end{array}$ & $\begin{array}{r}0 \\
-102 \\
-2,804 \\
8,614 \\
2 \\
-1,221\end{array}$ & $\begin{array}{r}4 \\
538 \\
4 \\
0 \\
3 \\
0\end{array}$ & $\begin{array}{r}7,228 \\
217,893 \\
198,380 \\
R_{135,164} \\
348,014 \\
104,649\end{array}$ \\
\hline 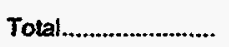 & $R_{18,981,915}$ & 886,455 & $R_{-109,593}$ & 0 & $2,209,931$ & 35,701 & 118,999 & $\mathbf{R}_{20,279,095}$ \\
\hline
\end{tabular}


Table 13. Natural Gas Production, Transmission, and Consumption by State, 1967-1994 (Continued) (Million Cubic Feet)

\begin{tabular}{|c|c|c|c|c|c|c|c|c|}
\hline State & $\begin{array}{l}\text { Marketed } \\
\text { Production }\end{array}$ & $\begin{array}{l}\text { Extraction } \\
\text { Loss }\end{array}$ & $\begin{array}{l}\text { Balancing } \\
\text { Item }\end{array}$ & $\begin{array}{l}\text { Not } \\
\text { Interstate } \\
\text { Movements }\end{array}$ & $\begin{array}{l}\text { Net Movo- } \\
\text { ments Across } \\
\text { U.S. Borders }\end{array}$ & $\begin{array}{l}\text { Not } \\
\text { Storage } \\
\text { Changes }\end{array}$ & $\begin{array}{c}\text { Supplemental } \\
\text { Gas } \\
\text { Supplies }\end{array}$ & Consumption \\
\hline & \multicolumn{8}{|c|}{1994} \\
\hline 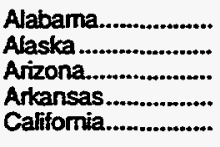 & $\begin{array}{r}515,271 \\
453,425 \\
752 \\
187,673 \\
309,427\end{array}$ & $\begin{array}{r}5,647 \\
30,945 \\
0 \\
553 \\
11,250\end{array}$ & $\begin{array}{r}-46,632 \\
43,398 \\
20,057 \\
-9,054 \\
-57,030\end{array}$ & $\begin{array}{r}-173,112 \\
0 \\
115,147 \\
63,880 \\
1,887,149\end{array}$ & $\begin{array}{r}0 \\
-62,682 \\
-2,459 \\
0 \\
0\end{array}$ & $\begin{array}{r}1,087 \\
0 \\
0 \\
-2,478 \\
4,985\end{array}$ & $\begin{array}{r}69 \\
0 \\
0 \\
0 \\
0\end{array}$ & $\begin{array}{r}288,863 \\
403,197 \\
133,497 \\
244,425 \\
2,123,310\end{array}$ \\
\hline 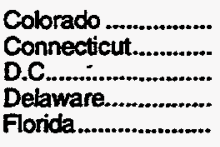 & $\begin{array}{r}453,207 \\
0 \\
0 \\
0 \\
7,486\end{array}$ & $\begin{array}{r}19,612 \\
0 \\
0 \\
0 \\
1,789\end{array}$ & $\begin{array}{r}48,328 \\
9,463 \\
1,042 \\
-3,781 \\
2,713\end{array}$ & $\begin{array}{r}-213,230 \\
110,478 \\
29,806 \\
49,408 \\
359,143\end{array}$ & $\begin{array}{l}0 \\
0 \\
0 \\
0 \\
0\end{array}$ & $\begin{array}{r}1,100 \\
-61 \\
0 \\
23 \\
0\end{array}$ & $\begin{array}{r}8,168 \\
29 \\
0 \\
3,032 \\
0\end{array}$ & $\begin{array}{r}275,761 \\
120,031 \\
30,849 \\
48,636 \\
367,552\end{array}$ \\
\hline 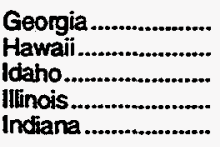 & $\begin{array}{r}0 \\
0 \\
0 \\
333 \\
107\end{array}$ & $\begin{array}{r}0 \\
0 \\
0 \\
80 \\
0\end{array}$ & $\begin{array}{r}9,376 \\
-53 \\
-4,498 \\
-131,627 \\
-80,586\end{array}$ & $\begin{array}{r}331,812 \\
0 \\
-661,486 \\
1,161,327 \\
600,860\end{array}$ & $\begin{array}{r}0 \\
0 \\
723,071 \\
0 \\
0\end{array}$ & $\begin{array}{r}-94 \\
0 \\
182 \\
12,916 \\
3,481\end{array}$ & $\begin{array}{r}123 \\
2,831 \\
0 \\
7,871 \\
2.457\end{array}$ & $\begin{array}{r}341,405 \\
2,778 \\
56,905 \\
1,024,908 \\
519,356\end{array}$ \\
\hline 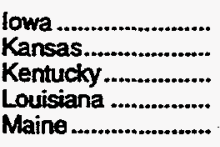 & $\begin{array}{r}0 \\
712,730 \\
73,081 \\
5,169,705 \\
0\end{array}$ & $\begin{array}{r}0 \\
46,936 \\
2,024 \\
128,583 \\
0\end{array}$ & $\begin{array}{r}-35,943 \\
20,700 \\
56,159 \\
409,022 \\
131\end{array}$ & $\begin{array}{r}287,281 \\
-262,252 \\
85,965 \\
-3,804,900 \\
4,928\end{array}$ & $\begin{array}{r}0 \\
0 \\
0 \\
17,887 \\
0\end{array}$ & $\begin{array}{r}3,109 \\
6,215 \\
4,845 \\
39,364 \\
5\end{array}$ & $\begin{array}{r}123 \\
0 \\
50 \\
0 \\
0\end{array}$ & $\begin{array}{r}248,351 \\
418,027 \\
208,386 \\
1,623,766 \\
5,055\end{array}$ \\
\hline $\begin{array}{l}\text { Maryland ................. } \\
\text { Massachusetts....... } \\
\text { Michigan ................. } \\
\text { Minnesota ............. } \\
\text { Mississippi .............. }\end{array}$ & $\begin{array}{r}26 \\
0 \\
222,657 \\
0 \\
63,448\end{array}$ & $\begin{array}{r}0 \\
0 \\
6,371 \\
0 \\
425\end{array}$ & $\begin{array}{r}-45,552 \\
53,615 \\
-197,890 \\
6,163 \\
52,312\end{array}$ & $\begin{array}{r}226,594 \\
243,880 \\
1,495,917 \\
-563,335 \\
167,621\end{array}$ & $\begin{array}{r}0 \\
32,891 \\
-520,977 \\
881,692 \\
0\end{array}$ & $\begin{array}{r}-1,680 \\
-6,820 \\
80,996 \\
994 \\
14,446\end{array}$ & $\begin{array}{r}987 \\
154 \\
13,688 \\
289 \\
0\end{array}$ & $\begin{array}{l}183,734 \\
337,361 \\
926,023 \\
323,815 \\
268,510\end{array}$ \\
\hline $\begin{array}{l}\text { Missouri .................. } \\
\text { Montana.................. } \\
\text { Nebraska ............... } \\
\text { Nevada .............. } \\
\text { New Hampshire ...... }\end{array}$ & $\begin{array}{r}8 \\
50,416 \\
2,898 \\
16 \\
0\end{array}$ & $\begin{array}{r}0 \\
631 \\
8 \\
0 \\
0\end{array}$ & $\begin{array}{r}21,145 \\
-7,062 \\
-24,879 \\
-893 \\
4,181\end{array}$ & $\begin{array}{r}245,985 \\
-531,252 \\
150,340 \\
102,628 \\
15,365\end{array}$ & $\begin{array}{r}0 \\
532,768 \\
0 \\
0 \\
0\end{array}$ & $\begin{array}{r}-85 \\
-7,819 \\
2,497 \\
-30 \\
0\end{array}$ & $\begin{array}{r}371 \\
0 \\
890 \\
9 \\
160\end{array}$ & $\begin{array}{r}267,594 \\
52,058 \\
126,744 \\
101,790 \\
19,706\end{array}$ \\
\hline $\begin{array}{l}\text { New Jersey ............ } \\
\text { New Mexico ........... } \\
\text { New York............ } \\
\text { North Carolina........ } \\
\text { North Dakota.......... }\end{array}$ & $\begin{array}{r}0 \\
1,557,689 \\
20,465 \\
0 \\
57,805\end{array}$ & $\begin{array}{r}0 \\
86,607 \\
0 \\
0 \\
5,671\end{array}$ & $\begin{array}{r}48,070 \\
-165,975 \\
26,839 \\
-10,433 \\
-4,439\end{array}$ & $\begin{array}{r}530,317 \\
-1,082,958 \\
376,865 \\
198,606 \\
-63,586\end{array}$ & $\begin{array}{r}0 \\
0 \\
588,983 \\
0 \\
1,617\end{array}$ & $\begin{array}{r}1,270 \\
1,379 \\
2,115 \\
316 \\
0\end{array}$ & $\begin{array}{r}7,737 \\
0 \\
1,460 \\
3 \\
57,127\end{array}$ & $\begin{array}{r}584,853 \\
220,770 \\
1,012,497 \\
187,861 \\
42,853\end{array}$ \\
\hline $\begin{array}{l}\text { Ohio ....................... } \\
\text { Oklahoma ............. } \\
\text { Oregon................ } \\
\text { Pennsylvania .......... } \\
\text { Rhode Island.......... }\end{array}$ & $\begin{array}{r}132,151 \\
1,934,864 \\
3,221 \\
150,228 \\
0\end{array}$ & $\begin{array}{r}104 \\
101,564 \\
0 \\
513 \\
0\end{array}$ & $\begin{array}{r}-40,803 \\
-303 \\
6,816 \\
-140,774 \\
12,678\end{array}$ & $\begin{array}{r}779,245 \\
-1,242,085 \\
136,833 \\
688,918 \\
58,749\end{array}$ & $\begin{array}{l}0 \\
0 \\
0 \\
0 \\
0\end{array}$ & $\begin{array}{r}28,576 \\
18,838 \\
463 \\
-26 \\
160\end{array}$ & $\begin{array}{r}1.432 \\
0 \\
2 \\
252 \\
0\end{array}$ & $\begin{array}{r}843,345 \\
572,074 \\
146,409 \\
698,138 \\
71,267\end{array}$ \\
\hline $\begin{array}{l}\text { South Carolina........ } \\
\text { South Dakota.......... } \\
\text { Tennessee............. } \\
\text { Texas..................... } \\
\text { Utah ........................ }\end{array}$ & $\begin{array}{r}0 \\
1,437 \\
1,990 \\
6,353,844 \\
270,858\end{array}$ & $\begin{array}{r}0 \\
0 \\
0 \\
381,020 \\
13,780\end{array}$ & $\begin{array}{r}14,766 \\
-773 \\
24,107 \\
-148,241 \\
-104,650\end{array}$ & $\begin{array}{r}129,772 \\
30,255 \\
220,081 \\
-2,068,270 \\
4,231\end{array}$ & $\begin{array}{r}0 \\
0 \\
0 \\
-37,029 \\
0\end{array}$ & $\begin{array}{r}165 \\
0 \\
106 \\
52,956 \\
19,587\end{array}$ & $\begin{array}{r}154 \\
61 \\
84 \\
1 \\
0\end{array}$ & $\begin{array}{r}144,526 \\
30,980 \\
246,157 \\
3,666,329 \\
137,073\end{array}$ \\
\hline 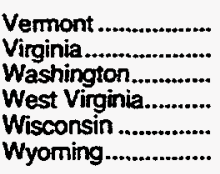 & $\begin{array}{r}0 \\
50,259 \\
0 \\
E_{182,000} \\
0 \\
696,018\end{array}$ & $\begin{array}{r}0 \\
0 \\
0 \\
10,901 \\
0 \\
33,486\end{array}$ & $\begin{array}{r}-12 \\
38,265 \\
-55,281 \\
94,283 \\
-124,878 \\
121,842\end{array}$ & $\begin{array}{r}-10,789 \\
140,723 \\
-52,739 \\
-105,063 \\
480,425 \\
-675,475\end{array}$ & $\begin{array}{r}18,091 \\
0 \\
323,013 \\
0 \\
0 \\
0\end{array}$ & $\begin{array}{r}0 \\
-121 \\
2,212 \\
14,932 \\
-50 \\
2,584\end{array}$ & $\begin{array}{r}9 \\
1,195 \\
0 \\
0 \\
5 \\
0\end{array}$ & $\begin{array}{r}7,299 \\
230,562 \\
212,782 \\
145,387 \\
355,602 \\
106,316\end{array}$ \\
\hline Total......................... & $19,635,495$ & 888,500 & $-296,577$ & 0 & $2,496,868$ & 302,641 & 110,826 & $20,755,471$ \\
\hline
\end{tabular}

Data for the District of Columbia are included with data for Maryland.

Data for New Hampshire and Vermont are included with data for Maine.

$R=$ Revised data.

E = Estimated data

NA $=$ Not Available

$=$ Volume is less than 500,000 cubic feet.

Note: Totals may not equal sum of components due to independent rounding.

Sources: Energy Information Administration (EIA). Form EIA-176. "Annual Report of Natural and Supplemental Gas Supply and Disposition"; Form EIA-627, "Annual Quantity and Value of Natural Gas Report"; Form EiA-857, "Monthly Report of Natural Gas Purchases and Deliveries to Consumers"; Form EIA-816, "Monthly Natural Gas Liquids Report"; Form EIA-759. "Monthly Power Plant Report;; Forms ElA-191/FERC-8, "Underground Gas Storage Feport"; Form FPC-14, "Annual Report for Importers and Exporters of Natural Gas"; Form ElA-64A, "Annual Report of the Origin of Natural Gas Liquids Production"; and the U.S. Minerals Management Service. 
Table 14. Consumption of Natural Gas by State, 1967-1992 (Million Cubic Feet)

\begin{tabular}{|c|c|c|c|c|}
\hline Stato & Delivered to Consumers & Lease and Plant Fuel & Pipeline Fued & Total Consumption \\
\hline & \multicolumn{4}{|c|}{1967} \\
\hline 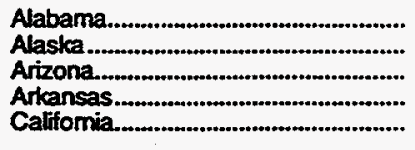 & $\begin{array}{r}238,798 \\
10,230 \\
135,009 \\
273,136 \\
1,792,221\end{array}$ & $\begin{array}{r}162 \\
1,659 \\
33 \\
10,267 \\
100,497\end{array}$ & $\begin{array}{r}15,221 \\
0 \\
23,724 \\
12,057 \\
18,414\end{array}$ & $\begin{array}{r}254,176 \\
11,889 \\
158,766 \\
295,460 \\
1,911,132\end{array}$ \\
\hline 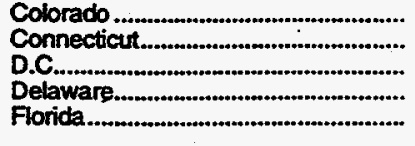 & $\begin{array}{r}227,225 \\
49,473 \\
a \\
21,063 \\
221,494\end{array}$ & $\begin{array}{r}2,668 \\
0 \\
a \\
0 \\
210\end{array}$ & $\begin{array}{r}1,615 \\
307 \\
\mathrm{a} \\
0 \\
3,827\end{array}$ & $\begin{array}{r}231,508 \\
49,780 \\
a \\
21,063 \\
225,531\end{array}$ \\
\hline $\begin{array}{l}\text { Georgia } \\
\text { Idaho } \\
\text { Illinois } \\
\text { Indiana } \\
\text { lowa }\end{array}$ & $\begin{array}{r}248,161 \\
32,877 \\
928,521 \\
423,462 \\
259,085\end{array}$ & $\begin{array}{r}0 \\
0 \\
430 \\
5 \\
0\end{array}$ & $\begin{array}{r}6,173 \\
1,406 \\
19,402 \\
11,165 \\
13,765\end{array}$ & $\begin{array}{r}254,334 \\
34,283 \\
948,353 \\
434,632 \\
272,850\end{array}$ \\
\hline 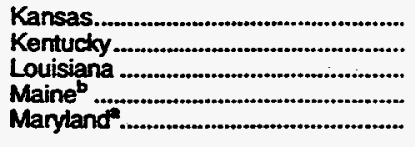 & $\begin{array}{r}385,899 \\
161,656 \\
1,141,450 \\
6,559 \\
137,771\end{array}$ & $\begin{array}{r}7,842 \\
1,828 \\
195,990 \\
0 \\
257\end{array}$ & $\begin{array}{r}57,222 \\
28,980 \\
56,936 \\
19 \\
1,825\end{array}$ & $\begin{array}{r}450,963 \\
192,464 \\
1,394,376 \\
6,578 \\
139,853\end{array}$ \\
\hline 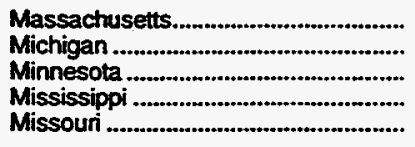 & $\begin{array}{l}126,236 \\
674,492 \\
280,432 \\
224,840 \\
350,164\end{array}$ & $\begin{array}{r}0 \\
2,798 \\
0 \\
8,582 \\
0\end{array}$ & $\begin{array}{r}1,981 \\
8,805 \\
2,654 \\
48,738 \\
10,539\end{array}$ & $\begin{array}{l}128,217 \\
686,095 \\
283,086 \\
282,160 \\
360,703\end{array}$ \\
\hline 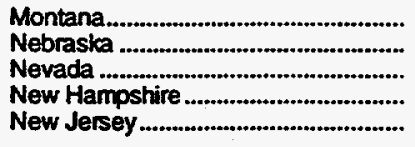 & $\begin{array}{r}58,358 \\
176,241 \\
35,011 \\
b \\
250,770\end{array}$ & $\begin{array}{r}5,904 \\
2,164 \\
0 \\
6 \\
0\end{array}$ & $\begin{array}{r}776 \\
10,256 \\
24 \\
b \\
712\end{array}$ & $\begin{array}{r}65,038 \\
188,661 \\
35,035 \\
b \\
251,482\end{array}$ \\
\hline 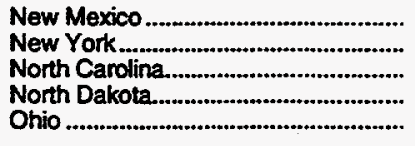 & $\begin{array}{r}184,357 \\
581,884 \\
93,628 \\
14,714 \\
946,821\end{array}$ & $\begin{array}{r}46,793 \\
508 \\
0 \\
17,133 \\
2,656\end{array}$ & $\begin{array}{r}24,440 \\
6,728 \\
4,353 \\
11 \\
13,344\end{array}$ & $\begin{array}{r}\mathbf{2 5 5 , 5 9 0} \\
589,120 \\
97,981 \\
31,858 \\
962,821\end{array}$ \\
\hline 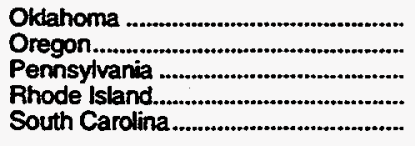 & $\begin{array}{r}370,027 \\
67,974 \\
652,596 \\
18,460 \\
98,120\end{array}$ & $\begin{array}{r}65,167 \\
0 \\
2,270 \\
0 \\
0\end{array}$ & $\begin{array}{r}14,184 \\
1,903 \\
23,612 \\
33 \\
2,419\end{array}$ & $\begin{array}{r}449,378 \\
69,877 \\
678,478 \\
18,493 \\
100,539\end{array}$ \\
\hline $\begin{array}{l}\text { South Dakota } \\
\text { Tennessee } \\
\text { Texas } \\
\text { Utah } \\
\text { Vemont }\end{array}$ & $\begin{array}{r}27,685 \\
209,589 \\
2,767,835 \\
102,886 \\
\text { b }\end{array}$ & $\begin{array}{r}0 \\
355 \\
645,058 \\
1,956 \\
b\end{array}$ & $\begin{array}{r}50 \\
22,268 \\
72,353 \\
210 \\
b\end{array}$ & $\begin{array}{r}27,735 \\
232,212 \\
3,485,246 \\
105,052 \\
\text { b }\end{array}$ \\
\hline 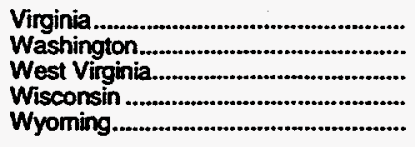 & $\begin{array}{r}108,867 \\
124,765 \\
132,316 \\
245,253 \\
53,236\end{array}$ & $\begin{array}{r}0 \\
0 \\
2,052 \\
0 \\
15,722\end{array}$ & $\begin{array}{r}7,020 \\
2,465 \\
16,710 \\
2,780 \\
4,326\end{array}$ & $\begin{array}{r}115,887 \\
127,230 \\
151,078 \\
248,033 \\
73,284\end{array}$ \\
\hline Total & $15,671,642$ & $1,140,966$ & $\mathbf{5 7 5 , 7 5 2}$ & $17,388,360$ \\
\hline
\end{tabular}

See footnotes at end of table. 
Table 14. Consumption of Natural Gas by State, 1967-1992 (Continued) (Million Cubic Feet)

\begin{tabular}{|c|c|c|c|c|}
\hline Stato & Delivered to Consumers & Lease and Plant Fuel & Pipeline Fuel & Total Consumption \\
\hline & \multicolumn{4}{|c|}{1968} \\
\hline 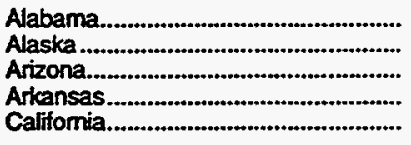 & $\begin{array}{r}269,677 \\
15,308 \\
150,626 \\
305,274 \\
1,936,146\end{array}$ & $\begin{array}{r}152 \\
2,240 \\
20 \\
4,027 \\
93,074\end{array}$ & $\begin{array}{r}17,383 \\
0 \\
25,901 \\
12,268 \\
16,860\end{array}$ & $\begin{array}{r}287,212 \\
17,548 \\
176,547 \\
321,569 \\
2,046,080\end{array}$ \\
\hline 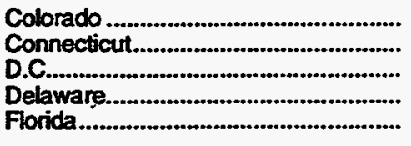 & $\begin{array}{r}252,772 \\
53,145 \\
a \\
24,059 \\
269,073\end{array}$ & $\begin{array}{r}2,361 \\
0 \\
a \\
0 \\
201\end{array}$ & $\begin{array}{r}1,687 \\
57 \\
a \\
0 \\
4,250\end{array}$ & $\begin{array}{r}256,820 \\
53,202 \\
a \\
24,059 \\
273,524\end{array}$ \\
\hline 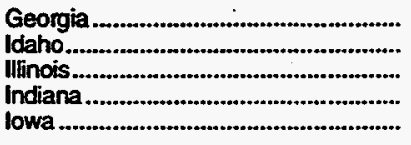 & $\begin{array}{r}276,638 \\
37,556 \\
976,405 \\
444,261 \\
284,889\end{array}$ & $\begin{array}{r}0 \\
0 \\
473 \\
0 \\
0\end{array}$ & $\begin{array}{r}6,477 \\
1,923 \\
17,526 \\
9,752 \\
12,609\end{array}$ & $\begin{array}{r}283,115 \\
39,479 \\
994,404 \\
454,013 \\
297,498\end{array}$ \\
\hline 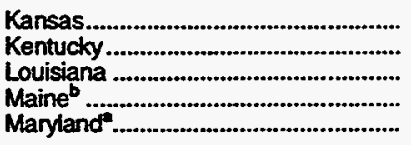 & $\begin{array}{r}421,517 \\
164,231 \\
1,252,378 \\
6,630 \\
147,384\end{array}$ & $\begin{array}{r}15,867 \\
1,992 \\
212,134 \\
0 \\
310\end{array}$ & $\begin{array}{r}59,166 \\
30,584 \\
56,980 \\
0 \\
1,431\end{array}$ & $\begin{array}{r}496,550 \\
196,807 \\
1,521,492 \\
6,630 \\
149,125\end{array}$ \\
\hline 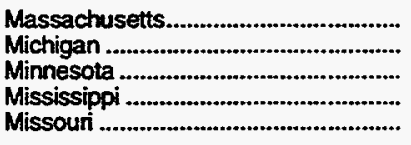 & $\begin{array}{l}130,676 \\
690,306 \\
309,139 \\
250,957 \\
356,191\end{array}$ & $\begin{array}{r}0 \\
2,012 \\
0 \\
9.158 \\
0\end{array}$ & $\begin{array}{r}1,649 \\
8,220 \\
2,759 \\
51,776 \\
9,355\end{array}$ & $\begin{array}{l}132,325 \\
700,538 \\
311,898 \\
311,891 \\
365,546\end{array}$ \\
\hline 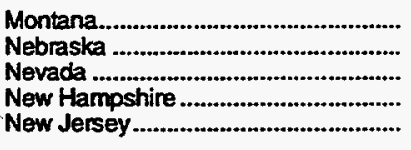 & $\begin{array}{r}57,148 \\
191,410 \\
37,029 \\
b \\
268,035\end{array}$ & $\begin{array}{r}5,188 \\
1,945 \\
0 \\
b \\
0\end{array}$ & $\begin{array}{r}562 \\
9,990 \\
0 \\
b \\
460\end{array}$ & $\begin{array}{r}62,898 \\
203,345 \\
37,029 \\
b \\
268,495\end{array}$ \\
\hline 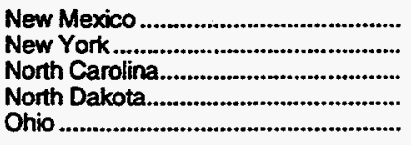 & $\begin{array}{r}188,381 \\
635,983 \\
109,980 \\
16,884 \\
971,719\end{array}$ & $\begin{array}{r}46,331 \\
538 \\
0 \\
16,163 \\
3,505\end{array}$ & $\begin{array}{r}26,062 \\
3,324 \\
4,829 \\
6 \\
12,617\end{array}$ & $\begin{array}{r}260,774 \\
639,845 \\
114,809 \\
33,053 \\
987,841\end{array}$ \\
\hline 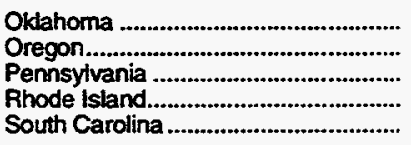 & $\begin{array}{r}398,333 \\
75,292 \\
692,866 \\
20,701 \\
124,876\end{array}$ & $\begin{array}{r}84,259 \\
0 \\
1,530 \\
0 \\
0\end{array}$ & $\begin{array}{r}13,873 \\
3,934 \\
23,513 \\
3 \\
2,638\end{array}$ & $\begin{array}{r}496,465 \\
79,226 \\
717,909 \\
20,704 \\
127,514\end{array}$ \\
\hline 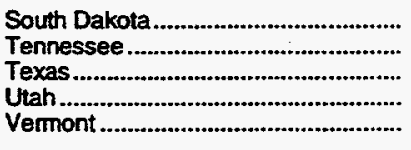 & $\begin{array}{r}28,792 \\
211,127 \\
2,899,609 \\
108,119 \\
b\end{array}$ & $\begin{array}{r}0 \\
753 \\
711,720 \\
1,503 \\
b\end{array}$ & $\begin{array}{r}23 \\
22,408 \\
85,067 \\
244 \\
b\end{array}$ & $\begin{array}{r}28,815 \\
234,288 \\
3,696,396 \\
109,866 \\
b\end{array}$ \\
\hline 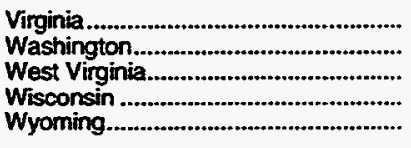 & $\begin{array}{r}114,140 \\
135,956 \\
163,927 \\
269,082 \\
59,339\end{array}$ & $\begin{array}{r}128 \\
0 \\
2,276 \\
0 \\
17,271\end{array}$ & $\begin{array}{r}7,660 \\
3,465 \\
16,800 \\
2,683 \\
2,191\end{array}$ & $\begin{array}{r}121,928 \\
139,421 \\
183,003 \\
271,765 \\
78,801\end{array}$ \\
\hline Total & $16,803,966$ & $1,237,131$ & 590,965 & $18,632,062$ \\
\hline
\end{tabular}

See footnotes at end of table. 
Table 14. Consumption of Natural Gas by State, 1967-1992 (Continued) (Million Cubic Feet)

\begin{tabular}{|c|c|c|c|c|}
\hline State & Delivered to Consumers & Lease and Piant Fuel & Pipeline Fuel & Total Consumption \\
\hline & \multicolumn{4}{|c|}{1969} \\
\hline 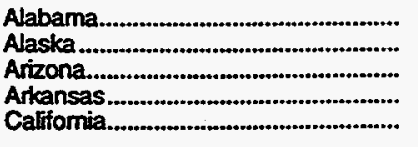 & $\begin{array}{r}280,344 \\
35,862 \\
168,547 \\
331,366 \\
1,948,269\end{array}$ & $\begin{array}{r}150 \\
6,864 \\
34 \\
6,268 \\
82,996\end{array}$ & $\begin{array}{r}20,398 \\
0 \\
26,895 \\
12,356 \\
17,269\end{array}$ & $\begin{array}{r}300,892 \\
42,726 \\
195,476 \\
349,990 \\
2,048,534\end{array}$ \\
\hline 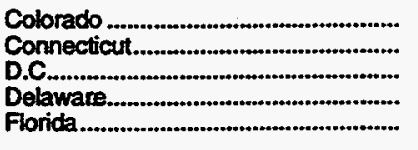 & $\begin{array}{r}268,027 \\
57,424 \\
a \\
25,863 \\
307,145\end{array}$ & $\begin{array}{r}2,604 \\
0 \\
a \\
0 \\
176\end{array}$ & $\begin{array}{r}1,806 \\
61 \\
a \\
0 \\
4,564\end{array}$ & $\begin{array}{r}272,437 \\
57,485 \\
a \\
25,863 \\
311,885\end{array}$ \\
\hline 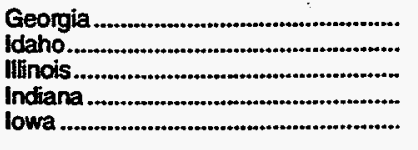 & $\begin{array}{r}304,697 \\
39,078 \\
1,063,157 \\
519,407 \\
302,441\end{array}$ & $\begin{array}{r}0 \\
0 \\
542 \\
0 \\
0\end{array}$ & $\begin{array}{r}6,846 \\
2,358 \\
21,693 \\
11,574 \\
15,900\end{array}$ & $\begin{array}{r}311,543 \\
41,436 \\
1,085,392 \\
530,981 \\
318,341\end{array}$ \\
\hline 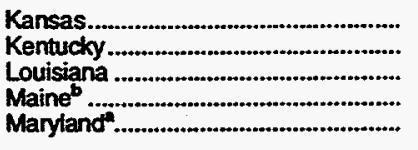 & $\begin{array}{r}465,979 \\
198,401 \\
1,417,837 \\
9,196 \\
166,547\end{array}$ & $\begin{array}{r}17,587 \\
2,277 \\
273,213 \\
0 \\
381\end{array}$ & $\begin{array}{r}63,661 \\
34,204 \\
71,905 \\
0 \\
2,016\end{array}$ & $\begin{array}{r}547,227 \\
234,882 \\
1,762,955 \\
9,196 \\
168,944\end{array}$ \\
\hline 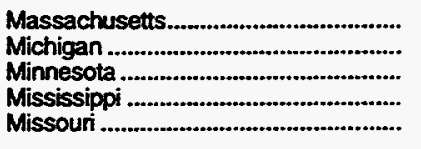 & $\begin{array}{l}136,023 \\
765,748 \\
322,694 \\
261,386 \\
389,230\end{array}$ & $\begin{array}{r}0 \\
2,074 \\
0 \\
8,521 \\
0\end{array}$ & $\begin{array}{r}965 \\
8,751 \\
2,993 \\
56,258 \\
9,467\end{array}$ & $\begin{array}{l}136,988 \\
776,573 \\
325,687 \\
326,165 \\
398,697\end{array}$ \\
\hline 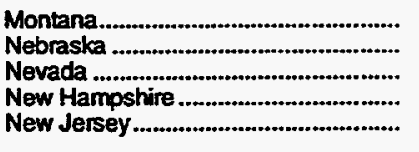 & $\begin{array}{r}71,493 \\
196,686 \\
44,140 \\
b \\
304,213\end{array}$ & $\begin{array}{r}6,183 \\
1,877 \\
0 \\
b \\
0\end{array}$ & $\begin{array}{r}607 \\
11,470 \\
0 \\
b \\
622\end{array}$ & $\begin{array}{r}78,283 \\
210,033 \\
44,140 \\
b \\
304,835\end{array}$ \\
\hline 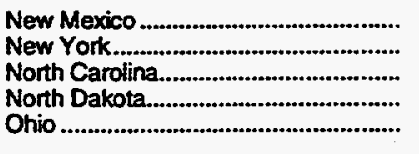 & $\begin{array}{r}178,102 \\
680,429 \\
130,836 \\
17,985 \\
1,016,942\end{array}$ & $\begin{array}{r}45,309 \\
561 \\
0 \\
14,691 \\
2,879\end{array}$ & $\begin{array}{r}28,494 \\
2,698 \\
5,815 \\
6 \\
12,142\end{array}$ & $\begin{array}{r}251,905 \\
683,688 \\
136,651 \\
32,682 \\
1,031,963\end{array}$ \\
\hline 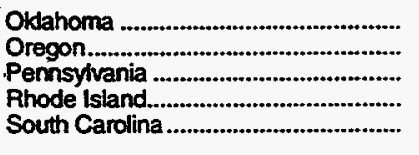 & $\begin{array}{r}428,781 \\
84,207 \\
738,775 \\
22,537 \\
137,973\end{array}$ & $\begin{array}{r}103,361 \\
0 \\
1,924 \\
0 \\
0\end{array}$ & $\begin{array}{r}14,049 \\
3,647 \\
25,242 \\
18 \\
2,853\end{array}$ & $\begin{array}{r}546,191 \\
87,854 \\
765,941 \\
22,555 \\
140,826\end{array}$ \\
\hline 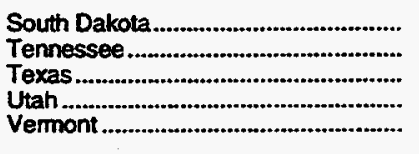 & $\begin{array}{r}33,811 \\
221,909 \\
3,049,172 \\
117,557 \\
b\end{array}$ & $\begin{array}{r}0 \\
986 \\
741,902 \\
2,113 \\
b\end{array}$ & $\begin{array}{r}15 \\
24,962 \\
86,302 \\
209 \\
b\end{array}$ & $\begin{array}{r}33,826 \\
247,857 \\
3,877,376 \\
119,879 \\
b\end{array}$ \\
\hline 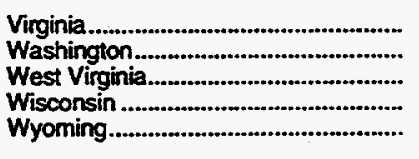 & $\begin{array}{r}120,584 \\
139,980 \\
169,841 \\
313,208 \\
75,801\end{array}$ & $\begin{array}{r}211 \\
0 \\
0 \\
0 \\
19,964\end{array}$ & $\begin{array}{r}7,953 \\
4,541 \\
0 \\
3,071 \\
4,306\end{array}$ & $\begin{array}{l}128,748 \\
144,521 \\
169,841 \\
316,279 \\
100,071\end{array}$ \\
\hline 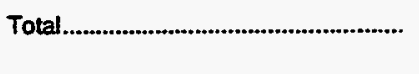 & $18,079,630$ & $\begin{array}{c}1,345,648 \\
.\end{array}$ & 630,962 & $20,056,240$ \\
\hline
\end{tabular}

See footnotes at end of table. 
Table 14. Consumption of Natural Gas by State, 1967-1992 (Continued) (Million Cubic Feet)

\begin{tabular}{|c|c|c|c|c|}
\hline State & Delivered to Consumers & Loase and Plant Fuel & Pipeline Fuel & Total Consumption \\
\hline & \multicolumn{4}{|c|}{1970} \\
\hline 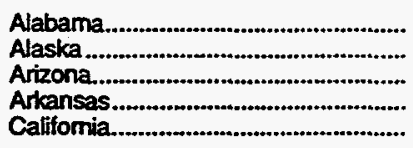 & $\begin{array}{r}278,414 \\
41,672 \\
168,994 \\
359,338 \\
2,017,393\end{array}$ & $\begin{array}{r}214 \\
4,748 \\
50 \\
9,184 \\
92,119\end{array}$ & $\begin{array}{l}19,869 \\
17,306 \\
23,952 \\
13,429 \\
16,954\end{array}$ & $\begin{array}{r}298,497 \\
63,726 \\
192,996 \\
381,951 \\
2,126,466\end{array}$ \\
\hline 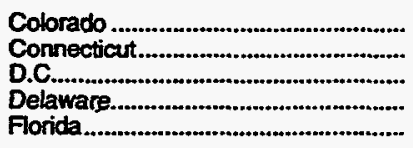 & $\begin{array}{r}277,739 \\
60,524 \\
a \\
26,421 \\
332,223\end{array}$ & $\begin{array}{r}2,726 \\
0 \\
a \\
0 \\
234\end{array}$ & $\begin{array}{r}1,863 \\
50 \\
-\quad a \\
0 \\
4,359\end{array}$ & $\begin{array}{r}282,328 \\
60,574 \\
a \\
26,421 \\
336,816\end{array}$ \\
\hline 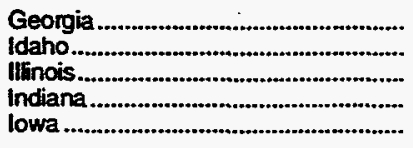 & $\begin{array}{r}325,650 \\
42,367 \\
1,145,379 \\
534,214 \\
330,363\end{array}$ & $\begin{array}{r}0 \\
0 \\
526 \\
0 \\
0\end{array}$ & $\begin{array}{r}6,876 \\
4,203 \\
27,973 \\
11,154 \\
18,299\end{array}$ & $\begin{array}{r}332,526 \\
46,570 \\
1,173,878 \\
545,368 \\
348,662\end{array}$ \\
\hline 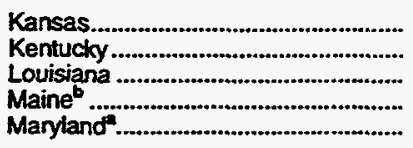 & $\begin{array}{r}481,483 \\
209,991 \\
1,482,275 \\
10,691 \\
179,784\end{array}$ & $\begin{array}{r}20,841 \\
2,317 \\
287,222 \\
0 \\
319\end{array}$ & $\begin{array}{r}73,370 \\
35,740 \\
71,343 \\
0 \\
2,032\end{array}$ & $\begin{array}{r}575,694 \\
248,048 \\
1,840,840 \\
10,691 \\
182,135\end{array}$ \\
\hline $\begin{array}{l}\text { Massachusetts..... } \\
\text { Michigan } \\
\text { Minnesota } \\
\text { Mississippi } \\
\text { Missouri }\end{array}$ & $\begin{array}{l}146,226 \\
795,317 \\
334,872 \\
293,154 \\
416,783\end{array}$ & $\begin{array}{r}0 \\
3,440 \\
0 \\
7,893 \\
0\end{array}$ & $\begin{array}{r}1,081 \\
10,367 \\
7,450 \\
59,335 \\
12,743\end{array}$ & $\begin{array}{l}147,307 \\
809,124 \\
342,322 \\
360,382 \\
429,526\end{array}$ \\
\hline $\begin{array}{l}\text { Montana } \\
\text { Nebraska } \\
\text { Nevada } \\
\text { New Hampshire } \\
\text { New Jersey }\end{array}$ & $\begin{array}{r}81,992 \\
207,550 \\
52,558 \\
\text { b } \\
321,910\end{array}$ & $\begin{array}{r}5,091 \\
1,650 \\
0 \\
b \\
0\end{array}$ & $\begin{array}{r}708 \\
13,135 \\
0 \\
b \\
943\end{array}$ & $\begin{array}{r}87,791 \\
222,335 \\
52,558 \\
b \\
322,853\end{array}$ \\
\hline $\begin{array}{l}\text { New Mexico } \\
\text { New York } \\
\text { North Carolina. } \\
\text { North Dakota. } \\
\text { Ohio }\end{array}$ & $\begin{array}{r}191,818 \\
707,219 \\
145,076 \\
18,645 \\
1,037,801\end{array}$ & $\begin{array}{r}47,998 \\
485 \\
0 \\
14,067 \\
3,140\end{array}$ & $\begin{array}{r}30,287 \\
3.181 \\
6,151 \\
5 \\
11,992\end{array}$ & $\begin{array}{r}270,103 \\
710,885 \\
151,227 \\
32,717 \\
1,052,933\end{array}$ \\
\hline 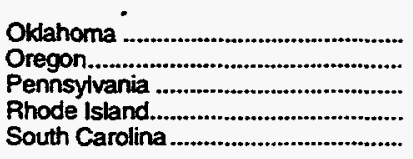 & $\begin{array}{r}475,974 \\
89,776 \\
743,471 \\
25,066 \\
156,559\end{array}$ & $\begin{array}{r}98,417 \\
0 \\
2,251 \\
0 \\
0\end{array}$ & $\begin{array}{r}22,778 \\
5,508 \\
26,666 \\
27 \\
3,271\end{array}$ & $\begin{array}{r}597,169 \\
95,284 \\
772,388 \\
25,093 \\
159,830\end{array}$ \\
\hline $\begin{array}{l}\text { South Dakota } \\
\text { Tennessee } \\
\text { Texas } \\
\text { Utah } \\
\text { Vermont }\end{array}$ & $\begin{array}{r}36,309 \\
228,424 \\
3,227,628 \\
120,814 \\
\text { b }\end{array}$ & $\begin{array}{r}0 \\
1,265 \\
769,500 \\
633 \\
\mathrm{~b}\end{array}$ & $\begin{array}{r}10 \\
26,459 \\
96,229 \\
490 \\
b\end{array}$ & $\begin{array}{r}36,319 \\
256,148 \\
4,093,357 \\
121,937 \\
\mathrm{~b}\end{array}$ \\
\hline 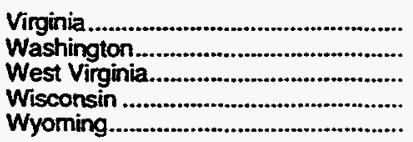 & $\begin{array}{r}128,492 \\
143,566 \\
170,830 \\
331,255 \\
84,462\end{array}$ & $\begin{array}{r}252 \\
0 \\
2,551 \\
0 \\
19,525\end{array}$ & $\begin{array}{l}7,779 \\
6,426 \\
7,897 \\
6,567 \\
5,909\end{array}$ & $\begin{array}{l}136,523 \\
149,992 \\
181,278 \\
337,822 \\
109,996\end{array}$ \\
\hline 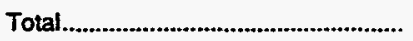 & $19,018,462$ & $1,398,758$ & 722,166 & $21,139,386$ \\
\hline
\end{tabular}

See footnotes at end of table. 
Table 14. Consumption of Natural Gas by State, 1967-1992 (Continued) (Million Cubic Feet)

\begin{tabular}{|c|c|c|c|c|}
\hline State & Delivered to Consumers & Lease and Plant Fuel & Pipoline Fuel & Total Consumption \\
\hline & \multicolumn{4}{|c|}{1971} \\
\hline 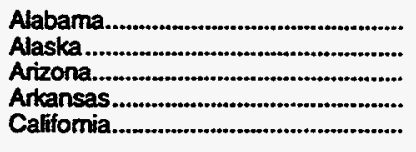 & $\begin{array}{r}264,881 \\
42,037 \\
187,140 \\
315,495 \\
2,055,347\end{array}$ & $\begin{array}{r}476 \\
8,459 \\
50 \\
6,433 \\
75,241\end{array}$ & $\begin{array}{l}20,616 \\
17,210 \\
26,123 \\
11,716 \\
18,676\end{array}$ & $\begin{array}{r}285,973 \\
67,706 \\
213,313 \\
333,644 \\
2,149,264\end{array}$ \\
\hline 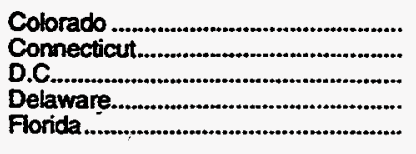 & $\begin{array}{r}284,271 \\
61,390 \\
a \\
26,452 \\
332,194\end{array}$ & $\begin{array}{r}3,231 \\
0 \\
a \\
0 \\
294\end{array}$ & $\begin{array}{r}1,867 \\
44 \\
a \\
0 \\
4,233\end{array}$ & $\begin{array}{r}289,369 \\
61,434 \\
\mathrm{a} \\
26,452 \\
336,721\end{array}$ \\
\hline 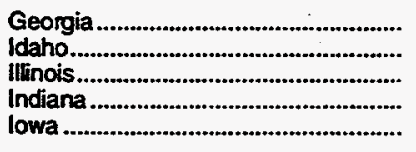 & $\begin{array}{r}335,879 \\
44,980 \\
1,205,618 \\
554,630 \\
324,806\end{array}$ & $\begin{array}{r}0 \\
0 \\
407 \\
0 \\
0\end{array}$ & $\begin{array}{r}6,700 \\
5,116 \\
23,252 \\
12,366 \\
19,833\end{array}$ & $\begin{array}{r}342,579 \\
50,096 \\
1,229,277 \\
566,996 \\
344,639\end{array}$ \\
\hline 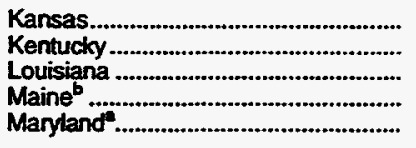 & $\begin{array}{r}504,318 \\
206,943 \\
1,515,209 \\
12,088 \\
185,809\end{array}$ & $\begin{array}{r}27,972 \\
2,212 \\
292,589 \\
0 \\
451\end{array}$ & $\begin{array}{r}74,699 \\
35,205 \\
76,126 \\
0 \\
2,111\end{array}$ & $\begin{array}{r}606,989 \\
244,360 \\
1,883,924 \\
12,088 \\
188,371\end{array}$ \\
\hline 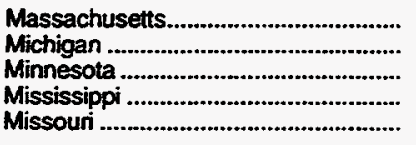 & $\begin{array}{l}155,796 \\
832,951 \\
343,573 \\
313,033 \\
419,121\end{array}$ & $\begin{array}{r}0 \\
2,145 \\
0 \\
5,840 \\
0\end{array}$ & $\begin{array}{r}655 \\
15,466 \\
7,869 \\
59,448 \\
9,984\end{array}$ & $\begin{array}{l}156,451 \\
850,562 \\
351,442 \\
378,321 \\
429,105\end{array}$ \\
\hline 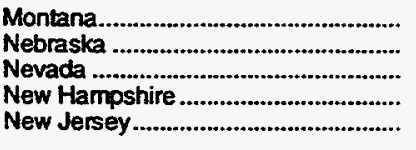 & $\begin{array}{r}81,363 \\
209,164 \\
66,511 \\
b \\
325,897\end{array}$ & $\begin{array}{r}6,148 \\
1,275 \\
0 \\
b \\
0\end{array}$ & $\begin{array}{r}760 \\
13,235 \\
0 \\
b \\
871\end{array}$ & $\begin{array}{r}88,271 \\
223,674 \\
66,511 \\
b \\
326,768\end{array}$ \\
\hline 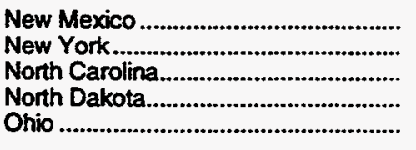 & $\begin{array}{r}194,159 \\
712,673 \\
154,332 \\
19,577 \\
1,070,151\end{array}$ & $\begin{array}{r}46,114 \\
460 \\
0 \\
13,990 \\
4,302\end{array}$ & $\begin{array}{r}29,095 \\
3,417 \\
6,235 \\
10 \\
12,673\end{array}$ & $\begin{array}{r}269,368 \\
716,550 \\
160,567 \\
33,577 \\
1,087,126\end{array}$ \\
\hline 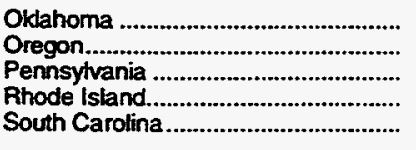 & $\begin{array}{r}484,585 \\
94,084 \\
771,795 \\
25,638 \\
153,068\end{array}$ & $\begin{array}{r}101,126 \\
0 \\
2,419 \\
0 \\
0\end{array}$ & $\begin{array}{r}25,871 \\
6,813 \\
27,899 \\
24 \\
3,195\end{array}$ & $\begin{array}{r}611,582 \\
100,897 \\
802,113 \\
25,662 \\
156,263\end{array}$ \\
\hline 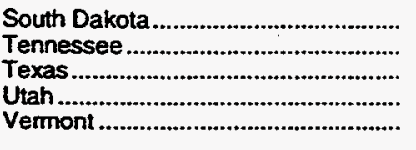 & $\begin{array}{r}31,827 \\
236,838 \\
3,480,864 \\
118,751 \\
\text { b }\end{array}$ & $\begin{array}{r}0 \\
1,524 \\
784,773 \\
2,115 \\
b\end{array}$ & $\begin{array}{r}5 \\
26,649 \\
99,091 \\
537 \\
b\end{array}$ & $\begin{array}{r}31,832 \\
265,011 \\
4,364,728 \\
121,403 \\
b\end{array}$ \\
\hline 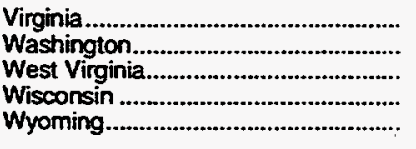 & $\begin{array}{r}136,648 \\
150,520 \\
165,273 \\
342,571 \\
86,962\end{array}$ & $\begin{array}{r}213 \\
0 \\
3,043 \\
0 \\
20,348\end{array}$ & $\begin{array}{r}7,153 \\
6,143 \\
10,064 \\
5,561 \\
7,976\end{array}$ & $\begin{array}{l}144,014 \\
156,663 \\
178,380 \\
348,132 \\
115,286\end{array}$ \\
\hline 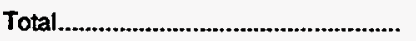 & $19,637,212$ & $1,413,650$ & 742,592 & $21,793,454$ \\
\hline
\end{tabular}

See tootnotes at end of table. 
Table 14. Consumption of Natural Gas by State, 1967-1992 (Continued) (Million Cubic Feet)

\begin{tabular}{|c|c|c|c|c|c|}
\hline State & Delivered to Consumers & Lease and Plant Fuel & Pipeline Fuel & Total Consumption & \\
\hline & \multicolumn{5}{|c|}{1972} \\
\hline 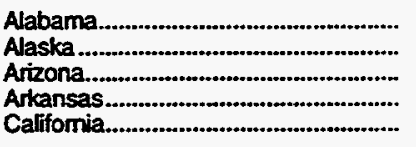 & $\begin{array}{r}258,331 \\
49,818 \\
201,968 \\
298,484 \\
2,098,094\end{array}$ & $\begin{array}{r}1,070 \\
16,056 \\
44 \\
4,740 \\
68,738\end{array}$ & $\begin{array}{r}19,066 \\
8,784 \\
25,897 \\
13,151 \\
18,711\end{array}$ & $\begin{array}{r}278,467 \\
74,658 \\
227,909 \\
316,375 \\
2,185,543\end{array}$ & \\
\hline 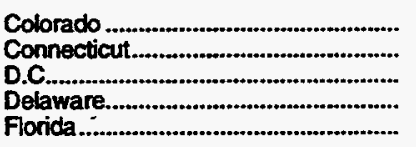 & $\begin{array}{r}302,033 \\
63,968 \\
a \\
24,088 \\
293,174\end{array}$ & $\begin{array}{r}4,676 \\
0 \\
a \\
0 \\
1,782\end{array}$ & $\begin{array}{r}2,994 \\
40 \\
2 \\
0 \\
4,021\end{array}$ & $\begin{array}{r}309,703 \\
64,008 \\
a \\
24,088 \\
298,977\end{array}$ & \\
\hline 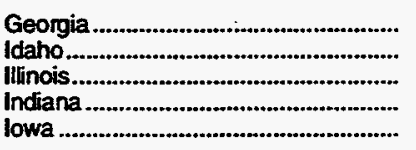 & $\begin{array}{r}323,186 \\
51,908 \\
1,183,746 \\
563,723 \\
324,247\end{array}$ & $\begin{array}{r}0 \\
0 \\
308 \\
0 \\
0\end{array}$ & $\begin{array}{r}7,957 \\
4,722 \\
23,235 \\
13,225 \\
20,269\end{array}$ & $\begin{array}{r}331,143 \\
56,630 \\
1,207,289 \\
576,948 \\
344,516\end{array}$ & \\
\hline $\begin{array}{l}\text { Kansas } \\
\text { Kentucky . } \\
\text { Louisiana } \\
\text { Maine } \\
\text { Manyland }\end{array}$ & $\begin{array}{r}519,835 \\
216,749 \\
1,548,083 \\
13,267 \\
201,254\end{array}$ & $\begin{array}{r}28,183 \\
1,509 \\
312,145 \\
0 \\
67\end{array}$ & $\begin{array}{r}80,091 \\
36,950 \\
79,534 \\
0 \\
3,601\end{array}$ & $\begin{array}{r}628,109 \\
255,208 \\
1,939,762 \\
13,267 \\
204,922\end{array}$ & \\
\hline 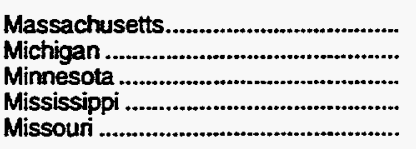 & $\begin{array}{l}159,623 \\
846,508 \\
343,940 \\
310,950 \\
415,596\end{array}$ & $\begin{array}{r}0 \\
2,143 \\
0 \\
9,153 \\
0\end{array}$ & $\begin{array}{r}657 \\
16,119 \\
7,468 \\
57,883 \\
9,619\end{array}$ & $\begin{array}{l}160,280 \\
864,770 \\
351,408 \\
377,986 \\
425,215\end{array}$ & \\
\hline 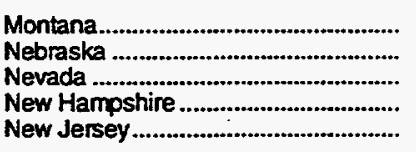 & $\begin{array}{r}77,348 \\
210,624 \\
69,522 \\
\text { b } \\
320,559\end{array}$ & $\begin{array}{r}5.924 \\
814 \\
0 \\
b \\
0\end{array}$ & $\begin{array}{r}1,050 \\
13,124 \\
0 \\
b \\
729\end{array}$ & $\begin{array}{r}84,322 \\
224,562 \\
69,522 \\
b \\
321,288\end{array}$ & \\
\hline $\begin{array}{l}\text { New Mexico } \\
\text { New York } \\
\text { North Carolina } \\
\text { North Dakota } \\
\text { Ohio }\end{array}$ & $\begin{array}{r}202,884 \\
689,329 \\
157,826 \\
23,437 \\
1,131,681\end{array}$ & $\begin{array}{r}48,803 \\
0 \\
0 \\
12,773 \\
3,397\end{array}$ & $\begin{array}{r}36,306 \\
3,401 \\
6,071 \\
263 \\
12,726\end{array}$ & $\begin{array}{r}287,993 \\
692,730 \\
163,897 \\
36,473 \\
1,147,804\end{array}$ & \\
\hline 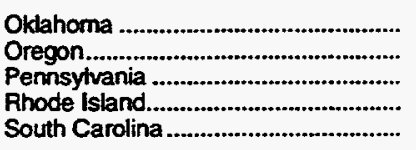 & $\begin{array}{r}506,377 \\
100,436 \\
798,559 \\
22,478 \\
141,194\end{array}$ & $\begin{array}{r}98,784 \\
0 \\
2,847 \\
0 \\
0\end{array}$ & $\begin{array}{r}24,596 \\
9,924 \\
27,555 \\
16 \\
3,006\end{array}$ & $\begin{array}{r}629,757 \\
110,360 \\
828,961 \\
22,494 \\
144,120\end{array}$ & \\
\hline $\begin{array}{l}\text { South Dakota } \\
\text { Tennessee } \\
\text { Texas } \\
\text { Utah } \\
\text { Vermont }\end{array}$ & $\begin{array}{r}34,067 \\
250,741 \\
3,506,146 \\
121,264 \\
\text { b }\end{array}$ & $\begin{array}{r}0 \\
1.150 \\
802,112 \\
1,978 \\
b\end{array}$ & $\begin{array}{r}10 \\
25,384 \\
104,378 \\
851 \\
\text { b }\end{array}$ & $\begin{array}{r}34,077 \\
277,275 \\
4,412,636 \\
124,093 \\
b\end{array}$ & \\
\hline $\begin{array}{l}\text { Virginia } \\
\text { Washington } \\
\text { West Virginia } \\
\text { Wisconsin } \\
\text { Wyoming }\end{array}$ & $\begin{array}{r}147,227 \\
163,054 \\
180,541 \\
314,592 \\
97,354\end{array}$ & $\begin{array}{r}157 \\
0 \\
3,808 \\
0 \\
22,402\end{array}$ & $\begin{array}{r}8,274 \\
7,394 \\
14,792 \\
6,234 \\
6,078\end{array}$ & $\begin{array}{l}155,658 \\
170,448 \\
199,141 \\
320,826 \\
125,834\end{array}$ & \\
\hline 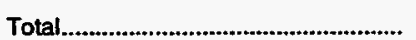 & $19,879,733$ & $1,455,563$ & 766,156 & $22,101,452$ & \\
\hline
\end{tabular}

See tootnotes at end of table. 
Table 14. Consumption of Natural Gas by State, 1967-1992 (Continued) (Million Cubic Feet)

\begin{tabular}{|c|c|c|c|c|}
\hline State & Delivered to Consumers & Lease and Plant Fuel & Pipeline Fuel & Total Consumption \\
\hline & \multicolumn{4}{|c|}{1973} \\
\hline 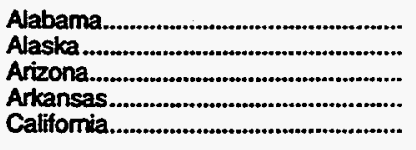 & $\begin{array}{r}250,944 \\
47,686 \\
190,300 \\
309,380 \\
1,953,313\end{array}$ & $\begin{array}{r}1,329 \\
15,217 \\
39 \\
3,000 \\
72,574\end{array}$ & $\begin{array}{r}19,795 \\
170 \\
23,984 \\
15,423 \\
19,740\end{array}$ & $\begin{array}{r}272,068 \\
63,073 \\
214,323 \\
327,803 \\
2,045,627\end{array}$ \\
\hline 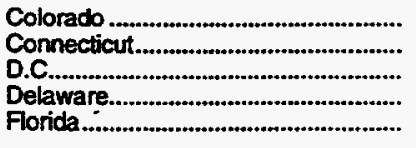 & $\begin{array}{r}314,225 \\
62,584 \\
a \\
22,949 \\
304,587\end{array}$ & $\begin{array}{r}7,202 \\
0 \\
a \\
0 \\
3,027\end{array}$ & $\begin{array}{r}2,580 \\
25 \\
-\quad 2 \\
0 \\
3,884\end{array}$ & $\begin{array}{r}324,007 \\
62,609 \\
a \\
22,949 \\
311,498\end{array}$ \\
\hline 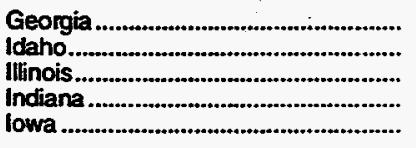 & $\begin{array}{r}341,971 \\
51,396 \\
1,128,649 \\
529,604 \\
348,156\end{array}$ & $\begin{array}{r}0 \\
0 \\
246 \\
0 \\
0\end{array}$ & $\begin{array}{r}6,118 \\
4,649 \\
21,371 \\
12,696 \\
16,484\end{array}$ & $\begin{array}{r}348,089 \\
56,045 \\
1,150,266 \\
542,300 \\
364,640\end{array}$ \\
\hline 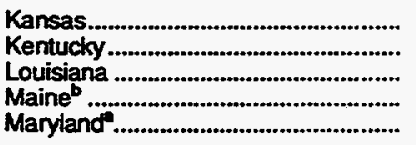 & $\begin{array}{r}498,865 \\
209,556 \\
1,592,829 \\
13,881 \\
199,153\end{array}$ & $\begin{array}{r}32,663 \\
1,238 \\
336,832 \\
0 \\
474\end{array}$ & $\begin{array}{r}72,932 \\
34,678 \\
80,198 \\
0 \\
2,334\end{array}$ & $\begin{array}{r}604,460 \\
245,472 \\
2,009,859 \\
13,881 \\
201,961\end{array}$ \\
\hline 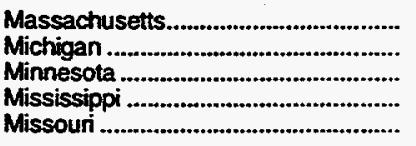 & $\begin{array}{l}154,967 \\
905,777 \\
355,372 \\
250,464 \\
417,638\end{array}$ & $\begin{array}{r}0 \\
2,551 \\
0 \\
6,152 \\
0\end{array}$ & $\begin{array}{r}580 \\
12,023 \\
5,439 \\
57,376 \\
9,169\end{array}$ & $\begin{array}{l}155,547 \\
920,351 \\
360,811 \\
313,992 \\
426,807\end{array}$ \\
\hline 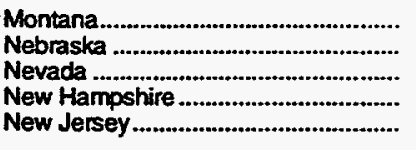 & $\begin{array}{r}84,286 \\
214,226 \\
73,072 \\
300,886\end{array}$ & $\begin{array}{r}4,281 \\
1,809 \\
0 \\
b \\
0\end{array}$ & $\begin{array}{r}1,663 \\
13,597 \\
0 \\
b \\
680\end{array}$ & $\begin{array}{r}90,230 \\
229,632 \\
73,072 \\
\text { b } \\
301,566\end{array}$ \\
\hline 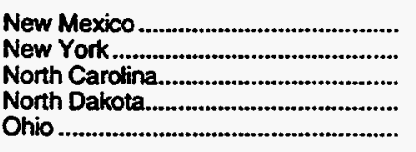 & $\begin{array}{r}174,742 \\
679,079 \\
154,879 \\
19,952 \\
1,087,810\end{array}$ & $\begin{array}{r}52,553 \\
442 \\
0 \\
12,462 \\
3,548\end{array}$ & $\begin{array}{r}29,516 \\
3,026 \\
5,992 \\
14 \\
12,798\end{array}$ & $\begin{array}{r}256,811 \\
682,547 \\
160,871 \\
32,428 \\
1,104,156\end{array}$ \\
\hline 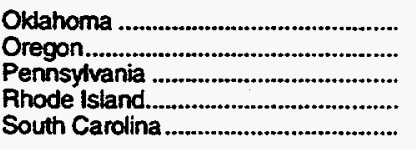 & $\begin{array}{r}505,444 \\
99,245 \\
758,187 \\
20,540 \\
149,623\end{array}$ & $\begin{array}{r}80,233 \\
0 \\
2,725 \\
0 \\
0\end{array}$ & $\begin{array}{r}26,061 \\
8,716 \\
22,385 \\
19 \\
3,524\end{array}$ & $\begin{array}{r}611,738 \\
107,961 \\
783,297 \\
20,559 \\
153,147\end{array}$ \\
\hline 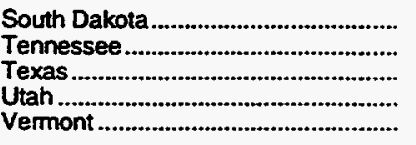 & $\begin{array}{r}31,209 \\
263,901 \\
3,688,652 \\
120,060 \\
b\end{array}$ & $\begin{array}{r}0 \\
1,263 \\
828,139 \\
2,435 \\
b\end{array}$ & $\begin{array}{r}12 \\
28,456 \\
104,587 \\
611 \\
b\end{array}$ & $\begin{array}{r}31,221 \\
293,620 \\
4,621,378 \\
123,106 \\
b\end{array}$ \\
\hline 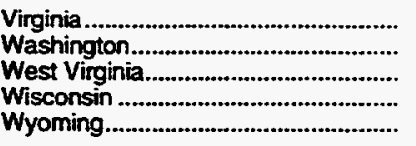 & $\begin{array}{r}146,850 \\
190,498 \\
166,624 \\
362,541 \\
78,719\end{array}$ & $\begin{array}{r}170 \\
0 \\
2,160 \\
0 \\
21,151\end{array}$ & $\begin{array}{r}5,828 \\
7,363 \\
17,532 \\
5,420 \\
8,729\end{array}$ & $\begin{array}{l}152,848 \\
197,861 \\
186,316 \\
367,961 \\
108,599\end{array}$ \\
\hline 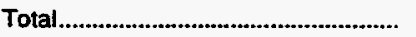 & $19,825,271$ & $1,495,915$ & 728,177 & $22,049,363$ \\
\hline
\end{tabular}

See footnotes at end of table. 
Table 14. Consumption of Natural Gas by State, 1967-1992 (Continued) (Million Cubic Feet)

\begin{tabular}{|c|c|c|c|c|}
\hline State & Delivered to Consumers & Lease and Plant Furl & Pipeline Fual & Total Consumption \\
\hline & \multicolumn{4}{|c|}{1974} \\
\hline 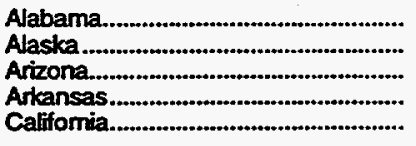 & $\begin{array}{r}254,133 \\
48,362 \\
170,221 \\
272,590 \\
1,743,734\end{array}$ & $\begin{array}{r}1,301 \\
14,402 \\
0 \\
4,246 \\
71,686\end{array}$ & $\begin{array}{r}19,327 \\
110 \\
22,225 \\
13,557 \\
18,993\end{array}$ & $\begin{array}{r}274,761 \\
62,874 \\
192,446 \\
290,393 \\
1,834,413\end{array}$ \\
\hline 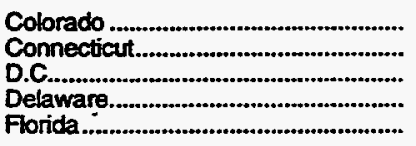 & $\begin{array}{r}304,770 \\
66,299 \\
a \\
20,365 \\
283,770\end{array}$ & $\begin{array}{r}5,822 \\
0 \\
a \\
0 \\
2,700\end{array}$ & $\begin{array}{r}2,464 \\
44 \\
2 \\
0 \\
3,081\end{array}$ & $\begin{array}{r}313,056 \\
66,343 \\
\text { a } \\
20,365 \\
289,551\end{array}$ \\
\hline $\begin{array}{l}\text { Georgia } \\
\text { Idaho } \\
\text { Illinois... }\end{array}$ & $\begin{array}{r}325,489 \\
49,084 \\
1,130,225 \\
519,352 \\
350,413\end{array}$ & $\begin{array}{r}0 \\
0 \\
102 \\
0 \\
0\end{array}$ & $\begin{array}{r}4,850 \\
3,973 \\
19,067 \\
12,520 \\
17,182\end{array}$ & $\begin{array}{r}330,339 \\
53,057 \\
1,149,394 \\
531,872 \\
367,595\end{array}$ \\
\hline 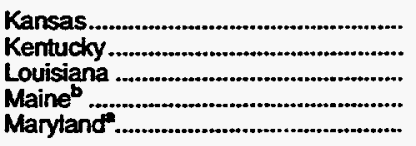 & $\begin{array}{r}477,071 \\
197,421 \\
1,585,030 \\
14,697 \\
197,176\end{array}$ & $\begin{array}{r}35,350 \\
1,206 \\
347,098 \\
0 \\
392\end{array}$ & $\begin{array}{r}74,592 \\
29,376 \\
76,236 \\
0 \\
1,763\end{array}$ & $\begin{array}{r}587,013 \\
228,003 \\
2,008,364 \\
14,697 \\
199,331\end{array}$ \\
\hline $\begin{array}{l}\text { Massachusetts } \\
\text { Michigan } \\
\text { Minnesota } \\
\text { Mississippi } \\
\text { Missouri }\end{array}$ & $\begin{array}{l}154,594 \\
921,898 \\
348,038 \\
220,534 \\
400,944\end{array}$ & $\begin{array}{r}0 \\
3,194 \\
0 \\
5,357 \\
0\end{array}$ & $\begin{array}{r}674 \\
10,951 \\
3,606 \\
50,308 \\
8,940\end{array}$ & $\begin{array}{l}155,268 \\
936,043 \\
351,644 \\
276,199 \\
409,884\end{array}$ \\
\hline 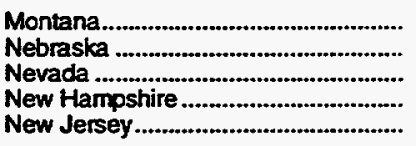 & $\begin{array}{r}74,505 \\
210,083 \\
63,438 \\
\text { b } \\
274,505\end{array}$ & $\begin{array}{r}3.683 \\
1,194 \\
0 \\
b \\
0\end{array}$ & $\begin{array}{r}1,721 \\
11,530 \\
0 \\
b \\
545\end{array}$ & $\begin{array}{r}79,909 \\
222,807 \\
63,438 \\
\text { b } \\
275,050\end{array}$ \\
\hline $\begin{array}{l}\text { New Mexico } \\
\text { New York } \\
\text { North Carolina. } \\
\text { North Dakota. } \\
\text { Ohio }\end{array}$ & $\begin{array}{r}181,638 \\
624,137 \\
135,721 \\
23,944 \\
1,073,671\end{array}$ & $\begin{array}{r}43,452 \\
340 \\
0 \\
11,483 \\
2,957\end{array}$ & $\begin{array}{r}32,346 \\
3,016 \\
4,496 \\
32 \\
10,023\end{array}$ & $\begin{array}{r}257,436 \\
627,493 \\
140,217 \\
35,459 \\
1,086,651\end{array}$ \\
\hline 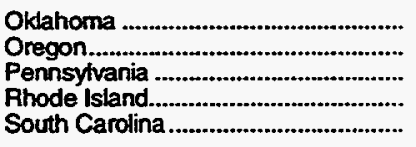 & $\begin{array}{r}555,166 \\
90,750 \\
692,980 \\
23,759 \\
129,827\end{array}$ & $\begin{array}{r}80,780 \\
0 \\
1,649 \\
0 \\
0\end{array}$ & $\begin{array}{r}24,064 \\
7,301 \\
20,919 \\
22 \\
2,164\end{array}$ & $\begin{array}{r}660,010 \\
98,051 \\
715,548 \\
23,781 \\
131,991\end{array}$ \\
\hline $\begin{array}{l}\text { South Dakota } \\
\text { Tennessee } \\
\text { Texas } \\
\text { Utah } \\
\text { Vermont }\end{array}$ & $\begin{array}{r}32,060 \\
235,100 \\
3,552,495 \\
116,232 \\
\text { b }\end{array}$ & $\begin{array}{r}0 \\
1,087 \\
817,194 \\
4,193 \\
b\end{array}$ & $\begin{array}{r}16 \\
23,984 \\
93,799 \\
590 \\
b\end{array}$ & $\begin{array}{r}32,076 \\
260,171 \\
4,463,488 \\
121,015 \\
b\end{array}$ \\
\hline 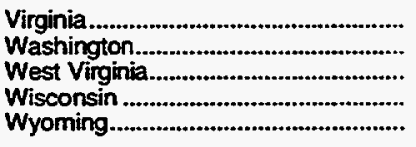 & $\begin{array}{r}139,121 \\
177,210 \\
164,777 \\
375,721 \\
73,905\end{array}$ & $\begin{array}{r}307 \\
0 \\
1,909 \\
0 \\
14,302\end{array}$ & $\begin{array}{r}4,222 \\
5,513 \\
15,684 \\
5,427 \\
7,539\end{array}$ & $\begin{array}{r}143,650 \\
182,723 \\
182,370 \\
381,148 \\
95,746\end{array}$ \\
\hline Total & $19,076,955$ & $1,477,386$ & 668,792 & $21,223,133$ \\
\hline
\end{tabular}

See footholes at end of table. 
Table 14. Consumption of Natural Gas by State, 1967-1992 (Continued) (Million Cubic Feet)

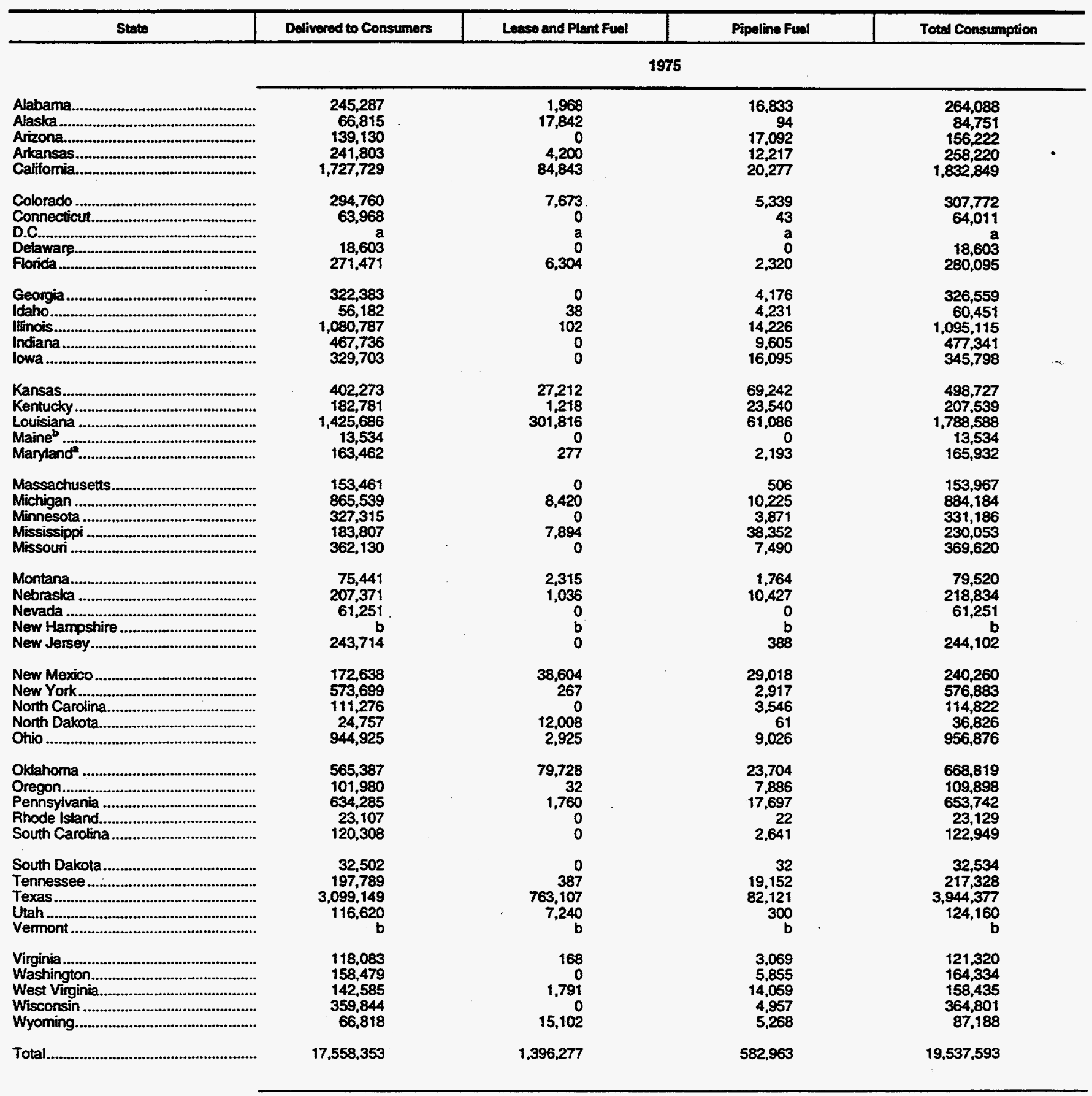

See footnotes at end of table. 
Table 14. Consumption of Natural Gas by State, 1967-1992 (Continued) (Million Cubic Feet)

\begin{tabular}{|c|c|c|c|c|}
\hline State & Delivered to Consumers & Lease and Plant Fund & Pipeline Fuel & Total Consumption \\
\hline & \multicolumn{4}{|c|}{1976} \\
\hline 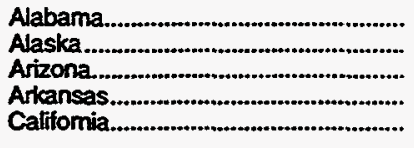 & $\begin{array}{r}215,071 \\
73,999 \\
155,904 \\
235,440 \\
1,661,751\end{array}$ & $\begin{array}{r}2,714 \\
15,972 \\
0 \\
4,049 \\
78,967\end{array}$ & $\begin{array}{r}8,194 \\
150 \\
15,371 \\
9,452 \\
15,893\end{array}$ & $\begin{array}{r}225,979 \\
90,121 \\
171,275 \\
248,941 \\
1,756,611\end{array}$ \\
\hline 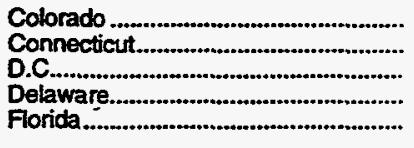 & $\begin{array}{r}287,904 \\
65,828 \\
a \\
19,182 \\
280,844\end{array}$ & $\begin{array}{r}7,739 \\
0 \\
a \\
0 \\
6,306\end{array}$ & $\begin{array}{r}6,641 \\
27 \\
a \\
0 \\
1,867\end{array}$ & $\begin{array}{r}302,284 \\
65,855 \\
a \\
19,182 \\
289,017\end{array}$ \\
\hline 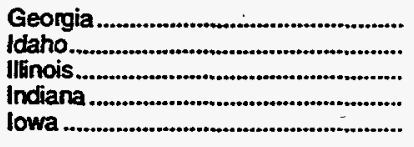 & $\begin{array}{r}257,866 \\
42,527 \\
1,158,567 \\
420,175 \\
302,557\end{array}$ & $\begin{array}{r}0 \\
5 \\
110 \\
0 \\
0\end{array}$ & $\begin{array}{r}3,454 \\
4,624 \\
16,558 \\
5,046 \\
8,868\end{array}$ & $\begin{array}{r}261,320 \\
47,156 \\
1,175,235 \\
425,221 \\
311,425\end{array}$ \\
\hline $\begin{array}{l}\text { Kansas } \\
\text { Kentucky . } \\
\text { Louisiana } \\
\text { Maine } \\
\text { Manyand }\end{array}$ & $\begin{array}{r}421,122 \\
224,329 \\
1,406,467 \\
13,545 \\
173,590\end{array}$ & $\begin{array}{r}31,044 \\
1,040 \\
556,772 \\
0 \\
415\end{array}$ & $\begin{array}{r}63,031 \\
20,598 \\
80,466 \\
0 \\
2,267\end{array}$ & $\begin{array}{r}515,197 \\
245,967 \\
2,043,705 \\
13,545 \\
176,272\end{array}$ \\
\hline $\begin{array}{l}\text { Massachusetts.... } \\
\text { Michigan } \\
\text { Minnesota } \\
\text { Mississippi } \\
\text { Missour }\end{array}$ & $\begin{array}{l}155,619 \\
868,592 \\
316,243 \\
163,763 \\
375,005\end{array}$ & $\begin{array}{r}0 \\
7,647 \\
0 \\
4,836 \\
0\end{array}$ & $\begin{array}{r}628 \\
11,796 \\
3,913 \\
30,523 \\
5,253\end{array}$ & $\begin{array}{l}156,247 \\
888,035 \\
320,156 \\
199,122 \\
380,258\end{array}$ \\
\hline $\begin{array}{l}\text { Montana } \\
\text { Nebraska } \\
\text { Nevada } \\
\text { New Hampshire } \\
\text { New Jersey }\end{array}$ & $\begin{array}{r}70,152 \\
187,520 \\
66,797 \\
\text { b } \\
321,033\end{array}$ & $\begin{array}{r}2,754 \\
708 \\
0 \\
b \\
0\end{array}$ & $\begin{array}{r}1,465 \\
10,406 \\
0 \\
6 \\
502\end{array}$ & $\begin{array}{r}74,371 \\
198,634 \\
66,797 \\
\text { b } \\
321,535\end{array}$ \\
\hline 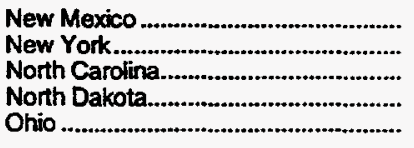 & $\begin{array}{r}201,915 \\
592,679 \\
98,391 \\
25,100 \\
995,460\end{array}$ & $\begin{array}{r}49,160 \\
273 \\
0 \\
15,998 \\
2,742\end{array}$ & $\begin{array}{r}27,901 \\
2,981 \\
2,784 \\
79 \\
7,725\end{array}$ & $\begin{array}{r}278,976 \\
595,933 \\
101,175 \\
41,177 \\
1,005,927\end{array}$ \\
\hline 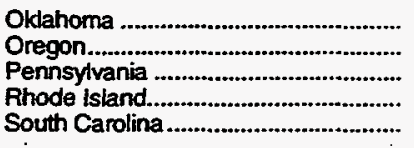 & $\begin{array}{r}648,957 \\
83,654 \\
688,901 \\
20,685 \\
145,587\end{array}$ & $\begin{array}{r}84,025 \\
30 \\
3,043 \\
0 \\
0\end{array}$ & $\begin{array}{r}27.128 \\
8,816 \\
21,574 \\
12 \\
3,402\end{array}$ & $\begin{array}{r}760,110 \\
92,500 \\
713,518 \\
20,697 \\
148,989\end{array}$ \\
\hline $\begin{array}{l}\text { South Dakota } \\
\text { Tennessee } \\
\text { Texas } \\
\text { Utah } \\
\text { Vermont }\end{array}$ & $\begin{array}{r}39,176 \\
196,695 \\
3,173,401 \\
136,649 \\
\text { b }\end{array}$ & $\begin{array}{r}0 \\
537 \\
729,946 \\
9,150 \\
b\end{array}$ & $\begin{array}{r}31 \\
15,094 \\
71,960 \\
406 \\
\mathrm{~b}\end{array}$ & $\begin{array}{r}39,207 \\
212,326 \\
3,975,307 \\
146,205 \\
\text { b }\end{array}$ \\
\hline 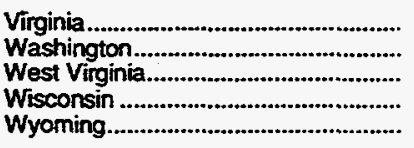 & $\begin{array}{r}120,647 \\
142,806 \\
135,378 \\
312,845 \\
63,500\end{array}$ & $\begin{array}{r}157 \\
0 \\
1,490 \\
0 \\
16,726\end{array}$ & $\begin{array}{r}2,705 \\
5,975 \\
13,855 \\
2,309 \\
6,593\end{array}$ & $\begin{array}{r}123,509 \\
148,781 \\
150,723 \\
315,154 \\
86,819\end{array}$ \\
\hline Total & $17,763,818$ & $1,634,355$ & 548,323 & $19,946,496$ \\
\hline
\end{tabular}

See footnotes at end of table. 
Table 14. Consumption of Natural Gas by State, 1967-1992 (Continued) (Million Cubic Feet)

\begin{tabular}{|c|c|c|c|c|}
\hline State & Delivered to Consumers & Lease and Plant Fuet & Pipeline Fuel & Total Consumption \\
\hline & \multicolumn{4}{|c|}{1977} \\
\hline 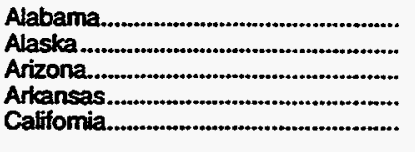 & $\begin{array}{r}225,603 \\
98,682 \\
152,181 \\
216,484 \\
1,677,718\end{array}$ & $\begin{array}{r}5,444 \\
17,336 \\
0 \\
4,032 \\
79,425\end{array}$ & $\begin{array}{r}10,190 \\
260 \\
14,911 \\
9,042 \\
14,898\end{array}$ & $\begin{array}{r}241,237 \\
116,278 \\
167,092 \\
229,558 \\
1,772,041\end{array}$ \\
\hline 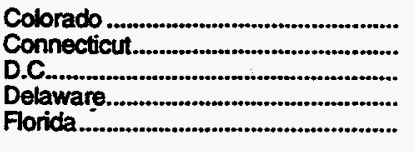 & $\begin{array}{r}266,285 \\
64,054 \\
a \\
15,787 \\
296,573\end{array}$ & $\begin{array}{r}9,124 \\
0 \\
a \\
0 \\
4,890\end{array}$ & $\begin{array}{r}6,806 \\
14 \\
a \\
0 \\
881\end{array}$ & $\begin{array}{r}282,215 \\
64,068 \\
a \\
15,787 \\
302,344\end{array}$ \\
\hline 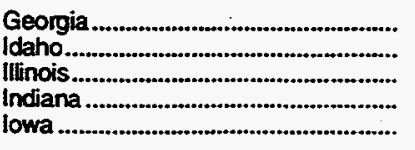 & $\begin{array}{r}261,733 \\
40,872 \\
1,147,816 \\
393,505 \\
273,271\end{array}$ & $\begin{array}{r}0 \\
6 \\
112 \\
0 \\
0\end{array}$ & $\begin{array}{r}2,932 \\
4,659 \\
19,171 \\
4,763 \\
6,975\end{array}$ & $\begin{array}{r}264,665 \\
45,537 \\
1,167,099 \\
398,268 \\
280,246\end{array}$ \\
\hline 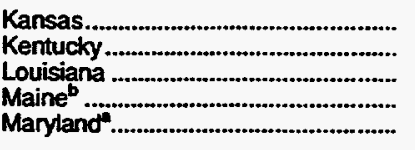 & $\begin{array}{r}421,450 \\
199,285 \\
1,516,475 \\
13,609 \\
156,380\end{array}$ & $\begin{array}{r}29.142 \\
1,107 \\
591,292 \\
0 \\
342\end{array}$ & $\begin{array}{r}56,318 \\
19,129 \\
83,081 \\
0 \\
2,116\end{array}$ & $\begin{array}{r}506,910 \\
219,521 \\
2,190,848 \\
13,609 \\
158,838\end{array}$ \\
\hline 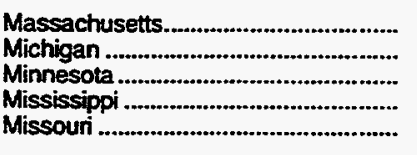 & $\begin{array}{l}159,856 \\
721,661 \\
289,735 \\
161,747 \\
362,314\end{array}$ & $\begin{array}{r}0 \\
8,022 \\
0 \\
4,979 \\
0\end{array}$ & $\begin{array}{r}487 \\
11,612 \\
3,646 \\
30,963 \\
4,656\end{array}$ & $\begin{array}{l}160,343 \\
741,295 \\
293,381 \\
197,689 \\
366,970\end{array}$ \\
\hline 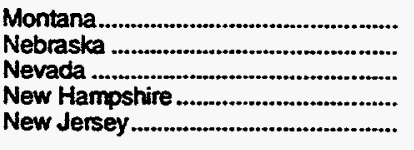 & $\begin{array}{r}66,515 \\
175,863 \\
71,052 \\
b \\
246,558\end{array}$ & $\begin{array}{r}2,972 \\
695 \\
0 \\
b \\
0\end{array}$ & $\begin{array}{r}1,469 \\
12,246 \\
0 \\
b \\
562\end{array}$ & $\begin{array}{r}70,956 \\
188,804 \\
71,052 \\
b \\
247,120\end{array}$ \\
\hline 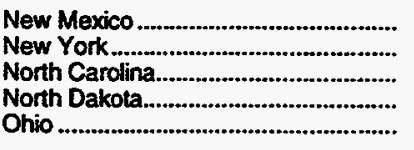 & $\begin{array}{r}163,905 \\
558,760 \\
70,330 \\
23,882 \\
836,628\end{array}$ & $\begin{array}{r}43,751 \\
278 \\
0 \\
13,697 \\
2,814\end{array}$ & $\begin{array}{r}22,157 \\
2,660 \\
2.197 \\
71 \\
8,055\end{array}$ & $\begin{array}{r}229,813 \\
561,698 \\
72,527 \\
37,650 \\
847,497\end{array}$ \\
\hline 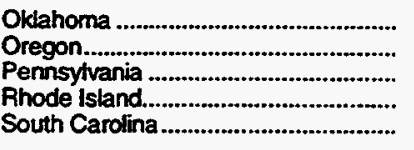 & $\begin{array}{r}661,931 \\
63,820 \\
641,890 \\
25,616 \\
135,388\end{array}$ & $\begin{array}{r}77,631 \\
37 \\
3,210 \\
0 \\
0\end{array}$ & $\begin{array}{r}27,424 \\
8,664 \\
23,237 \\
15 \\
3,197\end{array}$ & $\begin{array}{r}766,986 \\
72,521 \\
668,337 \\
25,631 \\
138,585\end{array}$ \\
\hline 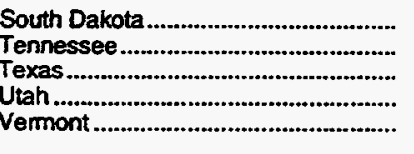 & $\begin{array}{r}36,070 \\
187,777 \\
3,344,075 \\
98,291 \\
\text { b }\end{array}$ & $\begin{array}{r}0 \\
509 \\
732,428 \\
7,585 \\
b\end{array}$ & $\begin{array}{r}27 \\
13,849 \\
66,520 \\
439 \\
b\end{array}$ & $\begin{array}{r}36,097 \\
202,135 \\
4,143,023 \\
106,315 \\
b\end{array}$ \\
\hline 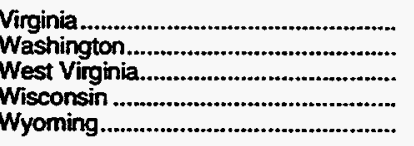 & $\begin{array}{r}115,143 \\
136,472 \\
128,239 \\
346,780 \\
60,706\end{array}$ & $\begin{array}{r}157 \\
0 \\
1,527 \\
0 \\
16,601\end{array}$ & $\begin{array}{r}2,720 \\
6,185 \\
14,769 \\
2,380 \\
6,316\end{array}$ & $\begin{array}{r}118,020 \\
142,657 \\
144,535 \\
349,160 \\
83,623\end{array}$ \\
\hline 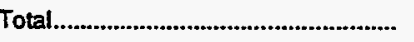 & $17,328,767$ & $1,659,145$ & 532,669 & $19,520,581$ \\
\hline
\end{tabular}

See foomotes at end of table. 
Table 14. Consumption of Natural Gas by State, 1967-1992 (Continued) (Million Cubic Feet)

\begin{tabular}{|c|c|c|c|c|}
\hline State & Delivered to Consumers & Lease and Plant Fual & Pipeline Fuel & Total Consumption \\
\hline & \multicolumn{4}{|c|}{1978} \\
\hline $\begin{array}{l}\text { Alabama } \\
\text { Alaska } \\
\text { Arizona } \\
\text { Arkansas } \\
\text { Califomia... }\end{array}$ & $\begin{array}{r}223,048 \\
128,943 \\
159,866 \\
205,680 \\
1,478,849\end{array}$ & $\begin{array}{r}3,371 \\
15,895 \\
0 \\
3,760 \\
69,624\end{array}$ & $\begin{array}{r}10,839 \\
187 \\
15,175 \\
11,259 \\
14,699\end{array}$ & $\begin{array}{r}237,258 \\
145,025 \\
175,041 \\
220,699 \\
1,563,172\end{array}$ \\
\hline 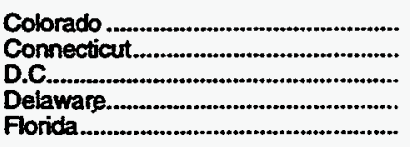 & $\begin{array}{r}252,360 \\
65,151 \\
a \\
20,623 \\
311,893\end{array}$ & $\begin{array}{r}10,619 \\
0 \\
a \\
0 \\
5,314\end{array}$ & $\begin{array}{r}4,859 \\
40 \\
2 \\
3 \\
1,137\end{array}$ & $\begin{array}{r}267,838 \\
65,191 \\
a \\
20,626 \\
318,344\end{array}$ \\
\hline 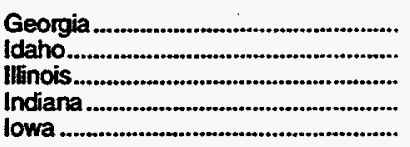 & $\begin{array}{r}274,832 \\
39,770 \\
1,161,536 \\
436,085 \\
233,298\end{array}$ & $\begin{array}{r}0 \\
22 \\
131 \\
0 \\
0\end{array}$ & $\begin{array}{r}3,440 \\
4,418 \\
13,267 \\
4,870 \\
4,931\end{array}$ & $\begin{array}{r}278,272 \\
44,210 \\
1,174,934 \\
440,955 \\
238,229\end{array}$ \\
\hline 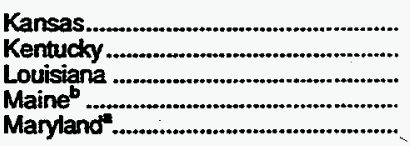 & $\begin{array}{r}425,698 \\
188,669 \\
1,609,552 \\
14,039 \\
158,945\end{array}$ & $\begin{array}{r}30,491 \\
1,160 \\
558,877 \\
0 \\
889\end{array}$ & $\begin{array}{r}63,157 \\
23,084 \\
80,743 \\
0 \\
1,861\end{array}$ & $\begin{array}{r}519,346 \\
212,913 \\
2,249,172 \\
14,039 \\
161,695\end{array}$ \\
\hline $\begin{array}{l}\text { Massachusetts... } \\
\text { Michigan } \\
\text { Minnesota } \\
\text { Mississippi } \\
\text { Missouri }\end{array}$ & $\begin{array}{l}160,000 \\
774,943 \\
309,570 \\
166,644 \\
353,992\end{array}$ & $\begin{array}{r}0 \\
11,076 \\
0 \\
5,421 \\
494\end{array}$ & $\begin{array}{r}503 \\
3,575 \\
3,659 \\
31,654 \\
4,419\end{array}$ & $\begin{array}{l}160,503 \\
789,594 \\
313,229 \\
203.719 \\
358,905\end{array}$ \\
\hline 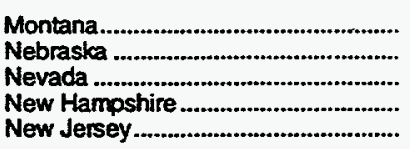 & $\begin{array}{r}68,305 \\
152,942 \\
64,506 \\
\text { b } \\
228,339\end{array}$ & $\begin{array}{r}2,792 \\
1,160 \\
0 \\
b \\
0\end{array}$ & $\begin{array}{r}1,552 \\
8,949 \\
0 \\
b \\
504\end{array}$ & $\begin{array}{r}72,649 \\
163,051 \\
64,506 \\
\text { b } \\
228,843\end{array}$ \\
\hline $\begin{array}{l}\text { New Mexico } \\
\text { New York } \\
\text { North Carolina. } \\
\text { North Dakota. } \\
\text { Ohio }\end{array}$ & $\begin{array}{r}152,844 \\
566,198 \\
79,390 \\
26,743 \\
917,194\end{array}$ & $\begin{array}{r}37,880 \\
109 \\
0 \\
12,218 \\
3,477\end{array}$ & $\begin{array}{r}22,974 \\
3,395 \\
2,599 \\
106 \\
8,922\end{array}$ & $\begin{array}{r}213,698 \\
569,702 \\
81,989 \\
39,067 \\
929,593\end{array}$ \\
\hline 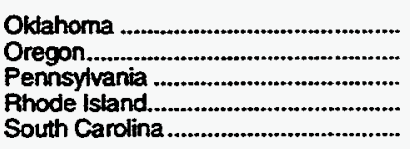 & $\begin{array}{r}669,121 \\
77,409 \\
647,175 \\
23,030 \\
113,690\end{array}$ & $\begin{array}{r}82,046 \\
30 \\
2,134 \\
0 \\
0\end{array}$ & $\begin{array}{r}19,082 \\
8,701 \\
24,461 \\
12 \\
3,883\end{array}$ & $\begin{array}{r}770,249 \\
86,140 \\
673,770 \\
23,042 \\
117,573\end{array}$ \\
\hline $\begin{array}{l}\text { South Dakota } \\
\text { Tennessee } \\
\text { Texas } \\
\text { Utah } \\
\text { Vermont }\end{array}$ & $\begin{array}{r}35,391 \\
169,117 \\
3,378,401 \\
109,210 \\
\mathrm{~b}\end{array}$ & $\begin{array}{r}0 \\
516 \\
757,853 \\
8,325 \\
b\end{array}$ & $\begin{array}{r}32 \\
14,415 \\
75,178 \\
978 \\
b\end{array}$ & $\begin{array}{r}35,423 \\
184,048 \\
4,211,432 \\
118,513 \\
\text { b }\end{array}$ \\
\hline 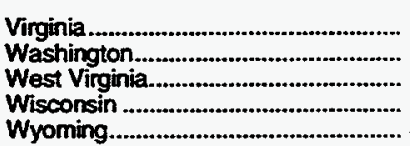 & $\begin{array}{r}131,270 \\
120,491 \\
135,370 \\
369,059 \\
59,935\end{array}$ & $\begin{array}{r}191 \\
440 \\
1.233 \\
0 \\
20,363\end{array}$ & $\begin{array}{r}2,683 \\
6,349 \\
15,236 \\
1,667 \\
6,994\end{array}$ & $\begin{array}{r}134,144 \\
127,280 \\
151,839 \\
370,726 \\
87,292\end{array}$ \\
\hline Total & $17,449,116$ & $1,647,911$ & 530,451 & $19,627,478$ \\
\hline
\end{tabular}

See footnotes at end of table. 
Table 14. Consumption of Natural Gas by State, 1967-1992 (Continued) (Million Cubic Feet)

\begin{tabular}{|c|c|c|c|c|}
\hline Stote & Delivered to Consumers & Lease and Plant Fual & Pipeline Fuel & Total Consumption \\
\hline & \multicolumn{4}{|c|}{1979} \\
\hline 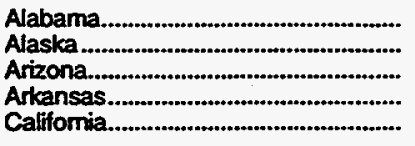 & $\begin{array}{r}248,944 \\
144,203 \\
152,366 \\
230,807 \\
1,726,714\end{array}$ & $\begin{array}{r}21,454 \\
12,153 \\
0 \\
7,661 \\
65,787\end{array}$ & $\begin{array}{r}13,037 \\
880 \\
20,372 \\
12,279 \\
17,880\end{array}$ & $\begin{array}{r}283,435 \\
157,236 \\
172,738 \\
250,747 \\
1,810,381\end{array}$ \\
\hline 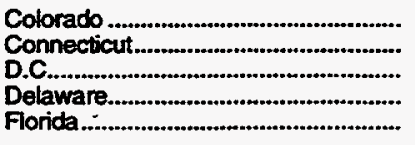 & $\begin{array}{r}263,629 \\
67,898 \\
a \\
24,977 \\
332,664\end{array}$ & $\begin{array}{r}21,610 \\
0 \\
2 \\
1 \\
7,628\end{array}$ & $\begin{array}{r}7,033 \\
59 \\
a \\
3 \\
3,885\end{array}$ & $\begin{array}{r}292,272 \\
67,957 \\
a \\
24,981 \\
344,177\end{array}$ \\
\hline 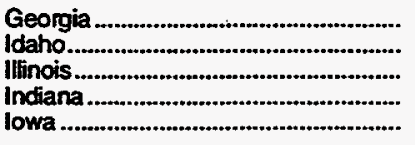 & $\begin{array}{r}308,177 \\
49,759 \\
1,123,836 \\
494,333 \\
280,749\end{array}$ & $\begin{array}{r}0 \\
4 \\
393 \\
1 \\
0\end{array}$ & $\begin{array}{r}4,122 \\
4,474 \\
18,503 \\
9,851 \\
10,772\end{array}$ & $\begin{array}{r}312,299 \\
54,237 \\
1,142,732 \\
504,185 \\
291,521\end{array}$ \\
\hline 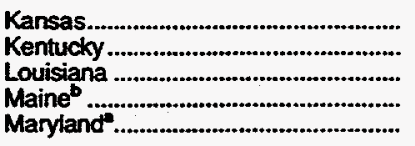 & $\begin{array}{r}481,956 \\
191,668 \\
1,615,568 \\
14,881 \\
196,774\end{array}$ & $\begin{array}{r}48,663 \\
1,214 \\
305,181 \\
0 \\
2,488\end{array}$ & $\begin{array}{r}53,617 \\
25,807 \\
57,633 \\
0 \\
2,322\end{array}$ & $\begin{array}{r}584,236 \\
218,689 \\
1,978,382 \\
14,881 \\
201,584\end{array}$ \\
\hline 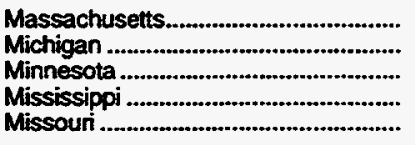 & $\begin{array}{l}155,808 \\
848,612 \\
323,172 \\
203,655 \\
340,195\end{array}$ & $\begin{array}{r}0 \\
14,695 \\
0 \\
8,645 \\
0\end{array}$ & $\begin{array}{r}651 \\
12,419 \\
11,030 \\
42,056 \\
7,062\end{array}$ & $\begin{array}{l}156,459 \\
875,726 \\
334,202 \\
254,366 \\
347,257\end{array}$ \\
\hline 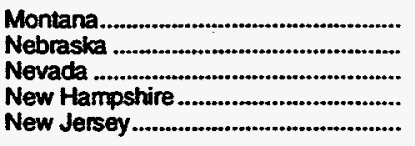 & $\begin{array}{r}62,706 \\
161,118 \\
84,433 \\
b \\
260,025\end{array}$ & $\begin{array}{r}4,796 \\
1,867 \\
0 \\
b \\
0\end{array}$ & $\begin{array}{r}2,303 \\
7,028 \\
0 \\
b \\
554\end{array}$ & $\begin{array}{r}69,805 \\
170,013 \\
84,433 \\
b \\
260,579\end{array}$ \\
\hline 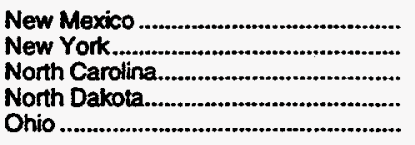 & $\begin{array}{r}131,248 \\
619,576 \\
125,867 \\
25,184 \\
861,391\end{array}$ & $\begin{array}{r}50,798 \\
961 \\
0 \\
3,950 \\
22,094\end{array}$ & $\begin{array}{r}29,136 \\
3,354 \\
5,017 \\
102 \\
14,544\end{array}$ & $\begin{array}{r}211,182 \\
623,891 \\
130,884 \\
29,236 \\
898,029\end{array}$ \\
\hline 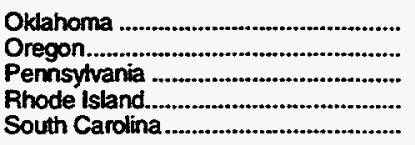 & $\begin{array}{r}671,025 \\
84,432 \\
711,702 \\
27,183 \\
116,421\end{array}$ & $\begin{array}{r}128,475 \\
30 \\
2,889 \\
0 \\
0\end{array}$ & $\begin{array}{r}25,408 \\
9,245 \\
26,227 \\
36 \\
2,898\end{array}$ & $\begin{array}{r}824,908 \\
93,707 \\
740,818 \\
27,219 \\
119,319\end{array}$ \\
\hline 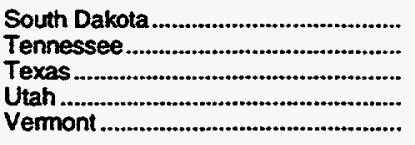 & $\begin{array}{r}25,326 \\
205,675 \\
3,206,026 \\
111,354 \\
\text { b }\end{array}$ & $\begin{array}{r}0 \\
616 \\
717,462 \\
14,123 \\
b\end{array}$ & $\begin{array}{r}398 \\
20,186 \\
77,867 \\
570 \\
b\end{array}$ & $\begin{array}{r}25,724 \\
226,477 \\
4,001,355 \\
126,047 \\
b\end{array}$ \\
\hline 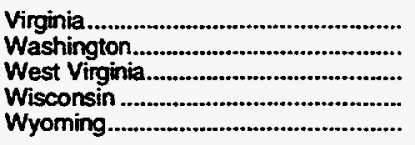 & $\begin{array}{r}129,779 \\
150,853 \\
130,376 \\
363,633 \\
54,589\end{array}$ & $\begin{array}{r}266 \\
326 \\
1,218 \\
0 \\
31,081\end{array}$ & $\begin{array}{r}4,043 \\
7,336 \\
16,944 \\
3,884 \\
8,127\end{array}$ & $\begin{array}{r}134,088 \\
158,515 \\
148,538 \\
367,517 \\
93,797\end{array}$ \\
\hline 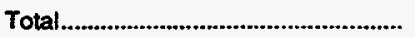 & $18,141,267$ & $1,498,530$ & 600,964 & $20,240,761$ \\
\hline
\end{tabular}

See footnotes at end of table. 
Table 14. Consumption of Natural Gas by State, 1967-1992 (Continued) (Million Cubic Feet)

\begin{tabular}{|c|c|c|c|c|}
\hline State & Delivered to Consumers & Lease and Plant Fuel & Pipoline Fuel & Total Consumption \\
\hline & \multicolumn{4}{|c|}{1980} \\
\hline 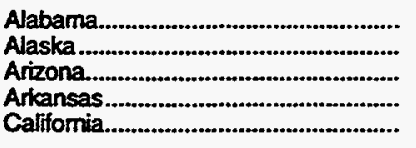 & $\begin{array}{r}242,793 \\
122,966 \\
144,511 \\
260,319 \\
1,729,650\end{array}$ & $\begin{array}{r}9,990 \\
30,250 \\
0 \\
1,949 \\
62,824\end{array}$ & $\begin{array}{r}16,457 \\
129 \\
21,339 \\
11,452 \\
15,257\end{array}$ & $\begin{array}{r}269,240 \\
153,345 \\
165,850 \\
273,720 \\
1,807,731\end{array}$ \\
\hline 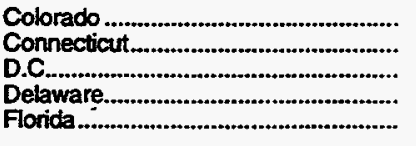 & $\begin{array}{r}241,765 \\
72,512 \\
27,868 \\
29,797 \\
304,638\end{array}$ & $\begin{array}{r}7,041 \\
0 \\
0 \\
0 \\
8,284\end{array}$ & $\begin{array}{r}7,557 \\
71 \\
0 \\
0 \\
3,666\end{array}$ & $\begin{array}{r}256,363 \\
72,583 \\
27,868 \\
29,797 \\
316,588\end{array}$ \\
\hline 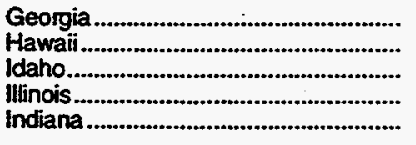 & $\begin{array}{r}307,827 \\
3,131 \\
44,835 \\
1,074,771 \\
480,346\end{array}$ & $\begin{array}{r}0 \\
0 \\
7 \\
385 \\
7\end{array}$ & $\begin{array}{r}7,374 \\
0 \\
4,205 \\
14,564 \\
8,901\end{array}$ & $\begin{array}{r}315,201 \\
3,131 \\
49,047 \\
1,089,720 \\
489,254\end{array}$ \\
\hline 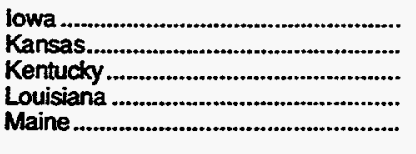 & $\begin{array}{r}256,900 \\
411,494 \\
180,368 \\
1,523,691 \\
2,166\end{array}$ & $\begin{array}{r}0 \\
24,521 \\
989 \\
196,033 \\
0\end{array}$ & $\begin{array}{r}12,681 \\
52,323 \\
20,927 \\
74,283 \\
102\end{array}$ & $\begin{array}{r}269,581 \\
488,338 \\
202,284 \\
1,794,007 \\
2,268\end{array}$ \\
\hline 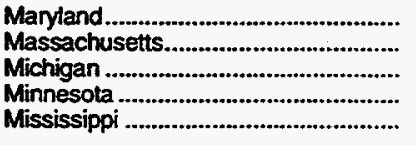 & $\begin{array}{l}156,300 \\
181,912 \\
846,278 \\
276,717 \\
219,828\end{array}$ & $\begin{array}{r}0 \\
0 \\
6,494 \\
0 \\
4,428\end{array}$ & $\begin{array}{r}3,944 \\
675 \\
12,365 \\
9,129 \\
39,274\end{array}$ & $\begin{array}{l}160,244 \\
182,587 \\
865,137 \\
285,846 \\
263,530\end{array}$ \\
\hline 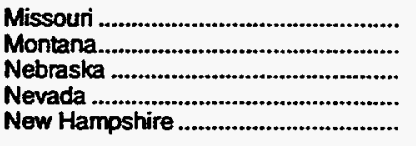 & $\begin{array}{r}312,872 \\
54,460 \\
152,283 \\
58,284 \\
9,448\end{array}$ & $\begin{array}{r}0 \\
3,425 \\
3,779 \\
0 \\
0\end{array}$ & $\begin{array}{r}5,578 \\
2,839 \\
7,017 \\
170 \\
26\end{array}$ & $\begin{array}{r}318,450 \\
60,724 \\
163,079 \\
58,454 \\
9,474\end{array}$ \\
\hline 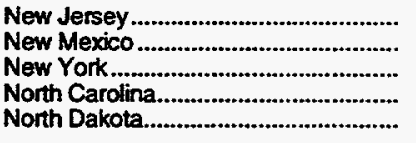 & $\begin{array}{r}339,358 \\
146,579 \\
733,800 \\
147,448 \\
21,660\end{array}$ & $\begin{array}{r}0 \\
36,859 \\
115 \\
0 \\
1,017\end{array}$ & $\begin{array}{r}467 \\
38,355 \\
3,528 \\
5,868 \\
171\end{array}$ & $\begin{array}{r}339,825 \\
221,793 \\
737,443 \\
153,316 \\
22,848\end{array}$ \\
\hline 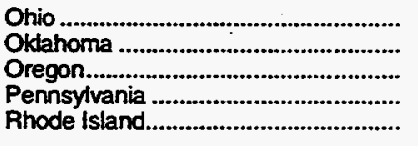 & $\begin{array}{r}883,613 \\
639,642 \\
73,083 \\
744,909 \\
27,477\end{array}$ & $\begin{array}{r}1,941 \\
59,934 \\
0 \\
1,320 \\
0\end{array}$ & $\begin{array}{r}11,429 \\
22,742 \\
5,620 \\
29,486 \\
153\end{array}$ & $\begin{array}{r}896,983 \\
722,318 \\
78,703 \\
775,715 \\
27,630\end{array}$ \\
\hline 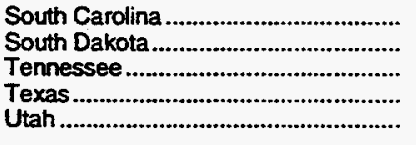 & $\begin{array}{r}139,214 \\
24,002 \\
213,169 \\
3,449,507 \\
106,647\end{array}$ & $\begin{array}{r}0 \\
0 \\
0 \\
536,766 \\
7,594\end{array}$ & $\begin{array}{r}3,014 \\
76 \\
16,492 \\
104,826 \\
851\end{array}$ & $\begin{array}{r}142,228 \\
24,078 \\
229,661 \\
4,091,099 \\
115,092\end{array}$ \\
\hline 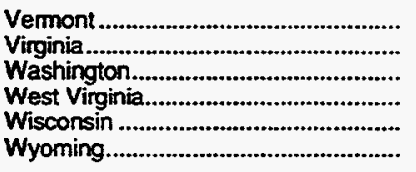 & $\begin{array}{r}3,991 \\
149,980 \\
125,107 \\
127,343 \\
343,611 \\
45,363\end{array}$ & $\begin{array}{r}0 \\
240 \\
0 \\
2,482 \\
0 \\
17,763\end{array}$ & $\begin{array}{r}0 \\
8,259 \\
3,663 \\
13,222 \\
8,246 \\
5,849\end{array}$ & $\begin{array}{r}3,991 \\
158,479 \\
128,770 \\
143,047 \\
351,857 \\
68,975\end{array}$ \\
\hline 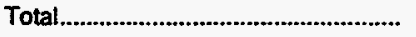 & $18,216,233$ & $1,026,438$ & 634,622 & $19,877,293$ \\
\hline
\end{tabular}

See footnotes at end of table. 
Table 14. Consumption of Natural Gas by State, 1967-1992 (Continued) (Million Cubic Feet)

\begin{tabular}{|c|c|c|c|c|}
\hline Sute & Delivered to Consumers & Lease and Plant Fuel & Pipeline Fued & Total Consumption \\
\hline & \multicolumn{4}{|c|}{1981} \\
\hline 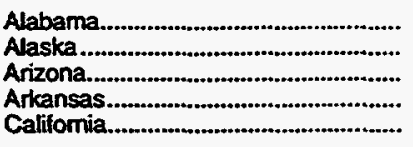 & $\begin{array}{r}247,289 \\
106,207 \\
157,993 \\
252,553 \\
1,789,444\end{array}$ & $\begin{array}{r}5,804 \\
15,249 \\
222 \\
2,549 \\
53,655\end{array}$ & $\begin{array}{r}18,187 \\
271 \\
24,318 \\
9,685 \\
15,079\end{array}$ & $\begin{array}{r}271,280 \\
121,727 \\
182,533 \\
264,787 \\
1,858,178\end{array}$ \\
\hline 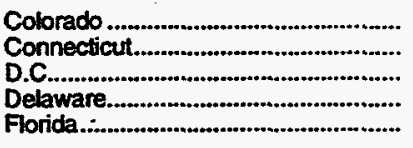 & $\begin{array}{r}197,998 \\
76,732 \\
29,023 \\
30,640 \\
324,414\end{array}$ & $\begin{array}{r}7,093 \\
0 \\
0 \\
0 \\
9,035\end{array}$ & $\begin{array}{r}6,689 \\
97 \\
0 \\
3 \\
4,108\end{array}$ & $\begin{array}{r}211,780 \\
76,829 \\
29,023 \\
30,643 \\
337,557\end{array}$ \\
\hline 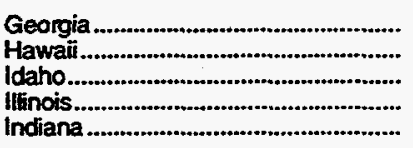 & $\begin{array}{r}308,949 \\
2,899 \\
41,034 \\
1,049,787 \\
487,670\end{array}$ & $\begin{array}{r}0 \\
0 \\
0 \\
17 \\
51\end{array}$ & $\begin{array}{r}7,664 \\
0 \\
3,926 \\
12,153 \\
8,628\end{array}$ & $\begin{array}{r}316,613 \\
2,899 \\
44,960 \\
1,061,957 \\
496,349\end{array}$ \\
\hline 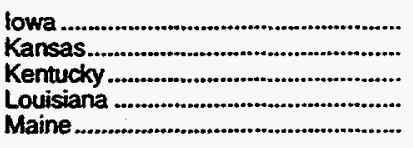 & $\begin{array}{r}242,357 \\
360,833 \\
174,550 \\
1,522,261 \\
2,321\end{array}$ & $\begin{array}{r}0 \\
19,665 \\
1,040 \\
180,687 \\
0\end{array}$ & $\begin{array}{r}10,874 \\
47,632 \\
23,855 \\
78,768 \\
5\end{array}$ & $\begin{array}{r}253,231 \\
428,130 \\
199,445 \\
1,781,716 \\
2,326\end{array}$ \\
\hline 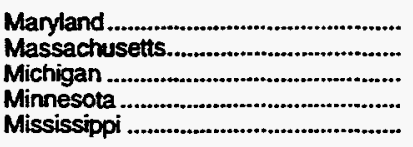 & $\begin{array}{l}172,915 \\
183,900 \\
783,775 \\
256,094 \\
198,396\end{array}$ & $\begin{array}{r}0 \\
0 \\
3,461 \\
0 \\
4,028\end{array}$ & $\begin{array}{r}2,374 \\
675 \\
13,637 \\
10,188 \\
40,563\end{array}$ & $\begin{array}{l}175,289 \\
184,575 \\
800,873 \\
266,282 \\
242,987\end{array}$ \\
\hline 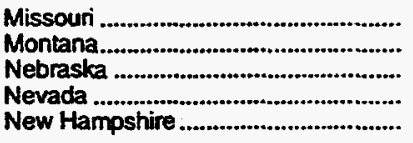 & $\begin{array}{r}277,914 \\
48,533 \\
132,059 \\
72,584 \\
10,154\end{array}$ & $\begin{array}{r}0 \\
1,832 \\
132 \\
168 \\
0\end{array}$ & $\begin{array}{r}5,600 \\
2,087 \\
6,131 \\
430 \\
66\end{array}$ & $\begin{array}{r}283,514 \\
52,452 \\
138,322 \\
73,182 \\
10,220\end{array}$ \\
\hline 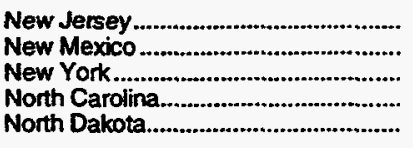 & $\begin{array}{r}389,458 \\
134,220 \\
756,522 \\
146,223 \\
20,512\end{array}$ & $\begin{array}{r}0 \\
22,685 \\
80 \\
0 \\
13,759\end{array}$ & $\begin{array}{r}663 \\
39,307 \\
3,861 \\
6,273 \\
174\end{array}$ & $\begin{array}{r}390,121 \\
196,212 \\
760,463 \\
152,496 \\
34,445\end{array}$ \\
\hline 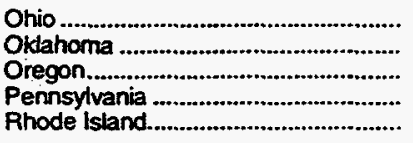 & $\begin{array}{r}855,704 \\
592,220 \\
71,914 \\
749,354 \\
29,086\end{array}$ & $\begin{array}{r}1,776 \\
56,785 \\
0 \\
1,580 \\
4\end{array}$ & $\begin{array}{r}12,861 \\
21,966 \\
3,648 \\
33,757 \\
112\end{array}$ & $\begin{array}{r}870,341 \\
670,971 \\
75,562 \\
784,691 \\
29,202\end{array}$ \\
\hline 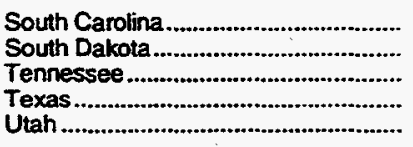 & $\begin{array}{r}138,728 \\
21,990 \\
205,979 \\
3,319,594 \\
101,007\end{array}$ & $\begin{array}{r}0 \\
0 \\
0 \\
505,322 \\
511\end{array}$ & $\begin{array}{r}3,196 \\
66 \\
17,550 \\
101,771 \\
721\end{array}$ & $\begin{array}{r}141,924 \\
22,056 \\
223,529 \\
3,926,687 \\
102,239\end{array}$ \\
\hline 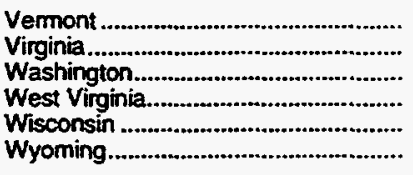 & $\begin{array}{r}4,383 \\
140,663 \\
122,658 \\
130,713 \\
316,501 \\
45,228\end{array}$ & $\begin{array}{r}0 \\
361 \\
0 \\
2,515 \\
0 \\
17,527\end{array}$ & $\begin{array}{r}0 \\
10,713 \\
2,284 \\
15,299 \\
8,110 \\
6,301\end{array}$ & $\begin{array}{r}4,383 \\
151,737 \\
124,942 \\
148,527 \\
324,611 \\
69,056\end{array}$ \\
\hline 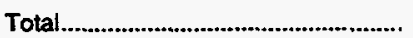 & $17,833,942$ & 927,591 & 642,325 & 19.403 .858 \\
\hline
\end{tabular}

See foomotes at end of table. 
Table.14. Consumption of Natural Gas by State, 1967-1992 (Continued) (Million Cubic Feet)

\begin{tabular}{|c|c|c|c|c|}
\hline Stute & Delivered to Consumers & Lease and Plant Fuel & Pipeline Fuel & Total Consumption \\
\hline & \multicolumn{4}{|c|}{1982} \\
\hline 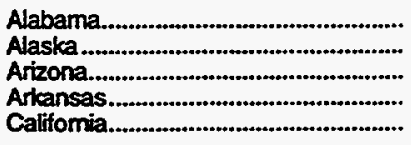 & $\begin{array}{r}220,087 \\
143,395 \\
116,536 \\
213,187 \\
1,647,535\end{array}$ & $\begin{array}{r}5,037 \\
94,232 \\
7 \\
5,096 \\
22,275\end{array}$ & $\begin{array}{r}15,833 \\
254 \\
18,488 \\
8,658 \\
12,908\end{array}$ & $\begin{array}{r}240,957 \\
237,881 \\
135,031 \\
226,941 \\
1,682,718\end{array}$ \\
\hline 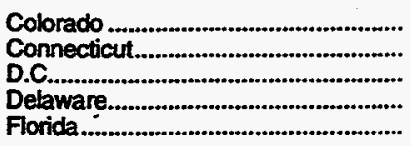 & $\begin{array}{r}202,482 \\
77,591 \\
28,922 \\
27,799 \\
310,076\end{array}$ & $\begin{array}{r}13,673 \\
0 \\
0 \\
0 \\
10,603\end{array}$ & $\begin{array}{r}8,836 \\
655 \\
358 \\
-34 \\
4,128\end{array}$ & $\begin{array}{r}224,991 \\
78,246 \\
29,280 \\
27,833 \\
324,807\end{array}$ \\
\hline 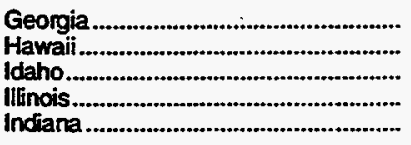 & $\begin{array}{r}287,463 \\
2,804 \\
36,870 \\
974,545 \\
459,114\end{array}$ & $\begin{array}{r}0 \\
0 \\
0 \\
5,586 \\
10\end{array}$ & $\begin{array}{r}7,188 \\
0 \\
3,101 \\
14,048 \\
8,718\end{array}$ & $\begin{array}{r}294,651 \\
2,804 \\
39,971 \\
994,179 \\
467,842\end{array}$ \\
\hline 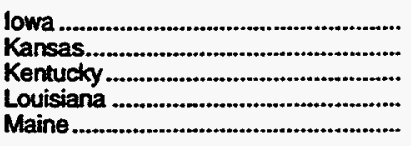 & $\begin{array}{r}228,229 \\
317,259 \\
159,446 \\
1,156,364 \\
2,617\end{array}$ & $\begin{array}{r}0 \\
41,392 \\
9,772 \\
337,398 \\
0\end{array}$ & $\begin{array}{r}8,860 \\
42,269 \\
19,318 \\
62,290 \\
74\end{array}$ & $\begin{array}{r}237,089 \\
400,920 \\
188,536 \\
1,556,052 \\
2,691\end{array}$ \\
\hline 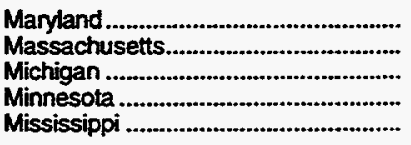 & $\begin{array}{l}155,507 \\
193,506 \\
725,050 \\
253,359 \\
224,857\end{array}$ & $\begin{array}{r}1 \\
0 \\
9,699 \\
0 \\
7,236\end{array}$ & $\begin{array}{r}2,482 \\
1,601 \\
13,392 \\
8,680 \\
37,038\end{array}$ & $\begin{array}{l}157,990 \\
195,107 \\
748,141 \\
262,039 \\
269,131\end{array}$ \\
\hline 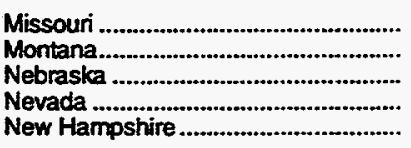 & $\begin{array}{r}274,897 \\
47,887 \\
132,933 \\
46,303 \\
9,993\end{array}$ & $\begin{array}{r}0 \\
2,012 \\
107 \\
0 \\
0\end{array}$ & $\begin{array}{r}4,552 \\
2,309 \\
5,198 \\
324 \\
85\end{array}$ & $\begin{array}{r}279,449 \\
52,208 \\
138,238 \\
46,627 \\
10,078\end{array}$ \\
\hline 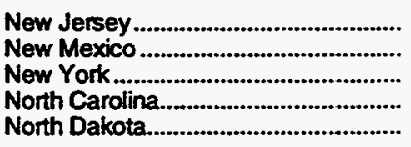 & $\begin{array}{r}374,702 \\
113,564 \\
770,665 \\
135,482 \\
24,374\end{array}$ & $\begin{array}{r}0 \\
55,722 \\
494 \\
0 \\
3,514\end{array}$ & $\begin{array}{r}958 \\
34,877 \\
4,109 \\
6,647 \\
482\end{array}$ & $\begin{array}{r}375,660 \\
204,163 \\
775,268 \\
142,129 \\
28,370\end{array}$ \\
\hline 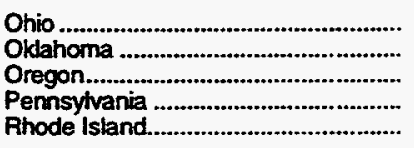 & $\begin{array}{r}795,963 \\
556,481 \\
67,412 \\
660,195 \\
27,702\end{array}$ & $\begin{array}{r}3,671 \\
91,465 \\
0 \\
3,278 \\
0\end{array}$ & $\begin{array}{r}13,885 \\
28,816 \\
3,412 \\
31,166 \\
172\end{array}$ & $\begin{array}{r}813,519 \\
676,762 \\
70,824 \\
694,639 \\
27,874\end{array}$ \\
\hline 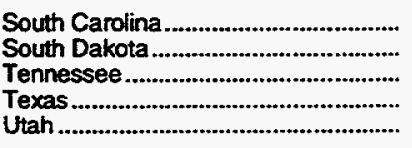 & $\begin{array}{r}95,220 \\
24,910 \\
190,520 \\
2,943,812 \\
110,615\end{array}$ & $\begin{array}{r}0 \\
63 \\
78 \\
347,846 \\
5,965\end{array}$ & $\begin{array}{r}2,880 \\
116 \\
16,563 \\
102,746 \\
1,126\end{array}$ & $\begin{array}{r}98,100 \\
25,089 \\
207,161 \\
3,394,404 \\
117,706\end{array}$ \\
\hline 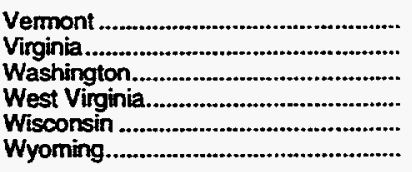 & $\begin{array}{r}4,366 \\
139,840 \\
106,942 \\
110,220 \\
308,039 \\
57,597\end{array}$ & $\begin{array}{r}0 \\
181 \\
0 \\
6,426 \\
0 \\
26,559\end{array}$ & $\begin{array}{r}4 \\
10,943 \\
1,711 \\
13,383 \\
3,968 \\
6,767\end{array}$ & $\begin{array}{r}4,370 \\
150,964 \\
108,653 \\
130,029 \\
312,007 \\
90,923\end{array}$ \\
\hline 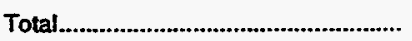 & $16,295,245$ & $1,109,398$ & 596,411 & $18,001,055$ \\
\hline
\end{tabular}

See footnotes at end of table. 
Țable 14. Consumption of Natural Gas by State, 1967-1992 (Continued) (Million Cubic Feet)

\begin{tabular}{|c|c|c|c|c|}
\hline State & Delivered to Consumers & Lease and Plant Fuel & Pipeline Fuel & Total Consumption \\
\hline & \multicolumn{4}{|c|}{1983} \\
\hline 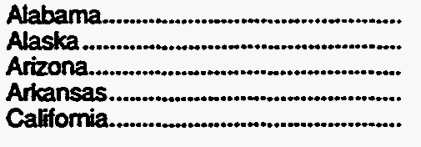 & $\begin{array}{r}203,687 \\
141,116 \\
102,807 \\
194,079 \\
1,502,575\end{array}$ & $\begin{array}{r}4,729 \\
97,828 \\
7 \\
5,384 \\
22,231\end{array}$ & $\begin{array}{r}13,167 \\
256 \\
12,419 \\
7,503 \\
10,225\end{array}$ & $\begin{array}{r}221,583 \\
239,200 \\
115,233 \\
206,966 \\
1,535,031\end{array}$ \\
\hline 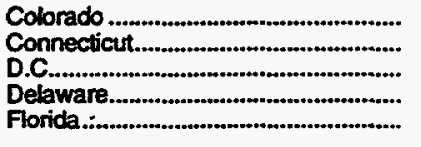 & $\begin{array}{r}195,700 \\
74,211 \\
28,952 \\
34,873 \\
293,623\end{array}$ & $\begin{array}{r}10,000 \\
0 \\
0 \\
0 \\
8,520\end{array}$ & $\begin{array}{r}8,112 \\
216 \\
388 \\
11 \\
4,164\end{array}$ & $\begin{array}{r}213,812 \\
74,427 \\
29,340 \\
34,884 \\
306,307\end{array}$ \\
\hline 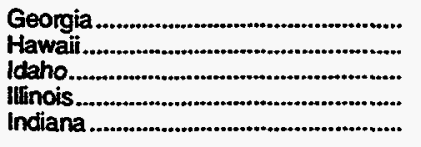 & $\begin{array}{r}289,574 \\
2,669 \\
32,412 \\
923,921 \\
421,252\end{array}$ & $\begin{array}{r}0 \\
0 \\
0 \\
4,873 \\
4\end{array}$ & $\begin{array}{r}5,957 \\
0 \\
2,767 \\
9,546 \\
5,514\end{array}$ & $\begin{array}{r}295,531 \\
2,669 \\
35,179 \\
938,340 \\
426,770\end{array}$ \\
\hline 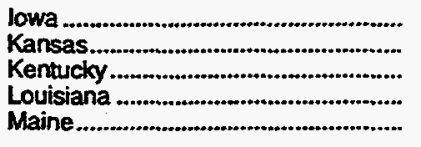 & $\begin{array}{r}212,587 \\
276,262 \\
151,187 \\
1,090,109 \\
2,419\end{array}$ & $\begin{array}{r}0 \\
37,901 \\
8,361 \\
275,698 \\
0\end{array}$ & $\begin{array}{r}7,930 \\
32,041 \\
14,758 \\
47,176 \\
5\end{array}$ & $\begin{array}{r}220,517 \\
346,204 \\
174,306 \\
1,412,993 \\
2,424\end{array}$ \\
\hline 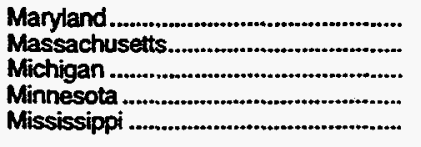 & $\begin{array}{l}143,527 \\
190,782 \\
680,452 \\
236,401 \\
203,222\end{array}$ & $\begin{array}{r}1 \\
0 \\
8,130 \\
0 \\
6,632\end{array}$ & $\begin{array}{r}2,100 \\
1,033 \\
7,873 \\
4,376 \\
28,005\end{array}$ & $\begin{array}{l}145,628 \\
191,815 \\
696,455 \\
240,777 \\
237,859\end{array}$ \\
\hline 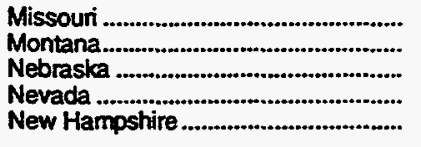 & $\begin{array}{r}254,823 \\
42,634 \\
125,134 \\
41,830 \\
9,635\end{array}$ & $\begin{array}{r}0 \\
1,970 \\
94 \\
0 \\
0\end{array}$ & $\begin{array}{r}3,737 \\
1,645 \\
4,062 \\
96 \\
20\end{array}$ & $\begin{array}{r}258,560 \\
46,249 \\
129,290 \\
41,926 \\
9,655\end{array}$ \\
\hline 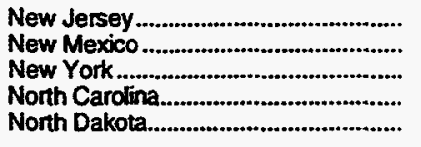 & $\begin{array}{r}404,398 \\
100,727 \\
716,488 \\
130,792 \\
21,368\end{array}$ & $\begin{array}{r}0 \\
47,630 \\
617 \\
0 \\
4,100\end{array}$ & $\begin{array}{r}989 \\
30,341 \\
3,293 \\
5,787 \\
658\end{array}$ & $\begin{array}{r}405,387 \\
178,698 \\
720,398 \\
136,579 \\
26,126\end{array}$ \\
\hline 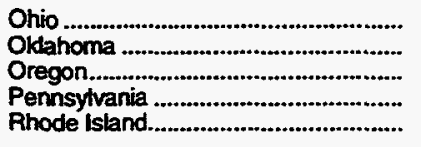 & $\begin{array}{r}732,686 \\
525,165 \\
64,042 \\
611,203 \\
28,884\end{array}$ & $\begin{array}{r}4,377 \\
79,230 \\
0 \\
3,543 \\
0\end{array}$ & $\begin{array}{r}10,205 \\
24,555 \\
3,003 \\
29,206 \\
160\end{array}$ & $\begin{array}{r}747,268 \\
628,950 \\
67,045 \\
643,952 \\
29,044\end{array}$ \\
\hline 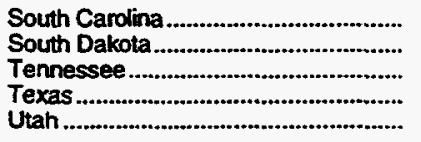 & $\begin{array}{r}98,998 \\
23,138 \\
183,608 \\
2,828,001 \\
104,429\end{array}$ & $\begin{array}{r}0 \\
61 \\
113 \\
307,717 \\
4,538\end{array}$ & $\begin{array}{r}2,634 \\
127 \\
10,889 \\
105,797 \\
1,218\end{array}$ & $\begin{array}{r}101,632 \\
23,326 \\
194,610 \\
3,241,515 \\
110,185\end{array}$ \\
\hline 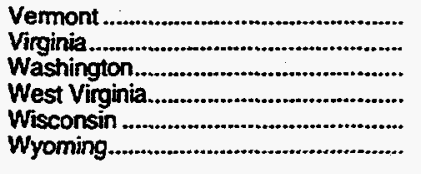 & $\begin{array}{r}4,354 \\
135,611 \\
105,639 \\
100,715 \\
296,345 \\
47,578\end{array}$ & $\begin{array}{r}0 \\
124 \\
0 \\
5,826 \\
0 \\
28,010\end{array}$ & $\begin{array}{r}5 \\
7,209 \\
1,554 \\
9,272 \\
2,754 \\
5,283\end{array}$ & $\begin{array}{r}4,359 \\
142,944 \\
107,193 \\
115,813 \\
299,099 \\
80,871\end{array}$ \\
\hline 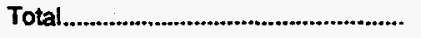 & $15,366,621$ & 978,249 & 490,042 & $16,834,914$ \\
\hline
\end{tabular}

See footnotes at end of table. 
Table 14. Consumption of Natural Gas by State, 1967-1992 (Continued) (Million Cubic Feet)

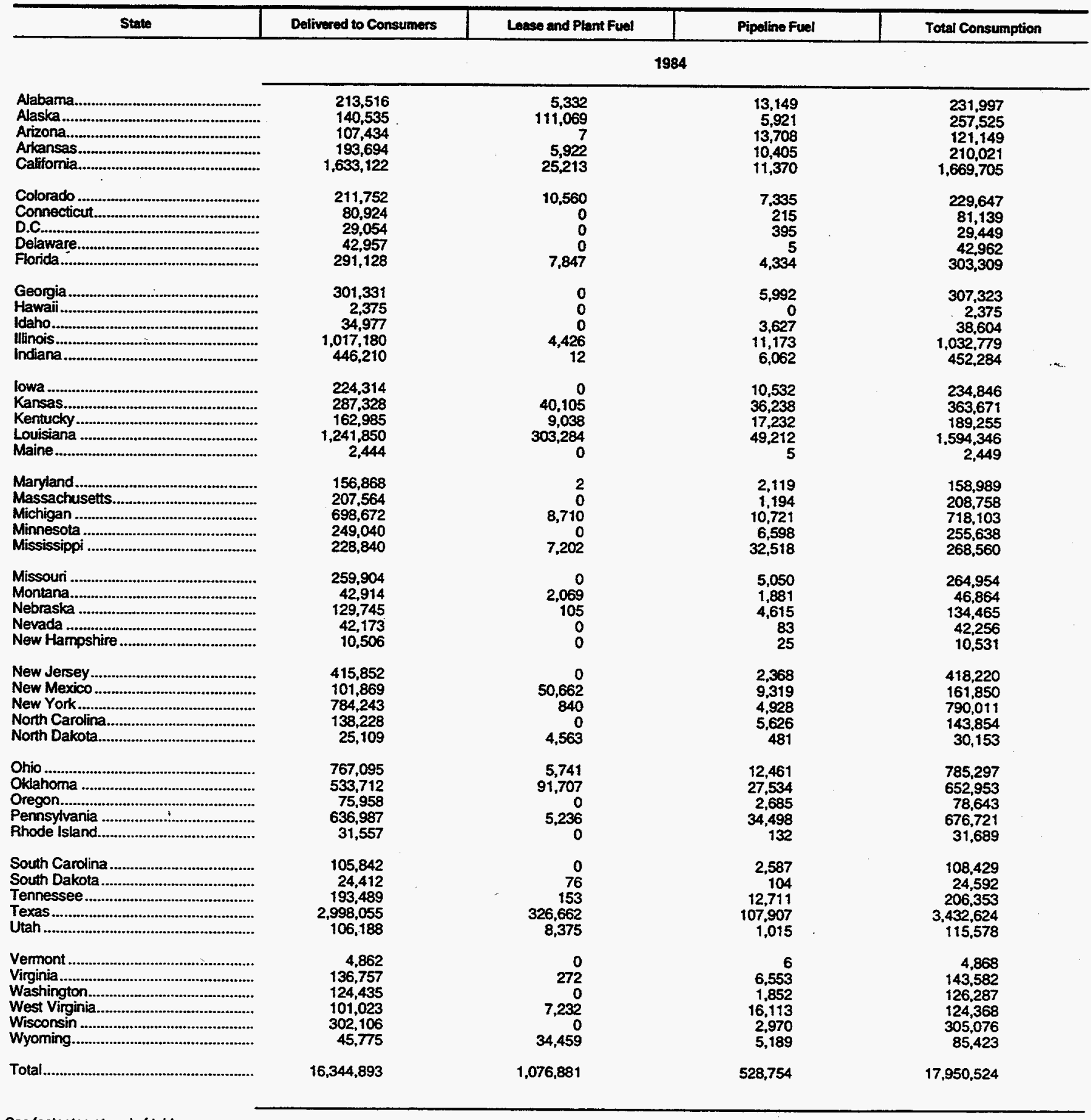

See footnotes at end of table. 
Table 14. Consumption of Natural Gas by State, 1967-1992 (Continued) (Million Cubic Feet)

\begin{tabular}{|c|c|c|c|c|}
\hline State & Delivered to Consumers & Lease and Plant Fuel & Pipeline Fuel & Total Consumption \\
\hline & \multicolumn{4}{|c|}{1985} \\
\hline 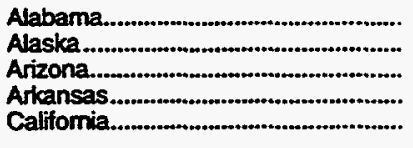 & $\begin{array}{r}202,901 \\
143,470 \\
112,228 \\
174,991 \\
1,806,398\end{array}$ & $\begin{array}{r}5,476 \\
64,148 \\
6 \\
12,439 \\
25,274\end{array}$ & $\begin{array}{r}11,078 \\
5,147 \\
18,542 \\
8,203 \\
14,406\end{array}$ & $\begin{array}{r}219,455 \\
212,765 \\
130,776 \\
195,633 \\
1,846,078\end{array}$ \\
\hline 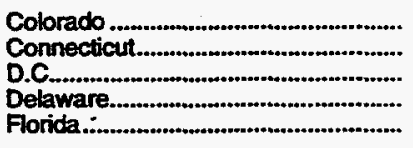 & $\begin{array}{r}200,976 \\
77,864 \\
28,526 \\
38,488 \\
278,666\end{array}$ & $\begin{array}{r}10,829 \\
0 \\
0 \\
0 \\
7,174\end{array}$ & $\begin{array}{r}7,137 \\
351 \\
376 \\
-\quad 5 \\
3,866\end{array}$ & $\begin{array}{r}218,942 \\
78,215 \\
28,902 \\
38,493 \\
289,706\end{array}$ \\
\hline 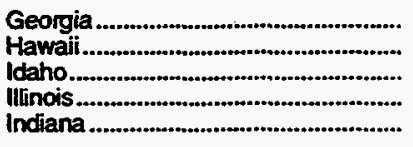 & $\begin{array}{r}276,446 \\
2,483 \\
36,243 \\
946,614 \\
428,124\end{array}$ & $\begin{array}{r}0 \\
0 \\
0 \\
4,237 \\
11\end{array}$ & $\begin{array}{r}5,359 \\
0 \\
2,951 \\
11,188 \\
4,823\end{array}$ & $\begin{array}{r}281,805 \\
2,483 \\
39,194 \\
962,039 \\
432,958\end{array}$ \\
\hline 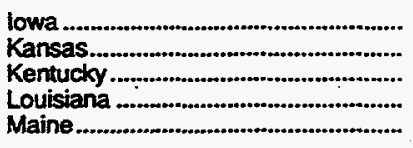 & $\begin{array}{r}215,553 \\
274,900 \\
149,102 \\
1,086,006 \\
2,520\end{array}$ & $\begin{array}{r}0 \\
42,457 \\
9,095 \\
258,069 \\
0\end{array}$ & $\begin{array}{r}10,350 \\
38,110 \\
14,313 \\
42,290 \\
11\end{array}$ & $\begin{array}{r}225,903 \\
355,467 \\
172,510 \\
1,386,365 \\
2,531\end{array}$ \\
\hline 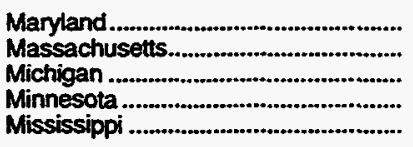 & $\begin{array}{l}148,589 \\
217,503 \\
690,493 \\
251,243 \\
195,058\end{array}$ & $\begin{array}{r}1 \\
0 \\
8,195 \\
0 \\
6,296\end{array}$ & $\begin{array}{r}2,248 \\
1,381 \\
10,544 \\
6,237 \\
25,309\end{array}$ & $\begin{array}{l}150,838 \\
218,884 \\
709,232 \\
257,480 \\
226,663\end{array}$ \\
\hline 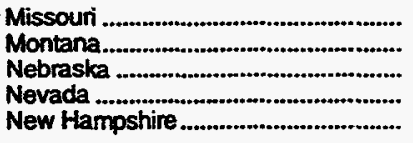 & $\begin{array}{r}255,636 \\
42,879 \\
120,496 \\
39,087 \\
10,545\end{array}$ & $\begin{array}{r}0 \\
2,138 \\
87 \\
0 \\
0\end{array}$ & $\begin{array}{r}4,264 \\
2,248 \\
5,552 \\
113 \\
84\end{array}$ & $\begin{array}{r}259,900 \\
47,265 \\
126,135 \\
39,200 \\
10,629\end{array}$ \\
\hline 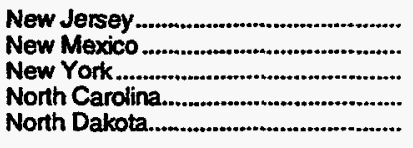 & $\begin{array}{r}376,982 \\
78,453 \\
758,031 \\
129,081 \\
22,682\end{array}$ & $\begin{array}{r}0 \\
46,709 \\
1.041 \\
0 \\
4,710\end{array}$ & $\begin{array}{r}2,248 \\
25,966 \\
3,549 \\
4,744 \\
704\end{array}$ & $\begin{array}{r}379,230 \\
151,128 \\
762,621 \\
133,825 \\
28,096\end{array}$ \\
\hline 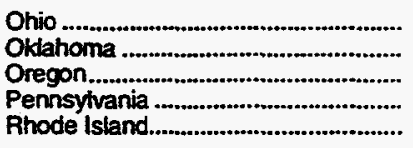 & $\begin{array}{r}719,393 \\
473,906 \\
78,297 \\
588,087 \\
29,733\end{array}$ & $\begin{array}{r}5,442 \\
88,185 \\
120 \\
4,575 \\
0\end{array}$ & $\begin{array}{r}8,281 \\
25,316 \\
4,585 \\
33,005 \\
141\end{array}$ & $\begin{array}{r}733,116 \\
587,407 \\
83,002 \\
625,667 \\
29,874\end{array}$ \\
\hline 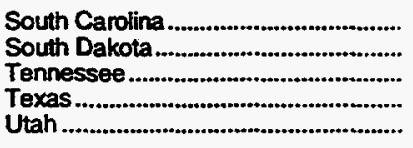 & $\begin{array}{r}95,225 \\
24,881 \\
179,942 \\
2,985,916 \\
104,915\end{array}$ & $\begin{array}{r}0 \\
93 \\
138 \\
307,759 \\
9,001\end{array}$ & $\begin{array}{r}2,244 \\
228 \\
10,186 \\
92,040 \\
1,201\end{array}$ & $\begin{array}{r}97,469 \\
25,202 \\
190,266 \\
3,385,715 \\
115,117\end{array}$ \\
\hline 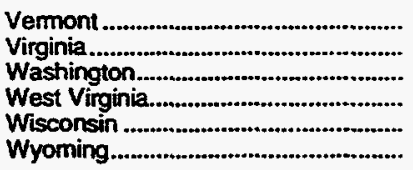 & $\begin{array}{r}4,993 \\
134,589 \\
131,712 \\
92,218 \\
305,571 \\
42,495\end{array}$ & $\begin{array}{r}0 \\
443 \\
0 \\
7,190 \\
0 \\
34,709\end{array}$ & $\begin{array}{r}5 \\
4,426 \\
2,887 \\
17,760 \\
2,794 \\
4,968\end{array}$ & $\begin{array}{r}4,998 \\
139,458 \\
134,599 \\
117,168 \\
308,365 \\
82,172\end{array}$ \\
\hline 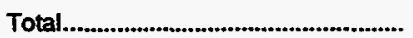 & $15,811,130$ & 966,047 & 503,766 & $17,280,943$ \\
\hline
\end{tabular}

See footnotes at end of table. 
Table 14. Consumption of Natural Gas by State, 1967-1992 (Continued) (Million Cubic Feet)

\begin{tabular}{|c|c|c|c|c|}
\hline Stato & Delivored to Consumers & Lease and Plant Fuel & Pipeline Fuel & Total Consumption \\
\hline & \multicolumn{4}{|c|}{1986} \\
\hline 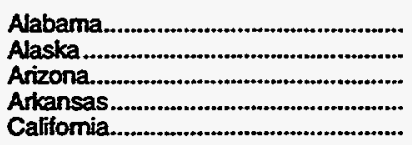 & $\begin{array}{r}187,654 \\
127,812 \\
88,587 \\
184,148 \\
1,496,008\end{array}$ & $\begin{array}{r}5,442 \\
72,686 \\
5 \\
9,062 \\
22,973\end{array}$ & $\begin{array}{r}9,827 \\
5,954 \\
12,657 \\
5,987 \\
12,342\end{array}$ & $\begin{array}{r}202,923 \\
206,452 \\
101,249 \\
199,197 \\
1,531,323\end{array}$ \\
\hline 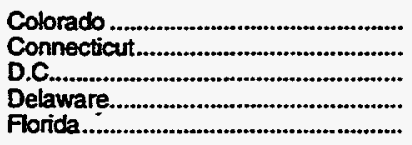 & $\begin{array}{r}181,770 \\
78,264 \\
29,229 \\
33,005 \\
278,439\end{array}$ & $\begin{array}{r}9,397 \\
0 \\
0 \\
0 \\
6,156\end{array}$ & $\begin{array}{r}6,680 \\
639 \\
357 \\
4 \\
3,946\end{array}$ & $\begin{array}{r}197,847 \\
78,903 \\
29,586 \\
33,009 \\
288,541\end{array}$ \\
\hline 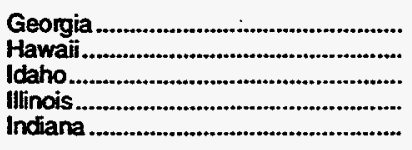 & $\begin{array}{r}273,799 \\
2,463 \\
32,110 \\
911,974 \\
389,312\end{array}$ & $\begin{array}{r}0 \\
0 \\
0 \\
3,998 \\
10\end{array}$ & $\begin{array}{r}5,283 \\
0 \\
2,611 \\
8,308 \\
5,859\end{array}$ & $\begin{array}{r}279,082 \\
2,463 \\
34,721 \\
924,280 \\
395,181\end{array}$ \\
\hline 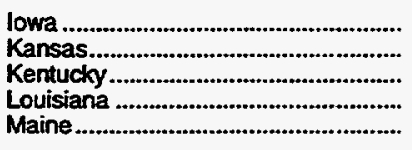 & $\begin{array}{r}199,640 \\
241,346 \\
140,704 \\
1,149,230 \\
2,465\end{array}$ & $\begin{array}{r}0 \\
38,885 \\
6,335 \\
243,283 \\
0\end{array}$ & $\begin{array}{r}7,262 \\
32,449 \\
20,134 \\
46,050 \\
8\end{array}$ & $\begin{array}{r}206,902 \\
312,680 \\
167,173 \\
1,438,563 \\
2,473\end{array}$ \\
\hline 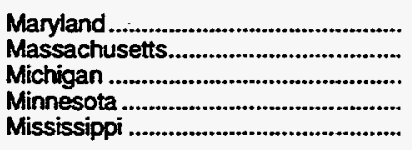 & $\begin{array}{l}150,477 \\
184,727 \\
648,981 \\
237,361 \\
179,610\end{array}$ & $\begin{array}{r}1 \\
0 \\
7,609 \\
0 \\
6,562\end{array}$ & $\begin{array}{r}2,064 \\
1,623 \\
14,733 \\
7,411 \\
28,652\end{array}$ & $\begin{array}{l}152,542 \\
186,350 \\
671,323 \\
244,772 \\
214,824\end{array}$ \\
\hline 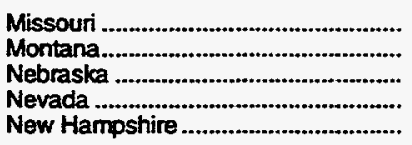 & $\begin{array}{r}238,144 \\
37,272 \\
100,762 \\
33,746 \\
10,269\end{array}$ & $\begin{array}{r}0 \\
1,808 \\
59 \\
0 \\
0\end{array}$ & $\begin{array}{r}3,516 \\
2,068 \\
3,911 \\
44 \\
22\end{array}$ & $\begin{array}{r}241,660 \\
41,148 \\
104,732 \\
33,790 \\
10,291\end{array}$ \\
\hline 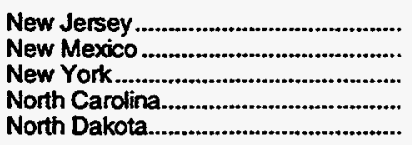 & $\begin{array}{r}350,632 \\
72,830 \\
724,481 \\
130,787 \\
21,189\end{array}$ & $\begin{array}{r}0 \\
35,615 \\
957 \\
0 \\
3,974\end{array}$ & $\begin{array}{r}2,833 \\
25,753 \\
3,364 \\
5,032 \\
308\end{array}$ & $\begin{array}{r}353,465 \\
134,198 \\
728,802 \\
135,819 \\
25,471\end{array}$ \\
\hline 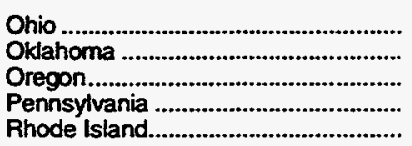 & $\begin{array}{r}702,851 \\
448,808 \\
67,349 \\
572,209 \\
26,270\end{array}$ & $\begin{array}{r}5,243 \\
84,200 \\
131 \\
4,715 \\
0\end{array}$ & $\begin{array}{r}8,684 \\
21,117 \\
3,493 \\
33,029 \\
84\end{array}$ & $\begin{array}{r}716,778 \\
554,125 \\
70,973 \\
609,953 \\
26,354\end{array}$ \\
\hline 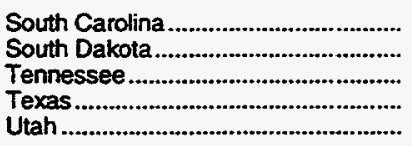 & $\begin{array}{r}96,175 \\
23,114 \\
174,333 \\
2,801,490 \\
90,784\end{array}$ & $\begin{array}{r}0 \\
70 \\
98 \\
302,266 \\
13,289\end{array}$ & $\begin{array}{r}2,374 \\
108 \\
13,569 \\
81,753 \\
1,102\end{array}$ & $\begin{array}{r}98,549 \\
23,292 \\
188,000 \\
3,185,509 \\
105,175\end{array}$ \\
\hline 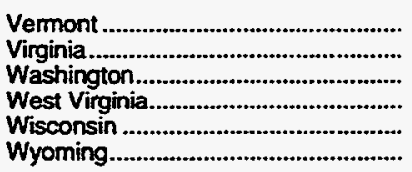 & $\begin{array}{r}5,014 \\
135,725 \\
116,389 \\
89,533 \\
275,112 \\
39,348\end{array}$ & $\begin{array}{r}0 \\
438 \\
0 \\
6.658 \\
0 \\
30,599\end{array}$ & $\begin{array}{r}5 \\
4,861 \\
1,971 \\
16,382 \\
3,736 \\
5,082\end{array}$ & $\begin{array}{r}5,019 \\
141,024 \\
118,360 \\
112,573 \\
278,848 \\
75,029\end{array}$ \\
\hline Total. & $14,813,731$ & 922,524 & 485,041 & $16,221,296$ \\
\hline
\end{tabular}

See footnotes at end of table. 
Table 14. Consumption of Natural Gas by State, 1967-1992 (Continued) (Million Cubic Feet)

\begin{tabular}{|c|c|c|c|c|}
\hline Stute & Delivered to Consumers & Lease and Plant Fuel & Pipoline Fuel & Total Consumption \\
\hline & \multicolumn{4}{|c|}{1987} \\
\hline $\begin{array}{l}\text { Alabama. } \\
\text { Alaska } \\
\text { Arizona... } \\
\text { Arkansas..... } \\
\text { Calfomia. }\end{array}$ & $\begin{array}{r}189,112 \\
130,478 \\
100,517 \\
151,856 \\
1,889,118\end{array}$ & $\begin{array}{r}6,878 \\
116,682 \\
6 \\
11,990 \\
26,846\end{array}$ & $\begin{array}{r}11,767 \\
2,109 \\
16,664 \\
5,780 \\
18,946\end{array}$ & $\begin{array}{r}207,757 \\
249,269 \\
117,187 \\
169,626 \\
1,934,909\end{array}$ \\
\hline 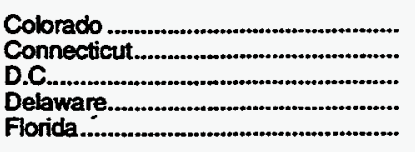 & $\begin{array}{r}189,364 \\
90,867 \\
30,728 \\
36,699 \\
288,317\end{array}$ & $\begin{array}{r}12,095 \\
0 \\
0 \\
0 \\
7,563\end{array}$ & $\begin{array}{r}8,688 \\
976 \\
260 \\
4 \\
4,459\end{array}$ & $\begin{array}{r}210,147 \\
91,842 \\
30,988 \\
36,703 \\
300,339\end{array}$ \\
\hline 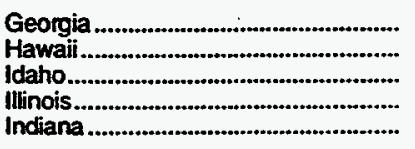 & $\begin{array}{r}297,249 \\
2,610 \\
33,583 \\
863,261 \\
406,661\end{array}$ & $\begin{array}{r}0 \\
0 \\
0 \\
3,425 \\
7\end{array}$ & $\begin{array}{r}6,171 \\
0 \\
3,564 \\
6,750 \\
5,921\end{array}$ & $\begin{array}{r}303,420 \\
2,610 \\
37,147 \\
873,436 \\
412,588\end{array}$ \\
\hline 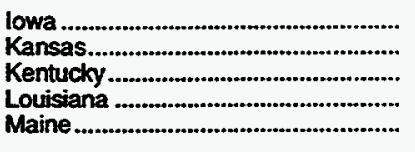 & $\begin{array}{r}194,914 \\
252,726 \\
147,258 \\
1,147,961 \\
2,629\end{array}$ & $\begin{array}{r}0 \\
44,505 \\
3,254 \\
301,279 \\
0\end{array}$ & $\begin{array}{r}8,149 \\
30,833 \\
21,398 \\
51,439 \\
11\end{array}$ & $\begin{array}{r}203,064 \\
328,064 \\
171,910 \\
1,500,679 \\
2,641\end{array}$ \\
\hline 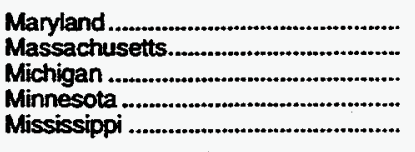 & $\begin{array}{l}166,428 \\
225,701 \\
635,568 \\
233,532 \\
168,075\end{array}$ & $\begin{array}{r}2 \\
0 \\
9,616 \\
0 \\
8,091\end{array}$ & $\begin{array}{r}2,123 \\
1,119 \\
12,212 \\
6,458 \\
32,416\end{array}$ & $\begin{array}{l}168,553 \\
226,820 \\
657,396 \\
239,990 \\
208,582\end{array}$ \\
\hline $\begin{array}{l}\text { Missouri } \\
\text { Montana } \\
\text { Nebraska } \\
\text { Nevada } \\
\text { New Hampshire }\end{array}$ & $\begin{array}{r}229,960 \\
34,687 \\
104,838 \\
41,161 \\
11,951\end{array}$ & $\begin{array}{r}0 \\
2,088 \\
74 \\
0 \\
0\end{array}$ & $\begin{array}{r}1,981 \\
2,011 \\
4,466 \\
172 \\
19\end{array}$ & $\begin{array}{r}231,941 \\
38,786 \\
109,378 \\
41,333 \\
11,970\end{array}$ \\
\hline 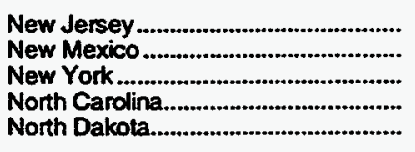 & $\begin{array}{r}418,018 \\
79,406 \\
771,003 \\
143,500 \\
18,672\end{array}$ & $\begin{array}{r}0 \\
48.138 \\
975 \\
0 \\
5.194\end{array}$ & $\begin{array}{r}3,382 \\
25,703 \\
6,580 \\
5,153 \\
961\end{array}$ & $\begin{array}{r}421,400 \\
153,247 \\
778,558 \\
148,653 \\
24,828\end{array}$ \\
\hline 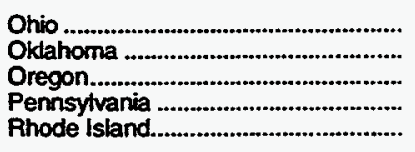 & $\begin{array}{r}697,895 \\
467,942 \\
72,143 \\
594,317 \\
35,865\end{array}$ & $\begin{array}{r}5,802 \\
104,415 \\
130 \\
5,799 \\
0\end{array}$ & $\begin{array}{r}11,232 \\
23,735 \\
7,976 \\
36,041 \\
65\end{array}$ & $\begin{array}{r}714,929 \\
596,092 \\
80,249 \\
636,157 \\
35,930\end{array}$ \\
\hline $\begin{array}{l}\text { South Carolina } \\
\text { South Dakota } \\
\text { Tennessee } \\
\text { Texas }\end{array}$ & $\begin{array}{r}103,273 \\
20,837 \\
185,200 \\
2,866,540 \\
80,494\end{array}$ & $\begin{array}{r}0 \\
125 \\
93 \\
355,765 \\
17,671\end{array}$ & $\begin{array}{r}2.388 \\
125 \\
15,278 \\
80,976 \\
822\end{array}$ & $\begin{array}{r}105,661 \\
21.087 \\
200,571 \\
3,303,281 \\
98,987\end{array}$ \\
\hline 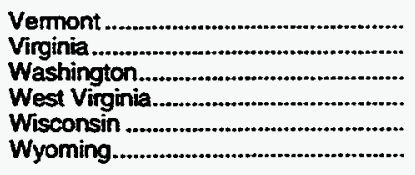 & $\begin{array}{r}5,181 \\
151,880 \\
127,965 \\
94,065 \\
275,958 \\
34,290\end{array}$ & $\begin{array}{r}0 \\
669 \\
0 \\
8,835 \\
0 \\
41,371\end{array}$ & $\begin{array}{r}0 \\
6,348 \\
3,781 \\
12,309 \\
3,408 \\
6,043\end{array}$ & $\begin{array}{r}5,181 \\
158,897 \\
131,746 \\
115,208 \\
279,366 \\
81,704\end{array}$ \\
\hline 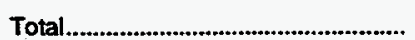 & $15,542,256$ & $1,149,383$ & 519,170 & $17,210,809$ \\
\hline
\end{tabular}

See footnoles at end of table. 
Table 14. Consumption of Natural Gas by State, 1967-1992 (Continued) (Million Cubic Feet)

\begin{tabular}{|c|c|c|c|c|}
\hline State & Delivered to Consumers & Lease and Plant Fuel & Pipeline Fuel & Total Consumption \\
\hline & \multicolumn{4}{|c|}{1988} \\
\hline 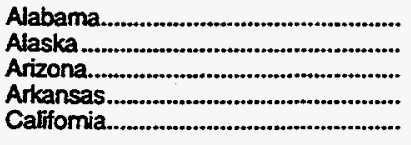 & $\begin{array}{r}217,586 \\
132,017 \\
106,017 \\
197,208 \\
1,762,480\end{array}$ & $\begin{array}{r}6,655 \\
153,670 \\
5 \\
12,115 \\
22,778\end{array}$ & $\begin{array}{r}12,115 \\
1,961 \\
18,343 \\
7,513 \\
19,194\end{array}$ & $\begin{array}{r}236,356 \\
287,648 \\
124,366 \\
216,836 \\
1,804,452\end{array}$ \\
\hline 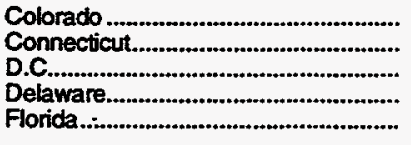 & $\begin{array}{r}208,087 \\
87,592 \\
32,483 \\
29,253 \\
282,792\end{array}$ & $\begin{array}{r}11,622 \\
0 \\
0 \\
0 \\
7,275\end{array}$ & $\begin{array}{r}7,875 \\
538 \\
236 \\
4 \\
3,366\end{array}$ & $\begin{array}{r}227,584 \\
88,130 \\
32,719 \\
29,258 \\
293,433\end{array}$ \\
\hline 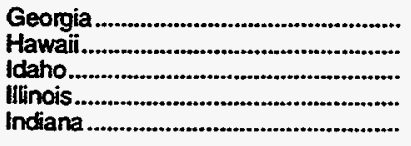 & $\begin{array}{r}316,105 \\
2,614 \\
36,646 \\
952,529 \\
447,542\end{array}$ & $\begin{array}{r}0 \\
0 \\
0 \\
62 \\
12\end{array}$ & $\begin{array}{r}6,925 \\
0 \\
4,091 \\
12,798 \\
9,259\end{array}$ & $\begin{array}{r}323,030 \\
2,614 \\
40,736 \\
965,388 \\
456,812\end{array}$ \\
\hline 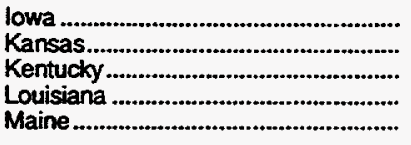 & $\begin{array}{r}228,538 \\
264,539 \\
160,332 \\
1,116,676 \\
3,191\end{array}$ & $\begin{array}{r}0 \\
45,928 \\
2,942 \\
272,455 \\
0\end{array}$ & $\begin{array}{r}10,589 \\
42,457 \\
20,804 \\
56,573 \\
6\end{array}$ & $\begin{array}{r}239,127 \\
352,924 \\
184,078 \\
1,445,703 \\
3,197\end{array}$ \\
\hline 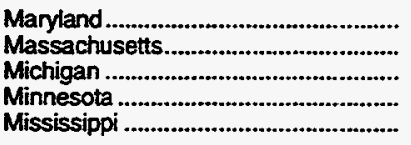 & $\begin{array}{l}170,326 \\
208,998 \\
722,598 \\
272,585 \\
171,168\end{array}$ & $\begin{array}{r}1 \\
0 \\
8,250 \\
0 \\
7,100\end{array}$ & $\begin{array}{r}2,573 \\
1.978 \\
18,377 \\
11,255 \\
34,511\end{array}$ & $\begin{array}{l}172,901 \\
210,975 \\
749,225 \\
283,840 \\
212,779\end{array}$ \\
\hline 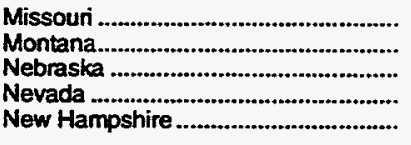 & $\begin{array}{r}248,022 \\
37,587 \\
117,234 \\
48,031 \\
12,987\end{array}$ & $\begin{array}{r}0 \\
1,994 \\
47 \\
0 \\
0\end{array}$ & $\begin{array}{r}4,901 \\
2,245 \\
4,698 \\
195 \\
22\end{array}$ & $\begin{array}{r}252,923 \\
41,825 \\
121,979 \\
48,226 \\
13,009\end{array}$ \\
\hline 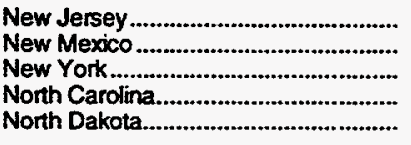 & $\begin{array}{r}411,415 \\
94,650 \\
784,673 \\
146,790 \\
22,876\end{array}$ & $\begin{array}{r}0 \\
41,706 \\
788 \\
0 \\
4,014\end{array}$ & $\begin{array}{r}2,864 \\
37,094 \\
4,757 \\
5,200 \\
1,724\end{array}$ & $\begin{array}{r}414,279 \\
173,450 \\
790,218 \\
151,990 \\
28,614\end{array}$ \\
\hline 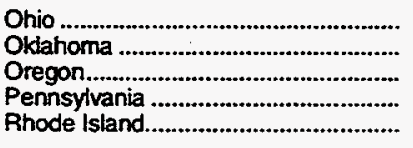 & $\begin{array}{r}790,436 \\
460,130 \\
78,996 \\
626,688 \\
30,668\end{array}$ & $\begin{array}{r}4,869 \\
100,926 \\
115 \\
4,983 \\
0\end{array}$ & $\begin{array}{r}10,004 \\
27,740 \\
8,052 \\
36,990 \\
119\end{array}$ & $\begin{array}{r}805,309 \\
588,796 \\
87,163 \\
668,661 \\
30,787\end{array}$ \\
\hline 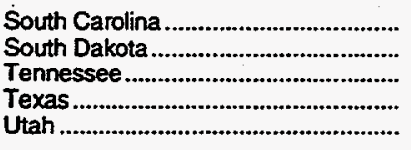 & $\begin{array}{r}109,817 \\
23,974 \\
197,095 \\
3,104,559 \\
90,702\end{array}$ & $\begin{array}{r}0 \\
123 \\
60 \\
318,922 \\
16,889\end{array}$ & $\begin{array}{r}2,493 \\
130 \\
17,089 \\
107,527 \\
1,362\end{array}$ & $\begin{array}{r}112,309 \\
24,227 \\
214,244 \\
3,531,008 \\
108,954\end{array}$ \\
\hline 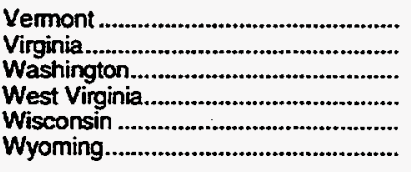 & $\begin{array}{r}5,551 \\
154,756 \\
142,825 \\
100,595 \\
312,832 \\
36,005\end{array}$ & $\begin{array}{r}0 \\
536 \\
0 \\
8,343 \\
0 \\
40,698\end{array}$ & $\begin{array}{r}0 \\
8,238 \\
3,953 \\
13,202 \\
4,314 \\
5,660\end{array}$ & $\begin{array}{r}5,551 \\
163,529 \\
146,778 \\
122,140 \\
317,146 \\
82,363\end{array}$ \\
\hline Total & $16,319,793$ & $1,095,883$ & 613,912 & $18,029,588$ \\
\hline
\end{tabular}

See footnotes at end of table. 
Table 14. Consumption of Natural Gas by State, 1967-1992 (Continued) (Million Cubic Feet)

\begin{tabular}{|c|c|c|c|c|}
\hline State & Delivered to Consumers & Lease and Plant Fual & Pipeline Fuel & Total Consumption \\
\hline & \multicolumn{4}{|c|}{1989} \\
\hline 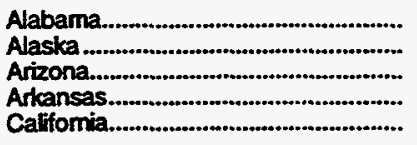 & $\begin{array}{r}225,395 \\
127,414 \\
127,177 \\
228,378 \\
1,799,042\end{array}$ & $\begin{array}{r}6,152 \\
192,239 \\
35 \\
11,586 \\
19,586\end{array}$ & $\begin{array}{r}13,534 \\
1,876 \\
18,430 \\
9,677 \\
19,203\end{array}$ & $\begin{array}{r}245,081 \\
321,529 \\
145,642 \\
249,641 \\
1,837,831\end{array}$ \\
\hline 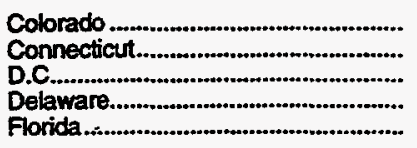 & $\begin{array}{r}218,766 \\
94,487 \\
33,174 \\
34,919 \\
310,493\end{array}$ & $\begin{array}{r}12,221 \\
0 \\
0 \\
0 \\
8,942\end{array}$ & $\begin{array}{r}11,228 \\
568 \\
249 \\
4 \\
4,156\end{array}$ & $\begin{array}{r}242,215 \\
95,055 \\
33,422 \\
34,924 \\
323,591\end{array}$ \\
\hline 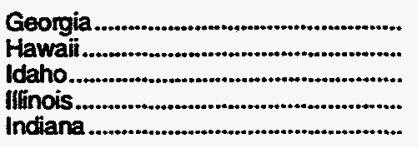 & $\begin{array}{r}310,542 \\
2,694 \\
40,710 \\
981,948 \\
453,585\end{array}$ & $\begin{array}{r}0 \\
0 \\
0 \\
52 \\
10\end{array}$ & $\begin{array}{r}7,060 \\
0 \\
4,961 \\
13,531 \\
8,457\end{array}$ & $\begin{array}{r}317,603 \\
2,694 \\
45,671 \\
995,532 \\
462,053\end{array}$ \\
\hline 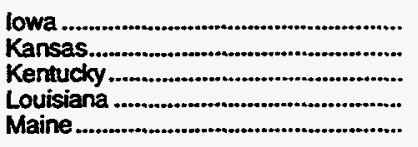 & $\begin{array}{r}215,294 \\
254,361 \\
165,565 \\
1,232,511 \\
3,672\end{array}$ & $\begin{array}{r}0 \\
43,630 \\
2,345 \\
256,123 \\
0\end{array}$ & $\begin{array}{r}10,446 \\
43,298 \\
20,610 \\
49,847 \\
6\end{array}$ & $\begin{array}{r}225,739 \\
341,289 \\
188,520 \\
1,538,481 \\
3,678\end{array}$ \\
\hline 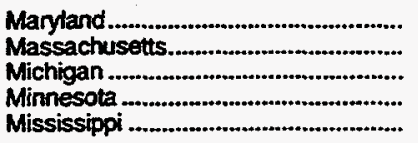 & $\begin{array}{l}187,512 \\
247,205 \\
749,613 \\
287,997 \\
186,597\end{array}$ & $\begin{array}{r}1 \\
0 \\
8,003 \\
0 \\
5,021\end{array}$ & $\begin{array}{r}2,193 \\
2,254 \\
16,824 \\
11,889 \\
34,007\end{array}$ & $\begin{array}{l}189,706 \\
249,459 \\
774,439 \\
299,886 \\
225,625\end{array}$ \\
\hline 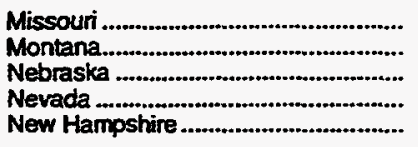 & $\begin{array}{r}247,363 \\
41,575 \\
115,293 \\
62,950 \\
13,925\end{array}$ & $\begin{array}{r}0 \\
1,766 \\
34 \\
0 \\
0\end{array}$ & $\begin{array}{r}5,164 \\
2,415 \\
4,909 \\
717 \\
19\end{array}$ & $\begin{array}{r}252,527 \\
45,756 \\
120,235 \\
63,667 \\
13,945\end{array}$ \\
\hline 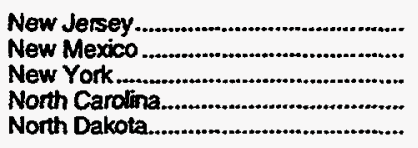 & $\begin{array}{r}453,110 \\
101,126 \\
839,957 \\
156,105 \\
24,959\end{array}$ & $\begin{array}{r}0 \\
42,224 \\
604 \\
0 \\
3,388\end{array}$ & $\begin{array}{r}3,998 \\
52,386 \\
5,292 \\
5,683 \\
1,805\end{array}$ & $\begin{array}{r}457,108 \\
195,736 \\
845,853 \\
161,788 \\
30,152\end{array}$ \\
\hline 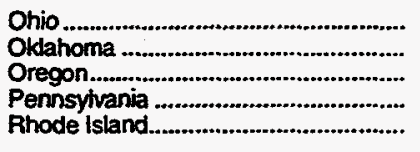 & $\begin{array}{r}799,852 \\
474,118 \\
99,448 \\
649,508 \\
33,821\end{array}$ & $\begin{array}{r}3,876 \\
90,225 \\
59 \\
4,767 \\
0\end{array}$ & $\begin{array}{r}10,395 \\
36,482 \\
8,522 \\
27,338 \\
116\end{array}$ & $\begin{array}{r}814,123 \\
600,824 \\
108,028 \\
681,614 \\
33,938\end{array}$ \\
\hline 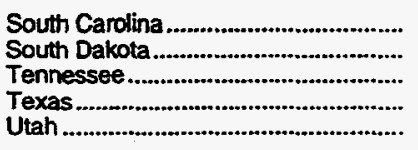 & $\begin{array}{r}114,237 \\
25,263 \\
203,626 \\
3,224,451 \\
96,288\end{array}$ & $\begin{array}{r}0 \\
112 \\
45 \\
291,977 \\
16,211\end{array}$ & $\begin{array}{r}2,581 \\
130 \\
17,810 \\
107.190 \\
1,037\end{array}$ & $\begin{array}{r}116,818 \\
25,504 \\
221,482 \\
3,623,618 \\
113,536\end{array}$ \\
\hline 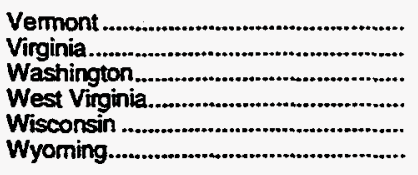 & $\begin{array}{r}6,145 \\
167,450 \\
158,420 \\
110,327 \\
326,613 \\
36,633\end{array}$ & $\begin{array}{r}0 \\
425 \\
0 \\
7,882 \\
0 \\
40,361\end{array}$ & $\begin{array}{r}5 \\
5,850 \\
4,359 \\
11,250 \\
4,179 \\
5,368\end{array}$ & $\begin{array}{r}6,151 \\
173,725 \\
162,779 \\
129,460 \\
330,792 \\
82,362\end{array}$ \\
\hline 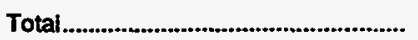 & $17,101,615$ & $1,069,902$ & 629,308 & $18,800,826$ \\
\hline
\end{tabular}

See footnotes at end of table. 
Table 14. Consumption of Natural Gas by State, 1967-1992 (Continued) (Million Cubic Feet)

\begin{tabular}{|c|c|c|c|c|c|}
\hline State & Delivered to Consumers & Loase and Plant Fuel & Pipeline Fuel & Total Consumption & \\
\hline & \multicolumn{5}{|c|}{1990} \\
\hline 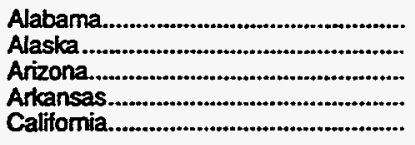 & $\begin{array}{r}219,286 \\
147,002 \\
101,378 \\
216,630 \\
1,821,213\end{array}$ & $\begin{array}{r}9,881 \\
193,875 \\
71 \\
7,101 \\
22,712\end{array}$ & $\begin{array}{r}14,636 \\
1,708 \\
25,277 \\
8,643 \\
20,132\end{array}$ & $\begin{array}{r}243,803 \\
342,585 \\
126,726 \\
232,374 \\
1,864,057\end{array}$ & \\
\hline 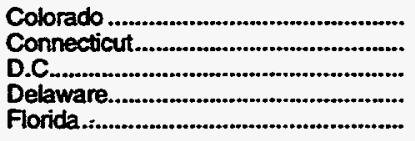 & $\begin{array}{r}212,655 \\
97,147 \\
28,611 \\
39,124 \\
322,516\end{array}$ & $\begin{array}{r}17,343 \\
0 \\
0 \\
0 \\
1,716\end{array}$ & $\begin{array}{r}9,114 \\
486 \\
253 \\
4 \\
2,790\end{array}$ & $\begin{array}{r}239,112 \\
97,634 \\
28,864 \\
39,127 \\
327,023\end{array}$ & \\
\hline 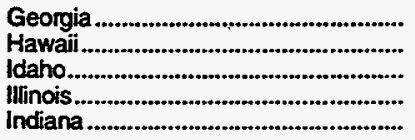 & $\begin{array}{r}303,674 \\
2,788 \\
40,431 \\
927,261 \\
442,512\end{array}$ & $\begin{array}{r}0 \\
0 \\
0 \\
131 \\
13\end{array}$ & $\begin{array}{r}7,342 \\
0 \\
5,081 \\
12,111 \\
8,429\end{array}$ & $\begin{array}{r}311,015 \\
2,788 \\
45,512 \\
939,502 \\
450,954\end{array}$ & \\
\hline 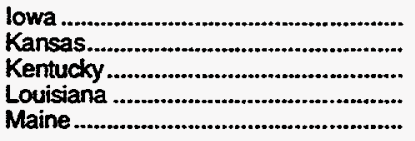 & $\begin{array}{r}209,051 \\
271,265 \\
156,560 \\
1,256,987 \\
4,350\end{array}$ & $\begin{array}{r}0 \\
40,914 \\
3,149 \\
258,267 \\
0\end{array}$ & $\begin{array}{r}9,150 \\
40,600 \\
24,624 \\
55,736 \\
5\end{array}$ & $\begin{array}{r}218,201 \\
352,780 \\
184,333 \\
1,570,991 \\
4,354\end{array}$ & - \\
\hline 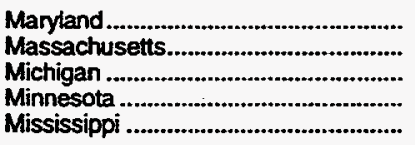 & $\begin{array}{l}169,863 \\
256,979 \\
790,441 \\
278,570 \\
208,699\end{array}$ & $\begin{array}{r}1 \\
0 \\
9,094 \\
0 \\
7,257\end{array}$ & $\begin{array}{r}2,403 \\
1,235 \\
17,928 \\
12,017 \\
37,735\end{array}$ & $\begin{array}{l}172,267 \\
258,214 \\
817,463 \\
290,587 \\
253,690\end{array}$ & \\
\hline 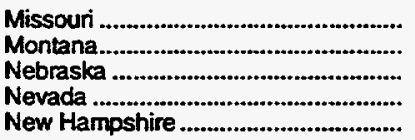 & $\begin{array}{r}233,408 \\
38,856 \\
107,500 \\
64,086 \\
14,252\end{array}$ & $\begin{array}{r}0 \\
2,262 \\
26 \\
0 \\
0\end{array}$ & $\begin{array}{r}5,302 \\
2,051 \\
3,536 \\
791 \\
22\end{array}$ & $\begin{array}{r}238,709 \\
43,169 \\
111,063 \\
64,876 \\
14,274\end{array}$ & \\
\hline 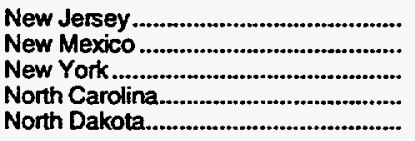 & $\begin{array}{r}425,218 \\
96,551 \\
857,517 \\
154,927 \\
23,779\end{array}$ & $\begin{array}{r}0 \\
65,889 \\
840 \\
0 \\
6,939\end{array}$ & $\begin{array}{r}2,624 \\
76,091 \\
4,733 \\
6,281 \\
1,771\end{array}$ & $\begin{array}{r}427,842 \\
238,531 \\
863,090 \\
161,208 \\
32,490\end{array}$ & \\
\hline 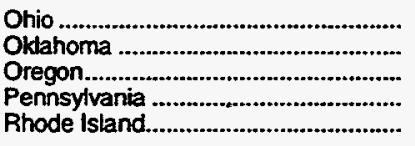 & $\begin{array}{r}731,609 \\
466,827 \\
100,108 \\
603,402 \\
35,668\end{array}$ & $\begin{array}{r}5,129 \\
111,567 \\
93 \\
6,031 \\
0\end{array}$ & $\begin{array}{r}9,981 \\
26,030 \\
9,014 \\
34,395 \\
118\end{array}$ & $\begin{array}{r}746,719 \\
604,423 \\
109,215 \\
643,828 \\
35,787\end{array}$ & \\
\hline 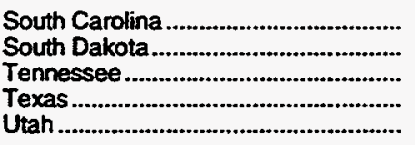 & $\begin{array}{r}127,595 \\
24,787 \\
200,161 \\
3,101,177 \\
96,054\end{array}$ & $\begin{array}{r}0 \\
158 \\
74 \\
394,605 \\
19.719\end{array}$ & $\begin{array}{r}2,858 \\
110 \\
19.596 \\
106.046 \\
875\end{array}$ & $\begin{array}{r}130,453 \\
25,056 \\
219,831 \\
3,601,828 \\
116,648\end{array}$ & \\
\hline 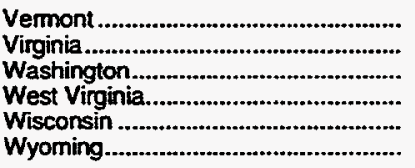 & $\begin{array}{r}6,761 \\
173,437 \\
157,682 \\
102,124 \\
304,688 \\
45,715\end{array}$ & $\begin{array}{r}0 \\
489 \\
0 \\
9.631 \\
0 \\
41.415\end{array}$ & $\begin{array}{r}5 \\
6,943 \\
5,053 \\
8,698 \\
4,392 \\
5,059\end{array}$ & $\begin{array}{r}6,766 \\
180,868 \\
162,735 \\
120,453 \\
309,080 \\
92,190\end{array}$ & \\
\hline 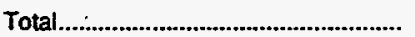 & $16,818,882$ & $1,236,392$ & 659,816 & $18,715,090$ & \\
\hline
\end{tabular}

See footnotes at end of table. 
Table.14. Consumption of Natural Gas by State, 1967-1992 (Continued) (Million Cubic Feet)

\begin{tabular}{|c|c|c|c|c|}
\hline State & Delivered to Consumers & Lease and Plant Fuel & Pipeline Fuel & Total Consumption \\
\hline & \multicolumn{4}{|c|}{1991} \\
\hline 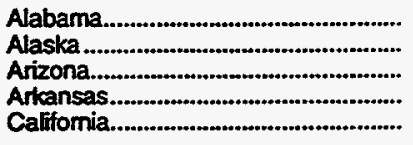 & $\begin{array}{r}228,765 \\
141,426 \\
101,473 \\
199,379 \\
1,847,949\end{array}$ & $\begin{array}{r}8,627 \\
223,194 \\
45 \\
1,406 \\
104,251\end{array}$ & $\begin{array}{r}16,482 \\
2,597 \\
23,534 \\
8,340 \\
18,509\end{array}$ & $\begin{array}{r}253,874 \\
367,218 \\
125,052 \\
209,124 \\
1,970,709\end{array}$ \\
\hline 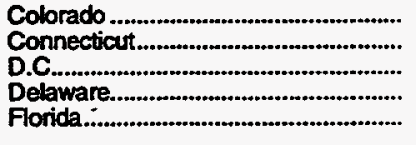 & $\begin{array}{r}228,283 \\
101,380 \\
30,836 \\
41,944 \\
336,895\end{array}$ & $\begin{array}{r}23,883 \\
0 \\
0 \\
0 \\
3,751\end{array}$ & $\begin{array}{r}8,346 \\
523 \\
265 \\
4 \\
3,469\end{array}$ & $\begin{array}{r}260,513 \\
101,904 \\
31,101 \\
41,948 \\
344,116\end{array}$ \\
\hline 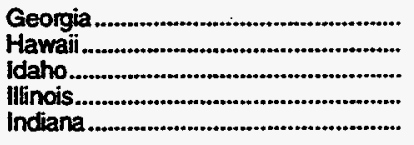 & $\begin{array}{r}315,634 \\
2,694 \\
46,467 \\
976,377 \\
452,690\end{array}$ & $\begin{array}{r}0 \\
0 \\
0 \\
142 \\
5\end{array}$ & $\begin{array}{r}7,432 \\
0 \\
4,589 \\
11,070 \\
4,617\end{array}$ & $\begin{array}{r}323,066 \\
2,694 \\
51,055 \\
987,589 \\
457,311\end{array}$ \\
\hline 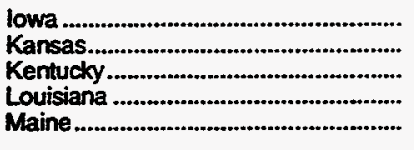 & $\begin{array}{r}226,533 \\
293,035 \\
165,028 \\
1,258,960 \\
4,789\end{array}$ & $\begin{array}{r}0 \\
44,614 \\
2,432 \\
195,526 \\
0\end{array}$ & $\begin{array}{r}6,648 \\
32,908 \\
19,983 \\
53,622 \\
3\end{array}$ & $\begin{array}{r}233,182 \\
370,556 \\
187,443 \\
1,508,108 \\
4,792\end{array}$ \\
\hline 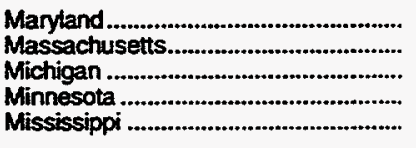 & $\begin{array}{l}170,561 \\
250,028 \\
798,489 \\
301,144 \\
210,531\end{array}$ & $\begin{array}{r}0 \\
0 \\
9,595 \\
0 \\
4,585\end{array}$ & $\begin{array}{r}2,519 \\
1,511 \\
19,590 \\
13,332 \\
34,645\end{array}$ & $\begin{array}{l}173,081 \\
251,539 \\
827,674 \\
314,476 \\
249,761\end{array}$ \\
\hline 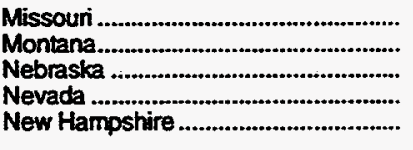 & $\begin{array}{r}253,765 \\
41,401 \\
113,409 \\
64,465 \\
14,094\end{array}$ & $\begin{array}{r}0 \\
1,680 \\
31 \\
53 \\
0\end{array}$ & $\begin{array}{r}2,563 \\
2,321 \\
2,368 \\
341 \\
33\end{array}$ & $\begin{array}{r}256,328 \\
45,402 \\
115,808 \\
64,859 \\
14,127\end{array}$ \\
\hline 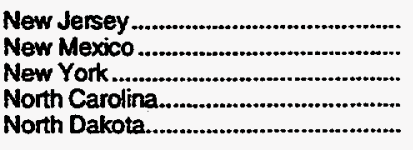 & $\begin{array}{r}460,521 \\
102,206 \\
869,100 \\
160,172 \\
26,195\end{array}$ & $\begin{array}{r}0 \\
44,766 \\
1,073 \\
0 \\
11,583\end{array}$ & $\begin{array}{r}2,917 \\
71,788 \\
5,011 \\
6,207 \\
2,011\end{array}$ & $\begin{array}{r}463,437 \\
218,760 \\
875,184 \\
166,380 \\
39,789\end{array}$ \\
\hline 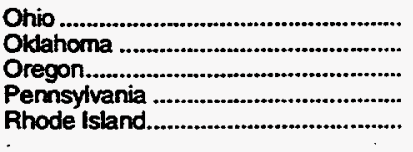 & $\begin{array}{r}755,118 \\
456,705 \\
114,557 \\
601,688 \\
54,148\end{array}$ & $\begin{array}{r}1,476 \\
88,366 \\
60 \\
3,502 \\
0\end{array}$ & $\begin{array}{r}9,046 \\
25,083 \\
8,819 \\
34,129 \\
161\end{array}$ & $\begin{array}{r}765,639 \\
570,154 \\
123,436 \\
639,319 \\
54,310\end{array}$ \\
\hline $\begin{array}{l}\text { South Carolina } \\
\text { South Dakota } \\
\text { Tennessee } \\
\text { Texas } \\
\text { Utah }\end{array}$ & $\begin{array}{r}131,020 \\
25,529 \\
211,309 \\
3,180,917 \\
118,164\end{array}$ & $\begin{array}{r}0 \\
393 \\
44 \\
297,233 \\
13,738\end{array}$ & $\begin{array}{r}2,808 \\
338 \\
15,756 \\
81,963 \\
864\end{array}$ & $\begin{array}{r}133,828 \\
26,260 \\
227,108 \\
3,560,113 \\
132,766\end{array}$ \\
\hline 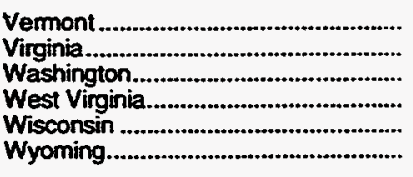 & $\begin{array}{r}7,069 \\
167,709 \\
167,901 \\
94,659 \\
327,124 \\
54,348\end{array}$ & $\begin{array}{r}0 \\
327 \\
0 \\
7,744 \\
0 \\
35,142\end{array}$ & $\begin{array}{r}3 \\
6,636 \\
5,094 \\
8,305 \\
4,400 \\
7,802\end{array}$ & $\begin{array}{r}7,073 \\
174,671 \\
172,996 \\
110,708 \\
331,524 \\
97,291\end{array}$ \\
\hline 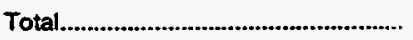 & $17,304,582$ & $1,129,268$ & 601,305 & $19,035,156$ \\
\hline
\end{tabular}

See footnotes at end of table. 
Table 14. Consumption of Natural Gas by State, 1967-1992 (Continued) (Million Cubic Feet)

\begin{tabular}{|c|c|c|c|c|}
\hline State & Delivered to Consumers & Leasa and Plant Fuel & Pipeline Fuel & Total Consumption \\
\hline & \multicolumn{4}{|c|}{1992} \\
\hline $\begin{array}{l}\text { Alabama } \\
\text { Alaska } \\
\text { Arizona } \\
\text { Arkansas... } \\
\text { Califomia... }\end{array}$ & $\begin{array}{r}247,295 \\
145,541 \\
106,234 \\
210,653 \\
1,923,573\end{array}$ & $\begin{array}{r}12,868 \\
234,716 \\
41 \\
5,838 \\
92,228\end{array}$ & $\begin{array}{r}18,631 \\
2,864 \\
23,376 \\
8,085 \\
14,763\end{array}$ & $\begin{array}{r}278,794 \\
383,121 \\
129,650 \\
224,576 \\
2,030,564\end{array}$ \\
\hline 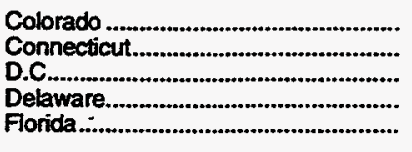 & $\begin{array}{r}223,656 \\
110,715 \\
32,690 \\
39,604 \\
343,521\end{array}$ & $\begin{array}{r}21,169 \\
0 \\
0 \\
0 \\
5,134\end{array}$ & $\begin{array}{r}8,248 \\
590 \\
266 \\
4 \\
4,337\end{array}$ & $\begin{array}{r}253,073 \\
111,305 \\
32,957 \\
39,608 \\
352,992\end{array}$ \\
\hline 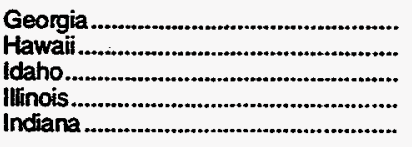 & $\begin{array}{r}335,464 \\
2,695 \\
45,635 \\
981,991 \\
478,765\end{array}$ & $\begin{array}{r}0 \\
0 \\
0 \\
107 \\
5\end{array}$ & $\begin{array}{r}7,501 \\
0 \\
3,280 \\
11,330 \\
4,726\end{array}$ & $\begin{array}{r}342,965 \\
2,695 \\
48,915 \\
993,428 \\
483,496\end{array}$ \\
\hline 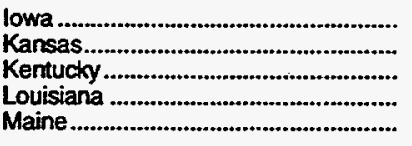 & $\begin{array}{r}223,992 \\
270,284 \\
171,218 \\
1,271,064 \\
5,129\end{array}$ & $\begin{array}{r}0 \\
43,736 \\
2,812 \\
220,711 \\
0\end{array}$ & $\begin{array}{r}6,940 \\
29,198 \\
15,847 \\
54,029 \\
2\end{array}$ & $\begin{array}{r}230,932 \\
343,217 \\
189,877 \\
1,545,804 \\
5,131\end{array}$ \\
\hline 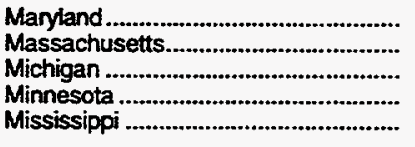 & $\begin{array}{l}178,881 \\
293,238 \\
862,217 \\
293,873 \\
201,221\end{array}$ & $\begin{array}{r}0 \\
0 \\
7,274 \\
0 \\
4,945\end{array}$ & $\begin{array}{r}2,419 \\
1,763 \\
21,690 \\
14,948 \\
33,276\end{array}$ & $\begin{array}{l}181,300 \\
295,001 \\
891,181 \\
308,821 \\
239,442\end{array}$ \\
\hline $\begin{array}{l}\text { Missouri } \\
\text { Montana } \\
\text { Nebraska } \\
\text { Nevada } \\
\text { New Hampshire }\end{array}$ & $\begin{array}{r}238,435 \\
40,671 \\
104,258 \\
67,912 \\
16,771\end{array}$ & $\begin{array}{r}1 \\
1,871 \\
40 \\
30 \\
0\end{array}$ & $\begin{array}{r}2,309 \\
3,019 \\
2,555 \\
474 \\
81\end{array}$ & $\begin{array}{r}240,745 \\
45,561 \\
106,853 \\
68,416 \\
16,852\end{array}$ \\
\hline 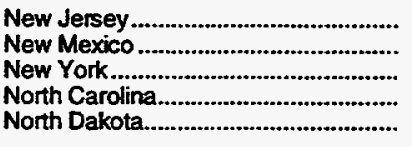 & $\begin{array}{r}\mathbf{5 4 2 , 6 9 5} \\
98,881 \\
952,161 \\
173,156 \\
25,397\end{array}$ & $\begin{array}{r}0 \\
53,697 \\
965 \\
0 \\
8,462\end{array}$ & $\begin{array}{r}3,566 \\
50,297 \\
5,878 \\
6,439 \\
2,729\end{array}$ & $\begin{array}{r}546,260 \\
202,875 \\
959,004 \\
179,595 \\
36,588\end{array}$ \\
\hline 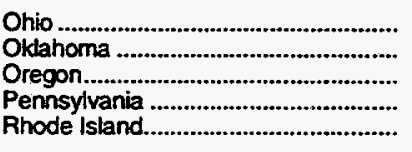 & $\begin{array}{r}799,093 \\
425,195 \\
115,469 \\
640,593 \\
77,476\end{array}$ & $\begin{array}{r}1,450 \\
92,978 \\
68 \\
3,381 \\
0\end{array}$ & $\begin{array}{r}9,578 \\
25,654 \\
6,812 \\
38,548 \\
357\end{array}$ & $\begin{array}{r}810,121 \\
543,827 \\
122,350 \\
682,521 \\
77,833\end{array}$ \\
\hline $\begin{array}{l}\text { South Carolina } \\
\text { South Dakota } \\
\text { Tennessee } \\
\text { Texas } \\
\text { Utah. }\end{array}$ & $\begin{array}{r}135,157 \\
24,454 \\
225,275 \\
3,101,526 \\
108,755\end{array}$ & $\begin{array}{r}0 \\
451 \\
39 \\
293,845 \\
12,611\end{array}$ & $\begin{array}{r}2,900 \\
1,741 \\
16,388 \\
80,903 \\
1,284\end{array}$ & $\begin{array}{r}138,057 \\
26,645 \\
241,702 \\
3,476,274 \\
122,649\end{array}$ \\
\hline 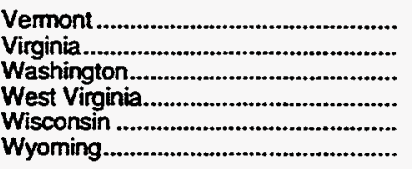 & $\begin{array}{r}7,598 \\
192,932 \\
166,092 \\
104,089 \\
327,599 \\
75,044\end{array}$ & $\begin{array}{r}0 \\
653 \\
0 \\
8,097 \\
0 \\
40,599\end{array}$ & $\begin{array}{r}3 \\
6,454 \\
3,069 \\
16,675 \\
3,983 \\
7,904\end{array}$ & $\begin{array}{r}7,601 \\
200,039 \\
169,161 \\
128,861 \\
331,581 \\
123,547\end{array}$ \\
\hline 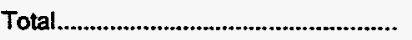 & $17,785,833$ & $1,170,821$ & 587,710 & $19,544,364$ \\
\hline
\end{tabular}

a Data for the District of Columbia are included with data for Maryland.

Data for New Hampshire and Vermont are included with data for Maine.

Note: Totals may not equal sum of components due to independent rounding.

Sources: 1967-1975: Bureau of Mines, Minerals Yearbook, "Natural Gas" chapter. 1976-1978: Energy Information Administration (ElA), Energy Data Reports, Natural Gas

Annual. 1979: ElA, Natural Gas Production and Consumption 1979. 1980-1992: Energy information Administration (ElA). Form ElA-176, Annual Report of Natural and

Supplemental Gas Supply and Disposition"; Fom EIA-64A. "Annual Report of the Origin of Natural Gas Liquids Production": and Form ElA-759, "Mionthly Power Plant Report." 
Table 15. Consumption of Natural Gas by State, 1993-1994 (Million Cubic Feet)

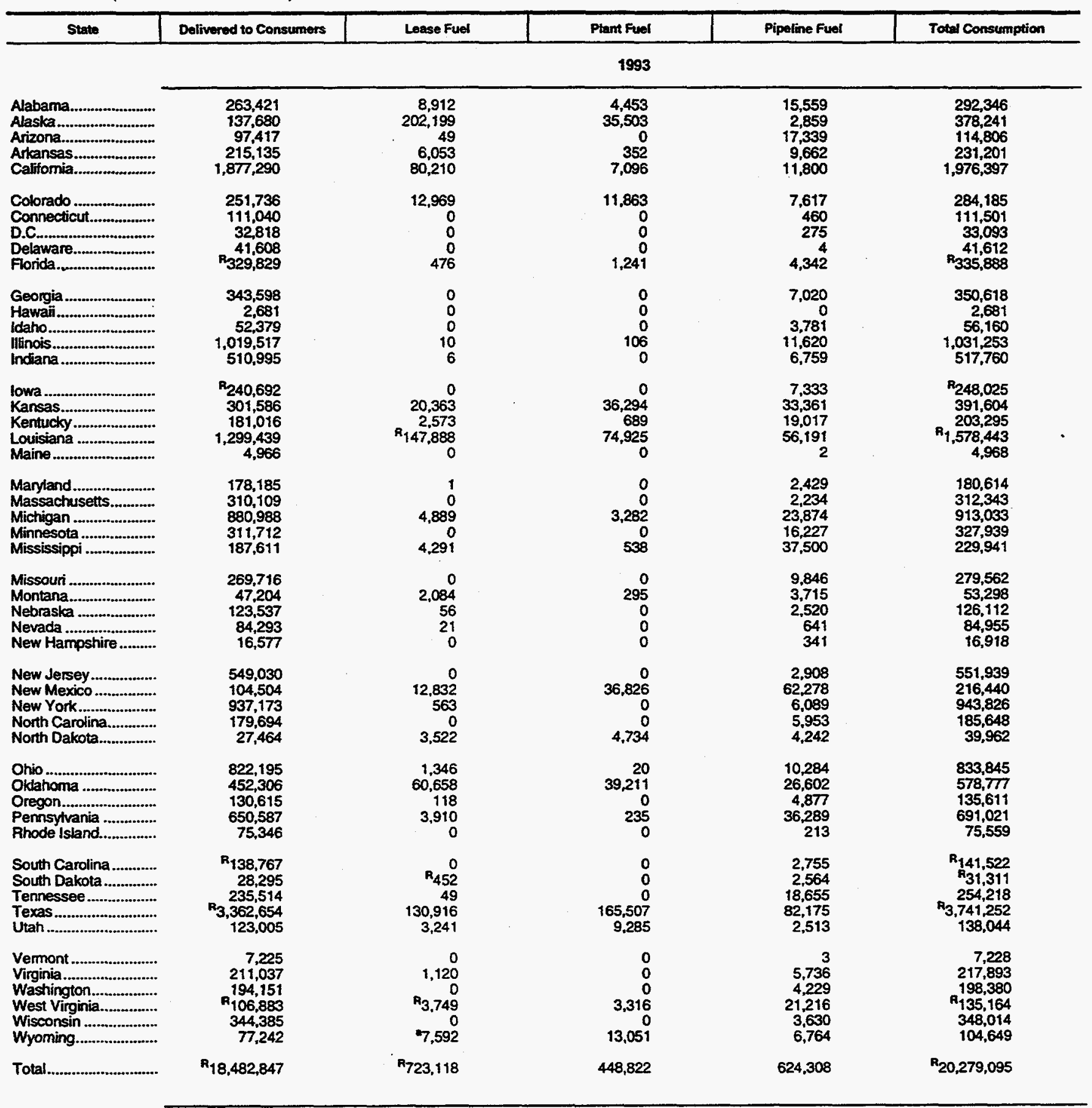

See footnotes at end of table. 
Table 15. Consumption of Natural Gas by State, 1993-1994 (Continued)

(Million Cubic Feet)

\begin{tabular}{|c|c|c|c|c|c|}
\hline State & Dolivered to Consumers & Lease Fuel & Plant Fuel & Pipeline Fuel & Total Consumption \\
\hline & \multicolumn{5}{|c|}{1994} \\
\hline 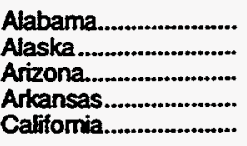 & $\begin{array}{r}260,830 \\
126,045 \\
108,517 \\
227,835 \\
2,041,539\end{array}$ & $\begin{array}{r}9,381 \\
236,781 \\
61 \\
4,283 \\
63,251\end{array}$ & $\begin{array}{r}3,747 \\
37,347 \\
0 \\
467 \\
6,388\end{array}$ & $\begin{array}{r}14,904 \\
3,024 \\
24,919 \\
11,840 \\
12,132\end{array}$ & $\begin{array}{r}288,863 \\
403,197 \\
133,497 \\
244,425 \\
2,123,310\end{array}$ \\
\hline 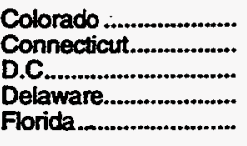 & $\begin{array}{r}241,416 \\
119,334 \\
30,607 \\
48,632 \\
361,428\end{array}$ & $\begin{array}{r}11,865 \\
0 \\
0 \\
0 \\
653\end{array}$ & $\begin{array}{r}12,482 \\
0 \\
0 \\
0 \\
-167\end{array}$ & $\begin{array}{r}9,998 \\
697 \\
242 \\
4 \\
5,304\end{array}$ & $\begin{array}{r}275,761 \\
120,031 \\
30,849 \\
48,636 \\
367,552\end{array}$ \\
\hline $\begin{array}{l}\text { Georgia } \\
\text { Hawaii } \\
\text { Idaho } \\
\text { Ilinois } \\
\text { indiana }\end{array}$ & $\begin{array}{r}334,418 \\
2,778 \\
52,164 \\
1,010,989 \\
512,482\end{array}$ & $\begin{array}{r}0 \\
0 \\
0 \\
10 \\
2\end{array}$ & $\begin{array}{r}0 \\
0 \\
0 \\
101 \\
0\end{array}$ & $\begin{array}{r}6,987 \\
0 \\
4,741 \\
13,808 \\
6,872\end{array}$ & $\begin{array}{r}341,405 \\
2,778 \\
56,905 \\
1,024,908 \\
519,356\end{array}$ \\
\hline 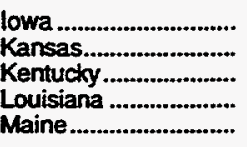 & $\begin{array}{r}237,614 \\
341,677 \\
182,710 \\
1,353,337 \\
5,045\end{array}$ & $\begin{array}{r}0 \\
15,623 \\
2.162 \\
140,571 \\
0\end{array}$ & $\begin{array}{r}0 \\
28.988 \\
611 \\
66,600 \\
0\end{array}$ & $\begin{array}{r}10,737 \\
31,739 \\
22,903 \\
63,257 \\
9\end{array}$ & $\begin{array}{r}248,351 \\
418,027 \\
208,386 \\
1,623,766 \\
5,055\end{array}$ \\
\hline 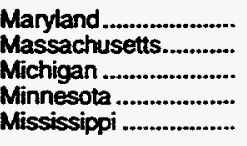 & $\begin{array}{l}181,259 \\
335,544 \\
893,735 \\
306,505 \\
225,730\end{array}$ & $\begin{array}{r}1 \\
0 \\
6,399 \\
0 \\
3,169\end{array}$ & $\begin{array}{r}0 \\
0 \\
3,367 \\
0 \\
463\end{array}$ & $\begin{array}{r}2,475 \\
1,817 \\
22,521 \\
17,310 \\
39,147\end{array}$ & $\begin{array}{l}183,734 \\
337,361 \\
926,023 \\
323,815 \\
268,510\end{array}$ \\
\hline 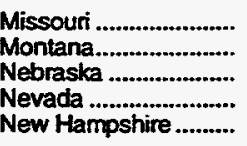 & $\begin{array}{r}264,715 \\
46,274 \\
123,373 \\
101,105 \\
18,732\end{array}$ & $\begin{array}{r}0 \\
2,037 \\
86 \\
16 \\
0\end{array}$ & $\begin{array}{r}0 \\
206 \\
3 \\
0 \\
0\end{array}$ & $\begin{array}{r}2,879 \\
3,542 \\
3,282 \\
669 \\
974\end{array}$ & $\begin{array}{r}267,594 \\
52,058 \\
126,744 \\
101,790 \\
19,706\end{array}$ \\
\hline 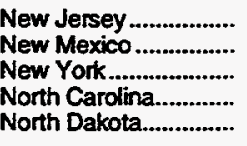 & $\begin{array}{r}582,356 \\
106,649 \\
1,005,676 \\
182,107 \\
27,301\end{array}$ & $\begin{array}{r}0 \\
18,476 \\
781 \\
0 \\
6,247\end{array}$ & $\begin{array}{r}0 \\
36,310 \\
0 \\
0 \\
5,059\end{array}$ & $\begin{array}{r}2,497 \\
59,135 \\
6,039 \\
5,753 \\
4,246\end{array}$ & $\begin{array}{r}584,853 \\
220,770 \\
1.012,497 \\
187,861 \\
42,853\end{array}$ \\
\hline 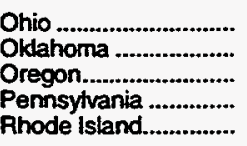 & $\begin{array}{r}824,119 \\
454,889 \\
140,526 \\
656,021 \\
70,901\end{array}$ & $\begin{array}{r}1,296 \\
55,607 \\
95 \\
4,042 \\
0\end{array}$ & $\begin{array}{r}36 \\
35.432 \\
0 \\
116 \\
0\end{array}$ & $\begin{array}{r}17,895 \\
26,146 \\
5,788 \\
37,959 \\
366\end{array}$ & $\begin{array}{r}843,345 \\
572,074 \\
146,409 \\
698,138 \\
71,267\end{array}$ \\
\hline 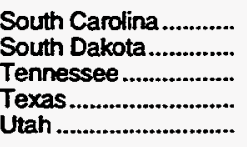 & $\begin{array}{r}141,863 \\
28,002 \\
228,007 \\
3,272,393 \\
120,993\end{array}$ & $\begin{array}{r}0 \\
437 \\
44 \\
139,427 \\
3,322\end{array}$ & $\begin{array}{r}0 \\
0 \\
0 \\
158,826 \\
9,951\end{array}$ & $\begin{array}{r}2,663 \\
2,541 \\
18,106 \\
95,684 \\
2,807\end{array}$ & $\begin{array}{r}144,526 \\
30,980 \\
246,157 \\
3,666,329 \\
137,073\end{array}$ \\
\hline 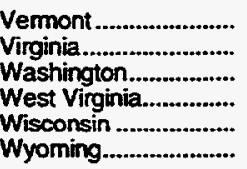 & $\begin{array}{r}7,297 \\
223,122 \\
206,346 \\
107,197 \\
345,748 \\
81,507\end{array}$ & $\begin{array}{r}0 \\
1,102 \\
0 \\
4,774 \\
0 \\
-4,676\end{array}$ & $\begin{array}{r}0 \\
0 \\
0 \\
3,272 \\
0 \\
13,939\end{array}$ & $\begin{array}{r}3 \\
6,338 \\
6,437 \\
30,144 \\
9,854 \\
6,193\end{array}$ & $\begin{array}{r}7,299 \\
230,562 \\
212,782 \\
145,387 \\
355,602 \\
106,316\end{array}$ \\
\hline Total................................ & $18,909,587$ & 736,678 & 423,878 & 685,327 & $20,755,471$ \\
\hline
\end{tabular}

2 Lease fuel quantities were estimated by assuming that the proportions of on-system production used as lease fuel by respondents to the Form ElA-176 "Annual Report of Nalural and Supplemental Gas Supply and Disposition," were the same as the proportions of gross withdrawals as reported on Fom ElA-627. "Annual Quantity and Value of Natural Gas Report," used as lease by all operators. Form ElA-176 respondents reported on-system production totaling 32.8 percent of gross withdrawals in Alaska and 8.3 percent of gross withdrawals in the lower 48 states. The average ratios of volumes 'Used in well, lease, and field operations' to "Company-owned natural gas produced on-system computed from form ElA-176 responses were .02891 for Alaska and 02602

where lease fuel was applicable, that did not report lease fuel use on the Form EIA-627.

$R=$ Revised data.

Note: Totals may not equal sum of components due to independent rounding

Sources: 1993-1994: Eneryy Information Administration (EIA), Form EIA-627, "Anuual Quantity and Value of Natural Gas Report," estimates based upon Form ElA-176, -Annual Report of Natural and Supplemental Gas Supply and Disposition"; Fom ElA-64A, "Annual Report of the Origin of Natural Gas Liquids Production"; and Form EIA-759, "Monthly Power Plant Report." 
Table 16. Natural Gas Delivered to Consumers by State, 1967-1994

\begin{tabular}{|c|c|c|c|c|c|c|}
\hline \multirow[b]{2}{*}{ State } & \multicolumn{2}{|c|}{ Residential } & \multicolumn{2}{|c|}{ Commercial } & \multicolumn{2}{|c|}{ Industrial } \\
\hline & $\begin{array}{c}\text { Quantity } \\
\text { (miltion } \\
\text { cubic faet) }\end{array}$ & Consumers & $\begin{array}{l}\text { Quantity } \\
\text { (milition } \\
\text { cubic foet) }\end{array}$ & Consumers & $\begin{array}{l}\text { Quantity } \\
\text { (million } \\
\text { cubic toet) }\end{array}$ & Consumers \\
\hline & & & \multicolumn{2}{|c|}{1957} & \multicolumn{2}{|c|}{$\cdot$} \\
\hline 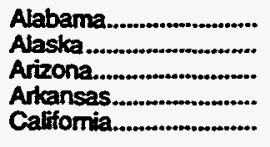 & $\begin{array}{r}45,543 \\
1,958 \\
25,376 \\
52,777 \\
522,122\end{array}$ & $\begin{array}{r}501,000 \\
9,000 \\
366,000 \\
348,000 \\
5,303,000\end{array}$ & $\begin{array}{r}30,401 \\
2,722 \\
23,335 \\
35,295 \\
184,630\end{array}$ & $\begin{array}{r}36,000 \\
2,000 \\
35,000 \\
47,000 \\
337,000\end{array}$ & $\begin{array}{r}155,108 \\
1,069 \\
46,354 \\
131,367 \\
505,517\end{array}$ & $\begin{array}{l}\text { NA } \\
\text { NA } \\
\text { NA } \\
\text { NA } \\
\text { NA }\end{array}$ \\
\hline 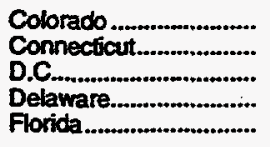 & $\begin{array}{r}75,351 \\
26,177 \\
a \\
6,844 \\
9,430\end{array}$ & $\begin{array}{r}474,000 \\
358,000 \\
a \\
73,000 \\
343,000\end{array}$ & $\begin{array}{r}39,942 \\
8,109 \\
a \\
1,968 \\
22,501\end{array}$ & $\begin{array}{r}57,000 \\
26,000 \\
a \\
5,000 \\
25,000\end{array}$ & $\begin{array}{r}75,399 \\
14,720 \\
a \\
8,338 \\
81,744\end{array}$ & $\begin{array}{l}\text { NA } \\
\text { NA } \\
\text { NA } \\
\text { NA } \\
\text { NA }\end{array}$ \\
\hline 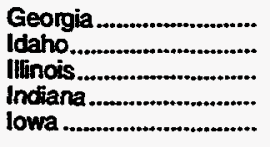 & $\begin{array}{r}80,322 \\
6,179 \\
382,277 \\
139,519 \\
81,592\end{array}$ & $\begin{array}{r}681,000 \\
58,000 \\
2,620,000 \\
932,000 \\
527,000\end{array}$ & $\begin{array}{r}30,202 \\
4,972 \\
175,281 \\
58,273 \\
45,118\end{array}$ & $\begin{array}{r}53,000 \\
10,000 \\
184,000 \\
90,000 \\
68,000\end{array}$ & $\begin{array}{r}128,777 \\
21,726 \\
325,116 \\
210,735 \\
71,869\end{array}$ & $\begin{array}{l}\text { NA } \\
\text { NA } \\
\text { NA } \\
\text { NA } \\
\text { NA }\end{array}$ \\
\hline 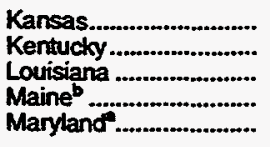 & $\begin{array}{r}84,912 \\
69,542 \\
74,386 \\
3,967 \\
77,130\end{array}$ & $\begin{array}{r}544,000 \\
484,000 \\
792,000 \\
59,000 \\
774,000\end{array}$ & $\begin{array}{r}37,141 \\
32,313 \\
51,062 \\
1,961 \\
28,154\end{array}$ & $\begin{array}{r}56,000 \\
47,000 \\
79,000 \\
4,000 \\
61,000\end{array}$ & $\begin{array}{r}127,302 \\
59,421 \\
792,730 \\
631 \\
32,115\end{array}$ & $\begin{array}{l}\text { NA } \\
\text { NA } \\
\text { NA } \\
\text { NA } \\
\text { NA }\end{array}$ \\
\hline $\begin{array}{l}\text { Massachusetts............... } \\
\text { Michigan ........................ } \\
\text { Minnesota .................... } \\
\text { Mississippi .................... } \\
\text { Missoun ..................... }\end{array}$ & $\begin{array}{r}73,471 \\
302,472 \\
89,020 \\
26,145 \\
133,355\end{array}$ & $\begin{array}{r}965,000 \\
1,729,000 \\
554,000 \\
297,000 \\
895,000\end{array}$ & $\begin{array}{r}24,737 \\
107,796 \\
63,740 \\
16,547 \\
82,524\end{array}$ & $\begin{array}{r}61,000 \\
148,000 \\
46,000 \\
34,000 \\
92,000\end{array}$ & $\begin{array}{r}18,782 \\
259,506 \\
72,081 \\
106,523 \\
87,529\end{array}$ & $\begin{array}{l}\text { NA } \\
\text { NA } \\
\text { NA } \\
\text { NA } \\
\text { NA }\end{array}$ \\
\hline 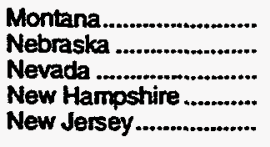 & $\begin{array}{r}19,756 \\
53,819 \\
5,230 \\
b \\
135,143\end{array}$ & $\begin{array}{r}129,000 \\
301,000 \\
56,000 \\
b \\
1,538,000\end{array}$ & $\begin{array}{r}15,516 \\
41,443 \\
6,164 \\
b \\
28,656\end{array}$ & $\begin{array}{r}16,000 \\
42,000 \\
3,000 \\
b \\
161,000\end{array}$ & $\begin{array}{r}22,584 \\
41,501 \\
7,162 \\
b \\
63,171\end{array}$ & $\begin{array}{l}\text { NA } \\
\text { NA } \\
\text { NA } \\
\text { NA } \\
\text { NA }\end{array}$ \\
\hline 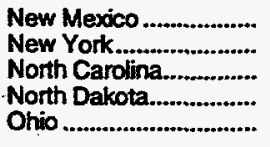 & $\begin{array}{r}31,126 \\
313,656 \\
21,416 \\
6,467 \\
442,360\end{array}$ & $\begin{array}{r}241,000 \\
3,797,000 \\
219,000 \\
44,000 \\
2,348,000\end{array}$ & $\begin{array}{r}27,447 \\
122,050 \\
17,100 \\
6,059 \\
153,376\end{array}$ & $\begin{array}{r}27,000 \\
276,000 \\
34,000 \\
6,000 \\
179,000\end{array}$ & $\begin{array}{r}75,511 \\
61,792 \\
53,049 \\
2,165 \\
344,723\end{array}$ & $\begin{array}{l}\text { NA } \\
\text { NA } \\
\text { NA } \\
\text { NA } \\
\text { NA }\end{array}$ \\
\hline $\begin{array}{l}\text { Okdahoma ................... } \\
\text { Oregon } \\
\text { Pennsyivania ..................... } \\
\text { Rhode Island.............. } \\
\text { South Carolina ............... }\end{array}$ & $\begin{array}{r}67,395 \\
13,427 \\
279,817 \\
10,350 \\
13,774\end{array}$ & $\begin{array}{r}612,000 \\
158,000 \\
2,202,000 \\
147,000 \\
197,000\end{array}$ & $\begin{array}{r}38,459 \\
6,961 \\
82,702 \\
3,142 \\
8,840\end{array}$ & $\begin{array}{r}64,000 \\
21,000 \\
137,000 \\
9,000 \\
22,000\end{array}$ & $\begin{array}{r}109,926 \\
47,265 \\
287,678 \\
4,703 \\
60,357\end{array}$ & $\begin{array}{l}\text { NA } \\
\text { NA } \\
\text { NA } \\
\text { NA } \\
\text { NA }\end{array}$ \\
\hline 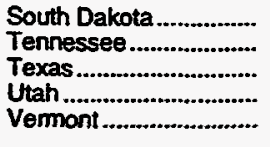 & $\begin{array}{r}9,910 \\
41,659 \\
201,407 \\
38,935 \\
b\end{array}$ & $\begin{array}{r}69,000 \\
376,000 \\
2,332,000 \\
232,000 \\
\text { b }\end{array}$ & $\begin{array}{r}10,444 \\
34,380 \\
139,727 \\
6,905 \\
b\end{array}$ & $\begin{array}{r}10,000 \\
47,000 \\
233,000 \\
15,000 \\
b\end{array}$ & $\begin{array}{r}3,876 \\
108,559 \\
1,652,534 \\
49,656 \\
b\end{array}$ & $\begin{array}{l}\text { NA } \\
\text { NA } \\
\text { NA } \\
\text { NA } \\
\text { NA }\end{array}$ \\
\hline 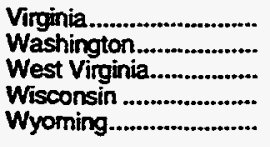 & $\begin{array}{l}41,495 \\
23,160 \\
50,202 \\
90,994 \\
11,939\end{array}$ & $\begin{array}{r}449,000 \\
212,000 \\
331,000 \\
691,000 \\
67,000\end{array}$ & $\begin{array}{l}22,756 \\
15,133 \\
18,511 \\
33,610 \\
10,865\end{array}$ & $\begin{array}{r}48,000 \\
30,000 \\
28,000 \\
52,000 \\
9,000\end{array}$ & $\begin{array}{r}42,136 \\
86,472 \\
62,985 \\
100,479 \\
30,273\end{array}$ & $\begin{array}{l}\text { NA } \\
\text { NA } \\
\text { NA } \\
\text { NA } \\
\text { NA }\end{array}$ \\
\hline 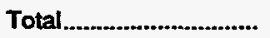 & $4,313,304$ & $36,434,000$ & $1,958,970$ & $3,077,000$ & $6,653,016$ & NA \\
\hline
\end{tabular}

See footnotes at end of table. 
Table 16. Natural Gas Delivered to Consumers by State, 1967-1994 (Continued)

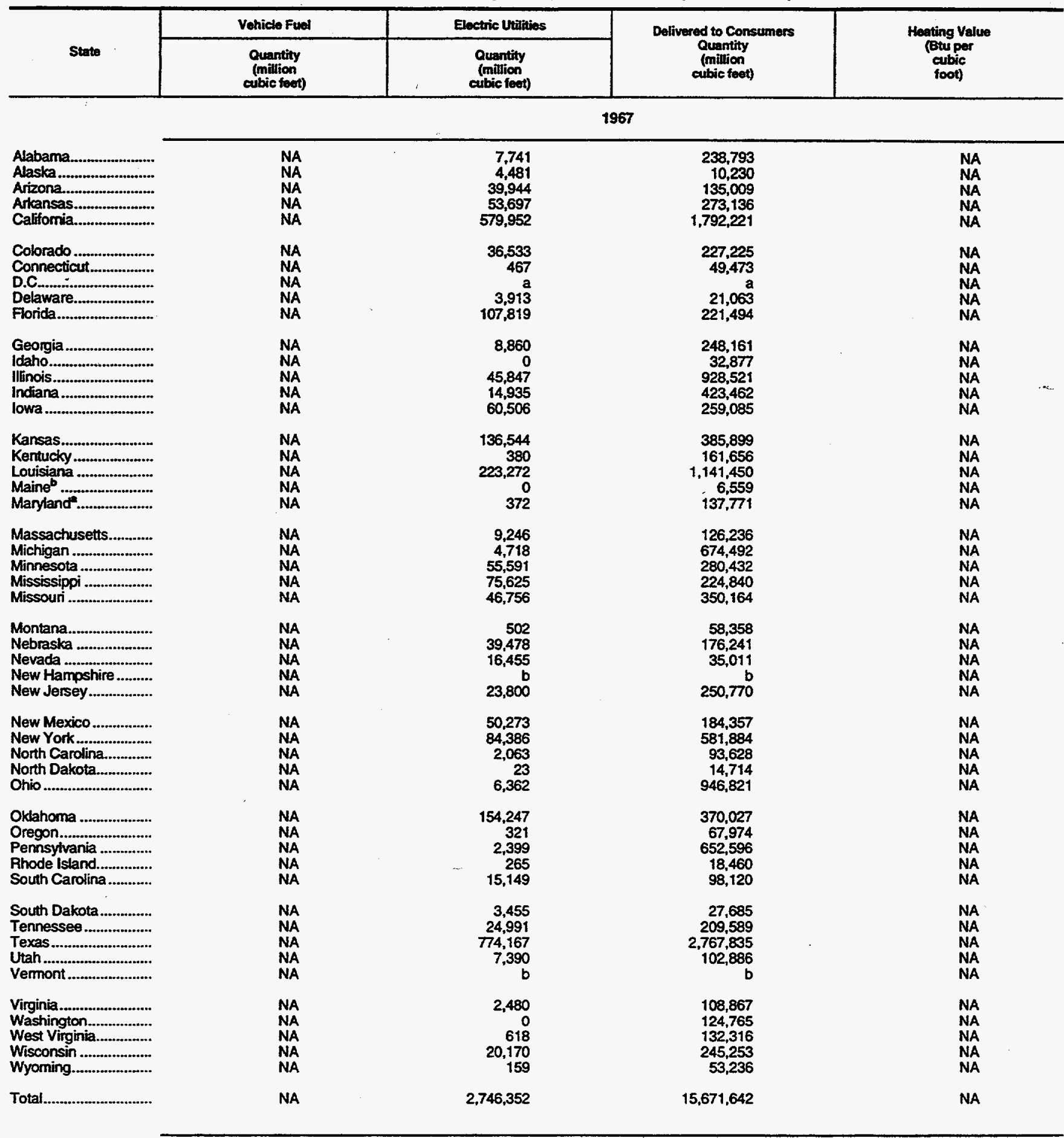

See footnotes at end of table. 
Table 16. Natural Gas Delivered to Consumers by State, 1967-1994 (Continued)

\begin{tabular}{|c|c|c|c|c|c|c|}
\hline \multirow[b]{2}{*}{ State } & \multicolumn{2}{|c|}{ Residential } & \multicolumn{2}{|c|}{ Commercial } & \multicolumn{2}{|c|}{ Industrial } \\
\hline & $\begin{array}{c}\text { Quantity } \\
\text { (million } \\
\text { cubic feet) }\end{array}$ & Consumers & $\begin{array}{l}\text { Quantity } \\
\text { (million } \\
\text { cubic foet) }\end{array}$ & Consumers & $\begin{array}{l}\text { Quantity } \\
\text { (million } \\
\text { cubic foet) }\end{array}$ & Consumers \\
\hline & \multicolumn{6}{|c|}{1968} \\
\hline 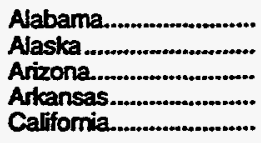 & $\begin{array}{r}51,708 \\
2,293 \\
26,681 \\
56,346 \\
517,636\end{array}$ & $\begin{array}{r}525,000 \\
11,000 \\
380,000 \\
357,000 \\
5,418,000\end{array}$ & $\begin{array}{r}34,749 \\
4,713 \\
23,389 \\
37,886 \\
189,903\end{array}$ & $\begin{array}{r}38,000 \\
2,000 \\
36,000 \\
47,000 \\
344,000\end{array}$ & $\begin{array}{r}171,755 \\
2,634 \\
53,699 \\
138,402 \\
544,292\end{array}$ & $\begin{array}{l}\text { NA } \\
\text { NA } \\
\text { NA } \\
\text { NA } \\
\text { NA }\end{array}$ \\
\hline 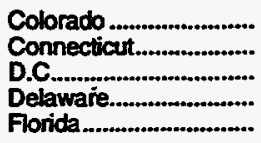 & $\begin{array}{r}78,371 \\
26,437 \\
a \\
7,068 \\
11,318\end{array}$ & $\begin{array}{r}484,000 \\
357,000 \\
a \\
75,000 \\
345,000\end{array}$ & $\begin{array}{r}47,287 \\
11,224 \\
a \\
2,084 \\
21,890\end{array}$ & $\begin{array}{r}63,000 \\
25,000 \\
2 \\
5,000 \\
26,000\end{array}$ & $\begin{array}{r}84,051 \\
15,045 \\
a \\
11,377 \\
88,265\end{array}$ & $\begin{array}{l}\text { NA } \\
\text { NA } \\
\text { NA } \\
\text { NA } \\
\text { NA }\end{array}$ \\
\hline 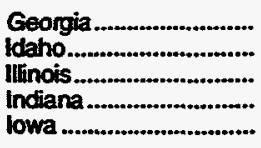 & $\begin{array}{r}84,072 \\
6,545 \\
392,325 \\
145,955 \\
84,936\end{array}$ & $\begin{array}{r}705,000 \\
62,000 \\
2,679,000 \\
962,000 \\
545,000\end{array}$ & $\begin{array}{r}36,034 \\
6,374 \\
174,565 \\
60,661 \\
48,034\end{array}$ & $\begin{array}{r}53,000 \\
10,000 \\
190,000 \\
95,000 \\
64,000\end{array}$ & $\begin{array}{r}140,115 \\
24,637 \\
336,384 \\
231,110 \\
82,674\end{array}$ & $\begin{array}{l}\text { NA } \\
\text { NA } \\
\text { NA } \\
\text { NA } \\
\text { NA }\end{array}$ \\
\hline 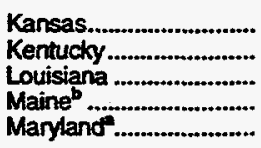 & $\begin{array}{r}89,372 \\
75,824 \\
77,762 \\
3,571 \\
79,015\end{array}$ & $\begin{array}{r}565,000 \\
495,000 \\
804,000 \\
60,000 \\
791,000\end{array}$ & $\begin{array}{r}46,232 \\
36,089 \\
56,937 \\
1,672 \\
30,419\end{array}$ & $\begin{array}{r}57,000 \\
47,000 \\
72,000 \\
4,000 \\
62,000\end{array}$ & $\begin{array}{r}147,186 \\
51,969 \\
864,413 \\
1,387 \\
37,514\end{array}$ & $\begin{array}{l}\text { NA } \\
\text { NA } \\
\text { NA } \\
\text { NA } \\
\text { NA }\end{array}$ \\
\hline 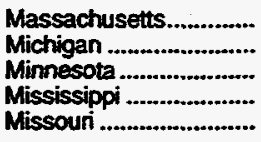 & $\begin{array}{r}74,919 \\
315,694 \\
90,410 \\
29,526 \\
138,764\end{array}$ & $\begin{array}{r}969,000 \\
1,812,000 \\
564,000 \\
297,000 \\
936,000\end{array}$ & $\begin{array}{r}25,396 \\
117,124 \\
65,536 \\
18,297 \\
79,821\end{array}$ & $\begin{array}{r}61,000 \\
152,000 \\
49,000 \\
35,000 \\
91,000\end{array}$ & $\begin{array}{r}21,867 \\
250,646 \\
88,468 \\
118,841 \\
93,796\end{array}$ & $\begin{array}{l}\text { NA } \\
\text { NA } \\
\text { NA } \\
\text { NA } \\
\text { NA }\end{array}$ \\
\hline 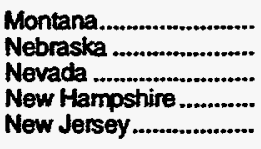 & $\begin{array}{r}19,711 \\
53,376 \\
5,493 \\
b \\
137,116\end{array}$ & $\begin{array}{r}131,000 \\
307,000 \\
61,000 \\
b \\
1,554,000\end{array}$ & $\begin{array}{r}13,651 \\
41,765 \\
6,997 \\
b \\
32,546\end{array}$ & $\begin{array}{r}17,000 \\
46,000 \\
3,000 \\
b \\
-165,000\end{array}$ & $\begin{array}{r}23,155 \\
47,701 \\
8,695 \\
\text { b } \\
70,850\end{array}$ & $\begin{array}{l}\text { NA } \\
\text { NA } \\
\text { NA } \\
\text { NA } \\
\text { NA }\end{array}$ \\
\hline 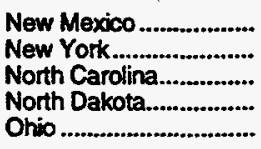 & $\begin{array}{r}31,568 \\
319,282 \\
24,646 \\
7,169 \\
444,964\end{array}$ & $\begin{array}{r}239,000 \\
3,842,000 \\
268,000 \\
46,000 \\
2,391,000\end{array}$ & $\begin{array}{r}30,713 \\
122,885 \\
20,624 \\
7,072 \\
165,414\end{array}$ & $\begin{array}{r}26,000 \\
269,000 \\
35,000 \\
6,000 \\
183,000\end{array}$ & $\begin{array}{r}76,784 \\
91,679 \\
60,538 \\
2,612 \\
350,342\end{array}$ & $\begin{array}{l}\text { NA } \\
\text { NA } \\
\text { NA } \\
\text { NA } \\
\text { NA }\end{array}$ \\
\hline 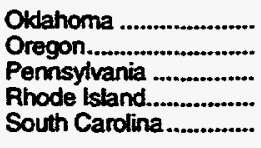 & $\begin{array}{r}74,782 \\
15,126 \\
285,978 \\
10,605 \\
16,756\end{array}$ & $\begin{array}{r}612,000 \\
169,000 \\
2,207,000 \\
149,000 \\
199,000\end{array}$ & $\begin{array}{r}42,751 \\
7,874 \\
87,620 \\
3,416 \\
10,544\end{array}$ & $\begin{array}{r}64,000 \\
22,000 \\
138,000 \\
8,000 \\
23,000\end{array}$ & $\begin{array}{r}118,771 \\
51,755 \\
314,913 \\
5,188 \\
68,615\end{array}$ & $\begin{array}{l}\text { NA } \\
\text { NA } \\
\text { NA } \\
\text { NA } \\
\text { NA }\end{array}$ \\
\hline $\begin{array}{l}\text { South Dakota.......... } \\
\text { Tennessee } \\
\text { Texas } \\
\text { Utah } \\
\text { Vermont }\end{array}$ & $\begin{array}{r}10,302 \\
43,784 \\
211,763 \\
40,779 \\
b\end{array}$ & $\begin{array}{r}71,000 \\
378,000 \\
2,393,000 \\
235,000 \\
\text { b }\end{array}$ & $\begin{array}{r}10,723 \\
38,325 \\
139,442 \\
8,114 \\
b\end{array}$ & $\begin{array}{r}10,000 \\
49,000 \\
240,000 \\
15,000 \\
b\end{array}$ & $\begin{array}{r}4,019 \\
107,476 \\
1,696,792 \\
53,720 \\
b\end{array}$ & $\begin{array}{l}\text { NA } \\
\text { NA } \\
\text { NA } \\
\text { NA } \\
\text { NA }\end{array}$ \\
\hline 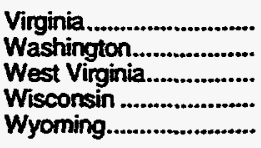 & $\begin{array}{l}43,582 \\
26,342 \\
54,665 \\
93,425 \\
12,592\end{array}$ & $\begin{array}{r}448,000 \\
233,000 \\
343,000 \\
717,000 \\
68,000\end{array}$ & $\begin{array}{l}24,594 \\
16,244 \\
20,402 \\
36,067 \\
11,637\end{array}$ & $\begin{array}{l}47,000 \\
32,000 \\
30,000 \\
55,000 \\
10,000\end{array}$ & $\begin{array}{r}42,493 \\
93,370 \\
88,069 \\
117,250 \\
34,651\end{array}$ & $\begin{array}{l}\text { NA } \\
\text { NA } \\
\text { NA } \\
\text { NA } \\
\text { NA }\end{array}$ \\
\hline Total .................................... & $4,450,354$ & $37,259,000$ & $2,075,736$ & $3,121,000$ & $7,129,967$ & NA \\
\hline
\end{tabular}

See footnotes at end of table. 
Table 16. Natural Gas Delivered to Consumers by State, 1967-1994 (Continued)

\begin{tabular}{|c|c|c|c|c|}
\hline \multirow[b]{2}{*}{ State } & Vehich Fuel & Electric Utilitios & \multirow{2}{*}{$\begin{array}{l}\text { Dolivered to Consumers } \\
\text { Quarntity } \\
\text { (million } \\
\text { cubic toet) }\end{array}$} & \multirow{2}{*}{$\begin{array}{l}\text { Heating Vatue } \\
\text { (Btup per } \\
\text { cubic } \\
\text { foot) }\end{array}$} \\
\hline & $\begin{array}{l}\text { Quantity } \\
\text { (million } \\
\text { cubic foet) }\end{array}$ & $\begin{array}{l}\text { Quantity } \\
\text { (million } \\
\text { cubic foet) }\end{array}$ & & \\
\hline & \multicolumn{4}{|c|}{1968} \\
\hline 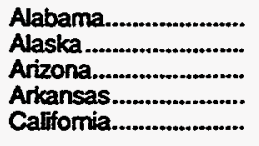 & $\begin{array}{l}\text { NA } \\
\text { NA } \\
\text { NA } \\
\text { NA } \\
\text { NA }\end{array}$ & $\begin{array}{r}11,465 \\
5,668 \\
46,857 \\
72,640 \\
684,315\end{array}$ & $\begin{array}{r}269,677 \\
15,308 \\
150,626 \\
305,274 \\
1,936,146\end{array}$ & $\begin{array}{l}\text { NA } \\
\text { NA } \\
\text { NA } \\
\text { NA } \\
\text { NA }\end{array}$ \\
\hline 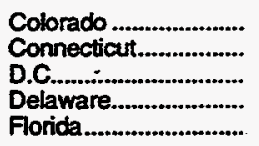 & $\begin{array}{l}\text { NA } \\
\text { NA } \\
\text { NA } \\
\text { NA } \\
\text { NA }\end{array}$ & $\begin{array}{r}43,063 \\
439 \\
2 \\
2 \\
3,530 \\
147,600\end{array}$ & $\begin{array}{r}252,772 \\
53,145 \\
a \\
24,059 \\
269,073\end{array}$ & $\begin{array}{l}\text { NA } \\
\text { NA } \\
\text { NA } \\
\text { NA } \\
\text { NA }\end{array}$ \\
\hline 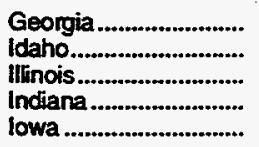 & $\begin{array}{l}\text { NA } \\
\text { NA } \\
\text { NA } \\
\text { NA } \\
\text { NA }\end{array}$ & $\begin{array}{r}16,417 \\
0 \\
73,131 \\
6,535 \\
69,245\end{array}$ & $\begin{array}{r}276,638 \\
37,556 \\
976,405 \\
444,261 \\
284,889\end{array}$ & $\begin{array}{l}\text { NA } \\
\text { NA } \\
\text { NA } \\
\text { NA } \\
\text { NA }\end{array}$ \\
\hline 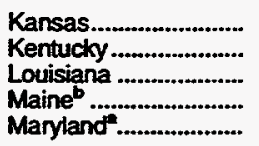 & $\begin{array}{l}\text { NA } \\
\text { NA } \\
\text { NA } \\
\text { NA } \\
\text { NA }\end{array}$ & $\begin{array}{r}138,727 \\
349 \\
253,266 \\
0 \\
436\end{array}$ & $\begin{array}{r}421,517 \\
164,231 \\
1,252,378 \\
6,630 \\
147,384\end{array}$ & $\begin{array}{l}\text { NA } \\
\text { NA } \\
\text { NA } \\
\text { NA } \\
\text { NA }\end{array}$ \\
\hline 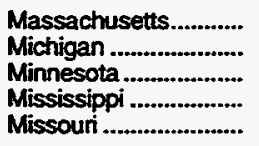 & $\begin{array}{l}\text { NA } \\
\text { NA } \\
\text { NA } \\
\text { NA } \\
\text { NA }\end{array}$ & $\begin{array}{r}8,494 \\
6,842 \\
64,725 \\
84,293 \\
43,810\end{array}$ & $\begin{array}{l}130,676 \\
690,306 \\
309,139 \\
250,957 \\
356,191\end{array}$ & $\begin{array}{l}\text { NA } \\
\text { NA } \\
\text { NA } \\
\text { NA } \\
\text { NA }\end{array}$ \\
\hline 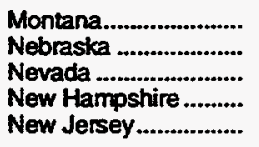 & $\begin{array}{l}\text { NA } \\
\text { NA } \\
\text { NA } \\
\text { NA } \\
\text { NA }\end{array}$ & $\begin{array}{r}631 \\
48,568 \\
15,844 \\
b \\
27,523\end{array}$ & $\begin{array}{r}57,148 \\
191,410 \\
37,029 \\
\text { b } \\
268,035\end{array}$ & $\begin{array}{l}\text { NA } \\
\text { NA } \\
\text { NA } \\
\text { NA } \\
\text { NA }\end{array}$ \\
\hline 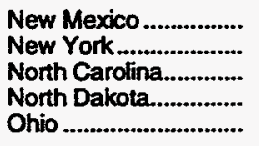 & $\begin{array}{l}\text { NA } \\
\text { NA } \\
\text { NA } \\
\text { NA } \\
\text { NA }\end{array}$ & $\begin{array}{r}49,316 \\
102,137 \\
4,172 \\
31 \\
10,999\end{array}$ & $\begin{array}{r}188,381 \\
635,983 \\
109,980 \\
16,884 \\
971,719\end{array}$ & $\begin{array}{l}\text { NA } \\
\text { NA } \\
\text { NA } \\
\text { NA } \\
\text { NA }\end{array}$ \\
\hline 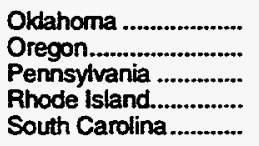 & $\begin{array}{l}\text { NA } \\
\text { NA } \\
\text { NA } \\
\text { NA } \\
\text { NA }\end{array}$ & $\begin{array}{r}162,029 \\
537 \\
4,355 \\
1,492 \\
28,961\end{array}$ & $\begin{array}{r}398,333 \\
75,292 \\
692,866 \\
20,701 \\
124,876\end{array}$ & $\begin{array}{l}\text { NA } \\
\text { NA } \\
\text { NA } \\
\text { NA } \\
\text { NA }\end{array}$ \\
\hline 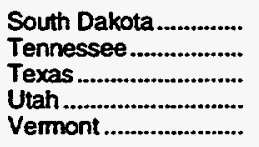 & $\begin{array}{l}\text { NA } \\
\text { NA } \\
\text { NA } \\
\text { NA } \\
\text { NA }\end{array}$ & $\begin{array}{r}3,748 \\
21,542 \\
851,612 \\
5,506 \\
b\end{array}$ & $\begin{array}{r}28,792 \\
211,127 \\
2,899,609 \\
108,119 \\
\text { b }\end{array}$ & $\begin{array}{l}\text { NA } \\
\text { NA } \\
\text { NA } \\
\text { NA } \\
\text { NA }\end{array}$ \\
\hline 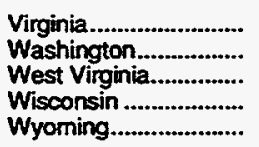 & $\begin{array}{l}\text { NA } \\
\text { NA } \\
\text { NA } \\
\text { NA } \\
\text { NA }\end{array}$ & $\begin{array}{r}3,471 \\
0 \\
791 \\
22,340 \\
459\end{array}$ & $\begin{array}{r}114,140 \\
135,956 \\
163,927 \\
269,082 \\
59,339\end{array}$ & $\begin{array}{l}\text { NA } \\
\text { NA } \\
\text { NA } \\
\text { NA } \\
\text { NA }\end{array}$ \\
\hline 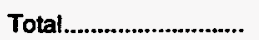 & NA & $3,147,909$ & $16,803,966$ & NA \\
\hline
\end{tabular}

See footnotes at end of table. 
Table 16. Natural Gas Delivered to Consumers by State, 1967-1994 (Continued)

\begin{tabular}{|c|c|c|c|c|c|c|}
\hline \multirow[b]{2}{*}{ State } & \multicolumn{2}{|c|}{ Residential } & \multicolumn{2}{|c|}{ Commercial } & \multicolumn{2}{|c|}{ Industrial } \\
\hline & $\begin{array}{l}\text { Quantity } \\
\text { (miltion } \\
\text { cubic feet) }\end{array}$ & Consumers & $\begin{array}{l}\text { Quantity } \\
\text { (million } \\
\text { cubic teet) }\end{array}$ & Consumers & $\begin{array}{l}\text { Quantity } \\
\text { (million } \\
\text { cubic toet) }\end{array}$ & Consumers \\
\hline & \multicolumn{6}{|c|}{1969} \\
\hline 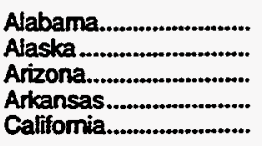 & $\begin{array}{r}54,804 \\
4,573 \\
28,426 \\
58,322 \\
562,127\end{array}$ & $\begin{array}{r}536,000 \\
14,000 \\
383,000 \\
373,000 \\
5,515,000\end{array}$ & $\begin{array}{r}37,275 \\
11,018 \\
24,501 \\
39,962 \\
206,861\end{array}$ & $\begin{array}{r}38,000 \\
4,000 \\
38,000 \\
53,000 \\
357,000\end{array}$ & $\begin{array}{r}173,508 \\
13,575 \\
58,432 \\
148,695 \\
589,736\end{array}$ & $\begin{array}{l}\text { NA } \\
\text { NA } \\
\text { NA } \\
\text { NA } \\
\text { NA }\end{array}$ \\
\hline 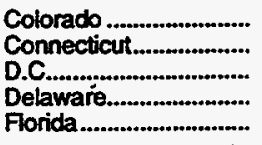 & $\begin{array}{r}81,068 \\
29,048 \\
a \\
7,475 \\
11,636\end{array}$ & $\begin{array}{r}542,000 \\
367,000 \\
a \\
76,000 \\
343,000\end{array}$ & $\begin{array}{r}52,256 \\
12,435 \\
a \\
2,526 \\
24,721\end{array}$ & $\begin{array}{r}66,000 \\
27,000 \\
0 \\
5,000 \\
26,000\end{array}$ & $\begin{array}{r}86,659 \\
15,651 \\
a \\
11,967 \\
90,982\end{array}$ & $\begin{array}{l}\text { NA } \\
\text { NA } \\
\text { NA } \\
\text { NA } \\
\text { NA }\end{array}$ \\
\hline 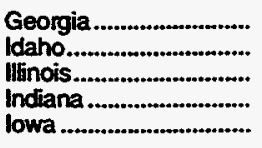 & $\begin{array}{r}87,878 \\
6,980 \\
434,065 \\
156,699 \\
91,219\end{array}$ & $\begin{array}{r}736,000 \\
69,000 \\
2,725,000 \\
988,000 \\
558,000\end{array}$ & $\begin{array}{r}39,020 \\
6,613 \\
189,006 \\
72,414 \\
52,700\end{array}$ & $\begin{array}{r}57,000 \\
11,000 \\
204,000 \\
103,000 \\
71,000\end{array}$ & $\begin{array}{r}142,965 \\
25,485 \\
358,704 \\
269,736 \\
89,753\end{array}$ & $\begin{array}{l}\text { NA } \\
\text { NA } \\
\text { NA } \\
\text { NA } \\
\text { NA }\end{array}$ \\
\hline 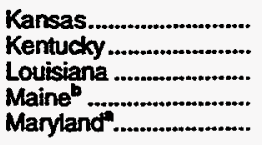 & $\begin{array}{r}94,320 \\
83,815 \\
82,965 \\
4,910 \\
84,406\end{array}$ & $\begin{array}{r}595,000 \\
522,000 \\
823,000 \\
75,000 \\
809,000\end{array}$ & $\begin{array}{r}54,062 \\
41,934 \\
54,010 \\
2,338 \\
34,674\end{array}$ & $\begin{array}{r}58,000 \\
50,000 \\
71,000 \\
5,000 \\
63,000\end{array}$ & $\begin{array}{r}156,700 \\
65,639 \\
964,191 \\
1,948 \\
40,923\end{array}$ & $\begin{array}{l}\text { NA } \\
\text { NA } \\
\text { NA } \\
\text { NA } \\
\text { NA }\end{array}$ \\
\hline $\begin{array}{l}\text { Massachusetts............... } \\
\text { Michigan ..................... } \\
\text { Minnesota .................... } \\
\text { Mississippi .................... } \\
\text { Missoun ..................... }\end{array}$ & $\begin{array}{r}78,451 \\
333,264 \\
95,580 \\
30,233 \\
151,778\end{array}$ & $\begin{array}{r}977,000 \\
1,863,000 \\
581,000 \\
316,000 \\
974,000\end{array}$ & $\begin{array}{r}29,821 \\
130,062 \\
70,232 \\
17,667 \\
79,019\end{array}$ & $\begin{array}{r}62,000 \\
157,000 \\
51,000 \\
36,000 \\
88,000\end{array}$ & $\begin{array}{r}21,517 \\
286,927 \\
92,641 \\
123,554 \\
100,833\end{array}$ & $\begin{array}{l}\text { NA } \\
\text { NA } \\
\text { NA } \\
\text { NA } \\
\text { NA }\end{array}$ \\
\hline 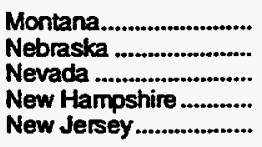 & $\begin{array}{r}21,463 \\
55,163 \\
6,297 \\
b \\
145,487\end{array}$ & $\begin{array}{r}133,000 \\
314,000 \\
64,000 \\
b \\
1,572,000\end{array}$ & $\begin{array}{r}16,593 \\
46,041 \\
8,204 \\
b \\
34,510\end{array}$ & $\begin{array}{r}19,000 \\
48,000 \\
4,000 \\
b \\
168,000\end{array}$ & $\begin{array}{r}31,918 \\
50,312 \\
9,796 \\
b \\
77,038\end{array}$ & $\begin{array}{l}\text { NA } \\
\text { NA } \\
\text { NA } \\
\text { NA } \\
\text { NA }\end{array}$ \\
\hline $\begin{array}{l}\text { New Mexico .................. } \\
\text { New York } \\
\text { North Carolina.................... } \\
\text { North Dakota................ } \\
\text { Ohio }\end{array}$ & $\begin{array}{r}28,061 \\
331,326 \\
27,784 \\
7,661 \\
456,414\end{array}$ & $\begin{array}{r}223,000 \\
3,852,000 \\
281,000 \\
47,000 \\
2,429,000\end{array}$ & $\begin{array}{r}28,680 \\
128,282 \\
24,524 \\
7,444 \\
175,372\end{array}$ & $\begin{array}{r}23,000 \\
270,000 \\
39,000 \\
7,000 \\
187,000\end{array}$ & $\begin{array}{r}66,863 \\
113,561 \\
70,189 \\
2,805 \\
367,761\end{array}$ & $\begin{array}{l}\text { NA } \\
\text { NA } \\
\text { NA } \\
\text { NA } \\
\text { NA }\end{array}$ \\
\hline $\begin{array}{l}\text { Oklahoma ................... } \\
\text { Oregon....................... } \\
\text { Pennsylvania ............... } \\
\text { Rhode Island.............. } \\
\text { South Carolina ............... }\end{array}$ & $\begin{array}{r}75,310 \\
20,507 \\
295,027 \\
11,374 \\
18,162\end{array}$ & $\begin{array}{r}628,000 \\
182,000 \\
2,212,000 \\
152,000 \\
205,000\end{array}$ & $\begin{array}{r}41,151 \\
9,965 \\
95,720 \\
3,850 \\
12,938\end{array}$ & $\begin{array}{r}66,000 \\
23,000 \\
140,000 \\
9,000 \\
24,000\end{array}$ & $\begin{array}{r}116,214 \\
53,271 \\
340,855 \\
6,170 \\
77,978\end{array}$ & $\begin{array}{l}\text { NA } \\
\text { NA } \\
\text { NA } \\
\text { NA } \\
\text { NA }\end{array}$ \\
\hline $\begin{array}{l}\text { South Dakota .................. } \\
\text { Tennessee .................. } \\
\text { Texas ............................. } \\
\text { Utah ............................ } \\
\text { Vermont }\end{array}$ & $\begin{array}{r}12,906 \\
45,396 \\
220,728 \\
43,948 \\
b\end{array}$ & $\begin{array}{r}73,000 \\
384,000 \\
2,494,000 \\
236,000 \\
b\end{array}$ & $\begin{array}{r}11,201 \\
41,069 \\
140,854 \\
9,443 \\
b\end{array}$ & $\begin{array}{r}10,000 \\
51,000 \\
239,000 \\
16,000 \\
b\end{array}$ & $\begin{array}{r}6,228 \\
117,205 \\
1,714,151 \\
60,589 \\
b\end{array}$ & $\begin{array}{l}\text { NA } \\
\text { NA } \\
\text { NA } \\
\text { NA } \\
\text { NA }\end{array}$ \\
\hline 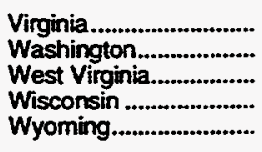 & $\begin{array}{r}46,663 \\
30,479 \\
56,366 \\
101,124 \\
16,592\end{array}$ & $\begin{array}{r}445,000 \\
251,000 \\
348,000 \\
737,000 \\
74,000\end{array}$ & $\begin{array}{l}27,155 \\
17,166 \\
21,534 \\
52,315 \\
14,069\end{array}$ & $\begin{array}{l}47,000 \\
32,000 \\
30,000 \\
57,000 \\
12,000\end{array}$ & $\begin{array}{r}42,284 \\
92,335 \\
91,182 \\
128,410 \\
42,665\end{array}$ & $\begin{array}{l}\text { NA } \\
\text { NA } \\
\text { NA } \\
\text { NA } \\
\text { NA }\end{array}$ \\
\hline 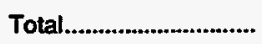 & $4,728,281$ & $38,096,000$ & $2,253,206$ & $3,222,000$ & $7,610,501$ & NA \\
\hline
\end{tabular}

See footnotes at end of table. 
Table 16. Natura! Gas Delivered to Consumers by State, 1967-1994 (Continued)

\begin{tabular}{|c|c|c|c|c|}
\hline \multirow[b]{2}{*}{ State } & Vehicte Fuol & Electric Utilities & \multirow{2}{*}{$\begin{array}{l}\text { Delivered to Consumers } \\
\text { Quantity } \\
\text { (million } \\
\text { cubic foet) }\end{array}$} & \multirow{2}{*}{$\begin{array}{l}\text { Heating Value } \\
\text { (Btuper } \\
\text { cubic } \\
\text { foot) }\end{array}$} \\
\hline & $\begin{array}{l}\text { Quamity } \\
\text { (million } \\
\text { cubic foet) }\end{array}$ & $\begin{array}{l}\text { Quantity } \\
\text { (million } \\
\text { cubic toot) }\end{array}$ & & \\
\hline & \multicolumn{4}{|c|}{1969} \\
\hline 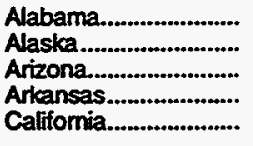 & $\begin{array}{l}\text { NA } \\
\text { NA } \\
\text { NA } \\
\text { NA } \\
\text { NA }\end{array}$ & $\begin{array}{r}14,757 \\
6,696 \\
57,188 \\
84,387 \\
589,545\end{array}$ & $\begin{array}{r}280,344 \\
35,862 \\
168,547 \\
331,366 \\
1,948,269\end{array}$ & $\begin{array}{l}\text { NA } \\
\text { NA } \\
\text { NA } \\
\text { NA } \\
\text { NA }\end{array}$ \\
\hline 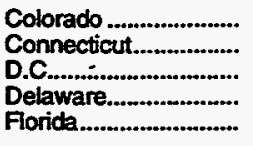 & $\begin{array}{l}\text { NA } \\
\text { NA } \\
\text { NA } \\
\text { NA } \\
\text { NA }\end{array}$ & $\begin{array}{r}48,044 \\
290 \\
a \\
3,895 \\
179,806\end{array}$ & $\begin{array}{r}268,027 \\
57,424 \\
a \\
25,863 \\
307,145\end{array}$ & $\begin{array}{l}\text { NA } \\
\text { NA } \\
\text { NA } \\
\text { NA } \\
\text { NA }\end{array}$ \\
\hline 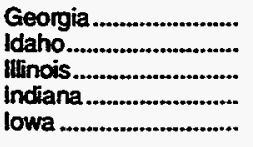 & $\begin{array}{l}\text { NA } \\
\text { NA } \\
\text { NA } \\
\text { NA } \\
\text { NA }\end{array}$ & $\begin{array}{r}34,833 \\
0 \\
81,382 \\
20,558 \\
68,769\end{array}$ & $\begin{array}{r}304,697 \\
39,078 \\
1,063,157 \\
519,407 \\
302,44 i\end{array}$ & $\begin{array}{l}\text { NA } \\
\text { NA } \\
\text { NA } \\
\text { NA } \\
\text { NA }\end{array}$ \\
\hline 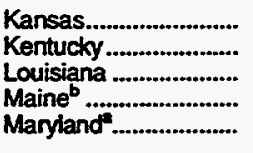 & $\begin{array}{l}\text { NA } \\
\text { NA } \\
\text { NA } \\
\text { NA } \\
\text { NA }\end{array}$ & $\begin{array}{r}160,897 \\
7,013 \\
316,671 \\
0 \\
6,544\end{array}$ & $\begin{array}{r}465,979 \\
198,401 \\
1,417,837 \\
9,196 \\
166,547\end{array}$ & $\begin{array}{l}\text { NA } \\
\text { NA } \\
\text { NA } \\
\text { NA } \\
\text { NA }\end{array}$ \\
\hline 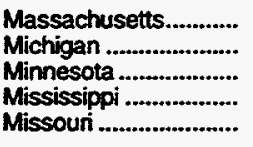 & $\begin{array}{l}\text { NA } \\
\text { NA } \\
\text { NA } \\
\text { NA } \\
\text { NA }\end{array}$ & $\begin{array}{r}6,234 \\
15,495 \\
64,241 \\
89,932 \\
57,600\end{array}$ & $\begin{array}{l}136,023 \\
765,748 \\
322,694 \\
261,386 \\
389,230\end{array}$ & $\begin{array}{l}\text { NA } \\
\text { NA } \\
\text { NA } \\
\text { NA } \\
\text { NA }\end{array}$ \\
\hline 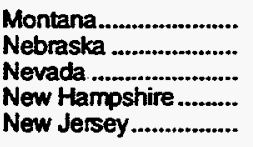 & $\begin{array}{l}\text { NA } \\
\text { NA } \\
\text { NA } \\
\text { NA } \\
\text { NA }\end{array}$ & $\begin{array}{r}1,519 \\
45,170 \\
19,843 \\
b \\
47,178\end{array}$ & $\begin{array}{r}71,493 \\
196,686 \\
44,140 \\
b \\
304,213\end{array}$ & $\begin{array}{l}\text { NA } \\
\text { NA } \\
\text { NA } \\
\text { NA } \\
\text { NA }\end{array}$ \\
\hline $\begin{array}{l}\text { New Mexico.............. } \\
\text { New York................ } \\
\text { North Carolina............ } \\
\text { North Dakota............. } \\
\text { Ohio }\end{array}$ & $\begin{array}{l}\text { NA } \\
\text { NA } \\
\text { NA } \\
\text { NA } \\
\text { NA }\end{array}$ & $\begin{array}{r}54,498 \\
107,260 \\
8,339 \\
75 \\
17,395\end{array}$ & $\begin{array}{r}178,102 \\
680,429 \\
130,836 \\
17,985 \\
1,016,942\end{array}$ & $\begin{array}{l}\text { NA } \\
\text { NA } \\
\text { NA } \\
\text { NA } \\
\text { NA }\end{array}$ \\
\hline 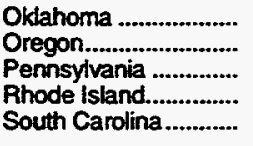 & $\begin{array}{l}\text { NA } \\
\text { NA } \\
\text { NA } \\
\text { NA } \\
\text { NA }\end{array}$ & $\begin{array}{r}196.106 \\
464 \\
7,173 \\
1,143 \\
28,895\end{array}$ & $\begin{array}{r}428.781 \\
84,207 \\
738,775 \\
22,537 \\
137,973\end{array}$ & $\begin{array}{l}\text { NA } \\
\text { NA } \\
\text { NA } \\
\text { NA } \\
\text { NA }\end{array}$ \\
\hline 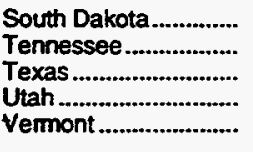 & $\begin{array}{l}\text { NA } \\
\text { NA } \\
\text { NA } \\
\text { NA } \\
\text { NA }\end{array}$ & $\begin{array}{r}3,476 \\
18,239 \\
973,439 \\
3,578 \\
b\end{array}$ & $\begin{array}{r}33,811 \\
221,909 \\
3,049,172 \\
117,557 \\
b\end{array}$ & $\begin{array}{l}\text { NA } \\
\text { NA } \\
\text { NA } \\
\text { NA } \\
\text { NA }\end{array}$ \\
\hline 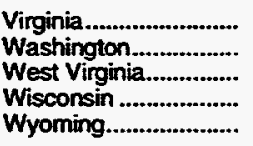 & $\begin{array}{l}\text { NA } \\
\text { NA } \\
\text { NA } \\
\text { NA } \\
\text { NA }\end{array}$ & $\begin{array}{r}4,482 \\
0 \\
759 \\
31,359 \\
2,475\end{array}$ & $\begin{array}{r}120,584 \\
139,980 \\
169,841 \\
313,208 \\
75,801\end{array}$ & $\begin{array}{l}\text { NA } \\
\text { NA } \\
\text { NA } \\
\text { NA } \\
\text { NA }\end{array}$ \\
\hline Total & NA & $3,487,642$ & $18,079,630$ & NA \\
\hline
\end{tabular}

See footnotes at end of table. 
Table 16. Natural Gas Delivered to Consumers by State, 1967-1994 (Continued)

\begin{tabular}{|c|c|c|c|c|c|c|}
\hline \multirow[b]{2}{*}{ State } & \multicolumn{2}{|c|}{ Residential } & \multicolumn{2}{|c|}{ Commercial } & \multicolumn{2}{|c|}{ Industrial } \\
\hline & $\begin{array}{c}\text { Quantity } \\
\text { (million } \\
\text { cubic foet) }\end{array}$ & Consumers & $\begin{array}{l}\text { Qurantity } \\
\text { (million } \\
\text { culbic foet) }\end{array}$ & Consumers & $\begin{array}{l}\text { Quantity } \\
\text { (mallion } \\
\text { cubic foet) }\end{array}$ & Consumers \\
\hline & \multicolumn{6}{|c|}{1970} \\
\hline 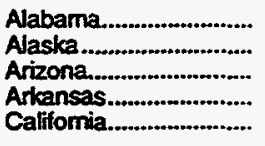 & $\begin{array}{r}55,779 \\
6,211 \\
29,679 \\
59,792 \\
552,544\end{array}$ & $\begin{array}{r}537,000 \\
15,000 \\
417,000 \\
376,000 \\
5,608,000\end{array}$ & $\begin{array}{r}36,254 \\
12,519 \\
22,705 \\
39,169 \\
209,945\end{array}$ & $\begin{array}{r}39,000 \\
4,000 \\
38,000 \\
51,000 \\
356,000\end{array}$ & $\begin{array}{r}170,937 \\
14,744 \\
57,712 \\
152,931 \\
618,634\end{array}$ & $\begin{array}{l}\text { NA } \\
\text { NA } \\
\text { NA } \\
\text { NA } \\
\text { NA }\end{array}$ \\
\hline 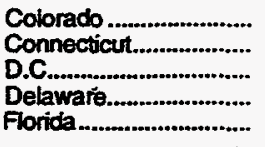 & $\begin{array}{r}82,595 \\
31,187 \\
2 \\
7,843 \\
14,702\end{array}$ & $\begin{array}{r}542,000 \\
369,000 \\
a \\
78,000 \\
345,000\end{array}$ & $\begin{array}{r}59,081 \\
14,500 \\
2 \\
2,804 \\
26,914\end{array}$ & $\begin{array}{r}69,000 \\
28,000 \\
a \\
5,000 \\
28,000\end{array}$ & $\begin{array}{r}84,869 \\
14,690 \\
a \\
12,030 \\
92,240\end{array}$ & $\begin{array}{l}\text { NA } \\
\text { NA } \\
\text { NA } \\
\text { NA } \\
\text { NA }\end{array}$ \\
\hline 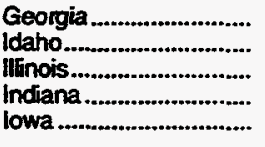 & $\begin{array}{r}87,359 \\
7,711 \\
439,152 \\
158,699 \\
96,219\end{array}$ & $\begin{array}{r}730,000 \\
68,000 \\
2,739,000 \\
996,000 \\
568,000\end{array}$ & $\begin{array}{r}38,726 \\
5,851 \\
193,434 \\
77,550 \\
57,266\end{array}$ & $\begin{array}{r}54,000 \\
11,000 \\
205,000 \\
103,000 \\
70,000\end{array}$ & $\begin{array}{r}140,891 \\
28,805 \\
380,411 \\
268,458 \\
98,968\end{array}$ & $\begin{array}{l}\text { NA } \\
\text { NA } \\
\text { NA } \\
\text { NA } \\
\text { NA }\end{array}$ \\
\hline 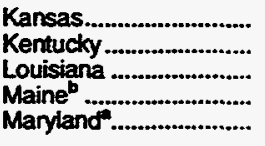 & $\begin{array}{r}97,317 \\
86,473 \\
86,148 \\
5,247 \\
86,811\end{array}$ & $\begin{array}{r}596,000 \\
523,000 \\
834,000 \\
75,000 \\
816,000\end{array}$ & $\begin{array}{r}52,632 \\
42,461 \\
70,321 \\
3,220 \\
37,529\end{array}$ & $\begin{array}{r}57,000 \\
50,000 \\
74,000 \\
5,000 \\
64,000\end{array}$ & $\begin{array}{r}163,649 \\
72,524 \\
994,056 \\
2,224 \\
44,008\end{array}$ & $\begin{array}{l}\text { NA } \\
\text { NA } \\
\text { NA } \\
\text { NA } \\
\text { NA }\end{array}$ \\
\hline $\begin{array}{l}\text { Massachusetts............. } \\
\text { Michigan ..................... } \\
\text { Minnesota................. } \\
\text { Mississippi ...................... } \\
\text { Missouri ........................ }\end{array}$ & $\begin{array}{r}82,646 \\
340,033 \\
101,764 \\
36,642 \\
156,571\end{array}$ & $\begin{array}{r}990,000 \\
1,901,000 \\
603,000 \\
328,000 \\
981,000\end{array}$ & $\begin{array}{r}35,356 \\
132,708 \\
76,585 \\
23,846 \\
87,644\end{array}$ & $\begin{array}{r}63,000 \\
160,000 \\
53,000 \\
39,000 \\
87,000\end{array}$ & $\begin{array}{r}22,556 \\
258,306 \\
97,569 \\
132,956 \\
109,597\end{array}$ & $\begin{array}{l}\text { NA } \\
\text { NA } \\
\text { NA } \\
\text { NA } \\
\text { NA }\end{array}$ \\
\hline $\begin{array}{l}\text { Montana...................... } \\
\text { Nebraska ..................... } \\
\text { Nevada ...................... } \\
\text { New Hampshire ............ } \\
\text { New Jersey.................... }\end{array}$ & $\begin{array}{r}24,794 \\
58,295 \\
7,262 \\
b \\
140,219\end{array}$ & $\begin{array}{r}136,000 \\
318,000 \\
69,000 \\
b \\
1,583,000\end{array}$ & $\begin{array}{r}18,564 \\
46,824 \\
9,633 \\
b \\
55,953\end{array}$ & $\begin{array}{r}18,000 \\
49,000 \\
4,000 \\
b \\
172,000\end{array}$ & $\begin{array}{r}36,105 \\
54,790 \\
10,327 \\
b \\
79,847\end{array}$ & $\begin{array}{l}\text { NA } \\
\text { NA } \\
\text { NA } \\
\text { NA }\end{array}$ \\
\hline $\begin{array}{l}\text { New Mexico .................. } \\
\text { New York.................. } \\
\text { North Carolina............. } \\
\text { North Dakota................ } \\
\text { Ohio .............................. }\end{array}$ & $\begin{array}{r}30,771 \\
346,533 \\
27,353 \\
8,186 \\
459,972\end{array}$ & $\begin{array}{r}229,000 \\
3,862,000 \\
279,000 \\
50,000 \\
2,444,000\end{array}$ & $\begin{array}{r}33,035 \\
139,498 \\
21,532 \\
8,315 \\
183,412\end{array}$ & $\begin{array}{r}24,000 \\
271,000 \\
38,000 \\
7,000 \\
188,000\end{array}$ & $\begin{array}{r}73,118 \\
115,047 \\
75,065 \\
1,782 \\
373,037\end{array}$ & $\begin{array}{l}\text { NA } \\
\text { NA } \\
\text { NA } \\
\text { NA }\end{array}$ \\
\hline $\begin{array}{l}\text { Oldahoma ..................... } \\
\text { Oregon,..................... } \\
\text { Pennsylvania ................ } \\
\text { Rhode Island............... } \\
\text { South Carolina............. }\end{array}$ & $\begin{array}{r}77,460 \\
19,742 \\
297,022 \\
11,940 \\
18,930\end{array}$ & $\begin{array}{r}632,000 \\
180,000 \\
2,214,000 \\
152,000 \\
211,000\end{array}$ & $\begin{array}{r}43,921 \\
11,360 \\
99,339 \\
5,064 \\
13,850\end{array}$ & $\begin{array}{r}68,000 \\
25,000 \\
141,000 \\
7,000 \\
26,000\end{array}$ & $\begin{array}{r}119,872 \\
57,664 \\
337,756 \\
5,743 \\
78,698\end{array}$ & $\begin{array}{l}\text { NA } \\
\text { NA } \\
\text { NA } \\
\text { NA } \\
\text { NA }\end{array}$ \\
\hline 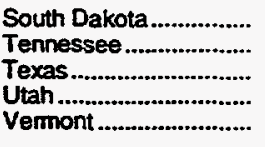 & $\begin{array}{r}13,784 \\
46,571 \\
232,189 \\
44,637 \\
b\end{array}$ & $\begin{array}{r}74,000 \\
391,000 \\
2,612,000 \\
236,000 \\
b\end{array}$ & $\begin{array}{r}11,361 \\
42,720 \\
146,090 \\
10,180 \\
b\end{array}$ & $\begin{array}{r}10,000 \\
51,000 \\
242,000 \\
16,000 \\
b\end{array}$ & $\begin{array}{r}6,800 \\
121,880 \\
1,787,724 \\
62,477 \\
b\end{array}$ & $\begin{array}{l}\text { NA } \\
\text { NA } \\
\text { NA } \\
\text { NA } \\
\text { NA }\end{array}$ \\
\hline 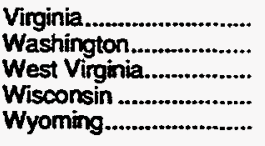 & $\begin{array}{r}49,554 \\
31,929 \\
57,973 \\
105,208 \\
17,984\end{array}$ & $\begin{array}{r}451,000 \\
262,000 \\
350,000 \\
759,000 \\
75,000\end{array}$ & $\begin{array}{l}30,090 \\
18,490 \\
21,678 \\
54,555 \\
14,026\end{array}$ & $\begin{array}{l}46,000 \\
35,000 \\
29,000 \\
62,000 \\
11,000\end{array}$ & $\begin{array}{r}44,572 \\
93,147 \\
90,474 \\
140,888 \\
50,079\end{array}$ & $\begin{array}{l}\text { NA } \\
\text { NA } \\
\text { NA } \\
\text { NA } \\
\text { NA }\end{array}$ \\
\hline 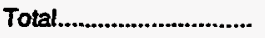 & $4,837,432$ & $38,604,000$ & $2,398,510$ & $3,253,000$ & $7,850,660$ & NA \\
\hline
\end{tabular}

See footnotes at end of table. 
Table 16. Natural Gas Delivered to Consumers by State, 1967-1994 (Continued)

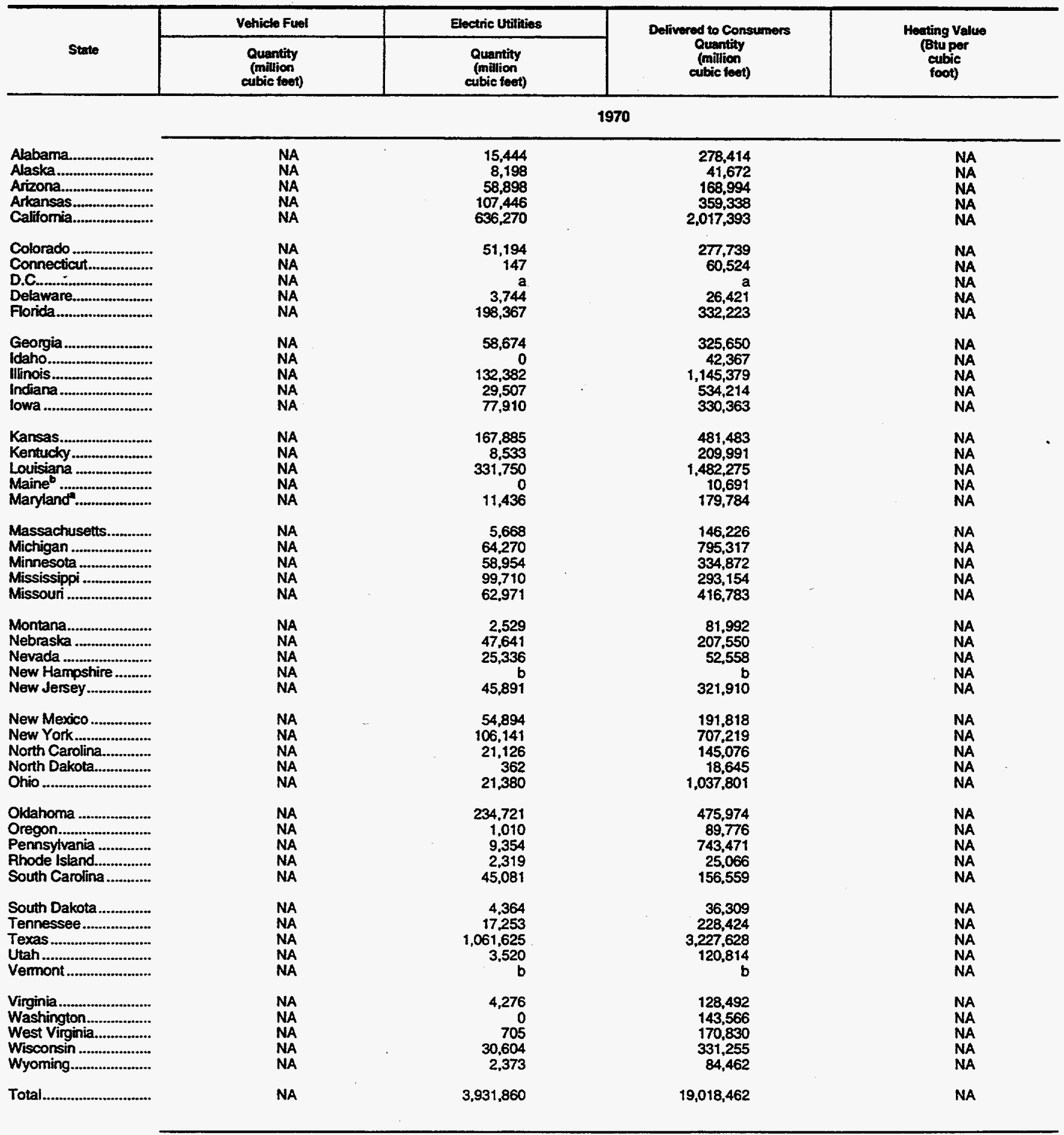

See foolnotes at end of table. 
Table 16. Natural Gas Delivered to Consumers by State, 1967-1994 (Continued)

\begin{tabular}{|c|c|c|c|c|c|c|}
\hline \multirow[b]{2}{*}{ State } & \multicolumn{2}{|c|}{ Residential } & \multicolumn{2}{|c|}{ Commercial } & \multicolumn{2}{|c|}{ Industrial } \\
\hline & $\begin{array}{l}\text { Quantity } \\
\text { (million } \\
\text { cubic feet) }\end{array}$ & Consumers & $\begin{array}{l}\text { Quantity } \\
\text { (million } \\
\text { cubie foet) }\end{array}$ & Consumers & $\begin{array}{l}\text { Quantity } \\
\text { (mittion } \\
\text { cubic feet) }\end{array}$ & Consumers \\
\hline & \multicolumn{6}{|c|}{1971} \\
\hline 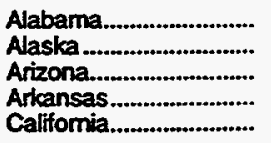 & $\begin{array}{r}54,867 \\
6,893 \\
32,619 \\
48,737 \\
630,998\end{array}$ & $\begin{array}{r}539,000 \\
18,000 \\
443,000 \\
381,000 \\
5,704,000\end{array}$ & $\begin{array}{r}36,657 \\
14,256 \\
25,604 \\
30,832 \\
239,685\end{array}$ & $\begin{array}{r}41,000 \\
3,000 \\
41,000 \\
50,000 \\
362,000\end{array}$ & $\begin{array}{r}163,370 \\
10,588 \\
60,535 \\
149,493 \\
621,837\end{array}$ & $\begin{array}{l}\text { NA } \\
\text { NA } \\
\text { NA } \\
\text { NA }\end{array}$ \\
\hline 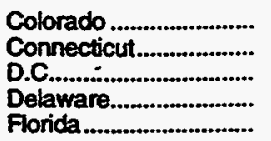 & $\begin{array}{r}84,864 \\
31,878 \\
a \\
8,172 \\
13,242\end{array}$ & $\begin{array}{r}558,000 \\
371,000 \\
a \\
78,000 \\
342,000\end{array}$ & $\begin{array}{r}62,805 \\
16,073 \\
a \\
3,010 \\
25,478\end{array}$ & $\begin{array}{r}72,000 \\
29,000 \\
a \\
5,000 \\
29,000\end{array}$ & $\begin{array}{r}76,415 \\
13,352 \\
a \\
11,297 \\
97,963\end{array}$ & $\begin{array}{l}\text { NA } \\
\text { NA } \\
\text { NA } \\
\text { NA }\end{array}$ \\
\hline 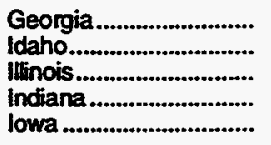 & $\begin{array}{r}88,319 \\
8,455 \\
462,644 \\
162,747 \\
92,231\end{array}$ & $\begin{array}{r}743,000 \\
75,000 \\
2,864,000 \\
1,019,000 \\
566,000\end{array}$ & $\begin{array}{r}41,881 \\
8,232 \\
210,424 \\
77,984 \\
59,138\end{array}$ & $\begin{array}{r}56,000 \\
11,000 \\
213,000 \\
102,000 \\
67,000\end{array}$ & $\begin{array}{r}142,209 \\
28,293 \\
406,716 \\
282,459 \\
102,116\end{array}$ & $\begin{array}{l}\text { NA } \\
\text { NA } \\
\text { NA } \\
\text { NA } \\
\text { NA }\end{array}$ \\
\hline 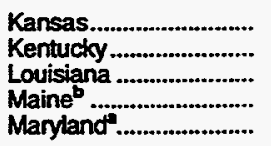 & $\begin{array}{r}98,644 \\
84,197 \\
79,893 \\
5,591 \\
87,617\end{array}$ & $\begin{array}{r}598,000 \\
525,000 \\
838,000 \\
66,000 \\
829,000\end{array}$ & $\begin{array}{r}56,246 \\
42,352 \\
67,515 \\
3,604 \\
40,988\end{array}$ & $\begin{array}{r}58,000 \\
51,000 \\
71,000 \\
5,000 \\
64,000\end{array}$ & $\begin{array}{r}174,587 \\
71.484 \\
1,006,170 \\
2,697 \\
47,781\end{array}$ & $\begin{array}{l}\text { NA } \\
\text { NA } \\
\text { NA } \\
\text { NA } \\
\text { NA }\end{array}$ \\
\hline $\begin{array}{l}\text { Massachusetts............... } \\
\text { Michigan .......................... } \\
\text { Minnesota ..................... } \\
\text { Mississippi .................... } \\
\text { Missount .......................... }\end{array}$ & $\begin{array}{r}83,434 \\
343,773 \\
102,325 \\
40,196 \\
153,384\end{array}$ & $\begin{array}{r}987,000 \\
1,929,000 \\
609,000 \\
341,000 \\
1,001,000\end{array}$ & $\begin{array}{r}36,994 \\
146,217 \\
76,441 \\
25,853 \\
89,534\end{array}$ & $\begin{array}{r}64,000 \\
166,000 \\
54,000 \\
44,000 \\
86,000\end{array}$ & $\begin{array}{r}25,673 \\
273,152 \\
122,034 \\
142,787 \\
108,424\end{array}$ & $\begin{array}{l}\text { NA } \\
\text { NA } \\
\text { NA } \\
\text { NA } \\
\text { NA }\end{array}$ \\
\hline $\begin{array}{l}\text { Montana......................... } \\
\text { Nebraska ........................ } \\
\text { Nevada ...................... } \\
\text { New Hampshire .............. } \\
\text { New Jersey.................... }\end{array}$ & $\begin{array}{r}25,379 \\
57,678 \\
7,994 \\
b \\
143,197\end{array}$ & $\begin{array}{r}140,000 \\
325,000 \\
81,000 \\
b \\
1,604,000\end{array}$ & $\begin{array}{r}18,109 \\
47,261 \\
11,014 \\
b \\
60,230\end{array}$ & $\begin{array}{r}18,000 \\
50,000 \\
40,000 \\
b \\
175,000\end{array}$ & $\begin{array}{r}36,800 \\
55,382 \\
10,012 \\
b \\
82,486\end{array}$ & $\begin{array}{l}\text { NA } \\
\text { NA } \\
\text { NA } \\
\text { NA } \\
\text { NA }\end{array}$ \\
\hline $\begin{array}{l}\text { New Mexico ................... } \\
\text { New York....................... } \\
\text { North Carolina.............. } \\
\text { North Dakota................. } \\
\text { Ohio ............................... }\end{array}$ & $\begin{array}{r}32,396 \\
352,085 \\
30,434 \\
8,502 \\
460,820\end{array}$ & $\begin{array}{r}232,000 \\
3,859,000 \\
294,000 \\
52,000 \\
2,473,000\end{array}$ & $\begin{array}{r}33,760 \\
145,458 \\
26,331 \\
9,059 \\
189,791\end{array}$ & $\begin{array}{r}23,000 \\
268,000 \\
44,000 \\
8,000 \\
190,000\end{array}$ & $\begin{array}{r}78,814 \\
116,594 \\
76,640 \\
1,640 \\
398,767\end{array}$ & $\begin{array}{l}\text { NA } \\
\text { NA } \\
\text { NA } \\
\text { NA } \\
\text { NA }\end{array}$ \\
\hline $\begin{array}{l}\text { Okdahoma ...................... } \\
\text { Oregon........................... } \\
\text { Pennsylvania ............... } \\
\text { Rhode Island................ } \\
\text { South Carolina ............... }\end{array}$ & $\begin{array}{r}75,238 \\
21,217 \\
304,327 \\
12,160 \\
19,607\end{array}$ & $\begin{array}{r}641,000 \\
193,000 \\
2,216,000 \\
153,000 \\
231,000\end{array}$ & $\begin{array}{r}41,978 \\
13,563 \\
110,014 \\
4,530 \\
14,371\end{array}$ & $\begin{array}{r}67,000 \\
25,000 \\
148,000 \\
10,000 \\
24,000\end{array}$ & $\begin{array}{r}126,598 \\
59,304 \\
347,707 \\
6,157 \\
79,256\end{array}$ & $\begin{array}{l}\text { NA } \\
\text { NA } \\
\text { NA } \\
\text { NA }\end{array}$ \\
\hline 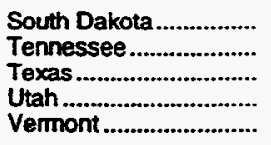 & $\begin{array}{r}12,436 \\
46,992 \\
237,387 \\
49,849 \\
b\end{array}$ & $\begin{array}{r}76,000 \\
394,000 \\
2,681,000 \\
256,000 \\
\mathrm{~b}\end{array}$ & $\begin{array}{r}10,592 \\
44,062 \\
142,423 \\
8,504 \\
b\end{array}$ & $\begin{array}{r}10,000 \\
51,000 \\
246,000 \\
15,000 \\
b\end{array}$ & $\begin{array}{r}5,480 \\
127,702 \\
1,933,081 \\
57,998 \\
b\end{array}$ & $\begin{array}{l}\text { NA } \\
\text { NA } \\
\text { NA } \\
\text { NA } \\
\text { NA }\end{array}$ \\
\hline 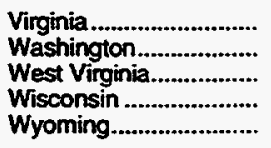 & $\begin{array}{r}49,488 \\
33,934 \\
55,629 \\
109,758 \\
19,463\end{array}$ & $\begin{array}{r}463,000 \\
272,000 \\
355,000 \\
776,000 \\
76,000\end{array}$ & $\begin{array}{l}34,672 \\
20,612 \\
23,106 \\
47,662 \\
14,072\end{array}$ & $\begin{array}{l}46,000 \\
35,000 \\
29,000 \\
64,000 \\
11,000\end{array}$ & $\begin{array}{r}48,283 \\
95,974 \\
86,153 \\
155,998 \\
52,266\end{array}$ & $\begin{array}{l}\text { NA } \\
\text { NA } \\
\text { NA } \\
\text { NA } \\
\text { NA }\end{array}$ \\
\hline 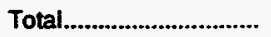 & $4,971,690$ & $39,267,000$ & $2,508,977$ & $3,341,000$ & $8,180,527$ & NA \\
\hline
\end{tabular}

See footnotes at end of table. 
Table 16. Natural Gas Delivered to Consumers by State, 1967-1994 (Continued)

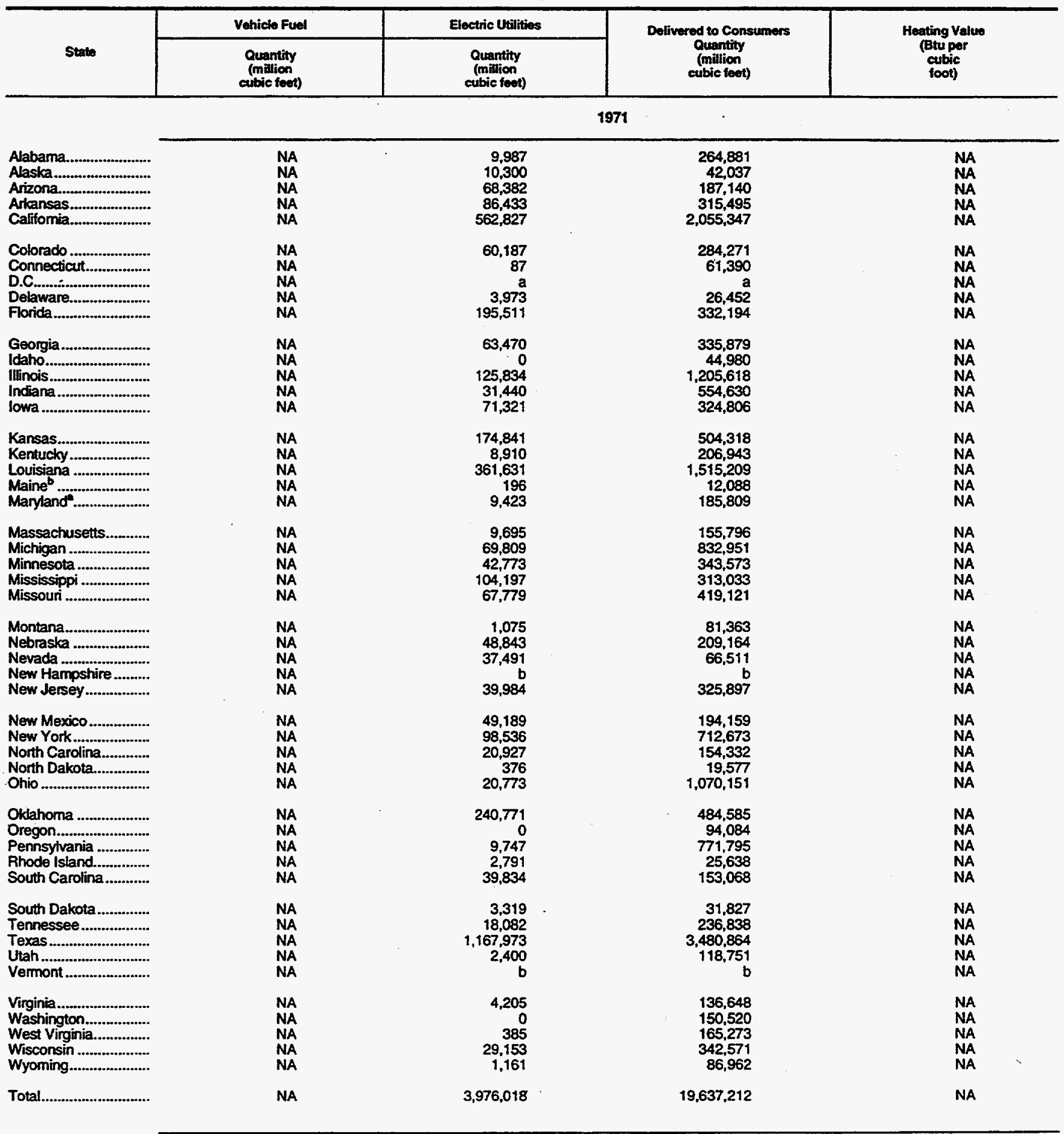

See footnotes at end of table. 
Țable 16. Natural Gas Delivered to Consumers by State, 1967-1994 (Continued)

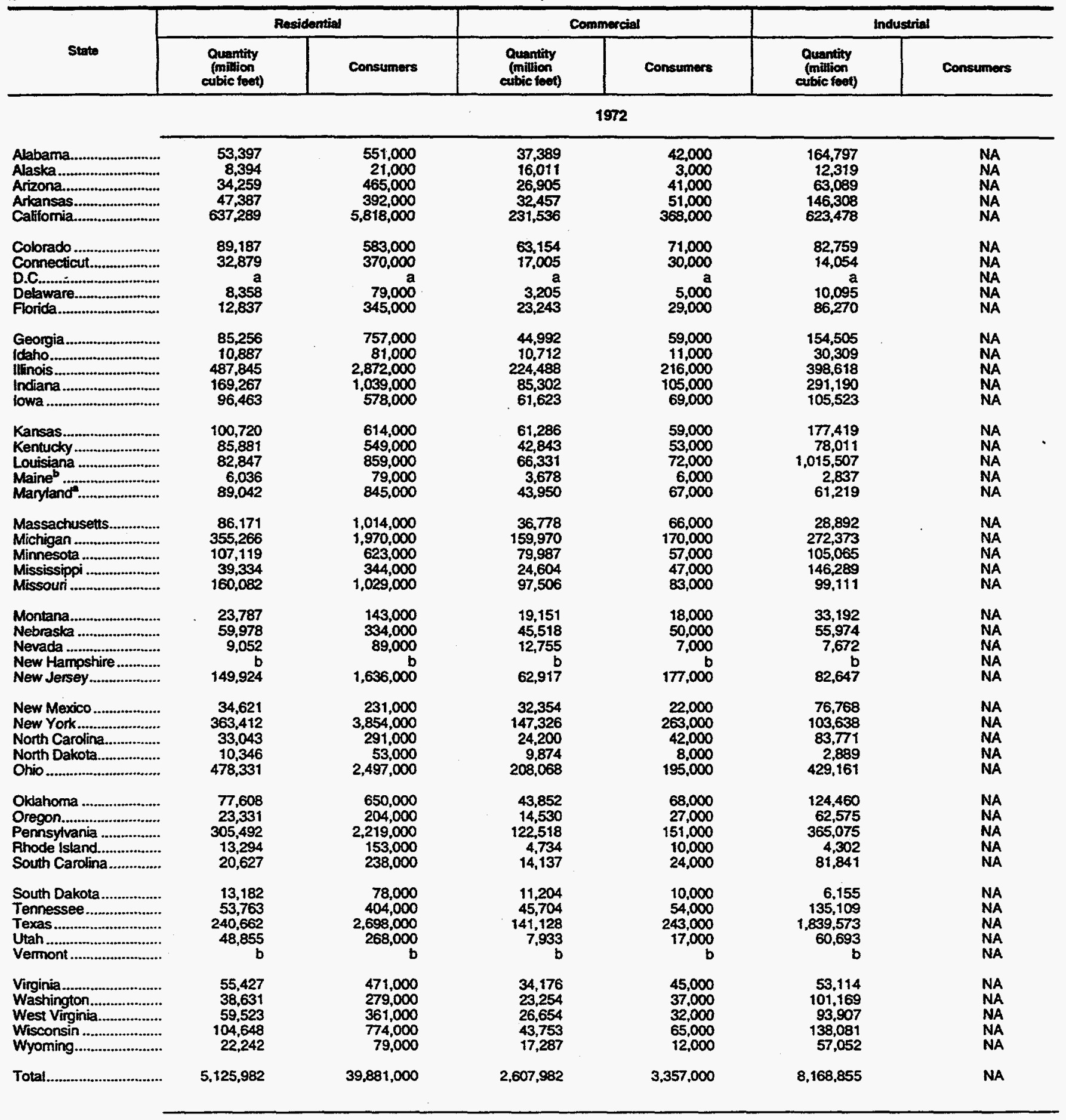

See footnotes at end of table. 
TTable 16. Natural Gas Delivered to Consumers by State, 1967-1994 (Continued)

\begin{tabular}{|c|c|c|c|c|}
\hline \multirow[b]{2}{*}{ State } & Vohicle Fuol & Electric Uititities & \multirow{2}{*}{$\begin{array}{l}\text { Delivered to Consumers } \\
\text { Quantity } \\
\text { (million } \\
\text { cubic foot) }\end{array}$} & \multirow{2}{*}{$\begin{array}{l}\text { Heating Value } \\
\text { (Btu per } \\
\text { cubic } \\
\text { foot) }\end{array}$} \\
\hline & $\begin{array}{l}\text { Quantity } \\
\text { (million } \\
\text { cubic feet) }\end{array}$ & $\begin{array}{l}\text { Quantity } \\
\text { (million } \\
\text { cubic feet) }\end{array}$ & & \\
\hline & \multicolumn{4}{|c|}{1972} \\
\hline 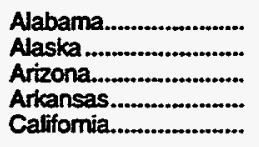 & $\begin{array}{l}\text { NA } \\
\text { NA } \\
\text { NA } \\
\text { NA } \\
\text { NA }\end{array}$ & $\begin{array}{r}2,748 \\
13,094 \\
77,715 \\
72,332 \\
605,791\end{array}$ & $\begin{array}{r}258,331 \\
49,818 \\
201,968 \\
298,484 \\
2,098,094\end{array}$ & $\begin{array}{l}\text { NA } \\
\text { NA } \\
\text { NA } \\
\text { NA } \\
\text { NA }\end{array}$ \\
\hline 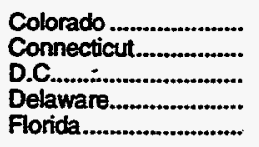 & $\begin{array}{l}\text { NA } \\
\text { NA } \\
\text { NA } \\
\text { NA } \\
\text { NA }\end{array}$ & $\begin{array}{r}66,933 \\
30 \\
a \\
2,430 \\
170,824\end{array}$ & $\begin{array}{r}302,033 \\
63,968 \\
\text { a } \\
24,088 \\
293,174\end{array}$ & $\begin{array}{l}\text { NA } \\
\text { NA } \\
\text { NA } \\
\text { NA } \\
\text { NA }\end{array}$ \\
\hline 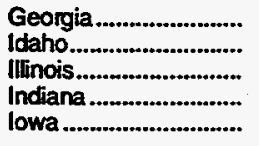 & $\begin{array}{l}\text { NA } \\
\text { NA } \\
\text { NA } \\
\text { NA } \\
\text { NA }\end{array}$ & $\begin{array}{r}38,433 \\
0 \\
72,795 \\
17,964 \\
60,638\end{array}$ & $\begin{array}{r}\mathbf{3 2 3 , 1 8 6} \\
\mathbf{5 1 , 9 0 8} \\
1,183,746 \\
\mathbf{5 6 3 , 7 2 3} \\
\mathbf{3 2 4 , 2 4 7}\end{array}$ & $\begin{array}{l}\text { NA } \\
\text { NA } \\
\text { NA } \\
\text { NA } \\
\text { NA }\end{array}$ \\
\hline 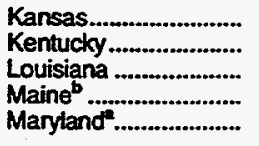 & $\begin{array}{l}\text { NA } \\
\text { NA } \\
\text { NA } \\
\text { NA } \\
\text { NA }\end{array}$ & $\begin{array}{r}180,410 \\
10,014 \\
383,398 \\
716 \\
7,043\end{array}$ & $\begin{array}{r}519,835 \\
216,749 \\
1,548,083 \\
13,267 \\
201,254\end{array}$ & $\begin{array}{l}\text { NA } \\
\text { NA } \\
\text { NA } \\
\text { NA } \\
\text { NA }\end{array}$ \\
\hline 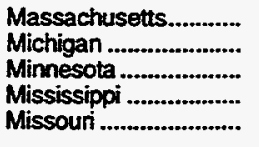 & $\begin{array}{l}\text { NA } \\
\text { NA } \\
\text { NA } \\
\text { NA } \\
\text { NA }\end{array}$ & $\begin{array}{r}7,782 \\
58,899 \\
51,769 \\
100,723 \\
58,897\end{array}$ & $\begin{array}{l}159,623 \\
846,508 \\
343,940 \\
310,950 \\
415,596\end{array}$ & $\begin{array}{l}\text { NA } \\
\text { NA } \\
\text { NA } \\
\text { NA } \\
\text { NA }\end{array}$ \\
\hline 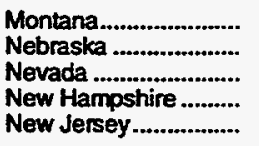 & $\begin{array}{l}\text { NA } \\
\text { NA } \\
\text { NA } \\
\text { NA } \\
\text { NA }\end{array}$ & $\begin{array}{r}1,218 \\
49,154 \\
40,043 \\
\text { b } \\
25,071\end{array}$ & $\begin{array}{r}77,348 \\
210,624 \\
69,522 \\
b \\
320,559\end{array}$ & $\begin{array}{l}\text { NA } \\
\text { NA } \\
\text { NA } \\
\text { NA } \\
\text { NA }\end{array}$ \\
\hline 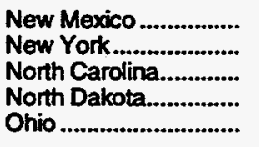 & $\begin{array}{l}\text { NA } \\
\text { NA } \\
\text { NA } \\
\text { NA } \\
\text { NA }\end{array}$ & $\begin{array}{r}59,141 \\
74,953 \\
16,812 \\
328 \\
16,121\end{array}$ & $\begin{array}{r}202,884 \\
689,329 \\
157,826 \\
23,437 \\
1,131,681\end{array}$ & $\begin{array}{l}\text { NA } \\
\text { NA } \\
\text { NA } \\
\text { NA } \\
\text { NA }\end{array}$ \\
\hline 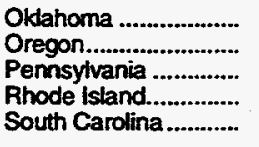 & $\begin{array}{l}\text { NA } \\
\text { NA } \\
\text { NA } \\
\text { NA } \\
\text { NA }\end{array}$ & $\begin{array}{r}260,457 \\
0 \\
5,474 \\
148 \\
24,509\end{array}$ & $\begin{array}{l}506,377 \\
100,436 \\
798,559 \\
22,478 \\
141,114\end{array}$ & $\begin{array}{l}\text { NA } \\
\text { NA } \\
\text { NA } \\
\text { NA } \\
\text { NA }\end{array}$ \\
\hline 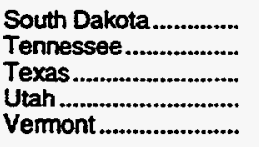 & $\begin{array}{l}\text { NA } \\
\text { NA } \\
\text { NA } \\
\text { NA } \\
\text { NA }\end{array}$ & $\begin{array}{r}3,526 \\
16,165 \\
1,284,783 \\
3,783 \\
b\end{array}$ & $\begin{array}{r}34,067 \\
250,741 \\
3,506,146 \\
121,264 \\
\text { b }\end{array}$ & $\begin{array}{l}\text { NA } \\
\text { NA } \\
\text { NA } \\
\text { NA } \\
\text { NA }\end{array}$ \\
\hline 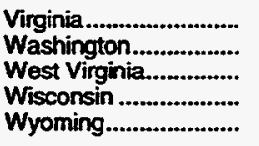 & $\begin{array}{l}\text { NA } \\
\text { NA } \\
\text { NA } \\
\text { NA } \\
\text { NA }\end{array}$ & $\begin{array}{r}4,510 \\
0 \\
457 \\
28,110 \\
773\end{array}$ & $\begin{array}{r}147,227 \\
163,054 \\
180,541 \\
314,592 \\
97,354\end{array}$ & $\begin{array}{l}\text { NA } \\
\text { NA } \\
\text { NA } \\
\text { NA } \\
\text { NA }\end{array}$ \\
\hline Total................................ & NA & $3,976,914$ & $19,879,733$ & NA \\
\hline
\end{tabular}

See footnotes at end of table. 
Table 16. Natural Gas Delivered to Consumers by State, 1967-1994 (Continued)

\begin{tabular}{|c|c|c|c|c|c|c|}
\hline \multirow[b]{2}{*}{ State } & \multicolumn{2}{|c|}{ Residential } & \multicolumn{2}{|c|}{ Commercial } & \multicolumn{2}{|c|}{ Industrial } \\
\hline & $\begin{array}{l}\text { Quantity } \\
\text { (million } \\
\text { cubic feot) }\end{array}$ & Consumers & $\begin{array}{l}\text { Quantity } \\
\text { (million } \\
\text { cubic teet) }\end{array}$ & Consumers & $\begin{array}{l}\text { Quantity } \\
\text { (million } \\
\text { cubic feet) }\end{array}$ & Consumers \\
\hline & \multicolumn{6}{|c|}{1973} \\
\hline 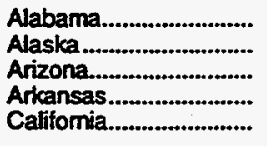 & $\begin{array}{r}55,685 \\
5,024 \\
36,280 \\
48,883 \\
615,719\end{array}$ & $\begin{array}{r}603,000 \\
23,000 \\
491,000 \\
412,000 \\
5,938,000\end{array}$ & $\begin{array}{r}33,126 \\
12,277 \\
31,812 \\
33,789 \\
232,774\end{array}$ & $\begin{array}{r}41,000 \\
3,000 \\
38,000 \\
51,000 \\
352,000\end{array}$ & $\begin{array}{r}157,828 \\
14,573 \\
65,519 \\
177,694 \\
649,294\end{array}$ & $\begin{array}{l}\text { NA } \\
\text { NA } \\
\text { NA } \\
\text { NA }\end{array}$ \\
\hline 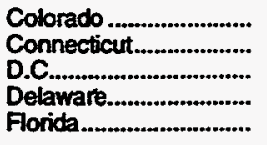 & $\begin{array}{r}98,454 \\
30,261 \\
a \\
7,514 \\
16,295\end{array}$ & $\begin{array}{r}639,000 \\
361,000 \\
a \\
78,000 \\
384,000\end{array}$ & $\begin{array}{r}69,844 \\
15,420 \\
a \\
3,093 \\
24,315\end{array}$ & $\begin{array}{r}78,000 \\
30,000 \\
a \\
5,000 \\
29,000\end{array}$ & $\begin{array}{r}87,107 \\
16,903 \\
a \\
10,032 \\
95,684\end{array}$ & $\begin{array}{l}\text { NA } \\
\text { NA } \\
\text { NA } \\
\text { NA }\end{array}$ \\
\hline 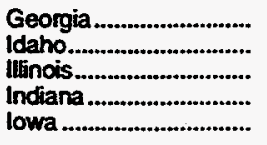 & $\begin{array}{r}86,191 \\
9,947 \\
445,723 \\
155,039 \\
91,310\end{array}$ & $\begin{array}{r}799,000 \\
86,000 \\
2,871,000 \\
1,065,000 \\
614,000\end{array}$ & $\begin{array}{r}47,253 \\
9,387 \\
218,530 \\
76,835 \\
63,350\end{array}$ & $\begin{array}{r}61,000 \\
13,000 \\
217,000 \\
107,000 \\
64,000\end{array}$ & $\begin{array}{r}174,124 \\
32,052 \\
424,801 \\
287,484 \\
131,632\end{array}$ & $\begin{array}{l}\text { NA } \\
\text { NA } \\
\text { NA } \\
\text { NA } \\
\text { NA }\end{array}$ \\
\hline 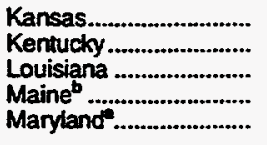 & $\begin{array}{r}96,468 \\
80,233 \\
93,072 \\
6,027 \\
86,670\end{array}$ & $\begin{array}{r}617,000 \\
588,000 \\
893,000 \\
69,000 \\
859,000\end{array}$ & $\begin{array}{r}52,674 \\
45,797 \\
59,518 \\
3,323 \\
42,953\end{array}$ & $\begin{array}{r}58,000 \\
58,000 \\
68,000 \\
5,000 \\
65,000\end{array}$ & $\begin{array}{r}173,619 \\
75,459 \\
1,075,671 \\
3,775 \\
60,661\end{array}$ & $\begin{array}{l}\text { NA } \\
\text { NA } \\
\text { NA } \\
\text { NA } \\
\text { NA }\end{array}$ \\
\hline $\begin{array}{l}\text { Massachusetts.............. } \\
\text { Michigan ..................... } \\
\text { Minnesota ..................... } \\
\text { Mississippi ................... } \\
\text { Missouri ........................ }\end{array}$ & $\begin{array}{r}83,988 \\
341,607 \\
102,671 \\
31,422 \\
153,543\end{array}$ & $\begin{array}{r}1,023,000 \\
2,043,000 \\
649,000 \\
337,000 \\
1,059,000\end{array}$ & $\begin{array}{r}39,288 \\
180,274 \\
80,219 \\
23,701 \\
91,038\end{array}$ & $\begin{array}{r}67,000 \\
177,000 \\
59,000 \\
34,000 \\
76,000\end{array}$ & $\begin{array}{r}25,722 \\
321,504 \\
114,976 \\
135,117 \\
118,275\end{array}$ & $\begin{array}{l}\text { NA } \\
\text { NA } \\
\text { NA } \\
\text { NA } \\
\text { NA }\end{array}$ \\
\hline $\begin{array}{l}\text { Montana...................... } \\
\text { Nebraska .................... } \\
\text { Nevada ....................... } \\
\text { New Hampshire ........... } \\
\text { New Jersey .................... }\end{array}$ & $\begin{array}{r}24,923 \\
50,383 \\
9,048 \\
b \\
136,625\end{array}$ & $\begin{array}{r}155,000 \\
326,000 \\
88,000 \\
b \\
1,619,000\end{array}$ & $\begin{array}{r}19,143 \\
38,690 \\
13,144 \\
b \\
61,846\end{array}$ & $\begin{array}{r}21,000 \\
49,000 \\
4,000 \\
b \\
183,000\end{array}$ & $\begin{array}{r}37,898 \\
71,014 \\
10,342 \\
b \\
77,954\end{array}$ & $\begin{array}{l}\text { NA } \\
\text { NA } \\
\text { NA } \\
\text { NA } \\
\text { NA }\end{array}$ \\
\hline 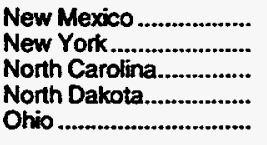 & $\begin{array}{r}23,730 \\
342,608 \\
28,435 \\
8,204 \\
439,212\end{array}$ & $\begin{array}{r}220,000 \\
3,878,000 \\
288,000 \\
54,000 \\
2,577,000\end{array}$ & $\begin{array}{r}25,569 \\
142,736 \\
23,044 \\
9,875 \\
196,663\end{array}$ & $\begin{array}{r}24,000 \\
262,000 \\
42,000 \\
8,000 \\
208,000\end{array}$ & $\begin{array}{r}59,012 \\
124,155 \\
95,652 \\
1,524 \\
435,791\end{array}$ & $\begin{array}{l}\text { NA } \\
\text { NA } \\
\text { NA } \\
\text { NA } \\
\text { NA }\end{array}$ \\
\hline 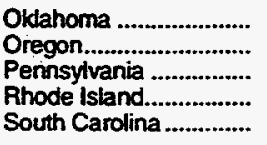 & $\begin{array}{r}73,744 \\
22,271 \\
292,531 \\
11,417 \\
22,758\end{array}$ & $\begin{array}{r}654,000 \\
224,000 \\
2,216,000 \\
150,000 \\
255,000\end{array}$ & $\begin{array}{r}40,403 \\
13,722 \\
116,265 \\
4,648 \\
16,053\end{array}$ & $\begin{array}{r}62,000 \\
28,000 \\
149,000 \\
9,000 \\
25,000\end{array}$ & $\begin{array}{r}120,813 \\
60,393 \\
346,854 \\
4,446 \\
85,695\end{array}$ & $\begin{array}{l}\text { NA } \\
\text { NA } \\
\text { NA } \\
\text { NA } \\
\text { NA }\end{array}$ \\
\hline 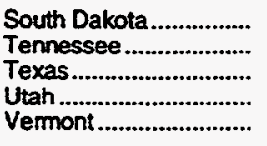 & $\begin{array}{r}11,190 \\
45,993 \\
241,478 \\
48,647 \\
b\end{array}$ & $\begin{array}{r}80,000 \\
431,000 \\
2,616,000 \\
261,000 \\
b\end{array}$ & $\begin{array}{r}10,568 \\
45,974 \\
155,070 \\
8,997 \\
b\end{array}$ & $\begin{array}{r}10,000 \\
54,000 \\
233,000 \\
16,000 \\
b\end{array}$ & $\begin{array}{r}5,391 \\
159,948 \\
2,026,176 \\
57,674 \\
b\end{array}$ & $\begin{array}{l}\text { NA } \\
\text { NA } \\
\text { NA } \\
\text { NA } \\
\text { NA }\end{array}$ \\
\hline $\begin{array}{l}\text { Virginia } \\
\text { Washington.................... } \\
\text { West Vinginia............... } \\
\text { Wisconsin .................... } \\
\text { Wyoming.................... }\end{array}$ & $\begin{array}{r}51,618 \\
36,468 \\
55,686 \\
110,524 \\
13,868\end{array}$ & $\begin{array}{r}481,000 \\
291,000 \\
369,000 \\
830,000 \\
81,000\end{array}$ & $\begin{array}{l}37,632 \\
32,333 \\
25,854 \\
55,012 \\
13,206\end{array}$ & $\begin{array}{l}41,000 \\
38,000 \\
33,000 \\
70,000 \\
10,000\end{array}$ & $\begin{array}{r}53,428 \\
121,697 \\
84,691 \\
167,338 \\
51,272\end{array}$ & $\begin{array}{l}\text { NA } \\
\text { NA } \\
\text { NA } \\
\text { NA } \\
\text { NA }\end{array}$ \\
\hline 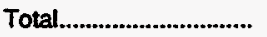 & $4,879,387$ & $40,645,000$ & $2,597,037$ & $3,335,000$ & $8,688,675$ & NA \\
\hline
\end{tabular}

See footnotes at end of table. 
Table 16. Natural Gas Delivered to Consumers by State, 1967-1994 (Continued)

\begin{tabular}{|c|c|c|c|c|}
\hline \multirow[b]{2}{*}{ State } & Vehicle Fuel & Electric Utilitios & \multirow{2}{*}{$\begin{array}{l}\text { Delivered to Consumers } \\
\text { Quantity } \\
\text { (mallion } \\
\text { cubic foet) }\end{array}$} & \multirow{2}{*}{$\begin{array}{l}\text { Heating Value } \\
\text { (Btu per } \\
\text { cubic } \\
\text { foot) }\end{array}$} \\
\hline & $\begin{array}{l}\text { Quantity } \\
\text { (million } \\
\text { cubic foet) }\end{array}$ & $\begin{array}{l}\text { Quantity } \\
\text { (million } \\
\text { cubic toet) }\end{array}$ & & \\
\hline & \multicolumn{4}{|c|}{1973} \\
\hline 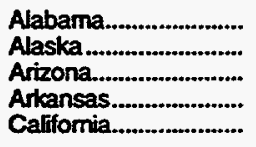 & $\begin{array}{l}\text { NA } \\
\text { NA } \\
\text { NA } \\
\text { NA } \\
\text { NA }\end{array}$ & $\begin{array}{r}4,305 \\
15,812 \\
56,689 \\
49,014 \\
455,526\end{array}$ & $\begin{array}{r}250,944 \\
47,686 \\
190,300 \\
309,380 \\
1,953,313\end{array}$ & $\begin{array}{l}\text { NA } \\
\text { NA } \\
\text { NA } \\
\text { NA } \\
\text { NA }\end{array}$ \\
\hline 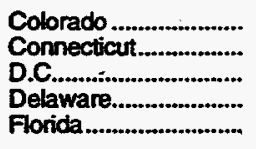 & $\begin{array}{l}\text { NA } \\
\text { NA } \\
\text { NA } \\
\text { NA } \\
\text { NA }\end{array}$ & $\begin{array}{r}58,820 \\
0 \\
a \\
2,310 \\
168,293\end{array}$ & $\begin{array}{r}314,225 \\
62,584 \\
a \\
22,949 \\
304,587\end{array}$ & $\begin{array}{l}\text { NA } \\
\text { NA } \\
\text { NA } \\
\text { NA } \\
\text { NA }\end{array}$ \\
\hline 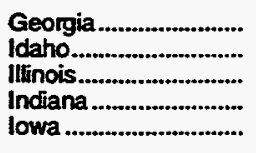 & $\begin{array}{l}\text { NA } \\
\text { NA } \\
\text { NA } \\
\text { NA } \\
\text { NA }\end{array}$ & $\begin{array}{r}34,403 \\
0 \\
39,595 \\
10,246 \\
61,864\end{array}$ & $\begin{array}{r}341,971 \\
51,396 \\
1,128,649 \\
529,604 \\
348,156\end{array}$ & $\begin{array}{l}\text { NA } \\
\text { NA } \\
\text { NA } \\
\text { NA } \\
\text { NA }\end{array}$ \\
\hline 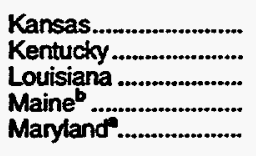 & $\begin{array}{l}\text { NA } \\
\text { NA } \\
\text { NA } \\
\text { NA } \\
\text { NA }\end{array}$ & $\begin{array}{r}176,104 \\
8,067 \\
364,568 \\
756 \\
8,869\end{array}$ & $\begin{array}{r}498,865 \\
209,556 \\
1,592,829 \\
13,881 \\
199,153\end{array}$ & $\begin{array}{l}\text { NA } \\
\text { NA } \\
\text { NA } \\
\text { NA } \\
\text { NA }\end{array}$ \\
\hline 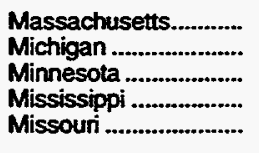 & $\begin{array}{l}\text { NA } \\
\text { NA } \\
\text { NA } \\
\text { NA } \\
\text { NA }\end{array}$ & $\begin{array}{r}5,969 \\
62,392 \\
57,506 \\
60,224 \\
54,782\end{array}$ & $\begin{array}{l}154,967 \\
905,777 \\
355,372 \\
250,464 \\
417,638\end{array}$ & $\begin{array}{l}\text { NA } \\
\text { NA } \\
\text { NA } \\
\text { NA } \\
\text { NA }\end{array}$ \\
\hline 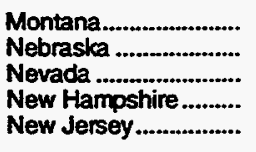 & $\begin{array}{l}\text { NA } \\
\text { NA } \\
\text { NA } \\
\text { NA } \\
\text { NA }\end{array}$ & $\begin{array}{r}2,322 \\
54,139 \\
40,538 \\
b \\
24,461\end{array}$ & $\begin{array}{r}84,286 \\
214,226 \\
73,072 \\
\text { b } \\
300,886\end{array}$ & $\begin{array}{l}\text { NA } \\
\text { NA } \\
\text { NA } \\
\text { NA } \\
\text { NA }\end{array}$ \\
\hline 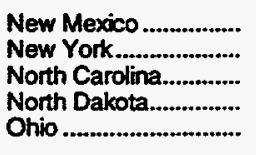 & $\begin{array}{l}\text { NA } \\
\text { NA } \\
\text { NA } \\
\text { NA } \\
\text { NA }\end{array}$ & $\begin{array}{r}66,431 \\
69,580 \\
7,748 \\
349 \\
16,144\end{array}$ & $\begin{array}{r}174,742 \\
679,079 \\
154,879 \\
19,952 \\
1,087,810\end{array}$ & $\begin{array}{l}\text { NA } \\
\text { NA } \\
\text { NA } \\
\text { NA } \\
\text { NA }\end{array}$ \\
\hline 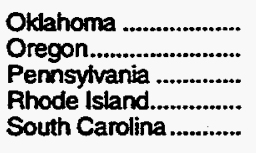 & $\begin{array}{l}\text { NA } \\
\text { NA } \\
\text { NA } \\
\text { NA } \\
\text { NA }\end{array}$ & $\begin{array}{r}270,484 \\
2,859 \\
2,537 \\
29 \\
25,117\end{array}$ & $\begin{array}{r}505,444 \\
99,245 \\
758,187 \\
20,540 \\
149,623\end{array}$ & $\begin{array}{l}\text { NA } \\
\text { NA } \\
\text { NA } \\
\text { NA } \\
\text { NA }\end{array}$ \\
\hline 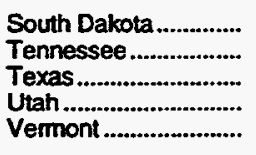 & $\begin{array}{l}\text { NA } \\
\text { NA } \\
\text { NA } \\
\text { NA } \\
\text { NA }\end{array}$ & $\begin{array}{r}4,060 \\
11,986 \\
1,265,928 \\
4,742 \\
b\end{array}$ & $\begin{array}{r}31,209 \\
263,901 \\
3,688,652 \\
120,060 \\
\text { b }\end{array}$ & $\begin{array}{l}\text { NA } \\
\text { NA } \\
\text { NA } \\
\text { NA } \\
\text { NA }\end{array}$ \\
\hline 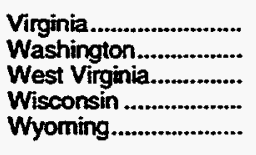 & $\begin{array}{l}\text { NA } \\
\text { NA } \\
\text { NA } \\
\text { NA } \\
\text { NA }\end{array}$ & $\begin{array}{r}4,172 \\
0 \\
393 \\
29,667 \\
373\end{array}$ & $\begin{array}{r}146,850 \\
190,498 \\
166,624 \\
362,541 \\
78,719\end{array}$ & $\begin{array}{l}\text { NA } \\
\text { NA } \\
\text { NA } \\
\text { NA } \\
\text { NA }\end{array}$ \\
\hline 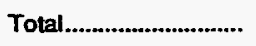 & NA & $3,660,172$ & $19,825,271$ & NA \\
\hline
\end{tabular}

See footnotes at end of table. 
Table 16. Natural Gas Delivered to Consumers by State, 1967-1994 (Continued)

\begin{tabular}{|c|c|c|c|c|c|c|}
\hline \multirow[b]{2}{*}{ State } & \multicolumn{2}{|c|}{ Residential } & \multicolumn{2}{|c|}{ Commercial } & \multicolumn{2}{|c|}{ Industrial } \\
\hline & $\begin{array}{l}\text { Quantity } \\
\text { (million } \\
\text { cubic foot) }\end{array}$ & Consumers & $\begin{array}{l}\text { Quantity } \\
\text { (million } \\
\text { cibic foot) }\end{array}$ & Consumers & $\begin{array}{l}\text { Quantity } \\
\text { (million } \\
\text { cubic foet) }\end{array}$ & Consumers \\
\hline & \multicolumn{6}{|c|}{1974} \\
\hline 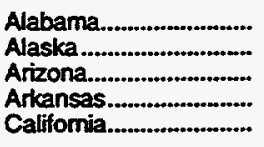 & $\begin{array}{r}55,117 \\
4,163 \\
32,335 \\
44,110 \\
580,009\end{array}$ & $\begin{array}{r}625,000 \\
22,000 \\
529,000 \\
415,000 \\
6,064,000\end{array}$ & $\begin{array}{r}35,349 \\
13,106 \\
32,742 \\
31,040 \\
228,988\end{array}$ & $\begin{array}{r}42,000 \\
4,000 \\
44,000 \\
53,000 \\
379,000\end{array}$ & $\begin{array}{r}158,709 \\
13,976 \\
64,895 \\
157,792 \\
641,778\end{array}$ & $\begin{array}{l}\text { NA } \\
\text { NA } \\
\text { NA } \\
\text { NA } \\
\text { NA }\end{array}$ \\
\hline 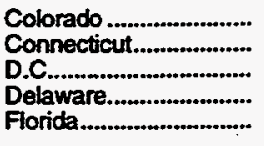 & $\begin{array}{r}91,809 \\
33,417 \\
N A \\
7,380 \\
14,793\end{array}$ & $\begin{array}{r}661,000 \\
372,000 \\
N A \\
78,000 \\
379,000\end{array}$ & $\begin{array}{r}68,322 \\
16,247 \\
0 \\
0 \quad 3,169 \\
-\quad 22,527\end{array}$ & $\begin{array}{r}84,000 \\
30,000 \\
N A \\
5,000 \\
37,000\end{array}$ & $\begin{array}{r}78,394 \\
16,100 \\
N A \\
8,925 \\
91,588\end{array}$ & $\begin{array}{l}\text { NA } \\
\text { NA } \\
\text { NA } \\
\text { NA } \\
\text { NA }\end{array}$ \\
\hline 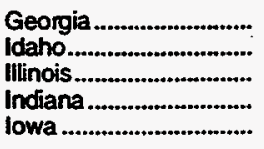 & $\begin{array}{r}76,207 \\
9,652 \\
461,746 \\
158,130 \\
91,936\end{array}$ & $\begin{array}{r}828,000 \\
88,000 \\
2,890,000 \\
1,069,000 \\
614,000\end{array}$ & $\begin{array}{r}44,317 \\
8,040 \\
216,114 \\
75,887 \\
64,052\end{array}$ & $\begin{array}{r}63,000 \\
13,000 \\
222,000 \\
101,000 \\
68,000\end{array}$ & $\begin{array}{r}161,879 \\
31,332 \\
409,573 \\
271,377 \\
133,224\end{array}$ & $\begin{array}{l}\text { NA } \\
\text { NA } \\
\text { NA } \\
\text { NA } \\
\text { NA }\end{array}$ \\
\hline 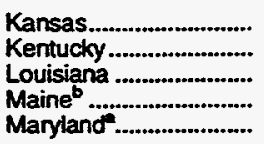 & $\begin{array}{r}93,363 \\
76,129 \\
91,844 \\
6,174 \\
82,999\end{array}$ & $\begin{array}{r}633,000 \\
586,000 \\
904,000 \\
69,000 \\
856,000\end{array}$ & $\begin{array}{r}53,461 \\
42,320 \\
58,097 \\
3,441 \\
43,080\end{array}$ & $\begin{array}{l}60,000 \\
57,000 \\
69,000 \\
6,000 \\
64,000\end{array}$ & $\begin{array}{r}164,768 \\
73,509 \\
1,091,472 \\
3,459 \\
57,584\end{array}$ & $\begin{array}{l}\text { NA } \\
\text { NA } \\
\text { NA } \\
\text { NA } \\
\text { NA }\end{array}$ \\
\hline 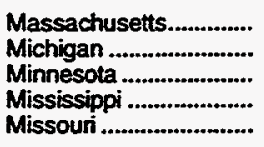 & $\begin{array}{r}85,495 \\
346,116 \\
112,922 \\
28,900 \\
152,832\end{array}$ & $\begin{array}{r}1,027,000 \\
2,048,000 \\
695,000 \\
350,000 \\
1,086,000\end{array}$ & $\begin{array}{r}37,384 \\
189,192 \\
90,412 \\
25,504 \\
90,291\end{array}$ & $\begin{array}{r}71,000 \\
181,000 \\
69,000 \\
38,000 \\
87,000\end{array}$ & $\begin{array}{r}24,409 \\
317,603 \\
106,236 \\
124,038 \\
109,702\end{array}$ & $\begin{array}{l}\text { NA } \\
\text { NA } \\
\text { NA } \\
\text { NA }\end{array}$ \\
\hline 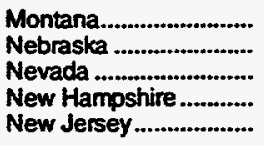 & $\begin{array}{r}21,590 \\
49,403 \\
9,388 \\
b \\
135,843\end{array}$ & $\begin{array}{r}157,000 \\
348,000 \\
101,000 \\
b \\
1,621,000\end{array}$ & $\begin{array}{r}16,602 \\
42,298 \\
14,078 \\
b \\
58,210\end{array}$ & $\begin{array}{r}22,000 \\
54,000 \\
5,000 \\
b \\
181,000\end{array}$ & $\begin{array}{r}35,202 \\
70,342 \\
9,272 \\
\mathrm{~b} \\
65,419\end{array}$ & $\begin{array}{l}\text { NA } \\
\text { NA } \\
\text { NA } \\
\text { NA } \\
\text { NA }\end{array}$ \\
\hline 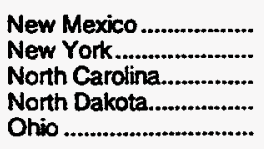 & $\begin{array}{r}25,331 \\
341,032 \\
26,830 \\
9,556 \\
435,800\end{array}$ & $\begin{array}{r}238,000 \\
3,926,000 \\
299,000 \\
59,000 \\
2,581,000\end{array}$ & $\begin{array}{r}25,221 \\
136,332 \\
21,002 \\
11,528 \\
192,497\end{array}$ & $\begin{array}{r}26,000 \\
273,000 \\
42,000 \\
9,000 \\
204,000\end{array}$ & $\begin{array}{r}63,192 \\
108,542 \\
86,817 \\
2,801 \\
424,694\end{array}$ & $\begin{array}{l}\text { NA } \\
\text { NA } \\
\text { NA } \\
\text { NA } \\
\text { NA }\end{array}$ \\
\hline 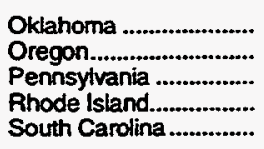 & $\begin{array}{r}72,937 \\
21,900 \\
271,877 \\
12,950 \\
20,383\end{array}$ & $\begin{array}{r}667,000 \\
230,000 \\
2,232,000 \\
155,000 \\
258,000\end{array}$ & $\begin{array}{r}41,074 \\
13,401 \\
102,495 \\
4,397 \\
14,820\end{array}$ & $\begin{array}{r}65,000 \\
29,000 \\
153,000 \\
9,000 \\
25,000\end{array}$ & $\begin{array}{r}147,313 \\
55,183 \\
310,783 \\
4,493 \\
73,114\end{array}$ & $\begin{array}{l}\text { NA } \\
\text { NA } \\
\text { NA } \\
\text { NA } \\
\text { NA }\end{array}$ \\
\hline 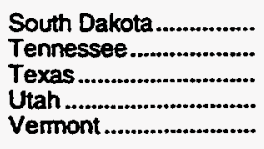 & $\begin{array}{r}11,338 \\
43,586 \\
222,603 \\
50,347 \\
b\end{array}$ & $\begin{array}{r}84,000 \\
440,000 \\
2,825,000 \\
279,000 \\
b\end{array}$ & $\begin{array}{r}11,671 \\
44,651 \\
134,418 \\
5,806 \\
b\end{array}$ & $\begin{array}{r}11,000 \\
57,000 \\
256,000 \\
14,000 \\
b\end{array}$ & $\begin{array}{r}5,418 \\
146,863 \\
1,860,637 \\
56,070 \\
\mathrm{~b}\end{array}$ & $\begin{array}{l}\text { NA } \\
\text { NA } \\
\text { NA } \\
\text { NA } \\
\text { NA }\end{array}$ \\
\hline 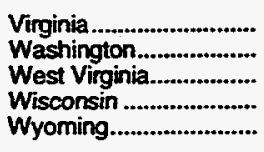 & $\begin{array}{r}48,160 \\
35,525 \\
53,793 \\
116,314 \\
12,064\end{array}$ & $\begin{array}{r}481,000 \\
301,000 \\
390,000 \\
851,000 \\
98,000\end{array}$ & $\begin{array}{l}35,281 \\
33,221 \\
24,586 \\
65,705 \\
13,241\end{array}$ & $\begin{array}{l}41,000 \\
40,000 \\
33,000 \\
72,000 \\
12,000\end{array}$ & $\begin{array}{r}50,991 \\
108,464 \\
86,022 \\
159,887 \\
47,940\end{array}$ & $\begin{array}{l}\text { NA } \\
\text { NA } \\
\text { NA } \\
\text { NA } \\
\text { NA }\end{array}$ \\
\hline 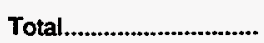 & $4,786,128$ & $41,509,000$ & $2,555,617$ & $3,480,000$ & $8,291,782$ & NA \\
\hline
\end{tabular}

See footnotes at end of table. 
Table 16. Natural Gas Delivered to Consumers by State, 1967-1994 (Continued)

\begin{tabular}{|c|c|c|c|c|c|}
\hline \multirow[b]{2}{*}{ State } & Vehicto Fuel & Electric Utilities & \multirow{2}{*}{$\begin{array}{l}\text { Delivered to Consumers } \\
\text { Quantity } \\
\text { (milition } \\
\text { ectic foot) }\end{array}$} & \multirow{2}{*}{$\begin{array}{l}\text { Heating Volue } \\
\text { (Btu per } \\
\text { cubic } \\
\text { (oot) }\end{array}$} & \\
\hline & $\begin{array}{c}\text { Quantity } \\
\text { (million } \\
\text { cubic toet) }\end{array}$ & $\begin{array}{l}\text { Quantity } \\
\text { (million } \\
\text { cubic toet) }\end{array}$ & & & \\
\hline & \multicolumn{5}{|c|}{1974} \\
\hline 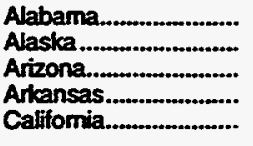 & $\begin{array}{l}\text { NA } \\
\text { NA } \\
\text { NA } \\
\text { NA } \\
\text { NA }\end{array}$ & $\begin{array}{r}4,958 \\
17,117 \\
40,249 \\
39,648 \\
292,959\end{array}$ & $\begin{array}{r}254,133 \\
48,362 \\
170,221 \\
272,590 \\
1,743,734\end{array}$ & $\begin{array}{l}\text { NA } \\
\text { NA } \\
\text { NA } \\
\text { NA } \\
\text { NA }\end{array}$ & \\
\hline 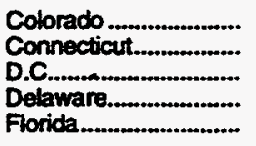 & $\begin{array}{l}\text { NA } \\
\text { NA } \\
\text { NA } \\
\text { NA } \\
\text { NA }\end{array}$ & $\begin{array}{r}66,245 \\
535 \\
a \\
891 \\
154,862\end{array}$ & $\begin{array}{r}304,770 \\
66,299 \\
a \\
20,365 \\
283,770\end{array}$ & $\begin{array}{l}\text { NA } \\
\text { NA } \\
\text { NA } \\
\text { NA } \\
\text { NA }\end{array}$ & \\
\hline $\begin{array}{l}\text { Georgia... } \\
\text { ldaho } \\
\text { Ilinois... } \\
\text { lindiana } \\
\text { lowa }\end{array}$ & $\begin{array}{l}\text { NA } \\
\text { NA } \\
\text { NA } \\
\text { NA } \\
\text { NA }\end{array}$ & $\begin{array}{r}43,086 \\
60 \\
42,792 \\
13,958 \\
61,201\end{array}$ & $\begin{array}{r}325,489 \\
49,084 \\
1,130,225 \\
519,352 \\
350,413\end{array}$ & $\begin{array}{l}\text { NA } \\
\text { NA } \\
\text { NA } \\
\text { NA } \\
\text { NA }\end{array}$ & 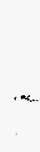 \\
\hline $\begin{array}{l}\text { Kansas } \\
\text { Kentucky. } \\
\text { Louisiana } \\
\text { Maine } \\
\text { Maryland }\end{array}$ & $\begin{array}{l}\text { NA } \\
\text { NA } \\
\text { NA } \\
\text { NA } \\
\text { NA }\end{array}$ & $\begin{array}{r}165,479 \\
5,463 \\
343,617 \\
1,623 \\
13,513\end{array}$ & $\begin{array}{r}477,071 \\
197,421 \\
1,585,030 \\
14,697 \\
197,176\end{array}$ & $\begin{array}{l}\text { NA } \\
\text { NA } \\
\text { NA } \\
\text { NA } \\
\text { NA }\end{array}$ & \\
\hline 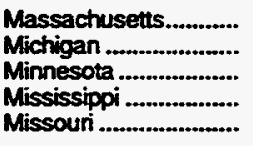 & $\begin{array}{l}\text { NA } \\
\text { NA } \\
\text { NA } \\
\text { NA } \\
\text { NA }\end{array}$ & $\begin{array}{l}7,306 \\
68,987 \\
38,468 \\
42,092 \\
48,119\end{array}$ & $\begin{array}{l}154,594 \\
921,898 \\
348,038 \\
220.534 \\
400,944\end{array}$ & $\begin{array}{l}\text { NA } \\
\text { NA } \\
\text { NA } \\
\text { NA } \\
\text { NA }\end{array}$ & \\
\hline 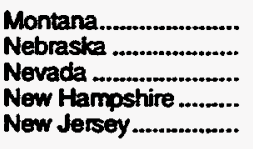 & $\begin{array}{l}\text { NA } \\
\text { NA } \\
\text { NA } \\
\text { NA } \\
\text { NA }\end{array}$ & $\begin{array}{r}1,111 \\
48,040 \\
30,700 \\
b \\
15,033\end{array}$ & $\begin{array}{r}74,505 \\
210,083 \\
63,438 \\
b \\
274,505\end{array}$ & $\begin{array}{l}\text { NA } \\
\text { NA } \\
\text { NA } \\
\text { NA } \\
\text { NA }\end{array}$ & \\
\hline 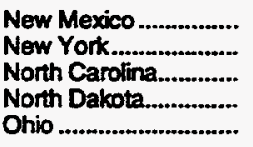 & $\begin{array}{l}\text { NA } \\
\text { NA } \\
\text { NA } \\
\text { NA } \\
\text { NA }\end{array}$ & $\begin{array}{r}67,694 \\
38,231 \\
1,072 \\
59 \\
20,680\end{array}$ & $\begin{array}{r}181,638 \\
624,137 \\
135,721 \\
23,944 \\
1,073,671\end{array}$ & $\begin{array}{l}\text { NA } \\
\text { NA } \\
\text { NA } \\
\text { NA } \\
\text { NA }\end{array}$ & \\
\hline 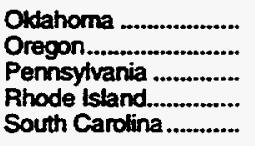 & $\begin{array}{l}\text { NA } \\
\text { NA } \\
\text { NA } \\
\text { NA } \\
\text { NA }\end{array}$ & $\begin{array}{r}293,842 \\
266 \\
7,825 \\
1,919 \\
21,510\end{array}$ & $\begin{array}{r}555,166 \\
90,750 \\
692,980 \\
23,759 \\
129,827\end{array}$ & $\begin{array}{l}\text { NA } \\
\text { NA } \\
\text { NA } \\
\text { NA } \\
\text { NA }\end{array}$ & \\
\hline 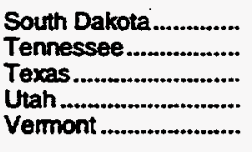 & $\begin{array}{l}\text { NA } \\
\text { NA } \\
\text { NA } \\
\text { NA } \\
\text { NA }\end{array}$ & $\begin{array}{r}3,633 \\
0 \\
1,334,837 \\
4,009 \\
b\end{array}$ & $\begin{array}{r}32,060 \\
235.100 \\
3,552,495 \\
116,232 \\
\mathrm{~b}\end{array}$ & $\begin{array}{l}\text { NA } \\
\text { NA } \\
\text { NA } \\
\text { NA } \\
\text { NA }\end{array}$ & \\
\hline 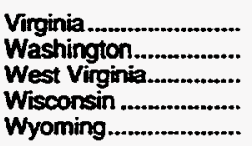 & $\begin{array}{l}\text { NA } \\
\text { NA } \\
\text { NA } \\
\text { NA } \\
\text { NA }\end{array}$ & $\begin{array}{r}4,689 \\
0 \\
376 \\
33,815 \\
660\end{array}$ & $\begin{array}{r}139,121 \\
177,210 \\
164,777 \\
375,721 \\
73,905\end{array}$ & $\begin{array}{l}\text { NA } \\
\text { NA } \\
\text { NA } \\
\text { NA } \\
\text { NA }\end{array}$ & \\
\hline 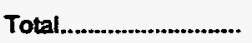 & NA & $3,443,428$ & $19,076,955$ & NA & \\
\hline
\end{tabular}

See tootnotes at end of table. 
Table 16. Natural Gas Delivered to Consumers by State, 1967-1994 (Continued)

\begin{tabular}{|c|c|c|c|c|c|c|}
\hline \multirow[b]{2}{*}{ Stave } & \multicolumn{2}{|c|}{ Rosidentives } & \multicolumn{2}{|c|}{ Commercial } & \multicolumn{2}{|c|}{ Industrial } \\
\hline & $\begin{array}{l}\text { Quantity } \\
\text { (mituion } \\
\text { cubie feot) }\end{array}$ & Consumers & $\begin{array}{l}\text { Quantity } \\
\text { (malion } \\
\text { cubic feet) }\end{array}$ & Coneumers & $\begin{array}{l}\text { Cuntity } \\
\text { (million } \\
\text { cubic feet) }\end{array}$ & Consumers \\
\hline 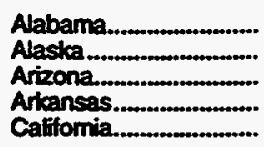 & $\begin{array}{r}52,314 \\
10,393 \\
37,931 \\
48,543 \\
631,398\end{array}$ & $\begin{array}{r}603,000 \\
25,000 \\
526,000 \\
411,000 \\
6,181,000\end{array}$ & $\begin{array}{r}33,439 \\
14,415 \\
32,638 \\
33,291 \\
240,239\end{array}$ & $\begin{array}{r}43,000 \\
4,000 \\
45,000 \\
52,000 \\
389,000\end{array}$ & $\begin{array}{r}153,540 \\
22,388 \\
50,868 \\
128,151 \\
581,530\end{array}$ & $\begin{array}{l}\text { NA } \\
\text { NA } \\
\text { NA } \\
\text { NA } \\
\text { NA }\end{array}$ \\
\hline 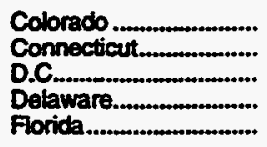 & $\begin{array}{r}99,933 \\
32,143 \\
\text { NA } \\
6,985 \\
15,209\end{array}$ & $\begin{array}{r}679,000 \\
373,000 \\
\mathrm{NA} \\
78,000 \\
373,000\end{array}$ & $\begin{array}{r}76,288 \\
15,928 \\
0 \\
2,964 \\
31,745\end{array}$ & $\begin{array}{r}86,000 \\
29,000 \\
N A \\
5,000 \\
38,000\end{array}$ & $\begin{array}{r}65,609 \\
15,553 \\
\text { NA } \\
6,957 \\
83,363\end{array}$ & $\begin{array}{l}\text { NA } \\
\text { NA } \\
\text { NA } \\
\text { NA }\end{array}$ \\
\hline $\begin{array}{l}\text { Georgia } \\
\text { Idaho. } \\
\text { Illanois } \\
\text { Indiana } \\
\text { Ind } \\
\text { lowa }\end{array}$ & $\begin{array}{r}87,184 \\
14,089 \\
478,602 \\
162,858 \\
94,370\end{array}$ & $\begin{array}{r}846,000 \\
119,000 \\
2,911,000 \\
1,087,000 \\
623,000\end{array}$ & $\begin{array}{r}49,438 \\
12,177 \\
215,718 \\
70,501 \\
66,915\end{array}$ & $\begin{array}{r}66,000 \\
17,000 \\
224,000 \\
99,000 \\
75,000\end{array}$ & $\begin{array}{r}145,479 \\
29,898 \\
352,222 \\
223,383 \\
121,489\end{array}$ & $\begin{array}{l}\text { NA } \\
\text { NA } \\
\text { NA } \\
\text { NA }\end{array}$ \\
\hline $\begin{array}{l}\text { Massachusetts............ } \\
\text { Michigan } \\
\text { Mirnesota } \\
\text { Mississippi ... } \\
\text { Missour . }\end{array}$ & $\begin{array}{r}90,226 \\
334,866 \\
114,416 \\
29.530 \\
155,178\end{array}$ & $\begin{array}{r}1,033,000 \\
2,068,000 \\
724,000 \\
347,000 \\
1,085,000\end{array}$ & $\begin{array}{r}37,812 \\
181,949 \\
89,651 \\
23,922 \\
90,719\end{array}$ & $\begin{array}{r}68,000 \\
166,000 \\
69,000 \\
36,000 \\
88,000\end{array}$ & $\begin{array}{r}23,986 \\
292,014 \\
100,539 \\
98,848 \\
89,913\end{array}$ & $\begin{array}{l}\text { NA } \\
\text { NA } \\
\text { NA } \\
\text { NA } \\
\text { NA }\end{array}$ \\
\hline 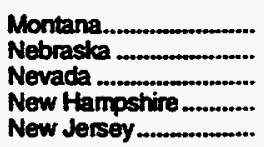 & $\begin{array}{r}24,097 \\
53,803 \\
11,091 \\
b \\
129,406\end{array}$ & $\begin{array}{r}159,000 \\
356,000 \\
109,000 \\
b \\
1,624,000\end{array}$ & $\begin{array}{r}18,654 \\
43.117 \\
14,965 \\
b \\
53,346\end{array}$ & $\begin{array}{r}21,000 \\
56,000 \\
5,000 \\
b \\
179,000\end{array}$ & $\begin{array}{r}31,631 \\
72,726 \\
10,043 \\
b \\
52,361\end{array}$ & $\begin{array}{l}\text { NA } \\
\text { NA } \\
\text { NA } \\
\text { NA } \\
\text { NA }\end{array}$ \\
\hline 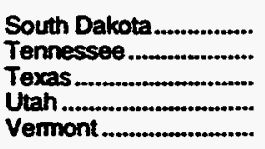 & $\begin{array}{r}11,969 \\
44,020 \\
232,320 \\
59,736 \\
b\end{array}$ & $\begin{array}{r}83,000 \\
432,000 \\
2,693,000 \\
294,000 \\
b\end{array}$ & $\begin{array}{r}11,488 \\
42,488 \\
116,749 \\
6.055 \\
b\end{array}$ & $\begin{array}{r}11,000 \\
57,000 \\
241,000 \\
14,000 \\
b\end{array}$ & $\begin{array}{r}5,813 \\
111,281 \\
1.396,783 \\
47,789 \\
b\end{array}$ & $\begin{array}{l}\text { NA } \\
\text { NA } \\
\text { NA } \\
\text { NA }\end{array}$ \\
\hline 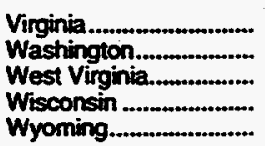 & $\begin{array}{r}48,802 \\
34,349 \\
51,296 \\
119,981 \\
12,128\end{array}$ & $\begin{array}{l}481,000 \\
289,000 \\
400,000 \\
868,000 \\
101,000\end{array}$ & $\begin{array}{l}32,358 \\
31,988 \\
24,776 \\
57,485 \\
10,253\end{array}$ & $\begin{array}{l}41,000 \\
38,000 \\
35,000 \\
74,000 \\
10,000\end{array}$ & $\begin{array}{r}36,427 \\
92,142 \\
66,155 \\
152,443 \\
43,933\end{array}$ & $\begin{array}{l}\text { NA } \\
\text { NA } \\
\text { NA } \\
\text { NA } \\
\text { NA }\end{array}$ \\
\hline Total.......................................... & 4.924 .124 & $41,516,000$ & $2,508,293$ & 3.438 .000 & $6,968,267$ & NA \\
\hline
\end{tabular}

See footnotes at end of table. 
Table 16. Natural Gas Delivered to Consumers by State, 1967-1994 (Continued)

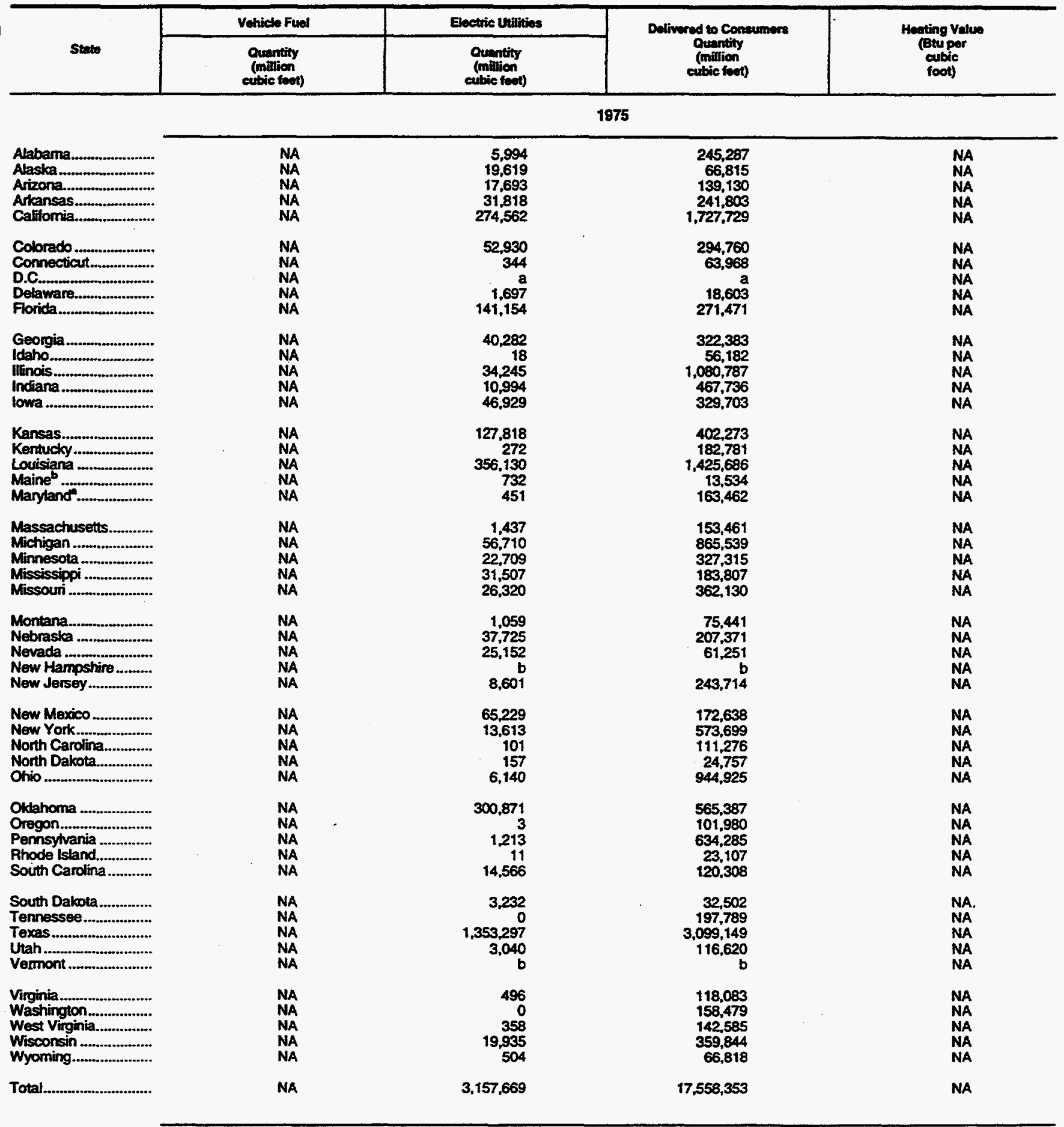

See footnotes at end of table. 
Table 16. Natural Gas Delivered to Consumers by State, 1967-1994' (Continued)

\begin{tabular}{|c|c|c|c|c|c|c|}
\hline \multirow[b]{2}{*}{ State } & \multicolumn{2}{|c|}{ Residentiol } & \multicolumn{2}{|c|}{ Commercial } & \multicolumn{2}{|c|}{ Industriat } \\
\hline & $\begin{array}{l}\text { Quantity } \\
\text { (mitlion } \\
\text { cubic twet) }\end{array}$ & Consumere & $\begin{array}{l}\text { Quantity } \\
\text { (milion } \\
\text { cubic font) }\end{array}$ & Consumers & $\begin{array}{l}\text { Ouantity } \\
\text { (million } \\
\text { eculic foet) }\end{array}$ & Consumers \\
\hline & \multicolumn{6}{|c|}{1976} \\
\hline 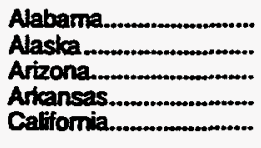 & $\begin{array}{r}56,869 \\
10,917 \\
40,267 \\
49,348 \\
599,631\end{array}$ & $\begin{array}{r}552,000 \\
28,000 \\
523,000 \\
418,000 \\
6,331,000\end{array}$ & $\begin{array}{r}34,450 \\
14,191 \\
36,763 \\
34,011 \\
219,840\end{array}$ & $\begin{array}{r}43,000 \\
4,000 \\
45,000 \\
54,000 \\
371,000\end{array}$ & $\begin{array}{r}119,817 \\
26,687 \\
54,536 \\
136,109 \\
547,271\end{array}$ & $\begin{array}{l}\text { NA } \\
\text { NA } \\
\text { NA } \\
\text { NA } \\
\text { NA }\end{array}$ \\
\hline $\begin{array}{l}\text { Colorado } \\
\text { Connecticut } \\
\text { D.C. } \\
\text { Delaware. } \\
\text { Florida. }\end{array}$ & $\begin{array}{r}107,355 \\
32,310 \\
N A \\
7,380 \\
16,839\end{array}$ & $\begin{array}{r}701,000 \\
361,000 \\
\mathrm{NA} \\
77,000 \\
371,000\end{array}$ & $\begin{array}{r}75,959 \\
16,694 \\
0 \\
3,078 \\
39,681\end{array}$ & $\begin{array}{r}86,000 \\
30,000 \\
N A \\
5,000 \\
44,000\end{array}$ & $\begin{array}{r}62,422 \\
16,378 \\
\text { NA } \\
6,427 \\
98,764\end{array}$ & $\begin{array}{l}\text { NA } \\
\text { NA } \\
\text { NA } \\
\text { NA }\end{array}$ \\
\hline $\begin{array}{l}\text { Georgia. } \\
\text { Idaho } \\
\text { Illinois. } \\
\text { Indiana } \\
\text { lowa }\end{array}$ & $\begin{array}{r}86,356 \\
12,512 \\
507,935 \\
152,860 \\
89,676\end{array}$ & $\begin{array}{r}835,000 \\
98,000 \\
2,931,000 \\
997,000 \\
562,000\end{array}$ & $\begin{array}{r}46,351 \\
8,742 \\
246,659 \\
67,481 \\
64,734\end{array}$ & $\begin{array}{r}66,000 \\
14,000 \\
227,000 \\
91,000 \\
63,000\end{array}$ & $\begin{array}{r}120,495 \\
21,169 \\
373,425 \\
196,677 \\
122,343\end{array}$ & $\begin{array}{l}\text { NA } \\
\text { NA } \\
\text { NA } \\
\text { NA }\end{array}$ \\
\hline $\begin{array}{l}\text { Kansas.............. } \\
\text { Kentucky } \\
\text { Louisiana } \\
\text { Maine } \\
\text { Manytand }\end{array}$ & $\begin{array}{r}101,330 \\
96,351 \\
95,457 \\
6,111 \\
87,408\end{array}$ & $\begin{array}{r}623,000 \\
559,000 \\
846,000 \\
66,000 \\
851,000\end{array}$ & $\begin{array}{r}57,310 \\
57,203 \\
43,567 \\
3,814 \\
42,422\end{array}$ & $\begin{array}{r}61,000 \\
52,000 \\
63,000 \\
6,000 \\
63,000\end{array}$ & $\begin{array}{r}139,536 \\
70,640 \\
901,600 \\
3,549 \\
43,529\end{array}$ & $\begin{array}{l}\text { NA } \\
\text { NA } \\
\text { NA } \\
\text { NA } \\
\text { NA }\end{array}$ \\
\hline 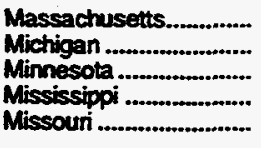 & $\begin{array}{r}95,107 \\
339,417 \\
105,760 \\
26,584 \\
160,198\end{array}$ & $\begin{array}{r}979,000 \\
2,086,000 \\
671,000 \\
287,000 \\
1,064,000\end{array}$ & $\begin{array}{r}37,763 \\
178,220 \\
76,981 \\
20,214 \\
98,435\end{array}$ & $\begin{array}{r}67,000 \\
167,000 \\
63,000 \\
30,000 \\
82,000\end{array}$ & $\begin{array}{r}20,261 \\
297,445 \\
120,059 \\
84,156 \\
90,950\end{array}$ & $\begin{array}{l}\text { NA } \\
\text { NA } \\
\text { NA } \\
\text { NA } \\
\text { NA }\end{array}$ \\
\hline 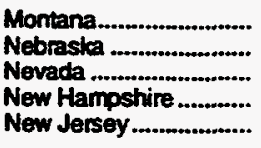 & $\begin{array}{r}23,525 \\
54,965 \\
10,670 \\
b \\
147,508\end{array}$ & $\begin{array}{r}161,000 \\
344,000 \\
118,000 \\
b \\
1,637,000\end{array}$ & $\begin{array}{r}17,831 \\
48,713 \\
18,389 \\
6 \\
90,463\end{array}$ & $\begin{array}{r}20,000 \\
53,000 \\
5,000 \\
b \\
179,000\end{array}$ & $\begin{array}{r}28,087 \\
64,224 \\
12,633 \\
b \\
73,046\end{array}$ & $\begin{array}{l}\text { NA } \\
\text { NA } \\
\text { NA } \\
\text { NA } \\
\text { NA }\end{array}$ \\
\hline $\begin{array}{l}\text { New Mexico..... } \\
\text { New York } \\
\text { North Carolina.......... } \\
\text { North Dakota............. } \\
\text { Ohio }\end{array}$ & $\begin{array}{r}36,476 \\
339,949 \\
33,727 \\
10,182 \\
440,190\end{array}$ & $\begin{array}{r}238,000 \\
3,741,000 \\
326,000 \\
68,000 \\
2,555,000\end{array}$ & $\begin{array}{r}33,708 \\
143,530 \\
20,042 \\
12,202 \\
179,392\end{array}$ & $\begin{array}{r}25,000 \\
233,000 \\
45,000 \\
9,000 \\
196,000\end{array}$ & $\begin{array}{r}62,068 \\
103,907 \\
44,616 \\
2,673 \\
370,556\end{array}$ & $\begin{array}{l}\text { NA } \\
\text { NA } \\
\text { NA } \\
\text { NA } \\
\text { NA }\end{array}$ \\
\hline 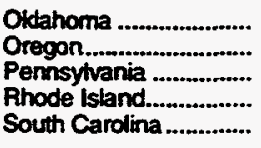 & $\begin{array}{r}82,078 \\
21.038 \\
290,439 \\
12,329 \\
33,231\end{array}$ & $\begin{array}{r}675,000 \\
234,000 \\
2,134,000 \\
150,000 \\
240,000\end{array}$ & $\begin{array}{r}44,862 \\
13,995 \\
124,517 \\
2,895 \\
35,062\end{array}$ & $\begin{array}{r}70,000 \\
30,000 \\
144,000 \\
7,000 \\
24,000\end{array}$ & $\begin{array}{r}191,014 \\
48,620 \\
273,465 \\
4,826 \\
73,501\end{array}$ & $\begin{array}{l}\text { NA } \\
\text { NA } \\
\text { NA } \\
\text { NA }\end{array}$ \\
\hline 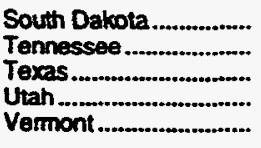 & $\begin{array}{r}14,510 \\
43,749 \\
235,637 \\
66,417 \\
b\end{array}$ & $\begin{array}{r}83,000 \\
400,000 \\
2,984,000 \\
276,000 \\
b\end{array}$ & $\begin{array}{r}15,344 \\
38,244 \\
135,452 \\
14,681 \\
b\end{array}$ & $\begin{array}{r}11,000 \\
50,000 \\
268,000 \\
24,000 \\
b\end{array}$ & $\begin{array}{r}8,078 \\
114,526 \\
1,423,778 \\
52,746 \\
b\end{array}$ & $\begin{array}{l}\text { NA } \\
\text { NA } \\
\text { NA } \\
\text { NA } \\
\text { NA }\end{array}$ \\
\hline $\begin{array}{l}\text { Virginia } \\
\text { Washington } \\
\text { West Virginia............. } \\
\text { Wisconsin } \\
\text { Wyoming }\end{array}$ & $\begin{array}{r}52,491 \\
32,348 \\
51,434 \\
122,786 \\
11,703\end{array}$ & $\begin{array}{r}408,000 \\
311,000 \\
385,000 \\
884,000 \\
69,000\end{array}$ & $\begin{array}{r}34,887 \\
31,652 \\
20,462 \\
57,702 \\
9,152\end{array}$ & $\begin{array}{r}32,000 \\
41,000 \\
34,000 \\
78,000 \\
8,000\end{array}$ & $\begin{array}{r}32,785 \\
78,806 \\
63,192 \\
120,372 \\
42,085\end{array}$ & $\begin{array}{l}\text { NA } \\
\text { NA } \\
\text { NA } \\
\text { NA } \\
\text { NA }\end{array}$ \\
\hline 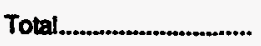 & $5,051,360$ & $41,238,000$ & $2,667,740$ & $3,383,000$ & $6,963,850$ & NA \\
\hline
\end{tabular}

See tootnotes at end of table. 
Table 16. Natural Gas Delivered to Consumers by State, 1967-1994 (Continued)

\begin{tabular}{|c|c|c|c|c|}
\hline \multirow[b]{2}{*}{ State } & Vohicio Fuel & Electric Utillties & \multirow{2}{*}{$\begin{array}{l}\text { Delivered to Consumers } \\
\text { Quantity } \\
\text { (milliton } \\
\text { cubic toet) }\end{array}$} & \multirow{2}{*}{$\begin{array}{l}\text { Hoeting Value } \\
\text { (Btuper } \\
\text { cubic } \\
\text { foot) }\end{array}$} \\
\hline & $\begin{array}{l}\text { Qumentity } \\
\text { (million } \\
\text { cubic foet) }\end{array}$ & $\begin{array}{l}\text { Ouantity } \\
\text { (mallion } \\
\text { cubie foet) }\end{array}$ & & \\
\hline & \multicolumn{4}{|c|}{1976} \\
\hline 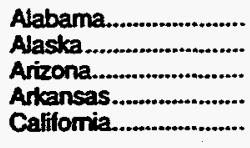 & $\begin{array}{l}\text { NA } \\
\text { NA } \\
\text { NA } \\
\text { NA } \\
\text { NA }\end{array}$ & $\begin{array}{r}3,985 \\
22,204 \\
24,338 \\
15,972 \\
295,009\end{array}$ & $\begin{array}{r}215,071 \\
73,999 \\
155,904 \\
235,440 \\
1,661,751\end{array}$ & $\begin{array}{l}\text { NA } \\
\text { NA } \\
\text { NA } \\
\text { NA } \\
\text { NA }\end{array}$ \\
\hline 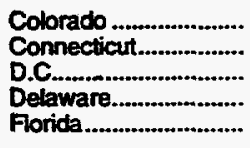 & $\begin{array}{l}\text { NA } \\
\text { NA } \\
\text { NA } \\
\text { NA } \\
\text { NA }\end{array}$ & $\begin{array}{r}42,168 \\
446 \\
a \\
2,297 \\
125,560\end{array}$ & $\begin{array}{r}287,904 \\
65,828 \\
a \\
19,182 \\
280,844\end{array}$ & $\begin{array}{l}\text { NA } \\
\text { NA } \\
\text { NA } \\
\text { NA } \\
\text { NA }\end{array}$ \\
\hline 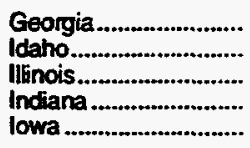 & $\begin{array}{l}\text { NA } \\
\text { NA } \\
\text { NA } \\
\text { NA } \\
\text { NA }\end{array}$ & $\begin{array}{r}4,664 \\
104 \\
30,548 \\
3,157 \\
25,804\end{array}$ & $\begin{array}{r}257,866 \\
42,527 \\
1,158,567 \\
420.175 \\
302,557\end{array}$ & $\begin{array}{l}\text { NA } \\
\text { NA } \\
\text { NA } \\
\text { NA } \\
\text { NA }\end{array}$ \\
\hline $\begin{array}{l}\text { Kansas } \\
\text { Kentucky } \\
\text { Louisiana } \\
\text { Maine } \\
\text { Marytand }\end{array}$ & $\begin{array}{l}\text { NA } \\
\text { NA } \\
\text { NA } \\
\text { NA } \\
\text { NA }\end{array}$ & $\begin{array}{r}122,946 \\
135 \\
365,843 \\
71 \\
231\end{array}$ & $\begin{array}{r}421,122 \\
224,329 \\
1,406,467 \\
13,545 \\
173,590\end{array}$ & $\begin{array}{l}\text { NA } \\
\text { NA } \\
\text { NA } \\
\text { NA } \\
\text { NA }\end{array}$ \\
\hline 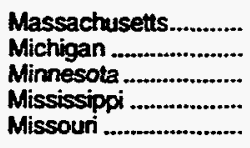 & $\begin{array}{l}\text { NA } \\
\text { NA } \\
\text { NA } \\
\text { NA } \\
\text { NA }\end{array}$ & $\begin{array}{r}2,488 \\
53,510 \\
13,443 \\
32,809 \\
25,422\end{array}$ & $\begin{array}{l}155,619 \\
868,592 \\
316,243 \\
163,763 \\
375,005\end{array}$ & $\begin{array}{l}\text { NA } \\
\text { NA } \\
\text { NA } \\
\text { NA } \\
\text { NA }\end{array}$ \\
\hline 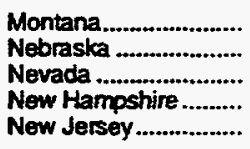 & $\begin{array}{l}\text { NA } \\
\text { NA } \\
\text { NA } \\
\text { NA } \\
\text { NA }\end{array}$ & $\begin{array}{r}709 \\
19,618 \\
25.105 \\
b \\
10,016\end{array}$ & $\begin{array}{r}70,152 \\
187,520 \\
66,797 \\
b \\
321,033\end{array}$ & $\begin{array}{l}\text { NA } \\
\text { NA } \\
\text { NA } \\
\text { NA } \\
\text { NA }\end{array}$ \\
\hline $\begin{array}{l}\text { New Mexico } \\
\text { New York } \\
\text { North Carolina.................. } \\
\text { North Dakota............. } \\
\text { Ohio }\end{array}$ & $\begin{array}{l}\text { NA } \\
\text { NA } \\
\text { NA } \\
\text { NA } \\
\text { NA }\end{array}$ & $\begin{array}{r}69,663 \\
5,293 \\
6 \\
43 \\
5,322\end{array}$ & $\begin{array}{r}201,915 \\
592,679 \\
98,391 \\
25,100 \\
995,460\end{array}$ & $\begin{array}{l}\text { NA } \\
\text { NA } \\
\text { NA } \\
\text { NA } \\
\text { NA }\end{array}$ \\
\hline 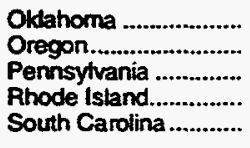 & $\begin{array}{l}\text { NA } \\
\text { NA } \\
\text { NA } \\
\text { NA } \\
\text { NA }\end{array}$ & $\begin{array}{r}331,003 \\
1 \\
480 \\
635 \\
3,793\end{array}$ & $\begin{array}{r}648,957 \\
83,654 \\
688,901 \\
20,685 \\
145.587\end{array}$ & $\begin{array}{l}\text { NA } \\
\text { NA } \\
\text { NA } \\
\text { NA } \\
\text { NA }\end{array}$ \\
\hline $\begin{array}{l}\text { South Dakota } \\
\text { Tennessee } \\
\text { Texas } \\
\text { Utah } \\
\text { Vermont }\end{array}$ & $\begin{array}{l}\text { NA } \\
\text { NA } \\
\text { NA } \\
\text { NA } \\
\text { NA }\end{array}$ & $\begin{array}{r}1,244 \\
176 \\
1,378.534 \\
2,805 \\
b\end{array}$ & $\begin{array}{r}39,176 \\
196,695 \\
3,173,401 \\
136,649 \\
b\end{array}$ & $\begin{array}{l}\text { NA } \\
\text { NA } \\
\text { NA } \\
\text { NA } \\
\text { NA }\end{array}$ \\
\hline 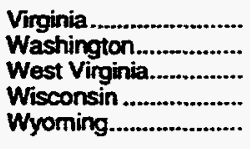 & $\begin{array}{l}\text { NA } \\
\text { NA } \\
\text { NA } \\
\text { NA } \\
\text { NA }\end{array}$ & $\begin{array}{r}484 \\
0 \\
290 \\
11,985 \\
560\end{array}$ & $\begin{array}{r}120,647 \\
142,806 \\
135,378 \\
312,845 \\
63,500\end{array}$ & $\begin{array}{l}\text { NA } \\
\text { NA } \\
\text { NA } \\
\text { NA } \\
\text { NA }\end{array}$ \\
\hline 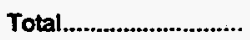 & NA & $3,080,868$ & $17,763,818$ & 1,021 \\
\hline
\end{tabular}

See footnotes at end of table. 
Table 16. Natural Gas Delivered to Consumers by State, 1967-1994' (Continued)

\begin{tabular}{|c|c|c|c|c|c|c|}
\hline \multirow[b]{2}{*}{ Stan: } & \multicolumn{2}{|c|}{ Residential } & \multicolumn{2}{|c|}{ Commercial } & \multicolumn{2}{|c|}{ Induatrial } \\
\hline & $\begin{array}{l}\text { Quantiny } \\
\text { (milifion } \\
\text { erbic teet) }\end{array}$ & Consumers: & $\begin{array}{l}\text { Quantity } \\
\text { (miltion } \\
\text { cubic teat) }\end{array}$ & Consumers & $\begin{array}{l}\text { Cuantity } \\
\text { (milion } \\
\text { erbie feot) }\end{array}$ & Consumers \\
\hline & \multicolumn{6}{|c|}{1977} \\
\hline 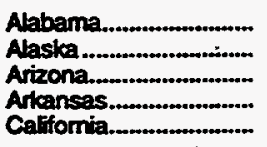 & $\begin{array}{r}56,503 \\
11,282 \\
38,286 \\
49,057 \\
541,728\end{array}$ & $\begin{array}{r}568,000 \\
30,000 \\
525,000 \\
377,000 \\
6,088,000\end{array}$ & $\begin{array}{r}34,303 \\
14,564 \\
34,076 \\
33,913 \\
227,543\end{array}$ & $\begin{array}{r}42,000 \\
5,000 \\
44,000 \\
48,000 \\
348,000\end{array}$ & $\begin{array}{r}131,065 \\
49,302 \\
50,326 \\
126,609 \\
549,396\end{array}$ & $\begin{array}{l}\text { NA } \\
\text { NA } \\
\text { NA } \\
\text { NA }\end{array}$ \\
\hline 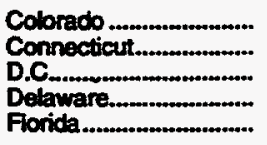 & $\begin{array}{r}99,946 \\
31,069 \\
\mathrm{NA} \\
7,209 \\
18,220\end{array}$ & $\begin{array}{r}719,000 \\
352,000 \\
N A \\
77,000 \\
\mathbf{3 8 3 , 0 0 0}\end{array}$ & $\begin{array}{r}72,597 \\
16,813 \\
0 \\
2,815 \\
41,236\end{array}$ & $\begin{array}{r}80,000 \\
30,000 \\
N A \\
5,000 \\
31,000\end{array}$ & $\begin{array}{r}59,466 \\
16,172 \\
N A \\
4,473 \\
99,651\end{array}$ & $\begin{array}{l}\mathbf{N A} \\
\mathbf{N A} \\
\mathbf{N A} \\
\mathbf{N A} \\
\mathbf{N A}\end{array}$ \\
\hline 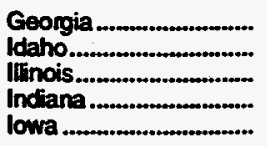 & $\begin{array}{r}98,384 \\
11,771 \\
519,973 \\
151,637 \\
86,950\end{array}$ & $\begin{array}{r}852,000 \\
96,000 \\
2,945,000 \\
1,098,000 \\
632,000\end{array}$ & $\begin{array}{r}55,268 \\
8,405 \\
243,686 \\
63,224 \\
60,519\end{array}$ & $\begin{array}{r}70,000 \\
14,000 \\
226,000 \\
101,000 \\
75,000\end{array}$ & $\begin{array}{r}102,040 \\
20,020 \\
369,727 \\
177,577 \\
112,212\end{array}$ & $\begin{array}{l}\text { NA } \\
\text { NA } \\
\text { NA } \\
\text { NA }\end{array}$ \\
\hline 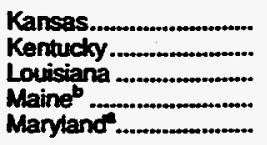 & $\begin{array}{r}94,592 \\
94,646 \\
94,350 \\
5,747 \\
77,575\end{array}$ & $\begin{array}{r}657,000 \\
555,000 \\
899,000 \\
65,000 \\
850,000\end{array}$ & $\begin{array}{r}51,815 \\
50,170 \\
44,563 \\
3,846 \\
40,532\end{array}$ & $\begin{array}{r}63,000 \\
52,000 \\
67,000 \\
5,000 \\
64,000\end{array}$ & $\begin{array}{r}145,989 \\
53,748 \\
1,027,576 \\
3,576 \\
37,956\end{array}$ & $\begin{array}{l}\mathbf{N A} \\
\mathbf{N A} \\
\mathbf{N A} \\
\mathbf{N A} \\
\mathbf{N A}\end{array}$ \\
\hline 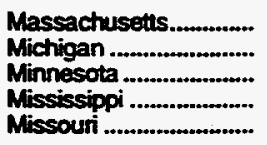 & $\begin{array}{r}93,214 \\
299,199 \\
100,483 \\
25,949 \\
154,078\end{array}$ & $\begin{array}{r}974,000 \\
2,123,000 \\
685,000 \\
349,000 \\
1,096,000\end{array}$ & $\begin{array}{r}40,598 \\
131,266 \\
67,839 \\
19,304 \\
93,323\end{array}$ & $\begin{array}{r}68,000 \\
159,000 \\
62,000 \\
33,000 \\
85,000\end{array}$ & $\begin{array}{r}22,995 \\
259,045 \\
116,208 \\
77,414 \\
89,114\end{array}$ & $\begin{array}{l}\text { NA } \\
\text { NA } \\
\text { NA } \\
\text { NA } \\
\text { NA }\end{array}$ \\
\hline 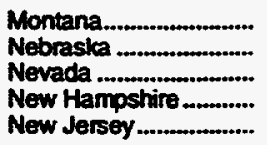 & $\begin{array}{r}21,596 \\
52,909 \\
11,165 \\
b \\
134,138\end{array}$ & $\begin{array}{r}162,000 \\
363,000 \\
123,000 \\
b \\
1,637,000\end{array}$ & $\begin{array}{r}16,706 \\
46,989 \\
17,436 \\
b \\
53,896\end{array}$ & $\begin{array}{r}19,000 \\
54,000 \\
6,000 \\
b \\
180,000\end{array}$ & $\begin{array}{r}27,260 \\
60,342 \\
9,583 \\
b \\
51,339\end{array}$ & $\begin{array}{l}\text { NA } \\
\text { NA } \\
\text { NA } \\
\text { NA } \\
\text { NA }\end{array}$ \\
\hline 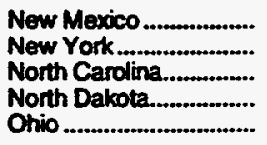 & $\begin{array}{r}25,525 \\
325,603 \\
32,277 \\
10,164 \\
-401,928\end{array}$ & $\begin{array}{r}258,000 \\
3,706,000 \\
331,000 \\
78,000 \\
2,548,000\end{array}$ & $\begin{array}{r}25,476 \\
130,898 \\
18,303 \\
11,234 \\
149,011\end{array}$ & $\begin{array}{r}27,000 \\
237,000 \\
42,000 \\
11,000 \\
194,000\end{array}$ & $\begin{array}{r}42,701 \\
98,170 \\
19,749 \\
2,439 \\
282,312\end{array}$ & $\begin{array}{l}\text { NA } \\
\text { NA } \\
\text { NA } \\
\text { NA }\end{array}$ \\
\hline 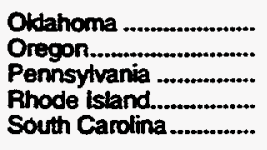 & $\begin{array}{r}86,822 \\
10,093 \\
277,340 \\
13,514 \\
31,875\end{array}$ & $\begin{array}{r}674,000 \\
228,000 \\
2,126,000 \\
149,000 \\
248,000\end{array}$ & $\begin{array}{r}48,253 \\
10,861 \\
111,885 \\
3,019 \\
32,117\end{array}$ & $\begin{array}{r}65,000 \\
31,000 \\
144,000 \\
10,000 \\
25,000\end{array}$ & $\begin{array}{r}193,090 \\
42,860 \\
252,342 \\
9,083 \\
68,892\end{array}$ & $\begin{array}{l}\text { NA } \\
\text { NA } \\
\text { NA } \\
\text { NA }\end{array}$ \\
\hline 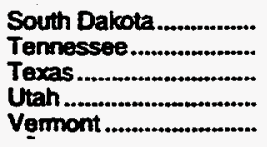 & $\begin{array}{r}14,141 \\
43,530 \\
269,964 \\
35,558 \\
b\end{array}$ & $\begin{array}{r}86,000 \\
444,000 \\
2,763,000 \\
305,000 \\
b\end{array}$ & $\begin{array}{r}14,786 \\
35,127 \\
158,683 \\
9,661 \\
b\end{array}$ & $\begin{array}{r}11,000 \\
53,000 \\
246,000 \\
20,000 \\
b\end{array}$ & $\begin{array}{r}6,961 \\
109,120 \\
1,426.610 \\
47.728 \\
b\end{array}$ & $\begin{array}{l}\text { NA } \\
\mathbf{N A} \\
\mathbf{N A} \\
\mathbf{N A} \\
\mathbf{N A}\end{array}$ \\
\hline 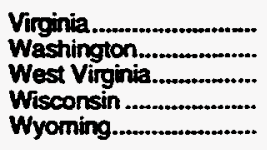 & $\begin{array}{r}48,953 \\
30,533 \\
51,609 \\
119,292 \\
11,158\end{array}$ & $\begin{array}{r}478,000 \\
317,000 \\
363,000 \\
888,000 \\
96,000\end{array}$ & $\begin{array}{r}34,685 \\
29,946 \\
19,556 \\
61,280 \\
8,767\end{array}$ & $\begin{array}{l}42,000 \\
42,000 \\
33,000 \\
73,000 \\
13,000\end{array}$ & $\begin{array}{r}30,143 \\
75,993 \\
57,043 \\
159,843 \\
40,027\end{array}$ & $\begin{array}{l}\text { NA } \\
\text { NA } \\
\text { NA } \\
\text { NA }\end{array}$ \\
\hline 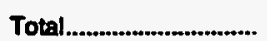 & $4,821,485$ & $41,366,000$ & $2,500,793$ & $3,355,000$ & $6,815,289$ & NA \\
\hline
\end{tabular}

See footnotes at end of table. 
Table 16. Natural Gas Delivered to Consumers by State, 1967-1994 (Continued)

\begin{tabular}{|c|c|c|c|c|}
\hline \multirow[b]{2}{*}{ State } & Vehicto Fuel & Electric Utailitios & \multirow{2}{*}{$\begin{array}{l}\text { Doliverod to Consumers } \\
\text { Qunitity } \\
\text { (milion } \\
\text { cubic foet) }\end{array}$} & \multirow{2}{*}{$\begin{array}{l}\text { Heating Value } \\
\text { (Btu por } \\
\text { cubic } \\
\text { foot) }\end{array}$} \\
\hline & $\begin{array}{l}\text { Quantity } \\
\text { (milfion } \\
\text { cubic foot) }\end{array}$ & $\begin{array}{l}\text { Qunntity } \\
\text { (mittion } \\
\text { cubic fact) }\end{array}$ & & \\
\hline & \multicolumn{4}{|c|}{1977} \\
\hline 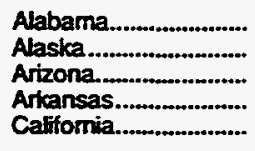 & $\begin{array}{l}\text { NA } \\
\text { NA } \\
\text { NA } \\
\text { NA } \\
\text { NA }\end{array}$ & $\begin{array}{r}3,732 \\
23,534 \\
29,493 \\
6,905 \\
359,051\end{array}$ & $\begin{array}{r}225,603 \\
98,682 \\
152,181 \\
216,484 \\
1,677,718\end{array}$ & $\begin{array}{l}\text { NA } \\
\text { NA } \\
\text { NA } \\
\text { NA } \\
\text { NA }\end{array}$ \\
\hline 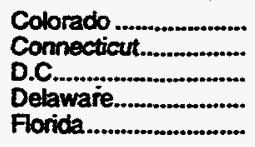 & $\begin{array}{l}\text { NA } \\
\text { NA } \\
\text { NA } \\
\text { NA } \\
\text { NA }\end{array}$ & $\begin{array}{r}34,276 \\
0 \\
a \\
1,290 \\
137,466\end{array}$ & $\begin{array}{r}266,285 \\
64,054 \\
a \\
15,787 \\
296,573\end{array}$ & $\begin{array}{l}\text { NA } \\
\text { NA } \\
\text { NA } \\
\text { NA } \\
\text { NA }\end{array}$ \\
\hline 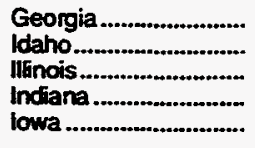 & $\begin{array}{l}\text { NA } \\
\text { NA } \\
\text { NA } \\
\text { NA } \\
\text { NA }\end{array}$ & $\begin{array}{r}6,091 \\
676 \\
14,430 \\
1,067 \\
13,590\end{array}$ & $\begin{array}{r}261,733 \\
40,872 \\
1,147,816 \\
393,505 \\
273,271\end{array}$ & $\begin{array}{l}\text { NA } \\
\text { NA } \\
\text { NA } \\
\text { NA } \\
\text { NA }\end{array}$ \\
\hline 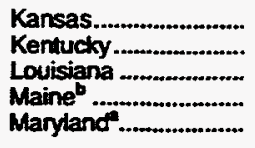 & $\begin{array}{l}\text { NA } \\
\text { NA } \\
\text { NA } \\
\text { NA } \\
\text { NA }\end{array}$ & $\begin{array}{r}129,054 \\
721 \\
349,986 \\
440 \\
317\end{array}$ & $\begin{array}{r}421,450 \\
199,285 \\
1,516,475 \\
13,609 \\
156,380\end{array}$ & $\begin{array}{l}\text { NA } \\
\text { NA } \\
\text { NA } \\
\text { NA } \\
\text { NA }\end{array}$ \\
\hline 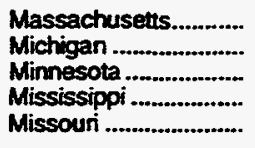 & $\begin{array}{l}\text { NA } \\
\text { NA } \\
\text { NA } \\
\text { NA } \\
\text { NA }\end{array}$ & $\begin{array}{r}3,049 \\
32,151 \\
5,205 \\
39,080 \\
25,799\end{array}$ & $\begin{array}{l}159,856 \\
721,661 \\
289,735 \\
161,747 \\
362,314\end{array}$ & $\begin{array}{l}\text { NA } \\
\text { NA } \\
\text { NA } \\
\text { NA } \\
\text { NA }\end{array}$ \\
\hline 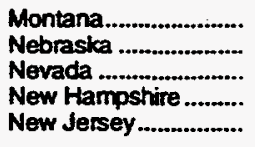 & $\begin{array}{l}\text { NA } \\
\text { NA } \\
\text { NA } \\
\text { NA } \\
\text { NA }\end{array}$ & $\begin{array}{r}953 \\
15,623 \\
32,868 \\
6 \\
7,185\end{array}$ & $\begin{array}{r}66,515 \\
175,863 \\
71,052 \\
b \\
246,558\end{array}$ & $\begin{array}{l}\text { NA } \\
\text { NA } \\
\text { NA } \\
\text { NA } \\
\text { NA }\end{array}$ \\
\hline 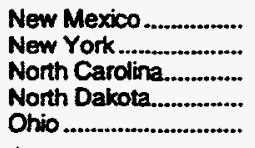 & $\begin{array}{l}\text { NA } \\
\text { NA } \\
\text { NA } \\
\text { NA } \\
\text { NA }\end{array}$ & $\begin{array}{r}70,203 \\
4,089 \\
1 \\
45 \\
3,377\end{array}$ & $\begin{array}{r}163,905 \\
558,760 \\
70,330 \\
23,882 \\
836,628\end{array}$ & $\begin{array}{l}\text { NA } \\
\text { NA } \\
\text { NA } \\
\text { NA } \\
\text { NA }\end{array}$ \\
\hline 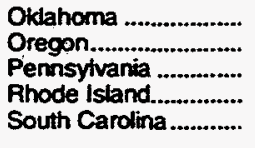 & $\begin{array}{l}\text { NA } \\
\text { NA } \\
\text { NA } \\
\text { NA } \\
\text { NA }\end{array}$ & $\begin{array}{r}333,766 \\
6 \\
323 \\
0 \\
2,504\end{array}$ & $\begin{array}{r}661,931 \\
63,820 \\
641,890 \\
25,616 \\
135,388\end{array}$ & $\begin{array}{l}\text { NA } \\
\text { NA } \\
\text { NA } \\
\text { NA } \\
\text { NA }\end{array}$ \\
\hline 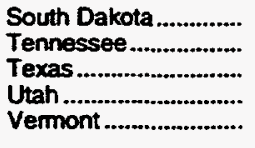 & $\begin{array}{l}\text { NA } \\
\text { NA } \\
\text { NA } \\
\text { NA } \\
\text { NA }\end{array}$ & $\begin{array}{r}182 \\
0 \\
1,488,818 \\
5,344 \\
b\end{array}$ & $\begin{array}{r}36,070 \\
187,777 \\
3,344,075 \\
98,291 \\
\text { b }\end{array}$ & $\begin{array}{l}\text { NA } \\
\text { NA } \\
\text { NA } \\
\text { NA } \\
\text { NA }\end{array}$ \\
\hline 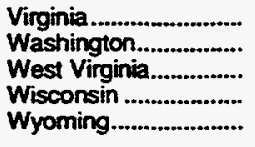 & $\begin{array}{l}\text { NA } \\
\text { NA } \\
\text { NA } \\
\text { NA } \\
\text { NA }\end{array}$ & $\begin{array}{r}1,362 \\
0 \\
31 \\
6,365 \\
754\end{array}$ & $\begin{array}{r}115,143 \\
136,472 \\
128,239 \\
346,780 \\
60,706\end{array}$ & $\begin{array}{l}\text { NA } \\
\text { NA } \\
\text { NA } \\
\text { NA } \\
\text { NA }\end{array}$ \\
\hline 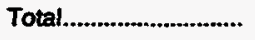 & NA & $3,191,200$ & $17,328,767$ & 1.019 \\
\hline
\end{tabular}

See footnotes at end of table. 
Table 16. Natural Gas Delivered to Consumers by State, 1967-1994' (Continued)

\begin{tabular}{|c|c|c|c|c|c|c|}
\hline \multirow[b]{2}{*}{ Stance } & \multicolumn{2}{|c|}{ Rosidential } & \multicolumn{2}{|c|}{ Commercial } & \multicolumn{2}{|c|}{ Induatrial } \\
\hline & $\begin{array}{l}\text { Quantity } \\
\text { (million } \\
\text { cuble twot) }\end{array}$ & Consumers & $\begin{array}{l}\text { Quantity } \\
\text { (million } \\
\text { cubic fect) }\end{array}$ & Conaumers & $\begin{array}{l}\text { Ouentity } \\
\text { (miltion } \\
\text { cursic trot) }\end{array}$ & Consumers \\
\hline & \multicolumn{6}{|c|}{1978} \\
\hline 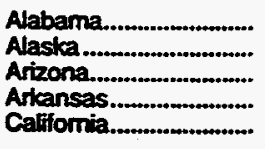 & $\begin{array}{r}56,957 \\
12,166 \\
30,115 \\
47,937 \\
537,412\end{array}$ & $\begin{array}{r}583,000 \\
33,000 \\
527,000 \\
386,000 \\
6,304,000\end{array}$ & $\begin{array}{r}29,649 \\
15,208 \\
29,581 \\
34,612 \\
221,441\end{array}$ & $\begin{array}{r}37,000 \\
5,000 \\
44,000 \\
53,000 \\
364,000\end{array}$ & $\begin{array}{r}129,427 \\
77,138 \\
45,791 \\
116,138 \\
417,829\end{array}$ & $\begin{array}{l}\text { NA } \\
\text { NA } \\
\text { NA } \\
\text { NA } \\
\text { NA }\end{array}$ \\
\hline 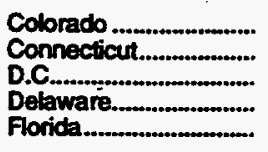 & $\begin{array}{r}92,064 \\
31,800 \\
\mathrm{NA} \\
7,458 \\
21,619\end{array}$ & $\begin{array}{r}722,000 \\
360,000 \\
N A \\
76,000 \\
364,000\end{array}$ & $\begin{array}{r}71,422 \\
16,940 \\
0 \\
3,005 \\
35,386\end{array}$ & $\begin{array}{r}81,000 \\
31,000 \\
N A \\
5,000 \\
43,000\end{array}$ & $\begin{array}{r}59,434 \\
16,411 \\
\mathrm{NA} \\
8,675 \\
96,846\end{array}$ & $\begin{array}{l}\text { NA } \\
\text { NA } \\
\text { NA } \\
\text { NA } \\
\text { NA }\end{array}$ \\
\hline 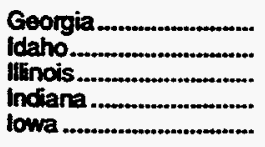 & $\begin{array}{r}96,368 \\
7,800 \\
520,525 \\
168,468 \\
80,877\end{array}$ & $\begin{array}{r}874,000 \\
95,000 \\
2,999,000 \\
1,123,000 \\
550,000\end{array}$ & $\begin{array}{r}60,266 \\
5,503 \\
251,895 \\
70,083 \\
49,200\end{array}$ & $\begin{array}{r}72,000 \\
14,000 \\
232,000 \\
101,000 \\
64,000\end{array}$ & $\begin{array}{r}112,317 \\
26,429 \\
366,550 \\
194,391 \\
95,044\end{array}$ & $\begin{array}{l}\text { NA } \\
\text { NA } \\
\text { NA } \\
\text { NA } \\
\text { NA }\end{array}$ \\
\hline 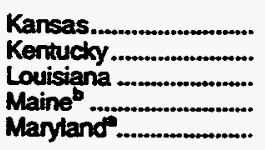 & $\begin{array}{r}99,411 \\
84,436 \\
81.978 \\
5,887 \\
83,391\end{array}$ & $\begin{array}{r}661,000 \\
562,000 \\
944,000 \\
64,000 \\
858,000\end{array}$ & $\begin{array}{r}64,532 \\
46,647 \\
65,300 \\
4,467 \\
39,821\end{array}$ & $\begin{array}{r}59,000 \\
51,000 \\
71,000 \\
7,000 \\
30,000\end{array}$ & $\begin{array}{r}143,661 \\
56,378 \\
1,093,091 \\
3,646 \\
35,214\end{array}$ & $\begin{array}{l}\text { NA } \\
\text { NA } \\
\text { NA } \\
\text { NA } \\
\text { NA }\end{array}$ \\
\hline 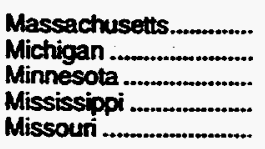 & $\begin{array}{r}86,756 \\
328,260 \\
106,827 \\
30,387 \\
159,013\end{array}$ & $\begin{array}{r}968,000 \\
2,173,000 \\
712,000 \\
306,000 \\
1,083,000\end{array}$ & $\begin{array}{r}45,657 \\
142,935 \\
81,121 \\
21,312 \\
98,680\end{array}$ & $\begin{array}{r}71,000 \\
154,000 \\
65,000 \\
33,000 \\
80,000\end{array}$ & $\begin{array}{r}26,030 \\
267,364 \\
120,086 \\
71,699 \\
69,030\end{array}$ & $\begin{array}{l}\text { NA } \\
\text { NA } \\
\text { NA } \\
\text { NA } \\
\text { NA }\end{array}$ \\
\hline 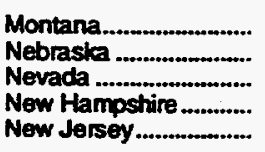 & $\begin{array}{r}22,944 \\
48,193 \\
11,778 \\
b \\
136,347\end{array}$ & $\begin{array}{r}164,000 \\
367,000 \\
139,000 \\
b \\
1,642,000\end{array}$ & $\begin{array}{r}17,766 \\
40,736 \\
19,940 \\
\text { b } \\
48,005\end{array}$ & $\begin{array}{r}20,000 \\
51,000 \\
6,000 \\
b \\
173,000\end{array}$ & $\begin{array}{r}26,696 \\
51,169 \\
11,039 \\
b \\
43,217\end{array}$ & $\begin{array}{l}\text { NA } \\
\text { NA } \\
\text { NA } \\
\text { NA } \\
\text { NA }\end{array}$ \\
\hline 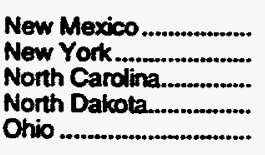 & $\begin{array}{r}25,882 \\
330,968 \\
35,072 \\
12,417 \\
416,721\end{array}$ & $\begin{array}{r}274,000 \\
3,691,000 \\
340,000 \\
73,000 \\
2,513,000\end{array}$ & $\begin{array}{r}25,706 \\
142,998 \\
20,366 \\
11,845 \\
172,429\end{array}$ & $\begin{array}{r}28,000 \\
232,000 \\
41,000 \\
10,000 \\
190,000\end{array}$ & $\begin{array}{r}37.977 \\
91,020 \\
23.948 \\
2,460 \\
324,903\end{array}$ & $\begin{array}{l}\text { NA } \\
\text { NA } \\
\text { NA } \\
\text { NA }\end{array}$ \\
\hline 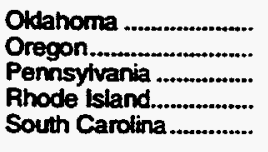 & $\begin{array}{r}84,046 \\
17,578 \\
286,163 \\
13,609 \\
28,214\end{array}$ & $\begin{array}{r}671,000 \\
233.000 \\
2.122,000 \\
149,000 \\
240,000\end{array}$ & $\begin{array}{r}45,729 \\
12,124 \\
110,620 \\
4,783 \\
24,681\end{array}$ & $\begin{array}{r}61,000 \\
27,000 \\
139,000 \\
7,000 \\
23,000\end{array}$ & $\begin{array}{r}191,712 \\
47,707 \\
249,953 \\
4,638 \\
55,611\end{array}$ & $\begin{array}{l}\text { NA } \\
\text { NA } \\
\text { NA } \\
\text { NA } \\
\text { NA }\end{array}$ \\
\hline $\begin{array}{l}\text { South Dakota..... } \\
\text { Tennessee ........... } \\
\text { Texas } \\
\text { Utah }\end{array}$ & $\begin{array}{r}14,874 \\
39,807 \\
274,849 \\
47,783 \\
b\end{array}$ & $\begin{array}{r}88,000 \\
372,000 \\
2,791,000 \\
318,000 \\
b\end{array}$ & $\begin{array}{r}13,547 \\
30,917 \\
168,946 \\
8,430 \\
b\end{array}$ & $\begin{array}{r}11,000 \\
45,000 \\
257,000 \\
19,000 \\
b\end{array}$ & $\begin{array}{r}6,946 \\
98,393 \\
1,443,920 \\
45,422 \\
b\end{array}$ & $\begin{array}{l}\text { NA } \\
\text { NA } \\
\text { NA } \\
\text { NA } \\
\text { NA }\end{array}$ \\
\hline 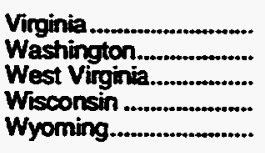 & $\begin{array}{r}54,250 \\
27.437 \\
53,395 \\
128,873 \\
13,894\end{array}$ & $\begin{array}{r}462,000 \\
303,000 \\
361,000 \\
1,093,000 \\
92,000\end{array}$ & $\begin{array}{r}43,064 \\
25,330 \\
22,501 \\
77,890 \\
8,100\end{array}$ & $\begin{array}{l}48,000 \\
38,000 \\
30,000 \\
82,000 \\
11,000\end{array}$ & $\begin{array}{r}32,961 \\
67,668 \\
59,460 \\
153,984 \\
37,228\end{array}$ & $\begin{array}{l}\text { NA } \\
\text { NA } \\
\text { NA } \\
\text { NA } \\
\text { NA }\end{array}$ \\
\hline 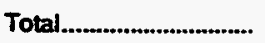 & $4,903,006$ & $41,845,000$ & $2,601,106$ & $3,316,000$ & $6.756,641$ & NA \\
\hline
\end{tabular}

See footnotes at end of table. 
Table 16. Natural Gas Delivered to Consumers by State, 1967-1994 (Continued)

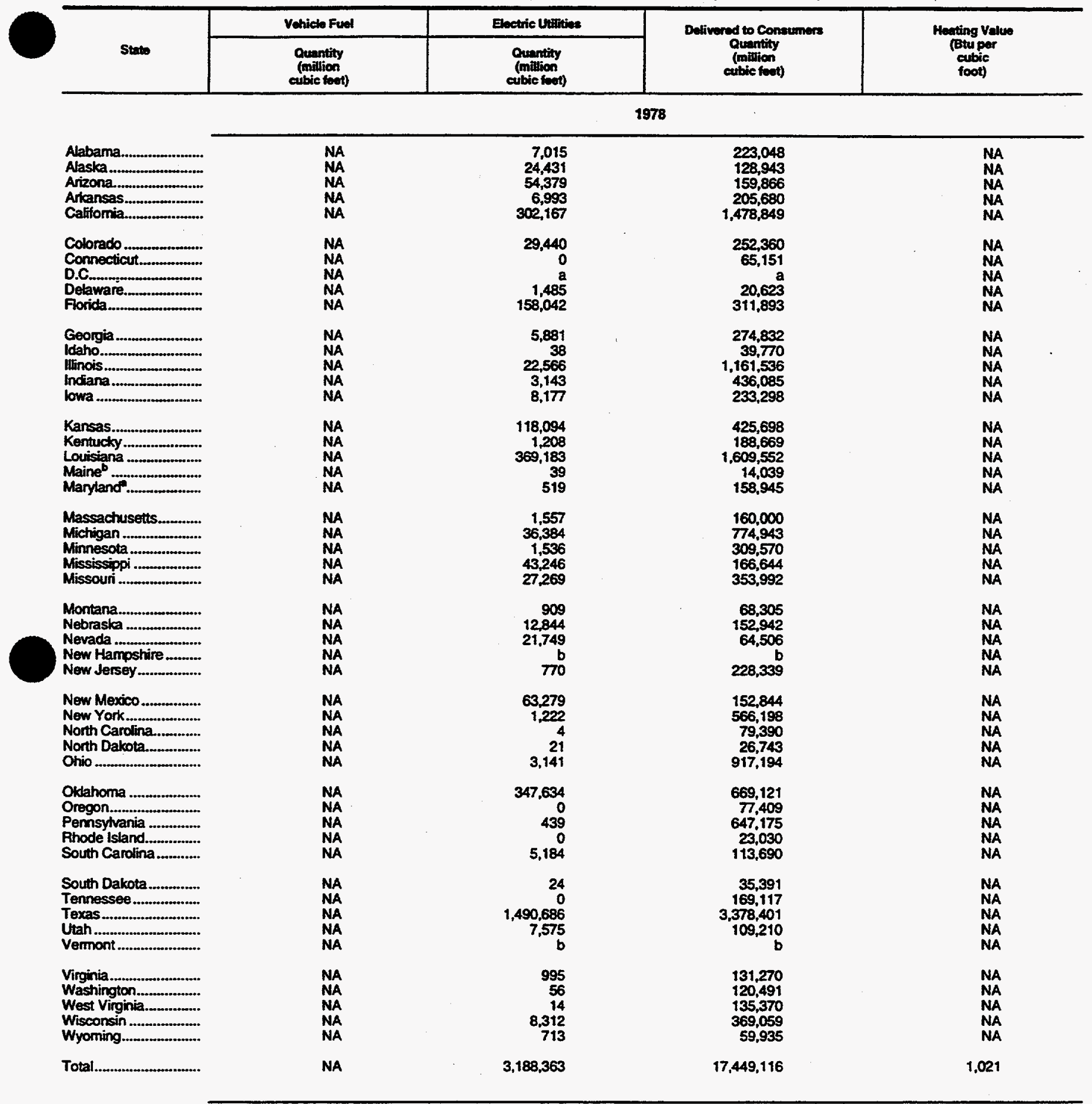

See foctnotes at end of table. 
Table 16. Natural Gas Delivered to Consumers by State, 1967-1994 (Continued)

\begin{tabular}{|c|c|c|c|c|c|c|}
\hline \multirow[b]{2}{*}{ Suto } & \multicolumn{2}{|c|}{ Racidontied } & \multicolumn{2}{|c|}{ Commercial } & \multicolumn{2}{|c|}{ Industrial } \\
\hline & $\begin{array}{l}\text { Quantity } \\
\text { (million } \\
\text { cubic foct) }\end{array}$ & Consumers: & $\begin{array}{l}\text { Quantity } \\
\text { (million } \\
\text { cubic feet) }\end{array}$ & Consuniess & $\begin{array}{l}\text { Ouantity } \\
\text { (milition } \\
\text { cubic tert) }\end{array}$ & Concuminers \\
\hline & \multicolumn{6}{|c|}{1979} \\
\hline 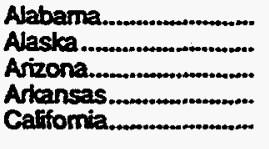 & $\begin{array}{r}52,535 \\
7,313 \\
29,538 \\
49,892 \\
590,732\end{array}$ & $\begin{array}{r}599,000 \\
36,000 \\
538,000 \\
449,000 \\
6,810,000\end{array}$ & $\begin{array}{r}36,717 \\
15,862 \\
26,971 \\
33,442 \\
258,490\end{array}$ & $\begin{array}{r}43,000 \\
6,000 \\
44,000 \\
19,000 \\
375,000\end{array}$ & $\begin{array}{r}152,758 \\
92,733 \\
44,599 \\
117,219 \\
432,891\end{array}$ & $\begin{array}{l}\text { NA } \\
\text { NA } \\
\text { NA } \\
\text { NA } \\
\text { NA }\end{array}$ \\
\hline 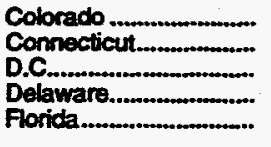 & $\begin{array}{r}97,751 \\
31,285 \\
\mathrm{NA} \\
6,986 \\
17,518\end{array}$ & $\begin{array}{r}753,000 \\
366,000 \\
N A \\
76,000 \\
412,000\end{array}$ & $\begin{array}{r}74,831 \\
16,830 \\
0 \\
2,842 \\
36,638\end{array}$ & $\begin{array}{r}88,000 \\
32,000 \\
N A \\
5,000 \\
34,000\end{array}$ & $\begin{array}{r}55,638 \\
19,783 \\
\mathrm{NA} \\
10,006 \\
111,064\end{array}$ & $\begin{array}{l}\mathbf{N A} \\
\mathbf{N A} \\
\mathbf{N A} \\
\mathbf{N A}\end{array}$ \\
\hline $\begin{array}{l}\text { Georgia } \\
\text { ldaho } \\
\text { Ilanois } \\
\text { Indiana } \\
\text { lowa }\end{array}$ & $\begin{array}{r}91,036 \\
8,752 \\
495,570 \\
173,147 \\
95,941\end{array}$ & $\begin{array}{r}901,000 \\
94,000 \\
3,030,000 \\
675,000 \\
657,000\end{array}$ & $\begin{array}{r}62,437 \\
6,923 \\
237,199 \\
74,231 \\
58,308\end{array}$ & $\begin{array}{r}75,000 \\
14,000 \\
236,000 \\
67,000 \\
76,000\end{array}$ & $\begin{array}{r}151,681 \\
33,593 \\
359,520 \\
244,181 \\
118,167\end{array}$ & $\begin{array}{l}\text { NA } \\
\text { NA } \\
\text { NA } \\
\text { NA }\end{array}$ \\
\hline 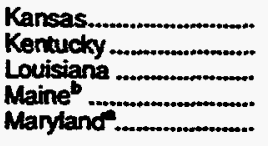 & $\begin{array}{r}102,413 \\
77,438 \\
87,808 \\
5,587 \\
82,784\end{array}$ & $\begin{array}{r}670,000 \\
574,000 \\
939,000 \\
65,000 \\
849,000\end{array}$ & $\begin{array}{r}60,931 \\
40,509 \\
115,743 \\
5,023 \\
47,326\end{array}$ & $\begin{array}{r}65,000 \\
54,000 \\
70,000 \\
8,000 \\
63,000\end{array}$ & $\begin{array}{r}201,784 \\
72,787 \\
1,010,618 \\
3,707 \\
56,844\end{array}$ & $\begin{array}{l}\text { NA } \\
\text { NA } \\
\text { NA } \\
\text { NA }\end{array}$ \\
\hline 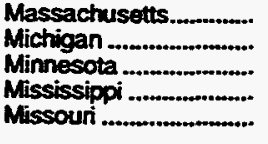 & $\begin{array}{r}80,839 \\
369,378 \\
112,332 \\
36,987 \\
161,208\end{array}$ & $\begin{array}{r}987,000 \\
2,149,000 \\
736,000 \\
418,000 \\
1,136,000\end{array}$ & $\begin{array}{r}46,701 \\
182,316 \\
60,509 \\
27,224 \\
94,629\end{array}$ & $\begin{array}{r}70,000 \\
158,000 \\
68,000 \\
47,000 \\
85,000\end{array}$ & $\begin{array}{r}21,382 \\
259,058 \\
143,365 \\
75,261 \\
63,975\end{array}$ & $\begin{array}{l}\text { NA } \\
\text { NA } \\
\text { NA } \\
\text { NA } \\
\text { NA }\end{array}$ \\
\hline $\begin{array}{l}\text { Montana...................... } \\
\text { Nebrasica ........................ } \\
\text { Nevada Hew Hamire............. } \\
\text { New Jersey ..................... }\end{array}$ & $\begin{array}{r}22,579 \\
53,526 \\
13,211 \\
6 \\
124,901\end{array}$ & $\begin{array}{r}164,000 \\
364,000 \\
149,000 \\
b \\
1,547,000\end{array}$ & $\begin{array}{r}17,396 \\
43,507 \\
19,638 \\
0 \\
52,314\end{array}$ & $\begin{array}{r}20,000 \\
46,000 \\
6,000 \\
b \\
175,000\end{array}$ & $\begin{array}{r}20,411 \\
50,076 \\
11,756 \\
b \\
52,083\end{array}$ & $\begin{array}{l}\text { NA } \\
\text { NA } \\
\text { NA } \\
\text { NA } \\
\text { NA }\end{array}$ \\
\hline 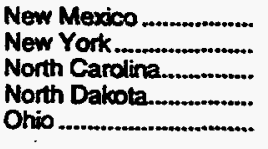 & $\begin{array}{r}27,874 \\
313,027 \\
32,244 \\
11,588 \\
373,631\end{array}$ & $\begin{array}{r}278,000 \\
3,694,000 \\
354,000 \\
75,000 \\
2,562,000\end{array}$ & $\begin{array}{r}26,371 \\
143,512 \\
23,916 \\
12,044 \\
158,117\end{array}$ & $\begin{array}{r}29,000 \\
236,000 \\
43,000 \\
10,000 \\
193,000\end{array}$ & $\begin{array}{r}16,593 \\
87,073 \\
69,116 \\
1,535 \\
324,039\end{array}$ & $\begin{array}{l}\text { NA } \\
\text { NA } \\
\text { NA } \\
\text { NA }\end{array}$ \\
\hline 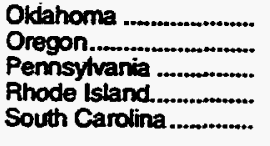 & $\begin{array}{r}85,285 \\
18,869 \\
288,582 \\
13,426 \\
17,675\end{array}$ & $\begin{array}{r}698,000 \\
212,000 \\
2,149,000 \\
151,000 \\
249,000\end{array}$ & $\begin{array}{r}52,036 \\
13,820 \\
111,498 \\
6,169 \\
17,943\end{array}$ & $\begin{array}{r}57,000 \\
28,000 \\
142,000 \\
10,000 \\
25,000\end{array}$ & $\begin{array}{r}199,258 \\
49,363 \\
309,760 \\
5,836 \\
75,626\end{array}$ & $\begin{array}{l}\text { NA } \\
\text { NA } \\
\text { NA } \\
\text { NA }\end{array}$ \\
\hline 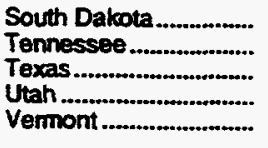 & $\begin{array}{r}11,830 \\
45,136 \\
315,857 \\
60,462 \\
b\end{array}$ & $\begin{array}{r}90,000 \\
438,000 \\
3,746,000 \\
365,000 \\
b\end{array}$ & $\begin{array}{r}9,951 \\
42,714 \\
233,758 \\
6 \\
b\end{array}$ & $\begin{array}{r}11,000 \\
61,000 \\
333,000 \\
4,000 \\
b\end{array}$ & $\begin{array}{r}3,416 \\
117,825 \\
1,256,043 \\
44,700 \\
b\end{array}$ & $\begin{array}{l}\text { NA } \\
\text { NA } \\
\text { NA } \\
\text { NA } \\
\text { NA }\end{array}$ \\
\hline 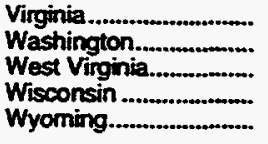 & $\begin{array}{r}50,999 \\
32,850 \\
47,964 \\
124,672 \\
14,407\end{array}$ & $\begin{array}{r}419,000 \\
331,000 \\
364,000 \\
942,000 \\
98,000\end{array}$ & $\begin{array}{r}33,946 \\
33,369 \\
22,337 \\
80,756 \\
8,211\end{array}$ & $\begin{array}{l}35,000 \\
45,000 \\
32,000 \\
81,000 \\
10,000\end{array}$ & $\begin{array}{r}41,277 \\
82,534 \\
60,006 \\
136,992 \\
31,485\end{array}$ & $\begin{array}{l}\text { NA } \\
\text { NA } \\
\text { NA } \\
\text { NA } \\
\text { NA }\end{array}$ \\
\hline Total....................... & $4,965,365$ & $43,358,000$ & 2,785,961. & $3,434,000$ & $6,899,418$ & NA \\
\hline
\end{tabular}

See foothotes at end of table. 
Table 16. Natural Gas Delivered to Consumers by State, 1967-1994 (Continued)

\begin{tabular}{|c|c|c|c|c|}
\hline \multirow[b]{2}{*}{ State } & Vohide Fuol & Electrie Utintios & \multirow{2}{*}{$\begin{array}{l}\text { Delivered to Consumers } \\
\text { Quantity } \\
\text { (miltion } \\
\text { calbic foet) }\end{array}$} & \multirow{2}{*}{$\begin{array}{l}\text { Hoating Value } \\
\text { (Btu per } \\
\text { cubic } \\
\text { foot) }\end{array}$} \\
\hline & $\begin{array}{l}\text { Quantity } \\
\text { (million } \\
\text { cubic foot) }\end{array}$ & $\begin{array}{l}\text { Quantity } \\
\text { (mullion } \\
\text { cubic feot) }\end{array}$ & & \\
\hline & \multicolumn{4}{|c|}{1979} \\
\hline 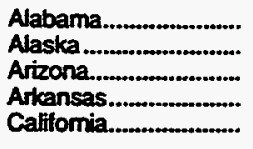 & $\begin{array}{l}\text { NA } \\
\text { NA } \\
\text { NA } \\
\text { NA } \\
\text { NA }\end{array}$ & $\begin{array}{r}6,934 \\
28,295 \\
51,258 \\
30,254 \\
444,601\end{array}$ & $\begin{array}{r}248,944 \\
144,203 \\
152,366 \\
230,807 \\
1,726,714\end{array}$ & $\begin{array}{l}\text { NA } \\
\text { NA } \\
\text { NA } \\
\text { NA }\end{array}$ \\
\hline 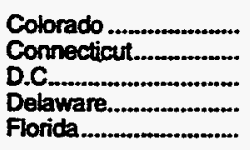 & $\begin{array}{l}\text { NA } \\
\text { NA } \\
\text { NA } \\
\text { NA } \\
\text { NA }\end{array}$ & $\begin{array}{r}35,409 \\
0 \\
a \\
5,143 \\
167,444\end{array}$ & $\begin{array}{r}263,629 \\
67,898 \\
a \\
24,977 \\
332,664\end{array}$ & $\begin{array}{l}\text { NA } \\
\text { NA } \\
\text { NA } \\
\text { NA } \\
\text { NA }\end{array}$ \\
\hline 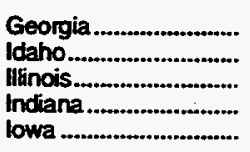 & $\begin{array}{l}\text { NA } \\
\text { NA } \\
\text { NA } \\
\text { NA } \\
\text { NA }\end{array}$ & $\begin{array}{r}3,023 \\
491 \\
31,547 \\
2,774 \\
8,333\end{array}$ & $\begin{array}{r}308,177 \\
49,759 \\
1,123,836 \\
494,333 \\
280,749\end{array}$ & $\begin{array}{l}\text { NA } \\
\text { NA } \\
\text { NA } \\
\text { NA } \\
\text { NA }\end{array}$ \\
\hline $\begin{array}{l}\text { Kansas... } \\
\text { Kentucky } \\
\text { Louisiana } \\
\text { Maine } \\
\text { Maryland }\end{array}$ & $\begin{array}{l}\text { NA } \\
\text { NA } \\
\text { NA } \\
\text { NA } \\
\text { NA }\end{array}$ & $\begin{array}{r}116,828 \\
934 \\
401,399 \\
564 \\
9,820\end{array}$ & $\begin{array}{r}481,956 \\
191,668 \\
1,615,568 \\
14,881 \\
196,774\end{array}$ & $\begin{array}{l}\text { NA } \\
\text { NA } \\
\text { NA } \\
\text { NA } \\
\text { NA }\end{array}$ \\
\hline 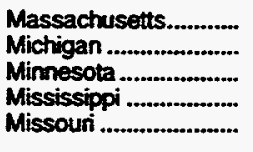 & $\begin{array}{l}\text { NA } \\
\text { NA } \\
\text { NA } \\
\text { NA } \\
\text { NA }\end{array}$ & $\begin{array}{r}6,886 \\
37,860 \\
6,966 \\
64,183 \\
20,383\end{array}$ & $\begin{array}{l}155,808 \\
848,612 \\
323,172 \\
203,655 \\
340,195\end{array}$ & $\begin{array}{l}\text { NA } \\
\text { NA } \\
\text { NA } \\
\text { NA } \\
\text { NA }\end{array}$ \\
\hline 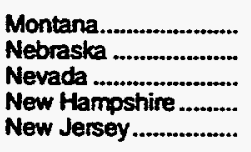 & $\begin{array}{l}\text { NA } \\
\text { NA } \\
\text { NA } \\
\text { NA } \\
\text { NA }\end{array}$ & $\begin{array}{r}2,320 \\
14,009 \\
39,828 \\
b \\
30,727\end{array}$ & $\begin{array}{r}62,706 \\
161.118 \\
84.433 \\
b \\
260,025\end{array}$ & $\begin{array}{l}\text { NA } \\
\text { NA } \\
\text { NA } \\
\text { NA } \\
\text { NA }\end{array}$ \\
\hline $\begin{array}{l}\text { New Mexico } \\
\text { New York } \\
\text { North Carolina....................... } \\
\text { North Dakota........... } \\
\text { Ohio }\end{array}$ & $\begin{array}{l}\text { NA } \\
\text { NA } \\
\text { NA } \\
\text { NA } \\
\text { NA }\end{array}$ & $\begin{array}{r}60,410 \\
75,964 \\
591 \\
17 \\
5,604\end{array}$ & $\begin{array}{r}131,248 \\
619,576 \\
125,867 \\
25,184 \\
861,391\end{array}$ & $\begin{array}{l}\text { NA } \\
\text { NA } \\
\text { NA } \\
\text { NA } \\
\text { NA }\end{array}$ \\
\hline 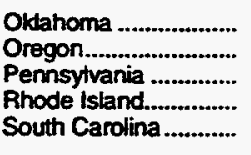 & $\begin{array}{l}\text { NA } \\
\text { NA } \\
\text { NA } \\
\text { NA } \\
\text { NA }\end{array}$ & $\begin{array}{r}334,446 \\
2,380 \\
1,862 \\
1,752 \\
5,177\end{array}$ & $\begin{array}{r}671,025 \\
84,432 \\
711,702 \\
27,183 \\
116,421\end{array}$ & $\begin{array}{l}\text { NA } \\
\text { NA } \\
\text { NA } \\
\text { NA } \\
\text { NA }\end{array}$ \\
\hline $\begin{array}{l}\text { South Dakota } \\
\text { Tennessee } \\
\text { Texas } \\
\text { Utah } \\
\text { Vermont }\end{array}$ & $\begin{array}{l}\text { NA } \\
\text { NA } \\
\text { NA } \\
\text { NA } \\
\text { NA }\end{array}$ & $\begin{array}{r}129 \\
0 \\
1,400,368 \\
6.186 \\
b\end{array}$ & $\begin{array}{r}25,326 \\
205,675 \\
3,206,026 \\
111,354 \\
b\end{array}$ & $\begin{array}{l}\text { NA } \\
\text { NA } \\
\text { NA } \\
\text { NA } \\
\text { NA }\end{array}$ \\
\hline 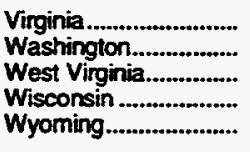 & $\begin{array}{l}\text { NA } \\
\text { NA } \\
\text { NA } \\
\text { NA } \\
\text { NA }\end{array}$ & $\begin{array}{r}3,557 \\
2,100 \\
69 \\
21,213 \\
486\end{array}$ & $\begin{array}{r}129,779 \\
150,853 \\
130,376 \\
363.633 \\
54,589\end{array}$ & $\begin{array}{l}\text { NA } \\
\text { NA } \\
\text { NA } \\
\text { NA } \\
\text { NA }\end{array}$ \\
\hline 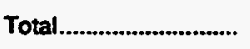 & NA & $3,490,523$ & $18,141,267$ & 1,021 \\
\hline
\end{tabular}

See footnotes at end of table. 
Table 16. Natural Gas Delivered to Consumers by State, 1967-1994 (Continued)

\begin{tabular}{|c|c|c|c|c|c|c|}
\hline \multirow[b]{2}{*}{ Sute } & \multicolumn{2}{|c|}{ Recidontied } & \multicolumn{2}{|c|}{ Commencial } & \multicolumn{2}{|c|}{ Industrial } \\
\hline & $\begin{array}{l}\text { Outantity } \\
\text { (miltion } \\
\text { cubic toot) }\end{array}$ & Conaumers & $\begin{array}{l}\text { Quantity } \\
\text { (million } \\
\text { cubic feet) }\end{array}$ & Consumers & $\begin{array}{l}\text { Qunntity } \\
\text { (million } \\
\text { cubic tiot) }\end{array}$ & Consemers \\
\hline & \multicolumn{6}{|c|}{1980} \\
\hline 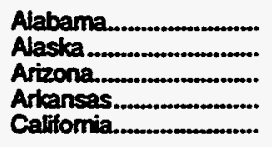 & $\begin{array}{r}52,334 \\
7,917 \\
29,518 \\
46,835 \\
529,342\end{array}$ & $\begin{array}{r}634,000 \\
37,000 \\
550,000 \\
456,000 \\
6,954,000\end{array}$ & $\begin{array}{r}28,525 \\
16,513 \\
27,487 \\
30,690 \\
258,151\end{array}$ & $\begin{array}{r}49,000 \\
6,000 \\
45,000 \\
58,000 \\
380,000\end{array}$ & $\begin{array}{r}160,552 \\
69,773 \\
37,807 \\
123,931 \\
423,349\end{array}$ & $\begin{array}{r}2,000 \\
N A \\
1,000 \\
2,000 \\
36,000\end{array}$ \\
\hline 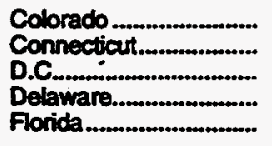 & $\begin{array}{r}89,700 \\
32,042 \\
13,730 \\
6,910 \\
15,134\end{array}$ & $\begin{array}{r}778,000 \\
373,000 \\
134,000 \\
77,000 \\
416,000\end{array}$ & $\begin{array}{r}66,952 \\
20,153 \\
13,752 \\
3,246 \\
30,182\end{array}$ & $\begin{array}{r}92,000 \\
33,000 \\
16,000 \\
5,000 \\
34,000\end{array}$ & $\begin{array}{r}53,185 \\
20,317 \\
386 \\
12,642 \\
93,275\end{array}$ & $\begin{array}{r}2,000 \\
2,000 \\
\mathrm{NA} \\
\mathrm{NA} \\
1,000\end{array}$ \\
\hline 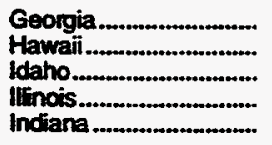 & $\begin{array}{r}90,240 \\
1,416 \\
7,387 \\
478,489 \\
163,665\end{array}$ & $\begin{array}{r}993,000 \\
24,000 \\
94,000 \\
3,068,000 \\
1,167,000\end{array}$ & $\begin{array}{r}58,763 \\
1,715 \\
5,756 \\
228,178 \\
70,048\end{array}$ & $\begin{array}{r}79,000 \\
3,000 \\
15,000 \\
245,000 \\
104,000\end{array}$ & $\begin{array}{r}155,158 \\
0 \\
31,646 \\
348,939 \\
244,729\end{array}$ & $\begin{array}{r}2,000 \\
N A \\
N A \\
19,000 \\
5,000\end{array}$ \\
\hline 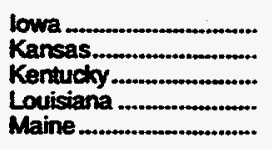 & $\begin{array}{r}84,955 \\
85,294 \\
74,235 \\
73,093 \\
555\end{array}$ & $\begin{array}{r}671,000 \\
683,000 \\
587,000 \\
970,000 \\
13,000\end{array}$ & $\begin{array}{r}50,588 \\
58,880 \\
39,359 \\
39,996 \\
864\end{array}$ & $\begin{array}{r}78,000 \\
67,000 \\
57,000 \\
69,000 \\
2,000\end{array}$ & $\begin{array}{r}114,523 \\
166,298 \\
64,872 \\
985,611 \\
747\end{array}$ & $\begin{array}{r}3,000 \\
6,000 \\
1,000 \\
2,000 \\
\text { NA }\end{array}$ \\
\hline 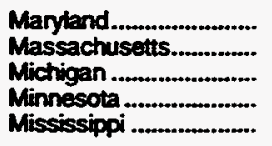 & $\begin{array}{r}68,080 \\
94,424 \\
387,279 \\
103,387 \\
29,485\end{array}$ & $\begin{array}{r}723,000 \\
1,005,000 \\
2,305,000 \\
765,000 \\
353,000\end{array}$ & $\begin{array}{r}28,576 \\
53,462 \\
190,268 \\
63,780 \\
20,886\end{array}$ & $\begin{array}{r}49,000 \\
73,000 \\
165,000 \\
71,000 \\
44,000\end{array}$ & $\begin{array}{r}54,414 \\
28,943 \\
242,353 \\
101,473 \\
74,384\end{array}$ & $\begin{array}{r}5,000 \\
3,000 \\
10,000 \\
2,000 \\
1,000\end{array}$ \\
\hline 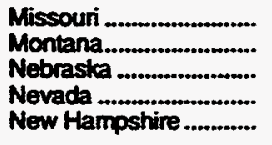 & $\begin{array}{r}143,425 \\
19,296 \\
48,915 \\
13,182 \\
4,331\end{array}$ & $\begin{array}{r}1,136,000 \\
165,000 \\
391,000 \\
166,000 \\
46,000\end{array}$ & $\begin{array}{r}76,054 \\
14,265 \\
43,356 \\
10,207 \\
4,116\end{array}$ & $\begin{array}{l}91,000 \\
20,000 \\
48,000 \\
7,000 \\
6,000\end{array}$ & $\begin{array}{l}78,064 \\
16,717 \\
48,162 \\
7,354 \\
1,001\end{array}$ & $\begin{array}{r}3,000 \\
N A \\
1,000 \\
N A \\
N A\end{array}$ \\
\hline $\begin{array}{l}\text { New Jersey .................... } \\
\text { New Mexico .................. } \\
\text { New York.................... } \\
\text { North Carolina................ } \\
\text { North Dalcota.................. }\end{array}$ & $\begin{array}{r}136,481 \\
28,579 \\
333,902 \\
33,963 \\
9,644\end{array}$ & $\begin{array}{r}1,559,000 \\
310,000 \\
3,708,000 \\
373,000 \\
78,000\end{array}$ & $\begin{array}{r}60,481 \\
24,505 \\
161,813 \\
26,172 \\
11,026\end{array}$ & $\begin{array}{r}155,000 \\
31,000 \\
231,000 \\
46,000 \\
10,000\end{array}$ & $\begin{array}{r}62,882 \\
37,215 \\
113,694 \\
85,611 \\
975\end{array}$ & $\begin{array}{r}5,000 \\
N A \\
17,000 \\
2,000 \\
N A\end{array}$ \\
\hline 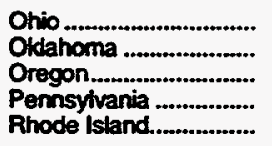 & $\begin{array}{r}393,759 \\
76,599 \\
18,389 \\
288,326 \\
13,960\end{array}$ & $\begin{array}{r}2,575,000 \\
751,000 \\
248,000 \\
2,203,000 \\
158,000\end{array}$ & $\begin{array}{r}166,210 \\
47,135 \\
15,171 \\
118,462 \\
6,751\end{array}$ & $\begin{array}{r}195,000 \\
76,000 \\
35,000 \\
149,000 \\
11,000\end{array}$ & $\begin{array}{r}318,938 \\
185,968 \\
39,202 \\
335,256 \\
5,087\end{array}$ & $\begin{array}{l}6,000 \\
3,000 \\
1,000 \\
6,000 \\
1,000\end{array}$ \\
\hline 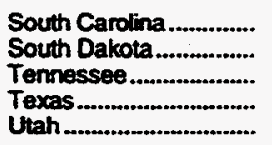 & $\begin{array}{r}18,866 \\
10,558 \\
44,894 \\
224,800 \\
57,639\end{array}$ & $\begin{array}{r}263,000 \\
93,000 \\
457,000 \\
2,932,000 \\
381,000\end{array}$ & $\begin{array}{r}22,885 \\
8,507 \\
44,048 \\
168,513 \\
330\end{array}$ & $\begin{array}{r}27,000 \\
12,000 \\
63,000 \\
266,000 \\
1,000\end{array}$ & $\begin{array}{r}92,046 \\
4,678 \\
123,122 \\
1,626,167 \\
43,545\end{array}$ & $\begin{array}{r}1,000 \\
N A \\
2,000 \\
18,000 \\
1,000\end{array}$ \\
\hline 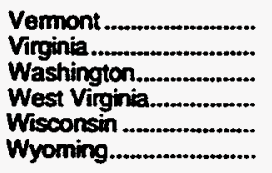 & $\begin{array}{r}1,301 \\
54,825 \\
29,734 \\
48,284 \\
123,233 \\
9,751\end{array}$ & $\begin{array}{r}11,000 \\
534,000 \\
337,000 \\
367,000 \\
966,000 \\
76,000\end{array}$ & $\begin{array}{r}828 \\
38,467 \\
30,754 \\
21,980 \\
77,107 \\
4,980\end{array}$ & $\begin{array}{r}1,000 \\
46,000 \\
45,000 \\
33,000 \\
85,000 \\
8,000\end{array}$ & $\begin{array}{r}1,623 \\
54,403 \\
63,678 \\
57,017 \\
129,532 \\
30,410\end{array}$ & $\begin{array}{r}\mathrm{NA} \\
1,000 \\
1,000 \\
\mathrm{NA} \\
6,000 \\
\mathrm{NA}\end{array}$ \\
\hline 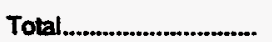 & $4,752,082$ & $44,114,000$ & $2,610,895$ & $3,535,000$ & $7,171,661$ & 183,000 \\
\hline
\end{tabular}


Table 16. Natural Gas Delivered to Consumers by State, 1967-1994 (Continued)

\begin{tabular}{|c|c|c|c|c|c|}
\hline \multirow[b]{2}{*}{ Stato } & Vehicle Ful & Eloctrie Utilitios & \multirow{2}{*}{$\begin{array}{l}\text { Delivered to Consumers } \\
\text { Quantity } \\
\text { (million } \\
\text { cubic teet) }\end{array}$} & \multirow{2}{*}{$\begin{array}{l}\text { Henting Value } \\
\text { (Btu per } \\
\text { cubic } \\
\text { toot) }\end{array}$} & \\
\hline & $\begin{array}{l}\text { Quantity } \\
\text { (million } \\
\text { cubic foet) }\end{array}$ & $\begin{array}{l}\text { Quaruity } \\
\text { (maltion } \\
\text { cubie fool) }\end{array}$ & & & \\
\hline & \multicolumn{5}{|c|}{1980} \\
\hline 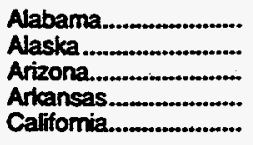 & $\begin{array}{l}\text { NA } \\
\text { NA } \\
\text { NA } \\
\text { NA } \\
\text { NA }\end{array}$ & $\begin{array}{r}1,382 \\
28,763 \\
49,699 \\
58,863 \\
518,808\end{array}$ & $\begin{array}{r}242,793 \\
122,966 \\
144,511 \\
260,319 \\
1,729,650\end{array}$ & $\begin{array}{l}1,034 \\
1,003 \\
1,049 \\
1,001 \\
1,046\end{array}$ & \\
\hline 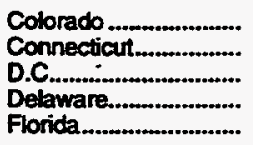 & $\begin{array}{l}\text { NA } \\
\text { NA } \\
\text { NA } \\
\text { NA } \\
\text { NA }\end{array}$ & $\begin{array}{r}31,928 \\
0 \\
0 \\
6,999 \\
165,047\end{array}$ & $\begin{array}{r}241,765 \\
72,512 \\
27,868 \\
29,797 \\
304,638\end{array}$ & $\begin{array}{r}993 \\
1,022 \\
1,003 \\
1,035 \\
1,041\end{array}$ & \\
\hline 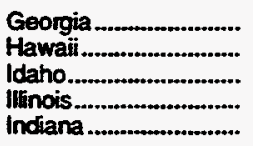 & $\begin{array}{l}\text { NA } \\
\text { NA } \\
\text { NA } \\
\text { NA }\end{array}$ & $\begin{array}{r}3,666 \\
0 \\
46 \\
19,165 \\
1,904\end{array}$ & $\begin{array}{r}307,827 \\
3,131 \\
44,835 \\
1,074,771 \\
480,346\end{array}$ & $\begin{array}{r}1,032 \\
963 \\
1,053 \\
1,022 \\
989\end{array}$ & $\ldots$ \\
\hline 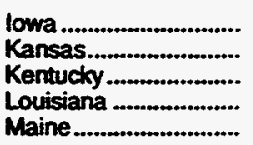 & $\begin{array}{l}\text { NA } \\
\text { NA } \\
\text { NA } \\
\text { NA } \\
\text { NA }\end{array}$ & $\begin{array}{r}6,834 \\
101,022 \\
1,902 \\
424,991 \\
0\end{array}$ & $\begin{array}{r}256,900 \\
411,494 \\
180,368 \\
1,523,691 \\
2,166\end{array}$ & $\begin{array}{r}1,003 \\
987 \\
1,009 \\
1.038 \\
1,024\end{array}$ & \\
\hline $\begin{array}{l}\text { Maryland .................... } \\
\text { Massachusetts............ } \\
\text { Michigan ................... } \\
\text { Minnesota .................. } \\
\text { Mississippi .................. }\end{array}$ & $\begin{array}{l}\text { NA } \\
\text { NA } \\
\text { NA } \\
\text { NA }\end{array}$ & $\begin{array}{r}5,230 \\
5,083 \\
26,368 \\
8,077 \\
95,073\end{array}$ & $\begin{array}{l}156,300 \\
181,912 \\
846,278 \\
276,717 \\
219,828\end{array}$ & $\begin{array}{r}1,020 \\
1,016 \\
1,011 \\
997 \\
1,028\end{array}$ & \\
\hline 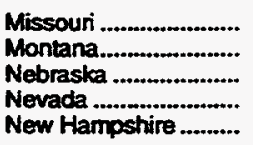 & $\begin{array}{l}\text { NA } \\
\text { NA } \\
\text { NA } \\
\text { NA } \\
\text { NA }\end{array}$ & $\begin{array}{r}15,329 \\
4,182 \\
11,850 \\
27,541 \\
0\end{array}$ & $\begin{array}{r}312,872 \\
54,460 \\
152,283 \\
58,284 \\
9,448\end{array}$ & $\begin{array}{r}1,014 \\
1,012 \\
978 \\
1.061 \\
1.020\end{array}$ & \\
\hline $\begin{array}{l}\text { New Jersey ................. } \\
\text { New Mexico ................ } \\
\text { New York................. } \\
\text { North Carolina............ } \\
\text { North Dakota.............. }\end{array}$ & $\begin{array}{l}\text { NA } \\
\text { NA } \\
\text { NA } \\
\text { NA }\end{array}$ & $\begin{array}{r}79,514 \\
56,280 \\
124,391 \\
1,702 \\
15\end{array}$ & $\begin{array}{r}339,358 \\
146,579 \\
733,800 \\
147,448 \\
21,660\end{array}$ & $\begin{array}{l}1,033 \\
1,043 \\
1,025 \\
1,012 \\
1,052\end{array}$ & \\
\hline 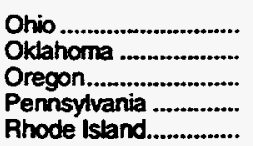 & $\begin{array}{l}\text { NA } \\
\text { NA } \\
\text { NA } \\
\text { NA } \\
\text { NA }\end{array}$ & $\begin{array}{r}4,706 \\
329,940 \\
321 \\
2,855 \\
1,679\end{array}$ & $\begin{array}{r}883,613 \\
639,642 \\
73,083 \\
744,909 \\
27,477\end{array}$ & $\begin{array}{l}1,016 \\
1,023 \\
1.046 \\
1.022 \\
1.021\end{array}$ & \\
\hline 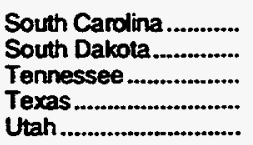 & $\begin{array}{l}\text { NA } \\
\text { NA } \\
\text { NA } \\
\text { NA }\end{array}$ & $\begin{array}{r}5,417 \\
259 \\
1,105 \\
1,430,027 \\
5,133\end{array}$ & $\begin{array}{r}139,214 \\
24,002 \\
213,169 \\
3,449,507 \\
106,647\end{array}$ & $\begin{array}{r}1.033 \\
998 \\
1.016 \\
1.033 \\
1.086\end{array}$ & \\
\hline 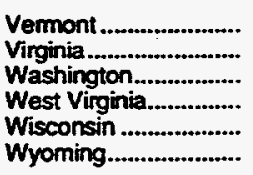 & $\begin{array}{l}\text { NA } \\
\text { NA } \\
\text { NA } \\
\text { NA } \\
\text { NA } \\
\text { NA }\end{array}$ & $\begin{array}{r}239 \\
2,285 \\
941 \\
62 \\
13.739 \\
222\end{array}$ & $\begin{array}{r}3,991 \\
149,980 \\
125,107 \\
127,343 \\
343,611 \\
45,363\end{array}$ & $\begin{array}{r}990 \\
1,016 \\
1,052 \\
1,032 \\
1,008 \\
1,060\end{array}$ & \\
\hline 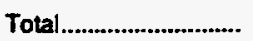 & NA & $3,681,595$ & $18,216,233$ & 1.026 & \\
\hline
\end{tabular}

See footnotes at end of table. 
Table 16. Natural Gas Delivered to Consumers by State, 1967-1994 (Continued)

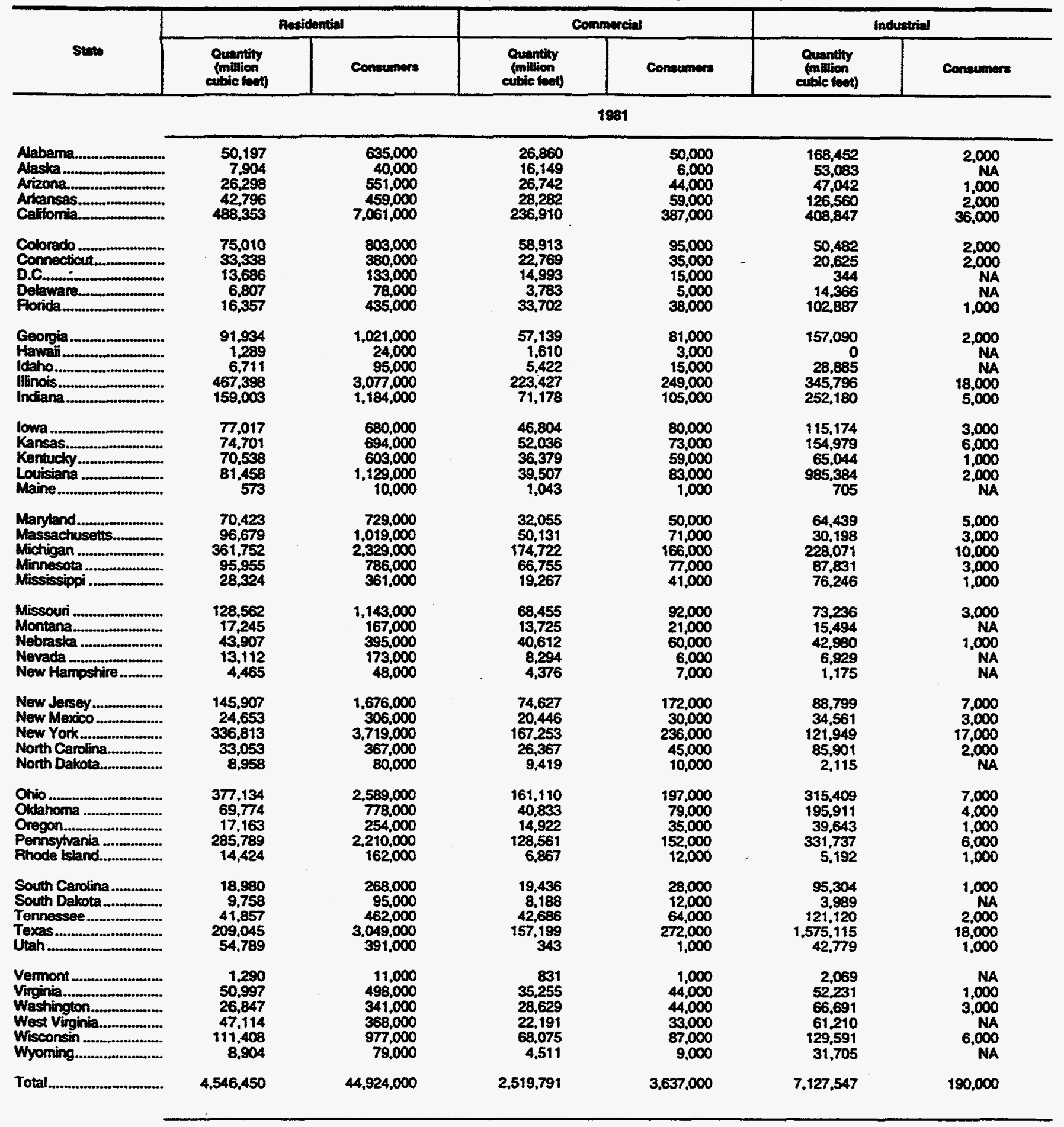


Table 16. Natural Gas Delivered to Consumers by State, 1967-1994 (Continued)

\begin{tabular}{|c|c|c|c|c|}
\hline \multirow[b]{2}{*}{ State } & Vohide Fuol & Electric Utiofites & \multirow{2}{*}{$\begin{array}{l}\text { Detivered to Consumers } \\
\text { Quentity } \\
\text { (inlition } \\
\text { cubic toet) }\end{array}$} & \multirow{2}{*}{$\begin{array}{l}\text { Hoating Value } \\
\text { (Btu por } \\
\text { cubic } \\
\text { foot) }\end{array}$} \\
\hline & $\begin{array}{l}\text { Quantity } \\
\text { (million } \\
\text { cubic toet) }\end{array}$ & $\begin{array}{l}\text { Qumitity } \\
\text { (million } \\
\text { cubic foot) }\end{array}$ & & \\
\hline & \multicolumn{4}{|c|}{1881} \\
\hline 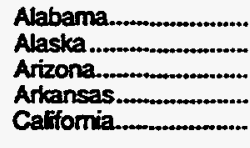 & $\begin{array}{l}\text { NA } \\
\text { NA } \\
\text { NA } \\
\text { NA } \\
\text { NA }\end{array}$ & $\begin{array}{r}1,780 \\
29,071 \\
57,911 \\
54,915 \\
655,334\end{array}$ & $\begin{array}{r}247,289 \\
106,207 \\
157,993 \\
252,553 \\
1,789,444\end{array}$ & $\begin{array}{l}1,036 \\
1,004 \\
1,053 \\
1,001 \\
1,048\end{array}$ \\
\hline 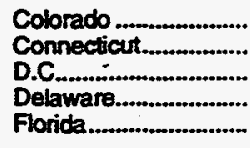 & $\begin{array}{l}\text { NA } \\
\text { NA } \\
\text { NA } \\
\text { NA } \\
\text { NA }\end{array}$ & $\begin{array}{r}13,593 \\
0 \\
0 \\
5,684 \\
171,468\end{array}$ & $\begin{array}{r}197,998 \\
76,732 \\
29,023 \\
30,640 \\
324,414\end{array}$ & $\begin{array}{r}994 \\
1,025 \\
1,014 \\
1,035 \\
1,059\end{array}$ \\
\hline 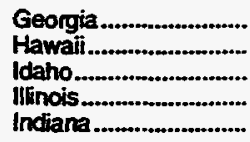 & $\begin{array}{l}\text { NA } \\
\text { NA } \\
\text { NA } \\
\text { NA } \\
\text { NA }\end{array}$ & $\begin{array}{r}2,786 \\
0 \\
16 \\
13,166 \\
5,309\end{array}$ & $\begin{array}{r}308,949 \\
2,899 \\
41,034 \\
1,049,787 \\
487,670\end{array}$ & $\begin{array}{r}1.027 \\
959 \\
1,070 \\
1.020 \\
993\end{array}$ \\
\hline $\begin{array}{l}\text { lowa } \\
\text { Kansas........... } \\
\text { Kentucky } \\
\text { Louisiana } \\
\text { Maine }\end{array}$ & $\begin{array}{l}\text { NA } \\
\text { NA } \\
\text { NA } \\
\text { NA } \\
\text { NA }\end{array}$ & $\begin{array}{r}3,362 \\
79,117 \\
2,589 \\
415,912 \\
0\end{array}$ & $\begin{array}{r}242,357 \\
360,833 \\
174,550 \\
1,522,261 \\
2,321\end{array}$ & $\begin{array}{r}1,003 \\
987 \\
1.014 \\
1,037 \\
1,025\end{array}$ \\
\hline 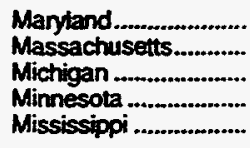 & $\begin{array}{l}\text { NA } \\
\text { NA } \\
\text { NA } \\
\text { NA } \\
\text { NA }\end{array}$ & $\begin{array}{r}5,998 \\
6,892 \\
19,230 \\
5,553 \\
74,559\end{array}$ & $\begin{array}{l}172,915 \\
183,900 \\
783,775 \\
256,094 \\
198,396\end{array}$ & $\begin{array}{r}1,014 \\
1,016 \\
1,017 \\
995 \\
1,025\end{array}$ \\
\hline 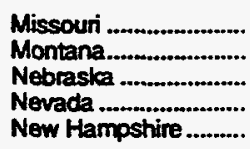 & $\begin{array}{l}\text { NA } \\
\text { NA } \\
\text { NA } \\
\text { NA } \\
\text { NA }\end{array}$ & $\begin{array}{r}7,661 \\
2,069 \\
4,560 \\
44,249 \\
138\end{array}$ & $\begin{array}{r}277,914 \\
48,533 \\
132,059 \\
72,584 \\
10,154\end{array}$ & $\begin{array}{r}1,015 \\
1,011 \\
978 \\
1,076 \\
1,022\end{array}$ \\
\hline 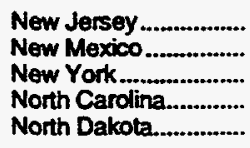 & $\begin{array}{l}\text { NA } \\
\text { NA } \\
\text { NA } \\
\text { NA } \\
\text { NA }\end{array}$ & $\begin{array}{r}80,125 \\
54,560 \\
130,507 \\
902 \\
20\end{array}$ & $\begin{array}{r}389,458 \\
134,220 \\
756,522 \\
146,223 \\
20,512\end{array}$ & $\begin{array}{l}1.034 \\
1,047 \\
1,020 \\
1.012 \\
1.042\end{array}$ \\
\hline 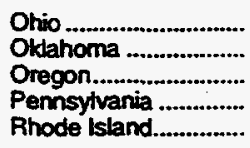 & $\begin{array}{l}\text { NA } \\
\text { NA } \\
\text { NA } \\
\text { NA } \\
\text { NA }\end{array}$ & $\begin{array}{r}2,051 \\
285,702 \\
186 \\
3,267 \\
2,603\end{array}$ & $\begin{array}{r}855,704 \\
592,220 \\
71,914 \\
749,354 \\
29,086\end{array}$ & $\begin{array}{l}1.023 \\
1,035 \\
1,044 \\
1,022 \\
1.022\end{array}$ \\
\hline 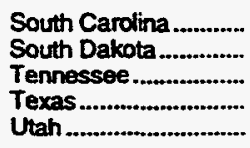 & $\begin{array}{l}\text { NA } \\
\text { NA } \\
\text { NA } \\
\text { NA } \\
\text { NA }\end{array}$ & $\begin{array}{r}5,008 \\
55 \\
316 \\
1,378,235 \\
3,097\end{array}$ & $\begin{array}{r}138,728 \\
21,990 \\
205,979 \\
3,319,594 \\
101.007\end{array}$ & $\begin{array}{l}1,023 \\
1,002 \\
1,016 \\
1,032 \\
1,073\end{array}$ \\
\hline 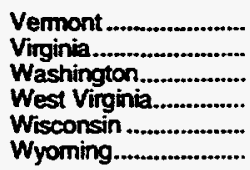 & $\begin{array}{l}\text { NA } \\
\text { NA } \\
\text { NA } \\
\text { NA } \\
\text { NA } \\
\text { NA }\end{array}$ & $\begin{array}{r}193 \\
2,180 \\
491 \\
198 \\
7.427 \\
108\end{array}$ & $\begin{array}{r}4,383 \\
140,663 \\
122,658 \\
130,713 \\
316,501 \\
45,228\end{array}$ & $\begin{array}{r}993 \\
1,024 \\
1,050 \\
1,040 \\
1,009 \\
1,059\end{array}$ \\
\hline 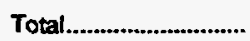 & NA & $3,640,154$ & $17,833,942$ & 1,027 \\
\hline
\end{tabular}

See footnotes at end of table. 
Table 16. Natural Gas Delivered to Consumers by State, 1967-1994 (Continued)

\begin{tabular}{|c|c|c|c|c|c|c|c|}
\hline \multirow[b]{2}{*}{ Stite } & \multicolumn{2}{|c|}{ Residamial } & \multicolumn{2}{|c|}{ Comsencial } & \multicolumn{3}{|c|}{ Industrial } \\
\hline & $\begin{array}{l}\text { Quentity } \\
\text { (maltion } \\
\text { cubie foet) }\end{array}$ & Consumere & $\begin{array}{c}\text { Quantity } \\
\text { (miltion } \\
\text { cubie foet) }\end{array}$ & Consumes: & $\begin{array}{l}\text { Quantity } \\
\text { (million } \\
\text { cubic tent) }\end{array}$ & Consumers & \\
\hline & \multicolumn{7}{|c|}{1982} \\
\hline 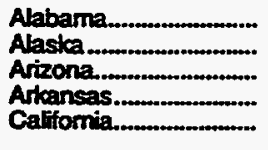 & $\begin{array}{r}46,950 \\
10,554 \\
29,449 \\
44,832 \\
537,194\end{array}$ & $\begin{array}{r}635,000 \\
48,000 \\
516,000 \\
456,000 \\
7,084,000\end{array}$ & $\begin{array}{r}25,876 \\
24,232 \\
26,085 \\
29,438 \\
236,202\end{array}$ & $\begin{array}{r}50,000 \\
7,000 \\
45,000 \\
58,000 \\
391,000\end{array}$ & $\begin{array}{r}145,922 \\
77,621 \\
29,716 \\
105,474 \\
340,307\end{array}$ & $\begin{array}{r}2,000 \\
\mathrm{NA} \\
1,000 \\
2,000 \\
36,000\end{array}$ & \\
\hline 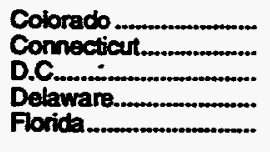 & $\begin{array}{r}84,688 \\
33,056 \\
13,041 \\
6,677 \\
13,622\end{array}$ & $\begin{array}{r}810,000 \\
380,000 \\
132,000 \\
79,000 \\
436,000\end{array}$ & $\begin{array}{r}66,991 \\
23,125 \\
15,881 \\
3,577 \\
29,788\end{array}$ & $\begin{array}{r}96,000 \\
26,000 \\
15,000 \\
5,000 \\
38,000\end{array}$ & $\begin{array}{r}44,758 \\
21,410 \\
0 \\
12,343 \\
84,195\end{array}$ & $\begin{array}{r}2,000 \\
2,000 \\
N A \\
N A \\
1,000\end{array}$ & \\
\hline 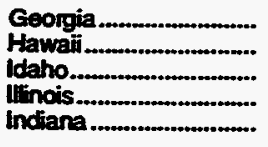 & $\begin{array}{r}86,822 \\
1,197 \\
6,861 \\
458,572 \\
160,066\end{array}$ & $\begin{array}{r}1,027,000 \\
24,000 \\
96,000 \\
3,057,000 \\
1,180,000\end{array}$ & $\begin{array}{r}54,718 \\
1,607 \\
5,729 \\
218,751 \\
71,900\end{array}$ & $\begin{array}{r}82,000 \\
3,000 \\
15,000 \\
247,000 \\
106,000\end{array}$ & $\begin{array}{r}144,414 \\
0 \\
24,275 \\
286,835 \\
224,443\end{array}$ & $\begin{array}{r}2,000 \\
N A \\
N A \\
18,000 \\
5,000\end{array}$ & \\
\hline 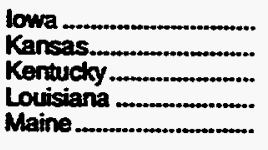 & $\begin{array}{r}84,791 \\
81,804 \\
67,590 \\
68,495 \\
585\end{array}$ & $\begin{array}{r}677,000 \\
691,000 \\
590,000 \\
1,002,000 \\
13,000\end{array}$ & $\begin{array}{r}51,536 \\
55,470 \\
35,260 \\
33,729 \\
1,192\end{array}$ & $\begin{array}{r}70,000 \\
74,000 \\
54,000 \\
71,000 \\
3,000\end{array}$ & $\begin{array}{r}89,401 \\
118,922 \\
55,074 \\
681,508 \\
840\end{array}$ & $\begin{array}{r}3,000 \\
6,000 \\
1,000 \\
2,000 \\
N A\end{array}$ & \\
\hline 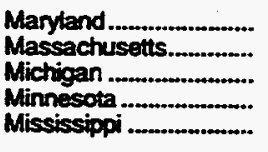 & $\begin{array}{r}67,500 \\
97,633 \\
358,778 \\
107,660 \\
27,516\end{array}$ & $\begin{array}{r}729,000 \\
1,016,000 \\
2,324,000 \\
786,000 \\
363,000\end{array}$ & $\begin{array}{r}30,871 \\
61,286 \\
170,269 \\
74,309 \\
17,213\end{array}$ & $\begin{array}{r}50,000 \\
78,000 \\
163,000 \\
77,000 \\
42,000\end{array}$ & $\begin{array}{r}56,200 \\
19,299 \\
183,276 \\
68,116 \\
96,932\end{array}$ & $\begin{array}{r}5,000 \\
3,000 \\
10,000 \\
3,000 \\
1,000\end{array}$ & \\
\hline 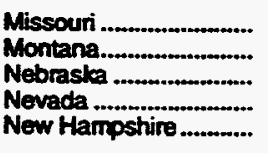 & $\begin{array}{r}135,984 \\
19,989 \\
51,381 \\
15,983 \\
4,526\end{array}$ & $\begin{array}{r}1,131,000 \\
166,000 \\
394,000 \\
178,000 \\
45,000\end{array}$ & $\begin{array}{r}69,913 \\
15,987 \\
43,022 \\
8,449 \\
4,414\end{array}$ & $\begin{array}{r}91,000 \\
21,000 \\
43,000 \\
6,000 \\
6,000\end{array}$ & $\begin{array}{r}64,559 \\
11,574 \\
36,977 \\
6,183 \\
1,053\end{array}$ & $\begin{array}{r}3,000 \\
\text { NA } \\
1,000 \\
\text { NA } \\
\text { NA }\end{array}$ & \\
\hline $\begin{array}{l}\text { New Jersey................... } \\
\text { New Mexico ................. } \\
\text { New York.................... } \\
\text { North Carolina.............. } \\
\text { North Dakota................ }\end{array}$ & $\begin{array}{r}148,845 \\
26,429 \\
343,029 \\
31,588 \\
10,932\end{array}$ & $\begin{array}{r}1,688,000 \\
308,000 \\
3,719,000 \\
352,000 \\
80,000\end{array}$ & $\begin{array}{r}78,750 \\
21,715 \\
164,784 \\
24,891 \\
11,361\end{array}$ & $\begin{array}{r}176,000 \\
34,000 \\
238,000 \\
44,000 \\
11,000\end{array}$ & $\begin{array}{r}81,603 \\
20,694 \\
110,275 \\
78,927 \\
2,064\end{array}$ & $\begin{array}{r}7,000 \\
\mathrm{NA} \\
20,000 \\
3,000 \\
\mathrm{NA}\end{array}$ & \\
\hline $\begin{array}{l}\text { Ohio ............................... } \\
\text { Oktahoma ...................... } \\
\text { Oregon............................ } \\
\text { Pennsyhania ................ } \\
\text { Rhode Island................ }\end{array}$ & $\begin{array}{r}369,437 \\
79,528 \\
18,712 \\
272,433 \\
14,823\end{array}$ & $\begin{array}{r}2,561,000 \\
796,000 \\
251,000 \\
2,210,000 \\
163,000\end{array}$ & $\begin{array}{r}157,654 \\
45,664 \\
16,330 \\
125,557 \\
7,156\end{array}$ & $\begin{array}{r}197,000 \\
83,000 \\
35,000 \\
151,000 \\
12,000\end{array}$ & $\begin{array}{r}267,632 \\
184,366 \\
32,338 \\
260,637 \\
4,929\end{array}$ & $\begin{array}{l}7,000 \\
3,000 \\
1,000 \\
6,000 \\
1,000\end{array}$ & \\
\hline 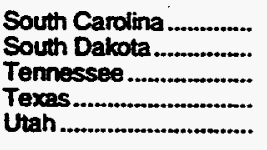 & $\begin{array}{r}17.548 \\
11,584 \\
42,023 \\
221,383 \\
45,957\end{array}$ & $\begin{array}{r}267,000 \\
95,000 \\
464,000 \\
3,067,000 \\
268,000\end{array}$ & $\begin{array}{r}15,560 \\
9,384 \\
38,697 \\
189,447 \\
21,831\end{array}$ & $\begin{array}{r}28,000 \\
12,000 \\
65,000 \\
276,000 \\
125,000\end{array}$ & $\begin{array}{r}61,595 \\
3,912 \\
109,800 \\
1,246,685 \\
39,804\end{array}$ & $\begin{array}{r}1,000 \\
N A \\
2,000 \\
16,000 \\
1,000\end{array}$ & \\
\hline 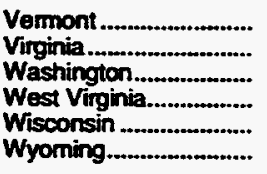 & $\begin{array}{r}1,278 \\
48.253 \\
29.143 \\
43.002 \\
118,145 \\
15.165\end{array}$ & $\begin{array}{r}11,000 \\
501,000 \\
340,000 \\
362,000 \\
978,000 \\
118,000\end{array}$ & $\begin{array}{r}853 \\
38,157 \\
30,559 \\
20,548 \\
69,694 \\
10,098\end{array}$ & $\begin{array}{r}1,000 \\
44,000 \\
45,000 \\
32,000 \\
86,000 \\
15,000\end{array}$ & $\begin{array}{r}2,128 \\
50,410 \\
47,119 \\
46,539 \\
+15,882 \\
32,201\end{array}$ & $\begin{array}{r}\text { NA } \\
1,000 \\
3,000 \\
\text { NA } \\
7,000 \\
\text { NA }\end{array}$ & \\
\hline 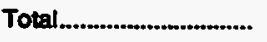 & $4,633,035$ & $44,667,000$ & $2,605,523$ & $3,742,000$ & $5,831,170$ & 189,000 & \\
\hline
\end{tabular}


Table 16. Natural Gas Delivered to Consumers by State, 1967-1994 (Continued)

\begin{tabular}{|c|c|c|c|c|}
\hline \multirow[b]{2}{*}{ Stato } & Vehicto Fuel & Electric Unilities & \multirow{2}{*}{$\begin{array}{l}\text { Delivered to Consumers } \\
\text { Ouanntity } \\
\text { (million } \\
\text { cubic foot) }\end{array}$} & \multirow{2}{*}{$\begin{array}{l}\text { Heating Value } \\
\text { (Btus per } \\
\text { cubic } \\
\text { tool) }\end{array}$} \\
\hline & $\begin{array}{l}\text { Quantity } \\
\text { (million } \\
\text { cutbie feet) }\end{array}$ & $\begin{array}{l}\text { Quantily } \\
\text { (million } \\
\text { cubic fect) }\end{array}$ & & \\
\hline & \multicolumn{4}{|c|}{$1982^{\circ}$} \\
\hline 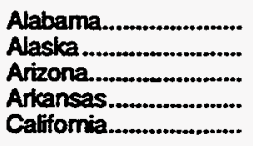 & $\begin{array}{l}\text { NA } \\
\text { NA } \\
\text { NA } \\
\text { NA } \\
\text { NA }\end{array}$ & $\begin{array}{r}1,339 \\
30,988 \\
31,286 \\
33,443 \\
533,832\end{array}$ & $\begin{array}{r}220,087 \\
143,395 \\
116,536 \\
213,187 \\
1,647,535\end{array}$ & $\begin{array}{l}1,052 \\
1,000 \\
1,054 \\
1,002 \\
1,049\end{array}$ \\
\hline 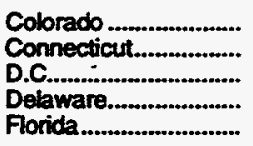 & $\begin{array}{l}\text { NA } \\
\text { NA } \\
\text { NA } \\
\text { NA } \\
\text { NA }\end{array}$ & $\begin{array}{r}6,045 \\
0 \\
0 \\
5,202 \\
182,471\end{array}$ & $\begin{array}{r}202,482 \\
77,591 \\
28,922 \\
27,799 \\
310,076\end{array}$ & $\begin{array}{l}1,000 \\
1,027 \\
1,017 \\
1,033 \\
1,044\end{array}$ \\
\hline 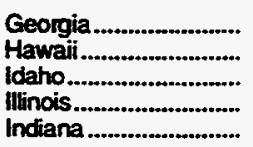 & $\begin{array}{l}\text { NA } \\
\text { NA } \\
\text { NA } \\
\text { NA } \\
\text { NA }\end{array}$ & $\begin{array}{r}1,509 \\
0 \\
5 \\
10,387 \\
2,705\end{array}$ & $\begin{array}{r}287,463 \\
2,804 \\
36,870 \\
974,545 \\
459,114\end{array}$ & $\begin{array}{r}1,030 \\
989 \\
1,072 \\
1,022 \\
1,016\end{array}$ \\
\hline $\begin{array}{l}\text { lowa } \\
\text { Kansas } \\
\text { Kentucky } \\
\text { Louisiana } \\
\text { Maine }\end{array}$ & $\begin{array}{l}\text { NA } \\
\text { NA } \\
\text { NA } \\
\text { NA } \\
\text { NA }\end{array}$ & $\begin{array}{r}2,501 \\
61,063 \\
1,522 \\
372,632 \\
0\end{array}$ & $\begin{array}{r}228,229 \\
317,259 \\
159,446 \\
1,156,364 \\
2,617\end{array}$ & $\begin{array}{r}1,008 \\
999 \\
1,014 \\
1,047 \\
1,025\end{array}$ \\
\hline 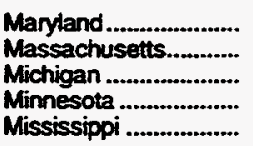 & $\begin{array}{l}\text { NA } \\
\text { NA } \\
\text { NA } \\
\text { NA } \\
\text { NA }\end{array}$ & $\begin{array}{r}936 \\
15,288 \\
12,727 \\
3,274 \\
83,196\end{array}$ & $\begin{array}{l}155,507 \\
193,506 \\
725,050 \\
253,359 \\
224,857\end{array}$ & $\begin{array}{l}1,018 \\
1,024 \\
1,022 \\
1,005 \\
1,028\end{array}$ \\
\hline 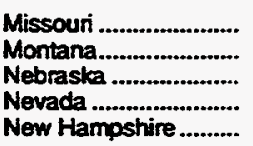 & $\begin{array}{l}\text { NA } \\
\text { NA } \\
\text { NA } \\
\text { NA } \\
\text { NA }\end{array}$ & $\begin{array}{r}4.441 \\
337 \\
1,553 \\
15,688 \\
0\end{array}$ & $\begin{array}{r}274,897 \\
47,887 \\
132,933 \\
46,303 \\
9,993\end{array}$ & $\begin{array}{r}1,018 \\
1,011 \\
981 \\
1,070 \\
1,020\end{array}$ \\
\hline 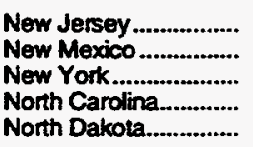 & $\begin{array}{l}\text { NA } \\
\text { NA } \\
\text { NA } \\
\text { NA } \\
\text { NA }\end{array}$ & $\begin{array}{r}65,504 \\
44,726 \\
152,577 \\
76 \\
17\end{array}$ & $\begin{array}{r}374,702 \\
113,564 \\
770,665 \\
135,482 \\
24,374\end{array}$ & $\begin{array}{l}1,031 \\
1,045 \\
1,023 \\
1,033 \\
1,026\end{array}$ \\
\hline 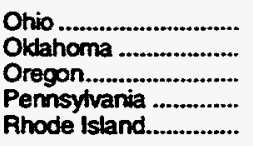 & $\begin{array}{l}\text { NA } \\
\text { NA } \\
\text { NA } \\
\text { NA } \\
\text { NA }\end{array}$ & $\begin{array}{r}1,230 \\
246,923 \\
32 \\
1,568 \\
794\end{array}$ & $\begin{array}{r}795,963 \\
556,481 \\
67,412 \\
660,195 \\
27,702\end{array}$ & $\begin{array}{l}1,029 \\
1,023 \\
1,044 \\
1,028 \\
1,036\end{array}$ \\
\hline 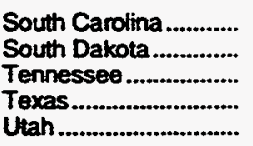 & $\begin{array}{l}\text { NA } \\
\text { NA } \\
\text { NA } \\
\text { NA } \\
\text { NA }\end{array}$ & $\begin{array}{r}517 \\
30 \\
0 \\
1,286,297 \\
3,023\end{array}$ & $\begin{array}{r}95.220 \\
24,910 \\
190,520 \\
2,943,812 \\
110,615\end{array}$ & $\begin{array}{r}1.030 \\
999 \\
1.024 \\
1,032 \\
939\end{array}$ \\
\hline 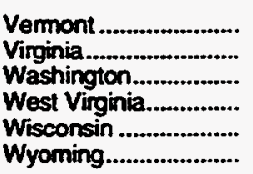 & $\begin{array}{l}\text { NA } \\
\text { NA } \\
\text { NA } \\
\text { NA } \\
\text { NA } \\
\text { NA }\end{array}$ & $\begin{array}{r}107 \\
3,020 \\
121 \\
131 \\
4,318 \\
133\end{array}$ & $\begin{array}{r}4,366 \\
139,840 \\
106,942 \\
110,220 \\
308,039 \\
57,597\end{array}$ & $\begin{array}{r}993 \\
1.027 \\
1,053 \\
1,047 \\
1,012 \\
1,002\end{array}$ \\
\hline 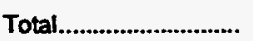 & NA & $3.225,518$ & $16,295,245$ & 1,028 \\
\hline
\end{tabular}

See lootnotes at end of table. 
Table 16. Natural Gas Delivered to Consumers by State, 1967-1994 (Continued)

\begin{tabular}{|c|c|c|c|c|c|c|}
\hline \multirow[b]{2}{*}{ State } & \multicolumn{2}{|c|}{ Reatidential } & \multicolumn{2}{|c|}{ Commereial } & \multicolumn{2}{|c|}{ Industrial } \\
\hline & $\begin{array}{l}\text { Quantity } \\
\text { (million } \\
\text { cubic fant) }\end{array}$ & Consermes: & $\begin{array}{l}\text { Qunntity } \\
\text { (million } \\
\text { cubic fot) }\end{array}$ & Consumers & $\begin{array}{l}\text { Quantity } \\
\text { (miltion } \\
\text { cubic faet) }\end{array}$ & Consumers \\
\hline & \multicolumn{6}{|c|}{1983} \\
\hline 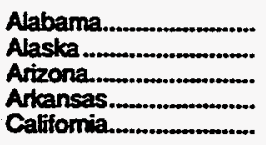 & $\begin{array}{r}48,267 \\
10,434 \\
29,255 \\
42,783 \\
498,601\end{array}$ & $\begin{array}{r}637,000 \\
55,000 \\
552,000 \\
460,000 \\
7,156,000\end{array}$ & $\begin{array}{r}26,665 \\
24,693 \\
24,612 \\
27,739 \\
215,918\end{array}$ & $\begin{array}{r}50,000 \\
8,000 \\
46,000 \\
58,000 \\
398,000\end{array}$ & $\begin{array}{r}128,201 \\
74,641 \\
29,731 \\
90,282 \\
322,990\end{array}$ & $\begin{array}{r}2,000 \\
N A \\
1,000 \\
2,000 \\
36,000\end{array}$ \\
\hline 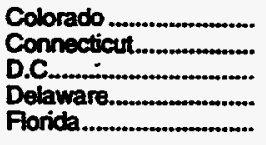 & $\begin{array}{r}84,173 \\
30,916 \\
13,007 \\
6,219 \\
15,372\end{array}$ & $\begin{array}{r}834,000 \\
384,000 \\
131,000 \\
78,000 \\
439,000\end{array}$ & $\begin{array}{r}64,615 \\
22,260 \\
15,945 \\
3,428 \\
29,228\end{array}$ & $\begin{array}{r}98,000 \\
35,000 \\
15,000 \\
5,000 \\
38,000\end{array}$ & $\begin{array}{r}42,386 \\
21,035 \\
0 \\
20,203 \\
74,210\end{array}$ & $\begin{array}{r}2,000 \\
2,000 \\
\text { NA } \\
\text { NA } \\
1,000\end{array}$ \\
\hline 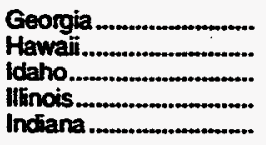 & $\begin{array}{r}91,376 \\
1,121 \\
6,510 \\
430,606 \\
145,255\end{array}$ & $\begin{array}{r}1,057,000 \\
24,000 \\
96,000 \\
3,061,000 \\
1,187,000\end{array}$ & $\begin{array}{r}56,280 \\
1,548 \\
5,758 \\
204,834 \\
65,409\end{array}$ & $\begin{array}{r}84,000 \\
4,000 \\
15,000 \\
249,000 \\
107,000\end{array}$ & $\begin{array}{r}140,285 \\
0 \\
20,135 \\
276,533 \\
207,711\end{array}$ & $\begin{array}{r}3,000 \\
N A \\
N A \\
18,000 \\
5,000\end{array}$ \\
\hline 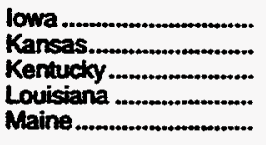 & $\begin{array}{r}77,323 \\
80,538 \\
63,049 \\
68,304 \\
541\end{array}$ & $\begin{array}{l}681,000 \\
696,000 \\
588,000 \\
990,000 \\
13,000\end{array}$ & $\begin{array}{r}46,854 \\
52,535 \\
34,111 \\
34,906 \\
1,124\end{array}$ & $\begin{array}{r}80,000 \\
74,000 \\
59,000 \\
71,000 \\
3,000\end{array}$ & $\begin{array}{r}85,161 \\
95,963 \\
52,831 \\
690,409 \\
754\end{array}$ & $\begin{array}{r}3,000 \\
6,000 \\
1,000 \\
2,000 \\
\text { NA }\end{array}$ \\
\hline 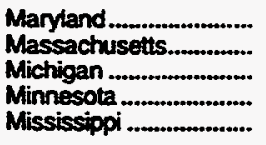 & $\begin{array}{r}64,716 \\
91,788 \\
340,732 \\
97,615 \\
27,552\end{array}$ & $\begin{array}{r}733,000 \\
1,025,000 \\
2,330,000 \\
800,000 \\
363,000\end{array}$ & $\begin{array}{r}30,758 \\
39,640 \\
159,916 \\
70,713 \\
17,158\end{array}$ & $\begin{array}{r}50,000 \\
75,000 \\
164,000 \\
79,000 \\
42,000\end{array}$ & $\begin{array}{r}46,253 \\
34,958 \\
167,186 \\
65,212 \\
108,739\end{array}$ & $\begin{array}{r}5,000 \\
5,000 \\
10,000 \\
3,000 \\
1,000\end{array}$ \\
\hline 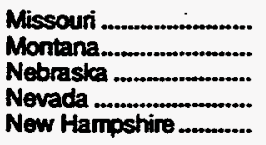 & $\begin{array}{r}126,604 \\
16,967 \\
47,236 \\
11,427 \\
4,309\end{array}$ & $\begin{array}{r}1,130,000 \\
167,000 \\
398,000 \\
173,000 \\
46,000\end{array}$ & $\begin{array}{r}66,106 \\
13,534 \\
39,055 \\
11,758 \\
4,437\end{array}$ & $\begin{array}{r}91,000 \\
21,000 \\
59,000 \\
15,000 \\
7,000\end{array}$ & $\begin{array}{r}59,307 \\
11,798 \\
37,262 \\
9,083 \\
869\end{array}$ & $\begin{array}{r}3,000 \\
\text { NA } \\
1,000 \\
\text { NA } \\
\text { NA }\end{array}$ \\
\hline 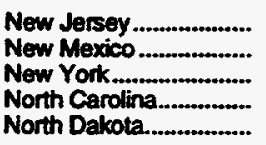 & $\begin{array}{r}146,674 \\
26,593 \\
321,949 \\
31,228 \\
9,685\end{array}$ & $\begin{array}{r}1,689,000 \\
315,000 \\
3,721,000 \\
364,000 \\
82,000\end{array}$ & $\begin{array}{r}79,624 \\
22,413 \\
161,770 \\
24,705 \\
9,828\end{array}$ & $\begin{array}{r}178,000 \\
34,000 \\
244,000 \\
46,000 \\
11,000\end{array}$ & $\begin{array}{r}81,214 \\
21,095 \\
96,958 \\
74,696 \\
1,844\end{array}$ & $\begin{array}{r}7,000 \\
2,000 \\
18,000 \\
3,000 \\
\mathrm{NA}\end{array}$ \\
\hline 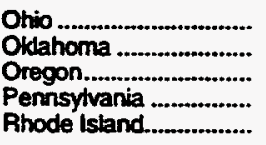 & $\begin{array}{r}329,647 \\
79,240 \\
16,779 \\
252,280 \\
13,749\end{array}$ & $\begin{array}{r}2,562,000 \\
826,000 \\
252,000 \\
2,215,000 \\
164,000\end{array}$ & $\begin{array}{r}143,568 \\
44,177 \\
15,143 \\
115,222 \\
6,976\end{array}$ & $\begin{array}{r}198,000 \\
86,000 \\
36,000 \\
151,000 \\
12,000\end{array}$ & $\begin{array}{r}258,425 \\
164,798 \\
32,119 \\
242,047 \\
5,080\end{array}$ & $\begin{array}{l}7,000 \\
3,000 \\
1,000 \\
6.000 \\
1,000\end{array}$ \\
\hline 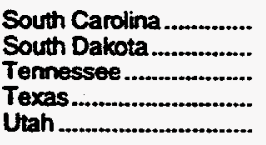 & $\begin{array}{r}18,741 \\
10,648 \\
40,596 \\
214,479 \\
54,938\end{array}$ & $\begin{array}{r}287,000 \\
96,000 \\
469,000 \\
3,093,000 \\
407,000\end{array}$ & $\begin{array}{r}16,548 \\
8,651 \\
42,903 \\
157,481 \\
7,986\end{array}$ & $\begin{array}{r}32,000 \\
12,000 \\
67,000 \\
457,000 \\
1,000\end{array}$ & $\begin{array}{r}62,767 \\
3,794 \\
100,002 \\
1,265,393 \\
40,246\end{array}$ & $\begin{array}{r}1,000 \\
N A \\
2,000 \\
15,000 \\
1,000\end{array}$ \\
\hline 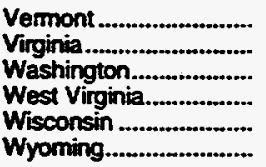 & $\begin{array}{r}1,252 \\
47,318 \\
25,998 \\
39,967 \\
112,316 \\
13,930\end{array}$ & $\begin{array}{l}11,000 \\
505,000 \\
343,000 \\
362,000 \\
987,000 \\
120,000\end{array}$ & $\begin{array}{r}856 \\
38,457 \\
28,728 \\
18,771 \\
68,020 \\
9,182\end{array}$ & $\begin{array}{r}1,000 \\
45,000 \\
45,000 \\
32,000 \\
86,000 \\
14,000\end{array}$ & $\begin{array}{r}2,026 \\
46,506 \\
50,883 \\
41,862 \\
112,495 \\
24,330\end{array}$ & $\begin{array}{r}\text { NA } \\
1.000 \\
3.000 \\
\text { NA } \\
7.000 \\
\text { NA }\end{array}$ \\
\hline 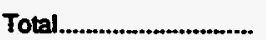 & $4,380,599$ & $45,153,000$ & $2,432,547$ & $3,890,000$ & $5,642,708$ & 190,000 \\
\hline
\end{tabular}


Table 16. Natural Gas Delivered to Consumers by State, 1967-1994 (Continued)

\begin{tabular}{|c|c|c|c|c|}
\hline \multirow[b]{2}{*}{ Stuto } & Vohicle Fuol & Electric Unifitios & \multirow{2}{*}{$\begin{array}{l}\text { Delivered to Consumere } \\
\text { Quantity } \\
\text { (milition } \\
\text { cubic foet) }\end{array}$} & \multirow{2}{*}{$\begin{array}{l}\text { Heating Value } \\
\text { (Btu por } \\
\text { cubic } \\
\text { foot) }\end{array}$} \\
\hline & $\begin{array}{l}\text { Quanntity } \\
\text { (milion } \\
\text { eubic tont) }\end{array}$ & $\begin{array}{l}\text { Quantity } \\
\text { (million } \\
\text { cubic tow) }\end{array}$ & & \\
\hline & \multicolumn{4}{|c|}{1983} \\
\hline 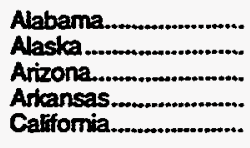 & $\begin{array}{l}\text { NA } \\
\text { NA } \\
\text { NA } \\
\text { NA } \\
\text { NA }\end{array}$ & $\begin{array}{r}554 \\
31,348 \\
19,209 \\
33,275 \\
465,066\end{array}$ & $\begin{array}{r}203,687 \\
141,116 \\
102,807 \\
194,079 \\
1,502,575\end{array}$ & $\begin{array}{l}1,038 \\
1,002 \\
1,045 \\
1,023 \\
1,043\end{array}$ \\
\hline 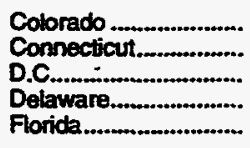 & $\begin{array}{l}\text { NA } \\
\text { NA } \\
\text { NA } \\
\text { NA } \\
\text { NA }\end{array}$ & $\begin{array}{r}4,526 \\
0 \\
0 \\
5,023 \\
174,813\end{array}$ & $\begin{array}{r}195,700 \\
74,211 \\
28,952 \\
34,873 \\
293,623\end{array}$ & $\begin{array}{l}1,006 \\
1,029 \\
1,010 \\
1,018 \\
1,048\end{array}$ \\
\hline 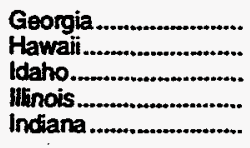 & $\begin{array}{l}\text { NA } \\
\text { NA } \\
\text { NA } \\
\text { NA } \\
\text { NA }\end{array}$ & $\begin{array}{r}1,633 \\
0 \\
9 \\
11,948 \\
2,877\end{array}$ & $\begin{array}{r}289,574 \\
2,669 \\
32,412 \\
923,921 \\
421,252\end{array}$ & $\begin{array}{l}1,026 \\
1,023 \\
1,047 \\
1,041 \\
1,006\end{array}$ \\
\hline 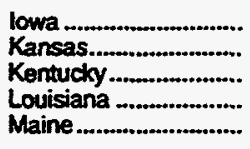 & $\begin{array}{l}\text { NA } \\
\text { NA } \\
\text { NA } \\
\text { NA } \\
\text { NA }\end{array}$ & $\begin{array}{r}3,249 \\
47,226 \\
1,196 \\
296,490 \\
0\end{array}$ & $\begin{array}{r}212,587 \\
276,262 \\
151,187 \\
1,090,109 \\
2,419\end{array}$ & $\begin{array}{r}1,014 \\
999 \\
1,020 \\
1,042 \\
1,026\end{array}$ \\
\hline 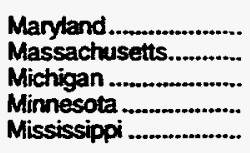 & $\begin{array}{l}\text { NA } \\
\text { NA } \\
\text { NA } \\
\text { NA } \\
\text { NA }\end{array}$ & $\begin{array}{r}1,800 \\
24,396 \\
12,618 \\
2,861 \\
49,773\end{array}$ & $\begin{array}{l}143,527 \\
190,782 \\
680,452 \\
236,401 \\
203,222\end{array}$ & $\begin{array}{l}1.021 \\
1,025 \\
1,024 \\
1,023 \\
1,027\end{array}$ \\
\hline 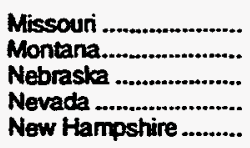 & $\begin{array}{l}\text { NA } \\
\text { NA } \\
\text { NA } \\
\text { NA } \\
\text { NA }\end{array}$ & $\begin{array}{r}2,806 \\
335 \\
1,581 \\
9,562 \\
20\end{array}$ & $\begin{array}{r}254,823 \\
42,634 \\
125,134 \\
41,830 \\
9,635\end{array}$ & $\begin{array}{r}1,027 \\
1,008 \\
982 \\
1,066 \\
1,021\end{array}$ \\
\hline 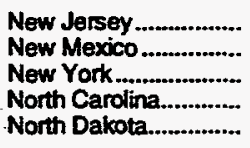 & $\begin{array}{l}\text { NA } \\
\text { NA } \\
\text { NA } \\
\text { NA } \\
\text { NA }\end{array}$ & $\begin{array}{r}96,886 \\
30,626 \\
135,811 \\
163 \\
11\end{array}$ & $\begin{array}{r}404,398 \\
100,727 \\
716,488 \\
130,792 \\
21,368\end{array}$ & $\begin{array}{l}1,031 \\
1,033 \\
1,027 \\
1,033 \\
1,045\end{array}$ \\
\hline 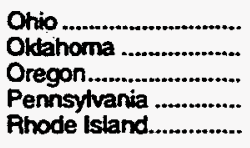 & $\begin{array}{l}\text { NA } \\
\text { NA } \\
\text { NA } \\
\text { NA } \\
\text { NA }\end{array}$ & $\begin{array}{r}1,046 \\
236,950 \\
1 \\
1,654 \\
3,079\end{array}$ & $\begin{array}{r}732,686 \\
525,165 \\
64,042 \\
611,203 \\
28,884\end{array}$ & $\begin{array}{l}1,034 \\
1,042 \\
1,041 \\
1,029 \\
1,035\end{array}$ \\
\hline 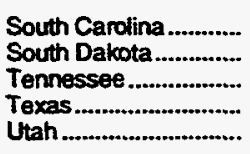 & $\begin{array}{l}\text { NA } \\
\text { NA } \\
\text { NA } \\
\text { NA } \\
\text { NA }\end{array}$ & $\begin{array}{r}942 \\
45 \\
107 \\
1.190,648 \\
1,259\end{array}$ & $\begin{array}{r}98,998 \\
23,138 \\
183,608 \\
2,828,001 \\
104,429\end{array}$ & $\begin{array}{l}1,027 \\
1,011 \\
1,023 \\
1,029 \\
1,075\end{array}$ \\
\hline 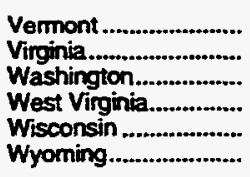 & $\begin{array}{l}\text { NA } \\
\text { NA } \\
\text { NA } \\
\text { NA } \\
\text { NA } \\
\text { NA }\end{array}$ & $\begin{array}{r}220 \\
3,330 \\
30 \\
115 \\
3,514 \\
136\end{array}$ & $\begin{array}{r}4,354 \\
135,611 \\
105,639 \\
100,715 \\
296,345 \\
47,578\end{array}$ & $\begin{array}{r}992 \\
1,030 \\
1,043 \\
1,038 \\
1,009 \\
1,059\end{array}$ \\
\hline 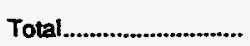 & NA & $2,910,767$ & $15,366,621$ & 1,031 \\
\hline
\end{tabular}

See footnotes at end of table. 
Table 16. Natural Gas Delivered to Consumers by State, 1967-1994 (Continued)

\begin{tabular}{|c|c|c|c|c|c|c|c|}
\hline \multirow[b]{2}{*}{ State } & \multicolumn{2}{|c|}{ Residential } & \multicolumn{2}{|c|}{ Commercia! } & \multicolumn{3}{|c|}{ Industrial } \\
\hline & $\begin{array}{l}\text { Quentity } \\
\text { (milition } \\
\text { cubic fint) }\end{array}$ & Contuners & $\begin{array}{l}\text { Qumpity } \\
\text { (million } \\
\text { cubicteet) }\end{array}$ & Consumers & $\begin{array}{l}\text { Qumntity } \\
\text { (miltion } \\
\text { eutic foet) }\end{array}$ & Consumers & \\
\hline & \multicolumn{7}{|c|}{1984} \\
\hline 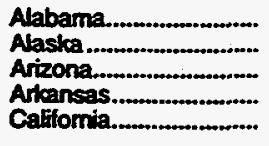 & $\begin{array}{r}50,526 \\
11,833 \\
27,606 \\
45,903 \\
472,151\end{array}$ & $\begin{array}{r}645,000 \\
63,000 \\
555,000 \\
464,000 \\
7,285,000\end{array}$ & $\begin{array}{r}27,567 \\
24,654 \\
25,309 \\
28,995 \\
191,838\end{array}$ & $\begin{array}{r}50,000 \\
10,000 \\
46,000 \\
59,000 \\
399,000\end{array}$ & $\begin{array}{r}135,058 \\
72,465 \\
29,154 \\
93,835 \\
396,133\end{array}$ & $\begin{array}{r}2,000 \\
N A \\
1,000 \\
2,000 \\
34,000\end{array}$ & \\
\hline 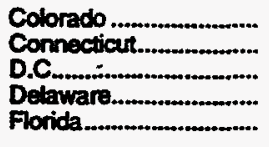 & $\begin{array}{r}93,439 \\
33,062 \\
17,374 \\
6,855 \\
14,866\end{array}$ & $\begin{array}{r}867,000 \\
388,000 \\
134,000 \\
79,000 \\
434,000\end{array}$ & $\begin{array}{r}71,890 \\
24,778 \\
11,680 \\
3,827 \\
30,481\end{array}$ & $\begin{array}{r}101,000 \\
36,000 \\
11,000 \\
5,000 \\
39,000\end{array}$ & $\begin{array}{r}41,523 \\
20,855 \\
0 \\
25,216 \\
71,041\end{array}$ & $\begin{array}{r}1,000 \\
2,000 \\
N A \\
N A \\
1,000\end{array}$ & \\
\hline 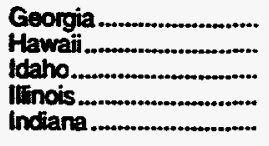 & $\begin{array}{r}95,299 \\
1,048 \\
7,339 \\
479,572 \\
151,568\end{array}$ & $\begin{array}{r}1,093,000 \\
27,000 \\
98,000 \\
3,069,000 \\
1,196,000\end{array}$ & $\begin{array}{r}55,909 \\
1,328 \\
8,493 \\
232,170 \\
71,819\end{array}$ & $\begin{array}{r}87,000 \\
3,000 \\
16,000 \\
251,000 \\
109,000\end{array}$ & $\begin{array}{r}149,517 \\
0 \\
19,140 \\
299,474 \\
221,372\end{array}$ & $\begin{array}{r}3,000 \\
N A \\
N A \\
18,000 \\
5,000\end{array}$ & \\
\hline 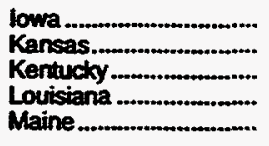 & $\begin{array}{r}79,767 \\
79,340 \\
66,895 \\
69,529 \\
540\end{array}$ & $\begin{array}{r}682,000 \\
701,000 \\
588,000 \\
979,000 \\
12,000\end{array}$ & $\begin{array}{r}48,104 \\
57,516 \\
36,138 \\
33,088 \\
1,124\end{array}$ & $\begin{array}{r}80,000 \\
77,000 \\
59,000 \\
71,000 \\
3,000\end{array}$ & $\begin{array}{r}93,373 \\
118,238 \\
58,186 \\
838,377 \\
781\end{array}$ & $\begin{array}{r}3,000 \\
5,000 \\
1,000 \\
2,000 \\
N A\end{array}$ & \\
\hline 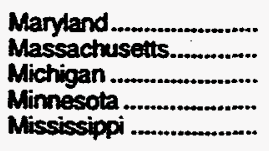 & $\begin{array}{r}73,012 \\
96,817 \\
338,996 \\
101,910 \\
28,760\end{array}$ & $\begin{array}{r}742,000 \\
1,035,000 \\
2,346,000 \\
810,000 \\
366,000\end{array}$ & $\begin{array}{r}25,299 \\
41,271 \\
160,952 \\
75,175 \\
17,860\end{array}$ & $\begin{array}{r}46,000 \\
73,000 \\
166,000 \\
80,000 \\
42,000\end{array}$ & $\begin{array}{r}57,265 \\
37,344 \\
189,014 \\
69,977 \\
119,538\end{array}$ & $\begin{array}{l}5,000 \\
6,000 \\
9,000 \\
2,000 \\
1,000\end{array}$ & \\
\hline 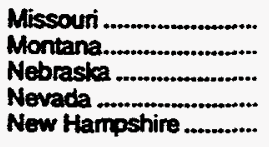 & $\begin{array}{r}130,683 \\
18,443 \\
47,834 \\
11,891 \\
4,613\end{array}$ & $\begin{array}{r}1,136,000 \\
168,000 \\
391,000 \\
177,000 \\
48,000\end{array}$ & $\begin{array}{r}67,218 \\
14,256 \\
41,900 \\
12,012 \\
4,100\end{array}$ & $\begin{array}{r}94,000 \\
21,000 \\
59,000 \\
16,000 \\
7,000\end{array}$ & $\begin{array}{r}59,502 \\
9,855 \\
38,517 \\
8,881 \\
1,726\end{array}$ & $\begin{array}{r}3,000 \\
\text { NA } \\
1,000 \\
\text { NA } \\
\text { NA }\end{array}$ & \\
\hline $\begin{array}{l}\text { New Jersey.................. } \\
\text { New Mexico ................... } \\
\text { New York.................. } \\
\text { North Cardina.............. } \\
\text { North Dakota.............. }\end{array}$ & $\begin{array}{r}151,755 \\
27,394 \\
337,253 \\
32,405 \\
9,974\end{array}$ & $\begin{array}{r}1,732,000 \\
324,000 \\
3,751,000 \\
391,000 \\
83,000\end{array}$ & $\begin{array}{r}83,906 \\
22,947 \\
170,365 \\
26,174 \\
9,961\end{array}$ & $\begin{array}{r}184,000 \\
35,000 \\
243,000 \\
49,000 \\
11,000\end{array}$ & $\begin{array}{r}84,868 \\
20,718 \\
107,004 \\
79,527 \\
5,165\end{array}$ & $\begin{array}{r}7,000 \\
2,000 \\
22,000 \\
3,000 \\
\text { NA }\end{array}$ & \\
\hline 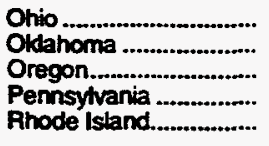 & $\begin{array}{r}350,296 \\
81,379 \\
19,495 \\
265,274 \\
15,041\end{array}$ & $\begin{array}{r}2,570,000 \\
830,000 \\
258,000 \\
2,216,000 \\
168,000\end{array}$ & $\begin{array}{r}155,350 \\
44,423 \\
17,012 \\
126,211 \\
7,466\end{array}$ & $\begin{array}{r}201,000 \\
87,000 \\
37,000 \\
154,000 \\
13,000\end{array}$ & $\begin{array}{r}260,755 \\
182,923 \\
39,450 \\
242,887 \\
5,390\end{array}$ & $\begin{array}{l}7,000 \\
3,000 \\
1,000 \\
6,000 \\
1,000\end{array}$ & \\
\hline 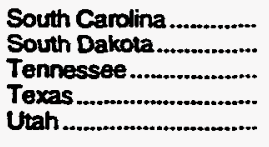 & $\begin{array}{r}19,246 \\
10,994 \\
44,045 \\
230,311 \\
54,639\end{array}$ & $\begin{array}{r}291,000 \\
97,000 \\
480,000 \\
3,127,000 \\
418,000\end{array}$ & $\begin{array}{r}16,635 \\
9,128 \\
46,544 \\
165,700 \\
8,569\end{array}$ & $\begin{array}{r}32,000 \\
12,000 \\
69,000 \\
285,000 \\
1,000\end{array}$ & $\begin{array}{r}69,526 \\
4,238 \\
102,900 \\
1,336,659 \\
42,709\end{array}$ & $\begin{array}{r}1,000 \\
N A \\
2,000 \\
15,000 \\
1,000\end{array}$ & \\
\hline 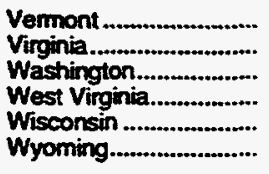 & $\begin{array}{r}1,352 \\
51,439 \\
29,242 \\
39,707 \\
112,952 \\
13,806\end{array}$ & $\begin{array}{r}12,000 \\
513,000 \\
351,000 \\
358,000 \\
999,000 \\
119,000\end{array}$ & $\begin{array}{r}1,467 \\
34,825 \\
32,371 \\
18,780 \\
70,230 \\
9,431\end{array}$ & $\begin{array}{l}2,000 \\
44,000 \\
46,000 \\
32,000 \\
88,000 \\
14,000\end{array}$ & $\begin{array}{r}1,771 \\
47,340 \\
62,790 \\
42,420 \\
116,981 \\
22,453\end{array}$ & $\begin{array}{r}\text { NA } \\
1,000 \\
3,000 \\
\text { NA } \\
7,000 \\
\text { NA }\end{array}$ & \\
\hline 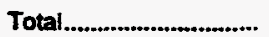 & $4,555,465$ & $45,670,000$ & $2,524,244$ & $3,755,000$ & $6,153,841$ & 189,000 & \\
\hline
\end{tabular}


Table 16. Natural Gas Delivered to Consumers by State, 1967-1994 (Continued)

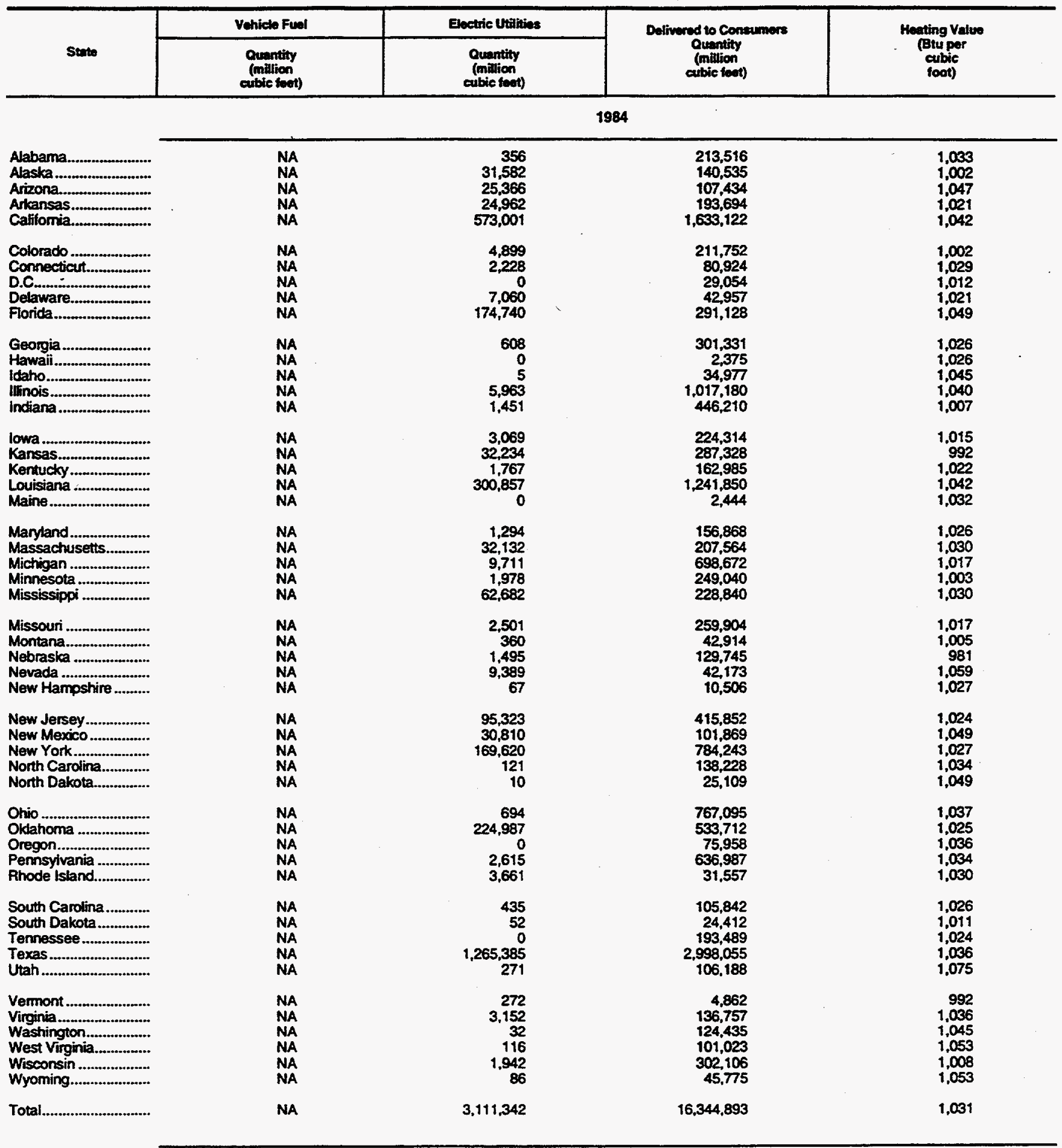

See footnotes at end of table. 
Table 16. Natural Gas Delivered to Consumers by State, 1967-1994 (Continued)

\begin{tabular}{|c|c|c|c|c|c|c|}
\hline \multirow[b]{2}{*}{$\operatorname{sen}$} & \multicolumn{2}{|c|}{ Residential } & \multicolumn{2}{|c|}{ Commercial } & \multicolumn{2}{|c|}{ Induetrial } \\
\hline & $\begin{array}{l}\text { Quantity } \\
\text { (million } \\
\text { cubic feet) }\end{array}$ & Consumers & $\begin{array}{l}\text { Quantity } \\
\text { (million } \\
\text { eubie fent) }\end{array}$ & Consumars & $\begin{array}{l}\text { Ouantity } \\
\text { (million } \\
\text { cubic teot) }\end{array}$ & Consumers \\
\hline & \multicolumn{6}{|c|}{1985} \\
\hline 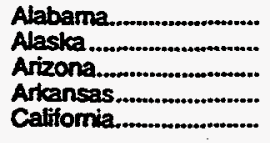 & $\begin{array}{r}43,706 \\
13,256 \\
28,634 \\
40,189 \\
527,495\end{array}$ & $\begin{array}{r}640,000 \\
65,000 \\
555,000 \\
470,000 \\
7,493,000\end{array}$ & $\begin{array}{r}25,836 \\
20,344 \\
25,360 \\
26,731 \\
205,044\end{array}$ & $\begin{array}{r}53,000 \\
10,000 \\
46,000 \\
60,000 \\
414,000\end{array}$ & $\begin{array}{r}132,281 \\
75,676 \\
16,503 \\
96,660 \\
407,585\end{array}$ & $\begin{array}{r}2,000 \\
N A \\
1,000 \\
2,000 \\
32,000\end{array}$ \\
\hline 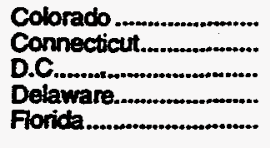 & $\begin{array}{r}90,154 \\
32,778 \\
16,605 \\
6,210 \\
13,533\end{array}$ & $\begin{array}{r}896,000 \\
394,000 \\
134,000 \\
80,000 \\
439,000\end{array}$ & $\begin{array}{r}68,975 \\
24,590 \\
11,921 \\
30,412 \\
30,674\end{array}$ & $\begin{array}{r}104,000 \\
37,000 \\
11,000 \\
5,000 \\
40,000\end{array}$ & $\begin{array}{r}36,934 \\
18,937 \\
0 \\
21,600 \\
68,776\end{array}$ & $\begin{array}{r}2,000 \\
3,000 \\
N A \\
N A \\
1,000\end{array}$ \\
\hline 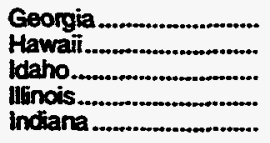 & $\begin{array}{r}84,033 \\
625 \\
7,759 \\
446,567 \\
146,251\end{array}$ & $\begin{array}{r}1,138,000 \\
27,000 \\
100,000 \\
3,084,000 \\
1,206,000\end{array}$ & $\begin{array}{r}51,519 \\
1,858 \\
8,999 \\
213,528 \\
69,641\end{array}$ & $\begin{array}{r}91,000 \\
3,000 \\
16,000 \\
256,000 \\
110,000\end{array}$ & $\begin{array}{r}140,009 \\
0 \\
19,461 \\
280,638 \\
211,115\end{array}$ & $\begin{array}{r}3,000 \\
N A \\
N A \\
18,000 \\
5,000\end{array}$ \\
\hline $\begin{array}{l}\text { lowra } \\
\text { Kansas } \\
\text { Kentucky } \\
\text { Louisiana } \\
\text { Maine }\end{array}$ & $\begin{array}{r}78,750 \\
78,350 \\
60,086 \\
60.679 \\
525\end{array}$ & $\begin{array}{r}682,000 \\
710,000 \\
588,000 \\
975,000 \\
12,000\end{array}$ & $\begin{array}{r}47,643 \\
56,522 \\
33,758 \\
30,228 \\
1,139\end{array}$ & $\begin{array}{r}81,000 \\
83,000 \\
60,000 \\
70,000 \\
3,000\end{array}$ & $\begin{array}{r}87,060 \\
118,847 \\
54,137 \\
710,060 \\
856\end{array}$ & $\begin{array}{l}3,000 \\
5,000 \\
1,000 \\
2,000 \\
\text { NA }\end{array}$ \\
\hline 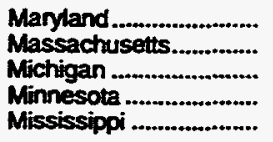 & $\begin{array}{r}68,399 \\
97,803 \\
341,026 \\
106,647 \\
25,714\end{array}$ & $\begin{array}{r}747,000 \\
1,049,000 \\
2,372,000 \\
822,000 \\
367,000\end{array}$ & $\begin{array}{r}24,134 \\
41,382 \\
157,758 \\
77,020 \\
16,591\end{array}$ & $\begin{array}{r}47,000 \\
75,000 \\
169.000 \\
82,000 \\
43,000\end{array}$ & $\begin{array}{r}54,684 \\
33,157 \\
181,583 \\
66,301 \\
99,174\end{array}$ & $\begin{array}{r}6.000 \\
6.000 \\
10.000 \\
2.000 \\
1,000\end{array}$ \\
\hline 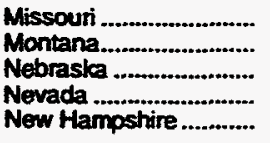 & $\begin{array}{r}128,123 \\
19,371 \\
46,674 \\
12,602 \\
4,698\end{array}$ & $\begin{array}{r}1,152,000 \\
168,000 \\
393,000 \\
184,000 \\
51,000\end{array}$ & $\begin{array}{r}60,345 \\
14,820 \\
39,404 \\
12,232 \\
4,955\end{array}$ & $\begin{array}{r}95,000 \\
21,000 \\
60,000 \\
16,000 \\
8,000\end{array}$ & $\begin{array}{r}65,702 \\
8,220 \\
33,134 \\
6,173 \\
892\end{array}$ & $\begin{array}{r}3,000 \\
N A \\
1,000 \\
N A \\
N A\end{array}$ \\
\hline 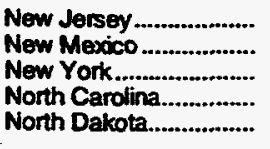 & $\begin{array}{r}150,911 \\
21,952 \\
320,073 \\
28,649 \\
10,353\end{array}$ & $\begin{array}{r}1,769,000 \\
335,000 \\
3,819,000 \\
407,000 \\
83,000\end{array}$ & $\begin{array}{r}83,467 \\
16,733 \\
165,498 \\
25,029 \\
10,118\end{array}$ & $\begin{array}{r}189,000 \\
36,000 \\
247,000 \\
51,000 \\
11,000\end{array}$ & $\begin{array}{r}81,242 \\
11,605 \\
99,829 \\
74,808 \\
2,209\end{array}$ & $\begin{array}{r}6,000 \\
2,000 \\
22,000 \\
3,000 \\
\text { NA }\end{array}$ \\
\hline 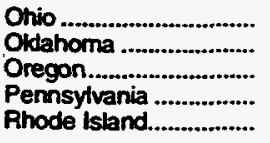 & $\begin{array}{r}327.591 \\
76.112 \\
21,478 \\
244,889 \\
14,992\end{array}$ & $\begin{array}{r}2.586,000 \\
829,000 \\
265,000 \\
2,221,000 \\
171,000\end{array}$ & $\begin{array}{r}143,311 \\
40,791 \\
19,043 \\
115,329 \\
7,590\end{array}$ & $\begin{array}{r}202,000 \\
88,000 \\
38,000 \\
156,000 \\
13,000\end{array}$ & $\begin{array}{r}247,792 \\
156,317 \\
37,776 \\
226,299 \\
4,619\end{array}$ & $\begin{array}{l}7,000 \\
3,000 \\
1,000 \\
6,000 \\
1,000\end{array}$ \\
\hline 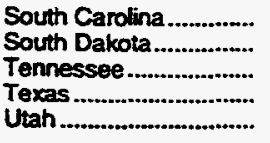 & $\begin{array}{r}16,434 \\
11,357 \\
39,434 \\
212,676 \\
58,727\end{array}$ & $\begin{array}{r}293,000 \\
99,000 \\
494,000 \\
3,148,000 \\
432,000\end{array}$ & $\begin{array}{r}15,270 \\
9,987 \\
43,399 \\
151,774 \\
8,505\end{array}$ & $\begin{array}{r}33,000 \\
12,000 \\
71,000 \\
288,000 \\
1,000\end{array}$ & $\begin{array}{r}63,038 \\
3,511 \\
97,109 \\
1,423,876 \\
37,448\end{array}$ & $\begin{array}{r}1,000 \\
\mathrm{NA} \\
2.000 \\
14,000 \\
1.000\end{array}$ \\
\hline 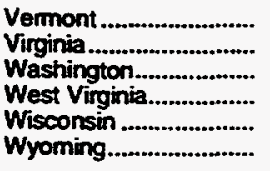 & $\begin{array}{r}1,456 \\
48,752 \\
33,000 \\
36,750 \\
116,184 \\
14,363\end{array}$ & $\begin{array}{r}13,000 \\
525,000 \\
360,000 \\
355,000 \\
1,013,000 \\
118,000\end{array}$ & $\begin{array}{r}1,575 \\
33,975 \\
35,459 \\
17,224 \\
72,803 \\
9,139\end{array}$ & $\begin{array}{r}2,000 \\
46,000 \\
47,000 \\
31,000 \\
90,000 \\
14,000\end{array}$ & $\begin{array}{r}1,867 \\
50,334 \\
63,176 \\
38,122 \\
115,257 \\
18,861\end{array}$ & $\begin{array}{r}\text { NA } \\
1,000 \\
3,000 \\
N A \\
7,000 \\
N A\end{array}$ \\
\hline Total.......................... & $4,433,377$ & $46,331,000$ & $2,432,382$ & $3,837,000$ & $5,901,288$ & 189,000 \\
\hline
\end{tabular}

See foctnotes at end of table. 
Table 16. Natural Gas Delivered to Consumers by State, 1967-1994 (Continued)

\begin{tabular}{|c|c|c|c|c|}
\hline \multirow[b]{2}{*}{ sento } & Vohich Fuel & Electric Utilities & \multirow{2}{*}{$\begin{array}{l}\text { Delivered to Consumers } \\
\text { Quanntity } \\
\text { (million } \\
\text { cubic feet) }\end{array}$} & \multirow{2}{*}{$\begin{array}{l}\text { Heoting Vatue } \\
\text { (Btup per } \\
\text { cubic } \\
\text { foot) }\end{array}$} \\
\hline & $\begin{array}{l}\text { Quentity } \\
\text { (milion } \\
\text { cubic toet) }\end{array}$ & $\begin{array}{l}\text { Quantity } \\
\text { (million } \\
\text { cutbic feot) }\end{array}$ & & \\
\hline & \multicolumn{4}{|c|}{1985} \\
\hline 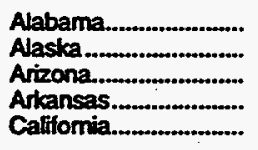 & $\begin{array}{l}\text { NA } \\
\text { NA } \\
\text { NA } \\
\text { NA } \\
\text { NA }\end{array}$ & $\begin{array}{r}1,078 \\
34,194 \\
41,731 \\
11,411 \\
666,274\end{array}$ & $\begin{array}{r}202,901 \\
143,470 \\
112,228 \\
174,991 \\
1,806,398\end{array}$ & $\begin{array}{l}1,038 \\
1,006 \\
1,050 \\
1,019 \\
1,043\end{array}$ \\
\hline 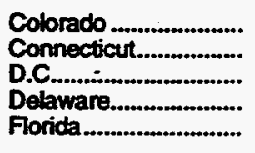 & $\begin{array}{l}\text { NA } \\
\text { NA } \\
\text { NA } \\
\text { NA } \\
\text { NA }\end{array}$ & $\begin{array}{r}4,913 \\
1,559 \\
0 \\
7,266 \\
165,683\end{array}$ & $\begin{array}{r}200,976 \\
77,864 \\
28,526 \\
38,488 \\
278,666\end{array}$ & $\begin{array}{r}999 \\
1,030 \\
1,015 \\
1,025 \\
1,053\end{array}$ \\
\hline 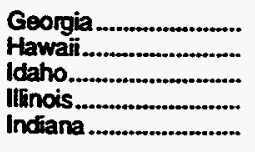 & $\begin{array}{l}\text { NA } \\
\text { NA } \\
\text { NA } \\
\text { NA } \\
\text { NA }\end{array}$ & $\begin{array}{r}885 \\
0 \\
24 \\
5,881 \\
1,117\end{array}$ & $\begin{array}{r}276,446 \\
2,483 \\
36,243 \\
946,614 \\
428,124\end{array}$ & $\begin{array}{l}1.028 \\
1.082 \\
1.049 \\
1.040 \\
1.008\end{array}$ \\
\hline 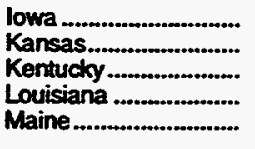 & $\begin{array}{l}\text { NA } \\
\text { NA } \\
\text { NA } \\
\text { NA } \\
\text { NA }\end{array}$ & $\begin{array}{r}2,100 \\
21,181 \\
1.121 \\
285,039 \\
0\end{array}$ & $\begin{array}{r}215,553 \\
274,900 \\
149,102 \\
1,086,006 \\
2,520\end{array}$ & $\begin{array}{r}1,011 \\
998 \\
1,030 \\
1,040 \\
1,035\end{array}$ \\
\hline 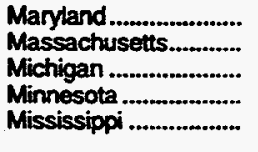 & $\begin{array}{l}\text { NA } \\
\text { NA } \\
\text { NA } \\
\text { NA } \\
\text { NA }\end{array}$ & $\begin{array}{r}1,372 \\
45,161 \\
10,126 \\
1,275 \\
53,579\end{array}$ & $\begin{array}{l}148,589 \\
217,503 \\
690,493 \\
251,243 \\
195,058\end{array}$ & $\begin{array}{l}1,034 \\
1,027 \\
1,015 \\
1,004 \\
1,028\end{array}$ \\
\hline 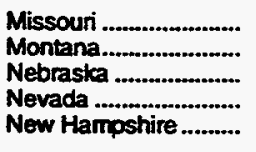 & $\begin{array}{l}\text { NA } \\
\text { NA } \\
\text { NA } \\
\text { NA } \\
\text { NA }\end{array}$ & $\begin{array}{r}1,466 \\
468 \\
1,284 \\
8,080 \\
0\end{array}$ & $\begin{array}{r}255,636 \\
42,879 \\
120,496 \\
39,087 \\
10,545\end{array}$ & $\begin{array}{r}1,017 \\
1,001 \\
982 \\
1,062 \\
1,027\end{array}$ \\
\hline 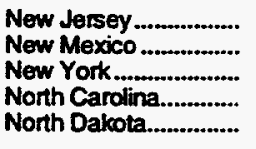 & $\begin{array}{l}\text { NA } \\
\text { NA } \\
\text { NA } \\
\text { NA } \\
\text { NA }\end{array}$ & $\begin{array}{r}61,362 \\
28,133 \\
172,631 \\
595 \\
2\end{array}$ & $\begin{array}{r}376,982 \\
78,453 \\
758,031 \\
129,081 \\
22,682\end{array}$ & $\begin{array}{l}1,026 \\
1,074 \\
1,029 \\
1,034 \\
1,062\end{array}$ \\
\hline 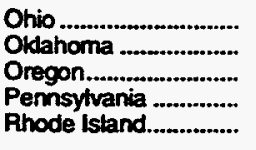 & $\begin{array}{l}\text { NA } \\
\text { NA } \\
\text { NA } \\
\text { NA } \\
\text { NA }\end{array}$ & $\begin{array}{r}699 \\
200,686 \\
0 \\
1,570 \\
2,532\end{array}$ & $\begin{array}{r}719,393 \\
473,906 \\
78,297 \\
588,087 \\
29,733\end{array}$ & $\begin{array}{l}1.044 \\
1.028 \\
1.030 \\
1.034 \\
1.033\end{array}$ \\
\hline 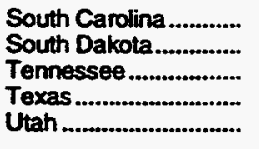 & $\begin{array}{l}\text { NA } \\
\text { NA } \\
\text { NA } \\
\text { NA } \\
\text { NA }\end{array}$ & $\begin{array}{r}483 \\
26 \\
0 \\
1,197,590 \\
235\end{array}$ & $\begin{array}{r}95,225 \\
24,881 \\
179,942 \\
2,985,916 \\
104,915\end{array}$ & $\begin{array}{l}1,028 \\
1,010 \\
1,034 \\
1.038 \\
1.075\end{array}$ \\
\hline 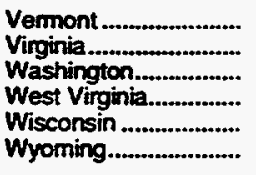 & $\begin{array}{l}\text { NA } \\
\text { NA } \\
\text { NA } \\
\text { NA } \\
\text { NA } \\
\text { NA }\end{array}$ & $\begin{array}{r}95 \\
1.528 \\
77 \\
122 \\
1.317 \\
132\end{array}$ & $\begin{array}{r}4,993 \\
134,589 \\
131,712 \\
92,218 \\
305,571 \\
42,495\end{array}$ & $\begin{array}{r}992 \\
1,039 \\
1,040 \\
1,067 \\
1,010 \\
1,051\end{array}$ \\
\hline Total........................... & NA & $3,044,083$ & $15,811,130$ & 1.032 \\
\hline
\end{tabular}

See tootnoles at end of table. 
Table 16. Natural Gas Delivered to Consumers by State, 1967-1994 (Continued)

\begin{tabular}{|c|c|c|c|c|c|c|}
\hline \multirow[b]{2}{*}{ State } & \multicolumn{2}{|c|}{ Residential } & \multicolumn{2}{|c|}{ Commercial } & \multicolumn{2}{|c|}{ Industrial } \\
\hline & $\begin{array}{l}\text { Quantity } \\
\text { (miltion } \\
\text { cubic feot) }\end{array}$ & Consumers: & $\begin{array}{l}\text { Ouantity } \\
\text { (million } \\
\text { cutic foet) }\end{array}$ & Consumes: & $\begin{array}{l}\text { Quantity } \\
\text { (million } \\
\text { cubic feet) }\end{array}$ & Consumers \\
\hline & \multicolumn{4}{|c|}{1986} & & \\
\hline 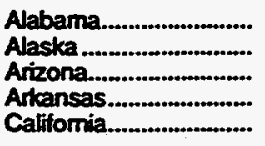 & $\begin{array}{r}44,674 \\
12,091 \\
25,412 \\
38,530 \\
464,307\end{array}$ & $\begin{array}{r}656,000 \\
66,000 \\
545,000 \\
475,000 \\
7,626,000\end{array}$ & $\begin{array}{r}25,128 \\
20,874 \\
24,081 \\
24,949 \\
182,794\end{array}$ & $\begin{array}{r}53,000 \\
11,000 \\
46,000 \\
60,000 \\
413,000\end{array}$ & $\begin{array}{r}116,798 \\
60,439 \\
8,487 \\
92,244 \\
404,681\end{array}$ & $\begin{array}{r}2,000 \\
N A \\
N A \\
1,000 \\
31,000\end{array}$ \\
\hline 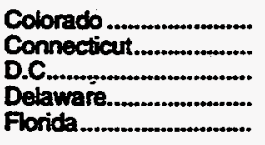 & $\begin{array}{r}81,151 \\
35,107 \\
17,296 \\
6,861 \\
13,860\end{array}$ & $\begin{array}{r}925,000 \\
400,000 \\
134,000 \\
81,000 \\
442,000\end{array}$ & $\begin{array}{r}61,620 \\
24,713 \\
11,934 \\
3,514 \\
35,829\end{array}$ & $\begin{array}{r}108,000 \\
39,000 \\
11,000 \\
6,000 \\
41,000\end{array}$ & $\begin{array}{r}34,348 \\
17,703 \\
0 \\
20,834 \\
59,217\end{array}$ & $\begin{array}{r}1,000 \\
2,000 \\
N A \\
N A \\
N A\end{array}$ \\
\hline 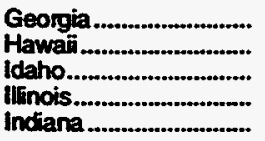 & $\begin{array}{r}89,171 \\
579 \\
7,283 \\
437,081 \\
140,135\end{array}$ & $\begin{array}{r}1,190,000 \\
28,000 \\
102,000 \\
3,108,000 \\
1,224,000\end{array}$ & $\begin{array}{r}50,405 \\
1,883 \\
8,543 \\
204,979 \\
64,821\end{array}$ & $\begin{array}{r}94,000 \\
3,000 \\
17,000 \\
261,000 \\
113,000\end{array}$ & $\begin{array}{r}128,420 \\
0 \\
16,279 \\
263,847 \\
183,270\end{array}$ & $\begin{array}{r}3,000 \\
\mathrm{NA} \\
\mathrm{NA} \\
18,000 \\
5,000\end{array}$ \\
\hline 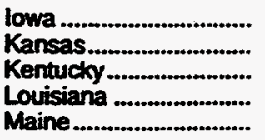 & $\begin{array}{r}74,202 \\
70,582 \\
59,372 \\
58,129 \\
542\end{array}$ & $\begin{array}{r}685,000 \\
716,000 \\
592,000 \\
963,000 \\
12,000\end{array}$ & $\begin{array}{r}43,709 \\
55,730 \\
32,666 \\
27,985 \\
1,214\end{array}$ & $\begin{array}{l}81,000 \\
83,000 \\
62,000 \\
70,000 \\
3,000\end{array}$ & $\begin{array}{r}80,364 \\
100,005 \\
48,229 \\
795,255 \\
708\end{array}$ & $\begin{array}{r}2,000 \\
7,000 \\
1,000 \\
1,000 \\
\mathrm{NA}\end{array}$ \\
\hline $\begin{array}{l}\text { Maryland................... } \\
\text { Massachusetts............ } \\
\text { Michigan ..................... } \\
\text { Minnesota ................... } \\
\text { Mississippi ................... }\end{array}$ & $\begin{array}{r}71,896 \\
102,295 \\
330,240 \\
103,303 \\
25,282\end{array}$ & $\begin{array}{r}752,000 \\
1,053,000 \\
2,408,000 \\
846,000 \\
367,000\end{array}$ & $\begin{array}{r}23,816 \\
43,651 \\
135,592 \\
74,478 \\
16,891\end{array}$ & $\begin{array}{r}49,000 \\
80,000 \\
174,000 \\
86,000 \\
44,000\end{array}$ & $\begin{array}{r}52,570 \\
23,896 \\
172,204 \\
57,847 \\
89,824\end{array}$ & $\begin{array}{r}5,000 \\
5,000 \\
10,000 \\
2,000 \\
1,000\end{array}$ \\
\hline 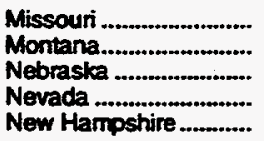 & $\begin{array}{r}120,564 \\
16,822 \\
42,303 \\
12,226 \\
5,102\end{array}$ & $\begin{array}{r}1,161,000 \\
168,000 \\
396,000 \\
209,000 \\
56,000\end{array}$ & $\begin{array}{r}61,890 \\
12,536 \\
36,357 \\
11,451 \\
4,438\end{array}$ & $\begin{array}{r}95,000 \\
21,000 \\
61,000 \\
18,000 \\
8,000\end{array}$ & $\begin{array}{r}54,508 \\
7,507 \\
20,389 \\
3,477 \\
729\end{array}$ & $\begin{array}{r}3,000 \\
N A \\
N A \\
N A \\
N A\end{array}$ \\
\hline $\begin{array}{l}\text { New Jersey................. } \\
\text { New Mexico ................ } \\
\text { New York................. } \\
\text { North Carolina............. } \\
\text { North Dakota................ }\end{array}$ & $\begin{array}{r}158,266 \\
24,019 \\
336,712 \\
31,701 \\
9,351\end{array}$ & $\begin{array}{r}1,816,000 \\
338,000 \\
3,790,000 \\
426,000 \\
84,000\end{array}$ & $\begin{array}{r}85,775 \\
20,642 \\
167,503 \\
25,474 \\
9,084\end{array}$ & $\begin{array}{r}195,000 \\
36,000 \\
255,000 \\
54,000 \\
12,000\end{array}$ & $\begin{array}{r}69,715 \\
7,988 \\
86,686 \\
72,475 \\
2,752\end{array}$ & $\begin{array}{r}6,000 \\
1,000 \\
22,000 \\
2,000 \\
N A\end{array}$ \\
\hline 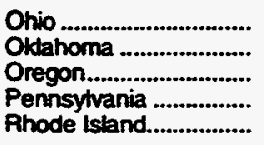 & $\begin{array}{r}327,300 \\
66,641 \\
19,058 \\
254,863 \\
16,100\end{array}$ & $\begin{array}{r}2,614,000 \\
819,000 \\
273,000 \\
2,239,000 \\
175,000\end{array}$ & $\begin{array}{r}139,119 \\
36,517 \\
16,843 \\
114,442 \\
6,718\end{array}$ & $\begin{array}{r}207,000 \\
88,000 \\
39,000 \\
162,000 \\
14,000\end{array}$ & $\begin{array}{r}235,826 \\
148,411 \\
31.447 \\
202,181 \\
3,452\end{array}$ & $\begin{array}{r}7,000 \\
2,000 \\
N A \\
6,000 \\
1,000\end{array}$ \\
\hline 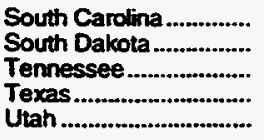 & $\begin{array}{r}17,440 \\
10,557 \\
40,240 \\
194,602 \\
57,654\end{array}$ & $\begin{array}{r}298,000 \\
100,000 \\
507,000 \\
3,164,000 \\
412,000\end{array}$ & $\begin{array}{r}15,894 \\
9,166 \\
42,589 \\
146,972 \\
4,636\end{array}$ & $\begin{array}{r}34,000 \\
12,000 \\
73,000 \\
288,000 \\
31,000\end{array}$ & $\begin{array}{r}61,455 \\
3,351 \\
91,504 \\
1,353,090 \\
28,264\end{array}$ & $\begin{array}{r}1,000 \\
N A \\
2,000 \\
13,000 \\
N A\end{array}$ \\
\hline 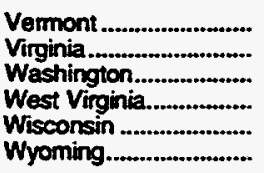 & $\begin{array}{r}1,595 \\
51,517 \\
30,217 \\
36,222 \\
110,780 \\
12,738\end{array}$ & $\begin{array}{r}14,000 \\
536,000 \\
373,000 \\
352,000 \\
1,032,000 \\
115,000\end{array}$ & $\begin{array}{r}1,688 \\
35,453 \\
32,022 \\
15,995 \\
55,275 \\
8,045\end{array}$ & $\begin{array}{l}2,000 \\
48,000 \\
49,000 \\
31,000 \\
92,000 \\
16,000\end{array}$ & $\begin{array}{r}1,728 \\
47,907 \\
54,027 \\
37,017 \\
107,274 \\
18,427\end{array}$ & $\begin{array}{r}\text { NA } \\
\text { NA } \\
3,000 \\
\text { NA } \\
7,000 \\
\text { NA }\end{array}$ \\
\hline 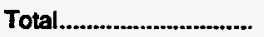 & $4,313,969$ & $46,877,000$ & $2,318,335$ & $3,950,000$ & $5.579,057$ & 192,000 \\
\hline
\end{tabular}


Table 16. Natural Gas Delivered to Consumers by State, 1967-1994 (Continued)

\begin{tabular}{|c|c|c|c|c|}
\hline \multirow[b]{2}{*}{ Stato } & Vehicte Funt & Eectric Utinties & \multirow{2}{*}{$\begin{array}{l}\text { Dulivered to Consumers } \\
\text { Ouartity } \\
\text { (mbilien } \\
\text { cubic feot) }\end{array}$} & \multirow{2}{*}{$\begin{array}{l}\text { Heating Value } \\
\text { (Btu por } \\
\text { cubie } \\
\text { foot) }\end{array}$} \\
\hline & $\begin{array}{l}\text { Quantity } \\
\text { (million } \\
\text { cubic foet) }\end{array}$ & $\begin{array}{l}\text { Quantity } \\
\text { (million } \\
\text { cubic foet) }\end{array}$ & & \\
\hline & \multicolumn{4}{|c|}{1986} \\
\hline 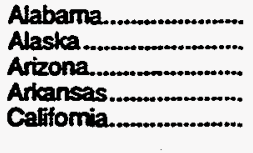 & $\begin{array}{l}\text { NA } \\
\text { NA } \\
\text { NA } \\
\text { NA } \\
\text { NA }\end{array}$ & $\begin{array}{r}1,054 \\
34,409 \\
30,607 \\
28,425 \\
444,226\end{array}$ & $\begin{array}{r}187,654 \\
127,812 \\
88,587 \\
184,148 \\
1,496,008\end{array}$ & $\begin{array}{l}1,036 \\
1,009 \\
1,039 \\
1,019 \\
1,039\end{array}$ \\
\hline 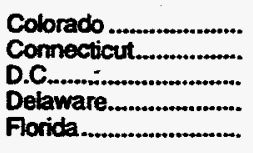 & $\begin{array}{l}\text { NA } \\
\text { NA } \\
\text { NA } \\
\text { NA } \\
\text { NA }\end{array}$ & $\begin{array}{r}4,650 \\
740 \\
0 \\
1,796 \\
169,533\end{array}$ & $\begin{array}{r}181,770 \\
78,264 \\
29,229 \\
33,005 \\
278,439\end{array}$ & $\begin{array}{l}1,003 \\
1,030 \\
1,013 \\
1,018 \\
1,036\end{array}$ \\
\hline 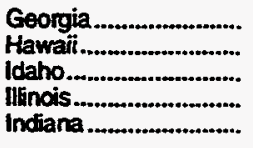 & $\begin{array}{l}\text { NA } \\
\text { NA } \\
\text { NA } \\
\text { NA } \\
\text { NA }\end{array}$ & $\begin{array}{r}5,803 \\
0 \\
5 \\
6,067 \\
1,086\end{array}$ & $\begin{array}{r}273,799 \\
2,463 \\
32,110 \\
911,974 \\
389,312\end{array}$ & $\begin{array}{l}1,027 \\
1,086 \\
1,021 \\
1,021 \\
1,009\end{array}$ \\
\hline $\begin{array}{l}\text { lowa } \\
\text { Kansas } \\
\text { Kentucky } \\
\text { Louisiana } \\
\text { Maine }\end{array}$ & $\begin{array}{l}\text { NA } \\
\text { NA } \\
\text { NA } \\
\text { NA } \\
\text { NA }\end{array}$ & $\begin{array}{r}1,365 \\
15,029 \\
437 \\
267,862 \\
0\end{array}$ & $\begin{array}{r}199,640 \\
241,346 \\
140,704 \\
1,149,230 \\
2,465\end{array}$ & $\begin{array}{r}1,010 \\
985 \\
1,038 \\
1,040 \\
1,031\end{array}$ \\
\hline 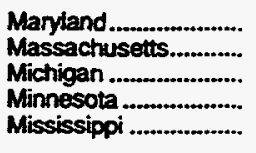 & $\begin{array}{l}\text { NA } \\
\text { NA } \\
\text { NA } \\
\text { NA } \\
\text { NA }\end{array}$ & $\begin{array}{r}2,194 \\
14,875 \\
10,945 \\
1,734 \\
47,613\end{array}$ & $\begin{array}{l}150,477 \\
184,727 \\
648,981 \\
237,361 \\
179,610\end{array}$ & $\begin{array}{r}1,036 \\
1,026 \\
1,027 \\
999 \\
1,025\end{array}$ \\
\hline 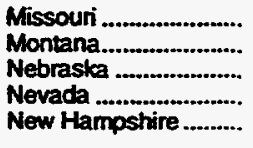 & $\begin{array}{l}\text { NA } \\
\text { NA } \\
\text { NA } \\
\text { NA } \\
\text { NA }\end{array}$ & $\begin{array}{r}1,182 \\
407 \\
1,713 \\
6,592 \\
0\end{array}$ & $\begin{array}{r}238,144 \\
37,272 \\
100,762 \\
33,746 \\
10,269\end{array}$ & $\begin{array}{r}1,011 \\
1,000 \\
993 \\
1,059 \\
1,027\end{array}$ \\
\hline $\begin{array}{l}\text { New Jersey................ } \\
\text { New Mexico............. } \\
\text { New York................ } \\
\text { North Carolina............ } \\
\text { North Dakota.............. }\end{array}$ & $\begin{array}{l}\text { NA } \\
\text { NA } \\
\text { NA } \\
\text { NA } \\
\text { NA }\end{array}$ & $\begin{array}{r}36,877 \\
20,182 \\
133,580 \\
1.137 \\
2\end{array}$ & $\begin{array}{r}350,632 \\
72,830 \\
724,481 \\
130,787 \\
21,189\end{array}$ & $\begin{array}{l}1,027 \\
1,077 \\
1,029 \\
1,033 \\
1,043\end{array}$ \\
\hline 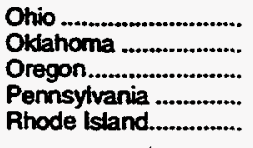 & $\begin{array}{l}\text { NA } \\
\text { NA } \\
\text { NA } \\
\text { NA } \\
\text { NA }\end{array}$ & $\begin{array}{r}606 \\
197,239 \\
0 \\
724 \\
0\end{array}$ & $\begin{array}{r}702,851 \\
448,808 \\
67,349 \\
572,209 \\
26,270\end{array}$ & $\begin{array}{l}1,046 \\
1,030 \\
1,022 \\
1,036 \\
1,029\end{array}$ \\
\hline $\begin{array}{l}\text { South Carolina ........... } \\
\text { South Dakota } \\
\text { Tennessee } \\
\text { Texas } \\
\text { Utah }\end{array}$ & $\begin{array}{l}\text { NA } \\
\text { NA } \\
\text { NA } \\
\text { NA } \\
\text { NA }\end{array}$ & $\begin{array}{r}1,386 \\
41 \\
0 \\
1,106.826 \\
230\end{array}$ & $\begin{array}{r}96,175 \\
23,114 \\
174,333 \\
2,801,490 \\
90,784\end{array}$ & $\begin{array}{r}1,030 \\
1,005 \\
1,032 \\
1,040 \\
948\end{array}$ \\
\hline 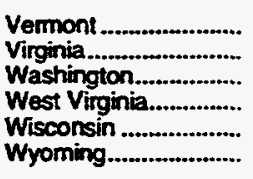 & $\begin{array}{l}\text { NA } \\
\text { NA } \\
\text { NA } \\
\text { NA } \\
\text { NA } \\
\text { NA }\end{array}$ & $\begin{array}{r}3 \\
847 \\
124 \\
298 \\
1.783 \\
138\end{array}$ & $\begin{array}{r}5,014 \\
135,725 \\
116,389 \\
89,533 \\
275,112 \\
39,348\end{array}$ & $\begin{array}{r}987 \\
1,040 \\
1,029 \\
1,076 \\
1,010 \\
1,050\end{array}$ \\
\hline 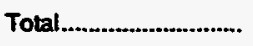 & NA & $2,602,370$ & $14,813,731$ & 1,030 \\
\hline
\end{tabular}

See footnotes at end of table. 
Table 16. Natural Gas Delivered to Consumers by State, 1967-1994 (Continued)

\begin{tabular}{|c|c|c|c|c|c|c|}
\hline \multirow[b]{2}{*}{ Sture } & \multicolumn{2}{|c|}{ Aeaidential } & \multicolumn{2}{|c|}{ Commercial } & \multicolumn{2}{|c|}{ Industrial } \\
\hline & $\begin{array}{l}\text { Quantity } \\
\text { (million } \\
\text { cubie foet) }\end{array}$ & Consumers & $\begin{array}{l}\text { Quantity } \\
\text { (miltion } \\
\text { cubic toet) }\end{array}$ & Consumers & $\begin{array}{l}\text { Quantity } \\
\text { (million } \\
\text { cubic foot) }\end{array}$ & Consumers: \\
\hline & \multicolumn{6}{|c|}{1987} \\
\hline 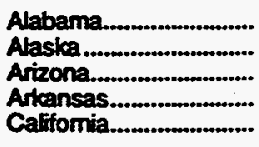 & $\begin{array}{r}49,077 \\
12,256 \\
28,426 \\
40,055 \\
503,473\end{array}$ & $\begin{array}{r}662,217 \\
67,648 \\
567,962 \\
480,839 \\
7,904,858\end{array}$ & $\begin{array}{r}22,384 \\
20,224 \\
27,669 \\
24,603 \\
212,904\end{array}$ & $\begin{array}{r}54,306 \\
11,484 \\
46,702 \\
60,355 \\
404,507\end{array}$ & $\begin{array}{r}116,177 \\
67,467 \\
17,757 \\
55,141 \\
529,405\end{array}$ & $\begin{array}{r}2,313 \\
10 \\
358 \\
1,410 \\
44,764\end{array}$ \\
\hline 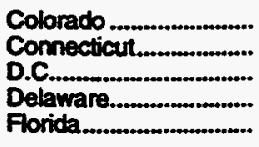 & $\begin{array}{r}86,263 \\
36,134 \\
16,729 \\
7,074 \\
14,566\end{array}$ & $\begin{array}{r}942,571 \\
411,349 \\
130,748 \\
82,829 \\
444,848\end{array}$ & $\begin{array}{r}64,355 \\
27,581 \\
13,999 \\
3,741 \\
37,492\end{array}$ & $\begin{array}{r}109,770 \\
40,886 \\
14,683 \\
6,180 \\
42,376\end{array}$ & $\begin{array}{r}30,921 \\
19,802 \\
0 \\
18,038 \\
60,583\end{array}$ & $\begin{array}{r}896 \\
2,709 \\
0 \\
241 \\
575\end{array}$ \\
\hline 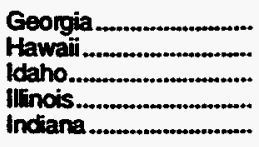 & $\begin{array}{r}100,630 \\
591 \\
7,007 \\
407,875 \\
139,048\end{array}$ & $\begin{array}{r}1,237,201 \\
28,502 \\
104,824 \\
3,170,364 \\
1,250,476\end{array}$ & $\begin{array}{r}54,592 \\
2,019 \\
7,618 \\
191,047 \\
64,903\end{array}$ & $\begin{array}{r}98,809 \\
2,896 \\
17,482 \\
241,367 \\
116,571\end{array}$ & $\begin{array}{r}141,201 \\
0 \\
18,956 \\
261,168 \\
201,395\end{array}$ & $\begin{array}{r}3.034 \\
0 \\
219 \\
19,460 \\
5,497\end{array}$ \\
\hline $\begin{array}{l}\text { lowa } \\
\text { Kansas....... } \\
\text { Kentucky. } \\
\text { Lovisiana } \\
\text { Maine }\end{array}$ & $\begin{array}{r}65,246 \\
69,653 \\
59,094 \\
61,377 \\
528\end{array}$ & $\begin{array}{r}690,532 \\
725,676 \\
596,320 \\
952,079 \\
12,134\end{array}$ & $\begin{array}{r}38,057 \\
53,609 \\
33,298 \\
27,845 \\
1,250\end{array}$ & $\begin{array}{r}80,797 \\
82,934 \\
63,024 \\
67,382 \\
3,435\end{array}$ & $\begin{array}{r}88,346 \\
113,390 \\
54,530 \\
811,827 \\
852\end{array}$ & $\begin{array}{r}2,033 \\
4,440 \\
1,391 \\
1,617 \\
73\end{array}$ \\
\hline 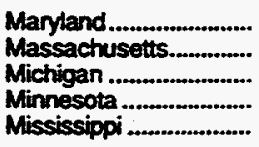 & $\begin{array}{r}70,670 \\
104,847 \\
314,293 \\
89,943 \\
26,599\end{array}$ & $\begin{array}{r}755,294 \\
1,082,777 \\
2,452,554 \\
872,148 \\
370,094\end{array}$ & $\begin{array}{r}25,544 \\
46,522 \\
185,956 \\
65,923 \\
17,922\end{array}$ & $\begin{array}{r}51,252 \\
84,636 \\
178,469 \\
88,789 \\
43,362\end{array}$ & $\begin{array}{r}58,456 \\
34,149 \\
124,565 \\
71,967 \\
82,435\end{array}$ & $\begin{array}{r}5,222 \\
5,626 \\
10,885 \\
2,585 \\
1,312\end{array}$ \\
\hline 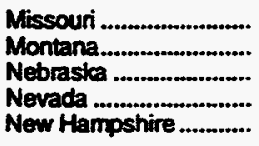 & $\begin{array}{r}116,050 \\
15,359 \\
38,871 \\
14,141 \\
5,604\end{array}$ & $\begin{array}{r}1.180,546 \\
167,883 \\
400,218 \\
213,422 \\
60,078\end{array}$ & $\begin{array}{r}58,205 \\
10,989 \\
34,205 \\
13,747 \\
4,601\end{array}$ & $\begin{array}{r}96,711 \\
21,382 \\
60,707 \\
18,294 \\
8,831\end{array}$ & $\begin{array}{r}54,326 \\
7,861 \\
30,019 \\
6,197 \\
1,731\end{array}$ & $\begin{array}{r}2.832 \\
435 \\
675 \\
93 \\
153\end{array}$ \\
\hline 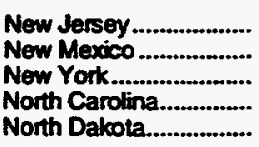 & $\begin{array}{r}168,641 \\
27,534 \\
334,417 \\
35,903 \\
8,063\end{array}$ & $\begin{array}{r}1.869,903 \\
348,759 \\
3,810,577 \\
435,826 \\
83,517\end{array}$ & $\begin{array}{r}94,459 \\
19,939 \\
167,178 \\
30,010 \\
7,908\end{array}$ & $\begin{array}{r}200,387 \\
36,444 \\
262,859 \\
56,191 \\
11,905\end{array}$ & $\begin{array}{r}79,779 \\
13,479 \\
96,081 \\
76,425 \\
2,698\end{array}$ & $\begin{array}{r}6.265 \\
1,703 \\
23,276 \\
3,236 \\
138\end{array}$ \\
\hline 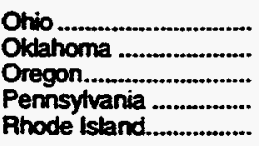 & $\begin{array}{r}326,480 \\
64,164 \\
18,750 \\
251,175 \\
16,742\end{array}$ & $\begin{array}{r}2,648,972 \\
809,171 \\
280,670 \\
2,237,877 \\
180,656\end{array}$ & $\begin{array}{r}146,983 \\
32,428 \\
16,718 \\
114,800 \\
9,395\end{array}$ & $\begin{array}{r}213,601 \\
87,824 \\
40,967 \\
166,901 \\
15,128\end{array}$ & $\begin{array}{r}223,561 \\
183,454 \\
36,676 \\
226,349 \\
4,392\end{array}$ & $\begin{array}{l}7,929 \\
2,772 \\
676 \\
6,089 \\
1,158\end{array}$ \\
\hline $\begin{array}{l}\text { South Carolina } \\
\text { South Dakota } \\
\text { Tennessee } \\
\text { Texas } \\
\text { Utah }\end{array}$ & $\begin{array}{r}20,200 \\
9,288 \\
43,483 \\
210,688 \\
41,536\end{array}$ & $\begin{array}{r}302,321 \\
101,468 \\
534,882 \\
3,155,948 \\
414,020\end{array}$ & $\begin{array}{r}17,195 \\
8,199 \\
44,144 \\
156,509 \\
14,811\end{array}$ & $\begin{array}{r}35,414 \\
12,480 \\
77,104 \\
294,879 \\
31,329\end{array}$ & $\begin{array}{r}65,340 \\
3.273 \\
97.574 \\
1.449 .539 \\
23,884\end{array}$ & $\begin{array}{r}1.256 \\
261 \\
2.206 \\
4.852 \\
551\end{array}$ \\
\hline 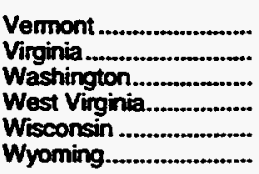 & $\begin{array}{r}1,663 \\
55,421 \\
29,799 \\
35,634 \\
103,154 \\
10,616\end{array}$ & $\begin{array}{r}15,553 \\
550,318 \\
392,469 \\
351,024 \\
1,054,347 \\
113,175\end{array}$ & $\begin{array}{r}1,833 \\
39,401 \\
32,366 \\
16,792 \\
57,750 \\
8,443\end{array}$ & $\begin{array}{r}2,447 \\
54,071 \\
51,365 \\
31,283 \\
96,760 \\
15,342\end{array}$ & $\begin{array}{r}1,684 \\
55,334 \\
65,706 \\
41,399 \\
112,877 \\
15,142\end{array}$ & $\begin{array}{r}22 \\
877 \\
3,355 \\
463 \\
7,411 \\
190\end{array}$ \\
\hline 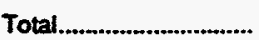 & $4,314,833$ & $47,710,444$ & $2,430,064$ & $4,013,040$ & $5,953,308$ & 195,544 \\
\hline
\end{tabular}

See tootnotes at end of table. 
Table 16. Natural Gas Delivered to Consumers by State, 1967-1994 (Continued)

\begin{tabular}{|c|c|c|c|c|}
\hline \multirow[b]{2}{*}{ State } & Vohicle Fuol & Electric Utilities & \multirow{2}{*}{$\begin{array}{l}\text { Delivered to Consumers } \\
\text { Quantity } \\
\text { (million } \\
\text { cubic foet) }\end{array}$} & \multirow{2}{*}{$\begin{array}{l}\text { Hoating Value } \\
\text { (Btu per } \\
\text { cubic } \\
\text { foot) }\end{array}$} \\
\hline & $\begin{array}{l}\text { Quantity } \\
\text { (million } \\
\text { cubic foet) }\end{array}$ & $\begin{array}{l}\text { Quantity } \\
\text { (million } \\
\text { eubic foet) }\end{array}$ & & \\
\hline & \multicolumn{4}{|c|}{1987} \\
\hline 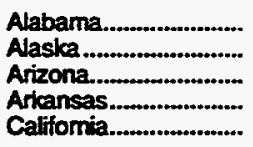 & $\begin{array}{l}\text { NA } \\
\text { NA } \\
\text { NA } \\
\text { NA } \\
\text { NA }\end{array}$ & $\begin{array}{r}1,474 \\
30,530 \\
26,665 \\
32,057 \\
643,335\end{array}$ & $\begin{array}{r}189,112 \\
130,478 \\
100,517 \\
151,856 \\
1,889,118\end{array}$ & $\begin{array}{l}1,033 \\
1,009 \\
1,036 \\
1,016 \\
1,030\end{array}$ \\
\hline 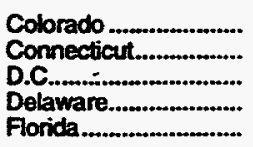 & $\begin{array}{l}\text { NA } \\
\text { NA } \\
\text { NA } \\
\text { NA } \\
\text { NA }\end{array}$ & $\begin{array}{r}7,826 \\
7,350 \\
0 \\
7,847 \\
175,675\end{array}$ & $\begin{array}{r}189,364 \\
90,867 \\
30,728 \\
36,699 \\
288,317\end{array}$ & $\begin{array}{l}1,000 \\
1,031 \\
1,014 \\
1,015 \\
1,044\end{array}$ \\
\hline 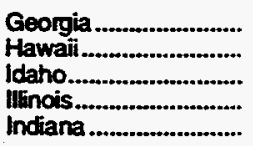 & $\begin{array}{l}\text { NA } \\
\text { NA } \\
\text { NA } \\
\text { NA } \\
\text { NA }\end{array}$ & $\begin{array}{r}826 \\
0 \\
4 \\
3,172 \\
1,315\end{array}$ & $\begin{array}{r}297,249 \\
2,610 \\
33,583 \\
863,261 \\
406,661\end{array}$ & $\begin{array}{l}1,026 \\
1,068 \\
1,017 \\
1,015 \\
1,009\end{array}$ \\
\hline 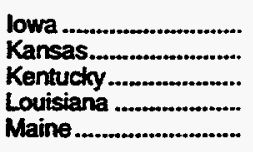 & $\begin{array}{l}\text { NA } \\
\text { NA } \\
\text { NA } \\
\text { NA } \\
\text { NA }\end{array}$ & $\begin{array}{r}3,265 \\
16,074 \\
336 \\
246,912 \\
0\end{array}$ & $\begin{array}{r}194,914 \\
252,726 \\
147,258 \\
1,147,961 \\
2,629\end{array}$ & $\begin{array}{l}1,008 \\
1,046 \\
1,037 \\
1,040 \\
1,040\end{array}$ \\
\hline 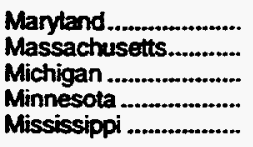 & $\begin{array}{l}\text { NA } \\
\text { NA } \\
\text { NA } \\
\text { NA } \\
\text { NA }\end{array}$ & $\begin{array}{r}11,757 \\
40,183 \\
10,754 \\
5,700 \\
41,119\end{array}$ & $\begin{array}{l}166,428 \\
225,701 \\
635,568 \\
233,532 \\
168,075\end{array}$ & $\begin{array}{r}1,034 \\
1,029 \\
1,021 \\
999 \\
1,018\end{array}$ \\
\hline $\begin{array}{l}\text { Missouri } \\
\text { Montana } \\
\text { Nebraska } \\
\text { Nevada } \\
\text { New Hampstire }\end{array}$ & $\begin{array}{l}\text { NA } \\
\text { NA } \\
\text { NA } \\
\text { NA } \\
\text { NA }\end{array}$ & $\begin{array}{r}1,379 \\
478 \\
1,743 \\
7,076 \\
15\end{array}$ & $\begin{array}{r}229,960 \\
34,687 \\
104,838 \\
41,161 \\
11,951\end{array}$ & $\begin{array}{r}1,011 \\
1,020 \\
985 \\
1,009 \\
1,029\end{array}$ \\
\hline 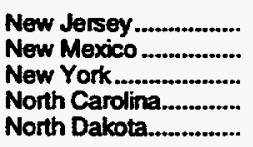 & $\begin{array}{l}\text { NA } \\
\text { NA } \\
\text { NA } \\
\text { NA } \\
\text { NA }\end{array}$ & $\begin{array}{r}75,138 \\
18,454 \\
173,328 \\
1,162 \\
3\end{array}$ & $\begin{array}{r}418,018 \\
79,406 \\
771,003 \\
143,500 \\
18,672\end{array}$ & $\begin{array}{l}1,026 \\
1,074 \\
1,030 \\
1,031 \\
1,048\end{array}$ \\
\hline 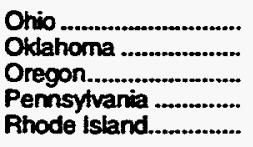 & $\begin{array}{l}\text { NA } \\
\text { NA } \\
\text { NA } \\
\text { NA } \\
\text { NA }\end{array}$ & $\begin{array}{r}871 \\
187,895 \\
0 \\
1,993 \\
5,336\end{array}$ & $\begin{array}{r}697,895 \\
467,942 \\
72,143 \\
594,317 \\
35,865\end{array}$ & $\begin{array}{l}1,045 \\
1,036 \\
1,028 \\
1,036 \\
1,028\end{array}$ \\
\hline 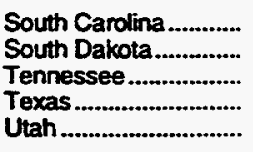 & $\begin{array}{l}\text { NA } \\
\text { NA } \\
\text { NA } \\
\text { NA } \\
\text { NA }\end{array}$ & $\begin{array}{r}538 \\
77 \\
0 \\
1,049,804 \\
263\end{array}$ & $\begin{array}{r}103,273 \\
20,837 \\
185,200 \\
2,866,540 \\
80,494\end{array}$ & $\begin{array}{l}1,028 \\
1,013 \\
1,032 \\
1,040 \\
1,080\end{array}$ \\
\hline 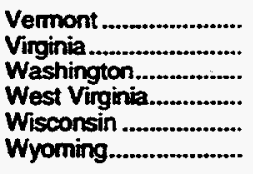 & $\begin{array}{l}\text { NA } \\
\text { NA } \\
\text { NA } \\
\text { NA } \\
\text { NA } \\
\text { NA }\end{array}$ & $\begin{array}{r}0 \\
1.724 \\
93 \\
239 \\
2.176 \\
90\end{array}$ & $\begin{array}{r}5,181 \\
151,880 \\
127,965 \\
94,065 \\
275,958 \\
34,290\end{array}$ & $\begin{array}{r}987 \\
1,040 \\
1,033 \\
1,074 \\
1,008 \\
1,057\end{array}$ \\
\hline 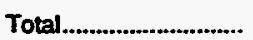 & NA & $2,844,051$ & $15,542,256$ & 1,031 \\
\hline
\end{tabular}

See footnotes at end of table. 
Table 16. Natural Gas Delivered to Consumers by State, 1967-1994 (Continued)

\begin{tabular}{|c|c|c|c|c|c|c|c|}
\hline \multirow[b]{2}{*}{ Sum } & \multicolumn{2}{|c|}{ Recidemial } & \multicolumn{2}{|c|}{ Commercial } & \multicolumn{3}{|c|}{ Industrial } \\
\hline & $\begin{array}{l}\text { Quantity } \\
\text { (million } \\
\text { cubic foet) }\end{array}$ & Consumers & $\begin{array}{l}\text { Qunmity } \\
\text { (miltion } \\
\text { cubic feot) }\end{array}$ & Consumers & $\begin{array}{l}\text { Quantity } \\
\text { (million } \\
\text { cubic fet) }\end{array}$ & Consumers & \\
\hline & \multicolumn{7}{|c|}{1998} \\
\hline 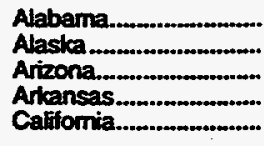 & $\begin{array}{r}48,913 \\
12,529 \\
28,206 \\
42,867 \\
497,138\end{array}$ & $\begin{array}{r}668,432 \\
68,612 \\
564,195 \\
485,112 \\
8,113,034\end{array}$ & $\begin{array}{r}25,562 \\
20,842 \\
28,299 \\
27,457 \\
248,397\end{array}$ & $\begin{array}{r}55,400 \\
11,649 \\
46,636 \\
61,630 \\
407,435\end{array}$ & $\begin{array}{r}140,536 \\
67,805 \\
24,185 \\
104,808 \\
464,008\end{array}$ & $\begin{array}{r}2,298 \\
11 \\
344 \\
1,151 \\
44,680\end{array}$ & \\
\hline $\begin{array}{l}\text { Colorado } \\
\text { Connecticut. } \\
\text { D.C. } \\
\text { Delaware... } \\
\text { Florida........ }\end{array}$ & $\begin{array}{r}92,888 \\
39,485 \\
17.471 \\
7.586 \\
14,891\end{array}$ & $\begin{array}{r}955,810 \\
417,831 \\
134,758 \\
84,328 \\
446,690\end{array}$ & $\begin{array}{r}68,515 \\
27,411 \\
15,012 \\
4,041 \\
37,834\end{array}$ & $\begin{array}{r}110,769 \\
41,594 \\
11,370 \\
6,566 \\
43,178\end{array}$ & $\begin{array}{r}38,197 \\
19,436 \\
0 \\
14,803 \\
75,518\end{array}$ & $\begin{array}{r}923 \\
2,818 \\
0 \\
233 \\
552\end{array}$ & \\
\hline 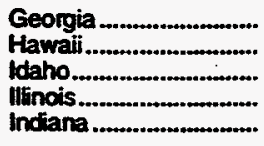 & $\begin{array}{r}108,125 \\
563 \\
7,683 \\
462,339 \\
153,609\end{array}$ & $\begin{array}{r}1,275,128 \\
28,761 \\
111,532 \\
3,180,199 \\
1,275,401\end{array}$ & $\begin{array}{r}55,963 \\
2,049 \\
8,252 \\
215,257 \\
71,709\end{array}$ & $\begin{array}{r}102,277 \\
2,852 \\
18,454 \\
278,473 \\
119,458\end{array}$ & $\begin{array}{r}150,448 \\
0 \\
20,710 \\
269.226 \\
218,769\end{array}$ & $\begin{array}{r}3,144 \\
0 \\
132 \\
20,015 \\
5,696\end{array}$ & $\cdots$ \\
\hline 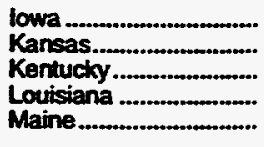 & $\begin{array}{r}76,111 \\
76,420 \\
64,027 \\
59,707 \\
568\end{array}$ & $\begin{array}{r}689,655 \\
733,101 \\
606,106 \\
946,970 \\
11,933\end{array}$ & $\begin{array}{l}44,955 \\
61,120 \\
35,718 \\
27,475 \\
1,461\end{array}$ & $\begin{array}{r}81,294 \\
83,810 \\
63,971 \\
66,472 \\
3,731\end{array}$ & $\begin{array}{r}102.013 \\
108.108 \\
60,136 \\
779.171 \\
1.162\end{array}$ & $\begin{array}{r}1,937 \\
4,314 \\
1,436 \\
1,503 \\
73\end{array}$ & \\
\hline 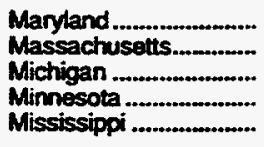 & $\begin{array}{r}74,918 \\
108,631 \\
348,512 \\
109,669 \\
26,889\end{array}$ & $\begin{array}{r}760,754 \\
1,100,635 \\
2,491,149 \\
894,380 \\
372,238\end{array}$ & $\begin{array}{r}25,879 \\
48,915 \\
167,900 \\
79,989 \\
18,108\end{array}$ & $\begin{array}{r}53,045 \\
93,005 \\
185,961 \\
90.256 \\
44.170\end{array}$ & $\begin{array}{r}64,194 \\
31,577 \\
191,159 \\
77,710 \\
92,910\end{array}$ & $\begin{array}{r}5,397 \\
7,199 \\
11,117 \\
2,670 \\
1,263\end{array}$ & \\
\hline $\begin{array}{l}\text { Missouri } \\
\text { Montana } \\
\text { Nebrasta } \\
\text { Nevada } \\
\text { New Hampshire }\end{array}$ & $\begin{array}{r}128,317 \\
16,900 \\
43,502 \\
15,275 \\
5,927\end{array}$ & $\begin{array}{r}1,194,985 \\
171,785 \\
403,657 \\
219,981 \\
61,969\end{array}$ & $\begin{array}{r}63,839 \\
12,041 \\
39,388 \\
14,879 \\
5,034\end{array}$ & $\begin{array}{r}97,939 \\
22,246 \\
61,365 \\
18,921 \\
9.159\end{array}$ & $\begin{array}{r}54,243 \\
8,360 \\
32,299 \\
7,218 \\
1,971\end{array}$ & $\begin{array}{r}2,880 \\
435 \\
684 \\
98 \\
295\end{array}$ & \\
\hline 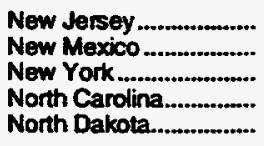 & $\begin{array}{r}181,506 \\
27,846 \\
357,260 \\
38,384 \\
9,147\end{array}$ & $\begin{array}{r}1,918,185 \\
356,192 \\
3,839,952 \\
472,928 \\
84,059\end{array}$ & $\begin{array}{r}101,325 \\
31,032 \\
188,037 \\
32,464 \\
9,827\end{array}$ & $\begin{array}{r}206,261 \\
36,940 \\
270,218 \\
60,663 \\
12,104\end{array}$ & $\begin{array}{r}77,518 \\
14,709 \\
90,883 \\
74,874 \\
3,901\end{array}$ & $\begin{array}{r}6,123 \\
1,668 \\
24,654 \\
3.196 \\
148\end{array}$ & \\
\hline 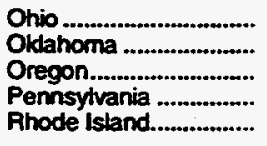 & $\begin{array}{r}350,612 \\
71,970 \\
20,819 \\
268,038 \\
17,678\end{array}$ & $\begin{array}{r}2,678,838 \\
805,107 \\
288,066 \\
2,271,801 \\
185,861\end{array}$ & $\begin{array}{r}158,790 \\
47,870 \\
18,406 \\
127,382 \\
8,352\end{array}$ & $\begin{array}{r}219,257 \\
86,666 \\
41,998 \\
172,615 \\
16,096\end{array}$ & $\begin{array}{r}280,059 \\
163,069 \\
39,771 \\
228,619 \\
4,453\end{array}$ & $\begin{array}{l}8,163 \\
2,689 \\
1,034 \\
6.070 \\
1,152\end{array}$ & \\
\hline 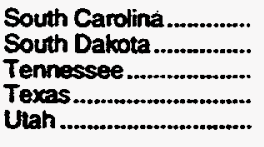 & $\begin{array}{r}20,790 \\
10,687 \\
47,668 \\
209,957 \\
42,241\end{array}$ & $\begin{array}{r}313,831 \\
102,084 \\
565,856 \\
3,166,168 \\
418,569\end{array}$ & $\begin{array}{r}17,472 \\
8,396 \\
45,852 \\
175,368 \\
17,911\end{array}$ & $\begin{array}{r}37.075 \\
12,438 \\
81.159 \\
284,013 \\
32,637\end{array}$ & $\begin{array}{r}69,177 \\
4,668 \\
103,349 \\
1,675,324 \\
30,354\end{array}$ & $\begin{array}{r}1,273 \\
267 \\
2.151 \\
4,427 \\
627\end{array}$ & \\
\hline 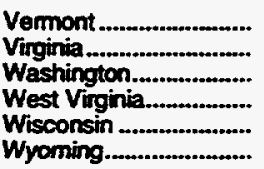 & $\begin{array}{r}1,868 \\
58,539 \\
34,981 \\
37,690 \\
121,335 \\
11,650\end{array}$ & $\begin{array}{r}16,616 \\
573,731 \\
413,008 \\
349,765 \\
1,072,585 \\
112,126\end{array}$ & $\begin{array}{r}1,941 \\
42,013 \\
36,674 \\
22,416 \\
66,939 \\
8,700\end{array}$ & $\begin{array}{r}2,698 \\
54,892 \\
56,487 \\
33,192 \\
99,157 \\
15,093\end{array}$ & $\begin{array}{r}1,741 \\
53,107 \\
69,418 \\
40,415 \\
121,819 \\
15,472\end{array}$ & $\begin{array}{r}21 \\
895 \\
3,564 \\
208 \\
7,218 \\
200\end{array}$ & \\
\hline Total............................ & $4,630,330$ & $48,474,449$ & $2,670,465$ & $4,124,745$ & $6,383,382$ & 199,041 & \\
\hline
\end{tabular}

See foctnoles at end of table. 
Table 16. Natural Gas Delivered to Consumers by State, 1967-1994 (Continued)

\begin{tabular}{|c|c|c|c|c|}
\hline \multirow[b]{2}{*}{ Sinto } & Vehicle Fuel & Eloctric Utitities & \multirow{2}{*}{$\begin{array}{l}\text { Delivered to Consumers } \\
\text { Qununtity } \\
\text { (million } \\
\text { cubic foet) }\end{array}$} & \multirow{2}{*}{$\begin{array}{l}\text { Heeting Value } \\
\text { (Btu per } \\
\text { cubic } \\
\text { foot) }\end{array}$} \\
\hline & $\begin{array}{c}\text { Quantity } \\
\text { (million } \\
\text { cubic foet) }\end{array}$ & $\begin{array}{l}\text { Quantity } \\
\text { (million } \\
\text { cubic feot) }\end{array}$ & & \\
\hline & \multicolumn{4}{|c|}{1988} \\
\hline 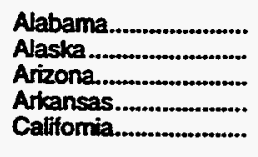 & $\begin{array}{l}\text { NA } \\
\text { NA } \\
\text { NA } \\
\text { NA } \\
\text { NA }\end{array}$ & $\begin{array}{r}2,574 \\
30,841 \\
25,328 \\
22,075 \\
552,988\end{array}$ & $\begin{array}{r}217,586 \\
132,017 \\
106,017 \\
197,208 \\
1,762,480\end{array}$ & $\begin{array}{l}1,029 \\
1,004 \\
1,034 \\
1,009 \\
1,031\end{array}$ \\
\hline 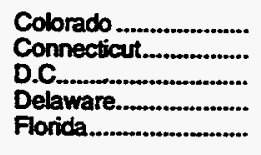 & $\begin{array}{l}\text { NA } \\
\text { NA } \\
\text { NA } \\
\text { NA } \\
\text { NA }\end{array}$ & $\begin{array}{r}8,488 \\
1,260 \\
0 \\
2,824 \\
154,550\end{array}$ & $\begin{array}{r}208,087 \\
87,592 \\
32,483 \\
29,253 \\
282,792\end{array}$ & $\begin{array}{l}1,006 \\
1,032 \\
1,011 \\
1,023 \\
1,042\end{array}$ \\
\hline 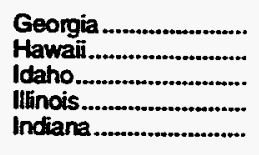 & $\begin{array}{l}\text { NA } \\
\text { NA } \\
\text { NA } \\
\text { NA } \\
\text { NA }\end{array}$ & $\begin{array}{r}1,569 \\
2 \\
0 \\
5,706 \\
3,455\end{array}$ & $\begin{array}{r}316,105 \\
2,614 \\
36,646 \\
952,529 \\
447,542\end{array}$ & $\begin{array}{l}1.025 \\
1.078 \\
1,020 \\
1,018 \\
1,015\end{array}$ \\
\hline 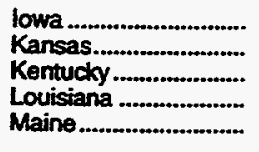 & $\begin{array}{l}\text { NA } \\
\text { NA } \\
\text { NA } \\
\text { NA } \\
\text { NA }\end{array}$ & $\begin{array}{r}5,459 \\
18,890 \\
452 \\
250,323 \\
0\end{array}$ & $\begin{array}{r}228,538 \\
264,539 \\
160,332 \\
1,116,676 \\
3,191\end{array}$ & $\begin{array}{r}1,007 \\
986 \\
1,037 \\
1,042 \\
1,027\end{array}$ \\
\hline 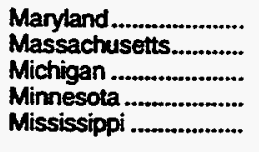 & $\begin{array}{l}\text { NA } \\
\text { NA } \\
\text { NA } \\
\text { NA } \\
\text { NA }\end{array}$ & $\begin{array}{r}5,336 \\
19,874 \\
15,027 \\
5,217 \\
33,261\end{array}$ & $\begin{array}{l}170,326 \\
208,998 \\
722,598 \\
272,585 \\
171,168\end{array}$ & $\begin{array}{l}1,032 \\
1,030 \\
1,022 \\
1,007 \\
1,017\end{array}$ \\
\hline 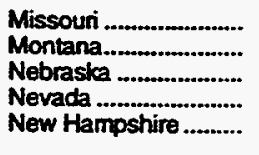 & $\begin{array}{l}\text { NA } \\
\text { NA } \\
\text { NA } \\
\text { NA } \\
\text { NA }\end{array}$ & $\begin{array}{r}1,623 \\
286 \\
2,046 \\
10,658 \\
55\end{array}$ & $\begin{array}{r}248,022 \\
37,587 \\
117,234 \\
48,031 \\
12,987\end{array}$ & $\begin{array}{r}1,006 \\
1,025 \\
983 \\
1,003 \\
1,025\end{array}$ \\
\hline 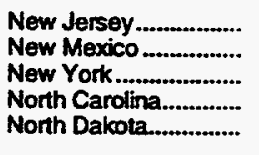 & $\begin{array}{l}\text { NA } \\
\text { NA } \\
\text { NA } \\
\text { NA } \\
\text { NA }\end{array}$ & $\begin{array}{r}51,066 \\
21,064 \\
148,493 \\
1,068 \\
2\end{array}$ & $\begin{array}{r}411,415 \\
94,650 \\
784,673 \\
146,790 \\
22,876\end{array}$ & $\begin{array}{l}1,026 \\
1,068 \\
1,029 \\
1,030 \\
1,055\end{array}$ \\
\hline 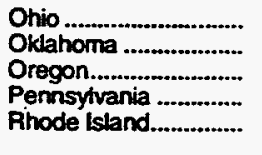 & $\begin{array}{l}\text { NA } \\
\text { NA } \\
\text { NA } \\
\text { NA } \\
\text { NA }\end{array}$ & $\begin{array}{r}974 \\
17,222 \\
0 \\
2,649 \\
185\end{array}$ & $\begin{array}{r}790,436 \\
460,130 \\
78,996 \\
626,688 \\
30,668\end{array}$ & $\begin{array}{l}1,040 \\
1,038 \\
1.023 \\
1,036 \\
1,027\end{array}$ \\
\hline 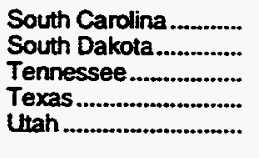 & $\begin{array}{l}\text { NA } \\
\text { NA } \\
\text { NA } \\
\text { NA } \\
\text { NA }\end{array}$ & $\begin{array}{r}2,378 \\
223 \\
225 \\
1,043,910 \\
196\end{array}$ & $\begin{array}{r}109,817 \\
23,974 \\
197,095 \\
3,104,559 \\
90,702\end{array}$ & $\begin{array}{l}1,027 \\
1,020 \\
1,031 \\
1,038 \\
1,081\end{array}$ \\
\hline 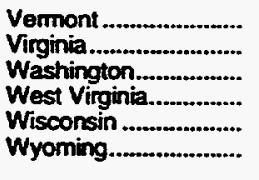 & $\begin{array}{l}\text { NA } \\
\text { NA } \\
\text { NA } \\
\text { NA } \\
\text { NA } \\
\text { NA }\end{array}$ & $\begin{array}{r}0 \\
1,096 \\
1,753 \\
73 \\
2,739 \\
183\end{array}$ & $\begin{array}{r}5,551 \\
154,756 \\
142,825 \\
100,595 \\
312,832 \\
36,005\end{array}$ & $\begin{array}{r}990 \\
1,041 \\
1,026 \\
1,077 \\
1,008 \\
1,053\end{array}$ \\
\hline Total....... & NA & $2,635,616$ & 16.319 .793 & 1,029 \\
\hline
\end{tabular}

See footnotes at end of table. 
Table 16. Natural Gas Delivered to Consumers by State, 1967-1994 (Continued)

\begin{tabular}{|c|c|c|c|c|c|c|}
\hline \multirow[b]{2}{*}{ Stute } & \multicolumn{2}{|c|}{ Rosidential } & \multicolumn{2}{|c|}{ Commercial } & \multicolumn{2}{|c|}{ industrial } \\
\hline & $\begin{array}{l}\text { Quantity } \\
\text { (million } \\
\text { cubic foot) }\end{array}$ & Consumeas & $\begin{array}{l}\text { Quantivy } \\
\text { (million } \\
\text { cibic feet) }\end{array}$ & Consumbers & $\begin{array}{l}\text { Quantity } \\
\text { (milion } \\
\text { cubic fuet) }\end{array}$ & Consumers \\
\hline & \multicolumn{6}{|c|}{$19 a 9$} \\
\hline 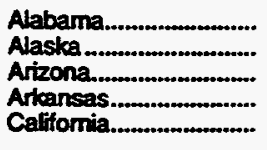 & $\begin{array}{r}48,118 \\
13,589 \\
27,084 \\
42,312 \\
514,276\end{array}$ & $\begin{array}{r}683,528 \\
69,540 \\
572,461 \\
491,110 \\
8,313,776\end{array}$ & $\begin{array}{r}26,469 \\
21,738 \\
28,600 \\
27,271 \\
259,118\end{array}$ & $\begin{array}{r}56,822 \\
11,806 \\
46,776 \\
61,848 \\
410,231\end{array}$ & $\begin{array}{r}149,047 \\
59,341 \\
20,685 \\
129,333 \\
507,948\end{array}$ & $\begin{array}{r}2,380 \\
8 \\
354 \\
1,412 \\
46,243\end{array}$ \\
\hline 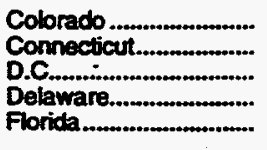 & $\begin{array}{r}91,567 \\
40,687 \\
17,433 \\
7,595 \\
13,089\end{array}$ & $\begin{array}{r}970,512 \\
424,036 \\
134,837 \\
86,428 \\
452,544\end{array}$ & $\begin{array}{r}67,477 \\
30,781 \\
15,741 \\
4,184 \\
35,105\end{array}$ & $\begin{array}{r}112,004 \\
43,703 \\
11,354 \\
7,074 \\
43,802\end{array}$ & $\begin{array}{r}51,348 \\
19,724 \\
0 \\
15,141 \\
75,485\end{array}$ & $\begin{array}{r}976 \\
2,908 \\
0 \\
235 \\
460\end{array}$ \\
\hline 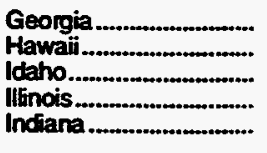 & $\begin{array}{r}103,681 \\
565 \\
8,783 \\
499,984 \\
155,934\end{array}$ & $\begin{array}{r}1,308,972 \\
28,970 \\
113,898 \\
3,248,117 \\
1,306,747\end{array}$ & $\begin{array}{r}53,089 \\
2,129 \\
9,024 \\
196,171 \\
73,625\end{array}$ & $\begin{array}{r}106,690 \\
2,842 \\
18,813 \\
252,791 \\
122,803\end{array}$ & $\begin{array}{r}153,088 \\
0 \\
22,903 \\
278,826 \\
219,952\end{array}$ & $\begin{array}{r}3,079 \\
0 \\
64 \\
25,161 \\
6,196\end{array}$ \\
\hline 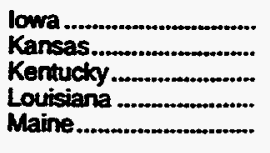 & $\begin{array}{r}77,403 \\
76,033 \\
65,086 \\
57,705 \\
638\end{array}$ & $\begin{array}{r}701,687 \\
731,792 \\
614,058 \\
934,472 \\
11,902\end{array}$ & $\begin{array}{r}46,142 \\
58,554 \\
36,148 \\
27,156 \\
1,660\end{array}$ & $\begin{array}{r}82,549 \\
85,143 \\
65,041 \\
64,114 \\
3,986\end{array}$ & $\begin{array}{r}89,347 \\
100,623 \\
64,003 \\
902,666 \\
1,374\end{array}$ & $\begin{array}{r}1,895 \\
4,366 \\
1,443 \\
1.531 \\
74\end{array}$ \\
\hline 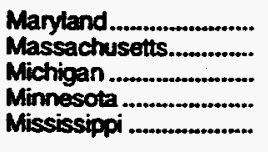 & $\begin{array}{r}75,138 \\
111,661 \\
361,667 \\
116,909 \\
26,312\end{array}$ & $\begin{array}{r}767,219 \\
1,114,920 \\
2,531,304 \\
911,001 \\
376,353\end{array}$ & $\begin{array}{r}26,920 \\
51,508 \\
176,182 \\
85,183 \\
17,568\end{array}$ & $\begin{array}{r}54,740 \\
92,252 \\
191,474 \\
92,916 \\
44,253\end{array}$ & $\begin{array}{r}66,271 \\
35,588 \\
192,981 \\
81,479 \\
97,790\end{array}$ & $\begin{array}{r}5,570 \\
13,057 \\
11,452 \\
2,638 \\
1,282\end{array}$ \\
\hline 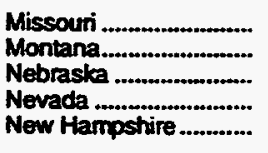 & $\begin{array}{r}129,144 \\
18,195 \\
44,804 \\
16,765 \\
6,290\end{array}$ & $\begin{array}{r}1,208,523 \\
171,156 \\
406,723 \\
236,237 \\
64,059\end{array}$ & $\begin{array}{r}63,039 \\
13,141 \\
37,351 \\
15,116 \\
5,371\end{array}$ & $\begin{array}{l}99,721 \\
22,219 \\
60,377 \\
19,924 \\
10,237\end{array}$ & $\begin{array}{r}\mathbf{5 3}, \mathbf{9 3 8} \\
\mathbf{9 , 9 0 3} \\
30,545 \\
7,859 \\
2,241\end{array}$ & $\begin{array}{r}3,063 \\
428 \\
702 \\
100 \\
376\end{array}$ \\
\hline 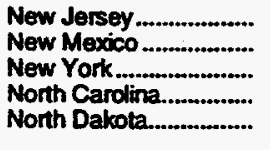 & $\begin{array}{r}195,542 \\
26,591 \\
364,713 \\
38,658 \\
9,825\end{array}$ & $\begin{array}{r}1,950,165 \\
361,521 \\
3,859,413 \\
492,821 \\
84,643\end{array}$ & $\begin{array}{r}117,385 \\
28,459 \\
196,380 \\
33,145 \\
10,609\end{array}$ & $\begin{array}{r}212,496 \\
36,960 \\
285,031 \\
63,562 \\
12,454\end{array}$ & $\begin{array}{r}84,771 \\
18,710 \\
96,854 \\
82,629 \\
4,525\end{array}$ & $\begin{array}{r}6,079 \\
1,653 \\
27,426 \\
3,381 \\
151\end{array}$ \\
\hline 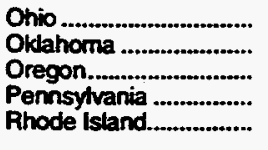 & $\begin{array}{r}359,148 \\
71,793 \\
22,504 \\
270,742 \\
18,283\end{array}$ & $\begin{array}{r}2,714,839 \\
806,875 \\
302,156 \\
2,291.242 \\
190.796\end{array}$ & $\begin{array}{r}161,516 \\
38,509 \\
20,249 \\
132,421 \\
8,767\end{array}$ & $\begin{array}{r}225,347 \\
86,172 \\
43,997 \\
178,545 \\
16,924\end{array}$ & $\begin{array}{r}278,205 \\
185,796 \\
43,752 \\
242,323 \\
4,624\end{array}$ & $\begin{array}{r}8,356 \\
2,877 \\
738 \\
6,023 \\
1,122\end{array}$ \\
\hline 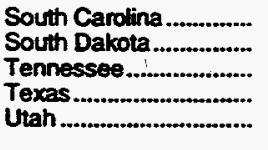 & $\begin{array}{r}20,472 \\
11,342 \\
49,196 \\
230,099 \\
45,168\end{array}$ & $\begin{array}{r}327,527 \\
103,538 \\
599,042 \\
3,201,316 \\
432,377\end{array}$ & $\begin{array}{r}16,525 \\
8,826 \\
47,513 \\
182,670 \\
16,522\end{array}$ & $\begin{array}{r}38,856 \\
12,771 \\
84,040 \\
270,227 \\
32,966\end{array}$ & $\begin{array}{r}74,534 \\
4,962 \\
106,898 \\
1,787,888 \\
33,963\end{array}$ & $\begin{array}{r}1,307 \\
270 \\
2,555 \\
13,383 \\
550\end{array}$ \\
\hline 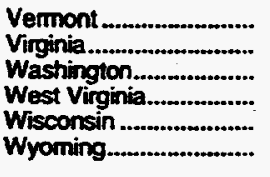 & $\begin{array}{r}2,126 \\
61,712 \\
38,359 \\
37,128 \\
127,009 \\
11,780\end{array}$ & $\begin{array}{r}16,920 \\
601,906 \\
425,624 \\
349,347 \\
1,097,514 \\
113,129\end{array}$ & $\begin{array}{r}2,081 \\
44,181 \\
38,502 \\
23,258 \\
70,090 \\
8,551\end{array}$ & $\begin{array}{r}2,768 \\
61,012 \\
55,231 \\
33,880 \\
102,492 \\
14,012\end{array}$ & $\begin{array}{r}1,901 \\
57,761 \\
73,239 \\
49,816 \\
127,439 \\
16,217\end{array}$ & $\begin{array}{r}14 \\
895 \\
3,365 \\
211 \\
7,307 \\
230\end{array}$ \\
\hline 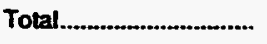 & $4,780,638$ & $49,309,593$ & $2,717,722$ & $4,168,048$ & $6,816,244$ & 225,346 \\
\hline
\end{tabular}

See foomotes at end of table. 
Table 16. Natural Gas Delivered to Consumers by State, 1967-1994 (Continued)

\begin{tabular}{|c|c|c|c|c|}
\hline \multirow[b]{2}{*}{ State } & Vohicte Fuel & Electric Utilltios & \multirow{2}{*}{$\begin{array}{l}\text { Delivered to Consumors } \\
\text { Qunitity } \\
\text { (nilition } \\
\text { cubtic foet) }\end{array}$} & \multirow{2}{*}{$\begin{array}{l}\text { Heating Value } \\
\text { (Btup per } \\
\text { cubic } \\
\text { foot) }\end{array}$} \\
\hline & $\begin{array}{l}\text { Quantity } \\
\text { (million } \\
\text { cubic feet) }\end{array}$ & $\begin{array}{l}\text { Quantity } \\
\text { (million } \\
\text { cubic feet) }\end{array}$ & & \\
\hline & \multicolumn{4}{|c|}{1989} \\
\hline 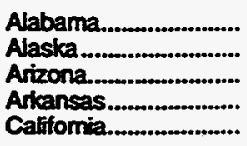 & $\begin{array}{l}\text { NA } \\
\text { NA } \\
\text { NA } \\
\text { NA } \\
\text { NA }\end{array}$ & $\begin{array}{r}1,760 \\
32,746 \\
50,807 \\
29,462 \\
517,700\end{array}$ & $\begin{array}{r}225,395 \\
127,414 \\
127,177 \\
228,378 \\
1,799,042\end{array}$ & $\begin{array}{r}1,030 \\
999 \\
1,040 \\
1,006 \\
1,037\end{array}$ \\
\hline 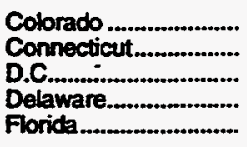 & $\begin{array}{l}\text { NA } \\
\text { NA } \\
\text { NA } \\
\text { NA } \\
\text { NA }\end{array}$ & $\begin{array}{r}8,375 \\
3,294 \\
0 \\
7,999 \\
186,814\end{array}$ & $\begin{array}{r}218,766 \\
94,487 \\
33,174 \\
34,919 \\
310,493\end{array}$ & $\begin{array}{l}1,011 \\
1,034 \\
1,010 \\
1,028 \\
1,042\end{array}$ \\
\hline 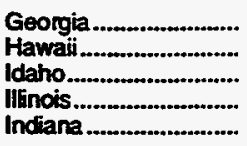 & $\begin{array}{l}\text { NA } \\
\text { NA } \\
\text { NA } \\
\text { NA } \\
\text { NA }\end{array}$ & $\begin{array}{r}684 \\
0 \\
0 \\
6,967 \\
4,075\end{array}$ & $\begin{array}{r}310,542 \\
2,694 \\
40,710 \\
981,948 \\
453,585\end{array}$ & $\begin{array}{l}1.026 \\
1,080 \\
1,027 \\
1,022 \\
1,016\end{array}$ \\
\hline 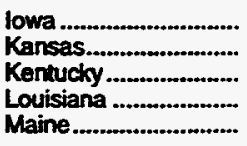 & $\begin{array}{l}\text { NA } \\
\text { NA } \\
\text { NA } \\
\text { NA } \\
\text { NA }\end{array}$ & $\begin{array}{r}2,402 \\
19,152 \\
328 \\
244,984 \\
0\end{array}$ & $\begin{array}{r}215,294 \\
254,361 \\
165,565 \\
1,232,511 \\
3,672\end{array}$ & $\begin{array}{r}1.011 \\
992 \\
1.039 \\
1.043 \\
1.003\end{array}$ \\
\hline 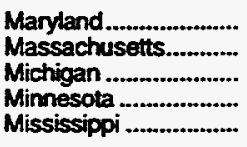 & $\begin{array}{l}\text { NA } \\
\text { NA } \\
\text { NA } \\
\text { NA } \\
\text { NA }\end{array}$ & $\begin{array}{r}19,184 \\
48,448 \\
18,782 \\
4,427 \\
44,927\end{array}$ & $\begin{array}{l}187,512 \\
247,205 \\
749,613 \\
287,997 \\
186,597\end{array}$ & $\begin{array}{l}1,032 \\
1,038 \\
1,029 \\
1,006 \\
1,030\end{array}$ \\
\hline $\begin{array}{l}\text { Missouri } \\
\text { Montana } \\
\text { Nebraska } \\
\text { Nevada } \\
\text { New Hampshire }\end{array}$ & $\begin{array}{l}\text { NA } \\
\text { NA } \\
\text { NA } \\
\text { NA } \\
\text { NA }\end{array}$ & $\begin{array}{r}1,242 \\
336 \\
2,593 \\
23,210 \\
23\end{array}$ & $\begin{array}{r}247,363 \\
41,575 \\
115,293 \\
62,950 \\
13,925\end{array}$ & $\begin{array}{r}1.008 \\
1.020 \\
987 \\
1.030 \\
1.019\end{array}$ \\
\hline 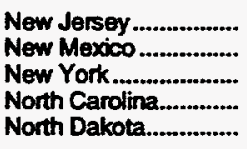 & $\begin{array}{l}\text { NA } \\
\text { NA } \\
\text { NA } \\
\text { NA } \\
\text { NA }\end{array}$ & $\begin{array}{r}55,412 \\
27,365 \\
182,000 \\
1,673 \\
1\end{array}$ & $\begin{array}{r}453,110 \\
101,126 \\
839,957 \\
156,105 \\
24,959\end{array}$ & $\begin{array}{l}1,026 \\
1,048 \\
1.029 \\
1.031 \\
1.049\end{array}$ \\
\hline 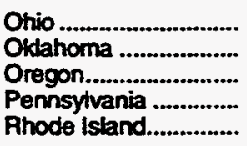 & $\begin{array}{l}\text { NA } \\
\text { NA } \\
\text { NA } \\
\text { NA } \\
\text { NA }\end{array}$ & $\begin{array}{r}983 \\
178,021 \\
12,942 \\
4,022 \\
2,147\end{array}$ & $\begin{array}{r}799,852 \\
474,118 \\
99,448 \\
649,508 \\
33,821\end{array}$ & $\begin{array}{l}1,042 \\
1,028 \\
1,035 \\
1,037 \\
1,027\end{array}$ \\
\hline 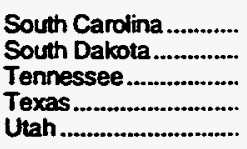 & $\begin{array}{l}\text { NA } \\
\text { NA } \\
\text { NA } \\
\text { NA } \\
\text { NA }\end{array}$ & $\begin{array}{r}2.705 \\
132 \\
18 \\
1,023.793 \\
636\end{array}$ & $\begin{array}{r}114,237 \\
25,263 \\
203,626 \\
3,224,451 \\
96,288\end{array}$ & $\begin{array}{l}1,026 \\
1.017 \\
1,032 \\
1,038 \\
1.087\end{array}$ \\
\hline 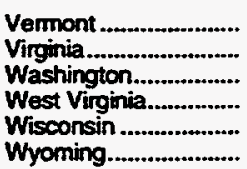 & $\begin{array}{l}\text { NA } \\
\text { NA } \\
\text { NA } \\
\text { NA } \\
\text { NA } \\
\text { NA }\end{array}$ & $\begin{array}{r}37 \\
3,796 \\
8,320 \\
124 \\
2,076 \\
85\end{array}$ & $\begin{array}{r}6,145 \\
167,450 \\
158,420 \\
110,327 \\
326,613 \\
36,633\end{array}$ & $\begin{array}{r}986 \\
1.041 \\
1.032 \\
1.077 \\
1.005 \\
1.055\end{array}$ \\
\hline 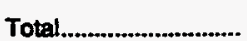 & NA & $2,787,012$ & $17,101,615$ & 1,031 \\
\hline
\end{tabular}

See tootnotes at end of table. 
Table 16. Natural Gas Delivered to Consumers by State, 1967-1994 (Continued)

\begin{tabular}{|c|c|c|c|c|c|c|}
\hline \multirow[b]{2}{*}{ sute } & \multicolumn{2}{|c|}{ Rocidential } & \multicolumn{2}{|c|}{ Commercial } & \multicolumn{2}{|c|}{ Industrial } \\
\hline & $\begin{array}{l}\text { Qunntity } \\
\text { (milition } \\
\text { cuchic foet) }\end{array}$ & Consumers & $\begin{array}{l}\text { Quantity } \\
\text { (miltion } \\
\text { cubic foot) }\end{array}$ & Consumers & $\begin{array}{l}\text { Oumntity } \\
\text { (minlion } \\
\text { cubic teet) }\end{array}$ & Consumers \\
\hline & \multicolumn{6}{|c|}{1990} \\
\hline 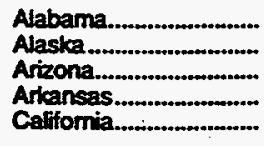 & $\begin{array}{r}45,411 \\
14,165 \\
30,320 \\
39,188 \\
514,507\end{array}$ & $\begin{array}{r}686,149 \\
70,808 \\
586,866 \\
488,850 \\
8,497,848\end{array}$ & $\begin{array}{r}24,287 \\
21,622 \\
28,401 \\
25,129 \\
285,090\end{array}$ & $\begin{array}{r}56,903 \\
11,921 \\
47,292 \\
61,530 \\
415,073\end{array}$ & $\begin{array}{r}145,628 \\
76,849 \\
18,379 \\
120,222 \\
565,206\end{array}$ & $\begin{array}{r}2,431 \\
8 \\
526 \\
1,396 \\
46,048\end{array}$ \\
\hline $\begin{array}{l}\text { Colorado } \\
\text { Connecticurt.... } \\
\text { D.C... } \\
\text { Delaware. } \\
\text { Fiorida..... }\end{array}$ & $\begin{array}{r}91,916 \\
37,446 \\
15,137 \\
7,270 \\
12,976\end{array}$ & $\begin{array}{r}983,592 \\
428,912 \\
136,183 \\
88,894 \\
457,648\end{array}$ & $\begin{array}{r}66,290 \\
29,410 \\
13,473 \\
4,042 \\
36,306\end{array}$ & $\begin{array}{r}112,661 \\
45,364 \\
11,322 \\
7,485 \\
43,674\end{array}$ & $\begin{array}{r}48,952 \\
25,448 \\
0 \\
17,036 \\
84,941\end{array}$ & $\begin{array}{r}1,018 \\
3,061 \\
0 \\
240 \\
452\end{array}$ \\
\hline 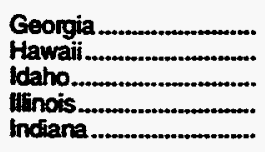 & $\begin{array}{r}90,263 \\
565 \\
8,569 \\
442,163 \\
140,492\end{array}$ & $\begin{array}{r}1,334,935 \\
29,137 \\
113,954 \\
3,287,091 \\
1,327,772\end{array}$ & $\begin{array}{r}49,486 \\
2,223 \\
8,535 \\
200,267 \\
67,223\end{array}$ & $\begin{array}{r}108,295 \\
2,837 \\
19,452 \\
257,851 \\
124,919\end{array}$ & $\begin{array}{r}161,992 \\
0 \\
23,327 \\
275,630 \\
228,126\end{array}$ & $\begin{array}{r}3,153 \\
0 \\
62 \\
25,991 \\
6,439\end{array}$ \\
\hline $\begin{array}{l}\text { lowa } \\
\text { Kansas... } \\
\text { Kentucky..... } \\
\text { Louisiana } \\
\text { Maine }\end{array}$ & $\begin{array}{r}71,380 \\
71,327 \\
56,064 \\
53,392 \\
648\end{array}$ & $\begin{array}{r}706,842 \\
747,081 \\
624,477 \\
934,007 \\
12,000\end{array}$ & $\begin{array}{r}43,953 \\
56,045 \\
31,806 \\
24,937 \\
1,678\end{array}$ & $\begin{array}{r}83,047 \\
85,539 \\
67.086 \\
62,770 \\
4,250\end{array}$ & $\begin{array}{r}90,240 \\
116,915 \\
68,408 \\
909,828 \\
2,024\end{array}$ & $\begin{array}{r}1,883 \\
4,357 \\
1,544 \\
1,504 \\
80\end{array}$ \\
\hline 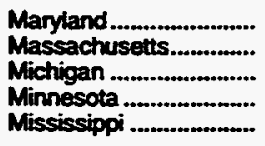 & $\begin{array}{r}66,428 \\
106,809 \\
327,396 \\
106,966 \\
25,045\end{array}$ & $\begin{array}{r}774,707 \\
1,118,429 \\
2,573,570 \\
946,107 \\
382,251\end{array}$ & $\begin{array}{r}24,051 \\
50,618 \\
159,429 \\
78,015 \\
17,548\end{array}$ & $\begin{array}{r}55,576 \\
85,775 \\
195,766 \\
95,474 \\
43,184\end{array}$ & $\begin{array}{r}61,848 \\
44,326 \\
280,615 \\
88,359 \\
100,801\end{array}$ & $\begin{array}{r}5,646 \\
6,539 \\
11,500 \\
2,574 \\
1,317\end{array}$ \\
\hline 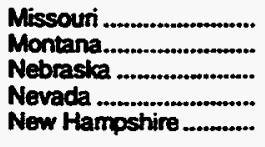 & $\begin{array}{r}115,950 \\
16,850 \\
41,499 \\
17,153 \\
5,903\end{array}$ & $\begin{array}{r}1,213,305 \\
174,384 \\
407,094 \\
256,119 \\
65,310\end{array}$ & $\begin{array}{r}59,387 \\
12,164 \\
36,489 \\
15,073 \\
5,073\end{array}$ & $\begin{array}{r}105.164 \\
23,331 \\
60,405 \\
20.694 \\
10.521\end{array}$ & $\begin{array}{r}54,538 \\
9,424 \\
25,746 \\
7.511 \\
3.276\end{array}$ & $\begin{array}{r}3.140 \\
457 \\
712 \\
100 \\
364\end{array}$ \\
\hline 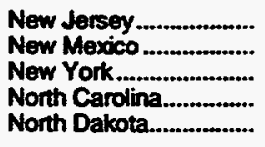 & $\begin{array}{r}171,660 \\
28,145 \\
337,988 \\
35,003 \\
9,183\end{array}$ & $\begin{array}{r}1,982,136 \\
369,451 \\
3,917,354 \\
520,140 \\
85,646\end{array}$ & $\begin{array}{r}115,591 \\
23,694 \\
194,990 \\
31,277 \\
10,236\end{array}$ & $\begin{array}{r}217,548 \\
38,026 \\
281,717 \\
68,088 \\
12,742\end{array}$ & $\begin{array}{r}90,376 \\
19,292 \\
101,285 \\
86,184 \\
4,359\end{array}$ & $\begin{array}{r}5,976 \\
1,407 \\
25,008 \\
2,802 \\
165\end{array}$ \\
\hline 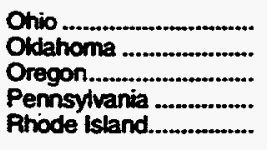 & $\begin{array}{r}308,321 \\
65,618 \\
23,383 \\
240,016 \\
17,724\end{array}$ & $\begin{array}{r}2,766,912 \\
814,296 \\
326,177 \\
2,311,795 \\
195,100\end{array}$ & $\begin{array}{r}143,503 \\
37,208 \\
20,449 \\
125,673 \\
8,071\end{array}$ & $\begin{array}{r}233.075 \\
85,790 \\
47,175 \\
186.772 \\
17,765\end{array}$ & $\begin{array}{r}278,459 \\
195,042 \\
48,890 \\
235,347 \\
4,381\end{array}$ & $\begin{array}{l}8,301 \\
2,889 \\
699 \\
6,238 \\
1,135\end{array}$ \\
\hline 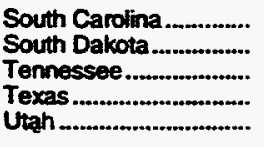 & $\begin{array}{r}18,396 \\
10,204 \\
46,340 \\
210,655 \\
43,424\end{array}$ & $\begin{array}{r}339,486 \\
105,436 \\
627,031 \\
3,232,849 \\
453,023\end{array}$ & $\begin{array}{r}15,394 \\
8,555 \\
43.552 \\
172.333 \\
16,220\end{array}$ & $\begin{array}{r}39,904 \\
13.443 \\
88,753 \\
268,181 \\
34,697\end{array}$ & $\begin{array}{r}86,831 \\
5,793 \\
109,703 \\
1,710,798 \\
35,502\end{array}$ & $\begin{array}{r}1,384 \\
275 \\
2,361 \\
13,659 \\
1,508\end{array}$ \\
\hline 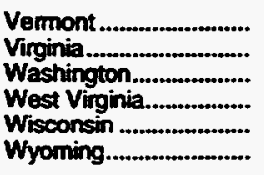 & $\begin{array}{r}2,150 \\
51,438 \\
40,346 \\
32,600 \\
114,050 \\
11,485\end{array}$ & $\begin{array}{r}18,300 \\
622,883 \\
458,013 \\
349,673 \\
1,123,557 \\
113,598\end{array}$ & $\begin{array}{r}2,049 \\
41,038 \\
38,671 \\
21,391 \\
66,339 \\
8,440\end{array}$ & $\begin{array}{r}2,949 \\
63,751 \\
58,148 \\
32,785 \\
106,043 \\
13,767\end{array}$ & $\begin{array}{r}1,878 \\
74,661 \\
78,424 \\
47,993 \\
121,896 \\
25,722\end{array}$ & $\begin{array}{r}15 \\
929 \\
3,428 \\
182 \\
7,154 \\
284\end{array}$ \\
\hline Total........................................... & $4,391,324$ & 50.187 .178 & $2,622,721$ & $4,236,280$ & $7,018,414$ & 218,341 \\
\hline
\end{tabular}

See foctinotes at end of table. 
Table 16. Natural Gas Delivered to Consumers by State, 1967-1994 (Continued)

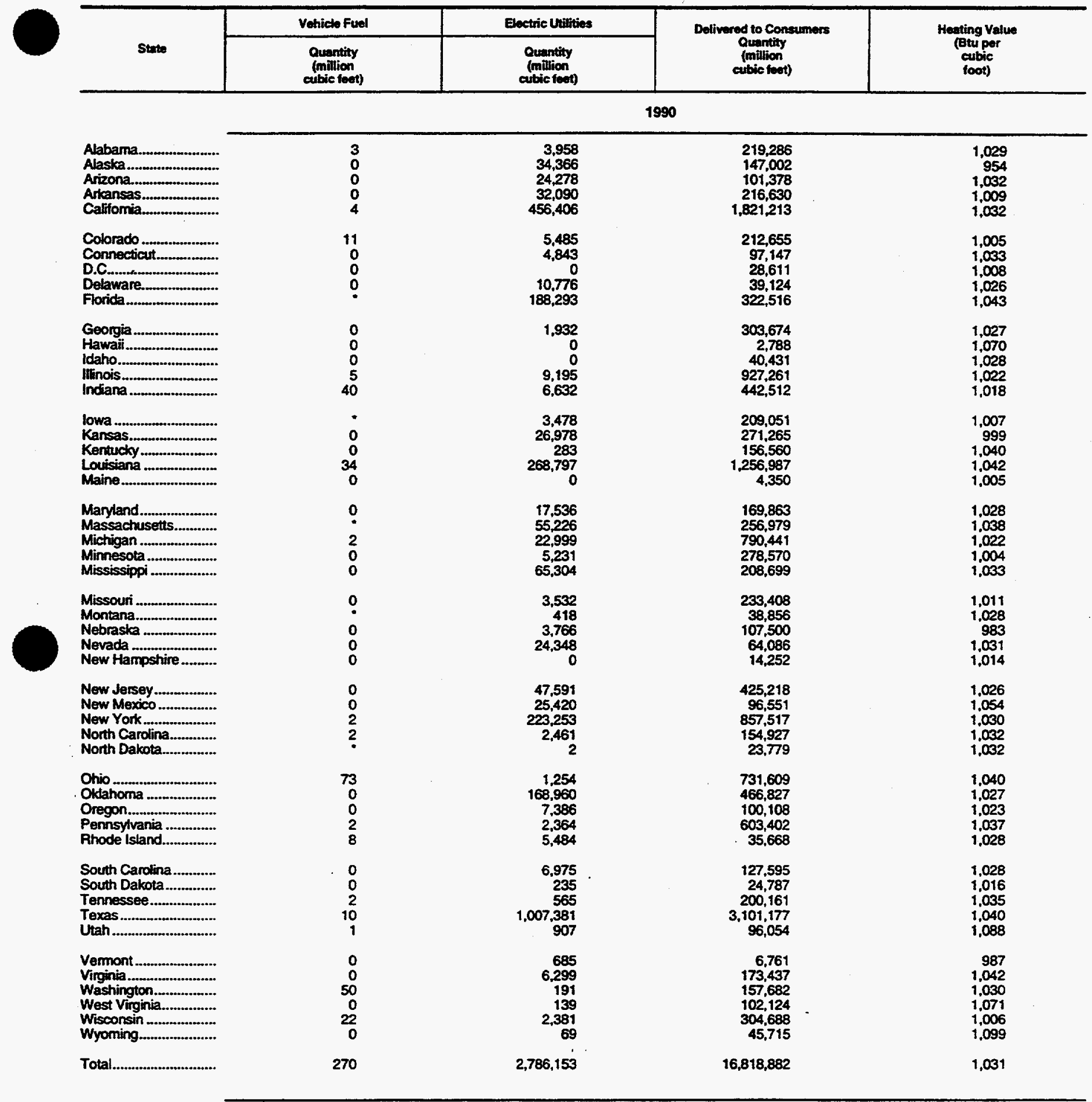

See footnotes at end of table. 
Table 16. Natural Gas Delivered to Consumers by State, 1967-1994 (Continued)

\begin{tabular}{|c|c|c|c|c|c|c|}
\hline \multirow[b]{2}{*}{ State } & \multicolumn{2}{|c|}{ Reaidential } & \multicolumn{2}{|c|}{ Commercial } & \multicolumn{2}{|c|}{ Induetrial } \\
\hline & $\begin{array}{l}\text { Quantity } \\
\text { (million } \\
\text { cubie twet) }\end{array}$ & Consumers & $\begin{array}{l}\text { Quantity } \\
\text { (million } \\
\text { cubie feet) }\end{array}$ & Consumers & $\begin{array}{l}\text { Quantity } \\
\text { (million } \\
\text { cubie fent) }\end{array}$ & Consumers: \\
\hline & \multicolumn{6}{|c|}{1991} \\
\hline 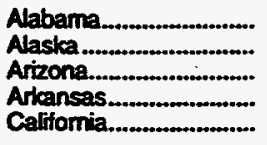 & $\begin{array}{r}46,149 \\
13,562 \\
31,353 \\
40,639 \\
508,697\end{array}$ & $\begin{array}{r}700,195 \\
72,565 \\
642,659 \\
495,148 \\
8,634,774\end{array}$ & $\begin{array}{r}23,711 \\
20,897 \\
27,597 \\
25,986 \\
287,608\end{array}$ & $\begin{array}{r}57,265 \\
12,071 \\
53,982 \\
61,731 \\
421,278\end{array}$ & $\begin{array}{r}154,825 \\
75,637 \\
19,204 \\
104,850 \\
602,619\end{array}$ & $\begin{array}{r}2,523 \\
8 \\
532 \\
1,367 \\
44,865\end{array}$ \\
\hline 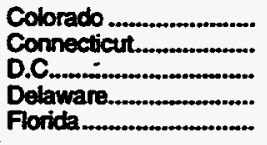 & $\begin{array}{r}97,440 \\
37,181 \\
15,286 \\
7,189 \\
12,908\end{array}$ & $\begin{array}{r}1,002,154 \\
430,078 \\
136,629 \\
91,467 \\
467,221\end{array}$ & $\begin{array}{r}68,938 \\
26,838 \\
15,550 \\
4,253 \\
39,264\end{array}$ & $\begin{array}{r}113,945 \\
45,925 \\
11,318 \\
7,895 \\
45,012\end{array}$ & $\begin{array}{r}56,176 \\
32,680 \\
0 \\
16,147 \\
83,398\end{array}$ & $\begin{array}{r}1,074 \\
2,921 \\
0 \\
243 \\
377\end{array}$ \\
\hline 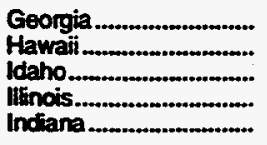 & $\begin{array}{r}96,662 \\
545 \\
10,223 \\
466,970 \\
146,446\end{array}$ & $\begin{array}{r}1,363,723 \\
29,701 \\
126,282 \\
3,320,285 \\
1,358,640\end{array}$ & $\begin{array}{r}51,036 \\
2,148 \\
9,582 \\
193,844 \\
68,383\end{array}$ & $\begin{array}{r}109,659 \\
2,786 \\
20,328 \\
261,107 \\
128,223\end{array}$ & $\begin{array}{r}167,098 \\
0 \\
26,662 \\
302,691 \\
227,769\end{array}$ & $\begin{array}{r}3,124 \\
0 \\
65 \\
26,489 \\
6,393\end{array}$ \\
\hline 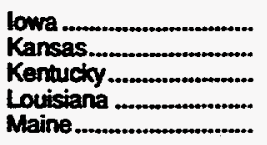 & $\begin{array}{r}78,801 \\
74,825 \\
59,465 \\
54,593 \\
722\end{array}$ & $\begin{array}{r}716,088 \\
753,839 \\
633,942 \\
936,423 \\
12,424\end{array}$ & $\begin{array}{r}46,615 \\
58,571 \\
33,700 \\
25,452 \\
1,860\end{array}$ & $\begin{array}{r}84,387 \\
86,874 \\
68,461 \\
61,574 \\
4,455\end{array}$ & $\begin{array}{r}97,446 \\
123,517 \\
71,637 \\
924,661 \\
2,207\end{array}$ & $\begin{array}{r}1,866 \\
3,445 \\
1,587 \\
1,469 \\
81\end{array}$ \\
\hline 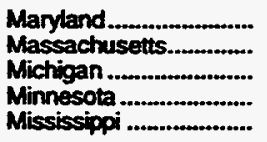 & $\begin{array}{r}69,235 \\
102,955 \\
337,205 \\
117,148 \\
25,756\end{array}$ & $\begin{array}{r}782,373 \\
1,127,536 \\
2,609,561 \\
970,941 \\
386,264\end{array}$ & $\begin{array}{r}38,117 \\
53,188 \\
165,558 \\
85,875 \\
17,743\end{array}$ & $\begin{array}{r}61,878 \\
88,746 \\
198,890 \\
97,388 \\
43,693\end{array}$ & $\begin{array}{r}47,150 \\
54,750 \\
271,987 \\
92,251 \\
104,622\end{array}$ & $\begin{array}{r}520 \\
5,006 \\
11,446 \\
2,486 \\
1,314\end{array}$ \\
\hline $\begin{array}{l}\text { Missouri ...................... } \\
\text { Montana } \\
\text { Nebrasle } \ldots \\
\text { Nevada } \ldots \ldots \\
\text { New Hampshire ............... }\end{array}$ & $\begin{array}{r}120,680 \\
18,413 \\
44,671 \\
19,135 \\
5,609\end{array}$ & $\begin{array}{r}1.211,342 \\
177,726 \\
413,354 \\
283,307 \\
67,991\end{array}$ & $\begin{array}{r}63,191 \\
12,846 \\
40,291 \\
16,960 \\
5,028\end{array}$ & $\begin{array}{r}117,675 \\
23,185 \\
60,947 \\
22,124 \\
11,088\end{array}$ & $\begin{array}{r}57,186 \\
9,873 \\
24,758 \\
6,624 \\
3,457\end{array}$ & $\begin{array}{r}3,096 \\
452 \\
718 \\
113 \\
361\end{array}$ \\
\hline 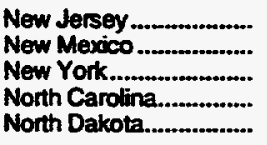 & $\begin{array}{r}176,640 \\
29,767 \\
338,892 \\
37,976 \\
10,338\end{array}$ & $\begin{array}{r}2,005,020 \\
379,472 \\
4,472,005 \\
5 \times 9,321 \\
87,880\end{array}$ & $\begin{array}{r}121,240 \\
24,993 \\
199,598 \\
34,313 \\
10,732\end{array}$ & $\begin{array}{r}215,408 \\
38,622 \\
310,941 \\
70,207 \\
12,082\end{array}$ & $\begin{array}{r}100,768 \\
19,346 \\
118,944 \\
84,863 \\
5,123\end{array}$ & $\begin{array}{r}8,444 \\
1,337 \\
28,837 \\
3,506 \\
170\end{array}$ \\
\hline 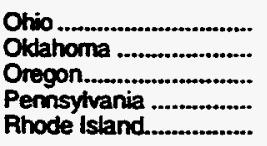 & $\begin{array}{r}321.724 \\
69,200 \\
26,324 \\
242,728 \\
17,366\end{array}$ & $\begin{array}{r}2,801,716 \\
824,172 \\
376,166 \\
2,333,377 \\
196,438\end{array}$ & $\begin{array}{r}150,339 \\
39,588 \\
22,328 \\
125,546 \\
8,269\end{array}$ & $\begin{array}{r}236,519 \\
86,744 \\
55,374 \\
191,103 \\
18,430\end{array}$ & $\begin{array}{r}279,750 \\
180,695 \\
55,049 \\
231,375 \\
26,867\end{array}$ & $\begin{array}{r}8,479 \\
2,840 \\
787 \\
6,344 \\
1,107\end{array}$ \\
\hline 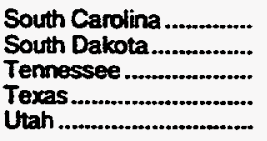 & $\begin{array}{r}19,612 \\
11,218 \\
49,357 \\
222,200 \\
50,572\end{array}$ & $\begin{array}{r}344.763 \\
107.846 \\
651,105 \\
3.274,482 \\
455,649\end{array}$ & $\begin{array}{r}15,796 \\
9,473 \\
45,953 \\
180,973 \\
19,276\end{array}$ & $\begin{array}{r}39,999 \\
13,692 \\
89,863 \\
269,411 \\
35,627\end{array}$ & $\begin{array}{r}85,790 \\
4,658 \\
115,786 \\
1,772,691 \\
43,120\end{array}$ & $\begin{array}{r}1,400 \\
283 \\
2,369 \\
+3,770 \\
631\end{array}$ \\
\hline 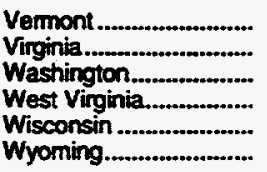 & $\begin{array}{r}2,203 \\
54,199 \\
46,222 \\
32,587 \\
124,081 \\
11,992\end{array}$ & $\begin{array}{r}19,879 \\
651,203 \\
492,189 \\
350,489 \\
1,151,939 \\
113,463\end{array}$ & $\begin{array}{r}2,058 \\
44,077 \\
41,738 \\
21,043 \\
71,516 \\
9,101\end{array}$ & $\begin{array}{r}3,154 \\
67,997 \\
60,887 \\
32,755 \\
109,616 \\
14,931\end{array}$ & $\begin{array}{r}1,717 \\
59,962 \\
79,735 \\
40,889 \\
128,798 \\
33,174\end{array}$ & $\begin{array}{r}13 \\
1,156 \\
3.495 \\
198 \\
7.194 \\
228\end{array}$ \\
\hline 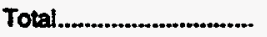 & $4,555,659$ & $51,593,206$ & $2,728,581$ & $4,357,252$ & $7,230,962$ & 216,529 \\
\hline
\end{tabular}


Table 16. Natural Gas Delivered to Consumers by State, 1967-1994 (Continued)

\begin{tabular}{|c|c|c|c|c|}
\hline \multirow[b]{2}{*}{ State } & Vehicte Fuel & Electric Utifities & \multirow{2}{*}{$\begin{array}{l}\text { Dolivered to Consumers } \\
\text { Quantity } \\
\text { (million } \\
\text { cubic toot) }\end{array}$} & \multirow{2}{*}{$\begin{array}{l}\text { Heating Value } \\
\text { (Btu per } \\
\text { cubic } \\
\text { foot) }\end{array}$} \\
\hline & $\begin{array}{l}\text { Quantity } \\
\text { (million } \\
\text { celbic foet) }\end{array}$ & $\begin{array}{l}\text { Quantity } \\
\text { (miltion } \\
\text { cubic foet) }\end{array}$ & & \\
\hline & \multicolumn{4}{|c|}{1991} \\
\hline 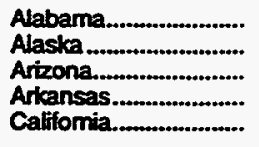 & $\begin{array}{r}0 \\
0 \\
37 \\
0 \\
9\end{array}$ & $\begin{array}{r}4,081 \\
31,330 \\
23,282 \\
27,903 \\
449,014\end{array}$ & $\begin{array}{r}228,765 \\
141,426 \\
101,473 \\
199,379 \\
1,847,949\end{array}$ & $\begin{array}{l}1,027 \\
1.002 \\
1.025 \\
1,017 \\
1,027\end{array}$ \\
\hline 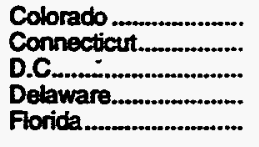 & $\begin{array}{r}15 \\
0 \\
0 \\
0 \\
7\end{array}$ & $\begin{array}{r}5,715 \\
4,702 \\
0 \\
14,354 \\
201,319\end{array}$ & $\begin{array}{r}228,283 \\
101,380 \\
30,836 \\
41,944 \\
336,895\end{array}$ & $\begin{array}{l}1,029 \\
1,031 \\
1,006 \\
1,034 \\
1,049\end{array}$ \\
\hline 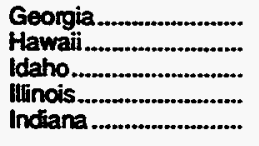 & $\begin{array}{r}0 \\
0 \\
0 \\
7 \\
49\end{array}$ & $\begin{array}{r}838 \\
0 \\
0 \\
12,865 \\
10,043\end{array}$ & $\begin{array}{r}315,634 \\
2,694 \\
46,467 \\
976,377 \\
452,690\end{array}$ & $\begin{array}{l}1,027 \\
1,080 \\
1,033 \\
1,019 \\
1,014\end{array}$ \\
\hline 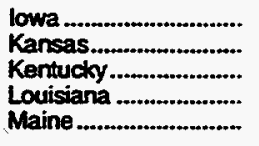 & $\begin{array}{l}1 \\
0 \\
0 \\
9 \\
0\end{array}$ & $\begin{array}{r}3,671 \\
36,122 \\
227 \\
254,245 \\
0\end{array}$ & $\begin{array}{r}226,533 \\
293,035 \\
165,028 \\
1,258,960 \\
4,789\end{array}$ & $\begin{array}{l}1,008 \\
1,007 \\
1,047 \\
1,047 \\
1,006\end{array}$ \\
\hline 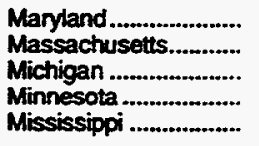 & $\begin{array}{l}0 \\
1 \\
3 \\
0 \\
0\end{array}$ & $\begin{array}{r}16,059 \\
39,133 \\
23,736 \\
5,870 \\
62,409\end{array}$ & $\begin{array}{l}170,561 \\
250,028 \\
798,489 \\
301,144 \\
210,531\end{array}$ & $\begin{array}{l}1,027 \\
1,039 \\
1.020 \\
1.012 \\
1.029\end{array}$ \\
\hline 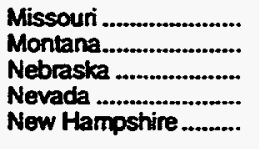 & $\begin{array}{l}0 \\
2 \\
0 \\
8 \\
0\end{array}$ & $\begin{array}{r}12,709 \\
268 \\
3,689 \\
21,738 \\
0\end{array}$ & $\begin{array}{r}253,765 \\
41,401 \\
113,409 \\
64,465 \\
14,094\end{array}$ & $\begin{array}{r}1.009 \\
1,029 \\
984 \\
1.032 \\
1.007\end{array}$ \\
\hline 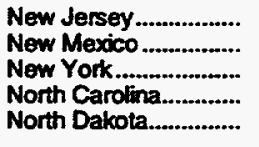 & $\begin{array}{r}0 \\
0 \\
25 \\
1 \\
1\end{array}$ & $\begin{array}{r}61,874 \\
28,100 \\
211,640 \\
3,020 \\
1\end{array}$ & $\begin{array}{r}460,521 \\
102,206 \\
869,100 \\
160,172 \\
26,195\end{array}$ & $\begin{array}{l}1,026 \\
1.039 \\
1.028 \\
1.032 \\
1.046\end{array}$ \\
\hline 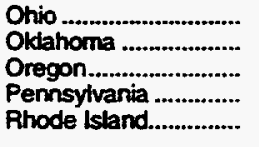 & $\begin{array}{r}67 \\
8 \\
0 \\
3 \\
9\end{array}$ & $\begin{array}{r}3,237 \\
167,214 \\
10,856 \\
2,037 \\
1,638\end{array}$ & $\begin{array}{r}755,118 \\
456,705 \\
114,557 \\
601,688 \\
54,148\end{array}$ & $\begin{array}{l}1.044 \\
1,021 \\
1.029 \\
1.035 \\
1.028\end{array}$ \\
\hline 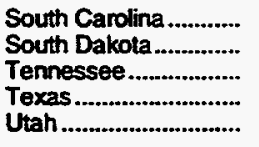 & $\begin{array}{l}0 \\
2 \\
1 \\
2 \\
6\end{array}$ & $\begin{array}{r}9,823 \\
177 \\
211 \\
1,005,051 \\
5,190\end{array}$ & $\begin{array}{r}131,020 \\
25,529 \\
211,309 \\
3,180,917 \\
118,164\end{array}$ & $\begin{array}{l}1,027 \\
1,018 \\
1,033 \\
1,037 \\
1,073\end{array}$ \\
\hline 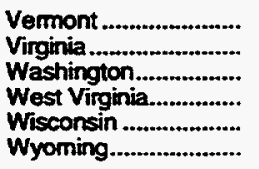 & $\begin{array}{r}0 \\
0 \\
66 \\
0 \\
23 \\
5\end{array}$ & $\begin{array}{r}1,091 \\
9,471 \\
139 \\
140 \\
2,706 \\
76\end{array}$ & $\begin{array}{r}7,069 \\
167,709 \\
167,901 \\
94,659 \\
327,124 \\
54,348\end{array}$ & $\begin{array}{r}988 \\
1,042 \\
1,031 \\
1,073 \\
1,007 \\
1,060\end{array}$ \\
\hline 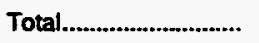 & 367 & $2,789,014$ & $17,304,582$ & 1.030 \\
\hline
\end{tabular}

See tootnoles at end of table. 
Table 16. Natural Gas Delivered to Consumers by State, 1967-1994 (Continued)

\begin{tabular}{|c|c|c|c|c|c|c|}
\hline \multirow[b]{2}{*}{ State } & \multicolumn{2}{|c|}{ Reaidential } & \multicolumn{2}{|c|}{ Commercial } & \multicolumn{2}{|c|}{ Industrial } \\
\hline & $\begin{array}{l}\text { Quantity } \\
\text { (million } \\
\text { eubie foct) }\end{array}$ & Consumers & $\begin{array}{l}\text { Quantity } \\
\text { (milation } \\
\text { cubic feet) }\end{array}$ & Consumers: & $\begin{array}{l}\text { Quentity } \\
\text { (mintion } \\
\text { cubic foet) }\end{array}$ & Concumers \\
\hline & \multicolumn{6}{|c|}{1992} \\
\hline 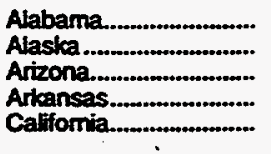 & $\begin{array}{r}49,644 \\
14,350 \\
28,386 \\
39,474 \\
479,537\end{array}$ & $\begin{array}{r}711,043 \\
74,268 \\
604,899 \\
504,722 \\
8,680,613\end{array}$ & $\begin{array}{r}25,232 \\
21,299 \\
27,089 \\
25,314 \\
285,008\end{array}$ & $\begin{array}{r}58,068 \\
12,204 \\
47,781 \\
62,221 \\
412,467\end{array}$ & $\begin{array}{r}169,049 \\
80,938 \\
19,774 \\
118,850 \\
594,569\end{array}$ & $\begin{array}{r}2,509 \\
10 \\
532 \\
1,319 \\
40,528\end{array}$ \\
\hline 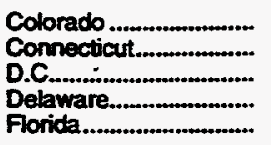 & $\begin{array}{r}94,614 \\
42,394 \\
16,587 \\
8,194 \\
14,380\end{array}$ & $\begin{array}{r}1,022,542 \\
432,244 \\
136,438 \\
94,027 \\
471,863\end{array}$ & $\begin{array}{r}66,420 \\
29,838 \\
16,103 \\
4,965 \\
41,727\end{array}$ & $\begin{array}{r}114,898 \\
46,859 \\
11,206 \\
8,173 \\
45,123\end{array}$ & $\begin{array}{r}57,579 \\
36,383 \\
0 \\
18,060 \\
84,829\end{array}$ & $\begin{array}{r}1,108 \\
2,923 \\
0 \\
248 \\
388\end{array}$ \\
\hline 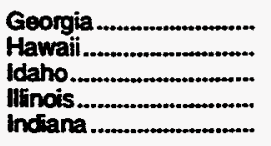 & $\begin{array}{r}108,214 \\
551 \\
9,659 \\
475,360 \\
152,692\end{array}$ & $\begin{array}{r}1,396,860 \\
29,805 \\
136,121 \\
3,354,679 \\
1,377,023\end{array}$ & $\begin{array}{r}53,861 \\
2,144 \\
8,932 \\
196,964 \\
72,720\end{array}$ & $\begin{array}{r}111,423 \\
2,793 \\
21,145 \\
263,988 \\
129,973\end{array}$ & $\begin{array}{r}172,227 \\
0 \\
27,044 \\
300,365 \\
245,523\end{array}$ & $\begin{array}{r}3,186 \\
0 \\
66 \\
27,178 \\
6,358\end{array}$ \\
\hline 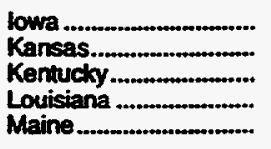 & $\begin{array}{r}74,879 \\
71,522 \\
61,911 \\
55,221 \\
872\end{array}$ & $\begin{array}{r}729,081 \\
762,545 \\
644,281 \\
940,403 \\
13,766\end{array}$ & $\begin{array}{r}46,095 \\
53,973 \\
35,419 \\
28,445 \\
2,209\end{array}$ & $\begin{array}{r}85,325 \\
86,840 \\
69,466 \\
61,030 \\
4,838\end{array}$ & $\begin{array}{r}100,752 \\
130,807 \\
73,619 \\
932,467 \\
2,048\end{array}$ & $\begin{array}{r}1,835 \\
3,296 \\
1,608 \\
1,452 \\
80\end{array}$ \\
\hline 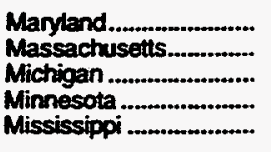 & $\begin{array}{r}75,122 \\
119,670 \\
358,088 \\
113,560 \\
26,487\end{array}$ & $\begin{array}{r}894,677 \\
1,137,911 \\
2,640,579 \\
998,201 \\
392,155\end{array}$ & $\begin{array}{r}42,464 \\
64,352 \\
173,802 \\
82,381 \\
17,942\end{array}$ & $\begin{array}{r}62,858 \\
85,873 \\
201,561 \\
99,707 \\
44,313\end{array}$ & $\begin{array}{r}49,720 \\
70,872 \\
305,416 \\
93,025 \\
102,612\end{array}$ & $\begin{array}{r}514 \\
8,723 \\
11,460 \\
2,515 \\
1,327\end{array}$ \\
\hline 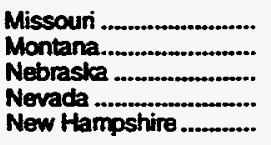 & $\begin{array}{r}116,655 \\
16,673 \\
41,414 \\
18,184 \\
6,449\end{array}$ & $\begin{array}{r}1,220,203 \\
182,641 \\
418,611 \\
295,714 \\
69,356\end{array}$ & $\begin{array}{r}60,963 \\
11,557 \\
34,490 \\
16,101 \\
5,862\end{array}$ & $\begin{array}{r}125,174 \\
23,610 \\
61,319 \\
22,799 \\
11,383\end{array}$ & $\begin{array}{r}58,466 \\
12,218 \\
26,451 \\
9,259 \\
3,828\end{array}$ & $\begin{array}{r}2,989 \\
459 \\
696 \\
114 \\
344\end{array}$ \\
\hline 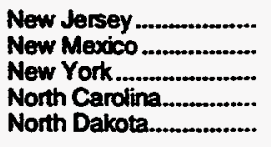 & $\begin{array}{r}198,462 \\
31,433 \\
378,689 \\
42,588 \\
9,693\end{array}$ & $\begin{array}{r}2,032,115 \\
389,063 \\
4,522,274 \\
575,096 \\
89,522\end{array}$ & $\begin{array}{r}130,891 \\
27,884 \\
217,214 \\
36,418 \\
9,759\end{array}$ & $\begin{array}{r}212,726 \\
40,312 \\
315,974 \\
72,647 \\
12,353\end{array}$ & $\begin{array}{r}174,569 \\
17,070 \\
147,520 \\
90,984 \\
5,940\end{array}$ & $\begin{array}{r}11,474 \\
141 \\
28,198 \\
3,119 \\
171\end{array}$ \\
\hline 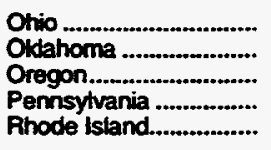 & $\begin{array}{r}340,628 \\
65,811 \\
23,109 \\
266,528 \\
20,000\end{array}$ & $\begin{array}{r}2,826,713 \\
832,677 \\
354,256 \\
2,363,575 \\
197,926\end{array}$ & $\begin{array}{r}160,645 \\
35,190 \\
19,570 \\
134,254 \\
9,080\end{array}$ & $\begin{array}{r}237,861 \\
87,120 \\
50,251 \\
193,863 \\
18,607\end{array}$ & $\begin{array}{r}294,805 \\
175,168 \\
58,519 \\
236,708 \\
47,917\end{array}$ & $\begin{array}{r}8,573 \\
2,859 \\
740 \\
6,496 \\
1,096\end{array}$ \\
\hline 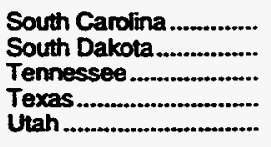 & $\begin{array}{r}22,392 \\
10,791 \\
52,220 \\
214,682 \\
44,701\end{array}$ & $\begin{array}{r}357,818 \\
110,291 \\
696,140 \\
3,285,025 \\
467,664\end{array}$ & $\begin{array}{r}16.644 \\
9.122 \\
46.532 \\
184,673 \\
16.584\end{array}$ & $\begin{array}{r}40,968 \\
14,133 \\
91,999 \\
292,990 \\
36,145\end{array}$ & $\begin{array}{r}94,327 \\
4,488 \\
126,230 \\
1,734,001 \\
40,878\end{array}$ & $\begin{array}{r}1,568 \\
319 \\
2,425 \\
5,481 \\
783\end{array}$ \\
\hline 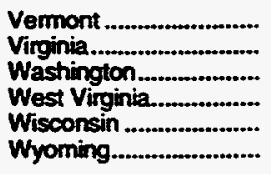 & $\begin{array}{r}2,520 \\
62,431 \\
43,048 \\
35,291 \\
123,405 \\
10,895\end{array}$ & $\begin{array}{r}20,468 \\
664,500 \\
528,913 \\
352,463 \\
1,182,834 \\
114,793\end{array}$ & $\begin{array}{r}2,319 \\
50,757 \\
37,800 \\
24,419 \\
71,314 \\
8,009\end{array}$ & $\begin{array}{r}3,198 \\
69,629 \\
63,391 \\
33,289 \\
112,761 \\
15,064\end{array}$ & $\begin{array}{r}1.958 \\
68,808 \\
79,766 \\
44,178 \\
130,267 \\
56,046\end{array}$ & $\begin{array}{r}18 \\
1.101 \\
3,490 \\
159 \\
7,396 \\
244\end{array}$ \\
\hline 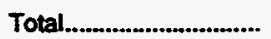 & $4,690,065$ & $52,331,397$ & $2,802.751$ & $4,409,699$ & $7,526,898$ & 209,616 \\
\hline
\end{tabular}

See tootnotes at end of table. 
Table 16. Natural Gas Delivered to Consumers by State, 1967-1994 (Continued)

\begin{tabular}{|c|c|c|c|c|c|}
\hline \multirow[b]{2}{*}{ Stote } & Vehiclo Fuol & Electric Utilities & \multirow{2}{*}{$\begin{array}{l}\text { Delivered to Consumers } \\
\text { Quenntity } \\
\text { (mbilion } \\
\text { curic toet) }\end{array}$} & \multirow{2}{*}{$\begin{array}{l}\text { Heating Valuo } \\
\text { (Bui per } \\
\text { cubic } \\
\text { foot) }\end{array}$} & \\
\hline & $\begin{array}{l}\text { Quantity } \\
\text { (million } \\
\text { culbic feot) }\end{array}$ & $\begin{array}{l}\text { Quantity } \\
\text { (million } \\
\text { cubic foet) }\end{array}$ & & & \\
\hline & \multicolumn{5}{|c|}{1992} \\
\hline 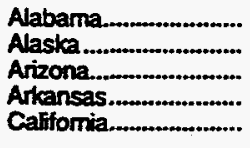 & $\begin{array}{r}3 \\
0 \\
46 \\
0 \\
27\end{array}$ & $\begin{array}{r}3,368 \\
28,953 \\
30,989 \\
27,015 \\
564,432\end{array}$ & $\begin{array}{r}247,295 \\
145,541 \\
106,234 \\
210,653 \\
1,923,573\end{array}$ & $\begin{array}{l}1,028 \\
1,002 \\
1,031 \\
1,009 \\
1,029\end{array}$ & \\
\hline 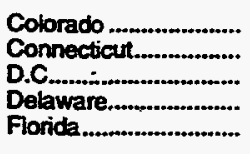 & $\begin{array}{l}23 \\
\dot{0} \\
0 \\
0 \\
9\end{array}$ & $\begin{array}{r}5,019 \\
2,100 \\
0 \\
8,384 \\
202,576\end{array}$ & $\begin{array}{r}223,656 \\
110,715 \\
32,690 \\
39,604 \\
343,521\end{array}$ & $\begin{array}{l}1.023 \\
1.028 \\
1.007 \\
1.035 \\
1.049\end{array}$ & \\
\hline 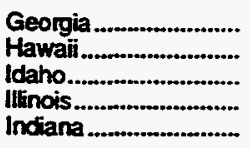 & $\begin{array}{r}0 \\
0 \\
0 \\
8 \\
59\end{array}$ & $\begin{array}{r}1,162 \\
0 \\
0 \\
9,298 \\
7,772\end{array}$ & $\begin{array}{r}335,464 \\
2,695 \\
45,635 \\
981,991 \\
478,765\end{array}$ & $\begin{array}{l}1,025 \\
1,073 \\
1,030 \\
1,018 \\
1,011\end{array}$ & ... \\
\hline $\begin{array}{l}\text { lowa } \\
\text { Kansas. } \\
\text { Kentucky } \\
\text { Louisiana } \\
\text { Maine }\end{array}$ & $\begin{array}{l}1 \\
0 \\
\dot{9} \\
0\end{array}$ & $\begin{array}{r}2,265 \\
13,981 \\
269 \\
254,922 \\
0\end{array}$ & $\begin{array}{r}223,992 \\
270,284 \\
171,218 \\
1,271,064 \\
5,129\end{array}$ & $\begin{array}{r}1,004 \\
987 \\
1,058 \\
1,044 \\
1,013\end{array}$ & \\
\hline 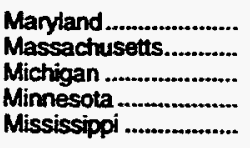 & $\begin{array}{l}0 \\
2 \\
4 \\
0 \\
0\end{array}$ & $\begin{array}{r}11,575 \\
38,341 \\
24,908 \\
4,906 \\
54,180\end{array}$ & $\begin{array}{l}178,881 \\
293,238 \\
862,217 \\
293,873 \\
201,221\end{array}$ & $\begin{array}{l}1,028 \\
1,037 \\
1,020 \\
1,011 \\
1,047\end{array}$ & \\
\hline 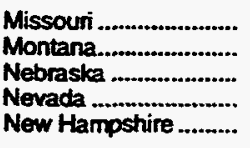 & $\begin{array}{r}0 \\
2 \\
12 \\
0\end{array}$ & $\begin{array}{r}2,351 \\
220 \\
1,903 \\
24,355 \\
633\end{array}$ & $\begin{array}{r}238,435 \\
40,671 \\
104,258 \\
67.912 \\
16.771\end{array}$ & $\begin{array}{r}1,002 \\
1,023 \\
979 \\
1,031 \\
1,009\end{array}$ & \\
\hline 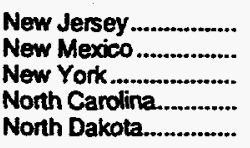 & $\begin{array}{l}0 \\
7 \\
6 \\
7 \\
3\end{array}$ & $\begin{array}{r}38,772 \\
22,486 \\
208,731 \\
3,159 \\
1\end{array}$ & $\begin{array}{r}542,695 \\
98,881 \\
952,161 \\
173,156 \\
25,397\end{array}$ & $\begin{array}{l}1,026 \\
1,040 \\
1,029 \\
1,034 \\
1,045\end{array}$ & \\
\hline 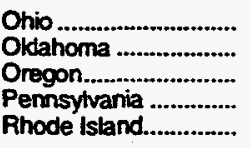 & $\begin{array}{r}59 \\
45 \\
6 \\
3 \\
9\end{array}$ & $\begin{array}{r}2,956 \\
148,980 \\
14,264 \\
3,100 \\
469\end{array}$ & $\begin{array}{r}799,093 \\
425,195 \\
115,469 \\
640,593 \\
77,476\end{array}$ & $\begin{array}{l}1,036 \\
1.026 \\
1.035 \\
1,036 \\
1,018\end{array}$ & \\
\hline 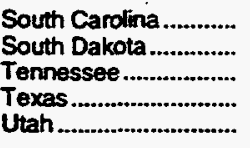 & $\begin{array}{r}0 \\
5 \\
2 \\
4 \\
15\end{array}$ & $\begin{array}{r}1,795 \\
48 \\
291 \\
968,165 \\
6,576\end{array}$ & $\begin{array}{r}135,157 \\
24,454 \\
225,275 \\
3,101,526 \\
108,755\end{array}$ & $\begin{array}{l}1,027 \\
1,015 \\
1,031 \\
1,043 \\
1,078\end{array}$ & \\
\hline 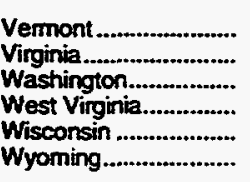 & $\begin{array}{r}0 \\
0 \\
94 \\
28 \\
10\end{array}$ & $\begin{array}{r}801 \\
10,936 \\
5,385 \\
201 \\
2,584 \\
83\end{array}$ & $\begin{array}{r}7,598 \\
192,932 \\
166,092 \\
104,089 \\
327,599 \\
75,044\end{array}$ & $\begin{array}{r}995 \\
1,039 \\
1,033 \\
1,065 \\
1,009 \\
1,058\end{array}$ & \\
\hline 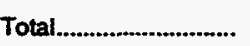 & 511 & $2,765,608$ & $17,785,833$ & 1,030 & \\
\hline
\end{tabular}

See footnotes at end of table. 
Table 16. Natural Gas Delivered to Consumers by State, 1967-1994 (Continued)

\begin{tabular}{|c|c|c|c|c|c|c|}
\hline \multirow[b]{2}{*}{ State } & \multicolumn{2}{|c|}{ Rosidential } & \multicolumn{2}{|c|}{ Commercial } & \multicolumn{2}{|c|}{ Industrial } \\
\hline & $\begin{array}{l}\text { Cuantity } \\
\text { (million } \\
\text { cubic twet) }\end{array}$ & Coneumers & $\begin{array}{l}\text { Quantity } \\
\text { (million } \\
\text { cubic foot) }\end{array}$ & Consumpers & $\begin{array}{l}\text { Quantity } \\
\text { (million } \\
\text { cribic faet) }\end{array}$ & Consumers \\
\hline & \multicolumn{6}{|c|}{1993} \\
\hline 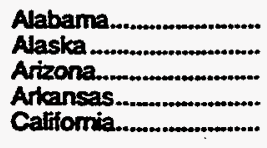 & $\begin{array}{r}51,366 \\
13,858 \\
28,161 \\
45,545 \\
500,968\end{array}$ & $\begin{array}{r}730,114 \\
75,842 \\
610,337 \\
513,466 \\
8,726,187\end{array}$ & $\begin{array}{r}25,723 \\
20,003 \\
27,568 \\
28,998 \\
250,283\end{array}$ & $\begin{array}{r}57,827 \\
12,359 \\
47,678 \\
62,952 \\
411,648\end{array}$ & $\begin{array}{r}181,692 \\
75,795 \\
21,164 \\
119,401 \\
659,723\end{array}$ & $\begin{array}{r}2,458 \\
11 \\
526 \\
1,364 \\
42,748\end{array}$ \\
\hline $\begin{array}{l}\text { Colorado } \\
\text { Connecticut... } \\
\text { D.C. } \\
\text { Delawane. } \\
\text { Florida }\end{array}$ & $\begin{array}{r}106,187 \\
42,213 \\
16,589 \\
8,295 \\
R_{13,940}\end{array}$ & $\begin{array}{r}1,044,699 \\
427,761 \\
135,986 \\
96,914 \\
484,816\end{array}$ & $\begin{array}{r}71,647 \\
31,427 \\
16,229 \\
5,195 \\
41,151\end{array}$ & $\begin{array}{r}115,924 \\
45,529 \\
11,133 \\
8,409 \\
47,344\end{array}$ & $\begin{array}{r}69,024 \\
36,842 \\
0 \\
19,453 \\
R_{100,350}\end{array}$ & $\begin{array}{r}1,032 \\
2,952 \\
0 \\
249 \\
433\end{array}$ \\
\hline 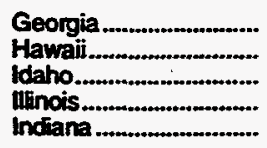 & $\begin{array}{r}115,655 \\
558 \\
12,557 \\
495,311 \\
163,944\end{array}$ & $\begin{array}{r}1,430,626 \\
29,984 \\
148,582 \\
3,388,983 \\
1,402,770\end{array}$ & $\begin{array}{r}57.525 \\
2,123 \\
10,675 \\
203,157 \\
78,047\end{array}$ & $\begin{array}{r}114,889 \\
3,222 \\
21,989 \\
268,104 \\
131,925\end{array}$ & $\begin{array}{r}167,388 \\
0 \\
29,146 \\
305,014 \\
263,283\end{array}$ & $\begin{array}{r}3,302 \\
0 \\
75 \\
27,807 \\
6,508\end{array}$ \\
\hline $\begin{array}{l}\text { lowa } \\
\text { Kansas..... } \\
\text { Kentucky. } \\
\text { Louisiana } \\
\text { Maine }\end{array}$ & $\begin{array}{r}f_{83,422} \\
84,896 \\
66,909 \\
56,609 \\
901\end{array}$ & $\begin{array}{r}740,722 \\
777,658 \\
654,664 \\
941,294 \\
13,880\end{array}$ & $\begin{array}{r}R_{50,337} \\
R_{56,023} \\
37,817 \\
25,157 \\
2,311\end{array}$ & $\begin{array}{r}86,452 \\
87,735 \\
71,998 \\
62,055 \\
4,979\end{array}$ & $\begin{array}{r}R_{102,625} \\
139,032 \\
76,020 \\
973,682 \\
1,753\end{array}$ & $\begin{array}{r}1,903 \\
4,369 \\
1,585 \\
1,592 \\
66\end{array}$ \\
\hline 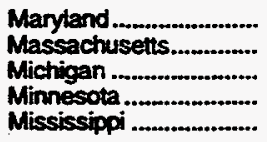 & $\begin{array}{r}76,871 \\
121,228 \\
369,801 \\
123,401 \\
28,347\end{array}$ & $\begin{array}{r}807,204 \\
1,155,443 \\
2,677,095 \\
1,074,631 \\
398,472\end{array}$ & $\begin{array}{r}43,635 \\
65,429 \\
180,230 \\
86,629 \\
19,199\end{array}$ & $\begin{array}{r}63,767 \\
102,187 \\
204,453 \\
93,062 \\
45,310\end{array}$ & $\begin{array}{r}48,842 \\
94,658 \\
312,050 \\
97,771 \\
100,166\end{array}$ & $\begin{array}{r}496 \\
7,283 \\
11,425 \\
2,477 \\
1,324\end{array}$ \\
\hline 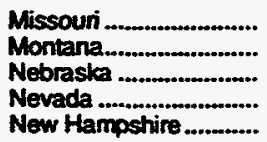 & $\begin{array}{r}134,172 \\
20,360 \\
48,256 \\
20,683 \\
6,493\end{array}$ & $\begin{array}{r}1,225,921 \\
188,879 \\
413,358 \\
305,099 \\
70,938\end{array}$ & $\begin{array}{r}69,670 \\
13,880 \\
R_{34,745} \\
17,549 \\
6,142\end{array}$ & $\begin{array}{r}125,571 \\
24,373 \\
P_{60,599} \\
23,207 \\
11,726\end{array}$ & $\begin{array}{r}60,982 \\
12,690 \\
R_{38,658} \\
24,734 \\
3,805\end{array}$ & $\begin{array}{r}3.040 \\
462 \\
7718 \\
117 \\
334\end{array}$ \\
\hline 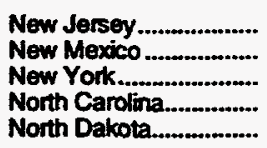 & $\begin{array}{r}195,569 \\
31,843 \\
384,216 \\
47,104 \\
10,717\end{array}$ & $\begin{array}{r}2,060,511 \\
397,681 \\
3,990,564 \\
607,388 \\
91,237\end{array}$ & $\begin{array}{r}128,942 \\
27,898 \\
220,729 \\
37,370 \\
10,642\end{array}$ & $\begin{array}{r}215,948 \\
40,166 \\
298,020 \\
76,386 \\
12,650\end{array}$ & $\begin{array}{r}188,889 \\
17,023 \\
160,406 \\
92,309 \\
6,096\end{array}$ & $\begin{array}{r}11,224 \\
152 \\
23,833 \\
2,664 \\
174\end{array}$ \\
\hline 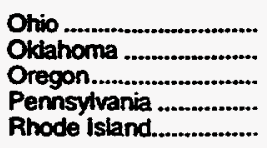 & $\begin{array}{r}354.110 \\
78,360 \\
29,777 \\
268,996 \\
19,722\end{array}$ & $\begin{array}{r}2,867,959 \\
842,130 \\
371,151 \\
2,386,249 \\
198,563\end{array}$ & $\begin{array}{r}164,044 \\
40,766 \\
24,047 \\
131,776 \\
9,205\end{array}$ & $\begin{array}{r}240,684 \\
88,181 \\
51,910 \\
198,299 \\
21,178\end{array}$ & $\begin{array}{r}301,261 \\
179,406 \\
60,617 \\
241,508 \\
46,031\end{array}$ & $\begin{array}{r}8,678 \\
2,912 \\
696 \\
6,407 \\
1,066\end{array}$ \\
\hline $\begin{array}{l}\text { South Carolina............ } \\
\text { South Dakota........... } \\
\text { Tennessee ........... } \\
\text { Texas } \\
\text { Utah }\end{array}$ & $\begin{array}{r}24,345 \\
12,431 \\
58,919 \\
231,799 \\
51,779\end{array}$ & $\begin{array}{r}370,411 \\
128,029 \\
733,363 \\
3,346,809 \\
484,438\end{array}$ & $\begin{array}{r}R_{17,014} \\
10,696 \\
50,754 \\
R_{175,988} \\
22,588\end{array}$ & $\begin{array}{r}\mathbf{P}_{42,191} \\
16,523 \\
94,860 \\
\mathbf{P}_{297,516} \\
37,816\end{array}$ & $\begin{array}{r}95,557 \\
4,976 \\
124,306 \\
R_{1,882,288} \\
42,301\end{array}$ & $\begin{array}{r}1,625 \\
355 \\
2,512 \\
\mathbf{F}_{5,823} \\
345\end{array}$ \\
\hline 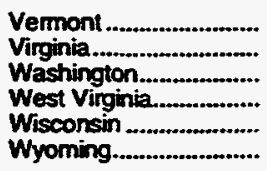 & $\begin{array}{r}2,530 \\
65,472 \\
53,258 \\
35,208 \\
130,134 \\
12,661\end{array}$ & $\begin{array}{r}21,553 \\
690,061 \\
565,475 \\
352,997 \\
1,220,500 \\
116,027\end{array}$ & $\begin{array}{r}2,382 \\
52,880 \\
43,620 \\
R_{24,381} \\
77,079 \\
10,268\end{array}$ & $\begin{array}{r}3,314 \\
70,161 \\
65,810 \\
33,611 \\
115,961 \\
15,315\end{array}$ & $\begin{array}{r}2,045 \\
72,949 \\
92,274 \\
R_{47,162} \\
134,073 \\
54,214\end{array}$ & $\begin{array}{r}20 \\
R_{2,706} \\
3,448 \\
197 \\
7.979 \\
194\end{array}$ \\
\hline Total.......................... & $A_{4,956,445}$ & $52,535,411$ & $A_{2,861,569}$ & $R_{4,464,906}$ & $\mathrm{R}_{7,981,433}$ & $R_{209,666}$ \\
\hline
\end{tabular}


Table 16. Natural Gas Delivered to Consumers by State, 1967-1994 (Continued)

\begin{tabular}{|c|c|c|c|c|}
\hline \multirow[b]{2}{*}{ Stane } & Vehiclo Fuel & Electric Utivitios & \multirow{2}{*}{$\begin{array}{l}\text { Dolivered to Consumers } \\
\text { Ouantity } \\
\text { (million } \\
\text { curbic foet) }\end{array}$} & \multirow{2}{*}{$\begin{array}{l}\text { Heating Value } \\
\text { (Btup per } \\
\text { cubic } \\
\text { foot) }\end{array}$} \\
\hline & $\begin{array}{l}\text { Quantity } \\
\text { (million } \\
\text { cubic foet) }\end{array}$ & $\begin{array}{l}\text { Quentity } \\
\text { (milition } \\
\text { eubic feet) }\end{array}$ & & \\
\hline & \multicolumn{4}{|c|}{1993} \\
\hline 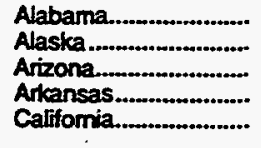 & $\begin{array}{r}4 \\
0 \\
44 \\
0 \\
255\end{array}$ & $\begin{array}{r}4,636 \\
28,025 \\
20,480 \\
21,191 \\
466,061\end{array}$ & $\begin{array}{r}263,421 \\
137,680 \\
97,417 \\
215,135 \\
1,877,290\end{array}$ & $\begin{array}{r}1,030 \\
994 \\
1,028 \\
1,014 \\
1,036\end{array}$ \\
\hline 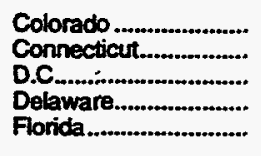 & $\begin{array}{r}18 \\
\dot{0} \\
0 \\
27\end{array}$ & $\begin{array}{r}4,860 \\
557 \\
0 \\
8,665 \\
174,361\end{array}$ & $\begin{array}{r}251,736 \\
111,040 \\
32,818 \\
41,608 \\
A_{329,829}\end{array}$ & $\begin{array}{l}1,011 \\
1,027 \\
1,007 \\
1,035 \\
1,052\end{array}$ \\
\hline 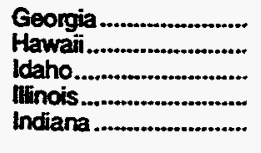 & $\begin{array}{r}4 \\
0 \\
0 \\
12 \\
54\end{array}$ & $\begin{array}{r}3,026 \\
0 \\
0 \\
16,022 \\
5,667\end{array}$ & $\begin{array}{r}343,598 \\
2,681 \\
52,379 \\
1,019,517 \\
510,995\end{array}$ & $\begin{array}{l}1,027 \\
1,062 \\
1,038 \\
1,021 \\
1,013\end{array}$ \\
\hline 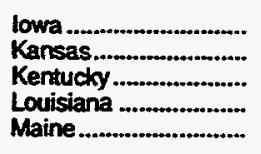 & $\begin{array}{l}5 \\
0 \\
1 \\
8 \\
0\end{array}$ & $\begin{array}{r}4,303 \\
21,636 \\
269 \\
243,983 \\
0\end{array}$ & $\begin{array}{r}R_{240,692} \\
301,586 \\
181,016 \\
1,299,439 \\
4,966\end{array}$ & $\begin{array}{r}1,003 \\
987 \\
1,048 \\
1,037 \\
1,014\end{array}$ \\
\hline 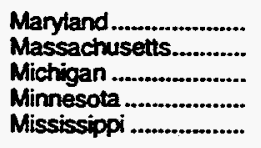 & $\begin{array}{r}19 \\
2 \\
10 \\
1 \\
0\end{array}$ & $\begin{array}{r}8,817 \\
28,793 \\
18,898 \\
3,910 \\
39,900\end{array}$ & $\begin{array}{l}178,185 \\
310,109 \\
880,988 \\
311,712 \\
187,611\end{array}$ & $\begin{array}{l}1,028 \\
1,038 \\
1,021 \\
1,011 \\
1,023\end{array}$ \\
\hline 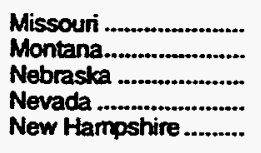 & $\begin{array}{r}0 \\
4 \\
1 \\
21 \\
0\end{array}$ & $\begin{array}{r}4,891 \\
270 \\
1,876 \\
21,305 \\
136\end{array}$ & $\begin{array}{r}269,716 \\
47,204 \\
123,537 \\
84,293 \\
16,577\end{array}$ & $\begin{array}{r}1,004 \\
1,018 \\
975 \\
1,034 \\
1,010\end{array}$ \\
\hline 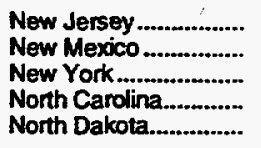 & $\begin{array}{r}0 \\
16 \\
20 \\
1 \\
8\end{array}$ & $\begin{array}{r}35.631 \\
27.725 \\
171.803 \\
2.911 \\
1\end{array}$ & $\begin{array}{r}549,030 \\
104,504 \\
937,173 \\
179,694 \\
27,464\end{array}$ & $\begin{array}{l}1,036 \\
1,039 \\
1,029 \\
1,035 \\
1,060\end{array}$ \\
\hline 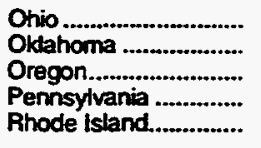 & $\begin{array}{r}44 \\
108 \\
8 \\
4 \\
1\end{array}$ & $\begin{array}{r}2,737 \\
153,666 \\
16.167 \\
8,304 \\
387\end{array}$ & $\begin{array}{l}822,195 \\
452,306 \\
130,615 \\
650,587 \\
75,346\end{array}$ & $\begin{array}{l}1,038 \\
1,026 \\
1,037 \\
1.037 \\
1,029\end{array}$ \\
\hline 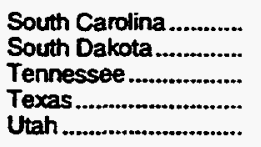 & $\begin{array}{r}0 \\
7 \\
4 \\
73 \\
33\end{array}$ & $\begin{array}{r}1,851 \\
186 \\
1,531 \\
1,072,506 \\
6,305\end{array}$ & $\begin{array}{r}A_{138,767} \\
28,295 \\
235,514 \\
A_{3,362,654} \\
123,005\end{array}$ & $\begin{array}{l}1,029 \\
1,013 \\
1,035 \\
1,028 \\
1,080\end{array}$ \\
\hline 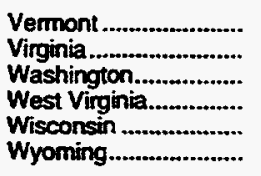 & $\begin{array}{r}0 \\
1 \\
100 \\
\dot{0} \\
29 \\
12\end{array}$ & $\begin{array}{r}268 \\
19.735 \\
4.899 \\
133 \\
3.070 \\
87\end{array}$ & $\begin{array}{r}7,225 \\
211,037 \\
194,151 \\
R_{106,883} \\
344,385 \\
77,242\end{array}$ & $\begin{array}{r}998 \\
1,044 \\
1,037 \\
R_{1}, 065 \\
1,011 \\
1,056\end{array}$ \\
\hline Total..................................... & 960 & $2,682,440$ & $A_{18,482,847}$ & 1,027 \\
\hline
\end{tabular}

See footnotes at end of table. 
Table 16. Natural Gas Delivered to Consumers by State, 1967-1994 (Continued)

\begin{tabular}{|c|c|c|c|c|c|c|c|}
\hline \multirow[b]{2}{*}{ Stat } & \multicolumn{2}{|c|}{ Residential } & \multicolumn{2}{|c|}{ Commencial } & \multicolumn{3}{|c|}{ Industrial } \\
\hline & $\begin{array}{l}\text { Quantity } \\
\text { (million } \\
\text { cubic feet) }\end{array}$ & Consurners & $\begin{array}{l}\text { Ouantity } \\
\text { (million } \\
\text { cubic foet) }\end{array}$ & Consumers: & $\begin{array}{l}\text { Ounntiny } \\
\text { (million } \\
\text { ctubic fuet) }\end{array}$ & Consumers & \\
\hline & \multicolumn{7}{|c|}{1994} \\
\hline 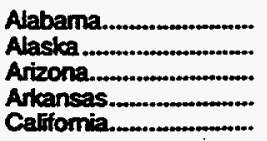 & $\begin{array}{r}49,748 \\
14,895 \\
29,684 \\
41,527 \\
520,959\end{array}$ & $\begin{array}{r}744,294 \\
77,670 \\
635,335 \\
521,176 \\
8,790,733\end{array}$ & $\begin{array}{r}25,526 \\
20,698 \\
29,187 \\
27,410 \\
261,999\end{array}$ & $\begin{array}{r}60,320 \\
12,475 \\
48,568 \\
63,821 \\
411,140\end{array}$ & $\begin{array}{r}181,718 \\
61,404 \\
25,869 \\
133,921 \\
656,751\end{array}$ & $\begin{array}{r}2,477 \\
11 \\
519 \\
1,417 \\
38,750\end{array}$ & \\
\hline 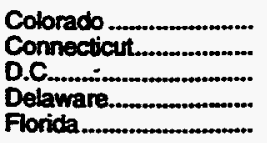 & $\begin{array}{r}99,504 \\
41,600 \\
15,865 \\
8,557 \\
13,855\end{array}$ & $\begin{array}{r}1,073,308 \\
428,157 \\
135,119 \\
100,431 \\
497,777\end{array}$ & $\begin{array}{r}65,870 \\
39,032 \\
14,742 \\
5,459 \\
39,935\end{array}$ & $\begin{array}{r}115,994 \\
45,042 \\
11,132 \\
8,721 \\
47,851\end{array}$ & $\begin{array}{r}71,093 \\
30,647 \\
0 \\
17,216 \\
126,873\end{array}$ & $\begin{array}{r}1,176 \\
3,754 \\
0 \\
252 \\
481\end{array}$ & \\
\hline 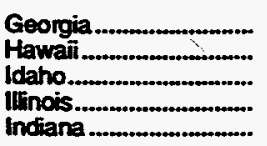 & $\begin{array}{r}105,436 \\
578 \\
12,285 \\
473,788 \\
157,467\end{array}$ & $\begin{array}{r}1,460,141 \\
30,614 \\
162,971 \\
3,418,052 \\
1,438,483\end{array}$ & $\begin{array}{r}54,051 \\
2,200 \\
10,088 \\
197,576 \\
75,819\end{array}$ & $\begin{array}{r}117,990 \\
2,805 \\
22,999 \\
202,308 \\
134,336\end{array}$ & $\begin{array}{r}173,901 \\
0 \\
29,781 \\
305,092 \\
270,128\end{array}$ & $\begin{array}{r}3,277 \\
0 \\
144 \\
25,788 \\
6,314\end{array}$ & $\ldots$ \\
\hline $\begin{array}{l}\text { lowa } \\
\text { Kansas } \\
\text { Kentucky } \\
\text { Lovisiana } \\
\text { Maine } \ldots \ldots \ldots \ldots \\
\end{array}$ & $\begin{array}{r}78,260 \\
74,156 \\
62,533 \\
52,981 \\
894\end{array}$ & $\begin{array}{r}750,678 \\
773,357 \\
668,774 \\
946,072 \\
14,104\end{array}$ & $\begin{array}{r}47,922 \\
52,253 \\
36,744 \\
24,184 \\
2,381\end{array}$ & $\begin{array}{r}86,918 \\
86,457 \\
73,462 \\
65,879 \\
5,297\end{array}$ & $\begin{array}{r}108,731 \\
187,979 \\
83,081 \\
999,034 \\
1,771\end{array}$ & $\begin{array}{r}1,957 \\
3,560 \\
1,621 \\
1,737 \\
89\end{array}$ & \\
\hline 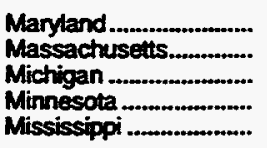 & $\begin{array}{r}76,688 \\
119,642 \\
364,588 \\
122,249 \\
27,006\end{array}$ & $\begin{array}{r}824,137 \\
1,179,869 \\
2,717,683 \\
1,049,263 \\
405,312\end{array}$ & $\begin{array}{r}44,136 \\
84,534 \\
183,068 \\
83,933 \\
19,232\end{array}$ & $\begin{array}{r}64,698 \\
92,744 \\
207,629 \\
102,857 \\
43,803\end{array}$ & $\begin{array}{r}47,691 \\
92,798 \\
327,848 \\
94,468 \\
96,863\end{array}$ & $\begin{array}{r}516 \\
8,019 \\
11,308 \\
2,592 \\
1,326\end{array}$ & \\
\hline 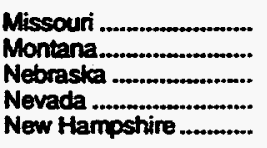 & $\begin{array}{r}122,566 \\
18,714 \\
44,397 \\
21,263 \\
6,572\end{array}$ & $\begin{array}{r}1,281,007 \\
194,357 \\
428,201 \\
336,353 \\
72,656\end{array}$ & $\begin{array}{r}66,196 \\
12,981 \\
38,946 \\
18,694 \\
6,412\end{array}$ & $\begin{array}{r}132,378 \\
25,349 \\
62,045 \\
24,521 \\
12,240\end{array}$ & $\begin{array}{r}71,602 \\
13,940 \\
36,960 \\
28,867 \\
4,471\end{array}$ & $\begin{array}{r}3,115 \\
453 \\
766 \\
119 \\
324\end{array}$ & \\
\hline 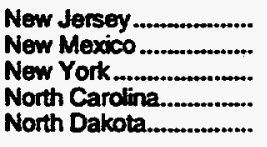 & $\begin{array}{r}216,873 \\
30,868 \\
385,408 \\
47,451 \\
10,661\end{array}$ & $\begin{array}{r}2,089,911 \\
409,095 \\
4,008,868 \\
652,307 \\
93,398\end{array}$ & $\begin{array}{r}132,008 \\
24,964 \\
223,256 \\
38,940 \\
10,783\end{array}$ & $\begin{array}{r}219,061 \\
39,846 \\
301,499 \\
80,739 \\
12,944\end{array}$ & $\begin{array}{r}190,845 \\
18,741 \\
214,438 \\
94,838 \\
5,846\end{array}$ & $\begin{array}{r}10,608 \\
1,097 \\
21,833 \\
3,401 \\
186\end{array}$ & \\
\hline 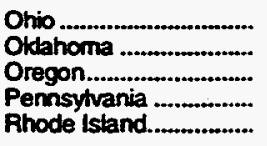 & $\begin{array}{r}343,331 \\
69,211 \\
28,848 \\
268,405 \\
17,384\end{array}$ & $\begin{array}{r}2,921,536 \\
845,448 \\
391,845 \\
2,393,053 \\
200,959\end{array}$ & $\begin{array}{r}166,798 \\
36,504 \\
22,960 \\
138,473 \\
12,049\end{array}$ & $\begin{array}{r}245.190 \\
87.494 \\
53.700 \\
206,812 \\
21,208\end{array}$ & $\begin{array}{r}311,123 \\
195,909 \\
62,569 \\
236,417 \\
40,921\end{array}$ & $\begin{array}{l}8,655 \\
2,853 \\
765 \\
6,388 \\
1,064\end{array}$ & \\
\hline 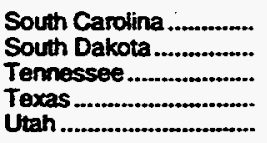 & $\begin{array}{r}23,486 \\
12,056 \\
57,334 \\
213,433 \\
48,922\end{array}$ & $\begin{array}{r}416,773 \\
119,544 \\
768,421 \\
3,350,314 \\
503,583\end{array}$ & $\begin{array}{r}17,870 \\
10,274 \\
50,760 \\
180,232 \\
26,501\end{array}$ & $\begin{array}{r}45,487 \\
15,539 \\
97,943 \\
306,376 \\
39,183\end{array}$ & $\begin{array}{r}97,500 \\
5,508 \\
118,889 \\
1,829,478 \\
36,618\end{array}$ & $\begin{array}{r}1,928 \\
381 \\
2,440 \\
5,222 \\
252\end{array}$ & \\
\hline 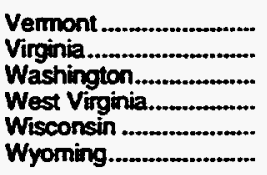 & $\begin{array}{r}2,438 \\
65,176 \\
53,144 \\
35,201 \\
128,175 \\
11,564\end{array}$ & $\begin{array}{r}22,546 \\
721,495 \\
604,315 \\
352,929 \\
1,253,333 \\
117,385\end{array}$ & $\begin{array}{r}2,669 \\
52,944 \\
42,982 \\
24,979 \\
78,609 \\
9,231\end{array}$ & $\begin{array}{r}3,512 \\
72,188 \\
68,118 \\
33,756 \\
119,788 \\
15,348\end{array}$ & $\begin{array}{r}2,023 \\
85,764 \\
107,603 \\
46,774 \\
135,106 \\
60,566\end{array}$ & $\begin{array}{r}24 \\
2.740 \\
3,586 \\
191 \\
7.342 \\
135\end{array}$ & \\
\hline 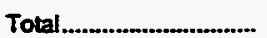 & $4,847,702$ & $53,393,142$ & $2,895,034$ & $4,537,500$ & $8,177,975$ & 202,953 & \\
\hline
\end{tabular}


Table 16. Natural Gas Delivered to Consumers by State, 1967-1994 (Continued)

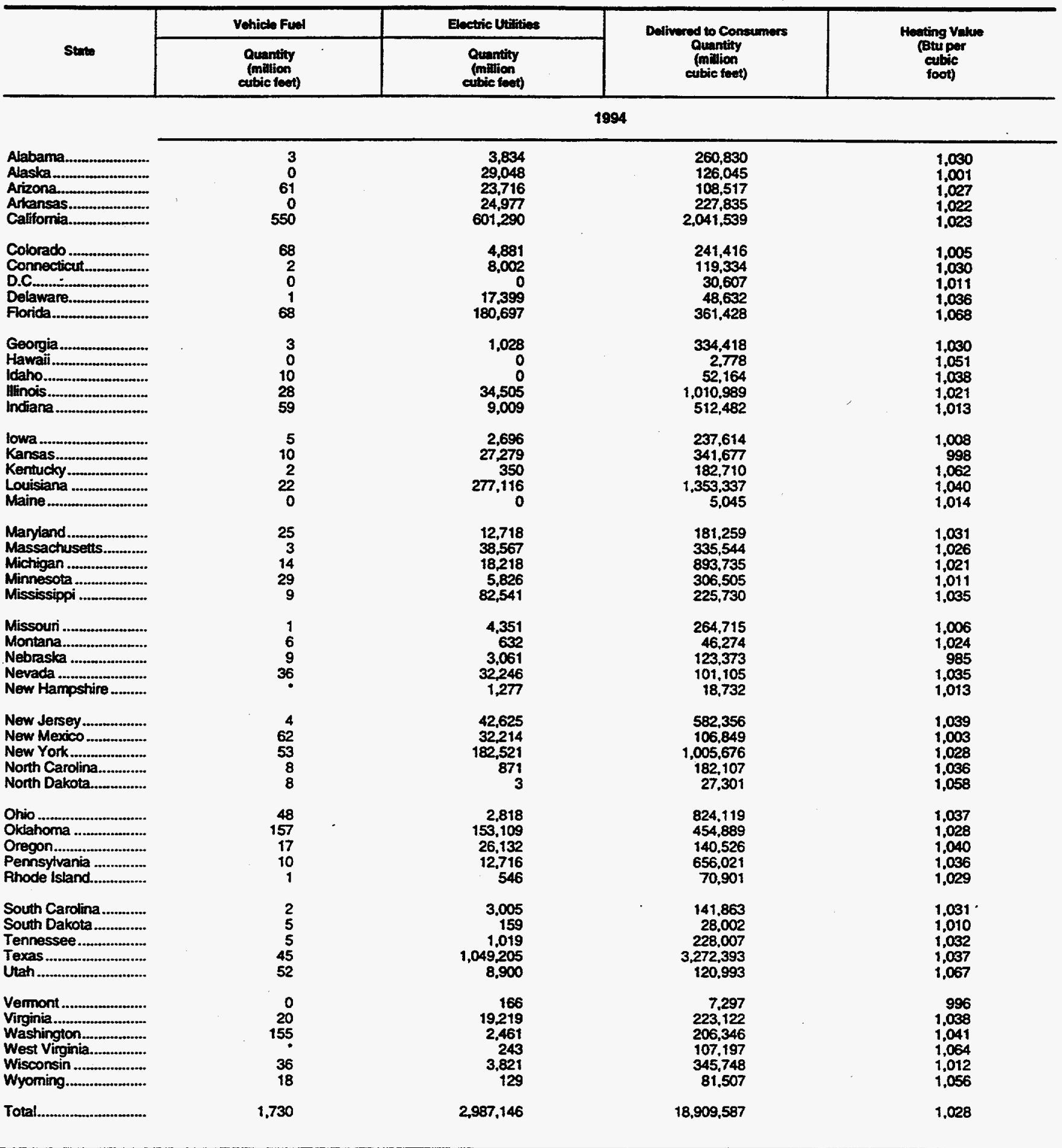

- Data for the District of Columbia are included with data for Maryand.

- Data for New Hampshire and Vermont are included with data for Maine.

$R=$ Revised data.

NA $=$ Not Available.

$=$ Volume is less than 500,000 cubic feet.

Notes: Number of vehicle fuel consumers generally refers to number of fueling stations. Totals may not equal sum of components due to independent roumding.

Sources: Eectric Uthlity Data: 1967-1977: Federal Power Commission (FPC). 1978-1989: Energy Intomation Administration (ElA), Form ElA-759. "Monthly Power Plant Report": Form -FERC-423, "Cost and Cuality of Fuets for Electric Utility Ptants"; and Form EiA-176, "Annual Report of Natural and Supplemental Gas Supply and Disposition." Heating Value: 1975: Federal Power Commission. 1976-1979: American Gas Association, Gas Facts. 1980-1989: Energy Information Administration, Form ElA-176. ALI other data: 1967-1980: ElA, Natural Gas Production and Consumption. 1990-1994: Energy Information Administration (EIA), Form ElA-759, "Monthly Power Plant Report," Form

FEAC-423, "Cost and Cuatity of Fuels for Electric Utity Plants." and Form ElA-176. "Annual Report of Natural and Supplemental Gas Supply and Disposition." 
Table 17. Firm Natural Gas Deliveries to Consumers by State, 1993-1994

(Million Cubic Feet)

\begin{tabular}{|c|c|c|c|c|c|c|}
\hline Stato & Reaidential & Commercial & Industrial & Vehicle Fuel & Eectric Utiluties & Total \\
\hline & \multicolumn{6}{|c|}{1993} \\
\hline 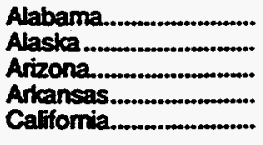 & $\begin{array}{r}51,366 \\
13,858 \\
28,161 \\
45,545 \\
500,968\end{array}$ & $\begin{array}{r}21,280 \\
20,003 \\
27,132 \\
28,043 \\
240,998\end{array}$ & $\begin{array}{r}56,379 \\
73,574 \\
20,121 \\
102,595 \\
582,492\end{array}$ & $\begin{array}{r}4 \\
0 \\
44 \\
0 \\
255\end{array}$ & $\begin{array}{r}33 \\
25,934 \\
27,219 \\
5,803 \\
416,941\end{array}$ & $\begin{array}{r}129,062 \\
133,368 \\
102,676 \\
181,985 \\
1,741,654\end{array}$ \\
\hline 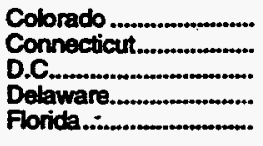 & $\begin{array}{r}106,187 \\
42,213 \\
16,589 \\
8,295 \\
14,837\end{array}$ & $\begin{array}{r}68,725 \\
22,635 \\
7,029 \\
5,195 \\
\mathbf{3 9 , 8 0 2}\end{array}$ & $\begin{array}{r}30,709 \\
18,187 \\
0 \\
13,144 \\
R_{27,195}\end{array}$ & $\begin{array}{r}7 \\
0 \\
0 \\
0 \\
27\end{array}$ & $\begin{array}{r}2,034 \\
108 \\
0 \\
8,322 \\
143,107\end{array}$ & $\begin{array}{r}207,661 \\
83,143 \\
23,618 \\
34,956 \\
225,532\end{array}$ \\
\hline 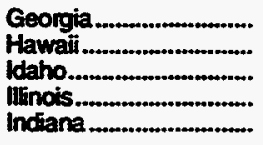 & $\begin{array}{r}115,655 \\
558 \\
12,557 \\
495,311 \\
163,944\end{array}$ & $\begin{array}{r}44,652 \\
1,779 \\
10,675 \\
200,101 \\
72,688\end{array}$ & $\begin{array}{r}28,771 \\
0 \\
25,765 \\
280,374 \\
62,865\end{array}$ & $\begin{array}{r}0 \\
0 \\
0 \\
12 \\
54\end{array}$ & $\begin{array}{r}3,080 \\
0 \\
0 \\
15,077 \\
743\end{array}$ & $\begin{array}{r}192,158 \\
2,337 \\
48,999 \\
990,875 \\
300,294\end{array}$ \\
\hline 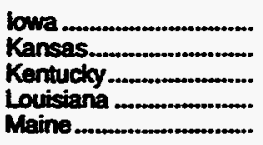 & $\begin{array}{r}83,288 \\
84,896 \\
66,909 \\
56,609 \\
901\end{array}$ & $\begin{array}{r}R_{45,573} \\
46,391 \\
R_{36,334} \\
18,275 \\
2,311\end{array}$ & $\begin{array}{r}R_{90,868} \\
61,599 \\
38,148 \\
596,135 \\
1,753\end{array}$ & $\begin{array}{l}5 \\
0 \\
1 \\
8 \\
0\end{array}$ & $\begin{array}{r}3,735 \\
1,407 \\
205 \\
97,059 \\
0\end{array}$ & $\begin{array}{r}223,395 \\
194,293 \\
141,662 \\
768,086 \\
4,966\end{array}$ \\
\hline 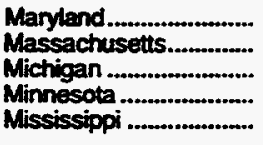 & $\begin{array}{r}76,871 \\
121,228 \\
369,801 \\
123,401 \\
28,347\end{array}$ & $\begin{array}{r}35,491 \\
58,104 \\
179,323 \\
62,193 \\
18,060\end{array}$ & $\begin{array}{r}12,535 \\
75,097 \\
284,928 \\
65,091 \\
31,867\end{array}$ & $\begin{array}{r}19 \\
2 \\
10 \\
1 \\
0\end{array}$ & $\begin{array}{r}1,231 \\
12,331 \\
16,621 \\
106 \\
30,631\end{array}$ & $\begin{array}{l}126,148 \\
266,761 \\
850,683 \\
250,793 \\
108,905\end{array}$ \\
\hline 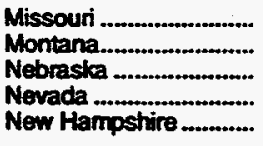 & $\begin{array}{r}134,172 \\
20,360 \\
48,256 \\
20,683 \\
6,493\end{array}$ & $\begin{array}{r}61,652 \\
13,576 \\
28,822 \\
17,305 \\
6,142\end{array}$ & $\begin{array}{r}29,882 \\
5,259 \\
\Omega_{28,230} \\
24,734 \\
3,697\end{array}$ & $\begin{array}{r}0 \\
4 \\
1 \\
21 \\
0\end{array}$ & $\begin{array}{r}1,374 \\
115 \\
668 \\
19,155 \\
0\end{array}$ & $\begin{array}{r}227,079 \\
39,314 \\
105,995 \\
81,898 \\
16,333\end{array}$ \\
\hline 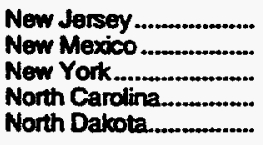 & $\begin{array}{r}195,569 \\
31,843 \\
384,216 \\
47,104 \\
10,717\end{array}$ & $\begin{array}{r}104,813 \\
27,764 \\
184,795 \\
35,630 \\
7,834\end{array}$ & $\begin{array}{r}73,920 \\
16,433 \\
104,437 \\
11,376 \\
400\end{array}$ & $\begin{array}{r}0 \\
16 \\
19 \\
1 \\
8\end{array}$ & $\begin{array}{r}34,366 \\
12,749 \\
21,288 \\
98 \\
1\end{array}$ & $\begin{array}{r}408,657 \\
88,805 \\
694,755 \\
94,209 \\
18,960\end{array}$ \\
\hline 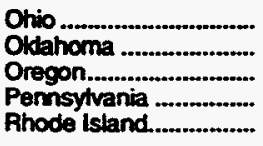 & $\begin{array}{r}354,110 \\
78,360 \\
29,777 \\
268,996 \\
19,722\end{array}$ & $\begin{array}{r}161,232 \\
37,460 \\
23,543 \\
117,745 \\
7,825\end{array}$ & $\begin{array}{r}258,309 \\
35,853 \\
16,057 \\
A_{152,465} \\
43,502\end{array}$ & $\begin{array}{r}44 \\
2 \\
8 \\
2 \\
1\end{array}$ & $\begin{array}{r}782 \\
154,024 \\
14,879 \\
5,984 \\
0\end{array}$ & $\begin{array}{r}774,477 \\
305,700 \\
84,275 \\
550,456 \\
71,050\end{array}$ \\
\hline $\begin{array}{l}\text { South Cerolina .............. } \\
\text { South Dakota ............... } \\
\text { Tennessee ................... } \\
\text { Texas } \\
\text { Utah .................................... }\end{array}$ & $\begin{array}{r}24,345 \\
12,431 \\
58,919 \\
231,799 \\
51,779\end{array}$ & $\begin{array}{r}R_{14,156} \\
8,890 \\
47,002 \\
R_{157,320} \\
21,258\end{array}$ & $\begin{array}{r}12,292 \\
2,040 \\
A_{38,150} \\
A_{1,014,361} \\
1,891\end{array}$ & $\begin{array}{r}0 \\
7 \\
4 \\
73 \\
33\end{array}$ & $\begin{array}{r}0 \\
0 \\
0 \\
R_{424,350} \\
0\end{array}$ & $\begin{array}{r}50,872 \\
23,368 \\
148,528 \\
1,827,903 \\
74,960\end{array}$ \\
\hline 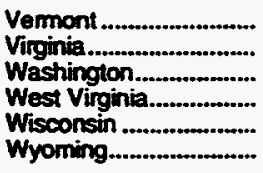 & $\begin{array}{r}2,530 \\
65,472 \\
53,258 \\
35,208 \\
130,134 \\
12,661\end{array}$ & $\begin{array}{r}2,382 \\
38,314 \\
\mathbf{3 3 , 5 3 3} \\
\beta_{6,908} \\
\mathbf{6 9 , 3 1 6} \\
\mathbf{5 , 6 7 2}\end{array}$ & $\begin{array}{r}100 \\
45,531 \\
47,153 \\
20,276 \\
47,369 \\
10,934\end{array}$ & $\begin{array}{r}0 \\
1 \\
77 \\
0 \\
6 \\
12\end{array}$ & $\begin{array}{r}0 \\
18,774 \\
0 \\
279 \\
1,359 \\
88\end{array}$ & $\begin{array}{r}5,012 \\
168,092 \\
134,022 \\
62,705 \\
248,183 \\
29,367\end{array}$ \\
\hline 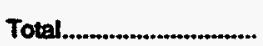 & $4,957,208$ & $R_{2,553,679}$ & $A_{4,624,853}$ & 792 & $A_{1,522,061}$ & $13,668,993$ \\
\hline
\end{tabular}

See fooinotes at end of table. 
Table 17. Firm Natural Gas Deliveries to Consumers by State, 1993-1994 (Continued) (Million Cubic Feet)

\begin{tabular}{|c|c|c|c|c|c|c|}
\hline State & Aceidential & Commercial & Industrial & Vehicle Fuel & Eloctric Utiatios & Total \\
\hline & \multicolumn{6}{|c|}{1994} \\
\hline 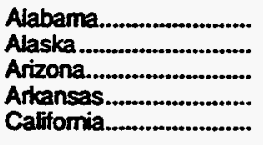 & $\begin{array}{r}49,748 \\
14,895 \\
29,684 \\
41,527 \\
520,959\end{array}$ & $\begin{array}{r}21,008 \\
20,698 \\
28,829 \\
23,654 \\
222,004\end{array}$ & $\begin{array}{r}71,344 \\
57,618 \\
24,898 \\
115,036 \\
399,736\end{array}$ & $\begin{array}{r}3 \\
0 \\
61 \\
0 \\
529\end{array}$ & $\begin{array}{r}83 \\
27,541 \\
32,636 \\
13,517 \\
288,054\end{array}$ & $\begin{array}{r}142,187 \\
120,751 \\
116,109 \\
193,734 \\
1,431,282\end{array}$ \\
\hline 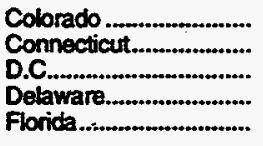 & $\begin{array}{r}99,504 \\
41,265 \\
15,865 \\
8,557 \\
13,855\end{array}$ & $\begin{array}{r}60,755 \\
27,680 \\
6,474 \\
5,459 \\
39,127\end{array}$ & $\begin{array}{r}22,625 \\
14,289 \\
0 \\
10,336 \\
47,194\end{array}$ & $\begin{array}{r}60 \\
1 \\
0 \\
1 \\
67\end{array}$ & $\begin{array}{r}1,532 \\
6,807 \\
0 \\
16,187 \\
169,240\end{array}$ & $\begin{array}{r}184,476 \\
90,041 \\
22,338 \\
40,541 \\
269,482\end{array}$ \\
\hline 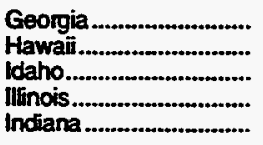 & $\begin{array}{r}105,436 \\
578 \\
12,285 \\
473,788 \\
157,467\end{array}$ & $\begin{array}{r}42,537 \\
1,837 \\
10,088 \\
197,467 \\
70,323\end{array}$ & $\begin{array}{r}46,311 \\
0 \\
26,511 \\
283,176 \\
61,982\end{array}$ & $\begin{array}{r}0 \\
0 \\
10 \\
28 \\
59\end{array}$ & $\begin{array}{r}1,137 \\
0 \\
0 \\
33,596 \\
2,353\end{array}$ & $\begin{array}{r}195,421 \\
2,415 \\
48,894 \\
988,056 \\
292,185\end{array}$ \\
\hline 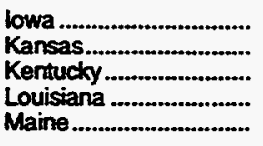 & $\begin{array}{r}78,260 \\
74,156 \\
62,451 \\
52,689 \\
894\end{array}$ & $\begin{array}{r}45,048 \\
43,171 \\
34,466 \\
18,058 \\
2,381\end{array}$ & $\begin{array}{r}92,964 \\
97,904 \\
44,181 \\
592,738 \\
1,166\end{array}$ & $\begin{array}{r}5 \\
10 \\
2 \\
22 \\
0\end{array}$ & $\begin{array}{r}1,826 \\
11,213 \\
267 \\
87,013 \\
0\end{array}$ & $\begin{array}{r}218,103 \\
226,454 \\
141,366 \\
750,520 \\
4,441\end{array}$ \\
\hline $\begin{array}{l}\text { Maryland..................... } \\
\text { Massachusetts............ } \\
\text { Michigan ........................ } \\
\text { Minnesota ................... } \\
\text { Mississippi .................. }\end{array}$ & $\begin{array}{r}76,688 \\
119,642 \\
364,588 \\
122,249 \\
27,086\end{array}$ & $\begin{array}{r}36,183 \\
60,879 \\
182,234 \\
62,668 \\
17,748\end{array}$ & $\begin{array}{r}11,836 \\
67,512 \\
294,701 \\
57,965 \\
59,080\end{array}$ & $\begin{array}{r}25 \\
1 \\
14 \\
29 \\
0\end{array}$ & $\begin{array}{r}2,977 \\
21,361 \\
18,019 \\
1,701 \\
1,701\end{array}$ & $\begin{array}{l}127,709 \\
269,395 \\
859,555 \\
244,611 \\
105,615\end{array}$ \\
\hline $\begin{array}{l}\text { Missouri ....................... } \\
\text { Montana ...................... } \\
\text { Nebraska ...................... } \\
\text { Nevada ..................... } \\
\text { New Hampshire ............ }\end{array}$ & $\begin{array}{r}122,566 \\
18,714 \\
44,397 \\
21,263 \\
6,572\end{array}$ & $\begin{array}{r}63,080 \\
12,678 \\
33,550 \\
18,407 \\
6,412\end{array}$ & $\begin{array}{r}57,967 \\
5,580 \\
29,892 \\
28,772 \\
3,654\end{array}$ & $\begin{array}{r}1 \\
6 \\
9 \\
20 \\
?\end{array}$ & $\begin{array}{r}1,243 \\
523 \\
55 \\
31,074 \\
0\end{array}$ & $\begin{array}{r}244,856 \\
37,501 \\
107,903 \\
99,536 \\
16,619\end{array}$ \\
\hline $\begin{array}{l}\text { New Jersey................... } \\
\text { New Mexico ................. } \\
\text { New York ...................... } \\
\text { North Carolina............. } \\
\text { North Dakota................. }\end{array}$ & $\begin{array}{r}216,873 \\
30,868 \\
382,713 \\
47,451 \\
10,661\end{array}$ & $\begin{array}{r}103,523 \\
24,849 \\
201,478 \\
36,567 \\
7,937\end{array}$ & $\begin{array}{r}74,939 \\
17,976 \\
135,471 \\
18,816 \\
506\end{array}$ & $\begin{array}{r}4 \\
62 \\
28 \\
8 \\
8\end{array}$ & $\begin{array}{r}29,126 \\
15,213 \\
34,310 \\
149 \\
2\end{array}$ & $\begin{array}{r}424,465 \\
88,968 \\
754,000 \\
102,989 \\
19,114\end{array}$ \\
\hline $\begin{array}{l}\text { Ohio } \\
\text { Otdahoma ........................ } \\
\text { Oregon....................... } \\
\text { Pennsylvania ............... } \\
\text { Phode Island................ }\end{array}$ & $\begin{array}{r}343,321 \\
69,211 \\
28,848 \\
268,405 \\
17,384\end{array}$ & $\begin{array}{r}163,205 \\
32,220 \\
22,529 \\
124,236 \\
10,524\end{array}$ & $\begin{array}{r}268,372 \\
40,023 \\
18,733 \\
172,414 \\
39,723\end{array}$ & $\begin{array}{r}48 \\
2 \\
17 \\
7 \\
1\end{array}$ & $\begin{array}{r}985 \\
153,602 \\
26,310 \\
6,195 \\
0\end{array}$ & $\begin{array}{r}775,931 \\
295,057 \\
96,438 \\
571,256 \\
67,633\end{array}$ \\
\hline 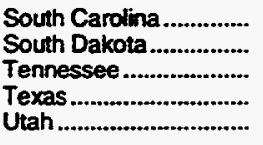 & $\begin{array}{r}23,486 \\
12,056 \\
57,057 \\
213,433 \\
48,922\end{array}$ & $\begin{array}{r}14,435 \\
9,491 \\
46,932 \\
167,798 \\
20,273\end{array}$ & $\begin{array}{r}17,424 \\
2,571 \\
44,500 \\
1,114,766 \\
1,999\end{array}$ & $\begin{array}{r}2 \\
5 \\
5 \\
6 \\
52\end{array}$ & $\begin{array}{r}60 \\
0 \\
0 \\
512,960 \\
6,200\end{array}$ & $\begin{array}{r}55,406 \\
24,124 \\
148,494 \\
2,008,963 \\
77,446\end{array}$ \\
\hline 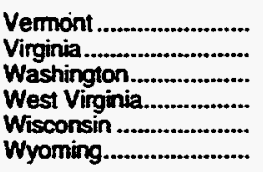 & $\begin{array}{r}2,438 \\
65,176 \\
53,144 \\
35,186 \\
128,175 \\
11,564\end{array}$ & $\begin{array}{r}2,669 \\
39,093 \\
34,631 \\
6,982 \\
70,222 \\
5,025\end{array}$ & $\begin{array}{r}116 \\
51,312 \\
48,545 \\
20,521 \\
28,563 \\
10,670\end{array}$ & $\begin{array}{r}0 \\
18 \\
60 \\
0 \\
10 \\
18\end{array}$ & $\begin{array}{r}0 \\
17,932 \\
2,307 \\
244 \\
3,416 \\
79\end{array}$ & $\begin{array}{r}5,222 \\
173,530 \\
138,687 \\
62,933 \\
230,386 \\
27,355\end{array}$ \\
\hline 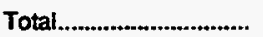 & $4,843,995$ & $2,559,521$ & $4,754,907$ & 1,325 & $1,580,745$ & $13,740,493$ \\
\hline
\end{tabular}

$R=$ Revised dala.

$=$ Volume is less than 500,000 cubic feet.

Note: Totals may not equal sum of components due to independent rounding.

Source: 1993-1994: Energy Information Administration (EIA), Form EIA-176, "Annual Report of Natural and Supplemental Gas Supply and Disposition." 
Table 18. Interruptible Natural Gas Deliveries to Consumers by State, 1993-1994 (Million Cubic Feet)

\begin{tabular}{|c|c|c|c|c|c|c|}
\hline Stan & Rosidentis: & Commercial & Induetrial & Vehicla full & Enctric Uatitio: & Total \\
\hline & \multicolumn{6}{|c|}{1993} \\
\hline 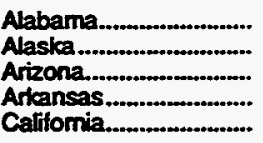 & $\begin{array}{l}0 \\
0 \\
0 \\
0 \\
0\end{array}$ & $\begin{array}{r}4,443 \\
0 \\
436 \\
955 \\
9,284\end{array}$ & $\begin{array}{r}125,313 \\
2,221 \\
1,043 \\
16,806 \\
77,232\end{array}$ & $\begin{array}{l}0 \\
0 \\
0 \\
0 \\
0\end{array}$ & $\begin{array}{r}4,483 \\
676 \\
2,678 \\
11,859 \\
45,071\end{array}$ & $\begin{array}{r}134,239 \\
2,897 \\
4,157 \\
29,620 \\
131,587\end{array}$ \\
\hline 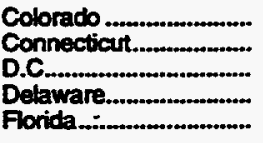 & $\begin{array}{l}\mathbf{0} \\
\mathbf{0} \\
\mathbf{0} \\
\mathbf{0} \\
\mathbf{0}\end{array}$ & $\begin{array}{r}2,922 \\
8,792 \\
9,200 \\
0 \\
1,349\end{array}$ & $\begin{array}{r}38,315 \\
18,655 \\
0 \\
6,309 \\
73,155\end{array}$ & $\begin{array}{r}11 \\
0 \\
0 \\
0 \\
0\end{array}$ & $\begin{array}{r}2,736 \\
276 \\
0 \\
141 \\
38,736\end{array}$ & $\begin{array}{r}43,984 \\
27,724 \\
9,200 \\
6,450 \\
113,239\end{array}$ \\
\hline 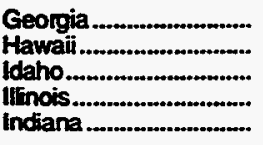 & $\begin{array}{l}0 \\
0 \\
0 \\
0 \\
0\end{array}$ & $\begin{array}{r}12,873 \\
344 \\
0 \\
3,056 \\
5,359\end{array}$ & $\begin{array}{r}138,617 \\
0 \\
3,380 \\
24,640 \\
200,417\end{array}$ & $\begin{array}{l}4 \\
0 \\
0 \\
0 \\
0\end{array}$ & $\begin{array}{r}0 \\
0 \\
0 \\
489 \\
4,204\end{array}$ & $\begin{array}{r}151,494 \\
344 \\
3,380 \\
28,185 \\
209,981\end{array}$ \\
\hline 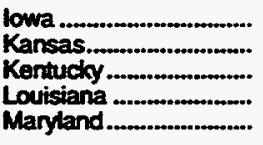 & $\begin{array}{l}0 \\
0 \\
0 \\
0 \\
0\end{array}$ & $\begin{array}{r}4,763 \\
9,632 \\
R_{1,484} \\
6,882 \\
8,144\end{array}$ & $\begin{array}{r}11,757 \\
77,433 \\
37,872 \\
377,547 \\
36,307\end{array}$ & $\begin{array}{l}0 \\
0 \\
0 \\
0 \\
0\end{array}$ & $\begin{array}{r}23 \\
12,581 \\
22 \\
123,289 \\
5,770\end{array}$ & $\begin{array}{r}16,543 \\
99,647 \\
39,312 \\
507,718 \\
50,220\end{array}$ \\
\hline 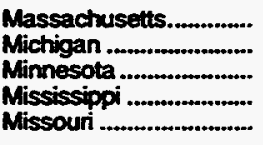 & $\begin{array}{l}0 \\
0 \\
0 \\
0 \\
0\end{array}$ & $\begin{array}{r}7,325 \\
907 \\
24,436 \\
1,139 \\
8,018\end{array}$ & $\begin{array}{l}19,562 \\
27,122 \\
32,680 \\
68,299 \\
31,101\end{array}$ & $\begin{array}{l}0 \\
0 \\
0 \\
0 \\
0\end{array}$ & $\begin{array}{r}10,311 \\
100 \\
2,201 \\
10,797 \\
3,723\end{array}$ & $\begin{array}{l}37,197 \\
28,128 \\
59,317 \\
80,235 \\
42,842\end{array}$ \\
\hline 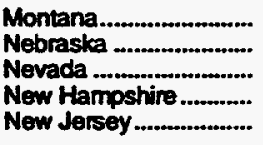 & $\begin{array}{l}0 \\
0 \\
0 \\
0 \\
0\end{array}$ & $\begin{array}{r}304 \\
R_{5}, 923 \\
245 \\
0 \\
24,129\end{array}$ & $\begin{array}{r}7,431 \\
10,428 \\
0 \\
109 \\
114,969\end{array}$ & $\begin{array}{l}0 \\
0 \\
0 \\
0 \\
0\end{array}$ & $\begin{array}{r}155 \\
615 \\
1,923 \\
0 \\
4,716\end{array}$ & $\begin{array}{r}7,891 \\
16,948 \\
2,168 \\
109 \\
143,814\end{array}$ \\
\hline 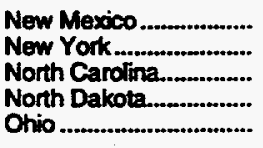 & $\begin{array}{l}0 \\
0 \\
0 \\
0 \\
0\end{array}$ & $\begin{array}{r}134 \\
35,934 \\
1,740 \\
2,809 \\
2,812\end{array}$ & $\begin{array}{r}590 \\
55,969 \\
80,933 \\
5,696 \\
42,951\end{array}$ & $\begin{array}{l}0 \\
1 \\
0 \\
0 \\
0\end{array}$ & $\begin{array}{r}8,239 \\
147,451 \\
2,644 \\
0 \\
1,939\end{array}$ & $\begin{array}{r}8,963 \\
239,355 \\
85,317 \\
8,504 \\
47,702\end{array}$ \\
\hline 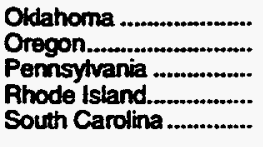 & $\begin{array}{l}0 \\
0 \\
0 \\
0 \\
0\end{array}$ & $\begin{array}{r}3,306 \\
504 \\
14,030 \\
1,380 \\
2,859\end{array}$ & $\begin{array}{r}143,553 \\
44,549 \\
R_{99,043} \\
2,529 \\
83,265\end{array}$ & $\begin{array}{r}106 \\
0 \\
1 \\
0 \\
0\end{array}$ & $\begin{array}{r}7.796 \\
1,162 \\
3,021 \\
0 \\
1,415\end{array}$ & $\begin{array}{r}154,760 \\
46,215 \\
100,832 \\
3,910 \\
87,538\end{array}$ \\
\hline 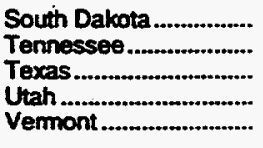 & $\begin{array}{l}0 \\
0 \\
0 \\
0 \\
0\end{array}$ & $\begin{array}{r}1,806 \\
3,752 \\
R_{1}, 667 \\
1,330 \\
0\end{array}$ & $\begin{array}{r}2,935 \\
R_{86,155} \\
R_{867,927} \\
40,410 \\
1,945\end{array}$ & $\begin{array}{l}0 \\
0 \\
0 \\
0 \\
0\end{array}$ & $\begin{array}{r}154 \\
1,625 \\
444,175 \\
5,009 \\
268\end{array}$ & $\begin{array}{r}4,896 \\
87,080 \\
1,330,770 \\
46,749 \\
2,213\end{array}$ \\
\hline 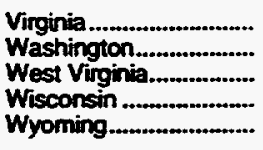 & $\begin{array}{l}0 \\
0 \\
0 \\
0 \\
0\end{array}$ & $\begin{array}{r}14,566 \\
10,087 \\
a_{17.472} \\
7,763 \\
4,595\end{array}$ & $\begin{array}{r}27,418 \\
45,121 \\
826,886 \\
86,705 \\
43,281\end{array}$ & $\begin{array}{r}0 \\
23 \\
0 \\
23 \\
0\end{array}$ & $\begin{array}{r}7,075 \\
1,195 \\
0 \\
2,220 \\
0\end{array}$ & $\begin{array}{l}49,059 \\
56,425 \\
48,600 \\
96,711 \\
47,876\end{array}$ \\
\hline Total & 0 & $R_{307,890}$ & $R_{3,356,581}$ & 168 & 922,962 & $4,582,045$ \\
\hline
\end{tabular}

See lootnotes at end of table. 
Table 18. Interruptible Natural Gas Deliveries to Consumers by State, 1993-1994 (Continued) (Million Cubic Feet)

\begin{tabular}{|c|c|c|c|c|c|c|}
\hline State & Residential & Commercial & Industrial & Vehicte Fuel & Eloctric Utifinies & Total \\
\hline & \multicolumn{6}{|c|}{1994} \\
\hline 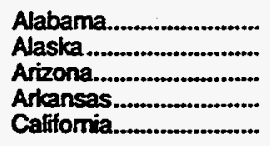 & $\begin{array}{l}0 \\
0 \\
0 \\
0 \\
0\end{array}$ & $\begin{array}{r}4,518 \\
0 \\
357 \\
3,756 \\
39,985\end{array}$ & $\begin{array}{r}110,374 \\
3,786 \\
971 \\
18,884 \\
257,015\end{array}$ & $\begin{array}{r}0 \\
0 \\
0 \\
0 \\
21\end{array}$ & $\begin{array}{r}3,569 \\
706 \\
594 \\
5,903 \\
308,720\end{array}$ & $\begin{array}{r}118,461 \\
4,492 \\
1,922 \\
28,543 \\
605,741\end{array}$ \\
\hline 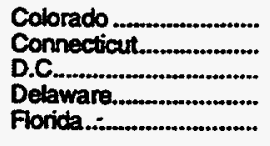 & $\begin{array}{r}0 \\
336 \\
0 \\
0 \\
0\end{array}$ & $\begin{array}{r}5,115 \\
11,402 \\
8,268 \\
0 \\
809\end{array}$ & $\begin{array}{r}48,468 \\
16,358 \\
0 \\
6,880 \\
79,679\end{array}$ & $\begin{array}{l}8 \\
1 \\
0 \\
0 \\
0\end{array}$ & $\begin{array}{r}2,687 \\
1,047 \\
0 \\
1,281 \\
15,105\end{array}$ & $\begin{array}{r}56,278 \\
29,144 \\
8,268 \\
8,161 \\
95,593\end{array}$ \\
\hline 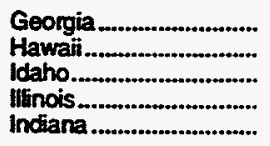 & $\begin{array}{l}0 \\
0 \\
0 \\
0 \\
0\end{array}$ & $\begin{array}{r}11.514 \\
363 \\
0 \\
108 \\
5.496\end{array}$ & $\begin{array}{r}127,590 \\
0 \\
3,270 \\
21,916 \\
208,146\end{array}$ & $\begin{array}{l}2 \\
0 \\
0 \\
0 \\
0\end{array}$ & $\begin{array}{r}0 \\
0 \\
0 \\
2 \\
7.058\end{array}$ & $\begin{array}{r}139,106 \\
363 \\
3,270 \\
22,027 \\
220,699\end{array}$ \\
\hline 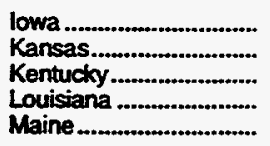 & $\begin{array}{r}0 \\
0 \\
82 \\
292 \\
0\end{array}$ & $\begin{array}{r}2,874 \\
9,082 \\
2,278 \\
6,126 \\
0\end{array}$ & $\begin{array}{r}15,766 \\
90,075 \\
38,900 \\
406,296 \\
604\end{array}$ & $\begin{array}{l}0 \\
0 \\
0 \\
0 \\
0\end{array}$ & $\begin{array}{r}648 \\
9,243 \\
3 \\
121,083 \\
0\end{array}$ & $\begin{array}{r}19,289 \\
108,399 \\
41,262 \\
533,797 \\
604\end{array}$ \\
\hline 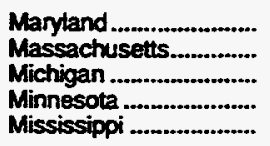 & $\begin{array}{l}0 \\
0 \\
0 \\
0 \\
0\end{array}$ & $\begin{array}{r}7,953 \\
23.656 \\
834 \\
21,265 \\
1,484\end{array}$ & $\begin{array}{l}35,856 \\
25,286 \\
33,148 \\
36,503 \\
37,783\end{array}$ & $\begin{array}{l}0 \\
1 \\
0 \\
0 \\
9\end{array}$ & $\begin{array}{r}9,910 \\
19,983 \\
199 \\
2,296 \\
31,943\end{array}$ & $\begin{array}{l}53,718 \\
68,926 \\
34,180 \\
60,063 \\
71,218\end{array}$ \\
\hline 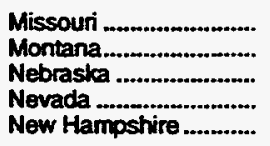 & $\begin{array}{l}0 \\
0 \\
0 \\
0 \\
0\end{array}$ & $\begin{array}{r}3,116 \\
303 \\
5,396 \\
286 \\
0\end{array}$ & $\begin{array}{r}13,635 \\
8,360 \\
7,069 \\
95 \\
837\end{array}$ & $\begin{array}{r}0 \\
0 \\
0 \\
16 \\
0\end{array}$ & $\begin{array}{r}1,911 \\
139 \\
563 \\
1,303 \\
1,271\end{array}$ & $\begin{array}{r}18,662 \\
8,803 \\
13,027 \\
1,700 \\
2,108\end{array}$ \\
\hline 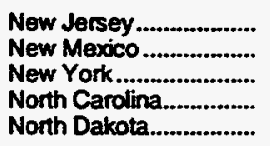 & $\begin{array}{r}0 \\
0 \\
2,695 \\
0 \\
0\end{array}$ & $\begin{array}{r}28,485 \\
115 \\
21,779 \\
2,374 \\
2,846\end{array}$ & $\begin{array}{r}115,906 \\
765 \\
78,967 \\
76,023 \\
5,340\end{array}$ & $\begin{array}{r}0 \\
0 \\
25 \\
0 \\
0\end{array}$ & $\begin{array}{r}6,286 \\
11,360 \\
135,488 \\
703 \\
0\end{array}$ & $\begin{array}{r}150,677 \\
12,240 \\
238,954 \\
79.099 \\
8.187\end{array}$ \\
\hline 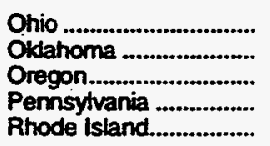 & $\begin{array}{r}11 \\
0 \\
0 \\
0 \\
0\end{array}$ & $\begin{array}{r}3,594 \\
4,284 \\
430 \\
14,237 \\
1,525\end{array}$ & $\begin{array}{r}42,751 \\
155,886 \\
43,835 \\
64,003 \\
1.197\end{array}$ & $\begin{array}{r}0 \\
154 \\
0 \\
3 \\
0\end{array}$ & $\begin{array}{r}1,703 \\
4,457 \\
0 \\
7.958 \\
0\end{array}$ & $\begin{array}{r}48,057 \\
164,782 \\
44,266 \\
86,202 \\
2,723\end{array}$ \\
\hline 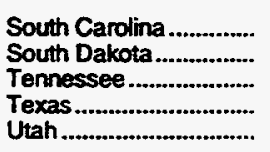 & $\begin{array}{r}0 \\
0 \\
277 \\
0 \\
0\end{array}$ & $\begin{array}{r}3,435 \\
784 \\
3,829 \\
12,433 \\
6,228\end{array}$ & $\begin{array}{r}80,076 \\
2,986 \\
74,389 \\
714,712 \\
34,619\end{array}$ & $\begin{array}{r}0 \\
0 \\
0 \\
40 \\
0\end{array}$ & $\begin{array}{r}2,961 \\
64 \\
971 \\
478,646 \\
1,756\end{array}$ & $\begin{array}{r}86,472 \\
3,784 \\
79,466 \\
1,205,831 \\
42,603\end{array}$ \\
\hline 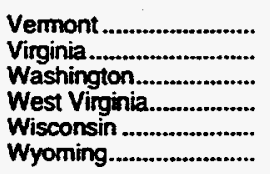 & $\begin{array}{r}0 \\
0 \\
0 \\
15 \\
0 \\
0\end{array}$ & $\begin{array}{r}0 \\
13,851 \\
8,352 \\
17,997 \\
8,386 \\
4,205\end{array}$ & $\begin{array}{r}1,908 \\
34,452 \\
59,059 \\
26,253 \\
106,544 \\
49,896\end{array}$ & $\begin{array}{r}0 \\
2 \\
95 \\
0 \\
26 \\
0\end{array}$ & $\begin{array}{r}165 \\
8,865 \\
20 \\
0 \\
1,885 \\
0\end{array}$ & $\begin{array}{r}2,072 \\
57,170 \\
67,525 \\
44,265 \\
116,841 \\
54,102\end{array}$ \\
\hline Total.................................... & 3,706 & 335,513 & $3,423,068$ & 405 & $1,210,453$ & $4,973,146$ \\
\hline
\end{tabular}

$R=$ Revised data.

Note: Totals may not equal sum of components due to independent rounding.

Source: 1993-1994: Energy Information Administration (EIA), Form ElA-176, "Annual Report of Natural and Supplemental Gas Supply and Disposition." 
Table 19. Natural Gas Deliveries to Commercial Consumers by State, 1993-1994 (Million Cubic Feet)

\begin{tabular}{|c|c|c|c|c|c|c|c|}
\hline \multirow{2}{*}{ State } & \multicolumn{3}{|c|}{ Firm } & \multicolumn{3}{|c|}{ imenuptible } & \multirow{2}{*}{ Total Volume } \\
\hline & $\begin{array}{l}\text { Soles } \\
\text { Volume }\end{array}$ & $\begin{array}{l}\text { Transported } \\
\text { Volume }\end{array}$ & $\begin{array}{l}\text { Toted } \\
\text { Volume }\end{array}$ & $\begin{array}{c}\text { Sales } \\
\text { Volume }\end{array}$ & $\begin{array}{l}\text { Transponted } \\
\text { Volume }\end{array}$ & $\begin{array}{l}\text { Total } \\
\text { Volume }\end{array}$ & \\
\hline & \multicolumn{7}{|c|}{1993} \\
\hline 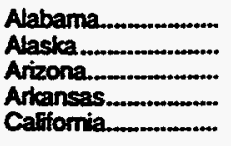 & $\begin{array}{r}20,114 \\
20,003 \\
24,888 \\
25,653 \\
192,273\end{array}$ & $\begin{array}{r}1,166 \\
0 \\
2,244 \\
2,390 \\
48,725\end{array}$ & $\begin{array}{r}21,280 \\
20,003 \\
27,132 \\
28,043 \\
240,998\end{array}$ & $\begin{array}{r}658 \\
0 \\
344 \\
952 \\
228\end{array}$ & $\begin{array}{r}3,785 \\
0 \\
92 \\
3 \\
9,056\end{array}$ & $\begin{array}{r}4,443 \\
0 \\
436 \\
955 \\
9,284\end{array}$ & $\begin{array}{r}25,723 \\
20,003 \\
27,568 \\
28,998 \\
250,283\end{array}$ \\
\hline 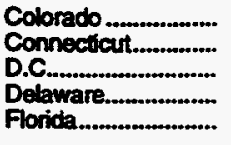 & $\begin{array}{r}67,603 \\
22,634 \\
6,697 \\
5,195 \\
R_{39,591}\end{array}$ & $\begin{array}{r}1,121 \\
0 \\
332 \\
0 \\
211\end{array}$ & $\begin{array}{r}68,725 \\
22,635 \\
7,029 \\
5,195 \\
R_{39,802}\end{array}$ & $\begin{array}{r}803 \\
8,191 \\
9,200 \\
0 \\
648\end{array}$ & $\begin{array}{r}2,119 \\
601 \\
0 \\
0 \\
700\end{array}$ & $\begin{array}{r}2,922 \\
8,792 \\
9,200 \\
0 \\
1,349\end{array}$ & $\begin{array}{r}71,647 \\
31,427 \\
16,229 \\
5,195 \\
R_{41,151}\end{array}$ \\
\hline 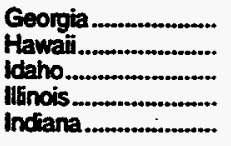 & $\begin{array}{r}44,652 \\
1,779 \\
9,270 \\
112,281 \\
69,890\end{array}$ & $\begin{array}{r}0 \\
0 \\
1,405 \\
87,820 \\
2,798\end{array}$ & $\begin{array}{r}44,652 \\
1.779 \\
10,675 \\
200,101 \\
72,688\end{array}$ & $\begin{array}{r}7,386 \\
344 \\
0 \\
64 \\
4,433\end{array}$ & $\begin{array}{r}5,487 \\
0 \\
0 \\
2,992 \\
926\end{array}$ & $\begin{array}{r}12,873 \\
344 \\
0 \\
3,056 \\
5,359\end{array}$ & $\begin{array}{r}57,525 \\
2,123 \\
10,675 \\
203,157 \\
78,047\end{array}$ \\
\hline 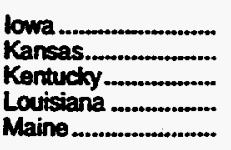 & $\begin{array}{r}R_{42,973} \\
R_{45,160} \\
R_{34,134} \\
18,140 \\
2,311\end{array}$ & $\begin{array}{r}2,600 \\
1,231 \\
2.199 \\
134 \\
0\end{array}$ & $\begin{array}{r}R_{45,573} \\
46,391 \\
R_{36,334} \\
18,275 \\
2,311\end{array}$ & $\begin{array}{r}4,715 \\
1,134 \\
6,574 \\
0\end{array}$ & $\begin{array}{r}48 \\
8,498 \\
610 \\
345 \\
0\end{array}$ & $\begin{array}{r}4,763 \\
9,632 \\
R_{1,484} \\
6,882 \\
0\end{array}$ & $\begin{array}{r}R_{50,337} \\
R_{56,023} \\
37,817 \\
25,157 \\
2,311\end{array}$ \\
\hline $\begin{array}{l}\text { Maryland ................... } \\
\text { Massachusetts........ } \\
\text { Michigan .................. } \\
\text { Mirnesota ............... } \\
\text { Mississippi ............... }\end{array}$ & $\begin{array}{r}34,272 \\
57,653 \\
123,595 \\
61,846 \\
17,909\end{array}$ & $\begin{array}{r}1,219 \\
441 \\
55.728 \\
347 \\
151\end{array}$ & $\begin{array}{r}35,491 \\
58,104 \\
179,323 \\
62,193 \\
18,060\end{array}$ & $\begin{array}{r}7,866 \\
6,141 \\
88 \\
22,160 \\
643\end{array}$ & $\begin{array}{r}278 \\
1,183 \\
819 \\
2,276 \\
496\end{array}$ & $\begin{array}{r}8,144 \\
7.325 \\
907 \\
24,436 \\
1,139\end{array}$ & $\begin{array}{r}43,635 \\
65,429 \\
180,230 \\
86,629 \\
19,199\end{array}$ \\
\hline $\begin{array}{l}\text { Missouri ................... } \\
\text { Montana................... } \\
\text { Nebraska ............... } \\
\text { Nevada .................. } \\
\text { New Hampshire ...... }\end{array}$ & $\begin{array}{r}57,358 \\
12,927 \\
25,680 \\
16,267 \\
6,142\end{array}$ & $\begin{array}{r}4,294 \\
648 \\
3,142 \\
1,038 \\
0\end{array}$ & $\begin{array}{r}61,652 \\
13,576 \\
28,822 \\
17,305 \\
6,142\end{array}$ & $\begin{array}{r}1,602 \\
14 \\
R_{5}, 923 \\
0 \\
0\end{array}$ & $\begin{array}{r}6,416 \\
291 \\
0 \\
245 \\
0\end{array}$ & $\begin{array}{r}8,018 \\
304 \\
R_{5}, 923 \\
245 \\
0\end{array}$ & $\begin{array}{r}69,670 \\
13,880 \\
n_{34,745} \\
17,549 \\
6,142\end{array}$ \\
\hline $\begin{array}{l}\text { New Jersey.............. } \\
\text { New Mexico .............. } \\
\text { New York................. } \\
\text { North Carclina......... } \\
\text { Noth Dakota........... }\end{array}$ & $\begin{array}{r}98,428 \\
17,305 \\
155,718 \\
35,101 \\
7,508\end{array}$ & $\begin{array}{r}6,386 \\
10,459 \\
29,077 \\
529 \\
326\end{array}$ & $\begin{array}{r}104,813 \\
27,764 \\
184,795 \\
35,630 \\
7,834\end{array}$ & $\begin{array}{r}19,613 \\
134 \\
14,731 \\
1,708 \\
227\end{array}$ & $\begin{array}{r}4,516 \\
0 \\
21,202 \\
32 \\
2,582\end{array}$ & $\begin{array}{r}24,129 \\
134 \\
35,934 \\
1,740 \\
2,809\end{array}$ & $\begin{array}{r}128,942 \\
27,898 \\
220,729 \\
37,370 \\
10,642\end{array}$ \\
\hline 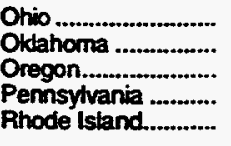 & $\begin{array}{r}137,671 \\
35,711 \\
23,543 \\
92,683 \\
7,825\end{array}$ & $\begin{array}{r}23,561 \\
1,749 \\
0 \\
25,063 \\
0\end{array}$ & $\begin{array}{r}161.232 \\
37,460 \\
23,543 \\
117.745 \\
7.825\end{array}$ & $\begin{array}{r}1,029 \\
959 \\
0 \\
9,335 \\
1,380\end{array}$ & $\begin{array}{r}1,783 \\
2,346 \\
504 \\
4,695 \\
0\end{array}$ & $\begin{array}{r}2,812 \\
3,306 \\
504 \\
14,030 \\
1,380\end{array}$ & $\begin{array}{r}164,044 \\
40,766 \\
24,047 \\
131,776 \\
9,205\end{array}$ \\
\hline $\begin{array}{l}\text { South Carolina ......... } \\
\text { South Dakota.......... } \\
\text { Tennessee.............. } \\
\text { Texas .......................... } \\
\text { Utah ....................... }\end{array}$ & $\begin{array}{r}14,024 \\
7,790 \\
45,388 \\
A_{142,968} \\
21,258\end{array}$ & $\begin{array}{r}A_{132} \\
1,100 \\
1,615 \\
R_{14,352} \\
0\end{array}$ & $\begin{array}{r}A_{14,156} \\
8,890 \\
47,002 \\
A_{157,320} \\
21,258\end{array}$ & $\begin{array}{r}2,859 \\
1,182 \\
3,237 \\
R_{4,596} \\
1,360\end{array}$ & $\begin{array}{r}0 \\
624 \\
514 \\
14,071 \\
0\end{array}$ & $\begin{array}{r}2,859 \\
1,806 \\
3,752 \\
R_{18,667} \\
1,330\end{array}$ & $\begin{array}{r}n_{17,014} \\
10,696 \\
50,754 \\
R_{175,988} \\
22,588\end{array}$ \\
\hline 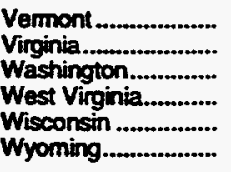 & $\begin{array}{r}2,382 \\
36,316 \\
33,494 \\
R_{5}, 835 \\
66,264 \\
5,645\end{array}$ & $\begin{array}{r}0 \\
1.997 \\
39 \\
1.074 \\
3.052 \\
27\end{array}$ & $\begin{array}{r}2,382 \\
\mathbf{3 8 , 3 1 4} \\
\mathbf{3 3 , 5 3 3} \\
\mathbf{1 6 , 9 0 8} \\
\mathbf{6 9 , 3 1 6} \\
\mathbf{5 , 6 7 2}\end{array}$ & $\begin{array}{r}0 \\
10,661 \\
7,455 \\
97,412 \\
6,502 \\
4,416\end{array}$ & $\begin{array}{r}0 \\
3,905 \\
2,632 \\
10,061 \\
1,261 \\
180\end{array}$ & $\begin{array}{r}0 \\
14,566 \\
10,087 \\
n_{17,472} \\
7,763 \\
4,595\end{array}$ & $\begin{array}{r}2,382 \\
52,880 \\
43,620 \\
R_{24,381} \\
77,079 \\
10,268\end{array}$ \\
\hline 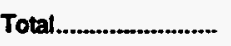 & $R_{2,211,756}$ & $A_{341,923}$ & $\mathrm{n}_{2,553,679}$ & $A_{189,716}$ & 118,174 & $A_{307,890}$ & $a_{2,861,569}$ \\
\hline
\end{tabular}


Table 19. Natural Gas Deliveries to Commercial Consumers by State, 1993-1994 (Continued) (Million Cubic Feet)

\begin{tabular}{|c|c|c|c|c|c|c|c|}
\hline \multirow{2}{*}{ State } & \multicolumn{3}{|c|}{ Firm } & \multicolumn{3}{|c|}{ Intemiptible } & \multirow{2}{*}{ Total Volume } \\
\hline & $\begin{array}{l}\text { Seles } \\
\text { Volume }\end{array}$ & $\begin{array}{l}\text { Transported } \\
\text { Volume }\end{array}$ & $\begin{array}{l}\text { Total } \\
\text { Volume }\end{array}$ & $\begin{array}{l}\text { Seles } \\
\text { Volume }\end{array}$ & $\begin{array}{l}\text { Transported } \\
\text { Volume }\end{array}$ & $\begin{array}{l}\text { Total } \\
\text { Volume }\end{array}$ & \\
\hline & \multicolumn{6}{|c|}{1994} & \\
\hline 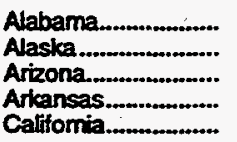 & $\begin{array}{r}19,944 \\
20,698 \\
26,205 \\
22,310 \\
119,882\end{array}$ & $\begin{array}{r}1,064 \\
0 \\
2,624 \\
1,344 \\
102,122\end{array}$ & $\begin{array}{r}21,008 \\
20,698 \\
28,829 \\
23,654 \\
222,004\end{array}$ & $\begin{array}{r}538 \\
0 \\
273 \\
3,749 \\
7,761\end{array}$ & $\begin{array}{r}3,979 \\
0 \\
84 \\
7 \\
32,224\end{array}$ & $\begin{array}{r}4,518 \\
0 \\
357 \\
3,756 \\
39,985\end{array}$ & $\begin{array}{r}25,526 \\
20,698 \\
29,187 \\
27,410 \\
261,989\end{array}$ \\
\hline 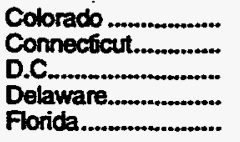 & $\begin{array}{r}59,660 \\
23,486 \\
6,474 \\
5,459 \\
38,267\end{array}$ & $\begin{array}{r}1,095 \\
4,194 \\
0 \\
0 \\
860\end{array}$ & $\begin{array}{r}60,755 \\
27,680 \\
6,474 \\
5,459 \\
39,127\end{array}$ & $\begin{array}{r}2,807 \\
8,141 \\
6,926 \\
0 \\
807\end{array}$ & $\begin{array}{r}2,308 \\
3,261 \\
1,343 \\
0 \\
1\end{array}$ & $\begin{array}{r}5,115 \\
11,402 \\
8,268 \\
0 \\
809\end{array}$ & $\begin{array}{r}65,870 \\
39,082 \\
14,742 \\
5,459 \\
39,935\end{array}$ \\
\hline 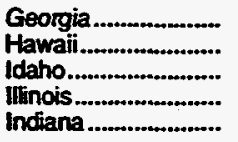 & $\begin{array}{r}42,537 \\
1,837 \\
8,662 \\
104,326 \\
66,621\end{array}$ & $\begin{array}{r}0 \\
0 \\
1,427 \\
93,141 \\
3,702\end{array}$ & $\begin{array}{r}42,537 \\
1,837 \\
10,088 \\
197,467 \\
70,323\end{array}$ & $\begin{array}{r}7,210 \\
363 \\
0 \\
43 \\
3,357\end{array}$ & $\begin{array}{r}4,304 \\
0 \\
0 \\
65 \\
2,139\end{array}$ & $\begin{array}{r}11,514 \\
363 \\
0 \\
108 \\
5,496\end{array}$ & $\begin{array}{r}54,051 \\
2,200 \\
10,088 \\
197,576 \\
75,819\end{array}$ \\
\hline 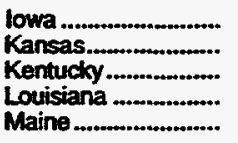 & $\begin{array}{r}40,529 \\
39,657 \\
31,904 \\
17,556 \\
2,381\end{array}$ & $\begin{array}{r}4,519 \\
3,514 \\
2,562 \\
501 \\
0\end{array}$ & $\begin{array}{r}45,048 \\
43,171 \\
34,466 \\
18,058 \\
2,381\end{array}$ & $\begin{array}{r}2,796 \\
1,301 \\
1,669 \\
6,123 \\
0\end{array}$ & $\begin{array}{r}78 \\
7,781 \\
609 \\
3 \\
0\end{array}$ & $\begin{array}{r}2,874 \\
9,082 \\
2,278 \\
6,126 \\
0\end{array}$ & $\begin{array}{r}47,922 \\
52,253 \\
36,744 \\
24,184 \\
2,381\end{array}$ \\
\hline $\begin{array}{l}\text { Maryland.................. } \\
\text { Massactusetts......... } \\
\text { Michigan .................. } \\
\text { Minnesota ................. } \\
\text { Mississippi ................ }\end{array}$ & $\begin{array}{r}35,228 \\
58,313 \\
120,166 \\
60,907 \\
17,242\end{array}$ & $\begin{array}{r}955 \\
2,565 \\
62,009 \\
1,761 \\
506\end{array}$ & $\begin{array}{r}36,183 \\
60,879 \\
182,234 \\
62,663 \\
17,748\end{array}$ & $\begin{array}{r}7,617 \\
6,089 \\
77 \\
19,689 \\
1,342\end{array}$ & $\begin{array}{r}335 \\
17,566 \\
756 \\
1,575 \\
141\end{array}$ & $\begin{array}{r}7,953 \\
23,656 \\
834 \\
21,265 \\
1,484\end{array}$ & $\begin{array}{r}44,136 \\
84,534 \\
183,068 \\
83,933 \\
19,232\end{array}$ \\
\hline $\begin{array}{l}\text { Missouri .................... } \\
\text { Montana.................. } \\
\text { Nebraska ................ } \\
\text { Nevada ................... } \\
\text { New Hampshire....... }\end{array}$ & $\begin{array}{r}53,748 \\
11,900 \\
25,824 \\
15,417 \\
6,412\end{array}$ & $\begin{array}{r}9,332 \\
778 \\
7,726 \\
2,990 \\
0\end{array}$ & $\begin{array}{r}63,080 \\
12,678 \\
33,550 \\
18,407 \\
6,412\end{array}$ & $\begin{array}{r}1,375 \\
11 \\
5,396 \\
0 \\
0\end{array}$ & $\begin{array}{r}1,741 \\
292 \\
0 \\
286 \\
0\end{array}$ & $\begin{array}{r}3,116 \\
303 \\
5,396 \\
286 \\
0\end{array}$ & $\begin{array}{r}66,196 \\
12,981 \\
38,946 \\
18,694 \\
6,412\end{array}$ \\
\hline $\begin{array}{l}\text { New Jersey.............. } \\
\text { New Mexico .............. } \\
\text { New York............. } \\
\text { North Carolina......... } \\
\text { North Dakota........... }\end{array}$ & $\begin{array}{r}97,758 \\
15,453 \\
161,176 \\
35,376 \\
7,937\end{array}$ & $\begin{array}{r}5,765 \\
9,395 \\
40,302 \\
1,191 \\
0\end{array}$ & $\begin{array}{r}103,523 \\
24,849 \\
201,478 \\
36,567 \\
7,937\end{array}$ & $\begin{array}{r}23,205 \\
115 \\
16,454 \\
2,251 \\
647\end{array}$ & $\begin{array}{r}5,280 \\
0 \\
5,325 \\
123 \\
2,199\end{array}$ & $\begin{array}{r}28,485 \\
115 \\
21,779 \\
2,374 \\
2,846\end{array}$ & $\begin{array}{r}132,008 \\
24,964 \\
223,256 \\
38,940 \\
10,783\end{array}$ \\
\hline $\begin{array}{l}\text { Ohio ......................... } \\
\text { Okdahoma ............... } \\
\text { Oregon................... } \\
\text { Pennsyhrania ........... } \\
\text { Rhode Island............ }\end{array}$ & $\begin{array}{r}134,654 \\
30,442 \\
22,529 \\
93,491 \\
10,524\end{array}$ & $\begin{array}{r}28,551 \\
1,777 \\
0 \\
30,745 \\
0\end{array}$ & $\begin{array}{r}163,205 \\
32,220 \\
22,529 \\
124,235 \\
10,524\end{array}$ & $\begin{array}{r}1,337 \\
1,847 \\
0 \\
9,468 \\
1,525\end{array}$ & $\begin{array}{r}2,256 \\
2,437 \\
430 \\
4,769 \\
0\end{array}$ & $\begin{array}{r}3,594 \\
4,284 \\
430 \\
14,237 \\
1,525\end{array}$ & $\begin{array}{r}166,798 \\
36,504 \\
22,960 \\
138,473 \\
12,049\end{array}$ \\
\hline 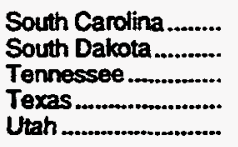 & $\begin{array}{r}14,304 \\
8,705 \\
44,503 \\
143,302 \\
20,273\end{array}$ & $\begin{array}{r}131 \\
786 \\
2,428 \\
24,496 \\
0\end{array}$ & $\begin{array}{r}14,435 \\
9,491 \\
46,932 \\
167,798 \\
20,273\end{array}$ & $\begin{array}{r}3,301 \\
445 \\
3,265 \\
5,187 \\
1,789\end{array}$ & $\begin{array}{r}134 \\
338 \\
564 \\
7,246 \\
4,438\end{array}$ & $\begin{array}{r}3,435 \\
784 \\
3,829 \\
12,433 \\
6,228\end{array}$ & $\begin{array}{r}17,870 \\
10,274 \\
50,760 \\
180,232 \\
26,501\end{array}$ \\
\hline $\begin{array}{l}\text { Vermont .................. } \\
\text { Virginia.................. } \\
\text { Washington............ } \\
\text { West Virginia............ } \\
\text { Wisconsin ................. } \\
\text { Wyoming................. }\end{array}$ & $\begin{array}{r}2,669 \\
36,397 \\
33,819 \\
6,078 \\
67,691 \\
4,875\end{array}$ & $\begin{array}{r}0 \\
2,696 \\
811 \\
904 \\
2,531 \\
150\end{array}$ & $\begin{array}{r}2,669 \\
39,093 \\
34,631 \\
6,982 \\
70,222 \\
5,025\end{array}$ & $\begin{array}{r}0 \\
9,507 \\
7,170 \\
7,707 \\
5,784 \\
3,998\end{array}$ & $\begin{array}{r}0 \\
4,343 \\
1,182 \\
10,290 \\
2,602 \\
208\end{array}$ & $\begin{array}{r}0 \\
13,851 \\
8,352 \\
17,997 \\
8,386 \\
4,205\end{array}$ & $\begin{array}{r}2,669 \\
\mathbf{5 2 , 9 4 4} \\
\mathbf{4 2 , 9 8 2} \\
24,979 \\
78,609 \\
9,231\end{array}$ \\
\hline Total......................... & $2,095,510$ & 464,011 & $2,559,521$ & 200,466 & 135,046 & 335,513 & $2,895,034$ \\
\hline
\end{tabular}

A = Revised data.

Note: Totals may not equal sum of components due to independent rounding.
Sounce: 1993-1994: Energy Information Administration (EIA). Form EIA-176, Annual Report of Natural and Supplemental Gas Supply and Disposition. 
Table 20. Natural Gas Deliveries to Industrial Consumers by State, 1993-1994 (Million Cubic Feet)

\begin{tabular}{|c|c|c|c|c|c|c|c|}
\hline \multirow{2}{*}{ Stute } & \multicolumn{3}{|c|}{ Fim } & \multicolumn{3}{|c|}{ Internipiole } & \multirow{2}{*}{ Total Vohme } \\
\hline & $\begin{array}{l}\text { Soles } \\
\text { Volune }\end{array}$ & $\begin{array}{c}\text { Transpertid } \\
\text { Volame }\end{array}$ & $\begin{array}{l}\text { Total } \\
\text { Vohume }\end{array}$ & Solten & $\begin{array}{l}\text { Trumsported } \\
\text { Volutin }\end{array}$ & $\begin{array}{l}\text { Total } \\
\text { Volume }\end{array}$ & \\
\hline & \multicolumn{7}{|c|}{1993} \\
\hline 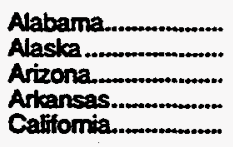 & $\begin{array}{r}16,449 \\
53,308 \\
5,015 \\
11,794 \\
167,512\end{array}$ & $\begin{array}{r}39,929 \\
20,266 \\
15,105 \\
90,801 \\
414,980\end{array}$ & $\begin{array}{r}56,379 \\
73,574 \\
20,121 \\
102,595 \\
582,492\end{array}$ & $\begin{array}{r}33,425 \\
228 \\
280 \\
4,704 \\
6,885\end{array}$ & $\begin{array}{r}91,888 \\
1,993 \\
763 \\
12,102 \\
70,347\end{array}$ & $\begin{array}{r}125,313 \\
2,221 \\
1,043 \\
16,806 \\
77,2022\end{array}$ & $\begin{array}{r}181,692 \\
75,795 \\
21,164 \\
119,401 \\
659,723\end{array}$ \\
\hline 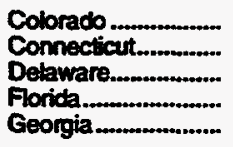 & $\begin{array}{r}8,470 \\
13,487 \\
8,222 \\
8,730 \\
12,930\end{array}$ & $\begin{array}{r}22,239 \\
4,700 \\
4,922 \\
17,465 \\
15,841\end{array}$ & $\begin{array}{r}30,709 \\
18,187 \\
13,144 \\
R_{27,195} \\
28,771\end{array}$ & $\begin{array}{r}16,089 \\
13,191 \\
6,309 \\
17,010 \\
41,967\end{array}$ & $\begin{array}{r}22,226 \\
5,464 \\
0 \\
56,144 \\
96,650\end{array}$ & $\begin{array}{r}38,315 \\
18,655 \\
6,309 \\
73,155 \\
138,617\end{array}$ & $\begin{array}{r}69,024 \\
36,842 \\
19,453 \\
R_{100,350} \\
167,388\end{array}$ \\
\hline 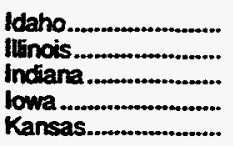 & $\begin{array}{r}90 \\
33,736 \\
32,197 \\
R_{8,389} \\
15,051\end{array}$ & $\begin{array}{r}25,676 \\
246,637 \\
30,669 \\
82,479 \\
46,548\end{array}$ & $\begin{array}{r}25,766 \\
280,374 \\
62,865 \\
R 90,868 \\
61,599\end{array}$ & $\begin{array}{r}0 \\
6,168 \\
20,783 \\
6,623 \\
3,018\end{array}$ & $\begin{array}{r}3,380 \\
18,472 \\
179,634 \\
5,134 \\
74,415\end{array}$ & $\begin{array}{r}3,380 \\
24,640 \\
200,417 \\
11,757 \\
77,433\end{array}$ & $\begin{array}{r}29,146 \\
305,014 \\
263,283 \\
R_{102,625} \\
139,032\end{array}$ \\
\hline 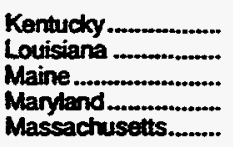 & $\begin{array}{r}12,337 \\
244,864 \\
1,753 \\
318 \\
19,669\end{array}$ & $\begin{array}{r}25,812 \\
351,272 \\
0 \\
12,217 \\
55,428\end{array}$ & $\begin{array}{r}38,148 \\
596,135 \\
1,753 \\
12,535 \\
75,097\end{array}$ & $\begin{array}{r}10,521 \\
57,994 \\
0 \\
9,535 \\
9,251\end{array}$ & $\begin{array}{r}27,351 \\
319,553 \\
0 \\
26,772 \\
10,311\end{array}$ & $\begin{array}{r}37,872 \\
377,547 \\
0 \\
36,307 \\
19,562\end{array}$ & $\begin{array}{r}76,020 \\
973,682 \\
1,753 \\
48,842 \\
94,658\end{array}$ \\
\hline $\begin{array}{l}\text { Michigan .................. } \\
\text { Minnesota ................. } \\
\text { Mississippi ................ } \\
\text { Missouri ................... } \\
\text { Montana..................... }\end{array}$ & $\begin{array}{r}27,126 \\
15,019 \\
16,085 \\
10,692 \\
1,136\end{array}$ & $\begin{array}{r}257,802 \\
50,072 \\
15,781 \\
19,189 \\
4,123\end{array}$ & $\begin{array}{r}284,928 \\
65,091 \\
31,867 \\
29,882 \\
5,259\end{array}$ & $\begin{array}{r}1,149 \\
27,397 \\
23,575 \\
3,682 \\
147\end{array}$ & $\begin{array}{r}25,973 \\
5,283 \\
44,725 \\
27,419 \\
7,284\end{array}$ & $\begin{array}{r}27,122 \\
32,680 \\
68,299 \\
31,101 \\
7,431\end{array}$ & $\begin{array}{r}312,050 \\
97,771 \\
100,166 \\
60,982 \\
12,690\end{array}$ \\
\hline $\begin{array}{l}\text { Nebraske ................ } \\
\text { Nevada ................. } \\
\text { New Hampshire ....... } \\
\text { New Jersey.............. } \\
\text { New Mexico .............. }\end{array}$ & $\begin{array}{r}n_{3,751} \\
1,074 \\
3,697 \\
26,208 \\
907\end{array}$ & $\begin{array}{r}24,478 \\
23,660 \\
0 \\
47,711 \\
15,527\end{array}$ & $\begin{array}{r}R_{28,230} \\
24,734 \\
3,697 \\
73,920 \\
16,433\end{array}$ & $\begin{array}{r}6,839 \\
0 \\
109 \\
79,464 \\
9\end{array}$ & $\begin{array}{r}3,589 \\
0 \\
0 \\
35,505 \\
\mathbf{5 8 1}\end{array}$ & $\begin{array}{r}10,428 \\
0 \\
109 \\
114,969 \\
590\end{array}$ & $\begin{array}{r}R_{38,658} \\
24,734 \\
3,805 \\
188,889 \\
17,023\end{array}$ \\
\hline $\begin{array}{l}\text { New York } \\
\text { North Carolina............. } \\
\text { North Dakota............ } \\
\text { Ohio .......................... } \\
\text { Okdahoma ................ }\end{array}$ & $\begin{array}{r}24,405 \\
9,541 \\
129 \\
27,790 \\
20,661\end{array}$ & $\begin{array}{r}80,032 \\
1,835 \\
270 \\
230,519 \\
15,192\end{array}$ & $\begin{array}{r}104,437 \\
11,376 \\
400 \\
258,309 \\
35,853\end{array}$ & $\begin{array}{r}10,085 \\
62,700 \\
1,396 \\
2,804 \\
33,820\end{array}$ & $\begin{array}{r}45,884 \\
18,233 \\
4,300 \\
40,147 \\
109,733\end{array}$ & $\begin{array}{r}55,969 \\
80,933 \\
5,696 \\
42,951 \\
143,553\end{array}$ & $\begin{array}{r}160,406 \\
92,309 \\
6,096 \\
301,261 \\
179,406\end{array}$ \\
\hline $\begin{array}{l}\text { Oregon................. } \\
\text { Pennsytrania .......... } \\
\text { Phode Island........... } \\
\text { South Carolina........ } \\
\text { South Dakota........... }\end{array}$ & $\begin{array}{l}11,090 \\
39,357 \\
2,297 \\
8,790 \\
1,730\end{array}$ & $\begin{array}{r}4,978 \\
R_{113,108} \\
41,205 \\
3,502 \\
311\end{array}$ & $\begin{array}{r}16,067 \\
A_{1} 52,465 \\
43,502 \\
12,292 \\
2,040\end{array}$ & $\begin{array}{r}5,969 \\
19,021 \\
2,491 \\
53,260 \\
818\end{array}$ & $\begin{array}{r}38,580 \\
\boldsymbol{R}_{70,022} \\
38 \\
30,005 \\
2,117\end{array}$ & $\begin{array}{r}44,549 \\
89,043 \\
2,529 \\
83,265 \\
2,935\end{array}$ & $\begin{array}{r}60,617 \\
241,508 \\
46,031 \\
95,557 \\
4,976\end{array}$ \\
\hline 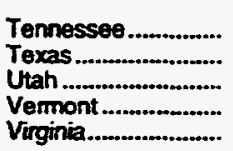 & $\begin{array}{r}26,893 \\
R_{523,888} \\
1,891 \\
100 \\
9,378\end{array}$ & $\begin{array}{r}R_{11,258} \\
R_{490,473} \\
0 \\
0 \\
36,153\end{array}$ & $\begin{array}{r}R_{38,150} \\
R_{1,014,361} \\
1,891 \\
100 \\
45,531\end{array}$ & $\begin{array}{r}30,633 \\
99,626 \\
1,023 \\
1,945 \\
8,779\end{array}$ & $\begin{array}{r}R_{55,523} \\
768,301 \\
39,387 \\
0 \\
18,638\end{array}$ & $\begin{array}{r}R_{86,155} \\
P_{867,927} \\
40,410 \\
1,945 \\
27,418\end{array}$ & $\begin{array}{r}124,306 \\
A_{1,882,288} \\
42,301 \\
2,045 \\
72,949\end{array}$ \\
\hline $\begin{array}{l}\text { Washington.............. } \\
\text { West Virginia........... } \\
\text { Wisconsin ................ } \\
\text { Wyoming................. }\end{array}$ & $\begin{array}{r}30,910 \\
5,790 \\
27,020 \\
868\end{array}$ & $\begin{array}{l}16,243 \\
14,486 \\
20,349 \\
10,066\end{array}$ & $\begin{array}{l}47,153 \\
20,276 \\
47,369 \\
10,934\end{array}$ & $\begin{array}{r}7,187 \\
34,164 \\
411\end{array}$ & $\begin{array}{l}37,934 \\
26,377 \\
52,541 \\
42,870\end{array}$ & $\begin{array}{l}45,121 \\
26,886 \\
86,705 \\
43,281\end{array}$ & $\begin{array}{r}92,274 \\
R_{47,162} \\
134,073 \\
54,214\end{array}$ \\
\hline Total........................... & $A_{1,553,545}$ & $R_{3,071,308}$ & $A_{4,624,853}$ & $\mathrm{~A}_{782,995}$ & $\mathrm{~A}_{2,573,586}$ & $A_{3,356,581}$ & $\mathbf{R}_{7,981,433}$ \\
\hline
\end{tabular}

See footnoles at end of table. 
Table 20. Natural Gas Deliveries to Industrial Consumers by State, 1993-1994 (Continued) (Million Cubic Feet)

\begin{tabular}{|c|c|c|c|c|c|c|c|}
\hline \multirow{2}{*}{ State } & \multicolumn{3}{|c|}{ Firm } & \multicolumn{3}{|c|}{ Internuptible } & \multirow{2}{*}{ Total Volume } \\
\hline & $\begin{array}{l}\text { Sales } \\
\text { Volume }\end{array}$ & $\begin{array}{l}\text { Tranaported } \\
\text { Volume }\end{array}$ & $\begin{array}{l}\text { Total } \\
\text { Volvine }\end{array}$ & $\begin{array}{l}\text { Sales } \\
\text { Volume }\end{array}$ & $\begin{array}{l}\text { Transported } \\
\text { Volutime }\end{array}$ & $\begin{array}{l}\text { Toted } \\
\text { Volutue }\end{array}$ & \\
\hline & \multicolumn{7}{|c|}{1994} \\
\hline 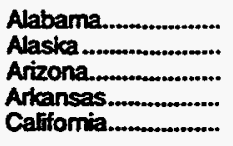 & $\begin{array}{r}12,276 \\
35,882 \\
7,539 \\
7,852 \\
96,508\end{array}$ & $\begin{array}{r}59,067 \\
21,736 \\
17,360 \\
107,184 \\
303,228\end{array}$ & $\begin{array}{r}71,344 \\
57,618 \\
24,898 \\
115,036 \\
399,736\end{array}$ & $\begin{array}{r}37,368 \\
0 \\
296 \\
10,608 \\
22,740\end{array}$ & $\begin{array}{r}73,006 \\
3,786 \\
675 \\
8,277 \\
234,275\end{array}$ & $\begin{array}{r}110,374 \\
3,786 \\
971 \\
18,884 \\
257,015\end{array}$ & $\begin{array}{r}181,718 \\
61,404 \\
25,869 \\
133,921 \\
656,751\end{array}$ \\
\hline 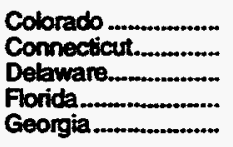 & $\begin{array}{r}6,654 \\
14,095 \\
4,705 \\
8,347 \\
13,725\end{array}$ & $\begin{array}{r}15,970 \\
194 \\
5,631 \\
38,847 \\
32,585\end{array}$ & $\begin{array}{l}22,625 \\
14,289 \\
10,336 \\
47,194 \\
46,311\end{array}$ & $\begin{array}{r}13,146 \\
15,118 \\
6,880 \\
12,360 \\
51,316\end{array}$ & $\begin{array}{r}35,322 \\
1,241 \\
0 \\
67,319 \\
76,274\end{array}$ & $\begin{array}{r}48,468 \\
16,358 \\
6,880 \\
79,679 \\
127,590\end{array}$ & $\begin{array}{r}71,093 \\
30,647 \\
17,216 \\
126,873 \\
173,901\end{array}$ \\
\hline 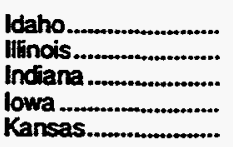 & $\begin{array}{r}467 \\
32,642 \\
28,181 \\
8,073 \\
3,393\end{array}$ & $\begin{array}{r}26,044 \\
250,534 \\
33,801 \\
84,891 \\
94,511\end{array}$ & $\begin{array}{r}26,511 \\
283,176 \\
61,982 \\
92,954 \\
97,904\end{array}$ & $\begin{array}{l}382 \\
5,102 \\
8,076 \\
4,641 \\
8,895\end{array}$ & $\begin{array}{r}2,888 \\
16,814 \\
200,070 \\
11,125 \\
81,180\end{array}$ & $\begin{array}{r}3,270 \\
21,916 \\
208,146 \\
15,766 \\
90,075\end{array}$ & $\begin{array}{r}29,781 \\
305,092 \\
270,128 \\
108,731 \\
187,979\end{array}$ \\
\hline 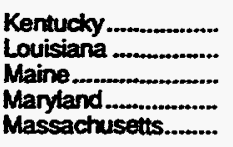 & $\begin{array}{r}13,607 \\
168,431 \\
1,166 \\
362 \\
16,112\end{array}$ & $\begin{array}{r}30,574 \\
424,307 \\
0 \\
11,473 \\
51,400\end{array}$ & $\begin{array}{r}44,181 \\
592,738 \\
1,166 \\
11,836 \\
67,512\end{array}$ & $\begin{array}{r}12,325 \\
70,856 \\
604 \\
7.633 \\
9,615\end{array}$ & $\begin{array}{r}26,575 \\
335,440 \\
0 \\
28,223 \\
15,672\end{array}$ & $\begin{array}{r}38,900 \\
406,296 \\
604 \\
35,856 \\
25,286\end{array}$ & $\begin{array}{r}83,081 \\
999,034 \\
1,771 \\
47,691 \\
92,798\end{array}$ \\
\hline 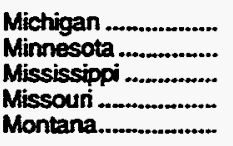 & $\begin{array}{r}33,961 \\
9,146 \\
15,067 \\
10,009 \\
545\end{array}$ & $\begin{array}{r}260,739 \\
48,819 \\
44,013 \\
47,958 \\
5,086\end{array}$ & $\begin{array}{r}294,701 \\
57,965 \\
59,080 \\
57,967 \\
5,580\end{array}$ & $\begin{array}{r}942 \\
31,394 \\
22,763 \\
4,720 \\
1\end{array}$ & $\begin{array}{r}32,205 \\
5,109 \\
15,019 \\
8,915 \\
8,359\end{array}$ & $\begin{array}{r}33,148 \\
36,503 \\
37,783 \\
13,635 \\
8,360\end{array}$ & $\begin{array}{r}327,848 \\
94,468 \\
96,863 \\
71,602 \\
13,940\end{array}$ \\
\hline $\begin{array}{l}\text { Nebraska ................. } \\
\text { Nevada ................... } \\
\text { New Hampshire....... } \\
\text { New Jersey.............. } \\
\text { New Mexico............ }\end{array}$ & $\begin{array}{r}2,957 \\
554 \\
3,409 \\
28,883 \\
1,839\end{array}$ & $\begin{array}{r}26,935 \\
28,218 \\
225 \\
46,056 \\
16,137\end{array}$ & $\begin{array}{r}29,892 \\
28,772 \\
3,634 \\
74,939 \\
17,976\end{array}$ & $\begin{array}{r}5,032 \\
0 \\
837 \\
80,741 \\
18\end{array}$ & $\begin{array}{r}2,037 \\
95 \\
0 \\
35,165 \\
747\end{array}$ & $\begin{array}{r}7.069 \\
95 \\
837 \\
115,906 \\
765\end{array}$ & $\begin{array}{r}36,960 \\
28,867 \\
4,471 \\
190,845 \\
18,741\end{array}$ \\
\hline $\begin{array}{l}\text { New York................ } \\
\text { North Canolina......... } \\
\text { North Dakota........... } \\
\text { Ohio ......................... } \\
\text { Otdahoma .............. }\end{array}$ & $\begin{array}{r}24,754 \\
12,219 \\
173 \\
27,551 \\
19,196\end{array}$ & $\begin{array}{r}110,717 \\
6,596 \\
333 \\
240,821 \\
20,826\end{array}$ & $\begin{array}{r}135,471 \\
18,816 \\
506 \\
268,372 \\
40,023\end{array}$ & $\begin{array}{r}9,683 \\
43,711 \\
1,271 \\
2,517 \\
28,373\end{array}$ & $\begin{array}{r}69,284 \\
32,311 \\
4,069 \\
40,234 \\
127,514\end{array}$ & $\begin{array}{r}78,967 \\
76,023 \\
5,340 \\
42,751 \\
155,886\end{array}$ & $\begin{array}{r}214,438 \\
94,838 \\
5,846 \\
311,123 \\
195,909\end{array}$ \\
\hline $\begin{array}{l}\text { Oregon.................... } \\
\text { Pernsylvania ........... } \\
\text { Phode Istand.......... } \\
\text { Sotth Carolina........ } \\
\text { South Dakota.......... }\end{array}$ & $\begin{array}{r}11,403 \\
31,793 \\
2,470 \\
12,794 \\
1,323\end{array}$ & $\begin{array}{r}7,350 \\
140,621 \\
37,253 \\
4,629 \\
1,248\end{array}$ & $\begin{array}{r}18,733 \\
172,414 \\
39,723 \\
17,424 \\
2,571\end{array}$ & $\begin{array}{r}8,274 \\
16.645 \\
1,193 \\
61,951 \\
736\end{array}$ & $\begin{array}{r}35,561 \\
47,359 \\
4 \\
18,125 \\
2,201\end{array}$ & $\begin{array}{r}43,835 \\
64,003 \\
1,197 \\
80,076 \\
2,936\end{array}$ & $\begin{array}{r}62,569 \\
236,417 \\
40,921 \\
97,500 \\
5,508\end{array}$ \\
\hline 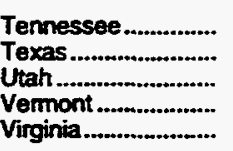 & $\begin{array}{r}27,719 \\
453,167 \\
1,999 \\
116 \\
7,641\end{array}$ & $\begin{array}{r}16,781 \\
661,600 \\
0 \\
0 \\
43,670\end{array}$ & $\begin{array}{r}44,500 \\
1,114,766 \\
1,999 \\
116 \\
51,312\end{array}$ & $\begin{array}{r}26,555 \\
55,004 \\
2,381 \\
1,908 \\
10,781\end{array}$ & $\begin{array}{r}47,834 \\
659,708 \\
32,238 \\
0 \\
23,671\end{array}$ & $\begin{array}{r}74,389 \\
714,712 \\
34,619 \\
1,908 \\
34,452\end{array}$ & $\begin{array}{r}118,889 \\
1,829,478 \\
36,618 \\
2,023 \\
85,764\end{array}$ \\
\hline $\begin{array}{l}\text { Washington............. } \\
\text { West Vinginia........... } \\
\text { Wisconsin ................ } \\
\text { Wyoming................ }\end{array}$ & $\begin{array}{r}35,492 \\
5,651 \\
24,215 \\
660\end{array}$ & $\begin{array}{r}13,052 \\
14,870 \\
4,347 \\
10,010\end{array}$ & $\begin{array}{l}48,545 \\
20,521 \\
28,563 \\
10,670\end{array}$ & $\begin{array}{r}9,234 \\
439 \\
41,700 \\
687\end{array}$ & $\begin{array}{l}49,825 \\
25,814 \\
64,843 \\
49,209\end{array}$ & $\begin{array}{r}59,059 \\
26,253 \\
106,544 \\
49,896\end{array}$ & $\begin{array}{r}107,603 \\
46,774 \\
135,106 \\
60,566\end{array}$ \\
\hline 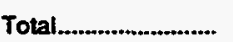 & $1,286,724$ & $3,468,182$ & $4,754,907$ & 767,453 & $2,655,615$ & $3,423,068$ & $8,177,975$ \\
\hline
\end{tabular}

$A=$ Revised data.

Note: Totals may not equal sum of components due to independent rounding. $1993-1994$ : Energy Information Administration (EIA). Form ElA-176, Annual Report of Natural and Supplemental Gas Supply and Disposition." 
Table 21. Natural Gas Deliveries to Electric Utilities by State, 1993-1994 (Million Cubic Feet)

\begin{tabular}{|c|c|c|c|c|c|c|c|}
\hline \multirow{2}{*}{ Sten } & \multicolumn{3}{|c|}{ Fim } & \multicolumn{3}{|c|}{ Inturruptible } & \multirow{2}{*}{ Total Volume } \\
\hline & $\begin{array}{c}\text { Seles } \\
\text { Volume }\end{array}$ & $\begin{array}{l}\text { Tranaported } \\
\text { Yolurwe }\end{array}$ & $\begin{array}{l}\text { Total } \\
\text { Volume }\end{array}$ & $\begin{array}{l}\text { Seles } \\
\text { Volume }\end{array}$ & $\begin{array}{l}\text { Truneported } \\
\text { Volvine }\end{array}$ & $\begin{array}{l}\text { Total } \\
\text { Volume }\end{array}$ & \\
\hline & \multicolumn{7}{|c|}{1993} \\
\hline 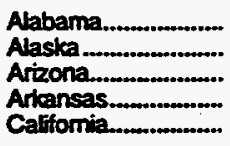 & $\begin{array}{r}0 \\
18,241 \\
31 \\
1,134 \\
75,209\end{array}$ & $\begin{array}{r}33 \\
7,693 \\
27,188 \\
4,669 \\
341,732\end{array}$ & $\begin{array}{r}33 \\
25,934 \\
27,219 \\
5,803 \\
416,941\end{array}$ & $\begin{array}{r}1,763 \\
676 \\
0 \\
0 \\
44,346\end{array}$ & $\begin{array}{r}2,720 \\
0 \\
2,678 \\
11,859 \\
724\end{array}$ & $\begin{array}{r}4,483 \\
676 \\
2,678 \\
11,859 \\
45,071\end{array}$ & $\begin{array}{r}4,516 \\
26,610 \\
29,897 \\
17,662 \\
462,012\end{array}$ \\
\hline 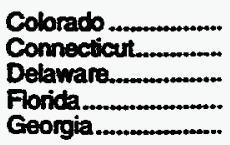 & $\begin{array}{r}1,604 \\
108 \\
8,264 \\
3,111 \\
3,080\end{array}$ & $\begin{array}{r}430 \\
0 \\
58 \\
139,996 \\
0\end{array}$ & $\begin{array}{r}2,034 \\
108 \\
8,322 \\
143,107 \\
3,080\end{array}$ & $\begin{array}{r}1 \\
136 \\
141 \\
777 \\
0\end{array}$ & $\begin{array}{r}2,735 \\
140 \\
0 \\
37,958 \\
0\end{array}$ & $\begin{array}{r}2,736 \\
276 \\
141 \\
38,736 \\
0\end{array}$ & $\begin{array}{r}4,770 \\
384 \\
8,463 \\
181,842 \\
3,080\end{array}$ \\
\hline 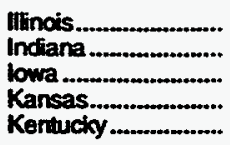 & $\begin{array}{r}850 \\
743 \\
1,834 \\
863 \\
205\end{array}$ & $\begin{array}{r}14,227 \\
0 \\
1,901 \\
544 \\
0\end{array}$ & $\begin{array}{r}15,077 \\
743 \\
3,735 \\
1,407 \\
205\end{array}$ & $\begin{array}{r}489 \\
0 \\
23 \\
5,035 \\
22\end{array}$ & $\begin{array}{r}0 \\
4,204 \\
0 \\
7,547 \\
0\end{array}$ & $\begin{array}{r}489 \\
4,204 \\
23 \\
12,581 \\
22\end{array}$ & $\begin{array}{r}15,566 \\
4,947 \\
3,758 \\
13,989 \\
227\end{array}$ \\
\hline $\begin{array}{l}\text { Louisiana ................. } \\
\text { Maryland.................. } \\
\text { Massachusetts........ } \\
\text { Michigan ................. } \\
\text { Minnesota ................ }\end{array}$ & $\begin{array}{r}17.928 \\
0 \\
6.895 \\
374 \\
106\end{array}$ & $\begin{array}{r}79,131 \\
1,231 \\
5,436 \\
16,248 \\
0\end{array}$ & $\begin{array}{r}97,059 \\
1,231 \\
12,331 \\
16,621 \\
106\end{array}$ & $\begin{array}{r}19,885 \\
3,966 \\
6,021 \\
24 \\
1,130\end{array}$ & $\begin{array}{r}103,404 \\
1,804 \\
4,290 \\
76 \\
1,071\end{array}$ & $\begin{array}{r}123,289 \\
5,770 \\
10,311 \\
100 \\
2,201\end{array}$ & $\begin{array}{r}220,347 \\
7,001 \\
22,642 \\
16,721 \\
2,307\end{array}$ \\
\hline 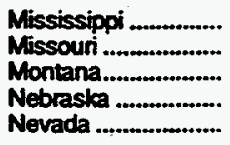 & $\begin{array}{r}15,125 \\
84 \\
115 \\
668 \\
13\end{array}$ & $\begin{array}{r}15,506 \\
1,290 \\
0 \\
0 \\
19,142\end{array}$ & $\begin{array}{r}30,631 \\
1,374 \\
115 \\
668 \\
19,155\end{array}$ & $\begin{array}{r}33 \\
2.406 \\
0 \\
131 \\
0\end{array}$ & $\begin{array}{r}10,764 \\
1,317 \\
155 \\
484 \\
1,923\end{array}$ & $\begin{array}{r}10,797 \\
3,723 \\
155 \\
615 \\
1,923\end{array}$ & $\begin{array}{r}41,428 \\
5,097 \\
270 \\
1,283 \\
21,079\end{array}$ \\
\hline $\begin{array}{l}\text { New Jersey .............. } \\
\text { New Mexico ............. } \\
\text { New York.............. } \\
\text { North Carolina.......... } \\
\text { North Dakota........... }\end{array}$ & $\begin{array}{r}30,447 \\
866 \\
21,288 \\
98 \\
1\end{array}$ & $\begin{array}{r}3,919 \\
11,884 \\
0 \\
0 \\
0\end{array}$ & $\begin{array}{r}34,366 \\
12,749 \\
21,288 \\
98 \\
1\end{array}$ & $\begin{array}{r}4,716 \\
0 \\
131,996 \\
953 \\
0\end{array}$ & $\begin{array}{r}0 \\
8,239 \\
15,455 \\
1,692 \\
0\end{array}$ & $\begin{array}{r}4,716 \\
8,239 \\
147,451 \\
2,644 \\
0\end{array}$ & $\begin{array}{r}39,082 \\
20,988 \\
168,739 \\
2,742 \\
1\end{array}$ \\
\hline $\begin{array}{l}\text { Ohio ....................... } \\
\text { Okdahoma ............... } \\
\text { Oregon.................. } \\
\text { Permsyhania ........... } \\
\text { South Cardina....... }\end{array}$ & $\begin{array}{r}612 \\
15,190 \\
0 \\
5,008 \\
0\end{array}$ & $\begin{array}{r}170 \\
138,834 \\
14,879 \\
976 \\
0\end{array}$ & $\begin{array}{r}782 \\
154,024 \\
14,879 \\
5,984 \\
0\end{array}$ & $\begin{array}{r}48 \\
1,413 \\
0 \\
732 \\
1,415\end{array}$ & $\begin{array}{r}1,891 \\
6,382 \\
1,162 \\
2,289 \\
0\end{array}$ & $\begin{array}{l}1,939 \\
7,796 \\
1,162 \\
3,021 \\
1,415\end{array}$ & $\begin{array}{r}2,721 \\
161,820 \\
16,041 \\
9,005 \\
1,415\end{array}$ \\
\hline 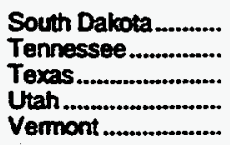 & $\begin{array}{r}0 \\
0 \\
A_{304,994} \\
0 \\
0\end{array}$ & $\begin{array}{r}0 \\
0 \\
119,356 \\
0 \\
0\end{array}$ & $\begin{array}{r}0 \\
0 \\
R_{424,350} \\
0 \\
0\end{array}$ & $\begin{array}{r}13 \\
609 \\
19,277 \\
5 \\
268\end{array}$ & $\begin{array}{r}142 \\
1,015 \\
424,899 \\
5,004 \\
0\end{array}$ & $\begin{array}{r}154 \\
1,625 \\
444,175 \\
5,009 \\
268\end{array}$ & $\begin{array}{r}154 \\
1,625 \\
R_{868,526} \\
5,009 \\
268\end{array}$ \\
\hline $\begin{array}{l}\text { Virginia .................... } \\
\text { Washington............. } \\
\text { West Virginia............ } \\
\text { Wisconsin ................ } \\
\text { Wyoming................... }\end{array}$ & $\begin{array}{r}6 \\
0 \\
0 \\
1,359 \\
88\end{array}$ & $\begin{array}{r}18,768 \\
0 \\
279 \\
0 \\
0\end{array}$ & $\begin{array}{r}18,774 \\
0 \\
279 \\
1,359 \\
88\end{array}$ & $\begin{array}{r}20 \\
0 \\
0 \\
1,572 \\
0\end{array}$ & $\begin{array}{r}7,055 \\
1,195 \\
0 \\
648 \\
0\end{array}$ & $\begin{array}{r}7.075 \\
1.195 \\
0 \\
2.220 \\
0\end{array}$ & $\begin{array}{r}25,849 \\
1,195 \\
279 \\
3,580 \\
88\end{array}$ \\
\hline Total & $A_{536,544}$ & 985,517 & $R_{1,522,061}$ & 250,041 & 672,920 & 922,962 & $A_{2,445,023}$ \\
\hline
\end{tabular}

See foomotes at end of table. 
Table 21. Natural Gas Deliveries to Electric Utilities by State, 1993-1994 (Continued) (Million Cubic Feet)

\begin{tabular}{|c|c|c|c|c|c|c|c|}
\hline \multirow{2}{*}{ Stute } & \multicolumn{3}{|c|}{ Firm } & \multicolumn{3}{|c|}{ Interruptible } & \multirow{2}{*}{ Totel Volume } \\
\hline & $\begin{array}{c}\text { Sales } \\
\text { Vohume }\end{array}$ & $\begin{array}{c}\text { Transported } \\
\text { Volume }\end{array}$ & $\begin{array}{l}\text { Total } \\
\text { Volume }\end{array}$ & $\begin{array}{l}\text { Soles } \\
\text { Volume }\end{array}$ & $\begin{array}{l}\text { Transported } \\
\text { Volume }\end{array}$ & $\begin{array}{l}\text { Total } \\
\text { Volume }\end{array}$ & \\
\hline & \multicolumn{7}{|c|}{1994} \\
\hline 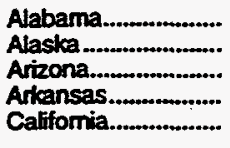 & $\begin{array}{r}0 \\
19,172 \\
42 \\
794 \\
46\end{array}$ & $\begin{array}{r}83 \\
8,368 \\
32,594 \\
12,723 \\
288,008\end{array}$ & $\begin{array}{r}83 \\
27,541 \\
32,636 \\
13,517 \\
288,054\end{array}$ & $\begin{array}{r}382 \\
706 \\
0 \\
0 \\
40,171\end{array}$ & $\begin{array}{r}3,187 \\
0 \\
594 \\
5,900 \\
268,549\end{array}$ & $\begin{array}{r}3,569 \\
706 \\
594 \\
5,903 \\
308,720\end{array}$ & $\begin{array}{r}3,652 \\
28,246 \\
33,230 \\
19,419 \\
596,774\end{array}$ \\
\hline 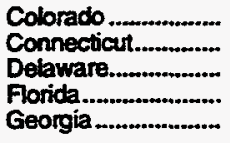 & $\begin{array}{r}1,532 \\
0 \\
68 \\
1,888 \\
1,137\end{array}$ & $\begin{array}{r}0 \\
6,807 \\
16,120 \\
167,352 \\
0\end{array}$ & $\begin{array}{r}1,532 \\
6,807 \\
16,187 \\
169,240 \\
1,137\end{array}$ & $\begin{array}{r}2 \\
913 \\
1,281 \\
78 \\
0\end{array}$ & $\begin{array}{r}2,685 \\
134 \\
0 \\
15,028 \\
0\end{array}$ & $\begin{array}{r}2,687 \\
1,047 \\
1,281 \\
15,105 \\
0\end{array}$ & $\begin{array}{r}4,219 \\
7,854 \\
17,468 \\
184,345 \\
1,137\end{array}$ \\
\hline 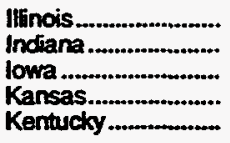 & $\begin{array}{r}1,532 \\
2.041 \\
644 \\
1,169 \\
267\end{array}$ & $\begin{array}{r}32,064 \\
312 \\
1,181 \\
10,044 \\
0\end{array}$ & $\begin{array}{r}33,596 \\
2,353 \\
1,826 \\
11,213 \\
267\end{array}$ & $\begin{array}{r}2 \\
0 \\
108 \\
4,670 \\
3\end{array}$ & $\begin{array}{r}0 \\
7,058 \\
540 \\
4,573 \\
0\end{array}$ & $\begin{array}{r}2 \\
7,058 \\
648 \\
9,243 \\
3\end{array}$ & $\begin{array}{r}33,599 \\
9,411 \\
2,474 \\
20,456 \\
269\end{array}$ \\
\hline $\begin{array}{l}\text { Louisiana ................. } \\
\text { Maryland ................ } \\
\text { Massachusetts.......... } \\
\text { Michigan .................. } \\
\text { Minnesota................ }\end{array}$ & $\begin{array}{r}18,503 \\
0 \\
9,706 \\
387 \\
1.701\end{array}$ & $\begin{array}{r}68,510 \\
2,977 \\
11,655 \\
17,632 \\
0\end{array}$ & $\begin{array}{r}87,013 \\
2,977 \\
21,361 \\
18,019 \\
1,701\end{array}$ & $\begin{array}{r}15,269 \\
8,701 \\
1,646 \\
11 \\
1,390\end{array}$ & $\begin{array}{r}105,814 \\
1,209 \\
18,336 \\
188 \\
906\end{array}$ & $\begin{array}{r}121,083 \\
9,910 \\
19,983 \\
199 \\
2,296\end{array}$ & $\begin{array}{r}208,096 \\
12,887 \\
41,343 \\
18,218 \\
3,996\end{array}$ \\
\hline 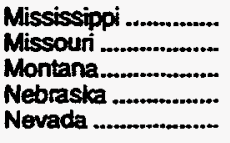 & $\begin{array}{r}1,357 \\
29 \\
523 \\
55 \\
0\end{array}$ & $\begin{array}{r}334 \\
1.214 \\
0 \\
0 \\
31.074\end{array}$ & $\begin{array}{r}1,701 \\
1,243 \\
523 \\
55 \\
31,074\end{array}$ & $\begin{array}{r}349 \\
1,879 \\
0 \\
528 \\
0\end{array}$ & $\begin{array}{r}31,594 \\
33 \\
139 \\
34 \\
1,303\end{array}$ & $\begin{array}{r}31,943 \\
1,911 \\
139 \\
563 \\
1,303\end{array}$ & $\begin{array}{r}33,643 \\
3,154 \\
663 \\
618 \\
32,377\end{array}$ \\
\hline $\begin{array}{l}\text { New Hampshire ....... } \\
\text { New Jersey ............. } \\
\text { New Mexico ............. } \\
\text { New York................. } \\
\text { North Carolina......... }\end{array}$ & $\begin{array}{r}0 \\
27.496 \\
1,556 \\
24,904 \\
104\end{array}$ & $\begin{array}{r}0 \\
1,629 \\
13,648 \\
9,406 \\
44\end{array}$ & $\begin{array}{r}0 \\
29,126 \\
15,213 \\
34,310 \\
149\end{array}$ & $\begin{array}{r}1,271 \\
6,278 \\
140 \\
130,812 \\
315\end{array}$ & $\begin{array}{r}0 \\
8 \\
11,220 \\
4,675 \\
388\end{array}$ & $\begin{array}{r}1,271 \\
6,286 \\
11,360 \\
135,488 \\
703\end{array}$ & $\begin{array}{r}1,271 \\
35,412 \\
26,573 \\
169,798 \\
852\end{array}$ \\
\hline 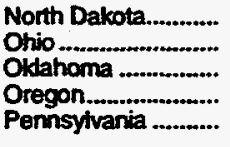 & $\begin{array}{r}2 \\
896 \\
17,323 \\
0 \\
4,439\end{array}$ & $\begin{array}{r}0 \\
89 \\
136,279 \\
26,310 \\
1,755\end{array}$ & $\begin{array}{r}2 \\
985 \\
153,602 \\
26,310 \\
6,195\end{array}$ & $\begin{array}{r}0 \\
166 \\
1,302 \\
0 \\
766\end{array}$ & $\begin{array}{r}0 \\
1,536 \\
3,155 \\
0 \\
7,192\end{array}$ & $\begin{array}{r}0 \\
1,703 \\
4,457 \\
0 \\
7,958\end{array}$ & $\begin{array}{r}2 \\
2,688 \\
158,059 \\
26,310 \\
14,153\end{array}$ \\
\hline 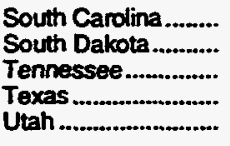 & $\begin{array}{r}60 \\
0 \\
0 \\
311.650 \\
0\end{array}$ & $\begin{array}{r}0 \\
0 \\
0 \\
201,310 \\
6.200\end{array}$ & $\begin{array}{r}60 \\
0 \\
0 \\
512,960 \\
6,200\end{array}$ & $\begin{array}{r}2,961 \\
0 \\
473 \\
20,246 \\
34\end{array}$ & $\begin{array}{r}0 \\
64 \\
498 \\
458,400 \\
1,723\end{array}$ & $\begin{array}{r}2,961 \\
64 \\
971 \\
478,646 \\
1,756\end{array}$ & $\begin{array}{r}3,021 \\
64 \\
971 \\
991,606 \\
7,956\end{array}$ \\
\hline $\begin{array}{l}\text { Vermont } \\
\text { Virginia........................ } \\
\text { Washington.............. } \\
\text { West Virginia............ } \\
\text { Wisconsin ................ } \\
\text { Wyoming............... }\end{array}$ & $\begin{array}{r}0 \\
0 \\
0 \\
0 \\
3,416 \\
79\end{array}$ & $\begin{array}{r}0 \\
17,932 \\
2,307 \\
244 \\
0 \\
0\end{array}$ & $\begin{array}{r}0 \\
17,932 \\
2,307 \\
244 \\
3,416 \\
79\end{array}$ & $\begin{array}{r}165 \\
91 \\
0 \\
0 \\
1,428 \\
0\end{array}$ & $\begin{array}{r}0 \\
8,774 \\
20 \\
0 \\
457 \\
0\end{array}$ & $\begin{array}{r}165 \\
8,865 \\
20 \\
0 \\
1,885 \\
0\end{array}$ & $\begin{array}{r}165 \\
26,797 \\
2,328 \\
244 \\
5,301 \\
79\end{array}$ \\
\hline Total................................. & 454,539 & $1,126,206$ & $1,580,745$ & 244,536 & 965,918 & $1,210,453$ & $2,791,198$ \\
\hline
\end{tabular}

R = Revised data.

Note: Totals may not equal sum of components the to independent rounding.

Source: 1993-1994: Energy information Administration (ElA), Form ElA-176. "Annual Report of Natural and Supplemental Gas Supply and Disposition." 
Table 22. Natural Gas Delivered to Consumers by Census Division, 1967-1994

\begin{tabular}{|c|c|c|c|c|c|c|}
\hline \multirow[b]{2}{*}{ Centurs Division } & \multicolumn{2}{|c|}{ Residential } & \multicolumn{2}{|c|}{ Commercial } & \multicolumn{2}{|c|}{ Industrial } \\
\hline & $\begin{array}{l}\text { Quantity } \\
\text { (mallion } \\
\text { cubic fent) }\end{array}$ & Consumers & $\begin{array}{l}\text { Quantity } \\
\text { (milition } \\
\text { cubic feet) }\end{array}$ & Contumers & $\begin{array}{l}\text { Qumitity } \\
\text { (milition } \\
\text { cubic fines) }\end{array}$ & Consumers \\
\hline & \multicolumn{6}{|c|}{1957} \\
\hline $\begin{array}{l}\text { New England ................ } \\
\text { Middle Attantic .............. } \\
\text { East North Central ....... } \\
\text { West North Central ...... } \\
\text { South Atlantic................ }\end{array}$ & $\begin{array}{r}113,965 \\
728,616 \\
1,357,622 \\
459,075 \\
300,613\end{array}$ & $\begin{array}{l}1,529,000 \\
7,537,000 \\
8,320,000 \\
2,934,000 \\
3,057,000\end{array}$ & $\begin{array}{r}37,949 \\
233,408 \\
528,336 \\
286,469 \\
150,032\end{array}$ & $\begin{array}{l}100,000 \\
574,000 \\
653,000 \\
320,000 \\
276,000\end{array}$ & $\begin{array}{r}38,836 \\
412,641 \\
1,240,559 \\
406,323 \\
469,501\end{array}$ & $\begin{array}{l}\text { NA } \\
\text { NA } \\
\text { NA } \\
\text { NA }\end{array}$ \\
\hline $\begin{array}{l}\text { East South Central....... } \\
\text { West South Central...... } \\
\text { Mountain. } \\
\text { Pacific Contiguous......... } \\
\text { Pacitic Noncontiguous. }\end{array}$ & $\begin{array}{r}182,889 \\
395,965 \\
213,892 \\
558,709 \\
1,958\end{array}$ & $\begin{array}{r}1,658,000 \\
4,084,000 \\
1,623,000 \\
5,673,000 \\
9,000\end{array}$ & $\begin{array}{r}113,641 \\
264,543 \\
135,146 \\
206,724 \\
2,722\end{array}$ & $\begin{array}{r}164,000 \\
428,000 \\
172,000 \\
388,000 \\
2,000\end{array}$ & $\begin{array}{r}429,611 \\
2,686,557 \\
328,665 \\
639,254 \\
1,069\end{array}$ & $\begin{array}{l}\text { NA } \\
\text { NA } \\
\text { NA } \\
\text { NA }\end{array}$ \\
\hline \multirow[t]{2}{*}{ 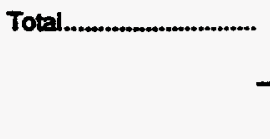 } & $4,313,304$ & $36,434,000$ & $1,958,970$ & $3,077,000$ & $6,653,016$ & NA \\
\hline & \multicolumn{6}{|c|}{1968} \\
\hline $\begin{array}{l}\text { New Engtand ................. } \\
\text { Middle Aftantic .............. } \\
\text { East North Central ....... } \\
\text { West North Central ....... } \\
\text { Sotth Attartic................ }\end{array}$ & $\begin{array}{r}115,532 \\
742,376 \\
1,392,363 \\
474,329 \\
321,122\end{array}$ & $\begin{array}{l}1,535,000 \\
7,603,000 \\
8,561,000 \\
3,034,000 \\
3,174,000\end{array}$ & $\begin{array}{r}41,708 \\
243,051 \\
553,831 \\
299,183 \\
166,591\end{array}$ & $\begin{array}{r}98,000 \\
572,000 \\
675,000 \\
323,000 \\
281,000\end{array}$ & $\begin{array}{r}43,487 \\
477,442 \\
1,285,732 \\
466,456 \\
536,986\end{array}$ & $\begin{array}{l}\text { NA } \\
\text { NA } \\
\text { NA } \\
\text { NA }\end{array}$ \\
\hline $\begin{array}{l}\text { East South Central........ } \\
\text { West South Central...... } \\
\text { Mountain................... } \\
\text { Pacific Contiguous........ } \\
\text { Pacific Noncontiguous. }\end{array}$ & $\begin{array}{r}200,842 \\
420,653 \\
221,740 \\
559,104 \\
2,293\end{array}$ & $\begin{array}{r}1,695,000 \\
4,166,000 \\
1,660,000 \\
5,820,000 \\
11,000\end{array}$ & $\begin{array}{r}127,460 \\
277,016 \\
148,162 \\
214,021 \\
4,713\end{array}$ & $\begin{array}{r}169,000 \\
423,000 \\
180,000 \\
398,000 \\
2,000\end{array}$ & $\begin{array}{r}450,041 \\
2,818,378 \\
359,392 \\
689,417 \\
2,634\end{array}$ & $\begin{array}{l}\text { NA } \\
\text { NA } \\
\text { NA } \\
\text { NA } \\
\text { NA }\end{array}$ \\
\hline \multirow[t]{2}{*}{ Total............................... } & $4,450,354$ & $37,259,000$ & $2,075,736$ & $3,121,000$ & $7,129,967$ & NA \\
\hline & \multicolumn{6}{|c|}{1980} \\
\hline $\begin{array}{l}\text { New England ................. } \\
\text { Middle Attantic ............. } \\
\text { East North Central....... } \\
\text { West North Central ....... } \\
\text { South Atlantic................ }\end{array}$ & $\begin{array}{r}123,783 \\
771,840 \\
1.481,566 \\
508,627 \\
340,370\end{array}$ & $\begin{array}{l}1,571,000 \\
7,636,000 \\
8,742,000 \\
3,142,000 \\
3,243,000\end{array}$ & $\begin{array}{r}48,444 \\
258,512 \\
619,169 \\
320,699 \\
187,092\end{array}$ & $\begin{array}{l}103,000 \\
578,000 \\
708,000 \\
333,000 \\
291,000\end{array}$ & $\begin{array}{r}45,286 \\
531,454 \\
1,411,538 \\
499,272 \\
568,470\end{array}$ & $\begin{array}{l}\text { NA } \\
\text { NA } \\
\text { NA } \\
\text { NA } \\
\text { NA }\end{array}$ \\
\hline $\begin{array}{l}\text { East South Central........ } \\
\text { West South Central...... } \\
\text { Mountain..................... } \\
\text { Pacific Contiguous ....... } \\
\text { Pacific Noncontiguous. }\end{array}$ & $\begin{array}{r}214,248 \\
437,325 \\
232,835 \\
613,113 \\
4,573\end{array}$ & $\begin{array}{r}1,758,000 \\
4,318,000 \\
1,724,000 \\
5,948,000 \\
14,000\end{array}$ & $\begin{array}{r}137,945 \\
275,977 \\
160,359 \\
233,992 \\
11,018\end{array}$ & $\begin{array}{r}175,000 \\
429,000 \\
189,000 \\
412,000 \\
4,000\end{array}$ & $\begin{array}{r}479,906 \\
2,943,251 \\
382,407 \\
735,342 \\
13,575\end{array}$ & $\begin{array}{l}\text { NA } \\
\text { NA } \\
\text { NA } \\
\text { NA } \\
\text { NA }\end{array}$ \\
\hline \multirow[t]{2}{*}{ 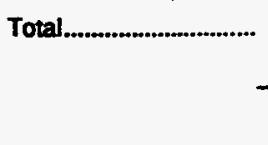 } & 4.728 .281 & $38.096,000$ & $2,253,206$ & 3.222 .000 & $7,610,501$ & $\mathbf{N A}$ \\
\hline & \multicolumn{6}{|c|}{1970} \\
\hline $\begin{array}{l}\text { New England ................. } \\
\text { Midolle Attantic ............. } \\
\text { East North Central........ } \\
\text { West North Central ....... } \\
\text { South Adantic................. }\end{array}$ & $\begin{array}{r}131,020 \\
783,774 \\
1,503,064 \\
532,136 \\
350,525\end{array}$ & $\begin{array}{l}1,586,000 \\
7,659,000 \\
8,839,000 \\
3,190,000 \\
3,260,000\end{array}$ & $\begin{array}{r}58,140 \\
294,790 \\
641,659 \\
340,627 \\
193,123\end{array}$ & $\begin{array}{l}103,000 \\
584,000 \\
718,000 \\
333,000 \\
290,000\end{array}$ & $\begin{array}{r}45,213 \\
532,650 \\
1,421,100 \\
533,155 \\
577,978\end{array}$ & $\begin{array}{l}\text { NA } \\
\text { NA } \\
\text { NA } \\
\text { NA }\end{array}$ \\
\hline $\begin{array}{l}\text { East South Central....... } \\
\text { West South Central...... } \\
\text { Mountain.................... } \\
\text { Pacilic Contiguous....... } \\
\text { Pacific Noncontiguous. }\end{array}$ & $\begin{array}{r}225,465 \\
455,589 \\
245,433 \\
604,215 \\
6,211\end{array}$ & $\begin{array}{r}1,779,000 \\
4,454,000 \\
1,772,000 \\
6,050,000 \\
15,000\end{array}$ & $\begin{array}{r}145,281 \\
299,501 \\
173,075 \\
239,795 \\
12,519\end{array}$ & $\begin{array}{r}179,000 \\
435,000 \\
191,000 \\
416,000 \\
4,000\end{array}$ & $\begin{array}{r}498,297 \\
3,054,583 \\
408,492 \\
769,445 \\
14,744\end{array}$ & $\begin{array}{l}\text { NA } \\
\text { NA } \\
\text { NA } \\
\text { NA }\end{array}$ \\
\hline Total...................................... & $4.837,432$ & $38,604,000$ & $2,398,510$ & $3,253,000$ & $7,850,680$ & NA \\
\hline
\end{tabular}

See footnotes at end of table. 
Table 22. Natural Gas Delivered to Consumers by Census Division, 1967-1994 (Continued)

\begin{tabular}{|c|c|c|c|c|}
\hline \multirow{2}{*}{ Cansers Diviaion } & Vohiele Fued & Electric Utilities & $\begin{array}{l}\text { Delimened } \\
\text { to Consumers }\end{array}$ & \multirow{2}{*}{$\begin{array}{l}\text { Heetung Volus } \\
\text { (Btu por cubic foot) }\end{array}$} \\
\hline & $\begin{array}{l}\text { Quantity } \\
\text { (million } \\
\text { cubic foet) }\end{array}$ & $\begin{array}{l}\text { Quantity } \\
\text { (miltion } \\
\text { cubic toet) }\end{array}$ & $\begin{array}{l}\text { Quantity } \\
\text { (miltion } \\
\text { cubie feot) }\end{array}$ & \\
\hline
\end{tabular}

1957

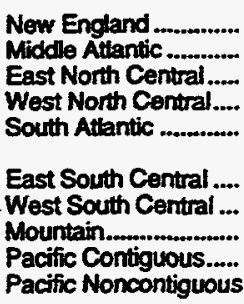

Total.

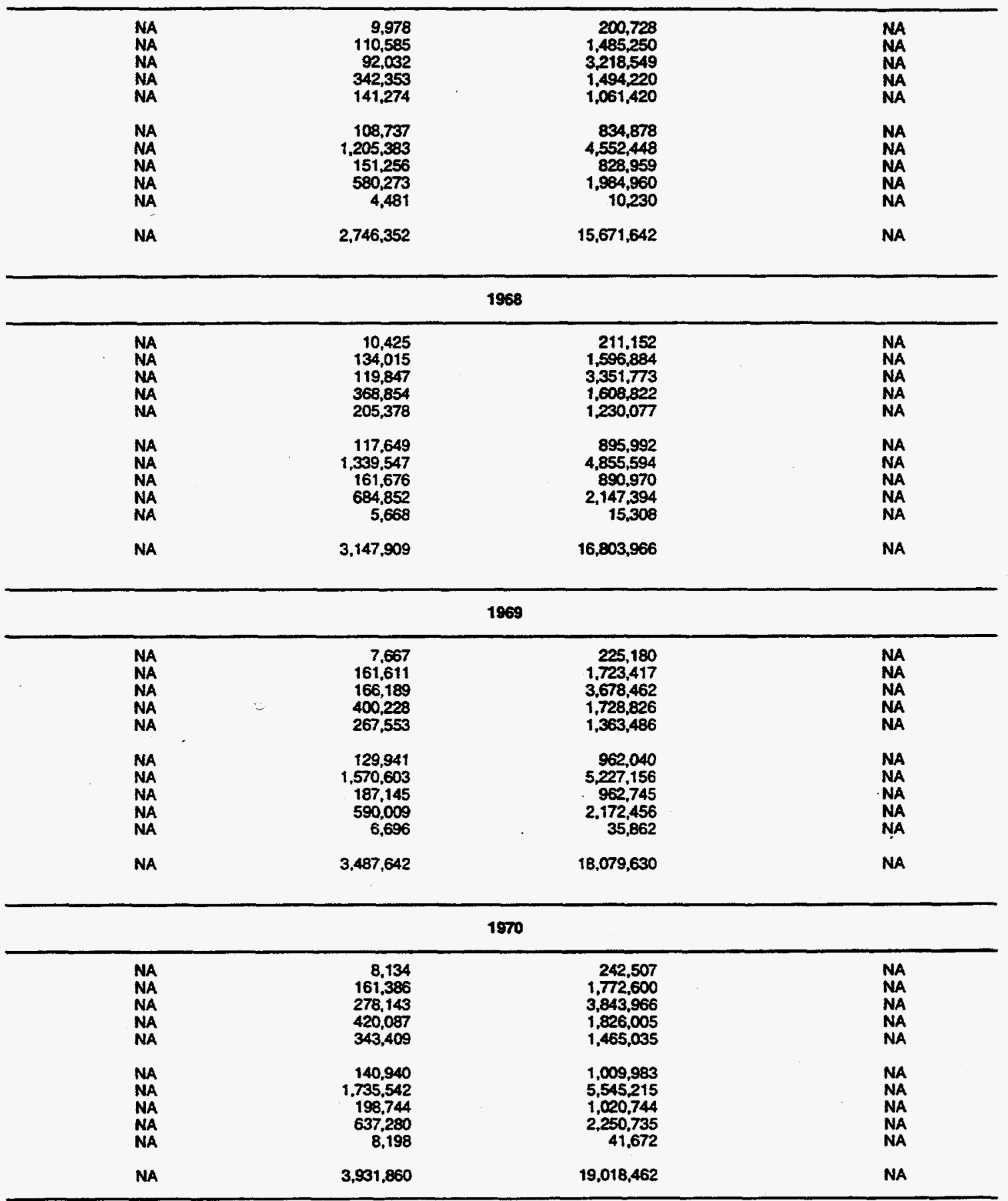

New England.

Middle Atantic

East North Central

West North Central ..

South Atantic

East South Central West South Central ... Mountain.

Pacife Pacific Noncontiguous

Total.

Middio

East Notth Central.

West North Central

South Attantic

East South Central

West South Central.

Mountain

Pacific Contiguous...

Pacific Noncontiguous

Total.

New England ............. Middle Atlantic

East North Central

West North Central

South Attantic

East South Central ... West South Central ... Mountain

Pacific Contiguous Pacific Noncontiguous

Total.

See footnoles at end of table.
15,30

$3,678,46$

$1,728,826$

002,040

962,745

72,456

$8,079,630$

Heating Valus 
Table 22. Natural Gas Delivered to Consumers by Census Division, 1967-1994 (Continued)

\begin{tabular}{|c|c|c|c|c|c|c|}
\hline \multirow[b]{2}{*}{ Centeus Division } & \multicolumn{2}{|c|}{ Residential } & \multicolumn{2}{|c|}{ Combercial } & \multicolumn{2}{|c|}{ Induetriel } \\
\hline & $\begin{array}{l}\text { Quantity } \\
\text { (millien } \\
\text { cubic feet) }\end{array}$ & Consumers & $\begin{array}{l}\text { Oummity } \\
\text { (million } \\
\text { cubic toot) }\end{array}$ & Consumer: & $\begin{array}{l}\text { Qumity } \\
\text { (maiton } \\
\text { cobic foot) }\end{array}$ & Consumers \\
\hline & \multicolumn{6}{|c|}{1971} \\
\hline $\begin{array}{l}\text { New England ............... } \\
\text { Middle Atlantic ............. } \\
\text { East North Central ....... } \\
\text { West North Central ....... } \\
\text { South Allantic............... }\end{array}$ & $\begin{array}{r}133,003 \\
799,609 \\
1,539,742 \\
525,200 \\
352,508\end{array}$ & $\begin{array}{l}1,577,000 \\
7,679,000 \\
9,061,000 \\
3,227,000 \\
3,325,000\end{array}$ & $\begin{array}{r}61,201 \\
315,702 \\
672,078 \\
348,271 \\
209,837\end{array}$ & $\begin{array}{l}108,000 \\
591,000 \\
735,000 \\
333,000 \\
297,000\end{array}$ & $\begin{array}{r}47,879 \\
546,787 \\
1,517,092 \\
569,663 \\
589,582\end{array}$ & $\begin{array}{l}\text { NA } \\
\text { NA } \\
\text { NA } \\
\text { NA }\end{array}$ \\
\hline $\begin{array}{l}\text { East South Central....... } \\
\text { West South Central..... } \\
\text { Mountain.................... } \\
\text { Pacific Contiguous...... } \\
\text { Pacific Noncontiguous. }\end{array}$ & $\begin{array}{r}226,252 \\
441,255 \\
261,019 \\
686,149 \\
6,893\end{array}$ & $\begin{array}{r}1,799,000 \\
4,541,000 \\
1,861,000 \\
6,169,000 \\
18,000\end{array}$ & $\begin{array}{r}148,924 \\
282,748 \\
182,100 \\
273,860 \\
14,256\end{array}$ & $\begin{array}{r}187,000 \\
434,000 \\
231,000 \\
422,000 \\
3,000\end{array}$ & $\begin{array}{r}505,343 \\
3,215,342 \\
401,133 \\
777,115 \\
10,588\end{array}$ & $\begin{array}{l}\mathbf{N A} \\
\mathbf{N A} \\
\mathbf{N A} \\
\mathbf{N A} \\
\mathbf{N A}\end{array}$ \\
\hline \multirow[t]{2}{*}{ 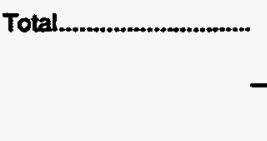 } & $4,971,690$ & $39,267,000$ & $2,508,977$ & $3,341,000$ & $8,180,527$ & $\mathbf{N A}$ \\
\hline & \multicolumn{6}{|c|}{1972} \\
\hline $\begin{array}{l}\text { New England ................. } \\
\text { Middle Atlantic ............. } \\
\text { East North Central ........ } \\
\text { West North Central ....... } \\
\text { South Atlantic............... }\end{array}$ & $\begin{array}{r}138,380 \\
818,828 \\
1,595,357 \\
547,890 \\
364,113\end{array}$ & $\begin{array}{l}1,616,000 \\
7,709,000 \\
9,152,000 \\
3,309,000 \\
3,387,000\end{array}$ & $\begin{array}{r}62,195 \\
332,761 \\
721,581 \\
366,998 \\
214,557\end{array}$ & $\begin{array}{l}112,000 \\
591,000 \\
751,000 \\
336,000 \\
303,000\end{array}$ & $\begin{array}{r}50,095 \\
551,360 \\
1,529,423 \\
552,136 \\
624,722\end{array}$ & $\begin{array}{l}\text { NA } \\
\text { NA } \\
\text { NA } \\
\text { NA } \\
\text { NA }\end{array}$ \\
\hline $\begin{array}{l}\text { East South Central....... } \\
\text { West South Central...... } \\
\text { Mountain................... } \\
\text { Pacific Contiguous...... } \\
\text { Pacific Noncontiguous. }\end{array}$ & $\begin{array}{r}232,375 \\
448,504 \\
272,890 \\
699,251 \\
8,394\end{array}$ & $\begin{array}{r}1,848,000 \\
4,599,000 \\
1,939,000 \\
6,301,000 \\
21,000\end{array}$ & $\begin{array}{r}150,540 \\
283,768 \\
190,251 \\
269,320 \\
16,011\end{array}$ & $\begin{array}{r}196,000 \\
434,000 \\
199,000 \\
432,000 \\
3,000\end{array}$ & $\begin{array}{r}524,206 \\
3,125,848 \\
411,534 \\
787,222 \\
12,319\end{array}$ & $\begin{array}{l}\text { NA } \\
\text { NA } \\
\text { NA } \\
\text { NA }\end{array}$ \\
\hline \multirow[t]{2}{*}{ Total................................. } & $5,125,982$ & $39,881,000$ & $2,607,982$ & $3,357,000$ & $8,168,855$ & NA \\
\hline & \multicolumn{6}{|c|}{1973} \\
\hline $\begin{array}{l}\text { New England ................. } \\
\text { Middle Attantic ............. } \\
\text { East North Central ........ } \\
\text { West North Central ....... } \\
\text { South Atantic................ }\end{array}$ & $\begin{array}{r}131,693 \\
771,764 \\
1,492,105 \\
513,769 \\
355,167\end{array}$ & $\begin{array}{l}1,603,000 \\
7,713,000 \\
9,386,000 \\
\mathbf{3 , 3 9 9 , 0 0 0} \\
\mathbf{3 , 5 1 3 , 0 0 0}\end{array}$ & $\begin{array}{r}62,679 \\
320,847 \\
727,314 \\
346,414 \\
220,197\end{array}$ & $\begin{array}{l}111,000 \\
594,000 \\
779,000 \\
324,000 \\
301,000\end{array}$ & $\begin{array}{r}50,846 \\
548,963 \\
1,636,918 \\
616,431 \\
659,967\end{array}$ & $\begin{array}{l}\text { NA } \\
\text { NA } \\
\text { NA } \\
\text { NA } \\
\text { NA }\end{array}$ \\
\hline $\begin{array}{l}\text { East South Central....... } \\
\text { West South Central...... } \\
\text { Mountain....................... } \\
\text { Pacitic Contiguous........ } \\
\text { Pacific Noncontiguous. }\end{array}$ & $\begin{array}{r}213,333 \\
457,177 \\
264,897 \\
674,458 \\
5,024\end{array}$ & $\begin{array}{r}1,959,000 \\
4,575,000 \\
2,021,000 \\
6,453,000 \\
23,000\end{array}$ & $\begin{array}{r}148,598 \\
288,780 \\
191,102 \\
278,829 \\
12,277\end{array}$ & $\begin{array}{r}187,000 \\
414,000 \\
204,000 \\
418,000 \\
3,000\end{array}$ & $\begin{array}{r}528,352 \\
3,400,354 \\
400,886 \\
831,384 \\
14,573\end{array}$ & $\begin{array}{l}\text { NA } \\
\text { NA } \\
\text { NA } \\
\text { NA }\end{array}$ \\
\hline \multirow[t]{2}{*}{ Total.................................. } & $4,879,387$ & $40,645,000$ & $2.597,037$ & $3,335,000$ & $8,688,675$ & NA \\
\hline & \multicolumn{6}{|c|}{1974} \\
\hline $\begin{array}{l}\text { New England .................. } \\
\text { Middle Adtantic ............ } \\
\text { East North Central ........ } \\
\text { West North Central ....... } \\
\text { South Atlantic................. }\end{array}$ & $\begin{array}{r}138,036 \\
748,752 \\
1,518,106 \\
521,350 \\
330,545\end{array}$ & $\begin{array}{l}1,623,000 \\
7,779,000 \\
9,439,000 \\
3,519,000 \\
3,569,000\end{array}$ & $\begin{array}{r}61,469 \\
297,037 \\
739,395 \\
363,713 \\
208,782\end{array}$ & $\begin{array}{l}116,000 \\
607,000 \\
780,000 \\
358,000 \\
310,000\end{array}$ & $\begin{array}{r}48,461 \\
484,744 \\
1,583,134 \\
592,491 \\
616,920\end{array}$ & $\begin{array}{l}\mathbf{N A} \\
\mathbf{N A} \\
\mathbf{N A} \\
\mathbf{N A}\end{array}$ \\
\hline $\begin{array}{l}\text { East South Central....... } \\
\text { West South Central...... } \\
\text { Mountain................. } \\
\text { Pacific Contiguous........ } \\
\text { Pacific Noncontiguous. }\end{array}$ & $\begin{array}{r}203,732 \\
431,494 \\
252,516 \\
637.434 \\
4,163\end{array}$ & $\begin{array}{r}2,001,000 \\
4,811,000 \\
2,151,000 \\
6,595,000 \\
22,000\end{array}$ & $\begin{array}{r}147,824 \\
264,629 \\
184,052 \\
275,610 \\
13,106\end{array}$ & $\begin{array}{r}194,000 \\
443,000 \\
220,000 \\
448,000 \\
4,000\end{array}$ & $\begin{array}{r}503,119 \\
3,257,214 \\
386,297 \\
805,425 \\
13,976\end{array}$ & $\begin{array}{l}\text { NA } \\
\text { NA } \\
\text { NA } \\
\text { NA }\end{array}$ \\
\hline Total & $4,786.128$ & $41,509,000$ & $2,555,617$ & $3,480,000$ & $8,291,782$ & NA \\
\hline
\end{tabular}

See footnotes at end of table. 
Table 22. Natural Gas Delivered to Consumers by Census Division, 1967-1994 (Continued)

\begin{tabular}{|c|c|c|c|c|}
\hline \multirow{2}{*}{ Census: Diviaion } & Vehicie Fuel & Electric Utilitios & $\begin{array}{l}\text { Dolivered } \\
\text { so Consetumers }\end{array}$ & \multirow{2}{*}{$\begin{array}{l}\text { Heating Value } \\
\text { (Btu per cubic foot) }\end{array}$} \\
\hline & $\begin{array}{l}\text { Quantity } \\
\text { (million } \\
\text { cubic foet) }\end{array}$ & $\begin{array}{l}\text { Qunntity } \\
\text { (million } \\
\text { cubie feet) }\end{array}$ & $\begin{array}{l}\text { Quantity } \\
\text { (milition } \\
\text { cubic foet) }\end{array}$ & \\
\hline
\end{tabular}

1971

Now Engtand.

Middie Attantic

West North Central ....

South Allantic.

East South Central...

West South Central....

Mountain.

Pacific Noncontiguous

Total.
East North Central ....

Pacific Contiguous.....

NA
NA
NA
NA
NA
NA
NA
NA
NA

$\begin{array}{lr}\text { NA } & 12,769 \\ \text { NA } & 148,267 \\ \text { NA } & 277,009 \\ \text { NA } & 409,25 \\ \text { NA } & 367,728 \\ \text { NA } & 141,17 \\ \text { NA } & 1,856,809 \\ \text { NA } & 219,88 \\ \text { NA } & 562,827 \\ & 10,300\end{array}$

254,912

$1,810,365$

$4,005,921$

$1,852,386$

$1,489,655$

$1,021,695$

$5,796,153$

$1,064,137$

$2,299,951$

42,037

$19,637,212$

AA

NA

NA

MA

NA

NA

NA

NA

NA

1972

New England

Middle Atlantic.

East North Central

West North Central

South Allantic.

East South Central.... West South Central....

Mountain.

Pacific Contiguous

Pacific Noncontiguous

Total

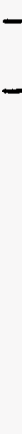

1972

$\begin{array}{lrrr}\text { NA } & 8,676 & 259,386 & \text { NA } \\ \text { NA } & 105,498 & 1,808,447 & \text { NA } \\ \text { NA } & 193,889 & 4,040,250 & \text { NA } \\ \text { NA } & 404,722 & 1,871,746 & \text { NA } \\ \text { NA } & 265,018 & 1,468,410 & \text { NA } \\ \text { NA } & 129,650 & 1,036,771 & \text { NA } \\ \text { NA } & 2,000,970 & 5,859,090 & \text { NA } \\ \text { NA } & 249,606 & 1,124,281 & \text { NA } \\ \text { NA } & 605,791 & 2,361,584 & \text { NA } \\ \text { NA } & 13,094 & 49,818 & \text { NA } \\ \text { NA } & 3,976,914 & 19,879,733 & \text { NA }\end{array}$

NA

NA

NA

NA

NA

NA

NA
79,733

1973

New England

Middle Atlantic .................

East North Central ....

West North Central .... South Allantic.

East South Central. West South Central.... Mountain.

Pacific Contiguous...... Pacific Noncontiguous

Total

\section{(1)}

\begin{tabular}{|c|c|c|c|}
\hline $\begin{array}{l}\text { NA } \\
\text { NA } \\
\text { NA } \\
\text { NA } \\
\text { NA }\end{array}$ & $\begin{array}{r}6,754 \\
96,578 \\
158,044 \\
408,804 \\
251,305\end{array}$ & $\begin{array}{r}251,972 \\
1,738,152 \\
4,014,381 \\
1,885,418 \\
1,486,636\end{array}$ & $\begin{array}{l}\text { NA } \\
\text { NA } \\
\text { NA } \\
\text { NA } \\
\text { NA }\end{array}$ \\
\hline $\begin{array}{l}\text { NA } \\
\text { NA } \\
\text { NA } \\
\text { NA } \\
\text { NA }\end{array}$ & $\begin{array}{r}84,582 \\
1,949,994 \\
229,915 \\
458,385 \\
15,812\end{array}$ & $\begin{array}{r}974,865 \\
6,096,305 \\
1,086,800 \\
2,243,056 \\
47,686\end{array}$ & $\begin{array}{l}\text { NA } \\
\text { NA } \\
\text { NA } \\
\text { NA } \\
\text { NA }\end{array}$ \\
\hline NA & $3,660,172$ & $19,825,271$ & NA \\
\hline & . \\
\hline $\begin{array}{l}\text { NA } \\
\text { NA } \\
\text { NA } \\
\text { NA } \\
\text { NA }\end{array}$ & $\begin{array}{r}11,383 \\
61,089 \\
180,232 \\
364,999 \\
239,999\end{array}$ & $\begin{array}{r}259,349 \\
1,591,622 \\
4,020,867 \\
1,842,553 \\
1,396,246\end{array}$ & $\begin{array}{l}\text { NA } \\
\text { NA } \\
\text { NA } \\
\text { NA } \\
\text { NA }\end{array}$ \\
\hline $\begin{array}{l}\text { NA } \\
\text { NA } \\
\text { NA } \\
N A \\
\text { NA }\end{array}$ & $\begin{array}{r}52,513 \\
2.011,944 \\
210,928 \\
293,225 \\
17,117\end{array}$ & $\begin{array}{r}907,188 \\
5,965,281 \\
1,033,793 \\
2,011,694 \\
48,362\end{array}$ & $\begin{array}{l}\text { NA } \\
\text { NA } \\
\text { NA } \\
\text { NA } \\
\text { NA }\end{array}$ \\
\hline NA & $3,443,428$ & $19,076,955$ & NA \\
\hline
\end{tabular}

See footnotes at end of table.

New England.

East North Central ...

West North Central.

East South Central... West South Central.... Mountain....................

Pacitic Contigu

Pacific Noncontiguto

Total.

NA 
Table 22. Natural Gas Delivered to Consumers by Census Division, 1967-1994 (Continued)

\begin{tabular}{|c|c|c|c|c|c|c|}
\hline \multirow[b]{2}{*}{ Ceneus Division } & \multicolumn{2}{|c|}{ Residential } & \multicolumn{2}{|c|}{ Comanereint } & \multicolumn{2}{|c|}{ Industrial } \\
\hline & $\begin{array}{l}\text { Quantity } \\
\text { (million } \\
\text { cubic teet) }\end{array}$ & Consumers & $\begin{array}{l}\text { Quantity } \\
\text { (million } \\
\text { cubic teot) }\end{array}$ & Consumer: & $\begin{array}{l}\text { Quantity } \\
\text { (million } \\
\text { cubic foet) }\end{array}$ & Consumers \\
\hline
\end{tabular}

1975

\begin{tabular}{|c|c|c|c|c|c|c|}
\hline $\begin{array}{l}\text { New England ................ } \\
\text { Middle Attantic ............ } \\
\text { East North Central ....... } \\
\text { West North Central ...... } \\
\text { South Atantic............... }\end{array}$ & $\begin{array}{r}140,990 \\
729,424 \\
1,524,124 \\
538,308 \\
337,533\end{array}$ & $\begin{array}{l}1,626,000 \\
7,594,000 \\
9,493,000 \\
3,587,000 \\
3,597,000\end{array}$ & $\begin{array}{r}61,857 \\
280,610 \\
705,010 \\
366,020 \\
217,564 .\end{array}$ & $\begin{array}{l}113,000 \\
564,000 \\
761,000 \\
373,000 \\
318,000\end{array}$ & $\begin{array}{r}48,689 \\
418,237 \\
1,361,673 \\
516,833 \\
513,969\end{array}$ & $\begin{array}{l}\text { NA } \\
\text { NA } \\
\text { NA } \\
\text { NA } \\
\text { NA }\end{array}$ \\
\hline $\begin{array}{l}\text { East South Central....... } \\
\text { West South Central...... } \\
\text { Mountain....................... } \\
\text { Pacific Contiguous...... } \\
\text { Pacific Noncontiguous. }\end{array}$ & $\begin{array}{l}205,020 \\
457,005 \\
286,831 \\
694,496 \\
10,393\end{array}$ & $\begin{array}{r}1,967,000 \\
4,698,000 \\
2,227,000 \\
6,702,000 \\
25,000\end{array}$ & $\begin{array}{l}138,346 \\
242,508 \\
193,830 \\
288,123 \\
14,415\end{array}$ & $\begin{array}{r}192,000 \\
433,000 \\
223,000 \\
457,000 \\
4,000\end{array}$ & $\begin{array}{r}428,525 \\
2,590,396 \\
336,554 \\
731,004 \\
22,398\end{array}$ & $\begin{array}{l}\text { NA } \\
\text { NA } \\
\text { NA } \\
\text { NA }\end{array}$ \\
\hline 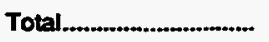 & $4,924,124$ & $41,516,000$ & $2,508,293$ & $3,438,000$ & $6,968,267$ & NA \\
\hline
\end{tabular}

\begin{tabular}{|c|c|c|c|c|c|c|}
\hline \multirow[b]{2}{*}{$\begin{array}{l}\text { New England................ } \\
\text { Niddle Attantic ........... } \\
\text { East North Central....... } \\
\text { West North Central ...... } \\
\text { South Atlantic............... }\end{array}$} & \multicolumn{6}{|c|}{1976} \\
\hline & $\begin{array}{r}145,857 \\
777,896 \\
1,563,188 \\
536,621 \\
368,866\end{array}$ & $\begin{array}{l}1,556,000 \\
7,512,000 \\
9,453,000 \\
3,415,000 \\
3,493,000\end{array}$ & $\begin{array}{r}61,166 \\
358,510 \\
729,454 \\
373,719 \\
241,985\end{array}$ & $\begin{array}{l}110,000 \\
555,000 \\
759,000 \\
342,000 \\
313,000\end{array}$ & $\begin{array}{r}45,014 \\
450,418 \\
1,358,475 \\
547,863 \\
483,309\end{array}$ & $\begin{array}{l}\text { NA } \\
\text { NA } \\
\text { NA } \\
\text { NA }\end{array}$ \\
\hline $\begin{array}{l}\text { East South Central....... } \\
\text { West South Central...... } \\
\text { Mountain................. } \\
\text { Pacitic Contiguous....... } \\
\text { Pacific Noncontiguous. }\end{array}$ & $\begin{array}{r}223,553 \\
462,520 \\
308,925 \\
653,017 \\
10,917\end{array}$ & $\begin{array}{r}1,798,000 \\
4,923,000 \\
2,184,000 \\
6,876,000 \\
28,000\end{array}$ & $\begin{array}{r}150,111 \\
257,892 \\
215,225 \\
265,487 \\
14,191\end{array}$ & $\begin{array}{r}175,000 \\
455,000 \\
227,000 \\
442,000 \\
4,000\end{array}$ & $\begin{array}{r}389,139 \\
2,652,501 \\
335,746 \\
674,697 \\
26,687\end{array}$ & $\begin{array}{l}\text { NA } \\
\text { NA } \\
\text { NA } \\
\text { NA }\end{array}$ \\
\hline Total.............................. & $5,051,360$ & $41,238,000$ & $2,667,740$ & $3,383,000$ & $6,963,250$ & NA \\
\hline
\end{tabular}

\begin{tabular}{|c|c|c|c|c|c|c|}
\hline \multirow[b]{2}{*}{$\begin{array}{l}\text { New England ................ } \\
\text { Middle Attandic ............. } \\
\text { East North Central ....... } \\
\text { West North Central ...... } \\
\text { South Attantic............... }\end{array}$} & \multicolumn{6}{|c|}{1977} \\
\hline & $\begin{array}{r}143,544 \\
737,081 \\
1,492,029 \\
513,317 \\
366,052\end{array}$ & $\begin{array}{l}1,540,000 \\
7,469,000 \\
9,602,000 \\
3,597,000 \\
3,582,000\end{array}$ & $\begin{array}{r}64,276 \\
296,679 \\
648,467 \\
346,505 \\
244,512\end{array}$ & $\begin{array}{l}113,000 \\
561,000 \\
753,000 \\
361,000 \\
312,000\end{array}$ & $\begin{array}{r}51,826 \\
401,851 \\
1,248,504 \\
533,265 \\
419,947\end{array}$ & $\begin{array}{l}\text { NA } \\
\text { NA } \\
\text { NA } \\
\text { NA } \\
\text { NA }\end{array}$ \\
\hline $\begin{array}{l}\text { East South Central....... } \\
\text { West South Central...... } \\
\text { Mountain......................... } \\
\text { Pacific Contiguous...... } \\
\text { Pacific Noncontiguous. }\end{array}$ & $\begin{array}{r}220,628 \\
500,193 \\
255,005 \\
582,354 \\
11,282\end{array}$ & $\begin{array}{r}1,916,000 \\
4,713,000 \\
2,284,000 \\
6,633,000 \\
30,000\end{array}$ & $\begin{array}{r}138,904 \\
285,412 \\
193,124 \\
268,350 \\
14,564\end{array}$ & $\begin{array}{r}180,000 \\
426,000 \\
223,000 \\
421,000 \\
5,000\end{array}$ & $\begin{array}{r}371,347 \\
2,773,885 \\
297,111 \\
668,249 \\
49,302\end{array}$ & $\begin{array}{l}\text { NA } \\
\text { NA } \\
\text { NA } \\
\text { NA } \\
\text { NA }\end{array}$ \\
\hline 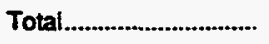 & $4,821,485$ & $41,366,000$ & $2,500,793$ & $3,355,000$ & $6,815,289$ & NA \\
\hline - & & & & & & \\
\hline $\begin{array}{l}\text { New England ................ } \\
\text { Middle Attantic ............ } \\
\text { East North Central....... } \\
\text { West North Central ...... } \\
\text { South Atlardic............... }\end{array}$ & $\begin{array}{r}138,052 \\
753,478 \\
1,562,847 \\
521,612 \\
379.767\end{array}$ & $\begin{array}{l}1,541,000 \\
7,455,000 \\
9,901,000 \\
3,534,000 \\
3,595,000\end{array}$ & $\begin{array}{r}71,847 \\
301,613 \\
715,232 \\
359,661 \\
249,090\end{array}$ & $\begin{array}{l}116,000 \\
544,000 \\
759,000 \\
340,000 \\
292,000\end{array}$ & $\begin{array}{r}50,725 \\
384,190 \\
1,307,192 \\
488,396 \\
425,032\end{array}$ & $\begin{array}{l}\text { NA } \\
\text { NA } \\
\text { NA } \\
\text { NA } \\
\text { NA }\end{array}$ \\
\hline $\begin{array}{l}\text { East South Central....... } \\
\text { West South Central..... } \\
\text { Mountain................... } \\
\text { Pacific Contiguous...... } \\
\text { Pacific Noncontiguous. }\end{array}$ & $\begin{array}{r}211,587 \\
488,810 \\
252,260 \\
582,427 \\
12,166\end{array}$ & $\begin{array}{r}1,823,000 \\
4,792,000 \\
2,331,000 \\
6,840,000 \\
33,000\end{array}$ & $\begin{array}{r}128,525 \\
314,587 \\
186,448 \\
258,895 \\
15,208\end{array}$ & $\begin{array}{r}166,000 \\
442,000 \\
223,000 \\
429,000 \\
5,000\end{array}$ & $\begin{array}{r}355,897 \\
2,844,861 \\
290,006 \\
533,204 \\
77,138\end{array}$ & $\begin{array}{l}\mathbf{N A} \\
\mathbf{N A} \\
\mathbf{N A} \\
\mathbf{N A} \\
\mathbf{N A}\end{array}$ \\
\hline Total & $4,903,006$ & $41,845,000$ & $2,601,106$ & $3,316,000$ & $6.756,641$ & NA \\
\hline
\end{tabular}

See footnotes at end of table. 
Table 22. Natural Gas Delivered to Consumers by Census Division, 1967-1994 (Continued)

\begin{tabular}{|c|c|c|c|c|c|}
\hline \multirow{2}{*}{ Census Division } & Venicle Fuel & Electric Uturities & $\begin{array}{l}\text { Deliversd } \\
\text { to Consumers }\end{array}$ & \multirow{2}{*}{$\begin{array}{l}\text { Heating Value } \\
\text { (Btu per cubic foot) }\end{array}$} & \\
\hline & $\begin{array}{l}\text { Quantity } \\
\text { (million } \\
\text { culbic foet) }\end{array}$ & $\begin{array}{l}\text { Quantity } \\
\text { (milion } \\
\text { cubic toat) }\end{array}$ & $\begin{array}{l}\text { Quantity } \\
\text { (million } \\
\text { cubic feot) }\end{array}$ & & \\
\hline & \multicolumn{5}{|c|}{1975} \\
\hline $\begin{array}{l}\text { New England.............. } \\
\text { Middle Atlantic ........... } \\
\text { East North Central ...... } \\
\text { West North Central .... } \\
\text { South Attamic.............. }\end{array}$ & $\begin{array}{l}\text { NA } \\
\text { NA } \\
\text { NA } \\
\text { NA } \\
\text { NA }\end{array}$ & $\begin{array}{r}2,524 \\
23,427 \\
128,024 \\
264,890 \\
199,105\end{array}$ & $\begin{array}{r}254,070 \\
1,451,698 \\
3,718,831 \\
1,686,051 \\
1,268,171\end{array}$ & $\begin{array}{l}\text { NA } \\
\text { NA } \\
\text { NA } \\
\text { NA } \\
\text { NA }\end{array}$ & - \\
\hline $\begin{array}{l}\text { East South Central..... } \\
\text { West South Central.... } \\
\text { Mountain. } \\
\text { Pacific Contiguous....... } \\
\text { Pacific Noncontiguous }\end{array}$ & $\begin{array}{l}\text { NA } \\
\text { NA } \\
\text { NA } \\
\text { NA } \\
\text { NA }\end{array}$ & $\begin{array}{r}37,773 \\
2,042,116 \\
165,625 \\
274,565 \\
19,619\end{array}$ & $\begin{array}{r}809,664 \\
5,332,025 \\
982,840 \\
1,988,188 \\
66,815\end{array}$ & $\begin{array}{l}\text { NA } \\
\text { NA } \\
\text { NA } \\
\text { NA }\end{array}$ & \\
\hline Total & NA & $3,157,669$ & $17,558,353$ & NA & \\
\hline
\end{tabular}

New England .............

East Noth Central...

West North Central ....

South Atlantic.

East South Central....

West South Central.

Mountain

Pacific Contiguous.....

Pacific Noncontiguous

Total.

al.

- n.............

\begin{tabular}{|c|c|c|c|}
\hline $\begin{array}{l}\text { NA } \\
\text { NA } \\
\text { NA } \\
\text { NA } \\
\text { NA }\end{array}$ & $\begin{array}{r}37,055 \\
2,091,352 \\
165,452 \\
295,010 \\
22,204\end{array}$ & $\begin{array}{r}799,858 \\
5,464,265 \\
1,025,348 \\
1,888,211 \\
73,999\end{array}$ & $\begin{array}{l}\text { NA } \\
\text { NA } \\
\text { NA } \\
\text { NA } \\
\text { NA }\end{array}$ \\
\hline NA & $3,080,868$ & $17,763,818$ & 1,021 \\
\hline
\end{tabular}

1977

New England

Middle Attantic .............

East North Central .....

West North Central ...

South Attantic.

East South Central.... West South Central...

Mountain ......................

Pacific Contiguous.....

Pacific Noncontiguous

Total

\begin{tabular}{|c|c|c|c|}
\hline $\begin{array}{l}\text { NA } \\
\text { NA } \\
\text { NA } \\
\text { NA } \\
\text { NA }\end{array}$ & $\begin{array}{r}3,489 \\
11,597 \\
57,390 \\
189,498 \\
149,062\end{array}$ & $\begin{array}{r}263,135 \\
1,447,208 \\
3,446,390 \\
1,582,585 \\
1,179,573\end{array}$ & $\begin{array}{l}\text { NA } \\
\text { NA } \\
\text { NA } \\
\text { NA } \\
\text { NA }\end{array}$ \\
\hline $\begin{array}{l}\text { NA } \\
\text { NA } \\
\text { NA } \\
\text { NA } \\
\text { NA }\end{array}$ & $\begin{array}{r}43,533 \\
2,179,475 \\
174,567 \\
359,057 \\
23,534\end{array}$ & $\begin{array}{r}774,412 \\
5,738,965 \\
919,807 \\
1,878,010 \\
98,682\end{array}$ & $\begin{array}{l}\text { NA } \\
\text { NA } \\
\text { NA } \\
\text { NA } \\
\text { NA }\end{array}$ \\
\hline NA & $3,191,200$ & $17,328,767$ & 1.019 \\
\hline \multicolumn{4}{|c|}{1978} \\
\hline $\begin{array}{l}\text { NA } \\
\text { NA } \\
\text { NA } \\
\text { NA } \\
\text { NA }\end{array}$ & $\begin{array}{r}1,596 \\
2,431 \\
73,546 \\
167,965 \\
172,124\end{array}$ & $\begin{array}{r}262,220 \\
1,441,712 \\
3,658,817 \\
1,537,634 \\
1,226,013\end{array}$ & $\begin{array}{l}\text { NA } \\
N A \\
N A \\
N A \\
N A\end{array}$ \\
\hline $\begin{array}{l}\text { NA } \\
\text { NA } \\
\text { NA } \\
\text { NA } \\
\text { NA }\end{array}$ & $\begin{array}{r}51,469 \\
2,214,496 \\
178,082 \\
302,223 \\
24,431\end{array}$ & $\begin{array}{r}747,478 \\
5,862,754 \\
906,796 \\
1,676,749 \\
128,943\end{array}$ & $\begin{array}{l}\text { NA } \\
\text { NA } \\
\text { NA } \\
\text { NA } \\
\text { NA }\end{array}$ \\
\hline NA & $3,188,363$ & $17,449,116$ & 1,021 \\
\hline
\end{tabular}

See foctnotes at end of table. 
Table 22. Natural Gas Delivered to Consumers by Census Division, 1967-1994 (Continued)

\begin{tabular}{|c|c|c|c|c|c|c|}
\hline \multirow[b]{2}{*}{ Cenaus Divition } & \multicolumn{2}{|c|}{ Residemtial } & \multicolumn{2}{|c|}{ Commereilal } & \multicolumn{2}{|c|}{ Industriat } \\
\hline & $\begin{array}{l}\text { Quentioy } \\
\text { (milion } \\
\text { eubie teot) }\end{array}$ & Conwumers: & $\begin{array}{l}\text { Cuncity } \\
\text { (mition } \\
\text { cubic foet) }\end{array}$ & Consumers: & $\begin{array}{l}\text { Qunutity } \\
\text { (mivion } \\
\text { cubic fent) }\end{array}$ & Consumers \\
\hline & \multicolumn{6}{|c|}{1979} \\
\hline $\begin{array}{l}\text { New England ................ } \\
\text { Middle Attantic ............ } \\
\text { East North Central ....... } \\
\text { West North Central ...... } \\
\text { South Atiantic................. }\end{array}$ & $\begin{array}{r}131,137 \\
726,510 \\
1,536,398 \\
548,838 \\
347,206\end{array}$ & $\begin{array}{l}1,569,000 \\
7,390,000 \\
9,358,000 \\
3,728,000 \\
3,624,000\end{array}$ & $\begin{array}{r}74,723 \\
307,324 \\
732,619 \\
339,879 \\
247,385\end{array}$ & $\begin{array}{l}120,000 \\
553,000 \\
735,000 \\
361,000 \\
312,000\end{array}$ & $\begin{array}{r}50,708 \\
448,916 \\
1,323,790 \\
582,318 \\
575,620\end{array}$ & $\begin{array}{l}\text { NA } \\
\text { NA } \\
\text { NA } \\
\text { NA }\end{array}$ \\
\hline $\begin{array}{l}\text { East South Certral........ } \\
\text { West South Central..... } \\
\text { Mountain.................... } \\
\text { Pacific Contiguous........ } \\
\text { Pacific Noncontiguous. }\end{array}$ & $\begin{array}{r}212,096 \\
538,842 \\
274,574 \\
642,451 \\
7,313\end{array}$ & $\begin{array}{r}2,029,000 \\
5,832,000 \\
2,439,000 \\
7,35 \times, 000 \\
36,000\end{array}$ & $\begin{array}{r}147,164 \\
434,979 \\
180,347 \\
305,679 \\
15,862\end{array}$ & $\begin{array}{r}205,000 \\
479,000 \\
215,000 \\
448,000 \\
6,000\end{array}$ & $\begin{array}{r}418,631 \\
2,583,138 \\
258,775 \\
564,788 \\
92,733\end{array}$ & $\begin{array}{l}\text { NA } \\
\text { NA } \\
\text { NA } \\
\text { NA } \\
\text { NA }\end{array}$ \\
\hline \multirow[t]{2}{*}{ Total.............................. } & $4,965,365$ & $43,358,000$ & $2,785,961$ & $3,434,000$ & $6.899,418$ & NA \\
\hline & \multicolumn{6}{|c|}{1980} \\
\hline $\begin{array}{l}\text { New England ................ } \\
\text { Middle Atlantic ............. } \\
\text { East North Central ........ } \\
\text { West North Central...... } \\
\text { South Attantic............... }\end{array}$ & $\begin{array}{r}146,613 \\
758,709 \\
1,546,425 \\
486,178 \\
350,032\end{array}$ & $\begin{array}{r}1,605,000 \\
7,470,000 \\
10,082,000 \\
3,817,000 \\
3,880,000\end{array}$ & $\begin{array}{r}86,174 \\
340,756 \\
731,811 \\
312,191 \\
244,023\end{array}$ & $\begin{array}{l}126,000 \\
535,000 \\
794,000 \\
377,000 \\
335,000\end{array}$ & $\begin{array}{r}57,718 \\
511,832 \\
1,284,501 \\
514,173 \\
604,952\end{array}$ & $\begin{array}{r}6,000 \\
28,000 \\
46,000 \\
15,000 \\
12,000\end{array}$ \\
\hline $\begin{array}{l}\text { East South Central......... } \\
\text { West South Central...... } \\
\text { Mountain...................... } \\
\text { Pacific Contiguous....... } \\
\text { Pacific Noncontiguous. }\end{array}$ & $\begin{array}{r}200,948 \\
421,327 \\
255,052 \\
577,465 \\
9,333\end{array}$ & $\begin{array}{r}2,031,000 \\
5,109,000 \\
2,520,000 \\
7,539,000 \\
61,000\end{array}$ & $\begin{array}{r}132,818 \\
286,334 \\
154,482 \\
304,076 \\
18,228\end{array}$ & $\begin{array}{r}213,000 \\
469,000 \\
219,000 \\
460,000 \\
9,000\end{array}$ & $\begin{array}{r}422,930 \\
2,921,677 \\
257,879 \\
526,229 \\
69,773\end{array}$ & $\begin{array}{r}6,000 \\
25,000 \\
6,000 \\
38,000 \\
\mathrm{NA}\end{array}$ \\
\hline \multirow[t]{2}{*}{ Total.................................. } & 4.752 .082 & $44,114,000$ & $2,610,895$ & $3,535,000$ & $7,171,661$ & 183,000 \\
\hline & \multicolumn{6}{|c|}{1981} \\
\hline $\begin{array}{l}\text { New England .................. } \\
\text { Middle Atlantic ............ } \\
\text { East North Centrat....... } \\
\text { West North Central ....... } \\
\text { South Atantic................. }\end{array}$ & $\begin{array}{r}150,769 \\
768,509 \\
1,476,695 \\
438,858 \\
349,351\end{array}$ & $\begin{array}{r}1,630,000 \\
7,605,000 \\
10,156,000 \\
3,873,000 \\
3,897,000\end{array}$ & $\begin{array}{r}86,017 \\
370,441 \\
698,512 \\
292,269 \\
244,921\end{array}$ & $\begin{array}{l}127,000 \\
560,000 \\
804,000 \\
404,000 \\
339,000\end{array}$ & $\begin{array}{r}59,964 \\
542,485 \\
1,271,047 \\
480,304 \\
633,772\end{array}$ & $\begin{array}{r}6,000 \\
30,000 \\
46,000 \\
16,000 \\
12,000\end{array}$ \\
\hline $\begin{array}{l}\text { East South Central........ } \\
\text { West South Central...... } \\
\text { Mountain ..................... } \\
\text { Pacific Contiguous....... } \\
\text { Pacitic Noncontiguous. }\end{array}$ & $\begin{array}{r}190,916 \\
403,073 \\
226,722 \\
532,363 \\
9,193\end{array}$ & $\begin{array}{r}2,051,000 \\
5,415,000 \\
2,565,000 \\
7,656,000 \\
64,000\end{array}$ & $\begin{array}{r}125,192 \\
265,821 \\
138,396 \\
280,461 \\
17,759\end{array}$ & $\begin{array}{r}214,000 \\
493,000 \\
221,000 \\
466,000 \\
9,000\end{array}$ & $\begin{array}{r}430,862 \\
2,882,970 \\
257,877 \\
515,181 \\
53,083\end{array}$ & $\begin{array}{r}6,000 \\
26,000 \\
8,000 \\
40,000 \\
\mathrm{NA}\end{array}$ \\
\hline \multirow[t]{2}{*}{ 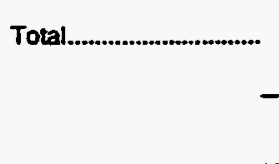 } & $4,546,450$ & $44,924,000$ & $2,519,791$ & $3,637,000$ & $7,127,547$ & 190,000 \\
\hline & \multicolumn{6}{|c|}{1882} \\
\hline $\begin{array}{l}\text { New England ................. } \\
\text { Middle Attantic ............. } \\
\text { East North Central ........ } \\
\text { West North Central....... } \\
\text { South Atlantic............... }\end{array}$ & $\begin{array}{r}151,901 \\
764,307 \\
1,464,998 \\
484,136 \\
328,053\end{array}$ & $\begin{array}{r}1,628,000 \\
7,617,000 \\
10,100,000 \\
3,854,000 \\
3,885,000\end{array}$ & $\begin{array}{r}98,026 \\
369,091 \\
688,278 \\
314,995 \\
233,991\end{array}$ & $\begin{array}{l}126,000 \\
565,000 \\
799,000 \\
378,000 \\
388,000\end{array}$ & $\begin{array}{r}49,659 \\
452,515 \\
1,078,068 \\
383,951 \\
534,623\end{array}$ & $\begin{array}{r}6,000 \\
33,000 \\
47,000 \\
16,000 \\
13,000\end{array}$ \\
\hline $\begin{array}{l}\text { East South Central........ } \\
\text { West South Central...... } \\
\text { Mountain..................... } \\
\text { Pacific Contigurous........ } \\
\text { Pacific Noncontiguous. }\end{array}$ & $\begin{array}{r}184,079 \\
414,238 \\
244,521 \\
585,049 \\
11,751\end{array}$ & $\begin{array}{r}2,052,000 \\
5,321,000 \\
2,460,000 \\
7,675,000 \\
72,000\end{array}$ & $\begin{array}{r}117,046 \\
298,278 \\
176,825 \\
283,091 \\
25,839\end{array}$ & $\begin{array}{r}211,000 \\
488,000 \\
357,000 \\
471,000 \\
10,000\end{array}$ & $\begin{array}{r}407,728 \\
2,218,033 \\
209,205 \\
419,764 \\
77,621\end{array}$ & $\begin{array}{r}6,000 \\
23,000 \\
5,000 \\
40,000 \\
N A\end{array}$ \\
\hline 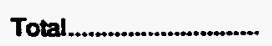 & $4,633,035$ & $44,667,000$ & $2,605,523$ & $3,742,000$ & $5,831,170$ & 189,000 \\
\hline
\end{tabular}

See foonotes at end of table. 
Table 22. Natural Gas Delivered to Consumers by Census Division, 1967-1994 (Continued)

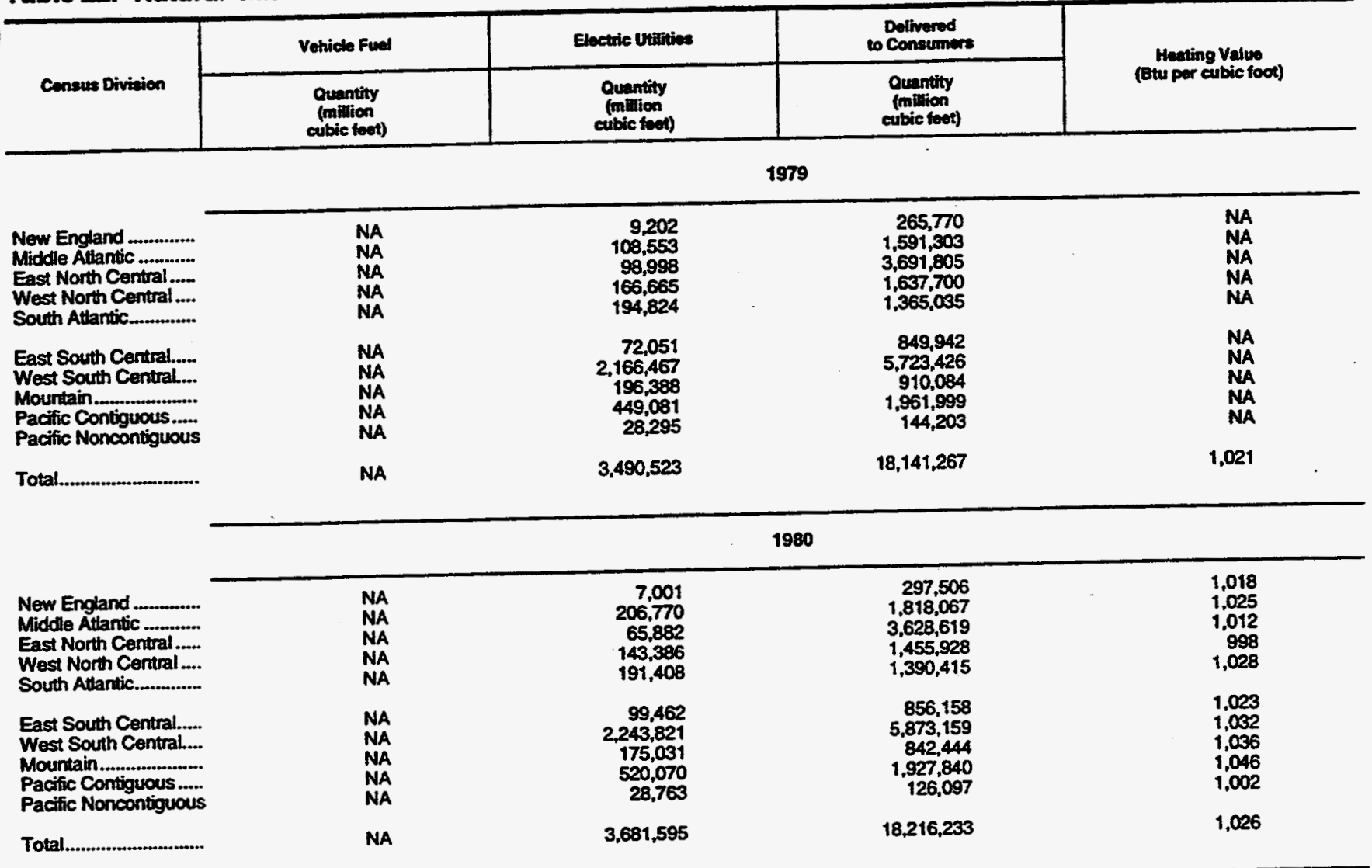

\begin{tabular}{|c|c|c|c|c|}
\hline \multirow[b]{2}{*}{$\begin{array}{l}\text { New England .............. } \\
\text { Middle Attantic ......... } \\
\text { East North Central ...... } \\
\text { West North Central .... } \\
\text { South Attantic............. }\end{array}$} & \multicolumn{4}{|c|}{1981} \\
\hline & $\begin{array}{l}\text { NA } \\
\text { NA } \\
\text { NA } \\
\text { NA } \\
\text { NA }\end{array}$ & $\begin{array}{r}9,826 \\
213,899 \\
47,183 \\
100,328 \\
194,224\end{array}$ & $\begin{array}{r}306,576 \\
1,895,334 \\
3,493,437 \\
1,311,759 \\
1,422,268\end{array}$ & $\begin{array}{l}1,019 \\
1.024 \\
1.015 \\
998 \\
1,032\end{array}$ \\
\hline $\begin{array}{l}\text { East South Central..... } \\
\text { West South Central.... } \\
\text { Mountain ................. } \\
\text { Pacific Contiguous...... } \\
\text { Pacific Noncontiguous }\end{array}$ & $\begin{array}{l}\text { NA } \\
\text { NA } \\
\text { NA } \\
\text { NA } \\
\text { NA }\end{array}$ & $\begin{array}{r}79,244 \\
2,134,764 \\
175,003 \\
655,011 \\
29,071\end{array}$ & $\begin{array}{r}826,214 \\
5,686,628 \\
798,597 \\
1,984,016 \\
109,106\end{array}$ & $\begin{array}{l}1,024 \\
1,032 \\
1,041 \\
1,048 \\
1,003\end{array}$ \\
\hline \multirow{2}{*}{ 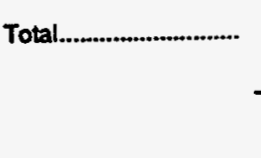 } & NA & $3,640,154$ & $17,833,942$ & 1,027 \\
\hline & \multicolumn{4}{|c|}{1982} \\
\hline $\begin{array}{l}\text { New England .............. } \\
\text { Middle Attantic ......... } \\
\text { East North Central ..... } \\
\text { West North Central ..... } \\
\text { South Atlantic.............. }\end{array}$ & $\begin{array}{l}\text { NA } \\
\text { NA } \\
\text { NA } \\
\text { NA } \\
\text { NA }\end{array}$ & $\begin{array}{r}16,189 \\
219,649 \\
31,367 \\
72,879 \\
193,862\end{array}$ & $\begin{array}{r}315,775 \\
1,805,562 \\
3,262,711 \\
1,255,961 \\
1,290,529\end{array}$ & $\begin{array}{l}1,025 \\
1,026 \\
1,022 \\
1,005 \\
1,033\end{array}$ \\
\hline $\begin{array}{l}\text { East South Central..... } \\
\text { West South Central.... } \\
\text { Mountain ................... } \\
\text { Pacific Contiguous..... } \\
\text { Pacific Nonoontigusous }\end{array}$ & $\begin{array}{l}\text { NA } \\
\text { NA } \\
\text { NA } \\
\text { NA } \\
\text { NA }\end{array}$ & $\begin{array}{r}86,057 \\
1,939,295 \\
101,243 \\
533,985 \\
30,988\end{array}$ & $\begin{array}{r}794,910 \\
4,869,844 \\
731,854 \\
1,821,889 \\
146,199\end{array}$ & $\begin{array}{l}1,031 \\
1.033 \\
1,015 \\
1.049 \\
1,000\end{array}$ \\
\hline 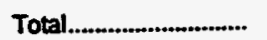 & NA & $3,225.518$ & $16,295,245$ & 1,028 \\
\hline
\end{tabular}

See footnotes at end of table. 
Table 22. Natural Gas Delivered to Consumers by Census Division, 1967-1994 (Continued)

\begin{tabular}{|c|c|c|c|c|c|c|}
\hline \multirow[b]{2}{*}{ Ceneus Diviaion } & \multicolumn{2}{|c|}{ Residential } & \multicolumn{2}{|c|}{ Commeciel } & \multicolumn{2}{|c|}{ Industrial } \\
\hline & $\begin{array}{l}\text { Quantity } \\
\text { (million } \\
\text { cuibic foot) }\end{array}$ & Convennere & $\begin{array}{l}\text { Quantity } \\
\text { (mittion } \\
\text { culbic twet) }\end{array}$ & Consumers & $\begin{array}{l}\text { Quantity } \\
\text { (miltion } \\
\text { cubic fien) }\end{array}$ & Conoumars \\
\hline & \multicolumn{6}{|c|}{1983} \\
\hline 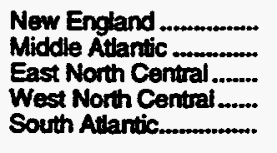 & $\begin{array}{r}142,555 \\
720,903 \\
1,358,556 \\
449,649 \\
327,944\end{array}$ & $\begin{array}{r}1,643,000 \\
7,625,000 \\
10,127,000 \\
3,883,000 \\
3,956,000\end{array}$ & $\begin{array}{r}75,293 \\
356,616 \\
641,747 \\
293,742 \\
234,120\end{array}$ & $\begin{array}{l}133,000 \\
573,000 \\
804,000 \\
406,000 \\
347,000\end{array}$ & $\begin{array}{r}64,722 \\
420,219 \\
1,022,350 \\
348,543 \\
506,782\end{array}$ & $\begin{array}{r}8,000 \\
31,000 \\
47,000 \\
16,000 \\
14,000\end{array}$ \\
\hline $\begin{array}{l}\text { East South Central....... } \\
\text { West South Central...... } \\
\text { Mountain. } \\
\text { Pacific Contiguous........ } \\
\text { Pacific Noncontiguous. }\end{array}$ & $\begin{array}{r}179,464 \\
404,806 \\
243,793 \\
541,378 \\
11,555\end{array}$ & $\begin{array}{r}2,057,000 \\
5,369,000 \\
2,664,000 \\
7,751,000 \\
79,000\end{array}$ & $\begin{array}{r}120,837 \\
264,303 \\
159,858 \\
259,789 \\
26,241\end{array}$ & $\begin{array}{r}218,000 \\
672,000 \\
244,000 \\
479,000 \\
12,000\end{array}$ & $\begin{array}{r}389,774 \\
2,210,882 \\
198,804 \\
405,992 \\
74,641\end{array}$ & $\begin{array}{r}6,000 \\
22,000 \\
6,000 \\
40,000 \\
N A\end{array}$ \\
\hline \multirow[t]{2}{*}{ 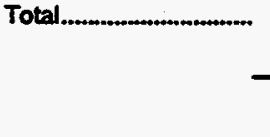 } & $4,380,599$ & $45,153,000$ & $2,432,547$ & $3,890,000$ & $5,642,708$ & 190,000 \\
\hline & \multicolumn{6}{|c|}{1984} \\
\hline $\begin{array}{l}\text { New England ............... } \\
\text { Middle Atlantic ............ } \\
\text { East North Central........ } \\
\text { West North Central ....... } \\
\text { South Attantic.............. }\end{array}$ & $\begin{array}{r}151,425 \\
754,282 \\
1,433,384 \\
460,501 \\
350,201\end{array}$ & $\begin{array}{r}1,664,000 \\
7,698,000 \\
10,181,000 \\
3,902,000 \\
4,036,000\end{array}$ & $\begin{array}{r}80,205 \\
380,482 \\
690,521 \\
309,002 \\
223,608\end{array}$ & $\begin{array}{l}133,000 \\
581,000 \\
815,000 \\
414,000 \\
346,000\end{array}$ & $\begin{array}{r}67,867 \\
434,759 \\
1,087,596 \\
389,010 \\
541,852\end{array}$ & $\begin{array}{l}10,000 \\
34,000 \\
46,000 \\
15,000 \\
14,000\end{array}$ \\
\hline $\begin{array}{l}\text { East South Central....... } \\
\text { West South Central...... } \\
\text { Mountain................... } \\
\text { Pacific Contiguous........ } \\
\text { Pacific Noncontiguous. }\end{array}$ & $\begin{array}{r}190,225 \\
427,122 \\
254,556 \\
520,888 \\
12,881\end{array}$ & $\begin{array}{r}2,078,000 \\
5,401,000 \\
2,726,000 \\
7,895,000 \\
90,000\end{array}$ & $\begin{array}{r}128,108 \\
272,206 \\
172,907 \\
241,221 \\
25,982\end{array}$ & $\begin{array}{r}220,000 \\
502,000 \\
250,000 \\
482,000 \\
13,000\end{array}$ & $\begin{array}{r}415,692 \\
2,451,794 \\
194,433 \\
498,373 \\
72,465\end{array}$ & $\begin{array}{r}7,000 \\
21,000 \\
6,000 \\
38,000 \\
\text { NA }\end{array}$ \\
\hline \multirow[t]{2}{*}{ Total........................................ } & $4,555,465$ & $45,670,000$ & $2,524,244$ & $3,755,000$ & $6,153,841$ & 189,000 \\
\hline & \multicolumn{6}{|c|}{1985} \\
\hline $\begin{array}{l}\text { New England ................ } \\
\text { Middtle Atlantic ............ } \\
\text { East North Central ........ } \\
\text { West North Central ....... } \\
\text { South Attantic................. }\end{array}$ & $\begin{array}{r}152,252 \\
715,873 \\
1,377,619 \\
460,254 \\
319,365\end{array}$ & $\begin{array}{r}1,690,000 \\
7,809,000 \\
10,261,000 \\
3,941,000 \\
4,118,000\end{array}$ & $\begin{array}{r}81,231 \\
364,294 \\
657,041 \\
301,039 \\
213,159\end{array}$ & $\begin{array}{l}138,000 \\
592,000 \\
827,000 \\
424,000 \\
355,000\end{array}$ & $\begin{array}{r}60,328 \\
407,370 \\
1,036,395 \\
376,764 \\
511,371\end{array}$ & $\begin{array}{l}10,000 \\
34,000 \\
47,000 \\
14,000 \\
15,000\end{array}$ \\
\hline $\begin{array}{l}\text { Easit South Certral....... } \\
\text { West South Central...... } \\
\text { Mountain .................... } \\
\text { Pacific Contiguous....... } \\
\text { Pacific Noncontiguous. }\end{array}$ & $\begin{array}{r}168,940 \\
389,656 \\
253,562 \\
581,973 \\
13,881\end{array}$ & $\begin{array}{r}2,089,000 \\
5,422,000 \\
2,788,000 \\
8,118,000 \\
92,000\end{array}$ & $\begin{array}{r}119,584 \\
249,524 \\
164,763 \\
259,546 \\
22,202\end{array}$ & $\begin{array}{r}227,000 \\
506,000 \\
254,000 \\
499,000 \\
13,000\end{array}$ & $\begin{array}{r}382,701 \\
2,386,913 \\
155,235 \\
508,537 \\
75,676\end{array}$ & $\begin{array}{r}6,000 \\
21,000 \\
6,000 \\
36,000 \\
\mathrm{NA}\end{array}$ \\
\hline \multirow[t]{2}{*}{ 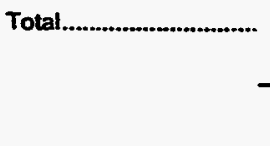 } & $4,433,377$ & $46,331,000$ & $2,432,382$ & $3,837,000$ & $5,901,288$ & 189,000 \\
\hline & \multicolumn{6}{|c|}{1986} \\
\hline $\begin{array}{l}\text { New England ................. } \\
\text { Middle Allantic ............ } \\
\text { East North Central ....... } \\
\text { West North Central ....... } \\
\text { South Atlantic................. }\end{array}$ & $\begin{array}{r}160,741 \\
749,841 \\
1,345,536 \\
430,862 \\
335,964\end{array}$ & $\begin{array}{r}1,720,000 \\
7,845,000 \\
10,386,000 \\
3,988,000 \\
4,211,000\end{array}$ & $\begin{array}{r}82,432 \\
367,720 \\
599,786 \\
290,414 \\
218,314\end{array}$ & $\begin{array}{l}145,000 \\
612,000 \\
847,000 \\
430,000 \\
368,000\end{array}$ & $\begin{array}{r}48,216 \\
358,582 \\
962,421 \\
319,216 \\
479,895\end{array}$ & $\begin{array}{r}8,000 \\
34,000 \\
47,000 \\
14,000 \\
11,000\end{array}$ \\
\hline 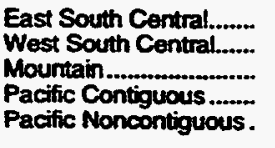 & $\begin{array}{r}169,568 \\
357,902 \\
237,305 \\
513,582 \\
12,670\end{array}$ & $\begin{array}{r}2,122,000 \\
5,421,000 \\
2,814,000 \\
8,272,000 \\
94,000\end{array}$ & $\begin{array}{r}117,274 \\
236,423 \\
151,554 \\
231,659 \\
22,757\end{array}$ & $\begin{array}{r}232,000 \\
506,000 \\
293,000 \\
501,000 \\
14,000\end{array}$ & $\begin{array}{r}346,355 \\
2,389,000 \\
124,777 \\
490,155 \\
60,439\end{array}$ & $\begin{array}{r}6,000 \\
17,000 \\
2,000 \\
34,000 \\
N A\end{array}$ \\
\hline Total.................................. & $4,313,969$ & $46,877,000$ & $2,318,335$ & $3,950,000$ & $\mathbf{5 , 5 7 9 , 0 5 7}$ & 192,000 \\
\hline
\end{tabular}

See focunotes at end of table. 
Table 22. Natural Gas Delivered to Consumers by Census Division, 1967-1994 (Continued)

\begin{tabular}{|c|c|c|c|c|}
\hline \multirow{2}{*}{ Consus Division } & \multirow{2}{*}{$\begin{array}{c}\text { Vchicle Fud } \\
\begin{array}{c}\text { Quantiny } \\
\text { (million } \\
\text { cubie fret) }\end{array}\end{array}$} & \multirow{2}{*}{$\begin{array}{l}\text { Eectric Utalities } \\
\begin{array}{c}\text { Quantity } \\
\text { (million } \\
\text { cubie foet) }\end{array}\end{array}$} & \multirow{2}{*}{ 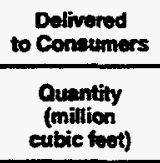 } & \multirow{2}{*}{$\begin{array}{l}\text { Heating Valus } \\
\text { (Btu per cubic foot) }\end{array}$} \\
\hline & & & & \\
\hline & \multicolumn{4}{|c|}{1983} \\
\hline $\begin{array}{l}\text { New England .............. } \\
\text { Middele Attantic ........... } \\
\text { East North Central ..... } \\
\text { West North Central .... } \\
\text { South Atartic............. }\end{array}$ & $\begin{array}{l}\text { NA } \\
\text { NA } \\
\text { NA } \\
\text { NA } \\
\text { NA }\end{array}$ & $\begin{array}{r}27,715 \\
234,351 \\
32,003 \\
57,779 \\
187,819\end{array}$ & $\begin{array}{r}310,285 \\
1,732,089 \\
3,054,656 \\
1,149,713 \\
1,256,665\end{array}$ & $\begin{array}{l}1,026 \\
1,029 \\
1,028 \\
1,012 \\
1,032\end{array}$ \\
\hline $\begin{array}{l}\text { East South Central...... } \\
\text { West Solth Central.... } \\
\text { Mountain................ } \\
\text { Pacific Contiguous...... } \\
\text { Pacific Noncontiguous }\end{array}$ & $\begin{array}{l}\text { NA } \\
\text { NA } \\
\text { NA } \\
\text { NA }\end{array}$ & $\begin{array}{r}51,629 \\
1,757,363 \\
65,662 \\
465,097 \\
31,348\end{array}$ & $\begin{array}{r}741,704 \\
4,637,354 \\
668,117 \\
1,672,256 \\
143,785\end{array}$ & $\begin{array}{l}1,028 \\
1,033 \\
1,037 \\
1,043 \\
1,002\end{array}$ \\
\hline \multirow[t]{2}{*}{ Total............................. } & NA & $2,910,767$ & $15,366,621$ & 1,031 \\
\hline & \multicolumn{4}{|c|}{1984} \\
\hline $\begin{array}{l}\text { New England .............. } \\
\text { Middle Atlantic ........... } \\
\text { East North Central..... } \\
\text { West North Central .... } \\
\text { South Atlantic.............. }\end{array}$ & $\begin{array}{l}\text { NA } \\
\text { NA } \\
\text { NA } \\
\text { NA } \\
\text { NA }\end{array}$ & $\begin{array}{r}38,360 \\
267,559 \\
19,762 \\
41,339 \\
187,526\end{array}$ & $\begin{array}{r}337,856 \\
1,837,082 \\
3,231,263 \\
1,199,852 \\
1,303,188\end{array}$ & $\begin{array}{l}1,029 \\
1,029 \\
1,027 \\
1,004 \\
1,035\end{array}$ \\
\hline $\begin{array}{l}\text { East South Central..... } \\
\text { West South Central.... } \\
\text { Mountain................. } \\
\text { Pacific Contiguous ..... } \\
\text { Pacific Noncontiguous }\end{array}$ & $\begin{array}{l}\text { NA } \\
\text { NA } \\
\text { NA } \\
\text { NA } \\
\text { NA }\end{array}$ & $\begin{array}{r}64,805 \\
1,816,190 \\
71,186 \\
573,033 \\
31,582\end{array}$ & $\begin{array}{r}798,830 \\
4,967,311 \\
693,082 \\
1,833,515 \\
142,910\end{array}$ & $\begin{array}{l}1,028 \\
1,036 \\
1,036 \\
1,042 \\
1,002\end{array}$ \\
\hline \multirow[t]{2}{*}{ 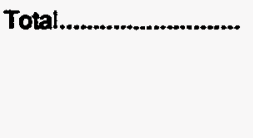 } & NA & $3,111,342$ & $16,344,893$ & 1,031 \\
\hline & \multicolumn{3}{|c|}{1985} & - \\
\hline $\begin{array}{l}\text { New England .............. } \\
\text { Middle Altantic .......... } \\
\text { East North Central ..... } \\
\text { West North Central .... } \\
\text { South Atlantic.............. }\end{array}$ & $\begin{array}{l}\text { NA } \\
\text { NA } \\
\text { NA } \\
\text { NA }\end{array}$ & $\begin{array}{r}49,347 \\
235,563 \\
19,140 \\
27,334 \\
177,934\end{array}$ & $\begin{array}{l}343,158 \\
1,723,100 \\
3,090,195 \\
1.165,391 \\
1,221,828\end{array}$ & $\begin{array}{l}1,028 \\
1,030 \\
1,028 \\
1,006 \\
1,039\end{array}$ \\
\hline $\begin{array}{l}\text { East South Central..... } \\
\text { West South Central.... } \\
\text { Mountain................. } \\
\text { Pacific Contiguous...... } \\
\text { Pacific Noncontiguous }\end{array}$ & $\begin{array}{l}\text { NA } \\
\text { NA } \\
\text { NA } \\
\text { NA } \\
\text { NA }\end{array}$ & $\begin{array}{r}55,778 \\
1,694,726 \\
83,716 \\
666,351 \\
34,194\end{array}$ & $\begin{array}{r}727,003 \\
4,720,819 \\
657,276 \\
2,016,407 \\
145,953\end{array}$ & $\begin{array}{l}1,033 \\
1,037 \\
1,039 \\
1,042 \\
1,007\end{array}$ \\
\hline \multirow[t]{2}{*}{ Total............................... } & NA & $3,044,083$ & $15,811,130$ & 1,032 \\
\hline & \multicolumn{4}{|c|}{1986} \\
\hline $\begin{array}{l}\text { New England............. } \\
\text { Midele Atlantic ........... } \\
\text { East North Central ..... } \\
\text { West North Central .... } \\
\text { South Attantic.............. }\end{array}$ & $\begin{array}{l}\text { NA } \\
\text { NA } \\
\text { NA } \\
\text { NA }\end{array}$ & $\begin{array}{r}15,618 \\
171,181 \\
20,487 \\
21,066 \\
182,994\end{array}$ & $\begin{array}{r}307,009 \\
1,647,322 \\
2,928,230 \\
1,061,556 \\
1,217,169\end{array}$ & $\begin{array}{l}1,027 \\
1,031 \\
1,026 \\
1,001 \\
1,036\end{array}$ \\
\hline $\begin{array}{l}\text { East South Central..... } \\
\text { West South Central.... } \\
\text { Mountain............... } \\
\text { Pacific Contiguous..... } \\
\text { Pacific Noncontiguous }\end{array}$ & $\begin{array}{l}\text { NA } \\
\text { NA } \\
\text { NA } \\
\text { NA } \\
\text { NA }\end{array}$ & $\begin{array}{r}49,104 \\
1,600,352 \\
62,811 \\
444,350 \\
34,409\end{array}$ & $\begin{array}{r}682,301 \\
4,583,676 \\
576,447 \\
1,679,746 \\
130,275\end{array}$ & $\begin{array}{l}1,032 \\
1,038 \\
1,017 \\
1,038 \\
1,010\end{array}$ \\
\hline 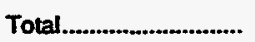 & NA & $2,602,370$ & $14,813,731$ & 1,030 \\
\hline
\end{tabular}

See foctnotes at end of table. 
Table 22. Natural Gas Delivered to Consumers by Census Division, 1967-1994 (Continued)

\begin{tabular}{|c|c|c|c|c|c|c|}
\hline \multirow[b]{2}{*}{ Conaus Division } & \multicolumn{2}{|c|}{ Pesidential } & \multicolumn{2}{|c|}{ Commercial } & \multicolumn{2}{|c|}{ Industrial } \\
\hline & $\begin{array}{l}\text { Qumity } \\
\text { (million } \\
\text { cubie fect) }\end{array}$ & Convumers: & $\begin{array}{l}\text { Cuantity } \\
\text { (million } \\
\text { culbic foet) }\end{array}$ & Consumers: & $\begin{array}{l}\text { Qusantity } \\
\text { (miltion } \\
\text { cubie font) }\end{array}$ & Corseumers: \\
\hline & \multicolumn{6}{|c|}{1987} \\
\hline $\begin{array}{l}\text { New England } \\
\text { Middle Atlantic ............... } \\
\text { East North Central....... } \\
\text { West North Central....... } \\
\text { South Atlantic................ }\end{array}$ & $\begin{array}{r}165,519 \\
754,233 \\
1,290,850 \\
397,114 \\
356,827\end{array}$ & $\begin{array}{r}1,762,547 \\
7,918,357 \\
10,576,713 \\
4,054,105 \\
4,290,409\end{array}$ & $\begin{array}{r}91,181 \\
376,437 \\
646,639 \\
266,106 \\
238,766\end{array}$ & $\begin{array}{l}155,363 \\
630,147 \\
846,768 \\
434,323 \\
390,259\end{array}$ & $\begin{array}{r}62,611 \\
402,209 \\
923,565 \\
364,018 \\
516,777\end{array}$ & $\begin{array}{r}9,741 \\
35,630 \\
51,182 \\
12,964 \\
14,904\end{array}$ \\
\hline $\begin{array}{l}\text { East South Central....... } \\
\text { West South Central..... } \\
\text { Mountain..................... } \\
\text { Pacific Contiguous...... } \\
\text { Pacific Noncontiguous. }\end{array}$ & $\begin{array}{r}178,254 \\
376,284 \\
230,882 \\
552,022 \\
12,847\end{array}$ & $\begin{array}{r}2,163,513 \\
5,398,037 \\
2,872,616 \\
8,577,997 \\
96,150\end{array}$ & $\begin{array}{r}117,747 \\
241,385 \\
167,570 \\
261,988 \\
22,243\end{array}$ & $\begin{array}{r}237,796 \\
510,420 \\
296,745 \\
496,839 \\
14,380\end{array}$ & $\begin{array}{r}350,715 \\
2,499,961 \\
134,196 \\
631,787 \\
67,467\end{array}$ & $\begin{array}{r}7,222 \\
10,651 \\
4,445 \\
48,795 \\
10\end{array}$ \\
\hline \multirow[t]{2}{*}{ 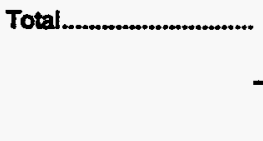 } & $4,314,833$ & $47,710,444$ & $2,430,064$ & $4,013,040$ & $5,953,308$ & 195,544 \\
\hline & \multicolumn{6}{|c|}{1988} \\
\hline $\begin{array}{l}\text { New England ................. } \\
\text { Middle Atantic ........... } \\
\text { East North Central....... } \\
\text { West North Central ...... } \\
\text { South Atantic............... }\end{array}$ & $\begin{array}{r}174,158 \\
806,803 \\
1,436,407 \\
453,854 \\
378,393\end{array}$ & $\begin{array}{r}1,794,845 \\
8,029,938 \\
10,698,172 \\
4,101,921 \\
4,411,913\end{array}$ & $\begin{array}{r}93,115 \\
416,745 \\
680,594 \\
307,513 \\
253,093\end{array}$ & $\begin{array}{l}166,283 \\
649,094 \\
902,306 \\
439,206 \\
402,258\end{array}$ & $\begin{array}{r}60,340 \\
397,020 \\
1,081,033 \\
382,942 \\
542,535\end{array}$ & $\begin{array}{l}11,558 \\
36,847 \\
52,209 \\
12,900 \\
14,898\end{array}$ \\
\hline $\begin{array}{l}\text { East South Central....... } \\
\text { West Sourth Central...... } \\
\text { Mountain ................. } \\
\text { Pacilic Contiguous...... } \\
\text { Pacilic Noncontiguous. }\end{array}$ & $\begin{array}{r}187,497 \\
384,501 \\
242,688 \\
552,938 \\
13,092\end{array}$ & $\begin{array}{r}2,212,632 \\
5,403,357 \\
2,910,190 \\
8,814,108 \\
97,373\end{array}$ & $\begin{array}{r}125,240 \\
278,169 \\
189,628 \\
303,476 \\
22,891\end{array}$ & $\begin{array}{r}244,700 \\
498,781 \\
301,696 \\
505,920 \\
14,501\end{array}$ & $\begin{array}{r}396,931 \\
2,722,373 \\
159,206 \\
573,196 \\
67,805\end{array}$ & $\begin{array}{r}7,143 \\
9,770 \\
4,427 \\
49,278 \\
11\end{array}$ \\
\hline \multirow[t]{2}{*}{ Total.................................... } & $4,630,330$ & $48,474,449$ & $2,670,465$ & $4,124,745$ & $6,383,382$ & 199,041 \\
\hline & \multicolumn{6}{|c|}{1999} \\
\hline $\begin{array}{l}\text { New England .............. } \\
\text { Middle Attantic ........... } \\
\text { East North Central ....... } \\
\text { West North Central ....... } \\
\text { South Attantic............... }\end{array}$ & $\begin{array}{r}179,686 \\
830,997 \\
1,503,742 \\
465,459 \\
\mathbf{3 7 4 , 9 0 6}\end{array}$ & $\begin{array}{r}1,822,633 \\
8,100,820 \\
10,898,521 \\
4,147,907 \\
4,521,601\end{array}$ & $\begin{array}{l}100,169 \\
446,186 \\
677,584 \\
309,704 \\
252,149\end{array}$ & $\begin{array}{l}169,870 \\
676,072 \\
894,907 \\
445,931 \\
420,970\end{array}$ & $\begin{array}{r}65,452 \\
423,957 \\
1,097,403 \\
365,417 \\
574,725\end{array}$ & $\begin{array}{l}17,551 \\
39,528 \\
58,472 \\
13,035 \\
15,138\end{array}$ \\
\hline $\begin{array}{l}\text { East South Central....... } \\
\text { West South Central...... } \\
\text { Mountain................ } \\
\text { Pacific Contiguous...... } \\
\text { Pacific Noncontiguous. }\end{array}$ & $\begin{array}{r}188,713 \\
401,909 \\
245,933 \\
575,138 \\
14,153\end{array}$ & $\begin{array}{r}2,272,981 \\
5,433,773 \\
2,971,291 \\
9,041,556 \\
98,510\end{array}$ & $\begin{array}{r}127,698 \\
275,606 \\
186,890 \\
317,869 \\
23,867\end{array}$ & $\begin{array}{r}250,156 \\
482,361 \\
303,674 \\
509,459 \\
14,648\end{array}$ & $\begin{array}{r}417,739 \\
3,005,683 \\
181,587 \\
624,939 \\
59,341\end{array}$ & $\begin{array}{r}7,660 \\
19,203 \\
4,355 \\
50,346 \\
8\end{array}$ \\
\hline \multirow[t]{2}{*}{ 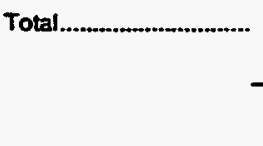 } & $4,780,638$ & $49,309,593$ & 2.717 .722 & $4,168.048$ & $6.816,244$ & 225,346 \\
\hline & \multicolumn{6}{|c|}{1890} \\
\hline $\begin{array}{l}\text { New England } \\
\text { Midd"............... } \\
\text { East North Central ........ } \\
\text { West North Central ...... } \\
\text { South Altantic................ }\end{array}$ & $\begin{array}{r}170,679 \\
749,663 \\
1,332,422 \\
426,509 \\
329,510\end{array}$ & $\begin{array}{r}1,838,051 \\
8,211,285 \\
11,078,902 \\
4,211,511 \\
4,624,549\end{array}$ & $\begin{array}{r}96,899 \\
436,254 \\
636,759 \\
292,679 \\
236,458\end{array}$ & $\begin{array}{l}166,624 \\
686,037 \\
917,654 \\
455,814 \\
430,880\end{array}$ & $\begin{array}{r}81,334 \\
427,009 \\
1,184,725 \\
385,950 \\
621,487\end{array}$ & $\begin{array}{l}11,194 \\
37,222 \\
59,385 \\
13,106 \\
14,788\end{array}$ \\
\hline $\begin{array}{l}\text { East South Central....... } \\
\text { West South Central..... } \\
\text { Mournain................... } \\
\text { Pacific Contiguous....... } \\
\text { Pacific Noncontiguous. }\end{array}$ & $\begin{array}{r}172,859 \\
368,853 \\
247,862 \\
578,235 \\
14,730\end{array}$ & $\begin{array}{r}2,319,908 \\
\mathbf{5 , 4 7 0 , 0 0 2} \\
\mathbf{3 , 0 5 0 , 9 8 7} \\
\mathbf{9 , 2 8 2 , 0 3 8} \\
\mathbf{9 9 , 9 4 5}\end{array}$ & $\begin{array}{r}117,193 \\
259,606 \\
178,818 \\
344,210 \\
23,845\end{array}$ & $\begin{array}{r}255,926 \\
478,271 \\
309,920 \\
520,396 \\
14,758\end{array}$ & $\begin{array}{r}424,540 \\
2,935,890 \\
188,109 \\
692,520 \\
76,849\end{array}$ & $\begin{array}{r}7,653 \\
19,448 \\
5,362 \\
50,175 \\
8\end{array}$ \\
\hline 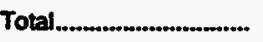 & $4,391,324$ & $50,187,178$ & $2,622,721$ & $4,236,280$ & $7.018,414$ & 218,341 \\
\hline
\end{tabular}

See tootnctes at end of table. 
Table 22. Natural Gas Delivered to Consumers by Census Division, 1967-1994 (Continued)

\begin{tabular}{|c|c|c|c|c|}
\hline \multirow{2}{*}{ Cansus Diviaion } & Vohicto Fual & Electric Uabitios & $\begin{array}{l}\text { Delivered } \\
\text { to Consumeors }\end{array}$ & \multirow{2}{*}{$\begin{array}{l}\text { Hoeding Volus } \\
\text { (Etu per cubie foot) }\end{array}$} \\
\hline & $\begin{array}{l}\text { Ouantity } \\
\text { (million } \\
\text { cubic feot) }\end{array}$ & $\begin{array}{l}\text { Ouantity } \\
\text { (mitlion } \\
\text { cubic foelt) }\end{array}$ & $\begin{array}{l}\text { Ounntity } \\
\text { (million } \\
\text { cubic teet) }\end{array}$ & \\
\hline & \multicolumn{4}{|c|}{1987} \\
\hline 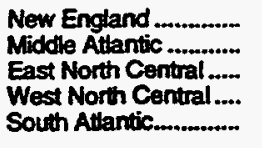 & $\begin{array}{l}\text { NA } \\
\text { NA } \\
\text { NA } \\
\text { NA } \\
\text { NA }\end{array}$ & $\begin{array}{r}52,884 \\
250,458 \\
18,288 \\
28,241 \\
199,769\end{array}$ & $\begin{array}{r}372,194 \\
1,783,339 \\
2,879,342 \\
1,055,480 \\
1,312,140\end{array}$ & $\begin{array}{l}1,029 \\
1,031 \\
1,022 \\
1,014 \\
1,006\end{array}$ \\
\hline $\begin{array}{l}\text { East South Central..... } \\
\text { West South Central.... } \\
\text { Mountain... } \\
\text { Pacific Contiguous....... } \\
\text { Pacific Noncontiguous }\end{array}$ & $\begin{array}{l}\text { NA } \\
\text { NA } \\
\text { NA } \\
\text { NA } \\
\text { NA }\end{array}$ & $\begin{array}{r}42,930 \\
1,516,669 \\
60,855 \\
643,428 \\
30,530\end{array}$ & $\begin{array}{r}689,646 \\
4,634,299 \\
593,503 \\
2,089,226 \\
133,088\end{array}$ & $\begin{array}{l}1,030 \\
1,039 \\
1,033 \\
1,030 \\
1,010\end{array}$ \\
\hline \multirow[t]{2}{*}{ Total........................ } & NA & $2,844,051$ & $15,542,256$ & 1,031 \\
\hline & \multicolumn{4}{|c|}{1988} \\
\hline $\begin{array}{l}\text { New England ............. } \\
\text { Middle Atlantic ......... } \\
\text { East North Central..... } \\
\text { West North Central.... } \\
\text { South Atlantic.............. }\end{array}$ & $\begin{array}{l}\text { NA } \\
\text { NA } \\
\text { NA } \\
\text { NA } \\
\text { NA }\end{array}$ & $\begin{array}{r}21,374 \\
202,208 \\
27,901 \\
33,460 \\
168,894\end{array}$ & $\begin{array}{r}348,986 \\
1,822,776 \\
3,225,936 \\
1,177,769 \\
1,342.916\end{array}$ & $\begin{array}{l}1,029 \\
1,031 \\
1,023 \\
1,001 \\
1,036\end{array}$ \\
\hline 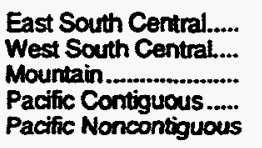 & $\begin{array}{l}\text { NA } \\
\text { NA } \\
\text { NA } \\
\text { NA } \\
\text { NA }\end{array}$ & $\begin{array}{r}36,512 \\
1,493,530 \\
66,203 \\
554,691 \\
30,843\end{array}$ & $\begin{array}{r}746,181 \\
4,878,573 \\
657,724 \\
1,984,301 \\
134,631\end{array}$ & $\begin{array}{l}1,028 \\
1,038 \\
1,034 \\
1,030 \\
1,005\end{array}$ \\
\hline \multirow[t]{2}{*}{ Total. } & NA & $2,635,616$ & $16,319,793$ & 1,029 \\
\hline & \multicolumn{4}{|c|}{1989} \\
\hline $\begin{array}{l}\text { New England .............. } \\
\text { Middie Atlantic ......... } \\
\text { East North Central ..... } \\
\text { West North Central.... } \\
\text { South Atlantic............... }\end{array}$ & $\begin{array}{l}\text { NA } \\
\text { NA } \\
\text { NA } \\
\text { NA } \\
\text { NA }\end{array}$ & $\begin{array}{r}53,949 \\
241,435 \\
32,883 \\
29.948 \\
222,979\end{array}$ & $\begin{array}{r}399,256 \\
1,942,575 \\
3,311,612 \\
1,170,528 \\
1,424,760\end{array}$ & $\begin{array}{l}1,034 \\
1,031 \\
1,026 \\
1,004 \\
1,036\end{array}$ \\
\hline $\begin{array}{l}\text { East South Central..... } \\
\text { West South Central.... } \\
\text { Mountain... } \\
\text { Pacific Contiguous........ } \\
\text { Pacific Noncontiguous }\end{array}$ & $\begin{array}{l}\text { NA } \\
\text { NA } \\
\text { NA } \\
\text { NA } \\
\text { NA }\end{array}$ & $\begin{array}{r}47,033 \\
1,476,260 \\
110,815 \\
538,962 \\
32,746\end{array}$ & $\begin{array}{r}781,183 \\
5.159,458 \\
725,226 \\
2,056,909 \\
130,108\end{array}$ & $\begin{array}{l}1,032 \\
1,037 \\
1,037 \\
1,037 \\
1,001\end{array}$ \\
\hline \multirow[t]{2}{*}{ 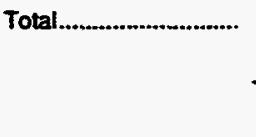 } & NA & $2,787.012$ & $17,101,615$ & 1,031 \\
\hline & \multicolumn{4}{|c|}{1990} \\
\hline $\begin{array}{l}\text { New England ............. } \\
\text { Middle Attantic ........ } \\
\text { East North Central..... } \\
\text { West North Central .... } \\
\text { South Adlantic.............. }\end{array}$ & $\begin{array}{r}8 \\
4 \\
142 \\
0 \\
2\end{array}$ & $\begin{array}{r}66,238 \\
273,208 \\
42,463 \\
43,223 \\
234,412\end{array}$ & $\begin{array}{r}415,157 \\
1,886,138 \\
3,196,511 \\
1,148,361 \\
1,421,869\end{array}$ & $\begin{array}{l}1,034 \\
1,031 \\
1,024 \\
1,004 \\
1,036\end{array}$ \\
\hline $\begin{array}{l}\text { East South Central..... } \\
\text { West South Central.... } \\
\text { Mourtain............................. } \\
\text { Pacitic Contiguous..... } \\
\text { Pacitic Noncontiguous }\end{array}$ & $\begin{array}{r}4 \\
44 \\
12 \\
54 \\
0\end{array}$ & $\begin{array}{r}70,110 \\
1,477,228 \\
80,924 \\
463,982 \\
34,366\end{array}$ & $\begin{array}{r}784,707 \\
5,041,621 \\
695,725 \\
2,079,002 \\
149,791\end{array}$ & $\begin{array}{l}1,034 \\
1,038 \\
1,038 \\
1,031 \\
956\end{array}$ \\
\hline Total.............................. & 270 & $2,786,153$ & $16,818,882$ & 1,031 \\
\hline
\end{tabular}

See footnotes at end of table. 
Table 22. Natural Gas Delivered to Consumers by Census Division; 1967-1994 (Continued)

\begin{tabular}{|c|c|c|c|c|c|c|}
\hline \multirow[b]{2}{*}{ Consus Divition } & \multicolumn{2}{|c|}{ Residential } & \multicolumn{2}{|c|}{ Commercial } & \multicolumn{2}{|c|}{ Industrial } \\
\hline & $\begin{array}{l}\text { Qunntity } \\
\text { (miltion } \\
\text { cubic iont) }\end{array}$ & Conwermers & $\begin{array}{l}\text { Quantity } \\
\text { (million } \\
\text { cubic feet) }\end{array}$ & Consumers & $\begin{array}{l}\text { Quantiny } \\
\text { (minion } \\
\text { cubic feot) }\end{array}$ & Conatumers \\
\hline
\end{tabular}

1991

\begin{tabular}{|c|c|c|c|c|c|c|}
\hline 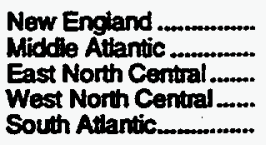 & $\begin{array}{r}166,036 \\
758,259 \\
1,396,426 \\
457,681 \\
345,654\end{array}$ & $\begin{array}{r}1,854,346 \\
8,810,402 \\
11,242,141 \\
4,261,290 \\
4,727,189\end{array}$ & $\begin{array}{r}97,242 \\
446,384 \\
649,640 \\
314,748 \\
263,448\end{array}$ & $\begin{array}{l}171,798 \\
717,452 \\
934,355 \\
473,045 \\
446,720\end{array}$ & $\begin{array}{r}121,658 \\
451,087 \\
1,210,995 \\
404,938 \\
585,297\end{array}$ & $\begin{array}{r}9,499 \\
43,625 \\
60,001 \\
12,064 \\
10,524\end{array}$ \\
\hline $\begin{array}{l}\text { East South Central....... } \\
\text { West South Central...... } \\
\text { Mountain................. } \\
\text { Pacilic Contiguous....... } \\
\text { Pacitic Noncontiguous. }\end{array}$ & $\begin{array}{r}180,726 \\
385,631 \\
268,895 \\
581,243 \\
14,107\end{array}$ & $\begin{array}{r}2,381,506 \\
5,530,225 \\
3,180,712 \\
9,503,129 \\
102,266\end{array}$ & $\begin{array}{r}121,107 \\
271,999 \\
189,292 \\
351,675 \\
23,046\end{array}$ & $\begin{array}{r}259,282 \\
479,460 \\
322,744 \\
537,539 \\
14,857\end{array}$ & $\begin{array}{r}446,870 \\
2,982,897 \\
214,179 \\
737,404 \\
75,637\end{array}$ & $\begin{array}{r}7,793 \\
19,446 \\
4,432 \\
49,147 \\
8\end{array}$ \\
\hline 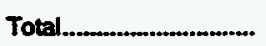 & $4,555,659$ & $51,593,206$ & $2,728,581$ & $4,357,252$ & $7.230,962$ & 216,529 \\
\hline
\end{tabular}

1992

New Engtand.

Midde Atlantic

East North Central

West North Central......

South Atantic.

East South Central......

West South Central.....

Mountain

Pacific Contigurous......

Pacific Noncontiguous.

Total.

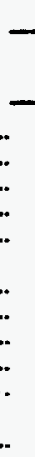

\begin{tabular}{|c|c|c|c|c|c|}
\hline $\begin{array}{r}191,906 \\
843,680 \\
1,450,173 \\
438,513 \\
385,200\end{array}$ & $\begin{array}{r}1,871,671 \\
8,917,964 \\
11,381,828 \\
4,328,454 \\
4,943,742\end{array}$ & $\begin{array}{l}113,660 \\
482,360 \\
675,446 \\
296,784 \\
287,357\end{array}$ & $\begin{array}{l}170,758 \\
722,563 \\
946,144 \\
484,851 \\
455,316\end{array}$ & $\begin{array}{r}163,006 \\
558,797 \\
1,276,376 \\
419,929 \\
623,133\end{array}$ & $\begin{array}{l}13,184 \\
46,168 \\
60,965 \\
11,821 \\
10,283\end{array}$ \\
\hline $\begin{array}{r}190,262 \\
375,189 \\
254,547 \\
545,694 \\
14,901\end{array}$ & $\begin{array}{r}2,443,619 \\
5,562,827 \\
3,213,437 \\
9,563,782 \\
104,073\end{array}$ & $\begin{array}{r}125,125 \\
273,622 \\
182,577 \\
342,378 \\
23,443\end{array}$ & $\begin{array}{r}263,846 \\
503,361 \\
321,754 \\
526,109 \\
14,997\end{array}$ & $\begin{array}{r}471,509 \\
2,960,486 \\
239,869 \\
732,854 \\
80,938\end{array}$ & $\begin{array}{r}7,869 \\
11,111 \\
3,447 \\
44,758 \\
10\end{array}$ \\
\hline $4,690,065$ & $52,331,397$ & $2.802,751$ & $4,409,699$ & $7,526,898$ & 209,616 \\
\hline
\end{tabular}

1993

New Engtand.

Middle Attantic

East North Central.......

West North Central

South Atlantic.

East South Central......

West South Central.....

Mountain ......................

Pacific Contiguous.......

Pacific Noncontiguous.

Total.

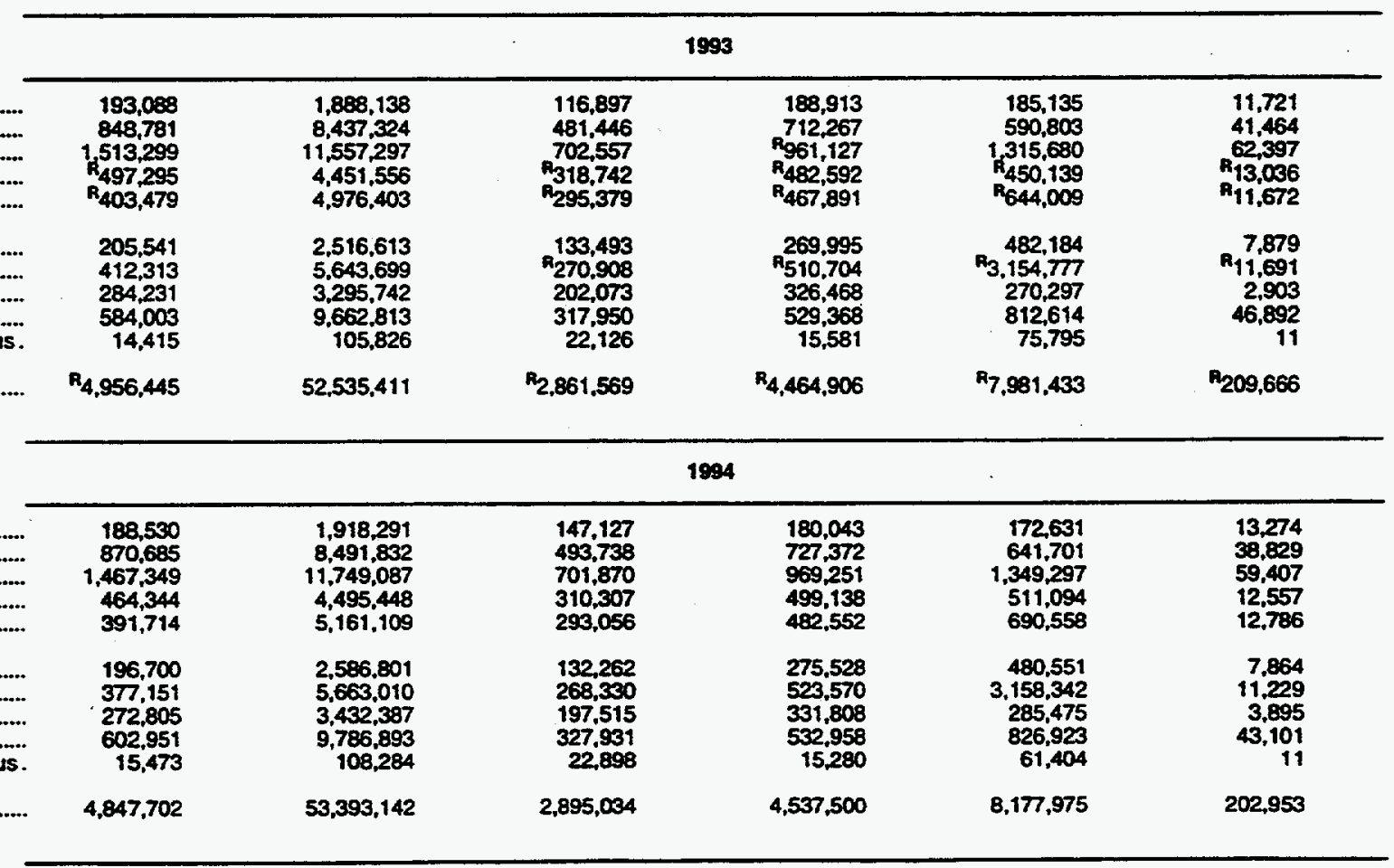

See footnotes at and of table. 
Table 22. Natural Gas Delivered to Consumers by Census Division; 1967-1994 (Continued)

\begin{tabular}{|c|c|c|c|c|c|}
\hline \multirow{2}{*}{ Centus Diviaion } & Vohicte Fuel & & Electric Utithies & $\begin{array}{l}\text { Delivened } \\
\text { to Consumers }\end{array}$ & \multirow{2}{*}{$\begin{array}{l}\text { Heating Value } \\
\text { (Btu per cubic foot) }\end{array}$} \\
\hline & $\begin{array}{l}\text { Quantity } \\
\text { (mallion } \\
\text { cubic foet) }\end{array}$ & & $\begin{array}{l}\text { Quantity } \\
\text { (miltion } \\
\text { cubic foet) }\end{array}$ & $\begin{array}{l}\text { Qumitity } \\
\text { (malition } \\
\text { cutic foot) }\end{array}$ & \\
\hline & \multicolumn{5}{|c|}{1991} \\
\hline $\begin{array}{l}\text { New England ............... } \\
\text { Middle Attantic .......... } \\
\text { East North Central ...... } \\
\text { West North Central .... } \\
\text { South Attantic.............. }\end{array}$ & $\begin{array}{r}9 \\
27 \\
149 \\
5 \\
8\end{array}$ & & $\begin{array}{r}46,564 \\
275,551 \\
52,588 \\
62,239 \\
255,024\end{array}$ & $\begin{array}{r}431,509 \\
1,931,309 \\
3,309,797 \\
1,239,610 \\
1,449,430\end{array}$ & $\begin{array}{l}1,033 \\
1,030 \\
1,023 \\
1,008 \\
1,037\end{array}$ \\
\hline $\begin{array}{l}\text { East South Central..... } \\
\text { West South Central.... } \\
\text { Mountain.................... } \\
\text { Pacific Contiguous..... } \\
\text { Pacific Noncontiguous }\end{array}$ & $\begin{array}{r}1 \\
19 \\
72 \\
76 \\
0\end{array}$ & & $\begin{array}{r}66,928 \\
1,454,413 \\
84,369 \\
460,009 \\
31,330\end{array}$ & $\begin{array}{r}815,633 \\
5,095,960 \\
756,808 \\
2,130,407 \\
144,120\end{array}$ & $\begin{array}{l}1,033 \\
1,037 \\
1,039 \\
1,027 \\
1,003\end{array}$ \\
\hline \multirow[t]{2}{*}{ Total................................. } & 367 & & $2,789,014$ & $17,304,582$ & 1,030 \\
\hline & \multicolumn{5}{|c|}{1992} \\
\hline $\begin{array}{l}\text { New England.............. } \\
\text { Middie Altantic .......... } \\
\text { East North Central ..... } \\
\text { West North Central ..... } \\
\text { South Atlantic............. }\end{array}$ & $\begin{array}{r}12 \\
9 \\
158 \\
10 \\
16\end{array}$ & & $\begin{array}{r}42,343 \\
250,602 \\
47,513 \\
25,456 \\
239,787\end{array}$ & $\begin{array}{r}510,928 \\
2,135,448 \\
3,449,665 \\
1,180,693 \\
1,535,494\end{array}$ & $\begin{array}{l}1,030 \\
1,030 \\
1,021 \\
1,000 \\
1,036\end{array}$ \\
\hline $\begin{array}{l}\text { East South Central..... } \\
\text { West South Central... } \\
\text { Mountain................. } \\
\text { Pacitic Contiguous...... } \\
\text { Pacitic Noncontiguous }\end{array}$ & $\begin{array}{r}5 \\
58 \\
115 \\
127 \\
0\end{array}$ & & $\begin{array}{r}58,109 \\
1,399,083 \\
89,679 \\
584,082 \\
28,953\end{array}$ & $\begin{array}{r}845,009 \\
5,008,438 \\
766,788 \\
2,205,134 \\
148,236\end{array}$ & $\begin{array}{l}1,039 \\
1,040 \\
1,039 \\
1,030 \\
1,003\end{array}$ \\
\hline 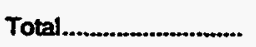 & 511 & " & $2,765,608$ & $17.785,833$ & 1,030 \\
\hline
\end{tabular}

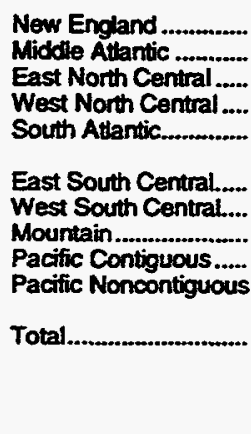

New England

Middle Attantic

East North Central

West North Central...

South Atlantic.

East South Central....

West South Central...

Mountain

Pacific Contiguous...

Pacific Noncontiguous

Total.

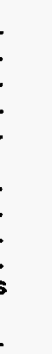

$\begin{array}{rr}3 & 30,141 \\ 24 & 215,737 \\ 149 & 46,394 \\ 22 & 36,803 \\ 53 & 219,499 \\ 10 & 46,335 \\ 189 & 1,491,347 \\ 147 & 81,032 \\ 363 & 487,127 \\ 0 & 28,025 \\ 960 & 2,682,440\end{array}$

\begin{tabular}{|c|c|c|c|}
\hline \multicolumn{4}{|c|}{1994} \\
\hline $\begin{array}{r}6 \\
67 \\
185 \\
67 \\
126\end{array}$ & $\begin{array}{r}48,558 \\
237,862 \\
68,371 \\
43,374 \\
235,179\end{array}$ & $\begin{array}{r}556,852 \\
2,244,053 \\
3,587,073 \\
1,329,186 \\
1,610,633\end{array}$ & $\begin{array}{l}1,026 \\
1,033 \\
1,022 \\
1,004 \\
1,042\end{array}$ \\
\hline $\begin{array}{r}19 \\
224 \\
312 \\
723 \\
0\end{array}$ & $\begin{array}{r}87,745 \\
1,504,407 \\
102,719 \\
629,883 \\
29,048\end{array}$ & $\begin{array}{r}897,277 \\
5,308,454 \\
858,826 \\
2,388,411 \\
128,823\end{array}$ & $\begin{array}{l}1,038 \\
1,036 \\
1,027 \\
1,025 \\
1,002\end{array}$ \\
\hline 1.730 & $2,987,146$ & $18,909,587$ & 1,028 \\
\hline
\end{tabular}

$R=$ Revised data.

NA $=$ Not Available.

Note: Totals may not equal sum of components due to independent rounding.

Sourcas: Electric Utility Dala: 1967-1977: Federal Power Commission (FPC). 1978-1994: Energy Information Administration (EIA), Form EIA-759, "Monthly Power Plamt

Report" (formenty Form FPC-4); Form FERC-423, "Cost and Qualty of Fuets for Electric Utility Plants" (formenty Form FPC-423); and Form ElA-176. "Annual Feport of Natural and Supplemental Gas Supply and Disposition. Heating Vahe: 1975: Federal Power Commission. 1976-1979: American Gas Association, Gas Facts. 1980-1989: ElA; and Form ElA-176. Annual Report of Natural and Supplemental Gas Supply and Disposition." All other data: 1967-1980: ElA, Natural Gas Prodtetion and Consumption. 
Table 23. Average Price of Natural Gas Delivered to U.S. Residential Consumers by State, 1967-1994 (Dollars per Thousand Cubic Feet)

\begin{tabular}{|c|c|c|c|c|c|c|c|}
\hline State & 1967 & 1968 & 1969 & 1970 & 1971 & 1972 & 1973 \\
\hline 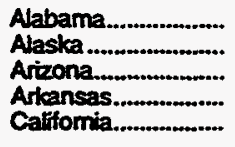 & $\begin{array}{l}1.13 \\
1.51 \\
0.96 \\
0.72 \\
0.93\end{array}$ & $\begin{array}{l}1.10 \\
1.52 \\
0.97 \\
0.70 \\
0.93\end{array}$ & $\begin{array}{l}1.09 \\
1.52 \\
1.04 \\
0.71 \\
0.93\end{array}$ & $\begin{array}{l}1.13 \\
1.52 \\
1.20 \\
0.75 \\
0.99\end{array}$ & $\begin{array}{l}1.19 \\
1.53 \\
1.23 \\
0.79 \\
1.03\end{array}$ & $\begin{array}{l}1.27 \\
1.55 \\
1.24 \\
0.83 \\
1.08\end{array}$ & $\begin{array}{l}1.37 \\
1.57 \\
1.37 \\
0.87 \\
1.16\end{array}$ \\
\hline 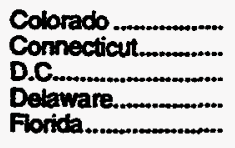 & $\begin{array}{r}0.66 \\
1.83 \\
a \\
1.60 \\
2.26\end{array}$ & $\begin{array}{r}0.68 \\
1.81 \\
a \\
1.59 \\
2.59\end{array}$ & $\begin{array}{r}0.69 \\
1.82 \\
8 \\
1.50 \\
2.48\end{array}$ & $\begin{array}{r}0.72 \\
1.91 \\
2 \\
1.58 \\
2.51\end{array}$ & $\begin{array}{r}0.75 \\
2.07 \\
a \\
1.63 \\
2.54\end{array}$ & $\begin{array}{r}0.78 \\
2.09 \\
a \\
1.71 \\
2.66\end{array}$ & $\begin{array}{r}0.83 \\
2.25 \\
a \\
1.85 \\
2.70\end{array}$ \\
\hline 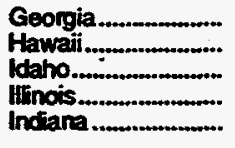 & $\begin{array}{l}1.03 \\
\text { NA } \\
1.29 \\
1.02 \\
0.98\end{array}$ & $\begin{array}{l}1.02 \\
\mathrm{NA} \\
1.36 \\
1.02 \\
0.94\end{array}$ & $\begin{array}{l}1.02 \\
\text { NA } \\
1.37 \\
1.00 \\
0.94\end{array}$ & $\begin{array}{l}1.05 \\
N A \\
1.39 \\
1.05 \\
1.01\end{array}$ & $\begin{array}{r}1.13 \\
\mathrm{NA} \\
1.49 \\
1.07 \\
1.08\end{array}$ & $\begin{array}{l}1.26 \\
\mathrm{NA} \\
1.51 \\
1.13 \\
1.14\end{array}$ & $\begin{array}{r}1.30 \\
N A \\
1.52 \\
1.21 \\
1.20\end{array}$ \\
\hline 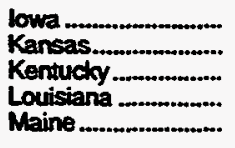 & $\begin{array}{r}0.93 \\
0.59 \\
0.84 \\
0.75 \\
61.96\end{array}$ & $\begin{array}{r}0.93 \\
0.63 \\
0.79 \\
0.75 \\
2.05\end{array}$ & $\begin{array}{r}0.94 \\
0.64 \\
0.80 \\
0.75 \\
1.97\end{array}$ & $\begin{array}{l}0.97 \\
0.68 \\
0.83 \\
0.77 \\
01.99\end{array}$ & $\begin{array}{l}1.03 \\
0.72 \\
0.88 \\
0.84 \\
0.05\end{array}$ & $\begin{array}{l}1.11 \\
0.74 \\
0.93 \\
0.91 \\
2.14\end{array}$ & $\begin{array}{l}1.17 \\
0.75 \\
0.99 \\
0.97 \\
6.17\end{array}$ \\
\hline 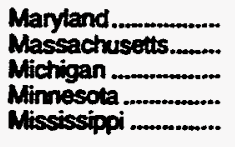 & $\begin{array}{l}1.44 \\
1.88 \\
0.98 \\
1.03 \\
0.88\end{array}$ & $\begin{array}{l}1.42 \\
1.86 \\
0.98 \\
1.03 \\
0.97\end{array}$ & $\begin{array}{l}1.42 \\
1.86 \\
0.98 \\
1.07 \\
0.88\end{array}$ & $\begin{array}{l}1.45 \\
1.92 \\
1.01 \\
1.10 \\
0.88\end{array}$ & $\begin{array}{l}-1.51 \\
2.12 \\
1.06 \\
1.18 \\
0.94\end{array}$ & $\begin{array}{r}-1.65 \\
2.29 \\
1.10 \\
1.23 \\
1.08\end{array}$ & $\begin{array}{l}9.68 \\
2.40 \\
1.18 \\
1.30 \\
1.09\end{array}$ \\
\hline $\begin{array}{l}\text { Missouri .................. } \\
\text { Montana................. } \\
\text { Nebraska ................. } \\
\text { Nevada ................. } \\
\text { New Hampshire ....... }\end{array}$ & $\begin{array}{r}0.84 \\
0.80 \\
0.79 \\
1.42 \\
b\end{array}$ & $\begin{array}{l}0.86 \\
0.82 \\
0.80 \\
1.51 \\
b\end{array}$ & $\begin{array}{r}0.89 \\
0.88 \\
0.83 \\
1.49 \\
b\end{array}$ & $\begin{array}{r}0.96 \\
0.91 \\
0.85 \\
1.51 \\
b\end{array}$ & $\begin{array}{r}1.02 \\
0.93 \\
0.92 \\
1.51 \\
b\end{array}$ & $\begin{array}{r}1.10 \\
0.97 \\
0.99 \\
1.52 \\
b\end{array}$ & $\begin{array}{r}1.16 \\
1.09 \\
1.04 \\
1.54 \\
b\end{array}$ \\
\hline $\begin{array}{l}\text { New Jersey .............. } \\
\text { New Mexico............ } \\
\text { New York............... } \\
\text { Noth Carctina......... } \\
\text { North Dakota.......... }\end{array}$ & $\begin{array}{l}1.91 \\
0.91 \\
1.42 \\
1.31 \\
0.94\end{array}$ & $\begin{array}{l}1.91 \\
0.89 \\
1.38 \\
1.29 \\
0.93\end{array}$ & $\begin{array}{l}1.85 \\
0.91 \\
1.37 \\
1.25 \\
0.95\end{array}$ & $\begin{array}{l}1.89 \\
0.93 \\
1.40 \\
1.30 \\
1.02\end{array}$ & $\begin{array}{l}1.95 \\
0.95 \\
1.50 \\
1.34 \\
1.10\end{array}$ & $\begin{array}{l}2.02 \\
0.97 \\
1.62 \\
1.41 \\
1.13\end{array}$ & $\begin{array}{l}2.08 \\
1.00 \\
1.74 \\
1.51 \\
1.14\end{array}$ \\
\hline $\begin{array}{l}\text { Ohio....................... } \\
\text { Otdahoma ............... } \\
\text { Oregon................... } \\
\text { Pennsyhania ........... } \\
\text { Rhode tstand........... }\end{array}$ & $\begin{array}{l}0.86 \\
0.78 \\
1.57 \\
1.15 \\
1.81\end{array}$ & $\begin{array}{l}0.85 \\
0.77 \\
1.54 \\
1.15 \\
1.78\end{array}$ & $\begin{array}{l}0.87 \\
0.82 \\
1.49 \\
1.18 \\
1.78\end{array}$ & $\begin{array}{l}0.90 \\
0.84 \\
1.51 \\
1.24 \\
1.83\end{array}$ & $\begin{array}{l}0.98 \\
0.87 \\
1.60 \\
1.28 \\
1.93\end{array}$ & $\begin{array}{l}1.05 \\
0.90 \\
1.68 \\
1.36 \\
2.05\end{array}$ & $\begin{array}{l}1.11 \\
0.92 \\
1.76 \\
1.48 \\
2.37\end{array}$ \\
\hline $\begin{array}{l}\text { South Carolina......... } \\
\text { South Dakota......... } \\
\text { Tennessee .............. } \\
\text { Texas...................... } \\
\text { Utah ........................ }\end{array}$ & $\begin{array}{l}1.40 \\
0.99 \\
0.90 \\
0.87 \\
0.68\end{array}$ & $\begin{array}{l}1.32 \\
0.99 \\
0.88 \\
0.87 \\
0.74\end{array}$ & $\begin{array}{l}1.33 \\
1.01 \\
0.89 \\
0.90 \\
0.83\end{array}$ & $\begin{array}{l}1.35 \\
1.04 \\
0.91 \\
0.92 \\
0.85\end{array}$ & $\begin{array}{l}1.47 \\
1.10 \\
0.98 \\
0.99 \\
0.87\end{array}$ & $\begin{array}{l}1.62 \\
1.13 \\
1.02 \\
1.01 \\
0.90\end{array}$ & $\begin{array}{l}1.65 \\
1.19 \\
1.08 \\
1.04 \\
0.99\end{array}$ \\
\hline $\begin{array}{l}\text { Vermont ................... } \\
\text { Virginia .................. } \\
\text { Washington............ } \\
\text { West Virginia........... } \\
\text { Wisconsin ................ } \\
\text { Wyoming................. }\end{array}$ & $\begin{array}{l}b \\
1.46 \\
1.48 \\
0.84 \\
1.02 \\
0.66\end{array}$ & $\begin{array}{l}b \\
1.44 \\
1.43 \\
0.87 \\
1.10 \\
0.67\end{array}$ & $\begin{array}{l}b \\
1.43 \\
1.36 \\
0.88 \\
1.16 \\
0.68\end{array}$ & $\begin{array}{l}b \\
1.49 \\
1.40 \\
0.89 \\
1.25 \\
0.68\end{array}$ & $\begin{array}{l}b \\
1.52 \\
1.43 \\
0.94 \\
1.26 \\
0.71\end{array}$ & $\begin{array}{l}b \\
1.60 \\
1.47 \\
0.96 \\
1.34 \\
0.74\end{array}$ & $\begin{array}{l}b \\
1.68 \\
1.55 \\
0.97 \\
1.43 \\
0.77\end{array}$ \\
\hline Average & 1.04 & 1.04 & 1.05 & 1.09 & 1.15 & 1.21 & 1.29 \\
\hline
\end{tabular}

See foctnotes at end of table. 
Table 23. Average Price of Natural Gas Delivered to U.S. Residential Consumers by State, 1967-1994 (Continued) (Dollars per Thousand Cubic Feet)

\begin{tabular}{|c|c|c|c|c|c|c|c|}
\hline State & 1974 & 1975 & 1976 & 197 & 1978 & 1979 & 1980 \\
\hline 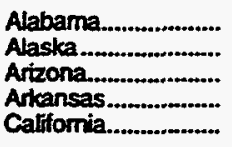 & $\begin{array}{l}1.55 \\
1.58 \\
1.50 \\
1.06 \\
1.38\end{array}$ & $\begin{array}{l}1.57 \\
1.63 \\
1.53 \\
1.12 \\
1.57\end{array}$ & $\begin{array}{l}1.99 \\
1.65 \\
2.12 \\
1.23 \\
1.77\end{array}$ & $\begin{array}{l}2.31 \\
1.71 \\
2.61 \\
1.98 \\
1.89\end{array}$ & $\begin{array}{l}2.71 \\
1.76 \\
3.07 \\
1.96 \\
1.99\end{array}$ & $\begin{array}{l}3.65 \\
1.71 \\
3.50 \\
1.57 \\
2.47\end{array}$ & $\begin{array}{l}4.04 \\
1.73 \\
4.05 \\
2.47 \\
3.51\end{array}$ \\
\hline 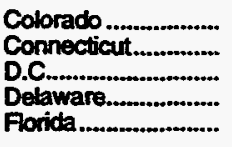 & $\begin{array}{r}1.00 \\
2.79 \\
a \\
2.11 \\
2.85\end{array}$ & $\begin{array}{r}1.16 \\
3.29 \\
a \\
2.43 \\
2.74\end{array}$ & $\begin{array}{r}1.27 \\
3.41 \\
a \\
2.61 \\
2.81\end{array}$ & $\begin{array}{r}1.62 \\
4.34 \\
a \\
3.25 \\
3.53\end{array}$ & $\begin{array}{r}1.94 \\
4.47 \\
a \\
4.06 \\
3.54\end{array}$ & $\begin{array}{r}2.48 \\
4.74 \\
a \\
4.03 \\
3.70\end{array}$ & $\begin{array}{l}3.23 \\
5.84 \\
4.57 \\
4.30 \\
4.80\end{array}$ \\
\hline 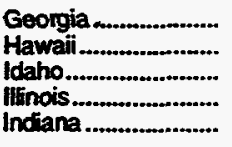 & $\begin{array}{l}1.40 \\
N A \\
1.80 \\
1.35 \\
1.28\end{array}$ & $\begin{array}{r}1.50 \\
\mathrm{NA} \\
2.18 \\
1.61 \\
1.45\end{array}$ & $\begin{array}{l}1.69 \\
N A \\
2.24 \\
1.90 \\
1.69\end{array}$ & $\begin{array}{l}1.97 \\
N A \\
2.86 \\
2.21 \\
2.02\end{array}$ & $\begin{array}{r}2.33 \\
N A \\
3.41 \\
2.50 \\
2.17\end{array}$ & $\begin{array}{r}2.88 \\
N A \\
3.73 \\
3.01 \\
2.55\end{array}$ & $\begin{array}{r}3.67 \\
12.99 \\
4.97 \\
3.61 \\
3.15\end{array}$ \\
\hline 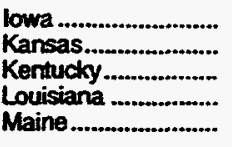 & $\begin{array}{l}1.22 \\
0.90 \\
1.10 \\
1.12 \\
2.38\end{array}$ & $\begin{array}{r}1.43 \\
1.03 \\
1.23 \\
1.37 \\
b 2.65\end{array}$ & $\begin{array}{r}1.61 \\
1.48 \\
1.32 \\
1.57 \\
62.68\end{array}$ & $\begin{array}{l}1.93 \\
1.73 \\
1.79 \\
1.97 \\
b .62\end{array}$ & $\begin{array}{l}2.25 \\
1.77 \\
1.94 \\
2.47 \\
3.57\end{array}$ & $\begin{array}{r}2.68 \\
1.95 \\
2.35 \\
2.71 \\
b 4.10\end{array}$ & $\begin{array}{l}3.19 \\
2.36 \\
3.03 \\
3.40 \\
6.34\end{array}$ \\
\hline $\begin{array}{l}\text { Maryland.................. } \\
\text { Massachusetts......... } \\
\text { Michigan ................... } \\
\text { Minnesota ................ } \\
\text { Mississippi .............. }\end{array}$ & $\begin{array}{l}0.50 \\
2.71 \\
1.37 \\
1.41 \\
1.23\end{array}$ & $\begin{array}{l}2.33 \\
3.15 \\
1.62 \\
1.57 \\
1.41\end{array}$ & $\begin{array}{l}2.57 \\
3.64 \\
1.90 \\
1.74 \\
1.71\end{array}$ & $\begin{array}{l}3.18 \\
3.95 \\
2.22 \\
2.13 \\
2.11\end{array}$ & $\begin{array}{l}3.40 \\
4.17 \\
2.31 \\
2.41 \\
2.40\end{array}$ & $\begin{array}{l}3.76 \\
4.55 \\
2.64 \\
2.86 \\
2.83\end{array}$ & $\begin{array}{l}4.46 \\
5.42 \\
3.19 \\
3.22 \\
3.47\end{array}$ \\
\hline $\begin{array}{l}\text { Missouri ................... } \\
\text { Montana.................. } \\
\text { Nebraska ................ } \\
\text { Nevada .................. } \\
\text { New Hampshire ....... }\end{array}$ & $\begin{array}{r}1.27 \\
1.12 \\
1.14 \\
1.72 \\
b\end{array}$ & $\begin{array}{r}1.49 \\
1.30 \\
1.28 \\
1.95 \\
b\end{array}$ & $\begin{array}{r}1.70 \\
1.36 \\
1.37 \\
2.04 \\
b\end{array}$ & $\begin{array}{r}2.18 \\
1.82 \\
1.80 \\
2.78 \\
b\end{array}$ & $\begin{array}{r}2.29 \\
1.89 \\
1.97 \\
2.80 \\
b\end{array}$ & $\begin{array}{r}2.75 \\
2.21 \\
2.30 \\
2.83 \\
b\end{array}$ & $\begin{array}{l}3.28 \\
3.05 \\
2.72 \\
4.06 \\
4.66\end{array}$ \\
\hline $\begin{array}{l}\text { New Jersey............... } \\
\text { New Mexico ............. } \\
\text { New York............... } \\
\text { North Carolina........ } \\
\text { North Dakota........... }\end{array}$ & $\begin{array}{l}2.25 \\
1.24 \\
2.00 \\
1.69 \\
1.19\end{array}$ & $\begin{array}{l}2.69 \\
1.33 \\
2.54 \\
2.02 \\
1.51\end{array}$ & $\begin{array}{l}3.14 \\
1.36 \\
2.87 \\
2.13 \\
1.79\end{array}$ & $\begin{array}{l}3.42 \\
2.11 \\
3.28 \\
2.81 \\
2.11\end{array}$ & $\begin{array}{l}3.53 \\
2.50 \\
3.68 \\
3.00 \\
2.33\end{array}$ & $\begin{array}{l}4.30 \\
2.73 \\
4.12 \\
3.52 \\
2.88\end{array}$ & $\begin{array}{l}5.06 \\
3.32 \\
4.95 \\
4.11 \\
3.85\end{array}$ \\
\hline 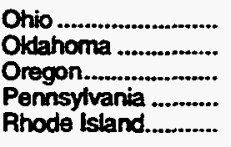 & $\begin{array}{l}1.24 \\
1.05 \\
2.00 \\
1.66 \\
2.55\end{array}$ & $\begin{array}{l}1.50 \\
1.22 \\
2.20 \\
1.93 \\
3.09\end{array}$ & $\begin{array}{l}1.77 \\
1.50 \\
2.68 \\
2.14 \\
3.36\end{array}$ & $\begin{array}{l}2.21 \\
1.78 \\
3.43 \\
2.51 \\
4.23\end{array}$ & $\begin{array}{l}2.43 \\
1.93 \\
3.83 \\
2.63 \\
4.18\end{array}$ & $\begin{array}{l}2.81 \\
2.20 \\
4.12 \\
3.19 \\
3.67\end{array}$ & $\begin{array}{l}3.54 \\
2.46 \\
5.60 \\
3.80 \\
5.69\end{array}$ \\
\hline $\begin{array}{l}\text { South Carolina......... } \\
\text { South Dakota.......... } \\
\text { Tennessee............... } \\
\text { Texas ........................ } \\
\text { Utah ......................... }\end{array}$ & $\begin{array}{l}1.97 \\
1.29 \\
1.17 \\
1.17 \\
1.07\end{array}$ & $\begin{array}{l}2.13 \\
1.40 \\
1.29 \\
1.52 \\
1.22\end{array}$ & $\begin{array}{l}2.29 \\
1.50 \\
1.61 \\
1.99 \\
1.38\end{array}$ & $\begin{array}{l}2.87 \\
1.83 \\
2.09 \\
2.39 \\
1.64\end{array}$ & $\begin{array}{l}3.00 \\
2.10 \\
2.14 \\
2.73 \\
1.93\end{array}$ & $\begin{array}{l}3.50 \\
2.61 \\
2.37 \\
3.21 \\
2.22\end{array}$ & $\begin{array}{l}4.19 \\
3.13 \\
2.89 \\
3.40 \\
2.74\end{array}$ \\
\hline 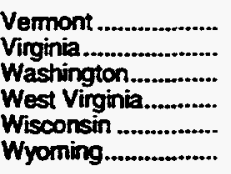 & $\begin{array}{l}\mathrm{b} \\
1.87 \\
1.77 \\
1.10 \\
1.50 \\
0.85\end{array}$ & $\begin{array}{r}b \\
2.24 \\
2.27 \\
1.45 \\
1.75 \\
1.02\end{array}$ & $\begin{array}{l}b \\
2.54 \\
2.70 \\
1.67 \\
2.11 \\
1.18\end{array}$ & $\begin{array}{r}b \\
3.03 \\
3.12 \\
2.55 \\
2.50 \\
1.59\end{array}$ & $\begin{array}{l}3.27 \\
3.48 \\
2.61 \\
2.68 \\
1.91\end{array}$ & $\begin{array}{l}b \\
3.72 \\
3.95 \\
2.93 \\
3.06 \\
2.51\end{array}$ & $\begin{array}{l}6.22 \\
4.26 \\
5.31 \\
3.59 \\
3.83 \\
2.81\end{array}$ \\
\hline Average .................... & 1.43 & 1.71 & 1.98 & 2.35 & 2.56 & 2.98 & 3.68 \\
\hline
\end{tabular}

See footnotes at end of table. 
Table 23. Average Price of Natural Gas Delivered to U.S. Residential Consumers by State, 1967-1994 (Continued) (Dollars per Thousand Cubic Feet)

\begin{tabular}{|c|c|c|c|c|c|c|c|}
\hline State & 1981 & 1982 & 1983 & 1984 & 1985 & 1986 & 1987 \\
\hline 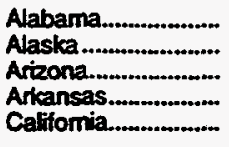 & $\begin{array}{l}4.77 \\
1.95 \\
4.63 \\
3.04 \\
3.74\end{array}$ & $\begin{array}{l}5.58 \\
1.79 \\
5.92 \\
3.82 \\
4.43\end{array}$ & $\begin{array}{l}6.22 \\
2.33 \\
6.63 \\
4.40 \\
5.41\end{array}$ & $\begin{array}{l}6.26 \\
2.49 \\
7.16 \\
4.37 \\
5.84\end{array}$ & $\begin{array}{l}6.41 \\
2.81 \\
7.00 \\
4.43 \\
5.72\end{array}$ & $\begin{array}{l}6.52 \\
3.25 \\
6.28 \\
4.88 \\
5.14\end{array}$ & $\begin{array}{l}6.64 \\
3.21 \\
6.11 \\
4.63 \\
5.26\end{array}$ \\
\hline 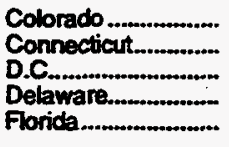 & $\begin{array}{l}4.17 \\
6.85 \\
5.50 \\
5.53 \\
5.31\end{array}$ & $\begin{array}{l}4.89 \\
8.51 \\
6.64 \\
6.04 \\
6.59\end{array}$ & $\begin{array}{l}5.51 \\
9.70 \\
8.10 \\
6.59 \\
6.85\end{array}$ & $\begin{array}{l}5.24 \\
8.80 \\
8.05 \\
6.67 \\
7.18\end{array}$ & $\begin{array}{l}5.10 \\
9.15 \\
7.91 \\
7.06 \\
7.46\end{array}$ & $\begin{array}{l}5.01 \\
8.83 \\
7.52 \\
7.09 \\
7.20\end{array}$ & $\begin{array}{l}4.74 \\
8.21 \\
7.09 \\
6.32 \\
7.48\end{array}$ \\
\hline 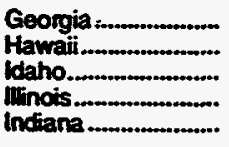 & $\begin{array}{r}4.34 \\
15.57 \\
5.57 \\
4.05 \\
3.60\end{array}$ & $\begin{array}{r}5.33 \\
15.70 \\
6.92 \\
4.73 \\
4.38\end{array}$ & $\begin{array}{r}6.10 \\
16.46 \\
7.38 \\
5.46 \\
5.49\end{array}$ & $\begin{array}{r}6.41 \\
17.36 \\
6.89 \\
5.37 \\
5.69\end{array}$ & $\begin{array}{r}6.60 \\
18.12 \\
6.89 \\
5.55 \\
5.54\end{array}$ & $\begin{array}{r}6.63 \\
16.09 \\
6.02 \\
5.07 \\
5.52\end{array}$ & $\begin{array}{r}6.34 \\
15.90 \\
5.50 \\
4.81 \\
4.95\end{array}$ \\
\hline 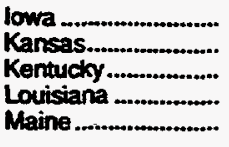 & $\begin{array}{l}3.89 \\
3.03 \\
3.49 \\
4.15 \\
7.45\end{array}$ & $\begin{array}{l}4.69 \\
4.06 \\
4.46 \\
5.32 \\
8.63\end{array}$ & $\begin{array}{l}5.52 \\
4.68 \\
5.30 \\
6.12 \\
9.82\end{array}$ & $\begin{array}{l}5.56 \\
4.49 \\
5.20 \\
5.96 \\
9.58\end{array}$ & $\begin{array}{l}5.39 \\
4.12 \\
5.31 \\
5.67 \\
9.07\end{array}$ & $\begin{array}{l}5.12 \\
3.89 \\
4.93 \\
5.77 \\
8.51\end{array}$ & $\begin{array}{l}4.75 \\
4.09 \\
4.53 \\
5.56 \\
8.04\end{array}$ \\
\hline $\begin{array}{l}\text { Maryland................ } \\
\text { Massachusetts........ } \\
\text { Michigan ................. } \\
\text { Minnesota .............. } \\
\text { Mississippi .............. }\end{array}$ & $\begin{array}{l}5.07 \\
6.37 \\
3.84 \\
4.09 \\
3.99\end{array}$ & $\begin{array}{l}6.12 \\
7.54 \\
4.79 \\
4.96 \\
4.93\end{array}$ & $\begin{array}{l}7.42 \\
8.32 \\
5.84 \\
5.90 \\
5.88\end{array}$ & $\begin{array}{l}7.44 \\
7.83 \\
5.97 \\
6.00 \\
5.52\end{array}$ & $\begin{array}{l}7.25 \\
7.83 \\
6.29 \\
5.80 \\
5.46\end{array}$ & $\begin{array}{l}6.88 \\
7.41 \\
\mathbf{5 . 7 4} \\
\mathbf{5 . 2 8} \\
\mathbf{5 . 5 9}\end{array}$ & $\begin{array}{l}6.37 \\
6.64 \\
5.46 \\
4.58 \\
6.10\end{array}$ \\
\hline 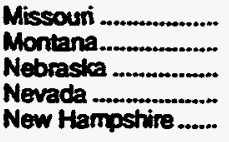 & $\begin{array}{l}4.02 \\
3.75 \\
3.45 \\
4.84 \\
5.68\end{array}$ & $\begin{array}{l}5.20 \\
4.45 \\
4.15 \\
5.56 \\
6.85\end{array}$ & $\begin{array}{l}6.12 \\
4.62 \\
4.95 \\
6.81 \\
7.47\end{array}$ & $\begin{array}{l}5.85 \\
4.86 \\
5.09 \\
6.95 \\
7.02\end{array}$ & $\begin{array}{l}5.49 \\
4.81 \\
5.01 \\
7.04 \\
7.15\end{array}$ & $\begin{array}{l}5.03 \\
4.45 \\
4.59 \\
5.96 \\
7.07\end{array}$ & $\begin{array}{l}4.76 \\
4.41 \\
4.36 \\
5.31 \\
6.50\end{array}$ \\
\hline $\begin{array}{l}\text { New Jersey............... } \\
\text { New Mexico .............. } \\
\text { New York................ } \\
\text { North Caroling.......... } \\
\text { North Dalcota.......... }\end{array}$ & $\begin{array}{l}5.87 \\
3.86 \\
5.50 \\
5.17 \\
4.28\end{array}$ & $\begin{array}{l}7.03 \\
4.94 \\
6.51 \\
5.73 \\
4.61\end{array}$ & $\begin{array}{l}7.43 \\
5.50 \\
7.87 \\
6.65 \\
5.56\end{array}$ & $\begin{array}{l}7.30 \\
5.90 \\
7.64 \\
6.68 \\
6.38\end{array}$ & $\begin{array}{l}7.49 \\
6.08 \\
7.74 \\
6.60 \\
5.59\end{array}$ & $\begin{array}{l}7.35 \\
5.72 \\
7.46 \\
6.62 \\
5.29\end{array}$ & $\begin{array}{l}6.60 \\
4.98 \\
6.88 \\
6.66 \\
5.47\end{array}$ \\
\hline $\begin{array}{l}\text { Ohio ........................ } \\
\text { Oldahoma ............... } \\
\text { Oregon................... } \\
\text { Pennsylvania ........... } \\
\text { Rhode Island.......... }\end{array}$ & $\begin{array}{l}3.97 \\
2.94 \\
6.06 \\
4.51 \\
6.61\end{array}$ & $\begin{array}{l}4.96 \\
3.53 \\
6.92 \\
5.42 \\
7.95\end{array}$ & $\begin{array}{l}6.08 \\
4.33 \\
7.23 \\
6.44 \\
8.66\end{array}$ & $\begin{array}{l}6.07 \\
4.56 \\
7.18 \\
6.56 \\
7.50\end{array}$ & $\begin{array}{l}6.04 \\
4.58 \\
6.93 \\
6.72 \\
7.87\end{array}$ & $\begin{array}{l}5.80 \\
5.01 \\
6.61 \\
6.39 \\
7.46\end{array}$ & $\begin{array}{l}5.35 \\
4.63 \\
6.62 \\
6.03 \\
6.81\end{array}$ \\
\hline $\begin{array}{l}\text { South Carolina......... } \\
\text { South Dakota........... } \\
\text { Teninessee ............... } \\
\text { Texas ........................ } \\
\text { Utah .......................... }\end{array}$ & $\begin{array}{l}4.90 \\
3.91 \\
3.44 \\
4.20 \\
3.23\end{array}$ & $\begin{array}{l}5.51 \\
4.71 \\
4.32 \\
5.21 \\
3.41\end{array}$ & $\begin{array}{l}6.38 \\
5.59 \\
5.26 \\
5.55 \\
4.26\end{array}$ & $\begin{array}{l}6.62 \\
6.16 \\
5.04 \\
5.82 \\
\mathbf{5 . 6 8}\end{array}$ & $\begin{array}{l}6.62 \\
5.75 \\
5.12 \\
5.77 \\
4.86\end{array}$ & $\begin{array}{l}6.54 \\
5.26 \\
4.97 \\
5.31 \\
4.64\end{array}$ & $\begin{array}{r}6.59 \\
4.87 \\
4.68 \\
5.21 \\
4.97\end{array}$ \\
\hline $\begin{array}{l}\text { Vermont ................... } \\
\text { Virginia................ } \\
\text { Washington............ } \\
\text { West Virginia........... } \\
\text { Wisconsin............... } \\
\text { Wyoming................. }\end{array}$ & $\begin{array}{l}7.00 \\
4.66 \\
6.02 \\
4.24 \\
4.77 \\
3.51\end{array}$ & $\begin{array}{l}7.24 \\
6.02 \\
6.87 \\
5.20 \\
5.64 \\
4.53\end{array}$ & $\begin{array}{l}6.79 \\
7.03 \\
6.87 \\
6.00 \\
6.48 \\
5.13\end{array}$ & $\begin{array}{l}6.30 \\
6.99 \\
6.84 \\
6.12 \\
6.51 \\
5.84\end{array}$ & $\begin{array}{l}6.28 \\
7.02 \\
6.60 \\
6.39 \\
6.47 \\
5.17\end{array}$ & $\begin{array}{l}6.28 \\
6.49 \\
5.93 \\
6.34 \\
6.20 \\
4.93\end{array}$ & $\begin{array}{l}6.23 \\
5.86 \\
5.42 \\
5.98 \\
5.99 \\
4.70\end{array}$ \\
\hline Average ....................... & 4.29 & 5.17 & 6.06 & 6.12 & 6.12 & 5.83 & 5.54 \\
\hline
\end{tabular}

See footnotes at end of table. 
Table 23. Average Price of Natural Gas Delivered to U.S. Residentiál Consumers by State, 1967-1994 (Continued) (Dollars per Thousand Cubic Feet)

\begin{tabular}{|c|c|c|c|c|c|c|c|}
\hline Stmets & 1988 & 1989 & 1990 & 1991 & 1992 & 1993 & 1994 \\
\hline 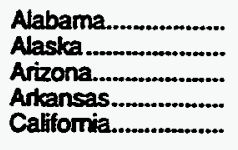 & $\begin{array}{l}6.51 \\
3.46 \\
6.99 \\
4.81 \\
5.64\end{array}$ & $\begin{array}{l}6.27 \\
3.63 \\
6.94 \\
4.85 \\
5.59\end{array}$ & $\begin{array}{l}6.57 \\
3.79 \\
6.85 \\
5.10 \\
5.78\end{array}$ & $\begin{array}{l}7.05 \\
4.18 \\
6.99 \\
4.98 \\
6.27\end{array}$ & $\begin{array}{l}6.74 \\
3.79 \\
7.24 \\
5.10 \\
5.97\end{array}$ & $\begin{array}{l}7.10 \\
3.96 \\
7.20 \\
5.38 \\
6.23\end{array}$ & $\begin{array}{l}7.41 \\
3.60 \\
7.54 \\
5.71 \\
6.39\end{array}$ \\
\hline 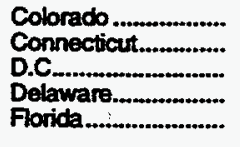 & $\begin{array}{l}4.42 \\
7.87 \\
6.96 \\
6.00 \\
7.49\end{array}$ & $\begin{array}{l}4.63 \\
8.25 \\
7.44 \\
6.42 \\
8.06\end{array}$ & $\begin{array}{l}4.57 \\
8.58 \\
7.18 \\
6.13 \\
8.47\end{array}$ & $\begin{array}{l}4.59 \\
8.74 \\
7.07 \\
5.86 \\
8.98\end{array}$ & $\begin{array}{l}4.56 \\
8.96 \\
7.61 \\
6.13 \\
9.08\end{array}$ & $\begin{array}{r}4.52 \\
9.43 \\
8.34 \\
6.70 \\
R_{10.02}\end{array}$ & $\begin{array}{r}4.92 \\
10.14 \\
8.29 \\
7.43 \\
9.98\end{array}$ \\
\hline 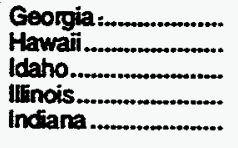 & $\begin{array}{r}6.22 \\
15.69 \\
5.49 \\
4.60 \\
5.16\end{array}$ & $\begin{array}{r}6.25 \\
15.66 \\
5.05 \\
4.92 \\
5.50\end{array}$ & $\begin{array}{r}6.82 \\
16.45 \\
5.05 \\
5.06 \\
5.38\end{array}$ & $\begin{array}{r}6.70 \\
22.93 \\
5.19 \\
4.95 \\
5.46\end{array}$ & $\begin{array}{r}6.44 \\
18.03 \\
5.23 \\
5.09 \\
5.43\end{array}$ & $\begin{array}{r}6.80 \\
17.51 \\
5.38 \\
5.52 \\
5.76\end{array}$ & $\begin{array}{r}7.32 \\
16.83 \\
5.29 \\
5.50 \\
6.24\end{array}$ \\
\hline 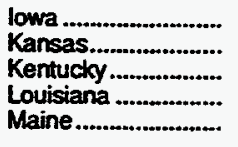 & $\begin{array}{l}4.79 \\
4.02 \\
4.48 \\
5.74 \\
7.26\end{array}$ & $\begin{array}{l}4.70 \\
4.17 \\
4.68 \\
5.97 \\
7.16\end{array}$ & $\begin{array}{l}4.99 \\
4.48 \\
4.93 \\
6.09 \\
7.61\end{array}$ & $\begin{array}{l}4.81 \\
4.38 \\
4.87 \\
5.77 \\
6.86\end{array}$ & $\begin{array}{l}5.23 \\
4.70 \\
5.01 \\
5.60 \\
6.95\end{array}$ & $\begin{array}{l}5.48 \\
4.91 \\
5.25 \\
6.09 \\
7.47\end{array}$ & $\begin{array}{l}5.40 \\
5.11 \\
5.46 \\
6.24 \\
7.83\end{array}$ \\
\hline $\begin{array}{l}\text { Marytand................... } \\
\text { Massachusetts......... } \\
\text { Michigan ................... } \\
\text { Minnesota ............... } \\
\text { Mississippi ............... }\end{array}$ & $\begin{array}{l}5.90 \\
6.47 \\
5.34 \\
4.64 \\
5.85\end{array}$ & $\begin{array}{l}6.30 \\
7.16 \\
5.19 \\
4.57 \\
5.10\end{array}$ & $\begin{array}{l}6.45 \\
7.82 \\
5.02 \\
4.63 \\
5.33\end{array}$ & $\begin{array}{l}6.16 \\
8.11 \\
5.07 \\
4.52 \\
5.21\end{array}$ & $\begin{array}{l}6.43 \\
7.92 \\
5.06 \\
4.86 \\
4.95\end{array}$ & $\begin{array}{l}7.08 \\
8.33 \\
5.04 \\
5.31 \\
5.23\end{array}$ & $\begin{array}{l}6.95 \\
8.94 \\
4.98 \\
5.18 \\
5.46\end{array}$ \\
\hline $\begin{array}{l}\text { Missouri .................. } \\
\text { Montana.................. } \\
\text { Nebraska .................. } \\
\text { Nevada ................ } \\
\text { New Hampshire..... }\end{array}$ & $\begin{array}{l}4.76 \\
4.30 \\
4.46 \\
5.87 \\
6.28\end{array}$ & $\begin{array}{l}4.84 \\
4.37 \\
4.48 \\
5.55 \\
6.85\end{array}$ & $\begin{array}{l}5.21 \\
4.59 \\
4.60 \\
5.66 \\
7.41\end{array}$ & $\begin{array}{l}5.14 \\
4.52 \\
4.64 \\
5.61 \\
7.14\end{array}$ & $\begin{array}{l}5.11 \\
4.80 \\
4.82 \\
5.59 \\
7.55\end{array}$ & $\begin{array}{l}5.37 \\
4.92 \\
4.96 \\
5.69 \\
7.66\end{array}$ & $\begin{array}{l}\mathbf{5 . 4 3} \\
\mathbf{5 . 2 3} \\
\mathbf{5 . 0 1} \\
\mathbf{6 . 6 6} \\
\mathbf{7 . 9 6}\end{array}$ \\
\hline $\begin{array}{l}\text { New Jersey............... } \\
\text { New Mexico ............... } \\
\text { New York................. } \\
\text { North Carolina......... } \\
\text { North Dakota............ }\end{array}$ & $\begin{array}{l}6.32 \\
5.23 \\
6.50 \\
6.25 \\
5.15\end{array}$ & $\begin{array}{l}6.51 \\
5.73 \\
7.22 \\
6.55 \\
4.68\end{array}$ & $\begin{array}{l}6.60 \\
5.67 \\
7.40 \\
6.17 \\
4.70\end{array}$ & $\begin{array}{l}6.73 \\
5.40 \\
7.35 \\
6.24 \\
4.82\end{array}$ & $\begin{array}{l}6.94 \\
4.75 \\
7.58 \\
6.60 \\
5.00\end{array}$ & $\begin{array}{l}6.99 \\
5.46 \\
8.15 \\
6.99 \\
5.23\end{array}$ & $\begin{array}{l}7.11 \\
5.61 \\
8.75 \\
7.30 \\
5.19\end{array}$ \\
\hline 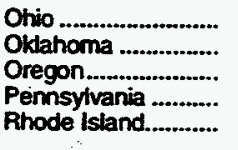 & $\begin{array}{l}5.21 \\
4.52 \\
6.79 \\
5.79 \\
6.60\end{array}$ & $\begin{array}{l}5.32 \\
4.50 \\
6.19 \\
6.14 \\
7.13\end{array}$ & $\begin{array}{l}5.29 \\
4.80 \\
6.27 \\
6.61 \\
7.22\end{array}$ & $\begin{array}{l}5.28 \\
4.72 \\
6.13 \\
6.76 \\
7.63\end{array}$ & $\begin{array}{l}5.20 \\
4.96 \\
6.17 \\
6.60 \\
7.68\end{array}$ & $\begin{array}{l}5.71 \\
4.94 \\
6.42 \\
6.84 \\
8.17\end{array}$ & $\begin{array}{l}5.88 \\
5.50 \\
6.99 \\
7.44 \\
9.12\end{array}$ \\
\hline 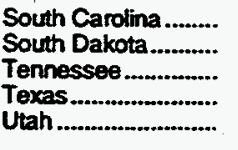 & $\begin{array}{l}6.73 \\
4.91 \\
4.65 \\
5.37 \\
5.11\end{array}$ & $\begin{array}{l}6.73 \\
4.85 \\
4.83 \\
5.55 \\
5.14\end{array}$ & $\begin{array}{l}7.17 \\
5.14 \\
5.11 \\
5.78 \\
5.28\end{array}$ & $\begin{array}{l}6.98 \\
4.94 \\
5.19 \\
5.71 \\
5.44\end{array}$ & $\begin{array}{l}7.03 \\
5.15 \\
5.50 \\
5.78 \\
5.44\end{array}$ & $\begin{array}{l}7.14 \\
5.30 \\
5.69 \\
5.91 \\
5.13\end{array}$ & $\begin{array}{l}7.65 \\
5.27 \\
6.13 \\
5.99 \\
4.96\end{array}$ \\
\hline $\begin{array}{l}\text { Vermont ................... } \\
\text { Virginia ................. } \\
\text { Washington............ } \\
\text { West Virginia............ } \\
\text { Wisconsin ................ } \\
\text { Wyoming .................. }\end{array}$ & $\begin{array}{l}5.65 \\
5.81 \\
5.50 \\
5.50 \\
5.89 \\
4.48\end{array}$ & $\begin{array}{l}5.62 \\
6.59 \\
5.49 \\
5.75 \\
5.64 \\
4.71\end{array}$ & $\begin{array}{l}5.79 \\
6.75 \\
5.02 \\
6.46 \\
5.74 \\
4.84\end{array}$ & $\begin{array}{l}6.23 \\
6.80 \\
4.68 \\
6.50 \\
5.61 \\
4.74\end{array}$ & $\begin{array}{l}6.70 \\
6.69 \\
5.00 \\
6.31 \\
\mathbf{5 . 8 7} \\
\mathbf{4 . 7 2}\end{array}$ & $\begin{array}{l}6.19 \\
7.51 \\
5.23 \\
6.45 \\
6.34 \\
4.77\end{array}$ & $\begin{array}{l}6.94 \\
7.63 \\
5.70 \\
6.66 \\
6.28 \\
5.10\end{array}$ \\
\hline Average ................... & 5.47 & 5.64 & 5.80 & 5.82 & 5.89 & 6.16 & 6.41 \\
\hline
\end{tabular}

a Data for the District of Columbia are included with data for Manland

- Data for New Hampshire and Vermont are included with data for Maine.

$R=$ Revised data.

NA = Not Available.

Sources: 1967-1975: Bureau of Mines, Minerals Yearbook, "Natural Gas" chapter. 1976-1978: Energy Information Administration (ElA), Energy Data Report, Natural Gas Annual. 1979: ElA. Natural Gas Production and Consumption 1979. 1980-1994: EIA, Form EIA-176, "Annual Report of Natural and Supplemental Gas Supply and Disposition." 
Table 24. Average Price of Natural Gas Delivered to U.S. Commercial Consumers by State, 1967-1992 (Dollars per Thousand Cubic Feet)

\begin{tabular}{|c|c|c|c|c|c|c|}
\hline State & 1967 & 1968 & 1969 & 1970 & 1971 & 1972 \\
\hline 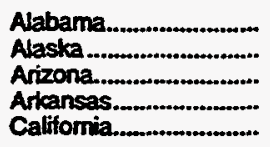 & $\begin{array}{l}0.56 \\
0.99 \\
0.51 \\
0.50 \\
0.68\end{array}$ & $\begin{array}{l}0.56 \\
0.76 \\
0.49 \\
0.49 \\
0.69\end{array}$ & $\begin{array}{l}0.55 \\
0.65 \\
0.58 \\
0.49 \\
0.69\end{array}$ & $\begin{array}{l}0.60 \\
0.68 \\
0.63 \\
0.53 \\
0.73\end{array}$ & $\begin{array}{l}0.66 \\
0.73 \\
0.69 \\
0.55 \\
0.76\end{array}$ & $\begin{array}{l}0.73 \\
0.82 \\
0.72 \\
0.57 \\
0.81\end{array}$ \\
\hline 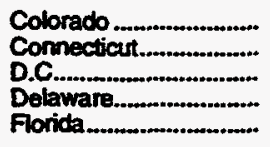 & $\begin{array}{r}0.56 \\
1.53 \\
a \\
1.22 \\
0.94\end{array}$ & $\begin{array}{r}0.55 \\
1.44 \\
a \\
1.27 \\
0.98\end{array}$ & $\begin{array}{r}0.55 \\
1.43 \\
a \\
1.22 \\
0.93\end{array}$ & $\begin{array}{r}0.57 \\
1.47 \\
8 \\
1.25 \\
0.93\end{array}$ & $\begin{array}{r}0.59 \\
1.55 \\
2 \mathrm{a} \\
1.27 \\
1.06\end{array}$ & $\begin{array}{r}0.64 \\
1.62 \\
8 \\
1.36 \\
1.20\end{array}$ \\
\hline 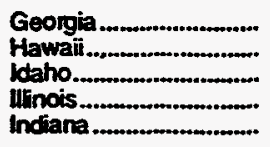 & $\begin{array}{l}0.69 \\
N A \\
0.95 \\
0.75 \\
0.84\end{array}$ & $\begin{array}{l}0.70 \\
N A \\
0.90 \\
0.73 \\
0.80\end{array}$ & $\begin{array}{l}0.70 \\
N A \\
0.91 \\
0.71 \\
0.79\end{array}$ & $\begin{array}{l}0.74 \\
N A \\
1.01 \\
0.75 \\
0.83\end{array}$ & $\begin{array}{l}0.85 \\
\text { NA } \\
1.01 \\
0.78 \\
0.88\end{array}$ & $\begin{array}{l}0.89 \\
\text { NA } \\
1.03 \\
0.84 \\
0.93\end{array}$ \\
\hline 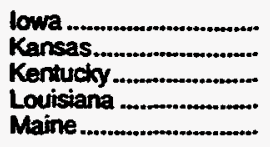 & $\begin{array}{l}0.66 \\
0.41 \\
0.68 \\
0.41 \\
01.36\end{array}$ & $\begin{array}{r}0.66 \\
0.43 \\
0.64 \\
0.37 \\
1.46\end{array}$ & $\begin{array}{l}0.67 \\
0.42 \\
0.65 \\
0.38 \\
01.40\end{array}$ & $\begin{array}{l}0.69 \\
0.45 \\
0.67 \\
0.38 \\
1.44\end{array}$ & $\begin{array}{r}0.73 \\
0.47 \\
0.71 \\
0.41 \\
-1.50\end{array}$ & $\begin{array}{r}0.83 \\
0.51 \\
0.75 \\
0.46 \\
01.63\end{array}$ \\
\hline 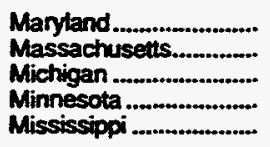 & $\begin{array}{l}-1.16 \\
1.38 \\
0.82 \\
0.61 \\
0.51\end{array}$ & $\begin{array}{l}1.13 \\
1.41 \\
0.81 \\
0.63 \\
0.51\end{array}$ & $\begin{array}{l}-1.11 \\
1.41 \\
0.81 \\
0.67 \\
0.55\end{array}$ & $\begin{array}{l}1.11 \\
1.42 \\
0.84 \\
0.70 \\
0.58\end{array}$ & $\begin{array}{l}1.15 \\
1.60 \\
0.87 \\
0.76 \\
0.63\end{array}$ & $\begin{array}{l}-1.22 \\
1.71 \\
0.90 \\
0.88 \\
0.68\end{array}$ \\
\hline 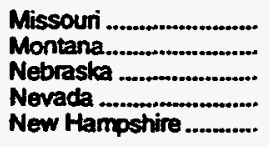 & $\begin{array}{l}0.56 \\
0.55 \\
0.48 \\
0.78 \\
b\end{array}$ & $\begin{array}{l}0.61 \\
0.57 \\
0.49 \\
0.78 \\
b\end{array}$ & $\begin{array}{l}0.59 \\
0.61 \\
0.51 \\
0.75 \\
b\end{array}$ & $\begin{array}{l}0.63 \\
0.62 \\
0.53 \\
0.76 \\
b\end{array}$ & $\begin{array}{l}0.65 \\
0.65 \\
0.59 \\
0.77 \\
b\end{array}$ & $\begin{array}{l}0.75 \\
0.66 \\
0.58 \\
0.80 \\
\text { b }\end{array}$ \\
\hline 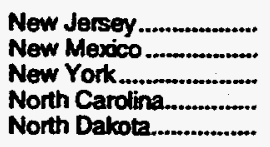 & $\begin{array}{l}1.41 \\
0.49 \\
1.22 \\
0.91 \\
0.62\end{array}$ & $\begin{array}{l}1.37 \\
0.47 \\
1.19 \\
0.90 \\
0.64\end{array}$ & $\begin{array}{l}1.38 \\
0.47 \\
1.19 \\
0.94 \\
0.64\end{array}$ & $\begin{array}{l}1.42 \\
0.48 \\
1.19 \\
0.96 \\
0.69\end{array}$ & $\begin{array}{l}1.46 \\
0.50 \\
1.27 \\
0.98 \\
0.76\end{array}$ & $\begin{array}{l}1.49 \\
0.53 \\
1.30 \\
1.07 \\
0.81\end{array}$ \\
\hline 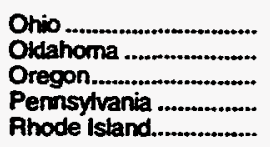 & $\begin{array}{l}0.74 \\
0.48 \\
1.39 \\
0.90 \\
1.47\end{array}$ & $\begin{array}{l}0.73 \\
0.47 \\
1.35 \\
0.90 \\
1.45\end{array}$ & $\begin{array}{l}0.75 \\
0.50 \\
1.27 \\
0.92 \\
1.46\end{array}$ & $\begin{array}{l}0.76 \\
0.52 \\
1.28 \\
0.96 \\
1.47\end{array}$ & $\begin{array}{l}0.82 \\
0.53 \\
1.31 \\
1.01 \\
1.62\end{array}$ & $\begin{array}{l}0.88 \\
0.56 \\
1.43 \\
1.09 \\
1.82\end{array}$ \\
\hline 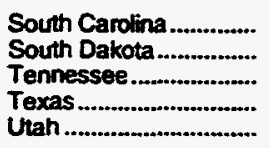 & $\begin{array}{l}0.94 \\
0.61 \\
0.69 \\
0.44 \\
0.56\end{array}$ & $\begin{array}{l}0.95 \\
0.58 \\
0.69 \\
0.44 \\
0.57\end{array}$ & $\begin{array}{l}0.87 \\
0.61 \\
0.69 \\
0.46 \\
0.58\end{array}$ & $\begin{array}{l}0.89 \\
0.64 \\
0.71 \\
0.45 \\
0.59\end{array}$ & $\begin{array}{l}0.98 \\
0.67 \\
0.77 \\
0.50 \\
0.64\end{array}$ & $\begin{array}{l}1.01 \\
0.69 \\
0.86 \\
0.52 \\
0.71\end{array}$ \\
\hline 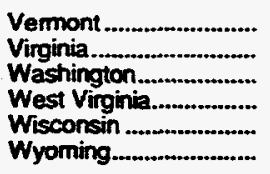 & $\begin{array}{l}b \\
0.93 \\
1.15 \\
0.69 \\
0.80 \\
0.43\end{array}$ & $\begin{array}{l}b \\
0.99 \\
1.09 \\
0.70 \\
0.85 \\
0.43\end{array}$ & $\begin{array}{l}b \\
0.97 \\
1.10 \\
0.70 \\
0.80 \\
0.43\end{array}$ & $\begin{array}{l}b \\
0.96 \\
1.11 \\
0.71 \\
0.83 \\
0.44\end{array}$ & $\begin{array}{l}b \\
1.00 \\
1.13 \\
0.73 \\
0.95 \\
0.48\end{array}$ & $\begin{array}{r}b \\
1.10 \\
1.16 \\
0.75 \\
1.00 \\
0.50\end{array}$ \\
\hline 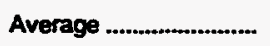 & 0.74 & 0.73 & 0.74 & 0.77 & 0.82 & 0.88 \\
\hline
\end{tabular}

See footnotes at end of table. 
Table 24. Average Price of Natural Gas Delivered to U.S. Commercial Consumers by State, 1967-1992 (Continued) (Dollars per Thousand Cubic Feet)

\begin{tabular}{|c|c|c|c|c|c|c|c|}
\hline State & 1973 & 1974 & 1975 & 1976 & 197 & 1978 & 1979 \\
\hline 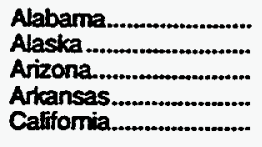 & $\begin{array}{l}0.74 \\
0.78 \\
0.77 \\
0.62 \\
0.85\end{array}$ & $\begin{array}{l}0.88 \\
0.87 \\
0.83 \\
0.76 \\
0.99\end{array}$ & $\begin{array}{l}1.07 \\
0.97 \\
1.16 \\
0.89 \\
1.29\end{array}$ & $\begin{array}{l}1.60 \\
1.04 \\
1.43 \\
1.02 \\
1.59\end{array}$ & $\begin{array}{l}1.83 \\
1.34 \\
1.76 \\
1.61 \\
2.07\end{array}$ & $\begin{array}{l}2.09 \\
1.32 \\
2.20 \\
1.62 \\
2.24\end{array}$ & $\begin{array}{l}2.78 \\
1.03 \\
2.64 \\
1.36 \\
2.73\end{array}$ \\
\hline 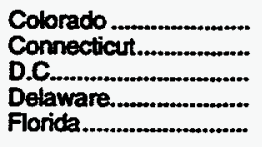 & $\begin{array}{r}0.68 \\
1.82 \\
2 \\
1.39 \\
1.29\end{array}$ & $\begin{array}{r}0.83 \\
2.23 \\
a \\
1.63 \\
1.64\end{array}$ & $\begin{array}{r}0.99 \\
2.66 \\
a \\
1.90 \\
1.70\end{array}$ & $\begin{array}{r}1.09 \\
3.22 \\
a \\
1.98 \\
1.72\end{array}$ & $\begin{array}{r}1.40 \\
3.56 \\
a \\
2.95 \\
2.01\end{array}$ & $\begin{array}{r}1.73 \\
3.77 \\
a \\
3.85 \\
2.03\end{array}$ & $\begin{array}{r}2.29 \\
3.95 \\
9 \\
3.74 \\
2.74\end{array}$ \\
\hline 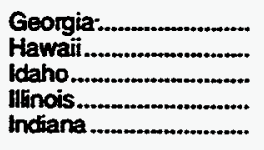 & $\begin{array}{r}0.94 \\
N A \\
1.07 \\
0.89 \\
0.98\end{array}$ & $\begin{array}{l}1.02 \\
\text { NA } \\
1.21 \\
1.02 \\
1.06\end{array}$ & $\begin{array}{l}1.10 \\
\text { NA } \\
1.55 \\
1.31 \\
1.24\end{array}$ & $\begin{array}{l}1.38 \\
\text { NA } \\
2.06 \\
1.64 \\
1.50\end{array}$ & $\begin{array}{r}1.75 \\
\text { NA } \\
2.42 \\
1.99 \\
1.84\end{array}$ & $\begin{array}{r}2.08 \\
N A \\
3.08 \\
2.27 \\
2.01\end{array}$ & $\begin{array}{r}2.52 \\
\mathrm{NA} \\
3.46 \\
2.81 \\
2.46\end{array}$ \\
\hline 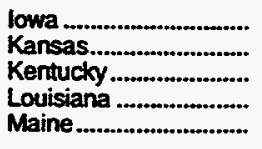 & $\begin{array}{r}0.90 \\
0.53 \\
0.81 \\
0.51 \\
1.70\end{array}$ & $\begin{array}{r}0.94 \\
0.60 \\
0.91 \\
0.60 \\
1.88\end{array}$ & $\begin{array}{r}1.06 \\
0.67 \\
1.06 \\
0.80 \\
2.12\end{array}$ & $\begin{array}{r}1.29 \\
1.10 \\
1.15 \\
1.10 \\
2.65\end{array}$ & $\begin{array}{r}1.65 \\
1.19 \\
1.66 \\
1.40 \\
3.23\end{array}$ & $\begin{array}{l}1.98 \\
1.17 \\
1.83 \\
1.44 \\
b 3.27\end{array}$ & $\begin{array}{l}2.39 \\
1.61 \\
2.20 \\
2.28 \\
b .61\end{array}$ \\
\hline $\begin{array}{l}\text { Maryland................... } \\
\text { Massachusetts............ } \\
\text { Michigan ..................... } \\
\text { Minnesota .................. } \\
\text { Mississippi .................. }\end{array}$ & $\begin{array}{l}1.26 \\
1.81 \\
0.96 \\
0.85 \\
1.99\end{array}$ & $\begin{array}{l}-1.43 \\
2.15 \\
1.13 \\
0.98 \\
0.75\end{array}$ & $\begin{array}{l}1.99 \\
2.65 \\
1.48 \\
1.16 \\
0.94\end{array}$ & $\begin{array}{l}2.16 \\
3.08 \\
1.82 \\
1.41 \\
1.29\end{array}$ & $\begin{array}{l}2.72 \\
3.43 \\
2.12 \\
1.72 \\
1.77\end{array}$ & $\begin{array}{l}2.96 \\
3.54 \\
2.23 \\
2.02 \\
2.03\end{array}$ & $\begin{array}{l}3.17 \\
3.84 \\
2.58 \\
2.59 \\
2.46\end{array}$ \\
\hline 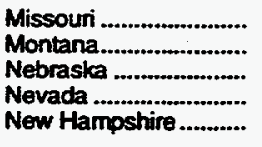 & $\begin{array}{r}0.78 \\
0.77 \\
0.76 \\
0.87 \\
b\end{array}$ & $\begin{array}{l}0.90 \\
0.90 \\
0.81 \\
1.06 \\
b\end{array}$ & $\begin{array}{r}1.15 \\
1.09 \\
0.99 \\
1.55 \\
b\end{array}$ & $\begin{array}{l}1.35 \\
1.19 \\
1.15 \\
1.77 \\
b\end{array}$ & $\begin{array}{r}1.86 \\
1.60 \\
1.39 \\
2.20 \\
b\end{array}$ & $\begin{array}{r}2.00 \\
1.66 \\
1.54 \\
2.40 \\
b\end{array}$ & $\begin{array}{r}2.53 \\
1.99 \\
2.00 \\
2.80 \\
b\end{array}$ \\
\hline $\begin{array}{l}\text { New Jersey................. } \\
\text { New Mexico ................. } \\
\text { New York.................. } \\
\text { North Carolina............. } \\
\text { North Dakota............... }\end{array}$ & $\begin{array}{l}1.55 \\
0.52 \\
1.37 \\
1.14 \\
0.87\end{array}$ & $\begin{array}{l}1.86 \\
0.72 \\
1.59 \\
1.28 \\
1.00\end{array}$ & $\begin{array}{l}2.33 \\
0.80 \\
2.00 \\
1.74 \\
1.11\end{array}$ & $\begin{array}{l}2.77 \\
1.07 \\
2.35 \\
2.04 \\
1.35\end{array}$ & $\begin{array}{l}3.10 \\
1.68 \\
2.85 \\
3.05 \\
1.67\end{array}$ & $\begin{array}{l}3.37 \\
2.00 \\
3.05 \\
2.79 \\
1.94\end{array}$ & $\begin{array}{l}3.99 \\
2.30 \\
3.50 \\
3.09 \\
2.47\end{array}$ \\
\hline 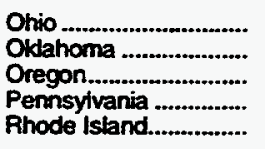 & $\begin{array}{l}0.92 \\
0.64 \\
1.45 \\
1.15 \\
1.89\end{array}$ & $\begin{array}{l}1.08 \\
0.75 \\
1.71 \\
1.28 \\
2.13\end{array}$ & $\begin{array}{l}1.34 \\
0.94 \\
1.86 \\
1.71 \\
2.75\end{array}$ & $\begin{array}{l}1.62 \\
1.17 \\
2.37 \\
1.72 \\
3.39\end{array}$ & $\begin{array}{l}2.07 \\
1.52 \\
3.08 \\
2.31 \\
3.46\end{array}$ & $\begin{array}{l}2.24 \\
1.68 \\
3.39 \\
2.39 \\
3.28\end{array}$ & $\begin{array}{l}2.60 \\
3.42 \\
3.72 \\
2.95 \\
3.09\end{array}$ \\
\hline 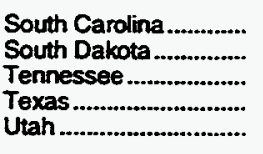 & $\begin{array}{l}1.02 \\
0.77 \\
0.91 \\
0.56 \\
0.80\end{array}$ & $\begin{array}{l}1.13 \\
1.13 \\
0.98 \\
0.71 \\
0.93\end{array}$ & $\begin{array}{l}1.25 \\
0.99 \\
1.13 \\
1.05 \\
1.52\end{array}$ & $\begin{array}{l}1.48 \\
1.13 \\
1.43 \\
1.42 \\
1.53\end{array}$ & $\begin{array}{l}2.12 \\
1.44 \\
2.07 \\
1.80 \\
1.73\end{array}$ & $\begin{array}{l}2.46 \\
1.72 \\
2.04 \\
2.20 \\
1.67\end{array}$ & $\begin{array}{l}2.78 \\
2.23 \\
2.47 \\
2.84 \\
2.33\end{array}$ \\
\hline 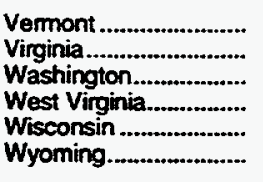 & $\begin{array}{l}b \\
1.13 \\
1.25 \\
0.76 \\
1.11 \\
0.53\end{array}$ & $\begin{array}{l}b \\
1.30 \\
1.33 \\
0.89 \\
1.12 \\
0.59\end{array}$ & $\begin{array}{l}b \\
1.72 \\
1.82 \\
1.22 \\
1.31 \\
0.67\end{array}$ & $\begin{array}{r}b \\
1.90 \\
2.23 \\
1.50 \\
1.71 \\
0.78\end{array}$ & $\begin{array}{r}b \\
2.43 \\
2.67 \\
2.25 \\
2.10 \\
1.20\end{array}$ & $\begin{array}{l}b \\
2.64 \\
2.85 \\
2.15 \\
2.35 \\
1.65\end{array}$ & $\begin{array}{r}b \\
3.13 \\
3.46 \\
2.69 \\
2.69 \\
2.37\end{array}$ \\
\hline 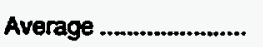 & 0.94 & 1.07 & 1.35 & 1.64 & 2.04 & 2.23 & 2.73 \\
\hline
\end{tabular}

See footnotes at end of table. 
Table 24. Average Price of Natural Gas Delivered to U.S. Commercial Consumers by State, 1967-1992 (Continued) (Dollars per Thousand Cubic Feet)

\begin{tabular}{|c|c|c|c|c|c|c|}
\hline State & 1980 & 1981 & 1982 & 1983 & 1984 & 1985 \\
\hline 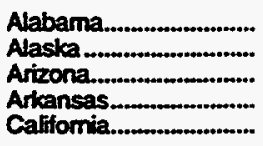 & $\begin{array}{l}3.38 \\
1.06 \\
3.14 \\
2.28 \\
3.98\end{array}$ & $\begin{array}{l}4.07 \\
1.40 \\
3.53 \\
2.82 \\
4.38\end{array}$ & $\begin{array}{l}4.82 \\
1.59 \\
4.90 \\
3.63 \\
5.32\end{array}$ & $\begin{array}{l}5.42 \\
1.94 \\
5.55 \\
4.17 \\
6.33\end{array}$ & $\begin{array}{l}5.44 \\
2.07 \\
5.60 \\
4.18 \\
6.95\end{array}$ & $\begin{array}{l}5.47 \\
2.36 \\
5.57 \\
4.13 \\
6.63\end{array}$ \\
\hline 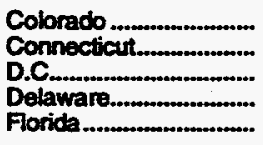 & $\begin{array}{l}3.01 \\
4.77 \\
4.20 \\
4.05 \\
3.43\end{array}$ & $\begin{array}{l}3.84 \\
5.60 \\
5.12 \\
5.18 \\
3.75\end{array}$ & $\begin{array}{l}4.57 \\
6.96 \\
6.28 \\
5.59 \\
4.67\end{array}$ & $\begin{array}{l}5.04 \\
7.45 \\
7.44 \\
6.08 \\
5.04\end{array}$ & $\begin{array}{l}4.77 \\
6.68 \\
7.04 \\
6.17 \\
5.20\end{array}$ & $\begin{array}{l}4.61 \\
6.79 \\
6.72 \\
6.44 \\
5.33\end{array}$ \\
\hline 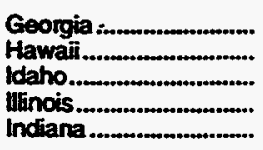 & $\begin{array}{r}3.22 \\
12.23 \\
4.59 \\
3.34 \\
2.95\end{array}$ & $\begin{array}{r}3.98 \\
14.74 \\
5.00 \\
3.74 \\
3.38\end{array}$ & $\begin{array}{r}4.74 \\
14.21 \\
6.12 \\
4.44 \\
4.17\end{array}$ & $\begin{array}{r}5.42 \\
14.70 \\
6.23 \\
4.97 \\
5.17\end{array}$ & $\begin{array}{r}5.66 \\
17.36 \\
5.71 \\
4.86 \\
5.23\end{array}$ & $\begin{array}{r}5.73 \\
14.44 \\
5.69 \\
5.03 \\
5.04\end{array}$ \\
\hline 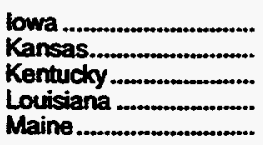 & $\begin{array}{l}2.85 \\
1.90 \\
2.92 \\
2.69 \\
5.12\end{array}$ & $\begin{array}{l}3.51 \\
2.41 \\
3.39 \\
3.69 \\
6.13\end{array}$ & $\begin{array}{l}4.31 \\
3.24 \\
4.39 \\
4.93 \\
7.32\end{array}$ & $\begin{array}{l}5.04 \\
4.56 \\
5.16 \\
5.71 \\
8.90\end{array}$ & $\begin{array}{l}\mathbf{5 . 0 5} \\
\mathbf{3 . 4 6} \\
\mathbf{5 . 0 4} \\
\mathbf{5 . 5 4} \\
\mathbf{8 . 6 1}\end{array}$ & $\begin{array}{l}4.86 \\
3.15 \\
5.10 \\
5.28 \\
8.00\end{array}$ \\
\hline 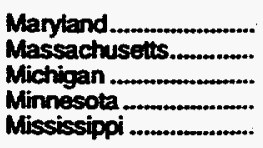 & $\begin{array}{l}3.96 \\
4.72 \\
3.19 \\
2.88 \\
3.07\end{array}$ & $\begin{array}{l}4.48 \\
5.73 \\
3.83 \\
3.64 \\
\mathbf{3 . 5 7}\end{array}$ & $\begin{array}{l}5.55 \\
6.42 \\
4.66 \\
4.55 \\
4.53\end{array}$ & $\begin{array}{l}6.71 \\
7.42 \\
5.63 \\
5.27 \\
\mathbf{5 . 4 7}\end{array}$ & $\begin{array}{l}6.66 \\
7.18 \\
5.57 \\
5.38 \\
5.14\end{array}$ & $\begin{array}{l}6.38 \\
7.04 \\
5.74 \\
5.20 \\
5.07\end{array}$ \\
\hline 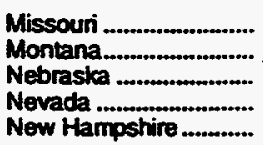 & $\begin{array}{l}2.93 \\
3.14 \\
2.29 \\
3.87 \\
4.13\end{array}$ & $\begin{array}{l}3.59 \\
4.18 \\
2.96 \\
4.58 \\
5.11\end{array}$ & $\begin{array}{l}4.77 \\
4.87 \\
3.49 \\
5.54 \\
6.07\end{array}$ & $\begin{array}{l}5.61 \\
5.06 \\
4.22 \\
6.03 \\
6.73\end{array}$ & $\begin{array}{l}5.27 \\
5.24 \\
4.27 \\
6.14 \\
6.64\end{array}$ & $\begin{array}{l}4.96 \\
5.09 \\
4.21 \\
6.12 \\
6.29\end{array}$ \\
\hline 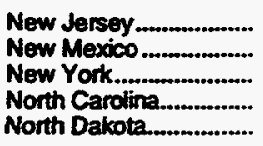 & $\begin{array}{l}4.60 \\
2.93 \\
4.27 \\
3.71 \\
3.43\end{array}$ & $\begin{array}{l}5.48 \\
3.39 \\
4.73 \\
4.72 \\
3.65\end{array}$ & $\begin{array}{l}6.36 \\
4.43 \\
5.48 \\
5.24 \\
4.10\end{array}$ & $\begin{array}{l}6.69 \\
4.80 \\
6.48 \\
6.01 \\
5.06\end{array}$ & $\begin{array}{l}6.53 \\
4.96 \\
6.25 \\
6.07 \\
5.85\end{array}$ & $\begin{array}{l}6.63 \\
5.81 \\
6.11 \\
5.84 \\
5.11\end{array}$ \\
\hline 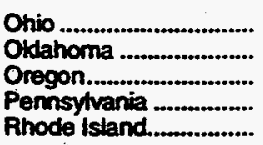 & $\begin{array}{l}3.32 \\
2.30 \\
5.11 \\
\mathbf{3 . 5 7} \\
\mathbf{5 . 1 1}\end{array}$ & $\begin{array}{l}3.71 \\
2.86 \\
5.43 \\
4.22 \\
5.83\end{array}$ & $\begin{array}{l}4.65 \\
3.45 \\
6.29 \\
5.04 \\
6.86\end{array}$ & $\begin{array}{l}5.71 \\
4.13 \\
6.49 \\
6.07 \\
7.10\end{array}$ & $\begin{array}{l}5.68 \\
4.42 \\
6.55 \\
6.20 \\
6.53\end{array}$ & $\begin{array}{l}5.57 \\
4.41 \\
6.25 \\
6.20 \\
6.67\end{array}$ \\
\hline 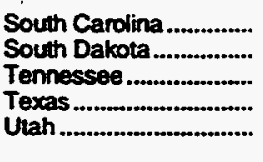 & $\begin{array}{l}3.21 \\
2.72 \\
3.00 \\
2.99 \\
5.59\end{array}$ & $\begin{array}{l}3.96 \\
3.41 \\
3.54 \\
3.68 \\
5.35\end{array}$ & $\begin{array}{l}4.81 \\
4.09 \\
4.43 \\
4.49 \\
3.43\end{array}$ & $\begin{array}{l}5.53 \\
4.88 \\
5.15 \\
5.05 \\
4.32\end{array}$ & $\begin{array}{l}5.86 \\
5.35 \\
4.87 \\
5.07 \\
4.96\end{array}$ & $\begin{array}{l}5.76 \\
4.60 \\
4.91 \\
4.88 \\
4.91\end{array}$ \\
\hline 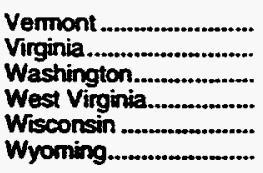 & $\begin{array}{l}6.15 \\
3.77 \\
4.83 \\
3.34 \\
3.46 \\
2.65\end{array}$ & $\begin{array}{l}6.85 \\
4.18 \\
5.35 \\
3.95 \\
4.38 \\
3.27\end{array}$ & $\begin{array}{l}7.06 \\
5.37 \\
6.21 \\
4.94 \\
4.94 \\
4.63\end{array}$ & $\begin{array}{l}6.51 \\
6.24 \\
6.08 \\
5.72 \\
5.31 \\
5.37\end{array}$ & $\begin{array}{l}5.68 \\
6.10 \\
6.08 \\
5.80 \\
5.23 \\
5.36\end{array}$ & $\begin{array}{l}\mathbf{5 . 7 2} \\
\mathbf{5 . 9 8} \\
\mathbf{5 . 4 5} \\
\mathbf{6 . 0 2} \\
\mathbf{5 . 2 0} \\
\mathbf{5 . 0 8}\end{array}$ \\
\hline 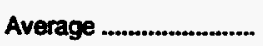 & 3.39 & 4.00 & 4.82 & 5.59 & 5.55 & 5.50 \\
\hline
\end{tabular}

See foctnotes at end of table. 
Table 24. Average Price of Natural Gas Delivered to U.S. Commercial Consumers by State, 1967-1992 (Continued) (Dollars per Thousand Cubic Feet)

\begin{tabular}{|c|c|c|c|c|c|c|c|}
\hline State & 1986 & 1987 & 1988 & 1989 & 1990 & 1991 & 1992 \\
\hline 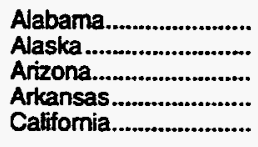 & $\begin{array}{l}5.40 \\
2.53 \\
4.64 \\
4.39 \\
5.86\end{array}$ & $\begin{array}{l}5.48 \\
2.41 \\
4.54 \\
4.26 \\
5.42\end{array}$ & $\begin{array}{l}5.28 \\
2.60 \\
4.97 \\
4.34 \\
4.68\end{array}$ & $\begin{array}{l}5.16 \\
2.57 \\
4.76 \\
4.38 \\
4.88\end{array}$ & $\begin{array}{l}5.43 \\
2.63 \\
4.79 \\
4.46 \\
5.12\end{array}$ & $\begin{array}{l}5.74 \\
2.89 \\
5.07 \\
4.35 \\
5.50\end{array}$ & $\begin{array}{l}5.71 \\
2.64 \\
5.20 \\
4.38 \\
5.15\end{array}$ \\
\hline 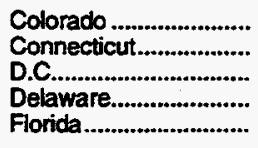 & $\begin{array}{l}4.43 \\
6.43 \\
5.91 \\
6.36 \\
4.43\end{array}$ & $\begin{array}{l}4.15 \\
5.76 \\
5.01 \\
5.17 \\
4.69\end{array}$ & $\begin{array}{l}3.86 \\
5.62 \\
5.03 \\
4.93 \\
4.54\end{array}$ & $\begin{array}{l}4.05 \\
6.08 \\
5.30 \\
5.39 \\
4.85\end{array}$ & $\begin{array}{l}3.99 \\
6.30 \\
5.63 \\
5.12 \\
5.04\end{array}$ & $\begin{array}{l}4.04 \\
6.90 \\
5.17 \\
4.81 \\
4.92\end{array}$ & $\begin{array}{l}4.00 \\
7.20 \\
5.36 \\
4.94 \\
4.98\end{array}$ \\
\hline 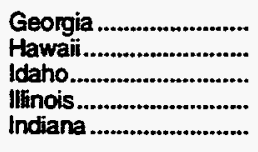 & $\begin{array}{r}5.61 \\
12.03 \\
4.78 \\
4.56 \\
4.94\end{array}$ & $\begin{array}{r}5.40 \\
11.76 \\
4.52 \\
4.39 \\
4.45\end{array}$ & $\begin{array}{r}5.45 \\
11.52 \\
4.52 \\
4.19 \\
4.60\end{array}$ & $\begin{array}{r}5.47 \\
11.44 \\
4.20 \\
4.55 \\
4.78\end{array}$ & $\begin{array}{r}5.76 \\
12.25 \\
4.18 \\
4.64 \\
4.61\end{array}$ & $\begin{array}{r}5.67 \\
13.36 \\
4.42 \\
4.56 \\
4.61\end{array}$ & $\begin{array}{r}5.55 \\
13.34 \\
4.40 \\
4.65 \\
4.57\end{array}$ \\
\hline $\begin{array}{l}\text { lowa } \\
\text { Kansas......................... } \\
\text { Kentucky....................... } \\
\text { Louisiana ................... } \\
\text { Maine ........................ }\end{array}$ & $\begin{array}{l}4.45 \\
2.86 \\
4.73 \\
5.25 \\
7.48\end{array}$ & $\begin{array}{l}3.87 \\
3.02 \\
4.26 \\
4.97 \\
6.98\end{array}$ & $\begin{array}{l}4.03 \\
3.03 \\
4.21 \\
5.14 \\
6.25\end{array}$ & $\begin{array}{l}3.90 \\
3.14 \\
4.35 \\
5.19 \\
6.30\end{array}$ & $\begin{array}{l}4.03 \\
3.36 \\
4.52 \\
5.26 \\
6.72\end{array}$ & $\begin{array}{l}3.99 \\
3.32 \\
4.44 \\
4.90 \\
6.02\end{array}$ & $\begin{array}{l}4.27 \\
3.53 \\
4.47 \\
4.79 \\
6.19\end{array}$ \\
\hline $\begin{array}{l}\text { Maryland .................... } \\
\text { Massachusetts........... } \\
\text { Michigan ...................... } \\
\text { Minnesota .................. } \\
\text { Mississippi .................. }\end{array}$ & $\begin{array}{l}5.74 \\
6.65 \\
5.23 \\
4.62 \\
4.98\end{array}$ & $\begin{array}{l}5.10 \\
5.92 \\
5.03 \\
3.89 \\
5.29\end{array}$ & $\begin{array}{l}5.09 \\
6.11 \\
5.00 \\
4.03 \\
5.02\end{array}$ & $\begin{array}{l}5.43 \\
5.87 \\
4.85 \\
4.00 \\
4.73\end{array}$ & $\begin{array}{l}5.35 \\
6.35 \\
4.63 \\
3.98 \\
4.48\end{array}$ & $\begin{array}{l}5.04 \\
6.17 \\
4.70 \\
3.81 \\
4.28\end{array}$ & $\begin{array}{l}5.24 \\
5.86 \\
4.65 \\
4.10 \\
4.13\end{array}$ \\
\hline $\begin{array}{l}\text { Missouri ........................ } \\
\text { Montana.................... } \\
\text { Nebraska ..................... } \\
\text { Nevada .................... } \\
\text { New Hampshire ........... }\end{array}$ & $\begin{array}{l}4.40 \\
4.48 \\
3.93 \\
4.91 \\
6.53\end{array}$ & $\begin{array}{l}4.11 \\
4.34 \\
3.70 \\
4.29 \\
5.81\end{array}$ & $\begin{array}{l}4.20 \\
4.30 \\
3.75 \\
4.62 \\
5.66\end{array}$ & $\begin{array}{l}4.34 \\
4.36 \\
3.77 \\
4.44 \\
6.23\end{array}$ & $\begin{array}{l}4.53 \\
4.64 \\
3.86 \\
4.38 \\
6.73\end{array}$ & $\begin{array}{l}4.50 \\
4.35 \\
3.87 \\
4.34 \\
6.35\end{array}$ & $\begin{array}{l}4.47 \\
4.46 \\
3.99 \\
4.33 \\
6.74\end{array}$ \\
\hline $\begin{array}{l}\text { New Jersey................... } \\
\text { New Mexico................. } \\
\text { New York................... } \\
\text { North Carolina............. } \\
\text { North Dakota................ }\end{array}$ & $\begin{array}{l}6.33 \\
4.37 \\
5.77 \\
5.56 \\
4.79\end{array}$ & $\begin{array}{l}5.54 \\
3.97 \\
5.17 \\
5.21 \\
4.75\end{array}$ & $\begin{array}{l}5.24 \\
3.31 \\
5.39 \\
4.94 \\
4.48\end{array}$ & $\begin{array}{l}5.30 \\
3.72 \\
5.62 \\
5.14 \\
4.19\end{array}$ & $\begin{array}{l}5.20 \\
4.43 \\
5.59 \\
4.63 \\
4.19\end{array}$ & $\begin{array}{l}5.21 \\
4.15 \\
5.47 \\
4.53 \\
4.34\end{array}$ & $\begin{array}{l}5.54 \\
3.36 \\
5.75 \\
4.79 \\
4.52\end{array}$ \\
\hline 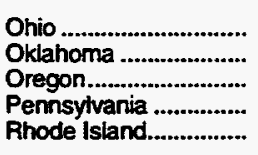 & $\begin{array}{l}5.35 \\
4.41 \\
5.59 \\
5.82 \\
6.39\end{array}$ & $\begin{array}{l}4.89 \\
4.18 \\
5.31 \\
5.42 \\
5.53\end{array}$ & $\begin{array}{l}4.75 \\
4.07 \\
5.36 \\
5.09 \\
5.80\end{array}$ & $\begin{array}{l}4.90 \\
3.94 \\
4.80 \\
5.35 \\
6.41\end{array}$ & $\begin{array}{l}4.68 \\
3.92 \\
4.85 \\
6.00 \\
6.20\end{array}$ & $\begin{array}{l}4.76 \\
3.91 \\
4.75 \\
6.00 \\
6.03\end{array}$ & $\begin{array}{l}4.72 \\
4.23 \\
4.73 \\
5.87 \\
6.32\end{array}$ \\
\hline 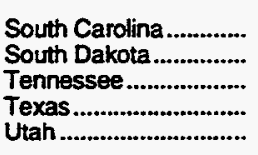 & $\begin{array}{l}5.63 \\
4.35 \\
4.67 \\
4.17 \\
4.73\end{array}$ & $\begin{array}{l}5.60 \\
4.22 \\
4.33 \\
4.26 \\
4.98\end{array}$ & $\begin{array}{l}5.59 \\
4.10 \\
4.38 \\
4.19 \\
4.08\end{array}$ & $\begin{array}{l}5.65 \\
3.99 \\
4.49 \\
4.11 \\
4.16\end{array}$ & $\begin{array}{l}5.90 \\
4.20 \\
4.80 \\
4.14 \\
4.30\end{array}$ & $\begin{array}{l}5.56 \\
4.04 \\
4.76 \\
4.01 \\
4.50\end{array}$ & $\begin{array}{l}5.65 \\
4.19 \\
5.06 \\
4.09 \\
4.40\end{array}$ \\
\hline 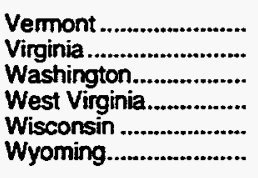 & $\begin{array}{l}5.12 \\
5.27 \\
5.05 \\
5.89 \\
5.01 \\
4.65\end{array}$ & $\begin{array}{l}4.88 \\
4.64 \\
4.50 \\
5.48 \\
4.78 \\
4.47\end{array}$ & $\begin{array}{l}4.67 \\
4.45 \\
4.59 \\
5.18 \\
4.68 \\
4.11\end{array}$ & $\begin{array}{l}4.74 \\
4.93 \\
4.68 \\
5.26 \\
4.44 \\
4.33\end{array}$ & $\begin{array}{l}5.05 \\
4.93 \\
4.14 \\
5.83 \\
4.75 \\
4.47\end{array}$ & $\begin{array}{l}5.24 \\
4.85 \\
4.06 \\
6.11 \\
4.62 \\
4.31\end{array}$ & $\begin{array}{l}5.67 \\
4.97 \\
4.32 \\
5.48 \\
4.81 \\
4.26\end{array}$ \\
\hline Average & 5.08 & 4.77 & 4.63 & 4.74 & 4.83 & 4.81 & 4.88 \\
\hline
\end{tabular}

a Data for the District of Columbia are included with data for Maryland.

- Data for New Hampshire and Vermont are included with data for Maine.

NA = Not Available. values and values imputed for gas delivered for the account of others.

values and values impuled for gas delivered for the account of others. Annual 1979: ElA, Natural Gas Production and Consumption 1979. 1980-1992: ElA, Fom ElA-176, "Annual Report of Natural and Supplemental Gas Supply and Disposition." 
Table 25. Average Price of Natural Gas Delivered to U.S. Commercial Consumers by State, 1993-1994 (Dollars per Thousand Cubic Feet)

\begin{tabular}{|c|c|c|c|c|}
\hline \multirow{2}{*}{ State } & \multicolumn{2}{|c|}{1993} & \multicolumn{2}{|c|}{1994} \\
\hline & Average Price & $\begin{array}{l}\text { Percentege of Total } \\
\text { Volume Defivered }\end{array}$ & Average Price & $\begin{array}{l}\text { Percentage of Total } \\
\text { Volume Delivered }\end{array}$ \\
\hline 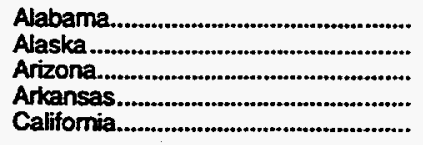 & $\begin{array}{l}6.19 \\
2.78 \\
5.06 \\
4.42 \\
6.03\end{array}$ & $\begin{array}{r}80.8 \\
100.0 \\
91.5 \\
91.7 \\
76.9\end{array}$ & $\begin{array}{l}6.38 \\
2.48 \\
5.27 \\
4.58 \\
7.12\end{array}$ & $\begin{array}{r}80.2 \\
100.0 \\
90.7 \\
95.1 \\
48.7\end{array}$ \\
\hline 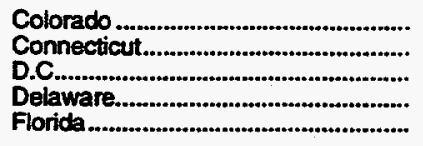 & $\begin{array}{r}4.04 \\
7.02 \\
5.75 \\
\mathbf{5 . 4 6} \\
\mathbf{8} .84\end{array}$ & $\begin{array}{r}95.5 \\
98.1 \\
98.0 \\
100.0 \\
97.8\end{array}$ & $\begin{array}{l}4.37 \\
7.39 \\
6.16 \\
6.17 \\
5.54\end{array}$ & $\begin{array}{r}94.8 \\
80.9 \\
90.9 \\
100.0 \\
97.8\end{array}$ \\
\hline 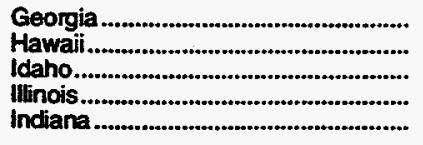 & $\begin{array}{r}5.83 \\
12.90 \\
4.65 \\
5.10 \\
4.99\end{array}$ & $\begin{array}{r}90.5 \\
100.0 \\
86.8 \\
55.3 \\
95.2\end{array}$ & $\begin{array}{r}6.18 \\
12.40 \\
5.01 \\
5.12 \\
5.33\end{array}$ & $\begin{array}{r}92.0 \\
100.0 \\
85.9 \\
52.8 \\
92.3\end{array}$ \\
\hline 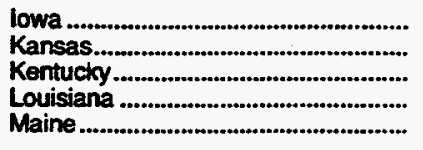 & $\begin{array}{l}4.52 \\
4.06 \\
4.82 \\
5.33 \\
6.76\end{array}$ & $\begin{array}{r}94.7 \\
82.6 \\
92.6 \\
98.1 \\
100.0\end{array}$ & $\begin{array}{l}4.51 \\
4.12 \\
4.98 \\
5.42 \\
6.97\end{array}$ & $\begin{array}{r}90.4 \\
78.4 \\
91.4 \\
97.9 \\
100.0\end{array}$ \\
\hline 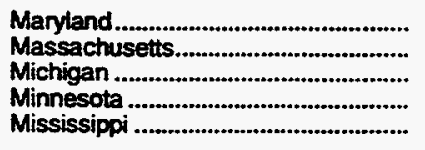 & $\begin{array}{l}5.72 \\
6.04 \\
4.66 \\
4.52 \\
4.38\end{array}$ & $\begin{array}{l}96.6 \\
97.5 \\
68.6 \\
97.0 \\
96.6\end{array}$ & $\begin{array}{l}5.46 \\
6.82 \\
4.68 \\
4.36 \\
4.56\end{array}$ & $\begin{array}{l}97.1 \\
76.2 \\
65.7 \\
96.0 \\
96.6\end{array}$ \\
\hline 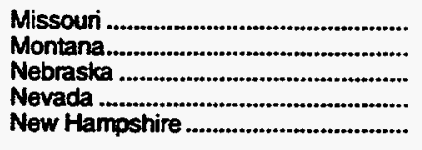 & $\begin{array}{l}4.76 \\
4.67 \\
4.27 \\
4.40 \\
6.83\end{array}$ & $\begin{array}{r}84.6 \\
93.2 \\
91.0 \\
92.7 \\
100.0\end{array}$ & $\begin{array}{l}4.85 \\
4.91 \\
4.24 \\
5.36 \\
7.17\end{array}$ & $\begin{array}{r}83.3 \\
91.8 \\
80.2 \\
82.5 \\
100.0\end{array}$ \\
\hline 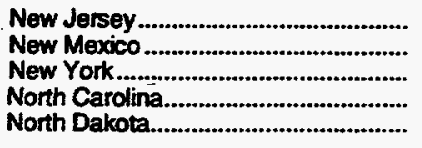 & $\begin{array}{l}5.60 \\
4.31 \\
6.16 \\
5.51 \\
4.75\end{array}$ & $\begin{array}{l}91.5 \\
62.5 \\
77.2 \\
98.5 \\
72.7\end{array}$ & $\begin{array}{l}6.03 \\
4.41 \\
6.51 \\
5.56 \\
4.48\end{array}$ & $\begin{array}{l}91.6 \\
62.4 \\
79.6 \\
96.6 \\
79.6\end{array}$ \\
\hline 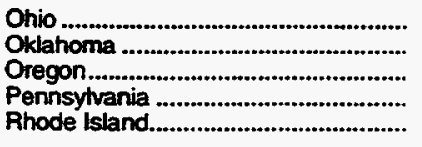 & $\begin{array}{l}5.24 \\
4.42 \\
5.04 \\
5.99 \\
7.10\end{array}$ & $\begin{array}{r}84.6 \\
90.0 \\
97.9 \\
77.4 \\
100.0\end{array}$ & $\begin{array}{l}5.38 \\
4.73 \\
5.52 \\
6.50 \\
7.57\end{array}$ & $\begin{array}{r}81.5 \\
88.5 \\
98.1 \\
74.4 \\
100.0\end{array}$ \\
\hline 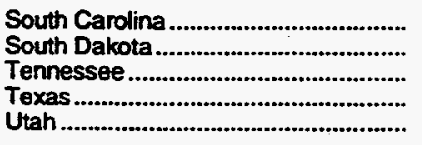 & $\begin{array}{r}5.82 \\
4.37 \\
5.27 \\
R_{4.45} \\
4.06\end{array}$ & $\begin{array}{r}98.8 \\
83.9 \\
95.8 \\
86.2 \\
100.0\end{array}$ & $\begin{array}{l}6.11 \\
4.35 \\
5.56 \\
4.33 \\
3.84\end{array}$ & $\begin{array}{l}98.5 \\
89.1 \\
94.1 \\
82.4 \\
83.3\end{array}$ \\
\hline 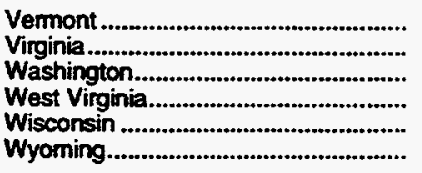 & $\begin{array}{l}5.25 \\
5.60 \\
4.53 \\
5.87 \\
5.16 \\
4.23\end{array}$ & $\begin{array}{r}100.0 \\
88.8 \\
93.9 \\
54.3 \\
94.4 \\
98.0\end{array}$ & $\begin{array}{l}5.60 \\
5.67 \\
4.90 \\
5.91 \\
4.91 \\
4.45\end{array}$ & $\begin{array}{r}100.0 \\
86.7 \\
95.4 \\
55.2 \\
93.5 \\
96.1\end{array}$ \\
\hline 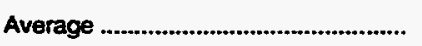 & $A_{5.22}$ & 84.1 & 5.44 & 79.3 \\
\hline
\end{tabular}

$R$ = Revised data.

Note: Totals may not equal sum of components due to independent rounding.

Sources: 1993-1994: ElA, Form EIA-176, "Annual Report of Natural and Supplemental Gas Supply and Disposition." 
Table 26. Prices of Natural Gas Deliveries to Commercial Consumers by State, 1993-1994 (Dollars per Thousand Cubic Feet)

\begin{tabular}{|c|c|c|c|c|c|c|}
\hline \multirow{2}{*}{ Stuto } & \multicolumn{2}{|c|}{ Firm } & \multicolumn{2}{|c|}{ Intermiptible } & \multicolumn{2}{|c|}{ Total } \\
\hline & Average Price & $\begin{array}{l}\text { Pereentege of Total } \\
\text { Volume Deffivered }\end{array}$ & Avernge Price & $\begin{array}{l}\text { Percentugs of Total } \\
\text { Volume Doffivered }\end{array}$ & Total Average Price & $\begin{array}{l}\text { Percentage of Total } \\
\text { Volume Dolivered }\end{array}$ \\
\hline & \multicolumn{6}{|c|}{1993} \\
\hline 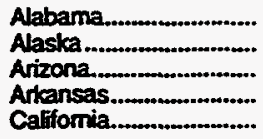 & $\begin{array}{l}6.25 \\
2.78 \\
5.06 \\
4.44 \\
6.04\end{array}$ & $\begin{array}{r}94.5 \\
100.0 \\
91.7 \\
91.5 \\
79.8\end{array}$ & $\begin{array}{r}4.39 \\
5.16 \\
3.88 \\
0.86\end{array}$ & $\begin{array}{r}14.8 \\
78.9 \\
99.7 \\
2.5\end{array}$ & $\begin{array}{l}6.19 \\
2.78 \\
5.05 \\
4.42 \\
6.03\end{array}$ & $\begin{array}{r}80.8 \\
100.0 \\
91.5 \\
91.7 \\
76.9\end{array}$ \\
\hline 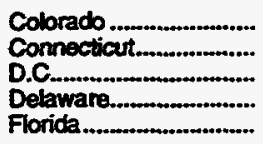 & $\begin{array}{r}4.04 \\
8.15 \\
7.92 \\
5.46 \\
75.86\end{array}$ & $\begin{array}{r}98.4 \\
100.0 \\
95.3 \\
100.0 \\
99.5\end{array}$ & $\begin{array}{r}3.44 \\
3.89 \\
4.16 \\
4.45\end{array}$ & $\begin{array}{r}27.5 \\
93.2 \\
100.0 \\
48.1\end{array}$ & $\begin{array}{r}4.04 \\
7.02 \\
5.75 \\
5.46 \\
R_{5.84}\end{array}$ & $\begin{array}{r}95.5 \\
98.1 \\
98.0 \\
100.0 \\
97.8\end{array}$ \\
\hline 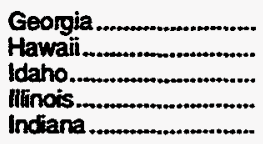 & $\begin{array}{r}6.13 \\
14.10 \\
4.65 \\
5.10 \\
5.06\end{array}$ & $\begin{array}{r}100.0 \\
100.0 \\
86.8 \\
56.1 \\
96.2\end{array}$ & $\begin{array}{r}4.06 \\
6.74 \\
-\overline{3} \\
3.83\end{array}$ & $\begin{array}{r}57.4 \\
100.0 \\
2 . \overline{2.1} \\
82.7\end{array}$ & $\begin{array}{r}5.83 \\
12.90 \\
4.65 \\
5.10 \\
4.99\end{array}$ & $\begin{array}{r}90.5 \\
100.0 \\
86.8 \\
55.3 \\
95.2\end{array}$ \\
\hline 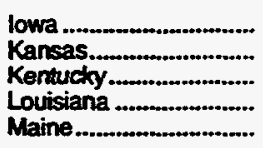 & $\begin{array}{l}4.66 \\
4.08 \\
4.84 \\
5.52 \\
6.76\end{array}$ & $\begin{array}{r}94.3 \\
97.3 \\
893.9 \\
99.3 \\
100.0\end{array}$ & $\begin{array}{r}3.26 \\
3.43 \\
8_{3.94} \\
4.79 \\
-\end{array}$ & $\begin{array}{r}99.0 \\
11.8 \\
\text { A8.9 } \\
95.0 \\
-\end{array}$ & $\begin{array}{l}4.52 \\
4.06 \\
4.82 \\
5.33 \\
6.76\end{array}$ & $\begin{array}{r}94.7 \\
82.6 \\
92.6 \\
98.1 \\
100.0\end{array}$ \\
\hline 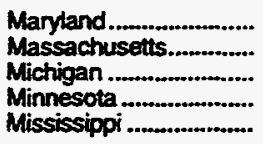 & $\begin{array}{l}6.04 \\
6.21 \\
4.66 \\
5.09 \\
4.44\end{array}$ & $\begin{array}{l}96.6 \\
99.2 \\
68.9 \\
99.4 \\
99.2\end{array}$ & $\begin{array}{l}4.33 \\
4.45 \\
4.20 \\
2.95 \\
2.78\end{array}$ & $\begin{array}{r}96.6 \\
83.8 \\
9.7 \\
90.7 \\
56.5\end{array}$ & $\begin{array}{l}5.72 \\
6.04 \\
4.66 \\
4.52 \\
4.38\end{array}$ & $\begin{array}{l}96.6 \\
97.5 \\
68.6 \\
97.0 \\
96.6\end{array}$ \\
\hline 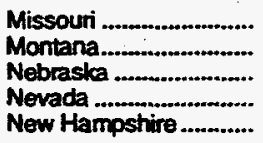 & $\begin{array}{l}4.78 \\
4.67 \\
4.55 \\
4.40 \\
6.83\end{array}$ & $\begin{array}{r}93.0 \\
95.2 \\
89.1 \\
94.0 \\
100.0\end{array}$ & $\begin{array}{r}3.94 \\
4.78 \\
3.02 \\
- \\
-\end{array}$ & $\begin{array}{r}20.0 \\
4.4 \\
100.0 \\
- \\
-\end{array}$ & $\begin{array}{l}4.76 \\
4.67 \\
4.27 \\
4.40 \\
6.83\end{array}$ & $\begin{array}{r}84.6 \\
93.2 \\
91.0 \\
92.7 \\
100.0\end{array}$ \\
\hline $\begin{array}{l}\text { New Jersey.................. } \\
\text { New Mexico ................... } \\
\text { New York.................. } \\
\text { North Carolina............... } \\
\text { North Dakota............... }\end{array}$ & $\begin{array}{l}6.02 \\
4.31 \\
6.35 \\
5.57 \\
4.78\end{array}$ & $\begin{array}{l}93.9 \\
62.3 \\
84.3 \\
98.5 \\
95.8\end{array}$ & $\begin{array}{l}3.47 \\
3.95 \\
4.21 \\
4.34 \\
3.67\end{array}$ & $\begin{array}{r}81.3 \\
100.0 \\
41.0 \\
98.2 \\
8.1\end{array}$ & $\begin{array}{l}5.60 \\
4.31 \\
6.16 \\
5.51 \\
4.75\end{array}$ & $\begin{array}{l}91.5 \\
62.5 \\
77.2 \\
98.5 \\
72.7\end{array}$ \\
\hline 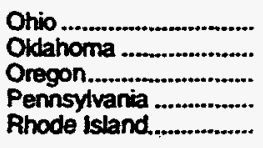 & $\begin{array}{l}5.26 \\
4.48 \\
5.04 \\
6.17 \\
7.78\end{array}$ & $\begin{array}{r}85.4 \\
95.3 \\
100.0 \\
78.7 \\
100.0\end{array}$ & $\begin{array}{r}3.36 \\
2.30 \\
-\overline{4} \\
3.21\end{array}$ & $\begin{array}{r}36.6 \\
29.0 \\
66.5 \\
100.0\end{array}$ & $\begin{array}{l}5.24 \\
4.42 \\
5.04 \\
5.99 \\
7.10\end{array}$ & $\begin{array}{r}84.6 \\
90.0 \\
97.9 \\
77.4 \\
100.0\end{array}$ \\
\hline 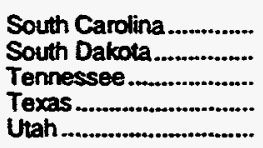 & $\begin{array}{r}6.30 \\
4.57 \\
5.41 \\
\mathrm{R}_{4.53} \\
4.12\end{array}$ & $\begin{array}{r}R_{99.1} \\
87.6 \\
96.6 \\
R_{90.9} \\
100.0\end{array}$ & $\begin{array}{r}3.47 \\
3.05 \\
3.22 \\
R_{2} .19 \\
3.09\end{array}$ & $\begin{array}{r}100.0 \\
65.4 \\
86.3 \\
R_{24.6} \\
100.0\end{array}$ & $\begin{array}{r}5.82 \\
4.37 \\
\quad 5.27 \\
R_{4.45} \\
4.06\end{array}$ & $\begin{array}{r}98.8 \\
83.9 \\
95.8 \\
86.2 \\
100.0\end{array}$ \\
\hline 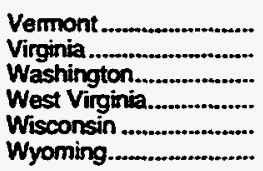 & $\begin{array}{r}5.25 \\
5.94 \\
4.73 \\
R_{5} .97 \\
5.36 \\
4.09\end{array}$ & $\begin{array}{r}100.0 \\
94.8 \\
99.9 \\
84.5 \\
95.6 \\
99.5\end{array}$ & $\begin{array}{r}4 . \overrightarrow{42} \\
3.67 \\
R_{5.78} \\
3.14 \\
4.42\end{array}$ & $\begin{array}{r}73 . \overline{2} \\
73.9 \\
R_{42.4} \\
83.8 \\
96.1\end{array}$ & $\begin{array}{l}5.25 \\
5.60 \\
4.53 \\
5.87 \\
5.16 \\
4.23\end{array}$ & $\begin{array}{r}100.0 \\
88.8 \\
93.9 \\
54.3 \\
94.4 \\
98.0\end{array}$ \\
\hline 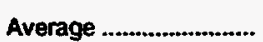 & $\mathbf{R}_{5.34}$ & $P_{86.6}$ & $\mathrm{~A}_{3.82}$ & $F_{61.6}$ & $A_{5.22}$ & 84.1 \\
\hline
\end{tabular}

See tootnotes at end of table. 
Table 26. Prices of Natural Gas Deliveries to Commercial Consumers by State, 1993-1994 (Continued). (Dollars per Thousand Cubic Feet)

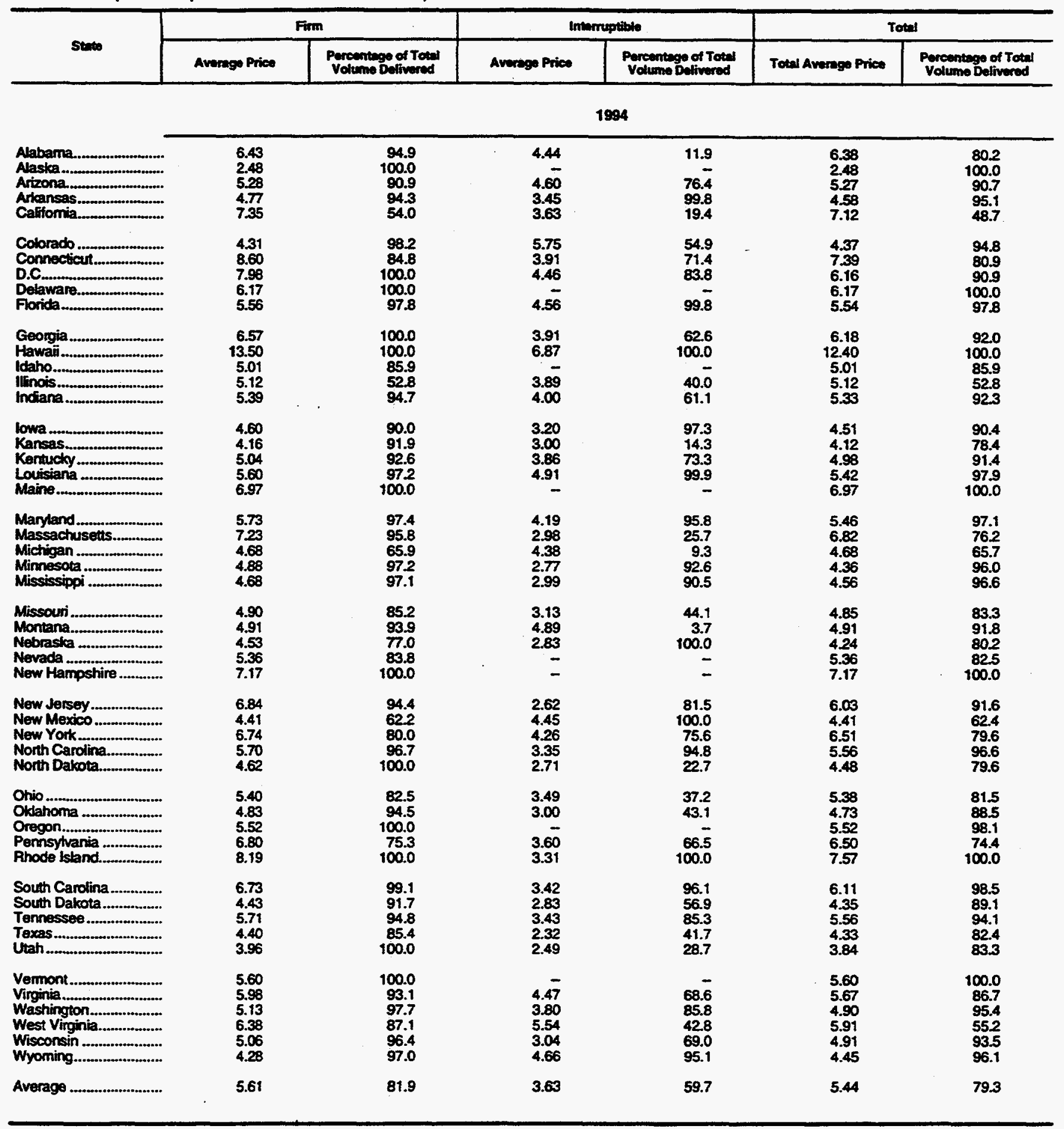

$R=$ Revised data.

Note: Totals may not equal sum of components due to independent munding.

Source: 1993-1994: Energy Information Administration (EAA), Form EIA-176, 'Annual Report of Naturai and Supplemental Gas Suppiy and Oisposition." 
Table 27. Average Price of Natural Gas Delivered to U.S. Industrial Consumers by State, 1967-1992 (Dollars per Thousand Cubic Feet)

\begin{tabular}{|c|c|c|c|c|c|c|}
\hline Stete & 1967 & 1968 & 1969 & 1970 & 1971 & 1972 \\
\hline 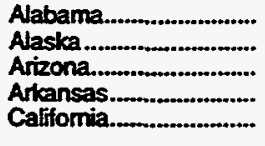 & $\begin{array}{l}0.32 \\
0.38 \\
0.39 \\
0.26 \\
0.35\end{array}$ & $\begin{array}{l}0.32 \\
0.45 \\
0.36 \\
0.28 \\
0.38\end{array}$ & $\begin{array}{l}0.32 \\
0.36 \\
0.42 \\
0.27 \\
0.39\end{array}$ & $\begin{array}{l}0.34 \\
0.43 \\
0.44 \\
0.28 \\
0.40\end{array}$ & $\begin{array}{l}0.39 \\
0.64 \\
0.47 \\
0.31 \\
0.44\end{array}$ & $\begin{array}{l}0.42 \\
0.68 \\
0.48 \\
0.35 \\
0.47\end{array}$ \\
\hline 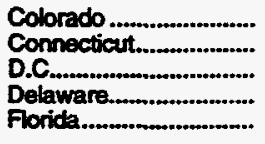 & $\begin{array}{r}0.24 \\
0.73 \\
2 \\
0.35 \\
0.32\end{array}$ & $\begin{array}{r}0.27 \\
0.10 \\
a \\
0.68 \\
0.38\end{array}$ & $\begin{array}{r}0.27 \\
1.02 \\
a \\
0.57 \\
0.36\end{array}$ & $\begin{array}{r}0.28 \\
1.04 \\
0 \\
0.59 \\
0.39\end{array}$ & $\begin{array}{r}0.30 \\
1.16 \\
a \\
0.63 \\
0.44\end{array}$ & $\begin{array}{r}0.33 \\
1.17 \\
a \\
0.76 \\
0.50\end{array}$ \\
\hline 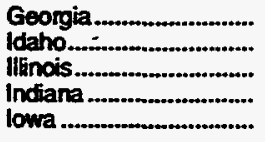 & $\begin{array}{l}0.52 \\
0.42 \\
0.46 \\
0.47 \\
0.33\end{array}$ & $\begin{array}{l}0.37 \\
0.43 \\
0.46 \\
0.42 \\
0.37\end{array}$ & $\begin{array}{l}0.38 \\
0.44 \\
0.46 \\
0.42 \\
0.31\end{array}$ & $\begin{array}{l}0.41 \\
0.45 \\
0.50 \\
0.47 \\
0.37\end{array}$ & $\begin{array}{l}0.52 \\
0.49 \\
0.56 \\
0.51 \\
0.39\end{array}$ & $\begin{array}{l}0.53 \\
0.54 \\
0.64 \\
0.56 \\
0.46\end{array}$ \\
\hline 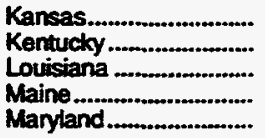 & $\begin{array}{r}0.34 \\
0.44 \\
0.21 \\
1.25 \\
0.71\end{array}$ & $\begin{array}{l}0.24 \\
0.44 \\
0.22 \\
0.90 \\
0.66\end{array}$ & $\begin{array}{l}0.24 \\
0.44 \\
0.21 \\
0.85 \\
0.67\end{array}$ & $\begin{array}{r}0.27 \\
0.48 \\
0.24 \\
0.85 \\
0.68\end{array}$ & $\begin{array}{r}0.29 \\
0.54 \\
0.27 \\
0.93 \\
0.72\end{array}$ & $\begin{array}{l}0.33 \\
0.55 \\
0.33 \\
01.01 \\
0.75\end{array}$ \\
\hline 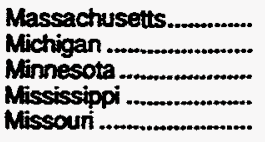 & $\begin{array}{l}0.71 \\
0.52 \\
0.39 \\
0.30 \\
0.35\end{array}$ & $\begin{array}{l}0.93 \\
0.52 \\
0.37 \\
0.28 \\
0.36\end{array}$ & $\begin{array}{l}0.98 \\
0.52 \\
0.40 \\
0.28 \\
0.37\end{array}$ & $\begin{array}{l}1.04 \\
0.54 \\
0.42 \\
0.30 \\
0.40\end{array}$ & $\begin{array}{l}1.07 \\
0.57 \\
0.45 \\
0.33 \\
0.43\end{array}$ & $\begin{array}{l}1.23 \\
0.63 \\
0.48 \\
0.34 \\
0.44\end{array}$ \\
\hline 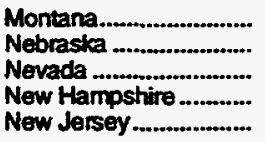 & $\begin{array}{r}0.34 \\
0.30 \\
0.47 \\
b \\
0.56\end{array}$ & $\begin{array}{r}0.33 \\
0.31 \\
0.46 \\
b \\
0.57\end{array}$ & $\begin{array}{r}0.34 \\
0.32 \\
0.49 \\
6 \\
0.69\end{array}$ & $\begin{array}{r}0.34 \\
0.32 \\
0.56 \\
b \\
0.70\end{array}$ & $\begin{array}{r}0.36 \\
0.37 \\
0.57 \\
b \\
0.74\end{array}$ & $\begin{array}{r}0.38 \\
0.49 \\
0.72 \\
b \\
0.81\end{array}$ \\
\hline 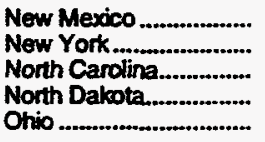 & $\begin{array}{l}0.24 \\
0.94 \\
0.49 \\
0.36 \\
0.53\end{array}$ & $\begin{array}{l}0.25 \\
0.64 \\
0.50 \\
0.35 \\
0.52\end{array}$ & $\begin{array}{l}0.25 \\
0.64 \\
0.51 \\
0.36 \\
0.53\end{array}$ & $\begin{array}{l}0.27 \\
0.70 \\
0.51 \\
0.39 \\
0.58\end{array}$ & $\begin{array}{l}0.32 \\
0.77 \\
0.53 \\
0.44 \\
0.62\end{array}$ & $\begin{array}{l}0.34 \\
0.86 \\
0.60 \\
0.49 \\
0.63\end{array}$ \\
\hline $\begin{array}{l}\text { Okdahoma ..................... } \\
\text { Oregon......................... } \\
\text { Pernsytvania ................ } \\
\text { Rhode Lstand.............. } \\
\text { South Carolina ............. }\end{array}$ & $\begin{array}{l}0.22 \\
0.43 \\
0.54 \\
0.81 \\
0.42\end{array}$ & $\begin{array}{l}0.24 \\
0.42 \\
0.53 \\
0.83 \\
0.41\end{array}$ & $\begin{array}{l}0.25 \\
0.43 \\
0.55 \\
0.82 \\
0.42\end{array}$ & $\begin{array}{l}0.25 \\
0.48 \\
0.59 \\
0.87 \\
0.46\end{array}$ & $\begin{array}{l}0.27 \\
0.51 \\
0.65 \\
0.96 \\
0.49\end{array}$ & $\begin{array}{l}0.29 \\
0.54 \\
0.72 \\
1.15 \\
0.55\end{array}$ \\
\hline 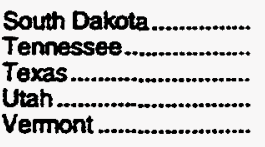 & $\begin{array}{l}0.32 \\
0.37 \\
0.19 \\
0.29 \\
b\end{array}$ & $\begin{array}{l}0.31 \\
0.37 \\
0.19 \\
0.29 \\
b\end{array}$ & $\begin{array}{r}0.32 \\
0.37 \\
0.20 \\
0.29 \\
b\end{array}$ & $\begin{array}{r}0.33 \\
0.39 \\
0.21 \\
0.30 \\
b\end{array}$ & $\begin{array}{r}0.35 \\
0.45 \\
0.25 \\
0.33 \\
b\end{array}$ & $\begin{array}{r}0.38 \\
0.50 \\
0.26 \\
0.36 \\
b\end{array}$ \\
\hline 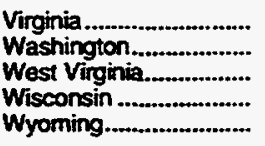 & $\begin{array}{l}0.48 \\
0.40 \\
0.46 \\
0.48 \\
0.24\end{array}$ & $\begin{array}{l}0.49 \\
0.39 \\
0.45 \\
0.53 \\
0.24\end{array}$ & $\begin{array}{l}0.50 \\
0.39 \\
0.45 \\
0.54 \\
0.24\end{array}$ & $\begin{array}{l}0.51 \\
0.40 \\
0.46 \\
0.55 \\
0.25\end{array}$ & $\begin{array}{l}0.57 \\
0.44 \\
0.52 \\
0.58 \\
0.27\end{array}$ & $\begin{array}{l}0.60 \\
0.47 \\
0.56 \\
0.64 \\
0.30\end{array}$ \\
\hline 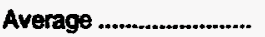 & 0.34 & 0.34 & 0.35 & 0.37 & 0.41 & 0.45 \\
\hline
\end{tabular}

See tootnotes at end of table. 
Table 27. Average Price of Natural Gas Delivered to U.S. Industrial'Consumers by State, 1967-1992 (Continued) (Dollars per Thousand Cubic Feet)

\begin{tabular}{|c|c|c|c|c|c|c|c|}
\hline Stute & 1973 & 1974 & 1975 & 1976 & 1977 & 1978 & 1979 \\
\hline 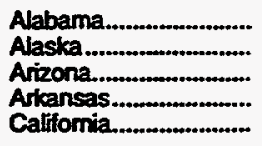 & $\begin{array}{l}0.48 \\
0.72 \\
0.49 \\
0.39 \\
0.53\end{array}$ & $\begin{array}{l}0.58 \\
0.75 \\
0.58 \\
0.48 \\
0.69\end{array}$ & $\begin{array}{l}0.75 \\
0.81 \\
0.76 \\
0.67 \\
1.11\end{array}$ & $\begin{array}{l}1.10 \\
0.87 \\
0.92 \\
0.81 \\
1.46\end{array}$ & $\begin{array}{l}1.33 \\
1.01 \\
1.30 \\
1.22 \\
1.95\end{array}$ & $\begin{array}{l}1.65 \\
0.96 \\
1.62 \\
1.15 \\
2.15\end{array}$ & $\begin{array}{l}2.33 \\
1.05 \\
2.15 \\
1.23 \\
2.73\end{array}$ \\
\hline 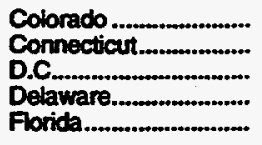 & $\begin{array}{r}0.38 \\
1.26 \\
2 \\
0.81 \\
0.58\end{array}$ & $\begin{array}{r}0.48 \\
1.73 \\
a \\
1.01 \\
0.75\end{array}$ & $\begin{array}{r}0.65 \\
2.25 \\
a \\
1.39 \\
1.03\end{array}$ & $\begin{array}{r}0.80 \\
2.67 \\
a \\
1.46 \\
1.06\end{array}$ & $\begin{array}{r}1.10 \\
2.97 \\
a \\
2.47 \\
1.15\end{array}$ & $\begin{array}{r}1.32 \\
3.08 \\
a \\
2.51 \\
1.19\end{array}$ & $\begin{array}{r}1.84 \\
3.29 \\
9 \\
2.01 \\
2.16\end{array}$ \\
\hline 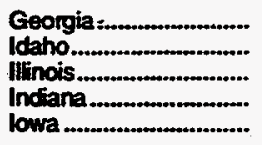 & $\begin{array}{l}0.61 \\
0.59 \\
0.68 \\
0.59 \\
0.52\end{array}$ & $\begin{array}{l}0.70 \\
0.71 \\
0.81 \\
0.70 \\
0.60\end{array}$ & $\begin{array}{l}0.84 \\
1.17 \\
1.22 \\
0.90 \\
0.78\end{array}$ & $\begin{array}{l}1.10 \\
1.54 \\
1.46 \\
1.08 \\
1.01\end{array}$ & $\begin{array}{l}1.41 \\
1.89 \\
1.85 \\
1.48 \\
1.35\end{array}$ & $\begin{array}{l}1.76 \\
2.24 \\
2.12 \\
1.69 \\
1.66\end{array}$ & $\begin{array}{l}2.23 \\
2.53 \\
2.63 \\
2.16 \\
1.95\end{array}$ \\
\hline 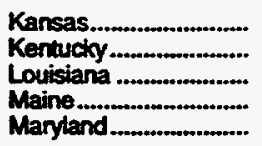 & $\begin{array}{l}0.36 \\
0.57 \\
0.38 \\
1.11 \\
0.78\end{array}$ & $\begin{array}{l}0.40 \\
0.66 \\
0.63 \\
61.20 \\
1.18\end{array}$ & $\begin{array}{r}0.54 \\
0.75 \\
0.76 \\
b_{1.46} \\
1.37\end{array}$ & $\begin{array}{l}0.81 \\
1.08 \\
0.94 \\
1.27 \\
1.62\end{array}$ & $\begin{array}{r}0.99 \\
1.41 \\
1.18 \\
b_{2} .69 \\
2.20\end{array}$ & $\begin{array}{l}1.15 \\
1.59 \\
0.96 \\
b 2.78 \\
2.63\end{array}$ & $\begin{array}{l}1.63 \\
1.98 \\
0.92 \\
3.26 \\
2.19\end{array}$ \\
\hline 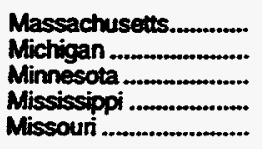 & $\begin{array}{l}1.30 \\
0.69 \\
0.54 \\
0.44 \\
0.46\end{array}$ & $\begin{array}{l}1.71 \\
0.91 \\
0.64 \\
0.57 \\
0.58\end{array}$ & $\begin{array}{l}2.29 \\
1.25 \\
0.84 \\
0.72 \\
0.80\end{array}$ & $\begin{array}{l}2.50 \\
1.55 \\
1.13 \\
1.05 \\
1.00\end{array}$ & $\begin{array}{l}2.60 \\
1.84 \\
1.12 \\
1.46 \\
1.45\end{array}$ & $\begin{array}{l}3.01 \\
1.94 \\
1.24 \\
1.52 \\
1.46\end{array}$ & $\begin{array}{l}3.23 \\
2.31 \\
1.45 \\
2.27 \\
1.95\end{array}$ \\
\hline 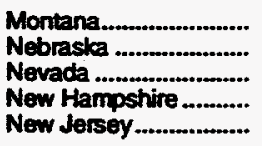 & $\begin{array}{r}0.43 \\
0.44 \\
0.79 \\
b \\
0.87\end{array}$ & $\begin{array}{r}0.58 \\
0.54 \\
0.88 \\
b \\
1.11\end{array}$ & $\begin{array}{r}0.95 \\
0.69 \\
1.13 \\
b \\
1.70\end{array}$ & $\begin{array}{r}1.00 \\
0.85 \\
1.43 \\
b \\
2.18\end{array}$ & $\begin{array}{r}1.56 \\
1.02 \\
1.97 \\
b \\
2.42\end{array}$ & $\begin{array}{r}1.64 \\
1.11 \\
1.78 \\
b \\
3.39\end{array}$ & $\begin{array}{r}1.75 \\
1.25 \\
2.33 \\
b \\
3.19\end{array}$ \\
\hline $\begin{array}{l}\text { New Mexico .................. } \\
\text { New York.................. } \\
\text { North Carolina............... } \\
\text { North Dakota............... } \\
\text { Ohio ........................... }\end{array}$ & $\begin{array}{l}0.38 \\
0.91 \\
0.68 \\
0.54 \\
0.67\end{array}$ & $\begin{array}{l}0.55 \\
1.11 \\
0.87 \\
0.64 \\
0.81\end{array}$ & $\begin{array}{l}0.62 \\
1.49 \\
1.36 \\
1.00 \\
1.11\end{array}$ & $\begin{array}{l}0.70 \\
1.58 \\
1.68 \\
1.33 \\
1.39\end{array}$ & $\begin{array}{l}1.48 \\
1.92 \\
2.37 \\
1.71 \\
1.90\end{array}$ & $\begin{array}{l}1.72 \\
227 \\
1.96 \\
1.96 \\
2.01\end{array}$ & $\begin{array}{l}2.12 \\
2.75 \\
2.68 \\
2.51 \\
2.36\end{array}$ \\
\hline $\begin{array}{l}\text { Oktahoma .................... } \\
\text { Oregon..................... } \\
\text { Pennsytvania .............. } \\
\text { Rhode Istand............... } \\
\text { South Carolina ............. }\end{array}$ & $\begin{array}{l}0.36 \\
0.70 \\
0.76 \\
1.34 \\
0.65\end{array}$ & $\begin{array}{l}0.49 \\
0.89 \\
0.94 \\
1.73 \\
0.72\end{array}$ & $\begin{array}{l}0.72 \\
0.96 \\
1.10 \\
2.13 \\
1.03\end{array}$ & $\begin{array}{l}0.89 \\
1.77 \\
1.35 \\
2.29 \\
1.29\end{array}$ & $\begin{array}{l}1.33 \\
2.11 \\
1.92 \\
2.95 \\
1.60\end{array}$ & $\begin{array}{l}1.49 \\
2.52 \\
2.02 \\
2.80 \\
1.85\end{array}$ & $\begin{array}{l}1.80 \\
2.90 \\
2.50 \\
2.67 \\
2.47\end{array}$ \\
\hline 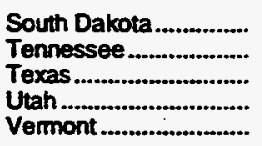 & $\begin{array}{r}0.41 \\
0.50 \\
0.31 \\
0.39 \\
b\end{array}$ & $\begin{array}{r}0.72 \\
0.61 \\
0.53 \\
0.46 \\
b\end{array}$ & $\begin{array}{r}0.60 \\
0.75 \\
0.95 \\
0.69 \\
b\end{array}$ & $\begin{array}{r}0.73 \\
1.17 \\
1.31 \\
0.96 \\
b\end{array}$ & $\begin{array}{r}0.96 \\
1.49 \\
1.27 \\
1.18 \\
b\end{array}$ & $\begin{array}{r}1.60 \\
1.61 \\
1.91 \\
1.43 \\
b\end{array}$ & $\begin{array}{r}2.04 \\
2.11 \\
1.90 \\
1.74 \\
b\end{array}$ \\
\hline 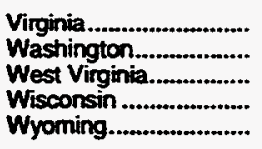 & $\begin{array}{l}0.66 \\
0.53 \\
0.63 \\
0.68 \\
0.31\end{array}$ & $\begin{array}{l}0.93 \\
0.81 \\
0.75 \\
0.77 \\
0.37\end{array}$ & $\begin{array}{l}1.10 \\
1.34 \\
1.01 \\
1.05 \\
0.52\end{array}$ & $\begin{array}{l}1.45 \\
1.74 \\
1.30 \\
1.40 \\
0.69\end{array}$ & $\begin{array}{l}1.93 \\
2.12 \\
2.02 \\
1.78 \\
0.94\end{array}$ & $\begin{array}{l}2.14 \\
2.51 \\
1.88 \\
2.03 \\
1.28\end{array}$ & $\begin{array}{l}2.33 \\
2.93 \\
2.46 \\
2.43 \\
1.91\end{array}$ \\
\hline Average ........................ & 0.50 & 0.67 & 0.96 & 1.24 & 1.50 & 1.70 & 1.99 \\
\hline
\end{tabular}

See tootnotes at end of table. 
Table 27. Average Price of Natural Gas Delivered to U.S. Industrial Consumers by State, 1967-1992 (Continued) (Dollars per Thousand Cubic Feet)

\begin{tabular}{|c|c|c|c|c|c|c|}
\hline State & 2980 & 1981 & 1982 & 1983 & 1984 & 1985 \\
\hline 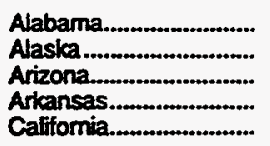 & $\begin{array}{l}2.54 \\
0.38 \\
2.68 \\
2.22 \\
3.80\end{array}$ & $\begin{array}{l}3.15 \\
0.36 \\
3.17 \\
2.76 \\
4.05\end{array}$ & $\begin{array}{l}4.24 \\
0.58 \\
4.04 \\
3.24 \\
4.88\end{array}$ & $\begin{array}{l}4.50 \\
0.67 \\
4.14 \\
3.63 \\
5.49\end{array}$ & $\begin{array}{l}4.37 \\
0.66 \\
4.36 \\
3.88 \\
5.20\end{array}$ & $\begin{array}{l}4.25 \\
0.71 \\
4.45 \\
3.71 \\
4.72\end{array}$ \\
\hline $\begin{array}{l}\text { Colorado } \\
\text { Comecticutt... } \\
\text { D.C } \\
\text { Delaware } \\
\text { Plorida }\end{array}$ & $\begin{array}{l}2.63 \\
4.17 \\
2.45 \\
2.80 \\
2.78\end{array}$ & $\begin{array}{l}3.40 \\
5.09 \\
3.00 \\
3.66 \\
3.27\end{array}$ & $\begin{array}{l}3.98 \\
6.02 \\
4.58 \\
4.07\end{array}$ & $\begin{array}{r}4.28 \\
5.93 \\
4.28 \\
4.10\end{array}$ & $\begin{array}{l}4.26 \\
5.63 \\
4.31 \\
4.26\end{array}$ & $\begin{array}{l}4.01 \\
5.54 \\
4 . \overline{88} \\
4.11\end{array}$ \\
\hline 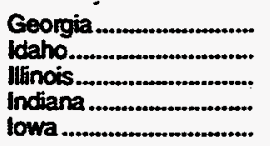 & $\begin{array}{l}2.84 \\
3.76 \\
3.17 \\
2.60 \\
2.51\end{array}$ & $\begin{array}{l}3.68 \\
3.99 \\
3.61 \\
3.04 \\
3.10\end{array}$ & $\begin{array}{l}4.17 \\
4.80 \\
4.26 \\
3.76 \\
3.74\end{array}$ & $\begin{array}{l}4.52 \\
5.12 \\
4.83 \\
4.36 \\
4.10\end{array}$ & $\begin{array}{l}4.58 \\
4.69 \\
4.61 \\
4.26 \\
4.00\end{array}$ & $\begin{array}{l}4.53 \\
4.53 \\
4.76 \\
4.07 \\
3.91\end{array}$ \\
\hline 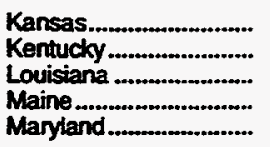 & $\begin{array}{l}2.33 \\
2.68 \\
1.28 \\
4.29 \\
3.25\end{array}$ & $\begin{array}{l}3.02 \\
3.18 \\
1.88 \\
5.21 \\
3.97\end{array}$ & $\begin{array}{l}2.94 \\
4.12 \\
3.16 \\
6.63 \\
5.04\end{array}$ & $\begin{array}{l}3.39 \\
4.57 \\
3.13 \\
7.66 \\
6.02\end{array}$ & $\begin{array}{l}4.08 \\
4.39 \\
3.18 \\
7.26 \\
6.00\end{array}$ & $\begin{array}{l}3.54 \\
4.38 \\
3.03 \\
6.36 \\
5.70\end{array}$ \\
\hline 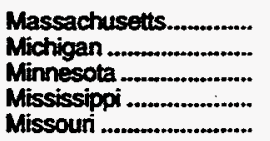 & $\begin{array}{l}4.15 \\
2.92 \\
2.49 \\
2.75 \\
2.65\end{array}$ & $\begin{array}{l}5.09 \\
3.55 \\
3.18 \\
3.32 \\
3.33\end{array}$ & $\begin{array}{l}5.67 \\
4.32 \\
4.10 \\
4.12 \\
4.41\end{array}$ & $\begin{array}{l}5.67 \\
5.13 \\
4.46 \\
4.30 \\
5.01\end{array}$ & $\begin{array}{l}5.48 \\
4.93 \\
4.31 \\
3.94 \\
4.81\end{array}$ & $\begin{array}{l}5.36 \\
5.06 \\
4.05 \\
3.77 \\
4.21\end{array}$ \\
\hline 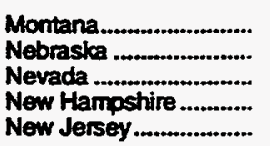 & $\begin{array}{l}3.14 \\
2.16 \\
2.97 \\
3.92 \\
3.74\end{array}$ & $\begin{array}{l}4.26 \\
2.78 \\
3.61 \\
4.63 \\
4.72\end{array}$ & $\begin{array}{l}5.49 \\
3.55 \\
4.41 \\
5.56 \\
5.24\end{array}$ & $\begin{array}{l}3.99 \\
3.72 \\
4.82 \\
6.00 \\
5.45\end{array}$ & $\begin{array}{l}5.17 \\
3.64 \\
5.07 \\
5.23 \\
5.62\end{array}$ & $\begin{array}{l}4.71 \\
3.60 \\
4.29 \\
5.56 \\
5.51\end{array}$ \\
\hline 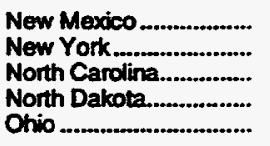 & $\begin{array}{l}2.57 \\
3.50 \\
3.36 \\
2.71 \\
3.05\end{array}$ & $\begin{array}{l}2.99 \\
3.96 \\
4.42 \\
4.10 \\
3.43\end{array}$ & $\begin{array}{l}3.61 \\
4.97 \\
4.64 \\
4.32 \\
4.32\end{array}$ & $\begin{array}{l}3.89 \\
5.68 \\
5.17 \\
4.77 \\
5.15\end{array}$ & $\begin{array}{l}4.09 \\
5.35 \\
5.31 \\
4.44 \\
5.04\end{array}$ & $\begin{array}{l}3.99 \\
5.27 \\
4.91 \\
4.45 \\
4.87\end{array}$ \\
\hline 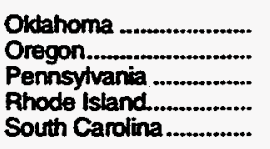 & $\begin{array}{l}2.11 \\
4.39 \\
3.06 \\
4.54 \\
2.99\end{array}$ & $\begin{array}{l}2.55 \\
4.62 \\
3.70 \\
5.32 \\
3.84\end{array}$ & $\begin{array}{l}2.96 \\
5.58 \\
4.50 \\
6.18 \\
4.37\end{array}$ & $\begin{array}{l}3.35 \\
5.34 \\
5.07 \\
6.17 \\
4.86\end{array}$ & $\begin{array}{l}3.33 \\
5.19 \\
5.09 \\
5.82 \\
5.04\end{array}$ & $\begin{array}{l}3.30 \\
4.79 \\
4.93 \\
5.89 \\
4.70\end{array}$ \\
\hline 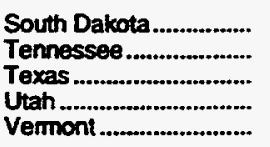 & $\begin{array}{l}2.34 \\
2.57 \\
2.31 \\
2.26 \\
4.88\end{array}$ & $\begin{array}{l}3.02 \\
3.15 \\
2.91 \\
2.58 \\
5.61\end{array}$ & $\begin{array}{l}3.90 \\
3.96 \\
3.40 \\
2.45 \\
5.46\end{array}$ & $\begin{array}{l}4.46 \\
4.31 \\
3.45 \\
3.15 \\
5.02\end{array}$ & $\begin{array}{l}4.65 \\
4.11 \\
3.82 \\
3.52 \\
5.18\end{array}$ & $\begin{array}{l}4.15 \\
4.25 \\
3.19 \\
3.23 \\
4.87\end{array}$ \\
\hline 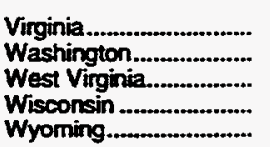 & $\begin{array}{l}3.03 \\
4.30 \\
2.99 \\
3.14 \\
2.46\end{array}$ & $\begin{array}{l}3.59 \\
4.62 \\
3.52 \\
3.77 \\
3.07\end{array}$ & $\begin{array}{l}4.39 \\
5.56 \\
4.38 \\
4.42 \\
3.42\end{array}$ & $\begin{array}{l}5.04 \\
5.26 \\
5.08 \\
4.69 \\
3.68\end{array}$ & $\begin{array}{l}4.94 \\
5.16 \\
4.79 \\
4.46 \\
3.65\end{array}$ & $\begin{array}{l}4.78 \\
4.76 \\
4.69 \\
4.49 \\
3.55\end{array}$ \\
\hline 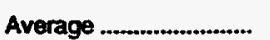 & 2.56 & 3.14 & 3.87 & 4.18 & 4.22 & 3.95 \\
\hline
\end{tabular}

See footnotes at end of table. 
Table 27. Average Price of Natural Gas Delivered to U.S. Industrial Consumers by State, 1967-1992 (Continued) (Dollars per Thousand Cubic Feet)

\begin{tabular}{|c|c|c|c|c|c|c|c|}
\hline Stat & 1986 & 1987 & 1988 & 1989 & 1990 & 1991 & 1992 \\
\hline 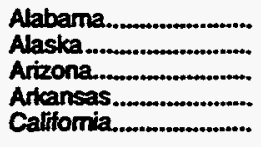 & $\begin{array}{l}3.66 \\
0.81 \\
3.91 \\
3.45 \\
3.59\end{array}$ & $\begin{array}{l}3.11 \\
0.74 \\
3.75 \\
3.14 \\
3.48\end{array}$ & $\begin{array}{l}3.00 \\
1.07 \\
3.78 \\
3.06 \\
3.76\end{array}$ & $\begin{array}{l}3.02 \\
1.08 \\
3.67 \\
3.09 \\
3.75\end{array}$ & $\begin{array}{l}3.16 \\
1.21 \\
3.71 \\
2.88 \\
3.91\end{array}$ & $\begin{array}{l}3.00 \\
1.18 \\
3.51 \\
3.06 \\
3.96\end{array}$ & $\begin{array}{l}3.07 \\
1.18 \\
4.16 \\
3.13 \\
3.67\end{array}$ \\
\hline 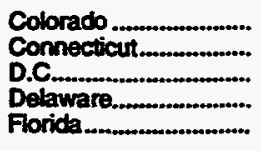 & $\begin{array}{r}3.83 \\
4.67 \\
3.47 \\
3.06\end{array}$ & $\begin{array}{r}3.60 \\
4.21 \\
- \\
3.30 \\
3.29\end{array}$ & $\begin{array}{r}3.45 \\
4.05 \\
-\overline{3.22} \\
2.84\end{array}$ & $\begin{array}{r}2.53 \\
4.51 \\
- \\
3.45 \\
3.13\end{array}$ & $\begin{array}{r}2.78 \\
4.80 \\
-\overline{3.44} \\
3.58\end{array}$ & $\begin{array}{r}2.34 \\
4.84 \\
3.09 \\
3.11\end{array}$ & $\begin{array}{r}2.20 \\
4.92 \\
3.25 \\
3.22\end{array}$ \\
\hline 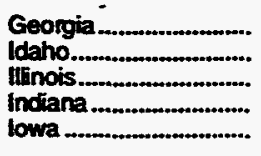 & $\begin{array}{l}3.91 \\
3.30 \\
4.14 \\
3.83 \\
3.39\end{array}$ & $\begin{array}{l}3.66 \\
6.70 \\
3.83 \\
3.41 \\
2.82\end{array}$ & $\begin{array}{l}3.61 \\
4.26 \\
3.42 \\
3.75 \\
3.11\end{array}$ & $\begin{array}{l}3.73 \\
2.92 \\
3.73 \\
3.89 \\
2.54\end{array}$ & $\begin{array}{l}3.59 \\
2.72 \\
4.10 \\
3.64 \\
2.87\end{array}$ & $\begin{array}{l}3.34 \\
2.94 \\
3.77 \\
3.58 \\
2.65\end{array}$ & $\begin{array}{l}3.50 \\
2.97 \\
3.75 \\
3.39 \\
3.55\end{array}$ \\
\hline 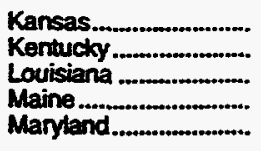 & $\begin{array}{l}3.12 \\
3.93 \\
1.91 \\
5.99 \\
\mathbf{5 . 6 2}\end{array}$ & $\begin{array}{l}3.07 \\
3.39 \\
1.80 \\
5.47 \\
5.14\end{array}$ & $\begin{array}{l}2.36 \\
3.44 \\
1.99 \\
4.51 \\
4.30\end{array}$ & $\begin{array}{l}3.06 \\
3.69 \\
1.97 \\
4.57 \\
4.81\end{array}$ & $\begin{array}{l}2.88 \\
3.61 \\
2.00 \\
5.06 \\
4.57\end{array}$ & $\begin{array}{l}2.67 \\
3.23 \\
1.74 \\
4.69 \\
3.51\end{array}$ & $\begin{array}{l}2.61 \\
3.23 \\
1.93 \\
4.14 \\
3.56\end{array}$ \\
\hline 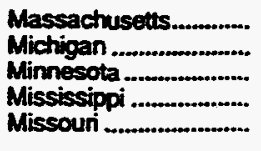 & $\begin{array}{l}5.01 \\
4.57 \\
3.41 \\
3.15 \\
3.79\end{array}$ & $\begin{array}{l}4.25 \\
4.42 \\
2.55 \\
2.75 \\
3.65\end{array}$ & $\begin{array}{l}4.03 \\
4.36 \\
2.81 \\
2.54 \\
3.81\end{array}$ & $\begin{array}{l}4.07 \\
4.22 \\
2.86 \\
2.54 \\
4.13\end{array}$ & $\begin{array}{l}4.14 \\
3.89 \\
2.97 \\
2.57 \\
4.19\end{array}$ & $\begin{array}{l}3.99 \\
4.00 \\
2.78 \\
2.35 \\
4.08\end{array}$ & $\begin{array}{l}4.14 \\
3.92 \\
3.05 \\
2.53 \\
3.87\end{array}$ \\
\hline 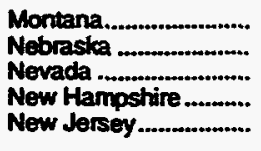 & $\begin{array}{l}3.91 \\
3.25 \\
3.99 \\
5.17 \\
4.38\end{array}$ & $\begin{array}{l}3.42 \\
2.77 \\
3.73 \\
4.34 \\
4.08\end{array}$ & $\begin{array}{l}3.08 \\
2.85 \\
3.83 \\
3.72 \\
3.87\end{array}$ & $\begin{array}{l}2.98 \\
2.92 \\
4.98 \\
4.20 \\
3.98\end{array}$ & $\begin{array}{l}3.27 \\
2.97 \\
4.10 \\
4.36 \\
3.95\end{array}$ & $\begin{array}{l}3.22 \\
2.76 \\
4.21 \\
4.31 \\
3.65\end{array}$ & $\begin{array}{l}4.19 \\
2.92 \\
4.07 \\
4.49 \\
3.42\end{array}$ \\
\hline 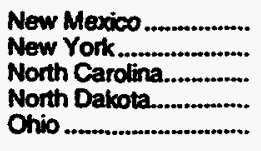 & $\begin{array}{l}3.30 \\
4.91 \\
4.00 \\
4.08 \\
4.68\end{array}$ & $\begin{array}{l}3.57 \\
4.28 \\
3.76 \\
3.24 \\
4.27\end{array}$ & $\begin{array}{l}3.39 \\
4.69 \\
3.57 \\
3.41 \\
4.10\end{array}$ & $\begin{array}{l}3.12 \\
4.83 \\
3.64 \\
3.55 \\
4.19\end{array}$ & $\begin{array}{l}3.69 \\
4.86 \\
3.47 \\
3.34 \\
4.08\end{array}$ & $\begin{array}{l}3.53 \\
4.72 \\
3.24 \\
3.19 \\
4.09\end{array}$ & $\begin{array}{l}6.86 \\
4.93 \\
3.34 \\
3.25 \\
4.15\end{array}$ \\
\hline 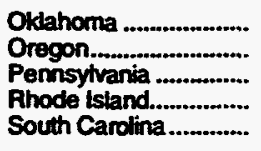 & $\begin{array}{l}2.63 \\
3.81 \\
4.36 \\
5.74 \\
3.73\end{array}$ & $\begin{array}{l}2.02 \\
3.39 \\
3.65 \\
5.37 \\
3.93\end{array}$ & $\begin{array}{l}1.76 \\
3.72 \\
3.63 \\
4.83 \\
3.43\end{array}$ & $\begin{array}{l}1.97 \\
3.52 \\
3.90 \\
5.16 \\
3.46\end{array}$ & $\begin{array}{l}1.74 \\
3.47 \\
4.17 \\
5.32 \\
3.35\end{array}$ & $\begin{array}{l}1.69 \\
3.41 \\
4.02 \\
5.40 \\
2.95\end{array}$ & $\begin{array}{l}2.02 \\
3.36 \\
3.75 \\
4.66 \\
3.13\end{array}$ \\
\hline 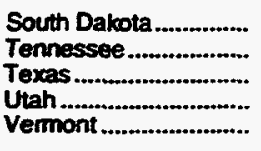 & $\begin{array}{l}3.55 \\
3.89 \\
2.46 \\
3.00 \\
3.52\end{array}$ & $\begin{array}{l}3.08 \\
3.15 \\
2.06 \\
3.20 \\
3.47\end{array}$ & $\begin{array}{l}3.18 \\
3.26 \\
2.19 \\
3.10 \\
2.97\end{array}$ & $\begin{array}{l}3.09 \\
3.37 \\
2.24 \\
3.30 \\
3.01\end{array}$ & $\begin{array}{l}3.79 \\
3.41 \\
2.18 \\
3.62 \\
3.51\end{array}$ & $\begin{array}{l}3.31 \\
3.22 \\
1.93 \\
3.69 \\
2.99\end{array}$ & $\begin{array}{l}3.63 \\
3.44 \\
2.12 \\
3.91 \\
3.28\end{array}$ \\
\hline $\begin{array}{l}\text { Virginia...................... } \\
\text { Washington................ } \\
\text { West Vinginia................ } \\
\text { Wisconsin ................... } \\
\text { Wyoming...................... }\end{array}$ & $\begin{array}{l}3.96 \\
3.60 \\
4.15 \\
4.22 \\
3.33\end{array}$ & $\begin{array}{l}3.64 \\
2.87 \\
3.48 \\
4.36 \\
3.38\end{array}$ & $\begin{array}{l}3.35 \\
2.97 \\
2.86 \\
4.08 \\
3.36\end{array}$ & $\begin{array}{l}3.91 \\
2.93 \\
2.92 \\
3.73 \\
3.23\end{array}$ & $\begin{array}{l}3.67 \\
2.72 \\
2.95 \\
3.39 \\
3.23\end{array}$ & $\begin{array}{l}3.81 \\
2.79 \\
2.95 \\
3.16 \\
3.03\end{array}$ & $\begin{array}{l}3.72 \\
2.91 \\
2.89 \\
3.38 \\
2.91\end{array}$ \\
\hline Average ........................... & 3.23 & 2.94 & 2.95 & 2.96 & 2.93 & 2.69 & 2.84 \\
\hline
\end{tabular}

- Data for the District of Columbia are included wth Marytand.

- Data for New Hampshire and Vermont are included with data for Maine.

Note: Beginning in 1987, prices for gas delivered to consumers are calculated using only onsystem sales data. In previous years, prices were calculated using reported values and values imputed for gas delivered for the account of others.

Sources: 1967-1975: Bureau of Mines, Ninemis Yeartook "Natural Gas" chapter, 1976-1978: Energy information Administration (Ela), Eneroy Data Report Natural Gas Annual. 1979: EIA, Natural Gas Production and Consumption 1979. 1980-1992: ElA, Form ElA-176. "Annual Report of Natural and Supplemental Gas Supply and Dispesition." 
Table 28. Average Price of Natural Gas Delivered to U.S. Industrial Consumers by State, 1993-1994 (Dollars per Thousand Cubic Feet)

\begin{tabular}{|c|c|c|c|c|c|}
\hline \multirow{2}{*}{ State } & \multicolumn{2}{|c|}{1993} & \multicolumn{2}{|c|}{1994} & \\
\hline & Average Price & $\begin{array}{l}\text { Percentwe of Total } \\
\text { Volume Dolivered }\end{array}$ & Average Price & $\begin{array}{l}\text { Percentage of Total } \\
\text { Volume Delivered }\end{array}$ & \\
\hline 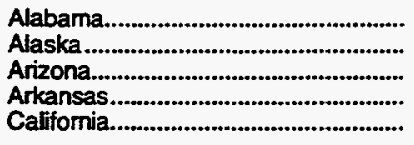 & $\begin{array}{r}R_{3.28} \\
1.29 \\
4.02 \\
3.31 \\
2.82\end{array}$ & $\begin{array}{l}27.5 \\
70.6 \\
25.0 \\
13.8 \\
26.4\end{array}$ & $\begin{array}{l}3.26 \\
1.42 \\
3.57 \\
3.28 \\
3.25\end{array}$ & $\begin{array}{l}27.3 \\
58.4 \\
30.3 \\
13.8 \\
18.2\end{array}$ & \\
\hline 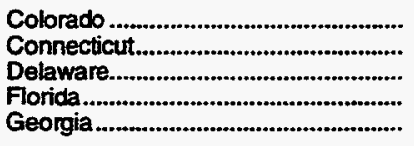 & $\begin{array}{r}2.35 \\
4.77 \\
3.40 \\
R_{3.88} \\
4.10\end{array}$ & $\begin{array}{l}35.6 \\
72.4 \\
74.7 \\
26.9 \\
32.8\end{array}$ & $\begin{array}{l}2.38 \\
4.49 \\
3.43 \\
3.51 \\
3.90\end{array}$ & $\begin{array}{l}27.9 \\
95.3 \\
67.3 \\
16.3 \\
37.4\end{array}$ & \\
\hline 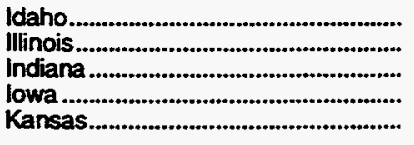 & $\begin{array}{r}3.02 \\
4.44 \\
3.71 \\
R_{3.76} \\
2.64\end{array}$ & $\begin{array}{r}0.3 \\
13.1 \\
20.1 \\
14.6 \\
13.0\end{array}$ & $\begin{array}{l}3.85 \\
4.39 \\
4.60 \\
3.99 \\
2.75\end{array}$ & $\begin{array}{r}2.9 \\
12.4 \\
13.4 \\
11.7 \\
6.5\end{array}$ & \\
\hline 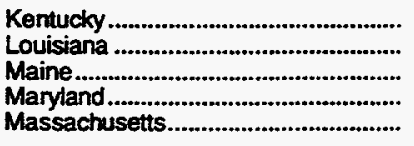 & $\begin{array}{l}3.66 \\
2.30 \\
4.65 \\
3.59 \\
5.08\end{array}$ & $\begin{array}{r}30.1 \\
31.1 \\
100.0 \\
20.2 \\
30.6\end{array}$ & $\begin{array}{l}3.64 \\
2.17 \\
4.79 \\
4.04 \\
5.25\end{array}$ & $\begin{array}{r}31.2 \\
24.0 \\
100.0 \\
16.8 \\
27.7\end{array}$ & \\
\hline 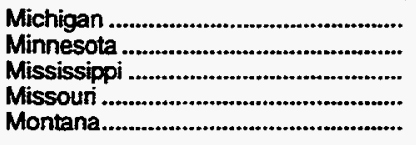 & $\begin{array}{l}3.91 \\
3.20 \\
2.99 \\
4.25 \\
2.76\end{array}$ & $\begin{array}{r}9.1 \\
43.4 \\
39.6 \\
23.6 \\
10.1\end{array}$ & $\begin{array}{l}3.93 \\
2.87 \\
2.98 \\
4.18 \\
4.91\end{array}$ & $\begin{array}{r}10.6 \\
42.9 \\
39.1 \\
20.6 \\
3.9\end{array}$ & \\
\hline 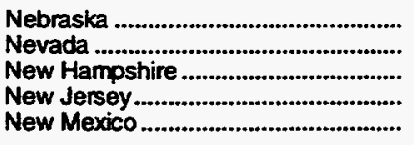 & $\begin{array}{l}3.09 \\
4.30 \\
4.68 \\
3.70 \\
3.82\end{array}$ & $\begin{array}{r}27.4 \\
4.3 \\
100.0 \\
55.9 \\
5.4\end{array}$ & $\begin{array}{l}3.12 \\
5.67 \\
4.44 \\
3.64 \\
3.39\end{array}$ & $\begin{array}{r}21.6 \\
1.9 \\
95.0 \\
57.4 \\
9.9\end{array}$ & \\
\hline 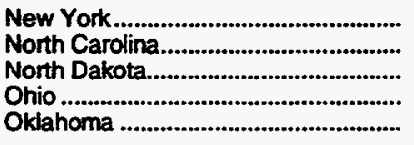 & $\begin{array}{l}5.17 \\
3.74 \\
3.42 \\
4.64 \\
2.20\end{array}$ & $\begin{array}{l}21.5 \\
78.3 \\
25.0 \\
10.2 \\
30.4\end{array}$ & $\begin{array}{l}5.22 \\
3.68 \\
3.31 \\
4.45 \\
2.14\end{array}$ & $\begin{array}{r}16.1 \\
59.0 \\
24.7 \\
9.7 \\
24.3\end{array}$ & \\
\hline 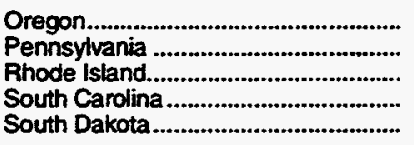 & $\begin{array}{l}3.48 \\
3.85 \\
5.11 \\
3.35 \\
3.76\end{array}$ & $\begin{array}{l}28.1 \\
24.2 \\
10.4 \\
64.9 \\
51.2\end{array}$ & $\begin{array}{l}3.61 \\
4.01 \\
4.43 \\
3.32 \\
3.72\end{array}$ & $\begin{array}{r}31.5 \\
20.5 \\
9.0 \\
76.7 \\
37.4\end{array}$ & \\
\hline 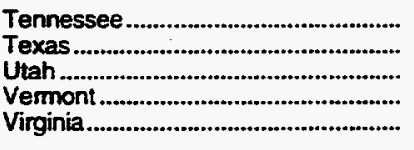 & $\begin{array}{r}3.89 \\
R_{2.51} \\
3.67 \\
3.57 \\
3.88\end{array}$ & $\begin{array}{r}46.3 \\
31.7 \\
6.9 \\
100.0 \\
24.9\end{array}$ & $\begin{array}{l}3.84 \\
2.20 \\
2.74 \\
3.47 \\
3.15\end{array}$ & $\begin{array}{r}45.7 \\
27.8 \\
12.0 \\
100.0 \\
21.5\end{array}$ & \\
\hline 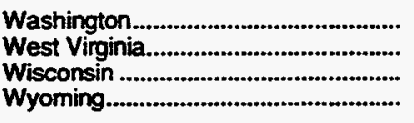 & $\begin{array}{r}3.22 \\
R_{2.74} \\
3.52 \\
3.62\end{array}$ & $\begin{array}{r}41.3 \\
20.6 \\
45.6 \\
2.4\end{array}$ & $\begin{array}{l}2.95 \\
2.93 \\
3.36 \\
3.51\end{array}$ & $\begin{array}{r}41.6 \\
13.0 \\
48.8 \\
2.2\end{array}$ & \\
\hline 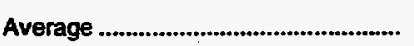 & $R_{3.07}$ & 29.0 & 3.05 & 25.1 & \\
\hline
\end{tabular}

$R=$ Revised data

Note: Totals may not equal sum of components due to independent rounding

Sources: 1993-1994: EIA, Form EIA-176, "Annual Report of Natural and Supplemental Gas Supply and Disposition." 
Table 29. Prices of Natural Gas Deliveries to Industrial Consumers by State, 1993-1994 (Dollars per Thousand Cubic Feet)

\begin{tabular}{|c|c|c|c|c|c|c|}
\hline \multirow{2}{*}{ Stop } & \multicolumn{2}{|c|}{ Fim } & \multicolumn{2}{|c|}{ Interruptiblo } & \multicolumn{2}{|c|}{ Total } \\
\hline & Avernge Price & $\begin{array}{l}\text { Porcentuge of Total } \\
\text { Volume Delivered }\end{array}$ & Avenge Price & $\begin{array}{l}\text { Percentege of Total } \\
\text { Volume Delivered }\end{array}$ & Total Average Price & $\begin{array}{l}\text { Parcentuge of Total } \\
\text { Volume Delivered }\end{array}$ \\
\hline & \multicolumn{6}{|c|}{1993} \\
\hline 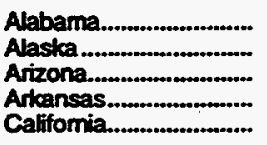 & $\begin{array}{l}R_{3.72} \\
1.29 \\
3.98 \\
3.27 \\
2.91\end{array}$ & $\begin{array}{l}29.2 \\
72.5 \\
24.9 \\
11.5 \\
28.8\end{array}$ & $\begin{array}{l}3.06 \\
1.36 \\
4.79 \\
3.40 \\
0.71\end{array}$ & $\begin{array}{r}26.7 \\
10.3 \\
26.9 \\
28.0 \\
8.9\end{array}$ & $\begin{array}{r}R_{3.28} \\
1.29 \\
4.02 \\
3.31 \\
2.82\end{array}$ & $\begin{array}{l}27.5 \\
70.6 \\
25.0 \\
13.8 \\
26.4\end{array}$ \\
\hline 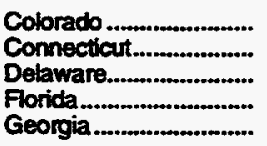 & $\begin{array}{r}2.48 \\
5.85 \\
3.70 \\
R_{3.87} \\
5.14\end{array}$ & $\begin{array}{r}27.6 \\
74.2 \\
62.6 \\
P_{35.8} \\
44.9\end{array}$ & $\begin{array}{l}2.28 \\
3.67 \\
3.01 \\
3.88 \\
3.78\end{array}$ & $\begin{array}{r}42.0 \\
70.7 \\
100.0 \\
23.3 \\
30.3\end{array}$ & $\begin{array}{r}2.35 \\
4.77 \\
3.40 \\
83.88 \\
4.10\end{array}$ & $\begin{array}{l}35.6 \\
72.4 \\
74.7 \\
26.9 \\
32.8\end{array}$ \\
\hline 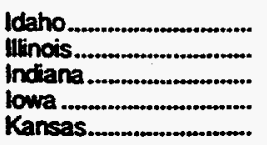 & $\begin{array}{r}3.02 \\
4.65 \\
4.23 \\
\mathrm{~A}_{4.28} \\
2.44\end{array}$ & $\begin{array}{r}0.3 \\
12.0 \\
51.2 \\
9.2 \\
24.4\end{array}$ & $\begin{array}{l}3.32 \\
2.90 \\
3.09 \\
3.60\end{array}$ & $\begin{array}{l}25 . \overline{0} \\
10.4 \\
56.3 \\
3.9\end{array}$ & $\begin{array}{r}3.02 \\
4.44 \\
3.71 \\
n_{3.76} \\
2.64\end{array}$ & $\begin{array}{r}0.3 \\
13.1 \\
20.1 \\
14.6 \\
13.0\end{array}$ \\
\hline 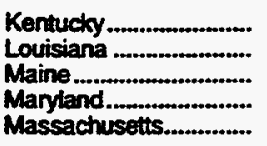 & $\begin{array}{l}3.98 \\
2.29 \\
4.65 \\
6.17 \\
5.89\end{array}$ & $\begin{array}{r}32.3 \\
41.1 \\
100.0 \\
2.5 \\
26.2\end{array}$ & $\begin{array}{r}3.28 \\
2.36 \\
-\overline{3.51} \\
3.35\end{array}$ & $\begin{array}{r}27.8 \\
15.4 \\
26 . \overline{3} \\
47.3\end{array}$ & $\begin{array}{l}3.66 \\
2.30 \\
4.65 \\
3.59 \\
5.08\end{array}$ & $\begin{array}{r}30.1 \\
31.1 \\
100.0 \\
20.2 \\
30.6\end{array}$ \\
\hline 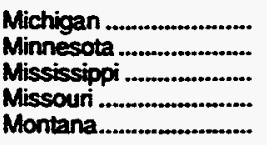 & $\begin{array}{l}3.92 \\
3.86 \\
2.98 \\
4.48 \\
2.78\end{array}$ & $\begin{array}{r}9.5 \\
23.1 \\
50.5 \\
35.8 \\
21.6\end{array}$ & $\begin{array}{l}3.69 \\
2.84 \\
2.99 \\
3.59 \\
2.59\end{array}$ & $\begin{array}{r}4.2 \\
83.8 \\
34.5 \\
11.8 \\
2.0\end{array}$ & $\begin{array}{l}3.91 \\
3.20 \\
2.99 \\
4.25 \\
2.76\end{array}$ & $\begin{array}{r}9.1 \\
43.4 \\
39.6 \\
23.6 \\
10.1\end{array}$ \\
\hline 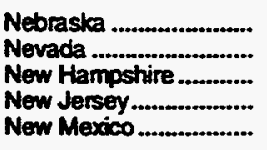 & $\begin{array}{l}3.63 \\
4.30 \\
4.71 \\
4.82 \\
3.81\end{array}$ & $\begin{array}{r}13.3 \\
4.3 \\
100.0 \\
35.5 \\
5.5\end{array}$ & $\begin{array}{r}2.80 \\
-\overline{3} \\
3.67 \\
3.98\end{array}$ & $\begin{array}{r}65.6 \\
100 . \overline{0} \\
69.1 \\
1.6\end{array}$ & $\begin{array}{l}3.09 \\
4.30 \\
4.68 \\
3.70 \\
3.82\end{array}$ & $\begin{array}{r}27.4 \\
4.3 \\
100.0 \\
55.9 \\
5.4\end{array}$ \\
\hline $\begin{array}{l}\text { New York..................... } \\
\text { North Carolina............... } \\
\text { North Dakota................ } \\
\text { Ohio .............................. } \\
\text { Oidahoma ..................... }\end{array}$ & $\begin{array}{l}5.87 \\
4.07 \\
4.81 \\
4.76 \\
2.61\end{array}$ & $\begin{array}{l}23.4 \\
83.9 \\
32.3 \\
10.8 \\
57.6\end{array}$ & $\begin{array}{l}3.49 \\
3.69 \\
3.29 \\
3.40 \\
1.95\end{array}$ & $\begin{array}{r}18.0 \\
77.5 \\
24.5 \\
6.5 \\
23.6\end{array}$ & $\begin{array}{l}5.17 \\
3.74 \\
3.42 \\
4.64 \\
2.20\end{array}$ & $\begin{array}{l}21.5 \\
78.3 \\
25.0 \\
10.2 \\
30.4\end{array}$ \\
\hline $\begin{array}{l}\text { Oregon ....................... } \\
\text { Pennsylvania ............... } \\
\text { Rhode tsland.............. } \\
\text { Soith Carolina............. } \\
\text { South Dakola................ }\end{array}$ & $\begin{array}{l}3.76 \\
4.01 \\
7.00 \\
4.35 \\
4.03\end{array}$ & $\begin{array}{r}69.0 \\
R_{25.8} \\
5.3 \\
71.5 \\
84.8\end{array}$ & $\begin{array}{l}2.95 \\
3.53 \\
3.36 \\
3.19 \\
3.18\end{array}$ & $\begin{array}{r}13.4 \\
R_{21.4} \\
98.5 \\
64.0 \\
27.9\end{array}$ & $\begin{array}{l}3.48 \\
3.85 \\
5.11 \\
3.35 \\
3.76\end{array}$ & $\begin{array}{l}28.1 \\
24.2 \\
10.4 \\
64.9 \\
51.2\end{array}$ \\
\hline 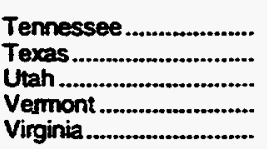 & $\begin{array}{r}4.43 \\
R_{2.50} \\
3.68 \\
5.27 \\
4.32\end{array}$ & $\begin{array}{r}A_{70.5} \\
A_{51.6} \\
100.0 \\
100.0 \\
20.6\end{array}$ & $\begin{array}{r}3.42 \\
\AA_{2.53} \\
3.63 \\
3.48 \\
3.41\end{array}$ & $\begin{array}{r}R_{35.6} \\
R_{11.5} \\
2.5 \\
100.0 \\
32.0\end{array}$ & $\begin{array}{r}3.89 \\
R_{2.51} \\
3.67 \\
3.57 \\
3.88\end{array}$ & $\begin{array}{r}46.3 \\
31.7 \\
6.9 \\
100.0 \\
24.9\end{array}$ \\
\hline 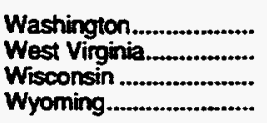 & $\begin{array}{l}3.15 \\
2.71 \\
3.58 \\
3.54\end{array}$ & $\begin{array}{r}65.6 \\
28.6 \\
57.0 \\
7.9\end{array}$ & $\begin{array}{r}3.52 \\
\mathbf{R}_{3.17} \\
\mathbf{3 . 4 7} \\
\mathbf{3 . 7 8}\end{array}$ & $\begin{array}{r}15.9 \\
R_{1.9} \\
39.4 \\
0.9\end{array}$ & $\begin{array}{r}3.22 \\
R_{2.74} \\
3.52 \\
3.62\end{array}$ & $\begin{array}{r}41.3 \\
20.6 \\
45.6 \\
2.4\end{array}$ \\
\hline 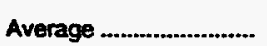 & $A_{3.06}$ & $\mathrm{~A}_{33.6}$ & $A_{3.08}$ & 23.3 & $A_{3.07}$ & 29.0 \\
\hline
\end{tabular}

See foomotes at end of table. 
Table 29. Prices of Natural Gas Deliveries to Industrial Consumers by State, 1993-1994 (Continued) (Dollars per Thousand Cubic Feet)

\begin{tabular}{|c|c|c|c|c|c|c|}
\hline \multirow{2}{*}{ State } & \multicolumn{2}{|c|}{ Firm } & \multicolumn{2}{|c|}{ Imerruptiblo } & \multicolumn{2}{|c|}{ Total } \\
\hline & Average Price & $\begin{array}{l}\text { Percentego of Totel } \\
\text { Vclume Delivered }\end{array}$ & Average Price & $\begin{array}{l}\text { Percemtege of Total } \\
\text { Volume Dolivered }\end{array}$ & Total Average Price & $\begin{array}{l}\text { Percentege of Totel } \\
\text { Volume Delivered }\end{array}$ \\
\hline & \multicolumn{6}{|c|}{1994} \\
\hline 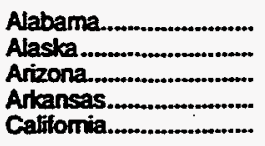 & $\begin{array}{l}3.97 \\
1.42 \\
3.53 \\
3.46 \\
3.20\end{array}$ & $\begin{array}{r}17.2 \\
62.3 \\
30.3 \\
6.8 \\
24.1\end{array}$ & $\begin{array}{r}3.02 \\
-\overline{-} \\
4.66 \\
3.15 \\
3.45\end{array}$ & $\begin{array}{r}33.9 \\
- \\
30.4 \\
56.2 \\
8.8\end{array}$ & $\begin{array}{l}3.26 \\
1.42 \\
3.57 \\
3.28 \\
3.25\end{array}$ & $\begin{array}{l}27.3 \\
58.4 \\
30.3 \\
13.8 \\
18.2\end{array}$ \\
\hline 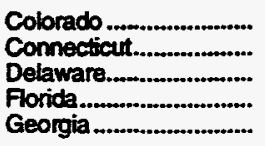 & $\begin{array}{l}2.63 \\
5.92 \\
4.52 \\
3.60 \\
5.21\end{array}$ & $\begin{array}{l}29.4 \\
98.6 \\
45.5 \\
17.7 \\
29.6\end{array}$ & $\begin{array}{l}2.25 \\
3.16 \\
2.69 \\
3.45 \\
3.55\end{array}$ & $\begin{array}{r}27.1 \\
92.4 \\
100.0 \\
15.5 \\
40.2\end{array}$ & $\begin{array}{l}2.38 \\
4.49 \\
3.43 \\
3.51 \\
3.90\end{array}$ & $\begin{array}{l}27.9 \\
95.3 \\
67.3 \\
16.3 \\
37.4\end{array}$ \\
\hline 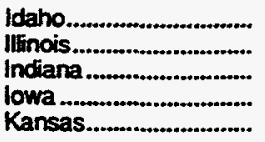 & $\begin{array}{l}3.73 \\
4.61 \\
4.75 \\
4.62 \\
3.25\end{array}$ & $\begin{array}{r}1.8 \\
11.5 \\
45.5 \\
8.7 \\
3.5\end{array}$ & $\begin{array}{l}3.99 \\
2.97 \\
4.05 \\
2.88 \\
2.56\end{array}$ & $\begin{array}{r}11.7 \\
23.3 \\
3.9 \\
29.4 \\
9.9\end{array}$ & $\begin{array}{l}3.85 \\
4.39 \\
4.60 \\
3.99 \\
2.75\end{array}$ & $\begin{array}{r}2.9 \\
12.4 \\
13.4 \\
11.7 \\
6.5\end{array}$ \\
\hline 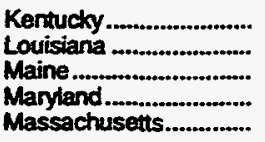 & $\begin{array}{l}4.02 \\
2.14 \\
5.77 \\
6.15 \\
6.69\end{array}$ & $\begin{array}{r}30.8 \\
28.4 \\
100.0 \\
3.1 \\
23.9\end{array}$ & $\begin{array}{l}3.23 \\
2.22 \\
2.91 \\
3.94 \\
2.82\end{array}$ & $\begin{array}{r}31.7 \\
17.4 \\
100.0 \\
21.3 \\
38.0\end{array}$ & $\begin{array}{l}3.64 \\
2.17 \\
4.79 \\
4.04 \\
5.25\end{array}$ & $\begin{array}{r}31.2 \\
24.0 \\
100.0 \\
16.8 \\
27.7\end{array}$ \\
\hline 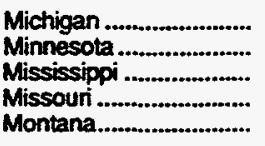 & $\begin{array}{l}3.94 \\
4.36 \\
2.98 \\
4.62 \\
4.91\end{array}$ & $\begin{array}{r}11.5 \\
15.8 \\
25.5 \\
17.3 \\
9.8\end{array}$ & $\begin{array}{l}3.53 \\
2.43 \\
2.98 \\
3.24 \\
4.61\end{array}$ & $\begin{array}{r}2.8 \\
86.0 \\
60.2 \\
34.6 \\
-\end{array}$ & $\begin{array}{l}3.93 \\
2.87 \\
2.98 \\
4.18 \\
4.91\end{array}$ & $\begin{array}{r}10.6 \\
42.9 \\
39.1 \\
20.6 \\
3.9\end{array}$ \\
\hline $\begin{array}{l}\text { Nebraska ....................... } \\
\text { Nevada ..................... } \\
\text { New Hampshire ............. } \\
\text { New Jersey................... } \\
\text { New Mexico.................. }\end{array}$ & $\begin{array}{l}3.90 \\
\mathbf{5 . 6 7} \\
\mathbf{4 . 8 1} \\
4.37 \\
\mathbf{3 . 3 9}\end{array}$ & $\begin{array}{r}9.9 \\
1.9 \\
93.8 \\
38.5 \\
10.2\end{array}$ & $\begin{array}{r}2.66 \\
2.50 \\
3.38 \\
4.05\end{array}$ & $\begin{array}{r}71.2 \\
100 . \overline{-} \\
69.7 \\
2.4\end{array}$ & $\begin{array}{l}3.12 \\
5.67 \\
4.44 \\
3.64 \\
3.39\end{array}$ & $\begin{array}{r}21.6 \\
1.9 \\
95.0 \\
57.4 \\
9.9\end{array}$ \\
\hline 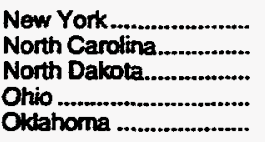 & $\begin{array}{l}5.84 \\
3.84 \\
4.44 \\
4.53 \\
2.48\end{array}$ & $\begin{array}{l}18.3 \\
64.9 \\
34.1 \\
10.3 \\
48.0\end{array}$ & $\begin{array}{l}3.62 \\
3.64 \\
3.16 \\
3.57 \\
1.91\end{array}$ & $\begin{array}{r}12.3 \\
57.5 \\
23.8 \\
5.9 \\
18.2\end{array}$ & $\begin{array}{l}5.22 \\
3.68 \\
3.31 \\
4.45 \\
2.14\end{array}$ & $\begin{array}{r}16.1 \\
59.0 \\
24.7 \\
9.7 \\
24.3\end{array}$ \\
\hline $\begin{array}{l}\text { Oregon } \\
\text { Pennsytvania .................... } \\
\text { Rhode Istand................ } \\
\text { South Carolina.............. } \\
\text { South Dakota............... }\end{array}$ & $\begin{array}{l}3.90 \\
4.21 \\
5.09 \\
4.44 \\
4.15\end{array}$ & $\begin{array}{r}60.9 \\
18.4 \\
6.2 \\
73.4 \\
51.5\end{array}$ & $\begin{array}{l}3.20 \\
3.65 \\
3.08 \\
3.09 \\
2.94\end{array}$ & $\begin{array}{l}18.9 \\
26.0 \\
99.7 \\
77.4 \\
25.1\end{array}$ & $\begin{array}{l}3.61 \\
4.01 \\
4.43 \\
3.32 \\
3.72\end{array}$ & $\begin{array}{r}31.5 \\
20.5 \\
9.0 \\
76.7 \\
37.4\end{array}$ \\
\hline 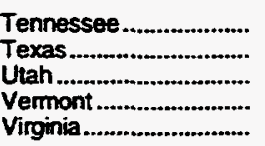 & $\begin{array}{l}4.26 \\
2.16 \\
2.91 \\
4.95 \\
4.06\end{array}$ & $\begin{array}{r}62.3 \\
40.7 \\
100.0 \\
100.0 \\
14.9\end{array}$ & $\begin{array}{l}3.40 \\
2.60 \\
2.61 \\
3.38 \\
2.50\end{array}$ & $\begin{array}{r}35.7 \\
7.7 \\
6.9 \\
100.0 \\
31.3\end{array}$ & $\begin{array}{l}3.84 \\
2.20 \\
2.74 \\
3.47 \\
3.15\end{array}$ & $\begin{array}{r}45.7 \\
27.8 \\
12.0 \\
100.0 \\
21.5\end{array}$ \\
\hline 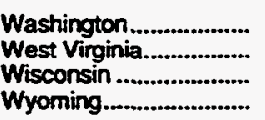 & $\begin{array}{l}2.88 \\
2.91 \\
4.34 \\
3.37\end{array}$ & $\begin{array}{r}73.1 \\
27.5 \\
84.8 \\
6.2\end{array}$ & $\begin{array}{l}3.23 \\
3.20 \\
2.80 \\
3.64\end{array}$ & $\begin{array}{r}15.6 \\
1.7 \\
39.1 \\
1.4\end{array}$ & $\begin{array}{l}2.95 \\
2.93 \\
3.36 \\
3.51\end{array}$ & $\begin{array}{r}41.6 \\
13.0 \\
48.8 \\
2.2\end{array}$ \\
\hline Average .......................... & 3.08 & 27.1 & 3.01 & 22.4 & 3.05 & 25.1 \\
\hline
\end{tabular}

$R=$ Revised data.

Note: Totals may not equal sum of components due to independent rouncing

Source: 1993-1994: Energy information Administration (ElA), Form ElA-176, "Annual Report of Natural and Supplemental Gas Supply and Disposition." 
Table 30. Average Price of Natural Gas Delivered to U.S. Vehicle Fuel Consumers by State, 1990-1994 (Dollars per Thousand Cubic Feet)

\begin{tabular}{|c|c|c|c|c|c|c|c|c|c|c|}
\hline \multirow[b]{2}{*}{ State } & \multicolumn{2}{|c|}{1990} & \multicolumn{2}{|c|}{1991} & \multicolumn{2}{|c|}{1992} & \multicolumn{2}{|c|}{1993} & \multicolumn{2}{|c|}{1994} \\
\hline & $\begin{array}{l}\text { Averege } \\
\text { Price }\end{array}$ & $\begin{array}{l}\text { Percentege } \\
\text { of Total } \\
\text { Yolume } \\
\text { Delivered }\end{array}$ & $\begin{array}{l}\text { Average } \\
\text { Price }\end{array}$ & $\begin{array}{l}\text { Percentage } \\
\text { of Total } \\
\text { Yolume } \\
\text { Delivered }\end{array}$ & $\begin{array}{l}\text { Avernge } \\
\text { Price }\end{array}$ & $\begin{array}{l}\text { Purcontage } \\
\text { of Total } \\
\text { Volume } \\
\text { Dolinened }\end{array}$ & $\begin{array}{l}\text { Average } \\
\text { Price }\end{array}$ & $\begin{array}{l}\text { Percentuge } \\
\text { of Total } \\
\text { Volume } \\
\text { Delivened }\end{array}$ & $\begin{array}{l}\text { Averege } \\
\text { Price }\end{array}$ & $\begin{array}{l}\text { Pereantage } \\
\text { of Total } \\
\text { Volume } \\
\text { Dolivered }\end{array}$ \\
\hline 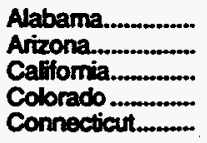 & $\begin{array}{r}0.74 \\
- \\
4.84 \\
3.48 \\
-\end{array}$ & $\begin{array}{l}- \\
\overline{-} \\
-\end{array}$ & $\begin{array}{r}3.82 \\
5.77 \\
3.44 \\
-\end{array}$ & $\begin{array}{l}\overline{-} \\
\overline{-}\end{array}$ & $\begin{array}{r}6.46 \\
3.63 \\
6.43 \\
3.45 \\
12.45\end{array}$ & $\begin{array}{l}- \\
=\end{array}$ & $\begin{array}{l}4.60 \\
3.57 \\
4.76 \\
2.70 \\
8.97\end{array}$ & $\begin{array}{r}100.0 \\
100.0 \\
88.9 \\
80.9 \\
100.0\end{array}$ & $\begin{array}{l}4.24 \\
3.93 \\
5.09 \\
3.55 \\
7.74\end{array}$ & $\begin{array}{r}100.0 \\
100.0 \\
65.7 \\
88.0 \\
100.0\end{array}$ \\
\hline 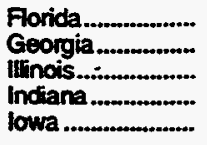 & $\begin{array}{l}2.72 \\
4.50 \\
2.69 \\
6.48\end{array}$ & $\begin{array}{l}- \\
\overline{-} \\
-\end{array}$ & $\begin{array}{r}4.73 \\
3.41 \\
4.71 \\
3.11\end{array}$ & $=$ & $\begin{array}{l}4.44 \\
3.80 \\
4.25 \\
3.99\end{array}$ & $\begin{array}{l}- \\
\overline{-} \\
\overline{-}\end{array}$ & $\begin{array}{l}4.45 \\
3.54 \\
4.04 \\
5.23 \\
3.84\end{array}$ & $\begin{array}{r}100.0 \\
100.0 \\
87.1 \\
100.0 \\
100.0\end{array}$ & $\begin{array}{l}4.36 \\
4.07 \\
3.26 \\
5.11 \\
3.51\end{array}$ & $\begin{array}{r}100.0 \\
100.0 \\
93.6 \\
100.0 \\
100.0\end{array}$ \\
\hline $\begin{array}{l}\text { Kansas................. } \\
\text { Kentucky............. } \\
\text { Louisiana ........... } \\
\text { Maryland............ } \\
\text { Massactusetts.... }\end{array}$ & $\frac{-}{3 . \overline{4}}$ & $\begin{array}{l}- \\
- \\
-\end{array}$ & $\begin{array}{c}\overline{-} \\
3.56 \\
3.50\end{array}$ & $\begin{array}{l}\bar{z} \\
\bar{z}\end{array}$ & $\begin{array}{r}3 . \overline{8} \\
4.30 \\
3.65\end{array}$ & $\begin{array}{l}- \\
\overline{-} \\
-\end{array}$ & $\begin{array}{l}5.30 \\
3.47 \\
3.57 \\
4.97\end{array}$ & $\begin{array}{l}100 . \overline{0} \\
100.0 \\
100.0 \\
100.0\end{array}$ & $\begin{array}{l}3.18 \\
4.62 \\
2.36 \\
3.76 \\
5.66\end{array}$ & $\begin{array}{l}100.0 \\
100.0 \\
100.0 \\
100.0 \\
100.0\end{array}$ \\
\hline $\begin{array}{l}\text { Michigan .............. } \\
\text { Mimesota........... } \\
\text { Mississippi ........... } \\
\text { Missoun .............. } \\
\text { Montana............. }\end{array}$ & $\begin{array}{r}2.03 \\
- \\
- \\
4.59\end{array}$ & $\begin{array}{l}- \\
- \\
-\end{array}$ & $\begin{array}{r}2.15 \\
- \\
4.50\end{array}$ & $\begin{array}{l}- \\
\overline{-}\end{array}$ & $\begin{array}{r}0.99 \\
\overline{-} \\
4.51\end{array}$ & $\begin{array}{l}- \\
\overline{-} \\
-\end{array}$ & $\begin{array}{r}3.36 \\
6.08 \\
- \\
5.17\end{array}$ & $\begin{array}{r}97.6 \\
100.0 \\
- \\
100.0\end{array}$ & $\begin{array}{l}2.84 \\
1.90 \\
2.82 \\
4.37 \\
4.34\end{array}$ & $\begin{array}{r}97.1 \\
100.0 \\
100.0 \\
100.0 \\
100.0\end{array}$ \\
\hline $\begin{array}{l}\text { Nebraska ............. } \\
\text { Nevada ............. } \\
\text { New Hampshire .. } \\
\text { New Jersey.......... } \\
\text { New Mexico........ }\end{array}$ & $\begin{array}{l}- \\
\overline{-} \\
-\end{array}$ & $\begin{array}{l}- \\
\overline{-} \\
-\end{array}$ & $\begin{array}{r}3.72 \\
- \\
-\end{array}$ & $\begin{array}{l}- \\
\overline{-} \\
\overline{-}\end{array}$ & $\begin{array}{r}3 . \overline{5} \\
\overline{-} \\
-\end{array}$ & $\begin{array}{l}- \\
\overline{-} \\
\overline{-}\end{array}$ & $\begin{array}{r}3.34 \\
- \\
-\end{array}$ & $\begin{array}{r}\overline{-} \\
\overline{-} \\
\overline{-}\end{array}$ & $\begin{array}{l}4.67 \\
3.81 \\
6.21 \\
4.26 \\
5.11\end{array}$ & $\begin{array}{r}100.0 \\
98.7 \\
100.0 \\
100.0 \\
72.4\end{array}$ \\
\hline $\begin{array}{l}\text { New York............ } \\
\text { North Carolina..... } \\
\text { North Dakota...... } \\
\text { Otio .................... } \\
\text { Odtahoma ............ }\end{array}$ & $\begin{array}{r}4.70 \\
4.56 \\
4.31 \\
3.16 \\
-\end{array}$ & $\begin{array}{l}- \\
- \\
-\end{array}$ & $\begin{array}{l}4.68 \\
4.65 \\
3.34 \\
2.97 \\
3.83\end{array}$ & $\begin{array}{l}- \\
- \\
-\end{array}$ & $\begin{array}{l}5.47 \\
5.08 \\
4.25 \\
3.12 \\
3.06\end{array}$ & $\overline{-}$ & $\begin{array}{l}4.45 \\
2.60 \\
4.61 \\
4.82 \\
2.66\end{array}$ & $\begin{array}{l}100.0 \\
100.0 \\
100.0 \\
100.0 \\
100.0\end{array}$ & $\begin{array}{l}3.64 \\
4.44 \\
4.19 \\
4.87 \\
2.36\end{array}$ & $\begin{array}{l}100.0 \\
100.0 \\
100.0 \\
100.0 \\
100.0\end{array}$ \\
\hline $\begin{array}{l}\text { Oregon............ } \\
\text { Pennsytvania ...... } \\
\text { Rhode Istand...... } \\
\text { South Carolina ..... } \\
\text { South Dakota...... }\end{array}$ & $\begin{array}{r}4.88 \\
3.87 \\
- \\
-\end{array}$ & $\begin{array}{l}- \\
\overline{-} \\
\overline{-}\end{array}$ & $\begin{array}{r}5 . \overline{26} \\
3.77 \\
4 . \overline{13}\end{array}$ & $\begin{array}{l}- \\
- \\
-\end{array}$ & $\begin{array}{r}2.17 \\
5.97 \\
3.88 \\
-- \\
4.08\end{array}$ & $\begin{array}{l}- \\
- \\
- \\
-\end{array}$ & $\begin{array}{r}3.77 \\
8.28 \\
7.09 \\
-19\end{array}$ & $\begin{array}{r}100.0 \\
100.0 \\
100.0 \\
100.0\end{array}$ & $\begin{array}{l}4.91 \\
6.46 \\
7.09 \\
3.40 \\
3.17\end{array}$ & $\begin{array}{l}100.0 \\
100.0 \\
100.0 \\
100.0 \\
100.0\end{array}$ \\
\hline $\begin{array}{l}\text { Tennessee ............ } \\
\text { Texas.................. } \\
\text { Utah ................. } \\
\text { Virginia................ } \\
\text { Washington......... }\end{array}$ & $\begin{array}{r}4.29 \\
3.09 \\
6.85 \\
4.05\end{array}$ & $\begin{array}{l}- \\
- \\
-\end{array}$ & $\begin{array}{r}4.11 \\
5.49 \\
5.52 \\
-. \\
4.06\end{array}$ & $\begin{array}{l}- \\
\overline{-} \\
\overline{-}\end{array}$ & $\begin{array}{r}4.35 \\
4.53 \\
5.42 \\
4.20\end{array}$ & $\begin{array}{l}- \\
- \\
-\end{array}$ & $\begin{array}{l}4.63 \\
5.03 \\
5.27 \\
5.62 \\
4.42\end{array}$ & $\begin{array}{r}100.0 \\
8.8 \\
100.0 \\
100.0 \\
100.0\end{array}$ & $\begin{array}{l}5.69 \\
3.41 \\
4.90 \\
2.57 \\
4.29\end{array}$ & $\begin{array}{l}100.0 \\
100.0 \\
100.0 \\
100.0 \\
100.0\end{array}$ \\
\hline $\begin{array}{l}\text { West Virginia....... } \\
\text { Wisconsin ............. } \\
\text { Wyoming........... }\end{array}$ & $3 . \overline{38}$ & - & $\begin{array}{l}3 . \overline{4} \\
5.66\end{array}$ & $\overline{-}$ & $\begin{array}{l}2.90 \\
3.69 \\
5.74\end{array}$ & $\overline{-}$ & $\begin{array}{l}2.90 \\
3.80 \\
5.66\end{array}$ & $\begin{array}{l}100.0 \\
100.0 \\
100.0\end{array}$ & $\begin{array}{l}3.82 \\
3.41 \\
4.62\end{array}$ & $\begin{array}{l}100.0 \\
100.0 \\
100.0\end{array}$ \\
\hline Average ................ & 3.39 & - & 3.96 & - & 4.05 & - & 4.27 & 87.8 & 4.13 & 86.9 \\
\hline
\end{tabular}

Note: Totals may not equal sum of components due to independent rouncing.

Source: 1990-1994: Energy Information Administration, Form ElA-176, "Annual Report of Natural and Supplemental Gas Supply and Disposition." 
Table 31. Average Price of Natural Gas Delivered to U.S. Electric Utilities by State, 1967-1994 (Dollars per Thousand Cubic Feet)

\begin{tabular}{|c|c|c|c|c|c|c|c|}
\hline State & 1967 & 1968 & 1969 & 1970 & 1971 & 1972 & 1973 \\
\hline 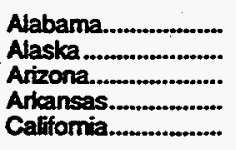 & $\begin{array}{l}0.22 \\
0.38 \\
0.31 \\
0.27 \\
0.35\end{array}$ & $\begin{array}{l}0.23 \\
0.36 \\
0.31 \\
0.25 \\
0.35\end{array}$ & $\begin{array}{l}0.26 \\
0.33 \\
0.34 \\
0.26 \\
0.33\end{array}$ & $\begin{array}{l}0.27 \\
0.37 \\
0.37 \\
0.25 \\
0.35\end{array}$ & $\begin{array}{l}0.32 \\
0.43 \\
0.42 \\
0.28 \\
0.36\end{array}$ & $\begin{array}{l}0.35 \\
0.43 \\
0.42 \\
0.31 \\
0.40\end{array}$ & $\begin{array}{l}0.39 \\
0.47 \\
0.45 \\
0.37 \\
0.45\end{array}$ \\
\hline 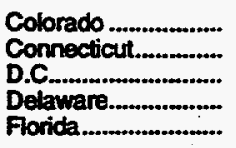 & $\begin{array}{r}0.22 \\
0.31 \\
a \\
0.29 \\
0.28\end{array}$ & $\begin{array}{l}0.22 \\
0.31 \\
a \\
0.32 \\
0.33\end{array}$ & $\begin{array}{r}0.23 \\
0.34 \\
a \\
0.34 \\
0.36\end{array}$ & $\begin{array}{l}0.23 \\
0.35 \\
a \\
0.38 \\
0.37\end{array}$ & $\begin{array}{r}0.26 \\
0.39 \\
2 \\
0.48 \\
0.40\end{array}$ & $\begin{array}{r}0.31 \\
0.43 \\
a \\
0.48 \\
0.40\end{array}$ & $\begin{array}{r}0.34 \\
-\bar{a} \\
0.57 \\
0.49\end{array}$ \\
\hline 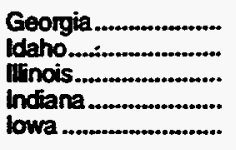 & $\begin{array}{l}0.28 \\
0.26 \\
0.27 \\
0.27\end{array}$ & $\begin{array}{l}0.27 \\
0.28 \\
0.28 \\
0.27\end{array}$ & $\begin{array}{r}0.28 \\
0.31 \\
0.29 \\
0.27\end{array}$ & $\begin{array}{l}0.29 \\
0.36 \\
0.35 \\
0.28\end{array}$ & $\begin{array}{l}0.32 \\
0.39 \\
0.39 \\
0.32\end{array}$ & $\begin{array}{l}0.36 \\
0 . \overline{4} \\
0.43 \\
0.38\end{array}$ & $\begin{array}{l}0.43 \\
0.51 \\
0.49 \\
0.41\end{array}$ \\
\hline 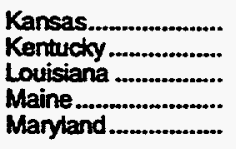 & $\begin{array}{r}0.27 \\
0.27 \\
0.21 \\
0.27\end{array}$ & $\begin{array}{r}0.28 \\
0.27 \\
0.21 \\
-\overline{0.28}\end{array}$ & $\begin{array}{r}0.27 \\
0.28 \\
0.22 \\
-\overline{0} \\
0.32\end{array}$ & $\begin{array}{l}0.29 \\
0.29 \\
0.22 \\
0.33\end{array}$ & $\begin{array}{r}0.32 \\
0.33 \\
0.24 \\
0.46 \\
0.35\end{array}$ & $\begin{array}{l}0.38 \\
0.36 \\
0.27 \\
0.45 \\
0.37\end{array}$ & $\begin{array}{l}0.40 \\
0.43 \\
0.29 \\
0.51 \\
0.42\end{array}$ \\
\hline $\begin{array}{l}\text { Massachuseits......... } \\
\text { Michigan .................. } \\
\text { Minnesota ............... } \\
\text { Mississippi ............... } \\
\text { Missouni .................. }\end{array}$ & $\begin{array}{l}0.32 \\
0.25 \\
0.25 \\
0.26 \\
0.23\end{array}$ & $\begin{array}{l}0.32 \\
0.33 \\
0.25 \\
0.26 \\
0.24\end{array}$ & $\begin{array}{l}0.34 \\
0.37 \\
0.26 \\
0.27 \\
0.25\end{array}$ & $\begin{array}{l}0.34 \\
0.42 \\
0.26 \\
0.27 \\
0.26\end{array}$ & $\begin{array}{l}0.44 \\
0.47 \\
0.29 \\
0.31 \\
0.31\end{array}$ & $\begin{array}{l}0.45 \\
0.49 \\
0.40 \\
0.32 \\
0.37\end{array}$ & $\begin{array}{l}0.54 \\
0.56 \\
0.41 \\
0.42 \\
0.42\end{array}$ \\
\hline $\begin{array}{l}\text { Montana................... } \\
\text { Nebraska ................ } \\
\text { Nevada ................. } \\
\text { New Hampshire ....... } \\
\text { New Jersey............... }\end{array}$ & $\begin{array}{r}0.24 \\
0.26 \\
0.39 \\
0.30\end{array}$ & $\begin{array}{r}0.24 \\
0.26 \\
0.38 \\
0.50\end{array}$ & $\begin{array}{r}0.23 \\
0.27 \\
0.40 \\
0.34\end{array}$ & $\begin{array}{r}0.28 \\
0.27 \\
0.41 \\
0 . \overline{-}\end{array}$ & $\begin{array}{r}0.33 \\
0.31 \\
0.45 \\
b \\
0.47\end{array}$ & $\begin{array}{r}0.34 \\
0.37 \\
0.47 \\
b \\
0.49\end{array}$ & $\begin{array}{r}0.35 \\
0.41 \\
0.53 \\
b \\
0.55\end{array}$ \\
\hline $\begin{array}{l}\text { New Mexico .............. } \\
\text { New York............... } \\
\text { North Carolina......... } \\
\text { North Dakota............ } \\
\text { Ohio ......................... }\end{array}$ & $\begin{array}{l}0.27 \\
0.43 \\
0.29 \\
0.26 \\
0.37\end{array}$ & $\begin{array}{l}0.28 \\
0.38 \\
0.31 \\
0.35 \\
0.36\end{array}$ & $\begin{array}{l}0.28 \\
0.38 \\
0.34 \\
0.35 \\
0.39\end{array}$ & $\begin{array}{l}0.32 \\
0.38 \\
0.38 \\
0.36 \\
0.40\end{array}$ & $\begin{array}{l}0.36 \\
0.44 \\
0.48 \\
0.40 \\
0.50\end{array}$ & $\begin{array}{l}0.37 \\
0.47 \\
0.50 \\
0.40 \\
0.50\end{array}$ & $\begin{array}{l}0.40 \\
0.59 \\
0.58 \\
0.42 \\
0.58\end{array}$ \\
\hline $\begin{array}{l}\text { Okdahoma .................. } \\
\text { Oregon................. } \\
\text { Pernsylvania ........... } \\
\text { Phode Istand........... } \\
\text { South Carolina........ }\end{array}$ & $\begin{array}{l}0.20 \\
0.40 \\
0.36 \\
0.37 \\
0.30\end{array}$ & $\begin{array}{l}0.19 \\
0.37 \\
0.33 \\
0.35 \\
0.30\end{array}$ & $\begin{array}{l}0.20 \\
0.37 \\
0.34 \\
0.37 \\
0.31\end{array}$ & $\begin{array}{l}0.20 \\
0.38 \\
0.43 \\
0.40 \\
0.38\end{array}$ & $\begin{array}{l}0.21 \\
0.44 \\
0.50 \\
0.50 \\
0.44\end{array}$ & $\begin{array}{l}0.25 \\
0.45 \\
0.50 \\
0.51 \\
0.49\end{array}$ & $\begin{array}{l}0.28 \\
0.49 \\
0.58 \\
0.57 \\
0.55\end{array}$ \\
\hline 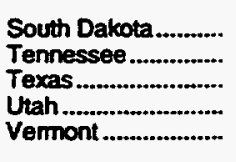 & $\begin{array}{r}0.26 \\
0.21 \\
0.26 \\
0.28 \\
-\end{array}$ & $\begin{array}{l}0.27 \\
0.21 \\
0.03 \\
0.28 \\
-\end{array}$ & $\begin{array}{l}0.30 \\
0.23 \\
0.22 \\
0.27 \\
-\end{array}$ & $\begin{array}{r}0.33 \\
0.25 \\
0.25 \\
0.29 \\
-\end{array}$ & $\begin{array}{l}0.35 \\
0.28 \\
0.29 \\
0.30 \\
b\end{array}$ & $\begin{array}{l}0.36 \\
0.33 \\
0.29 \\
0.32 \\
b\end{array}$ & $\begin{array}{r}0.42 \\
0.34 \\
0.32 \\
0.33 \\
b\end{array}$ \\
\hline $\begin{array}{l}\text { Virginia .................... } \\
\text { Washington............. } \\
\text { West Virginia............ } \\
\text { Wisconsin ................. } \\
\text { Wyoming.................. }\end{array}$ & $\begin{array}{l}0.29 \\
0.28 \\
0.29 \\
0.19\end{array}$ & $\begin{array}{l}0.28 \\
0.29 \\
0.34 \\
0.21\end{array}$ & $\begin{array}{l}0.29 \\
0.31 \\
0.35 \\
0.21\end{array}$ & $\begin{array}{l}0.30 \\
0.33 \\
0.43 \\
0.23\end{array}$ & $\begin{array}{l}0.37 \\
0.35 \\
0.45 \\
0.29\end{array}$ & $\begin{array}{l}0.42 \\
-\overline{38} \\
0.45 \\
0.30\end{array}$ & $\begin{array}{l}0.46 \\
-\overline{0.41} \\
0.52 \\
0.34\end{array}$ \\
\hline Average .................... & 0.28 & 0.22 & 0.27 & 0.29 & 0.32 & 0.34 & 0.38 \\
\hline
\end{tabular}

See footnotes at end of table. 
Table 31. Average Price of Natural Gas Delivered to U.S. Electric Utilities by State, 1967-1994 (Continued) (Dollars per Thousand Cubic Feet)

\begin{tabular}{|c|c|c|c|c|c|c|c|}
\hline $\sin$ & 1974 & 1975 & 1976 & 1977 & 1978 & 1979 & 1960 \\
\hline 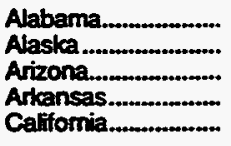 & $\begin{array}{l}0.61 \\
0.50 \\
0.54 \\
0.43 \\
0.63\end{array}$ & $\begin{array}{l}1.08 \\
0.51 \\
0.78 \\
0.67 \\
1.11\end{array}$ & $\begin{array}{l}1.12 \\
0.66 \\
0.86 \\
0.77 \\
1.50\end{array}$ & $\begin{array}{l}2.07 \\
0.76 \\
1.15 \\
1.02 \\
2.22\end{array}$ & $\begin{array}{l}2.35 \\
0.83 \\
1.42 \\
1.16 \\
2.31\end{array}$ & $\begin{array}{l}2.56 \\
0.87 \\
2.21 \\
1.76 \\
2.58\end{array}$ & $\begin{array}{l}2.96 \\
0.48 \\
2.55 \\
2.21 \\
3.71\end{array}$ \\
\hline 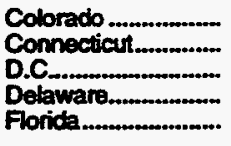 & $\begin{array}{l}0.44 \\
0.64 \\
a \\
0.80 \\
0.52\end{array}$ & $\begin{array}{l}0.60 \\
1.36 \\
\mathrm{a} \\
1.41 \\
0.56\end{array}$ & $\begin{array}{l}0.81 \\
1.66 \\
a \\
1.74 \\
0.67\end{array}$ & $\begin{array}{r}1.03 \\
\bar{a} \\
2.03 \\
0.89\end{array}$ & $\begin{array}{r}1.31 \\
\bar{a} \\
1.95 \\
1.06\end{array}$ & $\begin{array}{r}1.87 \\
\bar{a} \\
2.90 \\
1.30\end{array}$ & $\begin{array}{r}2.59 \\
3 . \overline{-} \\
1.55\end{array}$ \\
\hline 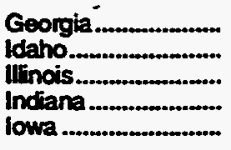 & $\begin{array}{l}0.55 \\
0.48 \\
0.73 \\
0.57 \\
0.55\end{array}$ & $\begin{array}{l}0.66 \\
0.61 \\
1.16 \\
0.82 \\
0.69\end{array}$ & $\begin{array}{l}0.98 \\
0.85 \\
1.47 \\
1.16 \\
0.93\end{array}$ & $\begin{array}{l}1.33 \\
2.04 \\
1.84 \\
1.35 \\
1.23\end{array}$ & $\begin{array}{l}1.74 \\
1.58 \\
2.94 \\
1.66 \\
1.69\end{array}$ & $\begin{array}{l}2.83 \\
2.80 \\
2.81 \\
2.26 \\
2.02\end{array}$ & $\begin{array}{l}2.65 \\
3.90 \\
3.26 \\
2.52 \\
2.43\end{array}$ \\
\hline 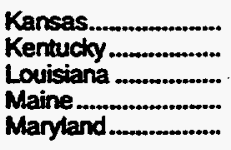 & $\begin{array}{l}0.46 \\
0.49 \\
0.49 \\
0.61 \\
0.60\end{array}$ & $\begin{array}{l}0.50 \\
0.91 \\
0.54 \\
60.69 \\
-1.02\end{array}$ & $\begin{array}{l}0.76 \\
0.96 \\
0.83 \\
0.1 .51 \\
1.30\end{array}$ & $\begin{array}{l}0.99 \\
1.11 \\
0.96 \\
0.01 \\
2.09\end{array}$ & $\begin{array}{l}1.18 \\
1.06 \\
1.18 \\
2.23 \\
2.23\end{array}$ & $\begin{array}{l}1.38 \\
1.72 \\
1.54 \\
02.63 \\
2.66\end{array}$ & $\begin{array}{r}1.71 \\
2.21 \\
2.09 \\
2.5 \overline{6}\end{array}$ \\
\hline 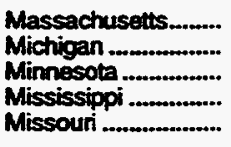 & $\begin{array}{l}0.87 \\
0.83 \\
0.47 \\
0.49 \\
0.50\end{array}$ & $\begin{array}{l}1.22 \\
1.31 \\
0.54 \\
0.72 \\
0.57\end{array}$ & $\begin{array}{l}1.7 \\
1.54 \\
0.79 \\
1.02 \\
0.74\end{array}$ & $\begin{array}{l}1.88 \\
1.33 \\
1.08 \\
1.38 \\
1.09\end{array}$ & $\begin{array}{l}1.87 \\
1.11 \\
1.35 \\
1.52 \\
1.11\end{array}$ & $\begin{array}{l}2.72 \\
1.40 \\
1.71 \\
1.83 \\
1.48\end{array}$ & $\begin{array}{l}3.40 \\
2.02 \\
1.97 \\
2.15 \\
2.17\end{array}$ \\
\hline 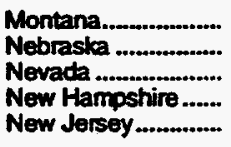 & $\begin{array}{l}0.38 \\
0.48 \\
0.76 \\
b \\
0.72\end{array}$ & $\begin{array}{l}0.49 \\
0.62 \\
1.24 \\
b \\
0.98\end{array}$ & $\begin{array}{r}0.61 \\
0.79 \\
1.45 \\
\text { b } \\
1.44\end{array}$ & $\begin{array}{l}0.79 \\
0.94 \\
1.84 \\
b \\
1.84\end{array}$ & $\begin{array}{r}0.82 \\
1.08 \\
1.68 \\
b \\
2.02\end{array}$ & $\begin{array}{r}2.28 \\
1.38 \\
2.43 \\
b \\
2.66\end{array}$ & $\begin{array}{r}4.06 \\
1.73 \\
2.78 \\
3.12\end{array}$ \\
\hline $\begin{array}{l}\text { New Mexico .............. } \\
\text { New York............. } \\
\text { North Carolina.......... } \\
\text { North Dakota.......... } \\
\text { Ohio }\end{array}$ & $\begin{array}{l}0.48 \\
0.90 \\
0.79 \\
0.47 \\
0.73\end{array}$ & $\begin{array}{l}0.54 \\
1.00 \\
0.92 \\
0.65 \\
1.30\end{array}$ & $\begin{array}{l}0.65 \\
1.24 \\
1.00 \\
0.86 \\
1.56\end{array}$ & $\begin{array}{l}1.48 \\
1.45 \\
1.00 \\
0.93 \\
0.99\end{array}$ & $\begin{array}{l}1.71 \\
1.54 \\
2.00 \\
1.38 \\
1.00\end{array}$ & $\begin{array}{l}2.14 \\
2.35 \\
4.54 \\
2.00 \\
1.39\end{array}$ & $\begin{array}{l}2.54 \\
2.76 \\
3.26 \\
2.59 \\
2.92\end{array}$ \\
\hline 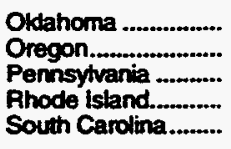 & $\begin{array}{l}0.38 \\
0.78 \\
0.87 \\
0.96 \\
0.71\end{array}$ & $\begin{array}{l}0.52 \\
1.00 \\
1.10 \\
1.27 \\
0.77\end{array}$ & $\begin{array}{l}0.85 \\
1.00 \\
1.33 \\
1.43 \\
0.92\end{array}$ & $\begin{array}{l}1.36 \\
2.00 \\
2.05 \\
1.26\end{array}$ & $\begin{array}{l}1.48 \\
2 . \overline{53} \\
1 . \overline{7}\end{array}$ & $\begin{array}{l}1.62 \\
3.05 \\
2.57 \\
2.58 \\
2.27\end{array}$ & $\begin{array}{l}1.82 \\
4.28 \\
3.67 \\
3.39 \\
2.48\end{array}$ \\
\hline 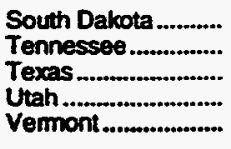 & $\begin{array}{r}0.49 \\
0.47 \\
0.43 \\
b\end{array}$ & $\begin{array}{r}0.63 \\
0.87 \\
0.64 \\
b\end{array}$ & $\begin{array}{l}0.89 \\
0.93 \\
0.98 \\
0.99 \\
b\end{array}$ & $\begin{array}{l}1.20 \\
1.25 \\
1.03 \\
b\end{array}$ & $\begin{array}{r}1.50 \\
1.44 \\
1.25 \\
b\end{array}$ & $\begin{array}{r}1.87 \\
1.66 \\
1.55 \\
b\end{array}$ & $\begin{array}{l}1.94 \\
2.37 \\
1.91 \\
1.91 \\
4.50\end{array}$ \\
\hline 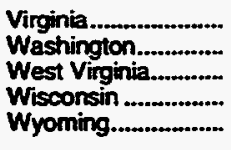 & $\begin{array}{l}0.54 \\
0 . \overline{49} \\
0.72 \\
0.47\end{array}$ & $\begin{array}{l}0.71 \\
0.63 \\
0.84 \\
0.79\end{array}$ & $\begin{array}{l}1.09 \\
0.66 \\
1.17 \\
0.80\end{array}$ & $\begin{array}{l}1.62 \\
1.94 \\
1.78 \\
1.78\end{array}$ & $\begin{array}{l}2.20 \\
2.39 \\
1.79 \\
1.99 \\
2.10\end{array}$ & $\begin{array}{l}2.87 \\
3.08 \\
2.77 \\
2.27 \\
2.71\end{array}$ & $\begin{array}{l}3.19 \\
3.54 \\
2.99 \\
2.96 \\
3.90\end{array}$ \\
\hline 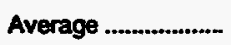 & 0.51 & 0.77 & 1.06 & 1.32 & 1.48 & 1.81 & 2.27 \\
\hline
\end{tabular}

See footnotes at end of table. 
Table 31. Average Price of Natural Gas Delivered to U.S. Electric Utilities by State, 1967-1994 (Continued) (Dollars per Thousand Cubic Feet)

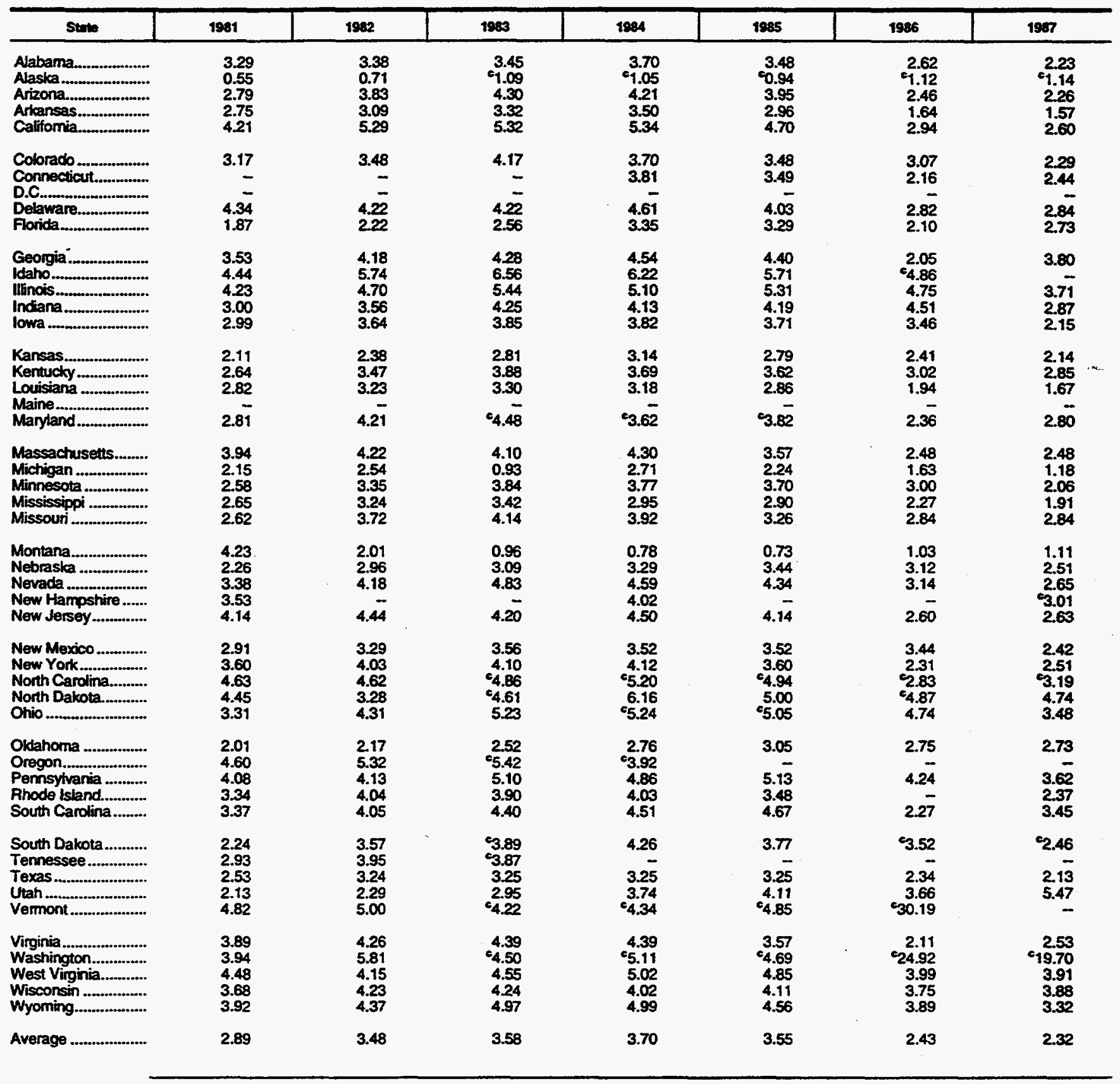

See footnotes at end of table. 
Table 31. Average Price of Natural Gas Delivered to U.S. Electric Utilities by State, 1967-1994 (Continued) (Dollars per Thousand Cubic Feet)

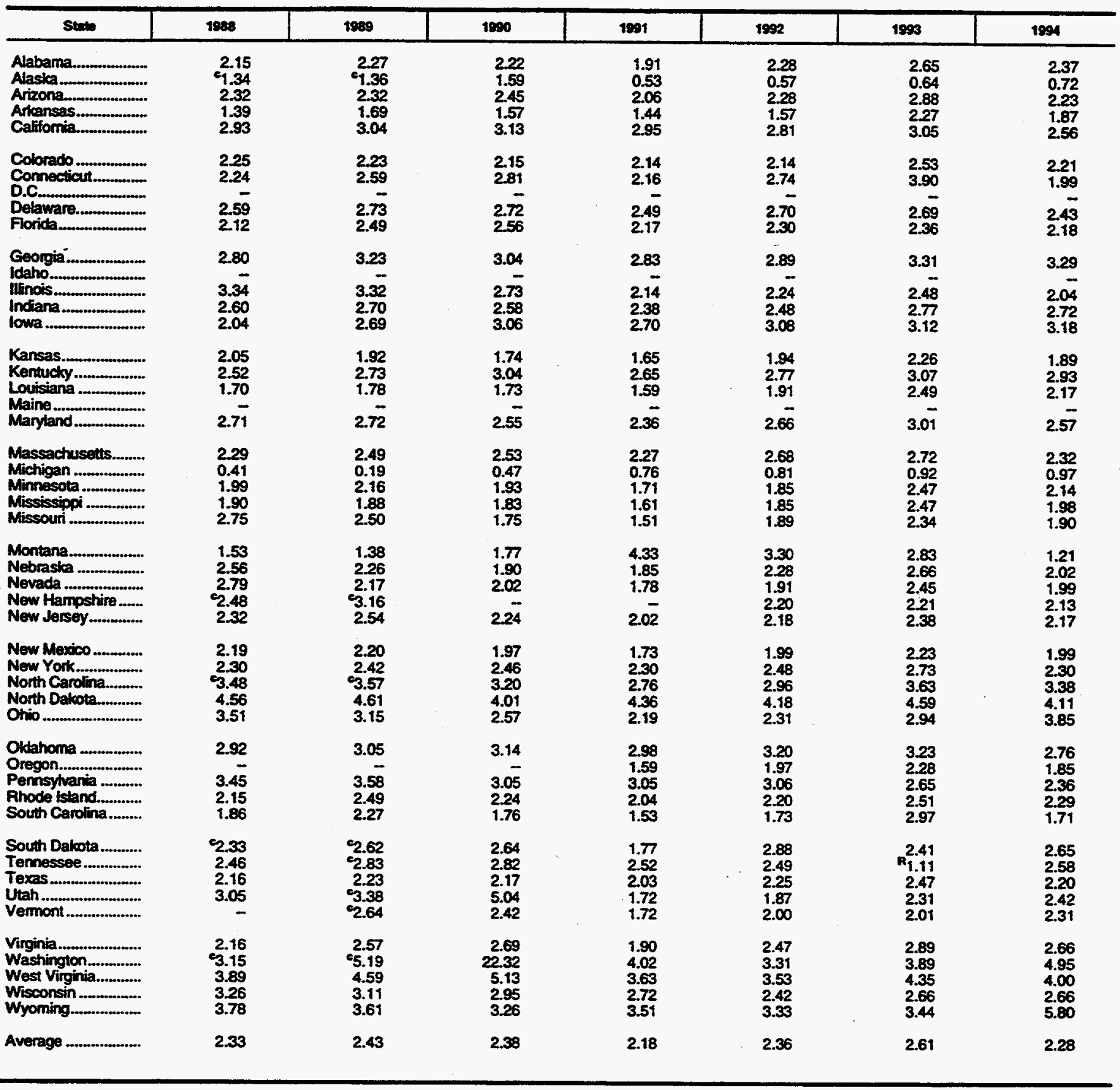

Data tor the District of Columbia are included with data for Maryland.

b Data tor New Hampstire and Vermont are included with data for Maine.

c Average prices calculated from data reported on Form EIA-176.

$\mathbf{R}=$ Revised data.

Sources: 1967-1977: Federal Power Commisston (FPC). 1978-1994: Energy Information Administration (ElA), Form ElA-759, "Monthly Power Plant Report (tormety Form FPC-4); Form FERC-423, "Cost and Cuality of Fuels for Electric Utity Plants" (formerty Form FPC-423); and Form ElA-176, "Annual Report of Natural and Supplemental Gas Supply and Disposition." 
Table 32. Prices of Natural Gas Deliveries to Electric Utilities by State, 1993-1994 (Dollars per Thousand Cubic Feet)

\begin{tabular}{|c|c|c|c|c|}
\hline \multirow{2}{*}{ State } & \multicolumn{2}{|c|}{ Firm } & \multicolumn{2}{|c|}{ Interruptible } \\
\hline & Average Price & $\begin{array}{l}\text { Percentage of Total Volume } \\
\text { Delivered }\end{array}$ & Avernge Price & $\begin{array}{l}\text { Percentage of Total Volume } \\
\text { Delivered }\end{array}$ \\
\hline & \multicolumn{4}{|c|}{1993} \\
\hline 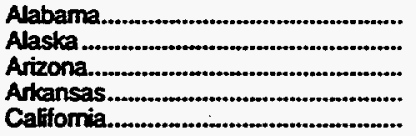 & $\begin{array}{l}1.05 \\
4.59 \\
2.25 \\
2.31\end{array}$ & $\begin{array}{r}70.3 \\
0.1 \\
19.5 \\
18.0\end{array}$ & $\begin{array}{r}2.67 \\
0.32 \\
- \\
48.70 \\
3.17\end{array}$ & $\begin{array}{r}39.3 \\
100.0 \\
98.4\end{array}$ \\
\hline 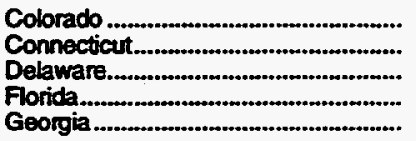 & $\begin{array}{l}2.27 \\
2.25 \\
3.02 \\
3.11 \\
2.39\end{array}$ & $\begin{array}{r}78.9 \\
100.0 \\
99.3 \\
2.2 \\
100.0\end{array}$ & $\begin{array}{r}2.51 \\
2.17 \\
3.03 \\
3.23 \\
-\end{array}$ & $\begin{array}{r}49.3 \\
100.0 \\
2.0 \\
-\end{array}$ \\
\hline 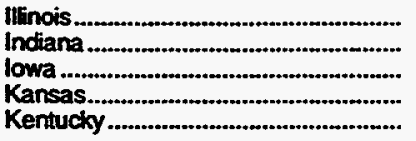 & $\begin{array}{l}4.94 \\
3.45 \\
3.07 \\
2.56 \\
2.94\end{array}$ & $\begin{array}{r}5.6 \\
100.0 \\
49.1 \\
61.3 \\
100.0\end{array}$ & $\begin{array}{l}2.71 \\
3.10 \\
2.28 \\
4.78\end{array}$ & $\begin{array}{r}100.0 \\
100 . \overline{0} \\
40.0 \\
100.0\end{array}$ \\
\hline 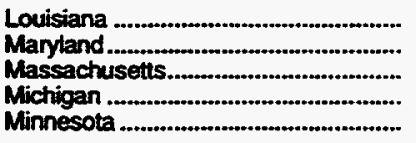 & $\begin{array}{l}2.38 \\
2.05 \\
4.02 \\
3.93\end{array}$ & $\begin{array}{r}18.5 \\
55 . \overline{9} \\
2.2 \\
100.0\end{array}$ & $\begin{array}{l}2.36 \\
3.08 \\
2.42 \\
3.67 \\
2.63\end{array}$ & $\begin{array}{l}16.1 \\
68.7 \\
58.4 \\
23.9 \\
51.3\end{array}$ \\
\hline 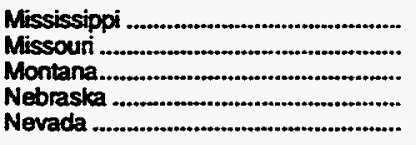 & $\begin{array}{r}2.50 \\
4.33 \\
2.62 \\
2.44 \\
12.86\end{array}$ & $\begin{array}{r}49.4 \\
6.1 \\
100.0 \\
100.0 \\
0.1\end{array}$ & $\begin{array}{r}2.79 \\
2.34 \\
-0 \\
3.00 \\
-\end{array}$ & $\begin{array}{r}0.3 \\
64.6 \\
-\overline{3} \\
-\end{array}$ \\
\hline 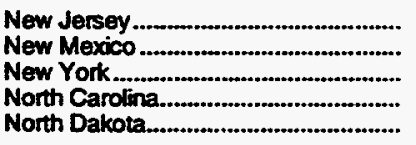 & $\begin{array}{l}2.44 \\
3.36 \\
3.06 \\
3.89 \\
5.29\end{array}$ & $\begin{array}{r}88.6 \\
6.8 \\
100.0 \\
100.0 \\
100.0\end{array}$ & $\begin{array}{r}2.70 \\
2.81 \\
3.61 \\
-\end{array}$ & $\begin{array}{r}100.0 \\
89 . \overline{5} \\
36.0 \\
-\end{array}$ \\
\hline 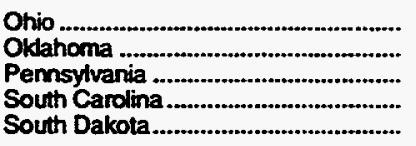 & $\begin{array}{r}4.39 \\
2.00 \\
2.68 \\
- \\
-\end{array}$ & $\begin{array}{r}78.3 \\
9.9 \\
83.7 \\
- \\
-\end{array}$ & $\begin{array}{l}3.39 \\
2.27 \\
2.99 \\
3.16 \\
2.69\end{array}$ & $\begin{array}{r}2.5 \\
18.1 \\
24.2 \\
100.0 \\
8.1\end{array}$ \\
\hline 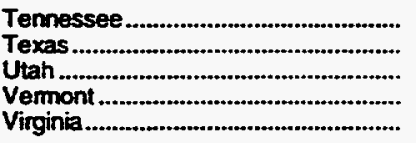 & $\begin{array}{r}2.64 \\
- \\
5.69\end{array}$ & $\begin{array}{r}R_{71.9} \\
\because \\
\hdashline\end{array}$ & $\begin{array}{r}2.78 \\
3.83 \\
12.67 \\
1.99 \\
3.20\end{array}$ & $\begin{array}{r}37.5 \\
4.3 \\
0.1 \\
100.0 \\
0.3\end{array}$ \\
\hline 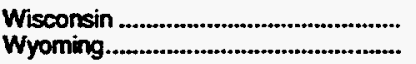 & $\begin{array}{l}3.71 \\
3.44\end{array}$ & $\begin{array}{l}100.0 \\
100.0\end{array}$ & 1.98 & 70.8 \\
\hline \multirow[t]{2}{*}{ 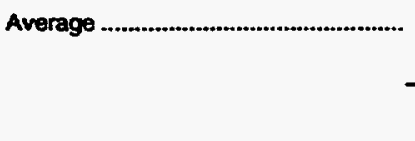 } & 2.53 & $\mathbf{R}_{35.3}$ & 2.89 & 27.1 \\
\hline & \multicolumn{4}{|c|}{1994} \\
\hline 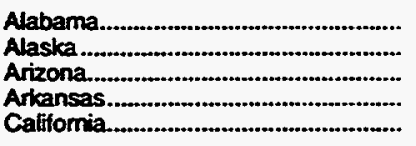 & $\begin{array}{l}1.05 \\
3.13 \\
2.19 \\
2.80\end{array}$ & $\begin{array}{r}69.6 \\
0.1 \\
5.9 \\
-\end{array}$ & $\begin{array}{r}2.29 \\
0.32 \\
- \\
2.97\end{array}$ & $\begin{array}{r}10.7 \\
100.0 \\
- \\
13 . \overline{0}\end{array}$ \\
\hline 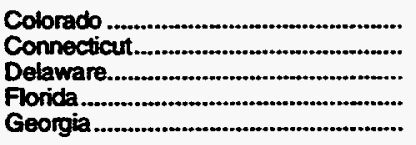 & $\begin{array}{l}2.33 \\
4.03 \\
2.85 \\
2.56\end{array}$ & $\begin{array}{r}100.0 \\
0 . \overline{4} \\
1.1 \\
100.0\end{array}$ & $\begin{array}{r}3.24 \\
2.28 \\
2.70 \\
3.17 \\
-\end{array}$ & $\begin{array}{r}0.1 \\
87.2 \\
100.0 \\
0.5 \\
-\end{array}$ \\
\hline 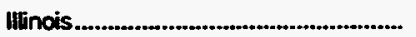 & 5.65 & 4.6 & 4.73 & 100.0 \\
\hline
\end{tabular}


Table 32. Prices of Natural Gas Deliveries to Electric Utilities by State, 1993-1994 (Continued) (Dollars per Thousand Cubic Feet)

\begin{tabular}{|c|c|c|c|c|}
\hline \multirow[b]{2}{*}{ State } & \multicolumn{2}{|c|}{ Firm } & \multicolumn{2}{|c|}{ Interreptible } \\
\hline & Average Price & $\begin{array}{l}\text { Percentiage of Totat Volume } \\
\text { Dolivered }\end{array}$ & Average Price & $\begin{array}{l}\text { Percemtage of Totel Volume } \\
\text { Delivered }\end{array}$ \\
\hline & \multicolumn{4}{|c|}{1994} \\
\hline 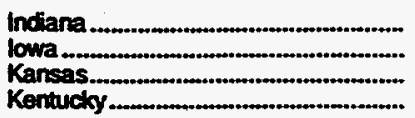 & $\begin{array}{l}2.26 \\
3.86 \\
2.20 \\
2.74\end{array}$ & $\begin{array}{r}86.7 \\
35.3 \\
10.4 \\
100.0\end{array}$ & $\begin{array}{l}2.50 \\
2.09 \\
5.10\end{array}$ & $\begin{array}{r}16 . \overline{7} \\
50.5 \\
100.0\end{array}$ \\
\hline 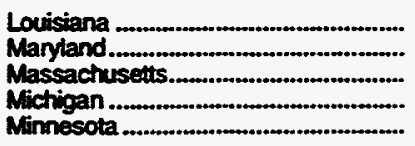 & $\begin{array}{l}2.22 \\
2.15 \\
4.00 \\
1.26\end{array}$ & $\begin{array}{r}21.3 \\
45 . \overline{4} \\
2.1 \\
100.0\end{array}$ & $\begin{array}{l}2.34 \\
2.61 \\
2.07 \\
4.25 \\
2.08\end{array}$ & $\begin{array}{r}12.6 \\
87.8 \\
8.2 \\
5.5 \\
60.5\end{array}$ \\
\hline $\begin{array}{l}\text { Mississippi } \\
\text { Missouri } \\
\text { Montana } \\
\text { Nebrastea } \\
\text { New Hampshire }\end{array}$ & $\begin{array}{l}2.08 \\
4.49 \\
2.68 \\
2.39 \\
-\end{array}$ & $\begin{array}{r}80.4 \\
2.4 \\
100.0 \\
100.0 \\
-\end{array}$ & $\begin{array}{l}2.41 \\
1.63 \\
2.20 \\
2.14\end{array}$ & $\begin{array}{r}1.1 \\
98.3 \\
93 . \overline{9} \\
100.0\end{array}$ \\
\hline $\begin{array}{l}\text { New Jersey. } \\
\text { New Mexico } \\
\text { Now York... } \\
\text { North Carokina } \\
\text { North Dakota. }\end{array}$ & $\begin{array}{l}2.15 \\
3.15 \\
2.44 \\
3.49 \\
4.47\end{array}$ & $\begin{array}{r}94.4 \\
10.3 \\
72.6 \\
70.2 \\
100.0\end{array}$ & $\begin{array}{r}2.58 \\
2.84 \\
2.50 \\
3.89 \\
-\end{array}$ & $\begin{array}{r}99.9 \\
1.2 \\
96.5 \\
44.8 \\
-\end{array}$ \\
\hline $\begin{array}{l}\text { Ohio } \\
\text { Oklahoma } \\
\text { Pennsylvania } \\
\text { South Carolina } \\
\text { Tennessee }\end{array}$ & $\begin{array}{l}4.47 \\
1.81 \\
2.73 \\
4.26 \\
-\end{array}$ & $\begin{array}{r}90.9 \\
11.3 \\
71.7 \\
100.0 \\
-\end{array}$ & $\begin{array}{l}4.07 \\
1.96 \\
2.98 \\
1.94 \\
2.58\end{array}$ & $\begin{array}{r}9.8 \\
29.2 \\
9.6 \\
100.0 \\
48.7\end{array}$ \\
\hline 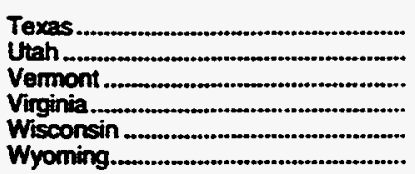 & $\begin{array}{r}2.37 \\
\overline{-} \\
3.46\end{array}$ & $\begin{array}{r}60.8 \\
\overline{-} \\
100 . \overline{0} \\
100.0\end{array}$ & $\begin{array}{r}3.41 \\
3.89 \\
2.08 \\
1.43 \\
2.37 \\
-\end{array}$ & $\begin{array}{r}4.2 \\
1.9 \\
100.0 \\
1.0 \\
75.7 \\
-\end{array}$ \\
\hline 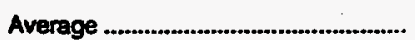 & 2.29 & 28.8 & 2.61 & 20.2 \\
\hline
\end{tabular}

$R=$ Revised data.

* = Volume is less than 500,000 cubic feet.

Nole: Totals may not equal sum of components due to independent rounding

Source: 1993-1994: Energy Intomation Administration (ELA). Form ElA-176, "Anmual Report of Natural and Supplemental Gas Supphy and Disposition." 
Table 33. Average Price of Natural Gas Delivered to All Consumers by State, 1967-1986 (Dollars per Thousand Cubic Feet)

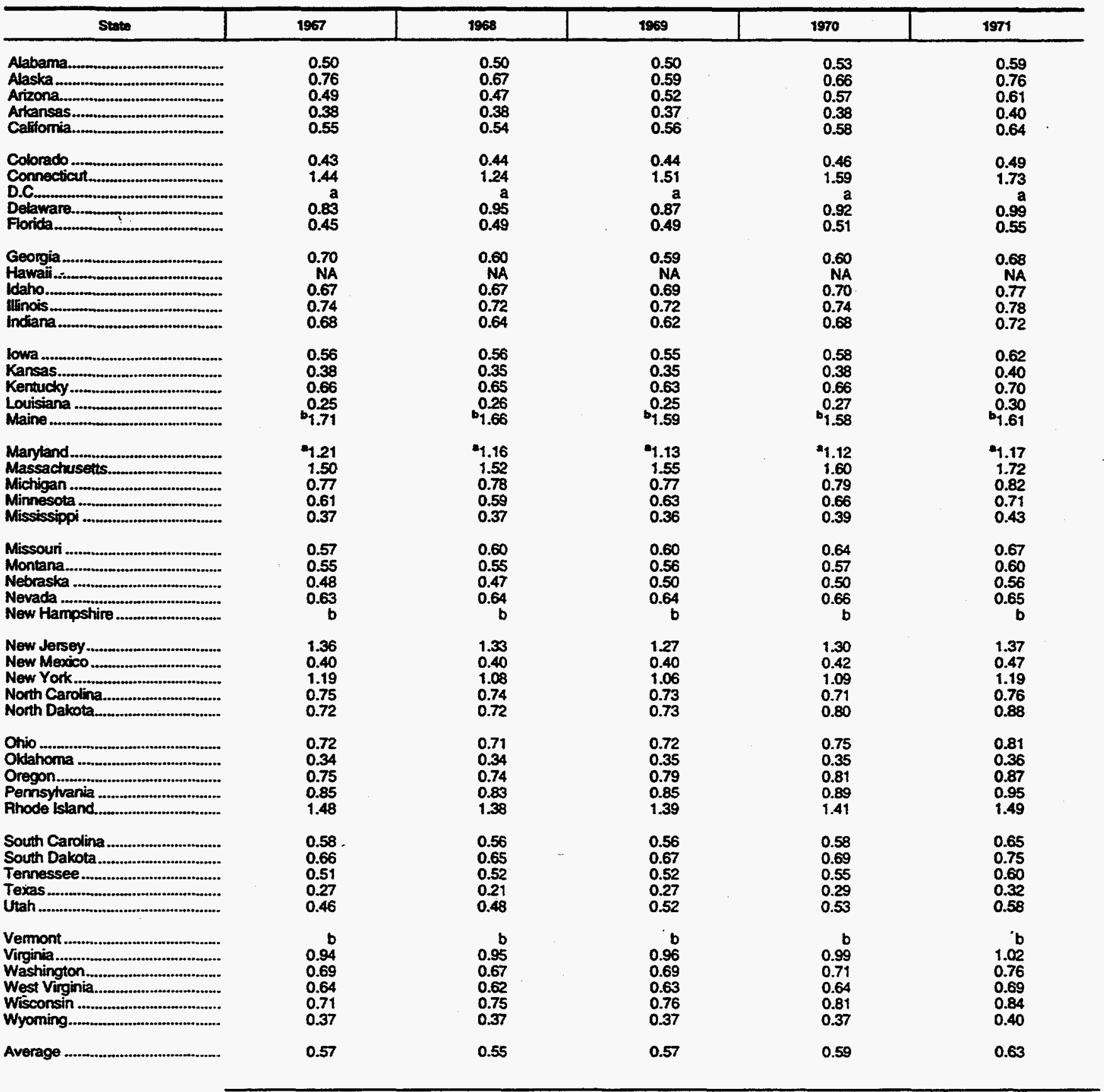

See footnotes at end of table. 
Table 33. Average Price of Natural Gas Delivered to All Consumer's by State, 1967-1986 (Continued) (Dollars per Thousand Cubic Feet)

\begin{tabular}{|c|c|c|c|c|c|}
\hline State & 1972 & 1973 & 1974 & 1975 & 1976 \\
\hline 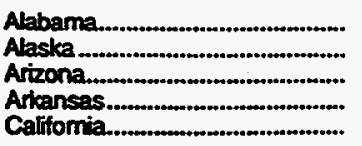 & $\begin{array}{l}0.64 \\
0.81 \\
0.62 \\
0.44 \\
0.67\end{array}$ & $\begin{array}{l}0.71 \\
0.74 \\
0.69 \\
0.49 \\
0.75\end{array}$ & $\begin{array}{l}0.83 \\
0.77 \\
0.79 \\
0.60 \\
0.95\end{array}$ & $\begin{array}{l}0.97 \\
0.89 \\
1.07 \\
0.79 \\
1.30\end{array}$ & $\begin{array}{l}1.42 \\
0.95 \\
1.34 \\
0.93 \\
1.60\end{array}$ \\
\hline 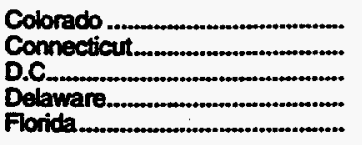 & $\begin{array}{r}0.52 \\
1.76 \\
a \\
1.14 \\
0.59\end{array}$ & $\begin{array}{r}0.58 \\
1.88 \\
a \\
1.21 \\
0.70\end{array}$ & $\begin{array}{r}0.71 \\
2.38 \\
a \\
1.50 \\
0.80\end{array}$ & $\begin{array}{r}0.80 \\
2.87 \\
a \\
1.86 \\
0.96\end{array}$ & $\begin{array}{r}1.05 \\
3.17 \\
a \\
2.02 \\
1.08\end{array}$ \\
\hline 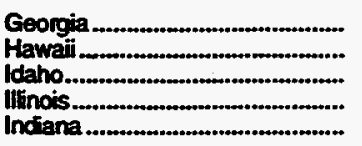 & $\begin{array}{r}0.75 \\
\text { NA } \\
0.84 \\
0.87 \\
0.78\end{array}$ & $\begin{array}{l}0.81 \\
N A \\
0.86 \\
0.93 \\
0.82\end{array}$ & $\begin{array}{r}0.89 \\
N A \\
1.01 \\
1.07 \\
0.93\end{array}$ & $\begin{array}{r}1.04 \\
N A \\
1.51 \\
1.41 \\
1.14\end{array}$ & $\begin{array}{r}1.35 \\
\text { NA } \\
1.85 \\
1.69 \\
1.37\end{array}$ \\
\hline 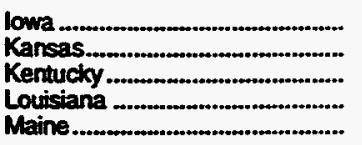 & $\begin{array}{r}0.71 \\
0.45 \\
0.73 \\
0.35 \\
1.67\end{array}$ & $\begin{array}{r}0.74 \\
0.47 \\
0.78 \\
0.40 \\
1.68\end{array}$ & $\begin{array}{r}0.82 \\
0.54 \\
0.88 \\
0.63 \\
61.79\end{array}$ & $\begin{array}{r}1.01 \\
0.67 \\
1.02 \\
0.75 \\
2.10\end{array}$ & $\begin{array}{l}1.24 \\
1.00 \\
1.20 \\
0.96 \\
2.56\end{array}$ \\
\hline 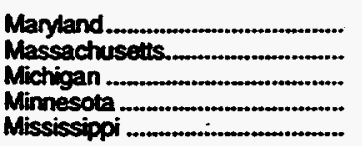 & $\begin{array}{l}1.24 \\
1.87 \\
0.87 \\
0.79 \\
0.46\end{array}$ & $\begin{array}{l}-1.26 \\
2.00 \\
0.92 \\
0.81 \\
0.66\end{array}$ & $\begin{array}{l}0.91 \\
2.33 \\
1.12 \\
0.96 \\
0.66\end{array}$ & $\begin{array}{l}2.00 \\
2.87 \\
1.45 \\
1.16 \\
0.86\end{array}$ & $\begin{array}{l}2.23 \\
3.33 \\
1.74 \\
1.39 \\
1.18\end{array}$ \\
\hline 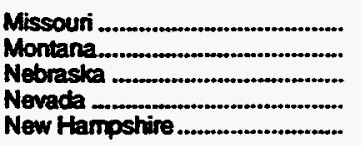 & $\begin{array}{r}0.76 \\
0.63 \\
0.62 \\
0.70 \\
\text { b }\end{array}$ & $\begin{array}{r}0.78 \\
0.70 \\
0.63 \\
0.75 \\
b\end{array}$ & $\begin{array}{r}0.90 \\
0.80 \\
0.72 \\
0.99 \\
b\end{array}$ & $\begin{array}{r}1.17 \\
1.09 \\
0.89 \\
1.43 \\
b\end{array}$ & $\begin{array}{r}1.37 \\
1.16 \\
1.07 \\
1.63 \\
b\end{array}$ \\
\hline 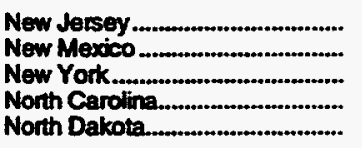 & $\begin{array}{l}1.48 \\
0.48 \\
1.31 \\
0.83 \\
0.91\end{array}$ & $\begin{array}{l}1.54 \\
0.50 \\
1.39 \\
0.90 \\
0.95\end{array}$ & $\begin{array}{l}1.81 \\
0.64 \\
1.69 \\
1.09 \\
1.03\end{array}$ & $\begin{array}{l}2.34 \\
0.73 \\
2.19 \\
1.60 \\
1.26\end{array}$ & $\begin{array}{l}2.76 \\
0.86 \\
2.50 \\
1.91 \\
1.53\end{array}$ \\
\hline 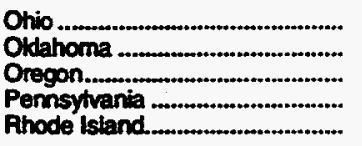 & $\begin{array}{l}0.85 \\
0.39 \\
0.94 \\
1.02 \\
1.82\end{array}$ & $\begin{array}{l}0.89 \\
0.42 \\
1.03 \\
1.10 \\
2.04\end{array}$ & $\begin{array}{l}1.03 \\
0.52 \\
1.28 \\
1.27 \\
2.19\end{array}$ & $\begin{array}{l}1.33 \\
0.70 \\
1.45 \\
1.55 \\
2.78\end{array}$ & $\begin{array}{l}1.60 \\
0.97 \\
2.10 \\
1.75 \\
3.06\end{array}$ \\
\hline 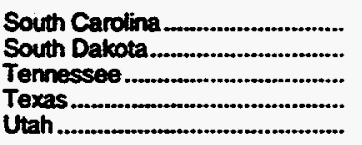 & $\begin{array}{l}0.74 \\
0.77 \\
0.66 \\
0.33 \\
0.60\end{array}$ & $\begin{array}{l}0.82 \\
0.81 \\
0.66 \\
0.37 \\
0.66\end{array}$ & $\begin{array}{l}0.96 \\
1.05 \\
0.78 \\
0.55 \\
0.75\end{array}$ & $\begin{array}{l}1.20 \\
1.04 \\
0.95 \\
0.96 \\
1.00\end{array}$ & $\begin{array}{l}1.56 \\
1.18 \\
1.32 \\
1.22 \\
1.23\end{array}$ \\
\hline 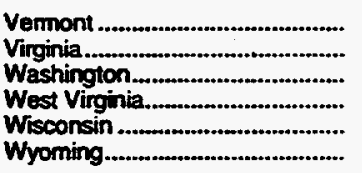 & $\begin{array}{l}b \\
1.09 \\
0.81 \\
0.72 \\
0.90 \\
0.44\end{array}$ & $\begin{array}{l}b \\
1.13 \\
0.85 \\
0.77 \\
0.96 \\
0.43\end{array}$ & $\begin{array}{l}b \\
1.34 \\
1.10 \\
0.88 \\
1.05 \\
0.49\end{array}$ & $\begin{array}{r}b \\
1.74 \\
1.64 \\
1.21 \\
1.32 \\
0.64\end{array}$ & $\begin{array}{l}b \\
2.05 \\
2.07 \\
1.47 \\
1.73 \\
0.80\end{array}$ \\
\hline 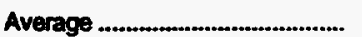 & 0.68 & 0.73 & 0.89 & 1.19 & 1.47 \\
\hline
\end{tabular}

See footnoles at end of table. 
Table 33. Average Price of Natural Gas Delivered to All Consumers by State, 1967-1986 (Continued) (Dollars per Thousand Cubic Feet)

\begin{tabular}{|c|c|c|c|c|c|}
\hline State & 1977 & 1978 & 1979 & 1980 & 1981 \\
\hline 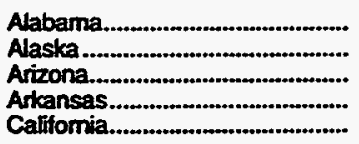 & $\begin{array}{l}1.66 \\
1.08 \\
1.70 \\
1.45 \\
2.00\end{array}$ & $\begin{array}{l}2.00 \\
1.05 \\
1.93 \\
1.42 \\
2.14\end{array}$ & $\begin{array}{l}2.68 \\
1.04 \\
2.52 \\
1.39 \\
2.60\end{array}$ & $\begin{array}{l}2.97 \\
0.59 \\
3.00 \\
2.27 \\
3.71\end{array}$ & $\begin{array}{l}3.58 \\
0.69 \\
3.34 \\
2.81 \\
4.07\end{array}$ \\
\hline $\begin{array}{l}\text { Colorado } \\
\text { Connecticut. } \\
\text { D.C. } \\
\text { Delaware. } \\
\text { Plorida. }\end{array}$ & $\begin{array}{l}1.37 \\
3.79 \\
a \\
2.88 \\
1.29\end{array}$ & $\begin{array}{l}1.66 \\
3.94 \\
\mathrm{a} \\
3.23 \\
1.38\end{array}$ & $\begin{array}{l}2.21 \\
4.12 \\
\mathrm{a} \\
2.95 \\
1.87\end{array}$ & $\begin{array}{l}2.96 \\
5.08 \\
4.37 \\
3.48 \\
2.28\end{array}$ & $\begin{array}{l}3.81 \\
6.01 \\
5.28 \\
4.38 \\
2.68\end{array}$ \\
\hline 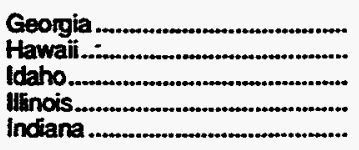 & $\begin{array}{r}1.69 \\
\text { NA } \\
2.28 \\
2.04 \\
1.74\end{array}$ & $\begin{array}{l}2.03 \\
N A \\
2.59 \\
2.34 \\
1.92\end{array}$ & $\begin{array}{l}2.49 \\
N A \\
2.87 \\
2.84 \\
2.38\end{array}$ & $\begin{array}{r}3.16 \\
12.58 \\
4.07 \\
3.40 \\
2.84\end{array}$ & $\begin{array}{r}3.93 \\
15.11 \\
4.38 \\
3.84 \\
3.27\end{array}$ \\
\hline $\begin{array}{l}\text { lowra } \\
\text { Kansas.... } \\
\text { Kentucky } \\
\text { Louisiana } \\
\text { Maine }\end{array}$ & $\begin{array}{r}1.60 \\
1.18 \\
1.65 \\
1.19 \\
3.22\end{array}$ & $\begin{array}{r}1.93 \\
1.31 \\
1.80 \\
1.11 \\
b 3.26\end{array}$ & $\begin{array}{r}2.29 \\
1.64 \\
2.18 \\
1.27 \\
03.67\end{array}$ & $\begin{array}{l}2.80 \\
2.12 \\
2.87 \\
1.65 \\
5.15\end{array}$ & $\begin{array}{l}3.43 \\
2.73 \\
3.34 \\
2.30 \\
6.18\end{array}$ \\
\hline $\begin{array}{l}\text { Marytand } \\
\text { Massachusetts... } \\
\text { Michigan } \\
\text { Minnesota } \\
\text { Mississippi }\end{array}$ & $\begin{array}{l}2.82 \\
3.58 \\
2.03 \\
1.61 \\
1.58\end{array}$ & $\begin{array}{r}3.12 \\
3.78 \\
2.11 \\
1.85 \\
1.74\end{array}$ & $\begin{array}{l}3.11 \\
4.08 \\
2.47 \\
2.16 \\
2.26\end{array}$ & $\begin{array}{l}3.89 \\
4.96 \\
3.08 \\
2.84 \\
2.62\end{array}$ & $\begin{array}{l}4.47 \\
5.89 \\
3.71 \\
3.63 \\
3.19\end{array}$ \\
\hline $\begin{array}{l}\text { Missouri } \\
\text { Montana } \\
\text { Nebraska } \\
\text { Nevada } \\
\text { New Hampshire }\end{array}$ & $\begin{array}{r}1.84 \\
1.64 \\
1.35 \\
2.09 \\
b\end{array}$ & $\begin{array}{r}1.96 \\
1.72 \\
1.49 \\
2.13 \\
b\end{array}$ & $\begin{array}{r}2.46 \\
2.00 \\
1.82 \\
2.56 \\
\mathrm{~b}\end{array}$ & $\begin{array}{l}2.99 \\
3.18 \\
2.35 \\
3.29 \\
4.35\end{array}$ & $\begin{array}{l}3.69 \\
4.06 \\
3.04 \\
3.80 \\
5.28\end{array}$ \\
\hline 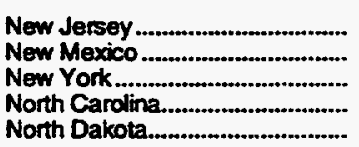 & $\begin{array}{l}3.10 \\
1.61 \\
2.93 \\
2.75 \\
1.86\end{array}$ & $\begin{array}{l}3.47 \\
1.89 \\
3.29 \\
2.63 \\
2.12\end{array}$ & $\begin{array}{l}3.82 \\
2.30 \\
3.57 \\
2.98 \\
2.66\end{array}$ & $\begin{array}{l}4.28 \\
2.77 \\
4.21 \\
3.59 \\
3.59\end{array}$ & $\begin{array}{l}5.18 \\
3.18 \\
4.75 \\
4.63 \\
3.97\end{array}$ \\
\hline 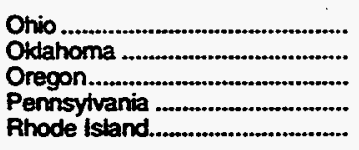 & $\begin{array}{l}2.08 \\
1.42 \\
2.48 \\
2.24 \\
3.68\end{array}$ & $\begin{array}{l}2.24 \\
1.55 \\
2.95 \\
2.35 \\
3.72\end{array}$ & $\begin{array}{l}2.59 \\
1.89 \\
3.31 \\
2.85 \\
3.25\end{array}$ & $\begin{array}{l}3.32 \\
2.02 \\
4.85 \\
3.44 \\
5.19\end{array}$ & $\begin{array}{l}3.72 \\
2.36 \\
5.13 \\
4.10 \\
5.90\end{array}$ \\
\hline $\begin{array}{l}\text { South Carolina } \\
\text { South Dakota } \\
\text { Tennessee } \\
\text { Texas }\end{array}$ & $\begin{array}{l}2.01 \\
1.50 \\
1.74 \\
1.38 \\
1.39\end{array}$ & $\begin{array}{l}2.27 \\
1.86 \\
1.82 \\
1.78 \\
1.65\end{array}$ & $\begin{array}{l}2.66 \\
2.38 \\
2.24 \\
1.99 \\
1.99\end{array}$ & $\begin{array}{l}3.17 \\
2.82 \\
2.73 \\
2.25 \\
2.52\end{array}$ & $\begin{array}{l}3.98 \\
3.56 \\
3.28 \\
2.87 \\
2.93\end{array}$ \\
\hline 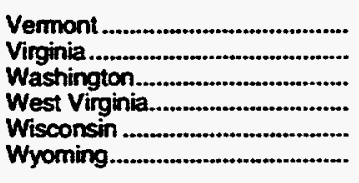 & $\begin{array}{l}b \\
2.54 \\
2.47 \\
2.27 \\
2.08 \\
1.11\end{array}$ & $\begin{array}{l}2.77 \\
2.80 \\
2.21 \\
2.33 \\
1.49\end{array}$ & $\begin{array}{r}b \\
3.10 \\
3.27 \\
2.67 \\
2.69 \\
2.14\end{array}$ & $\begin{array}{l}5.56 \\
3.67 \\
4.67 \\
3.28 \\
3.46 \\
2.57\end{array}$ & $\begin{array}{l}6.22 \\
4.13 \\
5.10 \\
3.85 \\
4.25 \\
3.18\end{array}$ \\
\hline 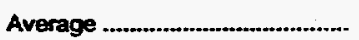 & 1.78 & 1.98 & 2.34 & 2.91 & 3.51 \\
\hline
\end{tabular}

See footnotes at end of table. 
Table 33. Average Price of Natural Gas Delivered to All Consumers by State, 1967-1986 (Continued) (Dollars per Thousand Cubic Feet)

\begin{tabular}{|c|c|c|c|c|c|}
\hline State & 1982 & 1983 & 1984 & 1985 & 1986 \\
\hline 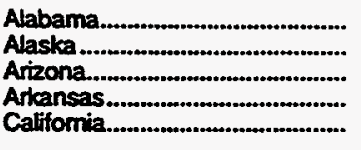 & $\begin{array}{l}4.59 \\
0.87 \\
4.65 \\
3.40 \\
4.93\end{array}$ & $\begin{array}{l}5.03 \\
1.09 \\
5.22 \\
3.83 \\
5.54\end{array}$ & $\begin{array}{l}4.95 \\
1.15 \\
5.34 \\
3.99 \\
5.64\end{array}$ & $\begin{array}{l}4.86 \\
1.19 \\
5.16 \\
3.88 \\
5.22\end{array}$ & $\begin{array}{l}4.57 \\
1.40 \\
4.29 \\
3.59 \\
4.15\end{array}$ \\
\hline 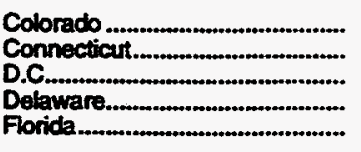 & $\begin{array}{l}4.54 \\
7.36 \\
6.44 \\
4.99 \\
3.15\end{array}$ & $\begin{array}{l}5.06 \\
7.96 \\
7.74 \\
4.86 \\
3.42\end{array}$ & $\begin{array}{l}4.86 \\
7.20 \\
7.64 \\
4.90 \\
3.96\end{array}$ & $\begin{array}{l}4.69 \\
7.41 \\
7.41 \\
4.98 \\
3.91\end{array}$ & $\begin{array}{l}4.54 \\
7.07 \\
6.86 \\
4.49 \\
2.86\end{array}$ \\
\hline 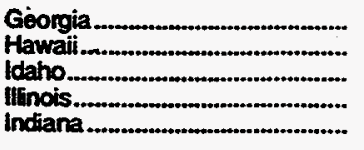 & $\begin{array}{r}4.63 \\
14.85 \\
5.40 \\
4.53 \\
4.04\end{array}$ & $\begin{array}{r}5.19 \\
15.45 \\
5.77 \\
5.17 \\
4.88\end{array}$ & $\begin{array}{r}5.36 \\
17.36 \\
5.40 \\
5.03 \\
4.90\end{array}$ & $\begin{array}{r}5.38 \\
15.36 \\
5.32 \\
5.19 \\
4.73\end{array}$ & $\begin{array}{r}5.07 \\
12.99 \\
4.31 \\
4.68 \\
4.62\end{array}$ \\
\hline 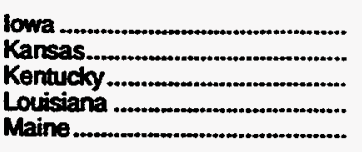 & $\begin{array}{l}4.22 \\
3.17 \\
4.32 \\
3.36 \\
7.40\end{array}$ & $\begin{array}{l}4.82 \\
3.83 \\
5.00 \\
3.45 \\
8.72\end{array}$ & $\begin{array}{l}4.78 \\
3.96 \\
4.86 \\
3.40 \\
8.40\end{array}$ & $\begin{array}{l}4.65 \\
3.56 \\
4.91 \\
3.19 \\
7.66\end{array}$ & $\begin{array}{l}4.27 \\
3.24 \\
4.53 \\
2.19 \\
7.28\end{array}$ \\
\hline 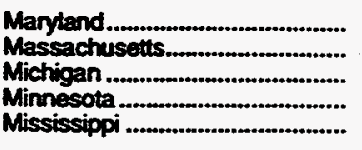 & $\begin{array}{l}5.61 \\
6.74 \\
4.60 \\
4.59 \\
3.93\end{array}$ & $\begin{array}{l}6.78 \\
7.11 \\
5.53 \\
5.29 \\
4.40\end{array}$ & $\begin{array}{l}6.76 \\
6.73 \\
5.55 \\
5.32 \\
\mathbf{3 . 9 6}\end{array}$ & $\begin{array}{l}6.50 \\
6.41 \\
5.77 \\
5.14 \\
3.86\end{array}$ & $\begin{array}{l}6.19 \\
6.53 \\
5.25 \\
4.60 \\
3.43\end{array}$ \\
\hline 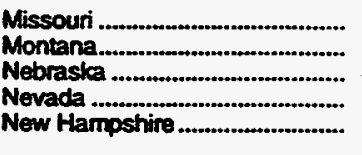 & $\begin{array}{l}4.88 \\
4.83 \\
3.76 \\
4.94 \\
6.37\end{array}$ & $\begin{array}{l}5.71 \\
4.56 \\
4.34 \\
5.71 \\
6.98\end{array}$ & $\begin{array}{l}5.44 \\
5.02 \\
4.37 \\
5.80 \\
6.56\end{array}$ & $\begin{array}{l}5.02 \\
4.84 \\
4.34 \\
5.75 \\
6.61\end{array}$ & $\begin{array}{l}4.57 \\
4.31 \\
4.05 \\
4.85 \\
6.70\end{array}$ \\
\hline 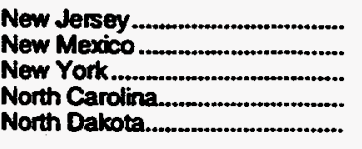 & $\begin{array}{l}6.05 \\
3.95 \\
5.58 \\
5.01 \\
4.35\end{array}$ & $\begin{array}{l}6.11 \\
4.42 \\
6.55 \\
5.68 \\
5.27\end{array}$ & $\begin{array}{l}6.16 \\
4.60 \\
6.26 \\
5.78 \\
5.77\end{array}$ & $\begin{array}{l}6.33 \\
4.79 \\
6.11 \\
5.46 \\
5.26\end{array}$ & $\begin{array}{l}6.01 \\
4.44 \\
5.81 \\
4.93 \\
4.92\end{array}$ \\
\hline 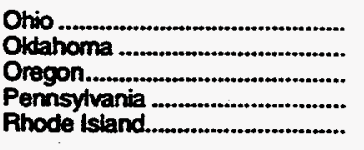 & $\begin{array}{l}4.68 \\
2.73 \\
6.13 \\
4.98 \\
7.25\end{array}$ & $\begin{array}{l}5.68 \\
3.19 \\
6.12 \\
5.83 \\
7.34\end{array}$ & $\begin{array}{l}5.64 \\
3.37 \\
6.01 \\
5.92 \\
6.58\end{array}$ & $\begin{array}{l}5.54 \\
3.49 \\
5.72 \\
5.92 \\
6.87\end{array}$ & $\begin{array}{l}5.33 \\
3.18 \\
5.05 \\
5.56 \\
6.96\end{array}$ \\
\hline 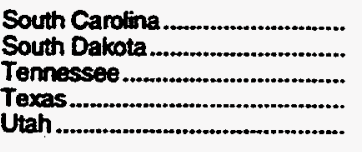 & $\begin{array}{l}4.65 \\
4.35 \\
4.13 \\
3.54 \\
3.04\end{array}$ & $\begin{array}{l}5.23 \\
5.13 \\
4.72 \\
3.61 \\
3.82\end{array}$ & $\begin{array}{l}5.45 \\
5.59 \\
4.50 \\
3.80 \\
4.75\end{array}$ & $\begin{array}{l}5.20 \\
5.06 \\
4.60 \\
3.48 \\
4.27\end{array}$ & $\begin{array}{l}4.53 \\
4.65 \\
4.33 \\
2.70 \\
4.13\end{array}$ \\
\hline 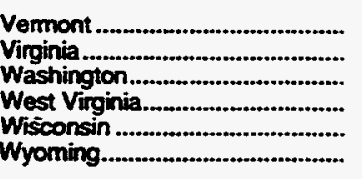 & $\begin{array}{l}6.29 \\
5.22 \\
6.11 \\
4.81 \\
5.00 \\
3.93\end{array}$ & $\begin{array}{l}5.78 \\
6.06 \\
5.88 \\
5.57 \\
5.50 \\
4.43\end{array}$ & $\begin{array}{l}5.60 \\
6.00 \\
5.79 \\
5.50 \\
5.41 \\
4.67\end{array}$ & $\begin{array}{l}5.54 \\
5.88 \\
5.40 \\
5.61 \\
5.40 \\
4.42\end{array}$ & $\begin{array}{l}4.95 \\
5.25 \\
4.62 \\
5.35 \\
5.18 \\
4.12\end{array}$ \\
\hline 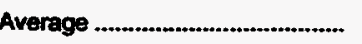 & 4.32 & 4.82 & 4.85 & 4.72 & 4.13 \\
\hline
\end{tabular}

- Data for the District of Columbia are included with data for Maryand.

Data for New Hampshire and Vermont are included with data for Maine.

NA = Not Available.

Sources: Electric Utitity Data: 1967-1977: Federal Power Commission (FPC). 1978-1986: Enorgy Information Adrninistration (ElA), Form ElA-759, "Monthly Power Plant Report" (formety FPC-4); Fom FEAC-423, "Cost and Quatity of Fuels for Eloctric Utiny Plants" (formerty Form FPC-423); and Fom EIA-176, Annual Repon of Natural and Supplemental Gas Supply and Disposition." Al other data: 1967-1975: Bureau of Mines, Minerals Yearbook, "Natural Gas" chapter. 1976-1978: E1A, Energy Data Report. Natural Gas Annual. 1979: ElA, Natural Gas Production and Consumption 1979. 1980-1986: ElA, Fom ElA-176, "Annual Report of Natural and Supplemental Gas Supphy and 
Table 34. Average Consumption and Annual Cost of Natural Gas per Consumer by State, 1967-1989

\begin{tabular}{|c|c|c|c|c|c|c|}
\hline \multirow[b]{2}{*}{ State } & \multicolumn{2}{|c|}{ Residontial } & \multicolumn{2}{|c|}{ Commercial } & \multicolumn{2}{|c|}{ Industrial } \\
\hline & $\begin{array}{c}\text { Consumption } \\
\text { (thousiand } \\
\text { cubic foot) }\end{array}$ & $\begin{array}{c}\text { Cost } \\
\text { (dollars) }\end{array}$ & $\begin{array}{l}\text { Consumption } \\
\text { (thousand } \\
\text { cubic foet) }\end{array}$ & $\begin{array}{c}\text { Cost } \\
\text { (dollers) }\end{array}$ & $\begin{array}{l}\text { Coneumption } \\
\text { (thous and } \\
\text { cubic feet) }\end{array}$ & $\begin{array}{c}\text { Cost } \\
\text { (dollars) }\end{array}$ \\
\hline & \multicolumn{6}{|c|}{1967} \\
\hline 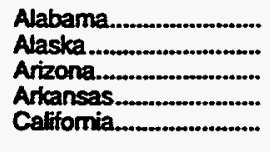 & $\begin{array}{r}91 \\
218 \\
69 \\
152 \\
98\end{array}$ & $\begin{array}{r}103 \\
329 \\
67 \\
108 \\
91\end{array}$ & $\begin{array}{r}844 \\
1.361 \\
667 \\
751 \\
548\end{array}$ & $\begin{array}{r}475 \\
1.348 \\
338 \\
374 \\
372\end{array}$ & $\begin{array}{l}\text { NA } \\
\text { NA } \\
\text { NA } \\
\text { NA } \\
\text { NA }\end{array}$ & $\begin{array}{l}\text { NA } \\
\text { NA } \\
\text { NA } \\
\text { NA } \\
\text { NA }\end{array}$ \\
\hline 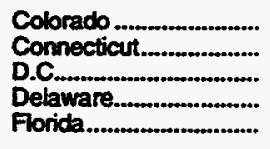 & $\begin{array}{r}159 \\
73 \\
a \\
94 \\
27\end{array}$ & $\begin{array}{r}106 \\
134 \\
a \\
150 \\
62\end{array}$ & $\begin{array}{r}701 \\
312 \\
a \\
394 \\
900\end{array}$ & $\begin{array}{r}389 \\
476 \\
a \\
481 \\
849\end{array}$ & $\begin{array}{l}\text { NA } \\
\text { NA } \\
\text { NA } \\
\text { NA } \\
\text { NA }\end{array}$ & $\begin{array}{l}\text { NA } \\
\text { NA } \\
\text { NA } \\
\text { NA }\end{array}$ \\
\hline 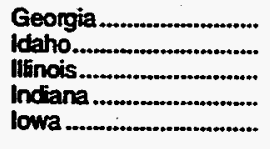 & $\begin{array}{l}118 \\
107 \\
146 \\
150 \\
155\end{array}$ & $\begin{array}{l}121 \\
138 \\
149 \\
147 \\
144\end{array}$ & $\begin{array}{l}570 \\
497 \\
953 \\
647 \\
664\end{array}$ & $\begin{array}{l}394 \\
470 \\
711 \\
545 \\
435\end{array}$ & $\begin{array}{l}\text { NA } \\
\text { NA } \\
\text { NA } \\
\text { NA } \\
\text { NA }\end{array}$ & $\begin{array}{l}\text { NA } \\
\text { NA } \\
\text { NA } \\
\text { NA } \\
\text { NA }\end{array}$ \\
\hline 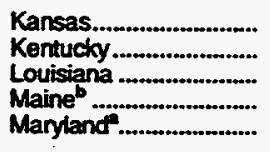 & $\begin{array}{r}156 \\
144 \\
94 \\
67 \\
100\end{array}$ & $\begin{array}{r}92 \\
121 \\
71 \\
132 \\
144\end{array}$ & $\begin{array}{l}663 \\
688 \\
646 \\
490 \\
462\end{array}$ & $\begin{array}{l}274 \\
467 \\
262 \\
667 \\
534\end{array}$ & $\begin{array}{l}\text { NA } \\
\text { NA } \\
\text { NA } \\
\text { NA } \\
\text { NA }\end{array}$ & $\begin{array}{l}\text { NA } \\
\text { NA } \\
\text { NA } \\
\text { NA } \\
\text { NA }\end{array}$ \\
\hline 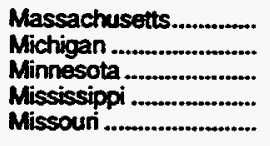 & $\begin{array}{r}76 \\
175 \\
161 \\
88 \\
149\end{array}$ & $\begin{array}{r}143 \\
179 \\
165 \\
78 \\
125\end{array}$ & $\begin{array}{r}406 \\
728 \\
1,386 \\
487 \\
897\end{array}$ & $\begin{array}{l}561 \\
597 \\
849 \\
246 \\
504\end{array}$ & $\begin{array}{l}\text { NA } \\
\text { NA } \\
\text { NA } \\
\text { NA } \\
\text { NA }\end{array}$ & $\begin{array}{l}\text { NA } \\
\text { NA } \\
\text { NA } \\
\text { NA } \\
\text { NA }\end{array}$ \\
\hline 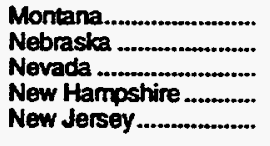 & $\begin{array}{r}153 \\
179 \\
93 \\
b \\
88\end{array}$ & $\begin{array}{r}122 \\
142 \\
132 \\
b \\
168\end{array}$ & $\begin{array}{r}970 \\
987 \\
2,055 \\
b \\
178\end{array}$ & $\begin{array}{r}530 \\
476 \\
1,608 \\
b \\
251\end{array}$ & $\begin{array}{l}\text { NA } \\
\text { NA } \\
\text { NA } \\
\text { NA } \\
\text { NA }\end{array}$ & $\begin{array}{l}\text { NA } \\
\text { NA } \\
\text { NA } \\
\text { NA } \\
\text { NA }\end{array}$ \\
\hline 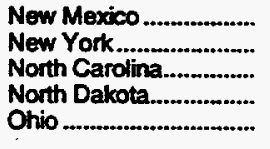 & $\begin{array}{r}129 \\
83 \\
98 \\
147 \\
188\end{array}$ & $\begin{array}{l}118 \\
118 \\
128 \\
138 \\
161\end{array}$ & $\begin{array}{r}1,017 \\
442 \\
503 \\
1,010 \\
897\end{array}$ & $\begin{array}{l}493 \\
538 \\
460 \\
628 \\
637\end{array}$ & $\begin{array}{l}\text { NA } \\
\text { NA } \\
\text { NA } \\
\text { NA } \\
\text { NA }\end{array}$ & $\begin{array}{l}\text { NA } \\
\text { NA } \\
\text { NA } \\
\text { NA } \\
\text { NA }\end{array}$ \\
\hline 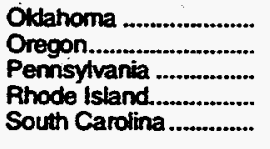 & $\begin{array}{r}110 \\
85 \\
127 \\
70 \\
70\end{array}$ & $\begin{array}{r}85 \\
134 \\
146 \\
127 \\
98\end{array}$ & $\begin{array}{l}601 \\
331 \\
604 \\
320 \\
402\end{array}$ & $\begin{array}{l}287 \\
\mathbf{4 5 9} \\
\mathbf{5 4 4} \\
\mathbf{5 1 5} \\
\mathbf{3 7 8}\end{array}$ & $\begin{array}{l}\text { NA } \\
\text { NA } \\
\text { NA } \\
\text { NA } \\
\text { NA }\end{array}$ & $\begin{array}{l}\text { NA } \\
\text { NA } \\
\text { NA } \\
\text { NA } \\
\text { NA }\end{array}$ \\
\hline 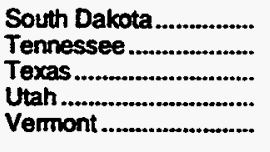 & $\begin{array}{r}144 \\
111 \\
86 \\
168 \\
b\end{array}$ & $\begin{array}{r}143 \\
100 \\
75 \\
115 \\
b\end{array}$ & $\begin{array}{r}1,044 \\
508 \\
381 \\
258 \\
b\end{array}$ & $\begin{array}{r}639 \\
508 \\
258 \\
258 \\
\text { b }\end{array}$ & $\begin{array}{l}\text { NA } \\
\text { NA } \\
\text { NA } \\
\text { NA } \\
\text { NA }\end{array}$ & $\begin{array}{l}\text { NA } \\
\text { NA } \\
\text { NA } \\
\text { NA } \\
\text { NA }\end{array}$ \\
\hline 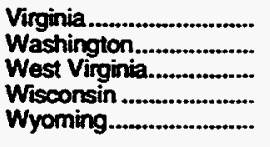 & $\begin{array}{r}92 \\
109 \\
152 \\
132 \\
178\end{array}$ & $\begin{array}{l}135 \\
162 \\
128 \\
135 \\
118\end{array}$ & $\begin{array}{r}474 \\
504 \\
661 \\
646 \\
1,207\end{array}$ & $\begin{array}{l}440 \\
580 \\
455 \\
520 \\
516\end{array}$ & $\begin{array}{l}\text { NA } \\
\text { NA } \\
\text { NA } \\
\text { NA } \\
\text { NA }\end{array}$ & $\begin{array}{l}\text { NA } \\
\text { NA } \\
\text { NA } \\
\text { NA } \\
\text { NA }\end{array}$ \\
\hline Average & 118 & 124 & 637 & 468 & NA & NA \\
\hline
\end{tabular}

See footnotes at end of table. 
Table 34. Average Consumption and Annual Cost of Natural Gas per Consumer by State, 1967-1989 (Continued)

\begin{tabular}{|c|c|c|c|c|c|c|}
\hline \multirow[b]{2}{*}{ sute } & \multicolumn{2}{|c|}{ Peesidontial } & \multicolumn{2}{|c|}{ Commareial } & \multicolumn{2}{|c|}{ Industrial! } \\
\hline & $\begin{array}{l}\text { Consumption } \\
\text { (thousind } \\
\text { cubie finet) }\end{array}$ & $\begin{array}{c}\text { Cost } \\
\text { (doliers) }\end{array}$ & $\begin{array}{l}\text { Consermption } \\
\text { (thousind } \\
\text { cubic feat) }\end{array}$ & $\begin{array}{c}\text { Cost } \\
\text { (dollers) }\end{array}$ & $\begin{array}{l}\text { Consumption } \\
\text { (thousand } \\
\text { cubic foet) }\end{array}$ & $\underset{\text { (dollats) }}{\text { Cost }}$ \\
\hline & \multicolumn{6}{|c|}{1958} \\
\hline 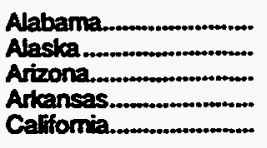 & $\begin{array}{r}98 \\
208 \\
70 \\
158 \\
96\end{array}$ & $\begin{array}{r}108 \\
316 \\
68 \\
111 \\
89\end{array}$ & $\begin{array}{r}914 \\
2,357 \\
650 \\
806 \\
552\end{array}$ & $\begin{array}{r}513 \\
1.786 \\
319 \\
395 \\
379\end{array}$ & $\begin{array}{l}\text { NA } \\
\text { NA } \\
\text { NA } \\
\text { NA } \\
\text { NA }\end{array}$ & $\begin{array}{l}\text { NA } \\
\text { NA } \\
\text { NA } \\
\text { NA } \\
\text { NA }\end{array}$ \\
\hline 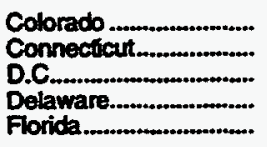 & $\begin{array}{r}162 \\
74 \\
a \\
94 \\
33\end{array}$ & $\begin{array}{r}110 \\
134 \\
a \\
150 \\
85\end{array}$ & $\begin{array}{r}751 \\
449 \\
2 \\
417 \\
842\end{array}$ & $\begin{array}{r}411 \\
648 \\
\mathrm{a} \\
528 \\
822\end{array}$ & $\begin{array}{l}\text { NA } \\
\text { NA } \\
\text { NA } \\
\text { NA } \\
\text { NA }\end{array}$ & $\begin{array}{l}\text { NA } \\
\text { NA } \\
\text { NA } \\
\text { NA }\end{array}$ \\
\hline 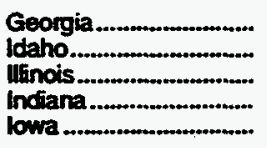 & $\begin{array}{l}119 \\
106 \\
146 \\
152 \\
156\end{array}$ & $\begin{array}{l}122 \\
143 \\
150 \\
142 \\
146\end{array}$ & $\begin{array}{l}680 \\
637 \\
919 \\
639 \\
751\end{array}$ & $\begin{array}{l}476 \\
572 \\
674 \\
513 \\
495\end{array}$ & $\begin{array}{l}\text { NA } \\
\text { NA } \\
\text { NA } \\
\text { NA } \\
\text { NA }\end{array}$ & $\begin{array}{l}\text { NA } \\
\text { NA } \\
\text { NA } \\
\text { NA }\end{array}$ \\
\hline 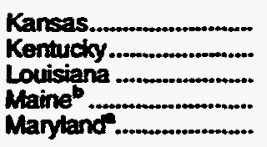 & $\begin{array}{r}158 \\
153 \\
97 \\
60 \\
100\end{array}$ & $\begin{array}{r}99 \\
122 \\
72 \\
122 \\
142\end{array}$ & $\begin{array}{l}811 \\
768 \\
791 \\
418 \\
491\end{array}$ & $\begin{array}{l}349 \\
493 \\
294 \\
608 \\
556\end{array}$ & $\begin{array}{l}\text { NA } \\
\text { NA } \\
\text { NA } \\
\text { NA }\end{array}$ & $\begin{array}{l}\text { NA } \\
\text { NA } \\
\text { NA } \\
\text { NA }\end{array}$ \\
\hline 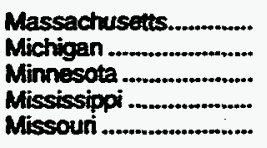 & $\begin{array}{r}77 \\
174 \\
160 \\
99 \\
148\end{array}$ & $\begin{array}{r}144 \\
170 \\
165 \\
97 \\
128\end{array}$ & $\begin{array}{r}416 \\
771 \\
1,337 \\
523 \\
877\end{array}$ & $\begin{array}{l}588 \\
624 \\
838 \\
267 \\
536\end{array}$ & $\begin{array}{l}\text { NA } \\
\text { NA } \\
\text { NA } \\
\text { NA }\end{array}$ & $\begin{array}{l}\text { NA } \\
\text { NA } \\
\text { NA } \\
\text { NA } \\
\text { NA }\end{array}$ \\
\hline 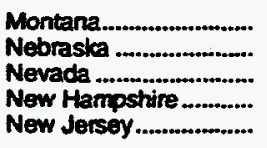 & $\begin{array}{r}150 \\
174 \\
90 \\
b \\
88\end{array}$ & $\begin{array}{r}124 \\
138 \\
136 \\
b \\
169\end{array}$ & $\begin{array}{r}803 \\
908 \\
2,332 \\
b \\
197\end{array}$ & $\begin{array}{r}457 \\
441 \\
1,828 \\
b \\
270\end{array}$ & $\begin{array}{l}\text { NA } \\
\text { NA } \\
\text { NA } \\
\text { NA }\end{array}$ & $\begin{array}{l}\text { NA } \\
\text { NA } \\
\text { NA } \\
\text { NA }\end{array}$ \\
\hline 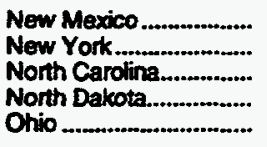 & $\begin{array}{r}132 \\
83 \\
92 \\
156 \\
186\end{array}$ & $\begin{array}{l}117 \\
115 \\
119 \\
146 \\
159\end{array}$ & $\begin{array}{r}1.181 \\
457 \\
589 \\
1,179 \\
904\end{array}$ & $\begin{array}{l}559 \\
543 \\
527 \\
751 \\
664\end{array}$ & $\begin{array}{l}\text { NA } \\
\text { NA } \\
\text { NA } \\
\text { NA } \\
\text { NA }\end{array}$ & $\begin{array}{l}\text { NA } \\
\text { NA } \\
\text { NA } \\
\text { NA } \\
\text { NA }\end{array}$ \\
\hline 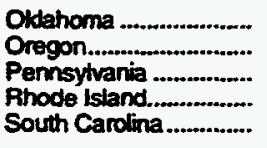 & $\begin{array}{r}122 \\
90 \\
130 \\
71 \\
84\end{array}$ & $\begin{array}{r}95 \\
138 \\
149 \\
126 \\
111\end{array}$ & $\begin{array}{l}668 \\
358 \\
635 \\
427 \\
458\end{array}$ & $\begin{array}{l}317 \\
485 \\
571 \\
620 \\
437\end{array}$ & $\begin{array}{l}\text { NA } \\
\text { NA } \\
\text { NA } \\
\text { NA } \\
\text { NA }\end{array}$ & $\begin{array}{l}\text { NA } \\
\text { NA } \\
\text { NA } \\
\text { NA }\end{array}$ \\
\hline 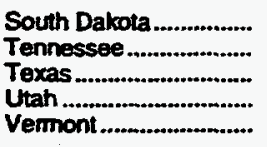 & $\begin{array}{r}145 \\
116 \\
88 \\
174 \\
b\end{array}$ & $\begin{array}{r}144 \\
102 \\
77 \\
129 \\
b\end{array}$ & $\begin{array}{r}1,072 \\
782 \\
581 \\
541 \\
b\end{array}$ & $\begin{array}{r}627 \\
540 \\
258 \\
307 \\
b\end{array}$ & $\begin{array}{l}\text { NA } \\
\text { NA } \\
\text { NA } \\
\text { NA } \\
\text { NA }\end{array}$ & $\begin{array}{l}\text { NA } \\
\text { NA } \\
\text { NA } \\
\text { NA } \\
\text { NA }\end{array}$ \\
\hline 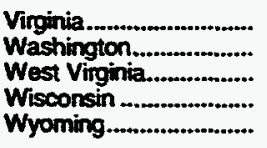 & $\begin{array}{r}97 \\
113 \\
159 \\
130 \\
185\end{array}$ & $\begin{array}{l}140 \\
161 \\
138 \\
143 \\
123\end{array}$ & $\begin{array}{r}523 \\
508 \\
680 \\
656 \\
1.164\end{array}$ & $\begin{array}{l}516 \\
553 \\
479 \\
556 \\
501\end{array}$ & $\begin{array}{l}\text { NA } \\
\text { NA } \\
\text { NA } \\
\text { NA } \\
\text { NA }\end{array}$ & $\begin{array}{l}\text { NA } \\
\text { NA } \\
\text { NA } \\
\text { NA }\end{array}$ \\
\hline Average ............................ & 119 & 124 & 665 & 487 & NA & NA \\
\hline
\end{tabular}

See footnotes at end of table. 
Table 34. Average Consumption and Annual Cost of Natural Gas per Consumer by State, 1967-1989 (Continued)

\begin{tabular}{|c|c|c|c|c|c|c|}
\hline \multirow[b]{2}{*}{ State } & \multicolumn{2}{|c|}{ Aesidentiv } & \multicolumn{2}{|c|}{ Commercial } & \multicolumn{2}{|c|}{ Industriat } \\
\hline & $\begin{array}{l}\text { Contumption } \\
\text { (thouseand } \\
\text { cubie foot) }\end{array}$ & $\underset{\text { (doltars) }}{\text { Cost }}$ & $\begin{array}{l}\text { Consumption } \\
\text { (thoussand } \\
\text { cubic foot) }\end{array}$ & $\begin{array}{c}\text { Cost } \\
\text { (dollers) }\end{array}$ & $\begin{array}{l}\text { Consumption } \\
\text { (thoutand } \\
\text { cuble feat) }\end{array}$ & $\begin{array}{c}\text { Cost } \\
\text { (dollars) }\end{array}$ \\
\hline & \multicolumn{6}{|c|}{1969} \\
\hline 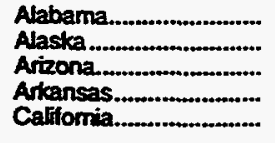 & $\begin{array}{r}102 \\
327 \\
74 \\
156 \\
102\end{array}$ & $\begin{array}{r}111 \\
496 \\
77 \\
111 \\
95\end{array}$ & $\begin{array}{r}981 \\
2,755 \\
645 \\
754 \\
579\end{array}$ & $\begin{array}{r}542 \\
1,790 \\
376 \\
372 \\
397\end{array}$ & $\begin{array}{l}\text { NA } \\
\text { NA } \\
\text { NA } \\
\text { NA } \\
\text { NA }\end{array}$ & $\begin{array}{l}\text { NA } \\
\text { NA } \\
\text { NA } \\
\text { NA }\end{array}$ \\
\hline 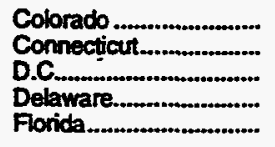 & $\begin{array}{r}150 \\
79 \\
a \\
98 \\
34\end{array}$ & $\begin{array}{r}103 \\
144 \\
a \\
148 \\
84\end{array}$ & $\begin{array}{r}792 \\
461 \\
a \\
505 \\
951\end{array}$ & $\begin{array}{r}434 \\
657 \\
a \\
618 \\
885\end{array}$ & $\begin{array}{l}\text { NA } \\
\text { NA } \\
\text { NA } \\
\text { NA } \\
\text { NA }\end{array}$ & $\begin{array}{l}\text { NA } \\
\text { NA } \\
\text { NA } \\
\text { NA } \\
\text { NA }\end{array}$ \\
\hline 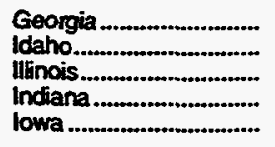 & $\begin{array}{l}119 \\
101 \\
159 \\
159 \\
163\end{array}$ & $\begin{array}{l}121 \\
139 \\
160 \\
149 \\
153\end{array}$ & $\begin{array}{l}685 \\
601 \\
927 \\
703 \\
742\end{array}$ & $\begin{array}{l}478 \\
548 \\
660 \\
558 \\
495\end{array}$ & $\begin{array}{l}\text { NA } \\
\text { NA } \\
\text { NA } \\
\text { NA }\end{array}$ & $\begin{array}{l}\text { NA } \\
\text { NA } \\
\text { NA } \\
\text { NA } \\
\text { NA }\end{array}$ \\
\hline 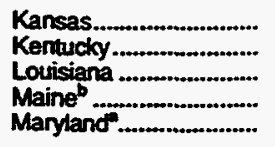 & $\begin{array}{r}159 \\
161 \\
101 \\
65 \\
104\end{array}$ & $\begin{array}{r}101 \\
128 \\
76 \\
129 \\
148\end{array}$ & $\begin{array}{l}932 \\
839 \\
761 \\
468 \\
550\end{array}$ & $\begin{array}{l}394 \\
543 \\
291 \\
655 \\
609\end{array}$ & $\begin{array}{l}\text { NA } \\
\text { NA } \\
\text { NA } \\
\text { NA }\end{array}$ & $\begin{array}{l}\text { NA } \\
\text { NA } \\
\text { NA } \\
\text { NA } \\
\text { NA }\end{array}$ \\
\hline $\begin{array}{l}\text { Massachusetts................ } \\
\text { Michigan ........................ } \\
\text { Minnesota .................... } \\
\text { Mississippi ..................... } \\
\text { Missouri ....................... }\end{array}$ & $\begin{array}{r}80 \\
179 \\
165 \\
96 \\
156\end{array}$ & $\begin{array}{r}149 \\
176 \\
177 \\
84 \\
138\end{array}$ & $\begin{array}{r}481 \\
828 \\
1,377 \\
491 \\
898\end{array}$ & $\begin{array}{l}679 \\
673 \\
917 \\
272 \\
534\end{array}$ & $\begin{array}{l}\text { NA } \\
\text { NA } \\
\text { NA } \\
\text { NA } \\
\text { NA }\end{array}$ & $\begin{array}{l}\text { NA } \\
\text { NA } \\
\text { NA } \\
\text { NA }\end{array}$ \\
\hline $\begin{array}{l}\text { Montana....................... } \\
\text { Nebraske ..................... } \\
\text { Nevada ........................ } \\
\text { New Hampshire ............. } \\
\text { New Jersey ................... }\end{array}$ & $\begin{array}{r}161 \\
176 \\
98 \\
b \\
93\end{array}$ & $\begin{array}{r}143 \\
146 \\
146 \\
b \\
172\end{array}$ & $\begin{array}{r}873 \\
959 \\
2,051 \\
b \\
205\end{array}$ & $\begin{array}{r}533 \\
491 \\
1,542 \\
b \\
284\end{array}$ & $\begin{array}{l}\text { NA } \\
\text { NA } \\
\text { NA } \\
\text { NA } \\
\text { NA }\end{array}$ & $\begin{array}{l}\text { NA } \\
\text { NA } \\
\text { NA } \\
\text { NA } \\
\text { NA }\end{array}$ \\
\hline 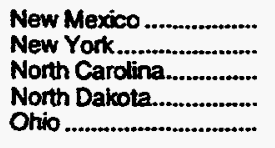 & $\begin{array}{r}126 \\
86 \\
99 \\
163 \\
188\end{array}$ & $\begin{array}{l}115 \\
118 \\
124 \\
155 \\
163\end{array}$ & $\begin{array}{r}1,247 \\
475 \\
629 \\
1.063 \\
938\end{array}$ & $\begin{array}{l}588 \\
567 \\
588 \\
684 \\
703\end{array}$ & $\begin{array}{l}\text { NA } \\
\text { NA } \\
\text { NA } \\
\text { NA } \\
\text { NA }\end{array}$ & $\begin{array}{l}\text { NA } \\
\text { NA } \\
\text { NA } \\
\text { NA }\end{array}$ \\
\hline 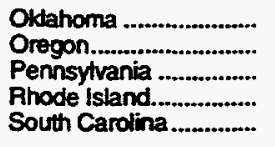 & $\begin{array}{r}120 \\
113 \\
133 \\
75 \\
89\end{array}$ & $\begin{array}{r}98 \\
168 \\
157 \\
133 \\
118\end{array}$ & $\begin{array}{l}624 \\
433 \\
684 \\
428 \\
539\end{array}$ & $\begin{array}{l}315 \\
551 \\
626 \\
625 \\
468\end{array}$ & $\begin{array}{l}\text { NA } \\
\text { NA } \\
\text { NA } \\
\text { NA } \\
\text { NA }\end{array}$ & $\begin{array}{l}\text { NA } \\
\text { NA } \\
\text { NA } \\
\text { NA } \\
\text { NA }\end{array}$ \\
\hline 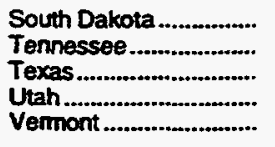 & $\begin{array}{r}177 \\
118 \\
89 \\
186 \\
b\end{array}$ & $\begin{array}{r}178 \\
105 \\
80 \\
155 \\
b\end{array}$ & $\begin{array}{r}1.120 \\
805 \\
589 \\
590 \\
b\end{array}$ & $\begin{array}{r}678 \\
554 \\
270 \\
342 \\
b\end{array}$ & $\begin{array}{l}\text { NA } \\
\text { NA } \\
\text { NA } \\
\text { NA } \\
\text { NA }\end{array}$ & $\begin{array}{l}\text { NA } \\
\text { NA } \\
\text { NA } \\
\text { NA } \\
\text { NA }\end{array}$ \\
\hline 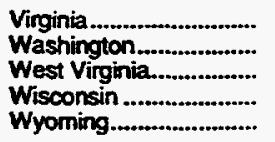 & $\begin{array}{l}105 \\
121 \\
162 \\
137 \\
224\end{array}$ & $\begin{array}{l}149 \\
165 \\
142 \\
159 \\
153\end{array}$ & $\begin{array}{r}578 \\
536 \\
718 \\
918 \\
1.172\end{array}$ & $\begin{array}{l}\mathbf{5 6 0} \\
591 \\
506 \\
737 \\
\mathbf{5 0 9}\end{array}$ & $\begin{array}{l}\text { NA } \\
\text { NA } \\
\text { NA } \\
\text { NA } \\
\text { NA }\end{array}$ & $\begin{array}{l}\text { NA } \\
\text { NA } \\
\text { NA } \\
\text { NA } \\
\text { NA }\end{array}$ \\
\hline 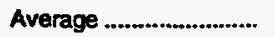 & 124 & 130 & 699 & 517 & NA & NA \\
\hline
\end{tabular}

See tootnotes at end of table. 
Table 34. Average Consumption and Annual Cost of Natural Gas pér Consumer by State, 1967-1989 (Continued)

\begin{tabular}{|c|c|c|c|c|c|c|}
\hline \multirow[b]{2}{*}{ Sten } & \multicolumn{2}{|c|}{ Residential } & \multicolumn{2}{|c|}{ Commercial } & \multicolumn{2}{|c|}{ Induntrial } \\
\hline & $\begin{array}{l}\text { Consumption } \\
\text { (thouand } \\
\text { cubic tent) }\end{array}$ & Cost & $\begin{array}{l}\text { Consumption } \\
\text { (thourand } \\
\text { cubic foet) }\end{array}$ & Cost & $\begin{array}{l}\text { Consumption } \\
\text { (thousand } \\
\text { cubic twet) }\end{array}$ & Cost \\
\hline & \multicolumn{6}{|c|}{1970} \\
\hline 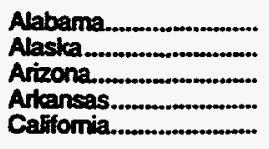 & $\begin{array}{r}104 \\
414 \\
71 \\
159 \\
99\end{array}$ & $\begin{array}{r}117 \\
629 \\
85 \\
120 \\
97\end{array}$ & $\begin{array}{r}930 \\
3,130 \\
598 \\
768 \\
590\end{array}$ & $\begin{array}{r}559 \\
2,143 \\
378 \\
404 \\
430\end{array}$ & $\begin{array}{l}\text { NA } \\
\text { NA } \\
\text { NA } \\
\text { NA }\end{array}$ & $\begin{array}{l}\text { NA } \\
\text { NA } \\
\text { NA } \\
\text { NA }\end{array}$ \\
\hline 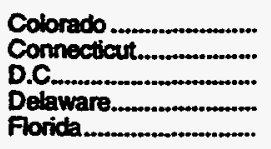 & $\begin{array}{r}152 \\
85 \\
a \\
101 \\
43\end{array}$ & $\begin{array}{r}110 \\
162 \\
a \\
159 \\
107\end{array}$ & $\begin{array}{r}856 \\
518 \\
a \\
561 \\
961\end{array}$ & $\begin{array}{r}480 \\
762 \\
a \\
698 \\
891\end{array}$ & $\begin{array}{l}\text { NA } \\
\text { NA } \\
\text { NA } \\
\text { NA }\end{array}$ & $\begin{array}{l}\text { NA } \\
\text { NA } \\
\text { NA } \\
\text { NA } \\
\text { NA }\end{array}$ \\
\hline 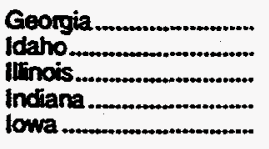 & $\begin{array}{l}120 \\
113 \\
160 \\
159 \\
169\end{array}$ & $\begin{array}{l}125 \\
158 \\
168 \\
161 \\
164\end{array}$ & $\begin{array}{l}717 \\
532 \\
944 \\
753 \\
818\end{array}$ & $\begin{array}{l}530 \\
539 \\
707 \\
627 \\
563\end{array}$ & $\begin{array}{l}\text { NA } \\
\text { NA } \\
\text { NA } \\
\text { NA } \\
\text { NA }\end{array}$ & $\begin{array}{l}\text { NA } \\
\text { NA } \\
\text { NA } \\
\text { NA }\end{array}$ \\
\hline 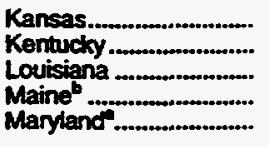 & $\begin{array}{r}163 \\
165 \\
103 \\
70 \\
106\end{array}$ & $\begin{array}{r}112 \\
137 \\
80 \\
139 \\
155\end{array}$ & $\begin{array}{l}923 \\
849 \\
950 \\
644 \\
586\end{array}$ & $\begin{array}{l}420 \\
567 \\
360 \\
925 \\
652\end{array}$ & $\begin{array}{l}\text { NA } \\
\text { NA } \\
\text { NA } \\
\text { NA }\end{array}$ & $\begin{array}{l}\text { NA } \\
\text { NA } \\
\text { NA } \\
\text { NA }\end{array}$ \\
\hline 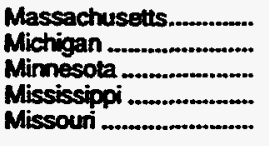 & $\begin{array}{r}83 \\
179 \\
169 \\
112 \\
160\end{array}$ & $\begin{array}{r}160 \\
182 \\
185 \\
99 \\
154\end{array}$ & $\begin{array}{r}561 \\
829 \\
1,445 \\
611 \\
1,007\end{array}$ & $\begin{array}{r}795 \\
696 \\
1,005 \\
356 \\
631\end{array}$ & $\begin{array}{l}\text { NA } \\
\text { NA } \\
\text { NA } \\
\text { NA } \\
\text { NA }\end{array}$ & $\begin{array}{l}\text { NA } \\
\text { NA } \\
\text { NA } \\
\text { NA } \\
\text { NA }\end{array}$ \\
\hline 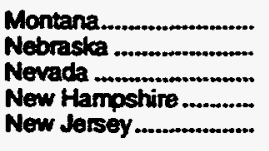 & $\begin{array}{r}182 \\
183 \\
105 \\
b \\
89\end{array}$ & $\begin{array}{r}166 \\
156 \\
159 \\
b \\
167\end{array}$ & $\begin{array}{r}1,031 \\
956 \\
2,408 \\
b \\
325\end{array}$ & $\begin{array}{r}638 \\
505 \\
1,821 \\
b \\
461\end{array}$ & $\begin{array}{l}\text { NA } \\
\text { NA } \\
\text { NA } \\
\text { NA }\end{array}$ & $\begin{array}{l}\text { NA } \\
\text { NA } \\
\text { NA } \\
\text { NA } \\
\text { NA }\end{array}$ \\
\hline $\begin{array}{l}\text { New Mexico ..................... } \\
\text { New York.................. } \\
\text { North Carolina................ } \\
\text { North Dakota................ } \\
\text { Ohio ............................... }\end{array}$ & $\begin{array}{r}134 \\
90 \\
98 \\
164 \\
188\end{array}$ & $\begin{array}{l}125 \\
125 \\
127 \\
168 \\
169\end{array}$ & $\begin{array}{r}1,376 \\
515 \\
567 \\
1.188 \\
976\end{array}$ & $\begin{array}{l}655 \\
612 \\
545 \\
823 \\
745\end{array}$ & $\begin{array}{l}\text { NA } \\
\text { NA } \\
\text { NA } \\
\text { NA } \\
\text { NA }\end{array}$ & $\begin{array}{l}\text { NA } \\
\text { NA } \\
\text { NA } \\
\text { NA }\end{array}$ \\
\hline 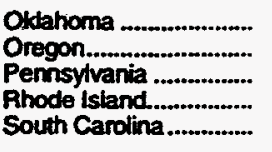 & $\begin{array}{r}123 \\
110 \\
134 \\
79 \\
90\end{array}$ & $\begin{array}{l}103 \\
166 \\
166 \\
144 \\
121\end{array}$ & $\begin{array}{l}646 \\
454 \\
705 \\
723 \\
533\end{array}$ & $\begin{array}{r}337 \\
581 \\
680 \\
1,066 \\
473\end{array}$ & $\begin{array}{l}\text { NA } \\
\text { NA } \\
\text { NA } \\
\text { NA } \\
\text { NA }\end{array}$ & $\begin{array}{l}\text { NA } \\
\text { NA } \\
\text { NA } \\
\text { NA } \\
\text { NA }\end{array}$ \\
\hline 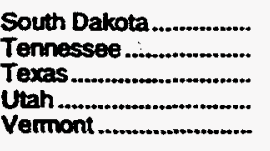 & $\begin{array}{r}186 \\
119 \\
89 \\
189 \\
b\end{array}$ & $\begin{array}{r}194 \\
109 \\
82 \\
161 \\
b\end{array}$ & $\begin{array}{r}1.136 \\
838 \\
604 \\
636 \\
b\end{array}$ & $\begin{array}{l}722 \\
597 \\
274 \\
376 \\
b\end{array}$ & $\begin{array}{l}\text { NA } \\
\text { NA } \\
\text { NA } \\
\text { NA }\end{array}$ & $\begin{array}{l}\text { NA } \\
\text { NA } \\
\text { NA } \\
\text { NA } \\
\text { NA }\end{array}$ \\
\hline 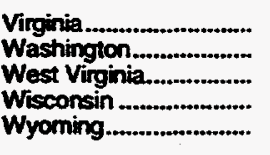 & $\begin{array}{l}110 \\
122 \\
166 \\
139 \\
240\end{array}$ & $\begin{array}{l}164 \\
171 \\
148 \\
173 \\
164\end{array}$ & $\begin{array}{r}654 \\
528 \\
748 \\
880 \\
1,275\end{array}$ & $\begin{array}{l}629 \\
584 \\
528 \\
734 \\
557\end{array}$ & $\begin{array}{l}\text { NA } \\
\text { NA } \\
\text { NA } \\
\text { NA } \\
\text { NA }\end{array}$ & $\begin{array}{l}\text { NA } \\
\text { NA } \\
\text { NA } \\
\text { NA } \\
\text { NA }\end{array}$ \\
\hline 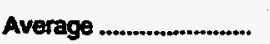 & 125 & 137 & 737 & 567 & NA & NA \\
\hline
\end{tabular}

See tootnotes at end of table. 
Table 34. Average Consumption and Annual Cost of Natural Gas per Consumer by State, 1967-1989 (Continued)

\begin{tabular}{|c|c|c|c|c|c|c|}
\hline \multirow[b]{2}{*}{ State } & \multicolumn{2}{|c|}{ Residential } & \multicolumn{2}{|c|}{ Commercial } & \multicolumn{2}{|c|}{ Inchustrial } \\
\hline & $\begin{array}{l}\text { Consumption } \\
\text { (thouteand } \\
\text { cubic feet) }\end{array}$ & $\begin{array}{c}\text { Cost } \\
\text { (dollars) }\end{array}$ & $\begin{array}{l}\text { Conaumption } \\
\text { (thourand } \\
\text { cubic teet) }\end{array}$ & (dollers) & $\begin{array}{l}\text { Conmumption } \\
\text { (thoutend } \\
\text { cubic toet) }\end{array}$ & $\begin{array}{c}\text { Cost } \\
\text { (doliars) }\end{array}$ \\
\hline & \multicolumn{6}{|c|}{1971} \\
\hline 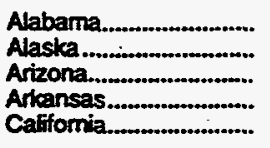 & $\begin{array}{r}102 \\
383 \\
74 \\
128 \\
111\end{array}$ & $\begin{array}{r}121 \\
586 \\
90 \\
101 \\
114\end{array}$ & $\begin{array}{r}894 \\
4,752 \\
624 \\
617 \\
662\end{array}$ & $\begin{array}{r}586 \\
3,477 \\
428 \\
337 \\
502\end{array}$ & $\begin{array}{l}\text { NA } \\
\text { NA } \\
\text { NA } \\
\text { NA }\end{array}$ & $\begin{array}{l}\mathbf{N A} \\
\mathbf{N A} \\
\mathbf{N A} \\
\mathbf{N A} \\
\mathbf{N A}\end{array}$ \\
\hline 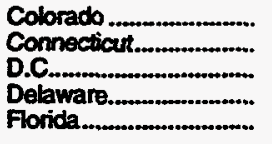 & $\begin{array}{r}152 \\
86 \\
a \\
105 \\
39\end{array}$ & $\begin{array}{r}113 \\
178 \\
a \\
170 \\
98\end{array}$ & $\begin{array}{r}872 \\
554 \\
a \\
602 \\
879\end{array}$ & $\begin{array}{r}517 \\
860 \\
a \\
765 \\
934\end{array}$ & $\begin{array}{l}\mathbf{N A} \\
\mathbf{N A} \\
\mathbf{N A} \\
\mathbf{N A}\end{array}$ & $\begin{array}{l}\text { NA } \\
\text { NA } \\
\text { NA } \\
\text { NA }\end{array}$ \\
\hline 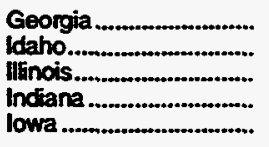 & $\begin{array}{l}119 \\
113 \\
162 \\
160 \\
163\end{array}$ & $\begin{array}{l}135 \\
168 \\
173 \\
172 \\
167\end{array}$ & $\begin{array}{l}748 \\
748 \\
988 \\
765 \\
883\end{array}$ & $\begin{array}{l}636 \\
756 \\
769 \\
674 \\
648\end{array}$ & $\begin{array}{l}\text { NA } \\
\text { NA } \\
\text { NA } \\
\text { NA }\end{array}$ & $\begin{array}{l}\text { NA } \\
\text { NA } \\
\text { NA } \\
\text { NA } \\
\text { NA }\end{array}$ \\
\hline 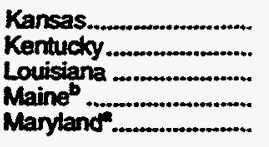 & $\begin{array}{r}165 \\
160 \\
95 \\
85 \\
106\end{array}$ & $\begin{array}{r}118 \\
141 \\
80 \\
174 \\
160\end{array}$ & $\begin{array}{l}970 \\
830 \\
951 \\
721 \\
640\end{array}$ & $\begin{array}{r}456 \\
587 \\
390 \\
1,078 \\
735\end{array}$ & $\begin{array}{l}\text { NA } \\
\text { NA } \\
\text { NA } \\
\text { NA } \\
\text { NA }\end{array}$ & $\begin{array}{l}\text { NA } \\
\text { NA } \\
\text { NA } \\
\text { NA }\end{array}$ \\
\hline 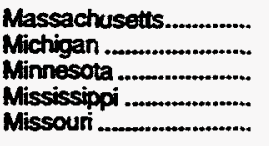 & $\begin{array}{r}85 \\
178 \\
168 \\
118 \\
153\end{array}$ & $\begin{array}{l}179 \\
189 \\
199 \\
111 \\
156\end{array}$ & $\begin{array}{r}578 \\
881 \\
1,416 \\
588 \\
1,041\end{array}$ & $\begin{array}{r}923 \\
765 \\
1,075 \\
367 \\
677\end{array}$ & $\begin{array}{l}\text { NA } \\
\text { NA } \\
\text { NA } \\
\text { NA }\end{array}$ & $\begin{array}{l}\text { NA } \\
\text { NA } \\
\text { NA } \\
\text { NA } \\
\text { NA }\end{array}$ \\
\hline 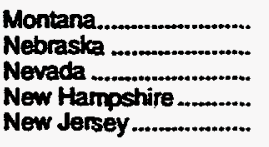 & $\begin{array}{r}181 \\
177 \\
99 \\
b \\
89\end{array}$ & $\begin{array}{r}169 \\
164 \\
149 \\
b \\
174\end{array}$ & $\begin{array}{r}1.006 \\
945 \\
275 \\
b \\
344\end{array}$ & $\begin{array}{r}658 \\
555 \\
213 \\
b \\
501\end{array}$ & $\begin{array}{l}\text { NA } \\
\text { NA } \\
\text { NA } \\
\text { NA }\end{array}$ & $\begin{array}{l}\text { NA } \\
\text { NA } \\
\text { NA } \\
\text { NA } \\
\text { NA }\end{array}$ \\
\hline $\begin{array}{l}\text { New Mexico } \ldots . . . . . . . . . . . . . \\
\text { New York................... } \\
\text { North Carolina............... } \\
\text { North Dakota................ } \\
\text { Ohio ............................. }\end{array}$ & $\begin{array}{r}140 \\
91 \\
104 \\
164 \\
186\end{array}$ & $\begin{array}{l}133 \\
137 \\
139 \\
180 \\
183\end{array}$ & $\begin{array}{r}1,468 \\
543 \\
598 \\
1,132 \\
999\end{array}$ & $\begin{array}{l}733 \\
687 \\
588 \\
866 \\
819\end{array}$ & $\begin{array}{l}\text { NA } \\
\text { NA } \\
\text { NA } \\
\text { NA }\end{array}$ & $\begin{array}{l}\text { NA } \\
\text { NA } \\
\text { NA }\end{array}$ \\
\hline $\begin{array}{l}\text { Oktahoma .................. } \\
\text { Oregon ....................... } \\
\text { Penmsytvania ................. } \\
\text { Rhode Lstand............... } \\
\text { South Carolina ............. }\end{array}$ & $\begin{array}{r}117 \\
110 \\
137 \\
79 \\
85\end{array}$ & $\begin{array}{l}103 \\
176 \\
176 \\
154 \\
125\end{array}$ & $\begin{array}{l}627 \\
543 \\
743 \\
453 \\
599\end{array}$ & $\begin{array}{l}335 \\
712 \\
748 \\
733 \\
590\end{array}$ & $\begin{array}{l}\text { NA } \\
\text { NA } \\
\text { NA } \\
\text { NA }\end{array}$ & $\begin{array}{l}\text { NA } \\
\text { NA } \\
\text { NA } \\
\text { NA }\end{array}$ \\
\hline 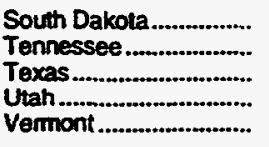 & $\begin{array}{r}164 \\
119 \\
89 \\
195 \\
b\end{array}$ & $\begin{array}{r}180 \\
116 \\
88 \\
170 \\
b\end{array}$ & $\begin{array}{r}1,059 \\
864 \\
579 \\
567 \\
b\end{array}$ & $\begin{array}{r}708 \\
663 \\
287 \\
361 \\
b\end{array}$ & $\begin{array}{l}\text { NA } \\
\text { NA } \\
\text { NA } \\
\text { NA } \\
\text { NA }\end{array}$ & $\begin{array}{l}\text { NA } \\
\text { NA } \\
\text { NA } \\
\text { NA } \\
\text { NA }\end{array}$ \\
\hline 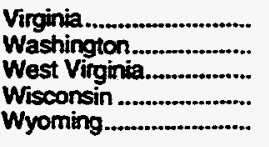 & $\begin{array}{l}107 \\
125 \\
157 \\
141 \\
256\end{array}$ & $\begin{array}{l}163 \\
179 \\
147 \\
179 \\
181\end{array}$ & $\begin{array}{r}754 \\
589 \\
797 \\
745 \\
1,279\end{array}$ & $\begin{array}{l}751 \\
664 \\
584 \\
709 \\
610\end{array}$ & $\begin{array}{l}\text { NA } \\
\text { NA } \\
\text { NA } \\
\text { NA }\end{array}$ & $\begin{array}{l}\text { NA } \\
\text { NA } \\
\text { NA } \\
\text { NA }\end{array}$ \\
\hline 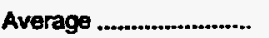 & 127 & 145 & 751 & 617 & NA & NA \\
\hline
\end{tabular}

See footnotes at end of table. 
Table 34. Average Consumption and Annual Cost of Natural Gas per Consumer by State, 1967-1989 (Continued)

\begin{tabular}{|c|c|c|c|c|c|c|}
\hline \multirow[b]{2}{*}{ Stute } & \multicolumn{2}{|c|}{ Residential } & \multicolumn{2}{|c|}{ Commereial } & \multicolumn{2}{|c|}{ Industrial } \\
\hline & $\begin{array}{l}\text { Consumption } \\
\text { (thousend } \\
\text { cubic fent) }\end{array}$ & $\begin{array}{c}\text { Cost } \\
\text { (dollars) }\end{array}$ & $\begin{array}{l}\text { Consumption } \\
\text { (thousand } \\
\text { cubic fwet) }\end{array}$ & $\begin{array}{c}\text { Cost } \\
\text { (dollars) }\end{array}$ & $\begin{array}{l}\text { Consumption } \\
\text { (thousand } \\
\text { cubic feet) }\end{array}$ & $\begin{array}{c}\text { Cost } \\
\text { (dolters) }\end{array}$ \\
\hline & \multicolumn{6}{|c|}{1972} \\
\hline 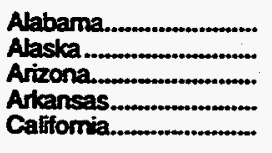 & $\begin{array}{r}97 \\
400 \\
74 \\
121 \\
110\end{array}$ & $\begin{array}{r}123 \\
621 \\
92 \\
100 \\
118\end{array}$ & $\begin{array}{r}890 \\
5.337 \\
656 \\
636 \\
629\end{array}$ & $\begin{array}{r}651 \\
4,363 \\
474 \\
362 \\
511\end{array}$ & $\begin{array}{l}\text { NA } \\
\text { NA } \\
\text { NA } \\
\text { NA }\end{array}$ & $\begin{array}{l}\mathbf{N A} \\
\mathbf{N A} \\
\mathbf{N A} \\
\mathbf{N A} \\
\mathbf{N A}\end{array}$ \\
\hline 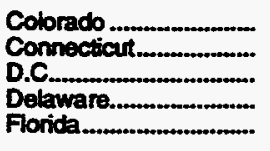 & $\begin{array}{r}153 \\
89 \\
a \\
106 \\
37\end{array}$ & $\begin{array}{r}120 \\
186 \\
a \\
181 \\
99\end{array}$ & $\begin{array}{r}889 \\
567 \\
a \\
641 \\
801\end{array}$ & $\begin{array}{r}573 \\
918 \\
a \\
869 \\
965\end{array}$ & $\begin{array}{l}\text { NA } \\
\text { NA } \\
\text { NA } \\
\text { NA } \\
\text { NA }\end{array}$ & $\begin{array}{l}\mathbf{N A} \\
\mathbf{N A} \\
\mathbf{N A} \\
\mathbf{N A}\end{array}$ \\
\hline $\begin{array}{l}\text { Georgia } \\
\text { ldaho } \\
\text { llinois } \\
\text { Indiana } \\
\text { lowa }\end{array}$ & $\begin{array}{l}113 \\
134 \\
170 \\
163 \\
167\end{array}$ & $\begin{array}{l}142 \\
203 \\
193 \\
185 \\
185\end{array}$ & $\begin{array}{r}763 \\
974 \\
1,089 \\
812 \\
893\end{array}$ & $\begin{array}{r}676 \\
1,003 \\
876 \\
753 \\
744\end{array}$ & $\begin{array}{l}\text { NA } \\
\text { NA } \\
\text { NA } \\
\text { NA } \\
\text { NA }\end{array}$ & $\begin{array}{l}\text { NA } \\
\text { NA } \\
\text { NA } \\
\text { NA }\end{array}$ \\
\hline 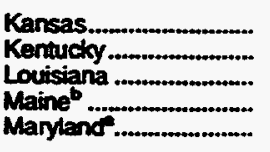 & $\begin{array}{r}164 \\
156 \\
96 \\
76 \\
105\end{array}$ & $\begin{array}{r}121 \\
145 \\
88 \\
164 \\
174\end{array}$ & $\begin{array}{r}1,039 \\
808 \\
921 \\
613 \\
656\end{array}$ & $\begin{array}{r}530 \\
607 \\
426 \\
1,002 \\
803\end{array}$ & $\begin{array}{l}\text { NA } \\
\text { NA } \\
\text { NA } \\
\text { NA }\end{array}$ & $\begin{array}{l}\text { NA } \\
\text { NA } \\
\text { NA } \\
\text { NA } \\
\text { NA }\end{array}$ \\
\hline 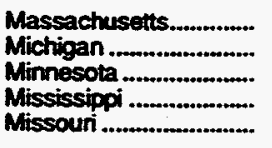 & $\begin{array}{r}85 \\
180 \\
172 \\
114 \\
156\end{array}$ & $\begin{array}{l}195 \\
198 \\
212 \\
124 \\
171\end{array}$ & $\begin{array}{r}557 \\
941 \\
1,403 \\
523 \\
1,175\end{array}$ & $\begin{array}{r}954 \\
850 \\
1.171 \\
354 \\
885\end{array}$ & $\begin{array}{l}\text { NA } \\
\text { NA } \\
\text { NA } \\
\text { NA } \\
\text { NA }\end{array}$ & $\begin{array}{l}\mathbf{N A} \\
\mathbf{N A} \\
\mathbf{N A} \\
\mathbf{N A} \\
\mathbf{N A}\end{array}$ \\
\hline 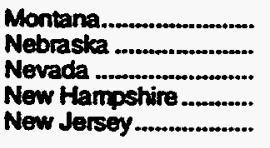 & $\begin{array}{r}166 \\
180 \\
102 \\
b \\
92\end{array}$ & $\begin{array}{r}161 \\
178 \\
155 \\
b \\
185\end{array}$ & $\begin{array}{r}1,064 \\
910 \\
1,822 \\
b \\
355\end{array}$ & $\begin{array}{r}705 \\
531 \\
1,458 \\
b \\
529\end{array}$ & $\begin{array}{l}\text { NA } \\
\text { NA } \\
\text { NA } \\
\text { NA } \\
\text { NA }\end{array}$ & $\begin{array}{l}\text { NA } \\
\text { NA } \\
\text { NA } \\
\text { NA } \\
\text { NA }\end{array}$ \\
\hline 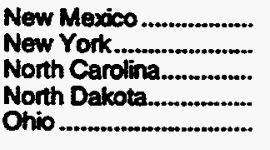 & $\begin{array}{r}150 \\
94 \\
114 \\
195 \\
192\end{array}$ & $\begin{array}{l}146 \\
152 \\
160 \\
221 \\
202\end{array}$ & $\begin{array}{r}1,471 \\
560 \\
576 \\
1,234 \\
1,067\end{array}$ & $\begin{array}{l}773 \\
729 \\
616 \\
996 \\
937\end{array}$ & $\begin{array}{l}\text { NA } \\
\text { NA } \\
\text { NA } \\
\text { NA } \\
\text { NA }\end{array}$ & $\begin{array}{l}\text { NA } \\
\text { NA } \\
\text { NA } \\
\text { NA }\end{array}$ \\
\hline $\begin{array}{l}\text { Oldahoma ........................ } \\
\text { Oregon........................ } \\
\text { Pennsylvania ................ } \\
\text { Phode Island................ } \\
\text { South Carolina.............. }\end{array}$ & $\begin{array}{r}119 \\
114 \\
138 \\
87 \\
87\end{array}$ & $\begin{array}{l}107 \\
192 \\
187 \\
178 \\
140\end{array}$ & $\begin{array}{l}645 \\
538 \\
811 \\
473 \\
589\end{array}$ & $\begin{array}{l}364 \\
771 \\
881 \\
863 \\
594\end{array}$ & $\begin{array}{l}\text { NA } \\
\text { NA } \\
\text { NA } \\
\text { NA }\end{array}$ & $\begin{array}{l}\text { NA } \\
\text { NA } \\
\text { NA } \\
\text { NA } \\
\text { NA }\end{array}$ \\
\hline 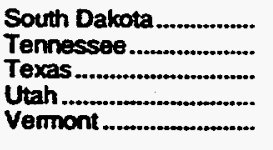 & $\begin{array}{r}169 \\
133 \\
89 \\
182 \\
b\end{array}$ & $\begin{array}{r}191 \\
136 \\
90 \\
164 \\
b\end{array}$ & $\begin{array}{r}1,120 \\
846 \\
581 \\
467 \\
b\end{array}$ & $\begin{array}{r}776 \\
727 \\
304 \\
331 \\
b\end{array}$ & $\begin{array}{l}\text { NA } \\
\text { NA } \\
\text { NA } \\
\text { NA }\end{array}$ & $\begin{array}{l}\text { NA } \\
\text { NA } \\
\text { NA } \\
\text { NA }\end{array}$ \\
\hline 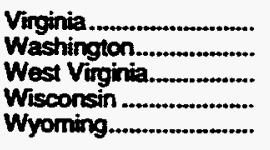 & $\begin{array}{l}118 \\
138 \\
165 \\
135 \\
282\end{array}$ & $\begin{array}{l}188 \\
203 \\
159 \\
181 \\
208\end{array}$ & $\begin{array}{r}759 \\
628 \\
833 \\
673 \\
1.441\end{array}$ & $\begin{array}{l}837 \\
730 \\
621 \\
672 \\
718\end{array}$ & $\begin{array}{l}\text { NA } \\
\text { NA } \\
\text { NA } \\
\text { NA }\end{array}$ & $\begin{array}{l}\text { NA } \\
\text { NA } \\
\text { NA } \\
\text { NA }\end{array}$ \\
\hline Average ........................... & 129 & 156 & 777 & 682 & NA & NA \\
\hline
\end{tabular}


Table 34. Average Consumption and Annual Cost of Natural Gas per Consumer by State, 1967-1989 (Continued)

\begin{tabular}{|c|c|c|c|c|c|c|}
\hline \multirow[b]{2}{*}{ State } & \multicolumn{2}{|c|}{ Rouidential } & \multicolumn{2}{|c|}{ Commercial } & \multicolumn{2}{|c|}{ Industrial } \\
\hline & $\begin{array}{c}\text { Consumption } \\
\text { (thouenend } \\
\text { cerbic foet) }\end{array}$ & $\begin{array}{c}\text { Cost } \\
\text { (dollars) }\end{array}$ & $\begin{array}{l}\text { Consumption } \\
\text { (thousend } \\
\text { celbic teet) }\end{array}$ & $\begin{array}{c}\text { Cost } \\
\text { (dolliers) }\end{array}$ & $\begin{array}{l}\text { Consumption } \\
\text { (thousend } \\
\text { cubic faet) }\end{array}$ & $\begin{array}{c}\text { Cost } \\
\text { (dollers) }\end{array}$ \\
\hline & \multicolumn{6}{|c|}{1973} \\
\hline 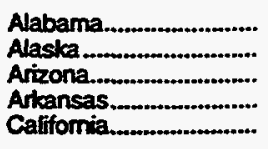 & $\begin{array}{r}92 \\
218 \\
74 \\
119 \\
104\end{array}$ & $\begin{array}{l}126 \\
344 \\
101 \\
103 \\
120\end{array}$ & $\begin{array}{r}808 \\
4,092 \\
837 \\
663 \\
661\end{array}$ & $\begin{array}{r}595 \\
3,176 \\
641 \\
409 \\
563\end{array}$ & $\begin{array}{l}\text { NA } \\
\text { NA } \\
\text { NA } \\
\text { NA }\end{array}$ & $\begin{array}{l}\text { NA } \\
\text { NA } \\
\text { NA } \\
\text { NA }\end{array}$ \\
\hline 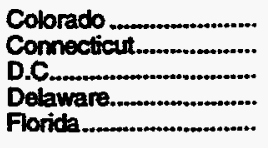 & $\begin{array}{r}154 \\
84 \\
8 \\
96 \\
42\end{array}$ & $\begin{array}{r}127 \\
188 \\
a \\
178 \\
115\end{array}$ & $\begin{array}{r}895 \\
514 \\
2 \\
619 \\
838\end{array}$ & $\begin{array}{r}611 \\
936 \\
a \\
857 \\
1,083\end{array}$ & $\begin{array}{l}\text { NA } \\
\text { NA } \\
\text { NA } \\
\text { NA } \\
\text { NA }\end{array}$ & $\begin{array}{l}\text { NA } \\
\text { NA } \\
\text { NA } \\
\text { NA } \\
\text { NA }\end{array}$ \\
\hline 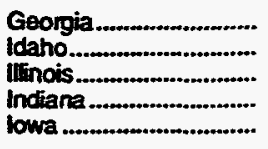 & $\begin{array}{l}108 \\
116 \\
155 \\
146 \\
149\end{array}$ & $\begin{array}{l}141 \\
176 \\
188 \\
174 \\
174\end{array}$ & $\begin{array}{r}775 \\
722 \\
1,007 \\
718 \\
990\end{array}$ & $\begin{array}{l}724 \\
773 \\
896 \\
707 \\
890\end{array}$ & $\begin{array}{l}\text { NA } \\
\text { NA } \\
\text { NA } \\
\text { NA } \\
\text { NA }\end{array}$ & $\begin{array}{l}\text { NA } \\
\text { NA } \\
\text { NA } \\
\text { NA } \\
\text { NA }\end{array}$ \\
\hline 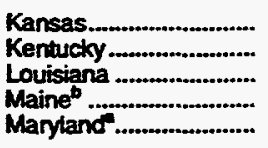 & $\begin{array}{r}156 \\
136 \\
104 \\
87 \\
101\end{array}$ & $\begin{array}{l}117 \\
135 \\
101 \\
190 \\
170\end{array}$ & $\begin{array}{l}908 \\
790 \\
875 \\
665 \\
661\end{array}$ & $\begin{array}{r}484 \\
636 \\
447 \\
1,132 \\
832\end{array}$ & $\begin{array}{l}\text { NA } \\
\text { NA } \\
\text { NA } \\
\text { NA }\end{array}$ & $\begin{array}{l}\text { NA } \\
\text { NA } \\
\text { NA } \\
\text { NA } \\
\text { NA }\end{array}$ \\
\hline 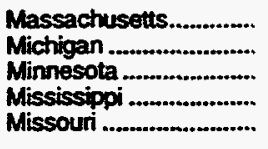 & $\begin{array}{r}82 \\
167 \\
158 \\
93 \\
145\end{array}$ & $\begin{array}{l}197 \\
198 \\
206 \\
102 \\
168\end{array}$ & $\begin{array}{r}586 \\
1,018 \\
1,360 \\
697 \\
1,198\end{array}$ & $\begin{array}{r}1,062 \\
977 \\
1,155 \\
328 \\
935\end{array}$ & $\begin{array}{l}\text { NA } \\
\text { NA } \\
\text { NA } \\
\text { NA } \\
\text { NA }\end{array}$ & $\begin{array}{l}\text { NA } \\
\text { NA } \\
\text { NA } \\
\text { NA } \\
\text { NA }\end{array}$ \\
\hline 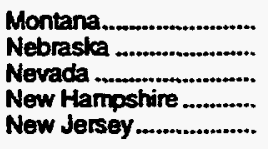 & $\begin{array}{r}161 \\
155 \\
103 \\
b \\
84\end{array}$ & $\begin{array}{r}175 \\
161 \\
158 \\
b \\
176\end{array}$ & $\begin{array}{r}912 \\
790 \\
3,286 \\
b \\
338\end{array}$ & $\begin{array}{r}643 \\
577 \\
2,867 \\
b \\
525\end{array}$ & $\begin{array}{l}\text { NA } \\
\text { NA } \\
\text { NA } \\
\text { NA } \\
\text { NA }\end{array}$ & $\begin{array}{l}\text { NA } \\
\text { NA } \\
\text { NA } \\
\text { NA } \\
\text { NA }\end{array}$ \\
\hline 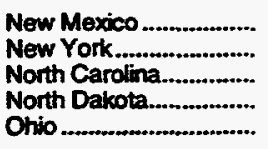 & $\begin{array}{r}108 \\
88 \\
99 \\
152 \\
170\end{array}$ & $\begin{array}{l}108 \\
154 \\
149 \\
174 \\
189\end{array}$ & $\begin{array}{r}1,065 \\
545 \\
549 \\
1,234 \\
945\end{array}$ & $\begin{array}{r}559 \\
746 \\
624 \\
1.078 \\
875\end{array}$ & $\begin{array}{l}\text { NA } \\
\text { NA } \\
\text { NA } \\
\text { NA } \\
\text { NA }\end{array}$ & $\begin{array}{l}\text { NA } \\
\text { NA } \\
\text { NA } \\
\text { NA } \\
\text { NA }\end{array}$ \\
\hline 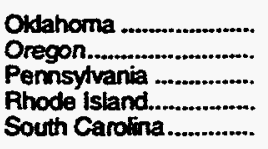 & $\begin{array}{r}113 \\
99 \\
132 \\
76 \\
89\end{array}$ & $\begin{array}{l}104 \\
175 \\
196 \\
181 \\
147\end{array}$ & $\begin{array}{l}652 \\
490 \\
780 \\
516 \\
642\end{array}$ & $\begin{array}{l}417 \\
712 \\
899 \\
974 \\
653\end{array}$ & $\begin{array}{l}\text { NA } \\
\text { NA } \\
\text { NA } \\
\text { NA } \\
\text { NA }\end{array}$ & $\begin{array}{l}\text { NA } \\
\text { NA } \\
\text { NA } \\
\text { NA }\end{array}$ \\
\hline $\begin{array}{l}\text { South Dakola ............ } \\
\text { Tennessee .............. } \\
\text { Texas } \\
\text { Utah . } \\
\text { Vermont }\end{array}$ & $\begin{array}{r}140 \\
107 \\
92 \\
186 \\
b\end{array}$ & $\begin{array}{r}167 \\
115 \\
96 \\
184 \\
b\end{array}$ & $\begin{array}{r}1.057 \\
851 \\
666 \\
562 \\
\text { b }\end{array}$ & $\begin{array}{r}810 \\
774 \\
370 \\
447 \\
b\end{array}$ & $\begin{array}{l}\text { NA } \\
\text { NA } \\
\text { NA } \\
\text { NA } \\
\text { NA }\end{array}$ & $\begin{array}{l}\text { NA } \\
\text { NA } \\
\text { NA } \\
\text { NA } \\
\text { NA }\end{array}$ \\
\hline 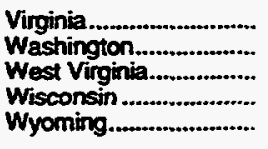 & $\begin{array}{l}107 \\
125 \\
151 \\
133 \\
171\end{array}$ & $\begin{array}{l}180 \\
194 \\
147 \\
190 \\
131\end{array}$ & $\begin{array}{r}918 \\
851 \\
783 \\
786 \\
1,321\end{array}$ & $\begin{array}{r}1.036 \\
1,060 \\
597 \\
871 \\
698\end{array}$ & $\begin{array}{l}\text { NA } \\
\text { NA } \\
\text { NA } \\
\text { NA } \\
\text { NA }\end{array}$ & $\begin{array}{l}\text { NA } \\
\text { NA } \\
\text { NA } \\
\text { NA } \\
\text { NA }\end{array}$ \\
\hline 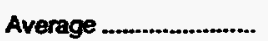 & 120 & 155 & $\pi 79$ & 735 & NA & NA \\
\hline
\end{tabular}

See footnotes at end of table. 
Table 34. Average Consumption and Annual Cost of Natural Gas per Consumer by State, 1967-1989 (Continued)

\begin{tabular}{|c|c|c|c|c|c|c|c|}
\hline \multirow[b]{2}{*}{ Stute } & \multicolumn{2}{|c|}{ Aocidentiel } & \multicolumn{2}{|c|}{ Commercial } & \multicolumn{3}{|c|}{ Industrital } \\
\hline & $\begin{array}{l}\text { Conmumption } \\
\text { (thouseand } \\
\text { cutbie foet) }\end{array}$ & $\begin{array}{c}\text { Coet } \\
\text { (dollers) }\end{array}$ & $\begin{array}{l}\text { Concamplion } \\
\text { (thoulationd } \\
\text { cubic fert) }\end{array}$ & $\begin{array}{c}\cos t \\
\text { (dollers) }\end{array}$ & $\begin{array}{l}\text { Consumption } \\
\text { (thousend } \\
\text { cubic toet) }\end{array}$ & $\begin{array}{c}\text { Cost } \\
\text { (dollarrs) }\end{array}$ & \\
\hline & \multicolumn{7}{|c|}{1974} \\
\hline 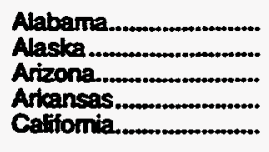 & $\begin{array}{r}88 \\
189 \\
61 \\
106 \\
96\end{array}$ & $\begin{array}{r}137 \\
299 \\
92 \\
113 \\
132\end{array}$ & $\begin{array}{r}842 \\
3.277 \\
744 \\
586 \\
604\end{array}$ & $\begin{array}{r}737 \\
2,863 \\
618 \\
443 \\
599\end{array}$ & $\begin{array}{l}\text { NA } \\
\text { NA } \\
\text { NA } \\
\text { NA } \\
\text { NA }\end{array}$ & $\begin{array}{l}\text { NA } \\
\text { NA } \\
\text { NA } \\
\text { NA } \\
\text { NA }\end{array}$ & \\
\hline $\begin{array}{l}\text { Colorado } \\
\text { Connecticut } \\
\text { D.C. } \\
\text { Delaware... } \\
\text { Florica. }\end{array}$ & $\begin{array}{r}139 \\
90 \\
\mathbf{a} \\
95 \\
39\end{array}$ & $\begin{array}{r}139 \\
251 \\
a \\
200 \\
111\end{array}$ & $\begin{array}{r}813 \\
542 \\
a \\
634 \\
609\end{array}$ & $\begin{array}{r}673 \\
1,207 \\
a \\
1,033 \\
1,000\end{array}$ & $\begin{array}{l}\text { NA } \\
\text { NA } \\
\text { NA } \\
\text { NA } \\
\text { NA }\end{array}$ & $\begin{array}{l}\text { NA } \\
\text { NA } \\
\text { NA } \\
\text { NA } \\
\text { NA }\end{array}$ & \\
\hline 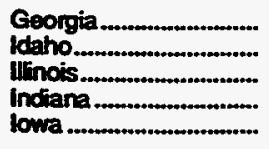 & $\begin{array}{r}92 \\
110 \\
160 \\
148 \\
150\end{array}$ & $\begin{array}{l}129 \\
197 \\
216 \\
189 \\
183\end{array}$ & $\begin{array}{l}703 \\
618 \\
973 \\
751 \\
942\end{array}$ & $\begin{array}{l}714 \\
749 \\
989 \\
794 \\
884\end{array}$ & $\begin{array}{l}\text { NA } \\
\text { NA } \\
\text { NA } \\
\text { NA } \\
\text { NA }\end{array}$ & $\begin{array}{l}\text { NA } \\
\text { NA } \\
\text { NA } \\
\text { NA } \\
\text { NA }\end{array}$ & $\cdots$ \\
\hline 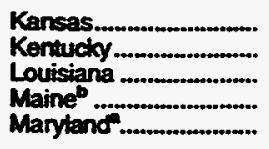 & $\begin{array}{r}147 \\
130 \\
102 \\
89 \\
97\end{array}$ & $\begin{array}{r}133 \\
143 \\
114 \\
213 \\
49\end{array}$ & $\begin{array}{l}891 \\
742 \\
842 \\
574 \\
673\end{array}$ & $\begin{array}{r}533 \\
675 \\
506 \\
1,081 \\
962\end{array}$ & $\begin{array}{l}\text { NA } \\
\text { NA } \\
\text { NA } \\
\text { NA } \\
\text { NA }\end{array}$ & $\begin{array}{l}\text { NA } \\
\text { NA } \\
\text { NA } \\
\text { NA } \\
\text { NA }\end{array}$ & \\
\hline 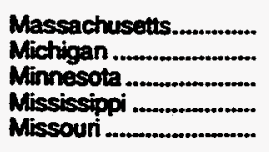 & $\begin{array}{r}83 \\
169 \\
162 \\
83 \\
141\end{array}$ & $\begin{array}{l}226 \\
232 \\
229 \\
102 \\
179\end{array}$ & $\begin{array}{r}527 \\
1,045 \\
1,310 \\
671 \\
1.038\end{array}$ & $\begin{array}{r}1.129 \\
1.181 \\
1.283 \\
506 \\
929\end{array}$ & $\begin{array}{l}\text { NA } \\
\text { NA } \\
\text { NA } \\
\text { NA } \\
\text { NA }\end{array}$ & $\begin{array}{l}\text { NA } \\
\text { NA } \\
\text { NA } \\
\text { NA } \\
\text { NA }\end{array}$ & \\
\hline 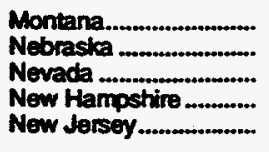 & $\begin{array}{r}138 \\
142 \\
93 \\
b \\
84\end{array}$ & $\begin{array}{r}154 \\
162 \\
160 \\
b \\
189\end{array}$ & $\begin{array}{r}755 \\
783 \\
2,816 \\
b \\
322\end{array}$ & $\begin{array}{r}677 \\
636 \\
2.978 \\
b \\
599\end{array}$ & $\begin{array}{l}\text { NA } \\
\text { NA } \\
\text { NA } \\
\text { NA } \\
\text { NA }\end{array}$ & $\begin{array}{l}\text { NA } \\
\text { NA } \\
\text { NA } \\
\text { NA } \\
\text { NA }\end{array}$ & \\
\hline 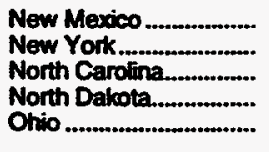 & $\begin{array}{r}106 \\
87 \\
90 \\
162 \\
169\end{array}$ & $\begin{array}{l}132 \\
174 \\
152 \\
193 \\
209\end{array}$ & $\begin{array}{r}970 \\
499 \\
500 \\
1,281 \\
944\end{array}$ & $\begin{array}{r}694 \\
794 \\
638 \\
1,281 \\
1,016\end{array}$ & $\begin{array}{l}\text { NA } \\
\text { NA } \\
\text { NA } \\
\text { NA } \\
\text { NA }\end{array}$ & $\begin{array}{l}\text { NA } \\
\text { NA } \\
\text { NA } \\
\text { NA } \\
\text { NA }\end{array}$ & \\
\hline 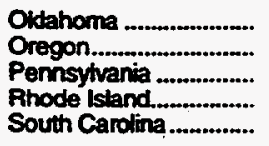 & $\begin{array}{r}109 \\
95 \\
122 \\
84 \\
79\end{array}$ & $\begin{array}{l}115 \\
190 \\
202 \\
213 \\
156\end{array}$ & $\begin{array}{l}632 \\
462 \\
670 \\
489 \\
593\end{array}$ & $\begin{array}{r}475 \\
790 \\
857 \\
1.041 \\
670\end{array}$ & $\begin{array}{l}\text { NA } \\
\text { NA } \\
\text { NA } \\
\text { NA } \\
\text { NA }\end{array}$ & $\begin{array}{l}\text { NA } \\
\text { NA } \\
\text { NA } \\
\text { NA } \\
\text { NA }\end{array}$ & \\
\hline $\begin{array}{l}\text { South Dakota..... } \\
\text { Tennessee } \\
\text { Texas } \\
\text { Utah } \\
\text { Vermont } \\
\end{array}$ & $\begin{array}{r}135 \\
99 \\
79 \\
180 \\
\mathrm{~b}\end{array}$ & $\begin{array}{r}174 \\
116 \\
92 \\
193 \\
b\end{array}$ & $\begin{array}{r}1.061 \\
783 \\
525 \\
415 \\
b\end{array}$ & $\begin{array}{r}1,204 \\
766 \\
372 \\
386 \\
b\end{array}$ & $\begin{array}{l}\text { NA } \\
\text { NA } \\
\text { NA } \\
\text { NA } \\
\text { NA }\end{array}$ & $\begin{array}{l}\text { NA } \\
\text { NA } \\
\text { NA } \\
\text { NA } \\
\text { NA }\end{array}$ & \\
\hline 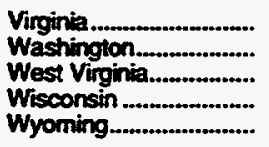 & $\begin{array}{l}100 \\
118 \\
138 \\
137 \\
123\end{array}$ & $\begin{array}{l}187 \\
209 \\
152 \\
205 \\
105\end{array}$ & $\begin{array}{r}861 \\
831 \\
745 \\
913 \\
1,103\end{array}$ & $\begin{array}{r}1,122 \\
1,106 \\
665 \\
1,025 \\
653\end{array}$ & $\begin{array}{l}\text { NA } \\
\text { NA } \\
\text { NA } \\
\text { NA } \\
\text { NA }\end{array}$ & $\begin{array}{l}\text { NA } \\
\text { NA } \\
\text { NA } \\
\text { NA } \\
\text { NA }\end{array}$ & \\
\hline Average & 115 & 165 & 734 & 788 & NA & NA & \\
\hline
\end{tabular}


Table 34. Average Consumption and Annual Cost of Natural Gas per Consumer by State, 1967-1989 (Continued)

\begin{tabular}{|c|c|c|c|c|c|c|}
\hline \multirow[b]{2}{*}{ State } & \multicolumn{2}{|c|}{ Residential } & \multicolumn{2}{|c|}{ Commercial } & \multicolumn{2}{|c|}{ Industrial } \\
\hline & $\begin{array}{l}\text { Consumption } \\
\text { (thousend } \\
\text { cubic feet) }\end{array}$ & $\begin{array}{c}\text { Cost } \\
\text { (dollars) }\end{array}$ & $\begin{array}{l}\text { Contsumption } \\
\text { (thoustand } \\
\text { cubic feot) }\end{array}$ & $\begin{array}{c}\text { Cost } \\
\text { (dollers) }\end{array}$ & $\begin{array}{l}\text { Consermption } \\
\text { (thousand } \\
\text { cubie faet) }\end{array}$ & $\begin{array}{c}\text { Cost } \\
\text { (dollars) }\end{array}$ \\
\hline & \multicolumn{6}{|c|}{1975} \\
\hline 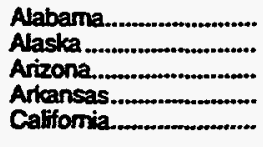 & $\begin{array}{r}87 \\
416 \\
72 \\
118 \\
102\end{array}$ & $\begin{array}{l}136 \\
676 \\
111 \\
132 \\
161\end{array}$ & $\begin{array}{r}778 \\
3,604 \\
725 \\
640 \\
618\end{array}$ & $\begin{array}{r}835 \\
3,510 \\
840 \\
570 \\
796\end{array}$ & $\begin{array}{l}\text { NA } \\
\text { NA } \\
\text { NA } \\
\text { NA } \\
\text { NA }\end{array}$ & $\begin{array}{l}\text { NA } \\
\text { NA } \\
\text { NA } \\
\text { NA }\end{array}$ \\
\hline 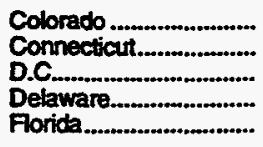 & $\begin{array}{r}147 \\
86 \\
a \\
90 \\
41\end{array}$ & $\begin{array}{r}170 \\
284 \\
a \\
217 \\
112\end{array}$ & $\begin{array}{r}887 \\
549 \\
a \\
593 \\
835\end{array}$ & $\begin{array}{r}878 \\
1,458 \\
a \\
1,127 \\
1,419\end{array}$ & $\begin{array}{l}\text { NA } \\
\mathbf{N A} \\
\mathbf{N A} \\
\mathbf{N A} \\
\mathbf{N A}\end{array}$ & $\begin{array}{l}\text { NA } \\
\text { NA } \\
\text { NA } \\
\text { NA }\end{array}$ \\
\hline 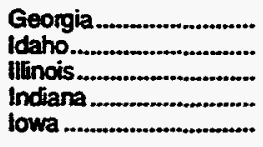 & $\begin{array}{l}103 \\
118 \\
164 \\
150 \\
151\end{array}$ & $\begin{array}{l}154 \\
258 \\
265 \\
218 \\
216\end{array}$ & $\begin{array}{l}749 \\
716 \\
963 \\
712 \\
892\end{array}$ & $\begin{array}{r}821 \\
1,109 \\
1,264 \\
886 \\
948\end{array}$ & $\begin{array}{l}\text { NA } \\
\text { NA } \\
\text { NA } \\
\text { NA } \\
\text { NA }\end{array}$ & $\begin{array}{l}\text { NA } \\
\text { NA } \\
\text { NA } \\
\text { NA } \\
\text { NA }\end{array}$ \\
\hline 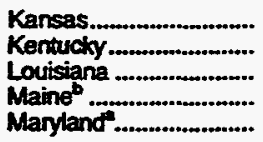 & $\begin{array}{r}151 \\
135 \\
105 \\
85 \\
96\end{array}$ & $\begin{array}{l}155 \\
166 \\
144 \\
224 \\
225\end{array}$ & $\begin{array}{l}795 \\
687 \\
768 \\
649 \\
585\end{array}$ & $\begin{array}{r}534 \\
729 \\
613 \\
1,375 \\
1,163\end{array}$ & $\begin{array}{l}\text { NA } \\
\text { NA } \\
\text { NA } \\
\text { NA }\end{array}$ & $\begin{array}{l}\text { NA } \\
\text { NA } \\
\text { NA } \\
\text { NA } \\
\text { NA }\end{array}$ \\
\hline 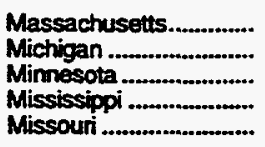 & $\begin{array}{r}87 \\
162 \\
158 \\
85 \\
143\end{array}$ & $\begin{array}{l}275 \\
262 \\
248 \\
120 \\
214\end{array}$ & $\begin{array}{r}556 \\
1,096 \\
1.299 \\
665 \\
1,031\end{array}$ & $\begin{array}{r}1,472 \\
1,625 \\
1,510 \\
627 \\
1,189\end{array}$ & $\begin{array}{l}\text { NA } \\
\text { NA } \\
\text { NA } \\
\text { NA } \\
\text { NA }\end{array}$ & $\begin{array}{l}\text { NA } \\
\text { NA } \\
\text { NA } \\
\text { NA } \\
\text { NA }\end{array}$ \\
\hline 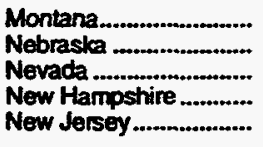 & $\begin{array}{r}152 \\
151 \\
102 \\
b \\
80\end{array}$ & $\begin{array}{r}196 \\
194 \\
198 \\
b \\
215\end{array}$ & $\begin{array}{r}888 \\
770 \\
2,993 \\
b \\
298\end{array}$ & $\begin{array}{r}973 \\
765 \\
4,632 \\
b \\
694\end{array}$ & $\begin{array}{l}\text { NA } \\
\text { NA } \\
\text { NA } \\
\text { NA }\end{array}$ & $\begin{array}{l}\text { NA } \\
\text { NA } \\
\text { NA } \\
\text { NA } \\
\text { NA }\end{array}$ \\
\hline 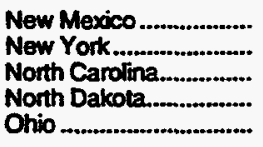 & $\begin{array}{r}116 \\
86 \\
90 \\
157 \\
167\end{array}$ & $\begin{array}{l}154 \\
218 \\
182 \\
237 \\
251\end{array}$ & $\begin{array}{r}912 \\
539 \\
503 \\
1,381 \\
855\end{array}$ & $\begin{array}{r}726 \\
1,079 \\
877 \\
1,527 \\
1,149\end{array}$ & $\begin{array}{l}\text { NA } \\
\text { NA } \\
\text { NA } \\
\text { NA } \\
\text { NA }\end{array}$ & $\begin{array}{l}\mathbf{N A} \\
\mathbf{N A} \\
\mathbf{N A} \\
\mathbf{N A} \\
\mathbf{N A}\end{array}$ \\
\hline 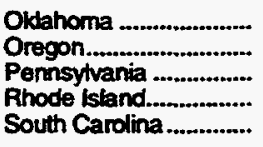 & $\begin{array}{r}118 \\
124 \\
126 \\
85 \\
70\end{array}$ & $\begin{array}{l}143 \\
272 \\
244 \\
261 \\
150\end{array}$ & $\begin{array}{l}565 \\
530 \\
673 \\
423 \\
662\end{array}$ & $\begin{array}{r}528 \\
987 \\
1.151 \\
1.162 \\
829\end{array}$ & $\begin{array}{l}\text { NA } \\
\text { NA } \\
\text { NA } \\
\text { NA } \\
\text { NA }\end{array}$ & $\begin{array}{l}\text { NA } \\
\text { NA } \\
\text { NA } \\
\text { NA }\end{array}$ \\
\hline 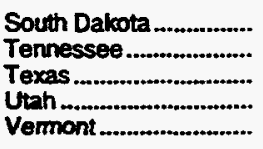 & $\begin{array}{r}144 \\
102 \\
86 \\
203 \\
b\end{array}$ & $\begin{array}{r}201 \\
132 \\
131 \\
247 \\
b\end{array}$ & $\begin{array}{r}1,044 \\
745 \\
484 \\
433 \\
b\end{array}$ & $\begin{array}{r}1.038 \\
840 \\
509 \\
657 \\
b\end{array}$ & $\begin{array}{l}\text { NA } \\
\text { NA } \\
\text { NA } \\
\text { NA } \\
\text { NA }\end{array}$ & $\begin{array}{l}\text { NA } \\
\text { NA } \\
\text { NA } \\
\text { NA } \\
\text { NA }\end{array}$ \\
\hline 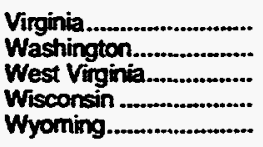 & $\begin{array}{l}101 \\
119 \\
128 \\
138 \\
120\end{array}$ & $\begin{array}{l}228 \\
270 \\
186 \\
241 \\
122\end{array}$ & $\begin{array}{r}789 \\
842 \\
708 \\
912 \\
1,025\end{array}$ & $\begin{array}{r}1.355 \\
1.531 \\
864 \\
1.197 \\
690\end{array}$ & $\begin{array}{l}\mathbf{N A} \\
\mathbf{N A} \\
\mathbf{N A} \\
\mathbf{N A} \\
\mathbf{N A}\end{array}$ & $\begin{array}{l}\text { NA } \\
\text { NA } \\
\text { NA } \\
\text { NA } \\
\text { NA }\end{array}$ \\
\hline 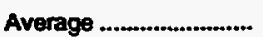 & 119 & 203 & 730 & 985 & NA & NA \\
\hline
\end{tabular}

See tootnotes at end of table. 
Table 34. Average Consumption and Annual Cost of Natural Gas per Consumer by State, 1967-1989 (Continued)

\begin{tabular}{|c|c|c|c|c|c|c|}
\hline \multirow[b]{2}{*}{ Stuto } & \multicolumn{2}{|c|}{ Rasidential } & \multicolumn{2}{|c|}{ Commercial } & \multicolumn{2}{|c|}{ Industrial } \\
\hline & $\begin{array}{l}\text { Convumption } \\
\text { (thoustind } \\
\text { eubie teot) }\end{array}$ & (dollent) & $\begin{array}{l}\text { Conaumption } \\
\text { (thousend } \\
\text { cubic teet) }\end{array}$ & Cost & $\begin{array}{l}\text { Consumption } \\
\text { (thoutand } \\
\text { cubic feet) }\end{array}$ & (dollar) \\
\hline & \multicolumn{5}{|c|}{1976} & 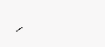 \\
\hline 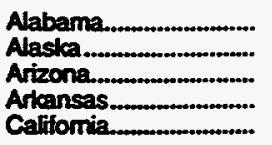 & $\begin{array}{r}103 \\
390 \\
77 \\
118 \\
95\end{array}$ & $\begin{array}{l}205 \\
645 \\
163 \\
145 \\
168\end{array}$ & $\begin{array}{r}801 \\
3,548 \\
817 \\
630 \\
593\end{array}$ & $\begin{array}{r}1,278 \\
3,693 \\
1,165 \\
640 \\
940\end{array}$ & \multicolumn{2}{|r|}{$\begin{array}{l}\text { NA } \\
\text { NA } \\
\text { NA } \\
\text { NA } \\
\text { NA }\end{array}$} \\
\hline 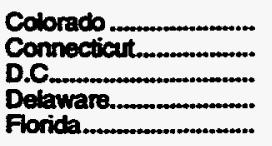 & $\begin{array}{r}153 \\
90 \\
8 \\
96 \\
45\end{array}$ & $\begin{array}{r}194 \\
305 \\
a \\
250 \\
128\end{array}$ & $\begin{array}{r}883 \\
556 \\
a \\
616 \\
902\end{array}$ & $\begin{array}{r}961 \\
1,792 \\
8 \\
1,216 \\
1,551\end{array}$ & $\begin{array}{l}\mathbf{N A} \\
\mathbf{N A} \\
\mathbf{N A} \\
\mathbf{N A}\end{array}$ & $\begin{array}{l}\mathbf{N A} \\
\mathbf{N A} \\
\mathbf{N A} \\
\mathbf{N A} \\
\mathbf{N A}\end{array}$ \\
\hline 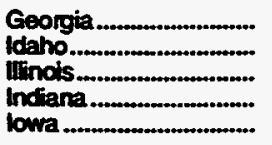 & $\begin{array}{l}103 \\
128 \\
173 \\
153 \\
160\end{array}$ & $\begin{array}{l}175 \\
286 \\
329 \\
260 \\
257\end{array}$ & $\begin{array}{r}702 \\
624 \\
1,087 \\
742 \\
1,028\end{array}$ & $\begin{array}{r}971 \\
1,286 \\
1,782 \\
1,110 \\
1,330\end{array}$ & $\begin{array}{l}\text { NA } \\
\text { NA } \\
\text { NA } \\
\text { NA } \\
\text { NA }\end{array}$ & $\begin{array}{l}\text { NA } \\
\text { NA } \\
\text { NA } \\
\text { NA } \\
\text { NA }\end{array}$ \\
\hline 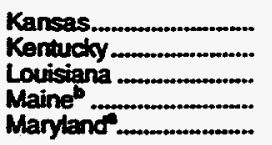 & $\begin{array}{r}163 \\
172 \\
113 \\
93 \\
103\end{array}$ & $\begin{array}{l}241 \\
228 \\
177 \\
248 \\
264\end{array}$ & $\begin{array}{r}940 \\
1,100 \\
692 \\
636 \\
673\end{array}$ & $\begin{array}{r}1,031 \\
1,262 \\
760 \\
1.686 \\
1.452\end{array}$ & $\begin{array}{l}\text { NA } \\
\text { NA } \\
\text { NA } \\
\text { NA } \\
\text { NA }\end{array}$ & $\begin{array}{l}\mathbf{N A} \\
\mathbf{N A} \\
\mathbf{N A} \\
\mathbf{N A} \\
\mathbf{N A}\end{array}$ \\
\hline 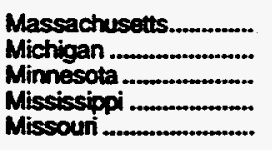 & $\begin{array}{r}97 \\
163 \\
158 \\
93 \\
151\end{array}$ & $\begin{array}{l}354 \\
309 \\
274 \\
159 \\
256\end{array}$ & $\begin{array}{r}564 \\
1,067 \\
1,222 \\
674 \\
1,200\end{array}$ & $\begin{array}{r}1,734 \\
1,944 \\
1,724 \\
870 \\
1,625\end{array}$ & $\begin{array}{l}\text { NA } \\
\text { NA } \\
\text { NA } \\
\text { NA } \\
\text { NA }\end{array}$ & $\begin{array}{l}\mathbf{N A} \\
\mathbf{N A} \\
\mathbf{N A} \\
\mathbf{N A} \\
\mathbf{N A}\end{array}$ \\
\hline 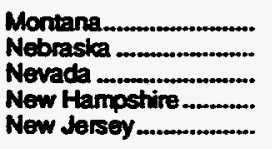 & $\begin{array}{r}146 \\
160 \\
90 \\
b \\
90\end{array}$ & $\begin{array}{r}199 \\
218 \\
185 \\
b \\
283\end{array}$ & $\begin{array}{r}892 \\
919 \\
3,678 \\
\quad b \\
505\end{array}$ & $\begin{array}{r}1,057 \\
1,061 \\
6,519 \\
b \\
1,399\end{array}$ & $\begin{array}{l}\text { NA } \\
\text { NA } \\
\text { NA } \\
\text { NA } \\
\text { NA }\end{array}$ & $\begin{array}{l}\text { NA } \\
\text { NA } \\
\text { NA } \\
\text { NA } \\
\text { NA }\end{array}$ \\
\hline 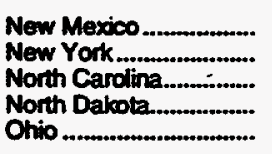 & $\begin{array}{r}153 \\
91 \\
103 \\
150 \\
172\end{array}$ & $\begin{array}{l}209 \\
261 \\
221 \\
268 \\
305\end{array}$ & $\begin{array}{r}1.348 \\
616 \\
445 \\
1.356 \\
915\end{array}$ & $\begin{array}{r}1,445 \\
1,447 \\
908 \\
1,835 \\
1,484\end{array}$ & $\begin{array}{l}\text { NA } \\
\text { NA } \\
\text { NA } \\
\text { NA } \\
\text { NA }\end{array}$ & $\begin{array}{l}\text { NA } \\
\text { NA } \\
\text { NA } \\
\text { NA } \\
\text { NA }\end{array}$ \\
\hline 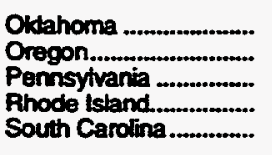 & $\begin{array}{r}122 \\
90 \\
136 \\
82 \\
138\end{array}$ & $\begin{array}{l}182 \\
241 \\
291 \\
276 \\
317\end{array}$ & $\begin{array}{r}641 \\
467 \\
865 \\
414 \\
1.461\end{array}$ & $\begin{array}{r}747 \\
1,107 \\
1,488 \\
1,401 \\
2,165\end{array}$ & $\begin{array}{l}\text { NA } \\
\text { NA } \\
\text { NA } \\
\text { NA } \\
\text { NA }\end{array}$ & $\begin{array}{l}\text { NA } \\
\text { NA } \\
\text { NA } \\
\text { NA } \\
\text { NA }\end{array}$ \\
\hline 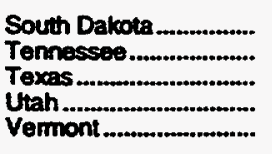 & $\begin{array}{r}175 \\
109 \\
79 \\
241 \\
b .\end{array}$ & $\begin{array}{r}262 \\
176 \\
157 \\
332 \\
b\end{array}$ & $\begin{array}{r}1,395 \\
765 \\
505 \\
612 \\
b\end{array}$ & $\begin{array}{r}1,580 \\
1,095 \\
718 \\
934 \\
b\end{array}$ & $\begin{array}{l}\text { NA } \\
\text { NA } \\
\text { NA } \\
\text { NA } \\
\text { NA }\end{array}$ & $\begin{array}{l}\text { NA } \\
\text { NA } \\
\text { NA } \\
\text { NA }\end{array}$ \\
\hline 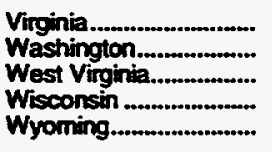 & $\begin{array}{l}129 \\
104 \\
134 \\
139 \\
170\end{array}$ & $\begin{array}{l}326 \\
280 \\
223 \\
293 \\
201\end{array}$ & $\begin{array}{r}1.090 \\
772 \\
602 \\
740 \\
t, 144\end{array}$ & $\begin{array}{r}2.066 \\
1.722 \\
904 \\
1.266 \\
895\end{array}$ & $\begin{array}{l}\text { NA } \\
\text { NA } \\
\text { NA } \\
\text { NA }\end{array}$ & $\begin{array}{l}\text { NA } \\
\text { NA } \\
\text { NA } \\
\text { NA } \\
\text { NA }\end{array}$ \\
\hline Average & 122 & 242 & 789 & 1,294 & NA & NA \\
\hline
\end{tabular}

See footnotes at end of table. 
Table 34. Average Consumption and Annual Cost of Natural Gas per Consumer by State, 1967-1989 (Continued)

\begin{tabular}{|c|c|c|c|c|c|c|}
\hline \multirow[b]{2}{*}{ State } & \multicolumn{2}{|c|}{ Residential } & \multicolumn{2}{|c|}{ Commercial } & \multicolumn{2}{|c|}{ Industrial } \\
\hline & $\begin{array}{l}\text { Consumption } \\
\text { (thousind } \\
\text { cubie fwet) }\end{array}$ & $\begin{array}{c}\text { Cost } \\
\text { (dollare) }\end{array}$ & $\begin{array}{l}\text { Comaunption } \\
\text { (thousand } \\
\text { cubic feol) }\end{array}$ & $\begin{array}{c}\text { Cost } \\
\text { (dollart) }\end{array}$ & $\begin{array}{l}\text { Consumption } \\
\text { (thousind } \\
\text { cubic foet) }\end{array}$ & $\begin{array}{c}\text { Cost } \\
\text { (dolturs) }\end{array}$ \\
\hline & \multicolumn{6}{|c|}{1977} \\
\hline 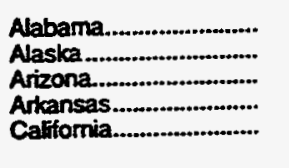 & $\begin{array}{r}99 \\
376 \\
73 \\
130 \\
89\end{array}$ & $\begin{array}{l}230 \\
643 \\
190 \\
258 \\
168\end{array}$ & $\begin{array}{r}817 \\
2,913 \\
774 \\
707 \\
654\end{array}$ & $\begin{array}{l}1,492 \\
3,917 \\
1,360 \\
1,140 \\
1,355\end{array}$ & $\begin{array}{l}\text { NA } \\
\text { NA } \\
\text { NA } \\
\text { NA }\end{array}$ & $\begin{array}{l}\text { NA } \\
\text { NA } \\
\text { NA } \\
\text { NA }\end{array}$ \\
\hline 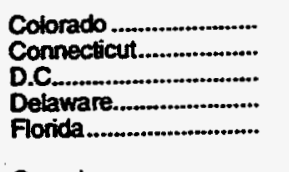 & $\begin{array}{r}139 \\
88 \\
a \\
94 \\
48\end{array}$ & $\begin{array}{r}226 \\
383 \\
a \\
304 \\
168\end{array}$ & $\begin{array}{r}907 \\
560 \\
a \\
563 \\
1,330\end{array}$ & $\begin{array}{r}1,273 \\
1,997 \\
a \\
1,659 \\
2,673\end{array}$ & $\begin{array}{l}\text { NA } \\
\text { NA } \\
\text { NA } \\
\text { NA }\end{array}$ & $\begin{array}{l}\text { NA } \\
\text { NA } \\
\text { NA } \\
\text { NA }\end{array}$ \\
\hline 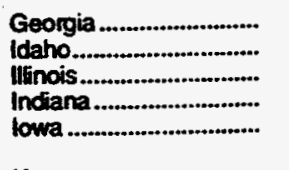 & $\begin{array}{l}115 \\
123 \\
177 \\
138 \\
138\end{array}$ & $\begin{array}{l}227 \\
350 \\
391 \\
279 \\
266\end{array}$ & $\begin{array}{r}790 \\
600 \\
1,078 \\
626 \\
807\end{array}$ & $\begin{array}{l}1,385 \\
1,453 \\
2,141 \\
1,151 \\
1,329\end{array}$ & $\begin{array}{l}\text { NA } \\
\text { NA } \\
\text { NA } \\
\text { NA }\end{array}$ & $\begin{array}{l}\text { NA } \\
\text { NA } \\
\text { NA } \\
\text { NA } \\
\text { NA }\end{array}$ \\
\hline 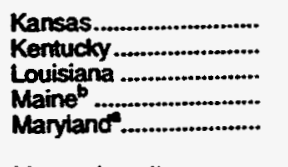 & $\begin{array}{r}144 \\
171 \\
105 \\
88 \\
91\end{array}$ & $\begin{array}{l}250 \\
305 \\
207 \\
320 \\
290\end{array}$ & $\begin{array}{l}822 \\
965 \\
665 \\
769 \\
633\end{array}$ & $\begin{array}{r}982 \\
1,597 \\
929 \\
2,485 \\
1,725\end{array}$ & $\begin{array}{l}\text { NA } \\
\text { NA } \\
\text { NA } \\
\text { NA }\end{array}$ & $\begin{array}{l}\text { NA } \\
\text { NA } \\
\text { NA } \\
\text { NA }\end{array}$ \\
\hline 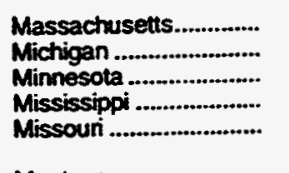 & $\begin{array}{r}96 \\
141 \\
147 \\
74 \\
141\end{array}$ & $\begin{array}{l}378 \\
313 \\
313 \\
157 \\
307\end{array}$ & $\begin{array}{r}597 \\
826 \\
1,094 \\
585 \\
1,098\end{array}$ & $\begin{array}{l}2,047 \\
1.748 \\
1,886 \\
1,033 \\
2,046\end{array}$ & $\begin{array}{l}\text { NA } \\
\text { NA } \\
\text { NA } \\
\text { NA }\end{array}$ & $\begin{array}{l}\text { NA } \\
\text { NA } \\
\text { NA } \\
\text { NA } \\
\text { NA }\end{array}$ \\
\hline 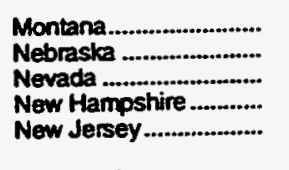 & $\begin{array}{r}133 \\
146 \\
91 \\
b \\
82\end{array}$ & $\begin{array}{r}242 \\
262 \\
253 \\
b \\
280\end{array}$ & $\begin{array}{r}879 \\
870 \\
2,906 \\
\mathbf{b} \\
299\end{array}$ & $\begin{array}{r}1,406 \\
1,213 \\
6,388 \\
b \\
927\end{array}$ & $\begin{array}{l}\text { NA } \\
\text { NA } \\
\text { NA } \\
\text { NA } \\
\text { NA }\end{array}$ & $\begin{array}{l}\text { NA } \\
\text { NA } \\
\text { NA } \\
\text { NA } \\
\text { NA }\end{array}$ \\
\hline $\begin{array}{l}\text { New Mexico .................. } \\
\text { New York................... } \\
\text { North Carolina.............. } \\
\text { North Dakota................ } \\
\text { Ohio }\end{array}$ & $\begin{array}{r}99 \\
88 \\
98 \\
130 \\
.158\end{array}$ & $\begin{array}{l}209 \\
288 \\
274 \\
274 \\
349\end{array}$ & $\begin{array}{r}944 \\
552 \\
436 \\
1,021 \\
768\end{array}$ & $\begin{array}{l}1,582 \\
1,577 \\
1,328 \\
1,707 \\
1,590\end{array}$ & $\begin{array}{l}\text { NA } \\
\text { NA } \\
\text { NA } \\
\text { NA } \\
\text { NA }\end{array}$ & $\begin{array}{l}\text { NA } \\
\text { NA } \\
\text { NA } \\
\text { NA } \\
\text { NA }\end{array}$ \\
\hline $\begin{array}{l}\text { Okdahoma .................... } \\
\text { Oregon..................... } \\
\text { Pemsylvania ................ } \\
\text { Rhode tstand............... } \\
\text { South Carolina .............. }\end{array}$ & $\begin{array}{r}129 \\
44 \\
130 \\
91 \\
129\end{array}$ & $\begin{array}{l}230 \\
152 \\
327 \\
383 \\
369\end{array}$ & $\begin{array}{r}742 \\
350 \\
777 \\
302 \\
1.285\end{array}$ & $\begin{array}{l}1,132 \\
1,078 \\
1,793 \\
1,045 \\
2,717\end{array}$ & $\begin{array}{l}\text { NA } \\
\text { NA } \\
\text { NA } \\
\text { NA } \\
\text { NA }\end{array}$ & $\begin{array}{l}\text { NA } \\
\text { NA } \\
\text { NA } \\
\text { NA }\end{array}$ \\
\hline 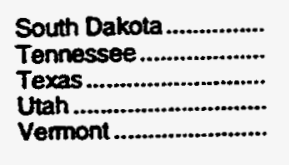 & $\begin{array}{r}164 \\
98 \\
98 \\
117 \\
b\end{array}$ & $\begin{array}{r}301 \\
205 \\
234 \\
191 \\
b\end{array}$ & $\begin{array}{r}1,344 \\
663 \\
645 \\
483 \\
\mathrm{~b}\end{array}$ & $\begin{array}{r}1,941 \\
1,374 \\
1,159 \\
836 \\
b\end{array}$ & $\begin{array}{l}\text { NA } \\
\text { NA } \\
\text { NA } \\
\text { NA } \\
\text { NA }\end{array}$ & $\begin{array}{l}\text { NA } \\
\text { NA } \\
\text { NA } \\
\text { NA }\end{array}$ \\
\hline 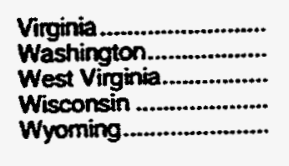 & $\begin{array}{r}102 \\
96 \\
142 \\
134 \\
116\end{array}$ & $\begin{array}{l}310 \\
301 \\
362 \\
335 \\
185\end{array}$ & $\begin{array}{l}826 \\
713 \\
593 \\
839 \\
674\end{array}$ & $\begin{array}{r}2,004 \\
1,906 \\
1,335 \\
1,760 \\
808\end{array}$ & $\begin{array}{l}\text { NA } \\
\text { NA } \\
\text { NA } \\
\text { NA }\end{array}$ & $\begin{array}{l}\text { NA } \\
\text { NA } \\
\text { NA } \\
\text { NA }\end{array}$ \\
\hline Average ........................... & 117 & 274 & 745 & 1.518 & NA & NA \\
\hline
\end{tabular}

See footnotes at end of table. 
Table 34. Average Consumption and Annual Cost of Natural Gas per Consumer by State, 1967-1989 (Continued)

\begin{tabular}{|c|c|c|c|c|c|c|}
\hline \multirow[b]{2}{*}{ State } & \multicolumn{2}{|c|}{ Residential } & \multicolumn{2}{|c|}{ Commercial } & \multicolumn{2}{|c|}{ Incuratriat } \\
\hline & $\begin{array}{c}\text { Consumption } \\
\text { (thouteand } \\
\text { cubic teet) }\end{array}$ & $\begin{array}{c}\text { Cost } \\
\text { (dollars) }\end{array}$ & $\begin{array}{l}\text { Consumption } \\
\text { (thoutic fond } \\
\text { curbic foet) }\end{array}$ & $\begin{array}{c}\text { Cost } \\
\text { (dollarns) }\end{array}$ & $\begin{array}{l}\text { Coneumption } \\
\text { (thousand } \\
\text { cubie font) }\end{array}$ & $\begin{array}{c}\text { Cost } \\
\text { (doliters) }\end{array}$ \\
\hline & \multicolumn{6}{|c|}{1978} \\
\hline 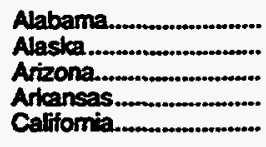 & $\begin{array}{r}98 \\
369 \\
57 \\
124 \\
85\end{array}$ & $\begin{array}{l}264 \\
649 \\
175 \\
243 \\
169\end{array}$ & $\begin{array}{r}801 \\
3,042 \\
672 \\
653 \\
608\end{array}$ & $\begin{array}{l}1,676 \\
4,030 \\
1,480 \\
1,061 \\
1,366\end{array}$ & $\begin{array}{l}\text { NA } \\
\text { NA } \\
\text { NA } \\
\text { NA }\end{array}$ & $\begin{array}{l}\text { NA } \\
\text { NA } \\
\text { NA } \\
\text { NA } \\
\text { NA }\end{array}$ \\
\hline 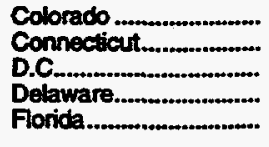 & $\begin{array}{r}128 \\
88 \\
2 \\
98 \\
56\end{array}$ & $\begin{array}{r}247 \\
395 \\
a \\
398 \\
199\end{array}$ & $\begin{array}{r}882 \\
546 \\
a \\
601 \\
823\end{array}$ & $\begin{array}{r}1,521 \\
2,059 \\
a \\
2,314 \\
1,672\end{array}$ & $\begin{array}{l}\text { NA } \\
\text { NA } \\
\text { NA } \\
\text { NA } \\
\text { NA }\end{array}$ & $\begin{array}{l}\text { NA } \\
\text { NA } \\
\text { NA } \\
\text { NA } \\
\text { NA }\end{array}$ \\
\hline 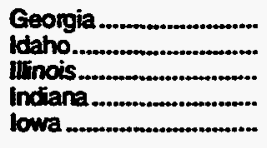 & $\begin{array}{r}110 \\
82 \\
174 \\
150 \\
147\end{array}$ & $\begin{array}{l}257 \\
280 \\
434 \\
325 \\
331\end{array}$ & $\begin{array}{r}837 \\
393 \\
1,086 \\
694 \\
769\end{array}$ & $\begin{array}{l}1,737 \\
1,209 \\
2,462 \\
1,394 \\
1,525\end{array}$ & $\begin{array}{l}\text { NA } \\
\text { NA } \\
\text { NA } \\
\text { NA } \\
\text { NA }\end{array}$ & $\begin{array}{l}\text { NA } \\
\text { NA } \\
\text { NA } \\
\text { NA } \\
\text { NA }\end{array}$ \\
\hline $\begin{array}{l}\text { Kansas } \\
\text { Kentucky. } \\
\text { Louissiana } \\
\text { Maine } \\
\text { Maryland }\end{array}$ & $\begin{array}{r}150 \\
150 \\
87 \\
92 \\
97\end{array}$ & $\begin{array}{l}266 \\
291 \\
214 \\
329 \\
330\end{array}$ & $\begin{array}{r}1,094 \\
915 \\
920 \\
638 \\
1,327\end{array}$ & $\begin{array}{l}1,280 \\
1,674 \\
1,326 \\
2,085 \\
3,933\end{array}$ & $\begin{array}{l}\text { NA } \\
\text { NA } \\
\text { NA } \\
\text { NA } \\
\text { NA }\end{array}$ & $\begin{array}{l}\text { NA } \\
\text { NA } \\
\text { NA } \\
\text { NA } \\
\text { NA }\end{array}$ \\
\hline 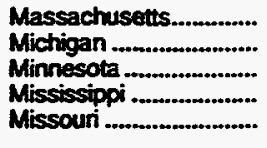 & $\begin{array}{r}90 \\
151 \\
150 \\
99 \\
147\end{array}$ & $\begin{array}{l}373 \\
349 \\
361 \\
238 \\
336\end{array}$ & $\begin{array}{r}643 \\
928 \\
1,248 \\
646 \\
1,234\end{array}$ & $\begin{array}{l}2,275 \\
2,068 \\
2,525 \\
1,308 \\
2,469\end{array}$ & $\begin{array}{l}\text { NA } \\
\text { NA } \\
\text { NA } \\
\text { NA } \\
\text { NA }\end{array}$ & $\begin{array}{l}\text { NA } \\
\text { NA } \\
\text { NA } \\
\text { NA } \\
\text { NA }\end{array}$ \\
\hline 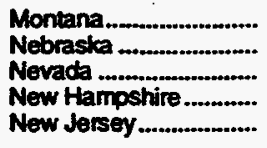 & $\begin{array}{r}140 \\
131 \\
85 \\
b \\
83\end{array}$ & $\begin{array}{r}265 \\
258 \\
237 \\
b \\
293\end{array}$ & $\begin{array}{r}888 \\
799 \\
3.323 \\
b \\
277\end{array}$ & $\begin{array}{r}1,473 \\
1,228 \\
7,992 \\
b \\
936\end{array}$ & $\begin{array}{l}\text { NA } \\
\text { NA } \\
\text { NA } \\
\text { NA } \\
\text { NA }\end{array}$ & $\begin{array}{l}\text { NA } \\
\text { NA } \\
\text { NA } \\
\text { NA } \\
\text { NA }\end{array}$ \\
\hline 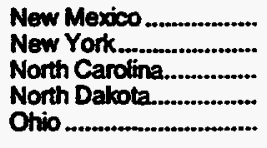 & $\begin{array}{r}94 \\
90 \\
103 \\
170 \\
166\end{array}$ & $\begin{array}{l}236 \\
330 \\
309 \\
396 \\
402\end{array}$ & $\begin{array}{r}918 \\
616 \\
497 \\
1.185 \\
908\end{array}$ & $\begin{array}{l}1,837 \\
1,881 \\
1,387 \\
2,296 \\
2,033\end{array}$ & $\begin{array}{l}\text { NA } \\
\text { NA } \\
\text { NA } \\
\text { NA }\end{array}$ & $\begin{array}{l}\text { NA } \\
\text { NA } \\
\text { NA } \\
\text { NA } \\
\text { NA }\end{array}$ \\
\hline 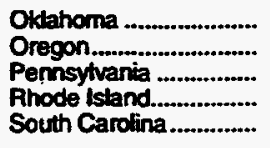 & $\begin{array}{r}125 \\
75 \\
135 \\
91 \\
118\end{array}$ & $\begin{array}{l}242 \\
289 \\
355 \\
382 \\
353\end{array}$ & $\begin{array}{r}750 \\
449 \\
796 \\
683 \\
1,073\end{array}$ & $\begin{array}{l}1,263 \\
1,521 \\
1,902 \\
2,241 \\
2,636\end{array}$ & $\begin{array}{l}\text { NA } \\
\text { NA } \\
\text { NA } \\
\text { NA } \\
\text { NA }\end{array}$ & $\begin{array}{l}\text { NA } \\
\text { NA } \\
\text { NA } \\
\text { NA } \\
\text { NA }\end{array}$ \\
\hline $\begin{array}{l}\text { South Dakota } \\
\text { Tennessee } \\
\text { Texas } \\
\text { Utah } \\
\text { Vemont }\end{array}$ & $\begin{array}{r}169 \\
107 \\
98 \\
150 \\
b\end{array}$ & $\begin{array}{r}355 \\
229 \\
269 \\
290 \\
b\end{array}$ & $\begin{array}{r}1.232 \\
687 \\
657 \\
444 \\
b\end{array}$ & $\begin{array}{r}2,124 \\
1,401 \\
1,444 \\
740 \\
b\end{array}$ & $\begin{array}{l}\text { NA } \\
\text { NA } \\
\text { NA } \\
\text { NA } \\
\text { NA }\end{array}$ & $\begin{array}{l}\text { NA } \\
\text { NA } \\
\text { NA } \\
\text { NA } \\
\text { NA }\end{array}$ \\
\hline 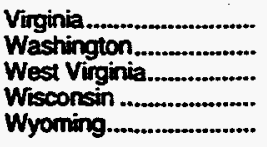 & $\begin{array}{r}117 \\
91 \\
148 \\
118 \\
151\end{array}$ & $\begin{array}{l}384 \\
315 \\
386 \\
316 \\
289\end{array}$ & $\begin{array}{l}897 \\
667 \\
750 \\
950 \\
736\end{array}$ & $\begin{array}{l}2,370 \\
1,899 \\
1,615 \\
2,230 \\
1,219\end{array}$ & $\begin{array}{l}\text { NA } \\
\text { NA } \\
\text { NA } \\
\text { NA } \\
\text { NA }\end{array}$ & $\begin{array}{l}\text { NA } \\
\text { NA } \\
\text { NA } \\
\text { NA } \\
\text { NA }\end{array}$ \\
\hline Average .......................... & 117 & 300 & 784 & 1,753 & NA & NA \\
\hline
\end{tabular}

See footinotes at end of table. 
Table 34. Average Consumption and Annual Cost of Natural Gas per Consumer by State, 1967-1989 (Continued)

\begin{tabular}{|c|c|c|c|c|c|c|}
\hline \multirow[b]{2}{*}{ State } & \multicolumn{2}{|c|}{ Residential } & \multicolumn{2}{|c|}{ Commercial } & \multicolumn{2}{|c|}{ Industrial } \\
\hline & $\begin{array}{l}\text { Consumption } \\
\text { (thoutand } \\
\text { cubic fiet) }\end{array}$ & $\begin{array}{c}\text { Cost } \\
\text { (dollart) }\end{array}$ & $\begin{array}{l}\text { Consumption } \\
\text { (thousand } \\
\text { cubic ieet) }\end{array}$ & $\begin{array}{c}\text { Cost } \\
\text { (dollars) }\end{array}$ & $\begin{array}{l}\text { Consumption } \\
\text { (thousand } \\
\text { cubic feet) }\end{array}$ & $\begin{array}{c}\text { Cost } \\
\text { (dollars) }\end{array}$ \\
\hline & \multicolumn{6}{|c|}{1979} \\
\hline 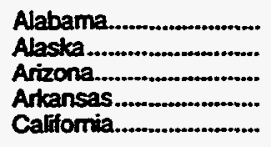 & $\begin{array}{r}88 \\
203 \\
55 \\
111 \\
87\end{array}$ & $\begin{array}{l}320 \\
347 \\
192 \\
174 \\
214\end{array}$ & $\begin{array}{r}854 \\
2,644 \\
613 \\
1,760 \\
689\end{array}$ & $\begin{array}{l}2,373 \\
2,727 \\
1,621 \\
2,397 \\
1,884\end{array}$ & $\begin{array}{l}\text { NA } \\
\mathbf{N A} \\
\mathbf{N A} \\
\mathbf{N A} \\
\mathbf{N A}\end{array}$ & $\begin{array}{l}\text { NA } \\
\text { NA } \\
\text { NA } \\
\text { NA }\end{array}$ \\
\hline 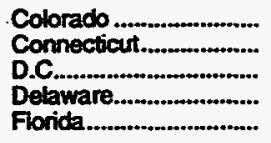 & $\begin{array}{r}130 \\
85 \\
a \\
92 \\
43\end{array}$ & $\begin{array}{r}321 \\
406 \\
2 \\
370 \\
157\end{array}$ & $\begin{array}{r}850 \\
526 \\
a \\
568 \\
1,078\end{array}$ & $\begin{array}{r}1,947 \\
2,075 \\
a \\
2,128 \\
2,948\end{array}$ & $\begin{array}{l}\text { NA } \\
\text { NA } \\
\text { NA } \\
\text { NA } \\
\text { NA }\end{array}$ & $\begin{array}{l}\text { NA } \\
\text { NA } \\
\text { NA } \\
\text { NA }\end{array}$ \\
\hline 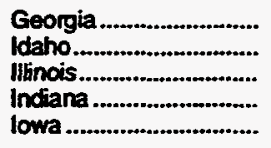 & $\begin{array}{r}101 \\
93 \\
164 \\
257 \\
146\end{array}$ & $\begin{array}{l}291 \\
347 \\
492 \\
679 \\
392\end{array}$ & $\begin{array}{r}832 \\
495 \\
1.005 \\
1,108 \\
767\end{array}$ & $\begin{array}{l}2,102 \\
1,709 \\
2,821 \\
2,724 \\
1,832\end{array}$ & $\begin{array}{l}\text { NA } \\
\text { NA } \\
\text { NA } \\
\text { NA } \\
\text { NA }\end{array}$ & $\begin{array}{l}\text { NA } \\
\text { NA } \\
\text { NA } \\
\text { NA } \\
\text { NA }\end{array}$ \\
\hline 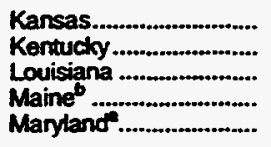 & $\begin{array}{r}153 \\
135 \\
94 \\
86 \\
98\end{array}$ & $\begin{array}{l}298 \\
317 \\
253 \\
353 \\
367\end{array}$ & $\begin{array}{r}937 \\
750 \\
1,653 \\
628 \\
751\end{array}$ & $\begin{array}{l}1,507 \\
1,654 \\
3,769 \\
2,265 \\
2,381\end{array}$ & $\begin{array}{l}\text { NA } \\
\text { NA } \\
\text { NA } \\
\text { NA } \\
\text { NA }\end{array}$ & $\begin{array}{l}\text { NA } \\
\text { NA } \\
\text { NA } \\
\text { NA } \\
\text { NA }\end{array}$ \\
\hline 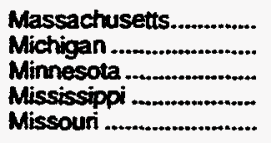 & $\begin{array}{r}82 \\
172 \\
153 \\
88 \\
142\end{array}$ & $\begin{array}{l}373 \\
454 \\
437 \\
251 \\
391\end{array}$ & $\begin{array}{r}667 \\
1.154 \\
890 \\
579 \\
1.113\end{array}$ & $\begin{array}{l}2,561 \\
2,975 \\
2,302 \\
1,423 \\
2,812\end{array}$ & $\begin{array}{l}\text { NA } \\
\text { NA } \\
\text { NA } \\
\text { NA } \\
\text { NA }\end{array}$ & $\begin{array}{l}\text { NA } \\
\text { NA } \\
\text { NA } \\
\text { NA } \\
\text { NA }\end{array}$ \\
\hline 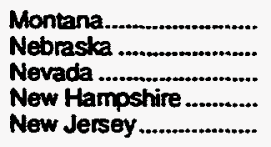 & $\begin{array}{r}138 \\
147 \\
89 \\
b \\
81\end{array}$ & $\begin{array}{r}305 \\
339 \\
251 \\
b \\
347\end{array}$ & $\begin{array}{r}870 \\
946 \\
3,273 \\
b \\
299\end{array}$ & $\begin{array}{r}1,735 \\
1,895 \\
9,159 \\
b \\
1,194\end{array}$ & $\begin{array}{l}\text { NA } \\
\text { NA } \\
\text { NA } \\
\text { NA } \\
\text { NA }\end{array}$ & $\begin{array}{l}\text { NA } \\
\text { NA } \\
\text { NA } \\
\text { NA } \\
\text { NA }\end{array}$ \\
\hline 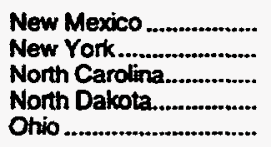 & $\begin{array}{r}100 \\
85 \\
91 \\
155 \\
146\end{array}$ & $\begin{array}{l}274 \\
349 \\
320 \\
445 \\
410\end{array}$ & $\begin{array}{r}909 \\
608 \\
556 \\
1,204 \\
819\end{array}$ & $\begin{array}{l}2,095 \\
2,128 \\
1,720 \\
2,977 \\
2,131\end{array}$ & $\begin{array}{l}\text { NA } \\
\text { NA } \\
\text { NA } \\
\text { NA } \\
\text { NA }\end{array}$ & $\begin{array}{l}\mathbf{N A} \\
\mathbf{N A} \\
\mathbf{N A} \\
\mathbf{N A} \\
\mathbf{N A}\end{array}$ \\
\hline $\begin{array}{l}\text { Oklahoma } \\
\text { Oregon............................ } \\
\text { Pennsytvania } \\
\text { Rhode Island.................. } \\
\text { South Carolina .............. }\end{array}$ & $\begin{array}{r}122 \\
89 \\
134 \\
89 \\
71\end{array}$ & $\begin{array}{l}269 \\
367 \\
429 \\
326 \\
249\end{array}$ & $\begin{array}{l}913 \\
494 \\
785 \\
617 \\
718\end{array}$ & $\begin{array}{l}3,120 \\
1,835 \\
2,317 \\
1,905 \\
1,998\end{array}$ & $\begin{array}{l}\text { NA } \\
\text { NA } \\
\text { NA } \\
\text { NA } \\
\text { NA }\end{array}$ & $\begin{array}{l}\text { NA } \\
\text { NA } \\
\text { NA } \\
\text { NA } \\
\text { NA }\end{array}$ \\
\hline 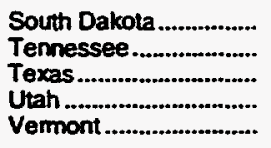 & $\begin{array}{r}131 \\
103 \\
84 \\
166 \\
b\end{array}$ & $\begin{array}{r}343 \\
244 \\
271 \\
368 \\
b\end{array}$ & $\begin{array}{r}905 \\
700 \\
702 \\
2 \\
b\end{array}$ & $\begin{array}{r}2.017 \\
1.729 \\
1.997 \\
4 \\
b\end{array}$ & $\begin{array}{l}\text { NA } \\
\text { NA } \\
\text { NA } \\
\text { NA } \\
\text { NA }\end{array}$ & $\begin{array}{l}\text { NA } \\
\text { NA } \\
\text { NA } \\
\text { NA } \\
\text { NA }\end{array}$ \\
\hline 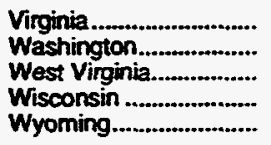 & $\begin{array}{r}122 \\
99 \\
132 \\
132 \\
147\end{array}$ & $\begin{array}{l}453 \\
392 \\
385 \\
405 \\
369\end{array}$ & $\begin{array}{l}970 \\
742 \\
698 \\
997 \\
821\end{array}$ & $\begin{array}{l}3,039 \\
2,568 \\
1,878 \\
2,682 \\
1,950\end{array}$ & $\begin{array}{l}\mathbf{N A} \\
\mathbf{N A} \\
\mathbf{N A} \\
\mathbf{N A} \\
\mathbf{N A}\end{array}$ & $\begin{array}{l}\text { NA } \\
\text { NA } \\
\text { NA } \\
\text { NA } \\
\text { NA }\end{array}$ \\
\hline Average ............................ & 115 & 341 & 811 & 2,211 & NA & NA \\
\hline
\end{tabular}

See footnotes at end of table. 
Table 34. Average Consumption and Annual Cost of Natural Gas pér Consumer by State, 1967-1989 (Continued)

\begin{tabular}{|c|c|c|c|c|c|c|}
\hline \multirow[b]{2}{*}{ State } & \multicolumn{2}{|c|}{ Residential } & \multicolumn{2}{|c|}{ Commorcial } & \multicolumn{2}{|c|}{ Industrial } \\
\hline & $\begin{array}{l}\text { Contumption } \\
\text { (thousend } \\
\text { cubic teet) }\end{array}$ & $\begin{array}{c}\text { Cost } \\
\text { (dollars) }\end{array}$ & $\begin{array}{l}\text { Conwumption } \\
\text { (thousend } \\
\text { cubic teet) }\end{array}$ & Cost & $\begin{array}{l}\text { Connumption } \\
\text { (thounand } \\
\text { cubic feet) }\end{array}$ & $\begin{array}{c}\text { Cost } \\
\text { (dollers) }\end{array}$ \\
\hline & \multicolumn{6}{|c|}{1980} \\
\hline 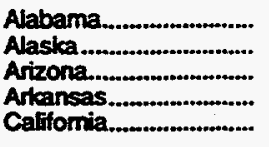 & $\begin{array}{r}83 \\
214 \\
54 \\
103 \\
76\end{array}$ & $\begin{array}{l}334 \\
371 \\
219 \\
254 \\
268\end{array}$ & $\begin{array}{r}582 \\
2.752 \\
611 \\
529 \\
679\end{array}$ & $\begin{array}{l}1,970 \\
2,912 \\
1,915 \\
1,204 \\
2,705\end{array}$ & $\begin{array}{r}67,487 \\
23,257,667 \\
34,716 \\
71,429 \\
11,777\end{array}$ & $\begin{array}{r}171,745 \\
9,024,657 \\
93,217 \\
158,760 \\
44,767\end{array}$ \\
\hline 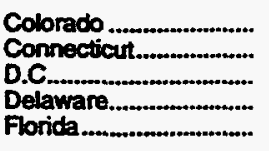 & $\begin{array}{r}115 \\
86 \\
103 \\
89 \\
36\end{array}$ & $\begin{array}{l}374 \\
503 \\
470 \\
383 \\
175\end{array}$ & $\begin{array}{l}728 \\
611 \\
860 \\
649 \\
888\end{array}$ & $\begin{array}{l}2,194 \\
2,913 \\
3,627 \\
2,626 \\
3,048\end{array}$ & $\begin{array}{r}31,676 \\
8,306 \\
385,000 \\
61,966 \\
142,188\end{array}$ & $\begin{array}{r}83,360 \\
34,643 \\
948,000 \\
173,784 \\
396,684\end{array}$ \\
\hline 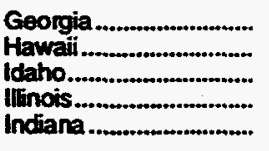 & $\begin{array}{r}91 \\
58 \\
79 \\
156 \\
140\end{array}$ & $\begin{array}{l}334 \\
753 \\
393 \\
563 \\
443\end{array}$ & $\begin{array}{l}744 \\
572 \\
384 \\
931 \\
674\end{array}$ & $\begin{array}{l}2,394 \\
6,990 \\
1,762 \\
3,109 \\
1,990\end{array}$ & $\begin{array}{r}65,439 \\
0 \\
57,643 \\
18,574 \\
52,811\end{array}$ & $\begin{array}{r}185,975 \\
0 \\
217,144 \\
58,898 \\
137,527\end{array}$ \\
\hline 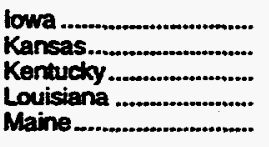 & $\begin{array}{r}127 \\
125 \\
126 \\
75 \\
43\end{array}$ & $\begin{array}{l}404 \\
296 \\
383 \\
256 \\
273\end{array}$ & $\begin{array}{l}649 \\
879 \\
691 \\
580 \\
432\end{array}$ & $\begin{array}{l}1,846 \\
1,667 \\
2,017 \\
1,562 \\
2,214\end{array}$ & $\begin{array}{r}39,973 \\
29,480 \\
61,665 \\
590,540 \\
14,346\end{array}$ & $\begin{array}{r}100,576 \\
68,731 \\
165,329 \\
757,511 \\
61,615\end{array}$ \\
\hline $\begin{array}{l}\text { Maryland .................... } \\
\text { Massachusetts............. } \\
\text { Michigan ...................... } \\
\text { Minnesota ..................... } \\
\text { Mississippi .................... }\end{array}$ & $\begin{array}{r}94 \\
94 \\
168 \\
135 \\
83\end{array}$ & $\begin{array}{l}421 \\
509 \\
536 \\
436 \\
290\end{array}$ & $\begin{array}{r}583 \\
732 \\
1.153 \\
898 \\
475\end{array}$ & $\begin{array}{l}2,307 \\
3,459 \\
3,677 \\
2,586 \\
1,456\end{array}$ & $\begin{array}{l}11,907 \\
10,102 \\
24,968 \\
41,983 \\
58,616\end{array}$ & $\begin{array}{r}38,709 \\
41,963 \\
73,072 \\
104,909 \\
161,409\end{array}$ \\
\hline 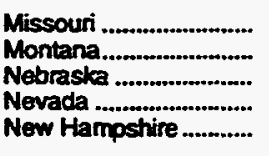 & $\begin{array}{l}126 \\
117 \\
125 \\
79 \\
95\end{array}$ & $\begin{array}{l}415 \\
356 \\
342 \\
322 \\
442\end{array}$ & $\begin{array}{r}836 \\
713 \\
903 \\
1,458 \\
686\end{array}$ & $\begin{array}{l}2,447 \\
2,243 \\
2,064 \\
5,650 \\
2,832\end{array}$ & $\begin{array}{r}25,527 \\
32,841 \\
71,775 \\
144,196 \\
8,938\end{array}$ & $\begin{array}{r}67,803 \\
103,218 \\
155,687 \\
429,686 \\
35,134\end{array}$ \\
\hline $\begin{array}{l}\text { New Jersey................. } \\
\text { New Mexico .................. } \\
\text { New York.................. } \\
\text { North Carolina.............. } \\
\text { North Dakota............... }\end{array}$ & $\begin{array}{r}88 \\
92 \\
90 \\
91 \\
124\end{array}$ & $\begin{array}{l}443 \\
307 \\
446 \\
374 \\
476\end{array}$ & $\begin{array}{r}390 \\
790 \\
700 \\
569 \\
1,103\end{array}$ & $\begin{array}{l}1,793 \\
2,314 \\
2,989 \\
2,112 \\
3,785\end{array}$ & $\begin{array}{r}12,376 \\
147,675 \\
6,702 \\
35,159 \\
17,709\end{array}$ & $\begin{array}{r}46,384 \\
380,373 \\
23,487 \\
118,141 \\
48,182\end{array}$ \\
\hline 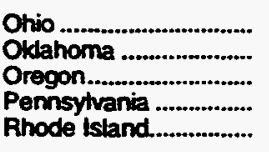 & $\begin{array}{r}153 \\
102 \\
74 \\
131 \\
88\end{array}$ & $\begin{array}{l}542 \\
251 \\
415 \\
499 \\
503\end{array}$ & $\begin{array}{l}852 \\
620 \\
433 \\
795 \\
614\end{array}$ & $\begin{array}{l}2,826 \\
1,426 \\
2,215 \\
2,837 \\
3,133\end{array}$ & $\begin{array}{r}49,455 \\
61,274 \\
62,422 \\
55,876 \\
3,517\end{array}$ & $\begin{array}{r}151,141 \\
129,293 \\
274,627 \\
171,326 \\
15,979\end{array}$ \\
\hline 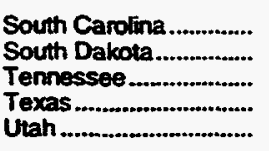 & $\begin{array}{r}72 \\
113 \\
98 \\
77 \\
151\end{array}$ & $\begin{array}{l}301 \\
355 \\
284 \\
261 \\
414\end{array}$ & $\begin{array}{l}848 \\
709 \\
699 \\
634 \\
330\end{array}$ & $\begin{array}{l}2,721 \\
1,928 \\
2,097 \\
1,896 \\
1,846\end{array}$ & $\begin{array}{l}88,420 \\
17,011 \\
54,818 \\
92,186 \\
73,306\end{array}$ & $\begin{array}{r}264,408 \\
39,876 \\
141,332 \\
212,621 \\
166,310\end{array}$ \\
\hline 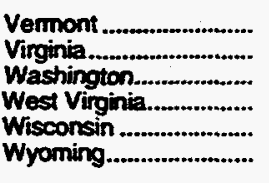 & $\begin{array}{r}120 \\
103 \\
88 \\
132 \\
128 \\
129\end{array}$ & $\begin{array}{l}747 \\
438 \\
469 \\
473 \\
490 \\
363\end{array}$ & $\begin{array}{l}828 \\
836 \\
683 \\
666 \\
907 \\
623\end{array}$ & $\begin{array}{l}5,093 \\
3,150 \\
3,304 \\
2,224 \\
3,139 \\
1,652\end{array}$ & $\begin{array}{r}64,890 \\
37,390 \\
43,142 \\
175,434 \\
21,210 \\
133,965\end{array}$ & $\begin{array}{r}317,000 \\
113,465 \\
185,619 \\
525,997 \\
66,678 \\
330,344\end{array}$ \\
\hline 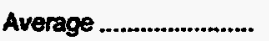 & 108 & 397 & 739 & 2,506 & 39,245 & 100,598 \\
\hline
\end{tabular}

See footnotes at end of table. 
Table 34. Average Consumption and Annual Cost of Natural Gas per Consumer by State, 1967-1989 (Continued)

\begin{tabular}{|c|c|c|c|c|c|c|}
\hline \multirow[b]{2}{*}{ State } & \multicolumn{2}{|c|}{ Rosidential } & \multicolumn{2}{|c|}{ Commercial } & \multicolumn{2}{|c|}{ Industrial } \\
\hline & $\begin{array}{l}\text { Consumption } \\
\text { (thousisind } \\
\text { cubic foet) }\end{array}$ & $\begin{array}{c}\text { Cost } \\
\text { (dollars) }\end{array}$ & $\begin{array}{l}\text { Consumption } \\
\text { (thousend } \\
\text { cubic tent) }\end{array}$ & $\underset{\text { (dolliers) }}{\text { Cost }}$ & $\begin{array}{l}\text { Consumption } \\
\text { (thousand } \\
\text { cubic teots) }\end{array}$ & $\begin{array}{c}\text { Cost' } \\
\text { (dollars) }\end{array}$ \\
\hline & \multicolumn{6}{|c|}{1981} \\
\hline 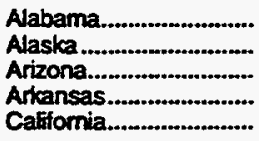 & $\begin{array}{r}79 \\
196 \\
48 \\
93 \\
69\end{array}$ & $\begin{array}{l}377 \\
384 \\
221 \\
284 \\
258\end{array}$ & $\begin{array}{r}537 \\
2,692 \\
608 \\
479 \\
612\end{array}$ & $\begin{array}{l}2,187 \\
3,782 \\
2,148 \\
1,350 \\
2,680\end{array}$ & $\begin{array}{r}82,332 \\
6,635,250 \\
38,685 \\
72,777 \\
11,391\end{array}$ & $\begin{array}{r}259,598 \\
2,385,125 \\
122,702 \\
201,029 \\
46,182\end{array}$ \\
\hline $\begin{array}{l}\text { Colorado } \\
\text { Connecticut } \\
\text { D.C............. } \\
\text { Delaware... } \\
\text { Florida }\end{array}$ & $\begin{array}{r}93 \\
88 \\
103 \\
87 \\
38\end{array}$ & $\begin{array}{l}390 \\
600 \\
565 \\
480 \\
200\end{array}$ & $\begin{array}{r}620 \\
651 \\
1.000 \\
757 \\
887\end{array}$ & $\begin{array}{l}2,380 \\
3,643 \\
5,121 \\
3,919 \\
3,327\end{array}$ & $\begin{array}{r}31,511 \\
8,516 \\
344,000 \\
68,737 \\
127,968\end{array}$ & $\begin{array}{r}107,157 \\
43,375 \\
1,034,000 \\
251,789 \\
418,563\end{array}$ \\
\hline 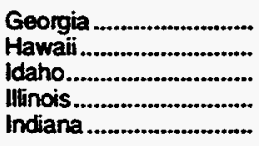 & $\begin{array}{r}90 \\
54 \\
71 \\
152 \\
134\end{array}$ & $\begin{array}{l}391 \\
835 \\
394 \\
615 \\
484\end{array}$ & $\begin{array}{l}705 \\
537 \\
361 \\
897 \\
678\end{array}$ & $\begin{array}{l}2,807 \\
7,912 \\
1,808 \\
3,358 \\
2,294\end{array}$ & $\begin{array}{l}65,618 \\
0 \\
55,228 \\
18,887 \\
53,839\end{array}$ & $\begin{array}{r}241,643 \\
0 \\
220,518 \\
68,216 \\
163,738\end{array}$ \\
\hline 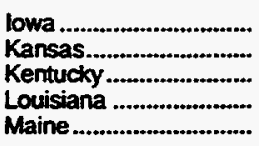 & $\begin{array}{r}113 \\
108 \\
117 \\
72 \\
59\end{array}$ & $\begin{array}{l}441 \\
326 \\
408 \\
299 \\
438\end{array}$ & $\begin{array}{r}585 \\
713 \\
617 \\
476 \\
1,043\end{array}$ & $\begin{array}{l}2,051 \\
1,715 \\
2,091 \\
1,758 \\
6,391\end{array}$ & $\begin{array}{r}41,104 \\
25,625 \\
51,828 \\
527,507 \\
27,115\end{array}$ & $\begin{array}{r}127.602 \\
77.433 \\
165,015 \\
990,057 \\
141,385\end{array}$ \\
\hline $\begin{array}{l}\text { Maryland } \\
\text { Massachusetts..... } \\
\text { Michigan } \\
\text { Minnesota } \\
\text { Mississippi }\end{array}$ & $\begin{array}{r}97 \\
95 \\
155 \\
122 \\
78\end{array}$ & $\begin{array}{l}489 \\
604 \\
597 \\
499 \\
313\end{array}$ & $\begin{array}{r}641 \\
706 \\
1,053 \\
867 \\
470\end{array}$ & $\begin{array}{l}2,874 \\
4,042 \\
4,028 \\
3,154 \\
1,679\end{array}$ & $\begin{array}{l}12,667 \\
10,588 \\
23,397 \\
30,486 \\
60,899\end{array}$ & $\begin{array}{r}50,337 \\
53,890 \\
82,943 \\
97,038 \\
201,953\end{array}$ \\
\hline 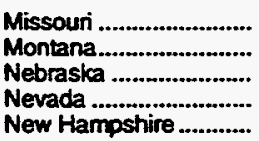 & $\begin{array}{r}112 \\
104 \\
111 \\
76 \\
93\end{array}$ & $\begin{array}{l}452 \\
389 \\
384 \\
366 \\
529\end{array}$ & $\begin{array}{r}744 \\
654 \\
677 \\
1,382 \\
625\end{array}$ & $\begin{array}{l}2,672 \\
2,734 \\
2,004 \\
6,329 \\
3,192\end{array}$ & $\begin{array}{r}23,662 \\
31,364 \\
55,746 \\
78,727 \\
7,298\end{array}$ & $\begin{array}{r}78,859 \\
133,551 \\
155,030 \\
283,875 \\
33,795\end{array}$ \\
\hline 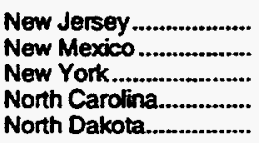 & $\begin{array}{r}87 \\
81 \\
91 \\
90 \\
112\end{array}$ & $\begin{array}{l}511 \\
312 \\
498 \\
466 \\
478\end{array}$ & $\begin{array}{l}434 \\
682 \\
709 \\
586 \\
942\end{array}$ & $\begin{array}{l}2,378 \\
2,309 \\
3,356 \\
2,765 \\
3,442\end{array}$ & $\begin{array}{r}13,432 \\
12,504 \\
7,062 \\
35,277 \\
14,381\end{array}$ & $\begin{array}{r}\mathbf{6 3 , 4 3 2} \\
37,403 \\
27,966 \\
\mathbf{1 5 5 , 7 7 8} \\
\mathbf{5 8 , 9 5 9}\end{array}$ \\
\hline 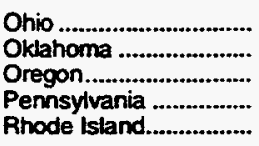 & $\begin{array}{r}146 \\
90 \\
68 \\
129 \\
89\end{array}$ & $\begin{array}{l}578 \\
264 \\
409 \\
583 \\
587\end{array}$ & $\begin{array}{l}818 \\
517 \\
426 \\
846 \\
572\end{array}$ & $\begin{array}{l}3,035 \\
1,476 \\
2,315 \\
3,567 \\
3,334\end{array}$ & $\begin{array}{r}47,034 \\
50,767 \\
62,038 \\
56,543 \\
3,735\end{array}$ & $\begin{array}{r}161,272 \\
129,608 \\
286,725 \\
209,129 \\
19,885\end{array}$ \\
\hline 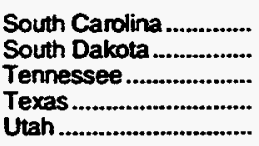 & $\begin{array}{r}71 \\
103 \\
91 \\
69 \\
140\end{array}$ & $\begin{array}{l}347 \\
401 \\
312 \\
288 \\
453\end{array}$ & $\begin{array}{l}694 \\
682 \\
667 \\
578 \\
343\end{array}$ & $\begin{array}{l}2.750 \\
2,328 \\
2,360 \\
2,127 \\
1,836\end{array}$ & $\begin{array}{l}89,236 \\
18,468 \\
59,198 \\
89,760 \\
78,926\end{array}$ & $\begin{array}{r}342,610 \\
55,843 \\
186,682 \\
260,816 \\
203,718\end{array}$ \\
\hline 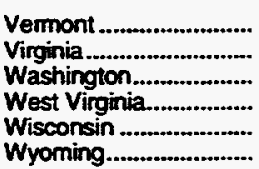 & $\begin{array}{r}117 \\
102 \\
79 \\
128 \\
114 \\
113\end{array}$ & $\begin{array}{l}817 \\
477 \\
474 \\
542 \\
544 \\
397\end{array}$ & $\begin{array}{l}831 \\
801 \\
651 \\
672 \\
782 \\
501\end{array}$ & $\begin{array}{l}5,693 \\
3,352 \\
3,479 \\
2,658 \\
3,425 \\
1,640\end{array}$ & $\begin{array}{r}89,957 \\
57.970 \\
23,180 \\
177.420 \\
20,966 \\
156,177\end{array}$ & $\begin{array}{r}504,957 \\
207,917 \\
107,207 \\
624,386 \\
79,032 \\
480,118\end{array}$ \\
\hline Average .................... & 101 & 434 & 693 & 2.773 & 37,530 & 117,680 \\
\hline
\end{tabular}

See foctnotes at end of table. 
Table 34. Average Consumption and Annual Cost of Natural Gas per Consumer by State, 1967-1989 (Continued)

\begin{tabular}{|c|c|c|c|c|c|c|}
\hline \multirow[b]{2}{*}{ Stan } & \multicolumn{2}{|c|}{ Residential } & \multicolumn{2}{|c|}{ Commercial } & \multicolumn{2}{|c|}{ Industrial } \\
\hline & $\begin{array}{l}\text { Consumption } \\
\text { (thousand } \\
\text { cubic feet) }\end{array}$ & $\begin{array}{c}\text { Cost } \\
\text { (dollars) }\end{array}$ & $\begin{array}{l}\text { Consermption } \\
\text { (thousend } \\
\text { cubic feet) }\end{array}$ & $\underset{\text { (dollers) }}{\text { Coast }}$ & $\begin{array}{l}\text { Conseumption } \\
\text { (thousand } \\
\text { cubic teat) }\end{array}$ & $\begin{array}{c}\text { Cost } \\
\text { (dollers) }\end{array}$ \\
\hline & \multicolumn{6}{|c|}{1982} \\
\hline 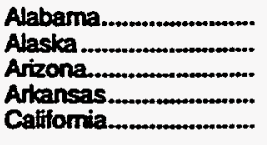 & $\begin{array}{r}74 \\
220 \\
57 \\
98 \\
76\end{array}$ & $\begin{array}{l}413 \\
396 \\
338 \\
376 \\
337\end{array}$ & $\begin{array}{r}515 \\
3,687 \\
578 \\
508 \\
604\end{array}$ & $\begin{array}{l}2,484 \\
5,868 \\
2,831 \\
1,842 \\
3,214\end{array}$ & $\begin{array}{r}75,412 \\
6,468,428 \\
25,098 \\
63,386 \\
9,372\end{array}$ & $\begin{array}{r}319,634 \\
3,756,851 \\
101,344 \\
205,602 \\
45,725\end{array}$ \\
\hline 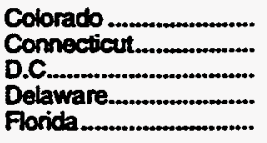 & $\begin{array}{r}105 \\
87 \\
99 \\
85 \\
31\end{array}$ & $\begin{array}{l}512 \\
740 \\
658 \\
512 \\
206\end{array}$ & $\begin{array}{r}698 \\
881 \\
1,042 \\
710 \\
792\end{array}$ & $\begin{array}{l}3,185 \\
6,133 \\
6,541 \\
3,969 \\
3,704\end{array}$ & $\begin{array}{r}28,454 \\
8,847 \\
0 \\
55,597 \\
123,092\end{array}$ & $\begin{array}{r}113,336 \\
53,287 \\
0 \\
254,585 \\
500,528\end{array}$ \\
\hline 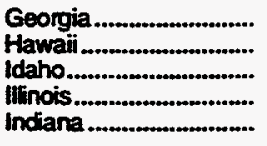 & $\begin{array}{r}85 \\
50 \\
72 \\
150 \\
136\end{array}$ & $\begin{array}{l}451 \\
787 \\
495 \\
710 \\
595\end{array}$ & $\begin{array}{l}671 \\
592 \\
379 \\
885 \\
680\end{array}$ & $\begin{array}{l}3,183 \\
8,412 \\
2,322 \\
3,927 \\
2,839\end{array}$ & $\begin{array}{r}59,577 \\
0 \\
45,374 \\
15,783 \\
47,958\end{array}$ & $\begin{array}{r}248,543 \\
0 \\
217,894 \\
67,262 \\
180,105\end{array}$ \\
\hline 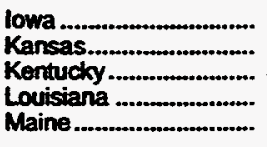 & $\begin{array}{r}125 \\
118 \\
115 \\
68 \\
46\end{array}$ & $\begin{array}{l}588 \\
481 \\
512 \\
364 \\
398\end{array}$ & $\begin{array}{l}739 \\
746 \\
651 \\
474 \\
434\end{array}$ & $\begin{array}{l}3,189 \\
2,415 \\
2,862 \\
2,337 \\
3,178\end{array}$ & $\begin{array}{r}32,498 \\
21,041 \\
43,953 \\
398,776 \\
11,665\end{array}$ & $\begin{array}{r}121,604 \\
61,830 \\
180,929 \\
1,259,416 \\
77.396\end{array}$ \\
\hline 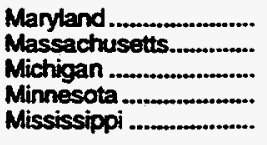 & $\begin{array}{r}93 \\
96 \\
154 \\
137 \\
76\end{array}$ & $\begin{array}{l}567 \\
724 \\
740 \\
680 \\
373\end{array}$ & $\begin{array}{r}615 \\
789 \\
1,043 \\
965 \\
410\end{array}$ & $\begin{array}{l}3,416 \\
5,060 \\
4,860 \\
4,390 \\
1,858\end{array}$ & $\begin{array}{r}11,404 \\
7,341 \\
18,592 \\
24,969 \\
78,551\end{array}$ & $\begin{array}{r}57,492 \\
41,647 \\
80,227 \\
102,292 \\
323,825\end{array}$ \\
\hline 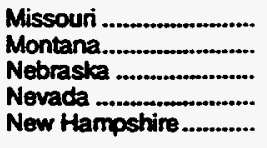 & $\begin{array}{r}120 \\
121 \\
130 \\
90 \\
100\end{array}$ & $\begin{array}{l}626 \\
538 \\
542 \\
500 \\
687\end{array}$ & $\begin{array}{r}772 \\
780 \\
995 \\
1.416 \\
688\end{array}$ & $\begin{array}{l}3,681 \\
3,800 \\
3,476 \\
7,852 \\
4,176\end{array}$ & $\begin{array}{r}19,963 \\
24,013 \\
44,875 \\
87,084 \\
5,345\end{array}$ & $\begin{array}{r}88,114 \\
131,770 \\
159,156 \\
384,385 \\
29,743\end{array}$ \\
\hline $\begin{array}{l}\text { New Jersey................. } \\
\text { New Mexico ................ } \\
\text { New York................. } \\
\text { North Carolina............... } \\
\text { North Dakota.............. }\end{array}$ & $\begin{array}{r}88 \\
86 \\
92 \\
90 \\
136\end{array}$ & $\begin{array}{l}620 \\
424 \\
601 \\
514 \\
628\end{array}$ & $\begin{array}{r}448 \\
642 \\
692 \\
563 \\
1,053\end{array}$ & $\begin{array}{l}2,849 \\
2,849 \\
3,791 \\
2,950 \\
4,315\end{array}$ & $\begin{array}{r}12,334 \\
100,945 \\
5,524 \\
30,229 \\
14,641\end{array}$ & $\begin{array}{r}64,640 \\
364,860 \\
27,453 \\
140,331 \\
63,220\end{array}$ \\
\hline 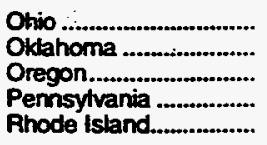 & $\begin{array}{r}144 \\
100 \\
75 \\
123 \\
91\end{array}$ & $\begin{array}{l}716 \\
353 \\
516 \\
669 \\
723\end{array}$ & $\begin{array}{l}799 \\
552 \\
463 \\
830 \\
609\end{array}$ & $\begin{array}{l}3,714 \\
1,907 \\
2,917 \\
4,185 \\
4,180\end{array}$ & $\begin{array}{r}39,544 \\
61,109 \\
50,926 \\
44,561 \\
3,556\end{array}$ & $\begin{array}{r}170,658 \\
181,095 \\
284,377 \\
200,473 \\
21,989\end{array}$ \\
\hline 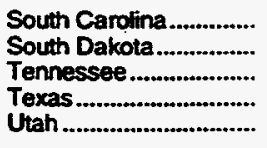 & $\begin{array}{r}66 \\
122 \\
90 \\
72 \\
171\end{array}$ & $\begin{array}{l}\mathbf{3 6 2} \\
\mathbf{5 7 4} \\
\mathbf{3 9 1} \\
\mathbf{3 7 6} \\
\mathbf{5 8 4}\end{array}$ & $\begin{array}{l}563 \\
790 \\
598 \\
686 \\
175\end{array}$ & $\begin{array}{r}2,710 \\
3,231 \\
2,646 \\
3,076 \\
599\end{array}$ & $\begin{array}{l}57,782 \\
15,968 \\
48,031 \\
77,156 \\
73,576\end{array}$ & $\begin{array}{r}252,708 \\
62,225 \\
190,205 \\
262,553 \\
180,464\end{array}$ \\
\hline 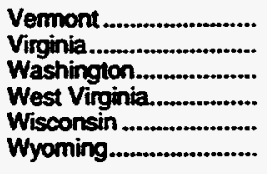 & $\begin{array}{r}117 \\
96 \\
86 \\
119 \\
121 \\
129\end{array}$ & $\begin{array}{l}848 \\
581 \\
588 \\
619 \\
682 \\
586\end{array}$ & $\begin{array}{l}638 \\
862 \\
686 \\
637 \\
813 \\
652\end{array}$ & $\begin{array}{l}4,505 \\
4,634 \\
4,261 \\
3,152 \\
4,017 \\
3,016\end{array}$ & $\begin{array}{r}96,726 \\
54,438 \\
16,597 \\
139,757 \\
15,935 \\
94,433\end{array}$ & $\begin{array}{r}528,531 \\
238,747 \\
92,332 \\
612,691 \\
70,392 \\
323,015\end{array}$ \\
\hline Average ........................... & 104 & 537 & 696 & 3,358 & 30,909 & 122,502 \\
\hline
\end{tabular}

See footnotes at end of table. 
Table 34. Average Consumption and Annual Cost of Natural Gas per Consumer by State, 1967-1989 (Continued)

\begin{tabular}{|c|c|c|c|c|c|c|}
\hline \multirow[b]{2}{*}{ State } & \multicolumn{2}{|c|}{ Residential } & \multicolumn{2}{|c|}{ Commereial } & \multicolumn{2}{|c|}{ Industrial } \\
\hline & $\begin{array}{l}\text { Consumption } \\
\text { (thoustand } \\
\text { cubic foot) }\end{array}$ & $\begin{array}{c}\text { Cost } \\
\text { (dollars) }\end{array}$ & $\begin{array}{l}\text { Consumption } \\
\text { (thousend } \\
\text { cubic feot) }\end{array}$ & Cost & $\begin{array}{l}\text { Consumption } \\
\text { (thousend } \\
\text { cubic feet) }\end{array}$ & $\begin{array}{c}\text { Cost } \\
\text { (dollars) }\end{array}$ \\
\hline & \multicolumn{6}{|c|}{1983} \\
\hline 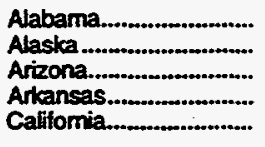 & $\begin{array}{r}76 \\
189 \\
53 \\
93 \\
70\end{array}$ & $\begin{array}{l}472 \\
441 \\
352 \\
410 \\
377\end{array}$ & $\begin{array}{r}528 \\
3,254 \\
530 \\
476 \\
543\end{array}$ & $\begin{array}{l}2,862 \\
6,313 \\
2,940 \\
1,986 \\
3,435\end{array}$ & $\begin{array}{r}64,618 \\
7,464,135 \\
26,858 \\
55,490 \\
9,019\end{array}$ & $\begin{array}{r}290,944 \\
5,025,421 \\
111,166 \\
201,380 \\
49,520\end{array}$ \\
\hline 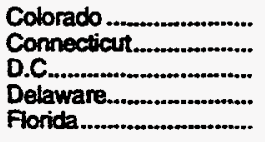 & $\begin{array}{r}101 \\
81 \\
99 \\
80 \\
35\end{array}$ & $\begin{array}{l}557 \\
781 \\
804 \\
528 \\
240\end{array}$ & $\begin{array}{r}659 \\
639 \\
1.061 \\
650 \\
765\end{array}$ & $\begin{array}{l}3,324 \\
4,760 \\
7,892 \\
3,947 \\
3,858\end{array}$ & $\begin{array}{r}24,028 \\
8,681 \\
0 \\
87,081 \\
125,993\end{array}$ & $\begin{array}{r}102,922 \\
51,466 \\
0 \\
373,132 \\
516,945\end{array}$ \\
\hline 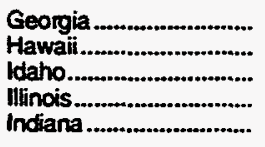 & $\begin{array}{r}86 \\
46 \\
67 \\
141 \\
122\end{array}$ & $\begin{array}{l}528 \\
758 \\
498 \\
769 \\
672\end{array}$ & $\begin{array}{l}667 \\
437 \\
375 \\
824 \\
610\end{array}$ & $\begin{array}{l}3,611 \\
6,419 \\
2,338 \\
4,092 \\
3,153\end{array}$ & $\begin{array}{r}53,058 \\
0 \\
46,609 \\
15,127 \\
43,812\end{array}$ & $\begin{array}{r}239,617 \\
0 \\
238,639 \\
73,100 \\
191,175\end{array}$ \\
\hline 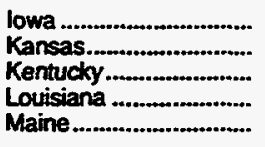 & $\begin{array}{r}114 \\
116 \\
107 \\
69 \\
43\end{array}$ & $\begin{array}{l}628 \\
542 \\
569 \\
422 \\
424\end{array}$ & $\begin{array}{l}582 \\
712 \\
576 \\
492 \\
397\end{array}$ & $\begin{array}{l}2,937 \\
3,244 \\
2,972 \\
2,813 \\
3,532\end{array}$ & $\begin{array}{r}31,378 \\
16,789 \\
41,996 \\
404,221 \\
10,927\end{array}$ & $\begin{array}{r}128,740 \\
56,974 \\
191,770 \\
1,266,058 \\
83,689\end{array}$ \\
\hline $\begin{array}{l}\text { Maryland ...................... } \\
\text { Massachusetts............ } \\
\text { Michigan ..................... } \\
\text { Minnesota ................. } \\
\text { Mississippi .................... }\end{array}$ & $\begin{array}{r}88 \\
90 \\
146 \\
122 \\
76\end{array}$ & $\begin{array}{l}655 \\
746 \\
855 \\
721 \\
447\end{array}$ & $\begin{array}{l}610 \\
530 \\
975 \\
899 \\
411\end{array}$ & $\begin{array}{l}4,096 \\
3,937 \\
5,493 \\
4,735 \\
2,247\end{array}$ & $\begin{array}{r}9,175 \\
6,996 \\
17,102 \\
25,533 \\
89,571\end{array}$ & $\begin{array}{r}55,210 \\
39,694 \\
87,682 \\
113,994 \\
385,037\end{array}$ \\
\hline 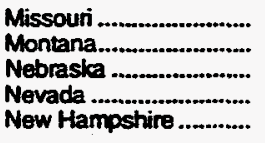 & $\begin{array}{r}112 \\
102 \\
119 \\
66 \\
94\end{array}$ & $\begin{array}{l}686 \\
470 \\
588 \\
450 \\
706\end{array}$ & $\begin{array}{l}723 \\
651 \\
659 \\
762 \\
657\end{array}$ & $\begin{array}{l}4,054 \\
3,298 \\
2,778 \\
4,601 \\
4,423\end{array}$ & $\begin{array}{r}18,493 \\
25,048 \\
48,267 \\
126,159 \\
6,249\end{array}$ & $\begin{array}{r}92,626 \\
99,956 \\
179,767 \\
607,559 \\
37,475\end{array}$ \\
\hline $\begin{array}{l}\text { New Jersey................... } \\
\text { New Mexico ................. } \\
\text { New York................... } \\
\text { Nonth Carolina.............. } \\
\text { Nonth Dakota................. }\end{array}$ & $\begin{array}{r}87 \\
85 \\
87 \\
86 \\
117\end{array}$ & $\begin{array}{l}646 \\
465 \\
681 \\
571 \\
654\end{array}$ & $\begin{array}{l}446 \\
662 \\
663 \\
533 \\
883\end{array}$ & $\begin{array}{l}2,987 \\
3,180 \\
4,293 \\
3,201 \\
4,466\end{array}$ & $\begin{array}{r}12,328 \\
10,181 \\
5,462 \\
27,311 \\
13,361\end{array}$ & $\begin{array}{r}67,131 \\
39,638 \\
31,030 \\
141,235 \\
63,673\end{array}$ \\
\hline $\begin{array}{l}\text { Ohio ........................... } \\
\text { Oklahoma } \\
\text { Oregon ............................... } \\
\text { Pennsylvania ............... } \\
\text { Rhode istand................. }\end{array}$ & $\begin{array}{r}129 \\
96 \\
66 \\
114 \\
84\end{array}$ & $\begin{array}{l}783 \\
416 \\
481 \\
734 \\
724\end{array}$ & $\begin{array}{l}727 \\
513 \\
426 \\
761 \\
581\end{array}$ & $\begin{array}{l}4,152 \\
2.118 \\
2,767 \\
4,626 \\
4,129\end{array}$ & $\begin{array}{r}38,110 \\
55,079 \\
50,265 \\
40,261 \\
3,926\end{array}$ & $\begin{array}{r}196,261 \\
184,597 \\
268,575 \\
204,111 \\
24,217\end{array}$ \\
\hline $\begin{array}{l}\text { South Carolina ............... } \\
\text { South Dakota ................ } \\
\text { Tennessee.................. } \\
\text { Texas............................ } \\
\text { Utah ............................. }\end{array}$ & $\begin{array}{r}65 \\
110 \\
87 \\
69 \\
135\end{array}$ & $\begin{array}{l}417 \\
617 \\
456 \\
385 \\
576\end{array}$ & $\begin{array}{r}525 \\
727 \\
642 \\
344 \\
6,364\end{array}$ & $\begin{array}{r}2,906 \\
3,543 \\
3,306 \\
1,737 \\
27,476\end{array}$ & $\begin{array}{l}54,063 \\
15,807 \\
47,171 \\
83,751 \\
77,395\end{array}$ & $\begin{array}{r}262,552 \\
70,444 \\
203,314 \\
288,940 \\
243,429\end{array}$ \\
\hline 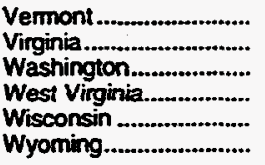 & $\begin{array}{r}112 \\
94 \\
76 \\
114 \\
110 \\
116\end{array}$ & $\begin{array}{l}760 \\
659 \\
521 \\
663 \\
738 \\
596\end{array}$ & $\begin{array}{l}589 \\
857 \\
641 \\
787 \\
590 \\
680\end{array}$ & $\begin{array}{l}3,839 \\
5,342 \\
3,895 \\
4,181 \\
3.378 \\
3,649\end{array}$ & $\begin{array}{r}101,324 \\
51,904 \\
16,961 \\
143,854 \\
16,866 \\
100,123\end{array}$ & $\begin{array}{r}508,045 \\
261,371 \\
89,169 \\
730,541 \\
79,073 \\
368,123\end{array}$ \\
\hline 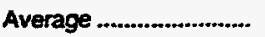 & 97 & 588 & 625 & 3,497 & 29,915 & 129,712 \\
\hline
\end{tabular}

See footnotes at end of table. 
Table 34. Average Consumption and Annual Cost of Natural Gas per Consumer by State, 1967-1989 (Continued)

\begin{tabular}{|c|c|c|c|c|c|c|}
\hline \multirow[b]{2}{*}{ Stute } & \multicolumn{2}{|c|}{ Residontial } & \multicolumn{2}{|c|}{ Commmelal } & \multicolumn{2}{|c|}{ Indentria! } \\
\hline & $\begin{array}{l}\text { Consumption } \\
\text { (thousand } \\
\text { cubic feot) }\end{array}$ & Coot & $\begin{array}{l}\text { Constumption } \\
\text { (thousend } \\
\text { eubic teet) }\end{array}$ & Cost & $\begin{array}{l}\text { Consumption } \\
\text { (thousand } \\
\text { cubie teot) }\end{array}$ & $\begin{array}{c}\text { Cost } \\
\text { (doliters) }\end{array}$ \\
\hline & \multicolumn{6}{|c|}{1984} \\
\hline 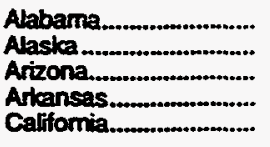 & $\begin{array}{r}78 \\
188 \\
50 \\
99 \\
65\end{array}$ & $\begin{array}{l}491 \\
467 \\
356 \\
433 \\
378\end{array}$ & $\begin{array}{r}550 \\
2.459 \\
554 \\
493 \\
480\end{array}$ & $\begin{array}{l}2,992 \\
5,081 \\
3,102 \\
2,061 \\
3,339\end{array}$ & $\begin{array}{r}58,706 \\
7,246,545 \\
29,154 \\
38,938 \\
10,951\end{array}$ & $\begin{array}{r}256,417 \\
4,791,502 \\
127,235 \\
151,222 \\
56,937\end{array}$ \\
\hline 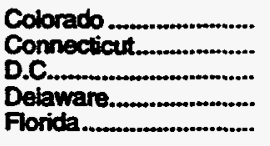 & $\begin{array}{r}108 \\
85 \\
130 \\
87 \\
34\end{array}$ & $\begin{array}{r}565 \\
750 \\
1,044 \\
578 \\
246\end{array}$ & $\begin{array}{r}712 \\
694 \\
1,037 \\
735 \\
780\end{array}$ & $\begin{array}{l}3,397 \\
4,638 \\
7,296 \\
4,533 \\
4,058\end{array}$ & $\begin{array}{r}41,048 \\
10,428 \\
0 \\
110,111 \\
68,016\end{array}$ & $\begin{array}{r}174,800 \\
58,747 \\
0 \\
474,758 \\
289,407\end{array}$ \\
\hline 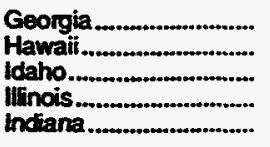 & $\begin{array}{r}87 \\
39 \\
75 \\
156 \\
127\end{array}$ & $\begin{array}{l}559 \\
673 \\
516 \\
839 \\
721\end{array}$ & $\begin{array}{l}644 \\
462 \\
533 \\
925 \\
661\end{array}$ & $\begin{array}{l}3,642 \\
8,012 \\
3,043 \\
4,494 \\
3,455\end{array}$ & $\begin{array}{r}49,839 \\
0 \\
0 \\
15,333 \\
42,115\end{array}$ & $\begin{array}{r}228,076 \\
0 \\
0 \\
70,632 \\
179,240\end{array}$ \\
\hline 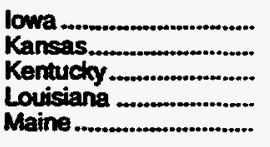 & $\begin{array}{l}117 \\
113 \\
114 \\
71 \\
45\end{array}$ & $\begin{array}{l}650 \\
508 \\
592 \\
423 \\
431\end{array}$ & $\begin{array}{l}598 \\
748 \\
610 \\
466 \\
381\end{array}$ & $\begin{array}{l}3,018 \\
2,587 \\
3,074 \\
2.581 \\
3.285\end{array}$ & $\begin{array}{r}31,124 \\
23,481 \\
56,517 \\
209,467 \\
0\end{array}$ & $\begin{array}{r}124,601 \\
95,825 \\
247,954 \\
666,795 \\
0\end{array}$ \\
\hline $\begin{array}{l}\text { Maryland ....................... } \\
\text { Massachusetts............. } \\
\text { Michigan ..................... } \\
\text { Minnesota .................... } \\
\text { Mississippi ................... }\end{array}$ & $\begin{array}{r}98 \\
94 \\
144 \\
126 \\
79\end{array}$ & $\begin{array}{l}732 \\
733 \\
862 \\
755 \\
434\end{array}$ & $\begin{array}{l}545 \\
569 \\
968 \\
938 \\
426\end{array}$ & $\begin{array}{l}3,627 \\
4,081 \\
5,392 \\
5,053 \\
2,192\end{array}$ & $\begin{array}{r}7,037 \\
6,224 \\
20,549 \\
34,989 \\
72,143\end{array}$ & $\begin{array}{r}42,229 \\
34,133 \\
101,371 \\
150,646 \\
284,401\end{array}$ \\
\hline 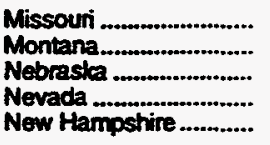 & $\begin{array}{r}115 \\
110 \\
122 \\
67 \\
96\end{array}$ & $\begin{array}{l}672 \\
534 \\
622 \\
467 \\
675\end{array}$ & $\begin{array}{l}715 \\
679 \\
706 \\
760 \\
565\end{array}$ & $\begin{array}{l}3,765 \\
3,558 \\
3,014 \\
4,668 \\
3,750\end{array}$ & $\begin{array}{r}19,822 \\
21,013 \\
38,517 \\
118,411 \\
11,986\end{array}$ & $\begin{array}{r}95,314 \\
108,703 \\
140,111 \\
600,809 \\
62,653\end{array}$ \\
\hline $\begin{array}{l}\text { New Jersey..................... } \\
\text { New Mexico ................. } \\
\text { New York..................... } \\
\text { North Carolina............... } \\
\text { North Dakota................. }\end{array}$ & $\begin{array}{r}88 \\
85 \\
90 \\
83 \\
120\end{array}$ & $\begin{array}{l}639 \\
498 \\
687 \\
554 \\
767\end{array}$ & $\begin{array}{l}455 \\
659 \\
701 \\
536 \\
884\end{array}$ & $\begin{array}{l}2,972 \\
3,269 \\
4,383 \\
3,255 \\
5,172\end{array}$ & $\begin{array}{r}11,163 \\
10,326 \\
4,668 \\
25,046 \\
36,891\end{array}$ & $\begin{array}{r}62,719 \\
42,253 \\
24,972 \\
133,109 \\
163,748\end{array}$ \\
\hline 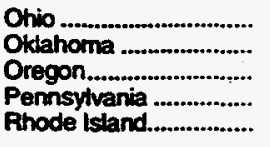 & $\begin{array}{r}136 \\
98 \\
76 \\
120 \\
90\end{array}$ & $\begin{array}{l}827 \\
447 \\
543 \\
785 \\
672\end{array}$ & $\begin{array}{l}774 \\
508 \\
462 \\
822 \\
585\end{array}$ & $\begin{array}{l}4,398 \\
2,246 \\
3,030 \\
5,095 \\
3,821\end{array}$ & $\begin{array}{r}24,231 \\
60,800 \\
36,864 \\
31,316 \\
5,390\end{array}$ & $\begin{array}{r}122,012 \\
202,298 \\
191,269 \\
159,514 \\
31,361\end{array}$ \\
\hline 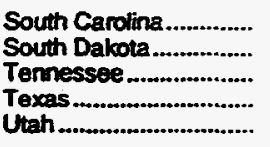 & $\begin{array}{r}66 \\
113 \\
92 \\
74 \\
131\end{array}$ & $\begin{array}{l}438 \\
698 \\
462 \\
429 \\
743\end{array}$ & $\begin{array}{r}515 \\
761 \\
677 \\
582 \\
6,839\end{array}$ & $\begin{array}{r}3,015 \\
4,072 \\
3,293 \\
2,953 \\
33,889\end{array}$ & $\begin{array}{l}67,707 \\
15,137 \\
51,335 \\
38,449 \\
42,709\end{array}$ & $\begin{array}{r}341,281 \\
70,326 \\
210,774 \\
147,019 \\
150,346\end{array}$ \\
\hline 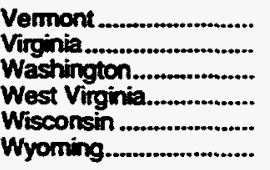 & $\begin{array}{r}113 \\
100 \\
83 \\
111 \\
113 \\
116\end{array}$ & $\begin{array}{l}710 \\
701 \\
570 \\
679 \\
736 \\
678\end{array}$ & $\begin{array}{l}916 \\
793 \\
702 \\
591 \\
798 \\
654\end{array}$ & $\begin{array}{l}5,205 \\
4,838 \\
4,268 \\
3,429 \\
4,176 \\
3,504\end{array}$ & $\begin{array}{r}126,504 \\
44,455 \\
20,885 \\
138,629 \\
16,712 \\
118,174\end{array}$ & $\begin{array}{r}655,070 \\
219,643 \\
107,746 \\
664,155 \\
74,587 \\
431,489\end{array}$ \\
\hline 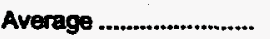 & 100 & 610 & 672 & 3,731 & 24,309 & 105,670 \\
\hline
\end{tabular}

See footnotes at end of table. 
Table 34. Average Consumption and Annual Cost of Natural Gas per Consumer by State, 1967-1989 (Continued)

\begin{tabular}{|c|c|c|c|c|c|c|}
\hline \multirow[b]{2}{*}{ Stato } & \multicolumn{2}{|c|}{ Residential } & \multicolumn{2}{|c|}{ Commercial } & \multicolumn{2}{|c|}{ Induestrial } \\
\hline & $\begin{array}{l}\text { Consumption } \\
\text { (thousand } \\
\text { cubie foet) }\end{array}$ & $\begin{array}{c}\text { Cost } \\
\text { (dollare) }\end{array}$ & $\begin{array}{l}\text { Constumption } \\
\text { (thousend } \\
\text { cubic fent) }\end{array}$ & $\begin{array}{c}\text { Cost } \\
\text { (dollars) }\end{array}$ & $\begin{array}{l}\text { Consumption } \\
\text { (thousend } \\
\text { cubic tient) }\end{array}$ & $\begin{array}{c}\text { Cost } \\
\text { (dollars) }\end{array}$ \\
\hline & \multicolumn{6}{|c|}{1985} \\
\hline 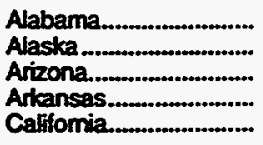 & $\begin{array}{r}68 \\
204 \\
52 \\
86 \\
70\end{array}$ & $\begin{array}{l}438 \\
573 \\
361 \\
379 \\
403\end{array}$ & $\begin{array}{r}487 \\
2,034 \\
551 \\
446 \\
495\end{array}$ & $\begin{array}{l}2,667 \\
4,811 \\
3,071 \\
1,841 \\
3,284\end{array}$ & $\begin{array}{r}62,250 \\
5,821,231 \\
19,530 \\
60,337 \\
12,605\end{array}$ & $\begin{array}{r}264,519 \\
4,138,154 \\
86,821 \\
223,792 \\
59,465\end{array}$ \\
\hline 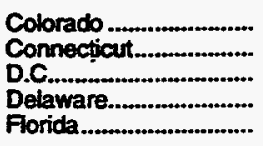 & $\begin{array}{r}101 \\
83 \\
124 \\
78 \\
31\end{array}$ & $\begin{array}{l}513 \\
761 \\
981 \\
548 \\
230\end{array}$ & $\begin{array}{r}663 \\
665 \\
1,084 \\
682 \\
767\end{array}$ & $\begin{array}{l}3,056 \\
4,510 \\
7,278 \\
4,396 \\
4,085\end{array}$ & $\begin{array}{r}23,968 \\
7,572 \\
0 \\
90,377 \\
116,569\end{array}$ & $\begin{array}{r}96,078 \\
41,972 \\
0 \\
404,565 \\
479,547\end{array}$ \\
\hline 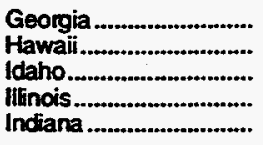 & $\begin{array}{r}74 \\
23 \\
78 \\
145 \\
121\end{array}$ & $\begin{array}{l}488 \\
419 \\
535 \\
804 \\
672\end{array}$ & $\begin{array}{l}566 \\
619 \\
562 \\
834 \\
633\end{array}$ & $\begin{array}{l}3,243 \\
8,941 \\
3,200 \\
4,195 \\
3,190\end{array}$ & $\begin{array}{r}47,834 \\
0 \\
117,235 \\
15,046 \\
42,206\end{array}$ & $\begin{array}{r}216,833 \\
0 \\
530,849 \\
71,575 \\
171,878\end{array}$ \\
\hline 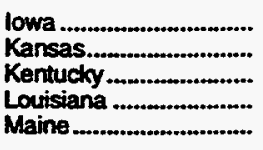 & $\begin{array}{r}115 \\
110 \\
102 \\
62 \\
44\end{array}$ & $\begin{array}{l}622 \\
454 \\
542 \\
353 \\
397\end{array}$ & $\begin{array}{l}588 \\
681 \\
563 \\
432 \\
380\end{array}$ & $\begin{array}{l}2,856 \\
2,145 \\
2,868 \\
2,281 \\
3,038\end{array}$ & $\begin{array}{r}34,713 \\
23,082 \\
41,999 \\
409,020 \\
11,413\end{array}$ & $\begin{array}{r}135,650 \\
81,643 \\
183,954 \\
1,239.629 \\
72,587\end{array}$ \\
\hline $\begin{array}{l}\text { Maryland ...................... } \\
\text { Massactusetts............. } \\
\text { Michigan ..................... } \\
\text { Minnesota ................... } \\
\text { Mississippi .................... }\end{array}$ & $\begin{array}{r}92 \\
93 \\
144 \\
130 \\
70\end{array}$ & $\begin{array}{l}664 \\
730 \\
904 \\
753 \\
382\end{array}$ & $\begin{array}{l}\mathbf{5 1 3} \\
\mathbf{5 5 2} \\
\mathbf{9 3 3} \\
\mathbf{9 3 9} \\
\mathbf{3 8 6}\end{array}$ & $\begin{array}{l}3,274 \\
3,886 \\
5,356 \\
4,881 \\
1,957\end{array}$ & $\begin{array}{r}9,314 \\
5,820 \\
18,339 \\
27,217 \\
83,479\end{array}$ & $\begin{array}{r}53,089 \\
31,216 \\
92,782 \\
110,357 \\
314,662\end{array}$ \\
\hline 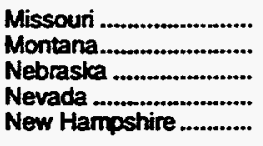 & $\begin{array}{r}111 \\
115 \\
119 \\
68 \\
92\end{array}$ & $\begin{array}{l}611 \\
555 \\
595 \\
482 \\
659\end{array}$ & $\begin{array}{l}635 \\
706 \\
657 \\
765 \\
619\end{array}$ & $\begin{array}{l}3.153 \\
3,595 \\
2,767 \\
4,681 \\
3,899\end{array}$ & $\begin{array}{r}20,116 \\
17,908 \\
46,601 \\
83,418 \\
6,968\end{array}$ & $\begin{array}{r}84,616 \\
84,267 \\
167,926 \\
358,148 \\
38,750\end{array}$ \\
\hline $\begin{array}{l}\text { New Jersey................ } \\
\text { New Mexico .................. } \\
\text { New York.................. } \\
\text { North Carolina.............. } \\
\text { North Dakota.............. }\end{array}$ & $\begin{array}{r}85 \\
66 \\
84 \\
70 \\
125\end{array}$ & $\begin{array}{l}639 \\
398 \\
649 \\
465 \\
697\end{array}$ & $\begin{array}{l}442 \\
465 \\
670 \\
491 \\
920\end{array}$ & $\begin{array}{l}2,929 \\
2,700 \\
4,092 \\
2,866 \\
4,702\end{array}$ & $\begin{array}{r}12,523 \\
5,960 \\
4,461 \\
26,584 \\
15,666\end{array}$ & $\begin{array}{r}69,057 \\
23,773 \\
23,512 \\
130,507 \\
69,680\end{array}$ \\
\hline 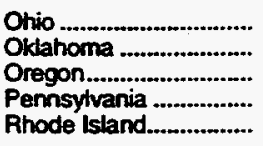 & $\begin{array}{r}127 \\
92 \\
81 \\
110 \\
88\end{array}$ & $\begin{array}{l}765 \\
420 \\
561 \\
741 \\
690\end{array}$ & $\begin{array}{l}709 \\
464 \\
501 \\
739 \\
584\end{array}$ & $\begin{array}{l}3,955 \\
2,043 \\
3,130 \\
4,581 \\
3,892\end{array}$ & $\begin{array}{r}35,353 \\
55,255 \\
56,382 \\
38,769 \\
3,947\end{array}$ & $\begin{array}{r}172,182 \\
182,141 \\
270,000 \\
191,085 \\
23,244\end{array}$ \\
\hline 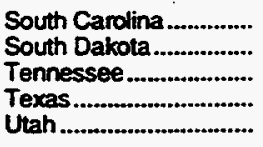 & $\begin{array}{r}56 \\
115 \\
80 \\
68 \\
136\end{array}$ & $\begin{array}{l}371 \\
660 \\
409 \\
390 \\
660\end{array}$ & $\begin{array}{r}463 \\
832 \\
611 \\
527 \\
8,505\end{array}$ & $\begin{array}{r}2,666 \\
3,832 \\
3,003 \\
2,574 \\
41,744\end{array}$ & $\begin{array}{l}51,883 \\
12,233 \\
46,687 \\
99,949 \\
65,813\end{array}$ & $\begin{array}{r}243,859 \\
50,731 \\
198,387 \\
318,751 \\
212,741\end{array}$ \\
\hline 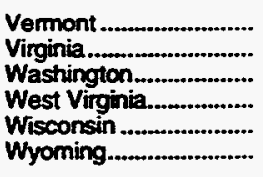 & $\begin{array}{r}112 \\
93 \\
92 \\
104 \\
115 \\
122\end{array}$ & $\begin{array}{l}703 \\
652 \\
605 \\
661 \\
742 \\
629\end{array}$ & $\begin{array}{l}788 \\
739 \\
754 \\
556 \\
809 \\
653\end{array}$ & $\begin{array}{l}4,502 \\
4,420 \\
4,113 \\
3,344 \\
4,203 \\
3,315\end{array}$ & $\begin{array}{r}93,350 \\
54,651 \\
19,144 \\
123,772 \\
15,885 \\
97,221\end{array}$ & $\begin{array}{r}454,700 \\
261,248 \\
91,212 \\
580,275 \\
71,306 \\
345,015\end{array}$ \\
\hline Average & 96 & 586 & 634 & 3.484 & 30,956 & 127,471 \\
\hline
\end{tabular}

See foomotes at end of table. 
Table 34. Average Consumption and Annual Cost of Natural Gas per Consumer by State, 1967-1989 (Continued)

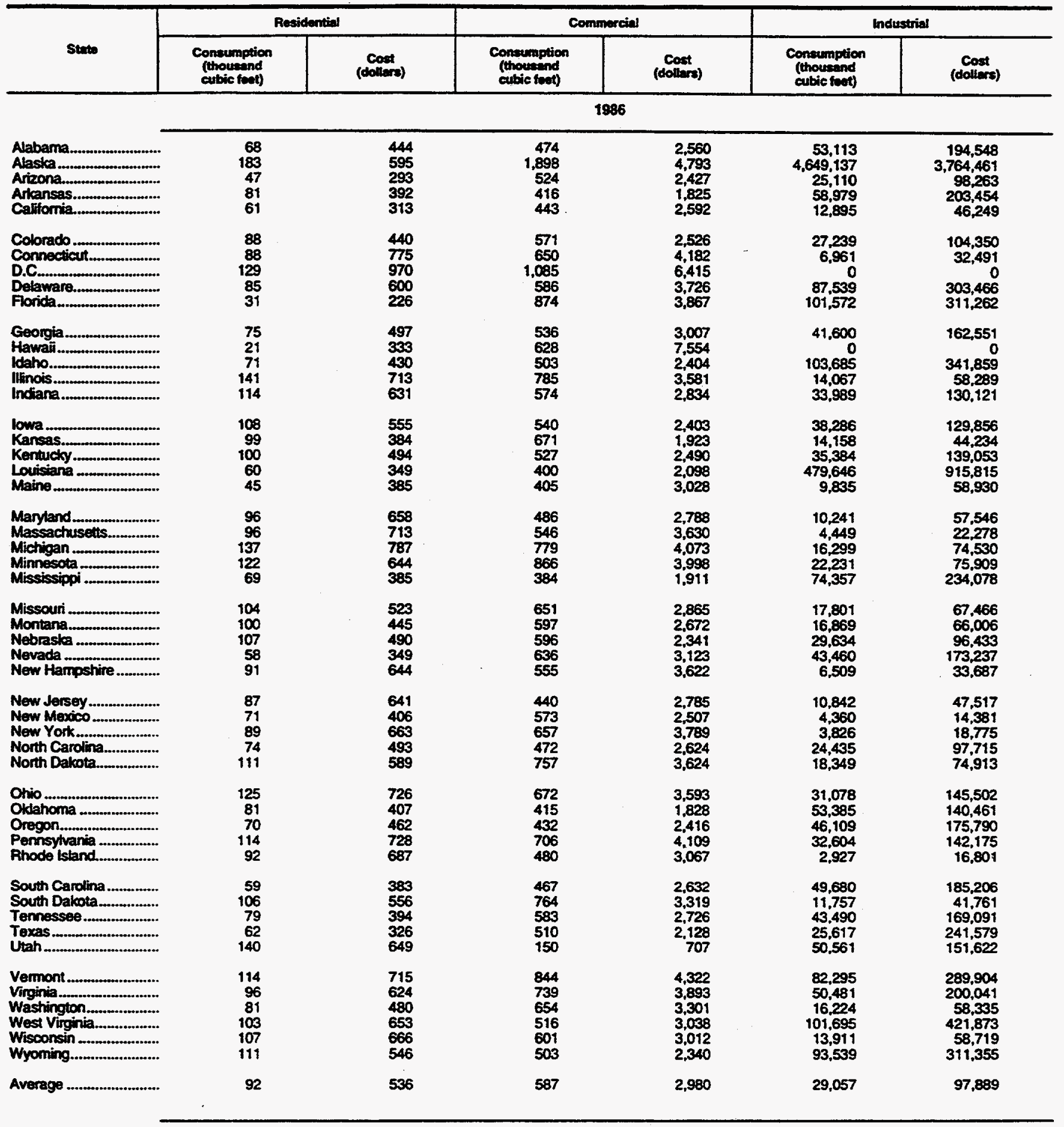

See toolnotes at end of table. 
Table 34. Average Consumption and Annual Cost of Natural Gas per Consumer by State, 1967-1989 (Continued)

\begin{tabular}{|c|c|c|c|c|c|c|}
\hline \multirow[b]{2}{*}{ State } & \multicolumn{2}{|c|}{ Recidential } & \multicolumn{2}{|c|}{ Commercial } & \multicolumn{2}{|c|}{ Industrial } \\
\hline & $\begin{array}{l}\text { Consumption } \\
\text { (thousand } \\
\text { cubie feot) }\end{array}$ & (dollara) & $\begin{array}{l}\text { Conseumption } \\
\text { (thousund } \\
\text { cubic fect) }\end{array}$ & $\underset{\text { (dollars) }}{\text { Cost }}$ & $\begin{array}{l}\text { Consumption } \\
\text { (thoustand } \\
\text { cubic feat) }\end{array}$ & $\begin{array}{c}\text { Cost } \\
\text { (dollars) }\end{array}$ \\
\hline & \multicolumn{6}{|c|}{1987} \\
\hline 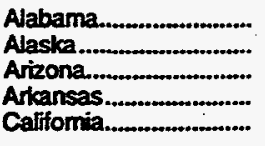 & $\begin{array}{r}74 \\
181 \\
50 \\
83 \\
64\end{array}$ & $\begin{array}{l}492 \\
582 \\
306 \\
386 \\
335\end{array}$ & $\begin{array}{r}412 \\
1,761 \\
592 \\
408 \\
526\end{array}$ & $\begin{array}{l}2,259 \\
4,253 \\
2,686 \\
1,737 \\
2,850\end{array}$ & $\begin{array}{r}50,228 \\
6,746,749 \\
50,161 \\
39,107 \\
11,827\end{array}$ & $\begin{array}{l}\text { NA } \\
\text { NA } \\
\text { NA } \\
\text { NA }\end{array}$ \\
\hline 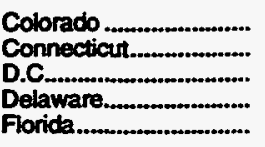 & $\begin{array}{r}92 \\
88 \\
128 \\
85 \\
33\end{array}$ & $\begin{array}{l}434 \\
721 \\
908 \\
540 \\
245\end{array}$ & $\begin{array}{l}586 \\
675 \\
953 \\
605 \\
885\end{array}$ & $\begin{array}{l}2,432 \\
3,889 \\
4,777 \\
3,131 \\
4,148\end{array}$ & $\begin{array}{r}34,471 \\
7,310 \\
0 \\
74,846 \\
105,362\end{array}$ & $\begin{array}{l}\text { NA } \\
\text { NA } \\
\text { NA } \\
\text { NA }\end{array}$ \\
\hline 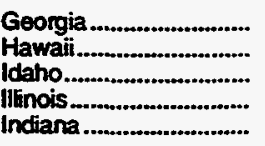 & $\begin{array}{r}81 \\
21 \\
67 \\
129 \\
111\end{array}$ & $\begin{array}{l}516 \\
330 \\
368 \\
618 \\
550\end{array}$ & $\begin{array}{l}552 \\
697 \\
436 \\
792 \\
557\end{array}$ & $\begin{array}{l}2,982 \\
8,202 \\
1,971 \\
3,476 \\
2,476\end{array}$ & $\begin{array}{r}46,540 \\
0 \\
86,555 \\
13,421 \\
36,637\end{array}$ & $\begin{array}{l}\text { NA } \\
\text { NA } \\
\text { NA } \\
\text { NA }\end{array}$ \\
\hline 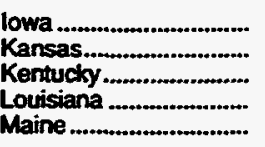 & $\begin{array}{l}94 \\
96 \\
99 \\
64 \\
43\end{array}$ & $\begin{array}{l}449 \\
393 \\
449 \\
359 \\
349\end{array}$ & $\begin{array}{l}471 \\
646 \\
528 \\
413 \\
364\end{array}$ & $\begin{array}{l}1,822 \\
1.954 \\
2,252 \\
2,055 \\
2,540\end{array}$ & $\begin{array}{r}43,413 \\
25,492 \\
39,202 \\
502,058 \\
11,674\end{array}$ & $\begin{array}{l}\text { NA } \\
\text { NA } \\
\text { NA } \\
\text { NA } \\
\text { NA }\end{array}$ \\
\hline 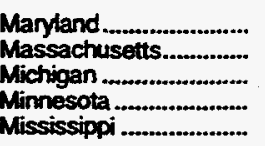 & $\begin{array}{r}94 \\
97 \\
128 \\
103 \\
72\end{array}$ & $\begin{array}{l}596 \\
643 \\
700 \\
473 \\
438\end{array}$ & $\begin{array}{r}498 \\
550 \\
1,042 \\
742 \\
413\end{array}$ & $\begin{array}{l}2,544 \\
3,252 \\
5,238 \\
2,891 \\
2,185\end{array}$ & $\begin{array}{r}11,194 \\
6,070 \\
11,444 \\
27,679 \\
62,831\end{array}$ & $\begin{array}{l}\text { NA } \\
\text { NA } \\
\text { NA } \\
\text { NA } \\
\text { NA }\end{array}$ \\
\hline 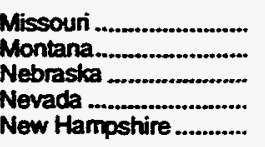 & $\begin{array}{l}98 \\
91 \\
97 \\
66 \\
93\end{array}$ & $\begin{array}{l}468 \\
404 \\
424 \\
352 \\
606\end{array}$ & $\begin{array}{l}602 \\
514 \\
563 \\
751 \\
521\end{array}$ & $\begin{array}{l}2,471 \\
2,231 \\
2,084 \\
3,226 \\
3,027\end{array}$ & $\begin{array}{l}19,183 \\
18,072 \\
44,080 \\
66,634 \\
11,316\end{array}$ & $\begin{array}{l}\text { NA } \\
\text { NA } \\
\text { NA } \\
\text { NA } \\
\text { NA }\end{array}$ \\
\hline $\begin{array}{l}\text { New Jersey................... } \\
\text { New Mexico ................... } \\
\text { New York................... } \\
\text { North Carolina.............. } \\
\text { North Dakota................ }\end{array}$ & $\begin{array}{l}90 \\
79 \\
88 \\
82 \\
97\end{array}$ & $\begin{array}{l}595 \\
393 \\
604 \\
549 \\
528\end{array}$ & $\begin{array}{l}471 \\
547 \\
636 \\
534 \\
664\end{array}$ & $\begin{array}{l}2.611 \\
2.173 \\
3,290 \\
2,785 \\
3,158\end{array}$ & $\begin{array}{r}12,734 \\
7,915 \\
4,118 \\
23,617 \\
19,554\end{array}$ & $\begin{array}{l}\text { NA } \\
\text { NA } \\
\text { NA } \\
\text { NA } \\
\text { NA }\end{array}$ \\
\hline $\begin{array}{l}\text { Ohio } \\
\text { Okdahoma ........................... } \\
\text { Oregon ....................... } \\
\text { Pennsytvania ................ } \\
\text { Rhode Island................. }\end{array}$ & $\begin{array}{r}123 \\
79 \\
67 \\
112 \\
93\end{array}$ & $\begin{array}{l}659 \\
367 \\
442 \\
677 \\
631\end{array}$ & $\begin{array}{l}688 \\
369 \\
408 \\
688 \\
621\end{array}$ & $\begin{array}{l}3,365 \\
1,542 \\
2,167 \\
3,728 \\
3,435\end{array}$ & $\begin{array}{r}28,195 \\
66,181 \\
54,254 \\
36,883 \\
3,793\end{array}$ & $\begin{array}{l}\text { NA } \\
\text { NA } \\
\text { NA } \\
\text { NA }\end{array}$ \\
\hline 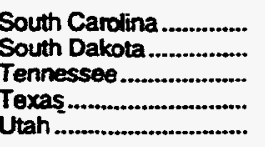 & $\begin{array}{r}67 \\
92 \\
81 \\
67 \\
100\end{array}$ & $\begin{array}{l}440 \\
446 \\
380 \\
347 \\
499\end{array}$ & $\begin{array}{l}486 \\
657 \\
573 \\
531 \\
473\end{array}$ & $\begin{array}{l}2,717 \\
2,775 \\
2,478 \\
2,258 \\
2,353\end{array}$ & $\begin{array}{r}52,023 \\
12,540 \\
44,231 \\
297,098 \\
43,346\end{array}$ & $\begin{array}{l}\text { NA } \\
\text { NA } \\
\text { NA } \\
\text { NA } \\
\text { NA }\end{array}$ \\
\hline 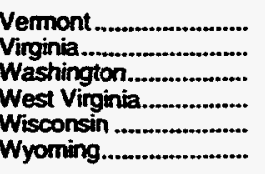 & $\begin{array}{r}107 \\
101 \\
76 \\
102 \\
98 \\
94\end{array}$ & $\begin{array}{l}666 \\
590 \\
412 \\
607 \\
588 \\
441\end{array}$ & $\begin{array}{l}749 \\
729 \\
630 \\
537 \\
600 \\
550\end{array}$ & $\begin{array}{l}3,658 \\
3,382 \\
2,838 \\
2,941 \\
2,866 \\
2,460\end{array}$ & $\begin{array}{l}76,567 \\
63,167 \\
19,585 \\
89,030 \\
15,276 \\
79,693\end{array}$ & $\begin{array}{l}\text { NA } \\
\text { NA } \\
\text { NA } \\
\text { NA } \\
\text { NA } \\
\text { NA }\end{array}$ \\
\hline Average .......................... & 90 & 501 & 606 & 2,886 & 30,423 & NA \\
\hline
\end{tabular}

See toctnotes at end of table. 
Table 34. Average Consumption and Annual Cost of Natural Gas pér Consumer by State, 1967-1989 (Continued)

\begin{tabular}{|c|c|c|c|c|c|c|}
\hline \multirow[b]{2}{*}{ Sute } & \multicolumn{2}{|c|}{ Residential } & \multicolumn{2}{|c|}{ Commercial } & \multicolumn{2}{|c|}{ Industrial } \\
\hline & $\begin{array}{l}\text { Consumption } \\
\text { (thouarand } \\
\text { cubie feet) }\end{array}$ & $\underset{\text { (dollert) }}{\text { Cost }}$ & $\begin{array}{l}\text { Consumption } \\
\text { (thourand } \\
\text { cubic fort) }\end{array}$ & Coet & $\begin{array}{l}\text { Consumption } \\
\text { (thousand } \\
\text { cubic fient) }\end{array}$ & $\begin{array}{c}\text { Cost } \\
\text { (dollars) }\end{array}$ \\
\hline & \multicolumn{6}{|c|}{1988} \\
\hline 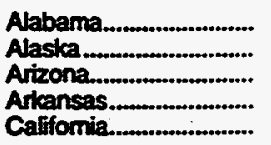 & $\begin{array}{r}73 \\
183 \\
50 \\
88 \\
61\end{array}$ & $\begin{array}{l}476 \\
632 \\
349 \\
425 \\
346\end{array}$ & $\begin{array}{r}461 \\
1,789 \\
607 \\
446 \\
610\end{array}$ & $\begin{array}{l}2,434 \\
4,660 \\
3,016 \\
1,935 \\
2,854\end{array}$ & $\begin{array}{r}61,289 \\
6,164,078 \\
70,306 \\
91,059 \\
10,385\end{array}$ & $\begin{array}{l}\text { NA } \\
\text { NA } \\
\text { NA } \\
\text { NA } \\
\text { NA }\end{array}$ \\
\hline 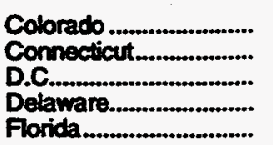 & $\begin{array}{r}97 \\
95 \\
130 \\
90 \\
33\end{array}$ & $\begin{array}{l}429 \\
744 \\
902 \\
540 \\
250\end{array}$ & $\begin{array}{r}619 \\
659 \\
1,320 \\
615 \\
876\end{array}$ & $\begin{array}{l}2,398 \\
3,703 \\
6,643 \\
3,005 \\
3,980\end{array}$ & $\begin{array}{r}41,383 \\
6,897 \\
0 \\
63,5 \times 2 \\
136,807\end{array}$ & $\begin{array}{l}\mathbf{N A} \\
\mathbf{N A} \\
\mathbf{N A} \\
\mathbf{N A} \\
\mathbf{N A}\end{array}$ \\
\hline 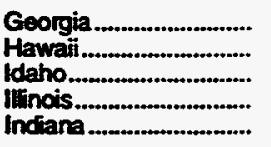 & $\begin{array}{r}85 \\
20 \\
69 \\
145 \\
120\end{array}$ & $\begin{array}{l}527 \\
307 \\
378 \\
669 \\
621\end{array}$ & $\begin{array}{l}547 \\
718 \\
447 \\
773 \\
600\end{array}$ & $\begin{array}{l}2,982 \\
8,276 \\
2,020 \\
3,241 \\
2,763\end{array}$ & $\begin{array}{r}47,852 \\
0 \\
156,897 \\
13,451 \\
38,407\end{array}$ & $\begin{array}{l}\text { NA } \\
\text { NA } \\
\text { NA } \\
\text { NA } \\
\text { NA }\end{array}$ \\
\hline 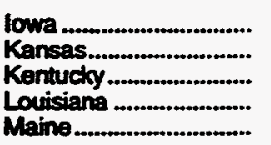 & $\begin{array}{r}110 \\
104 \\
106 \\
63 \\
48\end{array}$ & $\begin{array}{l}529 \\
419 \\
473 \\
362 \\
345\end{array}$ & $\begin{array}{l}553 \\
729 \\
558 \\
413 \\
392\end{array}$ & $\begin{array}{l}2,229 \\
2,211 \\
2,349 \\
2,125 \\
2,448\end{array}$ & $\begin{array}{r}52,665 \\
25,060 \\
41,877 \\
518,410 \\
15,919\end{array}$ & $\begin{array}{l}\mathbf{N A} \\
\mathbf{N A} \\
\mathbf{N A} \\
\mathbf{N A} \\
\mathbf{N A}\end{array}$ \\
\hline $\begin{array}{l}\text { Maryland........................ } \\
\text { Massachusetts............. } \\
\text { Michigan ....................... } \\
\text { Minnesota ...................... } \\
\text { Mississippi ...................... }\end{array}$ & $\begin{array}{r}98 \\
99 \\
140 \\
123 \\
72\end{array}$ & $\begin{array}{l}581 \\
639 \\
747 \\
569 \\
423\end{array}$ & $\begin{array}{l}488 \\
526 \\
903 \\
886 \\
410\end{array}$ & $\begin{array}{l}2,483 \\
3,215 \\
4,511 \\
3,574 \\
2,057\end{array}$ & $\begin{array}{r}11.894 \\
4,386 \\
17.195 \\
29,116 \\
73.563\end{array}$ & $\begin{array}{l}\text { NA } \\
\text { NA } \\
\text { NA } \\
\text { NA } \\
\text { NA }\end{array}$ \\
\hline 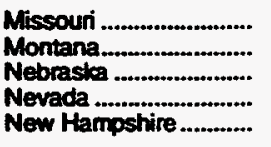 & $\begin{array}{r}107 \\
98 \\
108 \\
69 \\
96\end{array}$ & $\begin{array}{l}511 \\
423 \\
481 \\
407 \\
601\end{array}$ & $\begin{array}{l}652 \\
541 \\
642 \\
786 \\
550\end{array}$ & $\begin{array}{l}2,739 \\
2,329 \\
2,404 \\
3,635 \\
3,111\end{array}$ & $\begin{array}{r}18,834 \\
19,219 \\
47,221 \\
73,657 \\
6,681\end{array}$ & $\begin{array}{l}\text { NA } \\
\text { NA } \\
\text { NA } \\
\text { NA } \\
\text { NA }\end{array}$ \\
\hline $\begin{array}{l}\text { New Jersey...................... } \\
\text { New Mexico ................. } \\
\text { New York..................... } \\
\text { North Carolina.............. } \\
\text { North Daknta................ }\end{array}$ & $\begin{array}{r}95 \\
78 \\
93 \\
81 \\
109\end{array}$ & $\begin{array}{l}598 \\
409 \\
605 \\
507 \\
561\end{array}$ & $\begin{array}{l}491 \\
840 \\
696 \\
535 \\
812\end{array}$ & $\begin{array}{l}2,572 \\
2,779 \\
3,752 \\
2,644 \\
3,640\end{array}$ & $\begin{array}{r}12,660 \\
8,818 \\
3,686 \\
23,427 \\
26,359\end{array}$ & $\begin{array}{l}\text { NA } \\
\text { NA } \\
\text { NA } \\
\text { NA } \\
\text { NA }\end{array}$ \\
\hline $\begin{array}{l}\text { Ohio .............................. } \\
\text { Odahoma ....................... } \\
\text { Oregon........................ } \\
\text { Penrsytvania ................. } \\
\text { Rhode Istand............... }\end{array}$ & $\begin{array}{r}131 \\
89 \\
72 \\
118 \\
95\end{array}$ & $\begin{array}{l}682 \\
404 \\
491 \\
683 \\
628\end{array}$ & $\begin{array}{l}724 \\
552 \\
438 \\
738 \\
519\end{array}$ & $\begin{array}{l}3,440 \\
2,247 \\
2,349 \\
3,758 \\
3,007\end{array}$ & $\begin{array}{r}34,308 \\
60,643 \\
38,463 \\
37,664 \\
3,866\end{array}$ & $\begin{array}{l}\text { NA } \\
\text { NA } \\
\text { NA } \\
\text { NA } \\
\text { NA }\end{array}$ \\
\hline 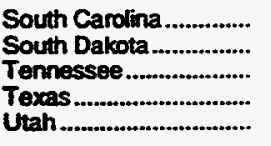 & $\begin{array}{r}66 \\
105 \\
84 \\
66 \\
101\end{array}$ & $\begin{array}{l}446 \\
515 \\
392 \\
356 \\
515\end{array}$ & $\begin{array}{l}471 \\
675 \\
565 \\
617 \\
549\end{array}$ & $\begin{array}{l}2,632 \\
2,769 \\
2,474 \\
2,590 \\
2,241\end{array}$ & $\begin{array}{r}54,342 \\
17,484 \\
48,047 \\
378,433 \\
48,411\end{array}$ & $\begin{array}{l}\text { NA } \\
\text { NA } \\
\text { NA } \\
\text { NA }\end{array}$ \\
\hline 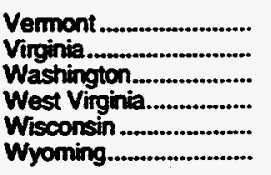 & $\begin{array}{r}112 \\
102 \\
85 \\
108 \\
113 \\
104\end{array}$ & $\begin{array}{l}636 \\
593 \\
466 \\
593 \\
666 \\
465\end{array}$ & $\begin{array}{l}720 \\
765 \\
649 \\
675 \\
675 \\
576\end{array}$ & $\begin{array}{l}3,358 \\
3,408 \\
2,980 \\
3,496 \\
3,162 \\
2,371\end{array}$ & $\begin{array}{r}82,920 \\
59,337 \\
19,478 \\
194,301 \\
16,877 \\
77,360\end{array}$ & $\begin{array}{l}\text { NA } \\
\text { NA } \\
\text { NA } \\
\text { NA } \\
\text { NA } \\
\text { NA }\end{array}$ \\
\hline 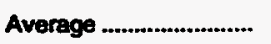 & 96 & 523 & 647 & 3.001 & 32,071 & NA \\
\hline
\end{tabular}

See foctnctes at end of table. 
Table 34. Average Consumption and Annual Cost of Natural Gas per Consumer by State, 1967-1989 (Continued)

\begin{tabular}{|c|c|c|c|c|c|c|}
\hline \multirow[b]{2}{*}{ State } & \multicolumn{2}{|c|}{ Reaidential } & \multicolumn{2}{|c|}{ Commerciel } & \multicolumn{2}{|c|}{ Industrial } \\
\hline & $\begin{array}{l}\text { Consumption } \\
\text { (thougand } \\
\text { cubie feet) }\end{array}$ & $\begin{array}{c}\text { Cost } \\
\text { (dollars) }\end{array}$ & $\begin{array}{l}\text { Consumption } \\
\text { (thourand } \\
\text { cubic feot) }\end{array}$ & $\underset{\text { (dollars) }}{\cos }$ & $\begin{array}{l}\text { Consumption } \\
\text { (thoustind } \\
\text { cubic feot) }\end{array}$ & $\begin{array}{c}\text { Cost } \\
\text { (dollers) }\end{array}$ \\
\hline & \multicolumn{6}{|c|}{1989} \\
\hline 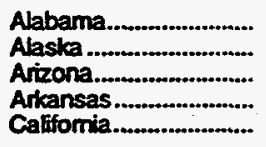 & $\begin{array}{r}70 \\
195 \\
47 \\
86 \\
62\end{array}$ & $\begin{array}{l}441 \\
710 \\
328 \\
418 \\
346\end{array}$ & $\begin{array}{r}466 \\
1,841 \\
611 \\
441 \\
632\end{array}$ & $\begin{array}{l}2,405 \\
4,730 \\
2,913 \\
1,931 \\
3,082\end{array}$ & $\begin{array}{r}62,625 \\
7,417,676 \\
58,432 \\
91,596 \\
10,984\end{array}$ & $\begin{array}{l}\text { NA } \\
\text { NA } \\
\text { NA } \\
\text { NA } \\
\text { NA }\end{array}$ \\
\hline 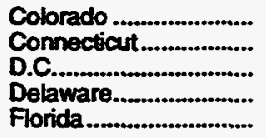 & $\begin{array}{r}94 \\
96 \\
129 \\
88 \\
29\end{array}$ & $\begin{array}{l}435 \\
791 \\
962 \\
564 \\
233\end{array}$ & $\begin{array}{r}602 \\
704 \\
1,386 \\
591 \\
801\end{array}$ & $\begin{array}{l}2,437 \\
4,282 \\
7,347 \\
3,189 \\
3,884\end{array}$ & $\begin{array}{r}52,610 \\
6,783 \\
0 \\
64,430 \\
164,097\end{array}$ & $\begin{array}{l}\text { NA } \\
\text { NA } \\
\text { NA } \\
\text { NA } \\
\text { NA }\end{array}$ \\
\hline 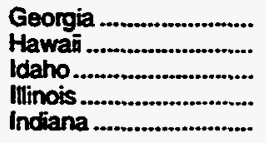 & $\begin{array}{r}79 \\
19 \\
77 \\
154 \\
119\end{array}$ & $\begin{array}{l}495 \\
305 \\
389 \\
757 \\
657\end{array}$ & $\begin{array}{l}498 \\
749 \\
480 \\
776 \\
600\end{array}$ & $\begin{array}{l}2,719 \\
8,570 \\
2,016 \\
3,528 \\
2,868\end{array}$ & $\begin{array}{r}49,720 \\
0 \\
357,860 \\
11,082 \\
35,499\end{array}$ & $\begin{array}{l}\text { NA } \\
\text { NA } \\
\text { NA } \\
\text { NA } \\
\text { NA }\end{array}$ \\
\hline 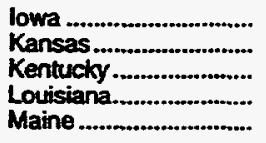 & $\begin{array}{r}110 \\
104 \\
106 \\
62 \\
54\end{array}$ & $\begin{array}{l}519 \\
434 \\
496 \\
369 \\
384\end{array}$ & $\begin{array}{l}559 \\
688 \\
556 \\
424 \\
416\end{array}$ & $\begin{array}{l}2,183 \\
2,162 \\
2,417 \\
2,197 \\
2,625\end{array}$ & $\begin{array}{r}47,149 \\
23,047 \\
44,354 \\
599,592 \\
18,564\end{array}$ & $\begin{array}{l}\text { NA } \\
\text { NA } \\
\text { NA } \\
\text { NA } \\
\text { NA }\end{array}$ \\
\hline $\begin{array}{l}\text { Maryland .................. } \\
\text { Massachusetts............ } \\
\text { Michigan...................... } \\
\text { Minnesota................. } \\
\text { Mississippi................. }\end{array}$ & $\begin{array}{r}98 \\
100 \\
143 \\
128 \\
70\end{array}$ & $\begin{array}{l}617 \\
718 \\
742 \\
587 \\
357\end{array}$ & $\begin{array}{l}492 \\
558 \\
920 \\
917 \\
397\end{array}$ & $\begin{array}{l}2,668 \\
3,280 \\
4,462 \\
3,666 \\
1,880\end{array}$ & $\begin{array}{r}11,898 \\
2,726 \\
16,851 \\
30,886 \\
76,279\end{array}$ & $\begin{array}{l}\text { NA } \\
\text { NA } \\
\text { NA } \\
\text { NA }\end{array}$ \\
\hline 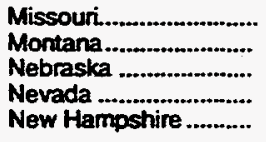 & $\begin{array}{r}107 \\
106 \\
110 \\
71 \\
98\end{array}$ & $\begin{array}{l}517 \\
464 \\
493 \\
394 \\
672\end{array}$ & $\begin{array}{l}632 \\
591 \\
619 \\
759 \\
525\end{array}$ & $\begin{array}{l}2,745 \\
2,579 \\
2,331 \\
3,369 \\
3,269\end{array}$ & $\begin{array}{r}17,610 \\
23,138 \\
43,511 \\
78,590 \\
5,950\end{array}$ & $\begin{array}{l}\text { NA } \\
\text { NA } \\
\text { NA } \\
\text { NA } \\
\text { NA }\end{array}$ \\
\hline $\begin{array}{l}\text { New Jersey ................... } \\
\text { New Mexico ................ } \\
\text { New York.................. } \\
\text { North Carolina............. } \\
\text { North Dakota................ }\end{array}$ & $\begin{array}{r}100 \\
74 \\
94 \\
78 \\
116\end{array}$ & $\begin{array}{l}653 \\
421 \\
682 \\
514 \\
543\end{array}$ & $\begin{array}{l}552 \\
770 \\
689 \\
521 \\
852\end{array}$ & $\begin{array}{l}2,926 \\
2,866 \\
3,874 \\
2,680 \\
3,565\end{array}$ & $\begin{array}{r}13,945 \\
11,319 \\
3,532 \\
24,439 \\
29,964\end{array}$ & $\begin{array}{l}\text { NA } \\
\text { NA } \\
\text { NA } \\
\text { NA }\end{array}$ \\
\hline 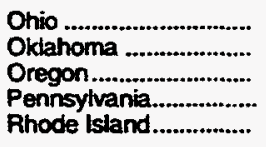 & $\begin{array}{r}132 \\
89 \\
74 \\
118 \\
96\end{array}$ & $\begin{array}{l}704 \\
401 \\
461 \\
726 \\
683\end{array}$ & $\begin{array}{l}717 \\
447 \\
460 \\
742 \\
518\end{array}$ & $\begin{array}{l}\mathbf{3 . 5 1 3} \\
1,762 \\
\mathbf{2 . 2 1 1} \\
\mathbf{3 , 9 6 8} \\
\mathbf{3 , 3 2 1}\end{array}$ & $\begin{array}{r}33,294 \\
64,580 \\
59,285 \\
40,233 \\
4,122\end{array}$ & $\begin{array}{l}\text { NA } \\
\text { NA } \\
\text { NA } \\
\text { NA } \\
\text { NA }\end{array}$ \\
\hline 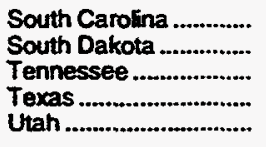 & $\begin{array}{r}63 \\
110 \\
82 \\
72 \\
104\end{array}$ & $\begin{array}{l}421 \\
531 \\
397 \\
399 \\
536\end{array}$ & $\begin{array}{l}425 \\
691 \\
565 \\
676 \\
501\end{array}$ & $\begin{array}{l}2,402 \\
2,757 \\
2,538 \\
2,779 \\
2,086\end{array}$ & $\begin{array}{r}57,027 \\
18,376 \\
41,839 \\
133,594 \\
61,750\end{array}$ & $\begin{array}{l}\mathbf{N A} \\
\mathbf{N A} \\
\mathbf{N A} \\
\mathbf{N A} \\
\mathbf{N A}\end{array}$ \\
\hline 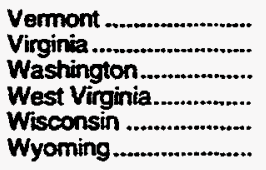 & $\begin{array}{r}126 \\
103 \\
90 \\
106 \\
116 \\
104\end{array}$ & $\begin{array}{l}707 \\
675 \\
495 \\
611 \\
652 \\
490\end{array}$ & $\begin{array}{l}752 \\
724 \\
697 \\
686 \\
684 \\
610\end{array}$ & $\begin{array}{l}3,564 \\
3,567 \\
3,259 \\
3,608 \\
3,039 \\
2,645\end{array}$ & $\begin{array}{r}135,779 \\
64,537 \\
21,765 \\
236,096 \\
17,441 \\
70,509\end{array}$ & $\begin{array}{l}\text { NA } \\
\text { NA } \\
\text { NA } \\
\text { NA } \\
\text { NA } \\
\text { NA }\end{array}$ \\
\hline 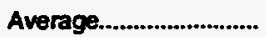 & 97 & 547 & 652 & 3,092 & 30,248 & NA \\
\hline
\end{tabular}

- Data for the District of Columbia are included with data for Maryland.

- Data for New Hampshire and Vemont are included with data for Maine.

NA $=$ Not Available.

Note: Beginning in 1987, industrial costs per consumer are not calculated since values associated with gas delivered for the account of others are not available. Each year since 1982, these values have represented an increasingty large portion of the total industrial value. By 1987, a meaningful average cost per consumer could no longer be calculated without them.

Source: Burreau of Mines(BOM), Forms BOM-6-1340-A and BOM-6-1341-A, "Supphy and Disposition of Natural Gas" Energy iniormation Administration (EIA) ElA-176,

"Annual Report of Natural and Supplemental Gas Supply and Disposthion." 
Table 35. Average Consumption and Annual Cost of Natural Gas per Consumer by State, 1990-1994

\begin{tabular}{|c|c|c|c|c|c|c|}
\hline \multirow[b]{2}{*}{ State } & \multicolumn{2}{|c|}{ Residential } & \multicolumn{2}{|c|}{ Commercial } & \multirow{2}{*}{$\begin{array}{l}\text { Industrial } \\
\text { Consumption } \\
\text { (thousand } \\
\text { cubic feet) }\end{array}$} & \multirow{2}{*}{$\begin{array}{l}\text { Venicle Fuel } \\
\text { Consumption } \\
\text { (thousend } \\
\text { cubic fent) }\end{array}$} \\
\hline & $\begin{array}{l}\text { Contrumption } \\
\text { (thoutiand } \\
\text { cubic toet) }\end{array}$ & $\begin{array}{c}\text { Cost } \\
\text { (dollars) }\end{array}$ & $\begin{array}{l}\text { Consoumption } \\
\text { (thousand } \\
\text { cubic teet) }\end{array}$ & $\begin{array}{c}\text { Cost } \\
\text { (dollers) }\end{array}$ & & \\
\hline & \multicolumn{6}{|c|}{1990} \\
\hline 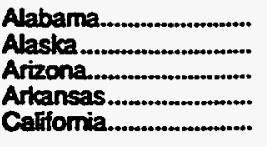 & $\begin{array}{r}66 \\
200 \\
52 \\
80 \\
61\end{array}$ & $\begin{array}{l}435 \\
759 \\
354 \\
409 \\
350\end{array}$ & $\begin{array}{r}427 \\
1.814 \\
601 \\
408 \\
687\end{array}$ & $\begin{array}{l}2,318 \\
4,776 \\
2,876 \\
1,821 \\
3,519\end{array}$ & $\begin{array}{r}59,904 \\
9,606,167 \\
34,941 \\
86,119 \\
12,274\end{array}$ & $\begin{array}{r}2,555 \\
0 \\
0 \\
0 \\
4,342\end{array}$ \\
\hline 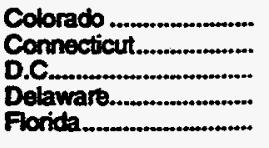 & $\begin{array}{r}93 \\
87 \\
111 \\
82 \\
28\end{array}$ & $\begin{array}{l}427 \\
749 \\
798 \\
501 \\
240\end{array}$ & $\begin{array}{r}588 \\
648 \\
1.190 \\
540 \\
831\end{array}$ & $\begin{array}{l}2,350 \\
4,084 \\
6,703 \\
2,765 \\
4,793\end{array}$ & $\begin{array}{r}48,087 \\
8,314 \\
0 \\
70,984 \\
187,923\end{array}$ & $\begin{array}{r}3,676 \\
0 \\
0 \\
0 \\
103\end{array}$ \\
\hline 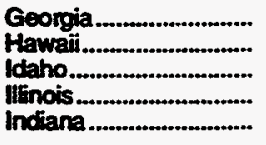 & $\begin{array}{r}68 \\
19 \\
75 \\
135 \\
106\end{array}$ & $\begin{array}{l}461 \\
319 \\
379 \\
681 \\
570\end{array}$ & $\begin{array}{l}457 \\
784 \\
439 \\
777 \\
538\end{array}$ & $\begin{array}{l}2,634 \\
9,599 \\
1,832 \\
3,604 \\
2,478\end{array}$ & $\begin{array}{r}51,377 \\
0 \\
376,240 \\
10,605 \\
35,429\end{array}$ & $\begin{array}{r}0 \\
0 \\
0 \\
\mathbf{5 3 7} \\
6,628\end{array}$ \\
\hline 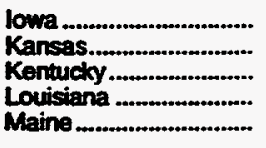 & $\begin{array}{r}101 \\
95 \\
90 \\
57 \\
54\end{array}$ & $\begin{array}{l}504 \\
428 \\
442 \\
348 \\
411\end{array}$ & $\begin{array}{l}529 \\
655 \\
474 \\
397 \\
395\end{array}$ & $\begin{array}{l}2,135 \\
2,203 \\
2,144 \\
2,088 \\
2,653\end{array}$ & $\begin{array}{r}47,923 \\
26,834 \\
44,305 \\
604,939 \\
25,297\end{array}$ & $\begin{array}{r}24 \\
0 \\
0 \\
34,282 \\
0\end{array}$ \\
\hline 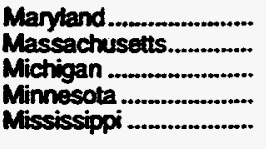 & $\begin{array}{r}86 \\
95 \\
127 \\
113 \\
66\end{array}$ & $\begin{array}{l}553 \\
746 \\
639 \\
\mathbf{5 2 3} \\
\mathbf{3 4 9}\end{array}$ & $\begin{array}{r}433 \\
590 \\
814 \\
817 \\
.406\end{array}$ & $\begin{array}{l}2,316 \\
3,749 \\
3,773 \\
3,250 \\
1,820\end{array}$ & $\begin{array}{r}10,954 \\
6,779 \\
24,401 \\
34,327 \\
76,539\end{array}$ & $\begin{array}{r}0 \\
54 \\
2,028 \\
0 \\
0\end{array}$ \\
\hline 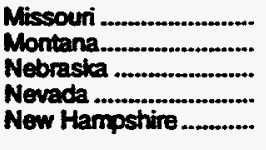 & $\begin{array}{r}96 \\
97 \\
102 \\
67 \\
90\end{array}$ & $\begin{array}{l}498 \\
444 \\
469 \\
379 \\
670\end{array}$ & $\begin{array}{l}565 \\
521 \\
604 \\
728 \\
482\end{array}$ & $\begin{array}{l}2,557 \\
2,419 \\
2,330 \\
3,188 \\
3,246\end{array}$ & $\begin{array}{r}17,369 \\
20,622 \\
36,160 \\
75,114 \\
9,001\end{array}$ & $\begin{array}{r}0 \\
82 \\
0 \\
0 \\
0\end{array}$ \\
\hline 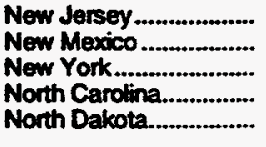 & $\begin{array}{r}87 \\
76 \\
86 \\
67 \\
107\end{array}$ & $\begin{array}{l}571 \\
432 \\
639 \\
415 \\
504\end{array}$ & $\begin{array}{l}531 \\
623 \\
692 \\
459 \\
803\end{array}$ & $\begin{array}{l}2,761 \\
2,762 \\
3,868 \\
2,126 \\
3,368\end{array}$ & $\begin{array}{r}15,123 \\
13,711 \\
4,050 \\
30,758 \\
26,416\end{array}$ & $\begin{array}{r}0 \\
0 \\
575 \\
1,824 \\
29\end{array}$ \\
\hline 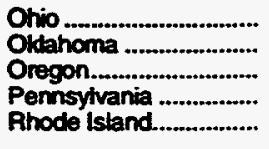 & $\begin{array}{r}111 \\
81 \\
72 \\
104 \\
91\end{array}$ & $\begin{array}{l}590 \\
387 \\
449 \\
686 \\
656\end{array}$ & $\begin{array}{l}616 \\
434 \\
433 \\
673 \\
454\end{array}$ & $\begin{array}{l}2,880 \\
1,700 \\
2,101 \\
4,038 \\
2,819\end{array}$ & $\begin{array}{r}33,545 \\
67,512 \\
69,943 \\
37,728 \\
3,860\end{array}$ & $\begin{array}{r}85 \\
0 \\
0 \\
216 \\
91\end{array}$ \\
\hline 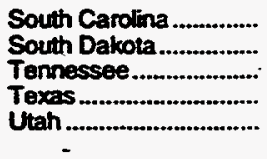 & $\begin{array}{l}54 \\
97 \\
74 \\
65 \\
96\end{array}$ & $\begin{array}{l}388 \\
498 \\
378 \\
376 \\
506\end{array}$ & $\begin{array}{l}386 \\
636 \\
491 \\
643 \\
467\end{array}$ & $\begin{array}{l}2,275 \\
2,674 \\
2,354 \\
2,661 \\
2,011\end{array}$ & $\begin{array}{r}62,739 \\
21,067 \\
46,465 \\
125,251 \\
23,542\end{array}$ & $\begin{array}{r}0 \\
.0 \\
928 \\
3,286 \\
310\end{array}$ \\
\hline 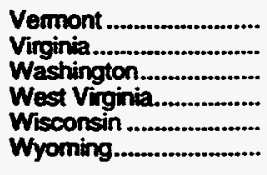 & $\begin{array}{r}117 \\
83 \\
88 \\
93 \\
102 \\
101\end{array}$ & $\begin{array}{l}680 \\
557 \\
442 \\
602 \\
582 \\
489\end{array}$ & $\begin{array}{l}695 \\
644 \\
665 \\
652 \\
626 \\
613\end{array}$ & $\begin{array}{l}3,509 \\
3,171 \\
2,752 \\
3,806 \\
2,971 \\
2,741\end{array}$ & $\begin{array}{r}125,194 \\
80,367 \\
22,878 \\
263,697 \\
17,039 \\
90,570\end{array}$ & $\begin{array}{r}0 \\
0 \\
3,563 \\
0 \\
2,770 \\
0\end{array}$ \\
\hline 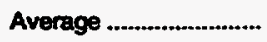 & 87 & 507 & 619 & 2,989 & 32,144 & 268 \\
\hline
\end{tabular}

See footnotes at end of table. 
Table 35. Average Consumption and Annual Cost of Natural Gas per Consumer by State, 1990-1994 (Continued)

\begin{tabular}{|c|c|c|c|c|c|c|}
\hline \multirow[b]{2}{*}{ Sunte } & \multicolumn{2}{|c|}{ Residential } & \multicolumn{2}{|c|}{ Commercial } & \multirow{2}{*}{$\begin{array}{l}\text { Industrial } \\
\begin{array}{c}\text { Consumplion } \\
\text { (thousand } \\
\text { cubic foot) }\end{array}\end{array}$} & \multirow{2}{*}{$\begin{array}{l}\text { Vehicie Fuel } \\
\begin{array}{c}\text { Consumption } \\
\text { (thousend } \\
\text { cubic foet) }\end{array}\end{array}$} \\
\hline & $\begin{array}{l}\text { Conwumption } \\
\text { (thousend } \\
\text { cubic fint) }\end{array}$ & $\begin{array}{c}\text { Cost } \\
\text { (dollars) }\end{array}$ & $\begin{array}{l}\text { Consumation } \\
\text { (thoursend } \\
\text { cubic toet) }\end{array}$ & $\begin{array}{c}\text { Cost } \\
\text { (dollars) }\end{array}$ & & \\
\hline & \multicolumn{6}{|c|}{1991} \\
\hline 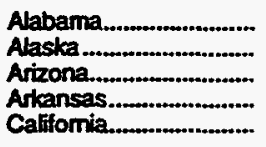 & $\begin{array}{r}66 \\
187 \\
49 \\
82 \\
59\end{array}$ & $\begin{array}{l}464 \\
781 \\
341 \\
408 \\
369\end{array}$ & $\begin{array}{r}414 \\
1,731 \\
511 \\
421 \\
683\end{array}$ & $\begin{array}{l}2,378 \\
5,011 \\
2,592 \\
1,831 \\
3,756\end{array}$ & $\begin{array}{r}61,365 \\
9,454,647 \\
36,098 \\
76,701 \\
13,432\end{array}$ & $\begin{array}{r}0 \\
0 \\
4,092 \\
0 \\
539\end{array}$ \\
\hline 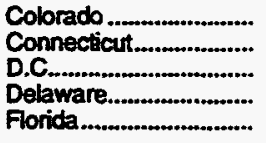 & $\begin{array}{r}97 \\
86 \\
112 \\
79 \\
28\end{array}$ & $\begin{array}{l}446 \\
756 \\
791 \\
460 \\
248\end{array}$ & $\begin{array}{r}605 \\
584 \\
1,374 \\
539 \\
872\end{array}$ & $\begin{array}{l}2,446 \\
4,034 \\
7,103 \\
2,591 \\
4,296\end{array}$ & $\begin{array}{r}52,305 \\
11,181 \\
0 \\
66,449 \\
221,215\end{array}$ & $\begin{array}{r}5,011 \\
0 \\
0 \\
0 \\
1,669\end{array}$ \\
\hline 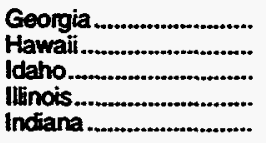 & $\begin{array}{r}71 \\
18 \\
81 \\
141 \\
108\end{array}$ & $\begin{array}{l}475 \\
421 \\
420 \\
696 \\
588\end{array}$ & $\begin{array}{l}465 \\
771 \\
471 \\
742 \\
533\end{array}$ & $\begin{array}{r}2,637 \\
10,300 \\
2,084 \\
3,383 \\
2,456\end{array}$ & $\begin{array}{r}53,489 \\
0 \\
410,178 \\
11,427 \\
35,628\end{array}$ & $\begin{array}{r}0 \\
0 \\
0 \\
562 \\
5,390\end{array}$ \\
\hline 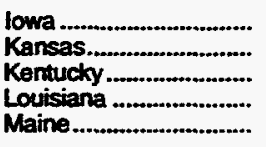 & $\begin{array}{r}110 \\
99 \\
94 \\
58 \\
58\end{array}$ & $\begin{array}{l}530 \\
435 \\
457 \\
336 \\
399\end{array}$ & $\begin{array}{l}552 \\
674 \\
492 \\
413 \\
418\end{array}$ & $\begin{array}{l}2,205 \\
2,237 \\
2,187 \\
2,024 \\
2,513\end{array}$ & $\begin{array}{r}52,222 \\
35,854 \\
45,140 \\
629,449 \\
27,248\end{array}$ & $\begin{array}{r}487 \\
0 \\
0 \\
2,961 \\
0\end{array}$ \\
\hline 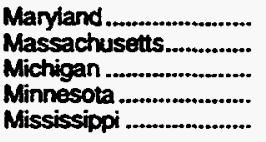 & $\begin{array}{r}88 \\
91 \\
129 \\
121 \\
67\end{array}$ & $\begin{array}{l}545 \\
741 \\
655 \\
545 \\
348\end{array}$ & $\begin{array}{l}616 \\
599 \\
832 \\
882 \\
406\end{array}$ & $\begin{array}{l}3,107 \\
3,699 \\
3,911 \\
3,358 \\
1,739\end{array}$ & $\begin{array}{l}90,673 \\
10,937 \\
23,763 \\
37,108 \\
79,621\end{array}$ & $\begin{array}{r}0 \\
725 \\
2,813 \\
0 \\
0\end{array}$ \\
\hline 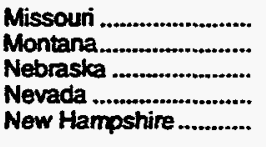 & $\begin{array}{r}100 \\
104 \\
108 \\
68 \\
82\end{array}$ & $\begin{array}{l}512 \\
468 \\
502 \\
379 \\
589\end{array}$ & $\begin{array}{l}537 \\
554 \\
661 \\
767 \\
454\end{array}$ & $\begin{array}{l}2,418 \\
2,411 \\
2,562 \\
3,328 \\
2,881\end{array}$ & $\begin{array}{r}18,471 \\
21,842 \\
34,482 \\
58,621 \\
9,575\end{array}$ & $\begin{array}{r}0 \\
1,936 \\
0 \\
8,152 \\
0\end{array}$ \\
\hline $\begin{array}{l}\text { New Jersey................. } \\
\text { New Mexico ................. } \\
\text { New York..................... } \\
\text { North Carolina............. } \\
\text { North Dakota............... }\end{array}$ & $\begin{array}{r}88 \\
78 \\
76 \\
70 \\
118\end{array}$ & $\begin{array}{l}593 \\
424 \\
557 \\
439 \\
568\end{array}$ & $\begin{array}{l}563 \\
647 \\
642 \\
489 \\
888\end{array}$ & $\begin{array}{l}2,932 \\
2,685 \\
3,510 \\
2,213 \\
3,851\end{array}$ & $\begin{array}{r}11,934 \\
14,470 \\
4,125 \\
24,205 \\
30,134\end{array}$ & $\begin{array}{r}0 \\
0 \\
3,098 \\
1,040 \\
1,408\end{array}$ \\
\hline 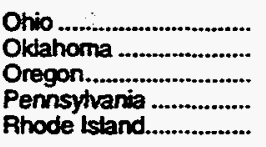 & $\begin{array}{r}115 \\
84 \\
70 \\
104 \\
88\end{array}$ & $\begin{array}{l}606 \\
396 \\
429 \\
703 \\
675\end{array}$ & $\begin{array}{l}636 \\
456 \\
403 \\
657 \\
449\end{array}$ & $\begin{array}{l}3,027 \\
1.784 \\
1.917 \\
3.944 \\
2,704\end{array}$ & $\begin{array}{l}32,993 \\
63,625 \\
69,949 \\
36,472 \\
24,270\end{array}$ & $\begin{array}{r}79 \\
1,629 \\
0 \\
292 \\
91\end{array}$ \\
\hline 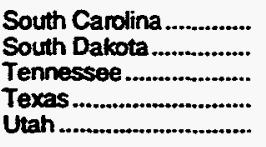 & $\begin{array}{r}57 \\
104 \\
75 \\
68 \\
111\end{array}$ & $\begin{array}{l}397 \\
514 \\
388 \\
388 \\
603\end{array}$ & $\begin{array}{l}395 \\
692 \\
511 \\
672 \\
541\end{array}$ & $\begin{array}{l}2,197 \\
2,795 \\
2,432 \\
2,695 \\
2,436\end{array}$ & $\begin{array}{r}61,279 \\
16,459 \\
48,876 \\
128,736 \\
68,336\end{array}$ & $\begin{array}{r}0 \\
2,433 \\
741 \\
394 \\
320\end{array}$ \\
\hline 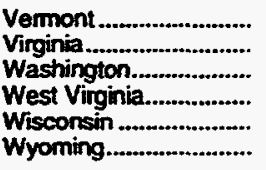 & $\begin{array}{r}111 \\
83 \\
94 \\
93 \\
108 \\
106\end{array}$ & $\begin{array}{l}691 \\
566 \\
440 \\
605 \\
605 \\
501\end{array}$ & $\begin{array}{l}652 \\
648 \\
686 \\
642 \\
652 \\
610\end{array}$ & $\begin{array}{l}3,421 \\
3,146 \\
2,783 \\
3,924 \\
3,013 \\
2,628\end{array}$ & $\begin{array}{r}132,070 \\
51,870 \\
22,814 \\
206,509 \\
17,904 \\
145,499\end{array}$ & $\begin{array}{r}0 \\
0 \\
2,078 \\
0 \\
2,114 \\
949\end{array}$ \\
\hline 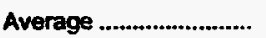 & 88 & 514 & 626 & 3.013 & 33,395 & 331 \\
\hline
\end{tabular}

See footnotes at end of table. 
Table 35. Average Consumption and Annual Cost of Natural Gas per Consumer by State, 1990-1994 (Continued)

\begin{tabular}{|c|c|c|c|c|c|c|}
\hline \multirow[b]{2}{*}{ State } & \multicolumn{2}{|c|}{ Aesidential } & \multicolumn{2}{|c|}{ Commercial } & \multirow{2}{*}{$\begin{array}{l}\text { Industriat } \\
\text { Consumpotion } \\
\text { (thoulind } \\
\text { cubic teet) }\end{array}$} & \multirow{2}{*}{$\begin{array}{l}\text { Vohicis Fuel } \\
\text { Consumption } \\
\text { (thousend } \\
\text { ctbie feot) }\end{array}$} \\
\hline & $\begin{array}{l}\text { Consuraption } \\
\text { (thoueind } \\
\text { cubic tont) }\end{array}$ & (doliters) & $\begin{array}{l}\text { Consumption } \\
\text { (thourend } \\
\text { cubic feet) }\end{array}$ & $\begin{array}{c}\text { Cost } \\
\text { (dollers) }\end{array}$ & & \\
\hline & \multicolumn{6}{|c|}{1992} \\
\hline 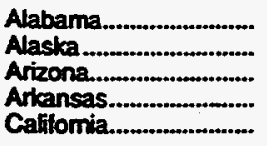 & $\begin{array}{r}70 \\
193 \\
47 \\
78 \\
55\end{array}$ & $\begin{array}{l}471 \\
732 \\
340 \\
399 \\
330\end{array}$ & $\begin{array}{r}435 \\
1,745 \\
567 \\
407 \\
691\end{array}$ & $\begin{array}{l}2,482 \\
4,606 \\
2,947 \\
1,783 \\
3,556\end{array}$ & $\begin{array}{r}67,377 \\
8,093,795 \\
37,169 \\
90,106 \\
14,671\end{array}$ & $\begin{array}{r}2,632 \\
0 \\
4,552 \\
0 \\
420\end{array}$ \\
\hline 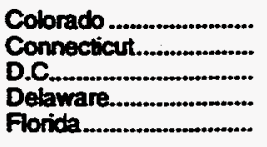 & $\begin{array}{r}93 \\
98 \\
122 \\
87 \\
30\end{array}$ & $\begin{array}{l}422 \\
879 \\
925 \\
535 \\
277\end{array}$ & $\begin{array}{r}578 \\
637 \\
1,437 \\
607 \\
925\end{array}$ & $\begin{array}{l}2,315 \\
4,584 \\
7,704 \\
2,999 \\
4,603\end{array}$ & $\begin{array}{r}51,967 \\
12,447 \\
0 \\
72,823 \\
218,632\end{array}$ & $\begin{array}{r}4.688 \\
109 \\
0 \\
0 \\
1.580\end{array}$ \\
\hline 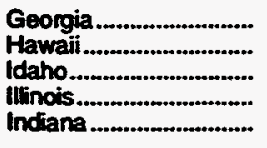 & $\begin{array}{r}77 \\
18 \\
71 \\
142 \\
111\end{array}$ & $\begin{array}{l}499 \\
334 \\
371 \\
721 \\
602\end{array}$ & $\begin{array}{l}483 \\
768 \\
422 \\
746 \\
559\end{array}$ & $\begin{array}{r}2,685 \\
10,243 \\
1,858 \\
3,466 \\
2,555\end{array}$ & $\begin{array}{r}54,057 \\
0 \\
409,762 \\
11,052 \\
38,616\end{array}$ & $\begin{array}{r}0 \\
0 \\
0 \\
479 \\
3,707\end{array}$ \\
\hline 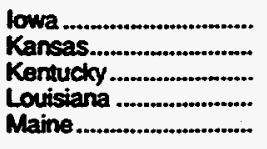 & $\begin{array}{r}103 \\
94 \\
96 \\
59 \\
63\end{array}$ & $\begin{array}{l}537 \\
441 \\
481 \\
329 \\
440\end{array}$ & $\begin{array}{l}540 \\
622 \\
510 \\
466 \\
457\end{array}$ & $\begin{array}{l}2,306 \\
2,195 \\
2,280 \\
2,234 \\
2,825\end{array}$ & $\begin{array}{r}54,905 \\
39,687 \\
45,783 \\
642,195 \\
25,595\end{array}$ & $\begin{array}{r}442 \\
0 \\
37 \\
4,270 \\
0\end{array}$ \\
\hline $\begin{array}{l}\text { Maryland..................... } \\
\text { Massachusetts ............ } \\
\text { Michigan ...................... } \\
\text { Minnesola ................... } \\
\text { Mississippi .................. }\end{array}$ & $\begin{array}{r}84 \\
105 \\
136 \\
114 \\
68\end{array}$ & $\begin{array}{l}540 \\
833 \\
686 \\
552 \\
335\end{array}$ & $\begin{array}{l}676 \\
749 \\
862 \\
826 \\
405\end{array}$ & $\begin{array}{l}3,537 \\
4.391 \\
4,008 \\
3,389 \\
1,672\end{array}$ & $\begin{array}{r}96,731 \\
8,125 \\
26,651 \\
36,988 \\
77,326\end{array}$ & $\begin{array}{r}0 \\
2,485 \\
3,603 \\
0 \\
0\end{array}$ \\
\hline $\begin{array}{l}\text { Missouri ....................... } \\
\text { Montana................... } \\
\text { Nebraska .................... } \\
\text { Nevada ..................... } \\
\text { New Hampshire ........... }\end{array}$ & $\begin{array}{l}96 \\
91 \\
99 \\
61 \\
93\end{array}$ & $\begin{array}{l}488 \\
439 \\
477 \\
344 \\
702\end{array}$ & $\begin{array}{l}487 \\
490 \\
562 \\
706 \\
515\end{array}$ & $\begin{array}{l}2,179 \\
2,185 \\
2,247 \\
3,055 \\
3,469\end{array}$ & $\begin{array}{l}19,560 \\
26,620 \\
38,005 \\
81,222 \\
11,128\end{array}$ & $\begin{array}{r}0 \\
1,054 \\
363 \\
6,008 \\
0\end{array}$ \\
\hline $\begin{array}{l}\text { New Jersey.................. } \\
\text { New Mexico ................. } \\
\text { Now York................... } \\
\text { North Carolina.............. } \\
\text { North Dakota................. }\end{array}$ & $\begin{array}{r}98 \\
81 \\
84 \\
74 \\
108\end{array}$ & $\begin{array}{l}678 \\
383 \\
635 \\
489 \\
541\end{array}$ & $\begin{array}{l}615 \\
692 \\
687 \\
501 \\
790\end{array}$ & $\begin{array}{l}3,411 \\
2,324 \\
3,954 \\
2,399 \\
3,567\end{array}$ & $\begin{array}{r}15,214 \\
121,064 \\
5,232 \\
29,171 \\
34,739\end{array}$ & $\begin{array}{r}0 \\
6,832 \\
600 \\
3,321 \\
856\end{array}$ \\
\hline 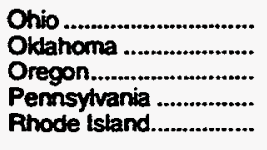 & $\begin{array}{r}121 \\
79 \\
65 \\
113 \\
101\end{array}$ & $\begin{array}{l}627 \\
392 \\
403 \\
745 \\
776\end{array}$ & $\begin{array}{l}675 \\
404 \\
389 \\
693 \\
488\end{array}$ & $\begin{array}{l}3.187 \\
1.709 \\
1.841 \\
4.055 \\
3,083\end{array}$ & $\begin{array}{l}34,388 \\
61,269 \\
79,080 \\
36,439 \\
43,720\end{array}$ & $\begin{array}{r}87 \\
3,485 \\
469 \\
165 \\
97\end{array}$ \\
\hline 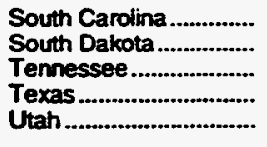 & $\begin{array}{l}63 \\
98 \\
75 \\
65 \\
96\end{array}$ & $\begin{array}{l}440 \\
503 \\
412 \\
377 \\
520\end{array}$ & $\begin{array}{l}406 \\
645 \\
506 \\
630 \\
459\end{array}$ & $\begin{array}{l}2,294 \\
2,707 \\
2,562 \\
2,578 \\
2,017\end{array}$ & $\begin{array}{r}60,158 \\
14,068 \\
52,054 \\
316,366 \\
52,207\end{array}$ & $\begin{array}{r}0 \\
2,403 \\
951 \\
2,190 \\
767\end{array}$ \\
\hline 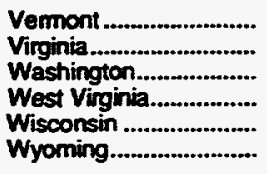 & $\begin{array}{r}123 \\
94 \\
81 \\
100 \\
104 \\
95\end{array}$ & $\begin{array}{l}825 \\
628 \\
407 \\
632 \\
613 \\
448\end{array}$ & $\begin{array}{l}725 \\
729 \\
596 \\
734 \\
632 \\
532\end{array}$ & $\begin{array}{l}4,110 \\
3,626 \\
2,575 \\
4,017 \\
3,041 \\
2,263\end{array}$ & $\begin{array}{r}108,751 \\
62,496 \\
22,856 \\
277,850 \\
17,613 \\
229,698\end{array}$ & $\begin{array}{r}0 \\
0 \\
4,921 \\
310 \\
2,362 \\
2,006\end{array}$ \\
\hline Average ........................ & 90 & 528 & 636 & 3,103 & 35,908 & 494 \\
\hline
\end{tabular}

See lootnotes at end of table. 
Table 35. Average Consumption and Annual Cost of Natural Gas per Consumer by State, 1990-1994 (Continued)

\begin{tabular}{|c|c|c|c|c|c|c|}
\hline \multirow[b]{2}{*}{ State } & \multicolumn{2}{|c|}{ Residential } & \multicolumn{2}{|c|}{ Commercial } & \multirow{2}{*}{$\begin{array}{l}\text { Industrial } \\
\text { Consumption } \\
\text { (thousend } \\
\text { cubic feet) }\end{array}$} & \multirow{2}{*}{$\begin{array}{l}\text { Vehicla Feal } \\
\text { Consumption } \\
\text { (thousand } \\
\text { cutbie feet) }\end{array}$} \\
\hline & $\begin{array}{l}\text { Consumption } \\
\text { (thousand } \\
\text { cubic feat) }\end{array}$ & $\begin{array}{c}\text { Coot } \\
\text { (dollare) }\end{array}$ & $\begin{array}{l}\text { Consewnption } \\
\text { (thouteand } \\
\text { cubic teet) }\end{array}$ & $\begin{array}{c}\text { Cost } \\
\text { (dollers) }\end{array}$ & & \\
\hline & \multicolumn{6}{|c|}{1993} \\
\hline 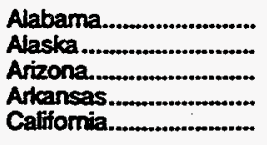 & $\begin{array}{r}70 \\
183 \\
46 \\
89 \\
57\end{array}$ & $\begin{array}{l}499 \\
724 \\
332 \\
477 \\
358\end{array}$ & $\begin{array}{r}445 \\
1,618 \\
578 \\
461 \\
608\end{array}$ & $\begin{array}{l}2,753 \\
4,498 \\
2,926 \\
2,034 \\
3,668\end{array}$ & $\begin{array}{r}73,919 \\
6,890,453 \\
40,236 \\
87,537 \\
15,433\end{array}$ & $\begin{array}{r}2,093 \\
0 \\
4,021 \\
0 \\
937\end{array}$ \\
\hline 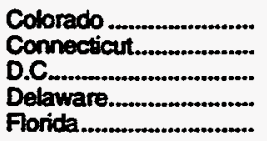 & $\begin{array}{r}102 \\
99 \\
122 \\
86 \\
R_{29}\end{array}$ & $\begin{array}{r}460 \\
931 \\
1,017 \\
573 \\
288\end{array}$ & $\begin{array}{r}618 \\
690 \\
1,458 \\
618 \\
\mathrm{R}_{869}\end{array}$ & $\begin{array}{r}2,495 \\
\mathbf{4 , 8 4 4} \\
\mathbf{8 , 3 7 8} \\
\mathbf{3 , 3 7 6} \\
\mathrm{R}_{\mathbf{5}, 076}\end{array}$ & $\begin{array}{r}66,884 \\
12,480 \\
0 \\
78,126 \\
R_{231,754}\end{array}$ & $\begin{array}{r}2,921 \\
100 \\
0 \\
0 \\
2,474\end{array}$ \\
\hline 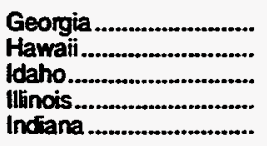 & $\begin{array}{r}81 \\
19 \\
85 \\
146 \\
117\end{array}$ & $\begin{array}{l}550 \\
326 \\
455 \\
807 \\
673\end{array}$ & $\begin{array}{r}501 \\
659 \\
485 \\
R_{758} \\
592\end{array}$ & $\begin{array}{r}2,920 \\
8,501 \\
2,257 \\
R_{3,866} \\
2,951\end{array}$ & $\begin{array}{r}50,693 \\
0 \\
388,619 \\
10,969 \\
40,455\end{array}$ & $\begin{array}{r}3,671 \\
0 \\
0 \\
604 \\
3,372\end{array}$ \\
\hline 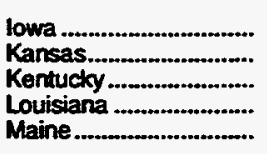 & $\begin{array}{r}R_{113} \\
109 \\
102 \\
60 \\
65\end{array}$ & $\begin{array}{l}617 \\
536 \\
536 \\
367 \\
485\end{array}$ & $\begin{array}{l}582 \\
639 \\
525 \\
405 \\
464\end{array}$ & $\begin{array}{l}2,630 \\
2,595 \\
2,531 \\
2,159 \\
3,136\end{array}$ & $\begin{array}{r}R_{53,928} \\
31,822 \\
47,962 \\
611,610 \\
26,564\end{array}$ & $\begin{array}{r}1,336 \\
0 \\
85 \\
1,988 \\
0\end{array}$ \\
\hline 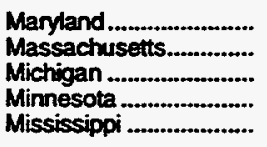 & $\begin{array}{r}95 \\
105 \\
138 \\
115 \\
71\end{array}$ & $\begin{array}{l}675 \\
874 \\
696 \\
610 \\
372\end{array}$ & $\begin{array}{l}684 \\
640 \\
882 \\
931 \\
424\end{array}$ & $\begin{array}{l}3,913 \\
3,869 \\
4,106 \\
4,210 \\
1,856\end{array}$ & $\begin{array}{l}98,472 \\
12,997 \\
27,313 \\
39,471 \\
75,654\end{array}$ & $\begin{array}{r}1,377 \\
585 \\
2.402 \\
77 \\
0\end{array}$ \\
\hline $\begin{array}{l}\text { Missouri ...................... } \\
\text { Montana................... } \\
\text { Nebraska .................. } \\
\text { Nevada ................... } \\
\text { New Hampshire ............ }\end{array}$ & $\begin{array}{r}109 \\
108 \\
117 \\
68 \\
92\end{array}$ & $\begin{array}{l}\mathbf{5 8 7} \\
\mathbf{5 3 0} \\
\mathbf{5 7 9} \\
\mathbf{3 8 5} \\
\mathbf{7 0 1}\end{array}$ & $\begin{array}{l}555 \\
569 \\
573 \\
756 \\
524\end{array}$ & $\begin{array}{r}2,642 \\
2,657 \\
R_{2,447} \\
3,331 \\
3,579\end{array}$ & $\begin{array}{r}20,060 \\
27,469 \\
R_{53,842} \\
211,398 \\
11,394\end{array}$ & $\begin{array}{r}0 \\
1.879 \\
1,108 \\
10,684 \\
0\end{array}$ \\
\hline $\begin{array}{l}\text { New Jersey................... } \\
\text { New Mexico .................. } \\
\text { New York.................... } \\
\text { North Carolina.............. } \\
\text { North Dakota................. }\end{array}$ & $\begin{array}{r}95 \\
80 \\
96 \\
78 \\
117\end{array}$ & $\begin{array}{l}664 \\
437 \\
784 \\
542 \\
614\end{array}$ & $\begin{array}{l}597 \\
695 \\
741 \\
489 \\
841\end{array}$ & $\begin{array}{l}3,341 \\
2,992 \\
4,564 \\
2,696 \\
3,993\end{array}$ & $\begin{array}{r}16,829 \\
111,995 \\
6,730 \\
34,650 \\
35,032\end{array}$ & $\begin{array}{r}0 \\
15,546 \\
740 \\
1,205 \\
1,680\end{array}$ \\
\hline $\begin{array}{l}\text { Ohio ............................ } \\
\text { Okdahoma .................... } \\
\text { Oregon ....................... } \\
\text { Pennsyvania ............... } \\
\text { Rhode Istand................ }\end{array}$ & $\begin{array}{r}123 \\
93 \\
80 \\
113 \\
99\end{array}$ & $\begin{array}{l}705 \\
459 \\
515 \\
771 \\
811\end{array}$ & $\begin{array}{l}682 \\
462 \\
463 \\
665 \\
435\end{array}$ & $\begin{array}{l}3,574 \\
2,043 \\
2,335 \\
3,982 \\
3,085\end{array}$ & $\begin{array}{l}34,715 \\
61,609 \\
87,093 \\
37.694 \\
43,181\end{array}$ & $\begin{array}{r}803 \\
4,681 \\
382 \\
96 \\
44\end{array}$ \\
\hline 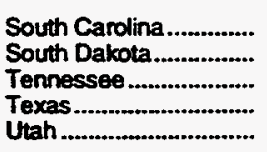 & $\begin{array}{r}66 \\
97 \\
80 \\
69 \\
107\end{array}$ & $\begin{array}{l}469 \\
515 \\
457 \\
409 \\
549\end{array}$ & $\begin{array}{r}A_{403} \\
647 \\
535 \\
R_{592} \\
597\end{array}$ & $\begin{array}{r}P_{2}, 347 \\
2,830 \\
2,817 \\
A_{2} .635 \\
2,424\end{array}$ & $\begin{array}{r}58,804 \\
14,016 \\
49,485 \\
\mathrm{~A}_{323,250} \\
122,611\end{array}$ & $\begin{array}{r}0 \\
1,640 \\
284 \\
3,654 \\
873\end{array}$ \\
\hline 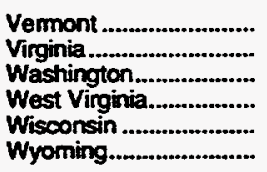 & $\begin{array}{r}117 \\
95 \\
94 \\
100 \\
107 \\
109\end{array}$ & $\begin{array}{l}727 \\
713 \\
492 \\
643 \\
676 \\
521\end{array}$ & $\begin{array}{l}719 \\
754 \\
663 \\
725 \\
665 \\
670\end{array}$ & $\begin{array}{l}3,773 \\
4,219 \\
3,006 \\
4,256 \\
3,430 \\
2,838\end{array}$ & $\begin{array}{r}102,255 \\
26,958 \\
26,762 \\
R_{239,399} \\
16,803 \\
279,455\end{array}$ & $\begin{array}{r}0 \\
730 \\
3,450 \\
234 \\
2,101 \\
1,651\end{array}$ \\
\hline 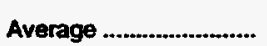 & 94 & 582 & $R_{641}$ & $\mathrm{~A}_{3,346}$ & $A_{38,057}$ & 1,311 \\
\hline
\end{tabular}

See footnotes at end of table. 
Table 35. Average Consumption and Annual Cost of Natural Gas per Consumer by State, 1990-1994 (Continued)

\begin{tabular}{|c|c|c|c|c|c|c|}
\hline \multirow[b]{2}{*}{ State } & \multicolumn{2}{|c|}{ Residential } & \multicolumn{2}{|c|}{ Commercial } & \multirow{2}{*}{$\begin{array}{l}\text { Industrial } \\
\text { Concumplion } \\
\text { (thousend } \\
\text { cubic font) }\end{array}$} & \multirow{2}{*}{$\begin{array}{l}\text { Vehicte Fed } \\
\text { Comeumption } \\
\text { (thousend } \\
\text { cutic feot) }\end{array}$} \\
\hline & $\begin{array}{l}\text { Consumption } \\
\text { (thoutiend } \\
\text { cubic fient) }\end{array}$ & $\begin{array}{c}\text { Cost } \\
\text { (dollers) }\end{array}$ & $\begin{array}{l}\text { Consumption } \\
\text { (thousend } \\
\text { cubic teet) }\end{array}$ & (dollars) & & \\
\hline & \multicolumn{6}{|c|}{1994} \\
\hline 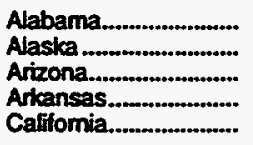 & $\begin{array}{r}67 \\
192 \\
47 \\
80 \\
59\end{array}$ & $\begin{array}{l}495 \\
690 \\
352 \\
455 \\
378\end{array}$ & $\begin{array}{r}423 \\
1.659 \\
601 \\
429 \\
637\end{array}$ & $\begin{array}{l}2,700 \\
4,110 \\
3,168 \\
1,969 \\
4,538\end{array}$ & $\begin{array}{r}73,362 \\
5,582,184 \\
49,844 \\
94,510 \\
16,948\end{array}$ & $\begin{array}{r}1,736 \\
0 \\
4,052 \\
0 \\
1,215\end{array}$ \\
\hline 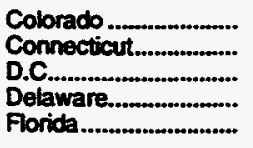 & $\begin{array}{r}93 \\
97 \\
117 \\
85 \\
28\end{array}$ & $\begin{array}{l}456 \\
985 \\
974 \\
633 \\
278\end{array}$ & $\begin{array}{r}568 \\
868 \\
1,324 \\
626 \\
835\end{array}$ & $\begin{array}{l}2,483 \\
6,413 \\
8,161 \\
3,864 \\
4,622\end{array}$ & $\begin{array}{r}60,453 \\
8,164 \\
0 \\
68,319 \\
263,770\end{array}$ & $\begin{array}{r}9.712 \\
152 \\
0 \\
662 \\
2,054\end{array}$ \\
\hline 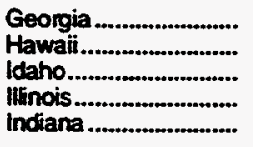 & $\begin{array}{r}72 \\
19 \\
75 \\
139 \\
109\end{array}$ & $\begin{array}{l}529 \\
318 \\
399 \\
763 \\
683\end{array}$ & $\begin{array}{l}458 \\
784 \\
439 \\
753 \\
564\end{array}$ & $\begin{array}{l}2,831 \\
9.729 \\
2,199 \\
3,855 \\
3,006\end{array}$ & $\begin{array}{r}53,067 \\
0 \\
206,812 \\
11,831 \\
42,782\end{array}$ & $\begin{array}{r}1,342 \\
0 \\
9,809 \\
1,871 \\
1,004\end{array}$ \\
\hline 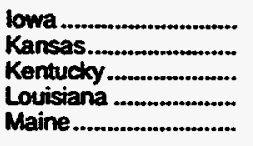 & $\begin{array}{r}104 \\
96 \\
94 \\
56 \\
63\end{array}$ & $\begin{array}{l}563 \\
490 \\
511 \\
349 \\
496\end{array}$ & $\begin{array}{l}551 \\
604 \\
500 \\
367 \\
449\end{array}$ & $\begin{array}{l}2,488 \\
2,489 \\
2,492 \\
1,990 \\
3,134\end{array}$ & $\begin{array}{r}\mathbf{5 5 , 5 6 0} \\
\mathbf{5 2 , 8 0 3} \\
\mathbf{5 1}, 253 \\
\mathbf{5 7 5 , 1 4 9} \\
19,895\end{array}$ & $\begin{array}{r}1,268 \\
1,243 \\
91 \\
3,214 \\
0\end{array}$ \\
\hline $\begin{array}{l}\text { Maryland ................... } \\
\text { Massachusetts........... } \\
\text { Michigan .................... } \\
\text { Minnesota .................. } \\
\text { Mississippi ................... }\end{array}$ & $\begin{array}{r}93 \\
101 \\
134 \\
117 \\
67\end{array}$ & $\begin{array}{l}647 \\
907 \\
669 \\
604 \\
365\end{array}$ & $\begin{array}{l}682 \\
911 \\
882 \\
816 \\
439\end{array}$ & $\begin{array}{l}3,724 \\
6,220 \\
4,130 \\
3,559 \\
2,002\end{array}$ & $\begin{array}{l}92,425 \\
11,572 \\
28,993 \\
36,446 \\
73,049\end{array}$ & $\begin{array}{r}667 \\
79 \\
278 \\
2,054 \\
9,017\end{array}$ \\
\hline 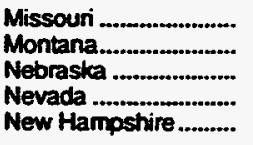 & $\begin{array}{r}96 \\
96 \\
104 \\
63 \\
90\end{array}$ & $\begin{array}{l}519 \\
503 \\
520 \\
421 \\
720\end{array}$ & $\begin{array}{l}500 \\
512 \\
628 \\
762 \\
524\end{array}$ & $\begin{array}{l}2,427 \\
2,516 \\
2,659 \\
4,090 \\
3,754\end{array}$ & $\begin{array}{r}22,986 \\
30,773 \\
48,251 \\
242,577 \\
13,799\end{array}$ & $\begin{array}{r}348 \\
1,390 \\
1,761 \\
5,140 \\
73\end{array}$ \\
\hline $\begin{array}{l}\text { New Jersey ................... } \\
\text { New Mexico .............. } \\
\text { New York................... } \\
\text { North Carolina............. } \\
\text { North Dakota................ }\end{array}$ & $\begin{array}{r}104 \\
75 \\
96 \\
73 \\
114\end{array}$ & $\begin{array}{l}738 \\
423 \\
841 \\
531 \\
592\end{array}$ & $\begin{array}{l}603 \\
627 \\
740 \\
482 \\
833\end{array}$ & $\begin{array}{l}3,633 \\
2,761 \\
4,823 \\
2.682 \\
3,728\end{array}$ & $\begin{array}{r}17,991 \\
17,084 \\
9,822 \\
27,885 \\
31,429\end{array}$ & $\begin{array}{l}2,168 \\
1,164 \\
1,817 \\
3,911 \\
1,677\end{array}$ \\
\hline 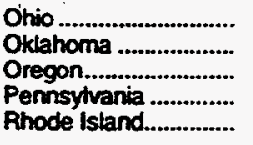 & $\begin{array}{r}118 \\
82 \\
74 \\
112 \\
87\end{array}$ & $\begin{array}{l}691 \\
450 \\
515 \\
835 \\
789\end{array}$ & $\begin{array}{l}680 \\
417 \\
428 \\
670 \\
568\end{array}$ & $\begin{array}{l}3,660 \\
1,973 \\
2,358 \\
4,355 \\
4,303\end{array}$ & $\begin{array}{l}35,947 \\
68,668 \\
81,789 \\
37,010 \\
38,459\end{array}$ & $\begin{array}{r}1,207 \\
4,605 \\
757 \\
225 \\
44\end{array}$ \\
\hline 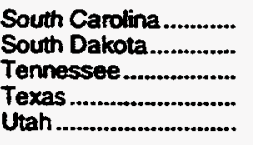 & $\begin{array}{r}56 \\
101 \\
75 \\
64 \\
97\end{array}$ & $\begin{array}{l}431 \\
532 \\
458 \\
382 \\
482\end{array}$ & $\begin{array}{l}393 \\
661 \\
518 \\
588 \\
676\end{array}$ & $\begin{array}{l}2,401 \\
2,877 \\
2,880 \\
2,547 \\
2,599\end{array}$ & $\begin{array}{r}50,571 \\
14,456 \\
48,725 \\
350,341 \\
145,310\end{array}$ & $\begin{array}{r}2,097 \\
1,093 \\
285 \\
5,028 \\
726\end{array}$ \\
\hline 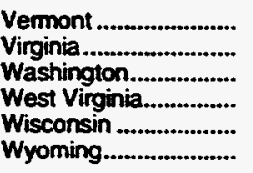 & $\begin{array}{r}108 \\
90 \\
88 \\
100 \\
102 \\
99\end{array}$ & $\begin{array}{l}751 \\
690 \\
501 \\
664 \\
642 \\
503\end{array}$ & $\begin{array}{l}760 \\
733 \\
631 \\
740 \\
656 \\
601\end{array}$ & $\begin{array}{l}4,254 \\
4,158 \\
3,091 \\
4,372 \\
3,219 \\
2,677\end{array}$ & $\begin{array}{r}84,307 \\
31,301 \\
30,007 \\
244,891 \\
18,402 \\
448,635\end{array}$ & $\begin{array}{r}0 \\
1,784 \\
5,535 \\
174 \\
2,265 \\
1,261\end{array}$ \\
\hline Average ....................... & 91 & 582 & 638 & 3,468 & 40,295 & 1.406 \\
\hline
\end{tabular}

R = Revised data.

Note: Begiming in 1987, industrial costs per consumer are not caleutated since vatues associaled with gas dolivered for the account of others are not available. Each year since $19 e 2$, these values heve represented an ncreasingty large portion of the blal industrial value. By 1587 , a meaninglul rverage cost per consumer could no bonger be calculated without them

Source: 1930-1932: Bureau of Mines (BOM), Forms BOM-1340-A and BOM-6-1341-A. "Supply and Disposition of Natural Ges." Energy hitormation Actrinistration (ElA), Form ElA-176. Suppty and Disposition. 
Appendix A

Selected

Recurring

Natural Gas

and Related

Reports 
-

0

○ 


\section{Selected Recurring Natural Gas and Related Reports}

\section{Recurring Natural Gas Reports}

- Natural Gas Monthly, DOE/EIA-0130. Published monthly.

Other Reports Covering Natural Gas, Natural Gas Liquids, and Other Energy Sources

- U.S. Crude Oil, Nazural Gas, and Natural Gas Liquids Reserves - 1994 Annual Report, DOE/EIA-0216(94), September 1995.

- Monthly Energy Review, DOE/ELA-0035. Published monthly. Provides national aggregate data for natural gas, natural gas liquids, and other energy sources.

- Annual Report to Congress 1994, DOE/ EIA0173(94), April 1995. Published annually.

- Annual Energy Outlook 1995, DOE/ EIA-0383(95), January 1995. Published annually.

- Annual Energy Review 1994, DOE/ EIA-0384(94), July 1995. Published annually.

- Short-Term Energy Outlook, DOE/EIA-0202. Published quarterly. Provides forecasts for next six quarters for natural gas and other energy sources.

- State Energy Data Report, Consumption Estimates, 1960-1992, DOE/EIA-0214(93), July 1995.
- State Energy Price and Expenditure Report 1992, DOE/EIA-0376(92), December 1994.

\section{One-Time Reports}

- U.S. Production of Natural Gas from Tight Reservoirs, DOE/EIA-TR-0574, October 1993.

- Natural Gas 1994: Issues and Trends, DOE/EIA0560(20), July 1994.

- Natural Gas Productive Capacity for the Lower 48 States 1980 Through 1995, DOE/EIA-0542(95), July 1994.

- Largest U.S. Oil and Gas Fields, DOE/EIA-TR-0567, August 1993.

- Geologic Distributions of U.S. Oil and Gas, DOE/EIA0557, July 1992.

- Capacity and Service on the Interstate Natural Gas Pipeline System 1990, DOE/EIA-0556, June 1992.

\section{Reference Reports}

- Directory of Energy Data Collection Forms, DOE/ EIA-0249(93), December 1993.

- Oil and Gas Field Code Master List, 1993, ELA0370(93), December 1993. 



\section{Glossary}

Balancing Item: Represents differences between the sum of the components of natural gas supply and the sum of the components of natural gas disposition. These differences may be due to quantities lost or to the effects of data-reporting problems. Reporting problems include differences due to the.net result of conversions of flow data metered at varying temperature and pressure bases and converted to a standard temperature and pressure base; the effect of variations in company accounting and billing practices; differences between billing cycle and calendar period time frames; and imbalances resulting from the merger of datareporting systems that vary in scope, format, definitions, and type of respondents.

Biomass Gas: A medium Btu gas containing methane and carbon dioxide, resulting from the action of microorganisms on organic materials such as a landfill.

British Thermal Unit (Btu): The quantity of heat required to raise the temperature of 1 pound of water by 1 degree Fahrenheit at or near 39.2 degrees Fahrenheit.

City Gate: A point or measuring station at which a gas distribution company receives gas from a pipeline company or transmission system.

Coke Oven Gas: The gaseous portion of volatile substances driven off in the coking process after other coal chemicals are removed.

Commercial Consumption: Gas used by nonmanufacturing establishments or agencies primarily engaged in the sale of goods or services. Included are such establishments as hotels, restaurants, wholesale and retail stores and other service enterprises; gas used by establishments engaged in agriculture, forestry, and fisheries; and gas used by local, State, and Federal agencies engaged in nonmanufacturing activities.

Delivered: The physical transfer of natural, synthetic, and/or supplemental gas from facilities operated by the responding company to facilities operated by others or to consumers.

Dry Natural Gas Production: Marketed production less extraction loss.
Electric Utility: An enterprise that is engaged in the generation, transmission, or distribution of electric energy primarily for use by the public and that is the major power supplier within a designated service area. Electric utilities include investor-owned, publicly-owned, cooperatively-owned, and government-owned (municipals, Federal agencies, State projects, and public power districts) systems.

Electric Utility Consumption: Gas used as fuel in electric utility plants.

Exports: Natural gas deliveries out of the continental United States and Alaska to foreign countries.

Extraction Loss: The reduction in volume of natural gas due to the removal of natural gas liquid constituents such as ethane, propane, and butane at natural gas processing plants.

Flared: Natural gas burned in flares at the base site or at gas-processing plants.

Gas Condensate Well: A gas well that produces from a gas reservoir containing considerable quantities of liquid hydrocarbons in the pentane and heavier range generally described as "condensate."

Gas Well: A well completed for the production of natural gas from one or more gas zones or reservoirs.

Gross Withdrawals: Full well-stream volume, including all natural gas plant liquids and all nonhydrocarbon gases, but excluding lease condensate.

Heating Value: The average number of British thermal units per cubic foot of natural gas as determined from tests of fuel samples.

Imports: Gas receipts into the United States from a foreign country.

Industrial Consumers: Establishments engaged in a process which creates or changes raw or unfinished materials into another form or product. Generation of electricity, other than by electric utilities, is included.

Industrial Consumption: Natural gas used by manufacturing and mining establishments for heat, power, and chemical feedstock. 
Intransit Deliveries: Redeliveries to a foreign country of foreign gas received for transportation across U.S. territory and deliveries of U.S. gas to a foreign country for transportation across its territory and redelivery to the United States.

Intransit Receipts: Receipts of foreign gas for transportation across U.S. territory and redelivery to a foreign country and redeliveries to the United States of U.S. gas transported across foreign territory.

Lease Fuel: Natural gas used in well, field, and lease operations (such as gas used in drilling operations, heaters, dehydrators, and field compressors).

Liquefied Natural Gas (LNG): Natural gas (primarily methane) that has been liquefied by reducing its temperature to minus $\mathbf{2 6 0}$ degrees Fahrenheit at atmospheric pressure.

Manufactured Gas: A gas obtained by destructive distillation of coal, or by the thermal decomposition of oil, or by the reaction of steam passing through a bed of heated coal or coke. Examples are coal gases, coke oven gases, producer gas, blast furnace gas, blue (water) gas, carbureted water gas. Btu content varies widely.

Marketed Production: Gross withdrawals less gas used for repressuring, quantities vented and flared, and nonhydrocarbon gases removed in treating or processing operations.

Natural Gas: A mixture of hydrocarbon compounds and small quantities of various nonhydrocarbons existing in the gaseous phase or in solution with crude oil in natural underground reservoirs at reservoir conditions.

Natural Gas, Wet After Lease Separation: The volume of natural gas remaining after removal of lease condensate in lease and/or field separation facilities, if any, and after exclusion of nonhydrocarbon gases where they occur in sufficient quantity to render the gas unmarketable. Natural gas liquids may be recovered from volumes of natural gas, wet after lease separation, at natural gas processing plants.

Nonhydrocarbon Gases: Typical nonhydrocarbon gases which may be present in reservoir natural gas, such as carbon dioxide, helium, hydrogen sulfide, and nitrogen.

Nonutility Power Producers: A company which owns electric generating capacity and is not an electric utility. Nonutility power producers include qualifying cogenerators, qualifying small power producers, and other nonutility generators (including independent power producers).

Offshore Reserves and Production: Unless otherwise indicated, reserves and production that are in either State or Federal domains, located seaward of the coastline.
Oil Well (Casinghead) Gas: Associated and dissolved gas produced along with crude oil from oil completions.

Outer Continental Shelf: Offshore Federal domain.

Pipeline: A continuous pipe conduit, complete with such equipment as valves, compressor stations, communications systems, and meters, for transporting natural and/or supplemental gas from one point to another, usually from a point in or beyond the producing field or processing plant to another pipeline or to points of use. Also refers to a company operating such facilities.

Pipeline Fuel: Gas consumed in the operation of pipelines, primarily in compressors.

Plant Fuel: Natural gas used as fuel in natural gas processing plants.

Production, Wet After Lease Separation: Gross withdrawals less gas used for repressuring and nonhydrocarbon gases removed in treating or processing operations.

Propane-air: A mixture of propane and air resulting in a gaseous fuel suitable for pipeline distribution.

Proved Reserves: The estimated quantities that analysis of geological and engineering data demonstrate with reasonable certainty to be recoverable in future years from known oil and gas reservoirs under existing economic and operating conditions.

Receipts: Gas physically transferred into the responding company's transportation, storage, and/or distribution facilities.

Refinery Gas: Noncondensate gas collected in petroleum refineries.

Repressuring: The injection of gas into oil or gas reservoir formations to effect greater ultimate recovery.

Residential Consumption: Gas used in private dwellings, including apartments, for heating, air-conditioning, cooking, water heating, and other household uses.

Storage Additions: Volumes of gas injected or otherwise added to underground natural gas reservoirs or liquefied natural gas storage.

Storage Withdrawals: Volumes of gas withdrawn from underground storage or liquefied natural gas storage. 
Supplemental Gaseous Fuels Supplies: Synthetic natural gas, propane-air, coke oven gas, refinery gas, biomass gas, air injected for Btu stabilization, and manufactured gas commingled and distributed with natural gas.

Synthetic Natural Gas (SNG): A manufactured product chemically similar in most respects to natural gas, resulting from the conversion or reforming of petroleum hydrocarbons or from coal gasification. It may easily be substituted for or interchanged with pipeline quality natural gas.

Therm: One hundred thousand British thermal units.

Underground Storage: The storage of natural gas in underground reservoirs at a different location from which it was produced.
Underground Storage Injections: Gas from extraneous sources put into underground storage reservoirs.

Underground Storage Withdrawals: Gas removed from underground storage reservoirs.

Unit Value, Consumption: Total price per specified unit, including all taxes, at the point of consumption.

Unit Value, Wellhead: The wellhead sales price, including charges for natural gas plant liquids subsequently removed from the gas, gathering and compression charges, and State production, severance, and/or similar charges.

Vented: Gas released into the air on the base site or at processing plants. 